\title{
Interventions for enhancing medication adherence (Review)
}

Nieuwlaat R, Wilczynski N, Navarro T, Hobson N, Jeffery R, Keepanasseril A, Agoritsas T, Mistry N, Iorio A, Jack S, Sivaramalingam B, Iserman E, Mustafa RA, Jedraszewski D, Cotoi C, Haynes RB

Nieuwlaat R, Wilczynski N, Navarro T, Hobson N, Jeffery R, Keepanasseril A, Agoritsas T, Mistry N, lorio A, Jack S, Sivaramalingam B, Iserman E, Mustafa RA, Jedraszewski D, Cotoi C, Haynes RB.

Interventions for enhancing medication adherence.

Cochrane Database of Systematic Reviews 2014, Issue 11. Art. No.: CD000011.

DOI: 10.1002/14651858.CD000011.pub4.

www.cochranelibrary.com 
HEADER 1

ABSTRACT

PLAIN LANGUAGE SUMMARY

BACKGROUND

OBJECTIVES

METHODS

Figure 1.

RESULTS

Figure 2.

DISCUSSION

AUTHORS' CONCLUSIONS

ACKNOWLEDGEMENTS

REFERENCES

CHARACTERISTICS OF STUDIES

DATA AND ANALYSES

Analysis 1.1. Comparison 1 Studies that met criteria, Outcome 1 Adherence and outcome. APPENDICES

WHAT'S NEW

HISTORY

CONTRIBUTIONS OF AUTHORS

DECLARATIONS OF INTEREST

SOURCES OF SUPPORT

DIFFERENCES BETWEEN PROTOCOL AND REVIEW

INDEX TERMS

\section{TABLE OF CONTENTS}


[Intervention Review]

\section{Interventions for enhancing medication adherence}

Robby Nieuwlaat ${ }^{1}$, Nancy Wilczynski ${ }^{1}$, Tamara Navarro ${ }^{1}$, Nicholas Hobson ${ }^{1}$, Rebecca Jeffery ${ }^{1}$, Arun Keepanasseril2, Thomas Agoritsas ${ }^{1}$, Niraj Mistry ${ }^{3}$, Alfonso lorioㄹ, Susan Jack ${ }^{4}$, Bhairavi Sivaramalingam 5 , Emma Iserman ${ }^{1}$, Reem A Mustafa1, Dawn Jedraszewski¹, Chris

Cotoi $^{1}$, R. Brian Haynes 2

1Department of Clinical Epidemiology and Biostatistics, McMaster University, Hamilton, Canada. 2Departments of Clinical Epidemiology \& Biostatistics, and Medicine, Faculty of Health Sciences, McMaster University, Hamilton, Canada. ${ }^{3}$ Department of Pediatrics,

St. Michael's Hospital, Toronto, Canada. ${ }^{4}$ School of Nursing, Faculty of Health Sciences, McMaster University, Hamilton, Canada.

5Department of Population Medicine, University of Guelph, Guelph, Canada

Contact address: Robby Nieuwlaat, Department of Clinical Epidemiology and Biostatistics, McMaster University, Hamilton General Hospital campus, Room C3-107, 237 Barton Street East, Hamilton, ON, L8L 2X2, Canada. robby.nieuwlaat@phri.ca.

Editorial group: Cochrane Consumers and Communication Group.

Publication status and date: New search for studies and content updated (no change to conclusions), published in Issue 11, 2014.

Citation: Nieuwlaat R, Wilczynski N, Navarro T, Hobson N, Jeffery R, Keepanasseril A, Agoritsas T, Mistry N, lorio A, Jack S, Sivaramalingam B, Iserman E, Mustafa RA, Jedraszewski D, Cotoi C, Haynes RB. Interventions for enhancing medication adherence. Cochrane Database of Systematic Reviews 2014, Issue 11. Art. No.: CD000011. DOI: 10.1002/14651858.CD000011.pub4.

Copyright @ 2014 The Cochrane Collaboration. Published by John Wiley \& Sons, Ltd.

\section{A B S T R A C T}

\section{Background}

People who are prescribed self administered medications typically take only about half their prescribed doses. Efforts to assist patients with adherence to medications might improve the benefits of prescribed medications.

\section{Objectives}

The primary objective of this review is to assess the effects of interventions intended to enhance patient adherence to prescribed medications for medical conditions, on both medication adherence and clinical outcomes.

\section{Search methods}

We updated searches of The Cochrane Library, including CENTRAL (via http://onlinelibrary.wiley.com/cochranelibrary/search/), MEDLINE, EMBASE, PsycINFO (all via Ovid), CINAHL (via EBSCO), and Sociological Abstracts (via ProQuest) on 11 January 2013 with no language restriction. We also reviewed bibliographies in articles on patient adherence, and contacted authors of relevant original and review articles.

\section{Selection criteria}

We included unconfounded RCTs of interventions to improve adherence with prescribed medications, measuring both medication adherence and clinical outcome, with at least $80 \%$ follow-up of each group studied and, for long-term treatments, at least six months follow-up for studies with positive findings at earlier time points.

\section{Data collection and analysis}

Two review authors independently extracted all data and a third author resolved disagreements. The studies differed widely according to medical condition, patient population, intervention, measures of adherence, and clinical outcomes. Pooling results according to one of these characteristics still leaves highly heterogeneous groups, and we could not justify meta-analysis. Instead, we conducted a qualitative analysis with a focus on the RCTs with the lowest risk of bias for study design and the primary clinical outcome. 


\section{Main results}

The present update included 109 new RCTs published since the previous update in January 2007, bringing the total number of RCTs to 182; we found five RCTs from the previous update to be ineligible and excluded them. Studies were heterogeneous for patients, medical problems, treatment regimens, adherence interventions, and adherence and clinical outcome measurements, and most had high risk of bias. The main changes in comparison with the previous update include that we now: 1) report a lack of convincing evidence also specifically among the studies with the lowest risk of bias; 2) do not try to classify studies according to intervention type any more, due to the large heterogeneity; 3) make our database available for collaboration on sub-analyses, in acknowledgement of the need to make collective advancement in this difficult field of research. Of all 182 RCTs, 17 had the lowest risk of bias for study design features and their primary clinical outcome, 11 from the present update and six from the previous update. The RCTs at lowest risk of bias generally involved complex interventions with multiple components, trying to overcome barriers to adherence by means of tailored ongoing support from allied health professionals such as pharmacists, who often delivered intense education, counseling (including motivational interviewing or cognitive behavioral therapy by professionals) or daily treatment support (or both), and sometimes additional support from family or peers. Only five of these RCTs reported improvements in both adherence and clinical outcomes, and no common intervention characteristics were apparent. Even the most effective interventions did not lead to large improvements in adherence or clinical outcomes.

\section{Authors' conclusions}

Across the body of evidence, effects were inconsistent from study to study, and only a minority of lowest risk of bias RCTs improved both adherence and clinical outcomes. Current methods of improving medication adherence for chronic health problems are mostly complex and not very effective, so that the full benefits of treatment cannot be realized. The research in this field needs advances, including improved design of feasible long-term interventions, objective adherence measures, and sufficient study power to detect improvements in patient-important clinical outcomes. By making our comprehensive database available for sharing we hope to contribute to achieving these advances.

\section{PLAIN LANGUAGE SUMMARY}

\section{Ways to help people follow prescribed medicines}

\section{Background}

Patients who are prescribed medicines take only about half of their doses and many stop treatment entirely. Assisting patients to adhere better to medicines could improve their health, and many studies have tested ways to achieve this.

\section{Question}

We updated our review from 2007 to answer the question: What are the findings of high-quality studies that tested ways to assist patients with adhering to their medicines?

\section{Search strategy}

We retrieved studies published until 11 January 2013. To find relevant studies we searched six online databases and references in other reviews, and we contacted authors of relevant studies and reviews.

\section{Selection criteria}

We selected studies reporting a randomized controlled trial (RCT) comparing a group receiving an intervention to improve medicine adherence with a group not receiving the intervention. We included trials if they measured both medicine adherence and a clinical outcome (e.g. blood pressure), with at least $80 \%$ of patients studied until the end.

\section{Main results}

The studies differed widely regarding included patients, treatments, adherence intervention types, medicine adherence measurement, and clinical outcomes. Therefore, we could not combine the results in statistical analysis to reach general conclusions, as it would be misleading to suggest that they are comparable. Instead, we provide the key features and findings of each study in tables, and we describe intervention effects in studies of the highest quality. The present update included 109 new studies, bringing the total number to 182 . In the 17 studies of the highest quality, interventions were generally complex with several different ways to try to improve medicine adherence. These frequently included enhanced support from family, peers, or allied health professionals such as pharmacists, who often delivered education, counseling, or daily treatment support. Only five of these RCTs improved both medicine adherence and clinical outcomes, and no common characteristics for their success could be identified. Overall, even the most effective interventions did not lead to large improvements.

\section{Authors' conclusions}

Characteristics and effects of interventions to improve medicine adherence varied among studies. It is uncertain how medicine adherence can consistently be improved so that the full health benefits of medicines can be realized. We need more advanced methods for researching 
ways to improve medicine adherence, including better interventions, better ways of measuring adherence, and studies that include sufficient patients to draw conclusions on clinically important effects. 


\section{B A C K G R O U N D}

\section{Description of the condition}

Low patient adherence is a major barrier to realizing the benefits of medications that have been shown to do more good than harm in clinical trials. Such trials are typically done among patients who are volunteers, and who are followed closely to assure high adherence. Benefits are greatly reduced or nullified in usual clinical practice where adherence rates are low. Interventions to improve adherence have the potential to multiply benefits for patients, but at the time of our previous review, Haynes 2008, no method of helping patients to follow self administered long-term treatments had been proven effective, actionable, and affordable in usual care settings.

Many patients stop taking their medication in the first months following initiation, often without informing their provider, with further attrition over time. In addition, many patients who continue their medication do not consistently take it as prescribed. As a result, adherence rates average around $50 \%$ and range from $0 \%$ to over $100 \%$, and there is no evidence for substantial change in the past 50 years (Sackett 1979; Gialamas 2009; Naderi 2012).

Medication non-adherence is often defined as taking less than $80 \%$ of prescribed doses, although it has to be noted that nonadherence can also include taking too many doses, and it is associated with an increased risk for poor health, adverse clinical events, and mortality. Thus many people who could benefit from medications do not, and much of the public and private investment in health research and health care is undermined. To make matters worse, low adherence, even to placebo, is independently associated with an increased risk of death ('healthy adherer' effect) (Simpson 2006). Therefore, enhancing medication adherence is a priority and could improve patient outcomes, primarily through the effect of medications, but also possibly through the overall 'healthy adherer' effect.

\section{Description of the intervention}

Our most recent update (search until January 2007) of this Cochrane review included 78 randomized controlled trials (RCTs) that had $\geq 80 \%$ follow-up and tested the effect of adherence interventions on both adherence and clinical outcomes (Haynes 2008). We believe it is essential to have measures of both adherence and clinical outcomes, as ethical standards for adherence research dictate that attempts to improve adherence should be judged by their clinical benefits (NHLBI 1982). Studies that measure only adherence cannot show that patients are better off as a result, and studies that measure only clinical outcomes cannot verify that effects on adherence were important to achieving these outcomes.

Further, we described findings across disease conditions, as the clinical condition is not a major determinant of medication adherence, with the exception of psychiatric disorders (Haynes 1979a). Do note that studies targeting adherence for medications to treat psychiatric disorders are included in our review.

Our 2008 update found, besides the expected variety in medical conditions and regimens, a large diversity and complexity of interventions and of measures for adherence and patient outcomes (Haynes 2008). Although some intervention types tended to improve adherence, no specific recommendations could be given, especially since high-quality evidence for consistent effects on both adherence and patient outcomes was lacking.

\section{Why it is important to do this review}

With increasing numbers of efficacious self administered treatments being available, the need for effective interventions to improve adherence is ever more apparent. In recent years, research efforts to better understand the multifactorial barriers that influence patient adherence and to refine theoretical frameworks have been increasing. However, whether these efforts have led to the emergence of more effective interventions needs to be assessed by summarizing the high-quality RCT evidence to date. Many systematic reviews have been published after our 2008 update, but all focused on a specific (demographic, disease, or medication) population, intervention, or on an even more specific combination of both. Generally, these reviews reported similar conclusions: some intervention components are potentially effective, but small sample sizes and suboptimal methodology often prevented strong conclusions; the variety of adherence measures limited study comparability; and most studies lacked a theoretical underpinning (van Dulmen 2007).

Considering the substantial efforts in adherence research since 2007, and inconclusive evidence from other recent systematic reviews, we have updated our comprehensive systematic review. Based on publication rates over time in the previous review update, we predicted that we would find at least 50 additional RCTs, and thereby potentially improve our confidence for specific conclusions and recommendations.

\section{O B JECTIVES}

The primary objective of this review is to assess the effects of interventions intended to enhance patient adherence to prescribed medications for medical conditions, on both medication adherence and clinical outcomes.

\section{MET HOD S}

\section{Criteria for considering studies for this review}

\section{Types of studies}

This systematic review is an update of the review by Haynes et al (Haynes 2008), which searched for studies until February 2007. As of 24 November 2013, no other comprehensive adherence reviews were registered in the Cochrane Database or PROSPERO, the International Prospective Register of Systematic Reviews (http:// www.crd.york.ac.uk/prospero/). We used a web-based database management system, developed by the Health Information Research Unit at McMaster University, to facilitate screening, data extraction, adjudication of disagreements, author review and confirmation of data, production of data tables, and production of data files for future research use. This system has been successfully used in conducting and completing several large, complex systematic reviews (Haynes 2010).

Studies for this review were included if they were RCTs that provided unconfounded tests of interventions expected to affect adherence. A confounder is a characteristic that is extraneous to the primary question being addressed in the study, but which can influence the outcome and is unequally distributed between the groups being compared in the trial. For example, in one study (Colcher 1972), two groups received the same prescription for phenoxymethyl penicillin, but different instructions, providing an unconfounded comparison for the instructions, but a third group in 
the same trial received a different drug (penicillin $\mathrm{G}$ benzathine) by a different route (intramuscularly) with a different dose (1.2 million units) and schedule (one dose), making it impossible to separate out independent adherence effects of this regimen. Thus, only the unconfounded comparison of instructions for phenoxymethyl penicillin was included in the review.

\section{Types of participants}

Patients who were prescribed medication for a medical (including psychiatric) disorder, but not for addictions (as these adherence problems are typically of a different nature and much more severe).

\section{Types of interventions}

Interventions of any sort intended to affect adherence with prescribed, self administered medications.

\section{Types of outcome measures}

We included studies if they reported at least one medication adherence measure and at least one clinical outcome. Regarding follow-up completion, studies needed to have at least $80 \%$ followup at the end of the recommended treatment period for shortterm treatments, and at least $80 \%$ follow-up during at least six months for long-term treatments with initially positive results. For long-term regimens, we included negative trials with less than six months follow-up and at least $80 \%$ data completion on the grounds that initial failure is unlikely to be followed by success (Sackett 1979). The $80 \%$ data completion was required for both adherence and clinical outcomes, and for any outcome other than mortality, the denominator for determining data completion excluded those patients who died before the outcome assessment.

Figure 1. Study flow diagram.

\section{Data collection and analysis}

We imported data from the 2008 review into the update database, and checked the data for accuracy. Extracted data included items as provided in the tables from the previous Cochrane review (Haynes 2008): the 'Characteristics of included studies' table (i.e. methods, participants, interventions, outcomes, additional notes pertaining to any one of the aforementioned items, detailed assessment of risk of bias), and the 'Adherence and outcome' table (i.e. clinical problem, intervention, control, effect on adherence outcome, effect on clinical outcome). We extracted the same items for new included studies. In addition, we extracted items from the Cochrane 'Risk of bias' tool for all included studies from the previous and current update (Higgins 2011). Two review authors independently extracted all new data, and an adjudicator resolved disagreements. We contacted primary or corresponding authors of all included RCTs to confirm extracted data and provide missing data.

We quantified review author agreement on study 'Risk of bias' criteria using the unweighted Cohen's kappa $(\mathrm{k})$ coefficient (Fleiss 1981). We carried out all analyses using SPSS, version 20.0. When reporting results from individual studies, we cited the measures of association and $\mathrm{P}$ values reported in the studies. We interpreted $P$ value $<0.05$ as indicating statistical significance. Due to the extreme heterogeneity in clinical conditions, participant selection criteria, medical regimens, interventions, adherence measures, and clinical outcome measures, pooling results according to any

\section{Search methods for identification of studies}

We searched: The Cochrane Library including CENTRAL (via http://onlinelibrary.wiley.com/cochranelibrary/search/), MEDLINE, EMBASE, PsycINFO (all via Ovid), CINAHL (via EBSCO), and Sociological Abstracts (via ProQuest). We completed database searches for relevant articles on 11 January 2013, updating previous searches that were undertaken on: 1 September 1993; 12 December 1993; 1 June 1994; 30 June 1995; 28 February 1997; 31 July 1998; 15 August 2001; 30 September 2004; and 1 February 2007. We searched new publications since 1 January 2007, that is, having a one-month overlap with the previous search. All databases were originally searched from their start date.

The search filters for each database, and from the current and previous update, are shown in Appendix 1. We checked articles cited in reviews and original studies of patient adherence. We contacted authors of included RCTs to identify additional studies.

We re-assessed all RCTs included in the 2008 update for eligibility to carry over into the current update. Retrieved citations from the updated search entered a first screening stage. Based on the title and abstract, studies moved to the second screening stage if they met all five eligibility criteria or if there was uncertainty about their eligibility. In the second screening stage, assessment of the full text determined if studies were included in the review. At both screening stages, two independent review authors assessed eligibility, and an adjudicator resolved disagreements. We recorded reasons for excluding citations in the second screening stage. The PRISMA flow chart showing the results for selection of papers is provided in Figure 1.

of these characteristics would still leave highly heterogeneous groups. In support of this, we refer to the meta-analysis reported by the Ascertaining Barriers for Compliance (ABC) project team, which exclusively focused on RCTs that measured adherence by means of electronic medication event monitoring systems (MEMS) and still found a very high heterogeneity of effects $\left(I^{2}=98.88 \%\right)$ (ABC Project Team 2012). Pooling of effects in our review was further undermined by the frequent use of complex interventions, which was already problematic for categorizing intervention types in the previous update. Studies also had very heterogeneous clinical outcomes; they also often lacked clearly defined primary outcomes. We could not justify even plotting intervention effects without pooling in meta-analysis, as this would imply some degree of comparability among the studies. Rather, as a best case alternative, we conducted a narrative analysis of the studies with the lowest risk of bias, using the Cochrane 'Risk of bias' tool (Higgins 2011), for study design (random sequence generation and concealment of allocation), and for their primary clinical outcome (blinding of outcome assessor, as relevant for the outcome in question). We did not require low risk of bias for the primary adherence measure, as this would have resulted in discussion of very few studies, as most adherence measures have a high or uncertain risk of bias, notably because of lack of blinding.

We reported intervention effects in individual RCTs for all outcomes for a) adherence and b) clinical outcomes. We reported effects in 
the RCTs identified as low risk of bias as described by the authors, with a focus on the primary outcomes, and with comments on methodological issues that might have influenced results, such as absence of correction for multiple comparisons. We considered adherence and clinical outcomes to be the primary outcome if they were:

1. indicated to be the primary outcome by the study author; OR

2. used in the study power calculation; OR

3. the first outcome described in the 'Results' section of the article.

\section{RE S U L T S}

\section{Description of studies}

\section{Results of the search}

The new search identified 26,312 citations of which we assessed 1673 in full text. Of these, we included 109, based on a full-text review in the second screening phase. The PRISMA flow chart shows the results for selection of papers and is provided in Figure 1.

\section{Included studies}

The previous update included 78 RCTs, of which 73 were carried over into the current update. We excluded five previously included RCTs: in the course of this review update, we identified that two did not address self administered medication (Canto De Cetina 2001; Ran 2003), one had less than $80 \%$ follow-up (Van Servellen 2005), one reported no data for clinical outcome (van Es 2001), and one was confounded (Piette 2001). Therefore, we included a total of 182 RCTs in the current update. The overall number of RCT participants was 46,962 . However, this overall number does not reflect the strength of the evidence base, considering that we could not meaningfully combine results of included studies. The newly added studies represent a growth in the knowledge base of $150 \%$ in the past six years, with more than twice the number of trials than we had predicted based on publication rates in the 2008 review.

Key features of all 182 RCTs are summarized in the table Characteristics of included studies. The most frequently targeted conditions in all RCTs were:

- HIV/AIDS (36);

- psychiatric disorders (29);

- chronic obstructive pulmonary disease (27);

- cardiovascular disease or cardiovascular risk (21);

- hypertension (17); and

- diabetes (16).

The remaining studies targeted:

- dyslipidemia (6);

- $\operatorname{antibiotics~(4);~}$

- arthritis (3);

- complex chronic care (3);

- dyspepsia (3);

- glaucoma (2);

- oral anticoagulation (2);

- osteoporosis (2);

- tuberculosis (2);

- acne (1);
- cancer (1);

- hepatitis (1);

- iron supplementation during pregnancy (1);

- liver transplant (1);

- malaria (1);

- oral contraceptives (1);

- tonsillectomy/adenoidectomy (1); and

- ulcerative colitis (1).

Among the 109 new RCTs, 80 were from high-income countries (44 from USA), 17 from middle-income countries, five from low-income countries, and seven from unknown geographic locations (World Bank classification, http://data.worldbank.org/ about/country-classifications/country-and-lending-groups). In a majority of new RCTs (67) the adherence intervention targeted more than one medication, while 27 targeted one medication (the number of medications was unknown for the remaining 15 RCTs).

There were substantive differences across studies in settings, clinical disorders, treatment regimens, adherence interventions, adherence measures, and clinical outcome measures, so that there was insufficient common ground for quantifying differences between groups or estimating pooled effect sizes that would permit meaningful quantitative analysis of findings across studies. Instead, we indicated which differences were statistically significant for adherence or clinical outcomes between the groups compared in each RCT (see Analysis 1.1). Of note, some of the negative results were unconvincing because of low statistical power: 44 RCTs did not meet the minimal required sample size of 60 patients per treatment group to detect an absolute difference of $25 \%$ in adherence with $80 \%$ power (Haynes 2008).

\section{Excluded studies}

Of the 26,312 unique citations detected, we excluded 24,639 studies during the title and abstract screen (Figure 1). We excluded an additional 1,564 studies during the full-text screen (Figure 1), of which 374 were excluded at the data extraction stage for the reasons indicated in Characteristics of excluded studies. There are also eight studies awaiting assessment, as noted in Characteristics of studies awaiting classification.

\section{Risk of bias in included studies}

Although all included studies were RCTs, their risk of bias varied considerably because of study design or conduct. Review author agreement was good for determining risk of bias for random sequence generation $(\mathrm{kappa}=0.71 ; 95 \%$ confidence interval (Cl) 0.61 to 0.80 ), moderate for the risk of bias for allocation concealment (kappa $=0.47 ; 95 \% \mathrm{Cl} 0.34$ to 0.59 ), and fair for the risk of bias for blinding of the primary clinical outcome assessor ( $k a p p a=0.32 ; 95 \% \mathrm{Cl} 0.16$ to 0.45 ). A third adjudicator resolved differences in the duplicate independent assessments. Authors responded to our requests to review our extractions and provide additional information on 126 occasions out of 182 attempts (69\%).

\section{Allocation}

The risk of bias for random sequence generation was low in 105 RCTs and unclear in 77 RCTs. For concealment of allocation, risk of bias was high in two RCTs, low in 58 RCTs, and unclear in 122 RCTs. 


\section{Blinding}

Also taking into account the risk of bias for the primary clinical outcome, 17 RCTs had a low risk of bias for both study design (random sequence generation and concealment of allocation) and for the primary clinical outcome (blinding of the outcome assessor): six from the previous update (Haynes 1976; Walley 2001; Nazareth 2001; Stevens 2002; Laporte 2003; Weber 2004), and 11 from the current update (Wu 2006; Simoni 2007; Martins 2009; Simoni 2009; Lester 2010; Chung 2011; Farooq 2011; Morgado 2011; Ellis 2012; Gray 2012; Solomon 2012). Only four RCTs also had a low risk of bias for the primary adherence outcome, since most adherence measures had a high or uncertain risk of bias (Haynes 1976; Chung 2011; Gray 2012; Solomon 2012).

We chose to focus our narrative on the 17 RCTs with low risk of bias for study design and primary clinical outcome to provide insights from the highest-quality evidence of adherence intervention. Details for all 182 RCTs are reported in the table Characteristics of included studies.

A summary of the risk of bias in all 182 studies is shown in Figure 2.

\section{Figure 2. 'Risk of bias' summary: review authors' judgments about each risk of bias item for each included study.}

\section{Effects of interventions}

\section{Intervention effects}

The diversity and complexity of interventions precluded a taxonomy of simple labels that would accurately summarize efficacy per intervention type. We also avoided the classification in general themes and groups as done for the previous update, as this would be more cumbersome and less helpful with the current volume of included randomized controlled trials (RCTs). Detailed information regarding treatment arms and outcomes for all 182 RCTs is provided in both the Characteristics of included studies and the Analysis 1.1 tables. To provide a reasonable sampling of the details and diversity of included adherence intervention RCTs, we chose to provide a narrative focused strictly on the RCTs with the lowest risk of bias.

\section{Summary of the RCTs with the lowest risk of bias}

Of all included RCTs, 17 had a low risk of bias for both the study design (random sequence generation and concealment of allocation) and the primary clinical outcome (blinding of outcome assessor, as relevant for the outcome). Four of these trials also had low risk of bias for measuring adherence, so we discuss these first, with the most recently published studies first, then the remaining 13 studies, again, with newest studies first.

Gray 2012 randomized 127 patients with newly diagnosed ocular hypertension or open-angle glaucoma to an individually tailored adherence intervention or care as usual. The intervention was delivered by a glaucoma trained nurse with an initial session to assess patient needs, beliefs, and potential solutions, and to devise a one-year individualized care plan that involved education, training, liaising with and training for informal caregivers and professional health care providers, and planning approximately five face-to-face or phone follow-up contacts with the nurse for reassessment. From 12 to 24 months follow-up no intervention was provided and both groups had usual care. The intervention group had a higher proportion of patients with $100 \%$ refill adherence $(70 \%$ versus $43 \%$; $P$ value $=0.002)$ as measured by low risk of bias practitioner and pharmacist report at 12 months. Intraocular pressure values and changes in management were recorded from routine medical care charts. The mean intraocular pressure, and fluctuations in ocular pressure and changes in management, were not different at 12 months. At 24 months, adherence was not measured. The mean intraocular pressure was almost identical in the two groups, but the fluctuation of intraocular pressure was higher and changes in management more frequent in the control group. It is possible that the differences at 24 months were found due to chance, especially as it is unlikely that a significant effect would be observed one year after stopping the intervention, while no effect was observed after one year of intensive intervention.

Solomon 2012 sent seven informational mailings addressing osteoporosis to 2097 low-income older adults who were initiating osteoporosis medication, and randomized them to receive eight phone counseling sessions by health educators using motivational interviewing techniques to promote adherence, or the mailings alone. The phone counseling intervention did not significantly improve the primary outcome, adherence as measured by the median medication possession ratio using low risk of bias pharmacy claims data. Further, secondary outcomes including medication persistence, and proportions with self reported fractures or falls were not improved. The authors indicated that the 113-day time lag between identifying persons initiating therapy in the database and making the first phone call in the intervention group was a missed opportunity, since many eligible or recruited persons had already stopped therapy before the first call.

Chung 2011 randomized 400 newly diagnosed HIV patients who were candidates for highly active antiretroviral therapy to one of four treatment groups in a $2 \times 2$ factorial design: 1) three adherence counseling sessions within one month of therapy initiation, or 2) a visual and audible alarm device, programmed by staff, to carry at all times during six months, or 3 ) both adherence counseling and the alarm device, or 4) neither counseling nor the alarm device (control). Counseling sessions, which followed a written standardized protocol and lasted between 30 and 45 minutes, had no significant effect on the proportion of participants who achieved adherence $\geq 80 \%$ or $\geq 95 \%$, as determined using low risk of bias pill counts at pharmacy refill visits, but resulted in a lower hazard rate of viral failure. The authors hypothesized that the clinical benefit of counseling could relate to providing the sessions in advance of, and just after, therapy initiation. The alarm device did not improve the adherence or viral outcomes.

Haynes 1976 randomly allocated, through the minimization method, 38 patients who were both hypertensive and nonadherent (less than $80 \%$ of prescribed pills) at the end of a six-month trial to an intensive adherence intervention or control. The intervention included care provided at the work site, special pill containers, counseling, reminders, self monitoring of adherence and blood pressure, support groups, feedback and reinforcement for adequate adherence and blood pressurelowering, all administered with bi-weekly contacts by a lay program 
co-ordinator who was supported from study funds. At six months follow-up, there was a significantly higher adherence in the intervention group, as measured by low risk of bias unobtrusive home pill count. The change in diastolic blood pressure after six months was not statistically significantly different between groups (difference in change $3.5 \mathrm{~mm} \mathrm{Hg}$; $\mathrm{P}$ value $=0.12$ ), although the small sample size might have meant insufficient power to detect a clinically meaningful difference. The authors discussed the possibility that simply the increased attention for intervention patients could have contributed to the improved adherence, rather than the specific intervention components. It has to be noted that medical therapy for intervention patients was more often intensified at the end of the study, while the intervention coordinator was not allowed to contact treating physicians.

Ellis 2012 tested whether an average of 5.6 months of multisystemic therapy (MST), a highly intensive, home-based, tailored family intervention, improved treatment adherence and $\mathrm{HbAlc}$ levels compared with weekly phone support during 4.9 months, among 146 poorly controlled adolescent diabetics (mean HbAlc $=11.7 \%$, where good control would be an A1c of $7 \%$ for most patients). In MST, therapists were expected to meet with families, their related contacts (e.g. extended family, physicians, and school personnel), or both, a minimum of two times per week at the beginning of treatment with an option for a reduced number of sessions at the end of treatment based on family progress toward treatment goals. Treatment was planned to last for approximately six months. All participants in the trial received standard medical care in addition to MST or telephone support. At seven and 12 months follow-up, the intervention lowered $\mathrm{HbAlc}$ and improved adherence (Diabetes Management Scale) as reported by the parent, but not as reported by the adolescent. As the authors acknowledged, it has to be evaluated whether such an intensive intervention is cost-effective, especially as the difference in improvements in $\mathrm{HbAlc}$ were relatively small (e.g. Alc $-0.74 \%$, $95 \%$ confidence interval $(\mathrm{Cl})-1.48 \%$ to $-0.01 \%$, at 12 months) in view of the poor control at baseline (A1C 11.7\%).

Farooq 2011 randomized 110 patients with schizophrenia or schizoaffective disorder to receive family supervised treatment (STOPS) or care as usual. In addition to usual care, participants in the STOPS arm each had a key care supervisor, defined as any family member living with the individual for at least six months and providing support for the treatment as identified by the participant. Education was provided to the key care supervisor about the nature of the illness, misconceptions about treatment, the relationship between supernatural and biological causes of illness (some people believing in supernatural causes might think they cannot do anything about the disease), and the importance of continuing the medication, as well as basic skills in how to administer and supervise the medication. It was emphasized that participants should not be antagonized and violence should never be used in case of refusal to accept the treatment. Steps involved in collecting medicine from the treatment center, storage at home, administering tablets and their ingestion by the participant and how to confirm this were demonstrated. Intervention participants also received free medicines while control group members were left to their own means to obtain their medications. The proportion of patients with perfect adherence, as measured by a five-point self report scale supplemented by pill count data, was higher at three and 12 months in the intervention group, but not at six months. Supervised therapy also improved symptoms as measured by the Global Assessment of Functioning Scale and Positive And Negative Syndrome Scale. However, it was unclear to what extent free provision of medication in the intervention group for the study contributed to the effect, since control patients could only apply for free drugs through a regular care process (not for the study), if eligible.

Morgado 2011 randomized 197 patients with arterial hypertension, who had been on antihypertensive therapy for at least six months, to receive either counseling from a hospital pharmacist at a specialized outpatient clinic, or regular care at a traditional hospital clinic without a hospital pharmacist. Hospital pharmacists interviewed patients, assessed problems with blood pressure control, educated patients, advised physicians on medication changes, and provided intervention patients with written educational material. Patients in the intervention group were also encouraged to bring all empty blisters and boxes of antihypertensive medication to clinic visits for recycling and to verify compliance with therapy. The intervention improved the primary outcome of proportion of patients with blood pressure controlled to target, and reduced the proportion of patients with low medication adherence as measured by a five-item questionnaire. The medical therapy advice from pharmacists to physicians might have contributed to the improved blood pressure control in addition to the improved adherence, although the authors report that there were no marked differences compared with the control group regarding therapy changes.

Lester 2010 randomized 538 patients newly initiating antiretroviral therapy, and who had access to a mobile phone and, if required, a partner able to read educational materials, to receive interactive short message service (SMS) or care as usual. Patients in the intervention group received a short education session on the intervention from clinicians, received an SMS every Monday asking "How are you?", and were required to respond within 48 hours to indicate that everything was fine or they had a problem. In case of no response within 48 hours or an indicated problem, the clinician called the patient. The intervention was based on existing mobile phone services and SMS messages were sent by available nurses or clinical officers; no personnel or SMS credits were provided specifically for the study. In the intention-to-treat analysis, the intervention improved the proportion of patients with self reported adherence greater than $95 \%$ as well as viral suppression (HIV-1 RNA $<400$ copies $/ \mathrm{ml}$ ). Of note, the intervention was reported to function well during a period of political turmoil and population displacement, directing patients to alternative health resources using interactive SMS.

Martins 2009 randomized 270 patients with pulmonary tuberculosis from urban community clinics in Timor-Leste, which had a well-functioning tuberculosis treatment program including direct observation of medication taking, to receive the intervention with supplementary food or nutritional advice only. Intervention patients were required to attend the clinic daily for routine tuberculosis treatment, and additionally were offered nutritious daily meals at the clinic during the first eight weeks with direct observation of consumption by clinic personnel, and received daily meal packages to take home during weeks 9 to 32 . Control group patients were also required to attend the clinic daily for routine care, and additionally received advice regarding a nutritious diet, but did not receive food. The intervention did not improve the primary outcome of proportion of patients completing treatment 
(sputum clearance) or completion of eight months of treatment, nor did it improve medication adherence or clinical symptoms including cough. The significant weight gain in the intervention group could be beneficial for the tuberculosis patient group, but was not achieved through better medication adherence and therefore not pertinent to the research question of this review. Of note, a civil conflict arose during the last months of the study, which caused displacement of a large population and complicated adequate completion of the study.

Simoni 2009 randomized 226 HIV-positive patients initiating or switching to a new antiretroviral medication in a factorial design to either peer support, pager messaging, both peer support and paper messaging, or care as usual only. Regarding peer support, clinic staff selected peer supporters who were also HIV patients on antiretroviral therapy, and had a high therapy adherence, regularly attended clinic visits, were socially skilled, and were able to participate in training and supervision. Peers were, as much as possible, matched to participants based on race/ethnicity, sex, and sexual orientation. During three months, aiming to use twice-monthly group meetings and thrice-weekly phone calls, peer supporters addressed barriers to medication adherence and potential solutions. Patients could choose to continue attending meetings and seeking assistance after three months. The three months pager intervention involved automated individually tailored interactive messaging, addressing medication adherence, education, entertainment, and adherence measurement. Messaging frequency could be tailored to the patient's preference with a minimum of three daily messages in the first two months, which was tapered in the third month. At three months, the only significant effect was for self reported adherence in the peer support group, compared with care as usual. No effects were found of either peer support or the pager intervention on self reported adherence, electronically monitored adherence, and viral load and CD4 count as reported in routine medical charts, at six and nine months. The one significant effect was likely a chance finding, considering the testing of multiple outcomes at different time points and the absence of confirmation by Medication Event Monitoring System (MEMS). The authors discussed that the lack of an effect could be related to the poor use of the intervention by participants, the high quality of usual care in this HIV-specialized clinic, and the inclusion of all patients on therapy rather than those with adherence problems only.

Simoni 2007 randomized 136 HIV-positive patients with prescribed antiretroviral therapy to receive a peer-led social support intervention or standard care. The three months peer support intervention was of similar design to the intervention for Simoni 2009 , with the difference that in the present study patients could not choose to continue attending meetings and seeking assistance after three months. The intervention did not improve adherence as measured by self report and MEMS, nor did it lower HIV-1 RNA viral load values as routinely reported in medical charts, at three and six months follow-up. The authors discussed the possibility that the lack of an effect could relate to the poor use of the intervention by participants due to multiple barriers-including poverty, substance abuse, and insufficient time to establish trust between patient and peer supporter-limiting consistent attendance at meetings and receiving phone calls for adherence.

Wu 2006 tested the effect on adherence and mortality of pharmacist phone counseling, addressing medication adherence, lifestyle, and the next follow-up visit, versus usual care, among nonadherent stable patients on five or more chronic medications. Of 442 randomized patients, 236 had become adherent since screening. Adherence was measured by pharmacists using a structured questionnaire in combination with medication dispensing information: taking $80 \%$ to $120 \%$ of prescribed pills was considered adherent. A proportion of all medications for which the patient was adherent was calculated, but it was unclear how this was used since the authors only distinguished adherent and non-adherent. After receiving six to eight pharmacist calls during two years, the intervention group had fewer baseline nonadherent patients who remained non-adherent, and more baseline adherent patients who remained adherent. The phone counseling intervention also reduced the risk of all-cause mortality from $18 \%$ to $11 \%$ (relative risk $0.59,95 \% \mathrm{Cl} 0.35$ to 0.97 ; $\mathrm{P}$ value $=$ 0.039 ). Considering that mortality is hard to improve solely with an adherence intervention, and the confidence interval for the relative risk is wide, this result needs to be replicated.

Weber 2004 randomized 60 HIV patients, who were stable on a combination of at least three antiretroviral medications and had a viral load of less than 50 copies/ml, to a cognitive behavioral intervention or standard care. Patients in the intervention group were given contact information for a psychotherapist, and asked to schedule a first appointment. The psychotherapist and patient determined a visit schedule for the year, with a minimum of two sessions and maximum of 25 (median was 11). In addition, they would identify at least two treatment goals, of which medication adherence was one, which would be targeted with treatment based on cognitive behavioral therapy principles. The proportion of patients with adherence of $95 \%$ or greater as measured by MEMS, and self reported adherence as measured on a visual analog scale, was higher in the intervention group at 10 to 12 months, but the regression coefficients for change in MEMS adherence during the study were not different between intervention and control. Viral load and CD4 count were not different between groups, but the intervention group showed an improvement in mental state, as measured by a standardized questionnaire on experience and behavior. This study was designed as a feasibility study, with no reported sample size calculation, and it is unclear to what extent the study was powered to detect differences in clinical outcomes, or if significant effects would remain after correction for multiple comparisons.

Laporte 2003 randomized 86 patients who were hospitalized for a thromboembolic disease and needed oral anticoagulation for at least three months, to either intensive education or standard education on anticoagulation. Patients in the intervention group received visual educational material, daily visits from healthcare providers, and daily tests on their education for the duration of the hospitalization, all aimed at the importance of medication adherence and causes of anticoagulation instability. Control group patients received standard education without any of these features for the entire duration of hospitalization. Following discharge, no differences were found regarding correct bottle openings, timing of bottle openings or pill count, all measured using MEMS. In addition, no differences were found regarding the clinical effect of anticoagulants, e.g. proportion of values or the proportion of days the INR (international normalized ratio) values were within the therapeutic target range. The study used a factorial design and also randomized patients to anticoagulation with either warfarin or acenocoumarol, but these medication groups did not differ 
regarding adherence and no statistical interaction was found between the medication and educational interventions.

Stevens 2002 randomized 335 patients with dyspepsia and confirmed Helicobacter pylori infection, who were prescribed seven-day treatment with omeprazole, bismuth subsalicylate, metronidazole, and tetracycline hydrochloride, to either an intensive pharmacist counseling intervention or regular pharmacist counseling. Intervention patients received a detailed 15-minute pharmacist counseling session at the start of therapy, addressing side effects, the importance of completing therapy, potential barriers and coping strategies related to adherence, and encouragement to call the pharmacist in case of problems, as well as a standard phone call by the pharmacist after two to three days. Patients in the control group received a standard five-minute pharmacist counseling session at therapy initiation, describing the proper protocol to take the medication and providing an opportunity to ask questions. Self reported medication adherence and Helicobacter pylori eradication rate, as measured by carbon 14 urea breath test, were not different between the intervention and control groups at three months. The authors indicated that the lack of an effect could relate to enrolment of motivated patients who were doing well at baseline, the use of daily blister packs in all patients, which might have enhanced adherence, or spill-over of the intervention to the control group due to the same pharmacists applying the two treatments, both of which included counseling.

Nazareth 2001 randomized 362 hospitalized patients over 75 years, who were taking more than four medications at discharge, to either an intensive or a standard pharmacist discharge plan. Patients in the intervention group received an assessment by a hospital pharmacist, who evaluated therapy appropriateness and the patient's ability to manage the medications, and educated patients on appropriate adherence and how to liaise with important healthcare providers. An individualized discharge plan was devised containing the patient's medications and required adherence support, and copies were given to the patient and an assigned community pharmacist, family physician and other involved providers. After 7 to 14 days the community pharmacist visited the patient at home to reassess therapy adherence and barriers, and intervene and schedule additional follow-up visits as deemed appropriate. Control group patients received standard discharge procedures by a hospital pharmacist, including a letter to the family physician. No differences were found at three and six months for hospital readmission, death, outpatient clinic visits, and family physician visits, nor for self reported measures including general well-being, satisfaction, adherence, medication knowledge, and medication hoarding. This study included old and high-risk patients, of whom $11 \%$ had a Mini-Mental State Examination score of 15 or less at baseline and $15 \%$ died during six months, leaving $74 \%$ of participants for interview on self reported measures at six months.

Walley 2001 tested the effect of direct observation of therapy, and randomized 497 new sputum-positive tuberculosis patients to one of three arms: 1) direct observation by health workers six days per week during two months, 2) direct observation by family members, 3) self administered therapy, obtained by bi-weekly visits to a health facility. At seven to eight months, both direct observation intervention groups had comparable rates to the control group for the outcomes of cure (sputum-negative on two most recent occasions) and cure or treatment completion (no smear results on at least two occasions, but treatment completed). The authors indicated that the lack of an effect might be due to challenges such as the high rate of patients not being able to comply with direct observation of therapy by health workers, and the implementation of interventions for this study on top of a recently strengthened tuberculosis care system.

\section{DISCUSSION}

\section{Summary of main results}

The current review updated our 2008 version, Haynes 2008, with 109 new RCTs, a substantially larger number than expected from previous publication rates. To our knowledge this is the only comprehensive (not restricted to specific settings, medications, or diseases) systematic review of interventions to improve medication adherence based on randomized controlled trials (RCTs) that assessed both adherence and clinical outcomes. Despite the more than two-fold increase in the knowledge base, the interventions and findings of these RCTs only slightly alter the conclusions of the previous version of our review. Compared with the previous update, we now: 1) report a lack of convincing evidence among studies with the lowest risk of bias; 2) no longer try to classify studies according to intervention type; 3) make our database available for collaboration on sub-analyses. The wide variety of settings, participants, intervention types, medications, adherence measures, and clinical outcomes precluded summarizing findings to reach reliable general conclusions. RCTs included in the current review reported effects that were inconsistent from study to study. A minority of lowest risk of bias RCTs reported improving both adherence and clinical outcome, but these typically had very complex interventions that would be difficult to implement in usual practice setting. Thus, as a qualitative generalization, methods of improving medication adherence for chronic health problems tested to date are mostly complex and not very effective, so that the full benefits of treatment cannot be realized. Therefore, the quest for effective and practical interventions to promote medication adherence and improve clinical outcomes must continue. In acknowledgement of the need for collective advancement, we make our database available for collaboration on sub-analyses.

To the extent that they represent true innovation, the increase of trials is most encouraging. Even when outcomes were improved, however, the effects were generally small. Effects were seldom assessed on major clinical events such as death or hospitalization, and when done these were rarely significant, albeit possibly due to insufficient study power. The diversity, complexity, and uncertain effects of the interventions, as well as the often uncertain risk of bias for blinding treatment allocation and outcomes assessment, make generalizations about which interventions work and which do not problematic.

\section{Quality of the evidence}

Our narrative focused on the RCTs with the lowest risk of bias, to provide a reasonable sampling of the details and diversity of included trials. We identified only 17 studies as having a low risk of bias for study design and clinical outcome assessment. Their interventions were generally complex, trying to overcome multiple barriers to adherence by several means of tailored ongoing support. The lowest risk of bias RCTs primarily involved enhanced support from family, peers, or allied health professionals such as pharmacists, who often delivered 
intense education, counseling (including motivational interviewing or cognitive behavioral therapy by professionals), and/or daily treatment support. Of these RCTs, five improved both adherence and clinical outcomes, three improved only adherence outcomes, one improved only clinical outcomes, and eight did not improve adherence or clinical outcomes. This was a similar success rate to that found in the 21 newly included studies in the 2008 update (Haynes 2008). Whether these numbers reflect the actual proportion of studies that had an important effect is uncertain, and simple 'vote counting' is not informative because:

1. a large variety of often complex interventions would be inappropriately treated as equal;

2. many studies tested multiple outcomes without statistical correction, thereby increasing the risk of false positives findings;

3. many studies were underpowered thereby potentially hiding a true effect;

4. most outcomes were surrogate measures (e.g. blood pressure) rather than patient-important outcomes.

No common intervention characteristics for success were apparent among these studies. Therefore, even in the studies with the strongest methodology, no consistent evidence exists that medication adherence can be improved within the resources usually available in clinical settings, and that this will predictably lead to important improvements in treatment outcomes. The results might have been different with more relaxed criteria for participant loss to follow-up, but this would further muddy the water with even lower-quality RCTs, and we prefer to stand by our criteria of at least $80 \%$ follow-up in all treatment groups. In addition, most studies enrolled patients who were willing to participate, rather than those that had low adherence. This makes it harder to show an effect, as opposed to applying the intervention only to those in need of adherence support. Although we were not able to assess potential publication bias, as we did not pool results, we estimate that some publication bias is likely due to the widespread lack of power to pick up potentially meaningful effects. If so, our low estimate of the benefits of interventions to date would likely only be reinforced by unpublished studies.

\section{Interventions}

\section{New developments}

Since the last update, some new or little studied intervention types have been reported. Although the technologies have been around for a while, we were now able to include several RCTs testing the effect of mobile text messages (Simoni 2009; Hou 2010; Lester 2010; Boker 2012; Zolfaghari 2012), and remote internet-based treatment support (Chan 2007; van der Meer 2009). Of the five RCTs testing the effect of mobile text messages, two were included in the lowest risk of bias group. Only Lester 2010 showed a significant effect, on antiretroviral therapy adherence and the clinical outcome of viral load in HIV patients. There may be potential to build on the opportunities provided by text messaging, including in lowresource settings. Simoni 2009 also targeted HIV patients, but did not show an effect of pager messages on adherence or viral load. The remaining three RCTs testing mobile text messages for oral contraceptives, acne therapy, and diabetes were not included in the lowest risk of bias group, and none had an effect on both adherence and the clinical outcome (Hou 2010; Boker 2012; Zolfaghari 2012). Further, Chan 2007, a study not included in the lowest risk of bias group, tested internet-based asthma telemonitoring for patients of 6 to 17 years, but found no effect on adherence or clinical outcomes. van der Meer 2009 tested internet-based asthma self management plus education among adults, whereby communication could also be done using mobile text messaging if preferred, and found no improvement in medication adherence, only moderate improvements in asthma control and lung function, and no clinically significant improvements in asthma-related quality of life and exacerbations. Further, no other RCTs testing the effect of internet-based disease telemonitoring made it through our selection process. Although both technologies have great potential to reach large population groups to improve adherence, further rigorous testing is necessary. Ongoing studies might strengthen the knowledge base and provide more details on how they could be better utilized. The present examples overall do not change our conclusion from the previous update that adherence research is lagging behind the rapid developments in technology, and that research methodology and evidence on their optimal use remain weak.

Allied healthcare providers such as nurses and pharmacists are increasingly delivering part of, or the entire intervention. In our previous update we advised further exploration of their role, and hypothesized that if their roles can be expanded to include counseling patients to enhance medication adherence, this may be feasible in practice. Considering that physicians have limited time, and sometimes skills, to counsel patients on medication adherence repeatedly, shifting these tasks to allied providers seems reasonable and potentially cost-effective. Several complex interventions involving allied providers were effective, but since they were often only part of the intervention and delivered a variety of intervention enhancing services, their efficacy has to be determined for specific roles and tasks. In addition to the role of allied health professionals, several studies tested family/ social interventions, lay health mentoring, or group meetings. It seems worthwhile to explore further involving non-professional personnel, since the patient's social context is important to optimize chronic care, and might improve cost-effectiveness.

As mentioned, complex interventions were often used in the new RCTs, typically involving intensive ongoing allied health care provider and social support, sometimes facilitating transitions in care. This seems logical considering that adherence is generally a complicated matter caused by multi-factorial barriers (ABC Project Team 2012; Kardas 2013), but also raises three primary concerns:

1. complex interventions are usually compared with care as usual, while it remains to be seen if they are more effective than a simple intervention;

2. if effective, the entire complex intervention should be implementable in other settings, without requirement of excessive additional personnel and costs (implementation flexibility and external validity); and

3. if the latter is not feasible, the effects of individual components should be teased out, such as by a factorial design, in order to be able to determine if all components were required or to select the most effective ones.

Related to complexity, many RCTs used personnel and resources supported by research funds. For example, pharmacists would be specifically allocated to the intervention and reimbursed accordingly, but outside this research setting they might not be able or willing to dedicate this time to the intervention. Even if a 
small effect on clinical outcomes was observed, it remains to be seen whether such interventions can be translated to other settings in a cost-effective manner. Regarding this, few adequate full costeffectiveness evaluations of adherence RCTs are being published (Oberje 2013). These will be needed if clinically important effects are documented.

Process evaluation of an effective complex intervention can be very useful to hypothesize which components were most effective and to identify individual or contextual barriers and facilitators to adherence (Craig 2008). However, we believe that this eventually requires direct comparison in an RCT, compared with usual care or a simple intervention. Two RCTs in the lowest risk of bias group, Simoni 2009 and Chung 2011, applied two different adherence interventions in a factorial design. This design allows testing of the separate effects of multiple intervention components, while also observing their additive effect. This will better inform which components are independently effective, or whether an effect is due to the combination of two components that individually might not be (very) effective. It has to be noted that to be able to test several components and their interactions with sufficient power, the required sample size has to be increased accordingly (McAlister 2003).

Of note, the European Ascertaining Barriers for Compliance project published its final report in 2013 (Demonceau 2013), which also included a comprehensive systematic review including intervention RCTs assessing adherence outcome by means of electronically compiled measures. The authors used a taxonomy to label intervention components and tried to tease out the effect of each component, although they acknowledged that many interventions were complex, highly variable, and not easily summarized. Of the 65 included RCTs, 32 also assessed clinical outcome, with only four showing an effect on clinical outcome.

\section{Promising interventions not included in our review}

There are likely many potential areas for which interventions are either in development or lacked high-quality RCT evidence with adherence and clinical outcomes at the time of our search. We will illustrate this with a selected example regarding cardiovascular prevention single-pill combination therapies, also since a recent Cochrane systematic review by Ryan et al showed promise for simplified dosing (Ryan 2014). Several of these combination pills, containing multiple proven cardiovascular medications, have already been developed and tested versus the same medications as individual therapies (Working Group on the Summit of Combination Therapy). These pills simplify therapy to only one pill per day, where most cardiovascular patients currently have to take at least four to five separate pills daily. The RCTs testing combination pills typically assessed effects on therapy persistence (e.g. not explicitly discontinuing), rather than daily pill adherence while still on medications, in addition to intermediate clinical outcomes such as blood pressure. However, an RCT published after our search showed that self reported adherence as well as intermediate clinical outcomes (blood pressure, lipid levels) were somewhat improved with a cardiovascular combination pill (Thom 2013). That said, medication was provided free to the combination pill intervention group, while control group participants had to fend for themselves in acquiring their medications (almost half lacked insurance coverage), leaving uncertainty as to whether the improved adherence was due to simplified therapy or facilitated access to medication and cost-lowering. This study would be a candidate to make it into our next update, but the provision of polypills free of charge constitutes a more complex intervention than the authors highlighted. As a related example, in our previous review we indicated that there is some evidence that a dose frequency of one to two times per day may be associated with better adherence than three to four times per day, and advised better exploration of this dose frequency. None of the new RCTs with the lowest risk of bias addressed this issue, and we would like to highlight this important issue.

\section{Measuring adherence and clinical outcomes}

To determine applicability to patient care, we only selected studies that measured both adherence and treatment outcome. This requirement has received the criticism that this resulted in a more negative message than some would like to see. It has been suggested that the findings would be more upbeat and positive if we included studies that measured only adherence. This criticism does not pertain to the purpose of this review, that is, to determine whether adherence interventions make a difference to clinical outcomes. It simply cannot be assumed that measures to increase adherence do more good than harm, even if they increase adherence. Nevertheless, we do agree that investigators who seek to advance the methods for enhancing adherence may find promising leads from studies that do not meet our criteria for measurement of both adherence and clinical outcomes.

Attempts to increase adherence can have adverse effects (loss of privacy and autonomy, increased adverse effects of treatments) (Simpson 2006), and so on. Few RCTs assessed such potential adverse effects. Further, many interventions with an effect on adherence and surrogate clinical outcomes measured relatively short-term outcomes, typically at 6 to 12 months, which does not mean that their effect would be sustained or that they would lead to important clinical outcomes in the long run.

\section{Adherence measures}

A well-known problem with adherence studies is the inability to measure adherence accurately and reliably, making it harder to pick up true differences, which could have contributed to the variable effects we observed among RCTs. Most studies used patient self report measures, which are known to overestimate adherence (Gordis 1979; Haynes 1980; Stephenson 1993); these studies are at especially high risk of bias when the patient is not blinded to the treatment allocation, which is usually the case. Some validated questionnaires are available, and should be used as much as possible if self report is chosen, but their accuracy and reliability are often limited and depend on the context they are used in.

Increasingly, studies are using Medication Event Monitoring System (MEMS) pill bottle caps. These caps contain a microchip that measures the date and time at which the bottles are opened, but do not register if the patient actually took the medication on those occasions. Although this method is more objective than self report, it could also function as an intervention (patients feel monitored) (Christensen 2009), and increase adherence in both groups, thus diminishing or concealing a true difference. It can also be 'gamed' by the patient who is aware of the MEMS function and wishes to keep non-adherence private.

A potentially more objective measure that was used in some studies was pill count, which is especially appealing if it is done unannounced, at home, and in an unobtrusive way, in order to 
prevent patient awareness and anticipation of pill count. However most pill counts are done on containers that the patient brings with them to a visit to a health professional, and in this circumstance counts can clearly be altered by the patient.

A method that was regularly used, and that probably has the highest likelihood of maintaining blinding of patients and providers, was the use of routine pharmacy refill records. Although this method depends on the assumption that the patient is actually consuming the medication, and the only one doing so, it better allows adequate blinding of outcome assessors. In our view, using more objective measures such as pharmacy records is a productive step forward in the field of adherence research, as it will lead to further valid and reliable results. With electronic records available in most pharmacies, this option is increasingly available, inexpensive, and acceptable, providing that patient consent is obtained.

It is important to note that our review may miss the most severe form of non-adherence, among those who do not attend for needed care or enter trials. Patients dropping out of care are unlikely to be receiving any medication, and if those in care average about 50\% adherence, keeping patients in care is arguably the most important adherence intervention at present. The same rationale can be used for keeping patients on medication, even if they do not attend clinic visits. Both assume, however, that for those who are prevented from dropping out or discontinuing medication, or who are returned to care or restart medication by intervention, adherence rates are sufficient to achieve clinically important benefits. This merits further testing.

\section{Clinical outcomes}

Consistent with the large variety in diseases and medications, many different clinical outcomes were reported. Most RCTs measured intermediate biological outcomes, such as blood pressure, serum cholesterol or HIV-1 RNA, or patient-reported outcomes such as quality of life, knowledge, beliefs, or attitudes. Very few studies examined major, patient-important, clinical endpoints such as death or hospitalization. The latter have the lowest risk of bias, as they are obvious and can easily be verified. Intermediate biological outcomes also often have a low risk of bias, although this could be compromised if measurement methods differ among subjects, and outcome assessors are not blinded. For example, measuring blood pressure requires a protocol whereby a fixed number of measurements are taken according to a standardized process, and a provider who is aware of a participant being in the intervention group might (subconsciously or otherwise) alter this process or interpret readings differently. Self reported outcomes such as symptoms and quality of life are more prone to bias, even if using well-validated general and disease-specific tools to assess them. Finally, many studies reported self reported knowledge, beliefs, and attitudes, often in addition to more objective clinical outcomes. Although these types of outcomes can be used to further clarify mechanisms of effects, they are often not validated or inadequately validated, are prone to self report or observer bias, and their measurement varies with time and clinical care experiences which limits their reliability.

\section{Study power}

Many RCTs had inadequate power to detect a meaningful difference in adherence, and this did not seem to be improved among newly identified RCTs. As a general guide, studies with a single intervention group and control group would need to include at least 60 participants per group if they are to have at least $80 \%$ power to detect an absolute difference of $25 \%$ in the proportion of patients judged to have adequate adherence. According to this rule, the new RCTs were as likely to be underpowered ( $40 \%$ (44/109)) as RCTs in the previous update, and even among the 17 lowest risk of bias RCTs in the present update, four had insufficient power (Haynes 1976; Laporte 2003; Weber 2004; Farooq 2011). For example, in a study of 38 patients (Haynes 1976), there was a significant increase in adherence associated with the intervention and an interesting within-group reduction of blood pressure within the intervention group. However, the difference between the intervention and control groups for blood pressure change was not statistically significant. Underpowered studies are more likely to miss a meaningful difference in adherence, even when improving adherence substantially, and showing an effect on clinical outcomes is likely even harder. This is especially true for major events. If RCTs with hundreds or thousands of participants are needed to show that the medication has an effect on major outcomes compared with usual care, it is unlikely that improving adherence among patients who are prescribed the medication will have a substantial effect on major outcomes in a small sample size.

\section{Quality of reporting}

Many articles did not provide sufficient detail to allow the risk of bias to be determined, or for the exact nature of what the study tested to be understood. In particular, details of the methods of random sequence generation, concealment of treatment allocation, and blinding of the outcome assessors as relevant for the outcomes were often not reported, and therefore we could not determine the risk of bias. As a consequence, it is possible that some of RCTs that we excluded from our narrative actually had a low risk of bias, but we were unable to determine this based on the manuscript, supplements, and (absence of) author response. The importance of adequate reporting is further illustrated by the initially included RCTs that were eventually discarded due to less than $80 \%$ follow-up after repeated detailed review. The way these studies were reported was sometimes confusing for something as simple as follow-up rate, and the full picture was only revealed after reading all the details, tables, figures, or supplements. Examples appear in the listing of studies excluded for cause in this review.

Treatment arms, both intervention and control, were also not always described in sufficient detail. For example, while the report might state clearly that patients received reminders, the method of administering the reminder program might not be described, or might be described in some part of the text other than the section on the intervention. Most studies paid research staff to administer interventions, raising issues in generalizability to usual practice settings. This also raised the issue of attribution in many studies: if the control group received 'usual care', there would be no 'attention control' in the study and any effects observed could be due to either the intervention proper or simply the nonspecific effects of increased attention paid to the intervention group. Furthermore, some studies reported that the patients in the control group received 'usual care', but did not describe what that encompassed. If the standard medical care is already performing relatively well, it will be harder to show an improvement with the intervention. Therefore, to understand the trial results better, it is recommended to provide sufficient details on the intervention design and delivery, the assumed change process the intervention 
aims to deliver, and the care process for the control group, whether this was an active control or usual care (Michie 2009).

\section{Potential biases in the review process}

\section{Missed studies}

Despite extensive searching, we may have missed some trials that met all of our criteria. The literature on patient adherence is not well indexed because the number of studies is quite small relative to the literature published on other topics, and because it is spread across traditional disease boundaries. We invite readers to send us any studies, published or unpublished, which may meet our criteria.

\section{Study eligibility criteria and 'Risk of bias' assessment}

We chose our eligibility criteria to summarize the current best evidence of unconfounded RCTs, with adequate follow-up completion in all treatment groups, assessing the effect on both adherence and clinical outcome. With other eligibility criteria, such as allowing a larger loss to follow-up or not requiring clinical outcome, the review results might have been different. In addition, in the absence of clear study details, we could have made judgment calls in our 'Risk of bias' assessment to avoid too many 'uncertain risk' assignments. This might have resulted in more studies being considered 'low risk', and therefore eligible for discussion in our main text. However, we anticipate that the quality of evidence in these trials would be even lower than the moderate study quality which was found in both the overall review and among the RCTs with the lowest risk of bias, and would lead us further from an accurate overview of the current best evidence in a field with a large number of small and low quality studies.

\section{Other reviews}

Our review is restricted to prescribed medications, excluding those prescribed for addiction, and to studies that assessed both adherence and treatment outcomes. There are many other systematic reviews of adherence interventions, too numerous to list, especially for specific clinical conditions, and also for nonmedication interventions (e.g. diet, exercise, addictions, and so on). We acknowledge that systematic reviews focusing on specific clinical conditions, medications, or intervention types might draw different conclusions. We chose to focus on all RCTs testing adherence interventions for any self administered therapy, to get a complete overview of the field and to account for the fact that adherence problems are often comparable for different medications. This resulted in the inclusion of a large variety of heterogeneous RCTs that could not reliably be pooled, but we encourage reviewers and researchers who find a signal for effective interventions for a specific condition or medication to share their findings with us and other reviewers. In addition, we invite reviewers interested in specific conditions, medications, or interventions to propose such a specific analysis in our comprehensive database.

\section{Sharing of review data}

As indicated, we did not feel it scientifically justified to summarize data across studies, but provided all the details on included RCTs in the tables, as well as a narrative of the RCTs with the lowest risk of bias. For this review we collected a wealth of information, and we invite readers to propose specific analyses of interest. Access to our database for additional analyses will be considered, based on requests to the corresponding author. Please e-mail your analysis proposal to par@mcmasterhkr.com.

\section{AUTHORS' CONCLUSIONS}

\section{Implications for practice}

Among 109 newly identified randomized controlled trials (RCTs), interventions were often complex, involving allied health care providers such as nurses and pharmacists, presumably attempting to overcome multifactorial barriers and to tailor support to individual patient needs. Only 17 RCTs had a low risk of bias for randomization and allocation concealment, and clinical outcome assessment; this low number is likely partly due to the fact that there was often insufficient detail provided to determine risk of bias. Among these 17 RCTs, only five improved both adherence and clinical outcome, which is comparable to the rate found among the 21 new RCTs in our previous update. If there is a common thread to these interventions, it is that they are complex and use frequent interaction with patients with a focus on adherence. However, these complex strategies for improving adherence with long-term medication prescriptions are not very effective, despite the amount of effort and other resources they can consume. There is insufficient evidence at present to conclude that newer intervention types, such as mobile text messaging and Internet-based care, can assist in improving adherence. There is no evidence that low adherence can be 'cured'. Thus, effective methods to improve adherence must be maintained for as long as the treatment is needed, requiring interventions that can be integrated into the care system in a costeffective manner.

\section{Implications for research}

Low adherence affects all self administered treatments, and as the numbers of efficacious treatments continue to grow, investments in fundamental and applied adherence research are likely to pay large dividends. It is possible that interventions to date are not very effective since we do not understand in sufficient detail exactly what the adherence problems are. Frameworks to assist in the development of complex interventions therefore advise preparatory qualitative assessments involving patients and other stakeholders, to understand better the problems and context (Craig 2008).

Despite the steep increase in number of RCTs, the field of adherence improvement research has persistent methodological weaknesses. Rather than increasing the volume of research while repeating weaknesses, several study methodology issues need to be addressed to ensure that we are not missing any true effects or creating false positive findings. Investigators should make use of best-in-class adherence measures, such as prescription monitoring. More objective measures for adherence are needed to accurately determine intervention effects. Patients should be recruited because their adherence is low, not just because they are willing to participate. Researchers should design studies to minimize risk of bias as much as possible and clearly report their procedures, especially concerning co-interventions, such as additional staff supported by research funds. Another priority is attaining sufficient study power for clinical outcomes that are important to patients. Around $40 \%$ of all studies were underpowered, with less than 60 patients per treatment group, and this was a comparable rate to the previous update. Smaller studies may be appropriate until an innovation appears to have clinically 
useful effects. At that point, the innovation should be tested in more substantial trials to document effects on clinically important outcomes (including adverse effects), feasibility in usual practice settings, and sustainability. If complex interventions show positive effects, it would be appropriate to test their components in factorial studies.

A cure for non-adherence is nowhere to be seen, but treatments that obviate the need for ongoing adherence, such as implantable treatments with minimal adverse effects (e.g. intrauterine devices) could be worth pursuing. Intervention components that could be explored further include well-established and newer information and communication technologies on top of regular care, and specific or co-ordinated roles for allied health professionals.

Finally, it is essential that researchers stop re-inventing the poorly performing 'wheels' of adherence interventions that we have seen to date. It seems that most adherence research is performed by clinicians and others who discover adherence problems while working within the context of the management of a specific disease condition, such as cardiovascular risk, diabetes,
HIV/AIDS, and the like. Low adherence with medications is a ubiquitous problem, found with self administered treatments for all medical conditions. Without considering what has been studied across disease conditions, researchers will find themselves with inadequate knowledge of what does not work, and will be unable to avoid repeating the painful lessons of adherence research to date. Rather, we need to begin with interventions that have shown some promise, or at least have not been tested with repeatedly negative results. The methods and innovations of adherence research must advance if we are to be able to help patients enjoy the benefits of modern therapeutics.

\section{A CKN OWLEDGEMENTS}

Our thanks to Norma Brown for assisting with articles screening and Sarah Quayyum for assisting with data extraction. Additionally, our thanks to Juan Manuel Reyes for assisting with the translation of the study published in Spanish. This review has benefited greatly from suggestions from external peer reviewers over the years and we thank them for their advice. 


\section{R E F E R E N C E S}

\section{References to studies included in this review}

\section{Abrahams 2010 \{published data only\}}

Abrahams N, Jewkes R, Lombard C, Mathews S, Campbell J, Meel B. Impact of telephonic psycho-social support on adherence to post-exposure prophylaxis (PEP) after rape. AIDS Care 2010;22(10):1173-81. [MEDLINE: 20640949]

\section{Ahmadipour 2010 \{published data only\}}

Ahmadipour H, Farajzadegan Z, Kachoei A, Pirdehghan A. Secondary prevention by enhancing adherence in diabetic patients. International Journal of Preventive Medicine 2010;1(1):50-5. [EMBASE: 2011116495]

\section{Al-Eidan 2002 \{published data only\}}

Al-Eidan FA, McElnay JC, Scott MG, McConnell JB. Management of Helicobacter pylori eradication--the influence of structured counselling and follow-up. British Journal of Clinical Pharmacology 2002;53(2):163-71. [MEDLINE: 11851640]

\section{Al Mazroui 2009 \{published data only\}}

Al Mazroui NR, Kamal MM, Ghabash NM, Yacout TA, Kole PL, McElnay JC. Influence of pharmaceutical care on health outcomes in patients with Type 2 diabetes mellitus. British Journal of Clinical Pharmacology 2009;67(5):547-57. [MEDLINE: 19552750]

\section{Amado 2011 \{published data only\}}

Amado Guirado E, Pujol Ribera E, Pacheco Huergo V, Borras JM, ADIEHTA Group. Knowledge and adherence to antihypertensive therapy in primary care: results of a randomized trial. Gaceta Sanitaria 2011;25(1):62-7. [MEDLINE: 21354671]

\section{Anderson 2010 \{published data only\}}

Anderson KH, Ford S, Robson D, Cassis J, Rodrigues C, Gray R. An exploratory, randomized controlled trial of adherence therapy for people with schizophrenia. International Journal of Mental Health Nursing 2010;19(5):340-9. [MEDLINE: 20887608]

\section{Andrade 2005 \{published data only\}}

Andrade ASA, McGruder HF, Wu AW, Cilano SA, Skolasky RL Jr, Selnes $\mathrm{OA}$, et al. A programmable prompting device improves adherence to highly active antiretroviral therapy in HIV-infected subjects with memory impairment. Clinical Infectious Diseases 2005;41(6):875-82.

\section{Ansah 2001 \{published data only\}}

Ansah EK, Gyapong JO, Agyepong IA, Evans DB. Improving adherence to malaria treatment for children: the use of prepacked chloroquine tablets vs. chloroquine syrup. Tropical Medicine and International Health 2001;6(7):496-504. [MEDLINE: 11469941]

\section{Antonicelli 2008 \{published data only\}}

Antonicelli R, Mazzanti I, Abbatecola AM, Parati G. Impact of home patient telemonitoring on use of beta-blockers in congestive heart failure. Drugs \& Aging 2010;27(10):801-5. [MEDLINE: 20883060]
* Antonicelli R, Testarmata P, Spazzafumo L, Gagliardi C, Bilo G, Valentini M, et al. Impact of telemonitoring at home on the management of elderly patients with congestive heart failure. Journal of Telemedicine \& Telecare 2008;14(6):300-5. [MEDLINE: 18776075]

\section{Apter 2011 \{published data only\}}

Apter AJ, Wang X, Bogen DK, Rand CS. Problem solving to improve adherence and asthma outcomes in urban adults with moderate or severe asthma: a randomized controlled trial. Journal of Allergy Clinical Immunology 2011;128(3):516-22. [EMBASE: 2011482641]

Bailey 1990 \{published data only\}

Bailey WC, Richards JM Jr, Brooks CM, Soong SJ, Windsor RA, Manzella BA. A randomized trial to improve self-management practices of adults with asthma. Archives of Internal Medicine 1990;150(8):1664-8.

\section{Bailey 1999 \{published data only\}}

Bailey WC, Kohler CL, Richards JM, Windsor RA, Brooks CM, Gerald LB, et al. Asthma self-management: do patient education programs always have an impact?. Archives of Internal Medicine 1999;159(20):2422-8.

\section{Baird 1984 \{published data only\}}

Baird MG, Bentley-Taylor MM, Carruthers SG, Dawson KG Laplante LE, Larochelle P, et al. A study of efficacy, tolerance and compliance of once-daily versus twice-daily metoprolol (Betaloc) in hypertension. Betaloc Compliance Canadian Cooperative Study Group. Clinical and Investigative Medicine 1984; 7(2):95-102

\section{Beaucage 2006 \{published data only\}}

Beaucage K, Lachance-Demers H, Ngo TT, Vachon C, Lamarre D, Guevin JF, et al. Telephone follow-up of patients receiving antibiotic prescriptions from community pharmacies. American Journal of Health-System Pharmacy 2006;63(6):557-63.

Becker 1986 \{published data only\}

Becker LA, Glanz K, Sobel E, Mossey J, Zinn SL, Knott KA. A randomized trial of special packaging of antihypertensive medications. Journal of the American Board of Family Practice 1986;22(4):357-61.

\section{Berrien 2004 \{published data only\}}

Berrien VM, Salazar JC, Reynolds E, McKay K, HIV Medication Adherence Intervention Group. Adherence to antiretroviral therapy in HIV-infected pediatric patients improves with homebased intensive nursing intervention. AIDS Patient Care STDS 2004;18(6):355-63. [MEDLINE: 15294086]

\section{Boker 2012 \{published data only\}}

Boker A, Feetham HJ, Armstrong A, Purcell P, Jacobe H. Do automated text messages increase adherence to acne therapy? Results of a randomized, controlled trial. Journal of the American Academy of Dermatology 2012;67(6):1136-42. [EMBASE: 2012668666] 


\section{Bond 2007 \{published data only\}}

Bond C. The MEDMAN study: A randomized controlled trial of community pharmacy-led medicines management for patients with coronary heart disease. Family Practice 2007;24(2):189-200. [EMBASE: 2007351003]

\section{Bonner 2009 \{published data only\}}

Bonner S, Zimmerman BJ, Evans D, Irigoyen M, Resnick D, Mellins RD. An individualized intervention to improve asthma management among urban Latino and African-American families. Journal of Asthma 2002;39(2):167-79. [2009-05630-008]

\section{Brown 1997a \{published data only\}}

Brown BG, Bardsley J, Poulin D, Hillger LA, Dowdy A, Maher VM, et al. Moderate dose, three-drug therapy with niacin, lovastatin, and colestipol to reduce low-density lipoprotein cholesterol $<100 \mathrm{mg} / \mathrm{dl}$ in patients with hyperlipidemia and coronary artery disease. American Journal of Cardiology 1997;80(2):111-5.

\section{Brus 1998 \{published data only\}}

Brus HL, van de Laar MA, Taal E, Rasker JJ, Wiegman O. Effects of patient education on compliance with basic treatment regimens and health in recent onset active rheumatoid arthritis. Annals of the Rheumatic Diseases 1998;57(3):146-51.

\section{Bruzzese 2011 \{published data only\}}

Bruzzese JM, Sheares BJ, Vincent EJ, Du Y, Sadeghi H, Levison MJ, et al. Effects of a school-based intervention for urban adolescents with asthma. A controlled trial. American Journal of Respiratory \& Critical Care Medicine 2011;183(8):998-1006. [MEDLINE: 21139088]

\section{Burgess 2007 \{published data only\}}

Burgess SW, Sly PD, Cooper DM, Devadason SG. Novel spacer device does not improve adherence in childhood asthma. Pediatric Pulmonology 2007;42(8):736-9. [MEDLINE: 17588243]

\section{Chamorro 2011 \{published data only\}}

Chamorro MA, Garcia-Jimenez E, Amariles P, Chamorro AR, Merino EM, Martinez FM, et al. Effect of pharmacist involvement in adherence to medications in patients with high to moderate cardiovascular risk (Study EMDADER-CV-INCUMPLIMIENTO) [Efecto de la actuación farmacéutica en la adherencia deltratamiento farmacológico de pacientes ambulatorios con riesgocardiovascular (Estudio EMDADER-CV-INCUMPLIMIENTO)] Atencion Primaria 2011;43(5):245-53. [MEDLINE: 21211865]

\section{Chan 2007 \{published data only\}}

Chan DS, Callahan CW, Hatch-Pigott VB, Lawless A, Proffitt HL, Manning NE, et al. Internet-based home monitoring and education of children with asthma is comparable to ideal officebased care: results of a 1-year asthma in-home monitoring trial. Pediatrics 2007;119(3):569-78. [MEDLINE: 17332210]

\section{Chaplin 1998 \{published data only\}}

Chaplin R, Kent A. Informing patients about tardive dyskinesia: controlled trial of patient education. British Journal of Psychiatry 1998;Jan(172):78-81. [MEDLINE: 98196336]
Charles 2007 \{published data only\}

Charles T, Quinn D, Weatherall M, Aldington S, Beasley R, Holt S. An audiovisual reminder function improves adherence with inhaled corticosteroid therapy in asthma. Journal of Allergy \& Clinical Immunology 2007;119(4):811-6. [MEDLINE: 17320942]

Choudhry 2011 \{published data only\}

* Choudhry NK, Avorn J, Glynn RJ, Antman EM, Schneeweiss S, Toscano M, et al. Full coverage for preventive medications after myocardial infarction. New England Journal of Medicine 2011;365(22):2088-97. [CENTRAL: CN-00804850]

Choudhry NK, Brennan T, Toscano M, Spettell C, Glynn RJ, Rubino M, et al. Rationale and design of the Post-MI FREEE trial: a randomized evaluation of first-dollar drug coverage for postmyocardial infarction secondary preventive therapies. American Heart Journal 2008;156(1):31-6. [MEDLINE: 18585494]

Chung 2011 \{published data only\}

Chung MH, Richardson BA, Tapia K, Benki-Nugent S, Kiarie JN, Simoni JM, et al. A randomized controlled trial comparing the effects of counseling and alarm device on HAART adherence and virologic outcomes. Public Library of Science 2011;8(3):e1000422. [MEDLINE: 21390262]

\section{Colcher 1972 \{published data only\}}

Colcher IS, Bass JW. Penicillin treatment of streptococcal pharyngitis. A comparison of schedules and the role of specific counseling. JAMA 1972;222(6):657-9.

Collier 2005 \{published data only\}

Collier AC, Ribaudo H, Mukherjee AL, Feinberg J, Fischl MA, Chesney M, Adult AIDS Clinical Trials Group 746 Substudy Team. A randomized study of serial telephone call support to increase adherence and thereby improve virologic outcome in persons initiating antiretroviral therapy. Journal of Infectious Diseases 2005;192(8):1398-406.

\section{Cooper 2010 \{published data only\}}

Cooper V, Horne R, Gellaitry G, Vrijens B, Lange AC, Fisher M, et al. The impact of once-nightly versus twice-daily dosing and baseline beliefs about HAART on adherence to efavirenz-based HAART over 48 weeks: the NOCTE study. Journal of Acquired Immune Deficiency Syndromes 2010;53(3):369-77. [CENTRAL: CN-00734255]

\section{Costa 2008 \{published data only\}}

Costa e Silva R, Pellanda L, Portal V, Maciel P, Furquim A, Schaan B. Transdisciplinary approach to the follow-up of patients after myocardial infarction. Clinics (Sao Paulo, Brazil) 2008;63(4):489-96. [CENTRAL: CN-00700502]

\section{Cote 1997 \{published data only\}}

Cote J, Cartier A, Robichaud P, Boutin H, Malo JL, Rouleau M, et al. Influence on asthma morbidity of asthma education programs based on self-management plans following treatment optimization. American Journal of Respiratory and Critical Care Medicine 1997;155(5):1509-14. 
Cote 2001 \{published data only\}

Cote J, Bowie DM, Robichaud P, Parent JG, Battisti L, Boulet LP. Evaluation of two different educational interventions for adult patients consulting with an acute asthma exacerbation. American Journal of Respiratory and Critical Care Medicine 2001;163(6):1415-9. [MEDLINE: 11371411]

\section{Coull 2004 \{published data only\}}

Coull AJ, Taylor VH, Elton R, Murdoch PS, Hargreaves AD. A randomised controlled trial of senior Lay Health Mentoring in older people with ischaemic heart disease: The Braveheart Project. Age and Ageing 2004;33(4):348-54. [MEDLINE: 15136288]

\section{Dejesus 2009 \{published data only\}}

* Dejesus E, Young B, Morales-Ramirez JO, Sloan L, Ward DJ, Flaherty JF, et al. Simplification of antiretroviral therapy to a single-tablet regimen consisting of efavirenz, emtricitabine, and tenofovir disoproxil fumarate versus unmodified antiretroviral therapy in virologically suppressed HIV-1-infected patients. Journal of Acquired Immune Deficiency Syndromes 2009;51(2):163-74. [MEDLINE: 19357529]

Hodder SL, Mounzer K, Dejesus E, Ebrahimi R, Grimm K, Esker S, et al. Al266073 Study Group. Patient-reported outcomes in virologically suppressed, HIV-1-Infected subjects after switching to a simplified, single-tablet regimen of efavirenz, emtricitabine, and tenofovir DF. AIDS Patient Care \& STDS 2010;24(2):87-96. [MEDLINE: 20156091]

\section{Dilorio 2008 \{published data only\}}

Dilorio C, McCarty F, Resnicow K, McDonnell Holstad M, Soet J, Yeager $\mathrm{K}$, et al. Using motivational interviewing to promote adherence to antiretroviral medications: a randomized controlled study. AIDS Care 2008;20(3):273-83. [MEDLINE: 18351473]

\section{Druss 2010 \{published data only\}}

Druss BG, Zhao L, von Esenwein SA, Bona JR, Fricks L, JenkinsTucker S, et al. The Health and Recovery Peer (HARP) Program: a peer-led intervention to improve medical self-management for persons with serious mental illness. Schizophrenia Research 2010;118(1-3):264-70. [MEDLINE: 20185272]

\section{Duncan 2012 \{published data only\}}

Duncan LG, Moskowitz JT, Neilands TB, Dilworth SE, Hecht FM, Johnson MO. Mindfulness-based stress reduction for HIV treatment side effects: a randomized, wait-list controlled trial. Journal of Pain \& Symptom Management 2012;43(2):161-71.

\section{Dusing 2009 \{published data only\}}

Dusing R, Handrock R, Klebs S, Tousset E, Vrijens B. Impact of supportive measures on drug adherence in patients with essential hypertension treated with valsartan: the randomized, open-label, parallel group study VALIDATE. Journal of Hypertension 2009;27(4):894-901. [MEDLINE: 19300114]

\section{Ellis 2005 \{published data only\}}

Ellis DA, Frey MA, Naar-King S, Templin T, Cunningham P, Cakan N. Use of multisystemic therapy to improve regimen adherence among adolescents with type 1 diabetes in chronic poor metabolic control: a randomized controlled trial. Diabetes Care 2005;28(7):1604-10.

Ellis 2012 \{published data only\}

Ellis DA, Naar-King S, Chen X, Moltz K, Cunningham PB, IdalskiCarcone A. Multisystemic therapy compared to telephone support for youth with poorly controlled diabetes: findings from a randomized controlled trial. Annals of Behavioral Medicine 2012;44(2):207-15. [2012-25446-010]

El Miedany 2011 \{published data only\}

El Miedany Y, El Gaafary M, Palmer D. A controlled pilot assessment of the utility of visual feedback in the treatment of early rheumatoid arthritis. Rheumatology International 2012;32(10):3061-8. [EMBASE: 70557966]

Evans 2010 \{published data only\}

Evans CD, Eurich DT, Taylor JG, Blackburn DF. The Collaborative Cardiovascular Risk Reduction in Primary Care (CCARP) study. Journal of Human Pharmacology \& Drug Therapy 2010;30(8):766-75. [MEDLINE: 20653352]

\section{Falces 2008 \{published data only\}}

Falces C, Lopez-Cabezas C, Andrea R, Arnau A, Ylla M, Sadurni J. An educative intervention to improve treatment compliance and to prevent readmissions of elderly patients with heart failure [Intervención educativa para mejorarel cumplimiento del tratamiento y prevenirreingresos en pacientes de edad avanzadacon insuficiencia cardíaca]. Medicina Clinica 2008;131(12):452-6. [MEDLINE: 18928735]

\section{Farber 2004 \{published data only\}}

Farber HJ, Oliveria L. Trial of an asthma education program in an inner-city pediatric emergency department. Pediatric Asthma Allergy \& Immunology 2004;17(2):107-15. [MEDLINE: Not available]

\section{Farooq 2011 \{published data only\}}

Farooq S, Nazar Z, Irfan M, Akhter J, Gul E, Irfan U, et al. Schizophrenia medication adherence in a resource-poor setting: randomised controlled trial of supervised treatment in out-patients for schizophrenia (STOPS). British Journal of Psychiatry 2011;199(6):467-72. [MEDLINE: 22130748]

\section{Fisher 2011 \{published data only\}}

Fisher JD, Amico KR, Fisher WA, Cornman DH, Shuper PA, Trayling C, et al. Computer-based intervention in HIV clinical care setting improves antiretroviral adherence: the LifeWindows Project. AIDS \& Behavior 2011;15(8):1635-46. [MEDLINE: 21452051]

\section{Fortney 2007 \{published data only\}}

Fortney JC, Pyne JM, Edlund MJ, Robinson DE, Mittal D, Henderson KL. Design and implementation of the telemedicineenhanced antidepressant management study. General Hospital Psychiatry 2006;28(1):18-26. [16377361]

* Fortney JC, Pyne JM, Edlund MJ, Williams DK, Robinson DE, Mittal D, et al. A randomized trial of telemedicine-based collaborative care for depression. Journal of General Internal Medicine 2007;22(8):1086-93. [MEDLINE: 17492326] 


\section{Friedman 1996 \{published data only\}}

Friedman RH, Kazis LE, Jette A, Smith MB, Stollerman J, Torgerson J, et al. A telecommunications system for monitoring and counseling patients with hypertension. Impact on medication adherence and blood pressure control. American Journal of Hypertension 1996;9(4 Pt 1):285-92.

\section{Gallefoss 1999 \{published data only\}}

Gallefoss E, Bakke PS, Kjaersgaard P. Quality of life assessment after patient education in a randomized controlled study on asthma and chronic obstructive pulmonary disease. American Journal of Respiratory and Critical Care Medicine 1999;159(3):812-7.

* Gallefoss F, Bakke PS. How does patient education and self-management among asthmatics and patients with chronic obstructive pulmonary disease affect medication?. American Journal of Respiratory and Critical Care Medicine 1999;160(6):2000-5.

\section{Gamble 2011 \{published data only\}}

Gamble J, Stevenson M, Heaney LG. A study of a multi-level intervention to improve non-adherence in difficult to control asthma. Respiratory Medicine 2011;105(9):1308-15. [MEDLINE: 21511454]

\section{Gani 2001 \{published data only\}}

Gani F, Pozzi E, Crivellaro MA, Senna G, Landi M, Lombardi C, et al. The role of patient training in the management of seasonal rhinitis and asthma: clinical implications. Allergy 2001;56(1):65-8. [MEDLINE: 11167354]

\section{Gensichen 2009 \{published data only\}}

Gensichen J, Torge M, Peitz M, Wendt-Hermainski H, Beyer M, Rosemann T, et al. Case management for the treatment of patients with major depression in general practices--rationale, design and conduct of a cluster randomized controlled trial-PRoMPT (PRimary care Monitoring for depressive Patient's Trial) [ISRCTN66386086] -Study protocol. BMC Public Health 2005;5(5):101. [16207375]

* Gensichen J, von Korff M, Peitz M, Muth C, Beyer M, Guthlin C, et al. Case management for depression by health care assistants in small primary care practices: a cluster randomized trial. Annals of Internal Medicine 2009;151(6):369-78. [MEDLINE: 19755362]

\section{Ginde 2003 \{published data only\}}

Ginde AA, Von Harz BC, Turnbow D, Lewis LM. The effect of ED prescription dispensing on patient compliance. American Journal of Emergency Medicine 2003;21(4):313-5. [MEDLINE: 12898489]

\section{Girvin 1999 \{published data only\}}

Girvin B, McDermott BJ, Johnston GD. A comparison of enalapril $20 \mathrm{mg}$ once daily vs. $10 \mathrm{mg}$ twice daily in terms of blood pressure lowering and patient compliance. Journal of Hypertension 1999;17(11):1627-31.
Gould 2009 \{published data only\}

Gould, KA. A randomized controlled trial of a discharge nursing intervention to promote self-regulation of care for early discharge interventional cardiology patients. Dimensions of Critical Care Nursing 2011;30(2):117-25. [2010543867]

Gray 2012 \{published data only\}

Gray TA, Fenerty C, Harper R, Spencer AF, Campbell M, Henson DB, et al. Individualised patient care as an adjunct to standard care for promoting adherence to ocular hypotensive therapy: an exploratory randomised controlled trial. Eye 2012;26(3):407-17. [MEDLINE: 22094303]

Hamann 2007 \{published data only\}

* Hamann J, Cohen R, Leucht S, Busch R, Kissling W. Shared decision making and long-term outcome in schizophrenia treatment. Journal of Clinical Psychiatry 2007;68(7):992-7. [MEDLINE: 17685733]

Hamann J, Langer B, Winkler V, Busch R, Cohen R, Leucht S, et al. Shared decision making for in-patients with schizophrenia. Acta Psychiatrica Scandinavica 2006;114(4):265-73. [000014]

Haynes 1976 \{published data only\}

Haynes RB, Sackett DL, Gibson ES, Taylor DW, Hackett BC, Roberts RS, et al. Improvement of medication compliance in uncontrolled hypertension. Lancet 1976;1(7972):1265-8.

Hederos 2005 \{published data only\}

* Hederos CA, Janson S, Hedlin G. Group discussions with parents have long-term positive benefits on the management of asthma with good cost-benefit. Acta Paediatrica 2005;94(5):602-8.

Hederos CA, Janson S, Hedlin G. Six-year follow-up of an intervention to improve the management of preschool children with asthma. Acta Paediatrica 2009;98(12):1939-44. [MEDLINE: 19689480]

\section{Heisler 2010 \{published data only\}}

Heisler M, Vijan S, Makki F, Piette JD. Diabetes control with reciprocal peer support versus nurse care management: a randomized trial. Annals of Internal Medicine 2010;153(8):507-15. [MEDLINE: 20956707]

\section{Henry 1999 \{published data only\}}

Henry A, Batey RG. Enhancing compliance not a prerequisite for effective eradication of Helicobacter pylori: the HelP Study. American Journal of Gastroenterology 1999;94(3):811-5.

Hill 2001 \{published data only\}

Hill J, Bird H, Johnson S. Effect of patient education on adherence to drug treatment for rheumatoid arthritis: a randomised controlled trial. Annals of the Rheumatic Diseases 2001;60(9):869-75. [MEDLINE: 11502614]

Holland 2007 \{published data only\}

Holland R, Brooksby I, Lenaghan E, Ashton K, Hay L, Smith R, et al. Effectiveness of visits from community pharmacists for patients with heart failure: HeartMed randomised controlled trial. BMJ 2007;334(7603):1098-101. 
Holstad 2011 \{published data only\}

Holstad MM, Dilorio C, Kelley ME, Resnicow K, Sharma S. Group motivational interviewing to promote adherence to antiretroviral medications and risk reduction behaviors in HIV infected women. AIDS \& Behavior 2011;15(5):885-96. [MEDLINE: 21165692]

\section{Hou 2010 \{published data only\}}

Hou MY, Hurwitz S, Kavanagh E, Fortin J, Goldberg AB. Using daily text-message reminders to improve adherence with oral contraceptives: a randomized controlled trial. Obstetrics and Gynecology 2010;116(3):633-40. [MEDLINE: 20733446]

\section{Howe 2005 \{published data only\}}

Howe CJ, Jawad AF, Tuttle AK, Moser JT, Preis C, Buzby M, et al. Education and telephone case management for children with type 1 diabetes: a randomized controlled trial. Journal of Pediatric Nursing 2005;20(2):83-95.

\section{Howland 1990 \{published data only\}}

Howland JS, Baker MG, Poe T. Does patient education cause side effects? A controlled trial. Journal of the American Board of Family Practice 1990;31(1):62-4.

\section{Huguelet 2011 \{published data only\}}

Huguelet P, Mohr S, Betrisey C, Borras L, Gillieron C, Marie AM, et al. A randomized trial of spiritual assessment of outpatients with schizophrenia: patients' and clinicians' experience. Psychiatric Services 2011;62(1):79-86. [MEDLINE: 21209304]

\section{Janson 2009 \{published data only\}}

Janson SL, McGrath KW, Covington JK, Cheng SC, Boushey HA. Individualized asthma self-management improves medication adherence and markers of asthma control. Journal of Allergy \& Clinical Immunology 2009;123(4):840-6. [MEDLINE: 19348923]

\section{Jarab 2012 a \{published data only\}}

Jarab AS, Alqudah SG, Mukattash TL, Shattat G, Al-Qirim T. Randomized controlled trial of clinical pharmacy management of patients with type 2 diabetes in an outpatient diabetes clinic in Jordan. Journal of Managed Care Pharmacy 2012;18(7):516-26. [EMBASE: 2012617789]

\section{Jarab 2012 b \{published data only\}}

Jarab AS, Alqudah SG, Khdour M, Shamssain M, Mukattash TL. Impact of pharmaceutical care on health outcomes in patients with COPD. International Journal of Clinical Pharmacy 2012;34(1):53-62. [MEDLINE: 22101426]

\section{Jiang 2007 \{published data only\}}

Jiang X, Sit JW, Wong TK. A nurse-led cardiac rehabilitation programme improves health behaviours and cardiac physiological risk parameters: evidence from Chengdu, China. Journal of Clinical Nursing 2007;16(10):1886-97. [MEDLINE: 17880478]

\section{Johnson 1978 \{published data only\}}

Johnson AL, Taylor DW, Sackett DL, Dunnett CW, Shimizu AG. Self recording of blood pressure in the management of hypertension. Canadian Medical Association Journal 1978;119(9):1034-9.

\section{Johnson 2011 \{published data only\}}

Johnson MO, Dilworth SE, Taylor JM, Neilands TB. Improving coping skills for self-management of treatment side effects can reduce antiretroviral medication nonadherence among people living with HIV. Annals of Behavioral Medicine 2011;41(1):83-91. [MEDLINE: 20922510]

\section{Kalichman 2011 \{published data only\}}

Kalichman SC, Cherry C, Kalichman MO, Amaral CM, White D, Pope $\mathrm{H}$, et al. Integrated behavioral intervention to improve HIV/AIDS treatment adherence and reduce HIV transmission. American Journal of Public Health 2011;101(3):531-8. [MEDLINE: 21233431]

\section{Kato 2008 \{published data only\}}

Kato PM, Cole SW, Bradlyn AS, Pollock BH. A video game improves behavioral outcomes in adolescents and young adults with cancer: a randomized trial. Pediatrics 2008;122(2):e305-17. [MEDLINE: 18676516]

\section{Katon 2001 \{published data only\}}

* Katon W, Rutter C, Ludman EJ, Von Korff M, Lin E, Simon G, et al. A randomized trial of relapse prevention of depression in primary care. Archives of General Psychiatry 2001;58(3):241-7.

Ludman E, Katon W, Bush T, Rutter C, Lin E, Simon M, et al. Behavioural factors associated with symptom outcomes in a primary care-based depression prevention intervention trial. Psychological Medicine 2003;33(6):1061-70.

Von Korff M, Katon W, Rutter C, Ludman E, Simon G, Lin E, et al. Effect on disability outcomes of a depression relapse prevention program. Psychosomatic Medicine 2003;65(6):938-43.

\section{Kemp 1996 \{published data only\}}

Kemp R, Hayward P, Applewhaite G, Everitt B, David A. Compliance therapy in psychotic patients: randomised controlled trial. BMJ 1996;312(7027):345-9.

\section{Kemp 1998 \{published data only\}}

Kemp R, Kirov G, Everitt B, Hayward P, David A. Randomised controlled trial of compliance therapy. 18-month follow-up. British Journal of Psychiatry 1998;172(May):413-9.

Khdour 2009 \{published data only\}

Khdour MR, Kidney JC, Smyth BM, McElnay JC. Clinical pharmacy-led disease and medicine management programme for patients with COPD. British Journal of Clinical Pharmacology 2009;68(4):588-98. [MEDLINE: 19843062]

\section{Kimmel 2012 \{published data only\}}

Kimmel SE, Troxel AB, Loewenstein G, Brensinger CM, Jaskowiak J, Doshi JA, et al. Randomized trial of lottery-based incentives to improve warfarin adherence. American Heart Journal 2012;164(2):268-74. [MEDLINE: 22877814]

Klein 2009 \{published data only\}

Klein A, Otto G, Kramer I. Impact of a pharmaceutical care program on liver transplant patients' compliance with immunosuppressive medication: a prospective, randomized, 
controlled trial using electronic monitoring. Transplantation 2009;87(6):839-47. [MEDLINE: 19300186]

Knobel 1999 \{published data only\}

Knobel H, Carmona A, Lopez LJ, Gimeno JL, Saballs P, Gonzalez A, et al. Adherence to very active antiretroviral treatment: impact of individualized assessment [Spanish] [Adherencia al tratamiento antirretroviral de gran actividad: impacto de una intervencion de asesoramiento individualizado]. Enfermedades Infecciosas y Microbiologia Clinica 1999;17(2):78-81.

\section{Kunutsor 2011 \{published data only\}}

Kunutsor S, Evans M, Thoulass J, Walley J, Katabira E, Newell JN, et al. Ascertaining baseline levels of antiretroviral therapy adherence in Uganda: a multimethod approach. Journal of Acquired Immune Deficiency Syndromes 2010;55(2):221-4. [MEDLINE: 20531208]

* Kunutsor S, Walley J, Katabira E, Muchuro S, Balidawa H, Namagala $\mathrm{E}$, et al. Improving clinic attendance and adherence to antiretroviral therapy through a treatment supporter intervention in Uganda: a randomized controlled trial. AIDS \& Behavior 2011;15(8):1795-802. [MEDLINE: 21424272]

\section{Lai 2011 \{published data only\}}

Lai PS, Chua SS, Chew YY, Chan SP. Effects of pharmaceutical care on adherence and persistence to bisphosphonates in postmenopausal osteoporotic women. Journal of Clinical Pharmacy \& Therapeutics 2011;36(5):557-67. [MEDLINE: 21916908]

\section{Laporte 2003 \{published data only\}}

Laporte S, Quenet S, Buchmuller-Cordier A, Reynaud J, TardyPoncet B, Thirion C, et al. Compliance and stability of INR of two oral anticoagulants with different half-lives: a randomised trial. Thrombosis and Haemostasis 2003;89(3):458-67. [MEDLINE: 12624628]

\section{Larrey 2011 \{published data only\}}

Larrey D, Salse A, Ribard D, Boutet O, Hyrailles-Blanc V, Niang $B$, et al. Education by a nurse increases response of patients with chronic hepatitis $C$ to therapy with peginterferonalpha2a and ribavirin. Clinical Gastroenterology \& Hepatology 2011;9(9):781-5. [MEDLINE: 21683161]

\section{Lee 2006 \{published data only\}}

Lee JK, Grace KA, Taylor AJ. Effect of a pharmacy care program on medication adherence and persistence, blood pressure, and low-density lipoprotein cholesterol: a randomized controlled trial. JAMA 2006;296(21):2563-71.

\section{Lester 2010 \{published data only\}}

Lester RT, Mills EJ, Kariri A, Ritvo P, Chung M, Jack W, et al. The HAART cell phone adherence trial (WelTel Kenya1): a randomized controlled trial protocol. Trials 2009;10(Sept):87-97. [CENTRAL: CN-00721966]

* Lester RT, Ritvo P, Mills EJ, Kariri A, Karanja S, Chung MH, et al. Effects of a mobile phone short message service on antiretroviral treatment adherence in Kenya (WelTel Kenya1): a randomised trial. Lancet 2010;376(9755):1838-45. [MEDLINE: 21071074]

Levy 2000 \{published data only\}

Levy ML, Robb M, Allen J, Doherty C, Bland JM, Winter RJD. A randomized controlled evaluation of specialist nurse education following accident and emergency department attendance for acute asthma. Respiratory Medicine 2000;94:900-8.

Maitland 2008 \{published data only\}

Maitland D, Jackson A, Osorio J, Mandalia S, Gazzard BG, Moyle GJ, et al. Switching from twice-daily abacavir and lamivudine to the once-daily fixed-dose combination tablet of abacavir and lamivudine improves patient adherence and satisfaction with therapy. HIV Medicine 2008;9(8):667-72. [MEDLINE: 18631255]

\section{Margolius 2012 \{published data only\}}

Bennett H, Laird K, Margolius D, Ngo V, Thom DH, Bodenheimer T. The effectiveness of health coaching, home blood pressure monitoring, and home-titration in controlling hypertension among low-income patients: protocol for a randomized controlled trial. BMC Public Health 2009;10(9):456. [000017]

* Margolius D, Bodenheimer T, Bennett H, Wong J, Ngo V, Padilla G, et al. Health coaching to improve hypertension treatment in a low-income, minority population. Annals of Family Medicine 2012;10(3):199-205. [5581]

\section{Marquez Contreras 2004 \{published data only\}}

Marquez Contreras E, Casado Martinez JJ, Corchado Albalat Y, Chaves Gonzalez R, Grandio A, Losada Velasco C, et al. Efficacy of an intervention to improve treatment compliance in hyperlipidemias [Eficacia de una intervención para mejorar elcumplimiento terapéutico en las dislipemias]. Atencion Primaria 2004;33(8):443-50. [MEDLINE: 15151791]

\section{Marquez Contreras 2005 \{published data only\}}

Marquez Contreras E, Vegazo Garcia O, Claros NM, Gil Guillen V, de la Figuera von Wichmann M, Casado Martinez JJ, et al. Efficacy of telephone and mail intervention in patient compliance with antihypertensive drugs in hypertension: ETECUM-HTA Study. Blood Pressure 2005;14(3):151-8.

\section{Marquez Contreras 2006 \{published data only\}}

Marquez-Contreras E, Martell-Claros N, Gil-Guillen V, de la Figuera-Von Wichmann M, Casado-Martinez JJ, Martin-de Pablos JL, et al. Compliance Group of the Spanish Society of Hypertension (SEE). Efficacy of a home blood pressure monitoring programme on therapeutic compliance in hypertension: the EAPACUM-HTA study. Journal of Hypertension 2006;24(1):169-75.

\section{Marquez Contreras 2007 \{published data only\}}

Marquez Contreras E, Casado Martinez JJ, Motero Carrasco J, Martin de Pablos JL, Chaves Gonzalez R, Losada Ruiz C, et al. Therapy compliance in cases of hyperlipaemia, as measured through electronic monitors. Is a reminder calendar to avoid forgetfulness effective? [El cumplimiento terapeutico en las dislipemias medido mediante monitores electronicos. Es eficaz 
un calendario reconrdatorio para evitar los olvidos?]. Atencion Primaria 2007;39(12):661-8. [MEDLINE: 18093505]

\section{Martins 2009 \{published data only\}}

Martins N, Morris P, Kelly PM. Food incentives to improve completion of tuberculosis treatment: randomised controlled trial in Dili, Timor-Leste. BMJ 2009;339(7730):b4248.

[2009-23305-002]

\section{Matsumura 2012 \{published data only\}}

Matsumura K, Arima H, Tominaga M, Ohtsubo T, Sasaguri T, Fujii K, et al. Does a combination pill of antihypertensive drugs improve medication adherence in Japanese? A randomized controlled trial. Circulation Journal 2012;76(6):1415-22. [22447014]

\section{Mehuys 2011 \{published data only\}}

Mehuys E, Van Bortel L, De Bolle L, Van Tongelen I, Annemans L, Remon JP, et al. Effectiveness of a community pharmacist intervention in diabetes care: a randomized controlled trial. Journal of Clinical Pharmacy \& Therapeutics 2011;36(5):602-13. [MEDLINE: 21143256]

\section{Merinder 1999 \{published data only\}}

Merinder LB, Viuff AG, Laugesen HD, Clemmensen K, Misfelt S, Espensen $B$. Patient and relative education in community psychiatry: a randomized controlled trial regarding its effectiveness. Social Psychiatry and Psychiatric Epidemiology 1999;34(6):287-94.

\section{Morgado 2011 \{published data only\}}

Morgado M, Rolo S, Castelo-Branco M. Pharmacist intervention program to enhance hypertension control: a randomised controlled trial. International Journal of Clinical Pharmacy 2011;33(1):132-40. [MEDLINE: 21365405]

\section{Morice 2001 \{published data only\}}

Morice $\mathrm{AH}$, Wrench $\mathrm{C}$. The role of the asthma nurse in treatment compliance and self-management following hospital admission. Respiratory Medicine 2001;95(11):851-6. [MEDLINE: 11716197]

\section{Moshkovska 2011 \{published data only\}}

Moshkovska T, Stone MA, Smith RM, Bankart J, Baker R, Mayberry JF. Impact of a tailored patient preference intervention in adherence to 5-aminosalicylic acid medication in ulcerative colitis: results from an exploratory randomized controlled trial. Inflammatory Bowel Diseases 2011;17(9):1874-81. [MEDLINE: 21830265]

\section{Mullan 2009 \{published data only\}}

Breslin M, Mullan RJ, Montori VM. The design of a decision aid about diabetes medications for use during the consultation with patients with type 2 diabetes. Patient Education \& Counseling 2008;73(3):465-72. [18771876]

* Mullan RJ, Montori VM, Shah ND, Christianson TJ, Bryant SC, Guyatt $\mathrm{GH}$, et al. The diabetes mellitus medication choice decision aid: a randomized trial. Archives of Internal Medicine 2009;169(17):1560-8. [MEDLINE: 19786674]
Muniz 2010 \{published data only\}

Muniz J, Gomez-Doblas JJ, Santiago-Perez MI, LekuonaGoya I, Murga-Eizagaetxebarria N, de Teresa-Galvan ss E, et al. The effect of post-discharge educational intervention on patients in achieving objectives in modifiable risk factors six months after discharge following an episode of acute coronary syndrome, (CAM-2 Project): a randomized controlled trial. Health and Quality of Life Outcomes 2010;8(Nov):137. [EMBASE: 2011011819]

\section{Murray 2007 \{published data only\}}

Murray MD, Young J, Hoke S, Tu W, Weiner M, Morrow D, et al. Pharmacist intervention to improve medication adherence in heart failure: a randomized trial. Annals of Internal Medicine 2007;146(10):714-25. [MEDLINE: 17502632]

\section{Nazareth 2001 \{published data only\}}

Nazareth I, Burton A, Shulman S, Smith P, Haines A, Timberal H. A pharmacy discharge plan for hospitalized elderly patients: a randomized controlled trial. Age and Ageing 2001;30(1):33-40. [MEDLINE: 11322670]

\section{Nguyen 2008 \{published data only\}}

Nguyen P, Nava-Ocampo A, Levy A, O'Connor DL, Einarson TR, Taddio A, et al. Effect of iron content on the tolerability of prenatal multivitamins in pregnancy. BMC Pregnancy \& Childbirth 2008;8(May):17-24. [MEDLINE: 18482454]

\section{Nieuwkerk 2012 \{published data only\}}

Nieuwkerk PT, Nierman MC, Vissers MN, Locadia M, GreggersPeusch P, Knape LP, et al. Intervention to improve adherence to lipid-lowering medication and lipid-levels in patients with an increased cardiovascular risk. American Journal of Cardiology 2012;110(5):666-72. [22621795]

\section{O'Donnell 2003 \{published data only\}}

O'Donnell C, Donohoe G, Sharkey L, Owens N, Migone M, Harries R, et al. Compliance therapy: a randomized trial in schizophrenia. BMJ 2003;327(7419):834-7. [MEDLINE: 14551096]

\section{Odegard 2005 \{published data only\}}

Odegard PS, Goo A, Hummel J, Williams KL, Gray SL. Caring for poorly controlled diabetes mellitus: a randomized pharmacist intervention. Annals of Pharmacotherapy 2005;39(3):433-40.

\section{Ogedegbe 2012 \{published data only\}}

Ogedegbe G, Schoenthaler A, Richardson T, Lewis L, Belue R, Espinosa E, et al. An RCT of the effect of motivational interviewing on medication adherence in hypertensive African Americans: rationale and design. Contemporary Clinical Trials 2007;28(2):169-81. [MEDLINE: 16765100]

* Ogedegbe GO, Boutin-Foster C, Wells MT, Allegrante JP, Isen AM, Jobe JB, et al. A randomized controlled trial of positive-affect intervention and medication adherence in hypertensive African Americans. Archives of Internal Medicine 2012;172(4):322-6. [MEDLINE: 22269592]

Okeke 2009 \{published data only\}

Okeke CO, Quigley HA, Jampel HD, Ying GS, Plyler RJ, Jiang Y, et al. Interventions improve poor adherence with once daily 
glaucoma medications in electronically monitored patients. Ophthalmology 2009;116(12):2286-93. [MEDLINE: 19815286]

Otsuki 2009 \{published data only\}

Otsuki M, Eakin MN, Rand CS, Butz AM, Hsu VD, Zuckerman IH, et al. Adherence feedback to improve asthma outcomes among inner-city children: a randomized trial. Pediatrics 2009;124(6):1513-21. [MEDLINE: 19948623]

\section{Parienti 2007 \{published data only\}}

Parienti JJ, Massari V, Reliquet V, Chaillot F, Le Moal G, Arvieux C, POSOVIR Study Group. Effect of twice-daily nevirapine on adherence in HIV-1-infected patients: a randomized controlled study. AIDS 2007;21(16):2217-22. [MEDLINE: 18090049]

\section{Parsons 2007 \{published data only\}}

Parsons JT, Golub SA, Rosof Elana, Holder C. Motivational interviewing and cognitive-behavioral intervention to improve HIV medication adherence among hazardous drinkers: a randomized controlled trial. Journal of Acquired Immune Deficiency Syndromes 2007;46(4):443-50. [2007-18587-003]

\section{Pearson 2007 \{published data only\}}

Pearson CR, Micek MA, Simoni JM, Hoff PD, Matediana E, Martin DP, et al. Randomized control trial of peer-delivered, modified directly observed therapy for HAART in Mozambique. Journal of Acquired Immune Deficiency Syndromes 2007;46(2):238-44. [MEDLINE: 17693890]

\section{Perrin 2010 \{published data only\}}

Perrin K, Williams M, Wijesinghe M, James K, Weatherall M, Beasley R. Randomized controlled trial of adherence with single or combination inhaled corticosteroid/long-acting betaagonist inhaler therapy in asthma. Journal of Allergy and Clinical Immunology 2010;126(3):505-10. [EMBASE: 2010485598]

\section{Peterson 1984 \{published data only\}}

Peterson GM, McLean S, Millingen KS. A randomised trial of strategies to improve patient compliance with anticonvulsant therapy. Epilepsia 1984;25(4):412-7.

\section{Peterson 2004 \{published data only\}}

Peterson GM, Fitzmaurice KD, Naunton M, Vial JH, Stewart K, Krum $\mathrm{H}$. Impact of pharmacist-conducted home visits on the outcomes of lipid-lowering drug therapy. Journal of Clinical Pharmacy and Therapeutics 2004;29(1):23-30. [MEDLINE: 14748894]

\section{Peveler 1999 \{published data only\}}

Peveler R, George C, Kimmonth AL, Campbell M, Thomson C. Effect of antidepressant drug counselling and information leaflets on adherence to drug treatment in primary care: a randomized controlled trial. BMJ 1999;319(7210):612-5.

\section{Phumipamorn 2008 \{published data only\}}

Phumipamorn S, Pongwecharak J, Soorapan S, Pattharachayakul S. Effects of the pharmacist's input on glycaemic control and cardiovascular risks in Muslim diabetes. Primary Care Diabetes 2008;2(1):31-7. [MEDLINE: 18684418]

\section{Portsmouth 2005 \{published data only\}}

Portsmouth SD, Osorio J, McCormick K, Gazzard BG, Moyle GJ. Better maintained adherence on switching from twice-daily to once-daily therapy for HIV: a 24-week randomized trial of treatment simplification using stavudine prolonged-release tablets. HIV Medicine 2005;6(3):185-90.

Powell 2010 \{published data only\}

* Powell LH, Calvin JE Jr, Richardson D, Janssen I CF, Flynn KJ, Grady KL, et al. Self-management counseling in patients with heart failure: the heart failure adherence and retention randomized behavioral trial. JAMA 2010;304(12):1331-8. [2010798757]

Powell LH, Calvin JE Jr, Mendes de Leon CF, Richardson D, Grady KL, Flynn KJ, et al. The Heart Failure Adherence and Retention Trial (HART): design and rationale. American Heart Journal 2008;156(3):152-60. [000009]

\section{Powers 2011 \{published data only\}}

Powers BJ, Danus S, Grubber JM, Olsen MK, Oddone EZ, Bosworth HB. The effectiveness of personalized coronary heart disease and stroke risk communication. American Heart Journal 2011;161(4):673-80. [CENTRAL: CN-00788303]

\section{Pradier 2003 \{published data only\}}

Pradier C, Bentz L, Spire B, Tourette-Turgis C, Morin M, Souville $\mathrm{M}$, et al. Efficacy of an educational and counseling intervention on adherence to highly active antiretroviral therapy: French prospective controlled study. HIV Clinical Trials 2003;4(2):121-31. [MEDLINE: 12671780]

Purcell 2007 \{published data only\}

* Purcell DW, Latka MH, Metsch LR, Latkin CA, Gomez CA, Mizuno Y, et al. INSPIRE Study Team. Results from a randomized controlled trial of a peer-mentoring intervention to reduce HIV transmission and increase access to care and adherence to HIV medications among HIV-seropositive injection drug users. Journal of Acquired Immune Deficiency Syndromes 2007;46(Suppl 2):s35-47. [MEDLINE: 18089983]

Purcell DW, Metsch LR, Latka M, Santibanez S, Gomez CA, Eldred L, et al. INSPIRE Study Group. Interventions for seropositive injectors-research and evaluation: an integrated behavioral intervention with HIV-positive injection drug users to address medical care, adherence, and risk reduction. Journal of Acquired Immune Deficiency Syndromes 2004;37(Suppl 2):s110-8. [15385907]

\section{Pyne 2011 \{published data only\}}

Pyne JM, Fortney JC, Curran GM, Tripathi S, Atkinson JH, Kilbourne AM, et al. Effectiveness of collaborative care for depression in human immunodeficiency virus clinics. Archives of Internal Medicine 2011;171(1):23-31. [MEDLINE: 21220657]

\section{Rawlings 2003 \{published data only\}}

Rawlings MK, Thompson MA, Farthing CF, Brown LS, Racine J, Scott RC, et al. NZTA4006 Helping Enhance Adherence to Antiretroviral Therapy (HEART) Study Team. Impact of an educational program on efficacy and adherence with a twice-daily lamivudine/zidovudine/abacavir regimen in 
underrepresented HIV-infected patients. Journal of Acquired Immune Deficiency Syndromes 2003;34(2):174-83. [MEDLINE: 14526206]

\section{Razali 2000 \{published data only\}}

Razali SM, Hasanah CI, Khan UA, Subramaniam M. Psychosocial interventions for schizophrenia. Journal of Mental Health 2000;9(3):283-9.

\section{Remien 2005 \{published data only\}}

Remien RH, Stirratt MJ, Dolezal C, Dognin JS, Wagner GJ, Carballo-Dieguez A, et al. Couple-focused support to improve HIV medication adherence: a randomized controlled trial. AIDS 2005;19(8):807-14.

\section{Rickles 2005 \{published data only\}}

Rickles NM, Svarstad BL, Statz-Paynter JL, Taylor LV, Kobak KA. Pharmacist telemonitoring of antidepressant use: effects on pharmacist-patient collaboration. Journal of the American Pharmacists Association 2005;45(3):344-53.

\section{Riesen 2008 \{published data only\}}

Riesen WF, Noll G, Dariolo R, ORBITAL trialists. Impact of enhanced compliance initiatives on the efficacy of rosuvastatin in reducing low density lipoprotein cholesterol levels in patients with primary hypercholesterolaemia. Swiss Medical Weekly 2008;138(29-30):420-6. [MEDLINE: 18654867]

\section{Rosen 2007 \{published data only\}}

Rosen MI, Dieckhaus K, McMahon TJ, Valdes B, Petry NM, Cramer J, et al. Improved adherence with contingency management. AIDS Patient Care and STDs 2007;21(1):30-40. [CENTRAL: CN-00578076]

\section{Rubak 2011 \{published data only\}}

Griffin SJ, Simmons RK, Williams KM, Prevost AT, Hardeman W, Grant J, et al. ADDITION-Plus study team. Protocol for the ADDITION-Plus study: a randomised controlled trial of an individually-tailored behaviour change intervention among people with recently diagnosed type 2 diabetes under intensive UK general practice care. BMC Public Health 2011;11(Apr):211. [CENTRAL: CN-00788426]

Lauritzen T, Griffen S, Borch-Johnsen K, Wareham NJ, Wolffenbuttel BHR, Rutten G, ADDITION Study Group. The ADDITION study: proposed trial of the cost-effectiveness of an intensive multifactorial intervention on morbidity and mortality among people with Type 2 diabetes detected by screening. International Journal of Obesity 2000;24(Suppl 3):s6-11. [000010]

* Rubak S, Sandbaek A, Lauritzen T, Borch-Johnsen K, Christensen B. Effect of "motivational interviewing" on quality of care measures in screen detected type 2 diabetes patients: a one-year follow-up of an RCT, ADDITION Denmark. Scandinavian Journal of Primary Health Care 2011;29(2):92-8. [MEDLINE: 21306296]

\section{Rudd 2004 \{published data only\}}

Rudd P, Miller NH, Kaufman J, Kraemer HC, Bandura A, Greenwald G, et al. Nurse management of hypertension: a systems approach. American Journal of Hypertension 2004;17(10):921-7.

Sabin 2010 \{published data only\}

Sabin LL, DeSilva MB, Hamer DH, Xu K, Zhang J, Li T, et al. Using electronic drug monitor feedback to improve adherence to antiretroviral therapy among HIV-positive patients in China. AIDS \& Behavior 2010;14(3):580-9. [MEDLINE: 19771504]

Sackett 1975 \{published data only\}

Sackett DL, Haynes RB, Gibson ES, Hackett BC, Taylor DW, Roberts RS, et al. Randomised clinical trial of strategies for improving medication compliance in primary hypertension. Lancet 1975;1(7918):1205-7.

Sadik 2005 \{published data only\}

Sadik A, Yousef M, McElnay JC. Pharmaceutical care of patients with heart failure. British Journal of Clinical Pharmacology 2005;60(2):183-93.

\section{Samet 2005 \{published data only\}}

Samet JH, Horton NJ, Meli S, Dukes K, Tripps T, Sullivan L, et al. A randomized controlled trial to enhance antiretroviral therapy adherence in patients with a history of alcohol problems. Antiviral Therapy 2005;10(1):83-93.

\section{Sarna 2008 \{published data only\}}

Sarna A, Luchters S, Geibel S, Chersich MF, Munyao P, Kaai S, et al. Short- and long-term efficacy of modified directly observed antiretroviral treatment in Mombasa, Kenya: a randomized trial. Journal of Acquired Immune Deficiency Syndromes 2008;48(5):611-9. [MEDLINE: 18645509]

\section{Schaffer 2004 \{published data only\}}

Schaffer SD, Tian L. Promoting adherence: effects of theory-based asthma education. Clinical Nursing Research 2004;13(1):69-89. [MEDLINE: 14768768]

\section{Schroeder 2005 \{published data only\}}

Schroeder K, Fahey T, Hollinghurst S, Peters TJ. Nurse-led adherence support in hypertension: a randomized controlled trial. Family Practice 2005;22(2):144-51.

\section{Sherrard 2009 \{published data only\}}

Sherrard H, Struthers C, Kearns SA, Wells G, Chen L, Mesana T. Using technology to create a medication safety net for cardiac surgery patients: a nurse-led randomized control trial. Canadian Journal of Cardiovascular Nursing 2009;19(3):9-15. [MEDLINE: 19694112]

\section{Simon 2011 \{published data only\}}

Simon GE, Ralston JD, Savarino J, Pabiniak C, Wentzel C, Operskalski BH. Randomized trial of depression follow-up care by online messaging. Journal of General Internal Medicine 2011;26(7):698-704. [MEDLINE: 21384219]

Simoni 2007 \{published data only\}

Simoni JM, Pantalone DW, Plummer MD, Huang B. A randomized controlled trial of a peer support intervention targeting antiretroviral medication adherence and depressive 
symptomatology in HIV-positive men and women. Health Psychology 2007;26(4):488-95. [MEDLINE: 17605569]

\section{Simoni 2009 \{published data only\}}

* Simoni JM, Huh D, Frick PA, Pearson CR, Andrasik MP, Dunbar PJ, et al. Peer support and pager messaging to promote antiretroviral modifying therapy in Seattle: a randomized controlled trial. Journal of Acquired Immune Deficiency Syndromes 2009;52(4):465-73. [MEDLINE: 19911481]

Yard SS, Huh D, King KM, Simoni JM. Patient-level moderators of the efficacy of peer support and pager reminder interventions to promote antiretroviral adherence. AIDS and Behavior 2011;15(8):1596-604. [2011-23578-002]

\section{Simoni 2011 \{published data only\}}

Simoni JM, Chen WT, Huh D, Fredriksen-Goldsen KI, Pearson C, Zhao $\mathrm{H}$, et al. A preliminary randomized controlled trial of a nurse-delivered medication adherence intervention among HIVpositive outpatients initiating antiretroviral therapy in Beijing, China. AIDS \& Behavior 2011;15(5):919-29. [MEDLINE: 20957423]

\section{Sirey 2010 \{published data only\}}

Sirey JA, Bruce ML, Kales HC. Improving antidepressant adherence and depression outcomes in primary care: the treatment initiation and participation (TIP) program. American Journal of Geriatric Psychiatry 2010;18(6):554-62. [MEDLINE: 20220604]

\section{Solomon 2012 \{published data only\}}

Solomon DH, Gleeson T, Iversen M, Avorn J, Brookhart MA, Lii J, et al. A blinded randomized controlled trial of motivational interviewing to improve adherence with osteoporosis medications: design of the OPTIMA trial. Osteoporosis International 2010;21(1):137-44. [MEDLINE: 19436935]

* Solomon DH, Iversen MD, Avorn J, Gleeson T, Brookhart MA, Patrick AR, et al. Osteoporosis telephonic intervention to improve medication regimen adherence: a large, pragmatic, randomized controlled trial. Archives of Internal Medicine 2012;172(6):477-83. [MEDLINE: 22371876]

\section{Sorensen 2007 \{published data only\}}

Sorensen JL, Haug NA, Delucchi KL, Gruber V, Kletter E, Batki SL, et al. Voucher reinforcement improves medication adherence in HIV-positive methadone patients: a randomized trial. Drug \& Alcohol Dependence 2007;88(1):54-63. [MEDLINE: 17056206]

\section{Staring 2010 \{published data only\}}

Staring AB, Van der Gaag M, Koopmans GT, Selten JP, Van Beveren JM, Hengeveld MW, et al. Treatment adherence therapy in people with psychotic disorders: randomised controlled trial. British Journal of Psychiatry 2010;197(6):448-55. [MEDLINE: 21119150]

\section{Stevens 2002 \{published data only\}}

Stevens V, Shneidman RJ, Johnson RE, Steele PE, Lee NL. Helicobacter pylori eradication in dyspeptic primary care patients: a randomized controlled trial of a pharmacy intervention. Western Journal of Medicine 2002;176(2):92-6. [MEDLINE: 11897728]

\section{Strang 1981 \{published data only\}}

Strang JS, Falloon IRH, Moss HB, Razani J, Boyd JL. The effects of family therapy on treatment compliance in schizophrenia. Psychopharmacology Bulletin 1981;17(3):87-8.

Taiwo 2010 \{published data only\}

Taiwo BO, Idoko JA, Welty LJ, Otoh I, Job G, lyaji PG, et al. Assessing the viorologic and adherence benefits of patientselected HIV treatment partners in a resource-limited setting. Journal of Acquired Immune Deficiency Syndromes 2010;54(1):85-92. [CENTRAL: CN-00743266]

Tuldra 2000 \{published data only\}

Tuldra A, Fumaz CR, Ferrer MJ, Bayes R, Arno A, Balague M, et al. Prospective randomized two-arm controlled study to determine the efficacy of a specific intervention to improve long-term adherence to highly active antiretroviral therapy. Journal of Acquired Immune Deficiency Syndromes 2000;25(3):221-8.

\section{Udelson 2009 \{published data only\}}

Udelson JE, Pressler SJ, Sackner-Bernstein J, Massaro J, Ordronneau P, Lukas MA, et al. Adherence with once daily versus twice daily carvedilol in patients with heart failure: the Compliance And Quality of Life Study Comparing Once-Daily Controlled-Release Carvedilol CR and Twice-Daily ImmediateRelease Carvedilol IR in Patients with Heart Failure (CASPER) Trial. Journal of Cardiac Failure 2009;15(5):385-93. [MEDLINE: 19477398]

\section{Valencia 2007 \{published data only\}}

Valencia M, Rascon ML, Juarez F, Murow E. A psychosocial skills training approach in Mexican out-patients with schizophrenia. Psychological Medicine 2007;37(10):1393-402. [MEDLINE: 17472761]

\section{Valenstein 2011 \{published data only\}}

Valenstein M, Kavanagh J, Lee T, Reilly P, Dalack GW, Grabowski J, et al. Using a pharmacy-based intervention to improve antipsychotic adherence among patients with serious mental illness. Schizophrenia Bulletin 2011;37(4):727-36. [MEDLINE: 19933540]

\section{van der Meer 2009 \{published data only\}}

* van der Meer V, Bakker MJ, van den Hout WB, Rabe KF, Sterk PJ, Kievit J, et al. Internet-based self-management plus education compared with usual care in asthma: a randomized trial. Annals of Internal Medicine 2009;151(2):110-20. [2010775594]

van der Meer V, van Stel HF, Bakker MJ, Roldaan AC, Assendelft WJ, Sterk PJ, et al. SMASHING (Self-Management of Asthma Supported by Hospitals, ICT, Nurses and General practitioners) Study Group. Weekly self-monitoring and treatment adjustment benefit patients with partly controlled and uncontrolled asthma: an analysis of the SMASHING study. Respiratory Research 2010;11(June):74. [MEDLINE: 20537124]

\section{Velligan 2008 \{published data only\}}

Velligan DI, Diamond PM, Mintz J, Maples N, Li X, Zeber J, et al. The use of individually tailored environmental supports to 
improve medication adherence and outcomes in schizophrenia. Schizophrenia Bulletin 2008;34(3):483-93. [MEDLINE: 17932089]

\section{Vergouwen 2005 \{published data only\}}

Vergouwen AC, Bakker A, Burger H, Verheij TJ, Koerselman F. A cluster-randomized trial comparing two interventions to improve treatment of major depression in primary care. Psychological Medicine 2005;35(1):25-33.

\section{Volume 2001 \{published data only\}}

Volume $\mathrm{Cl}$, Garris KB, Kassam R, Cox CE, Cave A. Pharmaceutical care research and education project: patient outcomes. Journal of the American Pharmaceutical Association 2001;41(3):411-20. [MEDLINE: 11372906]

\section{Wakefield 2011 \{published data only\}}

* Wakefield BJ, Holman JE, Ray A, Scherubel M, Adams MR, Hillis SL, et al. Effectiveness of home telehealth in comorbid diabetes and hypertension: a randomized, controlled trial. Telemedicine Journal \& E-Health 2011;17(4):254-61. [MEDLINE: 21476945]

Wakefield BJ, Holman JE, Ray A, Scherubel M, Burns TL, Kienzle MG, et al. Outcomes of a home telehealth intervention for patients with heart failure. Journal of Telemedicine \& Telecare 2009;15(1):46-50. [MEDLINE: 19139220]

\section{Walley 2001 \{published data only\}}

Walley JD, Khan MA, Newell JN, Khan MH. Effectiveness of the direct observation component of DOTS for tuberculosis: a randomised controlled trial in Pakistan. Lancet 2001;357(9257):664-9. [MEDLINE: 11247549]

\section{Wang 2010 a \{published data only\}}

Wang H, Zhou J, Huang L, Li X, Fennie KP, Williams AB. Effects of nurse-delivered home visits combined with telephone calls on medication adherence and quality of life in HIV-infected heroin users in Hunan of China. Journal of Clinical Nursing 2010;19(3-4):380-8. [MEDLINE: 20500277]

\section{Wang 2010 b \{published data only\}}

Wang KY, Chian CF, Lai HR, Tarn YH, Wu CP. Clinical pharmacist counseling improves outcomes for Taiwanese asthma patients. Pharmacy World \& Science 2010;32(6):721-9. [MEDLINE: 20798988]

\section{Weber 2004 \{published data only\}}

Weber R, Christen L, Christen S, Tschopp S, Znoj H, Schneider C, et al. Swiss HIV Cohort Study. Effect of individual cognitive behaviour intervention on adherence to antiretroviral therapy: prospective randomized trial. Antiviral Therapy 2004;9(1):85-95. [MEDLINE: 15040540]

\section{Weinberger 2002 \{published data only\}}

Weinberger M, Murray MD, Marrero DG, Brewer N, Lykens M, Harris LE, et al. Effectiveness of pharmacist care for patients with reactive airways disease: a randomized controlled trial. JAMA 2002;288(13):1594-602. [MEDLINE: 12350190]
Wiggins 2009 \{published data only\}

Wiggins SA. Family exemplars during implementation of a home pain management intervention. Issues in Comprehensive Pediatric Nursing 2009;32(May):160-79. [CENTRAL: CN-00728335]

Wilson 2010 \{published data only\} Wilson SR, Strub P, Buist AS, Knowles SB, Lavori PW, Lapidus J, et al. Better Outcomes of Asthma Treatment (BOAT) Study Group. Shared treatment decision making improves adherence and outcomes in poorly controlled asthma. American Journal of Respiratory \& Critical Care Medicine 2010;181(6):566-77. [MEDLINE: 20019345]

\section{Wolever 2010 \{published data only\}}

Wolever RQ, Dreusicke M, Fikkan J, Hawkins TV, Yeung S, Wakefield J, et al. Integrative health coaching for patients with type 2 diabetes: a randomized clinical trial. Diabetes Educator 2010;36(4):629-39. [MEDLINE: 20534872]

\section{Wu 2006 \{published data only\}}

Wu JY, Leung WY, Chang S, Lee B, Zee B, Tong PC, et al. Effectiveness of telephone counselling by a pharmacist in reducing mortality in patients receiving polypharmacy: randomised controlled trial. BMJ 2006;333(7567):522. [2009294932]

\section{Wu 2012 \{published data only\}}

Wu JR, Corley DJ, Lennie TA, Moser DK. Effect of a medicationtaking behavior feedback theory-based intervention on outcomes in patients with heart failure. Journal of Cardiac Failure 2012;18(1):1-9. [5494]

\section{Wysocki 2001 \{published data only\}}

Wysocki T, Greco P, Harris MA, Bubb J, White NH. Behavior therapy for families of adolescents with diabetes: maintenance of treatment effects. Diabetes Care 2001;24(3):441-6.

\section{Xiong 1994 \{published data only\}}

Xiong W, Phillips MR, Hu X, Wang R, Dai Q, Kleinman J, et al. Family-based intervention for schizophrenic patients in China. A randomised controlled trial. British Journal of Psychiatry 1994;165(2):239-47.

\section{Yopp 2004 \{unpublished data only\}}

Yopp JM. The Impact of Family Functioning on Treatment Adherence and Metabolic Control for Adolescents with Poorly Controlled T1DM [dissertation]. Mount Pleasant, Michigan: Central Michigan University, 2004.

\section{Zhang 1994 \{published data only\}}

Zhang M, Wang M, Li J, Phillips MR. Randomised-control trial of family intervention for 78 first-episode male schizophrenic patients. An 18-month study in Suzhou, Jiangsu. British Journal of Psychiatry 1994;165(Suppl 24):96-102.

\section{Zolfaghari 2012 \{published data only\}}

Zolfaghari M, Mousavifar SA, Pedram S, Haghani H. The impact of nurse short message services and telephone follow-ups on diabetic adherence: which one is more effective?. Journal of Clinical Nursing 2012;21(13-4):1922-31. [MEDLINE: 22239205] 


\section{References to studies excluded from this review}

\section{Adamian 2004 \{published data only\}}

Adamian MS, Golin CE, Shain LS, DeVellis B. Brief motivational interviewing to improve adherence to antiretroviral therapy: development and qualitative pilot assessment of an intervention. AIDS Patient Care and STDs 2004;18(4):229-38.

Adams 2000 \{published data only\}

Adams J, Scott J. Predicting medication adherence in severe mental disorders. Acta Psychiatrica Scandinavica 2000;101(2):119-24.

\section{Adams 2001 \{published data only\}}

Adams RJ, Boath K, Homan S, Campbell DA, Ruffin RE. A randomized trial of peak-flow and symptom-based action plans in adults with moderate-to-severe asthma. Respirology 2001;6(4):297-304.

\section{Adler 2004 \{published data only\}}

Adler DA, Bungay KM, Wilson B, Pei Y, Supran S, Peckham E, et al. The impact of a pharmacist intervention on 6-month outcomes in depressed primary care patients. General Hospital Psychiatry 2004;26(3):199-209.

\section{Alhalaiqa 2012 \{published data only\}}

Alhalaiqa F, Deane KH, Nawafleh AH, Clark A, Gray R. Adherence therapy for medication non-compliant patients with hypertension: a randomised controlled trial. Journal of Human Hypertension 2012;26(2):117-26. [MEDLINE: 21326328]

\section{Allen 2002 \{published data only\}}

Allen JK, Blumenthal RS, Margolis S, Rohm YD, Miller ER, et al. Nurse case management of hypercholesterolemia in patients with coronary heart disease: results of a randomized clinical trial. American Heart Journal 2002;144(4):678-86.

\section{Al Rashed 2002 \{published data only\}}

Al Rashed SA, Wright DJ, Roebuck N, Sunter W, Chrystyn H. The value of inpatient pharmaceutical counselling to elderly patients prior to discharge. British Journal of Clinical Pharmacology 2002;54(6):657-64.

\section{Al-Saffer 2005 \{published data only\}}

Al-Saffer N, Deshmekh AA, Carter P, Adib AM. Effect of information leaflets and counselling on antidepressant adherence: open randomized controlled trial in a psychiatric hospital in Kuwait. International Journal of Pharmacy Practice 2005;13(2):123-31.

\section{Alves da Costa 2005 \{published data only\}}

Alves da Costa F, Guerreiro JP, Nunes de Melo M, da Costa Miranda A, Martins AP, Garcao J, et al. Effect of reminder cards on compliance with antihypertensive medication. International Journal of Pharmacy Practice 2005;13(3):205-11.

Antoni 2006 \{published data only\}

Antoni MH, Carrico AW, Durán RE, Spitzer S, Penedo F, Ironson G, et al. Randomized clinical trial of cognitive behavioral stress management on human immunodeficiency virus viral load in gay men treated with highly active antiretroviral therapy. Psychosomatic Medicine 2006;68(1):143-51.

\section{Armour 2007 \{published data only\}}

Armour C, Bosnic-Anticevich S, Brillant M, Burton D, Emmerton L, Krass I, et al. Pharmacy Asthma Care Program (PACP) improves outcomes for patients in the community. Thorax 2007;62(6):496-502. [CENTRAL: CN-00586650]

Arthur 2002 \{published data only\}

Arthur AJ, Jagger C, Lindesay J, Matthews RJ. Evaluating a mental health assessment for older people with depressive symptoms in general practice: a randomised controlled trial. British Journal of General Practice 2002;52(476):202-7.

Atherton-Naji 2001 \{published data only\}

Atherton-Naji A, Hamilton R, Riddle W, Naji S. Improving adherence to antidepressant drug treatment in primary care: a feasibility study for a randomized controlled trial of education intervention. Primary Care Companion to the Journal of Clinical Psychiatry 2001;7(2):61-7.

Azrin 1998 \{published data only\}

Azrin NH, Teichner G. Evaluation of an instructional program for improving medication compliance for chronically mentally ill outpatients. Behavior Research and Therapy 1998;36(9):849-61.

\section{Baker 2001 \{published data only\}}

Baker R, Reddish S, Robertson N, Hearnshaw H, Jones B. Randomised controlled trial of tailored strategies to implement guidelines for the management of patients with depression in general practice. British Journal of General Practice 2001;51(470):737-41.

\section{Ball 2006 \{published data only\}}

Ball JR, Mitchell PB, Corry JC, Skillecorn A, Smith M, Malhi GS. $A$ randomized controlled trial of cognitive therapy for bipolar disorder: focus on long-term change. Journal of Clinical Psychiatry 2006;67(2):277-86.

Banet 1997 \{published data only\}

Banet GA, Felchlia MA. The potential utility of a shared medical record in a "first-time" stroke population. Journal of Vascular Nursing 1997;15(1):29-33.

\section{Barbanel 2003 \{published data only\}}

Barbanel D, Eldridge S, Griffiths C. Can a self-management programme delivered by a community pharmacist improve asthma control? A randomised trial. Thorax 2003;58(10):851-4.

\section{Barcelo 2001 \{published data only\}}

Barcelo A, Robles S, White F, Jadue L, Vega J. An intervention to improve diabetes control in Chile. Revista Panamericana de Salud Publica/Pan American Journal of Public Health 2001;10(5):328-33.

\section{Bass 1986 \{published data only\}}

Bass MJ, McWhinney IR, Donner A. Do family physicians need medical assistants to detect and manage hypertension?. Canadian Medical Association Journal 1986;134(11):1247-55. 


\section{Begley 1997 \{published data only\}}

Begley S, Livingstone C, Hodges N, Williamson V. Impact of domiciliary pharmacy visits on medication management in an elderly population. International Journal of Pharmacy Practice 1997;5(3):111-21.

\section{Berg 1997 \{published data only\}}

Berg J, Dunbar-Jacob J, Sereika SM. An evaluation of a selfmanagement program for adults with asthma. Clinical Nursing Research 1997;6(3):225-38.

\section{Berg 2011 \{published data only\}}

* Berg KM, Litwin A, Li X, Heo M, Arnsten JH. Directly observed antiretroviral therapy improves adherence and viral load in drug users attending methadone maintenance clinics: a randomized controlled trial. Drug \& Alcohol Dependence 2011;113(2-3):192-9. [MEDLINE: 20832196]

Berg KM, Litwin AH, Li X, Heo M, Arnsten JH. Lack of sustained improvement in adherence or viral load following a directly observed antiretroviral therapy intervention. Clinical Infectious Diseases 2011;53(9):936-43. [CENTRAL: CN-00806074]

Berg KM, Mouriz J, Li X, Duggan E, Goldberg U, Arnsten JH. Rationale, design, and sample characteristics of a randomized controlled trial of directly observed antiretroviral therapy delivered in methadone clinics. Contemporary Clinical Trials 2009;30(5):481-9. [MEDLINE: 19505589]

\section{Bertakis 1986 \{published data only\}}

Bertakis KD. An application of the health belief model to patient education and compliance: acute otitis media. Family Medicine 1986;18(6):347-50.

\section{Binstock 1986 \{published data only\}}

Binstock ML, Franklin KL, Formica EK. Therapeutic adherence programme improves compliance and lowers blood pressure. Journal of Hypertension 1986;4 Suppl:375-7.

\section{Birrer 1984 \{published data only\}}

Birrer RB, Chille E, Weiner M, Gruber S. Hypertension: a doubleblind study of compliance in an urban community. Family Practice Research Journal 1984;3:251.

\section{Birtwhistle 2004 \{published data only\}}

Birtwhistle RV, Godwin MS, Delva MD, Casson RI, Lam M, MacDonald SE, et al. Randomised equivalence trial comparing three and six months of follow up of patients with hypertension by family practitioners. BMJ 2004;328:204-6.

\section{Bisserbe 1997 \{published data only\}}

Bisserbe JC, Lane RM, Flament MF, the Franco-Belgian OCD Study Group. A double-blind comparison of sertraline and clomipramine in outpatients with obsessive-compulsive disorder. European Psychiatry 1997;12:82-93.

\section{Bodsworth 1997 \{published data only\}}

Bodsworth NJ, Crooks RJ, Borelli S, Vejlsgaard G, Paavonen J, Worm A-M, et al. The International Valaciclovir HSV Study Group. Valaciclovir versus aciclovir in patient initiated treatment of recurrent genital herpes - a randomised, double blind clinical trial. Genitourinary Medicine 1997;73:110-6.

Bogner 2008 \{published data only\}

Bogner HR, de Vries HF. Integration of depression and hypertension treatment: a pilot, randomized controlled trial. Annals of Family Medicine 2008;6(4):295-301. [CENTRAL: CN-00649720]

\section{BonAdASIA 2009 \{published data only\}}

BonAdASIA Study Group, Kung AW, Rachman IA, Adam JM, Roeshadi D, Torralba T, et al. Impact of bone marker feedback on adherence to once monthly ibandronate for osteoporosis among Asian postmenopausal women. International Journal of Rheumatic Diseases 2009;12(3):216-24. [MEDLINE: 20374349]

Bonner 2002 \{published data only\}

Bonner S, Zimmerman BJ, Evans D, Irigoyen M, Resnick D, Mellins RB. An individualized intervention to improve asthma management among urban Latino and African-American families. Journal of Asthma 2002;39:167-79.

\section{Bouvy 2003a \{published data only\}}

Bouvy ML, Heerdink ER, Urquhart J, Grobbee DE, Hoe AW, Leufkens HGM. Effect of a pharmacist-led intervention on diuretic compliance in heart failure patients: a randomized controlled study. Journal of Cardiac Failure 2003;9:404-11.

\section{Bouvy 2003b \{published data only\}}

Bouvy ML, Heerdink ER, Urquhart J, Grobbee DE, Hoe AW, Leufkens HGM. Guidance improves compliance. Pharmacist stimulates proper use of loop diuretics in patient with heart failure. Pharmaceutisch Weekblad 2003;138:1432-9.

\section{Brodaty 1983 \{published data only\}}

Brodaty $\mathrm{H}$, Andrews $\mathrm{G}$. Brief psychotherapy in family practice: a controlled prospective intervention trial. British Journal of Psychiatry 1983;143:11-9.

\section{Brook 2002 \{published data only\}}

Brook I. Antibacterial therapy for acute group A streptococcal pharyngotonsillitis: short-course versus traditional 10-day oral regimens. Paediatric Drugs 2002;4:747-54.

\section{Brook 2003 \{published data only\}}

Brook $\mathrm{O}$. Impact of coaching by community pharmacists on drug attitude of depressive primary care patients and acceptability to patients; a randomized controlled trial. European Neuropsychopharmacology 2003;13:1-9.

Brook 2005 \{published data only\}

Brook OH, van Hout H, Stalman W, Nieuwenhuyse H, Bakker B, Heerdink E, et al. A pharmacy-based coaching program to improve adherence to antidepressant treatment among primary care patients. Psychiatric Services 2005;56(4):487-9.

Brotons 2005 \{published data only\}

Brotons C, Martinez M, Rayo E, Morralla C, Ballarin E, Perez E, Investigadores del Estudio IC-DOM. Randomised clinical trial to evaluate the efficacy of a multi-factorial intervention to reduce 
hospitalisation and improve the quality of life of patients with heart failure. Atencion Primaria 2005;36(5):280-3.

Brown 1987 \{published data only\}

Brown CS, Wright RG, Christensen DB. Association between type of medication instruction and patients' knowledge, side effects, and compliance. Hospital \& Community Psychiatry 1987;38:55-60.

\section{Brown 1997b \{published data only\}}

Brown SJ, Lieberman DA, Gemeny BA, Fan YC, Wilson DM, Pasta DJ. Educational video game for juvenile diabetes: results of a controlled trial. Medical Informatics 1997;22(1):77-89.

\section{Browne 2002 \{published data only\}}

Browne G, Steiner M, Roberts J, Gafni A, Byrne C, Dunn E, et al. Sertraline and/or interpersonal psychotherapy for patients with dysthymic disorder in primary care: 6-month comparison with longitudinal 2-year follow-up of effectiveness and costs. Journal of Affective Disorders 2002;68:317-30.

\section{Buchanan-Lee 2002 \{published data only\}}

Buchanan-Lee B, Levetan BN, Lombard CJ, Commerford PJ. Fixed-dose versus adjusted-dose warfarin in patients with prosthetic heart valves in a peri-urban impoverished population. Journal of Heart Valve Disease 2002;11:583-93.

\section{Bukstein 2003 \{published data only\}}

Bukstein DA, Luskin AT, Bernstein A. "Real-world" effectiveness of daily controller medicine in children with mild persistent asthma. Annals of Allergy, Asthma, \& Immunology 2003;90:543-9.

\section{Bungay 2004 \{published data only\}}

Bungay KM, Adler DA, Rogers WH, McCoy C, Kaszuba M, Supran $S$, et al. Description of a clinical pharmacist intervention administered to primary care patients with depression. General Hospital Psychiatry 2004;26:210-8.

\section{Burkhart 2002 \{published data only\}}

Burkhart PV, Dunbar-Jacob JM, Fireman P, Rohay J. Children's adherence to recommended asthma self-management. Pediatric Nursing 2002;28:409-14.

\section{Burnand 2002 \{published data only\}}

Burnand Y, Andreoli A, Kolatte E, Venturini A, Rosset N. Psychodynamic psychotherapy and clomipramine in the treatment of major depression. Psychiatric Services 2002;53:585-90.

\section{Bussmann 2009 \{published data only\}}

Bussmann H, Wester CW, Thomas A, Novitsky V, Okezie R, Muzenda T, et al. Response to zidovudine/didanosinecontaining combination antiretroviral therapy among HIV-1 subtype C-infected adults in Botswana: two-year outcomes from a randomized clinical trial. Journal of Acquired Immune Deficiency Syndromes 2009;51(1):37-46. [MEDLINE: 19282782]

\section{Caine 2002 \{published data only\}}

Caine N, Sharples W, Hollingworth J, French J, Leogan A, Exley D, et al. A randomised controlled crossover trial of nurse practitioner versus doctor-led outpatient care in a bronchiectasis clinic. Health Technology Assessment 2002;6:1-71.

Canto De Cetina 2001 \{published data only\}

Canto De Cetina TE, Canto P, Ordonez Luna M. Effect of counseling to improve compliance in Mexican women receiving depot-medroxyprogesterone acetate. Contraception 2001;63(3):143-6

Cantor 1985 \{published data only\}

Cantor JC, Morisky DE, Green LW, Levine DM, Salkever DS. Cost-effectiveness of educational interventions to improve patient outcomes in blood pressure control. Preventive Medicine 1985; 14:782-800.

\section{Capoccia 2004 \{published data only\}}

Capoccia KL, Boudreau DM, Blough DK, Ellsworth AJ, Clark DR, Stevens NG, et al. Randomized trial of pharmacist interventions to improve depression care and outcomes in primary care. American Journal of Health-System Pharmacy 2004;61:364-72.

\section{Cargill 1992 \{published data only\}}

Cargill JM. Medication compliance in elderly people: influencing variables and interventions. Journal of Advanced Nursing 1992;17:422-6.

\section{Carroll 2004 \{published data only\}}

Carroll CL, Feldman SR, Camacho FT, Balkrishnan R. Better medication adherence results in greater improvement in severity of psoriasis. British Journal of Dermatology 2004;151(4):895-7.

\section{Celik 1997 \{published data only\}}

Celik O, Gok U, Yalcin S, Karlidag T, Susaman N, Cetinkaya T. Comparison of the clinical efficacy of azithromycin and cerufoxime axetile in the treatment of patients with acute otitis media. Mikrobiyoloji Bulteni 1997;31:253-61.

\section{Chaisson 2001 \{published data only\}}

Chaisson RE, Barnes GL, Hackman J, Watkinson L, Kimbrough L, Metha S, et al. A randomized, controlled trial of interventions to improve adherence to isoniazid therapy to prevent tuberculosis in injection drug users. American Journal of Medicine 2001;110:610-5.

\section{Chang 2010 \{published data only\}}

Chang LW, Kagaayi J, Nakigozi G, Ssempijja V, Packer AH, Serwadda D, et al. Effect of peer health workers on AIDS care in Rakai, Uganda: a cluster-randomized trial. PloS One 2010;5(6):e10923. [MEDLINE: 20532194]

\section{Chang 2011 \{published data only\}}

* Chang LW, Kagaayi J, Arem H, Nakigozi G, Ssempijja V, Serwadda D, et al. Impact of a mHealth intervention for peer health workers on AIDS care in rural Uganda: a mixed methods evaluation of a cluster-randomized trial. AIDS and Behavior 2011;15(8):1776-84. [3740] 
Cheng 2001 \{published data only\}

Cheng CL, Chee SP, Tan DT. Patient reliability in the administration of topical ocular medication. Singapore Medical Journal 2001;42:252-4.

\section{Cheung 1988 \{published data only\}}

Cheung R, Sullens CM, Seal D, Dickins J, Nicholson PW, Deshmukh AA, et al. The paradox of using a 7 day antibacterial course to treat urinary tract infections in the community. British Journal of Clinical Pharmacology 1988;26:391-8.

\section{Chien 2006 \{published data only\}}

Chien WT, Chan SW, Thompson DR. Effects of a mutual support group for families of Chinese people with schizophrenia: 18month follow-up. British Journal of Psychiatry 2006;189:41-9.

\section{Chiou-Tan 2003 \{published data only\}}

Chiou-Tan FY, Garza H, Chan KT, Parsons KC, Donovan WH, Robertson CS, et al. Comparison of dalteparin and enoxaparin for deep venous thrombosis prophylaxis in patients with spinal cord injury. American Journal of Physical Medicine \& Rehabilitation 2003;82:678-85.

\section{Chisholm 2001 \{published data only\}}

Chisholm MA, Mulloy LL, Jagadeesan M, DiPiro JT. Impact of clinical pharmacy services on renal transplant patients' compliance with immunosuppressive medications. Clinical Transplantation 2001;15:330-6.

\section{Choi 2002 \{published data only\}}

Choi IJ, Jung HC, Choi KW, Kim JH, Ahn DS, Yang US, et al. Efficacy of low-dose clarithromycin triple therapy and tinidazole-containing triple therapy for Helicobacter pylori eradication. Alimentary Pharmacology \& Therapeutics 2002; 16:145-51.

\section{Clancy 2003 \{published data only\}}

Clancy DE, Brown SB, Magruder KM, Huang P. Group visits in medically and economically disadvantaged patients with type 2 diabetes and their relationships to clinical outcomes. Topics in Health Information Management 2003;24:8-14.

\section{Clarkin 1998 \{published data only\}}

Clarkin JF, Carpenter D, Hull J, Wilner P, Glick I. Effects of psychoeducational intervention of married patients with bipolar disorder and their spouses. Psychiatric Services 1998;49(4):531-3.

\section{Clifford 2002 \{published data only\}}

Clifford RM, Batty KT, Davis TME, Davis W, Stein G, Stewart G, et al. A randomised controlled trial of a pharmaceutical care programme in high-risk diabetic patients in an outpatient clinic. International Journal of Pharmacy Practice 2002;10:85-9.

\section{Cochran 1984 \{published data only\}}

Cochran SD. Preventing medical noncompliance in the outpatient treatment of bipolar affective disorders. Journal of Consulting and Clinical Psychology 1984;52:873-8.

\section{Cockburn 1997 \{published data only\}}

Cockburn J, Thompson SC, Marks R, Jolley D, Schofield P, Hill D. Behavioural dynamics of a clinical trial of sunscreens for reducing solar keratoses in Victoria, Australia. Journal of Epidemiology and Community Health 1997;51(6):716-21.

Cohn 2002 \{published data only\}

Cohn SE, Kammann E, Williams P, Currier JS, Chesney MA. Association of adherence to Mycobacterium avium complex prophylaxis and antiretroviral therapy with clinical outcomes in acquired immunodeficiency syndrome. Clinical Infectious Diseases 2002;34:1129-36.

\section{Colom 2003 \{published data only\}}

Colom F, Vieta E, Reinares M, Martinez-Aran A, Torrent C, Goikolea JM, et al. Psychoeducation efficacy in bipolar disorders: beyond compliance enhancement. Journal of Clinical Psychiatry 2003;64:1101-5.

\section{Cooper 2004 \{published data only\}}

Cooper C. Efficacy and safety of oral weekly ibandronate in the treatment of postmenopausal osteoporosis. Journal of Clinical Endocrinology \& Metabolism 2004;88:4609-15.

Cordina 2001 \{published data only\}

Cordina M, McElnay JC, Hughes CM. Assessment of a community pharmacy-based program for patients with asthma. Pharmacotherapy 2001;21:1196-203.

\section{Couturaud 2002 \{published data only\}}

Couturaud F, Proust A, Frachon I, Dewitte JD, Oger E, Quiot JJ, et al. Education and self-management: a one-year randomized trial in stable adult asthmatic patients. Journal of Asthma 2002;39:493-500.

\section{Cramer 2003 \{published data only\}}

Cramer JA, Rosenheck R, Kirk G, Krol W, Krystal J. Medication compliance feedback and monitoring in a clinical trial: predictors and outcomes. Value in Health 2003;6:566-73.

\section{Crilly 2005 \{published data only\}}

Crilly M, Esmail A. Randomized controlled trial of a hypothyroid educational booklet to improve thyroxine adherence. British Journal of General Practice 2005;55(514):362-8.

\section{Criswell 2010 \{published data only\}}

Criswell TJ, Weber CA, Xu Y, Carter BL. Effect of self-efficacy and social support on adherence to antihypertensive drugs. Pharmacotherapy 2010;30(5):432-41. [MEDLINE: 20411995]

\section{Crockett 2006 \{published data only\}}

Crockett J, Taylor S, Grabham A, Stanford P. Patient outcomes following an intervention involving community pharmacists in the management of depression. Australian Journal of Rural Health 2006;14(6):263-9.

\section{Cukiernik 2007 \{published data only\}}

Cukiernik VA, Lim R, Warren D, Seabrook JA, Matsui D, Rieder MJ. Naproxen versus acetaminophen for therapy of soft tissue injuries to the ankle in children. Annals of 
Pharmacotherapy 2007;41(Sept):1368-74. [CENTRAL: $\mathrm{CN}-00706212]$

\section{Daley 1992 \{published data only\}}

Daley BJ. Sponsorship for adolescents with diabetes. Health \& Social Work 1992;17:173-82.

\section{Datto 2003 \{published data only\}}

Datto CJ, Thompson R, Horowitz D, Disbot M, Oslin DW. The pilot study of a telephone disease management program for depression. General Hospital Psychiatry 2003;25:169-77.

\section{de Bruin 2010 \{published data only\}}

* de Bruin M, Hospers HJ, van Breukelen GJ, Kok G, Koevoets WM, Prins JM. Electronic monitoring-based counseling to enhance adherence among HIV-infected patients: a randomized controlled trial. Health Psychology 2010;29(4):421-8. [MEDLINE: 20658830]

de Bruin MPH, Hospers HJ, Van Den Borne HW, Kok G, Prins JM. Theory- and evidence-based intervention to improve adherence to antiretroviral therapy among HIV infected patients in the Netherlands: a pilot study. Aids Patient Care and STDS 2005;19(6):384-94. [000019]

\section{Dehesa 2002 \{published data only\}}

Dehesa M, Larisch J, Dibildox M, Di Silvio M, Lopez LH, RamirezBarba E, et al. Comparison of three 7-day pantoprazolebased Helicobacter pylori eradication regimens in a Mexican population with high metronidazole resistance. Clinical Drug Investigation 2002;22:75-85.

\section{Deinzer 2006 \{published data only\}}

Deinzer A, Babel H, Veelken R, Kohnen R, Schmieder RE. Shared decision-making with hypertensive patients. Results of an implementation in Germany. Deutsche Medizinische Wochenschrift 2006;131(46):2592-6.

\section{De Jonghe 2001 \{published data only\}}

De Jonghe F, Kool S, van Aalst G, Dekker J, Peen J. Combining psychotherapy and antidepressants in the treatment of depression. Journal of Affective Disorders 2001;64:217-29.

\section{de Klerk 2001 \{published data only\}}

de Klerk E. Patient compliance with enteric-coated weekly fluoxetine during continuation treatment of major depressive disorder. Journal of Clinical Psychiatry 2001;62:43-7.

\section{Delaronde 2005 \{published data only\}}

Delaronde S, Peruccio DL, Bauer BJ. Improving asthma treatment in a managed care population. American Journal of Managed Care 2005;11(6):361-8.

\section{de Lusignan 2001 \{published data only\}}

de Lusignan S, Wells S, Johnson P, Meredith K, Leatham E. Compliance and effectiveness of 1 year's home telemonitoring. The report of a pilot study of patients with chronic heart failure. European Journal of Heart Failure 2001;3:723-30.
Demiralay 2002 \{published data only\}

Demiralay R. Comparison of the effects of three forms of individualized education on asthma knowledge in asthmatic patients. Turkish Journal of Medical Sciences 2002;32:57-64.

\section{Demyttenaere 1998 \{published data only\}}

Demyttenaere K, Van-Ganse E, Gregoire J, Gaens E, Mesters P. Compliance in depressed patients treated with fluoxetine or amitriptyline. International Clinical Psychopharmacology 1998;13(1):11-7.

\section{Demyttenaere 2001 \{published data only\}}

Demyttenaere K, Mesters P, Boulanger B, Dewe W, Delsemme MH, Gregoire J, et al. Adherence to treatment regimen in depressed patients treated with amitriptyline or fluoxetine. Journal of Affective Disorders 2001;65(3):243-52.

\section{de Wit 2001 \{published data only\}}

de Wit R, van Dam F, Loonstra S, Zandbelt L, van Buuren A, van der $\mathrm{HK}$, et al. Improving the quality of pain treatment by a tailored pain education programme for cancer patients in chronic pain. European Journal of Pain 2001;5:241-56.

Dilorio 2003 \{published data only\}

Dilorio C, Resnicow K, McDonnell M, Soet J, McCarty F, Yeager K. Using motivational interviewing to promote adherence to antiretroviral medications: a pilot study. Journal of the Association of Nurses in AIDS Care 2003;14:52-62.

Dittrich 2002 \{published data only\}

Dittrich R, Parker L, Rosen JB, Shangold G, Creasy GW, Fisher AC. Transdermal contraception: evaluation of three transdermal norelgestromin/ethinyl estradiol doses in a randomized, multicenter, dose-response study. American Journal of Obstetrics \& Gynecology 2002;186:15-20.

Donadio 2001 \{published data only\}

Donadio JV Jr, Larson TS, Bergstralh EJ, Grande JP. A randomized trial of high-dose compared with low-dose omega-3 fatty acids in severe IgA nephropathy. Journal of the American Society of Nephrology 2001;12:791-9.

Edworthy 1999 \{published data only\}

Edworthy SM, Devins GM. Improving medication adherence through patients education distinguishing between appropriate and inappropriate utilization. Journal of Rheumatology 1999;26:1793-801.

Elixhauser 1990 \{published data only\}

Elixhauser A, Eisen SA, Romeis JC, Homan SM. The effects of monitoring and feedback on compliance. Medical Care 1990;28:882-93.

\section{Eron 2000 \{published data only\}}

Eron JJ, Yetzer ES, Ruane PJ, Becker S, Sawyerr GA, Fisher RL, et al. Efficacy, safety and adherence with a twice-daily combination lamivudine/zidovudine tablet formulations, plus a protease inhibitor, in HIV infection. AIDS (London, England) 2000;14(6):671-81. 
Eshelman 1976 \{published data only\}

Eshelman FN, Fitzloff J. Effect of packaging on patient compliance with an antihypertensive medication. Current Therapeutic Research, Clinical and Experimental 1976;20:215-9.

\section{Evers 2002 \{published data only\}}

Evers AW, Kraaimaat FW, van Riel PL, de Jong AJ. Tailored cognitive-behavioral therapy in early rheumatoid arthritis for patients at risk: a randomized controlled trial. Pain 2002;100:141-53.

\section{Falloon 1985 \{published data only\}}

Falloon IR, Boyd JL, McGill CW, Williamson M, Razani J, Moss HB, et al. Family management in the prevention of morbidity of schizophrenia. Archives of General Psychiatry 1985;42:887-96.

\section{Feaster 2010 \{published data only\}}

Feaster DJ, Mitrani VB, Burns MJ, McCabe BE, Brincks AM, Rodriguez $A E$, et al. A randomized controlled trial of Structural Ecosystems Therapy for HIV medication adherence and substance abuse relapse prevention. Drug and Alcohol Dependence 2010;111(3):227-34. [EMBASE: 2010546207]

\section{Feinstein 1959 \{published data only\}}

Feinstein AR, Wood HF, Epstein JA, Taranta A, Simpson R, Turskey $E$. A controlled study of three methods of prophylaxis against streptococcal infection in a population of rheumatic children. II Results of the first three years of the study, including methods for evaluation the maintenance of oral prophylaxis. New England Journal of Medicine 1959;260:697-702.

\section{Fennell 1994 \{published data only\}}

Fennell RS, Foulkes LM, Boggs SR. Family-based program to promote medication compliance in renal transplant children. Transplantation Proceedings 1994;26:102-3.

\section{Ferrante 2010 \{published data only\}}

* Ferrante D, Varini S, Macchia A, Soifer S, Badra R, Nul D, et al. GESICA Investigators. Long-term results after a telephone intervention in chronic heart failure: DIAL (Randomized Trial of Phone Intervention in Chronic Heart Failure) follow-up. Journal of the American College of Cardiology 2010;56(5):372-8. [MEDLINE: 20650358]

GESICA Investigators. Randomised trial of telephone intervention in chronic heart failure: DIAL trial. BMJ 2005;331(7514):425. [16061499]

Grancelli H, Varini S, Ferrante D, Schwartzman R, Zambrano C, Soifer S, et al. GESICA Investigators. Randomized Trial of Telephone Intervention in Chronic Heart Failure (DIAL): study design and preliminary observations. Journal of Cardiac Failure 2003;9(3):172-9. [12815566]

\section{Finkelstein 2003 \{published data only\}}

Finkelstein JS, Hayes A, Hunzelman JL, Wyland JJ, Lee H, Neer RM. The effects of parathyroid hormone, alendronate, or both in men with osteoporosis. New England Journal of Medicine 2003;349(13):1216-26.

\section{Finley 2003 \{published data only\}}

Finley PR, Rens HR, Pont JT, Gess SL, Louie C, Bull SA, et al. Impact of a collaborative care model on depression in a primary care setting: a randomized controlled trial. Pharmacotherapy 2003;23:1175-85.

\section{Finney 1985 \{published data only\}}

Finney JW, Friman PC, Rapoff MA, Christophersen ER. Improving compliance with antibiotic regimens for otitis media. American Journal of Diseases of Children 1985;139:89-95.

\section{Fisher 2001 \{published data only\}}

Fisher RS, Sachdeo RC, Pellock J, Penovich PE, Magnus L, Bernstein P. Rapid initiation of gabapentin: a randomized, controlled trial. Neurology 2001;56:743-8.

\section{Franchini 2006 \{published data only\}}

Franchini L, Bongiorno F, Spagnolo C, Florita M, Santoro A, Dotoli $D$, et al. Psychoeducational group intervention in addition to antidepressant therapy as relapse preventive strategy in unipolar patients. Clinical Neuropsychiatry 2006;3(4):282-5.

\section{Francis 2001 \{published data only\}}

Francis C. School clinics for adolescents with asthma. Professional Nurse 2001;16:1281-4.

\section{Frangou 2005 \{published data only\}}

Frangou S, Sachpazidis I, Stassinakis A, Sakas G. Telemonitoring of medication adherence in patients with schizophrenia. Telemedicine Journal and e-Health 2005;11(6):675-83.

\section{Freemantle 2002 \{published data only\}}

Freemantle N, Nazareth I, Eccles M, Wood J, Haines A, Evidencebased OutReach trialists. A randomised controlled trial of the effect of educational outreach by community pharmacists on prescribing in UK general practice. British Journal of General Practice 2002;477:290-5.

\section{Frick 2001 \{published data only\}}

Frick PA, Lavreys L, Mandaliya K, Kreiss JK. Impact of an alarm device on medication compliance in women in Mombasa, Kenya. International Journal of STD \& AIDS 2001;12:329-33.

Fujioka 2003 \{published data only\} Fujioka K, Pans M, Joyal S. Glycemic control in patients with type 2 diabetes mellitus switched from twice-daily immediate-release metformin to a once-daily extended-release formulation. Clinical Therapeutics 2003;25:515-29.

\section{Fumaz 2002 \{published data only\}}

Fumaz CR, Tuldra A, Ferrer M, Paredes R, Bonjoch A, Jou T, et al. Quality of life, emotional status, and adherence of HIV-1infected patients treated with efavirenz versus protease inhibitor-containing regimens. Journal of Acquired Immune Deficiency Syndromes 2002;29:244-53.

\section{Gabriel 1977 \{published data only\}}

Gabriel M, Gagnon JP, Bryan CK. Improved patients compliance through use of a daily drug reminder chart. American Journal of Public Health 1977;67:968-9. 
Gallefoss 2004 \{published data only\}

Gallefoss F. The effects of patient education in COPD in a 1-year follow-up randomised, controlled trial. Patient Education \& Counseling 2004;52:259-66.

\section{Garcao 2002 \{published data only\}}

Garcao JA, Cabrita J. Evaluation of a pharmaceutical care program for hypertensive patients in rural Portugal. Journal of the American Pharmaceutical Association 2002;42:858-64.

\section{Garety 2006 \{published data only\}}

Garety PA, Craig TK, Dunn G, Fornells-Ambrojo M, Colbert S, Rahaman N, et al. Specialised care for early psychosis: symptoms, social functioning and patient satisfaction: randomised controlled trial. British Journal of Psychiatry: The Journal of Mental Science 2006;188:37-45.

\section{Garnett 1981 \{published data only\}}

Garnett WR, Davis LJ, McKenney JM, Steiner KC. Effect of telephone follow-up on medication compliance. American Journal of Hospital Pharmacy 1981;38:676-9.

\section{Gibbs 1989 \{published data only\}}

Gibbs S, Waters WE, George CF. The benefits of prescription information leaflets. British Journal of Clinical Pharmacology 1989;27:723-39.

\section{Gilfillin 2002 \{published data only\}}

Gilfillin C, Body JJ, Boonen S, Valimaki M, Roux C, Felsenberg D, et al. Two-year results of once-weekly administration of alendronate $70 \mathrm{mg}$ for the treatment of postmenopausal osteoporosis. Journal of Bone \& Mineral Research 2002;17:1988-96

\section{Godemann 2003 \{published data only\}}

Godemann F. Is interval medication a successful treatment regimen for schizophrenic patients with critical attitudes towards treatment?. European Psychiatry 2003;18:82-4.

\section{Goodyer 1995 \{published data only\}}

Goodyer LI, Miskelly F, Milligan P. Does encouraging good compliance improve patients' clinical condition in heart failure?. British Journal of Clinical Practice 1995;49:173-6.

\section{Goujard 2003 \{published data only\}}

Goujard C, Bernard N, Sohier N, Peyramond D, Lancon F, Chwalow J, et al. Impact of a patient education program on adherence to HIV medication: a randomized clinical trial. Journal of Acquired Immune Deficiency Syndromes 2003;34(2):191-4.

\section{Graham 2002a \{published data only\}}

Graham DY, Agrawal NM, Campbell DR, Haber MM, Collis C, Lukasik NL, et al. Ulcer prevention in long-term users of nonsteroidal anti-inflammatory drugs: results of a double-blind, randomized, multicenter, active- and placebo-controlled study of misoprostol vs lansoprazole. Archives of Internal Medicine 2002;162:169-75.
Graham 2002b \{published data only\}

Graham MR, Lindsey CC, Kennedy JA. Maintenance of lowdensity lipoprotein goal with step-down pravastatin therapy. Pharmacotherapy 2002;22:21-6.

Grant 2003 \{published data only\}

Grant RW, Devita NG, Singer DE, Meigs JB. Improving adherence and reducing medication discrepancies in patients with diabetes. Annals of Pharmacotherapy 2003;37:962-9.

Gray 2006 \{published data only\}

Gray R, Leese M, Bindman J, Becker T, Burti L, David A, et al. Adherence therapy for people with schizophrenia. European multicentre randomised controlled trial. British Journal of Psychiatry 2006;189(Dec):508-14. [17139034]

Gupta 2001 \{published data only\}

Gupta AK, Konnikov N, Lynde CW. Single-blind, randomized, prospective study on terbinafine and itraconazole for treatment of dermatophyte toenail onychomycosis in the elderly. Journal of the American Academy of Dermatology 2001;44:479-84.

\section{Gustafson 2012 \{published data only\}}

Gustafson D, Wise M, Bhattacharya A, Pulvermacher A, Shanovich K, Phillips B, et al. The effects of combining Webbased eHealth with telephone nurse case management for pediatric asthma control: a randomized controlled trial. Journal of Medical Internet Research 2012;14(4):e101. [MEDLINE: 22835804]

Guthrie 2001 \{published data only\}

Guthrie RM. The effects of postal and telephone reminders on compliance with pravastatin therapy in a national registry: results of the first myocardial infarction risk reduction program. Clinical Therapeutics 2001;23:970-80.

Gwadry-Sridhar 2005 \{published data only\}

Gwadry-Sridhar FH, Arnold JMO, Zhang Y, Brown JE, Marchiori G, Guyatt G. Pilot study to determine the impact of a multidisciplinary educational intervention or patients hospitalized with heart failure. American Heart Journal 2005;150(5):982.

\section{Hamet 2003 \{published data only\}}

Hamet P, Campbell N, Curnew G, Eastwood C, Pradhan A. Avapromise: a randomized clinical trial for increasing adherence through behavioural modification in essential hypertension. Experimental \& Clinical Cardiology 2003;7:165-72.

Hamilton 2003 \{published data only\}

Hamilton GA. Measuring adherence in a hypertension clinical trial. European Journal of Cardiovascular Nursing 2003;2:219-28.

Hammond 2001 \{published data only\}

Hammond A, Freeman K. One-year outcomes of a randomized controlled trial of an educational-behavioural joint protection programme for people with rheumatoid arthritis. Rheumatology 2001;40:1044-51. 
Hampton 2001 \{published data only\}

Hampton RM, Short M, Bieber E, Bouchard C, Ayotte N, Shangold G, et al. Comparison of a novel norgestimate/ethinyl estradiol oral contraceptive (Ortho Tri-Cyclen Lo) with the oral contraceptive Loestrin Fe 1/20. Contraception 2001;63:289-95.

\section{Hardstaff 2003 \{published data only\}}

Hardstaff R, Green K, Talbot D. Measurement of compliance posttransplantation: the results of a 12-month study using electronic monitoring. Transplantation Proceedings 2003;35:796-7.

\section{Haubrich 1999 \{published data only\}}

Haubrich RH, Little SJ, Currier JS, Forthal DN, Kemper CA, Beall GN, et al. the California Collaborative Treatment Group. The value of patient-reported adherence to antiretroviral therapy in predicting virologic and immunologic response. AIDS (London, England) 1999;13:1099-107.

\section{Hayes 2003 \{published data only\}}

Hayes A, Buffum M, Fuller D. Bowel preparation comparison: flavored versus unflavored colyte. Gastroenterology Nursing 2003;26:106-9.

\section{Heard 1999 \{published data only\}}

Heard AR, Richards IJ, Alpers JH, Pilotto LS, Smith BJ, Black JA. Randomized controlled trial of general practice based asthma clinics. Medical Journal of Australia 1999;171:68-71.

\section{Herschorn 2004 \{published data only\}}

Herschorn S, Becker D, Miller E, Thompson M, Forte L. Impact of a health education intervention in overactive bladder patients. Canadian Journal of Urology 2004;11(6):2430-7.

\section{Hertling 2003 \{published data only\}}

Hertling I, Philipp M, Dvorak A, Glaser T, Mast O, Beneke M, et al. Flupenthixol versus risperidone: subjective quality of life as an important factor for compliance in chronic schizophrenic patients. Neuropsychobiology 2003;47:37-46.

\section{Hesselink 2004 \{published data only\}}

Hesselink AE, Penninx BW, van der Windt DA, van Duin BJ, de Vries P, Twisk JW, et al. Effectiveness of an education programme by a general practice assistant for asthma and COPD patients: results from a randomised controlled trial. Patient Education and Counseling 2004;55:121-8.

\section{Hoffman 2003 \{published data only\}}

Hoffman L, Enders J, Luo J, Segal R, Pippins J, Kimberlin C. Impact of an antidepressant management program on medication adherence. American Journal of Managed Care 2003;9:70-80.

\section{Holzemer 2006 \{published data only\}} Holzemer WL, Bakken S, Portillo CJ, Grimes R, Welch J, Wantland $D$, et al. Testing a nurse-tailored HIV medication adherence intervention. Nurse Research 2006;55(3):189-97.

\section{Hommel 2012 \{published data only\}}

Hommel KA, Hente EA, Odell S, Herzer M, Ingerski LM, Guilfoyle SM, et al. Evaluation of a group-based behavioral intervention to promote adherence in adolescents with inflammatory bowel disease. European Journal of Gastroenterology \& Hepatology 2012;24(1):64-9. [MEDLINE: 21989119]

\section{Hornung 1998a \{published data only\}}

Hornung WP, Klingberg S, Feldmann R, Schonauer K, Schulze MH. Collaboration with drug treatment by schizophrenic patients with and without psychoeducational training: results of a 1-year follow-up. Acta Psychiatrica Scandinavica 1998;97:213-9.

\section{Hovell 2003 \{published data only\}}

Hovell MF, Sipan CL, Blumberg EJ, Hofstetter CR, Slymen D, Friedman L, et al. Increasing Latino adolescents' adherence to treatment for latent tuberculosis infection: a controlled trial. American Journal of Public Health 2003;93(11):1871-7.

Insull 2001 \{published data only\} Insull W Jr, Toth P, Mullican W, Hunninghake D, Burke S, Donovan JM, et al. Effectiveness of colesevelam hydrochloride in decreasing LDL cholesterol in patients with primary hypercholesterolemia: a 24-week randomized controlled trial. Mayo Clinic Proceedings 2001;76:971-82.

\section{Jameson 1995 \{published data only\}}

Jameson J, VanNoord G, Vanderwoud K. The impact of a pharmacotherapy consultation on the cost and outcome of medical therapy. Journal of Family Practice 1995;41:469-72.

\section{Johnson 1997 \{published data only\}}

Johnson GD, Girvin B, McGavock H. A comparison of conventional dose versus low dose and alternate day dosing of bendrofluazide in terms of blood pressure lowering and patient compliance. Journal of Hypertension 1997;15(121):1549-50.

\section{Johnson 2006 \{published data only\}}

Johnson MO, Gamarel KE, Dawson Rose C. Changing HIV treatment expectancies: a pilot study. AIDS Care 2006;18(6):550-3.

\section{Jones 2003 \{published data only\}}

Jones DL, Ishii M, LaPerriere A, Stanley H, Antoni M, Ironson G, et al. Influencing medication adherence among women with AIDS. AIDS Care 2003;15:463-74.

Kakuda 2001 \{published data only\}

Kakuda TN, Page LM, Anderson PL, Henry K, Schacker TW, Rhame FS, et al. Pharmacological basis for concentrationcontrolled therapy with zidovudine, lamivudine, and indinavir. Antimicrobial Agents \& Chemotherapy 2001;45:236-42.

\section{Kardas 2001 \{published data only\}}

Kardas P, Ratajczyk-Pakalska E. Patient adherence in respiratory tract infections: ceftibuten versus other antibiotics (PARTICULAR study). Polski Merkuriusz Lekarski 2001;10:445-9.

Katelaris 2002 \{published data only\}

Katelaris PH, Forbes GM, Talley NJ, Crotty B. A randomized comparison of quadruple and triple therapies for Helicobacter 
pylori eradication: the QUADRATE study. Gastroenterology 2002;123:1763-9.

\section{Katon 2002 \{published data only\}}

Katon W, Russo J, Von Korff M, Lin E, Simon G, Bush T, et al. Long-term effects of a collaborative care intervention in persistently depressed primary care patients. Journal of General Internal Medicine 2002;17:741-8.

\section{Katon 2004 \{published data only\}}

Katon WJ, Von Korff M, Lin EH, Simon G, Ludman E, Russo J, et al. The Pathways Study: a randomized trial of collaborative care in patients with diabetes and depression. Archives of General Psychiatry 2004;61(10):1042-9.

\section{Kelly 1988 \{published data only\}}

Kelly JM. Sublingual nitroglycerin: improving patient compliance with a demonstration dose. Journal of the American Board of Family Practice 1988;1:251-4.

\section{Kelly 1990 \{published data only\}}

Kelly GR, Scott JE, Mamon J. Medication compliance and health education among outpatients with chronic mental disorders. Medical Care 1990;28:1181-97.

\section{Kelly 1991 \{published data only\}}

Kelly GR, Scott JE, Mamon J. Medication compliance and health education among outpatients with chronic mental disorders [erratum]. Medical Care 1991;29:889.

\section{Kiarie 2003 \{published data only\}}

Kiarie JN, Kreiss JK, Richardson BA, John-Stewart GC. Compliance with antiretroviral regimens to prevent perinatal HIV-1 transmission in Kenya. AIDS (London, England) 2003;17:65-71.

\section{Klein 2001 \{published data only\}}

Klein JJ, Van der Palen J, Uil SM, Zielhuis GA, Seydel ER, Van Herwaarden CL. Benefit from the inclusion of self-treatment guidelines to a self-management programme for adults with asthma. European Respiratory Journal 2001;17:386-94.

\section{Kogos Jr. 2004 \{published data only\}}

Kogos Jr SC. Support groups and treatment adherence in a geriatric outpatient clinic. Journal of Clinical Psychology in Medical Settings 2004;11(4):275-82.

\section{Krantz 2008 \{published data only\}}

Krantz MJ, Havranek EP, Haynes DK, Smith I, BucherBartelson B, Long CS. Inpatient initiation of beta-blockade plus nurse management in vulnerable heart failure patients: a randomized study. Journal of Cardiac Failure 2008;14(4):303-9. [MEDLINE: 18474343]

\section{Krein 2004 \{published data only\}}

Krein SL, Klamerus ML, Vijan S, Lee JL, Fitzgerald JT, Pawlow A, et al. Case management for patients with poorly controlled diabetes: a randomized trial. American Journal of Medicine 2004;116:732-9.

\section{Kritikos 2007 \{published data only\}}

Kritikos V, Armour CL, Bosnic-Anticevich SZ. Interactive smallgroup asthma education in the community pharmacy setting: a pilot study. Journal of Asthma 2007;44(1):57-64. [MEDLINE: 17365206]

\section{Kronish 2012 \{published data only\}}

Burg MM, Lespérance F, Rieckmann N, Clemow L, Skotzko C, Davidson KW. Treating persistent depressive symptoms in postACS patients: the project COPES phase-I randomized controlled trial. Contemporary Clinical Trials 2007;29(2):231-40. [000013]

* Kronish IM, Rieckmann N, Burg MM, Edmondson D, Schwartz JE, Davidson KW. The effect of enhanced depression care on adherence to risk-reducing behaviors after acute coronary syndromes: findings from the COPES trial. American Heart Journal 2012;164(4):524-9. [MEDLINE: 23067910]

\section{Krudsood 2002 \{published data only\}}

Krudsood S, Looareesuwan S, Silachamroon U, Chalermrut K, Pittrow D, Cambon N, et al. Artesunate and mefloquine given simultaneously for three days via a prepacked blister is equally effective and tolerated as a standard sequential treatment of uncomplicated acute Plasmodium falciparum malaria: randomized, double-blind study in Thailand. American Journal of Tropical Medicine \& Hygiene 2002;67:465-72.

\section{Kumar 2002 \{published data only\}}

Kumar H, Sudan R, Sethi HS, Sony P. Timolol maleate $0.5 \%$ versus timolol maleate in gel forming solution $0.5 \%$ (Timolol GFS) in open angle glaucoma in India. Preliminary safety and efficacy study. Indian Journal of Ophthalmology 2002;50:21-3.

\section{Kutcher 2002 \{published data only\}}

Kutcher S, Leblanc J, Maclaren C, Hadrava V. A randomized trial of a specific adherence enhancement program in sertralinetreated adults with major depressive disorder in a primary care setting. Progress in Neuro-Psychopharmacology \& Biological Psychiatry 2002;26:591-6.

\section{Lafeuillade 2001 \{published data only\}}

Lafeuillade A. Factors affecting adherence and convenience in antiretroviral therapy. International Journal of STD \& AIDS 2001;12(Suppl 4):18-24.

\section{Laffel 2003 \{published data only\}}

Laffel LM, Vangsness L. Impact of ambulatory, family-focused teamwork intervention on glycemic control in youth with type 1 diabetes. Journal of Pediatrics 2003;142:409-16.

\section{Lam 2003 \{published data only\}}

Lam DH, Watkins ER, Hayward P, Bright J, Wright K, Kerr N, et al. A randomized controlled study of cognitive therapy for relapse prevention for bipolar affective disorder: outcome of the first year. Archives of General Psychiatry 2003;60:145-52.

\section{Laramee 2003 \{published data only\}}

Laramee AS, Levinsky SK, Sargent J, Ross R, Callas P. Case management in a heterogeneous congestive heart failure population: a randomized controlled trial. Archives of Internal Medicine 2003;163:809-17. 


\section{Lawson 2005 \{published data only\}}

Lawson ML, Cohen N, Richardson C, Orrbine E, Pham B. A randomized trial of regular standardized telephone contact by a diabetes nurse educator in adolescents with poor diabetes control. Pediatric Diabetes 2005;9:32-40.

\section{Leal 2004 \{published data only\}}

Leal HM, Abellan AJ, Martinez CJ, Bastida NA. Written information on the use of aerosols in COPD patients. Can we improve their use? [see comment]. Atencion Primaria 2004;33:6-10.

\section{Lee 2003 \{published data only\}}

Lee TJ, Baraff LJ, Wall SP, Guzy J, Johnson D, Woo H. Parental compliance with after hours telephone triage advice: nurse advice service versus on-call pediatricians. Clinical Pediatrics 2003;42:613-9.

\section{Leenan 1997 \{published data only\}}

Leenen FHH, Wilson TW, Bolli P, Larochelle P, Myers M, Handa SP, et al. Patterns of compliance with once versus twice daily antihypertensive drug therapy in primary care: a randomized clinical trial using electronic monitoring. Canadian Journal of Cardiology 1997;13(10):914-20.

\section{Lemstra 2002 \{published data only\}}

Lemstra M, Stewart B, Olszynski WP. Effectiveness of multidisciplinary intervention in the treatment of migraine: a randomized clinical trial. Headache 2002;42:845-54.

\section{Lerman 2009 \{published data only\}}

Lerman I, Lopez-Ponce A, Villa AR, Escobedo M, Caballero EA, Velasco ML, et al. Pilot study of two different strategies to reinforce self care behaviors and treatment compliance among type 2 diabetes patients from low income strata. Gaceta Medica de Mexico 2009;145(1):15-9. [MEDLINE: 19256406]

\section{Leung 2003 \{published data only\}}

Leung CC, Law WS, Chang KC, Tam CM, Yew WW, Chan CK, et al. Initial experience on rifampin and pyrazinamide vs isoniazid in the treatment of latent tuberculosis infection among patients with silicosis in Hong Kong. Chest 2003;124(6):2112-8.

\section{Levesque 1983 \{published data only\}}

Levesque D, Pare P, Lacerte M, Parent JP, Rousseau B, Halle M, et al. Comparative efficacy of two dosage regimens of cimetidine in the treatment of symptomatic duodenal ulcer: results of a multicenter clinical trial. Current Therapeutic Research, Clinical and Experimental 1983;33:70-4.

Levine 1979 \{published data only\}

Levine DM, Green LW, Deeds SG, Chwalow J, Russell RP, Finlay J. Health education for hypertensive patients. JAMA 1979;241:1700-3.

\section{Levy 2004 \{published data only\}}

Levy RW, Rayner CR, Fairley CK, Kong DC, Mijch A, Costello K, et al. Melbourne Adherence Group. Multidisciplinary HIV adherence intervention: a randomized study. AIDS Patient Care and STDs 2004;18(12):728-35.
Lewis 1984 \{published data only\}

Lewis CE, Rachelefsky G, Lewis MA, de la Sota A, Kaplan M. A randomized trial of A.C.T. (asthma care training) for kids. Pediatrics 1984;74:478-86.

\section{Lin 2003 \{published data only\}}

Lin EHB, Von Korff M, Ludman EJ, Rutter C, Bush TM, Simon GE, et al. Enhancing adherence to prevent depression relapse in primary care. General Hospital Psychiatry 2003;25:303-10.

\section{Linkewich 1974 \{published data only\}}

Linkewich JA, Catalano RB, Flack HS. The effect of packaging and instruction on outpatient compliance with medication regimens. Drug Intelligence \& Clinical Pharmacy 1974;8:10-5.

\section{Linszen 1996 \{published data only\}}

Linszen D, Dingemans P, Van der Does JW, Nugter A, Scholte P, Lenior R, et al. Treatment, expressed emotion and relapse in recent onset schizophrenic disorders. Psychological Medicine 1996;26:333-42.

\section{Logan 1979 \{published data only\}}

Logan AG, Milne BJ, Achber C, Campbell WP, Haynes RB. Costeffectiveness of a worksite hypertension treatment program. Hypertension 1981;3(2):211-8.

* Logan AG, Milne BJ, Achber C, Campbell WP, Haynes RB. Worksite treatment of hypertension by specially trained nurses: a controlled trial. Lancet 1979;2:1175-8. [MEDLINE: 91901]

\section{Lopez-Vina 2000 \{published data only\}}

Lopez-Vina A, del Castillo-Arevalo F. Influence of peak expiratory flow monitoring on an asthma self-management education programme. Respiratory Medicine 2000;94:760-6.

\section{Lwilla 2003 \{published data only\}}

Lwilla F, Schellenberg D, Masanja H, Acosta C, Galindo C, Aponte $\mathrm{J}$, et al. Evaluation of efficacy of community-based vs. institutional-based direct observed short-course treatment for the control of tuberculosis in Kilombero district, Tanzania. Tropical Medicine \& International Health 2003;8:204-10.

\section{Macalino 2007 \{published data only\}}

Macalino GE, Hogan JW, Mitty JA, Bazerman LB, Delong AK, Loewenthal $\mathrm{H}$, et al. A randomized clinical trial of communitybased directly observed therapy as an adherence intervention for HAART among substance users. AIDS 2007;21(11):1473-7. [MEDLINE: 17589194]

\section{MacIntyre 2003 \{published data only\}}

MacIntyre CR, Goebel K, Brown GV, Skull S, Starr M, Fullinfaw RO. A randomised controlled clinical trial of the efficacy of family-based direct observation of anti-tuberculosis treatment in an urban, developed-country setting. International Journal of Tuberculosis and Lung Disease 2003;7(9):848-54.

\section{Maiman 1978 \{published data only\}}

Maiman LA, Becker MH, Liptak GS, Nazarian LF, Rounds KA. Improving pediatricians' compliance-enhancing practices: a randomized trial. American Journal of Diseases of Children 1978;142:773-9. 
Malotte 2001 \{published data only\}

Malotte CK, Hollingshead JR, Larro M. Incentives vs outreach workers for latent tuberculosis treatment in drug users. American Journal of Preventive Medicine 2001;20:103-7.

\section{Manders 2001 \{published data only\}}

Manders AJ, Banerjee A, van den Borne HW, Harries AD, Kok GJ, Salaniponi FM. Can guardians supervise TB treatment as well as health workers? A study on adherence during the intensive phase. International Journal of Tuberculosis \& Lung Disease 2001;5:838-42.

Mann 2001 \{published data only\}

Mann T. Effects of future writing and optimism on health behaviors in HIV-infected women. Annals of Behavioral Medicine 2001;23:26-33.

\section{Mannheimer 2002 \{published data only\}}

Mannheimer S, Friedland G, Matts J, Child C, Chesney M. The consistency of adherence to antiretroviral therapy predicts biologic outcomes for human immunodeficiency virusinfected persons in clinical trials. Clinical Infectious Diseases 2002;34:1115-21.

\section{Mannheimer 2006 \{published data only\}}

Mannheimer SB, Morse E, Matts JP, Andrews L, Child C, Schmetter B, et al. Community Programs for Clinical Research on AIDS. Sustained benefit from a long-term antiretroviral adherence intervention. Results of a large randomized clinical trial. Journal of Acquired Immune Deficiency Syndromes 2006;43(Suppl 1):S41-7.

\section{Mantzaris 2002 \{published data only\}}

Mantzaris GJ, Petraki K, Archavlis E, Amberiadis P, Christoforidis P, Kourtessas D, et al. Omeprazole triple therapy versus omeprazole quadruple therapy for healing duodenal ulcer and eradication of Helicobacter pylori infection: a 24month follow-up study. European Journal of Gastroenterology \& Hepatology 2002;14:1237-43.

\section{Marquez Contreras 2004b \{published data only\}}

Marquez Contreras E, de la Figuera von Wichmann M, Gil Guillen V, Ylla-Catala A, Figueras M, et al. Effectiveness of an intervention to provide information to patients with hypertension as short text messages and reminders sent to their mobile phone (HTA-Alert). Atencion Primaria 2004;34(8):399-405.

\section{Maslennikova 1998 \{published data only\}}

Maslennikova GY, Morosova ME, Salman NV, Kulikov SM, Oganov RG. Asthma education programme in Russia: educating patients. Patient Education \& Counseling 1998;33:113-27.

\section{Maspero 2001 \{published data only\}}

Maspero JF, Duenas-Meza E, Volovitz B, Pinacho DC, Kosa L, Vrijens F, et al. Oral montelukast versus inhaled beclomethasone in 6- to 11-year-old children with asthma: results of an open-label extension study evaluating longterm safety, satisfaction, and adherence with therapy. Current Medical Research \& Opinion 2001;17:96-104.

\section{Matsuyama 1993 \{published data only\}}

Matsuyama JR, Mason BJ, Jue SG. Pharmacists' interventions using an electronic medication-event monitoring device's adherence data versus pill counts. Annals of Pharmacotherapy 1993;27:851-5.

\section{Maxwell 2002 \{published data only\}}

Maxwell GL, Synan I, Hayes RP, Clarke-Pearson DL. Preference and compliance in postoperative thromboembolism prophylaxis among gynecologic oncology patients. Obstetrics \& Gynecology 2002;100:451-5.

\section{Mazzuca 1986 \{published data only\}}

Mazzuca SA, Moorman NH, Wheeler ML, Norton JA, Fineberg NS, Vinicor F, et al. The diabetes education study: a controlled trial of the effects of diabetes patient education. Diabetes Care 1986;9:1-10.

\section{McCrindle 1997 \{published data only\}}

McCrindle BW, O'Neill MB, Cullen-Dean G, Helden E. Acceptability and compliance with two forms of cholestyramine in the treatment of hypercholesterolemia in children: a randomized, crossover trial. Journal of Pediatrics 1997;130(2):266-73.

\section{McFarlane 1995 \{published data only\}}

McFarlane WR, Lukens E, Link B, Dushay R, Deakins SA, Newmark M, et al. Multiple-family groups and psychoeducation in the treatment of schizophrenia. Archives of General Psychiatry 1995;52:679-87.

\section{Miklowitz 2000 \{published data only\}}

Miklowitz DJ, Simoneau TL, George EL, Richards JA, Kalbag A Sachs-Ericsson N, et al. Family-focused treatment of bipolar disorder: 1-year effects of a psychoeducational program in conjunction with pharmacotherapy. Biological Psychiatry 2000;48(6):582-92.

\section{Miklowitz 2003 \{published data only\}}

Miklowitz DJ, George EL, Richards JA, Simoneau TL, Suddath RL. A randomized study of family-focused psychoeducation and pharmacotherapy in the outpatient management of bipolar disorder. Archives of General Psychiatry 2003;60(9):904-12.

\section{Millard 2003 \{published data only\}}

Millard MW, Johnson PT, McEwen M, Neatherlin J, Lawrence G, Kennerly DK, et al. A randomized controlled trial using the school for anti-inflammatory therapy in asthma. Journal of Asthma 2003;40:769-76.

\section{Miller 1990 \{published data only\}}

Miller P, Wikoff R, Garrett MJ, McMahon M, Smith T. Regimen compliance two years after myocardial infarction. Nursing Research 1990;39(6):333-6.

\section{Mita 2003 \{published data only\}}

Mita Y, Dobashi K, Shimizu Y, Akiyama M, Ono A, Nakazawa, T, et al. Levofloxacin $300 \mathrm{mg}$ once-daily versus levofloxacin $100 \mathrm{mg}$ three-times-daily in the treatment of respiratory tract infections in elderly patients. Kitakanto Medical Journal 2003;53:251-5. 
Morisky 1980 \{published data only\}

Morisky DE, Levine DM, Green LW, Russell RP, Smith C, Benson P, et al. The relative impact of health education for low- and high-risk patients with hypertension. Preventive Medicine 1980;9:550-8.

\section{Morisky 1983 \{published data only\}}

Morisky DE, Levine DM, Green LW, Shapiro S, Russell RP, Smith CR. Five-year blood pressure control and mortality following health education for hypertensive patients. American Journal of Public Health 1983;73:153-62.

\section{Morisky 1990 \{published data only\}}

Morisky DE, Malotte CK, Choi P, Davidson P, Rigler S, Sugland B, et al. A patient education program to improve adherence rates with antituberculosis drug regimens. Health Education Quarterly 1990;17:253-67.

\section{Morisky 2001 \{published data only\}}

Morisky DE, Malotte CK, Ebin V, Davidson P, Cabrera D, Trout PT, et al. Behavioral interventions for the control of tuberculosis among adolescents. Public Health Reports 2001;116:568-74.

\section{Moulding 2002 \{published data only\}}

Moulding TS, Caymittes M. Managing medication compliance of tuberculosis patients in Haiti with medication monitors. International Journal of Tuberculosis \& Lung Disease 2002;6:313-9.

\section{Moya 2006 \{published data only\}}

Moya J, Casado JL, Aranzabal L, Moreno A, Antela A, Dronda F, et al. Limitations of a simplification antiretroviral strategy for HIV-infected patients with decreasing adherence to a protease inhibitor regimen. HIV Clinical Trials 2006;7(4):210-4.

\section{Muhlig 2001 \{published data only\}}

Muhlig S, Bergmann KC, Twesten O, Petermann F. Therapy participation in ambulatory asthma patients: empirical comparison of compliance rates using different operationalization methods for drug compliance. Pneumologie 2001;55:177-89.

\section{Mundt 2001 \{published data only\}}

Mundt JC, Clarke GN, Burroughs D, Brenneman DO, Griest GH. Effectiveness of an antidepressant pharmacotherapy: the impact of medication compliance and patient education. Depression and Anxiety 2001;13:1-10.

\section{Murphy 2002 \{published data only\}}

Murphy DA, Lu MC, Martin D, Hoffman D, Marelich WD. Results of a pilot intervention trial to improve antiretroviral adherence among HIV-positive patients. Journal of the Association of Nurses in AIDS Care 2002;13:57-69.

\section{Murphy 2007 \{published data only\}}

Murphy DA, Marelich WD, Rappaport NB, Hoffman D, Farthing C. Results of an Antiretroviral Adherence Intervention: STAR (Staying Healthy: Taking Antiretrovirals Regularly). Journal of the International Association of Physicians in AIDS Care (Chicago) 2007;6(2):113-24. [17538003]

\section{Murray 1993 \{published data only\}}

Murray MD, Birt JA, Manatunga AK, Darnell JC. Medication compliance in elderly outpatients using twice-daily dosing and unit-of-use packaging. Annals of Pharmacotherapy 1993;27:616-21.

\section{Myers 1984 \{published data only\}}

Myers ED, Calvert EJ. Information, compliance and side-effects: a study of patients on antidepressant medication. British Journal of Clinical Pharmacology 1984;17:21-5.

Myers 1992 \{published data only\}

Myers ED, Branthwaite A. Out-patient compliance with antidepressant medication. British Journal of Psychiatry 1992;160:83-6.

\section{Nachega 2010 \{published data only\}}

Nachega JB, Chaisson RE, Goliath R, Efron A, Chaudhary MA, Ram M, et al. Randomized controlled trial of trained patientnominated treatment supporters providing partial directly observed antiretroviral therapy. AIDS 2010;24(9):1273-80. [MEDLINE: 20453627]

\section{Nansel 2007 \{published data only\}}

Nansel TR, lannotti RJ, Simons-Morton BG, Cox C, Plotnick LP, Clark LM, et al. Diabetes personal trainer outcomes: shortterm and 1-year outcomes of a diabetes personal trainer intervention among youth with type 1 diabetes. Diabetes Care 2007;30(10):2471-7. [MEDLINE: 17620445]

Naunton 2003 \{published data only\}

Naunton M, Peterson GM. Evaluation of home-based follow-up of high-risk elderly patients discharged from hospital. Journal of Pharmacy Practice \& Research 2003;33:176-82.

Nessman 1980 \{published data only\}

Nessman DG, Carnahan JE, Nugent CA. Increasing compliance. Patient-operated hypertension groups. Archives of Internal Medicine 1980;140:1427-30.

Ngoh 1997 \{published data only\}

Ngoh LN, Shepherd MD. Design, development, and evaluation of visual aids for communicating prescription drug instructions to nonliterate patients in rural Cameroon. Patient Education \& Counseling 1997;30:257-70.

Nides 1993 \{published data only\} Nides MA, Tashkin DP, Simmons MS, Wise RA, Li VC, Rand CS. Improving inhaler adherence in a clinical trial through the use of the nebulizer chronolog. Chest 1993;104:501-7.

Noonan 2001 \{published data only\}

Noonan M, Karpel JP, Bensch GW, Ramsdell JW, Webb DR, Nolop KB, et al. Comparison of once-daily to twice-daily treatment with mometasone furoate dry powder inhaler. Annals of Allergy, Asthma, \& Immunology 2001;86:36-43.

Nyomba 2004 \{published data only\}

Nyomba BLG, Berard L, Murphy LJ. Facilitating access to glucometer reagents increases blood glucose self-monitoring frequency and improves glycaemic control: a prospective 
study in insulin-treated diabetic patients. Diabetic Medicine 2004;21:129-35.

\section{O'Connor 1996 \{published data only\}}

O'Connor PJ, Rush WA, Peterson J, Morben P, Cherney L, Keogh C, et al. Continuous quality improvement can improve glycemic control for $\mathrm{HMO}$ patients with diabetes. Archives of Family Medicine 1996;5:502-6.

\section{O'Suilleabhain 2002 \{published data only\}}

O'Suilleabhain P, Dewey RB Jr. Randomized trial comparing primidone initiation schedules for treating essential tremor. Movement Disorders 2002;17:382-6.

\section{Obreli Neto 2011 \{published data only\}}

Obreli-Neto PR, Guidoni CM, De Oliveira Baldoni A, Pilger D, Cruciol-Souza JM, Gaeti-Franco WP, et al. Effect of a 36-month pharmaceutical care program on pharmacotherapy adherence in elderly diabetic and hypertensive patients. International Journal of Clinical Pharmacy 2011;33(4):642-9. [EMBASE: 2011492556]

\section{Ogedegbe 2008 \{published data only\}}

* Ogedegbe G, Chaplin W, Schoenthaler A, Statman D, Berger D, Richardson T, et al. A practice-based trial of motivational interviewing and adherence in hypertensive African Americans. American Journal of Hypertension 2008;21(10):1137-43. [MEDLINE: 18654123]

Ogedegbe G, Schoenthaler A, Richardson T, Lewis L, Belue R, Espinosa E, et al. An RCT of the effect of motivational interviewing on medication adherence in hypertensive African Americans: rationale and design. Contemporary Clinical Trials 2007;28(2):169-81. [MEDLINE: 16765100]

\section{Onyirimba 2003 \{published data only\}}

Onyirimba F, Apter A, Reisine S, Litt M, McCusker C, Connors M, et al. Direct clinician-to-patient feedback discussion of inhaled steroid use: its effect on adherence. Annals of Allergy, Asthma, \& Immunology 2003;90:411-5.

\section{Pearce 2008 \{published data only\}}

Love MM, Pearce KA, Williamson MA, Barron MA, Shelton BJ. Patients, practices, and relationships: challenges and lessons learned from the Kentucky Ambulatory Network (KAN) CaRESS clinical trial. Journal of the American Board of Family Medicine 2006;19(1):75-84. [16492009]

* Pearce KA, Love MM, Shelton BJ, Schoenberg NE, Williamson MA, Barron MA, et al. Kentucky Ambulatory Network. Cardiovascular risk education and social support (CaRESS): report of a randomized controlled trial from the Kentucky Ambulatory Network (KAN). Journal of the American Board of Family Medicine 2008;21(4):269-81. [CENTRAL: CN-00649609]

\section{Phan 1995 \{published data only\}}

Phan TT. Enhancing client adherence to psychotropic medication regimens: a psychosocial nursing approach. International Journal of Psychiatric Nursing Research 1995;2(1):146-72.
Piette 2001 \{published data only\}

Piette JD, Weinberger M, Kraemer FB, McPhee SJ. Impact of automated calls with nurse follow-up on diabetes treatment outcomes in a Department of Veterans Affairs health care system: a randomized controlled trial. Diabetes Care 2001;24(2):202-8.

Pladevall 2010 \{published data only\}

Pladevall M, Brotons C, Gabriel R, Arnau A, Suarez C, de la Figuera $M$, et al. Writing Committee on behalf of the COM99 Study Group. Multicenter cluster-randomized trial of a multifactorial intervention to improve antihypertensive medication adherence and blood pressure control among patients at high cardiovascular risk (the COM99 study). Circulation 2010;122(12):1183-91. [MEDLINE: 20823391]

Polonsky 2003 \{published data only\}

Polonsky WH, Earles J, Smith S, Pease DJ, Macmillan M, Christensen $\mathrm{R}$, et al. Integrating medical management with diabetes self-management training: a randomized control trial of the Diabetes Outpatient Intensive Treatment program. Diabetes Care 2003;26:3048-53.

\section{Ponnusankar 2004 \{published data only\}}

Ponnusankar S, Surulivelrajan M, Anandamoorthy N, Suresh B. Assessment of impact of medication counseling on patients' medication knowledge and compliance in an outpatient clinic in South India. Patient Education \& Counseling 2004;54:55-60.

\section{Pop Eleches 2011 \{published data only\}}

Pop-Eleches C, Thirumurthy H, Habyarimana JP, Zivin JG, Goldstein MP, de Walque D, et al. Mobile phone technologies improve adherence to antiretroviral treatment in a resourcelimited setting: a randomized controlled trial of text message reminders. AIDS (London, England) 2011;25(6):825-3. [CENTRAL: $\mathrm{CN}-00785025]$

\section{Poplawska 2004 \{published data only\}}

Poplawska R, Czernikiewicz A, Szulc A, Galinska B, Konarzewska B, Rudnik-Szalaj I. The effectiveness of psychoeducation in schizophrenic and depressive patientspreliminary report. Psychiatria Polska 2004;38:433-42.

\section{Portilla 2003 \{published data only\}}

Portilla J, Jorda P, Esteban J, Sanchez-Paya J, Merino E, Boix V, et al. Directly observed treatment of latent tuberculosis infection: comparative study of two isoniazid regimens. Enfermedades Infecciosas y Microbiologia Clinica 2003;21:293-5.

Purcell 2004 \{published data only\}

Purcell DW, Metsch LR, Latka M, Santibanez S, Gomez CA, Eldred L, et al. INSPIRE Study Group. Interventions for seropositive injectors-research and evaluation: an integrated behavioral intervention with HIV-positive injection drug users to address medical care, adherence, and risk reduction. Journal of Acquired Immune Deficiency Syndromes 2004;37(Suppl 2):S110-8. 
Putnam 1994 \{published data only\}

Putnam DE, Finney JW, Barkley PL, Bonner MJ. Enhancing commitment improves adherence to a medical regimen. Journal of Consulting and Clinical Psychology 1994;62(1):191-4

\section{Qazi 2002 \{published data only\}}

Qazi S. Clinical efficacy of 3 days versus 5 days of oral amoxicillin for treatment of childhood pneumonia: a multicentre double-blind trial. Lancet 2002;360:835-41.

\section{Ran 2003 \{published data only\}}

Ran MS, Xiang MZ, Chan CLW, Leff J, Simpson P, Huang MS, et al. Effectiveness of psychoeducational intervention for rural Chinese families experiencing schizophrenia; a randomised controlled trial. Social Psychiatry and Psychiatric Epidemiology 2003;38(2):69-75. [MEDLINE: 12563548]

\section{Rapoff 2002 \{published data only\}}

Rapoff MA, Belmont J, Lindsley C, Olson N, Morris J, Padur J. Prevention of nonadherence to nonsteroidal anti-inflammatory medications for newly diagnosed patients with juvenile rheumatoid arthritis. Health Psychology 2002;21:620-3.

Rathbun 2005 \{published data only\}

Rathbun RC, Farmer KC, Stephens JR, Lockhart SM. Impact of an adherence clinic on behavioral outcomes and virologic response in treatment of HIV infection: a prospective, randomized, controlled pilot study. Clinical Therapeutics 2005;27(2):199-209.

\section{Raynor 1993 \{published data only\}}

Raynor DK, Booth TG, Blenkinsopp A. Effects of computer generated reminder charts on patients' compliance with drug regimens. BMJ 1993;306:1158-61.

\section{Razali 1997 \{published data only\}}

Razali SM, Yahya H. Health education and drug counseling for schizophrenia. International Medical Journal 1997;4:187-9.

\section{Rehder 1980 \{published data only\}}

Rehder TL, McCoy LK, Blackwell B, Whitehead W, Robinson A. Improving medication compliance by counseling and special prescription container. American Journal of Hospital Pharmacy 1980;37:379-85.

\section{Reid 2005 \{published data only\}}

Reid SC, Teesson M, Sannibale C, Matsuda M, Haber PS. The efficacy of compliance therapy in pharmacotherapy for alcohol dependence: a randomized controlled trial. Journal of Studies of Alcohol 2005;66(6):833-41.

\section{Rettig 1986 \{published data only\}}

Rettig BA, Shrauger DG, Recker RR, Gallagher TF, Wiltse H. A randomized study of the effects of a home diabetes education program. Diabetes Care 1986;9(2):173-8.

\section{Rich 1996 \{published data only\}}

Rich MW, Gray DB, Beckham V, Wittenberg C, Luther P. Effect of a multidisciplinary intervention on medication compliance in elderly patients with congestive heart failure. American Journal of Medicine 1996;101:270-6.

\section{Rickheim 2002a \{published data only\}}

Rickheim PL, Weaver TW, Flader JL, Kendall DM. Assessment of group versus individual diabetes education: a randomized study. Diabetes Care 2002;25:269-74.

\section{Rickheim 2002b \{published data only\}}

Rickheim PL, Weaver TW, Flader JL, Kendall DM. Assessment of group versus individual diabetes education: a randomized study. Diabetes Care 2002;25:269-74.

Rigsby 2000 \{published data only\}

Rigsby MO, Rosen MI, Beauvais JE, Cramer JA, Rainey PM, O'Malley SS, et al. Pilot study of an antiretroviral adherence intervention. Journal of General Internal Medicine 2000;15:841-7.

\section{Riis 2001 \{published data only\}}

Riis BJ, Ise J, von Stein T, Bagger Y, Christiansen C. Ibandronate: a comparison of oral daily dosing versus intermittent dosing in postmenopausal osteoporosis. Journal of Bone \& Mineral Research 2001;16:1871-8.

\section{Rimer 1987 \{published data only\}}

Rimer B, Levy MH, Keintz MK, Fox L, Engstrom PF, MacElwee N. Enhancing cancer pain control regimens through patient education. Patient Education \& Counseling 1987;10:267-77.

Robinson 1986 \{published data only\}

Robinson GL, Gilbertson AD, Litwack L. The effects of a psychiatric patient education to medication program on postdischarge compliance. The Psychiatric Quarterly 1986;58:113-8.

Rodriguez 2003 \{published data only\}

Rodriguez RM, Sanchez F. Effectiveness of a group educational intervention in patients with chronic obstructive pulmonary disease. Enfermeria Clinica 2003;13:131-6.

Rosen 2004 \{published data only\}

Rosen MI, Rigsby MO, Salahi JT, Ryan CE, Cramer JA. Electronic monitoring and counseling to improve medication adherence. Behaviour Research \& Therapy 2004;42:409-22.

Ross 2004 \{published data only\}

Ross SE, Moore LA, Earnest MA, Wittevrongel L, Lin CT. Providing a web-based online medical record with electronic communication capabilities to patients with congestive heart failure: randomized trial. Journal of Medical Internet Research 2004;6(2):e12.

\section{Roy-Byrne 2001 \{published data only\}}

Roy-Byrne PD, Katon W, Cowley DS, Russo J. A randomized effectiveness trial of collaborative care for patients with panic disorder in primary care. Archives of General Psychiatry 2001;58:869-76.

\section{Rudnicka 2003 \{published data only\}}

Rudnicka AR, Ashby D, Brennan P, Meade T. Thrombosis prevention trial: compliance with warfarin treatment and investigation of a retained effect. Archives of Internal Medicine 2003;163:1454-60 
Ruiz 2010 \{published data only\}

Ruiz I, Olry A, Lopez MA, Prada JL, Causse M. Prospective, randomized, two-arm controlled study to evaluate two interventions to improve adherence to antiretroviral therapy in Spain. Enfermedades Infecciosas y Microbiologia Clinica 2010;28(7):409-15. [MEDLINE: 20381924]

\section{Ruoff 2005 \{published data only\}}

Ruoff G. A method that dramatically improves patient adherence to depression treatment. Journal of Family Practice 2005;54(10):846-52.

\section{Rytter 2010 \{published data only\}}

Rytter L, Jakobsen HN, Ronholt F, Hammer AV, Andreasen AH, Nissen A, et al. Comprehensive discharge follow-up in patients' homes by GPs and district nurses of elderly patients. A randomized controlled trial. Scandinavian Journal of Primary Health Care 2010;28(3):146-53. [MEDLINE: 20429738]

\section{Sáez 2011 \{published data only\}}

Sáez de la Fuente J, Granja Berná V, Lechuga Vázquez P, Otero Perpiña B, Herreros de Tejada López-Coterilla A, et al. Efficiency of the information given at discharge and adherence of polymedicated patients. Farmacia Hospitalaria 2011;35(3):128-34. [CENTRAL: CN-00801165]

\section{Safren 2003 \{published data only\}}

Safren SA, Hendriksen ES, Desousa N, Boswell SL, Mayer KH. Use of an on-line pager system to increase adherence to antiretroviral medications. AIDS Care 2003;15:787-93.

\section{Safren 2009 \{published data only\}}

Safren SA, O'Cleirigh C, Tan JY, Raminani SR, Reilly LC, Otto MW, et al. A randomized controlled trial of cognitive behavioral therapy for adherence and depression (CBT-AD) in HIV-infected individuals. Health Psychology 2009;28(1):1-10. [MEDLINE: 19210012]

\section{Sanchez 2002 \{published data only\}}

Sanchez F, Balague M, Hernandez P, Lopez-Colomes JL, De Olalla PG, Garcia-Vidal, J, et al. Treatment of latent tuberculosis infection in injecting drug users co-infected by HIV. Enfermedades Emergentes 2002;4:62-5.

\section{Sanmarti 1993 \{published data only\}}

Salleras Sanmarti L, Alcaide Megias J, Altet Gomez MN, Canela Soler J, Navas Alcala E, Sune Puigbo MR, et al. Evaluation of the efficacy of health education on the compliance with antituberculosis chemoprophylaxis in school children. A randomized clinical trial. Tubercle and Lung Disease 1993;74:28-31.

\section{Santschi 2008 \{published data only\}}

Santschi V, Rodondi N, Bugnon O, Burnier M. Impact of electronic monitoring of drug adherence on blood pressure control in primary care: a cluster 12-month randomised controlled study. European Journal of Internal Medicine 2008;19(6):427-34. [MEDLINE: 18848176]

\section{Saunders 1991 \{published data only\}}

Saunders LD, Irwig LM, Gear JS, Ramushu DL. A randomized controlled trial of compliance improving strategies in Soweto hypertensives. Medical Care 1991;29:669-78.

\section{Sawicki 1999 \{published data only\}}

Sawicki PT. A structured teaching and self-management program for patients receiving oral anticoagulation. JAMA 1999;281:145-50.

\section{Schmaling 2001 \{published data only\}}

Schmaling KB, Blume AW, Afari N. A randomized controlled pilot study of motivational interviewing to change attitudes about adherence to medications for asthma. Journal of Clinical Psychology in Medical Settings 2001;8:167-72.

Schneider 2008 \{published data only\}

Schneider PJ, Murphy JE, Pedersen CA. Impact of medication packaging on adherence and treatment outcomes in older ambulatory patients. Journal of the American Pharmacists Association 2008;48(1):58-63. [MEDLINE: 18192132]

Schoenbaum 2001 \{published data only\}

Schoenbaum M, Unutzer J, Sherbourne C, Duan N, Rubenstein LV, Miranda J, et al. Cost-effectiveness of practiceinitiated quality improvement for depression: results of a randomized controlled trial. JAMA 2001;286:1325-30.

\section{Schousboe 2005 \{published data only\}}

Schousboe JT, DeBod RC, Kuno LS, Weiss TW, Chen YT, Abbott TA. Education and phone follow-up in postmenopausal women at risk for osteoporosis. Disease Management \& Health Outcomes 2005;13(6):395-404.

\section{Schwartz 1981 \{published data only\}}

Schwartz RH, Wientzen RL Jr, Pedreira F, Feroli EJ, Mella GW, Guandolo VL. Penicillin V for group A streptococcal pharyngotonsillitis: a randomized trial of seven vs ten days' therapy. JAMA 1981;246:1790-5.

Sclar 1991 \{published data only\}

Sclar DA, Chin A, Skaer TL, Okamoto MP, Nakahiro RK, Gill MA. Effect of health education in promoting prescription refill compliance among patients with hypertension. Clinical Therapeutics 1991;13:489-95.

\section{Seal 2003 \{published data only\}}

Seal KH, Kral AH, Lorvick J, McNees A, Gee L, Edlin BR. A randomized controlled trial of monetary incentives vs. outreach to enhance adherence to the hepatitis $B$ vaccine series among injection drug users. Drug \& Alcohol Dependence 2003;71:127-31.

\section{Segador 2005 \{published data only\}}

Segador J, Gil-Guillen VF, Orozco D, Quirce F, Carratala MC, Fernandez-Parker $A$, et al. The effect of written information on adherence to antibiotic treatment in acute sore throat. International Journal of Antimicrobial Agents 2005;26(1):56-61. 
Seggev 1998 \{published data only\}

Seggev JS, Enrique RR, Brandon ML, Larsen LS, Van Tuyl RA, Rowinski CA, Acute Bacterial Maxillary Sinusitis Collaborative Study Group. A combination of amoxicillin and clavulanate every 12 hours vs every 8 hours for treatment of acute bacterial maxillary sinusitis. Archives of Otolaryngology -- Head and Neck Surgery 1998;124:921-5.

\section{Sellors 1997 \{published data only\}}

Sellors J, Pickard L, Mahony JB, Jackson K, Nelligan P, ZimicVincetic $M$, et al. Understanding and enhancing compliance with the second dose of hepatitis B vaccine: a cohort analysis and a randomized controlled trial. Canadian Medical Association Journal 1997;157:143-8.

\section{Sellwood 2001 \{published data only\}}

Sellwood W, Barrowclough C, Tarrier N, Quinn J, Mainwaring J, Lewis S. Needs-based cognitive-behavioural family intervention for carers of patients suffering from schizophrenia: 12-month follow-up. Acta Psychiatrica Scandinavica 2001;104:346-55.

\section{Serfaty 2002 \{published data only\}}

Serfaty D, Bruhat MA, Colau JC, de Reilhac P, De Lignieres B, Roger $\mathrm{D}$, et al. Compliance with hormone replacement therapy in menopausal women: effect of an original education program. The COMET study. Gynecologie, Obstetrique \& Fertilite 2002;30:374-82.

\section{Serfaty 2003 \{published data only\}}

Serfaty D, de Reilhac P, Eschwege E, Ringa V, Blin P, Nandeuil A, et al. Compliance with hormone replacement therapy in menopausal women: results of a two-year prospective French study comparing transdermal treatment with fixed oral combination therapy. Gynecologie, Obstetrique \& Fertilite 2003;31:525-33.

\section{Shames 2004 \{published data only\}}

Shames RS, Sharek P, Mayer, M, Robinson TN, Hoyte EG, Gonzalez-Hensley F, et al. Effectiveness of a multicomponent self-management program in at-risk, school-aged children with asthma. Annals of Allergy, Asthma, \& Immunology 2004;92:611-8.

\section{Sharpe 1974 \{published data only\}}

Sharpe TR, Mikeal RL. Patient compliance with antibiotic regimens. American Journal of Hospital Pharmacy 1974;31:479-84.

\section{Shepard 1979 \{published data only\}}

Shepard DS, Foster SB, Stason WB, Solomon HS, McArdle PJ, Gallagher SS. Cost-effectiveness of interventions to improve compliance with anti-hypertensive therapy. Preventive Medicine 1979;8:229.

\section{Sherbourne 2001 \{published data only\}}

Sherbourne CD, Wells KB, Duan N, Miranda J, Unutzer J, Jaycox $L$, et al. Long-term effectiveness of disseminating quality improvement for depression in primary care. Archives of General Psychiatry 2001;58:696-703.

\section{Sherman 2001 \{published data only\}}

Sherman J, Patel P, Hutson A, Chesrown S, Hendeles L. Adherence to oral montelukast and inhaled fluticasone in children with persistent asthma. Pharmacotherapy 2001;21:1464-7.

\section{Shetty 1997 \{published data only\}}

Shetty MK, Chowdhury SA, Trivus RH, Lynn DL, Titus R. Flexible therapy versus traditional psychotherapy: a preliminary study. 150th Annual Meeting of the American Psychiatric Association. San Diego, California, May 1997:17-22.

\section{Silverman 2002 \{published data only\}}

Silverman BL, Blethen SL, Reiter EO, Attie KM, Neuwirth RB, Ford KM. A long-acting human growth hormone (Nutropin Depot): efficacy and safety following two years of treatment in children with growth hormone deficiency. Journal of Pediatric Endocrinology \& Metabolism 2002;15:715-22.

Simkins 1986 \{published data only\} Simkins CV, Wenzloff NJ. Evaluation of a computerized reminder system in the enhancement of patient medication refill compliance. Drug Intelligence \& Clinical Pharmacy 1986;20:799-802.

\section{Simmons 2001 \{published data only\}}

Simmons SF, Alessi C, Schnelle JF. An intervention to increase fluid intake in nursing home residents: prompting and preference compliance. Journal of the American Geriatrics Society 2001;49:926-33.

\section{Simon 2002 \{published data only\}}

Simon JA, Lewiecki EM, Smith ME, Petruschke RA, Wang L, Palmisano JJ. Patient preference for once-weekly alendronate $70 \mathrm{mg}$ versus once-daily alendronate $10 \mathrm{mg}$ : a multicenter, randomized, open-label, crossover study. Clinical Therapeutics 2002;24:1871-86.

\section{Simon 2005 \{published data only\}}

Simon SR, Majumdar SR, Prosser LA, Salem-Schatz S, Warner C, Kleinman K, et al. Group versus individual academic detailing to improve the use of antihypertensive medications in primary care: a cluster-randomized controlled trial. American Journal of Medicine 2005;118(5):521-8.

\section{Simon 2006 \{published data only\}}

Simon GE, Ludman EJ, Bauer MS, Unutzer J, Operskalski B. Long-term effectiveness and cost of a systematic care program for bipolar disorder. Archives of General Psychiatry 2006;63(5):500-8.

\section{Smith 1986 \{published data only\}}

Smith NA, Seale JP, Ley P, Shaw J, Bracs PU. Effects of intervention on medication compliance in children with asthma. Medical Journal of Australia 1986;144:119-22.

\section{Smith 2003 \{published data only\}}

Smith SR, Rublein JC, Marcus C, Brock TP, Chesney MA. A medication self-management program to improve adherence to HIV therapy regimens. Patient Education \& Counseling 2003;50:187-99. 
Solomon 1988 \{published data only\}

Solomon MZ, DeJong W. The impact of a clinic-based educational videotape on knowledge and treatment behavior of men with gonorrhea. Sexually Transmitted Diseases 1988;15:127-32.

Solomon MZ, DeJong W, Jodrie TA. Improving drug regimen adherence among patients with sexually transmitted disease. Journal of Compliance in Health Care 1988;3:41-56.

Solomon 1997 \{published data only\}

Solomon PL. Outcomes of two brief family education programs. 150th Annual Meeting of the American Psychiatric Association. San Diego, California, May 17-22, 1979.

\section{Stringer 2003 \{published data only\}}

Stringer JS, Sinkala M, Stout JP, Goldenberg RL, Acosta EP, Chapman V, et al. Comparison of two strategies for administering nevirapine to prevent perinatal HIV transmission in high-prevalence, resource-poor settings. Journal of Acquired Immune Deficiency Syndromes 2003;32:506-13.

\section{Stuart 2003 \{published data only\}}

Stuart GW, Laraia MT, Ornstein SM, Nietert PJ. An interactive voice response system to enhance antidepressant medication compliance. Topics in Health Information Management 2003;24:15-20.

\section{Sturgess 2003 \{published data only\}}

Sturgess IK, McElnay JC, Hughes CM, Crealey G. Community pharmacy based provision of pharmaceutical care to older patients. Pharmacy World \& Science 2003;25:218-26.

\section{Stuurman-Bieze 2005 \{published data only\}}

Stuurman-Bieze AG, de Boer WO, Kokenberg ME, Hugtenburg JG, de Jong-van den Berg LT, Tromp TF. Complex pharmaceutical care intervention in pulmonary care: part A. The process and pharmacists' professional satisfaction. Pharmacy World \& Science 2005;27(5):376-84.

\section{Suppapitiporn 2005 \{published data only\}}

Suppapitiporn S. Effect of diabetes drug counseling by pharmacist, diabetic disease booklet and special medication containers on glycemic control of type 2 diabetes mellitus: a randomized controlled trial. Journal of the Medical Association of Thailand 2005;88(Suppl 4):S134-41.

\section{Surwit 2002 \{published data only\}}

Surwit RS, van Tilburg MA, Zucker N, McCaskill CC, Parekh P, Feinglos MN, et al. Stress management improves long-term glycemic control in type 2 diabetes. Diabetes Care 2002;25:30-4.

\section{Svoren 2003 \{published data only\}}

Svoren BM, Butler D. Reducing acute adverse outcomes in youths with type 1 diabetes: a randomized, controlled trial. Pediatrics 2003;112:914-22.

\section{Swartz 2001 \{published data only\}}

Swartz MS, Swanson JW, Wagner HR, Burns BJ, Hiday VA Effects of involuntary outpatient commitment and depot antipsychotics on treatment adherence in persons with severe mental illness. Journal of Nervous \& Mental Disease 2001;189:583-92.

Taggart 1981 \{published data only\}

Taggart AJ, Johnston GD, McDevitt DG. Does the frequency of daily dosage influence compliance with digoxin therapy?. British Journal of Clinical Pharmacology 1981;11:31-4.

Takala 1979 \{published data only\}

Takala J, Niemela N, Rosti J, Sievers K. Improving compliance with therapeutic regimens in hypertensive patients in a community health center. Circulation 1979;59:540-3.

Tan 2011 \{published data only\}

Tan MY, Magarey JM, Chee SS, Lee LF, Tan MH. A brief structured education programme enhances self-care practices and improves glycaemic control in Malaysians with poorly controlled diabetes. Health Education Research 2011;26(5):896-907. [MEDLINE: 21715653]

\section{Tapanya 1997 \{published data only\}}

Tapanya S. A biopsychosocial intervention program to improve medical regimen adherence and glycemic control in type II diabetic patients. Dissertation Abstracts International: Section B: the Sciences and Engineering 1997.

Taylor 2001 \{published data only\}

Taylor R, Mallinger AG, Frank E, Rucci P, Thase ME, Kupfer DJ. Variability of erythrocyte and serum lithium levels correlates with therapist treatment adherence efforts and maintenance treatment outcome. Neuropsychopharmacology 2001;24:192-7.

Taylor 2003 \{published data only\}

Taylor CT, Byrd DC, Krueger K. Improving primary care in rural Alabama with a pharmacy initiative. American Journal of HealthSystem Pharmacy 2003;60(11):1123-9.

\section{Ting 2012 \{published data only\}}

Ting TV, Kudalkar D, Nelson S, Cortina S, Pendl J, Budhani S, et al. Usefulness of cellular text messaging for improving adherence among adolescents and young adults with systemic lupus erythematosus. Journal of Rheumatology 2012;39(1):174-9. [MEDLINE: 22089460]

Tinkelman 1980 \{published data only\}

Tinkelman DG, Vanderpool GE, Carroll MS, Page EG, Spangler DL. Compliance differences following administration of theophylline at six- and twelve-hour intervals. Annals of Allergy 1980;44:283-6.

Tobari 2010 \{published data only\}

Tobari H, Arimoto T, Shimojo N, Yuhara K, Noda H, Yamagishi K, et al. Physician-pharmacist cooperation program for blood pressure control in patients with hypertension: a randomized-controlled trial. American Journal of Hypertension 2010;23(10):1144-52. [MEDLINE: 20616786]

Toyota 2003 \{published data only\}

Toyota E, Kobayashi N, Houjou M, Yoshizawa A, Kawana A, Kudo K. Usefulness of directly observed therapy (DOT) 
during hospitalization as DOTS in Japanese style. Kekkaku 2003;78:581-5.

\section{Treiber 2002 \{published data only\}}

Treiber G, Wittig J, Ammon S, Walker S, Van Doom L-J, Klotz U. Clinical outcome and influencing factors of a new short-term quadruple therapy for Helicobacter pylori eradication: a randomized controlled trial (MACLOR study). Archives of Internal Medicine 2002;162:153-60.

\section{Trienekens 1993 \{published data only\}}

Trienekens TA, London NH, Houben AW, De Jong RA, Stobberingh EE. Treating acute urinary tract infections. An RCT of 3-day versus 7-day norfloxacin. Canadian Family Physician 1993;39:514-8.

\section{Unutzer 2001 \{published data only\}}

Unutzer J, Rubenstein L, Katon WJ, Tang L, Duan N, Lagomasino IT, et al. Two-year effects of quality improvement programs on medication management for depression. Archives of General Psychiatry 2001;58:935-42.

\section{Unutzer 2002 \{published data only\}}

Unutzer J, Katon W, Callahan CM, Williams JW Jr, Hunkeler E, Harpole L, et al. IMPACT Investigators. Improving moodpromoting access to collaborative treatment. Collaborative care management of late-life depression in the primary care setting: a randomized controlled trial. JAMA 2002;288:2836-45.

\section{Vale 2003 \{published data only\}}

Vale MJ, Jelinek MV, Best JD, Dart AM, Grigg LE, Hare DL, et al. $\mathrm{COACH}$ Study Group. Coaching patients On Achieving Cardiovascular Health ( $\mathrm{COACH}$ ): a multicenter randomized trial in patients with coronary heart disease. Archives of Internal Medicine 2003;163(22):2775-83.

\section{Valles 2003 \{published data only\}}

Valles J-A, Barreiro M, Cereza G, Ferro J-J, Martinez, M-J, EscribaJ-M, et al. A prospective multicenter study of the effect of patient education on acceptability of generic prescribing in general practice. Health Policy 2003;65:269-75.

\section{Van der 2001 \{published data only\}}

Van der PJ, Klein JJ, Zielhuis GA, van Herwaarden CL, Seydel ER. Behavioural effect of self-treatment guidelines in a selfmanagement program for adults with asthma. Patient Education \& Counseling 2001;43:161-9.

\section{Vander Stichele 1992 \{published data only\}}

Vander Stichele RH, Thomson M, Verkoelen K, Droussin AM. Measuring patient compliance with electronic monitoring: lisinopril versus atenolol in essential hypertension. Post Market Surveillance 1992;6:77-90.

\section{Van Dyke 2002 \{published data only\}}

Van Dyke RB, Lee S, Johnson GM, Wiznia A, Mohan K, Stanley K, et al. Reported adherence as a determinant of response to highly active antiretroviral therapy in children who have human immunodeficiency virus infection. Pediatrics 2002;109:61-7.

\section{van Es 2001 \{published data only\}}

van Es SM, Nagelkerke AF, Colland VT, Scholten RJ, Bouter LM. An intervention programme using the ASE-model aimed at enhancing adherence in adolescents with asthma. Patient Education \& Counseling 2001;44:193-203.

\section{Van Servellen 2005 \{published data only\}}

van Servellen G, Nyamathi A, Carpio F, Pearce D, GarciaTeague L, Herrera G, et al. Effects of a treatment adherence enhancement program on health literacy, patient-provider relationships, and adherence to HAART among low-income HIVPositive Spanish-Speaking Latinos. AIDS Patient Care and STDS 2005;19(11):745-59.

\section{Velasco 2002 \{published data only\}}

Velasco A, Roman C, Aragues M, Noguera X, Ventura C, Leris E. Comparison of the efficacy of $1 \%$ flutrimazole cream twice a day with $1 \%$ flutrimazole cream once a day for the treatment of superficial dermatophytoses. Revista Iberoamericana de Micologia 2002;19:169-72.

\section{VeldhuizenScott 1995 \{published data only\}}

Van Veldhuizen-Scott MK, Widmer LB, Stacey SA, Popovich NG. Developing and implementing a pharmaceutical care model in an ambulatory care setting for patients with diabetes. The Diabetes Educator 1995;21(2):117-23.

\section{Vestergaard 1997 \{published data only\}}

Vestergaard P, Hermann AP, Gram J, Jensen LB, Kolthoff N, Abrahamsen B, et al. Improving compliance with hormonal replacement therapy in primary osteoporosis prevention. Maturitas 1997;28:137-45.

\section{Vetter 1999 \{published data only\}}

Vetter N, Argryopoulou-Pataka P, Droszcz W, Estruch-Riba R, Thomas P, MacLeod CM. Efficacy and safety of once-daily and twice-daily clarithromycin formulations in the treatment of acute exacerbations of chronic bronchitis. Advances in Therapy 1999;16(1):13-21.

\section{Villeneuve 2010 \{published data only\}}

Villeneuve J, Genest J, Blais L, Vanier MC, Lamarre D, Fredette M, et al. A cluster randomized controlled Trial to Evaluate an Ambulatory primary care Management program for patients with dyslipidemia: the TEAM study. Canadian Medical Association Journal 2010;182(5):447-55. [MEDLINE: 20212029]

\section{Vivian 2002 \{published data only\}}

Vivian EM. Improving blood pressure control in a pharmacist-managed hypertension clinic. Pharmacotherapy 2002;22:1533-40.

\section{Vrijens 1997 \{published data only\}}

Vrijens B, Goetghebeur E. Comparing compliance patterns between randomized treatments. Controlled Clinical Trials 1997;18:187-203.

\section{Wagner 2002 \{published data only\}}

Wagner GJ, Ghosh-Dastidar B. Electronic monitoring: adherence assessment or intervention?. HIV Clinical Trials 2002;3(1):45-51. 
Walker 2006 \{published data only\}

Walker EA, Molitch M, Kramer MK, Kahn S, Ma Y, Edelstein S, et al. Adherence to preventive medications: predictors and outcomes in the Diabetes Prevention Program. Diabetes Care 2006;29(9):1997-2002.

\section{Walker 2011 \{published data only\}}

Walker EA, Shmukler C, Ullman R, Blanco E, ScollanKoliopoulus M, Cohen HW. Results of a successful telephonic intervention to improve diabetes control in urban adults: a randomized trial. Diabetes Care 2011;34(1):2-7. [MEDLINE: 21193619]

\section{Wang 2011 \{published data only\}}

Wang J, Wu J, Yang J, Zhuang Y, Chen J, Qian W, et al. Effects of pharmaceutical care interventions on blood pressure and medication adherence of patients with primary hypertension in China. Clinical Research and Regulatory Affairs 2011;28(1):1-6. [EMBASE: 2011119097]

\section{Wasilewski 2000 \{published data only\}}

Wasilewski MM, Wilson MG, Sides GD, Stotka JL. Comparative efficacy of 5 days of dirithromycin and 7 days of erythromycin in skin and soft tissue infections. Journal of Antimicrobial Chemotherapy 2000;46:255-62.

\section{Webb 1980 \{published data only\}}

Webb PA. Effectiveness of patient education and psychosocial counseling in promoting compliance and control among hypertensive patients. Journal of Family Practice 1980;10(6):1047-55.

\section{Weiss 2002 \{published data only\}}

Weiss K, Vanjaka A. An open-label, randomized, multicenter, comparative study of the efficacy and safety of 7 days of treatment with clarithromycin extended-release tablets versus clarithromycin immediate-release tablets for the treatment of patients with acute bacterial exacerbation of chronic bronchitis. Clinical Therapeutics 2002;24:2102-22.

\section{Wells 2004 \{published data only\}}

Wells K, Sherbourne C, Schoenbaum M, Ettner S, Duan N, Miranda J, et al. Five-year impact of quality improvement for depression: results of a group-level randomized controlled trial. Archives of General Psychiatry 2004;61:378-86.

\section{Williams 1986 \{published data only\}}

Williams RL, Maiman LA, Broadbent DN, Kotok D, Lawrence RA Longfield LA, et al. Educational strategies to improve compliance with an antibiotic regimen. American Journal of Diseases of Children 1986;140:216-20.

\section{Williams 2006 \{published data only\}}

Williams AB, Fennie KP, Bova CA, Burgess JD, Danvers KA, Dieckhaus KD. Home visits to improve adherence to highly active antiretroviral therapy: a randomized controlled trial. Journal of Acquired Immune Deficiency Syndromes 2006;42(3):314-21.

\section{Williams 2012 \{published data only\}}

Williams A, Manias E, Walker R, Gorelik A. A multifactorial intervention to improve blood pressure control in co-existing diabetes and kidney disease: a feasibility randomized controlled trial. Journal of Advanced Nursing 2012;68(11):2515-5. [5342]

Windsor 1990 \{published data only\}

Windsor RA, Bailey WC, Richard JM Jr, Manzella B, Soong SJ, Brooks M. Evaluation of the efficacy and cost effectiveness of health education methods to increase medication adherence among adults with asthma. American Journal of Public Health 1990;80:1519-21.

\section{Wise 1986 \{published data only\}}

Wise PH, Dowlatshahi DC, Farrant S, Fromson S, Meadows KA. Effect of computer-based learning on diabetes knowledge and control. Diabetes Care 1986;9(5):504-8.

\section{Wohl 2006 \{published data only\}}

Wohl AR, Garland WH, Valencia R, Squires K, Witt MD, Kovacs A, et al. A randomized trial of directly administered antiretroviral therapy and adherence case management intervention. Clinical Infectious Diseases 2006;42(11):1619-27.

\section{Wong 1987 \{published data only\}}

Wong BS, Norman DC. Evaluation of a novel medication aid, the calendar blister-pak, and its effect on drug compliance in a geriatric outpatient clinic. Journal of the American Geriatrics Society 1987;35:21-6.

\section{Wright 2003 \{published data only\}}

Wright SP, Walsh H, Ingley KM, Muncaster SA, Gamble GD, Pearl A, et al. Uptake of self-management strategies in a heart failure management programme. European Journal of Heart Failure 2003;5(3):371-80.

\section{Wu 2006 \{published data only\}}

Wu AW, Snyder CF, Huang IC, Skolasky R, McGruder HF, Celano SA, et al. A randomized trial of the impact of a programmable medication reminder device on quality of life in patients with AIDS. AIDS Patient Care and STDS 2006;20(11):773-81.

\section{Xiang 1994 \{published data only\}}

Xiang M, Ran M, Li S. A controlled evaluation of psychoeducational family intervention in a rural Chinese community. British Journal of Psychiatry 1994;165:544-8.

\section{Xiao 2001 \{published data only\}}

Xiao SD, Liu WZ, Hu PJ, Ouyang Q, Wang JL, Zhou LY, et al. A multicentre study on eradication of Helicobacter pylori using four 1-week triple therapies in China. Alimentary Pharmacology \& Therapeutics 2001;15:81-6.

Yeboah-Antwi 2001 \{published data only\}

Yeboah-Antwi K, Gyapong JO, Asare IK, Barnish G, Evans DB, Adjei S. Impact of prepackaging antimalarial drugs on cost to patients and compliance with treatment. Bulletin of the World Health Organization 2001;79:394-9. 
Yuan 2003 \{published data only\}

Yuan Y, Hay JW, McCombs JS. Effects of ambulatory-care pharmacist consultation on mortality and hospitalization. American Journal of Managed Care 2003;9:45-56.

\section{Zarnke 1997 \{published data only\}}

Zarnke KB, Feagan BG, Mahon JL, Feldman RD. A randomized study comparing a patient-directed hypertension management strategy with usual office-based care. American Journal of Hypertension 1997;10:58-67.

\section{Zermansky 2002 \{published data only\}}

Zermansky AG, Petty DR, Raynor DK, Lowe CJ, Freemantle N, Vail A. Clinical medication review by a pharmacist of patients on repeat prescriptions in general practice: a randomised controlled trial. Health Technology Assessment 2002;6:76.

\section{Ziauddin Hyder 2002 \{published data only\}}

Ziauddin Hyder SM, Persson LA, Chowdhury AMR, Ekstrom E-C. Do side-effects reduce compliance to iron supplementation? A study of daily- and weekly-dose regimens in pregnancy. Journal of Health, Population \& Nutrition 2002;20:175-9.

\section{References to studies awaiting assessment}

\section{Andres 2007 \{published data only\}}

Andres Rodriguez NF, Fornos Perez JA, Andres Iglesias JC. Assessment of knowledge/compliance in a drug therapy followup program involving type 2 diabetic patients in community pharmacy: a randomized study. Pharmaceutical Care Espana 2007;9(1):2-9. [CENTRAL: CN-00754602]

\section{Clowes 2004 \{published data only\}}

Clowes JA, Peel NF, Eastell R. The impact of monitoring on adherence and persistence with antiresorptive treatment for postmenopausal osteoporosis: a randomized controlled trial. Journal of Clinical Endocrinology \& Metabolism 2004;89(3):1117-23.

\section{Gallefoss 2002 \{published data only\}}

Gallefoss F, Bakke PS. The effects of patient education in asthma: a randomised, controlled trial. Tidsskrift for Den Norske Laegeforening 2002;28:2702-6.

\section{Hornung 1998b \{published data only\}}

Hornung WP, Schonauer K, Feldmann R, Monking HS. Medication-related attitudes of chronic schizophrenic patients: a follow-up for 24 months after psychoeducational intervention. Psychiatrische Praxis 1998;25:25-8.

Kripalani 2006 \{unpublished data only\}

Kripalani S. A randomized controlled trial to improve medication compliance among patients with coronary heart disease. http://clinicaltrials.gov/show/NCT00208832 (accessed 1 February 2008).

\section{Marquez 2000 \{published data only\}}

Marquez Contreras E, Casado Martinez JJ, Celotti Gomez B, Gascon Vivo JL, Martin de Pablos JL, Gil Rodriguez R, et al. Therapeutic compliance in hypertension. Trial of two-year health education intervention [El cumplimiento terapeutico en la hipertension arterial. Ensayo sobre la inervencion durante 2 anos mediante educacion sanitaria]. Atencion Primaria 2000;26(1):5-10.

\section{Marquez 2009 \{published data only\}}

Marquez Contreras E, Martel Claros N, Gil Guillen V, Martin De Pablos JL, De la Figuera Von Wichman M, Casado Martinez JJ, et al. Non-pharmacological intervention as a strategy to improve antihypertensive treatment compliance. Atencion Primaria 2009;41(9):501-10. [MEDLINE: 19497643]

\section{Shon 2002 \{published data only\}}

Shon K-H, Park S-S. Medication and symptom management education program for the rehabilitation of psychiatric patients in Korea: the effects of promoting schedule on self-efficacy theory. Yonsei Medical Journal 2002;43:579-89.

\section{Additional references}

\section{ABC Project Team 2012}

ABC Project Team. Ascertaining Barriers for Compliance: Policies for Safe, Effective and Cost-effective Use of Medicines in Europe. Final Report of the ABC Project (Deliverable 7.1) 2012; Vol. June:1-542.

\section{Christensen 2009}

Christensen A, Osterberg LG, Hansen EH. Electronic monitoring of patient adherence to oral antihypertensive medical treatment: a systematic review. Journal of Hypertension 2009;27(8):1540-51. [PUBMED: 19474761]

\section{Craig 2008}

Craig P, Dieppe P, Macintyre S, Michie S, Nazareth I, Petticrew M. Developing and evaluating complex interventions: the new Medical Research Council guidance. BMJ 2008;29(337):a1655. [DOI: 10.1136/bmj.a1655]

\section{Demonceau 2013}

Demonceau J, Ruppar T, Kristanto P, Hughes DA, Fargher E, Kardas P, et al. ABC Project Team. Identification and assessment of adherence-enhancing interventions in studies assessing medication adherence through electronically compiled drug dosing histories: a systematic literature review and meta-analysis. Drugs 2013;73(6):545-62. [DOI: 10.1007/ s40265-013-0041-3]

\section{Fleiss 1981}

Fleiss J. Statistical Methods for Rates and Proportions. 2nd Edition. New York: Wiley-Interscience, 1981.

\section{Gialamas 2009}

Gialamas A, Yelland LN, Ryan P, Willson K, Laurence CO, Bubner TK, et al. Does point-of-care testing lead to the same or better adherence to medication? A randomised controlled trial: the PoCT in General Practice Trial. Medical Journal of Australia 2009;191:487-91.

\section{Gordis 1979}

Gordis L. Conceptual and methodologic problems in measuring compliance. In: Haynes RB, Taylor DW, Sackett DL editor(s). 
Compliance in Health Care. Baltimore: Johns Hopkins University Press, 1979:23-5.

\section{Haynes 1979a}

Haynes RB. Determinants of compliance: the disease and the mechanics of treatment. In: Haynes RB, Taylor DW, Sackett DL editor(s). Compliance in Health Care. Baltimore, USA: Johns Hopkins University Press, 1979:49-62.

\section{Haynes 1980}

Haynes RB, Taylor DW, Sackett DL, Gibson ES, Bernholz CD, Mukherjee J. Can simple clinical measurements detect patient compliance?. Hypertension 1980;2:757-64.

\section{Haynes 2010}

Haynes RB, Wilczynski NL, Computerized Clinical Decision Support System (CCDSS) Systematic Review Team. Effects of computerized clinical decision support systems on practitioner performance and patient outcomes: methods of a decision-maker-researcher partnership systematic review. Implementation Science 2010;5(5):12. [DOI: 10.1186/1748-5908-5-12]

\section{Higgins 2011}

Higgins JPT, Altman DG, Sterne JAC (editors). Chapter 8: Assessing risk of bias in included studies. In: Higgins JPT, Green S (editors). Cochrane Handbook for Systematic Reviews of Interventions Version 5.1.0 [updated March 2011]. The Cochrane Collaboration, 2011. Available from www.cochranehandbook.org.

\section{Kardas 2013}

Kardas P, Lewek P, Matyjaszczyk M. Determinants of patient adherence: a review of systematic reviews. Frontiers in Pharmacology 2013;4:91. [10.3389/ fphar.2013.00091.eCollection 2013]

\section{McAlister 2003}

McAlister FA, Straus SE, Sackett DL, Altman DG. Analysis and reporting of factorial trials: a systematic review. JAMA 2003;289(19):2545-53. [PUBMED: 12759326]

\section{Michie 2009}

Michie S, Fixsen D, Gimshaw JM, Eccles MP. Specifying and reporting complex behaviour change interventions: the need for a scientific method. Implementation Science 2009;4:40. [DOI: 10.1186/1748-5908-4-40]

\section{Naderi 2012}

Naderi SH, Bestwick JP, Wald DS. Adherence to drugs that prevent cardiovascular disease: meta-analysis on 376,162 patients. American Journal of Medicine 2012;125(9):882-7. [10.1016/j.amjmed.2011.12.013. epub 2012 Jun 27]

\section{NHLBI 1982}

National Heart, Lung and Blood Institute Working Group on Patient Compliance. Management of patient compliance in the treatment of hypertension. Hypertension 1982; Vol. 4:415-23.

\section{Oberje 2013}

Oberjé EJ, de Kinderen RJ, Evers SM, van Woerkum CM, de Bruin M. Cost effectiveness of medication adherenceenhancing interventions: a systematic review of trialbased economic evaluations. Pharmacoeconomics 2013;31(12):1155-68. [DOI: 10.1007/s40273-013-0108-8]

\section{Ryan 2014}

Ryan R, Santesso N, Lowe D, Hill S, Grimshaw J, Prictor M, et al. Interventions to improve safe and effective medicines use by consumers: an overview of systematic reviews. Cochrane Database of Systematic Reviews 2014, Issue 4. [DOI: 10.1002/14651858.CD007768.pub3]

\section{Sackett 1979}

Sackett DL, Snow JC. The magnitude of adherence and nonadherence. In: Haynes RB, Taylor DW, Sackett DL editor(s). Compliance in Health Care. Baltimore: Johns Hopkins University Press, 1979:11-22.

\section{Simpson 2006}

Simpson SH, Eurich DT, Majumdar SR, Padwal RS, Tsuyuki RT, Varney J, et al. A meta-analysis of the association between adherence to drug therapy and mortality. BMJ 2006;333(7557):15

\section{Stephenson 1993}

Stephenson BJ, Rowe BH, Macharia WM, Leon G, Haynes RB. Is this patient taking their medication?. JAMA 1993;269:2779-81.

\section{Thom 2013}

Thom S, Poulter N, Field J, Patel A, Prabhakaran D, Stanton A, et al. UMPIRE Collaborative Group. Effects of a fixed-dose combination strategy on adherence and risk factors in patients with or at high risk of CVD: the UMPIRE randomized clinical trial. JAMA 2013;310(9):918-29. [DOI: 10.1001/jama.2013.277064; PUBMED: 24002278]

\section{van Dulmen 2007}

van Dulmen S, Sluijs E, van Dijk L, de Ridder D, Heerdink R, Bensing J. Patient adherence to medical treatment: a review of reviews. BMC Health Services Research 2007;7:55.

\section{Working Group on the Summit of Combination Therapy} Working Group on the Summit on Combination Therapy for CVD. Combination pharmacotherapy to prevent cardiovascular disease: present status and challenges. European Heart Journal 2014; Vol. 35, issue 6:353-64. [DOI: 10.1093/eurheartj/eht407; PUBMED: 24288261]

\section{References to other published versions of this review}

\section{Haynes 1996}

Haynes RB, McKibbon KA, Kanani R. Systematic review of randomised trials of interventions to assist patients to follow prescriptions for medications. Lancet 1996;348:383-6.

\section{Haynes 2002a}

Haynes RB, McDonald H, Garg AX, Montague P. Interventions for helping patients to follow prescriptions for medications. 
Cochrane Database of Systematic Reviews 2002, Issue 2. [DOI: 10.1002/14651858.CD000011]

\section{Haynes 2002b}

McDonald HP, Garg AX, Haynes RB. Interventions to enhance patient adherence to medication prescriptions. Scientific review. JAMA 2002;288:2868-79.

\section{Haynes 2005}

Haynes RB, Yao X, Degani A, Kripalani S, Garg A, McDonald HP. Interventions to enhance medication adherence. Cochrane

\section{CHARACTERISTICS OF STUDIES}

Characteristics of included studies [ordered by study ID]
Database of Systematic Reviews 2005, Issue 4. [DOI: 10.1002/14651858.CD000011.pub2]

\section{Haynes 2008}

Haynes RB, Ackloo E, Sahota N, McDonald HP, Yao X. Interventions for enhancing medication adherence. Cochrane Database of Systematic Reviews 2008, Issue 2. [DOI: 10.1002/14651858.CD000011.pub3]

* Indicates the major publication for the study

Abrahams 2010

\begin{tabular}{ll}
\hline Methods & Randomized controlled trial \\
\hline Participants & $\begin{array}{l}\text { The study location was Sinawe sexual assault service, Mthatha, South Africa, and Karl Bremer Hospital, } \\
\text { Victoria Hospital, and the Simelela Centre; all in Khayelitsha, South Africa }\end{array}$
\end{tabular}

136 participants were randomized to the intervention group and 138 participants were randomized to the control group

The inclusion criteria were women and girl children; girls under 16 years of age were eligible if accompanied by a care giver

The exclusion criteria were rape victims who did not get post-exposure prophylaxis (PEP) (due to being HIV positive or because they did not take an HIV test), those unable to give consent for reason of severe injury or severe mental distress (including severely distressed guardians), and those who were not contactable telephonically

Interventions Intervention: TELEPHONE COUNSELING

Patients in the intervention group received standard care and telephone counseling sessions. The telephone counseling included 4 calls in the first week, 3 calls in the 2 nd and 3 rd week, and 2 calls in the last week, but more were made if necessary. The support included the application of basic counseling skills including listening and validating the traumatic events, encouraging participants to take their medication, to seek support from family and friends, to attend formal counseling services, to read the pamphlet, use the diary, and return to the clinic for follow-up medication

\section{Control: STANDARD CARE}

Standard care consisted of psychological containment, medical examination, and collection of forensic evidence; HIV testing with pre- and post-test counseling; providing emergency contraception, treatment of sexually transmitted infections and PEP for HIV. Follow-up was arranged to collect further HIV PEP medication. All patients had an interactive information session to explain the content of the pamphlet, answer questions, and demonstrate initiation of the use of the medication diary. The pamphlet contained specific information about taking PEP after a sexual assault; a diary for the 28-day period on which pill taking was to be marked and contact information on support services. No further contact was made with participants in the control group until the final interview, but they continued to receive standard care from the service

Outcomes

The measures of adherence were assessed within 5 days of the 28-day treatment period ending in a face to face interview conducted by a fieldworker. Non-adherence was defined as missing 3 or more doses of medication (of 56 doses). Patients who did not return to the facility to collect the full 28 days of medication, or who were found to have more than 3 doses remaining when pills were counted/volume of syrup was assessed, were considered non-adherent. If medication containers were not available at the interview, participants were asked to estimate the number of pills or volume of syrup remaining 
Abrahams 2010 (Continued)

The patient outcomes were depressive symptomatology, measured by the Centre for Epidemiological Studies Depression Scale, measured 4 weeks after the beginning of treatment (within 4 days of treatment ending). The scale was administered by a fieldworker

\begin{tabular}{lll}
\hline Notes & - \\
\hline Risk of bias & Authors' judgement & Support for judgement \\
\hline Bias & Low risk & $\begin{array}{l}\text { A computer-generated randomization list was generated by the study statisti- } \\
\text { cian and random block sizes of } 4,6 \text { and } 8 \text { were used to ensure balance in the } 2 \\
\text { arms (pg 1176) }\end{array}$ \\
\hline $\begin{array}{l}\text { Random sequence genera- } \\
\text { tion (selection bias) }\end{array}$ & Unclear risk & $\begin{array}{l}\text { Allocation concealment not specified; (pg 1176) a computer-generated ran- } \\
\text { domization list was generated by the study statistician and random block sizes } \\
\text { of 4, } 6 \text { and } 8 \text { were used to ensure balance in the } 2 \text { arms. Participants were al- } \\
\text { located to an arm by the study co-ordinator after the initial data had been col- } \\
\text { lected and leaflet explained }\end{array}$
\end{tabular}

\begin{tabular}{lll}
\hline $\begin{array}{l}\text { Selective reporting (re- } \\
\text { porting bias) }\end{array}$ & Unclear risk & $\begin{array}{l}\text { No protocol available, therefore unable to determine if everything was report- } \\
\text { ed }\end{array}$ \\
\hline Other bias & Unclear risk & $\begin{array}{l}\text { There appears to be weaknesses in the intervention delivery such as variations } \\
\text { in the number of telephone calls, which may have attenuated the differences } \\
\text { between the intervention and the control group }\end{array}$
\end{tabular}

\begin{tabular}{lll}
\hline Blinding of outcome as- & Unclear risk & (PRIMARY) PILL COUNT/SYRUP MEASURE - fieldworkers who did the final inter- \\
sessment (detection bias) & & view were blinded to study arm, but this may have been disclosed by the par- \\
Adherence measure & ticipants during the final interviews. Participants could not be blinded to the \\
& study arm(pg 1176)
\end{tabular}

\begin{tabular}{|c|c|c|}
\hline $\begin{array}{l}\text { Blinding of outcome as- } \\
\text { sessment (detection bias) }\end{array}$ & Unclear risk & $\begin{array}{l}\text { (PRIMARY) DEPRESSIVE SYMPTOMOLOGY - fieldworkers were blind to condi- } \\
\text { tion but blinding could have been broken by the patients (pg 1176) }\end{array}$ \\
\hline
\end{tabular}

Patient outcome

\begin{tabular}{|c|c|c|}
\hline $\begin{array}{l}\text { Blinding of participants } \\
\text { (performance bias) } \\
\text { Adherence measure }\end{array}$ & High risk & $\begin{array}{l}\text { (PRIMARY) PILL COUNT/SYRUP MEASURE - participants could not be blinded to } \\
\text { the study arm }\end{array}$ \\
\hline $\begin{array}{l}\text { Blinding of participants } \\
\text { (performance bias) } \\
\text { Patient outcome }\end{array}$ & Unclear risk & $\begin{array}{l}\text { (PRIMARY) DEPRESSIVE SYMPTOMOLOGY - patients could not be blinded (pg } \\
1176) \text {, but unclear if this might have affected their responses to the scale }\end{array}$ \\
\hline $\begin{array}{l}\text { Blinding of personnel (per- } \\
\text { formance bias) } \\
\text { Adherence measure }\end{array}$ & Low risk & $\begin{array}{l}\text { (PRIMARY) PILL COUNT/SYRUP MEASURE - outcome unlikely to be affected if } \\
\text { other personnel were not blinded }\end{array}$ \\
\hline $\begin{array}{l}\text { Blinding of personnel (per- } \\
\text { formance bias) } \\
\text { Patient outcome }\end{array}$ & Low risk & $\begin{array}{l}\text { (PRIMARY) DEPRESSIVE SYMPTOMOLOGY - not specified, but other personnel } \\
\text { are unlikely to have influenced the data collection }\end{array}$ \\
\hline $\begin{array}{l}\text { Incomplete outcome data } \\
\text { (attrition bias) } \\
\text { Adherence measure }\end{array}$ & Unclear risk & $\begin{array}{l}\text { (PRIMARY) PILL COUNT/SYRUP MEASURE - not enough detail given on reasons } \\
\text { for loss to follow-up. Number is small and balanced across groups but still un- } \\
\text { clear what impact this would have }\end{array}$ \\
\hline
\end{tabular}


Abrahams 2010 (Continued)

Incomplete outcome data Unclear risk (PRIMARY) DEPRESSIVE SYMPTOMOLOGY - not enough detail given on reasons (attrition bias) for loss to follow-up. Number is small and balanced across groups but still un-

Patient outcome

clear what impact this would have

Ahmadipour 2010

\begin{tabular}{ll}
\hline Methods & Randomized controlled trial \\
\hline Participants & The study location was the Isfahan Diabetes Institute, Isfahan, Iran \\
50 participants were randomized to the intervention group and 50 participants were randomized to the \\
control group \\
The inclusion criteria were patients with type 2 diabetes mellitus taking oral hypoglycemic agents for at \\
least 1 year and had given informed consent \\
\hline $\begin{array}{l}\text { Intervention: DIARY CHECKLIST } \\
\text { The intervention group was asked to complete a diary checklist about how they took their drugs dur- } \\
\text { ing the study period. The duration was } 12 \text { weeks } \\
\text { Control: COLLCTION OF MEDICATION SHELLS } \\
\text { The control group patients were asked to collect the shells of oral hypoglycemic agents after taking in } \\
\text { a pocket. Duration was } 12 \text { weeks }\end{array}$ \\
$\begin{array}{l}\text { The measures of adherence were a diary checklist about how the drugs were taken } \\
\text { The patient outcome was HbAlc level measured using a chromatographic method }\end{array}$ \\
$\begin{array}{l}\text { There is a discrepancy between the abstract and the text of the article in terms of the number of partic- } \\
\text { ipants in the control and intervention groups. According to abstract there are } 100 \text { participants divided } \\
\text { equally into } 2 \text { groups, but in figure } 1 \text {, as well as in methods, there are } 30 \text { participants in the intervention } \\
\text { group and } 57 \text { in the control }\end{array}$ \\
\hline Notes
\end{tabular}

\section{Risk of bias}

\begin{tabular}{lll}
\hline Bias & Authors' judgement & Support for judgement \\
\hline $\begin{array}{l}\text { Random sequence genera- } \\
\text { tion (selection bias) }\end{array}$ & Unclear risk & $\begin{array}{l}\text { Insufficient information on method of randomization (pg 1 Abstract). A num- } \\
\text { ber of } 100 \text { type 2-diabetic patients were selected through systematic sampling } \\
\text { method and then were randomly allocated to 2 groups of equal number (pg 3 } \\
\text { Methods) }\end{array}$ \\
\hline $\begin{array}{l}\text { Allocation concealment } \\
\text { (selection bias) }\end{array}$ & Unclear risk & $\begin{array}{l}\text { Not described. Participants were selected from the patients list of the Institute } \\
\text { through a systematic sampling method and then they were randomly allocat- } \\
\text { ed to 2 groups }\end{array}$ \\
\hline $\begin{array}{l}\text { Selective reporting (re- } \\
\text { porting bias) }\end{array}$ & Unclear risk & $\begin{array}{l}\text { No protocol and no details about what outcomes would be looked at, only } \\
\text { that HbAlc was measured in each group }\end{array}$ \\
\hline $\begin{array}{l}\text { Other bias } \\
\text { Blinding of outcome as- }\end{array}$ & Unclear risk & $\begin{array}{l}\text { Intervention and control not adequately described. Discrepancy in sample size } \\
\text { description }\end{array}$ \\
$\begin{array}{l}\text { Adherence measure } \\
\text { (PRIMARY) MEDICINE SHELLS - Insufficient information. Blinding not men- } \\
\text { tioned }\end{array}$ & Unclear risk &
\end{tabular}


Ahmadipour 2010 (Continued)

Blinding of outcome as- Unclear risk $\quad$ (PRIMARY) CHECKLIST DIARY - Insufficient information. Blinding not mensessment (detection bias) tioned

Adherence measure

$\begin{aligned} & \text { Blinding of outcome as- } \\ & \text { sessment (detection bias) }\end{aligned} \quad$ Unclear risk

Patient outcome

\begin{tabular}{|c|c|c|}
\hline $\begin{array}{l}\text { Blinding of participants } \\
\text { (performance bias) }\end{array}$ & High risk & $\begin{array}{l}\text { (PRIMARY) CHECKLIST DIARY - Patients would have been aware due to the na- } \\
\text { ture of the intervention }\end{array}$ \\
\hline
\end{tabular}

Adherence measure

\begin{tabular}{|c|c|c|}
\hline $\begin{array}{l}\text { Blinding of participants } \\
\text { (performance bias) } \\
\text { Adherence measure }\end{array}$ & High risk & $\begin{array}{l}\text { (PRIMARY) MEDICINE SHELLS - Patients likely to be aware of the intervention } \\
\text { due to its nature }\end{array}$ \\
\hline
\end{tabular}

Blinding of participants Low risk

(performance bias) participant is not likely to affect this outcome

Patient outcome

Blinding of personnel (per- Unclear risk

formance bias)

(PRIMARY) MEDICINE SHELLS - Insufficient information. Blinding not men-

Adherence measure tioned

\begin{tabular}{|c|c|c|}
\hline $\begin{array}{l}\text { Blinding of personnel (per- } \\
\text { formance bias) }\end{array}$ & Unclear risk & $\begin{array}{l}\text { (PRIMARY) CHECKLIST DIARY - Insufficient information. Blinding not men- } \\
\text { tioned }\end{array}$ \\
\hline
\end{tabular}

Adherence measure

Blinding of personnel (per- Unclear risk formance bias)

Patient outcome

(PRIMARY) HBA1C LEVEL - Insufficient information. Blinding not mentioned

Incomplete outcome data Unclear risk
(attrition bias)
Adherence measure

(PRIMARY) CHECKLIST DIARY - Insufficient information provided. However, there appears to be an error in paper regarding the number of participants randomized to each group. States in Abstract Methods (pg 1): "A number of 100 type 2-diabetic patients were selected through systematic sampling method and then were randomly allocated to two groups of equal number" but then states twice in the article (pg 4 under Results), including Figure 1, that there were 57 at the end of the study in the "reference" (control) group

Incomplete outcome data Unclear risk
(attrition bias)

Adherence measure

(PRIMARY) MEDICINE SHELLS - Insufficient information provided. However, there appears to be an error in paper regarding the number of participants randomized to each group. States in Abstract Methods (pg 1): "A number of 100 type 2-diabetic patients were selected through systematic sampling method and then were randomly allocated to two groups of equal number" but then states twice in the article (pg 4 under Results), including Figure 1, that there were 57 at the end of the study in the "reference" (control) group

$\begin{array}{ll}\begin{array}{l}\text { Incomplete outcome data } \\ \text { (attrition bias) }\end{array} & \text { Unclear risk } \\ \begin{array}{ll}\text { Patient outcome } & \text { (PRIMARY) HBA1C LEVEL - Insufficient information provided. However, there } \\ & \text { appears to be an error in paper regarding the number of participants random- } \\ & \text { ized to each group. States in Abstract Methods (pg 1): "A number of } 100 \text { type } 2- \\ \text { diabetic patients were selected through systematic sampling method and then } & \text { were randomly allocated to two groups of equal number" but then states twice } \\ & \text { in the article (pg } 4 \text { under Results), including Figure 1, that there were } 57 \text { at the } \\ \text { end of the study in the "reference" (control) group }\end{array}\end{array}$




\begin{tabular}{ll}
\hline Methods & Randomized controlled trial \\
\hline
\end{tabular}

Participants

The study location was Zayed Military Hospital, United Arab Emirates

120 participants were randomized to the intervention group and 120 participants were randomized to the control group

The inclusion criteria were diagnosis of type 2 diabetes mellitus, receiving oral hypoglycemic therapy, hospital consultant consented to patient entering trial, patient provided written informed consent to their participation in the research

The exclusion criteria were secondary forms of hypertension, serum creatinine $>184 \mathrm{mmol} \mathrm{l}^{-1}$, macroalbuminuria $>300 \mathrm{mg} 24 \mathrm{~h}^{-1}$, history of cerebrovascular accidents, convulsive disorder, diabetic proliferative retinopathy or diabetic autonomic neuropathy

For all patients randomized to the intervention group, the research pharmacist had discussions with their physicians regarding drug therapy and, if necessary, treatment modification was recommended, e.g. more intensive management of hypertension or simplification of dosage regimens if deemed appropriate, taking account of the latest American Diabetes Association (ADA) recommendations. Patients who were randomized to the intervention group were educated on their illness and their medication in a structured fashion, including discussion on risk of diabetes complications, proper dosage, side effects and storage of medications, healthy lifestyle and management of diabetes mellitus signs and symptoms through self monitoring. A printed leaflet to assist with the education program was developed and the patient was given a copy to take home. Supplementary leaflets containing information about hypertension and hyperlipidemia were also given to the patients if they suffered from these conditions. The educational advice was reinforced when patients came to the hospital pharmacy to collect their prescribed medicines on their monthly schedule. In addition, behavioral modification aspects of the Pharmacist Care intervention involved advice on the following: self monitoring of glycemic control (patients were encouraged to monitor their blood glucose levels 3 times per day, to record these values and bring a record book to all subsequent appointments); physical exercise (this involved initiation of an exercise plan that could be incorporated into the patient's daily schedule, after taking into consideration their level of fitness, e.g. 1-hour walk daily; diet (the patient was assisted with the identification of dietary behavior that adversely influences blood glucose control, lipid levels, weight management, and of the times of day when the patient was most vulnerable to overeating, and given improved understanding of the relative effects of certain food choices on blood glucose control); medication adherence (patients were asked about any problems that they had encountered with regard to taking their medication and were offered education and practical help to encourage them to take the medicines prescribed for them by their physician); and smoking cessation (patients were encouraged to stop smoking by advising them about the danger of smoking to health, with emphasis on the increased dangers of smoking in diabetic patients)

Control: USUAL CARE

Control group participants received normal care from medical and nursing staff. They did not receive any pharmacy clinical service but received advice on self monitoring their blood glucose by medical or nursing staff

Outcomes

The measures of adherence were self report. Adherence was measured at baseline and 12 months using a standard protocol for questionnaire administration to reduce potential bias. Patients who reported forgetting doses, intentionally missing or taking extra doses were classed as non-adherent. No account was taken of intelligent non-adherence, i.e. when a patient decides for good reason, for example, to take an extra dose or miss a dose

The patient outcomes were BMI, fasting blood glucose, $\mathrm{HbA1c}$, blood pressure, cholesterol, health-related QoL, and 10-year risk assessments. BMI, blood work, and QoL scores were collected by the research pharmacist and/or clinical pharmacy staff at baseline and then every 4 months until the study was completed (12 months). 10-year risk assessments were done at the end of the study using British National Formulary (BNF) prediction charts and the Framingham scoring method. These methodologies take account of age, gender, smoking status, total cholesterol, HDL, and systolic blood pressure 
Al Mazroui 2009 (Continued)

Notes
It is unclear what information was gathered at the face to face interview and what was gathered from a review of the medical charts

\section{Risk of bias}

\section{Bias Authors' judgement Support for judgement}

Random sequence genera- Unclear risk tion (selection bias)
Insufficient information about the process of randomization: "After recruitment, patients were randomly assigned to one of two groups: intervention group or control group. The group allocations were carried out using restricted randomization with both groups being matched as closely as possible for gender and presence of hypertension i.e. diastolic blood pressure $>=90 \mathrm{mmHg}$ (hypertensive) or $<90 \mathrm{mmHg}$ (normotensive)" (pg 548)

\section{Allocation concealment Unclear risk} (selection bias)

Insufficient information about the allocation process: "After recruitment, patients were randomly assigned to one of two groups: intervention group or control group. The group allocations were carried out using restricted randomization with both groups being matched as closely as possible for gender and presence of hypertension i.e. diastolic blood pressure $>=90 \mathrm{mmHg}$ (hypertensive) or $<90 \mathrm{mmHg}$ (normotensive)" (pg 548)

\begin{tabular}{lll}
\hline $\begin{array}{l}\text { Selective reporting (re- } \\
\text { porting bias) }\end{array}$ & Unclear risk & No protocol available \\
\hline Other bias & Unclear risk & No limitations are given \\
\hline $\begin{array}{l}\text { Blinding of outcome as- } \\
\text { sessment (detection bias) } \\
\begin{array}{l}\text { Adherence measure } \\
\text { Und }\end{array}\end{array}$ & Unclear risk & $\begin{array}{l}\text { (PRIMARY) SELF REPORT - QUESTIONNAIRE - Insufficient information to permit } \\
\text { judgment of 'Low risk' or 'High risk' of bias. No information about the blinding } \\
\text { of data collectors is given }\end{array}$ \\
\hline
\end{tabular}

Blinding of outcome as- Unclear risk (PRIMARY) BMI AND BLOOD TESTS CHART REVIEW - Outcomes collected sessment (detection bias) through a chart review. Unclear if staff extracting the data were blind

Patient outcome
Blinding of participants High risk (PRIMARY) SELF REPORT - QUESTIONNAIRE - Patient self report - subject to (performance bias)

Adherence measure

Blinding of participants Low risk
(performance bias)

Patient outcome bias. No mention of patient blinding

(PRIMARY) BMI AND BLOOD TESTS CHART REVIEW - The lack of blinding of the study participant is not likely to affect this outcome
Blinding of personnel (per- Unclear risk

formance bias)

Adherence measure
(PRIMARY) SELF REPORT - QUESTIONNAIRE - Insufficient information to permit judgment of 'Low risk' or 'High risk' of bias. No indication of blinding of key study personnel

(PRIMARY) BMI AND BLOOD TESTS CHART REVIEW - Outcomes collected through a chart review. Unclear if study personnel were blind

formance bias)

Unclear risk

Patient outcome

(PRIMARY) SELF REPORT - QUESTIONNAIRE - Few dropouts; evenly across groups

(attrition bias)

Low risk

Adherence measure

\section{Incomplete outcome data Low risk}

(attrition bias)

Patient outcome

(PRIMARY) BMI AND BLOOD TESTS CHART REVIEW - Few dropouts; evenly distributed across groups 
Al-Eidan 2002

Methods

Participants

Interventions

Interventions
Patients were randomly assigned to the intervention or control group using a sealed envelope technique

76 dyspeptic patients, who at endoscopy were found to have gastritis, duodenitis, or ulceration, and a positive Helicobacter pylori (H. pylori) urease test, were recruited. Patients were excluded if they were unsuitable for eradication therapy or hypersensitive to its ingredients

After diagnosis and enrolment, all patients were to be prescribed a 1-week regimen of lansoprazole $30 \mathrm{mg}$ daily, amoxicillin $1 \mathrm{~g}$ twice a day (bid), and clarithromycin $500 \mathrm{mg}$ bid. Patients in the intervention group received their medication from the hospital pharmacy and were counseled by the hospital pharmacist (average 9.5 minutes) on: their disease and the importance of eradication of the organism; the medicines to be taken and possible side effects, the importance of compliance with the prescribed dosage. Intervention patients received a patient information leaflet about their medication and the need for $\mathrm{H}$. pylori eradication. They were also given a compliance diary chart and telephoned 3 days after the initiation of therapy to provide further counseling about the importance of complying to the medication regimen. Control patients were treated according to normal hospital procedures. They were given a letter to be given to their GP with the recommendation to start triple-therapy and a letter explaining the nature of infection, the need for treatment, and the importance of compliance (ambiguous in the article, but it seems that the latter letter went to the patient rather than (just) their doctor)

Compliance measurements 1) Patient interview by telephone (structured questionnaire) by the same
pharmacist for both groups, after the intended end of the eradication course 2) Pill counts on returned
medication when patients returned for a urea breath test. Patient clinical outcome measures includ-
ed: $H$. pylori status: assessed with a urea breath test 4 to 6 weeks post-eradication therapy. Eradication
was defined as an absence of $H$. pylori. Adverse effects: contacted by hospital pharmacist 10 days post-
endoscopy and asked about any adverse effects experienced from the eradication therapy. Modified
version of the Gastrointestinal Symptom Rating Scale: to assess the presence and severity of dyspeptic
symptoms. The presence and severity symptoms was judged by the patient. They were assessed at the
time of endoscopy, at 1 month and 6 months

Notes -

\section{Risk of bias}

\begin{tabular}{|c|c|c|}
\hline Bias & Authors' judgement & Support for judgement \\
\hline $\begin{array}{l}\text { Random sequence genera- } \\
\text { tion (selection bias) }\end{array}$ & Unclear risk & $\begin{array}{l}\text { Minimal information given: (pg 164) Using a sealed envelope technique pa- } \\
\text { tients were randomly assigned to either the control group or the intervention } \\
\text { group }\end{array}$ \\
\hline $\begin{array}{l}\text { Allocation concealment } \\
\text { (selection bias) }\end{array}$ & Low risk & $\begin{array}{l}\text { Minimal information given: (pg 164) Using a sealed envelope technique pa- } \\
\text { tients were randomly assigned to either the control group or the intervention } \\
\text { group }\end{array}$ \\
\hline $\begin{array}{l}\text { Selective reporting (re- } \\
\text { porting bias) }\end{array}$ & Unclear risk & No protocol available \\
\hline Other bias & Unclear risk & $\begin{array}{l}\text { No other biases noted in discussion section or otherwise obvious but difficult } \\
\text { to determine if the study if free of other types of bias }\end{array}$ \\
\hline $\begin{array}{l}\text { Blinding of outcome as- } \\
\text { sessment (detection bias) } \\
\text { Adherence measure }\end{array}$ & Unclear risk & $\begin{array}{l}\text { (PRIMARY) PATIENT INTERVIEW BY TELEPHONE - No mention of blinding of } \\
\text { study staff collecting the data }\end{array}$ \\
\hline $\begin{array}{l}\text { Blinding of outcome as- } \\
\text { sessment (detection bias) }\end{array}$ & Low risk & $\begin{array}{l}\text { (PRIMARY) UREA BREATH TEST TO ASSESS H. PYLORI ERADICATION RATE - ob- } \\
\text { jective measure }\end{array}$ \\
\hline
\end{tabular}


Al-Eidan 2002 (Continued)

Patient outcome

\begin{tabular}{|c|c|c|}
\hline $\begin{array}{l}\text { Blinding of participants } \\
\text { (performance bias) } \\
\text { Adherence measure }\end{array}$ & High risk & $\begin{array}{l}\text { (PRIMARY) PATIENT INTERVIEW BY TELEPHONE - Patient would know if they } \\
\text { saw the hospital pharmacist or not }\end{array}$ \\
\hline $\begin{array}{l}\text { Blinding of participants } \\
\text { (performance bias) } \\
\text { Patient outcome }\end{array}$ & Low risk & $\begin{array}{l}\text { (PRIMARY) UREA BREATH TEST TO ASSESS H. PYLORI ERADICATION RATE - Ob- } \\
\text { jective measure }\end{array}$ \\
\hline
\end{tabular}

(PRIMARY) PATIENT INTERVIEW BY TELEPHONE - No mention of blinding of staff
Blinding of personnel (per- Unclear risk

formance bias)

Adherence measure
Blinding of personnel (per- Low risk

formance bias)

Patient outcome
(PRIMARY) UREA BREATH TEST TO ASSESS H. PYLORI ERADICATION RATE - objective measure

$\begin{array}{ll}\begin{array}{l}\text { Incomplete outcome data } \\ \text { (attrition bias) }\end{array} & \text { Unclear risk } \\ \text { Adherence measure } & \begin{array}{l}\text { (PRIMARY) PATIENT INTERVIEW BY TELEPHONE - Not enough information } \\ \text { about how the data were collected or analyzed (used } 2 \text { methods to measure } \\ \text { compliance, but no explanation of how they took and combined the data) }\end{array}\end{array}$

Incomplete outcome data Unclear risk

Amado 2011

\begin{tabular}{|c|c|}
\hline Methods & Randomized controlled trial \\
\hline \multirow[t]{4}{*}{ Participants } & The study location was Primary Health Care Centres (PHCC), Barcelona and its metropolitan area, Spain \\
\hline & $\begin{array}{l}515 \text { participants were randomized to the intervention group and } 481 \text { participants were randomized to } \\
\text { the control group }\end{array}$ \\
\hline & $\begin{array}{l}\text { The inclusion criteria were patients between } 18 \text { and } 80 \text { years old with hypertension who were visiting } \\
\text { the clinic for at least } 6 \text { months for long-term follow-up and control of hypertension using anti-hyperten- } \\
\text { sive drug therapy }\end{array}$ \\
\hline & The exclusion criteria were serious psychiatric, physical, or sensory alterations \\
\hline \multirow[t]{4}{*}{ Interventions } & Intervention: INTERVENTION (IG) \\
\hline & $\begin{array}{l}\text { Patients in the Intervention Group (IG) had } 4 \text { visits with specially trained nurses who used standard- } \\
\text { ized guidelines and who had attended a } 10 \text {-hour workshop that focused on the antihypertensive med- } \\
\text { ications. Each visit lasted for an average of } 15 \text { minutes. Information was personalized to the needs of } \\
\text { the patient. Schedule sheets with the treatment plan were provided, which contained information on } \\
\text { the prescribed drugs and dosage schedule as well as basic advice on how to maximize the treatment } \\
\text { schedule. The sheets were provided to reinforce the nurse's verbal instructions }\end{array}$ \\
\hline & Control: CONTROL GROUP (CG) \\
\hline & Control patients received usual clinic care without any standardized intervention \\
\hline \multirow[t]{2}{*}{ Outcomes } & $\begin{array}{l}\text { The measures of adherence were self reported adherence and pill counts. The Haynes-Sackett and } \\
\text { Morisky-Green tests were used to collect self reported adherence over the previous } 3 \text { months }\end{array}$ \\
\hline & $\begin{array}{l}\text { The patient outcomes were systolic and diastolic blood pressure, hypertension control, BMI, and num- } \\
\text { ber of hypertensive drugs at } 12 \text { months compared with baseline measures }\end{array}$ \\
\hline
\end{tabular}


Amado 2011 (Continued)

Notes

\section{Risk of bias}

\begin{tabular}{lll}
\hline Bias & Authors' judgement & Support for judgement \\
\hline $\begin{array}{l}\text { Random sequence genera- } \\
\text { tion (selection bias) }\end{array}$ & Unclear risk & $\begin{array}{l}\text { No information about sequence generation. "The study was designed as mul- } \\
\text { ti-centre, prospective, cluster randomised, controlled clinical trial, using the } \\
\text { primary healthcare centre as a randomization unit." (pg 63) }\end{array}$ \\
\hline
\end{tabular}

\begin{tabular}{ll}
\hline $\begin{array}{l}\text { Allocation concealment } \\
\text { (selection bias) }\end{array}$ & Unclear risk \\
& $\begin{array}{l}\text { Method of allocation not described. "The study was designed as multi-centre, } \\
\text { prospective, cluster randomised, controlled clinical trial, using the primary } \\
\text { healthcare centre as a randomization unit." (pg 63) }\end{array}$ \\
\hline
\end{tabular}

\begin{tabular}{|c|c|c|}
\hline $\begin{array}{l}\text { Selective reporting (re- } \\
\text { porting bias) }\end{array}$ & Unclear risk & No protocol \\
\hline $\begin{array}{l}\text { Blinding of outcome as- } \\
\text { sessment (detection bias) } \\
\text { Adherence measure }\end{array}$ & Unclear risk & $\begin{array}{l}\text { (PRIMARY) SELF REPORT - QUESTIONNAIRES - Not stated whether the nurses } \\
\text { collecting the data were blinded }\end{array}$ \\
\hline $\begin{array}{l}\text { Blinding of outcome as- } \\
\text { sessment (detection bias) } \\
\text { Patient outcome }\end{array}$ & Unclear risk & $\begin{array}{l}\text { (PRIMARY) BLOOD PRESSURE - Not stated whether nurse collecting data was } \\
\text { blinded }\end{array}$ \\
\hline
\end{tabular}

\begin{tabular}{|c|c|c|}
\hline $\begin{array}{l}\text { Blinding of outcome as- } \\
\text { sessment (detection bias) } \\
\text { Patient outcome }\end{array}$ & Unclear risk & (PRIMARY) BMI - Not stated whether nurse collecting data was blinded \\
\hline $\begin{array}{l}\text { Blinding of participants } \\
\text { (performance bias) } \\
\text { Adherence measure }\end{array}$ & Unclear risk & $\begin{array}{l}\text { (PRIMARY) SELF REPORT - QUESTIONNAIRES - subjective outcome; no mention } \\
\text { of blinding }\end{array}$ \\
\hline $\begin{array}{l}\text { Blinding of participants } \\
\text { (performance bias) } \\
\text { Patient outcome }\end{array}$ & Low risk & $\begin{array}{l}\text { (PRIMARY) BLOOD PRESSURE - Lack of blinding is not likely to affect the out- } \\
\text { come }\end{array}$ \\
\hline $\begin{array}{l}\text { Blinding of participants } \\
\text { (performance bias) } \\
\text { Patient outcome }\end{array}$ & Low risk & $\begin{array}{l}\text { (PRIMARY) BMI - No blinding of patients mentioned but lack of blinding not } \\
\text { likely to affect this outcome }\end{array}$ \\
\hline $\begin{array}{l}\text { Blinding of personnel (per- } \\
\text { formance bias) } \\
\text { Adherence measure }\end{array}$ & Unclear risk & $\begin{array}{l}\text { (PRIMARY) SELF REPORT - QUESTIONNAIRES - Insufficient information about } \\
\text { the blinding of key personnel }\end{array}$ \\
\hline
\end{tabular}

\begin{tabular}{|c|c|c|}
\hline $\begin{array}{l}\text { Blinding of personnel (per- } \\
\text { formance bias) } \\
\text { Patient outcome }\end{array}$ & Unclear risk & (PRIMARY) BMI - No blinding of other study personnel mentioned \\
\hline $\begin{array}{l}\text { Blinding of personnel (per- } \\
\text { formance bias) } \\
\text { Patient outcome }\end{array}$ & Unclear risk & $\begin{array}{l}\text { (PRIMARY) BLOOD PRESSURE - No blinding of other study personnel men- } \\
\text { tioned }\end{array}$ \\
\hline $\begin{array}{l}\text { Incomplete outcome data } \\
\text { (attrition bias) }\end{array}$ & Low risk & $\begin{array}{l}\text { (PRIMARY) SELF REPORT - QUESTIONNAIRES - Reasons for dropouts were } \\
\text { lar in both groups }\end{array}$ \\
\hline
\end{tabular}


Amado 2011 (Continued)

Adherence measure

\begin{tabular}{|c|c|c|}
\hline Incomplete outcome data & Low risk & (PRIMARY) BLOOD PRESSURE - Reasons for dropouts similar in both groups \\
\hline
\end{tabular}
(attrition bias)

Patient outcome

Incomplete outcome data Low risk

(attrition bias)

(PRIMARY) BMI - Reasons for dropouts similar in both groups

Patient outcome

Anderson 2010

Methods Randomized controlled trial

Participants

The study location was a community mental health center in the southeast of the USA

12 participants were randomized to the intervention group and 14 participants were randomized to the control group

The inclusion criteria were male and female patients aged over 18 years with a diagnosis of schizophrenia or schizoaffective disorder, and were able to read and understand English

The exclusion criteria were (i) a comorbid axis I diagnosis of moderate or severe learning disability or organic brain disorder; (ii) a comorbid axis I diagnosis of drug or alcohol dependence; (iii) inpatient status at the start of the study; and (iv) suicidal or homicidal ideation at the start of the study

\section{Interventions Intervention: ADHERENCE TREATMENT}

The intervention was 'adherence therapy' a manualized, patient centric approach that seeks to address a broad range of factors known to affect adherence. This individual therapy focuses on the needs, concerns, fears, values, goals, and experiences of the individual with the aim of encouraging people to take their medications. It was delivered by 4 therapists with Master's degree in social work. There were 8 one to one sessions of between 20 to 60 minutes, over 8 weeks. Follow-up was conducted after the completion of the therapy. All intervention patients also received treatment as usual

Control: TREATMENT AS USUAL

TAU included day treatment, case management, employment placement, medication monitoring, and individual counseling. During the trial, AT participants did not see their own therapist for therapy sessions, but continued their other treatment activities

Outcomes

The measures of adherence were the Personal Evaluation of Transitions in Treatment (PETiT; Voruganti \& Awad 2002), a 30-item, self rated measure of patients' subjective evaluation of treatment with 6 questions specifically addressing medication adherence. The 30 items are rated on a 3-point scale, with higher scores indicating greater satisfaction and adherence. Voruganti and Awad (2002) report high internal consistency, with a Cronbach's alpha of 0.96 and good split-half reliability; they describe the scale as an indicator of medication adherence. The follow-up was conducted after therapy completion (8 weeks)

The patient outcomes were severity of schizophrenia symptoms, measured with PANSS (Positive and negative syndrome scale), administered at baseline and completion of the 8-week therapy by a researcher who was trained to administer the measure

\section{Notes}

\section{Risk of bias}

Bias Authors' judgement Support for judgement


Anderson 2010 (Continued)

Random sequence genera- Low risk Randomization by an independent randomization service(pg 342) tion (selection bias)

Allocation concealment Unclear risk
(selection bias)

(selection bias)
Insufficient information to permit judgment of 'Low risk' or 'High risk' of bias. "Written, informed consent was obtained from patients prior to randomization. Randomization was performed by an independent randomization service."

Selective reporting (re- Unclear risk $\quad$ Protocol unavailable
porting bias)

\begin{tabular}{ll}
\hline Other bias & Follow-up period is not clearly defined in the article; it says after completion of \\
therapy only(pg 348). Several factors during this pilot study had the potential & to influence the study results negatively. They included: (i) the small sample \\
size, making the study underpowered and increasing the risk of type Il errors; & (ii) the possibility of outliers in a sample this size might have skewed the data; \\
& (iii) selection bias, considering the high rate of refusal to participate and a pos- \\
sibility of those who agreed already were more medication adherent; (iv) time & constraints, as follow-up was conducted only 6 to 8 weeks after the beginning \\
of the intervention and within 1 to 2 days of the last counseling session; and (v) & therapists' knowledge level of psychotropic medication could mean that cues \\
from patients might have been missed
\end{tabular}

\begin{tabular}{|c|c|c|}
\hline $\begin{array}{l}\text { Blinding of outcome as- } \\
\text { sessment (detection bias) }\end{array}$ & Low risk & $\begin{array}{l}\text { (PRIMARY) SELF REPORT - QUESTIONNAIRE - This is a single masked trial (pg } \\
\text { 340). "Ratings were conducted masked" (pg 346) }\end{array}$ \\
\hline
\end{tabular}

sessment (detection bias)

(PRIMARY) SELF REPORT - QUESTIONNAIRE - This is a single masked trial (pg Adherence measure

\begin{tabular}{|c|c|c|}
\hline $\begin{array}{l}\text { Blinding of outcome as- } \\
\text { sessment (detection bias) } \\
\text { Patient outcome }\end{array}$ & Low risk & $\begin{array}{l}\text { (PRIMARY) POSITIVE AND NEGATIVE SYNDROME SCALE (PANSS) - This is a sin- } \\
\text { gle masked trial (pg 340). "The PANSS structured clinical interview rating } \\
\text { was completed by a researcher (SF) who was trained to administer the mea- } \\
\text { sure." (pg 343). "Ratings were conducted masked" (pg 346) }\end{array}$ \\
\hline
\end{tabular}

\begin{tabular}{|c|c|c|}
\hline $\begin{array}{l}\text { Blinding of participants } \\
\text { (performance bias) } \\
\text { Adherence measure }\end{array}$ & High risk & $\begin{array}{l}\text { (PRIMARY) SELF REPORT - QUESTIONNAIRE - Patients not blind due to the na- } \\
\text { ture of the intervention }\end{array}$ \\
\hline $\begin{array}{l}\text { Blinding of participants } \\
\text { (performance bias) } \\
\text { Patient outcome }\end{array}$ & High risk & $\begin{array}{l}\text { (PRIMARY) POSITIVE AND NEGATIVE SYNDROME SCALE (PANSS) - Patients not } \\
\text { blind due to the nature of the intervention }\end{array}$ \\
\hline $\begin{array}{l}\text { Blinding of personnel (per- } \\
\text { formance bias) } \\
\text { Adherence measure }\end{array}$ & Unclear risk & $\begin{array}{l}\text { (PRIMARY) SELF REPORT - QUESTIONNAIRE - Insufficient information to permit } \\
\text { judgment of 'Low risk' or 'High risk' of bias }\end{array}$ \\
\hline $\begin{array}{l}\text { Blinding of personnel (per- } \\
\text { formance bias) } \\
\text { Patient outcome }\end{array}$ & Unclear risk & $\begin{array}{l}\text { (PRIMARY) POSITIVE AND NEGATIVE SYNDROME SCALE (PANSS) - Insufficient } \\
\text { information to determine if study personnel were blinded }\end{array}$ \\
\hline $\begin{array}{l}\text { Incomplete outcome data } \\
\text { (attrition bias) } \\
\text { Adherence measure }\end{array}$ & Unclear risk & $\begin{array}{l}\text { (PRIMARY) SELF REPORT - QUESTIONNAIRE - Missing data not balanced; dis- } \\
\text { similar reasons but difficult to determine what impact this would have on the } \\
\text { study }\end{array}$ \\
\hline $\begin{array}{l}\text { Incomplete outcome data } \\
\text { (attrition bias) } \\
\text { Patient outcome }\end{array}$ & Unclear risk & $\begin{array}{l}\text { (PRIMARY) POSITIVE AND NEGATIVE SYNDROME SCALE (PANSS) - Missing da- } \\
\text { ta not balanced; dissimilar reasons but difficult to determine what impact this } \\
\text { would have on the study }\end{array}$ \\
\hline
\end{tabular}


Andrade 2005

\section{Methods}

\section{Participants}

64 patients were randomized in this study with 32 in the intervention group and 32 in the control group. Allocation concealment and method of randomization were not described

Enrolled patients who were 18 years of age or older, able to self medicate, and currently receiving care at the Johns Hopkins Moore (HIV) Clinic. Subjects eligible for inclusion were either previously treatment-naive and initiating highly active antiretroviral therapy (HAART) for the first time or antiretroviral experienced and switching HAART regimens. Among subjects in the latter group, we included only those who had received 3 or less HAART regimens before study enrolment. Exclusion criteria were inability to self medicate, presence of severe dementia, and institutionalization

Interventions

All subjects participated in an individualized, 30-minute adherence counseling session each month and received adherence feedback from a standardized transcript that provided general education about the barriers to adherence, the hazards of non-adherence, and their prescribed HAART regimen. A clinical pharmacist with extensive experience in the field of Human Immunodeficiency Virus/Acquired Immunodeficiency Syndrome (HIV/AIDS) provided adherence counseling and feedback. Patients in the intervention group were also given the Disease Management Assistance System (DMAS) device for 24 weeks. The DMAS device was programmed with reminder messages and dosing times for each medication in the HAART regimen. Devices were inspected monthly and reprogrammed when the HAART regimen was changed or replaced if they were lost or malfunctioning. Patients in the control group did not receive the DMAS

\section{Outcomes}

Adherence was assessed monthly with the DMAS, data from the electronic drug-exposure monitoring (eDEM) caps and completion of the AIDS Clinical Trials Group (ACTG) Baseline Adherence Questionnaire during the initial study visit and the ACTG Follow-up Adherence Questionnaire during subsequent visits. 4-day average adherence was calculated as the number of prescribed doses minus the number of missed doses, divided by the number of prescribed doses. For the DMAS device, adherence was calculated as the number of times the response button was pressed divided by the number of medication prompts during the 4-day period preceding the study visit. Clinical endpoints included CD4+ cell count and plasma HIV RNA load were assessed at baseline and at weeks 12 and 24 of follow-up. Validated neuropsychological (NP) tests were used to assess attention, memory, new learning, psychomotor speed, and executive functions and administered twice during the study, at baseline and after 24 weeks of HAART. Symptoms of depression were assessed using the Center for Epidemiologic Studies Depression (CES-D) scale. Patients were also questioned about active illicit drug use and alcohol use during the past 4 days

\section{Notes}

The DMAS prompting device improved adherence for memory-impaired subjects but not for memory-intact subjects; this was shown at 24 weeks with a $20 \%$ increase in adherence for the memory-impaired group compared with $6 \%$ for the memory-intact patients. Although the DMAS resulted in improved adherence, the overall mean adherence score was only $77 \%$ for DMAS users with memory deficits. This is lower than the optimal adherence rate of $95 \%$ required for optimal viral suppression

\section{Risk of bias}

\begin{tabular}{lll}
\hline Bias & Authors' judgement & Support for judgement \\
\hline $\begin{array}{l}\text { Random sequence genera- } \\
\text { tion (selection bias) }\end{array}$ & Low risk & $\begin{array}{l}\text { Author note: Subjects were randomized using a random number generator } \\
\text { that produced a list of treatment slots }\end{array}$ \\
\hline $\begin{array}{l}\text { Allocation concealment } \\
\text { (selection bias) }\end{array}$ & Unclear risk & $\begin{array}{l}\text { No mention of allocation concealment. (pg 876) "Subjects were randomly as- } \\
\text { signed to intervention or control groups." }\end{array}$ \\
\hline $\begin{array}{l}\text { Selective reporting (re- } \\
\text { porting bias) }\end{array}$ & Unclear risk & No protocol available \\
\hline $\begin{array}{l}\text { Other bias } \\
\text { High risk }\end{array}$ & $\begin{array}{l}\text { Low external generalizability. (pg 881) "Third, substance abuse was relatively } \\
\text { uncommon in our study, and therefore the results might not be generalizable } \\
\text { to populations in which drug abuse is more prevalent." }\end{array}$ \\
\hline
\end{tabular}


Andrade 2005 (Continued)

Blinding of outcome as- Unclear risk (PRIMARY) ELECTRONIC DRUG EXPOSURE MONITORING - No mention of blindsessment (detection bias) ing of outcome assessors

Adherence measure

\begin{tabular}{|c|c|c|}
\hline $\begin{array}{l}\text { Blinding of outcome as- } \\
\text { sessment (detection bias) } \\
\text { Patient outcome }\end{array}$ & Low risk & (PRIMARY) CD4 CELL COUNT - Author note: Laboratory staff were blind \\
\hline $\begin{array}{l}\text { Blinding of participants } \\
\text { (performance bias) } \\
\text { Adherence measure }\end{array}$ & High risk & $\begin{array}{l}\text { (PRIMARY) ELECTRONIC DRUG EXPOSURE MONITORING - Participants would } \\
\text { have known they were in the intervention group }\end{array}$ \\
\hline
\end{tabular}

Adherence measure

(PRIMARY) CD4 CELL COUNT - No mention of blinding but this outcome is objective

(performance bias)

Patient outcome

Blinding of personnel (per- Unclear risk

formance bias)

Adherence measure

(PRIMARY) ELECTRONIC DRUG EXPOSURE MONITORING - No mention of blinding of study staff

Blinding of personnel (per- Unclear risk

formance bias)

Patient outcome

\begin{tabular}{|c|c|c|}
\hline $\begin{array}{l}\text { Incomplete outcome data } \\
\text { (attrition bias) }\end{array}$ & Unclear risk & $\begin{array}{l}\text { (PRIMARY) ELECTRONIC DRUG EXPOSURE MONITORING - Even dropouts but } \\
\text { imputation method was unclear }\end{array}$ \\
\hline
\end{tabular}

(PRIMARY) CD4 CELL COUNT - No mention of blinding of study staff

$\begin{array}{ll}\begin{array}{l}\text { Incomplete outcome data } \\ \text { (attrition bias) }\end{array} & \text { Unclear risk } \\ \text { Patient outcome } & \begin{array}{l}\text { (PRIMARY) CD4 CELL COUNT - Even dropouts but the imputation method was } \\ \text { unclear }\end{array}\end{array}$

Ansah 2001

\begin{tabular}{ll} 
Methods & $\begin{array}{l}\text { If children coming in on Monday received pre-packed tablets, those who came in on Tuesday received } \\
\text { syrup. The formulation assigned to a particular day changed from week to week. } 155 \text { received pre- } \\
\text { packed chloroquine tablets, and } 146 \text { received syrup }\end{array}$ \\
\hline Participants & $\begin{array}{l}\text { Children aged } 0 \text { to } 5 \text { years diagnosed with malaria at the clinic over a 6-week period received either pre- } \\
\text { packed tablets or syrup by random assignment }(\mathrm{n}=301)\end{array}$ \\
\hline Interventions & $\begin{array}{l}\text { Chloroquine tablets were dispensed in polythene packages divided into } 3 \text { parts each containing the } \\
\text { daily dose. The brand of tablets used for this study easily dissolved in water to form a homogenous sus- } \\
\text { pension. Caregivers were advised at the dispensary to crush the tablets and to add a little honey or sug- } \\
\text { ar to the mixture to mask its bitter taste. Staff of the health centers pre-packed the chloroquine on a } \\
\text { weekly basis. Packages were available for } 8 \text { treatment regimes based on weight. The other group got } \\
\text { chloroquine syrup }\end{array}$
\end{tabular}

Outcomes

The measure used to dispense the medication (in the case of syrups), frequency, and duration of administration. A standard graded measuring syringe was used to assess the volume of the implement used for measuring the dose at home, and then compared adherence to treatment and its cost between the 2 groups

Notes

The investigators varied which day of the week was assigned to which intervention, making this trial closer in methodology to a cluster-randomized trial 
Ansah 2001 (Continued)

Risk of bias

\begin{tabular}{lll}
\hline Bias & Authors' judgement & Support for judgement \\
\hline $\begin{array}{ll}\text { Random sequence genera- } \\
\text { tion (selection bias) }\end{array}$ & $\begin{array}{l}\text { Unclear risk } \\
\text { Randomization based on day of the week. (pg 497) "All caregivers visiting the } \\
\text { two health centres over a 6-week period whose children had malaria received } \\
\text { either pre-packed chloroquine tablets or chloroquine syrup by random assign- } \\
\text { ment..... Thus if children coming in on Monday received pre-packed tablets, } \\
\text { those who came in on Tuesday received syrup. The formulation assigned to a } \\
\text { particular day changed from week to week." }\end{array}$ \\
\hline
\end{tabular}

\begin{tabular}{ll}
\hline $\begin{array}{l}\text { Allocation concealment } \\
\text { (selection bias) }\end{array}$ & Unclear risk \\
& $\begin{array}{l}\text { (pg 497) "Thus if children coming in on Monday received pre-packed tablets, } \\
\text { those who came in on Tuesday received syrup. The formulation assigned to a } \\
\text { particular day changed from week to week." }\end{array}$
\end{tabular}

\begin{tabular}{lll}
\hline Selective reporting (re- $\quad$ Unclear risk $\quad$ No protocol available &
\end{tabular}

porting bias)

\begin{tabular}{lll}
\hline Other bias & Unclear risk & Insufficient information provided \\
\hline $\begin{array}{l}\text { Blinding of outcome as- } \\
\text { sessment (detection bias) } \\
\text { Adherence measure }\end{array}$ & High risk & (PRIMARY) SELF REPORT - INTERVIEW - No blinding of staff and personnel \\
\end{tabular}

\begin{tabular}{lll}
\hline Blinding of outcome as- & High risk & (PRIMARY) RECOVERY - No mention of blinding of data collectors \\
sessment (detection bias) &
\end{tabular}

Patient outcome

\begin{tabular}{|c|c|c|}
\hline $\begin{array}{l}\text { Blinding of participants } \\
\text { (performance bias) } \\
\text { Adherence measure }\end{array}$ & High risk & $\begin{array}{l}\text { (PRIMARY) SELF REPORT - INTERVIEW - Patients could not be blinded due to } \\
\text { the intervention }\end{array}$ \\
\hline $\begin{array}{l}\text { Blinding of participants } \\
\text { (performance bias) } \\
\text { Patient outcome }\end{array}$ & High risk & (PRIMARY) RECOVERY - Patients were not blinded to study groups \\
\hline
\end{tabular}

Blinding of personnel (per- High risk

(PRIMARY) SELF REPORT - INTERVIEW - No blinding of key study personnel

formance bias)

Adherence measure

Blinding of personnel (per- High risk

(PRIMARY) RECOVERY - No mention of blinding of study staff

formance bias)

Patient outcome

Incomplete outcome data $\quad$ Unclear risk $\quad$ (PRIMARY) SELF REPORT - INTERVIEW - Insufficient information provided
(attrition bias)

Adherence measure

Incomplete outcome data Unclear risk (PRIMARY) RECOVERY - No reasons given for missing outcome data

(attrition bias)

Patient outcome

Antonicelli 2008

Methods Randomized controlled trial


Antonicelli 2008 (Continued)

Participants

The study location was the Italian National Research Centre on Aging, Ancona, Italy

29 participants were randomized to the intervention group and 28 participants were randomized to the control group

The inclusion criteria were patients with congestive heart failure of NYHA class II-IV

The exclusion criteria were lack of co-operation and/or of reliable family assistance at home, severe dementia or debilitating psychiatric disorders, inability to access a home telephone line, end-stage heart failure requiring regular inotropic drug infusions, cachexia, chronic renal failure, requiring dialysis treatment, and unstable angina

Interventions

\section{Intervention: HOME TELEMONITORING}

Patients were in a 12-month follow-up period. Patients (or one of their relatives) were contacted by telephone at least once a week by the chronic heart failure (CHF) team to obtain information on symptoms and adherence to prescribed treatment, as well as blood pressure, heart rate, bodyweight, and 24-hour urine output data for the previous day. A weekly ECG transmission was also required. Evaluation of these parameters was followed by reassessment of the therapeutic regimen and modification whenever needed. In addition, clinic visits were arranged as required on the basis of the data provided by telemonitoring or telephone interviews. Decisions on hospital re-admission during follow-up in both groups were made after consultation with a CHF team member

\section{Control: STANDARD CARE}

Patients (or one of their relatives) in the control group were contacted monthly for 12 months of follow-up by telephone to obtain data on new hospital admissions, cardiovascular complications, and death. These patients were also routinely seen in the CHF outpatient clinic every 4 months, with additional visits being arranged whenever changes in clinical status made this necessary

Outcomes

The measures of adherence were in the telemonitoring group, patients (or one of their relatives) were contacted by telephone at least once a week by the CHF team to obtain information on adherence to prescribed treatment. It is not clear how adherence was measured in the control group

The patient outcomes were new hospital admissions, cardiovascular complications and death, and symptoms, which were assessed by telephone contact at least once a week by the CHF team with patients (or one of their relatives). These calls also assessed blood pressure, heart rate, bodyweight, and 24-hour urine output data for the previous day. A weekly ECG transmission was also required. The primary composite endpoint was the combined rate of mortality and re-admission to hospital because of CHF. The secondary endpoints were rates of mortality and re-hospitalization considered separately over the follow-up period.

Notes -

\section{Risk of bias}

\begin{tabular}{lll}
\hline Bias & Authors' judgement & Support for judgement \\
\hline $\begin{array}{l}\text { Random sequence genera- } \\
\text { tion (selection bias) }\end{array}$ & Unclear risk & Author's note: All randomization steps were done by the statistician \\
\hline $\begin{array}{l}\text { Allocation concealment } \\
\text { (selection bias) }\end{array}$ & Low risk & $\begin{array}{l}\text { Author's note: All randomization steps were done by the statistician. All en- } \\
\text { velopes were concealed; there was no possibility for investigator bias }\end{array}$ \\
\hline $\begin{array}{l}\text { Selective reporting (re- } \\
\text { porting bias) }\end{array}$ & Low risk & $\begin{array}{l}\text { Author note: We followed the protocol from the previous study, published at } \\
\text { Journal of Telemedicine and Telecare 2008;14:300-5. All outcomes were re- } \\
\text { ported }\end{array}$ \\
\hline $\begin{array}{l}\text { Other bias } \\
\text { Blinding of outcome as- } \\
\text { sessment (detection bias) }\end{array}$ & Unclear risk & $\begin{array}{l}\text { Limitations noted by author: small sample size and short follow-up period } \\
\text { (PRIMARY) TELEPHONE SURVEY - No information about blinding is provided }\end{array}$ \\
\hline
\end{tabular}


Antonicelli 2008 (Continued)

Adherence measure

\begin{tabular}{|c|c|c|}
\hline $\begin{array}{l}\text { Blinding of outcome as- } \\
\text { sessment (detection bias) }\end{array}$ & Low risk & $\begin{array}{l}\text { (PRIMARY) SELF REPORT - QUESTIONNAIRE - Author note - Yes, outcome asses- } \\
\text { sors were blind }\end{array}$ \\
\hline
\end{tabular}

Patient outcome

$\begin{array}{ll}\begin{array}{l}\text { Blinding of participants } \\ \text { (performance bias) }\end{array} & \text { High risk } \\ \text { Adherence measure } & \begin{array}{l}\text { (PRIMARY) TELEPHONE SURVEY - No information about blinding in the man- } \\ \text { uscript, but likely that patients were not blinded because it is impossible to } \\ \text { blind participants to the study group }\end{array}\end{array}$

\begin{tabular}{ll}
\hline $\begin{array}{l}\text { Blinding of participants } \\
\text { (performance bias) }\end{array}$ & Unclear risk \\
$\begin{array}{l}\text { Patient outcome } \\
\text { (PRIMARY) SELF REPORT - QUESTIONNAIRE - Author note - Patients were blind } \\
\text { to the intervention }\end{array}$
\end{tabular}

\begin{tabular}{|c|c|c|}
\hline $\begin{array}{l}\text { Blinding of personnel (per- } \\
\text { formance bias) } \\
\text { Adherence measure }\end{array}$ & Unclear risk & $\begin{array}{l}\text { (PRIMARY) TELEPHONE SURVEY - No mention of blinding study staff or note on } \\
\text { role in study; unclear how this would impact the outcome }\end{array}$ \\
\hline
\end{tabular}

\begin{tabular}{|c|c|c|}
\hline $\begin{array}{l}\text { Blinding of personnel (per- } \\
\text { formance bias) } \\
\text { Patient outcome }\end{array}$ & Low risk & $\begin{array}{l}\text { (PRIMARY) SELF REPORT - QUESTIONNAIRE - Author note - Yes, study person- } \\
\text { nel were blind }\end{array}$ \\
\hline $\begin{array}{l}\text { Incomplete outcome data } \\
\text { (attrition bias) } \\
\text { Adherence measure }\end{array}$ & Unclear risk & $\begin{array}{l}\text { (PRIMARY) TELEPHONE SURVEY - No mention of dropouts; thus may have } \\
100 \% \text { follow-up but not sure }\end{array}$ \\
\hline $\begin{array}{l}\text { Incomplete outcome data } \\
\text { (attrition bias) } \\
\text { Patient outcome }\end{array}$ & Unclear risk & $\begin{array}{l}\text { (PRIMARY) SELF REPORT - QUESTIONNAIRE - No mention of dropouts; thus as- } \\
\text { sume } 100 \% \text { follow-up but this is unclear }\end{array}$ \\
\hline
\end{tabular}

Apter 2011

\begin{tabular}{|c|c|}
\hline Methods & Randomized controlled trial \\
\hline \multirow[t]{4}{*}{ Participants } & $\begin{array}{l}\text { The study location was primary care and asthma specialty practices serving low-income, inner-city } \\
\text { neighborhoods in Pennsylvania, USA }\end{array}$ \\
\hline & $\begin{array}{l}165 \text { participants were randomized to the intervention group and } 168 \text { participants were randomized to } \\
\text { the control group }\end{array}$ \\
\hline & $\begin{array}{l}\text { The inclusion criteria were (1) age of } 18 \text { years or greater; (2) physician's diagnosis of asthma; ( } 3 \text { ) pre- } \\
\text { scription for an ICS-containing medication for asthma; and (4) evidence of reversible airflow obstruc- } \\
\text { tion (i.e. either an increase of } 15 \% \text { or greater and } 200 \mathrm{ml} \text { in FEV1 with asthma treatment over the pre- } \\
\text { vious } 3 \text { years or an increase in FEV1 or forced vital capacity (FVC) of } 12 \% \text { or greater and } 200 \mathrm{ml} \text { in FEV1 } \\
\text { within } 30 \text { minutes of inhaled albuterol) }\end{array}$ \\
\hline & $\begin{array}{l}\text { The exclusion criteria were patients with severe psychiatric problems, such as obvious mania or schizo- } \\
\text { phrenia, which would make it impossible for them to understand or carry out problem solving }\end{array}$ \\
\hline \multirow[t]{2}{*}{ Interventions } & Intervention: PROBLEM SOLVING INTERVENTION \\
\hline & $\begin{array}{l}\text { Participants met with a research co-ordinator for } 4 \text { sessions of a problem solving (PS) intervention. PS } \\
\text { comprised } 430 \text {-minute sessions. The individualized intervention involved } 4 \text { interactive steps, usually } \\
1 \text { per research session. For the } 158 \text { participants who reported missing doses of inhaled corticosteroids } \\
\text { (ICS), the goal was to improve adherence. For the } 7 \text { participants who declared adherence to the pre- } \\
\text { scribed regimen, the goal was to maintain adherence. The first PS step consisted of defining the prob- } \\
\text { lem: improving or preserving adherence to ICS use within the patient's unique context and orientation. } \\
\text { Problem orientation facilitated the adoption of a rational, positive, and constructive appraisal of how } \\
\text { to achieve adherence, with non-adherence being presented as a problem to be solved. PS was present- }\end{array}$ \\
\hline
\end{tabular}


Apter 2011 (Continued)

ed as a means of coping with problems more generally and modifying attitudes or beliefs that inhibit or interfere with attempts to solve problems. It was a motivational technique to help the participant view the occurrence of problems as inevitable, normal, and solvable. This first step involved breaking problems into small achievable pieces. The second step was brainstorming for alternative solutions. The third step was choosing the best solution by weighing the consequences, both desirable and undesirable, of each candidate solution. Between the third and fourth meetings, the solution was tried. For the fourth step, the chosen solution was evaluated and revised. As part of this intervention, downloaded data from monitored ICSs were shared with the participant in a nonjudgmental fashion at each visit. At these sessions, subjects followed the same PS steps for addressing an additional problem of their own choosing, such as increasing physical activity. The problems were sometimes interrelated; for example, a father wants to play sports with his child, and improving asthma management makes this easier

\section{Control: ASTHMA EDUCATION}

Patients attended 4 30-minute sessions, conducted by a research co-ordinator. Each session was about an asthma education topic unrelated to self management, adherence, or inhaled corticosteroid (ICS) therapy. The topics covered, 1 at each session, were the following: (1) the proper technique for using an albuterol rescue metered-dose inhaler and a dry powder inhaler or spacer, depending on the patient's medications; (2) the use of peak flow meters; (3) common asthma triggers; and (4) the pathophysiology of asthma. These sessions did not involve discussion of problem solving or adherence, only didactic presentation of health information The electronic monitor can record multiple actuations over a short time period and thus can detect medication 'dumping', multiple actuations of an ICS unaccompanied by inhalation. Only 2 electronic monitors that measure the time and date of ICS use were available at the time of the study. Although no commercial monitor was available for fluticasone-salmeterol, the most frequent ICS prescribed to subjects during the study period, we were able to use the Diskus Adherence Logger (DAL). Fluticasone and beclomethasone administered by means of metered-dose inhalers were the next most frequently prescribed; for these, we used a commercial monitor, MDILog (Life Link Monitoring, Inc, Kingston, NY). Approximately $90 \%$ of study participants were prescribed an ICS that could be monitored with the DAL or MDILog. 14 patients were initially prescribed inhaled mometasone, but they were switched to a medication that could be monitored, fluticasone, during the study period with their physician's permission. We truncated adherence at $100 \%$ for each monitoring period to control for multiple actuations over a very short period of time and to provide a better measure of adherence

The patient outcomes were asthma-related quality of life, asthma control, FEV1, hospitalizations and emergency room visits. Asthma-related quality of life (AQOL) was measured at visits 1,5 , and 8 with the Mini-Asthma Quality of Life Questionnaire. This 15-item questionnaire, reflecting well-being over the past 2 weeks, has a 7-point response scale that provides a mean summary score. A 0.5-unit change is considered clinically meaningful. The Asthma Quality of Life Questionnaire has been shown to be a useful indicator of AQOL in low-income adults. Asthma control was measured at each visit by using the 7item version of the Asthma Control Questionnaire, which asks about symptoms over the past week. The score is the mean of all responses ( 0 , total control; 6 , extremely uncontrolled). The minimal important clinical difference is 0.5 . A score of greater than 1.5 is considered inadequate control. Spirometry was obtained by using American Thoracic Society procedures for FEV1 and FVC. At each research visit, participants reported hospitalizations and emergency department (ED) visits for asthma or any cause that had occurred since the previous meeting. Measures were taken by research co-ordinators at each study visit, at monthly visits, for 8 months

\footnotetext{
Notes
} $-$

\section{Risk of bias}

\begin{tabular}{lll}
\hline Bias & Authors' judgement & Support for judgement \\
\hline $\begin{array}{l}\text { Random sequence genera- } \\
\text { tion (selection bias) }\end{array}$ & Low risk & $\begin{array}{l}\text { 2 weeks later (visit 2), subjects were randomized according to a computer-gen- } \\
\text { erated algorithm in a 1:1 ratio to intervention or control group }\end{array}$ \\
\hline
\end{tabular}


Apter 2011 (Continued)

$\begin{array}{ll}\begin{array}{l}\text { Allocation concealment } \\ \text { (selection bias) }\end{array} & \text { Unclear risk } \\ & \begin{array}{l}\text { jllocation concealment is not specified. Only state: } 2 \text { weeks later (visit 2), sub- } \\ \text { ratio to either the intervention or control group }\end{array}\end{array}$

\begin{tabular}{|c|c|c|}
\hline $\begin{array}{l}\text { Selective reporting (re- } \\
\text { porting bias) }\end{array}$ & Low risk & $\begin{array}{l}\text { The study protocol is not available but it is clear that the published reports in- } \\
\text { clude all expected outcomes, including those that were pre-specified }\end{array}$ \\
\hline
\end{tabular}

Other bias High risk The authors indicate on pg 522 that "The limitations of our study are infor-
mative. As noted, electronic monitoring of adherence cannot be achieved divorced from the Hawthorne effect. Because of monitoring, many members of the asthma education group (control group) (66\%) thought researchers were teaching about adherence. Thus the interventions might have been perceived similarly by participants. Although the intervention was complicated and labor intensive, it focused only on the patient's behavior and did not consider the environment of the practice site or that of the patient's larger social context."

\begin{tabular}{|c|c|c|}
\hline $\begin{array}{l}\text { Blinding of outcome as- } \\
\text { sessment (detection bias) } \\
\text { Adherence measure }\end{array}$ & Low risk & $\begin{array}{l}\text { (PRIMARY) ELECTRONIC MONITORING - Objective measure/research co-ordina- } \\
\text { tor who collected the data was not blinded (was the one who delivered the in- } \\
\text { tervention) but probably would not affect electronic monitor data }\end{array}$ \\
\hline
\end{tabular}

\begin{tabular}{|c|c|c|}
\hline $\begin{array}{l}\text { Blinding of outcome as- } \\
\text { sessment (detection bias) }\end{array}$ & High risk & $\begin{array}{l}\text { (PRIMARY) ASTHMA CONTROL QUESTIONNAIRE - Open-label trial/no mention } \\
\text { of blinding of study staff/Subjective measure }\end{array}$ \\
\hline
\end{tabular}

Patient outcome

Blinding of participants Low risk
(performance bias)

Adherence measure

(PRIMARY) ELECTRONIC MONITORING - Objective measure/data dumping is accounted for(pg 518) "We electronically monitored the date and time of ICS actuation. The electronic monitor can record multiple actuations over a short time period and thus can detect medication "dumping", multiple actuations of an ICS unaccompanied by inhalation."

\begin{tabular}{|c|c|c|}
\hline $\begin{array}{l}\text { Blinding of participants } \\
\text { (performance bias) }\end{array}$ & High risk & $\begin{array}{l}\text { (PRIMARY) ASTHMA CONTROL QUESTIONNAIRE - Open-label trial/no mention } \\
\text { of blinding of patients/Subjective measure }\end{array}$ \\
\hline
\end{tabular}

Patient outcome

Blinding of personnel (per- Low risk $\quad$ (PRIMARY) ELECTRONIC MONITORING - Objective measure
formance bias)

Adherence measure

Blinding of personnel (per- High risk

(PRIMARY) ASTHMA CONTROL QUESTIONNAIRE - Open-label trial/no mention

formance bias)

Patient outcome of blinding of study personnel/Subjective measure

\begin{tabular}{|c|c|c|}
\hline $\begin{array}{l}\text { Incomplete outcome data } \\
\text { (attrition bias) } \\
\text { Adherence measure }\end{array}$ & High risk & $\begin{array}{l}\text { (PRIMARY) ELECTRONIC MONITORING - A large amount of missing data for this } \\
\text { measure. (pg 520) Monitor downloads failed in } 380(20 \%) \text { of } 2360 \text { downloads, } \\
18 \% \text { of the PS group and } 22 \% \text { of the AE group. Failures were attributed to mon- } \\
\text { itor failure, battery failure, and proximity to other batteries or magnets }\end{array}$ \\
\hline
\end{tabular}

\begin{tabular}{|c|c|c|}
\hline $\begin{array}{l}\text { Incomplete outcome data } \\
\text { (attrition bias) }\end{array}$ & Unclear risk & (PRIMARY) ASTHMA CONTROL QUESTIONNAIRE - Insufficient information \\
\hline
\end{tabular}

Patient outcome

\section{Bailey 1990}

Methods

Random allocation by sealed envelope technique. Blinding of patients or staff to the experimental treatment that individual patients were receiving was not performed, however, contacts/care givers of control patients were kept separate from those of the intervention group 
Bailey 1990 (Continued)

Participants Patients meeting the following diagnostic criteria were included in the study: recurrent episodes of wheezing or dyspnea, objective evidence of significantly increased airflow resistance during episodes, objective evidence of improvement in airflow when symptom free. Patients excluded from the study were those less than 18 years of age, those who refused to participate, or those with another pulmonary or severely debilitating disease that may have confused result interpretation

Interventions

Patients randomized to the control or usual care group were provided with a standardized set of asthma pamphlets, which contained comprehensive information about asthma. No special steps, however, were taken to ensure that patients actually read the pamphlets, and no special counseling, support groups, or systematic encouragement beyond routine physician encouragement were provided. While patients in the interventional self management group were also provided with the standardized asthma pamphlets, they in addition were provided with a skill-oriented self help workbook, a one-to-one counseling session, and were subject to several adherence-enhancing strategies, such as attending an asthma support group and receiving telephone calls from a health educator. Physicians emphasized these skills at regular clinic visits. A standard protocol for classifying patients in terms of level of severity and for relating their treatment regimen to their level of severity was employed

\section{Outcomes}

Measurement of adherence: 3 outcome measures directly assessed adherence to recommended regimens: a 10-item observational checklist to assess inhaler use skills, self report scales to determine adherence to medications and inhaler use, and subjective assessment on a 3-point scale by a project staff member. Measurement of healthcare outcomes: 4 status scales were employed in assessing healthcare outcomes: the first assessed the severity of asthma symptoms during the past 7 days, the next focused on psychological/psychosomatic aspects of asthma (whether the patients were 'bothered' by asthma in the past 7 days), the next scale assessed the number of episodes of respiratory problems/diseases experienced in the last 3 months, and the final scale measured whether asthma had interfered with the patients' lives in the last 3 months (prevented them from doing something)

Notes -

\section{Risk of bias}

Bias Authors' judgement Support for judgement

Random sequence genera- Low risk tion (selection bias)
Closed envelope method used. Physicians treating the patients were involved in stratification. (pg 1666) "Patients were then randomized to two groups by using the closed envelope method. Patients were then stratified by 11 UAB pulmonary physicians based on severity of asthma. Randomization envelopes were prepared in advance, using a separate schedule for each strata".

\begin{tabular}{ll}
\hline $\begin{array}{l}\text { Allocation concealment } \\
\text { (selection bias) }\end{array}$ & Low risk \\
& envelope method."
\end{tabular}

Selective reporting (re- Unclear risk
porting bias)

Unclear risk

All the 9 pre-specified outcome measures reported. Protocol required for further evaluation (Table 2pg 1667). (pg 1666) "Nine outcome measures assessed at baseline and at the 12-month"

\begin{tabular}{lll}
\hline Other bias & Unclear risk & Insufficient information to determine if other bias occurred \\
\hline $\begin{array}{l}\text { Blinding of outcome as- } \\
\text { sessment (detection bias) }\end{array}$ & High risk & $\begin{array}{l}\text { (PRIMARY) 10-ITEM OBSERVATION CHECKLIST - (pg 1666) "It proved impossi- } \\
\text { ble to blind either patients or project staff to the experimental treatment that } \\
\text { individual patients were receiving. To minimize the contamination of the usu- } \\
\text { al care condition with the Self management group all contacts with the usual } \\
\text { care group were limited to a staff member who had no part in implementing } \\
\text { the intervention program". }\end{array}$ \\
\hline $\begin{array}{l}\text { Blinding of outcome as- } \\
\text { sessment (detection bias) } \\
\text { Patient outcome }\end{array}$ & High risk & $\begin{array}{l}\text { (PRIMARY) ASTHMA SEVERITY SCALE - (pg 1666) "It proved impossible to blind } \\
\text { either patients or project staff to the experimental treatment that individual } \\
\text { patients were receiving. To minimize the contamination of the usual care con- } \\
\text { dition with the Self management group all contacts with the usual care group }\end{array}$ \\
\hline
\end{tabular}

Interventions for enhancing medication adherence (Review)

Copyright $\odot 2014$ The Cochrane Collaboration. Published by John Wiley \& Sons, Ltd. 
Bailey 1990 (Continued)

were limited to a staff member who had no part in implementing the intervention program".

Blinding of participants High risk
(performance bias)

Adherence measure
(PRIMARY) 10-ITEM OBSERVATION CHECKLIST - (pg 1666) "It proved impossible to blind either patients or project staff to the experimental treatment that individual patients were receiving. To minimize the contamination of the usual care condition with the Self management group all contacts with the usual care group were limited to a staff member who had no part in implementing the intervention program"

\begin{tabular}{|c|c|c|}
\hline $\begin{array}{l}\text { Blinding of participants } \\
\text { (performance bias) } \\
\text { Patient outcome }\end{array}$ & High risk & $\begin{array}{l}\text { (PRIMARY) ASTHMA SEVERITY SCALE - (pg 1666) "It proved impossible to blind } \\
\text { either patients or project staff to the experimental treatment that individual } \\
\text { patients were receiving." }\end{array}$ \\
\hline
\end{tabular}

Blinding of personnel (per- High risk formance bias)

Adherence measure
(PRIMARY) 10-ITEM OBSERVATION CHECKLIST - (pg 1666) "It proved impossible to blind either patients or project staff to the experimental treatment that individual patients were receiving. To minimize the contamination of the usual care condition with the Self management group all contacts with the usual care group were limited to a staff member who had no part in implementing the intervention program".

\section{Blinding of personnel (per- High risk} formance bias)

Patient outcome
(PRIMARY) ASTHMA SEVERITY SCALE - (pg 1666) "It proved impossible to blind either patients or staff to the experimental treatment that individual patients were receiving. To minimize the "contamination" of the usual care condition with the Self-Management Program, all contacts with usual care patients were limited to a Staff member who had no part in implementing the intervention program."
Incomplete outcome data Unclear risk

(attrition bias)

Adherence measure
(PRIMARY) 10-ITEM OBSERVATION CHECKLIST - 34 patients from the usual care and 8 from the self management program were lost at the 12-month follow-up and were excluded from data analysis. Originally the groups were balanced 135 and 132 to usual care and SMP groups and were closely matched at baseline. Excluding the dropouts analysis was carried out for 101 patients from the usual care and 123 from intervention group. It is stated in the paper (pg 1666) that "Analyses of baseline data indicated that dropouts were highly similar to subjects who persisted in the study, and that there was no dropout". However, not sure whether the imbalance in numbers could have affected the results

(PRIMARY) ASTHMA SEVERITY SCALE - 34 patients from the usual care and 8 from the self management program were lost at the 12-month follow-up and were excluded from data analysis. Originally the groups were balanced - 135 and 132 to usual care and SMP groups and were closely matched at baseline. Excluding the dropouts analysis was carried out for 101 patients from the usual care and 123 from intervention group. It is stated in the paper (pg 1666) that " Analyses of baseline data indicated that dropouts were highly similar to subjects who persisted in the study, and that there was no dropout". However, not sure whether the imbalance in numbers could have affected the results.

Bailey 1999

Patients $(n=236)$ were stratified by asthma severity (moderate or severe) and randomly assigned to the
3 groups using the closed-envelope technique: University of Alabama at Birmingham (UAB) Asthma Self
Management group $(n=78)$, UAB Core-Elements group $(n=76)$ and usual care group $(n=78)$. As well,
standard computer procedures were employed to create a stratified, blocked randomization schedule,
which consisted of block sizes of 6 to ensure 2 out of every 6 patients in each stratum were assigned to
each group. Immediately following randomization, staff collected baseline data and implemented the
designated educational treatment


Bailey 1999 (Continued)

Participants

All subjects were patients in the clinics of the UAB Division of Pulmonary and Critical Care Medicine with a primary diagnosis of asthma who met the following diagnostic criteria: (1) recurrent episodes of dyspnea or wheezing, (2) objective evidence of significantly increased resistance to airflow during episodes, (3) objective evidence of improvement in airflow when symptom-free, and (4) moderate to severe (rather than mild) asthma as assessed by their asthma care physician. New and current patients were included in the study; although patients who had participated in the earlier self management study were excluded

Interventions

UAB Asthma Self Management Program $(n=78)$ : the core component of the UAB Asthma Self Management Program (ASMP) was a skill-oriented self help workbook, which patients were counseled about in a one-on-one session and during 2 asthma support group meetings. The workbook included information on physiology of asthma, asthma medications, identification and avoidance of triggers, detection of and response to asthma attacks, and asthma care services. The 1-hour counseling session included reviewing the workbook content and skills, identifying personal expectations, asthma triggers, and barriers to adherence, and practicing inhaler use until patients were able to do so correctly. Patients were also given peak flow meters and trained to use them for early detection of impending asthma attacks. Asthma support groups, facilitated by a health educator, consisted of 4 to 6 patients with asthma and, if possible, asthma control partners (spouses or close friends). Support group meetings were held once each month many patients came every month. Patients were encouraged to share asthma concerns, discuss adherence problems, and exchange patient-initiated solutions. Patients received 2 telephone calls and a follow-up letter at 1, 2, and 4 weeks, after the counseling session. The first telephone call allowed the discussion of problems and to collect baseline peak flow readings and to help determine their expected peak flow rates. The letter reinforced actions to take at different levels of peak flow readings. The second telephone call provided closure for the intervention. Overall, the intervention spanned about 6 to 8 weeks for patients. UAB Core-Elements Program $(n=76)$ : this program consisted of a revised, shortened workbook that was given to patients. It was reviewed in a brief (15 to 20 minutes) one-to-one counseling session. Patients were trained to use inhalers and peak flow meters and rehearsed until these devices were used correctly. A follow-up telephone counseling session was conducted approximately one week later to review the patient's medication regimen and inhaler and peak flow meter skills. 2 weeks later, a follow-up letter was sent to patients, stressing the importance of adhering to the prescribed regimen and responding immediately to a drop in peak flow rate or other early signs of an attack

Usual-care control group $(n=78)$ : patients received the education that was the standard practice of their physician. They also received a standardized set of pamphlets that contained information about asthma. No steps were taken to ensure that patients read the pamphlets, and no special counseling, support groups, or telephone calls were provided

Compliance was measured using 2 4-item self reports, which were based on the prototype self report scale described by Morisky et al but were modified to be more applicable to asthma. The psychometric characteristics of the asthma therapy adherence scales were good to excellent. Adherence was analyzed in terms of the percentage of subjects with the highest possible scores on these scales. 4 clinical outcome measures addressed asthma status, specifically, the impact of asthma on respiratory symptoms and illnesses, functional status, and use of healthcare services. 2 scales addressed the severity of asthma symptoms in the past 7 days and the number of respiratory illnesses in the past 3 months. The functional impairment scale assessed the extent to which asthma had a negative impact on daily activities in the past 3 months. The scale for measurement of use of healthcare services classified patients as users if they had visited an emergency department for asthma and/or been hospitalized for asthma in the past 6 months. Other patients were classifies as nonusers. These measures also analyzed the percentage of subjects who obtained the highest possible score as users

\begin{tabular}{lll}
\hline Notes & - \\
\hline Risk of bias & \\
\hline Bias & Authors' judgement & Support for judgement \\
\hline $\begin{array}{l}\text { Random sequence genera- } \\
\text { tion (selection bias) }\end{array}$ & Low risk & $\begin{array}{l}\text { Stratified randomization using computer-generated numbers, closed en- } \\
\text { velopes (pg 2424) }\end{array}$ \\
\hline
\end{tabular}


Bailey 1999 (Continued)

$\begin{aligned} & \text { Allocation concealment } \\ & \text { (selection bias) }\end{aligned} \quad$ Low risk Central randomization using computer-generated numbers, closed envelopes

Selective reporting (re- Unclear risk Insufficient information; no protocol available

porting bias)

\begin{tabular}{|c|c|c|}
\hline Other bias & Low risk & No other obvious biases noted \\
\hline $\begin{array}{l}\text { Blinding of outcome as- } \\
\text { sessment (detection bias) } \\
\text { Adherence measure }\end{array}$ & Low risk & $\begin{array}{l}\text { (PRIMARY) SELF REPORT - INTERVIEW (ASTHMA THERAPY ADHERENCE SCALE) - } \\
\text { Author note: data collectors were blind }\end{array}$ \\
\hline $\begin{array}{l}\text { Blinding of outcome as- } \\
\text { sessment (detection bias) } \\
\text { Patient outcome }\end{array}$ & Low risk & $\begin{array}{l}\text { (PRIMARY) ASTHMA STATUS QUESTIONNAIRES - Author note: data collectors } \\
\text { were blind }\end{array}$ \\
\hline $\begin{array}{l}\text { Blinding of participants } \\
\text { (performance bias) } \\
\text { Adherence measure }\end{array}$ & Unclear risk & $\begin{array}{l}\text { (PRIMARY) SELF REPORT - INTERVIEW (ASTHMA THERAPY ADHERENCE SCALE) } \\
\text { - Patients were blind to allocation, but it is possible that they became aware of } \\
\text { their group later on during one-to-one sessions. If the patients came to know } \\
\text { about their group they might exaggerate responses during the telephone in- } \\
\text { terview. The authors have not mentioned about any measure taken to ensure } \\
\text { that patients remained blinded throughout the study. Author's note: the only } \\
\text { effect was not to discuss which intervention was being used }\end{array}$ \\
\hline
\end{tabular}

$\begin{array}{ll}\begin{array}{l}\text { Blinding of participants } \\ \text { (performance bias) }\end{array} & \text { Unclear risk } \\ \begin{array}{ll}\text { Patient outcome } & \text { (PRIMARY) ASTHMA STATUS QUESTIONNAIRES - Patients were blind to allo- } \\ & \text { ing one-to-one sessions. If the patients came to know about their group they } \\ & \text { might exaggerate responses during the telephone interview. Authors have not } \\ & \text { mentioned about any measure taken to ensure that patients remained blinded } \\ \text { throughout the study. Author's note: the only effect was not to discuss which } \\ \text { intervention was used }\end{array}\end{array}$

Blinding of personnel (per- Unclear risk (PRIMARY) SELF REPORT - INTERVIEW (ASTHMA THERAPY ADHERENCE SCALE) formance bias) Author's note: study staff were blind

Adherence measure

\begin{tabular}{lll}
\hline $\begin{array}{l}\text { Blinding of personnel (per- } \\
\text { formance bias) } \\
\text { Patient outcome }\end{array}$ & Unclear risk & $\begin{array}{l}\text { (PRIMARY) ASTHMA STATUS QUESTIONNAIRES - Author's note: study staff were } \\
\text { blind }\end{array}$ \\
\hline $\begin{array}{l}\text { Incomplete outcome data } \\
\text { (attrition bias) } \\
\text { Adherence measure }\end{array}$ & Unclear risk & $\begin{array}{l}\text { (PRIMARY) SELF REPORT - INTERVIEW (ASTHMA THERAPY ADHERENCE SCALE) } \\
\text { - Unclear whether the missed data could have changed the outcome, hence } \\
\text { marked unclear. However, attrition is fairly low, possibly low bias }\end{array}$ \\
\hline $\begin{array}{l}\text { Incomplete outcome data } \\
\text { (attrition bias) } \\
\text { Patient outcome }\end{array}$ & Unclear risk & $\begin{array}{l}\text { (PRIMARY) ASTHMA STATUS QUESTIONNAIRES - Unclear whether the missed } \\
\text { data could have changed the outcome, hence marked unclear. However, attri- } \\
\text { tion is fairly low, possibly low bias }\end{array}$ \\
\hline
\end{tabular}

\section{Baird 1984}

\begin{tabular}{ll}
\hline Methods & Random allocation without indication of concealment. \\
\hline Participants & Mild-moderate hypertensive patients who, at the time of study entry, were adequately controlled with \\
a regimen of metoprolol $200 \mathrm{mg}$ (range 150 to $250 \mathrm{mg}$ ) daily, or propranolol $160 \mathrm{mg}$ (range 120 to 200 \\
mg) daily, either as monotherapy or in conjunction with a diuretic were included in the study. Patients \\
excluded from the study were those with a condition in which beta-blockade was contraindicated
\end{tabular}


Baird 1984 (Continued)

Interventions

Patients were taken off whatever beta-blocker they were taking at entry and then allocated to one of the 2 interventional groups: (1) Betaloc tablets $100 \mathrm{mg}$ in the morning (0600 to 0900 hours), and in the evening (12 hours later), or (2) Betaloc Durules $200 \mathrm{mg}$ every morning (0600 to 0900 hours)

Outcomes

2 measurements of adherence were utilized: (1) tablet counts at 6 and 10 weeks, and (2) spot checks of metoprolol concentration in the urine at 6 and 10 weeks. The mean heart rate, systolic and diastolic blood pressures were assessed before, during, and after the trial, and compared between the 2 treatment regimens

Notes Outcome assessments were not blinded to study group

\section{Risk of bias}

\section{Bias} Authors' judgement Support for judgement

\begin{tabular}{|c|c|c|}
\hline $\begin{array}{l}\text { Random sequence genera- } \\
\text { tion (selection bias) }\end{array}$ & Unclear risk & $\begin{array}{l}\text { No discussion of randomization process. "Patients were allocated random- } \\
\text { ly" (pg 96) }\end{array}$ \\
\hline
\end{tabular}

\begin{tabular}{lll}
\hline $\begin{array}{l}\text { Allocation concealment } \\
\text { (selection bias) }\end{array}$ & Unclear risk & $\begin{array}{l}\text { No mention of allocation concealment. "Patients were allocated random- } \\
\text { ly" (pg 96) }\end{array}$ \\
\hline $\begin{array}{l}\text { Selective reporting (re- } \\
\text { porting bias) }\end{array}$ & Unclear risk & Unclear. No protocol available \\
\hline Other bias & Unclear risk & Not enough details provided in the article \\
\hline $\begin{array}{l}\text { Blinding of outcome as- } \\
\text { sessment (detection bias) } \\
\text { Adherence measure }\end{array}$ & Unclear risk & (PRIMARY) PILL COUNT - No mention of blinding of study staff \\
\hline
\end{tabular}

\begin{tabular}{|c|c|c|}
\hline $\begin{array}{l}\text { Blinding of outcome as- } \\
\text { sessment (detection bias) } \\
\text { Patient outcome }\end{array}$ & Unclear risk & $\begin{array}{l}\text { (PRIMARY) BLOOD PRESSURE AND HEART RATE - No information is provided in } \\
\text { the article on blinding }\end{array}$ \\
\hline
\end{tabular}

Blinding of participants High risk (PRIMARY) PILL COUNT - No blinding and outcome is possibly affected

(performance bias)

Adherence measure

$\begin{array}{ll}\begin{array}{l}\text { Blinding of participants } \\ \text { (performance bias) }\end{array} & \text { Low risk } \\ \begin{array}{l}\text { Patient } \\ \text { the article, but non-blinding of the patient is unlikely to affect this outcome }\end{array}\end{array}$

Patient outcome the article, but non-blinding of the patient is unlikely to affect this outcome
Blinding of personnel (per- Unclear risk formance bias)

Adherence measure

\section{(PRIMARY) PILL COUNT - No mention of blinding of study staff}

\section{(PRIMARY) BLOOD PRESSURE AND HEART RATE - No mention of blinding of} staff

formance bias)

Patient outcome

\section{Incomplete outcome data Unclear risk}

(attrition bias)

Adherence measure

(PRIMARY) PILL COUNT - Unclear how many patients withdrew from this portion of the trial, otherwise reasons for dropouts are provided in Table 3

Incomplete outcome data Unclear risk

(attrition bias)

Patient outcome
(PRIMARY) BLOOD PRESSURE AND HEART RATE - Unclear how many patients withdrew from this portion of the trial, otherwise reasons for dropouts are provided in Table 3 
Patients ( $\mathrm{n}=255$ ) were randomly assigned to (1) Pharmacist telephone follow-up intervention (PTFI; $\mathrm{n}$ $=126$ ) or (2) usual pharmacist intervention (UPI; $n=129$ ). Randomization was stratified by pharmacy in balanced blocks of 10 patients (1:1 ratio) using a computer-generated random number table and provided to the pharmacist investigators in sealed envelopes identified by patient number. Patients were randomized sequentially by patient number

Participants
were able to converse over the telephone, and were available for a telephone call during and at the ex-
pected end of antibiotic treatment and for up to 48 hours thereafter. Patients were excluded from the
trial if they were initiating prophylactic antibiotic treatment, were not self managing their medication,
were already participating in a clinical trial, in the opinion of the pharmacist, required intense clinical
follow-up, or would benefit from more intensive follow-up in a special medical hospital clinic

Interventions Pharmacist telephone follow-up intervention (PTFI) patients received a telephone call from a pharmacist on day 3 of their antibiotic treatment. The pharmacist documented the patient's general condition, checked for adverse effects and the patient's understanding of the dosage, stressed the importance of adherence to treatment, and offered encouragement. Patients were invited to ask questions and to contact their pharmacist if needed. At the initial pharmacy visit, Usual Pharmacist Intervention (UPI) patients were invited to contact their pharmacist if needed. They received no telephone calls during their treatment

Outcomes

Compliance was measured by patients reporting the number of antibiotic tablets or capsules left. Compliance was defined as the percentage of tablets consumed of the total number of tablets provided. Patients receiving azithromycin treatment and those who had a change in antibiotics during their treatment were excluded from this analysis. The clinical outcomes of patients were measured by asking for the number of infectious symptoms and their descriptions; in addition, a 5-point Likert scale was used to evaluate the severity of the infections. This was measured at baseline and upon completion of the treatment

Notes -

\section{Risk of bias}

Bias Authors' judgement Support for judgement

Random sequence genera- Low risk tion (selection bias)
Low bias because "Randomization was stratified by pharmacy in balanced blocks of 10 patients ( $1: 1$ ratio) using a computer-generated random-number table and provided to the pharmacist investigators in sealed envelopes identified by patient number. Patients were randomized sequentially by patient number." (pg 558)

Allocation concealment Low risk
(selection bias)

Allocation concealment detailed and appropriate. (pg 558) "... using a computer-generated random-number table and provided to the pharmacist investigators in sealed envelopes identified by patient number. Patients were randomized sequentially by patient number."

\begin{tabular}{|c|c|c|}
\hline $\begin{array}{l}\text { Selective reporting (re- } \\
\text { porting bias) }\end{array}$ & Unclear risk & No protocol available \\
\hline Other bias & Unclear risk & $\begin{array}{l}\text { Some limitations noted in discussion - (pg 562) "because the access to clinical } \\
\text { data was limited, the main study outcome consisted of a patient's subjective } \\
\text { evaluation rather than microbiological cultures... Moreover, a significant pro- } \\
\text { portion of the patients included in the study were probably suffering from vi- } \\
\text { ral infections. Because antibiotics are not efficacious against such infections, } \\
\text { it is unlikely that optimizing antibiotic treatment would affect the symptoms } \\
\text { of these patients. Indeed, in a secondary analysis, by excluding patients suffer- } \\
\text { ing from upper- or lower-respiratory tract infections (the patients most likely }\end{array}$ \\
\hline
\end{tabular}

Interventions for enhancing medication adherence (Review) 


Blinding of outcome as- $\quad$ Low risk
sessment (detection bias)

Adherence measure
(PRIMARY) SELF REPORT - INTERVIEW - The pharmacist that contacted patients to discuss adherence were blinded to group (pg 559) "The final evaluation was conducted over the telephone by a pharmacist blinded to the patient's assignment group."
Blinding of outcome as- Low risk sessment (detection bias)

Patient outcome
(PRIMARY) NUMBER OF INFECTIOUS SYMPTOMS - Pharmacist collecting data blinded to patient group (pg 559) "The final evaluation was conducted over the telephone by a pharmacist blinded to the patient's assignment group. The interview was scheduled for the expected last day of antibiotic treatment, except for patients on azithromycin treatment for five days, who were contacted on day 10; due to long tissue half-life and large volume of distribution, therapeutic concentrations are maintained over a 10-day period. 15 of the patient could not be reached, additional telephone calls were made at least three times a day for up to three days. To maintain blinding, the pharmacist who performed the final evaluation was different from the recruiting pharmacist and had access only to the patient's name and telephone number and the name and dosage of his or her antibiotic treatment. At the end of the interview, the pharmacist was asked if, in her opinion, blinding was maintained. If a DRP was identified at the final evaluation, the patient was referred to his or her treating pharmacist. The number of infectious symptoms and the infection severity score were evaluated as in the initial evaluation. The interviewing pharmacist did not have access to the initial evaluation and was unaware of the patient's diagnosis".

(PRIMARY) SELF REPORT - INTERVIEW - Open-label trial and self report of adherence is highly subjective

High risk

(performance bias)

Adherence measure

\begin{tabular}{ll}
\hline $\begin{array}{l}\text { Blinding of participants } \\
\text { (performance bias) }\end{array}$ & High risk \\
Patient outcome & $\begin{array}{l}\text { (PRIMARY) NUMBER OF INFECTIOUS SYMPTOMS - Patient symptom severity } \\
\text { and number of symptoms is subjective and patients were likely aware of their } \\
\text { study group allocation }\end{array}$ \\
\hline
\end{tabular}

Blinding of personnel (per- Unclear risk formance bias) (PRIMARY) SELF REPORT - INTERVIEW - No mention of blinding of study personnel

Adherence measure
(PRIMARY) NUMBER OF INFECTIOUS SYMPTOMS - No mention of blinding of other study personnel

Patient outcome

(PRIMARY) SELF REPORT - INTERVIEW - 21 patients had missing data across the 2 groups. 7 and 15 each in intervention and control groups. Reasons for missing data not reported individually for 2 groups. Unable to predict if it would have made a difference. Hence, marked unclear
Incomplete outcome data Unclear risk (attrition bias)

Adherence measure
(PRIMARY) NUMBER OF INFECTIOUS SYMPTOMS - The reasons for dropouts are

Incomplete outcome data Unclear risk

(attrition bias)

Patient outcome unclear

\section{Becker 1986}

Methods Random allocation without an indication of concealment


Becker 1986 (Continued)

Participants

Patients between the ages of 20 and 80 years who were already taking medication for previously diagnosed hypertension, and who had already demonstrated poor blood pressure control (diastolic blood pressure $>90 \mathrm{~mm} \mathrm{Hg}$ ) on at least 1 visit during the preceding 2 years were included in the study. Patients who had significant visual, auditory, or mental problems that could interfere with their adherence were excluded

Interventions

Patients in the control group received all of their antihypertensive medications in the traditional pill vials (separate vials for each pill that were labeled with the drug name, the dosage, the medication instructions, and the physician's name), whereas patients assigned to the experimental group received all their medications in the special packaging format (all pills taken together were packaged in a single plastic blister sealed with a foil backing on which was printed the day of the week and the time of day at which each medication was to be taken). All medications for both groups were provided free of charge to ensure that all patients would receive their medications

Outcomes Patient self reports of adherence, where patients were asked non-threatening, non-judgmental questions about their adherence behavior (patients who admitted less than perfect adherence were considered non-adherent), pill counts (patients were considered adherent if they had taken $80 \%$ or more of their prescribed medication) and the Hybrid model were employed in order to assess adherence. Blood pressure was taken 3 times during each visit. The first measure was discarded and an average of the second and third measures was used as the blood pressure measurement for that visit. Blood pressure control was defined as diastolic blood pressure less than $90 \mathrm{~mm} \mathrm{Hg}$

Notes All data collection was done by a nurse research assistant prior to regular office visits. Physicians caring for patients were aware that adherence studies were in progress, but were not told the aims of the study nor the group to which an individual patient had been assigned

\section{Risk of bias}

\begin{tabular}{lll}
\hline Bias & Authors' judgement & Support for judgement \\
\hline $\begin{array}{l}\text { Random sequence genera- } \\
\text { tion (selection bias) }\end{array}$ & Unclear risk & $\begin{array}{l}\text { Method not described in the article. (pg 358) "Patients who agreed were ran- } \\
\text { domly assigned into either the experimental of the control group." }\end{array}$ \\
\hline $\begin{array}{l}\text { Allocation concealment } \\
\text { (selection bias) }\end{array}$ & Unclear risk & $\begin{array}{l}\text { (pg 358) "Patients who agreed were randomly assigned into either the experi- } \\
\text { mental or the control group..." No description of allocation concealment }\end{array}$ \\
\hline $\begin{array}{l}\text { Selective reporting (re- } \\
\text { porting bias) }\end{array}$ & Unclear risk & $\begin{array}{l}\text { Probably all outcomes reported, but insufficient information in the article to } \\
\text { judge }\end{array}$ \\
\hline $\begin{array}{l}\text { Other bias } \\
\text { Low risk }\end{array}$ & $\begin{array}{l}\text { Authors identify possible co-intervention effect, but similar in both arms, so } \\
\text { unlikely to have introduced bias. (pg 361) "The magnitude of this cointerven- } \\
\text { tion effect is suggested by the increase in the proportion of patients in both } \\
\text { groups whose (...) pressure was controlled between the time of the pre-enroll- } \\
\text { ment and the baseline visit (i.e. before the special packaging intervention was } \\
\text { initiated)." This co-intervention appears to have affected both groups equally } \\
\text { and is thus unlikely to have biased the results }\end{array}$
\end{tabular}

Blinding of outcome as- Unclear risk sessment (detection bias) Adherence measure
(PRIMARY) SELF REPORT - INTERVIEW - Unclear if nurses were blinded. (pg 358) "All data collection was done by a nurse research assistant immediately before a regular office visit. Physicians caring for these patients were aware that compliance study was in progress but were not told the aims of the study or informed of whether any individual patient was in the experimental or control group."

Low risk

(PRIMARY) BLOOD PRESSURE - Blinding. (pg 358) "Physicians caring for these patients were aware that a compliance study was in progress but were not told the aims of the study of informed of whether any individual patient was in the experimental or control group." 
Becker 1986 (Continued)

\begin{tabular}{|c|c|c|}
\hline $\begin{array}{l}\text { Blinding of participants } \\
\text { (performance bias) }\end{array}$ & High risk & $\begin{array}{l}\text { (PRIMARY) SELF REPORT - INTERVIEW - No blinding and likely to affect the out- } \\
\text { come }\end{array}$ \\
\hline
\end{tabular}

\begin{tabular}{ll}
\hline $\begin{array}{l}\text { Blinding of participants } \\
\text { (performance bias) }\end{array}$ & Low risk \\
Patient outcome & $\begin{array}{l}\text { (PRIMARY) BLOOD PRESSURE - Patients not blinded but likely would not im- } \\
\text { pact outcome }\end{array}$ \\
\hline
\end{tabular}

Blinding of personnel (per- Low risk formance bias)

(PRIMARY) SELF REPORT - INTERVIEW - Physicians were blinded. (pg 358) "All Adherence measure data collection was done by a nurse research assistant immediately before a regular office visit. Physicians caring for these patients were aware that compliance study was in progress but were not told the aims of the study or informed of whether any individual patient was in the experimental or control group."

Blinding of personnel (per- Low risk
formance bias)

Patient outcome
(PRIMARY) BLOOD PRESSURE - Physicians were blinded. (pg 358) "Physicians caring for these patients were aware that compliance study was in progress but were not told the aims of the study or informed of whether any individual patient was in the experimental or control group."

Incomplete outcome data Unclear risk
(attrition bias)
Adherence measure

Incomplete outcome data Unclear risk

Adherence measure
(PRIMARY) SELF REPORT - INTERVIEW - Not enough information to judge. We do not know to which arm the drop outs belong. (pg 359) "Most of these patients did not show up for appointments and could not be contacted by telephone. Other reasons for dropouts included death (1) and discontinuation of medications (1). No patients indicated that problems with the medication packaging were involved in their reasons for dropping out."

(PRIMARY) BLOOD PRESSURE - Not enough information to judge. We do not know to which arm the dropouts belong. (pg 359) "Most of these patients did not show up for appointments and could not be contacted by telephone. Other reasons for dropouts included death (1) and discontinuation of medications (1). No patients indicated that problems with the medication packaging were involved in their reasons for dropping out."

\begin{tabular}{|c|c|c|}
\hline $\begin{array}{l}\text { Incomplete outcome data } \\
\text { (attrition bias) } \\
\text { Patient outcome }\end{array}$ & Unclear risk & $\begin{array}{l}\text { (PRIMARY) BLOOD PRESSURE - Not enough information to judge. We do not } \\
\text { know to which arm the dropouts belong. (pg 359) "Most of these patients did } \\
\text { not show up for appointments and could not be contacted by telephone. Oth- } \\
\text { er reasons for dropouts included death (1) and discontinuation of medications } \\
\text { (1). No patients indicated that problems with the medication packaging were } \\
\text { involved in their reasons for dropping out." }\end{array}$ \\
\hline
\end{tabular}

\section{Berrien 2004}

\begin{tabular}{ll}
\hline Methods & 37 patients were randomized 1:1 to either the home intervention or control group using the Small Ta- \\
ble of Random Digits. The randomization process was number-based, with patient names not iden- \\
tified. The randomization list was held by the clinical co-ordinator of the HIV program and kept in a \\
locked file
\end{tabular}
Participants All eligible HIV-positive patients $(n=37)$ followed in the program. Informed consent was obtained from each participant's legal guardian. Children ranged in age between 1.5 to 12 years of age (mean 8.7 years) for the intervention group and 5 to 11 years (mean 8.4 years) in the control group. Assent was ob- tained from all minors older than 7 years of age

Interventions The intervention group received 8 structured home visits over a 3-month period by the same home care
experienced registered nurse. The visits were designed to improve knowledge and understanding of
HIV infection, to identify and resolve real and potential barriers to medication adherence, and ultimate-
ly to improve adherence. Spanish-speaking case managers, incentives, notebooks with stickers, and
pill-swallowing training were also part of the home visit training sessions. In the clinic setting for con-
trol group, the physician, nurse, and social worker provided standard medication adherence education
at clinic appointments generally scheduled at 3-month intervals. Phone follow-ups and a single home
visit were planned if the staff felt they were needed. Visual aids for remembering medications, med-
ication boxes, beepers, and general technical and emotional support were regularly offered. The clinic
nurse contacted the family by telephone when the patient was starting a new medication, was having
difficulty with adherence, or needed clarification and support. A single home visit was planned when 
Berrien 2004 (Continued)

and if the clinic staff believed medication adherence was poor despite the implementation of the above listed techniques

Knowledge and adherence were measured at the beginning of the study and at the end of the inter-
vention. These were measures via self report and pharmacy fill record. Changes in viral load and CD4
counts were measured at baseline and after treatment, or for 6 to 11 months beyond the initial study
period

Notes -

\section{Risk of bias}

\begin{tabular}{lll}
\hline Bias & Authors' judgement & Support for judgement \\
\hline $\begin{array}{l}\text { Random sequence genera- } \\
\text { tion (selection bias) }\end{array}$ & Low risk & $\begin{array}{l}\text { Random number table was used. Hence low bias. (pg 356) "Patients were ran- } \\
\text { domized 1:1 to either the home intervention or control group using the Small } \\
\end{array}$ \\
& $\begin{array}{l}\text { Table of Random Digits. The randomization process was number based, with } \\
\text { patient names not identified". }\end{array}$ \\
\hline
\end{tabular}

$\begin{array}{ll}\begin{array}{l}\text { Allocation concealment } \\ \text { (selection bias) }\end{array} & \text { Low risk } 356) \text { "Patients were randomized 1:1 to either the home intervention or } \\ & \text { control group using the Small Table of Random Digits. The randomization } \\ \text { process was number based, with patient names not identified. The randomiza- } \\ \text { tion list was held by the clinical coordinator of the HIV Program and kept in a } \\ \text { locked file." }\end{array}$

Selective reporting (re- Low risk
porting bias) Primary and secondary outcomes were explicitly stated. (pg 356) "Primary
study outcomes included changes in patient knowledge of HIV and their med-
ications, and changes in adherence, the latter being measured by self report
and by pharmacy drug refill history". (pg 357) "Secondary outcomes included
changes in viral load (Roche Amplicor HIV-1 Monitor Test) and CD4= T-cell per-
centages and counts". All those have been accounted in the results

\begin{tabular}{lll}
\hline Other bias & Unclear risk & None noted but insufficient information provided \\
\hline $\begin{array}{l}\text { Blinding of outcome as- } \\
\text { sessment (detection bias) }\end{array}$ & High risk & $\begin{array}{l}\text { (PRIMARY) PHARMACY FILL RECORD - Non-blinded trial. (pg 356) "a random- } \\
\text { ized, nonblinded, pilot clinical study at CCMC's pediatric and youth HIV pro- } \\
\text { gram." }\end{array}$ \\
\hline
\end{tabular}

\begin{tabular}{|c|c|c|}
\hline $\begin{array}{l}\text { Blinding of outcome as- } \\
\text { sessment (detection bias) }\end{array}$ & Unclear risk & $\begin{array}{l}\text { (PRIMARY) CD4+ T CELL PERCENTAGES AND COUNTS - No details given about } \\
\text { how these measures were collected }\end{array}$ \\
\hline
\end{tabular}

Patient outcome

\begin{tabular}{|c|c|c|}
\hline $\begin{array}{l}\text { Blinding of participants } \\
\text { (performance bias) } \\
\text { Adherence measure }\end{array}$ & High risk & $\begin{array}{l}\text { (PRIMARY) PHARMACY FILL RECORD - Non-blinded trial. (pg 356) "a random- } \\
\text { ized, nonblinded, pilot clinical study at CCMC's pediatric and youth HIV pro- } \\
\text { gram." }\end{array}$ \\
\hline $\begin{array}{l}\text { Blinding of participants } \\
\text { (performance bias) } \\
\text { Patient outcome }\end{array}$ & Low risk & $\begin{array}{l}\text { (PRIMARY) CD4+ T CELL PERCENTAGES AND COUNTS - No blinding but patient } \\
\text { lack of blinding unlikely to impact this outcome }\end{array}$ \\
\hline $\begin{array}{l}\text { Blinding of personnel (per- } \\
\text { formance bias) } \\
\text { Adherence measure }\end{array}$ & High risk & $\begin{array}{l}\text { (PRIMARY) PHARMACY FILL RECORD - Intervention provider was involved in } \\
\text { evaluation steps also. Non-blinded trial. (pg 356) "a randomized, non-blinded, } \\
\text { pilot clinical study at CCMC's pediatric and youth HIV program." }\end{array}$ \\
\hline $\begin{array}{l}\text { Blinding of personnel (per- } \\
\text { formance bias) } \\
\text { Patient outcome }\end{array}$ & Unclear risk & $\begin{array}{l}\text { (PRIMARY) CD4+ T CELL PERCENTAGES AND COUNTS - No details given about } \\
\text { how these measures were collected }\end{array}$ \\
\hline
\end{tabular}


Berrien 2004 (Continued)

Incomplete outcome data Low risk (attrition bias)

Adherence measure
(PRIMARY) PHARMACY FILL RECORD - 3 patients were not included in analysis - either dead or withdrew from the study; one from the intervention group and two from the control group. Missing data are accounted for and excluded from analysis. It is not known whether missing data would have made a plausible size effect. However, intention-to-treat analyses results were similar to the analysis which excluded the 3 missing data

$\begin{array}{ll}\begin{array}{l}\text { Incomplete outcome data } \\ \text { (attrition bias) }\end{array} & \text { (PRIMARY) CD4+ T CELL PERCENTAGES AND COUNTS - } 3 \text { patients were not in- } \\ \text { Patient outcome } & \text { cluded in analysis - either dead or withdrew from the study; one from the in- } \\ & \text { tervention group and two from the control group. Missing data are accounted } \\ & \text { and excluded from analysis. It is not known whether missing data would have } \\ & \text { made a plausible size effect. However, intention-to-treat analyses results were } \\ & \text { similar to the analysis which excluded the } 3 \text { missing data }\end{array}$

Boker 2012

\begin{tabular}{ll}
\hline Methods & Randomized controlled trial \\
\hline Participants & $\begin{array}{l}\text { The study location was University of Texas Southwestern Medical Center, Texas, and University of Cali- } \\
\text { fornia at Davis, California, USA }\end{array}$
\end{tabular}

20 participants were randomized to the intervention group and 20 participants were randomized to the control group

The inclusion criteria were healthy patients 12 to 35 years of age with mild to moderate facial acne suitable for treatment with topical medications; male or female of any ethnic background; a clinical diagnosis of acne vulgaris with facial involvement for at least 6 months; a minimum of 30 non-inflammatory facial lesions (open and/or closed comedones) and at least 20 inflammatory lesions (papules or pustules); a score of 2 or 3 on the Investigator Global Assessment (IGA) scale; and possession of a personal mobile telephone with SMS text messaging capabilities. Women of childbearing potential were required to use an acceptable birth control measure such as abstinence, condoms, or vaginal diaphragms. Hormonal-based oral contraception was only allowed if treatment had been initiated at least 5 months before study enrollment and was given for reasons other than specific treatment of acne. Minors (less than 18 years) were required to have parental or legal guardian consent to participate

The exclusion criteria were known pregnancy, the presence of nodular or cystic acne, acne conglobata or acne fulminans, exposure to environmental or chemical comedogenic agents, women with hyperandrogenism (polycystic ovarian syndrome) or on any form of specific acne-directed hormonal therapy, a history of Cushing syndrome or congenital adrenal hyperplasia, and use of tanning beds within 4 weeks of enrollment. All female patients of childbearing potential were required to undergo a baseline urine pregnancy test that was repeated at each follow-up visit. Required washout periods included: acne-specific systemic antibiotics, 2 months; isotretinoin, 6 months; and topical acne medications (prescription or over the counter), 4 weeks

Interventions Intervention: TEXT MESSAGE REMINDERS
20 patients were then randomized to receive daily, customized text-message reminders at a predeter-
mined time. The website LetterMeLater.com was used to create an automated and customized elec-
tronic reminder schedule for each patient in this group at their baseline visit. Individual texting sched-
ules were chosen based on each patient's preference and the anticipated time of each medication use.
Once the schedule was created, patients in the reminder group received a customized text message
twice daily (morning and evening), reminding them to apply the Duac (Stiefel Laboratories) or Differin
(Galderma) gels, respectively. The content of each text message was identical for each patient and var-
ied only by including the recipient's first name at the start of the message. Patients in the reminder
group were asked to text back a reply if and when each application was completed in an attempt to
compare actual adherence (measured by MEMS caps opening/closing events) and self reported adher-
ence. All medication tubes and their corresponding MEMS caps were clearly labeled to avoid mix-ups

Control: USUAL CARE 
Boker 2012 (Continued)

Control group patients received usual care and were not provided with text message reminders

Outcomes The measures of adherence were MEMS. Patients were given medication tubes. Each medication tube was fitted with a customized Medication Event Monitoring System (MEMS) cap(MEMS, Aardex Group, Sion, Switzerland) that has the ability to record the date and time of every opening/closing of the medication cap. Each opening/closing is recorded as one individual event (date/time stamp). Patients were not informed that their adherence was monitored electronically. Data were downloaded at the 12week exit visit

The patient outcomes were acne severity assessed by Investigator Global Assessment, Patient Global Assessment, and quality of life assessed by Dermatology Quality of Life Index questionnaire. All questionnaires were administered by a blinded investigator at baseline 6 and 12 weeks

Notes

\section{Risk of bias}

\begin{tabular}{lll}
\hline Bias & Authors' judgement & Support for judgement \\
\hline $\begin{array}{l}\text { Random sequence genera- } \\
\text { tion (selection bias) }\end{array}$ & Unclear risk & $\begin{array}{l}\text { Not enough information given. Patients were randomized in a 1:1 ratio and } \\
\text { assigned in a sequential manner to either receive electronic text message re- } \\
\text { minders or to serve as control subjects }\end{array}$ \\
\hline $\begin{array}{l}\text { Allocation concealment } \\
\text { (selection bias) }\end{array}$ & Unclear risk & $\begin{array}{l}\text { Not enough information provided. ('sequential manner' = possibly high bias?). } \\
\text { Patients were randomized in a 1:1 ratio and assigned in a sequential manner } \\
\text { to either receive electronic text message reminders or to serve as control sub- } \\
\text { jects }\end{array}$ \\
\hline
\end{tabular}

\begin{tabular}{lll}
\hline $\begin{array}{l}\text { Selective reporting (re- } \\
\text { porting bias) }\end{array}$ & Unclear risk & None detected. Protocol not available \\
\hline Other bias & Low risk & None noted \\
\hline
\end{tabular}

Blinding of outcome as- Low risk sessment (detection bias) Adherence measure (PRIMARY) MEMS - Unblinded, but MEMS data unlikely to be biased by the data collectors

\begin{tabular}{|c|c|c|}
\hline $\begin{array}{l}\text { Blinding of outcome as- } \\
\text { sessment (detection bias) }\end{array}$ & Unclear risk & $\begin{array}{l}\text { (PRIMARY) ACNE SEVERITY - it is unclear from description if the investigator } \\
\text { was only blinded at baseline or was blinded at follow-up as well }\end{array}$ \\
\hline
\end{tabular}
Patient outcome

\begin{tabular}{|c|c|c|}
\hline $\begin{array}{l}\text { Blinding of participants } \\
\text { (performance bias) } \\
\text { Adherence measure }\end{array}$ & High risk & $\begin{array}{l}\text { (PRIMARY) MEMS - Patients were not informed that their adherence was moni- } \\
\text { tored electronically, but nature of intervention might have unblinded them }\end{array}$ \\
\hline
\end{tabular}

Blinding of participants Low risk
$\begin{aligned} & \text { (performance bias) } \\ & \text { Patient outcome }\end{aligned}$

\begin{tabular}{ll}
\hline $\begin{array}{l}\text { Blinding of personnel (per- } \\
\text { formance bias) }\end{array}$ & Low risk \\
Adherence measure & $\begin{array}{l}\text { (PRIMARY) MEMS - Unblinded, but MEMS data unlikely to be biased by the } \\
\text { study staff }\end{array}$
\end{tabular}

\begin{tabular}{lll}
\hline $\begin{array}{l}\text { Blinding of personnel (per- } \\
\text { formance bias) } \\
\text { Patient outcome }\end{array}$ & High risk & (PRIMARY) ACNE SEVERITY - study co-ordinator was not blinded \\
\hline $\begin{array}{l}\text { Incomplete outcome data } \\
\text { (attrition bias) }\end{array}$ & Unclear risk & $\begin{array}{l}\text { (PRIMARY) MEMS - Attrition not balanced between groups; not enough infor- } \\
\text { mation provided on reasons for dropout }\end{array}$
\end{tabular}


Boker 2012 (Continued)

Adherence measure

\section{Incomplete outcome data Unclear risk} (attrition bias)

Patient outcome

(PRIMARY) ACNE SEVERITY - Attrition rates imbalanced; not enough information provided to judge

Bond 2007

\begin{tabular}{ll}
\hline Methods & Randomized controlled trial \\
\hline Participants & $\begin{array}{l}\text { The study location was } 9 \text { primary care organizations, England, UK } \\
980 \text { participants were randomized to the intervention group and } 513 \text { participants were randomized to } \\
\text { the control group }\end{array}$
\end{tabular}

The inclusion criteria were registered with the general practices, aged over 17 years, and with CHD (previous myocardial infarction, angina, coronary artery bypass graft, and/or angioplasty)

The exclusion criteria were illiterate/innumerate, history of alcohol/drug misuse, terminal/serious illness, severe mental illness, and unable to provide informed consent or otherwise unsuitable for the trial

Interventions Intervention: MEDICINE MANAGEMENT SERVICE (MEDMAN)

The intervention was a comprehensive, community pharmacy-led medicines management called MEDMAN. This intervention comprised of an initial consultation with a community pharmacist to review the appropriateness of therapy, compliance, lifestyle, social, and support issues. Further consultations were provided according to pharmacist-determined patient need. Recommendations were recorded on a referral form which was sent to the GP, who returned annotated copies to the pharmacists. The intervention lasted 12 months

Control: STANDARD CARE

Control group patients not provided with MEDMAN intervention. Follow-up data were collected at 12 months by audit clerks and postal questionnaire as at baseline. Intervention patients were also asked about their experience of the medicine management service

Outcomes The measures of adherence were self reported compliance. 12 statements about medicine taking were included and summated to derive a self reported compliance score. Data were collected from participants at baseline and at 12 months. Baseline and follow-up data were collected by audit clerks and postal questionnaire

The patient outcomes were health status, 5-year risk of cardiovascular death, and patient satisfaction. Health status was assessed using SF-3619 Euro-Quality of Life questionnaire. 5-year risk of cardiovascular death was assessed based on an existing score modified to allow for the absence of data on history of stroke and creatinine concentration. The final satisfaction score included experience of and satisfaction with the community pharmacy service and was assessed by measuring response to 15 positive and negative statements regarding their most recent pharmacy visit. Possible responses ranged from 5 to 1 for strongly agree to strongly disagree for positive statements and from 1 to 5 for negative statements, summated to give an overall satisfaction score. Data were collected at baseline and 12 months by audit clerks and research assistants who were blinded

Notes -

\section{Risk of bias}

Bias Authors' judgement Support for judgement


Bond 2007 (Continued)

Random sequence genera- Low risk tion (selection bias)

Allocation concealment Unclear risk

(selection bias)
"Patients were randomized in a ratio of 2:1, intervention to control group. This was done independently of the research team using a password protected computer programme in permuted blocks stratified by practice." (pg 190)

Selective reporting (re- Unclear risk None detected but protocol not available porting bias)

Insufficient information provided - (pg 190) Community pharmacists were given an indicative allocation of 20 patients. If more than 20 patients chose 1 pharmacy, the pharmacist could choose to go 'over quota', or refuse the patient who was asked to choose another pharmacy, or was excluded (designated over quota in Figure 1)

\begin{tabular}{lll}
\hline Other bias & Unclear risk & Insufficient information provided \\
\hline $\begin{array}{ll}\text { Blinding of outcome as- } \\
\text { sessment (detection bias) }\end{array}$ & Low risk & (PRIMARY) SELF REPORT - QUESTIONNAIRE - "Audit clerks performing data ex- \\
Adherence measure & & $\begin{array}{l}\text { traction were blind to the randomization status of participants, as were the re- } \\
\text { searchers conducting the statistical analyses." (pg 193) }\end{array}$
\end{tabular}

\begin{tabular}{|c|c|c|}
\hline $\begin{array}{l}\text { Blinding of outcome as- } \\
\text { sessment (detection bias) } \\
\text { Patient outcome }\end{array}$ & Low risk & $\begin{array}{l}\text { (PRIMARY) HEALTH STATUS - "Audit clerks performing data extraction were } \\
\text { blind to the randomization status of participants, as were the researchers con- } \\
\text { ducting the statistical analyses." (pg 192) }\end{array}$ \\
\hline
\end{tabular}

\begin{tabular}{|c|c|c|}
\hline $\begin{array}{l}\text { Blinding of participants } \\
\text { (performance bias) }\end{array}$ & High risk & $\begin{array}{l}\text { (PRIMARY) SELF REPORT - QUESTIONNAIRE (pg 192) "Patients could not be } \\
\text { blind to trial intervention because of its nature." }\end{array}$ \\
\hline
\end{tabular}

Adherence measure blind to trial intervention because of its nature."

\begin{tabular}{ll}
\hline $\begin{array}{l}\text { Blinding of participants } \\
\text { (performance bias) }\end{array}$ & High risk \\
Patient outcome & $\begin{array}{l}\text { (PRIMARY) HEALTH STATUS - "Patients could not be blind to trial intervention } \\
\text { because of its nature." (pg 193) }\end{array}$
\end{tabular}

\section{Blinding of personnel (per- Low risk} formance bias)

(PRIMARY) SELF REPORT - QUESTIONNAIRE - Except participants, communiAdherence measure ty pharmacists, audit clerks performing data extraction, and researchers conducting the statistical analyses were blinded. "Community pharmacists were not informed which control patients had nominated their pharmacy. Audit clerks performing data extraction were blind to the randomization status of participants, as were the researchers conducting the statistical analyses." (pg 190)

$\begin{array}{ll}\begin{array}{l}\text { Blinding of personnel (per- } \\ \text { formance bias) }\end{array} & \text { (PRIMARY) HEALTH STATUS - Except participants, community pharmacists, au- } \\ \text { Patient outcome } & \text { dit clerks performing data extraction, and researchers conducting the statisti- } \\ & \text { cal analyses were blinded. "Community pharmacists were not informed which } \\ & \text { control patients had nominated their pharmacy. Audit clerks performing data } \\ \text { extraction were blind to the randomization status of participants, as were the } & \text { researchers conducting the statistical analyses." (pg 190) }\end{array}$

\begin{tabular}{lll}
\hline $\begin{array}{l}\text { Incomplete outcome data } \\
\text { (attrition bias) } \\
\text { Adherence measure }\end{array}$ & Unclear risk & $\begin{array}{l}\text { (PRIMARY) SELF REPORT - QUESTIONNAIRE - Missing data not balanced, espe- } \\
\text { cially with regards to withdrawn patients. ITT analysis done, but bias is unclear }\end{array}$ \\
\hline $\begin{array}{l}\text { Incomplete outcome data } \\
\begin{array}{l}\text { (attrition bias) } \\
\text { Patient outcome }\end{array}\end{array}$ & $\begin{array}{l}\text { Unclear risk } \\
\text { (PRIMARY) HEALTH STATUS - Missing data not balanced, especially with re- } \\
\text { gards to withdrawn patients. ITT analysis done, but the potential for bias is un- } \\
\text { clear }\end{array}$ \\
\hline
\end{tabular}


Bonner 2009

\begin{tabular}{ll}
\hline Methods & Randomized controlled trial \\
\hline Participants & The study location was not stated \\
56 participants were randomized to the intervention group and 63 participants were randomized to the \\
control group \\
$\begin{array}{l}\text { The inclusion criteria were pediatric patients who had been treated for asthma in either the general pe- } \\
\text { diatric practice or the pulmonary clinic of a university hospital during the previous } 12 \text { months }\end{array}$
\end{tabular}

Interventions Intervention: INDIVIDUALIZED ASTHMA MANAGEMENT INTERVENTION

Families in the intervention group received asthma education by a trained Family Co-ordinator who also provided individualized support in helping caregivers monitor their children's asthma using diaries. The Family Co-ordinator helped caregivers interpret the diaries and communicate the contents to their doctors. 3 group education workshops were held at 1-month intervals that followed the asthma self regulation model. Families were trained to use the diaries and peak flow meters. Family Co-ordinators regularly called families to discuss their diary records. The second workshop used patients' diary records as illustrations of the relative effectiveness of controller medicines over rescue/quick-relief drugs in preventing asthma symptoms over time. Participants reviewed their own records of medicines and symptoms. The third workshop described asthma management as a 2-pronged effort of pharmacotherapy and trigger control. Between the first and second workshops, the Family Co-ordinator prepared families for their doctor visit. The Family Co-ordinator accompanied families to the doctor visit where he intervened if the family failed to communicate a thorough asthma history. The children in the intervention group were tested for allergies by an attending allergist at the hospital if they had not recently been tested by their own physician. Family Co-ordinator conducted a home environment assessment and suggested strategies for reducing asthma triggers

Control: USUAL CARE

Control patients $(n=63)$ received usual medical care at private or hospital-affiliated community pediatric practice

Outcomes

The measures of adherence were family's adherence to frequency and dosage of prescribed medication and prophylactic bronchodilator use measured at 3 months in face-to-face at-home interviews by the trained Family Co-ordinator

The patient outcomes were self reported symptom persistence and activity restriction as reported in a diary by the caregiver

\begin{tabular}{lll}
\hline Notes & - & \\
\hline Risk of bias & Authors' judgement & Support for judgement \\
\hline Bias & Unclear risk & $\begin{array}{l}\text { Sequence generation not described. (pg 169) "After the baseline interview, } \\
\text { families were randomly assigned to control or intervention conditions." }\end{array}$ \\
\hline $\begin{array}{l}\text { Random sequence genera- } \\
\text { tion (selection bias) }\end{array}$ & Unclear risk & $\begin{array}{l}\text { Allocation concealment not described. (pg 169) "After the baseline interview, } \\
\text { families were randomly assigned to control or intervention conditions." }\end{array}$ \\
\hline $\begin{array}{l}\text { Allocation concealment } \\
\text { (selection bias) }\end{array}$ & $\begin{array}{l}\text { None detected; protocol not available } \\
\text { Selective reporting (re- } \\
\text { porting bias) }\end{array}$ & $\begin{array}{l}\text { Unclear risk } \\
\text { Other bias }\end{array}$ \\
\hline $\begin{array}{l}\text { The authors note (pg 177) "A limitation of this study was that a single Family } \\
\text { Coordinator delivered the intervention. This precluded any measurement of } \\
\text { the Family Coordinator's personal characteristics that may have contributed } \\
\text { to patients' skill development. Only } 28 \% \text { of the patients who were originally } \\
\text { contacted finally consented to participate in the study, which precludes gener- } \\
\text { alization to the entire population of urban clinic patients. Another limitation is } \\
\text { that an intervention period of three months was insufficient to measure how }\end{array}$
\end{tabular}


lasting were the gains in patient behavior or how robust was relationship between patient and physician. Another limitation of the study is that reliance on self reported data without confirmation by objective measures may overestimate the impact of the intervention because of participants' response bias towards success." However, it is not clear what impact these limitations would have had on this study

\begin{tabular}{|c|c|c|}
\hline $\begin{array}{l}\text { Blinding of outcome as- } \\
\text { sessment (detection bias) } \\
\text { Adherence measure }\end{array}$ & Unclear risk & (PRIMARY) FAMILY'S SELF REPORTED ADHERENCE - No blinding mentioned \\
\hline $\begin{array}{l}\text { Blinding of outcome as- } \\
\text { sessment (detection bias) }\end{array}$ & Unclear risk & $\begin{array}{l}\text { (PRIMARY) SELF EFFICACY FOR MANAGING ASTHMA - Insufficient information } \\
\text { regarding blinding of the research assistant }\end{array}$ \\
\hline
\end{tabular}

(PRIMARY) SELF EFFICACY FOR MANAGING ASTHMA - Insufficient information
(PRIMARY) FAMILY'S SELF REPORTED ADHERENCE - Patients likely to be aware of the intervention due to it's nature

(performance bias)

Adherence measure

Blinding of participants High risk

(performance bias)

Patient outcome

(PRIMARY) SELF EFFICACY FOR MANAGING ASTHMA - Patients likely to be aware of the intervention due to it's nature

Blinding of personnel (per- Unclear risk formance bias)

Adherence measure

(PRIMARY) FAMILY'S SELF REPORTED ADHERENCE - Blinding of other personnel to study group not mentioned

Blinding of personnel (per- Unclear risk formance bias)

Patient outcome

(PRIMARY) SELF EFFICACY FOR MANAGING ASTHMA - Insufficient information about blinding

Incomplete outcome data Low risk

(attrition bias)

Adherence measure
(PRIMARY) FAMILY'S SELF REPORTED ADHERENCE - (pg 174) Control: 50/63 (13 families dropped out) Intervention: 50/56 (6 families dropped out). "There were no significant differences between the dropout rates in the two groups (i.e., 13 control families and 6 intervention families). Nor was there a significant demographic difference at baseline between those who did or did not drop out of either the control group, $F(3,59)=1.57$, n.s., or the intervention group, $F(3,52)=0.05$, n.s. Finally, there was no significant difference at baseline in the health outcome measures between those who did or did not drop out of either the control group, $F(10,52)=0.57$, n.s., or the intervention group, $\mathrm{F}(10,45)=1.08$, n.s."

(PRIMARY) SELF EFFICACY FOR MANAGING ASTHMA - (pg 174) Control: 50/63 (13 families dropped out) Intervention: 50/56 (6 families dropped out). "There were no significant differences between the dropout rates in the two groups (i.e., 13 control families and 6 intervention families). Nor was there a significant demographic difference at baseline between those who did or did not drop out of either the control group, $F(3,59)=1.57$, n.s., or the intervention group, $F(3,52)=0.05$, n.s. Finally, there was no significant difference at baseline in the health outcome measures between those who did or did not drop out of either the control group, $F(10,52)=0.57$, n.s., or the intervention group, $\mathrm{F}(10,45)=1.08$, n.s."

Methods The method of random allocation was not described


Brown 1997a (Continued)

Participants
Patients were men $<$ or $=65$ years of age at high risk for future cardiac events by virtue of: 1 ) an elevated apoprotein $B>$ or $=125 \mathrm{mg} / \mathrm{dl}, 2$ ) at least 1 coronary lesion $>$ or $=50 \%$ stenosis or 2 lesions $>$ or $=30 \%$ stenosis as documented by baseline angiogram, and 3) a family history of premature cardiovascular events

Interventions

Regular niacin (4 times each day) versus polygel controlled release niacin (twice-daily dosage (bid)). All patients received lovastatin $20 \mathrm{mg}$ bid, colestipol $10 \mathrm{~g}$ bid, and niacin $500 \mathrm{mg} 4$ times each day for 12 months, with dosage adjustment to target cholesterol of 150 to $175 \mathrm{mg} / \mathrm{dl}$, and to minimize side effects. At 12 months, patients were randomly assigned to 1) continue with regular niacin at a dose identical to that established during the 12-month dose-finding period, or 2) change to polygel controlled-release niacin at that daily dosage, but given twice rather than 4 times/day. At 20 months, groups 1) and 2) were reversed (cross-over). This regimen continued for 8 more months

Outcomes

Compliance with the recommended (and variable) dosage was calculated for each drug using a computer program that accounted for all drug supplies given, the recommended dosage, and a count of returned medication. It is expressed as a percentage of the dose recommended for the patient at the time

Clinical outcome measurements included plasma very low-density lipoprotein (VLDL), low-density lipoprotein (LDL), and high-density lipoprotein (HDL) cholesterol, triglycerides, apolipoprotein $B$, and asparate aminotransferase measured at baseline and every 4 months. Other laboratory measurements included uric acid, fasting glucose, fasting insulin, creatinine kinase and fibrinogen at entry (before treatment), 6 months, 12 months, 20 months, 28 months, and 6 weeks after stopping the triple-drug regimen

\section{Notes}

$-$

\section{Risk of bias}

\begin{tabular}{lll}
\hline Bias & Authors' judgement & Support for judgement \\
\hline $\begin{array}{l}\text { Random sequence genera- } \\
\text { tion (selection bias) }\end{array}$ & Unclear risk & $\begin{array}{l}\text { No details on randomization provided in article. (pg 112) At 12 months, pa- } \\
\text { tients were randomly assigned to: (1) continue with regular niacin at a dosage } \\
\text { identical to that established in the 12-month dose-finding period, or (2) } \\
\text { change to polygel controlled-release niacin at that daily dosage, but given } \\
\text { twice rather than 4 times/day. At 20 months, groups (1) and (2) were reversed } \\
\text { (cross-over). This regimen continued for 8 more months }\end{array}$ \\
\hline
\end{tabular}

$\begin{array}{ll}\begin{array}{l}\text { Allocation concealment } \\ \text { (selection bias) }\end{array} & \text { Unclear risk } \\ & \text { months, patients were randomly assigned to: (1) continue with regular niacin } \\ & \text { at a dosage identical to that established in the 12-month dose-finding peri- } \\ & \text { od, or (2) change to polygel controlled-release niacin at that daily dosage, but } \\ & \text { given twice rather than } 4 \text { times/day. At } 20 \text { months, groups (1) and (2) were re- } \\ & \text { versed (cross-over). This regimen continued for } 8 \text { more months }\end{array}$

\begin{tabular}{|c|c|c|}
\hline $\begin{array}{l}\text { Selective reporting (re- } \\
\text { porting bias) }\end{array}$ & Unclear risk & No protocol available \\
\hline Other bias & Unclear risk & No apparent bias but unclear \\
\hline $\begin{array}{l}\text { Blinding of outcome as- } \\
\text { sessment (detection bias) } \\
\text { Adherence measure }\end{array}$ & Unclear risk & $\begin{array}{l}\text { (PRIMARY) PILL COUNT - No information given in article about who collected } \\
\text { the data }\end{array}$ \\
\hline $\begin{array}{l}\text { Blinding of outcome as- } \\
\text { sessment (detection bias) } \\
\text { Patient outcome }\end{array}$ & Low risk & $\begin{array}{l}\text { (PRIMARY) LIPID LEVELS - BLOOD TEST - Probably unblinded - trial is open-la- } \\
\text { bel; there is insufficient information, but marked low risk because blood test is } \\
\text { an objective measure not affected by blinding }\end{array}$ \\
\hline
\end{tabular}


Brown 1997a (Continued)

Blinding of participants (performance bias)

Adherence measure
High risk

(PRIMARY) PILL COUNT - Patient would have been aware of their study group; open-label trial

\begin{tabular}{|c|c|c|}
\hline $\begin{array}{l}\text { Blinding of participants } \\
\text { (performance bias) } \\
\text { Patient outcome }\end{array}$ & Low risk & $\begin{array}{l}\text { (PRIMARY) LIPID LEVELS - BLOOD TEST - Laboratory outcomes are unlikely to } \\
\text { be influenced by lack of blinding of participants }\end{array}$ \\
\hline $\begin{array}{l}\text { Blinding of personnel (per- } \\
\text { formance bias) } \\
\text { Adherence measure }\end{array}$ & Unclear risk & $\begin{array}{l}\text { (PRIMARY) PILL COUNT - No information given in the article about general } \\
\text { blinding to study group }\end{array}$ \\
\hline $\begin{array}{l}\text { Blinding of personnel (per- } \\
\text { formance bias) } \\
\text { Patient outcome }\end{array}$ & Low risk & $\begin{array}{l}\text { (PRIMARY) LIPID LEVELS - BLOOD TEST - Probably unblinded - trial is open-la- } \\
\text { bel; there is insufficient information, but marked low risk because blood test is } \\
\text { an objective measure not affected by blinding }\end{array}$ \\
\hline
\end{tabular}

Incomplete outcome data Low risk

(attrition bias)

(PRIMARY) PILL COUNT - Reason for missing data unlikely to be related to the

Adherence measure outcome ( 2 patients left the study because of time constraints)

Incomplete outcome data Low risk

(attrition bias)

(PRIMARY) LIPID LEVELS - BLOOD TEST - Reason for missing data unlikely to be

Patient outcome related to the outcome (2 patients left the study because of time constraints)

\section{Brus 1998}

Methods Patients were allocated at random to experimental $(n=29)$ or control group $(n=31)$. The randomization was carried out block-wise per rheumatologist. No statement concerning concealment of allocation. Outcome assessors were blinded for allocation

Participants

Patients suffering from rheumatoid arthritis (RA), based on ACR criteria, for less than 3 years. Active disease defined by an erythrocyte sedimentation rate (ESR) greater than $28 \mathrm{~mm}$ 1st hour, the presence of 6 or more painful joints, and the presence of 3 or more swollen joints. Disease-modifying anti-rheumatic drug (DMARD) therapy with sulphasalazine had to be indicated by the attending rheumatologist and agreed for by the patients. Patients who had used any DMARD other than hydroxychloroquine were excluded

The experimental group attended 6 patient education meetings. The education program focused on compliance with sulphasalazine therapy, physical exercises, endurance activities (walking, swimming, bicycling), advice on energy conservation, and joint protection. 4 (2-hour) meetings were offered during the first months. Reinforcement meetings were given after 4 and 8 months. The program was implemented in groups and partners were invited to attend the meetings. 1 instructor (HB) provided information on RA, attendant problems, and basic treatment. The related beliefs of the patients were discussed and, when necessary, corrected. If patients anticipated problems with the applications of any of the treatments, these were discussed, including possible solutions. A training was given in proper execution of physical exercise. Patients were encouraged to plan their treatment regimens. Their intentions were discussed and help was given in recasting unrealistic ones. Patients made contracts with themselves regarding their intentions. Feedback on the eventual implementation of therapeutic advice was included in each meeting. The control group received a brochure on RA, as provided by the Dutch League against Rheumatism. This brochure gives comprehensive information on medication, physical, and occupational therapy. Sulphasalazine in the form of $500 \mathrm{mg}$ enteric coated tablets was prescribed to all patients. The daily dose was increased in 4 weeks by steps of 1 tablet, until a daily dose of 4 tablets was reached. In individual cases, this could be increased to 6 tablets a day, reduced as deemed necessary, or stopped in case of inefficacy or toxicity, at the description of the attending rheumatologist. All patients obtained the sulphasalazine tablets from the pharmacists according to the local Health Care System 
Brus 1998 (Continued)

Outcomes Compliance with sulphasalazine therapy was evaluated at 3, 6, and 12 months. Medical records and pharmacy records were the source of data on the number of tablets prescribed and the number of tablets obtained. At each evaluation, the number of remaining tablets were counted. Compliance was defined as the number of tablets that had been taken during the preceding period divided by the number of tablets prescribed. Disease activity was measured by the disease activity score (DAS). This is a function of ESR, Ritchie score (0 to 78), and number of swollen joints (0 to 52). The DAS ranges from 0 to 10 , where 0 represents the lowest level of disease activity possible, and 10 the highest. Physical function was measured by a Dutch version of the M-HAQ. The Dutch-AIMS questionnaire was used to assess physical function, psychological function, pain, and social activities. Compliance rates with prescriptions for physical exercise and with endurance activity regiments (walking, swimming, bicycling) were measured by questionnaire. Compliance with prescriptions for energy conservation was measured by questioning whether patients spread their activities over the day to prevent fatigue. A test for joint protection performance was used as an indication for the level of compliance with the prescription of joint protection. Patients were asked to perform actions, representing relevant ergonomic principles. The test score ranges from 0 to 10, where 0 represents a poor performance and a 10 good performance

Notes -

\section{Risk of bias}

\begin{tabular}{lll}
\hline Bias & Authors' judgement & Support for judgement \\
\hline $\begin{array}{l}\text { Random sequence genera- } \\
\text { tion (selection bias) }\end{array}$ & Unclear risk & $\begin{array}{l}\text { No details provided in the article. (pg 147) Patients were allocated at ran- } \\
\text { dom to the experimental or control group. The randomization was carried out } \\
\text { block-wise per rheumatologist }\end{array}$ \\
\hline
\end{tabular}

\begin{tabular}{|c|c|c|}
\hline $\begin{array}{l}\text { Allocation concealment } \\
\text { (selection bias) }\end{array}$ & Unclear risk & $\begin{array}{l}\text { Allocation concealment not detailed. (pg 147) "randomised, controlled, asses- } \\
\text { sor blinded, clinical trial. It was intended to follow up all patients for one year. } \\
\text { Patients were allocated at random to the experimental or control group. The } \\
\text { randomisation was carried out blockwise per rheumatologist." }\end{array}$ \\
\hline
\end{tabular}

Selective reporting (re- Unclear risk porting bias)

Reasons for missing data unclear. (pg 148) "Sixty five patients were selected. Thirty two were randomised to the experimental condition. Three patients in the experimental group and two in the control group refused informed consent. Sixty patients entered the study: 29 in the experimental condition and 31 in the control. Ten groups of patients received the education programme. Eleven partners attended the meetings. From each group one patient refused the evaluation at six months. Another three patients refused the final evaluation. The results presented here concern the available data on the remaining 25 experimental and 30 control subjects."

Other bias High risk

\begin{abstract}
Inappropriate co-intervention. (pg 148) "Three patients of these 10 received another DMARD together with a low dose prednisone, four another DMARD alone, and three used neither of these. (...) One of these seven patients was using another DMARD in combination with a low dose prednisone, one was using only prednisone, and five were using neither of these." Inclusion/Exclusion criteria were not systematically applied. p.149 "According to the described randomisation procedure the attending rheumatologists selected the patients. Therefore, at inclusion, the data on disease activity as scored by the independent measurement technician, did not always fulfill the selection criteria, but according to the protocol patients were included because they were selected previously."
\end{abstract}

(PRIMARY) PILL COUNT - (pg 147) "Evaluations were made by the same assessor, a measurement technician. He was blinded for the allocation". Blinding was done for assessor who collected data sessment (detection bias)

Adherence measure
Low risk 
Brus 1998 (Continued)

Blinding of outcome as- Low risk (PRIMARY) DISEASE ACTIVITY SCORES - Blinding done for outcome assessor. sessment (detection bias) (pg 147) "Evaluations were made by the same assessor, a measurement techPatient outcome nician. He was blinded for the allocation."

\begin{tabular}{lll}
$\begin{array}{l}\text { Blinding of participants } \\
\text { (performance bias) } \\
\text { Adherence measure }\end{array}$ & High risk & $\begin{array}{l}\text { (PRIMARY) PILL COUNT - No blinding and could have influenced pill count over } \\
\text { long periods of time (3, 6, 12 months) }\end{array}$ \\
\hline $\begin{array}{l}\text { Blinding of participants } \\
\text { (performance bias) }\end{array}$ & High risk & (PRIMARY) DISEASE ACTIVITY SCORES - No blinding of patient \\
\hline
\end{tabular}

\begin{tabular}{|c|c|c|}
\hline $\begin{array}{l}\text { Blinding of personnel (per- } \\
\text { formance bias) } \\
\text { Adherence measure }\end{array}$ & Unclear risk & $\begin{array}{l}\text { (PRIMARY) PILL COUNT - No information on whether the rest of the study group } \\
\text { was blinded }\end{array}$ \\
\hline
\end{tabular}

Blinding of personnel (per- Unclear risk

(PRIMARY) DISEASE ACTIVITY SCORES - No information provided

formance bias)

Patient outcome

\begin{tabular}{|c|c|c|}
\hline $\begin{array}{l}\text { Incomplete outcome data } \\
\text { (attrition bias) } \\
\text { Adherence measure }\end{array}$ & Unclear risk & $\begin{array}{l}\text { (PRIMARY) PILL COUNT - see 1.5. Uneven attrition, with more dropouts in the } \\
\text { intervention group, among a small numbers, but insufficient information pro- } \\
\text { vided to make a judgment }\end{array}$ \\
\hline
\end{tabular}

\begin{tabular}{|c|c|c|}
\hline $\begin{array}{l}\text { Incomplete outcome data } \\
\text { (attrition bias) }\end{array}$ & Unclear risk & $\begin{array}{l}\text { (PRIMARY) DISEASE ACTIVITY SCORES - Balanced loss to follow-up but reasons } \\
\text { for loss to follow-up not clear }\end{array}$ \\
\hline
\end{tabular}

Patient outcome

Bruzzese 2011

\begin{tabular}{ll}
\hline Methods & Randomized controlled trial \\
\hline Participants & The study location was 5 high schools in New York City, New York, USA \\
& 175 participants were randomized to the intervention group and 170 participants were randomized to \\
the control group & \\
The inclusion criteria were 9th or 10th graders with diagnosed moderate to severe persistent asthma \\
(defined by NHLBI guidelines) and taking prescribed asthma medication in the past 12 months \\
Intervention: ASTHMA SELF MANAGEMENT FOR ADOLESCENTS (ASMA) \\
Students in the ASMA group receive an 8-week intensive program. The intervention consists of 345 - to \\
60-minute group sessions, and individual tailored coaching sessions held at least once per week for 5 \\
weeks. Sessions were delivered by trained health educators during the school day. In addition to teach- \\
ing asthma management skills and ways to cope with asthma, the health educators encouraged stu- \\
dents to see their medical provider for a clinical evaluation and treatment. The individual sessions rein- \\
forced the educational messages taught in the group, helped students identify and overcome barriers \\
to managing their asthma, and coached students regarding their medical visits. The health educator of- \\
fered to accompany the student to the medical visit to provide moral support, coaching, or advocacy \\
when coaching failed. Medical providers received a presentation by experts in person or by telephone \\
about a recommended change in therapy. The medical providers were first mailed a packet containing: \\
a letter informing them that one of their patients was in the study and would be referred to him/her for \\
a clinical evaluation; a blank asthma checklist the students complete throughout the intervention and \\
bring to the visit with the provider; and a blank asthma action plan the provider is asked to complete. \\
Within 2 weeks, a pediatric pulmonologist or adolescent medicine specialist called the students' med- \\
ical providers to discuss the concepts presented in the program and to answer any questions regarding \\
NHLBI Institute criteria for treating asthma
\end{tabular}


Bruzzese 2011 (Continued)

Control: WAIT LIST CONTROL

The control group were kept on wait list until the completion of 12-month interviews and then received the ASMA intervention

Outcomes

The measures of adherence were use of asthma controller medication at 6 and 12 months measured by trained staff

The patient outcomes were self reported quality of life, asthma symptom days in prior 2 weeks, night awakening in prior 2 weeks, days with activity restriction in the prior 2 weeks, school absences in prior 2 weeks and urgent healthcare usage. All the outcomes were self reported except for school absences where data were obtained from the school board. Outcome evaluations were done at 6 and 12 months by blinded interviewers

Notes -

\section{Risk of bias}

Bias Authors' judgement Support for judgement

Random sequence genera- Low risk tion (selection bias)

(pg 1000) "On completion of baseline surveys, students were randomized to ASMA or a wait-list control group. Within each school, we stratified students by asthma severity (moderate vs. severe persistent asthma). Within each stratum, we randomized students to control or intervention using computerized randomization lists generated in advance by the data manager who concealed them until randomization."

$\begin{array}{ll}\begin{array}{l}\text { Allocation concealment } \\ \text { (selection bias) }\end{array} & \text { Unclear risk }\end{array} \quad \begin{aligned} & \text { Allocation is unclear. (pg 1000) "...we randomized students to control or inter- } \\ & \text { vention using computerized randomization lists generated in advance by the } \\ & \text { data manager who concealed them until randomization. Interviewers were } \\ & \text { blind to group assignment." }\end{aligned}$

Selective reporting (re- Unclear risk $\quad$ None detected, protocol unavailable
porting bias)

\begin{tabular}{|c|c|c|}
\hline Other bias & Unclear risk & $\begin{array}{l}\text { Author's note: possibility of contamination of sample; control students from } \\
\text { same schools. (pg 1004) "The study has several limitations. We relied primari- } \\
\text { ly on self reported data and did not corroborate self report data with objective } \\
\text { data. Therefore, the potential self report bias found in our school attendance } \\
\text { data may also be present in our other outcome data. Similarly, our case de- } \\
\text { tection was by self report and thus has the potential for misclassification bias. } \\
\text { Because we targeted those with moderate and severe persistent asthma, the } \\
\text { chance of enrolling a student who did not have asthma was low. However, we } \\
\text { may have had false-negatives, missing students in need. Although recruitment } \\
\text { of eligible students exceeded that in other asthma trials with urban adoles- } \\
\text { cents (15), just less than } 40 \% \text { of eligible youth were not enrolled; this limits the } \\
\text { extrapolation of study results to a larger population of urban, minority high } \\
\text { school students with moderate to severe persistent asthma. We are also un- } \\
\text { able to extrapolate study results to other populations of high school students } \\
\text { with asthma (e.g., white suburban adolescents with mild asthma) because we } \\
\text { limited enrollment to minority youth with moderate to severe persistent asth- } \\
\text { ma. The control group was a wait-list control group who received no attention. } \\
\text { Although unlikely, it is possible that treatment benefits of ASMA were due to } \\
\text { "nonspecific therapeutic factors", including the effects of attention and posi- } \\
\text { tive regard received by those in the intervention condition. At the same time, } \\
\text { treatment differences may have been mitigated (1) if the consent process and/ } \\
\text { or surveys fostered attention to treating asthma in the control students; ( } 2 \text { ) if } \\
\text { participants received interim treatments from other sources, which we did not } \\
\text { assess; and/or (3) if there was contamination of control subjects by the treated } \\
\text { adolescents. However, we had sufficient power to control for contamination, } \\
\text { and our informal interviews with control subjects regarding their contact with }\end{array}$ \\
\hline
\end{tabular}


other students in the program suggest that such contamination did not occur. Although cigarette use is prevalent among adolescents, and smoke is an asthma trigger, we did not assess the impact of smoking behavior nor exposure to second hand smoke."

\begin{tabular}{|c|c|c|}
\hline $\begin{array}{l}\text { Blinding of outcome as- } \\
\text { sessment (detection bias) }\end{array}$ & Low risk & $\begin{array}{l}\text { (PRIMARY) USE OF CONTROLLER MEDICATION - (pg 1000) "Interviewers were } \\
\text { blind to group assignment." }\end{array}$ \\
\hline
\end{tabular}

Adherence measure

(PRIMARY) SYMPTOM DAYS - (pg 1000) "Interviewers were blind to group assignment." sessment (detection bias)

Patient outcome

\begin{tabular}{|c|c|c|}
\hline $\begin{array}{l}\text { Blinding of outcome as- } \\
\text { sessment (detection bias) } \\
\text { Patient outcome }\end{array}$ & Low risk & $\begin{array}{l}\text { (PRIMARY) QUALITY OF LIFE - (pg 1000) "Interviewers were blind to group as- } \\
\text { signment." }\end{array}$ \\
\hline
\end{tabular}

\begin{tabular}{|c|c|c|}
\hline $\begin{array}{l}\text { Blinding of participants } \\
\text { (performance bias) } \\
\text { Adherence measure }\end{array}$ & High risk & $\begin{array}{l}\text { (PRIMARY) USE OF CONTROLLER MEDICATION - Patients highly likely to know } \\
\text { group allocation because of the nature of the intervention }\end{array}$ \\
\hline
\end{tabular}

\begin{tabular}{|c|c|c|}
\hline $\begin{array}{l}\text { Blinding of participants } \\
\text { (performance bias) }\end{array}$ & High risk & $\begin{array}{l}\text { (PRIMARY) SYMPTOM DAYS - Patients likely to be non-blinded due to the nature } \\
\text { of intervention; subjective outcome }\end{array}$ \\
\hline
\end{tabular}

\begin{tabular}{ll}
\hline $\begin{array}{l}\text { Blinding of personnel (per- } \\
\text { formance bias) }\end{array}$ & Low risk \\
$\begin{array}{l}\text { Adherence measure } \\
\text { personnel were blind. The project director was not. However, the PI and statis- } \\
\text { tician were blind, as were the senior advisors }\end{array}$
\end{tabular}

$\begin{array}{ll}\begin{array}{l}\text { Blinding of personnel (per- } \\ \text { formance bias) }\end{array} & \text { Low risk } \\ \begin{array}{l}\text { Patient outcome } \\ \text { Staff were also blind }\end{array}\end{array}$

\begin{tabular}{|c|c|c|}
\hline $\begin{array}{l}\text { Blinding of personnel (per- } \\
\text { formance bias) } \\
\text { Patient outcome }\end{array}$ & Low risk & $\begin{array}{l}\text { (PRIMARY) QUALITY OF LIFE - interviewers blinded. Author's note: other study } \\
\text { staff were also blind }\end{array}$ \\
\hline $\begin{array}{l}\text { Incomplete outcome data } \\
\text { (attrition bias) } \\
\text { Adherence measure }\end{array}$ & Low risk & $\begin{array}{l}\text { (PRIMARY) USE OF CONTROLLER MEDICATION - (pg 1001) "Attrition, which was } \\
\text { primarily attributable to truancy or no longer being enrolled in the school, did } \\
\text { not differ by group assignment at any follow-up time point (P=0.26-0.99); 12- } \\
\text { month retention was } 81 \% \text { (Figure } 1 \text { )." }\end{array}$ \\
\hline $\begin{array}{l}\text { Incomplete outcome data } \\
\text { (attrition bias) } \\
\text { Patient outcome }\end{array}$ & Low risk & $\begin{array}{l}\text { (PRIMARY) QUALITY OF LIFE - (pg 1001) "Attrition, which was primarily attrib- } \\
\text { utable to truancy or no longer being enrolled in the school, did not differ by } \\
\text { group assignment at any follow-up time point ( } \mathrm{P}=0.26-0.99) ; 12 \text {-month reten- } \\
\text { tion was } 81 \% \text {." }\end{array}$ \\
\hline $\begin{array}{l}\text { Incomplete outcome data } \\
\text { (attrition bias) } \\
\text { Patient outcome }\end{array}$ & Low risk & $\begin{array}{l}\text { (PRIMARY) SYMPTOM DAYS - (pg 1001) "Attrition, which was primarily attrib- } \\
\text { utable to truancy or no longer being enrolled in the school, did not differ by } \\
\text { group assignment at any follow-up time point ( } \mathrm{P}=0.26-0.99) ; 12 \text {-month reten- } \\
\text { tion was } 81 \% . "\end{array}$ \\
\hline
\end{tabular}


Burgess 2007

\begin{tabular}{|c|c|}
\hline Methods & Randomized controlled trial \\
\hline \multirow[t]{3}{*}{ Participants } & The study location was Australia \\
\hline & $\begin{array}{l}26 \text { participants were randomized to the intervention group and } 21 \text { participants were randomized to the } \\
\text { control group }\end{array}$ \\
\hline & $\begin{array}{l}\text { The inclusion criteria were children diagnosed with asthma, aged } 18 \text { months to } 7 \text { years, taking preven- } \\
\text { tive asthma medication on a daily basis }\end{array}$ \\
\hline \multirow[t]{4}{*}{ Interventions } & Intervention: FUNHALER \\
\hline & $\begin{array}{l}\text { Patients received a Funhaler for their daily asthma medication. The Funhaler (FH) is a small-volume } \\
\text { spacer that incorporates an incentive toy (spinning disk and whistle) that is driven by the child's ex- } \\
\text { pired breath }\end{array}$ \\
\hline & Control: CONTROL SPACER \\
\hline & Patients received a standard spacer for administering asthma medication \\
\hline \multirow[t]{2}{*}{ Outcomes } & $\begin{array}{l}\text { The measures of adherence were collected using a Smartinhaler. Adherence was evaluated as a per- } \\
\text { centage of prescribed doses registered by the Smartinhaler either between midnight and midday or be- } \\
\text { tween midday and midnight for morning and evening doses, respectively, or at any time during the day } \\
\text { for once daily dosing.The child was provided with preventive medication loaded into a Smartinhaler. } \\
\text { The parent was informed that the Smartinhaler would "count" the number of doses dispensed but that } \\
\text { the data would remain confidential. The subjects were reviewed every } 4 \text { weeks for } 3 \text { months. During } \\
\text { each review the parent was provided with a clean spacer and Smartinhaler containing a new canister of } \\
\text { medication }\end{array}$ \\
\hline & $\begin{array}{l}\text { The patient outcome was exacerbation of asthma. The subjects were reviewed every } 4 \text { weeks for } 3 \\
\text { months. During each review the parent completed a symptom questionnaire. An exacerbation of asth- } \\
\text { ma was defined as the child having received a course of prednisolone either initiated by the parent in } \\
\text { response to an escalation of symptoms requiring regular reliever medication more than } 4 \text { th hourly for } \\
24 \text { hours as per their asthma management plan or prescription of prednisolone by the child's primary } \\
\text { care physician }\end{array}$ \\
\hline
\end{tabular}

\section{Notes}

\section{Risk of bias}

\begin{tabular}{lll}
\hline Bias & Authors' judgement & Support for judgement \\
\hline $\begin{array}{ll}\text { Random sequence genera- } \\
\text { tion (selection bias) }\end{array}$ & Low risk & $\begin{array}{l}\text { (pg 737) "All subjects were then randomized to either the FH or a control spac- } \\
\text { er (Aerochamber Plus; ACP; Trudell Medical International, London, Canada) us- } \\
\text { ing a minimization computer program (Minim) with equal weighting for age, } \\
\text { sex and level of maternal education." }\end{array}$
\end{tabular}

Allocation concealment Unclear risk

No information about allocation concealment is given in the paper. "All sub(selection bias) jects were then randomized to either the $\mathrm{FH}$ or a control spacer (Aerochamber Plus; ACP; Trudell Medical International, London, Canada) using a minimization computer program (Minim) with equal weighting for age, sex and level of maternal education." (pg 737)

\begin{tabular}{lll}
\hline $\begin{array}{l}\text { Selective reporting (re- } \\
\text { porting bias) }\end{array}$ & Low risk & $\begin{array}{l}\text { The study protocol is not available but it is clear that the published reports in- } \\
\text { clude all expected outcomes, including those that were pre-specified }\end{array}$ \\
\hline Other bias & Low risk & None noted \\
\hline $\begin{array}{l}\text { Blinding of outcome as- } \\
\text { sessment (detection bias) } \\
\begin{array}{l}\text { Adherence measure } \\
\hline\end{array}\end{array}$ & Low risk & (PRIMARY) SMARTINHALER - Objective measure, unlikely to be biased \\
\hline
\end{tabular}


Burgess 2007 (Continued)

Blinding of outcome as- Unclear risk $\quad$ (PRIMARY) ASTHMA EXACERBATION - No mention of blinding of staff sessment (detection bias)

Patient outcome

\begin{tabular}{lll}
\hline $\begin{array}{l}\text { Blinding of participants } \\
\text { (performance bias) } \\
\text { Adherence measure }\end{array}$ & High risk & (PRIMARY) SMARTINHALER - Unlikely that patients/parents were blind \\
\hline $\begin{array}{l}\text { Blinding of participants } \\
\text { (performance bias) }\end{array}$ & Unclear risk & $\begin{array}{l}\text { (PRIMARY) ASTHMA EXACERBATION - self report questionnaire, parents could } \\
\text { Patient outcome }\end{array}$
\end{tabular}

Blinding of personnel (per- Low risk

(PRIMARY) SMARTINHALER - Objective measure, unlikely to be biased

formance bias)

Adherence measure

Blinding of personnel (per- Unclear risk

(PRIMARY) ASTHMA EXACERBATION - No mention of blinding of key personnel

formance bias)

Patient outcome

\begin{tabular}{ll}
\hline $\begin{array}{l}\text { Incomplete outcome data } \\
\text { (attrition bias) }\end{array}$ & Low risk \\
Adherence measure & $\begin{array}{l}\text { (PRIMARY) SMARTINHALER - Few missing data; does not appear likely to be bi- } \\
\text { ased }\end{array}$
\end{tabular}

$\begin{array}{ll}\begin{array}{l}\text { Incomplete outcome data } \\ \text { (attrition bias) }\end{array} & \text { Low risk } \\ \text { Patient outcome } & \text { (PRIMARY) ASTHMA EXACERBATION - Limited dropouts, balanced across the } \\ \end{array}$

Patient outcome

Chamorro 2011

\begin{tabular}{ll}
\hline Methods & Randomized controlled trial \\
\hline Participants & The study location was in 9 community pharmacies of Granada, Spain \\
& 44 participants were randomized to the intervention group and 41 participants were randomized to the \\
control group & \\
& The inclusion criteria were patient presenting to the pharmacy to file a prescription in their name for \\
one or more of antihypertensives, anti-dyslipidemia, cardiovascular prevention, antidiabetics at mod- \\
erate or high CV risk \\
The exclusion criteria were BP > 180/110, history of MI within 3 months, on cardiac rehabilitation, ter- \\
minally ill, low CV risk, refusing consent. They were excluded if their physician prescriber did not see fit \\
to include them in the pharmacotherapy follow-up
\end{tabular}

Interventions Intervention: PHARMACOTHERAPY FOLLOW-UP

The intervention consisted of follow-up of the patients by the pharmacist. He gave written and oral information about cardiovascular prevention and adherence to the patients in the first interview. The pharmacist adopted a pharmacotherapy follow-up program, for 4 visits over 16 to 18 weeks. The final assessment was at 32 weeks

Control: EDUCATION

This procedure consisted of health education, written and oral material all given in 1 session at enrollment

Outcomes

The measure of adherence was the Morisky-Green-Levine (MGL) test. A patient was considered adherent when they answered all questions correctly. Adherence was measured at baseline, 16 weeks, and 
Chamorro 2011 (Continued)

32 weeks in the control group and the intervention group by a pharmacist. Adherence in each group was calculated in terms of the percentage of patients who were achievers with the therapy

The patient outcomes were blood pressure and cholesterol level. Blood pressure was considered to have achieved the therapeutic goal when values were under $140 / 90 \mathrm{~mm} \mathrm{Hg}$, or under $130 / 80 \mathrm{~mm} \mathrm{Hg}$ in patients with diabetes, renal failure and acute myocardial infarction. Cholesterol levels were considered to have achieved the therapeutic goal in primary prevention when values were under $200 \mathrm{mg} /$ $\mathrm{dl}$ and in secondary prevention under $175 \mathrm{mg} / \mathrm{dl}$. The measures were made for control group at baseline, 16 weeks, and 32 weeks. The intervention group was assessed at the baseline, 2 to 4 weeks, 6 to 8 weeks, 16 to 18 weeks, and 32 weeks. They were made by the same pharmacist

Notes

\title{
Risk of bias
}

\begin{tabular}{lll}
\hline Bias & Authors' judgement & Support for judgement \\
\hline $\begin{array}{l}\text { Random sequence genera- } \\
\text { tion (selection bias) }\end{array}$ & Unclear risk & Insufficient information provided about the sequence generation process \\
\hline $\begin{array}{l}\text { Allocation concealment } \\
\text { (selection bias) }\end{array}$ & Low risk & Centralized randomization \\
\hline $\begin{array}{l}\text { Selective reporting (re- } \\
\text { porting bias) }\end{array}$ & Unclear risk & Protocol not available \\
\hline Other bias & Unclear risk & $\begin{array}{l}\text { The information in the article was insufficient to determine if there were other } \\
\text { types of bias }\end{array}$ \\
\hline
\end{tabular}

Blinding of outcome as- Unclear risk (PRIMARY) SELF REPORT - QUESTIONNAIRE MGL - Blinding not mentioned; self sessment (detection bias) report

Adherence measure

\begin{tabular}{|c|c|c|}
\hline $\begin{array}{l}\text { Blinding of outcome as- } \\
\text { sessment (detection bias) } \\
\text { Patient outcome }\end{array}$ & Unclear risk & (PRIMARY) BLOOD PRESSURE - No blinding statement \\
\hline $\begin{array}{l}\text { Blinding of participants } \\
\text { (performance bias) } \\
\text { Adherence measure }\end{array}$ & High risk & $\begin{array}{l}\text { (PRIMARY) SELF REPORT - QUESTIONNAIRE MGL - self report - subjective mea- } \\
\text { sure - patient not blinded }\end{array}$ \\
\hline $\begin{array}{l}\text { Blinding of participants } \\
\text { (performance bias) } \\
\text { Patient outcome }\end{array}$ & Unclear risk & (PRIMARY) BLOOD PRESSURE - No blinding statement \\
\hline
\end{tabular}

Blinding of personnel (per- Unclear risk formance bias) (PRIMARY) SELF REPORT - QUESTIONNAIRE MGL - Blinding not mentioned; self Adherence measure report

Blinding of personnel (per- Unclear risk

formance bias)

Patient outcome

\author{
Incomplete outcome data Unclear risk (PRIMARY) SELF REPORT - QUESTIONNAIRE MGL - Missing data not reported \\ (attrition bias)
}

Adherence measure

Incomplete outcome data Unclear risk $\quad$ (PRIMARY) BLOOD PRESSURE - Not reported
(attrition bias)


Chamorro 2011 (Continued)

Patient outcome

Chan 2007

\begin{tabular}{ll}
\hline Methods & Randomized controlled trial \\
\hline Participants & The study location was the island of Oahu, Hawaii, USA \\
& 60 participants were randomized to the intervention group and 60 participants were randomized to the \\
control group & \\
The inclusion criteria were children 6 to 17 years of age with persistent asthma, dependents of US mil- \\
itary personnel, not moving from Oahu for 12 months, ability to receive cable modem connections in \\
the home, willing to learn to record and to send inhaler technique and peak flow data 2 times per week, \\
willing to attend asthma education follow-up visits either in person or electronically (virtually) at 2- \\
week, 6-week, 3-month, and 6-month intervals after initiation into the study, willing to complete satis- \\
faction and education surveys at the end of the study period, and willing to sign informed written con- \\
sent forms
\end{tabular}

Interventions Intervention: INTERNET-BASED HOME MONITORING AND EDUCATION

Both groups had 6 visits scheduled at $0,2,6,12,26$, and 52 weeks, with the study pediatrician and 1 of the 4 assigned nurse case managers or the pediatric clinical pharmacist case manager. The intervention group received 3 in-person visits, at 0, 26, and 52 weeks, and the rest as virtual visits. Virtual visits included asthma education, a video recording of peak flow meter and inhaler use forwarded to the Web site, daily asthma diaries, and communication with the case manager electronically via the Web site. Patients were provided a home computer system, camera, and Internet access. On-site in-home instruction was provided by technical experts on equipment use and Web site capabilities and use. Each patient received the same models of computer and computer equipment, as well as broadband Internet access. Patients and their parents were taught how to use the equipment and how to record and to submit videos by using a computer-mounted digital video camera, to capture the patient's peak flow meter and inhaler technique. A detailed asthma symptom diary and quality of life survey were included on the website. Patients and families were instructed regarding the submission of daily symptom diary entries. Videos were recorded and loaded on the site for the case manager, who scored them with standardized checklists and provided instruction through e-mail back to the patient/family. Videos were sent 2 times per week for 6 weeks and then once-weekly thereafter. Moreover, patients received the following same service as the control group: they were contacted (by e-mail) by the case manager 2 times per week for 6 weeks and once per week thereafter, to review the asthma action and home management plans, to assess the symptom diary, to remind the patient to perform and to record peak flow measurements daily in the diary, to remind the patient to complete symptom diary information every day, to answer questions, and to intervene if needed. All patients were able to contact the case manager 24 hours per day, 7 days per week

\section{Control: OFFICE-BASED VISITS}

Patients were treated with an ambulatory asthma clinical pathway, with 6 visits scheduled $0,2,6,12$, 26 , and 52 weeks after enrollment. At each visit, patients and their parents received in-depth asthma education from the case manager, with specific subjects being determined by an asthma educational pathway. Office-based group patients received all of their information in person at the pediatric clinic. Patients were able to contact their case manager by telephone

Outcomes

The measures of adherence were total number of inhalers refilled (assessed by pharmacy refill data fro the entire study duration of 52 weeks), controller inhaler use (assessed by metered dose inhalers) and inhaler videos (to be submitted twice weekly for 6 weeks and once weekly thereafter until 52 weeks). Controller inhaler use was calculated as inhalers per patient - month, inhaler videos were also converted to number per patient-months

The patient outcomes were 1) lung function tests (spirometry performed at intake and study exit at 1 year) 2) peak flow (percentage of personal best), 3) patient and caregiver pediatric asthma quality of life questionnaires (analyzed at intake and study exit at 1 year), 4) utilization of services (emergency department visits, hospitalizations, and unscheduled acute visits because of asthma, from centralized 
Chan 2007 (Continued)

medical chart database and case manager records), 5) rescue therapy use (beta-receptor agonist use and refills and use of oral prednisone rescue therapy, from computerized pharmacy records), 6) symptom control (diary symptom score)

\begin{tabular}{ll}
\hline Notes & - \\
\hline Risk of bias &
\end{tabular}

\begin{tabular}{lll}
\hline Bias & Authors' judgement & Support for judgement \\
\hline $\begin{array}{l}\text { Random sequence genera- } \\
\text { tion (selection bias) }\end{array}$ & Low risk & $\begin{array}{l}\text { Explicitly refers to table of random numbers. (pg 570) "Patients underwent } \\
\text { block randomization with a table of random numbers and were enrolled in ei- } \\
\text { ther the "virtual" group (60 subjects) or the office-based group (60 subjects)." }\end{array}$ \\
\hline $\begin{array}{l}\text { Allocation concealment } \\
\text { (selection bias) }\end{array}$ & Unclear risk & No mention of allocation concealment in the article \\
\hline $\begin{array}{l}\text { Selective reporting (re- } \\
\text { porting bias) }\end{array}$ & Unclear risk & $\begin{array}{l}\text { Insufficient information. Many outcomes are reported, but only broad cate- } \\
\text { gories are specified in the methods (pg 570) "to improved outcomes, including } \\
\text { therapeutic and diagnostic adherence and disease control (quality of life, lung } \\
\text { function, utilization of services, rescue therapy, symptom control, patient edu- } \\
\text { cation, and patient satisfaction)" }\end{array}$
\end{tabular}

\begin{tabular}{|c|c|c|}
\hline Other bias & Unclear risk & $\begin{array}{l}\text { The different number of dropouts between intervention and comparison may } \\
\text { lead to bias, but insufficient evidence to judge it. (pg 573) Table 1: } 13 \text { dropouts } \\
\text { in the virtual group versus } 5 \text { in the office-based group }\end{array}$ \\
\hline
\end{tabular}

\begin{tabular}{|c|c|c|}
\hline $\begin{array}{l}\text { Blinding of outcome as- } \\
\text { sessment (detection bias) } \\
\text { Adherence measure }\end{array}$ & Low risk & (PRIMARY) CONTROLLER REFILL - Objective measure \\
\hline $\begin{array}{l}\text { Blinding of outcome as- } \\
\text { sessment (detection bias) } \\
\text { Patient outcome }\end{array}$ & High risk & $\begin{array}{l}\text { (PRIMARY) LUNG FUNCTION TEST - staff and personnel were not blinded to al- } \\
\text { location group and assessment of lung function could have been biased }\end{array}$ \\
\hline $\begin{array}{l}\text { Blinding of participants } \\
\text { (performance bias) } \\
\text { Adherence measure }\end{array}$ & Low risk & $\begin{array}{l}\text { (PRIMARY) CONTROLLER REFILL - Patients are not blinded to the information, } \\
\text { but it is unlikely that this may bias pharmacy refill }\end{array}$ \\
\hline $\begin{array}{l}\text { Blinding of participants } \\
\text { (performance bias) } \\
\text { Patient outcome }\end{array}$ & Low risk & $\begin{array}{l}\text { (PRIMARY) LUNG FUNCTION TEST - Patient not blinded, but unlikely bias of the } \\
\text { assessment of lung function }\end{array}$ \\
\hline
\end{tabular}

Blinding of personnel (per- Low risk

(PRIMARY) CONTROLLER REFILL - Objective measure

formance bias)

Adherence measure

$\begin{array}{ll}\begin{array}{l}\text { Blinding of personnel (per- } \\ \text { formance bias) }\end{array} & \text { High risk } \\ \text { Patient outcome } & \begin{array}{l}\text { (PRIMARY) LUNG FUNCTION TEST - staff and personnel were not blinded to al- } \\ \text { location group and assessment of lung function could have been biased }\end{array}\end{array}$

\begin{tabular}{lll}
\hline $\begin{array}{l}\text { Incomplete outcome data } \\
\text { (attrition bias) } \\
\text { Adherence measure }\end{array}$ & Unclear risk & $\begin{array}{l}\text { (PRIMARY) CONTROLLER REFILL - Number of lost data imbalanced across } \\
\text { groups; not clear how this would have impacted results }\end{array}$ \\
\hline $\begin{array}{l}\text { Incomplete outcome data } \\
\begin{array}{l}\text { (attrition bias) } \\
\text { Patient outcome }\end{array}\end{array}$ & High risk & $\begin{array}{l}\text { (PRIMARY) LUNG FUNCTION TEST - Differential dropout may be associated } \\
\text { with prognosis in lung functions }\end{array}$ \\
\hline
\end{tabular}


Chaplin 1998

Methods

Participants

Patients were randomly assigned to 2 groups of 28 patients each. No statement concerning concealment of randomization living in the community, and receiving antipsychotic medication for at least 6 months. Patients were excluded if they were prescribed clozapine or were hospital in-patients. 60 patients were approached. 56 patients agreed to participate

Interventions

The study group participated in a discussion about the risks and benefits of neuroleptic medications based on individual semi-structured educational sessions with reference to a standardized information sheet modified from Kleinman et al (1989). The patients were asked whether they had heard of tardive dyskinesia (TD). The common movements of TD were modeled and the patients were asked whether they thought they had the condition or had seen others with it. They were informed that they were receiving an antipsychotic drug and were given information about extrapyramidal symptoms and TD, its risk factors, prevalence, treatment, potential irreversibility and the $1 \%$ risk of TD in non-antipsychotic-treated patients. They were told that gradual discontinuation of antipsychotic medication was the best way to prevent the condition but if done abruptly carries a high risk of relapse and of precipitating TD. It was stated that the optimum maintenance treatment, taking into account its risks and benefits, was to use the lowest dose of antipsychotic drug that would keep them well. Most importantly, they were asked not to make any changes to their treatment without discussion with their psychiatrist. Finally, they were given the opportunity to ask questions in an informal interactive session lasting 30 minutes, and were given an information sheet for reference. The control group received usual care

Outcomes

1. Relapse, defined as a period of hospitalization, evidence of clear clinical deterioration in the case notes or in discussion with the keyworker, or evidence of deterioration at follow-up interview. 2. Increase in antipsychotic dose of $>200 \mathrm{mg}$ chlorpromazine equivalents. 3 . If the patient missed more than 2 weeks of their antipsychotic medication they were considered non-compliant

Notes In this study, the intent was not to increase compliance, rather to test whether information about benefits and adverse effects of the treatment would decrease compliance

\section{Risk of bias}

\begin{tabular}{lll}
\hline Bias & Authors' judgement & Support for judgement \\
\hline $\begin{array}{l}\text { Random sequence genera- } \\
\text { tion (selection bias) }\end{array}$ & Unclear risk & $\begin{array}{l}\text { Random number sequence generation not described. (pg 79) "Those who } \\
\text { agreed to be interviewed were randomly assigned to two groups, each of 28 } \\
\text { patients." }\end{array}$ \\
\hline $\begin{array}{l}\text { Allocation concealment } \\
\text { (selection bias) }\end{array}$ & Unclear risk & Allocation not described \\
\hline $\begin{array}{l}\text { Selective reporting (re- } \\
\text { porting bias) }\end{array}$ & Unclear risk & No protocol available \\
\hline Other bias & High risk & $\begin{array}{l}\text { Authors note in discussion that control participants might have inquired and } \\
\text { received education. Potential Hawthorne effect noted (pg 3). In the commu- } \\
\text { nity teams and control patients, there was surprisingly little opposition to the } \\
\text { study. All consultant psychiatrists gave agreement for a researcher to recruit } \\
\text { patients but some team members declined permission. It was essential to brief } \\
\text { the teams about the nature of the study and how previous work had shown } \\
\text { good clinical outcome, because key workers or psychiatrists were likely to be } \\
\text { asked by patients or their relatives to explain about tardive dyskinesia. The } \\
\text { modest gain in knowledge by the control patients could have resulted from } \\
\text { the community teams' awareness of the study (the Hawthorne effect) or en- } \\
\text { quiry about tardive dyskinesia after exposure to the questionnaire }\end{array}$
\end{tabular}


Chaplin 1998 (Continued)

Blinding of outcome as- High risk (PRIMARY) SELF REPORT - INTERVIEW - (pg 80) "The researcher was not blind sessment (detection bias) to the study and control groups."

Adherence measure

\begin{tabular}{|c|c|c|}
\hline $\begin{array}{l}\text { Blinding of outcome as- } \\
\text { sessment (detection bias) }\end{array}$ & High risk & $\begin{array}{l}\text { (PRIMARY) RELAPSE - (pg 80) "The researcher was not blind to the study and } \\
\text { control groups." }\end{array}$ \\
\hline
\end{tabular}

Patient outcome

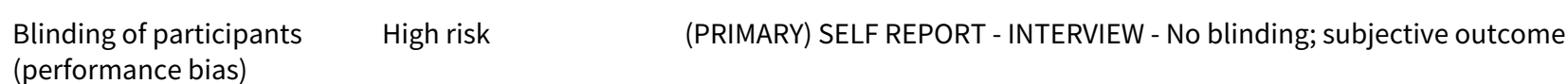

(performance bias)

Adherence measure

\begin{tabular}{ll}
\hline $\begin{array}{l}\text { Blinding of participants } \\
\text { (performance bias) }\end{array}$ & Low risk \\
$\begin{array}{l}\text { Patient outcome } \\
\text { (PRIMARY) RELAPSE - it is unlikely that this measure could be influenced by pa- } \\
\text { tient's knowledge of their group membership }\end{array}$
\end{tabular}

Blinding of personnel (per- High risk (PRIMARY) SELF REPORT - INTERVIEW - (pg 80) "The researcher was not blind formance bias) to the study and control groups."

Adherence measure

\begin{tabular}{|c|c|c|}
\hline $\begin{array}{l}\text { Blinding of personnel (per- } \\
\text { formance bias) }\end{array}$ & High risk & $\begin{array}{l}\text { (PRIMARY) RELAPSE - (pg 80) "The researcher was not blind to the study and } \\
\text { control groups." }\end{array}$ \\
\hline
\end{tabular}

Patient outcome

\begin{tabular}{|c|c|c|}
\hline $\begin{array}{l}\text { Incomplete outcome data } \\
\text { (attrition bias) } \\
\text { Adherence measure }\end{array}$ & Unclear risk & $\begin{array}{l}\text { (PRIMARY) SELF REPORT - INTERVIEW - Insufficient reporting of details regard- } \\
\text { ing missing data }\end{array}$ \\
\hline
\end{tabular}

Adherence measure

Incomplete outcome data Unclear risk (PRIMARY) RELAPSE - Insufficient missing data information

(attrition bias)

Patient outcome

\section{Charles 2007}

\begin{tabular}{ll}
\hline Methods & Randomized controlled trial \\
\hline Participants & The study location was Wellington, New Zealand \\
& 55 participants were randomized to the intervention group and 55 participants were randomized to the \\
control group & The inclusion criteria were age 12 to 65 years with a diagnosis of asthma, required to take regular in- \\
haled corticosteroid (ICS) at a fixed dose, no exacerbation in the previous month or run-in period, not \\
pregnant or lactating, and if of child-bearing potential, using contraception \\
The exclusion criteria were a diagnosis of chronic obstructive pulmonary disease, the use of a long-act- \\
ing beta-agonist, or a history of other clinically significant disease \\
Intervention: AUDIOVISUAL REMINDER \\
The intervention was an audiovisual reminder function (AVRF) attached to the inhaler. When the alarm \\
was switched on, it generated a single beep, which sounded once every 30 seconds for 60 minutes af- \\
ter the predesignated time, which was programmed into the device. The alarm stopped if the MDI was \\
actuated or after 60 minutes if not taken. The device was programmed to emit the alarm at predeter- \\
mined times twice a day. The AVRF also had a colored light, which was green before MDI use, changing \\
to red once the MDI was taken. This function served to remind patients whether they had taken the MDI \\
as scheduled. Follow-up period was 12 weeks
\end{tabular}


Charles 2007 (Continued)

Control: SMARTINHALER

Control participants received the same Smartinhaler as intervention participants, but it did not have the audiovisual reminder device

Outcomes

The measures of adherence were a covert electronic monitor inside the asthma inhaler used by participants during the study. Participants were not aware of the monitor, which recorded each time the inhaler was used. Adherence was calculated based on the percentage of prescribed doses that were taken. Participants were prescribed 2 separate doses each day, taken at least 6 hours apart. A correction was applied to dose dumping (when 10 or more doses were actuated within a 3-hour period).

The patient outcomes were Asthma Control Questionnaire (ACQ) scores and Peak Expiratory Flow (PEF). Measures were taken at clinic visits at weeks $0,6,12,18$, and 24. At the clinic visits, subjects completed the ACQ and had 3 measurements of PEF with the highest value recorded. Subjects were instructed not to take their short-acting beta-agonist for 6 hours before the clinic visits

Notes -

\section{Risk of bias}

\begin{tabular}{lll}
\hline Bias & Authors' judgement & Support for judgement \\
\hline $\begin{array}{ll}\text { Random sequence genera- } \\
\text { tion (selection bias) }\end{array}$ & Low risk & $\begin{array}{l}\text { (pg 813) The randomization was by reference to a computer-generated ran- } \\
\text { dom code concealed from the researcher, who opened an envelope at the } \\
\text { time of randomization. After a 2-week run-in period, subjects were random- } \\
\text { ized to receive } 1 \text { of the 2 fluticasone propionate (FP) treatment regimens for a } \\
\text { 24-week period }\end{array}$ \\
\end{tabular}

\begin{tabular}{ll}
\hline $\begin{array}{l}\text { Allocation concealment } \\
\text { (selection bias) }\end{array}$ & $\begin{array}{l}\text { Does not specify opaque envelopes; description not clear enough to permit } \\
\text { judgment of low risk. The randomization was by reference to a computer-gen- } \\
\text { erated random code concealed from the researcher who opened an envelope } \\
\text { at the time of randomization. After a 2-week run-in period, subjects were ran- } \\
\text { domized to receive } 1 \text { of the } 2 \text { FP treatment regimens for a 24-week period }\end{array}$
\end{tabular}

\begin{tabular}{lll}
\hline $\begin{array}{l}\text { Selective reporting (re- } \\
\text { porting bias) }\end{array}$ & Unclear risk & None detected, protocol not available \\
\hline Other bias & Unclear risk & None noted but insufficient information provided \\
\hline $\begin{array}{l}\text { Blinding of outcome as- } \\
\text { sessment (detection bias) } \\
\begin{array}{l}\text { Adherence measure } \\
\text { L }\end{array}\end{array}$ & Low risk & $\begin{array}{l}\text { (PRIMARY) SMARTINHALER - ELECTRONIC MONITORING - Data are objective; } \\
\text { no indication staff were involved in altering data }\end{array}$ \\
\hline
\end{tabular}

\begin{tabular}{|c|c|c|}
\hline $\begin{array}{l}\text { Blinding of outcome as- } \\
\text { sessment (detection bias) } \\
\text { Patient outcome }\end{array}$ & Low risk & $\begin{array}{l}\text { (PRIMARY) PEAK EXPIRATORY FLOW - The article does not provide information } \\
\text { on the staff who collected the data, but it is an objective measure }\end{array}$ \\
\hline $\begin{array}{l}\text { Blinding of participants } \\
\text { (performance bias) } \\
\text { Adherence measure }\end{array}$ & Low risk & $\begin{array}{l}\text { (PRIMARY) SMARTINHALER - ELECTRONIC MONITORING - Patients were not } \\
\text { aware that adherence was being measured or that the study was about adher- } \\
\text { ence }\end{array}$ \\
\hline $\begin{array}{l}\text { Blinding of participants } \\
\text { (performance bias) } \\
\text { Patient outcome }\end{array}$ & Low risk & $\begin{array}{l}\text { (PRIMARY) PEAK EXPIRATORY FLOW - The patients were not aware of the pur- } \\
\text { pose of the study }\end{array}$ \\
\hline $\begin{array}{l}\text { Blinding of personnel (per- } \\
\text { formance bias) } \\
\text { Adherence measure }\end{array}$ & Low risk & $\begin{array}{l}\text { (PRIMARY) SMARTINHALER - ELECTRONIC MONITORING - Data are objective; } \\
\text { procedures outlined for applying correction factors (i.e. dose dumping) }\end{array}$ \\
\hline
\end{tabular}


Charles 2007 (Continued)

Blinding of personnel (per- Low risk (PRIMARY) PEAK EXPIRATORY FLOW - Objective measure, unlikely to be biased formance bias)

Patient outcome

\begin{tabular}{|c|c|c|}
\hline $\begin{array}{l}\text { Incomplete outcome data } \\
\text { (attrition bias) } \\
\text { Adherence measure }\end{array}$ & Unclear risk & $\begin{array}{l}\text { (PRIMARY) SMARTINHALER - ELECTRONIC MONITORING - Dropouts are rela- } \\
\text { tively balanced across conditions, but there are a significant number of them. } \\
\text { Insufficient information to made a judgment }\end{array}$ \\
\hline
\end{tabular}

Adherence measure

(PRIMARY) PEAK EXPIRATORY FLOW - Not enough information provided to

Incomplete outcome data Unclear risk

(attrition bias)

judge

Patient outcome

Choudhry 2011

\begin{tabular}{ll}
\hline Methods & Randomized controlled trial \\
\hline Participants & The study location was Harford, Connecticut, USA \\
& 2845 participants were randomized to the intervention group and 3010 participants were randomized \\
to the control group & \\
The inclusion criteria were having received both medical and prescription drug benefits through Aet- \\
na, discharged from the hospital with a principal or secondary diagnosis code of International Classifi- \\
cation of Diseases, 9th Revision, Clinical Modification (ICD-9- CM) 410 (except when the fifth digit was 2) \\
and a length of stay of 3 to 180 days \\
The exclusion criteria were enrollment in a health savings account, 65 years of age or older, plan spon- \\
sor has opted out of the study, and receive only medical services or pharmacy coverage but not both \\
through Aetna
\end{tabular}

Interventions

Intervention: FULL PRESCRIPTION COVERAGE

The intervention involved changing the pharmacy benefits of the intervention group patients so that they had no cost sharing for any brand or generic statin, beta-blocker, ACE inhibitor or ARB for every prescription after randomization

Control: USUAL PRESCRIPTION COVERAGE

Control patients received usual prescription-drug coverage

Outcomes

The measures of adherence were medication possession ratios (i.e. the number of days a patient had a supply of each medication class available, divided by the number of days of eligibility for that medication) and proportion of patients with full adherence (defined as a medication possession of $=80 \%$ ). The data were sourced from the medical coverage provider's database

The patient outcomes were "a composite of the first readmission for a major vascular event or coronary revascularization, first major revascular event and health expenditure". All the data were sourced from the insurance company database

\begin{tabular}{lll}
\hline Notes & - \\
\hline Risk of bias & Authors' judgement & Support for judgement \\
\hline Bias & Low risk & $\begin{array}{l}\text { Use of random number generator. (pg 2089) "...randomly assigned to full cov- } \\
\text { erage (full-coverage group) or usual pharmacy benefits (usual-coverage group) } \\
\text { with the use of a random-number generator, and all subsequently eligible pa- } \\
\text { tionts of that plan sponsor were assigned to the same group." }\end{array}$ \\
\hline
\end{tabular}


Choudhry 2011 (Continued)

Allocation concealment Unclear risk Insufficient information to permit judgment of 'Low risk' or 'High risk' of bias (selection bias) - (pg s33) "When a newly eligible post-MI patient is identified, an investigator blinded to the identity of the plan sponsor will determine whether that patient's plan sponsor has previously been randomized, and if not, the plan sponsor's block assignment. Plan sponsors will be randomly assigned in a 1:1 ratio to intervention or control using a random number generator. All subsequent patients of that plan sponsor will be assigned to the same group."

Selective reporting (re- Low risk None detected, protocol available
porting bias)
porting bias)

Other bias Unclear risk

\begin{abstract}
(pg 2096) "Several limitations of our study should be acknowledged. We relied on administrative claims to identify patients and evaluate outcomes. The use of such data for the outcomes that were studied has been validated, and we did not adjudicate study events with medical records. We recruited patients with hospital discharge claims that take time to become available in administrative databases. During the resultant delay, some patients may have become nonadherent to their prescribed therapies. Although this approach increases the generalizability of our findings to other insurers that seek to institute similar plans, it may have diminished the observed effect of the intervention. We evaluated relatively young patients who had been discharged from the hospital after myocardial infarction and who were covered by a large national insurer, and our results may not be generalizable to patients with other conditions or to those who receive health benefits through other means. We do not report the effect of eliminating copayments on the rate of out-of-hospital deaths from cardiovascular causes, since such rates will be ascertained by means of data from death certificates recorded in the Centers for Disease Control and Prevention National Death Index (NDI), for which there is a lag between the date of death and its documentation in the NDI. The clinical outcomes we report include only verifiable deaths from cardiovascular causes (i.e., those that occurred during the course of a hospital admission)."
\end{abstract}

\begin{tabular}{|c|c|c|}
\hline $\begin{array}{l}\text { Blinding of outcome as- } \\
\text { sessment (detection bias) } \\
\text { Adherence measure }\end{array}$ & Low risk & $\begin{array}{l}\text { (PRIMARY) MEDICATION ADHERENCE RATE - Data sourced from electronic } \\
\text { database of the drug coverage company. Objective outcome }\end{array}$ \\
\hline
\end{tabular}

\begin{tabular}{|c|c|c|}
\hline $\begin{array}{l}\text { Blinding of outcome as- } \\
\text { sessment (detection bias) }\end{array}$ & Low risk & $\begin{array}{l}\text { (PRIMARY) COMPOSITE OF FIRST MAJOR VASCULAR EVENT OR CORONARY RE- } \\
\text { VASCULARIZATION - Objective data retrieved from health records }\end{array}$ \\
\hline
\end{tabular}

Patient outcome

\begin{tabular}{ll}
$\begin{array}{l}\text { Blinding of participants } \\
\text { (performance bias) }\end{array}$ & High risk \\
$\begin{array}{l}\text { Adherence measure } \\
\text { (PRIMARY) MEDICATION ADHERENCE RATE - Participants were not blinded } \\
\text { to the study. "Patients in the full-coverage group were also informed of the } \\
\text { change in their pharmacy benefits." (pg 2090) }\end{array}$ \\
\hline
\end{tabular}

$\begin{array}{ll}\begin{array}{l}\text { Blinding of participants } \\ \text { (performance bias) }\end{array} & \text { Low risk } \\ \begin{array}{l}\text { Patient outcome } \\ \text { (PRIMARY) COMPOSITE OF FIRST MAJOR VASCULAR EVENT OR CORONARY RE- }\end{array} \\ \end{array}$

$\begin{array}{ll}\text { Blinding of personnel (per- } & \text { Low risk } \\ \begin{array}{l}\text { formance bias) } \\ \text { Adherence measure }\end{array} & \text { (PRIMARY) MEDICATION ADHERENCE RATE - Data sourced from electronic } \\ \text { database of the drug coverage company. Objective outcome }\end{array}$

Blinding of personnel (per- Low risk

formance bias)

(PRIMARY) COMPOSITE OF FIRST MAJOR VASCULAR EVENT OR CORONARY RE-

Patient outcome VASCULARIZATION - Objective data retrieved from health records

$\begin{array}{ll}\begin{array}{l}\text { Incomplete outcome data } \\ \text { (attrition bias) }\end{array} & \text { Low risk } \\ & \begin{array}{l}\text { (PRIMARY) MEDICATION ADHERENCE RATE - Rate of missing data balanced. ITT } \\ \text { analysis done }\end{array}\end{array}$


Choudhry 2011 (Continued)

Adherence measure

Incomplete outcome data Low risk (attrition bias)

Patient outcome
(PRIMARY) COMPOSITE OF FIRST MAJOR VASCULAR EVENT OR CORONARY REVASCULARIZATION - Rate of missing data balanced. ITT analysis performed

Chung 2011

\begin{tabular}{ll} 
Methods & Randomized controlled trial \\
\hline Participants & The study location was Coptic Hope Center for Infectious Diseases in Nairobi, Kenya \\
& $\begin{array}{l}\text { Patients were randomized as follows: } 100 \text { patients to counseling, } 100 \text { patients to the alarm device, } 100 \\
\text { patients to counseling plus the alarm device, and } 100 \text { patients to the control group }\end{array}$
\end{tabular}
patients to counseling plus the alarm device, and 100 patients to the control group

The inclusion criteria were a CD4 count $<250$ cells $/ \mathrm{mm}^{3}$, World Health Organization (WHO) clinical stage IV disease, or a CD4 count $<350$ cells $/ \mathrm{mm}^{3}$ with WHO clinical stage III disease. In addition, patients had to be 18 or older, antiretroviral naive, agree to home visits, and plan to live in Kenya for at least 2 years

In the adherence counseling intervention, trained counselors administered 2 counseling sessions to participants prior to HAART initiation and a third session one month after HAART initiation. Counseling sessions around HAART initiation were based on a model of successful antiretroviral adherence promotion at a large University of Washington-affiliated HIV treatment program in Seattle, Washington. All counseling sessions followed a written standardized protocol and lasted between 30 and 45 minutes. In the first session, counselors explored personal barriers to good adherence and taught participants about HIV, the virus that causes AIDS, antiretroviral medications, and the risks of treatment failure due to poor adherence. The second session occurred on a separate day and involved a review of a participant's understanding and readiness to begin antiretroviral medications. The third session allowed the counselor to examine practical and personal issues that the participant may have encountered on HAART. The adherence counseling intervention had been previously used and adapted at the same site in Kenya for over 2 years and was delivered in English and Kiswahili

\section{Intervention: COUNSELING PLUS ALARM}

Participants in counseling plus alarm group received both adherence counseling and alarm reminders. 3 adherence counseling sessions ( 2 prior to HAART initiation and 1 after HAART initiation) were conducted. All counseling sessions followed a written standardized protocol and lasted between 30 and 45 minutes. In the first session, counselors explored personal barriers to good adherence and taught participants about the HIV, the virus that causes AIDS, antiretroviral medications, and the risks of treatment failure due to poor adherence. The second session occurred on a separate day and involved a review of a participant's understanding and readiness to begin antiretroviral medications. The third session allowed the counselor to examine practical and personal issues that the participant may have encountered on HAART. The counseling session was delivered in English and Kiswahili. In addition, participants were given a small pocket digital alarm, which the individual was to carry at all times for 6 months. The device was programmed by the study staff to beep and flash twice a day at a time convenient to the participant when medications were to be taken. The digital alarm could not be reprogrammed or inactivated by the individual and was utilized for 6 months after HAART initiation before being disabled by study staff

\section{Intervention: ALARM DEVICE}

Participants in the alarm device intervention received a small pocket digital alarm which the individual was to carry at all times for 6 months duration. The device was programmed by the study staff to beep and flash twice a day at a time convenient to the participant when medications were to be taken. The digital alarm could not be reprogrammed or inactivated by the individual and was utilized for 6 months after HAART initiation before being disabled by study staff

Control: USUAL CARE 
"At HAART initiation, the study pharmacist explained the side effects of medications and problems associated with poor adherence in a 15-min session prior to dispensing drugs. All participants, including those in the control arm, received this educational message. Participants randomized to the control group did not receive adherence counseling or an alarm device." (pg 2)

Outcomes

The measures of adherence were pill counts and pharmacy refill visits. After initiating HAART, participants returned to the study clinic monthly with their pill bottles to pick up antiretroviral medications. At each monthly visit, the study pharmacist counted and recorded the number of pills remaining in the bottle, the visit date, whether the participant took his or her morning dose, and the number of pills dispensed that day. Adherence was calculated as the percentage of dispensed doses that were taken since the previous visit to the study pharmacy. Total time between the last date the participant visited the pharmacy and the participant's subsequent pharmacy visit included any missed visits to the pharmacy or time when the participant was not attending the clinic. This calculated adherence was assumed to be constant and the same as daily adherence throughout this time period. Continuous adherence and time to monthly adherence $<80 \%$ and $<95 \%$ were calculated

The patient outcomes were viral failure, mortality, and change in CD4 count. Participants had blood drawn at 6,12 , and 18 months. RNA was measured using the Gen-Probe quantitative HIV-1 viral load assay. CD4 counts were determined using flow cytometry. Viral failure was defined as the first plasma HIV-1 RNA level greater than or equal to 5000 copies $/ \mathrm{ml}$ measured at least 4 months after HAART initiation

Notes -

\section{Risk of bias}

\begin{tabular}{lll}
\hline Bias & Authors' judgement & Support for judgement \\
\hline $\begin{array}{ll}\text { Random sequence genera- } \\
\text { tion (selection bias) }\end{array}$ & Low risk & $\begin{array}{l}\text { (pg 2) "In a } 262 \text { factorial design, participants were randomized in a 1:1:1:1 ratio } \\
\text { to one of four arms prior to initiating HAART: (1) adherence counseling alone; } \\
\text { (2) alarm device alone; (3) both adherence counseling and alarm device to- } \\
\text { gether; and (4) a control group that received neither adherence counseling nor } \\
\text { alarm device. Randomization was performed at enrollment by the study nurse } \\
\text { who opened a sealed envelope containing a computer-generated block ran- } \\
\text { domization code that was developed by the study biostatistician." }\end{array}$ \\
\hline
\end{tabular}

Allocation concealment Low risk
(selection bias)

Randomization was performed at enrollment by the study nurse who opened a (selection bias) sealed envelope containing a computer-generated block randomization code that was developed by the study biostatistician. Study investigators and participants were not blinded to the interventions

\begin{tabular}{|c|c|c|}
\hline $\begin{array}{l}\text { Selective reporting (re- } \\
\text { porting bias) }\end{array}$ & Low risk & All relevant results appear to be reported; protocol is available \\
\hline Other bias & Unclear risk & $\begin{array}{l}\text { The authors note several limitations of the study but insufficient information is } \\
\text { provided to make a judgment }\end{array}$ \\
\hline $\begin{array}{l}\text { Blinding of outcome as- } \\
\text { sessment (detection bias) } \\
\text { Adherence measure }\end{array}$ & Low risk & $\begin{array}{l}\text { (PRIMARY) PHARMACY REFILL RECORDS - Not blinded, but refill records are un- } \\
\text { likely to be biased }\end{array}$ \\
\hline $\begin{array}{l}\text { Blinding of outcome as- } \\
\text { sessment (detection bias) } \\
\text { Patient outcome }\end{array}$ & Low risk & (PRIMARY) CD4 CELL COUNT AND VIRAL LOAD - This an objective outcome \\
\hline $\begin{array}{l}\text { Blinding of participants } \\
\text { (performance bias) } \\
\text { Adherence measure }\end{array}$ & Unclear risk & $\begin{array}{l}\text { (PRIMARY) PHARMACY REFILL RECORDS - No mention of blinding of study par- } \\
\text { ticipants. Possible bias that participants might discard medicine instead of } \\
\text { taking it }\end{array}$ \\
\hline
\end{tabular}


Chung 2011 (Continued)
Blinding of participants
Low risk
(PRIMARY) CD4 CELL COUNT AND VIRAL LOAD - This an objective outcome (performance bias)

Patient outcome

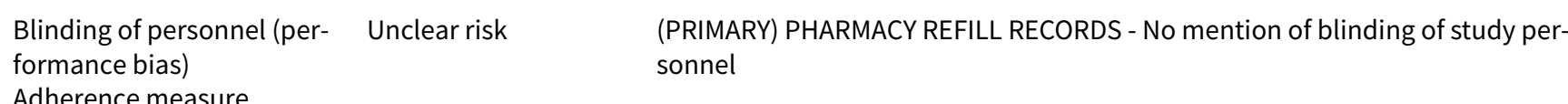

Adherence measure

(PRIMARY) PHARMACY REFILL RECORDS - No mention of blinding of study per-

(PRIMARY) CD4 CELL COUNT AND VIRAL LOAD - This an objective outcome

Blinding of personnel (per- Low risk

formance bias)

Patient outcome

\begin{tabular}{lll}
\hline $\begin{array}{l}\text { Incomplete outcome data } \\
\text { (attrition bias) } \\
\text { Adherence measure }\end{array}$ & Unclear risk & $\begin{array}{l}\text { (PRIMARY) PHARMACY REFILL RECORDS - Missing data appear relatively bal- } \\
\text { anced across groups but insufficient information provided to make a judgment }\end{array}$ \\
\hline $\begin{array}{l}\text { Incomplete outcome data } \\
\begin{array}{l}\text { (attrition bias) } \\
\text { Patient outcome }\end{array}\end{array}$ & Unclear risk & $\begin{array}{l}\text { (PRIMARY) CD4 CELL COUNT AND VIRAL LOAD - Losses to follow-up relatively } \\
\text { balanced across the groups }\end{array}$ \\
\hline
\end{tabular}

\section{Colcher 1972}

\begin{tabular}{ll}
\hline Methods & Random allocation without an indication of concealment \\
\hline Participants & $\begin{array}{l}\text { All children (aged } 1 \text { to } 15) \text { presenting to a pediatric outpatient clinic with streptococcal pharyngitis } \\
\text { were included except those known to have received previous antimicrobial therapy of any type during } \\
\text { the previous month, or those known to be allergic to penicillin }\end{array}$
\end{tabular}

Interventions

The parents of the 'normally informed' group were given instructions that the penicillin was to be taken 3 times per day for 10 days, and any questions that they had were answered. Parents of the 'optimally informed' group received specific counseling stressing the necessity that the penicillin be taken for the full 10 days in order to achieve the best cure/prevent relapse, and further, were given written instructions

\begin{tabular}{ll}
\hline Outcomes & There was a single measurement of adherence: Sarcina lutea growth inhibition by urine (a test for the \\
presence of antimicrobial activity). Throat cultures were obtained at 9 days, 3 , and 6 weeks post-treat- \\
ment. In addition, the incidence of relapse was estimated in the various patient groups
\end{tabular}

Notes

There was no indication of blinding of the outcome measures

\section{Risk of bias}

\begin{tabular}{lll}
\hline Bias & Authors' judgement & Support for judgement \\
\hline $\begin{array}{l}\text { Random sequence genera- } \\
\text { tion (selection bias) }\end{array}$ & Unclear risk & $\begin{array}{l}\text { No mention of method of randomization. (pg 657) "...during this period were } \\
\text { randomly assigned to one of three treatment groups." }\end{array}$ \\
\hline $\begin{array}{l}\text { Allocation concealment } \\
\text { (selection bias) }\end{array}$ & Unclear risk & No mention of allocation concealment \\
\hline $\begin{array}{l}\text { Selective reporting (re- } \\
\text { porting bias) }\end{array}$ & Low risk & $\begin{array}{l}\text { Clear the studies report all prestated outcomes; although, protocol is not } \\
\text { available. (Study is from 1972) }\end{array}$ \\
\hline Other bias & Low risk & No obvious other types of bias \\
\hline
\end{tabular}


Colcher 1972 (Continued)

Blinding of outcome as- Low risk (PRIMARY) URINE DRUG CONCENTRATION - Not enough information in the arsessment (detection bias) ticle to assess blinding, but assessment is unlikely to be affected by lack of Adherence measure blinding

\begin{tabular}{|c|c|c|}
\hline $\begin{array}{l}\text { Blinding of outcome as- } \\
\text { sessment (detection bias) } \\
\text { Patient outcome }\end{array}$ & Low risk & $\begin{array}{l}\text { (PRIMARY) FAILURE AND RELAPSES - Not enough information in the article to } \\
\text { assess blinding, but assessment is unlikely to be affected by lack of blinding }\end{array}$ \\
\hline $\begin{array}{l}\text { Blinding of participants } \\
\text { (performance bias) } \\
\text { Adherence measure }\end{array}$ & Low risk & $\begin{array}{l}\text { (PRIMARY) URINE DRUG CONCENTRATION - Not blinded, but assessment is un- } \\
\text { likely to be affected by lack of blinding }\end{array}$ \\
\hline
\end{tabular}

Adherence measure

(PRIMARY) FAILURE AND RELAPSES - No blinding, but assessment is unlikely to be affected by lack of blinding

(performance bias)

Patient outcome

Blinding of personnel (per- Low risk

formance bias)

Adherence measure

(PRIMARY) URINE DRUG CONCENTRATION - Not enough information in the article to assess blinding, but assessment is unlikely to be affected by lack of blinding

Blinding of personnel (per- Low risk

formance bias)

Patient outcome

(PRIMARY) FAILURE AND RELAPSES - Not enough information in the article to assess blinding, but assessment is unlikely to be affected by lack of blinding
Incomplete outcome data Unclear risk

(attrition bias)

Adherence measure
(PRIMARY) URINE DRUG CONCENTRATION - Reasons and losses to follow-up not described

Incomplete outcome data Unclear risk

(attrition bias)

(PRIMARY) FAILURE AND RELAPSES - We do not know to which study arms the dropouts belong

Patient outcome

\section{Collier 2005}

\section{Methods}

Patients $(n=282)$ were randomized upon entry to receive either each study site's usual adherence support measures $(n=140)$ or each study site's usual adherence support measures and scripted serial telephone calls from study site staff members $(n=142)$. Exact method of allocation concealment was not described

Participants

Patients had $<$ or $=$ to $200 \mathrm{CD} 4+\mathrm{T}$ cells/mm3 or $>80,000$ HIV RNA copies/ml of plasma at screening, no or limited previous antiretroviral therapy (no previous use of lamivudine, nonnucleoside reverse transcriptase inhibitors, or protease inhibitors), hemoglobin $>$ or $=$ to $9.1 \mathrm{~g} / \mathrm{dl}$ (for men) or $>$ or $=$ to $8.9 \mathrm{~g} / \mathrm{dl}$ (for women), $>$ or $=$ to 850 neutrophils $/ \mathrm{mm}^{3},>65,000$ platelets $/ \mathrm{mm}^{3}$, hepatic aminotransferase levels $<$ 5 times the upper limit of reference values, and amylase levels $<1.5$ times the upper limit of reference values, and could not be pregnant or breast-feeding

Interventions

The intervention group received serial, supportive telephone calls. Study site staff members (mostly nurses) followed a standardized script for telephone calls and received training by the study team. Spanish and Italian translations of the English script were provided. The telephone calls focused on each subject's medication-taking behavior, and study site staff members identified barriers to adherence and developed individualized strategies to increase adherence. During the telephone calls, the study site staff members also provided social support and assistance with the management of side effects. The telephone calls were to be made at specific times: 1 to 3 days after the initiation of the study regimen and at weeks $1,2,3,6,12$, and every 8 weeks thereafter, as long as the subject continued to receive the assigned study regimen, for a maximum of 16 telephone calls over the course of 96 weeks. For each telephone call, a minimum of 2 attempts were made to contact the patient before leaving a 
Collier 2005 (Continued)

counseling or general message. Also, a complete telephone call was one where all the topics described above were discussed, however, if that did not occur, calls were categorized as being only partially completed. The usual adherence support measures included an average of 35 minutes of in-person counseling provided by a study site nurse or pharmacist at the start of treatment. According to a study site survey, $67 \%$ of study sites reported providing written materials to study subjects as part of their usual adherence support measures. As well, $41 \%$ reported making at least 1 telephone call to selected subjects (deemed at being high risk for low adherence) as part of their usual support measures; however, the telephone calls were made to a minority of patients, the number of calls per patient was limited, and the content was not standardized

Outcomes Compliance was measured at baseline using a standardized adherence questionnaire and a follow-up questionnaire evaluating medication-taking behavior during the preceding 4 days at weeks $8,16,24$, 48,72 , and 96

The primary health outcome was a measure of antiretroviral drug activity, specifically, the time to virologic failure. Virologic failure was defined as (1) having $>$ than or $=$ to 200 HIV RNA copies $/ \mathrm{ml}$ of plasma at or after week 24 or (2) having an increase of $>1.0 \log 10$ above nadir levels or an increase to or above baseline levels before week 24 or (3) having 2 consecutive HIV RNA levels $>$ than or $=$ to $200 \mathrm{copies} / \mathrm{ml}$ at any time after having 2 consecutive HIV RNA levels $<200$ copies $/ \mathrm{ml}$

Notes -

\section{Risk of bias}

Bias Authors' judgement Support for judgement

Random sequence genera- Unclear risk tion (selection bias)

Random number generation was not described. (pg 1399) "Subjects in the substudy were randomized at entry to receive either each study site's usual adherence support measures (usual support measures group) or each study site's usual adherence support measures and scripted serial telephone calls from study site staff members (calls group)."

\begin{tabular}{|c|c|c|}
\hline $\begin{array}{l}\text { Allocation concealment } \\
\text { (selection bias) }\end{array}$ & Unclear risk & $\begin{array}{l}\text { No mention of allocation concealment - (pg 1399) "Subjects in the substudy } \\
\text { were randomized at entry to receive either each study site's usual adherence } \\
\text { support measures (usual support measures group) or each study site's usual } \\
\text { adherence support measures and scripted serial telephone calls from study } \\
\text { site staff members (calls group). Study site staff members (mostly nurses) fol- } \\
\text { lowed a standardized script for telephone calls and received training by the } \\
\text { study team by conference call before the study started." }\end{array}$ \\
\hline
\end{tabular}

\begin{tabular}{lll}
\hline $\begin{array}{l}\text { Selective reporting (re- } \\
\text { porting bias) }\end{array}$ & Unclear risk & No protocol available \\
\hline Other bias & Unclear risk & $\begin{array}{l}\text { Some limitations were noted by the authors but insufficient information to } \\
\text { make a judgment }\end{array}$
\end{tabular}

Blinding of outcome as- High risk sessment (detection bias) Adherence measure

(PRIMARY) SELF REPORT - QUESTIONNAIRE - Adherence assessors (not explicitly stated) were apparently not blinded. The original trial, of which this is a substudy was open-labeled. The phone calls were made by nurses; no statement regarding their blinding. (pg 1399) "Study site staff members (mostly nurses) followed a standardized script for telephone calls and received training by the study team by conference call before the study started."

\begin{tabular}{lll}
\hline $\begin{array}{l}\text { Blinding of outcome as- } \\
\text { sessment (detection bias) } \\
\text { Patient outcome }\end{array}$ & Low risk & (PRIMARY) VIRAL LOAD - Objective outcome \\
\hline $\begin{array}{l}\text { Blinding of participants } \\
\text { (performance bias) }\end{array}$ & High risk & $\begin{array}{l}\text { (PRIMARY) SELF REPORT - QUESTIONNAIRE - No blinding done in this study, } \\
\text { subjective outcome. (pg 1399) "open-label study" }\end{array}$
\end{tabular}


Collier 2005 (Continued)

Adherence measure

$\begin{aligned} & \text { Blinding of participants } \\ & \text { (performance bias) }\end{aligned}$
$\begin{aligned} & \text { Patient outcome } \\ & \text { (PRIMARY) VIRAL LOAD - Objective outcome }\end{aligned}$

Patient outcome

Blinding of personnel (per- Unclear risk formance bias)

(PRIMARY) SELF REPORT - QUESTIONNAIRE - No blinding done in this study; Adherence measure not clear how study personnel might influence outcome - (pg 1399) "open-label study"

Blinding of personnel (per- Low risk

(PRIMARY) VIRAL LOAD - Objective outcome

formance bias)

Patient outcome

Incomplete outcome data Unclear risk

(attrition bias)

Adherence measure the 282 enrollees, 239 (85\%) completed ACTG 746, 35 (12\%) prematurely discontinued ACTG 388 (and, thus, ACTG 746), 6 (2\%) died, and 2 discontinued for other reasons. The categories were similar between the groups but insufficient information to make a judgment

Incomplete outcome data Unclear risk

(attrition bias)

(PRIMARY) VIRAL LOAD - Unclear whether the missing data would have

Patient outcome changed the results

\section{Cooper 2010}

Methods

36 patients were randomized to the Cognitive Adaptation Training (PharmCAT), which was focused only on medication and appointment adherence; 37 were randomized to the Cognitive Adaptation Training (Full-CAT), which focused on many aspects of community adaptation; 32 participants were randomized to the control group. Randomized controlled trial

Participants

The study location was 9 sites across UK (Brighton, Birmingham Heartlands, Kings College London, Birmingham Whittall Street, Newcastle General, Leicester, St. Mary's London, Oxford, Newham) UK

44 participants were randomized to the intervention group and 43 participants were randomized to the control group

The inclusion criteria were being HIV positive, age $>18$ years, able to give informed consent, being antiretroviral naive, with CD4 lymphocyte count, $<350$ cells per cubic millimeter and/or HIV viral load $>$ 20,000 copies per milliliter and/or AIDS-defining illness, and likely to live more than 2 years with antiviral therapy

The exclusion criteria were alkaline phosphatase or hepatic transaminases $>5$ times upper limit of normal, neutrophil count of $<0.5 \times 109 / \mathrm{L}$, medical history of pancreatitis, prior exposure to any antiretroviral agent, pregnancy or female patient trying to become pregnant, patients who do not self medicate, those unwilling or unable to use Medication Event Monitoring Systems (MEMS) monitors, patients who are unable to comprehend the written questionnaires with the help of a clinician or interpreter, and those needing medication other than their proposed antiretrovirals that is either more than 3 additional tablets or capsules per day, that cannot be taken at the same time as their antiretrovirals, or that may have a significant pharmacological interaction with their proposed antiretrovirals $400 \mathrm{mg}$ (250 mg if weight less than $60 \mathrm{~kg}$ ), 2 x lamivudine (3TC) $150 \mathrm{mg}$ tablet, 1 x efavirenz (Sustiva) 600 mg tablet each evening

Control: TWICE DAILY REGIMEN 
Outcomes

The measures of adherence were persistence with treatment and execution of the dosing regimen and measured using MEMS 6 to collect 3TC drug dosing histories. Persistence was defined as the length of time during which the medication is taken, that is, the time from the first-taken dose to the last taken dose, measured using MEMS. Execution of the Dosing Regimen measured how closely the patient's dosing history corresponds to the prescribed drug-dosing regimen by reporting the proportion of prescribed doses taken and was summarized as binary time series where for each consecutive day that the patient was still engaged with treatment, the variable indicated whether or not the patient had taken at least the prescribed number of doses. MEMS data were downloaded at 4, 12, 24, 36, and 48 weeks after each patient initiated treatment

The patient outcomes were measured in the clinic before patients initiated treatment (baseline) and each subsequent time point (4, 12, 24, 36, and 48 weeks). Patient outcomes included: 1 ) Beliefs about HAART measured using the Beliefs about Medicines Questionnaire-HAART specific version, which comprises 2 scales: HAART necessity scale which consists of 8 items assessing individuals' beliefs about their personal need for HAART for controlling their HIV, maintaining their health, and preventing illness, and HAART concerns scale which consists of 11 items which bring together a range of separate concerns about the potential adverse effects of HAART that have been identified across studies. Participants were presented with a series of statements about which they were told "these are statements that other people have made about combination therapy". They were then asked to rate their level of agreement with each item on a scale, where responses ranged from strongly agree (scored 5) to strongly disagree (scored 1). Scores for the individual items within each scale were summed to give a total scale score. A mean scale score was computed by dividing each scale by the number of items, giving a range of 1 to 5 for both necessity and concerns scales. This was done to facilitate comparison of scores between scales and to calculate a necessity-concerns differential (NCD) by subtracting concerns scores from necessity scores. The NCD score can be thought of as a crude indicator of the way the individual rates their perceived need for the treatment relative to their concerns about taking it. 2) HAART Intrusiveness Scale Consists of 10 items addressing the degree to which HAART is perceived to interfere with 10 aspects of daily life, each ranked on a scale from 1 to 5 , where 1 indicates low interference and 5 indicates high interference. A total score was computed by adding up responses to each item. For comparison with other scales, an average score was computed by dividing the total score by the number of items. Possible responses ranged from 1 to 5 with higher scores indicating higher perceived intrusiveness. 3) Viral load was assessed at 4, 12, 24, 36, and 48 weeks after each patient initiated treatment using locally available method in each case. Viral load failure was defined as viral load $>50$ copies per milliliter at 48 weeks

Notes -

\section{Risk of bias}

\begin{tabular}{lll}
\hline Bias & Authors' judgement & Support for judgement \\
\hline $\begin{array}{l}\text { Random sequence genera- } \\
\text { tion (selection bias) }\end{array}$ & Low risk & $\begin{array}{l}\text { Random number table used (pg 370) - The sequential allocation of consecutive } \\
\text { patients was predetermined by random number tables }\end{array}$ \\
\hline
\end{tabular}

\begin{tabular}{lll}
\hline $\begin{array}{l}\text { Allocation concealment } \\
\text { (selection bias) }\end{array}$ & Unclear risk & Insufficient information to permit judgment of 'Low risk' or 'High risk' \\
\hline $\begin{array}{l}\text { Selective reporting (re- } \\
\text { porting bias) }\end{array}$ & Unclear risk & None detected but protocol unavailable \\
\hline Other bias & Unclear risk & $\begin{array}{l}\text { Insufficient information provided to make a judgment. But noted that the } \\
\text { study was not powered to compare the effect on viral load between the } 2 \text { dose } \\
\text { regimens (pg 375) }\end{array}$
\end{tabular}

Blinding of outcome as-
sessment (detection bias) $\quad$ Low risk

(PRIMARY) MEMS - Not likely to be affected by staff and personnel collecting the data 
Cooper 2010 (Continued)

Adherence measure

\begin{tabular}{|c|c|c|}
\hline $\begin{array}{l}\text { Blinding of outcome as- } \\
\text { sessment (detection bias) }\end{array}$ & High risk & $\begin{array}{l}\text { (PRIMARY) HAART BELIEFS AND INTRUSIVENESS - Open-label study; subjective } \\
\text { measure; no mention of blinding }\end{array}$ \\
\hline
\end{tabular}

Patient outcome

$\begin{array}{ll}\begin{array}{l}\text { Blinding of participants } \\ \text { (performance bias) }\end{array} & \text { High risk } \\ \text { Adherence measure } & \begin{array}{l}\text { (PRIMARY) MEMS - Patients likely to be non-blinded because of the nature of } \\ \text { the intervention }\end{array}\end{array}$

Blinding of participants High risk

(performance bias)

(PRIMARY) HAART BELIEFS AND INTRUSIVENESS - Open-label study; subjective

Patient outcome measure; no mention of blinding

Blinding of personnel (per- Low risk

formance bias)

(PRIMARY) MEMS - Not likely to be affected key study personnel collecting the

Adherence measure data
Blinding of personnel (per- High risk (PRIMARY) HAART BELIEFS AND INTRUSIVENESS - Open-label study; subjective formance bias) measure; no mention of blinding

Patient outcome

Incomplete outcome data Low risk $\quad$ (PRIMARY) MEMS - Low dropout rate and excellent follow-up
(attrition bias)

Adherence measure

\begin{tabular}{l}
\hline Incomplete outcome data Low risk \\
(attrition bias) \\
Patient outcome
\end{tabular}

\title{
Costa 2008
}

\begin{tabular}{ll}
\hline Methods & Randomized controlled trial \\
\hline Participants & The study location was a tertiary outpatient clinic in Brazil \\
& $\begin{array}{l}78 \text { participants were randomized to the intervention group and } 75 \text { participants were randomized to the } \\
\text { control group }\end{array}$ \\
& The inclusion criterion was hospitalization because of first acute myocardial infarction \\
\hline
\end{tabular}

Interventions

\begin{abstract}
Intervention: TRANSDISCIPLINARY APPROACH
The transdisciplinary intervention consisted of clinical follow-up, smoking cessation assistance, dietary advice and lifestyle modification advice. The intervention was delivered by a team consisting of an endocrinologist, a cardiologist, a nurse, and a dietician. There were 2 follow-up assessments - at 60 to 90 days after MI and 120 to 180 days after MI. In diabetic patients, capillary glycemia was measured (Advantage reagent strips, Roche, Indianapolis, IN, USA), lower limbs were examined, and adherence to prescribed oral antidiabetic agents and insulin was reviewed. Those patients who were still smoking were advised to stop smoking by the nurse and also by the cardiologist. No oral medication was prescribed in this regard since these drugs are not routinely provided by the Public Health System in Brazil. After the above-described procedures, the dietitian evaluated body weight and performed a nutritional review. This review was followed by reinforcement of healthy nutritional habits, which included information on the characteristics and amount of healthy meals according to each case and also lifestyle modification reinforcement. The management plan was formulated as an individualized therapeutic alliance among the patient and family, the physician, and other members of the healthcare team. Finally, patients were evaluated by the cardiologist, who completed the visit with the specific medical history, physical examination and specific complementary tests. Drug prescription by the cardiologist followed
\end{abstract}


Costa 2008 (Continued)

the AHA guidelines for both groups (statins, antiplatelet therapy, beta-blockers, and angiotensin-converting enzyme inhibitors). Diabetic patients were evaluated by an endocrinologist. Drug prescription by the endocrinologist followed the American Diabetes Association (ADA) guidelines for both groups

\section{Control: CONVENTIONAL CARE}

Conventional care group received regular care. Before discharge, they were visited by a dietitian who prescribed a post-discharge diet plan after nutritional evaluation. Then they were referred to the conventional outpatient clinic for heart care, where the patients were seen only by the appointed cardiologist. Cardiologists kept a routine schedule with the patients and were seen for no more than 15 minutes. Then these participants were asked to be present at the clinic 180 days after AMI to perform a clinical examination and to obtain blood samples

Outcomes The measures of adherence were a questionnaire administered to the patient/family members twice during the follow-up period, 60 to 90 days after $\mathrm{MI}$ and 120 to 180 days after $\mathrm{MI}$

The patient outcomes were clinical improvement, which was evaluated by means of a constructed index comprising lowering of body weight ( $>5 \%$ from baseline), lowering of blood pressure levels (< $135 / 85 \mathrm{~mm} \mathrm{Hg}$ ), cessation of smoking (yes or no), increased physical activity and compliance with medication. Reduction in smoking was not counted as cessation. Blood pressure was measured with the patient seated for 5 minutes and using an aneroid or mercury sphygmomanometer, periodically calibrated according to the recommendations of the VII Joint National Committee (JNC). Body weight and height were measured on a manual balance (Filizzola, SP, Brazil), with a maximum capacity for a 150 $\mathrm{kg}$ load and $1.90 \mathrm{~m}$ height. Compliance with medication was evaluated by asking questions directly to the patient/family members. For each item with a positive change, 1 point value was assigned. A final sum of greater than or equal to 4 points was considered very good. In addition blood samples were collected at the outpatient clinic for the measurement of total plasma cholesterol and triglycerides. All the measurements were performed during the 2 follow-up visits, first one between days 60 to 90 post MI and the second 120 to 180 days post MI

\section{Notes}

$-$

\section{Risk of bias}

\begin{tabular}{lll}
\hline Bias & Authors' judgement & Support for judgement \\
\hline $\begin{array}{l}\text { Random sequence genera- } \\
\text { tion (selection bias) }\end{array}$ & Low risk & $\begin{array}{l}\text { (pg 490) "This randomized clinical trial contained two groups, control and in- } \\
\text { tervention, which were distributed randomly in blocks of 20 by randomization } \\
\text { software (Random, PEPI 4.0)." }\end{array}$ \\
\hline $\begin{array}{l}\text { Allocation concealment } \\
\text { (selection bias) }\end{array}$ & Unclear risk & $\begin{array}{l}\text { Insufficient information was provided. "This randomized clinical trial con- } \\
\text { tained two groups, control and intervention, which were distributed randomly } \\
\text { in blocks of 20 by randomization software (Random, PEPI 4.0)." (pg 490) }\end{array}$ \\
\hline
\end{tabular}

\begin{tabular}{|c|c|c|}
\hline $\begin{array}{l}\text { Selective reporting (re- } \\
\text { porting bias) }\end{array}$ & High risk & $\begin{array}{l}\text { Fasting plasma glucose was measured using the automated enzymatic } \\
\text { method. (pg 491) This outcome is not reported anywhere }\end{array}$ \\
\hline
\end{tabular}

\begin{tabular}{|c|c|c|}
\hline Other bias & High risk & $\begin{array}{l}\text { Self reporting bias. Large amount of data are missing. E.g. for primary out- } \\
\text { come } 48 \text { and } 51 \text { missing from CC and TC groups }\end{array}$ \\
\hline
\end{tabular}

\begin{tabular}{lll}
\hline $\begin{array}{l}\text { Blinding of outcome as- } \\
\text { sessment (detection bias) } \\
\begin{array}{l}\text { Adherence measure } \\
\text { High risk }\end{array}\end{array}$ & $\begin{array}{l}\text { (PRIMARY) SELF REPORT - QUESTIONNAIRE - The patients and health profes- } \\
\text { sionals involved in outpatient treatment were not blinded as to their alloca- } \\
\text { tion (pg 490) }\end{array}$ \\
\hline
\end{tabular}

$\begin{array}{lll}\begin{array}{l}\text { Blinding of outcome as- } \\ \text { sessment (detection bias) } \\ \text { Patient outcome }\end{array} & \text { High risk } & \begin{array}{l}\text { (PRIMARY) CLINICAL EXAMINATION - The patients and health professionals in- } \\ \text { volved in outpatient treatment were not blinded as to their allocation (pg 490) }\end{array}\end{array}$

Patient outcome

Blinding of participants High risk
(performance bias)

(PRIMARY) SELF REPORT - QUESTIONNAIRE - Participants were aware of the intervention due to its nature 
Costa 2008 (Continued)

Adherence measure

$\begin{array}{ll}\begin{array}{l}\text { Blinding of participants } \\ \text { (performance bias) }\end{array} & \text { High risk } \\ \text { Patient } \text { (PRIMARY) CLINICAL EXAMINATION - The patients and health professionals in- } \\ \text { volved in outpatient treatment were not blinded as to their allocation }\end{array}$

Patient outcome

Blinding of personnel (per- Unclear risk formance bias)

Adherence measure

Blinding of personnel (per- High risk

formance bias)

Patient outcome

Incomplete outcome data Unclear risk

(attrition bias)

Adherence measure

Incomplete outcome data Unclear risk

(attrition bias)

Patient outcome
(PRIMARY) SELF REPORT - QUESTIONNAIRE - The patients and health professionals involved in outpatient treatment were not blinded as to their allocation (pg 490)
(PRIMARY) CLINICAL EXAMINATION - The patients and health professionals involved in outpatient treatment were not blinded as to their allocation (pg 490)

Cote 1997

Methods The method of random allocation was not described

Participants

Patients were 16 years of age or older, with moderate to severe asthma and the need to take daily anti-inflammatory agent. The diagnosis of asthma was confirmed by either a documented reversibility greater than $15 \%$ in FEV1 or a PC20 methacholine less than or equal to $8 \mathrm{mg} / \mathrm{ml}$ when determined by the method described by Cockcroft and coworkers

Interventions

The intervention is an asthma education program with an action plan based on peak-flow monitoring (Group P) or an action plan based on asthma symptoms (Group S). The Control group (Group C) received instructions from their pulmonologists regarding medication use and influence of allergenic and non-allergenic triggers. They were taught how to use their inhaler properly by the educator. A verbal action plan could be given by the physician. Groups $\mathrm{P}$ and $\mathrm{S}$ received the same education as the controls plus individual counseling with the specialized educator during a 1-hour session. All participants received a book entitled "Understand and Control Your Asthma" at no extra charge. Group P received a self management plan based on peak expiratory flow (PEF). They were asked to continue measuring PEF twice a day and to keep a diary of the results. Each time, subjects only recorded the best of 3 measurements. Every attempt was made to ensure that patients knew how to interpret the measurement and how to respond to a change in PEF. At each follow-up visit, the patient's diary card was reviewed, and if the action plan had not been implemented when required, further explanations were given regarding when treatment should be modified. Group $\mathrm{S}$ received a self management plan based on asthma symptom monitoring. These patients were asked to keep a daily diary of asthma symptom scores, using a scale of 0 (no symptoms) to 3 (night-time asthma symptoms, severe daily symptoms preventing usual activities), and adjust their medications according to the severity of respiratory symptoms using the guidelines of the action plan

Outcomes

Adherence was assessed at each follow-up by weighing the used medication canisters. Patients were unaware of this. Treatment outcome was assessed, in terms of asthma morbidity, by a count of the days missed from work or school, the number of hospitalizations or visits to the emergency room for asthma, and the number of oral corticosteroids courses used since their last visit. These were self reported in a diary and recorded at each of the 1, 3, 6, 9, and 12-month visits after randomization. Data regarding the number of visits to the emergency room, number of hospitalizations, and absenteeism at work or school during the 12 months prior to enrollment in the study were also collected for all pa- 
Cote 1997 (Continued)

tients by administering a questionnaire and reviewing the medical charts. Knowledge of asthma was also measured pre-run-in, at randomization, and at the final visit using a questionnaire

\section{Notes}

To reduce financial barriers to treatment adherence, the investigators supplied asthma medication at no charge throughout the trial

\section{Risk of bias}

\begin{tabular}{lll}
\hline Bias & Authors' judgement & Support for judgement \\
\hline $\begin{array}{l}\text { Random sequence genera- } \\
\text { tion (selection bias) }\end{array}$ & Unclear risk & $\begin{array}{l}\text { No details given. (pg 2) Visit R (randomization). Randomization into one of the } \\
\text { 3 groups was done in each center, taking into account the name of the partici- } \\
\text { pating physician }\end{array}$
\end{tabular}

\begin{tabular}{|c|c|c|}
\hline $\begin{array}{l}\text { Allocation concealment } \\
\text { (selection bias) }\end{array}$ & Unclear risk & $\begin{array}{l}\text { No information given. No details given. (pg 2) Visit R (randomization). Ran- } \\
\text { domization into one of the } 3 \text { groups was done in each center, taking into ac- } \\
\text { count the name of the participating physician }\end{array}$ \\
\hline
\end{tabular}

Selective reporting (re- Unclear risk $\quad$ Protocol not found
porting bias)

Other bias High risk

\begin{abstract}
In the discussion section, the authors note that the fact that the patients were provided with free medication and sustained care may have contributed to the success of the study. All patients also received some sort of asthma education that may have influenced the results. Also, the inhaled corticosteroid therapy was adjusted prior to randomization and this may have had an effect on the success of the intervention. (pg 4) "The results of this study surprised us, as we had expected to find a greater decrease in asthma morbidity among patients who took part in the structured educational program. It can probably be explained by the fact that the control group may have been influenced by facilitating and reinforcing factors such as free medication and sustained care, including several follow-up visits with the educator, as described in the PRECEDE model contrary to what happened in one of our previous studies. In the present study, however, control patients were instructed on how to use their inhalers properly, and physicians could give information regarding allergenic and nonallergenic triggers if judged important. To differentiate the benefits of optimal asthma treatment from those of asthma education, inhaled corticosteroid therapy was adjusted prior to randomization using peak-flow monitoring. We agree that all patients received some degree of education during the run-in period, as optimization of therapy itself requires interaction with the patient to document symptoms and adjust or change medication if necessary, an inherently educational process. Although the control group received more than the usual care treatment, there were marked differences between control and educated patients, as none of the patients from Group $C$ received the book Understand and Control Asthma, none were given a written action plan, and none took part in a structured educational program. Finally, none of these patients had a peak-flow meter at home after completion of the run-in period. Apart from physician's recommendations, no reinforcement was given by the specialized educator with regard to compliance in patients in Group C. Enrolled in this study were patients with moderate to severe asthma (daily respiratory symptoms) who required chronic use of inhaled corticosteroids to maintain good control of their illness. We did not select a very high-risk group of patients: these subjects did not have socioeconomic problems, nor had they had several visits to the emergency room or hospitalizations related to asthma in the year prior to enrollment. Previous studies have already shown that asthma morbidity can be decreased by education in these specific subgroups of patients. The results of our study do not rule out the possibility that education could decrease asthma morbidity under other circumstances. Indeed, this study was conducted in a tertiary care setting by asthma specialists, and had we conducted this study in patients with less optimal care or in high-risk
\end{abstract}


Cote 1997 (Continued)

populations, we might have obtained different results. Furthermore, referring the patient to a specialized asthma educator may help physicians to complete the educational interventions, sometimes difficult to provide in a busy clinic. In order to assess compliance with treatment, we supplied the medication at no charge throughout the study. As inhaled corticosteroids are expensive, some patients, particularly those receiving high dosages, cannot afford this treatment. Had the asthmatic subjects paid for their own medication, it is possible that compliance with treatment would have been lower among control patients than among patients from the two educated groups, and this might have biased the outcome of the control group."

\begin{tabular}{lll}
\hline $\begin{array}{l}\text { Blinding of outcome as- } \\
\text { sessment (detection bias) } \\
\text { Adherence measure }\end{array}$ & Unclear risk & (PRIMARY) WEIGHT OF USED CANISTERS - Blinding information not provid \\
\hline $\begin{array}{l}\text { Blinding of outcome as- } \\
\text { sessment (detection bias) } \\
\begin{array}{l}\text { Patient outcome } \\
\hline\end{array}\end{array}$ & Unclear risk & $\begin{array}{l}\text { (PRIMARY) DAYS LOST FROM WORK OR SCHOOL - Insufficient information } \\
\text { about blinding provided }\end{array}$ \\
\hline
\end{tabular}

\begin{tabular}{|c|c|c|}
\hline $\begin{array}{l}\text { Blinding of participants } \\
\text { (performance bias) } \\
\text { Adherence measure }\end{array}$ & High risk & $\begin{array}{l}\text { (PRIMARY) WEIGHT OF USED CANISTERS - Although it states that canisters } \\
\text { were weighed without patients knowing, the patient was still asked to bring in } \\
\text { the canister. Any blinding could have been broken due to the nature of the in- } \\
\text { tervention }\end{array}$ \\
\hline
\end{tabular}

\begin{tabular}{|c|c|c|}
\hline $\begin{array}{l}\text { Blinding of participants } \\
\text { (performance bias) } \\
\text { Patient outcome }\end{array}$ & High risk & $\begin{array}{l}\text { (PRIMARY) DAYS LOST FROM WORK OR SCHOOL - subjective measure; blinding } \\
\text { could have been broken due to the nature of the intervention }\end{array}$ \\
\hline
\end{tabular}

Blinding of personnel (per- Unclear risk

(PRIMARY) WEIGHT OF USED CANISTERS - Blinding information not provided

formance bias)

Adherence measure

\begin{tabular}{|c|c|c|}
\hline $\begin{array}{l}\text { Blinding of personnel (per- } \\
\text { formance bias) }\end{array}$ & Unclear risk & $\begin{array}{l}\text { (PRIMARY) DAYS LOST FROM WORK OR SCHOOL - Insufficient information } \\
\text { about blinding provided }\end{array}$ \\
\hline
\end{tabular}

Patient outcome

\begin{tabular}{lll}
$\begin{array}{l}\text { Incomplete outcome data } \\
\text { (attrition bias) } \\
\text { Adherence measure }\end{array}$ & Low risk & $\begin{array}{l}\text { (PRIMARY) WEIGHT OF USED CANISTERS - Dropouts/missing information ac- } \\
\text { counted for. Missing outcomes not enough to have an impact on the effect size }\end{array}$ \\
\hline $\begin{array}{l}\text { Incomplete outcome data } \\
\begin{array}{l}\text { (attrition bias) } \\
\text { Patient outcome }\end{array}\end{array}$ & Low risk & $\begin{array}{l}\text { (PRIMARY) DAYS LOST FROM WORK OR SCHOOL - incomplete data are account- } \\
\text { ed for }\end{array}$ \\
\hline
\end{tabular}

\begin{tabular}{ll} 
Cote 2001 & \\
\hline Methods & $\begin{array}{l}\text { All patients were stratified for treatment center. The first } 45 \text { patients among } 126 \text { patients were recruit- } \\
\text { ed in the control group to avoid contamination. Subsequent eligible patients were randomized in the } 2 \\
\text { educated groups. Only the randomized groups are eligible for our review }\end{array}$ \\
\hline Participants & $\begin{array}{l}126 \text { patients were enrolled in the study, but } 105 \text { attended for randomization. Patients (aged }>18 \text { years) } \\
\text { with an acute exacerbation of asthma who had not previously taken part in any asthma educational } \\
\text { program. Patients older than } 40 \text { years of age in whom the best forced expiratory volume in } 1 \text { second } \\
\text { (FEV1) was lower than } 80 \% \text { of predicted were excluded. All patients with concurrent medical illnesses } \\
\text { that in the judgment of the investigators contraindicated study participation were also excluded }\end{array}$ \\
\hline
\end{tabular}


Cote 2001 (Continued)

Interventions

The patients in Group C (control) received the usual treatment given for an acute asthma exacerbation. In addition to standard treatment as for Group C treatment, patients in Group Limited Education (LE) were given a self action plan that was explained by the on call physician. The action plan used "traffic lights" (green, yellow, red) to describe specific states of asthma control based on Peak Expiratory Flow and symptoms and actions that the patient should take for each state (pages 1415 to 1416). Subjects were all instructed by a respiratory therapist or study nurse in the proper use of an inhaler. In addition to what patients in Group LE received, the patients in Group Structured Education participated in a structured asthma educational program based on the PRECEDE model of health education within 2 weeks after their randomization. Structured educational intervention group Group SE. In addition to what patients in Group LE received, the patients in Group SE participated in a structured asthma educational program based on the PRECEDE model of health education within 2 weeks after their randomization. Briefly, this model takes into consideration 3 different issues that are important when dealing with health-related behaviors: predisposing factors (belief, attitude, knowledge); enabling factors (community resource, family support); and reinforcement. The teaching was provided individually or in small groups according to patient preference. The intervention focused mainly on self management. To increase patient self confidence in making his or her own treatment decisions, the interaction with the patient was based on the self efficacy theory of Bandura. Reinforcement was provided at the 6-month follow-up visit

Compliance with inhaled corticosteroids was evaluated according to the patient's own estimation at 2
weeks and 12 months. Patient outcome measures included number of urgent visits for an acute exacer-
bation of asthma, lung function tests, knowledge, use of an action plan, compliance with inhaled corti-
costeroids, quality of life score

Notes

The method of measuring adherence is very insensitive because it only indicates whether the person had a prescription for inhaled corticosteroids, not whether they used it

\section{Risk of bias}

\begin{tabular}{lll} 
Bias & Authors' judgement & Support for judgement \\
\hline $\begin{array}{ll}\text { Random sequence genera- } \\
\text { tion (selection bias) }\end{array}$ & Unclear risk & $\begin{array}{l}\text { No mention of process of randomization. (pg 1415) "All patients were stratified } \\
\text { for treatment center. To avoid contamination of the control group, the first } \\
45 \text { patients were recruited in the control group. Subsequent eligible patients } \\
\text { were randomized in the two educated groups. At this point in time, physicians } \\
\text { unfamiliar with the prescription of self action plans were given information ei- } \\
\text { ther by the study coordinator or the investigator". }\end{array}$ \\
&
\end{tabular}

$\begin{array}{lll}\begin{array}{l}\text { Allocation concealment } \\ \text { (selection bias) }\end{array} & \text { Unclear risk } & \text { No information provided on allocation concealment. (pg 1) "All patients were } \\ \text { stratified for treatment center. To avoid contamination of the control group, } \\ \text { the first } 45 \text { patients were recruited in the control group. Subsequent eligible } \\ \text { patients were randomized in the two educated groups." }\end{array}$

\begin{tabular}{|c|c|c|}
\hline $\begin{array}{l}\text { Selective reporting (re- } \\
\text { porting bias) }\end{array}$ & Unclear risk & $\begin{array}{l}\text { Apparently, all declared outcomes were reported but protocol was not avail- } \\
\text { able. Hence, marked uncertain }\end{array}$ \\
\hline
\end{tabular}

\begin{tabular}{lll}
\hline Other bias & Unclear risk & No limitations noted in discussion and no clear biases \\
\hline $\begin{array}{l}\text { Blinding of outcome as- } \\
\text { sessment (detection bias) } \\
\text { Adherence measure }\end{array}$ & Unclear risk & (PRIMARY) SELF REPORT - INTERVIEW - No information provided \\
\hline
\end{tabular}

\begin{tabular}{|c|c|c|}
\hline $\begin{array}{l}\text { Blinding of outcome as- } \\
\text { sessment (detection bias) } \\
\text { Patient outcome }\end{array}$ & Unclear risk & (PRIMARY) URGENCY VISITS - No information provided \\
\hline $\begin{array}{l}\text { Blinding of participants } \\
\text { (performance bias) }\end{array}$ & High risk & (PRIMARY) SELF REPORT - INTERVIEW - Subjective outcome \\
\hline
\end{tabular}


Cote 2001 (Continued)

Adherence measure

\begin{tabular}{|c|c|c|}
\hline Blinding of participants & High risk & $\begin{array}{l}\text { (PRIMARY) URGENCY VISITS - Patients kept track of this information. Any blind- } \\
\text { ing could have been broken }\end{array}$ \\
\hline
\end{tabular}

Patient outcome

Blinding of personnel (per- Unclear risk

(PRIMARY) SELF REPORT - INTERVIEW - No information provided

formance bias)

Adherence measure

Blinding of personnel (per- Unclear risk

(PRIMARY) URGENCY VISITS - No information provided

formance bias)

Patient outcome

Incomplete outcome data Unclear risk

(attrition bias)

Adherence measure

(PRIMARY) SELF REPORT - INTERVIEW - Compliance data collected from 48 only. No group-wise distribution available: thus, unable to predict the effect

\section{Incomplete outcome data Unclear risk \\ (attrition bias) \\ (PRIMARY) URGENCY VISITS - No dropout information provided}

Patient outcome

(20)

Coull 2004

319 patients were randomized by the researchers after giving informed consent. 165 patients were
in the mentoring group and 154 in the control group. Eligible patients were stratified by sex, disease
modality (myocardial infarction or angina), and location ( 5 areas identified)

Participants
partment, with a clinical diagnosis of ischemic heart disease (IHD). Exclusion criteria were terminal ill-
ness, an abbreviated mental health test score $<8$, inability to complete 3 minutes of Bruce Protocol ex-
ercise tolerance testing, awaiting angioplasty or coronary artery bypass grafting, participation in an-
other clinical study involving coronary risk factor modification or at the request of their consultant or
general practitioner

Interventions

Intervention consisted of participation in a mentor-led group, through attending monthly 2-hour-long meetings in community facilities over a 1-year period. There was an average of 10 patients per group, each led by 2 mentors. Both intervention and control groups continued to receive standard care. The core activities covered in the program were lifestyle risk factors of smoking, diet and exercise; blood pressure and cholesterol; understanding of and ability to cope with IHD; and drug concordance. Each mentored group was also encouraged to develop its own agenda. Input was provided from a pharmacist, cardiac rehabilitation specialist nurse, dietician, welfare benefits advisor, and Recreation Services. Volunteer lay health mentors, aged 54 to 74 recruited from the local community, led the groups

Outcomes

Perceived change in taking of medication was measured using a 5-point Likert scale in the exit questionnaire. Outcome measures were changes in blood pressure, cholesterol and medication, and cardiovascular events; non-medical support requirement, health status and psychological functioning, and social inclusion

Notes

This is self reported concordance and there was no attempt to standardize the regimens, so this may be explained by differences in medications, insensitive/biased measure of adherence, or low power

\section{Risk of bias}

\section{Bias}

Authors' judgement Support for judgement 
Coull 2004 (Continued)

Random sequence genera- Low risk tion (selection bias)
Randomization was done appropriately. (pg 350) "Patients were randomised by the researchers after giving informed consent. Eligible patients were stratified by sex, disease modality (myocardial infarction or angina) and location (five areas identified). They were allocated using computer-generated sealed envelopes supplied by the University of Edinburgh Medical Statistics Unit."

\begin{tabular}{|c|c|c|}
\hline $\begin{array}{l}\text { Allocation concealment } \\
\text { (selection bias) }\end{array}$ & Unclear risk & $\begin{array}{l}\text { Allocation concealment via sealed envelopes but unclear if opaque or ordered. } \\
\text { (pg 350) "...They were allocated using computer-generated sealed envelopes } \\
\text { supplied by the University of Edinburgh Medical Statistics Unit." }\end{array}$ \\
\hline
\end{tabular}

Selective reporting (re- Unclear risk No reporting bias detected but protocol not available porting bias)

Other bias High risk

Some major limitations were noted in discussion. (pg 353) "We recognise limitations of our study due to potential referral bias introduced by focussing on fitter individuals who could complete exercise testing. The inclusion of food and physical activity diaries was open to recall bias but changes were biologically consistent in a beneficial direction. The widespread community interest in this study and subsequent increased awareness of risk factors for coronary heart disease may have diluted the effect of mentoring. Our study was not sufficiently powered to elicit differences in clinical events and mortality. We also recognise that a small number of our significant results may be explained by multiple testing."

Blinding of outcome as- Low risk sessment (detection bias)

Adherence measure
(PRIMARY) SELF REPORT - QUESTIONNAIRE - Outcome assessors were blinded. (pg 349) "Exit evaluation was blinded."
Blinding of outcome as- Unclear risk sessment (detection bias)

Patient outcome

Blinding of participants (performance bias)

Adherence measure

Blinding of participants High risk
(performance bias)

Patient outcome
(PRIMARY) HEALTH QUESTIONNAIRES - (pg 349) "Exit assessments were by blinded staff". Health status and food data were collected separately; no mention about blinding
High risk

(PRIMARY) SELF REPORT - QUESTIONNAIRE - No mention of patient blinding and interviews are subjective. Likely high risk due to the nature of the intervention

\begin{tabular}{|c|c|c|}
\hline $\begin{array}{l}\text { Blinding of personnel (per- } \\
\text { formance bias) } \\
\text { Adherence measure }\end{array}$ & Unclear risk & $\begin{array}{l}\text { (PRIMARY) SELF REPORT - QUESTIONNAIRE - No mention of study personnel } \\
\text { blinding }\end{array}$ \\
\hline $\begin{array}{l}\text { Blinding of personnel (per- } \\
\text { formance bias) } \\
\text { Patient outcome }\end{array}$ & Unclear risk & $\begin{array}{l}\text { (PRIMARY) HEALTH QUESTIONNAIRES - No mention of blinding of other study } \\
\text { personnel }\end{array}$ \\
\hline $\begin{array}{l}\text { Incomplete outcome data } \\
\text { (attrition bias) } \\
\text { Adherence measure }\end{array}$ & Low risk & $\begin{array}{l}\text { (PRIMARY) SELF REPORT - QUESTIONNAIRE - Balanced dropouts and reasons } \\
\text { provided }\end{array}$ \\
\hline $\begin{array}{l}\text { Incomplete outcome data } \\
\text { (attrition bias) } \\
\text { Patient outcome }\end{array}$ & Unclear risk & $\begin{array}{l}\text { (PRIMARY) HEALTH QUESTIONNAIRES - Low rate of completion for food diary } \\
\text { but likely to be low bias for other outcomes in the questionnaire list }\end{array}$ \\
\hline
\end{tabular}

(PRIMARY) HEALTH QUESTIONNAIRES - Likely high risk due to the nature of the intervention. No mention of blinding of patients and subjective interviews 
Dejesus 2009

\begin{tabular}{ll}
\hline Methods & Randomized controlled trial \\
\hline Participants & The study location was 53 sites in the United States and 2 sites in Puerto Rico \\
& 203 participants were randomized to the intervention group and 97 participants were randomized to \\
the control group & \\
The inclusion criteria were male or nonpregnant female patients 18 years or older with adequate renal \\
function, documented HIV-1 seropositivity, demonstrated maintenance of virologic suppression for at \\
least 3 months on their current regimen and patients have a life expectancy of greater than or equal to \\
1 year \\
The exclusion criteria were taking an nonnucleoside reverse transcriptase inhibitor (NNRTI)-based reg- \\
imen consisting of EFV plus TDF and FTC, had taken NRTI-only therapy for $>7$ days before their current \\
therapy, individuals with known hypersensitivity to any of the components of EFV/FTC/TDF, have resis- \\
tance to any of the study agents at any time in the past, a new AIDS defining condition (with the excep- \\
tion of CD4 criteria) diagnosed within 30 days of baseline, taking nephrotoxic medications or agents \\
known to interact with EFV
\end{tabular}

$\begin{array}{ll}\text { Interventions } & \text { Intervention: SINGLE TABLET REGIMEN (EFV/FTC/TDF) } \\ \text { Intervention group patients were prescribed a single-tablet regimen consisting of efavirenz/emtric- } \\ \text { itabine/tenofovir disoproxil fumarate (EFV/FTC/TDF) } \\ \text { Control: ART } \\ \text { Control group patients were prescribed to be on regular multi-drug ART }\end{array}$

Outcomes The measures of adherence were self reported adherence and pill count. Visual analog scale (VAS) was used to measure self reported adherence. Subjects were required to estimate adherence to their antiretroviral therapy regimen by marking a linear scale. Both the measures were taken at baseline and 48 months

The patient outcomes were virologic suppression, health-related quality of life (assessed by SF-36 questionnaire), and HIV symptom index. The measurements were performed at 4, 12, 24, 36, and 48 weeks

Notes $\quad-\quad$

\section{Risk of bias}

\section{Bias Authors' judgement Support for judgement}

Random sequence genera- Unclear risk tion (selection bias)

Insufficient information to permit judgment of 'Low risk' or 'High risk' of bias. (pg 164) "Patients on stable ART with HIV-1 RNA < 200 copies per milliliter for $>$ or $=3$ months were stratified by prior nonnucleoside reverse transcriptase inhibitor-based or protease inhibitor-based therapy and randomized (2:1) to simplify treatment to EFV/FTC/TDF or to stay on their baseline regimen (SBR)."

Allocation concealment Unclear risk
(selection bias)

Insufficient information to permit judgment of 'Low risk' or 'High risk' of bias. (pg 164) "Patients on stable ART with HIV-1 RNA < 200 copies per milliliter for $>$ or $=3$ months were stratified by prior nonnucleoside reverse transcriptase inhibitor-based or protease inhibitor-based therapy and randomized (2:1) to simplify treatment to EFV/FTC/TDF or to stay on their baseline regimen (SBR)."

\begin{tabular}{|c|c|c|}
\hline $\begin{array}{l}\text { Selective reporting (re- } \\
\text { porting bias) }\end{array}$ & Low risk & $\begin{array}{l}\text { The study protocol is not available but it is clear that the published reports in- } \\
\text { clude all expected outcomes, including those that were pre-specified }\end{array}$ \\
\hline Other bias & Unclear risk & $\begin{array}{l}\text { (pg 173) Authors indicate that there are certain limitations to this study. In gen- } \\
\text { eral, studies that involve switching therapy tend to attract patients motivat- } \\
\text { ed to make a change in treatment, and such studies can have an intrinsic bias } \\
\text { toward favoring the switch strategy under evaluation. More than } 90 \% \text { of sub- }\end{array}$ \\
\hline
\end{tabular}


Dejesus 2009 (Continued)

jects cited regimen simplification as a reason for participation. This is not surprising given that the median duration of prior ART was 3 years, and individuals showing poor regimen tolerability would be much less likely to be receiving such long-term therapy. Thus, the motivation to simplify therapy in this stable population could have affected patients reporting of AEs, adherence, and/or medication preference

\begin{tabular}{lll}
\hline $\begin{array}{l}\text { Blinding of outcome as- } \\
\text { sessment (detection bias) }\end{array}$ & High risk & $\begin{array}{l}\text { (PRIMARY) VISUAL ANALOG SCALE (VAS) - This is an open-label study and the } \\
\text { outcome is subjective. Therefore, lack of blinding is likely to have an impact on } \\
\text { the outcome results }\end{array}$
\end{tabular}

Adherence measure the outcome results

\begin{tabular}{|c|c|c|}
\hline $\begin{array}{l}\text { Blinding of outcome as- } \\
\text { sessment (detection bias) }\end{array}$ & Low risk & $\begin{array}{l}\text { (PRIMARY) VIROLOGIC SUPPRESSION - Blood test are objective. The lack of } \\
\text { blinding of data collectors in this study is not likely to affect the outcome }\end{array}$ \\
\hline
\end{tabular}

Patient outcome

$\begin{array}{ll}\begin{array}{l}\text { Blinding of participants } \\ \text { (performance bias) }\end{array} & \text { High risk } \\ \text { Adherence measure } & \begin{array}{l}\text { (PRIMARY) VISUAL ANALOG SCALE (VAS) - This is an open-label study and the } \\ \text { outcome is subjective. Therefore, lack of blinding is likely to have an impact on } \\ \text { the outcome results }\end{array}\end{array}$

Adherence measure

Blinding of participants Low risk

(PRIMARY) VIROLOGIC SUPPRESSION - Blood test are objective. The lack of

(performance bias) blinding of data collectors in this study is not likely to affect the outcome

Patient outcome

Blinding of personnel (per- High risk

formance bias)

Adherence measure

(PRIMARY) VISUAL ANALOG SCALE (VAS) - This is an open-label study and the outcome is subjective. Therefore, lack of blinding is likely to have an impact on the outcome results

Blinding of personnel (per- Low risk formance bias)

(PRIMARY) VIROLOGIC SUPPRESSION - Blood tests are objective. The lack of

Patient outcome blinding of data collectors in this study is not likely to affect the outcome

\begin{tabular}{|c|c|c|}
\hline $\begin{array}{l}\text { Incomplete outcome data } \\
\text { (attrition bias) } \\
\text { Adherence measure }\end{array}$ & Low risk & $\begin{array}{l}\text { (PRIMARY) VISUAL ANALOG SCALE (VAS) - Author's note: this is a 2:1 random- } \\
\text { ization to intervention arm:control arm, so the percentage of attrition is } 11 \% \\
\text { versus } 12 \% \text {; there is no imbalance }\end{array}$ \\
\hline
\end{tabular}

Adherence measure versus $12 \%$; there is no imbalance

$\begin{array}{ll}\begin{array}{l}\text { Incomplete outcome data } \\ \text { (attrition bias) }\end{array} & \text { Low risk } \\ \text { Patient outcome } & \text { tion to intervention arm:control arm, so the percentage of attrition is } 11 \% \text { ver- } \\ & \text { sus } 12 \% \text {; there is no imbalance }\end{array}$
tion to intervention arm:control arm, so the percentage of attrition is $11 \%$ versus $12 \%$; there is no imbalance

\section{Dilorio 2008}

\begin{tabular}{ll}
\hline Methods & Randomized controlled trial \\
\hline Participants & The study location was a HIV/AIDS clinic in Atlanta, Georgia, USA \\
& 125 participants were randomized to the intervention group and 122 participants were randomized to \\
the control group & \\
The inclusion criteria were 1$)$ infected with HIV, (2) referred to the nurse educator for adherence educa- \\
tion, (3) prescribed for the first time a multi-drug regimen or had a recent change in their regimen, (4) \\
18 years of age or older, (5) able to speak English and (6) willing to talk with a Get Busy Living recruiter
\end{tabular}

Interventions

Intervention: MOTIVATIONAL INTERVIEWING

Intervention group receives usual adherence education and motivational interview. Participants received 5 individual $\mathrm{MI}$ counseling sessions with a study nurse counselor over a 3-month period. The goal of these sessions was to help participants gain an understanding of their medication-taking behaviors and the actions necessary to successfully maintain a high level of adherence. The counselor 
Dilorio 2008 (Continued)

used a MI script to guide the interaction with the participants. During the session participants were encouraged to identify and discuss barriers to adherence, to express and resolve ambivalence about taking medications, and to support motivation to attain or maintain adherence. After each medication was discussed and an action plan developed, the counselor ended each session by summarizing the discussion and the action plan agreed upon by the participant and counselor. Session 1 was completed in-person for all participants. Telephone sessions (for sessions 2 though 5) were conducted as needed for participants who were unable to meet the counselor in the clinic. Participants were paid USD 10 for completing the first MI session and USD 5 for each of the remaining 4 sessions. Participants in the intervention group also received a copy of the Get Busy Living video, a journal and a calendar

Control: CONTROL

Participants randomized to the control group received the usual adherence education provided at the clinic. 3 nurse educators employed at the HIV clinic provide comprehensive adherence education to patients who are initiating or changing ART. They use a variety of teaching methods that are tailored for each individual based on factors such as education level, culture, type of regimen and time schedule. Patients were referred to the Get Busy Living staff when the nurse educators cleared them to begin taking their medications. Participants could continue to meet with the nurse educators for adherence assistance as needed after the initial education sessions

Outcomes

The measure of adherence was a Medication Event Monitoring System (MEMS) as the primary measure of adherence. MEMS consist of a microprocessor that is contained within the cap of the medication bottle. When the cap is opened, the date and time of opening are recorded and stored. These data are downloaded to a computer and used to calculate a variety of adherence measures. For the present study, 2 MEMS adherence rates were calculated. The first was based on the correspondence between the number of doses prescribed per day and the number of cap openings per day. The second was based on the number of cap openings occurring within one hour of the prescribed time for the dose. Each was converted to a percentage, i.e. per cent of doses taken and per cent of doses taken on schedule. Only one medication per person was monitored using MEMS. The staff selected the medication for monitoring using a predetermined list of possible medication combinations. MEMS caps have been used in a number of research studies assessing ART adherence and have been found to be a reliable and valid measure of adherence.

The patient outcomes were viral load and CD4 counts, assessed based on medical records, where viral load was measured by the AMPLICOR HIV-1 MONITOR Test, and CD4 cell count was determined by the BD FACSCalibur system. All tests were conducted by the medical center laboratory, which used appropriate techniques to ensure reliability and validity of the results of the tests

Notes -

\section{Risk of bias}

\begin{tabular}{lll}
\hline Bias & Authors' judgement & Support for judgement \\
\hline $\begin{array}{l}\text { Random sequence genera- } \\
\text { tion (selection bias) }\end{array}$ & Low risk & $\begin{array}{l}\text { The study was a randomized controlled trial in which participants were ran- } \\
\text { domized by use of computer-generated codes to either the usual care or inter- } \\
\text { vention condition(pg 274) }\end{array}$ \\
\hline
\end{tabular}

\begin{tabular}{|c|c|c|}
\hline $\begin{array}{l}\text { Allocation concealment } \\
\text { (selection bias) }\end{array}$ & Unclear risk & $\begin{array}{l}\text { No mention of allocation concealment - (pg 274) "The study was a random- } \\
\text { ized controlled trial in which participants were randomized by use of comput- } \\
\text { er-generated codes to either the usual care or intervention condition." }\end{array}$ \\
\hline
\end{tabular}

Selective reporting (re- Unclear risk No protocol available
porting bias)

Other bias Unclear risk

\begin{abstract}
Some questions on generalizability; no other serious or apparent bias in trial. (pg 281-2) "...there are several limitations of this study. First, the sample was composed primarily of low-income African American men. Thus, the results cannot be generalized to those in other groups who are also prescribed ART. Future research should focus on other groups affected by HIV, including women and gay men and other cultural groups, including Hispanic and Asian
\end{abstract}


Dilorio 2008 (Continued)

men and women. Second, all men and women who were initiating or changing ART were eligible to participate provided they met other study criteria. We did not limit participants to those who were reported difficulties taking their medications. We found that many participants maintained a high level of adherence throughout the study, limiting our ability to fully test the usefulness of MI in promoting behavioral change. Finally, we asked participants to use MEMS $\dagger$ caps throughout the one-year study. This proved difficult for some individuals. In future studies, researchers might consider limiting the use of these caps to short periods of time around the follow-up assessment periods. Finally, cost of lab tests limited our ability to fully test the effect of the intervention on viral load and CD4 counts. Although there was some indication that those in the intervention group had more favorable lab values, future research should include systematic assessment of these indices. Finally, the types and doses of medications changed over the course of the study..."

$\begin{array}{ll}\begin{array}{l}\text { Blinding of outcome as- } \\ \text { sessment (detection bias) }\end{array} & \text { Low risk }\end{array} \quad \begin{aligned} & \text { (PRIMARY) MEMS - No mention of blinding but MEMS is unlikely to be affected } \\ & \text { by outcome assessors }\end{aligned}$

Adherence measure by outcome assessors

\begin{tabular}{|c|c|c|}
\hline $\begin{array}{l}\text { Blinding of outcome as- } \\
\text { sessment (detection bias) }\end{array}$ & Unclear risk & $\begin{array}{l}\text { (PRIMARY) VIRAL LOAD - The information about CD4 cell count was collected } \\
\text { from medical records. No mention of blinding }\end{array}$ \\
\hline
\end{tabular}

Patient outcome

$\begin{aligned} & \text { Blinding of participants } \\ & \text { (performance bias) }\end{aligned} \quad$ High risk
(PRIMARY) MEMS - No mention of patient blinding

Adherence measure

\begin{tabular}{ll}
\hline $\begin{array}{l}\text { Blinding of participants } \\
\text { (performance bias) }\end{array}$ & Low risk \\
Patient outcome & $\begin{array}{l}\text { (PRIMARY) VIRAL LOAD - The data were abstracted from medical records; it is } \\
\text { unlikely the patient would influence data }\end{array}$ \\
\hline
\end{tabular}

\begin{tabular}{|c|c|c|}
\hline $\begin{array}{l}\text { Blinding of personnel (per- } \\
\text { formance bias) } \\
\text { Adherence measure }\end{array}$ & Unclear risk & $\begin{array}{l}\text { (PRIMARY) MEMS - No mention of blinding of staff. Insufficient information to } \\
\text { permit judgment of 'Low risk' or 'High risk }\end{array}$ \\
\hline
\end{tabular}

\begin{tabular}{|c|c|c|}
\hline $\begin{array}{l}\text { Blinding of personnel (per- } \\
\text { formance bias) } \\
\text { Patient outcome }\end{array}$ & Unclear risk & $\begin{array}{l}\text { (PRIMARY) VIRAL LOAD - it is unclear from the paper whether key personnel } \\
\text { were blinded or not }\end{array}$ \\
\hline $\begin{array}{l}\text { Incomplete outcome data } \\
\text { (attrition bias) } \\
\text { Adherence measure }\end{array}$ & Low risk & $\begin{array}{l}\text { (PRIMARY) MEMS - Dropouts fairly balanced and reasons for withdrawals noted } \\
\text { "A total of } 23 \text { participants actively withdrew, were withdrawn from the study } \\
\text { at various points or died: } 14 \text { in the control and nine in the intervention group. } \\
\text { Most of these participants had died ( } 70 \%) \text {. Other reasons for withdrawal in- } \\
\text { cluded: moved, time constraints and loss of interest. Because the primary } \\
\text { measures of adherence were based on data obtained from MEMS cap use, par- } \\
\text { ticipants with at least one month ( } 4 \text { weeks) of monitored days beyond the date } \\
\text { of baseline assessment were included in the main analyses." }\end{array}$ \\
\hline
\end{tabular}

\begin{tabular}{|c|c|c|}
\hline $\begin{array}{l}\text { Incomplete outcome data } \\
\text { (attrition bias) } \\
\text { Patient outcome }\end{array}$ & Low risk & $\begin{array}{l}\text { (PRIMARY) VIRAL LOAD - Missing outcome data are balanced in numbers across } \\
\text { intervention groups, with similar reasons for missing data across groups }\end{array}$ \\
\hline
\end{tabular}

Patient outcome

Druss 2010

\begin{tabular}{ll}
\hline Methods & Randomized controlled trial \\
\hline Participants & The study location was an urban Community Mental Health Center (CMHC) \\
\hline
\end{tabular}


Druss 2010 (Continued)

41 participants were randomized to the intervention group and 39 participants were randomized to the control group

The inclusion criteria were to be on the active patient roster at the $\mathrm{CMHC}$, have a severe mental illness, have one or more chronic medical condition, and have the capacity to provide informed consent

\begin{abstract}
Interventions
Intervention: HEALTH AND RECOVERY PROGRAM (HARP)

Participants in the intervention group attended up to 6 group sessions led by mental health peer specialists. Sessions covered the following topics related to chronic disease self management: 1 . Overview of self management 2. Exercise and physical activity 3. Pain and fatigue management 4. Healthy eating on a limited budget 5 . Medication management and 6 . Finding and working with a regular doctor. During the sessions, peer educators modeled appropriate behaviors and responses, and participation from each group member helped model behavior and improve motivation for other members. Attendees are taught to develop short-term "action plans" for choosing domains of health behavior change. This process involves identifying a problem that is of particular concern, listing ideas for solving the problem, and then developing a plan outlining specific, short-term goals for improvement. 2 certified mental health peer specialists participated in a community-based, 5-day chronic disease self-management program (CDSMP) master training course to become master trainers in the CDSMP program. Subsequently, they received 3 additional days of training from the team's principal investigator and health educator in the Health and Recovery Peer (HARP) program
\end{abstract}

Control: USUAL CARE

Subjects assigned to usual care continued to receive all medical, mental health, and peer-based services that they were otherwise receiving prior to entry into the study

Outcomes The measures of adherence were a validated self report measure of problems in adherence to medication

The patient outcomes were patient activation, which reflects an individual's perceived ability to manage his or her illness and health behaviors, and act as an effective patient. This construct was measured using the 13-item Patient Activation Measure (PAM). Patient activation is calculated on a 0 to 100 score, with 100 as the highest possible degree of activation. Disease self management was assessed using questions about physical activity, health services use. Questions about physical activity and source of a primary care provider were drawn from the Behavioral Risk Factor Surveillance System (BRFSS). Health-related quality of life (HRQOL) was measured by the SF-36, constructed for use in the Medical Outcomes Study. A Physical Component Summary (PCS) and Mental Component Summary (MCS) scores were constructed from the survey, scored between 0 (poor health) and 100 (perfect health)

Notes -

\title{
Risk of bias
}

\begin{tabular}{lll}
\hline Bias & Authors' judgement & Support for judgement \\
\hline $\begin{array}{l}\text { Random sequence genera- } \\
\text { tion (selection bias) }\end{array}$ & Low risk & $\begin{array}{l}\text { Computer randomization program. (pg 266) "Using a computerized algo- } \\
\text { rithm, patients were randomized to the intervention or usual care group by the } \\
\text { project manager. After randomization, interviews were administered at base- } \\
\text { line and again at } 6 \text { months post-baseline. Interviewers were blinded to sub- } \\
\text { jects' randomization status." }\end{array}$ \\
\hline $\begin{array}{l}\text { Allocation concealment } \\
\text { (selection bias) }\end{array}$ & Unclear risk & $\begin{array}{l}\text { No mention of allocation concealment. (pg 266) "Using a computerized algo- } \\
\text { rithm, patients were randomized to the intervention or usual care group by the } \\
\text { project manager. After randomization, interviews were administered at base- } \\
\text { line and again at } 6 \text { months post-baseline. Interviewers were blinded to sub- } \\
\text { jects' randomization status." }\end{array}$ \\
\hline
\end{tabular}
Selective reporting (re-
Unclear risk No protocol available porting bias) 
Druss 2010 (Continued)

Other bias High risk Several limitations and it is a pilot study. (pg 268) "As a pilot study, the study had several limitations, including reliance on self report outcome measures, a relatively brief follow-up period, and lack of adequate power to assess statistical significance for many of the study outcomes. Further testing using a broader range of outcome measures, longer follow-up periods, and larger sample sizes will be needed to establish the HARP program as an evidence-based practice."

\begin{tabular}{|c|c|c|}
\hline $\begin{array}{l}\text { Blinding of outcome as- } \\
\text { sessment (detection bias) } \\
\text { Adherence measure }\end{array}$ & Low risk & $\begin{array}{l}\text { (PRIMARY) SELF REPORTED ADHERENCE - Outcome assessors blinded. (pg } \\
\text { "Interviewers were blinded to subjects' randomization status" }\end{array}$ \\
\hline $\begin{array}{l}\text { Blinding of outcome as- } \\
\text { sessment (detection bias) } \\
\text { Patient outcome }\end{array}$ & Low risk & $\begin{array}{l}\text { (PRIMARY) PATIENT ACTIVATION - Outcome assessors blind. (pg 266) "Inter- } \\
\text { viewers were blinded to subjects' randomization status" }\end{array}$ \\
\hline
\end{tabular}

\begin{tabular}{|c|c|c|}
\hline $\begin{array}{l}\text { Blinding of participants } \\
\text { (performance bias) } \\
\text { Adherence measure }\end{array}$ & High risk & $\begin{array}{l}\text { (PRIMARY) SELF REPORTED ADHERENCE - No mention of patient blinding and } \\
\text { this is a subjective self report measure }\end{array}$ \\
\hline
\end{tabular}

$\begin{array}{ll}\begin{array}{l}\text { Blinding of participants } \\ \text { (performance bias) }\end{array} & \text { High risk } \\ \begin{array}{l}\text { Patient outcome } \\ \text { (PRIMARY) PATIENT ACTIVATION - No mention of blinding of patients and sub- } \\ \text { jective questionnaire }\end{array}\end{array}$

\begin{tabular}{|c|c|c|}
\hline $\begin{array}{l}\text { Blinding of personnel (per- } \\
\text { formance bias) }\end{array}$ & Unclear risk & $\begin{array}{l}\text { (PRIMARY) SELF REPORTED ADHERENCE - No mention of blinding of other } \\
\text { study staff }\end{array}$ \\
\hline
\end{tabular}

Adherence measure

\section{(PRIMARY) SELF REPORTED ADHERENCE - No mention of blinding of other study staff}

(PRIMARY) PATIENT ACTIVATION - No mention of blinding study staff

Blinding of personnel (per- Unclear risk

formance bias)

Patient outcome

\begin{tabular}{|c|c|c|}
\hline $\begin{array}{l}\text { Incomplete outcome data } \\
\text { (attrition bias) } \\
\text { Adherence measure }\end{array}$ & Unclear risk & $\begin{array}{l}\text { (PRIMARY) SELF REPORTED ADHERENCE - More dropouts in control group; un- } \\
\text { clear if reasons related to intervention }\end{array}$ \\
\hline
\end{tabular}

\begin{tabular}{|c|c|c|}
\hline $\begin{array}{l}\text { Incomplete outcome data } \\
\text { (attrition bias) } \\
\text { Patient outcome }\end{array}$ & Unclear risk & $\begin{array}{l}\text { (PRIMARY) PATIENT ACTIVATION - Unequal dropouts and reasons for loss to fol- } \\
\text { low-up unclear if related to intervention }\end{array}$ \\
\hline
\end{tabular}

Duncan 2012

\begin{tabular}{ll}
\hline Methods & Randomized controlled trial \\
\hline Participants & The study location was not available \\
& 40 participants were randomized to the intervention group and 36 participants were randomized to the \\
control group & $\begin{array}{l}\text { The inclusion criteria were currently taking a recognized ART regimen and reporting a level of side ef- } \\
\text { fect-related bother for the previous } 30 \text { days at or above } 8 \text { (corresponding to the } 40 \text { th percentile in an- } \\
\text { other sample) on the side effect and symptom distress scale }\end{array}$ \\
The exclusion criteria were enrollment in another behavioral coping or HIV adherence intervention \\
research study or MBSR program, severe cognitive impairment, active psychosis, or active substance \\
abuse that would interfere with capacity to participate in MBSR
\end{tabular}


Duncan 2012 (Continued)

Interventions
Intervention: MINDFULNESS-BASED STRESS REDUCTION

MBSR aims to teach participants to respond to stressful situations "mindfully" - a state in which one focuses on the present moment, accepting and acknowledging it without getting caught up in thoughts that are about the situation or emotional reactions. This enables people to respond to the situation by making conscious choices to respond instead of reacting automatically. The MBSR program consists of the following elements: (1) individual pre-program intake interviews performed by the course instructor with each participant, lasting 30 minutes; (2) 8 weekly classes of 2.5 to 3 hours; (3) an all-day silent retreat during the 6 th week of the program; and (4) daily home assignments including a minimum of 45 minutes per day of formal mindfulness practice and 5 to 15 minutes of informal practice, 6 days per week for the entire duration of the course. The total in-class contact is approximately 30 hours, and the total home assignments are a minimum of 42 to 48 hours. In addition, one to 2 additional individual interview sessions may be provided, at instructor discretion, to individual participants during the course. In addition to teaching mindfulness practices, the course includes didactic presentations that include information on stress physiology and stress reactivity. The course also addresses the effects of perception, appraisal, and attitude on health habits and behavior and on interpersonal communication

\section{Control: STANDARD CARE}

Control group received standard care and went through the same assessment procedure as the intervention group

Outcomes

The measures of adherence were AIDS Clinical Trials Group self report adherence measure to assess pills and doses skipped in the last 3 days for each ART medication and a visual analog scale (VAS) developed by Walsh et al to assess 30 -day adherence. The instruments were administered as audio computer-administered self interview (ACASI) and computer-assisted personal interviewing (CAPI) at 3 time points: baseline, 3 and 6 months

The patient outcomes were side effects, perceived stress, depression, positive and negative affect, and mindfulness assessed at baseline, 3 and 6 months. Side effects was measured using a AIDS clinical trial group checklist in which respondents were asked whether they had experienced each of 25 possible symptoms in the preceding 30 days, and whether they attributed these to their ART medications, their HIV infection, or to other causes. Symptoms were coded as: $0=$ did not experience the symptom versus 1 = experienced the symptom; the individual symptoms were then summed to create overall counts of symptoms and symptoms attributable to ART medications. To measure severity, participants were asked how much each symptom bothered them (on a Likert-type scale: $0=$ not present; $1=$ present but does not bother me; ranging to $4=$ present and bothers me terribly). Average symptom bother scores were computed as the mean of these individual Likert items to quantify the overall average bother and bother attributable to ART medications. Residual plots of the sum of symptoms attributable to ART medications variable appeared skewed and heteroskedastic in our data, so log transformation was applied to this outcome. The residual plots of log-transformed symptoms attributable to ART and their average related bother/distress appeared close to normal and homoskedastic. Depression was assessed using the Beck Depression Inventory (BDI). Perceived stress was assessed using the Perceived Stress Scale (PSS). The Positive and Negative Affect Schedule (PANAS), was used to assess the intensity of positive and negative affect during the previous week. Mindfulness was assessed using a 5-factor mindfulness questionnaire. The instruments were administered as audio computer-administered self interview (ACASI) and computer-assisted personal interviewing (CAPI) at 3 time points: baseline, 3, and 6 months

\begin{tabular}{lll}
\hline Notes & - \\
\hline Risk of bias & Authors' judgement & Support for judgement \\
\hline $\begin{array}{l}\text { Random sequence genera- } \\
\text { tion (selection bias) }\end{array}$ & Low risk & $\begin{array}{l}\text { (pg 163) "Randomization was performed in blocks of six using the SAS sys- } \\
\text { tem's PLAN procedure (SAS Institute, Cary, NC). Groups of six participant IDs } \\
\text { were sorted in ascending order and aligned with the treatment output from } \\
\text { the procedure. When less than six participants were available, dummy partici- } \\
\text { pant IDs were used to complete the block." }\end{array}$ \\
\hline
\end{tabular}


Duncan 2012 (Continued)

\begin{tabular}{|c|c|c|}
\hline $\begin{array}{l}\text { Allocation concealment } \\
\text { (selection bias) }\end{array}$ & Unclear risk & Insufficient information about allocation concealment \\
\hline $\begin{array}{l}\text { Selective reporting (re- } \\
\text { porting bias) }\end{array}$ & Unclear risk & None detected; protocol not available \\
\hline Other bias & Unclear risk & $\begin{array}{l}\text { (pg 8) Authors report: low level of intervention participation with only one } \\
\text { third sample completing the } 5 \text { or more of the } 8 \text { sessions }\end{array}$ \\
\hline $\begin{array}{l}\text { Blinding of outcome as- } \\
\text { sessment (detection bias) } \\
\text { Adherence measure }\end{array}$ & Unclear risk & $\begin{array}{l}\text { (PRIMARY) AIDS CLINICAL TRIALS GROUP SELF REPORT ADHERENCE MEASURE } \\
\text { - No mention of outcome assessor blinding }\end{array}$ \\
\hline $\begin{array}{l}\text { Blinding of outcome as- } \\
\text { sessment (detection bias) } \\
\text { Patient outcome }\end{array}$ & Unclear risk & (PRIMARY) SIDE EFFECTS - No mention of outcome assessor blinding \\
\hline $\begin{array}{l}\text { Blinding of participants } \\
\text { (performance bias) } \\
\text { Adherence measure }\end{array}$ & High risk & $\begin{array}{l}\text { (PRIMARY) AIDS CLINICAL TRIALS GROUP SELF REPORT ADHERENCE MEASURE } \\
\text { - Patients likely to be aware of interventions }\end{array}$ \\
\hline
\end{tabular}

\begin{tabular}{lll}
\hline $\begin{array}{l}\text { Blinding of participants } \\
\text { (performance bias) } \\
\text { Patient outcome }\end{array}$ & High risk & $\begin{array}{l}\text { (PRIMARY) SIDE EFFECTS - Insufficient information about the blinding of par- } \\
\text { ticipants. The outcome is self reported. Thus, the outcome could be biased }\end{array}$ \\
\hline $\begin{array}{l}\text { Blinding of personnel (per- } \\
\text { formance bias) }\end{array}$ & Unclear risk & $\begin{array}{l}\text { (PRIMARY) AIDS CLINICAL TRIALS GROUP SELF REPORT ADHERENCE MEASURE } \\
\text { Adherence measure }\end{array}$
\end{tabular}

\begin{tabular}{lll}
\hline $\begin{array}{l}\text { Blinding of personnel (per- } \\
\text { formance bias) } \\
\text { Patient outcome }\end{array}$ & Unclear risk & (PRIMARY) SIDE EFFECTS - No mention of study staff blinding \\
\hline $\begin{array}{l}\text { Incomplete outcome data } \\
\text { (attrition bias) }\end{array}$ & Low risk & $\begin{array}{l}\text { (PRIMARY) AIDS CLINICAL TRIALS GROUP SELF REPORT ADHERENCE MEASURE } \\
\text { - The number of missing participants is similar in both groups and for similar } \\
\text { reasons. Refer to Figure 1: at 3-month assessment, } 6 \text { participants in the inter- } \\
\text { vention group and 5 participants in the control group were lost to follow-up } \\
\text { because they were unable to contact/schedule. At 6-month follow-up, } 3 \text { from } \\
\text { the intervention and } 3 \text { from the control group were lost to follow-up because } \\
\text { unable to contact/schedule, move outs, or health problems(pg 166) }\end{array}$
\end{tabular}

$\begin{array}{ll}\begin{array}{l}\text { Incomplete outcome data } \\ \text { (attrition bias) }\end{array} & \text { Low risk } \\ \text { Patient } & \text { both groups and for similar reasons }\end{array}$

Patient outcome both groups and for similar reasons

\begin{tabular}{|c|c|}
\hline Methods & Randomized controlled trial \\
\hline \multirow[t]{3}{*}{ Participants } & The study location was not provided \\
\hline & $\begin{array}{l}101 \text { participants were randomized to the intervention group and } 105 \text { participants were randomized to } \\
\text { the control group }\end{array}$ \\
\hline & $\begin{array}{l}\text { The inclusion criteria were patients at least } 18 \text { years of age who were either newly diagnosed or not } \\
\text { treated for at least } 1 \text { year. Except for hypertension, patients had to be healthy and not requiring any } \\
\text { regular long-term drug treatment (e.g. for asthma, chronic obstructive pulmonary disease (COPD), dia- }\end{array}$ \\
\hline
\end{tabular}


Dusing 2009 (Continued)

betes, rheumatoid arthritis, pain medication, depression, psychotropic drugs, inflammatory bowel disease, estrogen replacement therapy, thyroid hormones, hypercholesterolemia, and oral contraception)

Interventions Intervention: MULTIFACTORIAL INTERVENTION

The set of supportive measures provided for selected centers and all patients recruited in these centers is listed below. It was up to the patients to select the tools they would like to use on an individual basis. For the patient: (a) 24-hour timer: the timer can be set to an individual time and provides an acoustic signal every 24 hours at this point of time; (b) Set of 10 reminding stickers to be positioned at prominent places at home (e.g. refrigerator and bathroom mirror); (c) Information brochure for patients with hypertension published by the German Hypertension Society; (d) Information letter for the patient; (e) Information letter the patient can give to next of kin to receive support or his therapy (e.g. spouse reminding of drug intake); (f) Home BP measurement device; (g) Booklet to document home BP measurements

\section{Control: STANDARD CARE}

At the baseline visit, all eligible patients were started on study treatment with valsartan $160 \mathrm{mg}$ daily for 4 weeks. Patients with controlled BP were continued on treatment with valsartan $160 \mathrm{mg}$. Patients not achieving BP values less than $140 / 90 \mathrm{~mm} \mathrm{Hg}$ by week 4 were then uptitrated to valsartan $160 \mathrm{mg}$ and hydrochlorothiazide (HCTZ) $12.5 \mathrm{mg}$ as a fixed-dose combination. Follow-up visits were scheduled after 2 (3rd visit), 4 (4th visit), 8 (5th visit), 14 (6h visit), 24 weeks (7th visit), and at the end of the observation period at 34 weeks ( $8 \mathrm{~h}$ visit). Dispensing of the study drugs was as follows. At baseline, patients received MEMS bottles containing 48 tablets of $160 \mathrm{mg}$ valsartan. At 4th and 5 th visits, that is, after 4 and 8 weeks, patients received further MEMS bottles containing 48 tablets of either $160 \mathrm{mg}$ valsartan or $160 \mathrm{mg}$ valsartan and $12.5 \mathrm{mg}$ of HCTZ depending on their BP. At the 6th and 7th visits, that is, after 14 and 24 weeks of treatment, patients received MEMS bottles containing 76 tablets. Patients were instructed to take their medication per mouth with water in the morning between 0700 and 1100 hours, regardless of meals. No supportive measures were given to patients

Outcomes The measures of adherence were electronic MEMS, which compiled date and time of drug intake through the opening of the medication bottle for every day. The MEMS monitors were drug containers designed to compile the dosing history of ambulatory patients prescribed oral medications. Each monitor consisted of a conventional medicine bottle filled with a special closure that recorded the time and date of each opening and closing of the container through integrated microcircuitry. Monitors were designed to be used by one patient with one drug. A communicator transferred the dose-timing data from the MEMS monitor to a computer. At the 2 nd and 6 th visits, MEMS monitors were to be provided for all patients. At the 6 th and $8 \mathrm{~h}$ visits, the monitors used by the patients were collected by the investigator for data analysis

The patient outcomes were blood pressure response and normalization in the 2 randomized groups

Notes -

\section{Risk of bias}

Bias Authors' judgement Support for judgement

Random sequence genera- Unclear risk tion (selection bias)
No mention of randomization methods. (pg 895) "...cluster-randomized (by center), open-label, multicenter parallel-group study... Centers were assigned to one of the following two treatment arms in a ratio of $1: 1$, centers providing their patients with supportive measures and centers not providing their patients with supportive measures. To avoid any investigator bias in treating one patient with and another patient without supportive measures, investigators rather than patients were randomized to provide only treatment with or without supportive measures for all patients at a single participating center."

No mention of allocation concealment. (pg 895) "...cluster-randomized (by center), open-label, multicenter parallel-group study... Centers were assigned to one of the following two treatment arms in a ratio of $1: 1$, centers providing their patients with supportive measures and centers not providing their patients with supportive measures. To avoid any investigator bias in treating one 
Dusing 2009 (Continued)

patient with and another patient without supportive measures, investigators rather than patients were randomized to provide only treatment with or without supportive measures for all patients at a single participating center."

\begin{tabular}{|c|c|c|}
\hline $\begin{array}{l}\text { Selective reporting (re- } \\
\text { porting bias) }\end{array}$ & Unclear risk & None detected but protocol not available \\
\hline Other bias & Unclear risk & No clear other biases and no limitations mentioned in article \\
\hline $\begin{array}{l}\text { Blinding of outcome as- } \\
\text { sessment (detection bias) } \\
\text { Adherence measure }\end{array}$ & Low risk & (PRIMARY) MEMS - Outcome not likely to be affected by outcome assessors \\
\hline $\begin{array}{l}\text { Blinding of outcome as- } \\
\text { sessment (detection bias) } \\
\text { Patient outcome }\end{array}$ & Unclear risk & $\begin{array}{l}\text { (PRIMARY) BLOOD PRESSURE AND NORMALIZATION - Method of data collec- } \\
\text { tion not detailed in the article and no mention of blinding }\end{array}$ \\
\hline $\begin{array}{l}\text { Blinding of participants } \\
\text { (performance bias) } \\
\text { Adherence measure }\end{array}$ & High risk & (PRIMARY) MEMS - Patients aware of intervention and the measure \\
\hline $\begin{array}{l}\text { Blinding of participants } \\
\text { (performance bias) } \\
\text { Patient outcome }\end{array}$ & Low risk & $\begin{array}{l}\text { (PRIMARY) BLOOD PRESSURE AND NORMALIZATION - Patients not being blind- } \\
\text { ed is unlikely to affect this outcome }\end{array}$ \\
\hline $\begin{array}{l}\text { Blinding of personnel (per- } \\
\text { formance bias) } \\
\text { Adherence measure }\end{array}$ & Low risk & $\begin{array}{l}\text { (PRIMARY) MEMS - It seems other staff were blind. (pg 896) "The centers pro- } \\
\text { viding standard care were blinded with regard to the content of the 'support- } \\
\text { ive measures'" }\end{array}$ \\
\hline $\begin{array}{l}\text { Blinding of personnel (per- } \\
\text { formance bias) } \\
\text { Patient outcome }\end{array}$ & Low risk & $\begin{array}{l}\text { (PRIMARY) BLOOD PRESSURE AND NORMALIZATION - Other staff were blinded. } \\
\text { (pg 895) "The centers providing standard care were blinded with regard to the } \\
\text { content of the 'supportive measures'." Also, open-label but cluster RCT and } \\
\text { objective outcome }\end{array}$ \\
\hline
\end{tabular}

\begin{tabular}{|c|c|c|}
\hline $\begin{array}{l}\text { Incomplete outcome data } \\
\text { (attrition bias) } \\
\text { Adherence measure }\end{array}$ & Unclear risk & $\begin{array}{l}\text { (PRIMARY) MEMS - Uneven loss to follow-up and not all reasons for dropout are } \\
\text { clear; adverse events was one reason for dropouts }\end{array}$ \\
\hline $\begin{array}{l}\text { Incomplete outcome data } \\
\text { (attrition bias) } \\
\text { Patient outcome }\end{array}$ & Unclear risk & $\begin{array}{l}\text { (PRIMARY) BLOOD PRESSURE AND NORMALIZATION - Uneven loss to follow-up } \\
\text { and not all reasons for dropout are clear; adverse events was one reason for } \\
\text { dropouts }\end{array}$ \\
\hline
\end{tabular}

El Miedany 2011

\begin{tabular}{ll}
\hline Methods & Randomized controlled trial \\
\hline Participants & The study location was not available \\
& 55 participants were randomized to the intervention group and 56 participants were randomized to the \\
control group & The inclusion criteria were to have early inflammatory arthritis according to the new ACR/EULAR crite- \\
ria & $\begin{array}{l}\text { Intervention: VISUAL FEEDBACK } \\
\text { The active group consisted of a visual feedback facility (visualization of computer charts showing the } \\
\text { disease progression) that was added to their management protocol. Visual feedback is a relatively new }\end{array}$ \\
\hline Interventions &
\end{tabular}


tool that enables the patient to visualize as well as monitor a real-time change of their disease activity parameters as well as the patient's reported outcome measures. Integrating electronic data recording in the standard rheumatology clinical practice facilitated the introduction of visual feedback into the standard rheumatology practice. During their visit, the patients were given the chance to view the progression of their disease on the computer, discuss the changes in their disease activity parameters, comorbidity risks, functional disability, and quality of life. The patients were assessed at 3-month intervals for another 6 months (unless they sustained a flare up of their condition, at which time they would be reviewed earlier). Before every assessment in the clinic, every patient completed the multidimensional patient reported outcome measures questionnaire

Control: ROUTINE MANAGEMENT

Control group patients continued their routine standard management and assessment every 3 months. All the patient's disease activity parameters, patient-reported outcome measures (PROMs), medications, scores of falls, and cardiovascular risks were recorded and discussed verbally with the patient. Each patient was allowed to view his former completed forms and compare between his/her current scores in comparison to the earlier records

Outcomes The measures of adherence were measured using the Electronic Recording of Outcome Measures for Inflammatory arthritis and Ankylosing spondylitis - EROMIA. Using this system, medication intake could be recorded and downloaded when needed. Adherence to drug therapy was monitored every month for a 6-month period and then every 3 months for another 6 months.

The patient outcomes were disease activity score (DAS-28) and PROMS domains: pain score, patient global assessment, functional disability, and quality of life

\begin{tabular}{ll}
\hline Notes & - \\
\hline Risk of bias &
\end{tabular}

\begin{tabular}{|c|c|c|}
\hline Bias & Authors' judgement & Support for judgement \\
\hline $\begin{array}{l}\text { Random sequence genera- } \\
\text { tion (selection bias) }\end{array}$ & Unclear risk & $\begin{array}{l}\text { No information given in article. This was a double-blind, randomized con- } \\
\text { trolled study, which included } 111 \text { patients diagnosed to have early inflamma- } \\
\text { tory arthritis according to the new ACR/EULAR criteria }\end{array}$ \\
\hline $\begin{array}{l}\text { Allocation concealment } \\
\text { (selection bias) }\end{array}$ & Unclear risk & $\begin{array}{l}\text { No information given in article. This was a double-blind, randomized con- } \\
\text { trolled study, which included } 111 \text { patients diagnosed to have early inflamma- } \\
\text { tory arthritis according to the new ACR/EULAR criteria }\end{array}$ \\
\hline $\begin{array}{l}\text { Selective reporting (re- } \\
\text { porting bias) }\end{array}$ & High risk & No protocol available \\
\hline Other bias & Unclear risk & $\begin{array}{l}\text { Did not report any limitations in the manuscript, but there is a lot of miss- } \\
\text { ing information in the study, such as percentage of participants who were re- } \\
\text { tained in the study, the randomization details etc., so more information is } \\
\text { needed }\end{array}$ \\
\hline $\begin{array}{l}\text { Blinding of outcome as- } \\
\text { sessment (detection bias) } \\
\text { Adherence measure }\end{array}$ & Low risk & (PRIMARY) EROMIA - This was a double-blinded study (pg 3061) \\
\hline $\begin{array}{l}\text { Blinding of outcome as- } \\
\text { sessment (detection bias) } \\
\text { Patient outcome }\end{array}$ & Low risk & $\begin{array}{l}\text { (PRIMARY) DISEASE ACTIVITY SCORE (DAS-28) AND PROMS DOMAINS - Dou- } \\
\text { ble-blind, randomized controlled study (pg 3061) }\end{array}$ \\
\hline $\begin{array}{l}\text { Blinding of participants } \\
\text { (performance bias) } \\
\text { Adherence measure }\end{array}$ & Low risk & (PRIMARY) EROMIA - This was a double-blinded study (pg 3061) \\
\hline
\end{tabular}


El Miedany 2011 (Continued)
Blinding of participants
Unclear risk
(PRIMARY) DISEASE ACTIVITY SCORE (DAS-28) AND PROMS DOMAINS - Not (performance bias) enough information in article to judge

Patient outcome

(PRIMARY) EROMIA - Insufficient information to permit judgment of 'Low risk' or 'High risk'
Blinding of personnel (per- Unclear risk formance bias)

Adherence measure
(PRIMARY) DISEASE ACTIVITY SCORE (DAS-28) AND PROMS DOMAINS - Insufficient information to permit judgment of 'Low risk' or 'High risk

Blinding of personnel (per- Unclear risk

formance bias)

Patient outcome

Incomplete outcome data Unclear risk

(attrition bias)

Adherence measure

(PRIMARY) EROMIA - Refer to Table 1: total number of participants who stopped the medication in active group is 4 and in control group is 17. Reasons for stopping are intolerance and side effects. Based on the data in Table 1, it seems that there is a large imbalance between control and active groups, but it is not clear whether there are more missing data due to other reasons

Incomplete outcome data Unclear risk
(attrition bias)

(attrition bias)

(PRIMARY) DISEASE ACTIVITY SCORE (DAS-28) AND PROMS DOMAINS - Refer to

Patient outcome

Table 1: total number of participants who stopped the medication in the active group is 4 and in the control group is 17 . Reasons for stopping are intolerance and side effects. Based on the data in Table 1, it seems that there is a large imbalance between the control and active groups, but it is not clear whether there are more missing data due to other reasons

\section{Ellis 2005}

\section{Methods}

Randomization was completed immediately after baseline data collection by the project statistician. To ensure equivalence across treatment condition, randomization was stratified by level of glycosylated hemoglobin levels $(\mathrm{HbA} 1 \mathrm{c})$ at the baseline visit. A total of 127 adolescents and their families were randomized to either receive the multisystemic therapy (MST) (intervention group) ( $n=64)$ or to the control group $(n=63)$

\section{Participants}

Patients were 1 ) diagnosed with type 1 diabetes for at least 1 year; 2 ) had an average $\mathrm{HbA} 1 \mathrm{c}(\mathrm{A} 1 \mathrm{C})>$ or $=$ to $8 \%$ during the year before study entry, as well as a most recent $\mathrm{A} 1 \mathrm{C}>$ or $=$ to $8 \% ; 3$ ) aged 10 to 17 years, and 4) sufficient mastery of English to communicate with therapists and complete study measures. Patients were excluded from the study if they possessed moderate/severe mental retardation or psychosis 
Ellis 2005 (Continued)

Notes

\section{Risk of bias}

Bias Authors' judgement Support for judgement

Random sequence genera- Unclear risk
tion (selection bias)

Not enough information about randomization process. (pg 1605) "Randomization to the treatment condition was completed immediately after baseline data collection by the project statistician"

\begin{tabular}{|c|c|c|}
\hline $\begin{array}{l}\text { Allocation concealment } \\
\text { (selection bias) }\end{array}$ & Unclear risk & Method of allocation concealment not described \\
\hline $\begin{array}{l}\text { Selective reporting (re- } \\
\text { porting bias) }\end{array}$ & Unclear risk & No protocol available \\
\hline Other bias & Unclear risk & No other apparent bias but insufficient information provided \\
\hline $\begin{array}{l}\text { Blinding of outcome as- } \\
\text { sessment (detection bias) } \\
\text { Adherence measure }\end{array}$ & Unclear risk & $\begin{array}{l}\text { (PRIMARY) 24-HOUR RECALL INTERVIEW - No blinding measure described. Not } \\
\text { clear who collected the data }\end{array}$ \\
\hline $\begin{array}{l}\text { Blinding of outcome as- } \\
\text { sessment (detection bias) } \\
\text { Patient outcome }\end{array}$ & Low risk & $\begin{array}{l}\text { (PRIMARY) A1C - Outcome less likely to be influenced by lack of blinding. No } \\
\text { blinding measures described in the text }\end{array}$ \\
\hline $\begin{array}{l}\text { Blinding of participants } \\
\text { (performance bias) } \\
\text { Adherence measure }\end{array}$ & High risk & $\begin{array}{l}\text { (PRIMARY) 24-HOUR RECALL INTERVIEW - No evidence of blinding, subjective } \\
\text { outcome }\end{array}$ \\
\hline $\begin{array}{l}\text { Blinding of participants } \\
\text { (performance bias) } \\
\text { Patient outcome }\end{array}$ & Low risk & $\begin{array}{l}\text { (PRIMARY) A1C - Outcome less likely to be influenced by lack of blinding. No } \\
\text { blinding measures described in the text }\end{array}$ \\
\hline $\begin{array}{l}\text { Blinding of personnel (per- } \\
\text { formance bias) } \\
\text { Adherence measure }\end{array}$ & Unclear risk & (PRIMARY) 24-HOUR RECALL INTERVIEW - No blinding measure described \\
\hline $\begin{array}{l}\text { Blinding of personnel (per- } \\
\text { formance bias) } \\
\text { Patient outcome }\end{array}$ & Low risk & $\begin{array}{l}\text { (PRIMARY) A1C - Outcome less likely to be influenced by lack of blinding. No } \\
\text { blinding measures described in the text }\end{array}$ \\
\hline $\begin{array}{l}\text { Incomplete outcome data } \\
\text { (attrition bias) } \\
\text { Adherence measure }\end{array}$ & Unclear risk & $\begin{array}{l}\text { (PRIMARY) 24-HOUR RECALL INTERVIEW - } 6 \text { (9\%) of intervention group used } \\
\text { insulin pumps - they were not evaluated for insulin adherence; } 4 \text { of the same } \\
\text { group did not receive intervention. Not known whether this had an effect. Also } \\
\text { "Data were collected at } 7,12,18 \text {, and } 24 \text { months after baseline data collection. } \\
\text { The present study reports on data from } 7 \text { months posttest, as data collection } \\
\text { at later time points is not yet complete." }\end{array}$ \\
\hline $\begin{array}{l}\text { Incomplete outcome data } \\
\text { (attrition bias) } \\
\text { Patient outcome }\end{array}$ & Unclear risk & $\begin{array}{l}\text { (PRIMARY) A1C - } 6 \text { (9\%) of intervention group used insulin pumps - they were } \\
\text { not evaluated for insulin adherence; } 4 \text { of the same group did not receive inter- } \\
\text { vention. Not known whether this had an effect. Also "Data were collected at } 7 \text {, } \\
12,18 \text {, and } 24 \text { months after baseline data collection. The present study reports } \\
\text { on data from } 7 \text { months posttest, as data collection at later time points is not } \\
\text { yet complete." }\end{array}$ \\
\hline
\end{tabular}


Ellis 2012

\begin{tabular}{|c|c|}
\hline Methods & Randomized controlled trial \\
\hline \multirow[t]{4}{*}{ Participants } & The study location was Children's Hospital of Michigan, Detroit, Michigan, USA \\
\hline & $\begin{array}{l}74 \text { participants were randomized to the intervention group and } 72 \text { participants were randomized to the } \\
\text { control group }\end{array}$ \\
\hline & $\begin{array}{l}\text { The inclusion criteria were between } 10 \text { and } 18 \text { years old with type } 1 \text { or } 2 \text { diabetes for at least } 1 \text { year that } \\
\text { required management with insulin, a current } \mathrm{HbA1c} \text { of } 8 \% \text { or higher, a mean } \mathrm{HbA1c} \text { of } 8 \% \text { or higher } \\
\text { during the year before the study entry, and residing in a home setting }\end{array}$ \\
\hline & $\begin{array}{l}\text { The exclusion criteria were moderate or severe mental retardation, psychosis, not English speaking, or } \\
\text { unable to complete study measures in English }\end{array}$ \\
\hline \multirow[t]{4}{*}{ Interventions } & Intervention: MULTISYSTEMIC THERAPY \\
\hline & $\begin{array}{l}\text { Patients in the MST group received both standard medical care and treatment sessions by } 5 \text { mas- } \\
\text { ters-level therapists trained to have sufficient knowledge regarding diabetes to enable them to con- } \\
\text { duct diabetes adherence interventions with families. Treatment included 1-hour family treatment ses- } \\
\text { sions, skills practice (e.g. spending } 15 \text { minutes in home to observe a caregiver implementing a reward } \\
\text { or consequence as part of a behavior plan), attending school meetings to provide information to staff } \\
\text { regarding diabetes care (e.g. } 1 \text { to } 2 \text {-hour staff training), and attending clinic visits with families ( } 2 \text { hours } \\
\text { or more) }\end{array}$ \\
\hline & Control: TELEPHONE SUPPORT \\
\hline & $\begin{array}{l}\text { Control patients (telephone support) received an initial home visit where the program was explained } \\
\text { to the adolescent and primary caregiver by either a master level therapists or doctoral students in clin- } \\
\text { ical psychology or social work. Weekly phone calls (approximately } 30 \text { minutes each) focused on emo- } \\
\text { tional support for diabetes care using client-centered, nondirective counseling, assessing adherence } \\
\text { to diabetes for the previous week, reviewing readings in the blood glucose meter, and helping the ado- } \\
\text { lescent identify solutions to any barriers in their diabetes care. Non-diabetes-related problems such as } \\
\text { peer, school, or family relationship problems were also addressed during the call if desired by the ado- } \\
\text { lescent. Telephone support therapists completed the same formal diabetes education training com- } \\
\text { pleted by MST therapists }\end{array}$ \\
\hline
\end{tabular}

Outcomes The measures of adherence were parent-reported adherence and patient-reported adherence using the Diabetes Management Scale, a questionnaire that measures a broad range of diabetes management behaviors (insulin, diet, blood glucose, symptom response). The questionnaires were administered to parents and patients by a trained research assistant in the participants' homes at baseline and at 7 and 12 months (6-month follow-up)

The patient outcome was hemoglobin $\mathrm{A} 1 \mathrm{c}(\mathrm{HbA1c})$, as measured by a pediatric endocrinologist every 3 to 4 months

\begin{tabular}{ll}
\hline Notes ClinicalTrials protocol found \\
\hline
\end{tabular}

\section{Risk of bias}

\begin{tabular}{lll}
\hline Bias & Authors' judgement & Support for judgement \\
\hline $\begin{array}{l}\text { Random sequence genera- } \\
\text { tion (selection bias) }\end{array}$ & Low risk & $\begin{array}{l}\text { (pg 208) Minimization used: "Randomization... using a permuted block algo- } \\
\text { rithm to ensure equivalence across treatment condition. The project statisti- } \\
\text { cian generated the randomization sequence..." }\end{array}$ \\
\hline $\begin{array}{l}\text { Allocation concealment } \\
\text { (selection bias) }\end{array}$ & Low risk & $\begin{array}{l}\text { The project statistician generated the randomization sequence - randomiza- } \\
\text { tion controlled by independent administration group }\end{array}$ \\
\hline $\begin{array}{l}\text { Selective reporting (re- } \\
\text { porting bias) }\end{array}$ & High risk & $\begin{array}{l}\text { They do not report on diabetic ketoacidosis (DKA) admissions and emergency } \\
\text { room (ER) visits as noted in NCT00372814 }\end{array}$ \\
\hline
\end{tabular}


Ellis 2012 (Continued)

Other bias

Unclear risk
Limitations: Adherence measures: self report and by primary caregiver not always present to verify adherence. Intervention (MST) had more contacts per week than control (telephone): 2 to 3/week compared with 1/week. "In addition, the follow-up period in the current study was limited to 6 months after the conclusion of treatment. While still significant, reductions in average blood glucose levels were attenuated at 6 months follow-up. Longer-term follow-up is needed to better assess the sustainability of MST effects over time. MST and telephone support were not matched on dose (e.g., two to three contacts per week versus one contact per week). Therefore, the possibility that a higher intervention dose in the MST condition accounted for better health outcomes for youth receiving MST cannot be ruled out." sessment (detection bias)

Adherence measure

(PRIMARY) SELF REPORTED QUESTIONNAIRE - (pg 209) "All measures were collected by a trained research assistant in the participants' homes. The research assistant was blind to treatment assignment to the extent possible in a behavioral trial"

\begin{tabular}{|c|c|c|}
\hline $\begin{array}{l}\text { Blinding of outcome as- } \\
\text { sessment (detection bias) } \\
\text { Patient outcome }\end{array}$ & Low risk & (PRIMARY) HBA1C - Blinding not mentioned but this an objective measure \\
\hline $\begin{array}{l}\text { Blinding of participants } \\
\text { (performance bias) } \\
\text { Adherence measure }\end{array}$ & High risk & $\begin{array}{l}\text { (PRIMARY) SELF REPORTED QUESTIONNAIRE - Participant (primary caregiv- } \\
\text { er/parent) blinding not mentioned and likely to affect outcome }\end{array}$ \\
\hline
\end{tabular}

Blinding of participants Low risk $\quad$ (PRIMARY) HBA1C - Blinding not mentioned but this an objective measure
(performance bias)

(performance bias)

Patient outcome

$\begin{array}{ll}\begin{array}{l}\text { Blinding of personnel (per- } \\ \text { formance bias) }\end{array} & \text { Low risk } \\ \text { Adherence measure } & \text { (PRIMARY) SELF REPORTED QUESTIONNAIRE - The study does not mention } \\ \text { blinding of other personnel but unlikely to affect outcome; intervention and } \\ \text { control involved different study personnel }\end{array}$

Patient outcome

Incomplete outcome data Low risk

(attrition bias)

Adherence measure
(PRIMARY) SELF REPORTED QUESTIONNAIRE - Low rate of missing data, reasons not related to outcome, ITT analysis used

Incomplete outcome data Low risk

(attrition bias)

(PRIMARY) HBA1C - Low rate of missing data, reasons not related to outcome,

Patient outcome ITT analysis used

\section{Evans 2010}

\begin{tabular}{ll}
\hline Methods & Randomized controlled trial \\
\hline Participants & The study location was Saskatoon, Saskatchewan, Canada \\
& 88 participants were randomized to the intervention group and 88 participants were randomized to the \\
control group & \\
The inclusion criteria were patients who exhibited any cardiovascular risk factors (hypertension, dys- \\
lipidemia, diabetes mellitus, or a previous cardiovascular event), a calculated Framingham risk score
\end{tabular}


Evans 2010 (Continued)

(FRS) of at least $15 \%$ or a coronary artery disease risk equivalent (coronary artery disease, peripheral artery disease, cerebrovascular disease, or diabetes mellitus)

The exclusion criteria were severe psychiatric conditions or dementia, symptomatic heart failure (New York Heart Association class III or IV), terminal illness, concurrent participation in an investigational study, or were pregnant or breastfeeding

Interventions

Intervention: PHARMACIST FOLLOW-UP

The pharmacist established goals for the patient. Goals were documented in the patient records. When any of the risk factors were uncontrolled, the pharmacist alerted the patient by telephone and mail, and the physician was notified through the patient's medical record and face to face (when possible). Patients received continuous follow-up by the pharmacist at a minimum of every 8 weeks by telephone, mail, electronic mail, or face to face appointments. Mailed letters were reserved for patients who were successfully controlled or had been recently contacted. Information delivered during follow-up was patient specific and did not require that a standard content be covered. Reasons for follow-up included 1) To communicate relevant laboratory results, including proximity to individual targets; 2) To monitor clinical status within 7 to 10 days after the initiation or change of a drug; 3) To monitor clinical status within 7 to 10 days after experiencing an adverse event; 4) To ensure that the patient was able to procure necessary follow-up appointments; 5) To provide patients with clinical goal reminders, disease-specific information, or timely topics using periodic mailers. Emphasis was placed on conducting short follow-up contacts that reminded and reinforced the importance of drug adherence and clinical targets. All patients were followed for a minimum of 6 months

Control: SINGLE-CONTACT GROUP

Patients met at the beginning of the study with the study pharmacist, and received a booklet about cardiovascular disease. After that meeting they received usual care and had no more contact with the study pharmacist

Outcomes

The measures of adherence were calculated based on pharmacy refill records using the proportion of days covered; that is, the sum of the days supply for all statin prescription fills during the study period, divided by the number of days between the index date and the end of the study period

The patient outcomes were global cardiovascular risk status as measured by the 10-year FRS, systolic and diastolic blood pressure, hemoglobin A1C, and cholesterol. FRS was measured by the study pharmacist based on medical record review and a patient interview. Laboratory values were taken from the patient's medical charts

Notes -

\section{Risk of bias}

\begin{tabular}{|c|c|c|}
\hline Bias & Authors' judgement & Support for judgement \\
\hline $\begin{array}{l}\text { Random sequence genera- } \\
\text { tion (selection bias) }\end{array}$ & Low risk & $\begin{array}{l}\text { Randomization lists were stratified by each physician and were created by us- } \\
\text { ing a table of random numbers in permuted blocks of } 4 \text { (pg 768) }\end{array}$ \\
\hline $\begin{array}{l}\text { Allocation concealment } \\
\text { (selection bias) }\end{array}$ & Low risk & $\begin{array}{l}\text { Randomization codes were kept in individually sealed envelopes and opened } \\
\text { by the study pharmacist at the end of the initial visit (pg 768) }\end{array}$ \\
\hline $\begin{array}{l}\text { Selective reporting (re- } \\
\text { porting bias) }\end{array}$ & Low risk & $\begin{array}{l}\text { The study protocol is not available but it is clear that the published reports in- } \\
\text { clude all expected outcomes, including those that were pre-specified (convinc- } \\
\text { ing text of this nature may be uncommon) }\end{array}$ \\
\hline Other bias & Low risk & Author's note: we present evidence for bias towards the null \\
\hline $\begin{array}{l}\text { Blinding of outcome as- } \\
\text { sessment (detection bias) } \\
\text { Adherence measure }\end{array}$ & High risk & $\begin{array}{l}\text { (PRIMARY) PHARMACY RECORDS - The pharmacist was not blinded and was the } \\
\text { lead investigator of the study }\end{array}$ \\
\hline
\end{tabular}


Evans 2010 (Continued)

Blinding of outcome as- High risk $\quad$ (PRIMARY) FRAMINGHAM RISK SCORE - Collected by staff pharmacist who was sessment (detection bias) not blinded and was also lead investigator for the study

Patient outcome

$\begin{array}{ll}\text { Blinding of participants } & \text { Low risk } \\ \text { (performance bias) } & \text { (PRIMARY) PHARMACY RECORDS - Patients were not blinded but pharmacy re- } \\ \text { Adherence measure } & \text { fill records unlikely to be affected }\end{array}$

Adherence measure fill records unlikely to be affected

\begin{tabular}{|c|c|c|}
\hline $\begin{array}{l}\text { Blinding of participants } \\
\text { (performance bias) }\end{array}$ & Unclear risk & $\begin{array}{l}\text { (PRIMARY) FRAMINGHAM RISK SCORE - Patients were not blinded; unknown } \\
\text { how this may affect this outcome }\end{array}$ \\
\hline
\end{tabular}

Patient outcome

Blinding of personnel (per- Unclear risk (PRIMARY) PHARMACY RECORDS - Unclear if other personnel were blind

formance bias)

Adherence measure

$\begin{array}{ll}\begin{array}{l}\text { Blinding of personnel (per- } \\ \text { formance bias) }\end{array} & \text { Unclear risk } \\ \text { Patient outcome } & \begin{array}{l}\text { (PRIMARY) FRAMINGHAM RISK SCORE - Unclear if any other personnel were } \\ \text { blind }\end{array}\end{array}$

\begin{tabular}{lll}
\hline $\begin{array}{l}\text { Incomplete outcome data } \\
\text { (attrition bias) }\end{array}$ & Unclear risk & $\begin{array}{l}\text { (PRIMARY) PHARMACY RECORDS - There is not enough information given about } \\
\text { the missing data, or if there were additional missing data due to participants } \\
\text { not picking up prescription }\end{array}$ \\
\hline $\begin{array}{l}\text { Incomplete outcome data } \\
\begin{array}{l}\text { (attrition bias) } \\
\text { Patient outcome }\end{array}\end{array}$ & Low risk & $\begin{array}{l}\text { (PRIMARY) FRAMINGHAM RISK SCORE - Incomplete data evenly spread across } \\
\text { conditions; does not seem likely to bias the results }\end{array}$ \\
\hline
\end{tabular}

Falces 2008

\begin{tabular}{ll}
\hline Methods $\quad$ Randomized controlled trial \\
\hline
\end{tabular}

Participants

The study location was a cardiology clinic, Hospital General de Vic, Osona, Barcelona, Spain

53 participants were randomized to the intervention group and 50 participants were randomized to the control group

The inclusion criteria were over 70 years and hospitalized at the General de Vic hospital. The Framingham criteria were employed; 2 major criteria or 1 major and 2 minor criteria had to be present

The exclusion criteria were residence outside the hospital area bounds, nursing home residence, waiting on surgery, another center, dementia or psychological instability, or refusal to participate

Interventions

Intervention: EDUCATIONAL INTERVENTION

A research team pharmacist carried out the intervention. It consisted of an interview at hospital release followed by telephone reinforcement. The intervention focused on information about the disorder, diet education, and information about the medication. Simple language adapted to the cultural needs of the patient was used. This was backed up by audiovisual and written material. Phone calls took place during the first 6 months and for 2 months following. Patient questions or issues we also discussed. Patients were also given a contact phone number which they could call if they had doubts about their treatment or illness

Control: CONTROL GROUP

Visits were done at 6 and 12 months. A cardiologist provided treatment as usual and a pharmacist did a pill count 
Falces 2008 (Continued)

Outcomes
The measures of adherence were pill count - a pharmacist did a pill count at 6 and 12 months. He/she then categorized patients as 1 ) adherent if the patient had taken $95 \%$ to $100 \%$ of prescribed dose; 2 ) partially adherent ( $85 \%$ to $95 \%$ of dose taken); 3 ) not adherent if $<85 \%$ of dose taken

The patient outcomes were 1) Time to rehospitalization, 2) percentage and 3) total number of patients rehospitalized, 4) total number of days in the hospital during the study period. Also 5) quality of life and 6) mortality during the follow-up period

Notes -

\section{Risk of bias}

\begin{tabular}{lll}
\hline Bias & Authors' judgement & Support for judgement \\
\hline $\begin{array}{l}\text { Random sequence genera- } \\
\text { tion (selection bias) }\end{array}$ & Low risk & Software-assisted block randomization was used \\
\hline $\begin{array}{l}\text { Allocation concealment } \\
\text { (selection bias) }\end{array}$ & Low risk & Allocation was handled by an admissions service \\
\hline $\begin{array}{l}\text { Selective reporting (re- } \\
\text { porting bias) }\end{array}$ & Unclear risk & None noted but protocol not available \\
\hline $\begin{array}{l}\text { Other bias } \\
\begin{array}{l}\text { Blinding of outcome as- } \\
\text { sessment (detection bias) } \\
\text { Adherence measure }\end{array}\end{array}$ & High risk & Insufficient information to assess whether an important risk of bias exists \\
\hline
\end{tabular}

Blinding of outcome as- High risk

(PRIMARY) QUALITY OF LIFE (QLS) - Open study; subjective measure sessment (detection bias)

Patient outcome

\begin{tabular}{|c|c|c|}
\hline $\begin{array}{l}\text { Blinding of participants } \\
\text { (performance bias) } \\
\text { Adherence measure }\end{array}$ & High risk & $\begin{array}{l}\text { (PRIMARY) PILL COUNT - Open study. Does not mention if the pill count was } \\
\text { done unbeknownst to patient }\end{array}$ \\
\hline
\end{tabular}

\begin{tabular}{lll}
\hline $\begin{array}{l}\text { Blinding of participants } \\
\text { (performance bias) }\end{array}$ & High risk & (PRIMARY) QUALITY OF LIFE (QLS) - Open study; subjective measure \\
Patient outcome & \\
\hline $\begin{array}{l}\text { Blinding of personnel (per- } \\
\text { formance bias) }\end{array}$ & Low risk & $\begin{array}{l}\text { (PRIMARY) PILL COUNT - Outcome not likely to be affected by key study per- } \\
\text { Adherence measure }\end{array}$
\end{tabular}

\begin{tabular}{|c|c|c|}
\hline $\begin{array}{l}\text { Blinding of personnel (per- } \\
\text { formance bias) } \\
\text { Patient outcome }\end{array}$ & High risk & (PRIMARY) QUALITY OF LIFE (QLS) - Open study; subjective measure \\
\hline $\begin{array}{l}\text { Incomplete outcome data } \\
\text { (attrition bias) } \\
\text { Adherence measure }\end{array}$ & Low risk & (PRIMARY) PILL COUNT - Loss to follow-up similar in the 2 groups \\
\hline $\begin{array}{l}\text { Incomplete outcome data } \\
\text { (attrition bias) } \\
\text { Patient outcome }\end{array}$ & Low risk & (PRIMARY) QUALITY OF LIFE (QLS) - Loss to follow-up similar in the 2 groups \\
\hline
\end{tabular}


Farber 2004

Rethods
ly allocated between 2 and 4 to ensure that the size of the intervention and control groups was equiva-
lent. Randomization was not balanced on any other variables. Random group assignments were gener-
ated and were placed in sequentially numbered envelopes. Envelopes were not opened to reveal group
assignments until informed consent was obtained and enrolment (baseline) interviews were complet-
ed

\begin{abstract}
Participants
56 subjects to be included in the study; subjects were between the ages of 2 to 18 years, had State of Louisiana Medicaid insurance, had a telephone at home, had a history of asthma, had not been intubated or mechanically ventilated for asthma, did not have other clinically significant (i.e. moderate to severe) chronic illness, presented to the ED when an investigator was available, had informed consent provided by a parent or guardian, child voluntarily assents to participation in the study if older than 12 years
\end{abstract}

Interventions

Subjects in the intervention group received basic asthma education; instructions on use of a metered-dose inhaler with holding chamber; a written asthma self management plan illustrated by zones colored green, yellow, and red; a sample age-appropriate holding chamber; and prescriptions for medication needed to implement the plan. This medication included an inhaled corticosteroid drug for everyday use and a quick-acting bronchodilator for use as needed. The importance of seeking urgent medical care in the red zone was emphasized. 3 brief follow-up phone calls were placed to patients in the intervention group at 1 to 2 weeks, 4 to 6 weeks, and 3 months after enrolment

Outcomes

Self reported method to measure the compliance plus pharmacy refills. Medicaid claims files used to assess frequency of medication dispensing, dates of asthma-related hospital admissions, and dates of ED visits (identified by ICD-9) discharge diagnosis)

\title{
Notes
}

$$
-
$$

\section{Risk of bias}

\begin{tabular}{lll}
\hline Bias & Authors' judgement & Support for judgement \\
\hline $\begin{array}{ll}\text { Random sequence genera- } \\
\text { tion (selection bias) }\end{array}$ & Unclear risk & $\begin{array}{l}\text { No mention of method of random number creation. (pg 108) "Randomization } \\
\text { was accomplished using a randomized block design in which block size was } \\
\text { randomly allocated between } 2 \text { and } 4 \text { to ensure that the size of the intervention } \\
\text { and control groups was equivalent. Randomization was not balanced on any } \\
\text { other variables. Random group assignments were generated and were placed } \\
\text { in sequentially numbered opaque (manila) envelopes by someone not associ- } \\
\text { ated with the study. Envelopes were not opened to reveal group assignments } \\
\text { until informed consent was obtained and enrollment (baseline) interviews } \\
\text { were completed." }\end{array}$
\end{tabular}

\begin{tabular}{|c|c|c|}
\hline $\begin{array}{l}\text { Allocation concealment } \\
\text { (selection bias) }\end{array}$ & Low risk & $\begin{array}{l}\text { (pg 108) "Randomization was accomplished using a randomized block design } \\
\text { in which block size was randomly allocated between } 2 \text { and } 4 \text { to ensure that } \\
\text { the size of the intervention and control groups was equivalent. Randomiza- } \\
\text { tion was not balanced on any other variables. Random group assignments } \\
\text { were generated and were placed in sequentially numbered opaque (mani- } \\
\text { la) envelopes by someone not associated with the study. Envelopes were not } \\
\text { opened to reveal group assignments until informed consent was obtained and } \\
\text { enrollment (baseline) interviews were completed." }\end{array}$ \\
\hline
\end{tabular}

\begin{tabular}{lll}
\hline $\begin{array}{l}\text { Selective reporting (re- } \\
\text { porting bias) }\end{array}$ & Unclear risk & No protocol available \\
\hline Other bias & Low risk & No important risks of bias noted in limitations; no obvious risks of bias in trial \\
\hline $\begin{array}{l}\text { Blinding of outcome as- } \\
\text { sessment (detection bias) }\end{array}$ & Unclear risk & $\begin{array}{l}\text { (PRIMARY) MEDICATION DISPENSING EVENTS - No blinding reported for out- } \\
\text { come assessment of frequency of medication dispensing }\end{array}$ \\
\hline
\end{tabular}


Farber 2004 (Continued)

Adherence measure

\begin{tabular}{|c|c|c|}
\hline $\begin{array}{l}\text { Blinding of outcome as- } \\
\text { sessment (detection bias) } \\
\text { Patient outcome }\end{array}$ & Low risk & $\begin{array}{l}\text { (PRIMARY) FUNCTIONAL SEVERITY OF ASTHMA - (pg 109) "The telephone in- } \\
\text { terviewer was blinded as to study group assignment." Outcome assessor was } \\
\text { blinded }\end{array}$ \\
\hline
\end{tabular}

\begin{tabular}{ll}
\hline $\begin{array}{l}\text { Blinding of participants } \\
\text { (performance bias) }\end{array}$ & Unclear risk
\end{tabular}
come assessment of frequency

Adherence measure

Blinding of participants High risk
(performance bias)

(performance bias)

(PRIMARY) FUNCTIONAL SEVERITY OF ASTHMA - Blinding of patient was not reported and mostly likely not feasible. This may introduce recall bias since the parents in the intervention group will have more knowledge on asthma and may likely to pay more attention to children symptoms as a result. Since the measurement is purely based on the recall of the parents, there is a high risk of bias

\begin{tabular}{|c|c|c|}
\hline Blinding of personnel (per- & Unclear risk & $\begin{array}{l}\text { (PRIMARY) MEDICATION DISPENSING EVENTS - No mention of blinding for this } \\
\text { outcome }\end{array}$ \\
\hline
\end{tabular}

\begin{tabular}{lll}
\hline $\begin{array}{l}\text { Blinding of personnel (per- } \\
\text { formance bias) } \\
\text { Patient outcome }\end{array}$ & Unclear risk & $\begin{array}{l}\text { (PRIMARY) FUNCTIONAL SEVERITY OF ASTHMA - No report of blinding for other } \\
\text { key study personnel. Risk of bias cannot be determined }\end{array}$ \\
\hline $\begin{array}{l}\text { Incomplete outcome data } \\
\text { (attrition bias) }\end{array}$ & Low risk & $\begin{array}{l}\text { (PRIMARY) MEDICATION DISPENSING EVENTS - Missing data were balanced in } \\
\text { number across groups and missing outcomes were not enough to have a clini- } \\
\text { cally relevant impact on observed effect size }\end{array}$ \\
\hline $\begin{array}{l}\text { Incomplete outcome data } \\
\text { (attrition bias) } \\
\text { Patient outcome }\end{array}$ & Low risk & $\begin{array}{l}\text { (PRIMARY) FUNCTIONAL SEVERITY OF ASTHMA - Missing data were balanced in } \\
\text { number across groups and missing outcomes were not enough to have a clini- } \\
\text { cally relevant impact on observed effect size }\end{array}$ \\
\hline
\end{tabular}

\section{Farooq 2011}

\begin{tabular}{ll}
\hline Methods & Randomized controlled trial \\
\hline Participants & The study location was the psychiatry department of Lady Reading Hospital, Peshawar, Pakistan \\
& 55 participants were randomized to the intervention group and 55 participants were randomized to the
\end{tabular}
control group

The inclusion criteria were (a) aged 17 to 60 years; (b) a diagnosis of schizophrenia or schizoaffective disorder based on the ICD-10 Research Diagnostic Criteria (RDC); and (c) residence in Peshawar district

The exclusion criteria were evidence of organic disorder, ICD-10 'mental retardation', and severe drug dependence requiring in-patient treatment and/or detoxification

Interventions Intervention: Supevised Treatment in Out-patients for Schizophrenia (STOPS)
Participants in the STOPS arm received usual care plus specific education given to a key care supervi-
sor about the illness and the importance of adherence, medications were provided 1 month at a time
free of charge
Control: TAU
Psychiatrists provided treatment as they would normally deliver in routine out-patient settings. These
included prescribing evidence-based pharmacological treatments, out-patient attendance in the psy-
chiatry department as deemed appropriate by the consultant and brief counseling about the treatment 
Farooq 2011 (Continued) and outcome. Participants who could not afford to buy medication had the option to seek free drug treatment from the social welfare department of the hospital

Outcomes

The measures of adherence were measurement by interview using a questionnaire with a 5-point scale (where 1 is always and 5 is never). The assessments for adherence to treatment were done quarterly from baseline with the help of information provided by participants and relatives. All assessments were carried out by doctors with at least 2 years' training in psychiatry. These researchers were masked to participant group assignment and instructed not to enquire about a participant's treatment during interviews

The patient outcomes were Global Assessment of Functioning (GAF) ratings and Positive and Negative Syndrome Scale (PANSS) for schizophrenia, taken at 3, 6 months, and 1 year by doctors with psychiatry training and researchers masked to participant group

Notes -

\title{
Risk of bias
}

\begin{tabular}{lll}
\hline Bias & Authors' judgement & Support for judgement \\
\hline $\begin{array}{l}\text { Random sequence genera- } \\
\text { tion (selection bias) }\end{array}$ & Low risk & $\begin{array}{l}\text { Author's note: to us there was low risk of bias as an epidemiologist was con- } \\
\text { tacted for the same and she used random number tables for it. However, this } \\
\text { was not explicitly mentioned in the article as is mentioned in 3.1.1 }\end{array}$ \\
\hline $\begin{array}{l}\text { Allocation concealment } \\
\text { (selection bias) }\end{array}$ & Low risk & $\begin{array}{l}\text { Opaque, sealed, sequential envelopes. (pg 468) "Individuals who met inclusion } \\
\text { criteria were randomly assigned to each treatment group. The random alloca- } \\
\text { tions of patients to each group were enclosed in opaque envelopes which were } \\
\text { sealed and numbered sequentially. These allocations were placed away from } \\
\text { the site of assessment. After assessment and satisfying the inclusion criteria, } \\
\text { the staff which were not part of the study were asked to open the sealed enve- } \\
\text { lope and reveal the treatment arm for each patient." }\end{array}$
\end{tabular}

\begin{tabular}{|c|c|c|}
\hline $\begin{array}{l}\text { Selective reporting (re- } \\
\text { porting bias) }\end{array}$ & Unclear risk & $\begin{array}{l}\text { Author's note: tablet counts are not reported in the article although this was } \\
\text { stated in the protocol }\end{array}$ \\
\hline
\end{tabular}

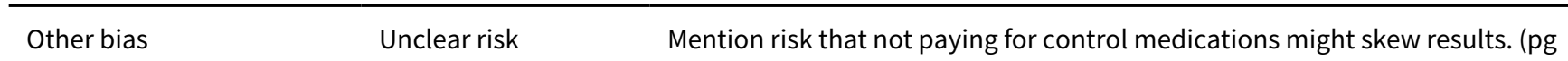
471 ) "It can be argued that the provision of free drugs could have contributed to the better outcome in the STOPS group. The average cost of medication for a month using atypical drugs is about 900 rupees ( $£ 1$ is equivalent to approximately 136 rupees), which can be quite costly for patients and families from lower socioeconomic backgrounds presenting in a public hospital such as Lady Reading Hospital. The DOTS is a complex intervention and free access to medication is an essential component of the DOTS programme as applied in tuberculosis control. The participants in the TAU group had the option of accessing free drugs from the social welfare department. Providing free medication as part of the trial would have grossly distorted the TAU condition in these settings. The evidence, however, suggests that even if drugs were free, non-adherence persists. One recent study showed that even among people who have health plans with no cost-sharing for medication, rates of non-adherence were nearly $40 \%$."

Blinding of outcome as- $\quad$ Low risk
sessment (detection bias)

Adherence measure

\begin{abstract}
(PRIMARY) SELF REPORT - QUESTIONNAIRE - It states outcome assessors were masked. (pg 469) "The follow-up assessments were done by researchers who were masked to participant group assignment and instructed not to enquire about a participant's treatment during interviews. To ensure this, the administration of STOPS was kept completely separate from the research team assessing adherence and administering questionnaires for the trial and they were not associated with clinical care of the participants in the trial. The partici-
\end{abstract}


Farooq 2011 (Continued)

pants and relatives were briefed not to discuss their treatment with the assessors."

Blinding of outcome as- Low risk

sessment (detection bias)

Patient outcome
(PRIMARY) GAF AND PANSS SCORES - it states outcome assessors were blind. pg 469 "The same team of psychiatrists carried out all the follow-up assessments. The follow-up assessments were done by researchers who were masked to participant group assignment and instructed not to enquire about a participant's treatment during interviews. To ensure this, the administration of STOPS was kept completely separate from the research team assessing adherence and administering questionnaires for the trial and they were not associated with clinical care of the participants in the trial. The participants and relatives were briefed not to discuss their treatment with the assessors."

$\begin{array}{ll}\begin{array}{l}\text { Blinding of participants } \\ \text { (performance bias) }\end{array} & \text { High risk } \\ \text { Adherence measure } & \text { (PRIMARY) SELF REPORT - QUESTIONNAIRE - No mention of patient blinding; } \\ & \text { questionnaire responses would be influenced by lack of blinding. Since pa- } \\ \text { tients were receiving free pills in the STOPS intervention, it is probably easy for } \\ \text { the patients to figure out which group they belonged to }\end{array}$

\begin{tabular}{ll}
\hline $\begin{array}{l}\text { Blinding of participants } \\
\text { (performance bias) }\end{array}$ & Low risk \\
$\begin{array}{l}\text { Patient outcome } \\
\text { (PRIMARY) GAF AND PANSS SCORES - Author's note: patients/participants were } \\
\text { blinded }\end{array}$
\end{tabular}

Blinding of personnel (per- Unclear risk

formance bias)

Adherence measure

(PRIMARY) SELF REPORT - QUESTIONNAIRE - Insufficient information to permit judgment of 'Low risk' or 'High risk'. No mention of study staff blinding or role in study

Blinding of personnel (per- Low risk

formance bias)

Patient outcome

(PRIMARY) GAF AND PANSS SCORES - Author's note: although not mentioned explicitly in the write up, there was "low risk of bias" as the blinding was maintained for all the staff used to assess the patients on various scales. Only the co-ordinator was aware of the participants' respective group

\begin{tabular}{|c|c|c|}
\hline $\begin{array}{l}\text { Incomplete outcome data } \\
\text { (attrition bias) }\end{array}$ & Low risk & $\begin{array}{l}\text { (PRIMARY) SELF REPORT - QUESTIONNAIRE - Nearly equal dropouts acrosS } \\
\text { groups, reasons for dropouts seemingly unrelated to intervention }\end{array}$ \\
\hline
\end{tabular}

Incomplete outcome data Low risk

(attrition bias)

(PRIMARY) GAF AND PANSS SCORES - Nearly equal dropouts across groups;

Patient outcome

Fisher 2011

\begin{tabular}{|c|c|}
\hline Methods & Randomized controlled trial \\
\hline \multirow[t]{3}{*}{ Participants } & The study location was 5 large HIV care clinics in Connecticut, USA \\
\hline & $\begin{array}{l}277 \text { participants were randomized to the intervention group and } 287 \text { participants were randomized to } \\
\text { the control group }\end{array}$ \\
\hline & $\begin{array}{l}\text { The inclusion criteria were 1) } 18 \text { years of age or older; } 2 \text { ) have English language comprehension; 3) free } \\
\text { of marked cognitive impairment; 4) prescribed ARV therapy at study inception }\end{array}$ \\
\hline \multirow[t]{2}{*}{ Interventions } & Intervention: LIFEWINDOWS \\
\hline & $\begin{array}{l}\text { The intervention was computer-based, interactive ARV adherence promotion called LifeWindows de- } \\
\text { veloped based on the Information-Motivation-Behavioral skills (IMB) model. The nature of this inter- } \\
\text { vention is to identify and address, through interventions, an individual's deficits in adherence-related } \\
\text { information, motivation, and behavioral skills. The intervention activities consisted of } 20 \text { different in- } \\
\text { teractive activities that would be selected by the participants according to their goals. Patients on av- }\end{array}$ \\
\hline
\end{tabular}


Fisher 2011 (Continued)

erage spent 26 minutes to complete the full intervention with an average of 8 minutes dedicated to adherence intervention modules. Participants received USD 20 for completion of each session. Participants completed 1 session per month over 18 months

Control: STANDARD OF CARE

Control patients received standard of care at the clinic they attended. Average total time spent to complete the full control session was 14 minutes. Participants received USD 20 for completion of the session per month over 18 months

Outcomes The measures of adherence were the AIDS Clinical Trials Group (ACTG) 3-day recall measure of doses taken, and a visual analog scale (VAS) 3 to 4-week ARV adherence assessment adapted for computer delivery. These data were collected at each LifeWindows session from both intervention and control groups. Adherence to regimen was calculated as the total number of pills taken over 3 days divided by the total number of pills prescribed for all agents for that period (ACTG) and as the average per cent adherence over 3 to 4 weeks for all agents (VAS)

The patient outcome was HIV viral load, measured as per standard of care, and data were extracted from patient charts at the conclusion of the research period

Notes -

\section{Risk of bias}

\begin{tabular}{|c|c|c|}
\hline Bias & Authors' judgement & Support for judgement \\
\hline $\begin{array}{l}\text { Random sequence genera- } \\
\text { tion (selection bias) }\end{array}$ & Low risk & $\begin{array}{l}\text { "Randomization at enrollment to control and intervention conditions involved } \\
\text { use of randomly generated numbers, which were sequentially assigned." (pg } \\
\text { 1637) }\end{array}$ \\
\hline $\begin{array}{l}\text { Allocation concealment } \\
\text { (selection bias) }\end{array}$ & Unclear risk & $\begin{array}{l}\text { No information about the concealment of allocation is given. "Randomization } \\
\text { at enrollment to control and intervention conditions involved use of randomly } \\
\text { generated numbers, which were sequentially assigned." (pg 1637) }\end{array}$ \\
\hline $\begin{array}{l}\text { Selective reporting (re- } \\
\text { porting bias) }\end{array}$ & Unclear risk & $\begin{array}{l}\text { Insufficient information to permit judgment of 'Low risk' or 'High risk'. No pro- } \\
\text { tocol available }\end{array}$ \\
\hline Other bias & Unclear risk & Insufficient information provided to make a judgment \\
\hline $\begin{array}{l}\text { Blinding of outcome as- } \\
\text { sessment (detection bias) } \\
\text { Adherence measure }\end{array}$ & Low risk & $\begin{array}{l}\text { (PRIMARY) SELF REPORT - QUESTIONNAIRE - (pg 1643) All outcome data for } \\
\text { adherence were collected using a computer. While this limits bias of staff and } \\
\text { personnel, they did not mentioned who had access to these data. Author's } \\
\text { note: the research assistant at the site did not have access to the data generat- } \\
\text { ed by the research participant }\end{array}$ \\
\hline
\end{tabular}

\begin{tabular}{|c|c|c|}
\hline $\begin{array}{l}\text { Blinding of outcome as- } \\
\text { sessment (detection bias) } \\
\text { Patient outcome }\end{array}$ & Low risk & (PRIMARY) VIRAL LOAD - Outcome not likely influenced by lack of blinding \\
\hline $\begin{array}{l}\text { Blinding of participants } \\
\text { (performance bias) } \\
\text { Adherence measure }\end{array}$ & Low risk & $\begin{array}{l}\text { (PRIMARY) SELF REPORT - QUESTIONNAIRE - Author's note: the participant } \\
\text { was blind }\end{array}$ \\
\hline
\end{tabular}

\begin{tabular}{|c|c|c|}
\hline $\begin{array}{l}\text { Blinding of participants } \\
\text { (performance bias) } \\
\text { Patient outcome }\end{array}$ & Low risk & (PRIMARY) VIRAL LOAD - Outcome not likely influenced by lack of blinding \\
\hline $\begin{array}{l}\text { Blinding of personnel (per- } \\
\text { formance bias) } \\
\text { Adherence measure }\end{array}$ & Low risk & $\begin{array}{l}\text { (PRIMARY) SELF REPORT - QUESTIONNAIRE - Author's note: only staff at the } \\
\text { central office had access to the research data; the research assistant at the } \\
\text { study site did not have access }\end{array}$ \\
\hline
\end{tabular}


Fisher 2011 (Continued)
Blinding of personnel (per- Low risk
(PRIMARY) VIRAL LOAD - Outcome not likely influenced by lack of blinding
formance bias)

Patient outcome

Incomplete outcome data Low risk (attrition bias)

Adherence measure
(PRIMARY) SELF REPORT - QUESTIONNAIRE - (pg 5, Figure 1 and Table 2) Baselined participants $(\mathrm{N}=594)$ completed from one to 18 LifeWindows sessions (Mode $=6$ sessions) during their clinical care visits over approximately 18 months, taking part in an overall total of 4155 sessions of which 3924 included assessments of ARV adherence. Of 594 baselined participants, 328 (55\%) met the inclusion criteria for the on protocol (OP) sample (see Figure 1). Participant characteristics for the ITT, OP-included, and OP-excluded samples are presented in Table 2. Those included in the OP sample are similar in most respects to those excluded with the exception that those included reflected larger numbers of women, unemployed, individuals on disability, and were slightly older. The OP sample also had a higher number of individuals with undetectable viral load at baseline. Note that these elements did not differ by study arm within the OP sample. No differences in baseline values by study arm assignment were noted in the ITT sample; study arm was not related to inclusion or exclusion in the OP sample, and the only differences between study arm in the OP sample were total income (lower income in the intervention arm) and self reported sexual orientation (lower proportion of gay participants in the intervention arm)

Incomplete outcome data Low risk

(attrition bias)

(PRIMARY) VIRAL LOAD - While not mentioned, the authors undertook adequate procedures to take missing data into account in analyses

Patient outcome

\section{Fortney 2007}

\begin{tabular}{ll}
\hline Methods & Randomized controlled trial \\
\hline Participants & $\begin{array}{l}\text { The study location was Veterans Affairs (VA) community-based outpatient clinics (CBOCs), South Cen- } \\
\text { tral Veterans Healthcare Network, USA }\end{array}$
\end{tabular}

177 patients ( 3 practices) were randomized to the intervention group and 218 patients (4 practices) were randomized to the control group

The inclusion criteria were patients with depression that PCPs would be comfortable treating. Patients were screened with a Patient Health Questionnaire depression scale (PHQ9)

The exclusion criteria were diagnosis of schizophrenia, current suicide ideation, recent bereavement, pregnancy, a court-appointed guardian, substance dependence, bipolar disorder, cognitive impairment, or receiving specialty mental health treatment

Interventions Intervention: TELEMEDICINE ENHANCED ANTIDEPRESSANT MANAGEMENT (TEAM) Patients at intervention sites received a stepped-care model of depression treatment for up to 12 months. Treatment intensity was increased for patients failing to respond to lower levels of care by involving a greater number of intervention personnel with increasing mental health expertise. The intervention involved 5 types of providers: (1) PCPs located at CBOCs; 2) consult telepsychiatrists located at parent Veterans Affairs Medical Centers (VAMCs); (3) an off-site depression nurse care manager (RN); (4) an off-site clinical pharmacist (PharmD); and 5) an off-site supervising psychiatrist. The consult-telepsychiatrist accepted consultations or referrals from PCPs. The supervising psychiatrist provided clinical supervision to the care manager and clinical pharmacist via weekly face-to-face meetings. Patients and providers could choose either watchful waiting or antidepressant treatment (Step 1). Nurse care manager encounters were conducted via telephone and were scripted to enhance standardization and reproducibility. During the initial care management encounter, patients were: (1) administered the PHQ9 symptom monitoring tool; (2) educated and activated using a semi-structured script4; and 3) assessed for treatment barriers using semi-structured scripts for endorsed barriers. Follow-up encoun- 
Fortney 2007 (Continued)

ters to monitor symptoms, medication adherence, and side effects were scheduled every 2 weeks during acute treatment and every 4 weeks during watchful waiting or continuation treatment. Non-adherent patients or those experiencing severe side effects were administered semi-structured scripts. A trial was considered to have failed in the acute phase if the patient: (1) was non-adherent to the medication, (2) experienced severe side effects, (3) experienced = 5-point increase in their PHQ9 score, or (4) did not respond ( $50 \%$ decrease in PHQ9 score) after 8 weeks of antidepressant therapy. All feedback was provided to PCPs using the electronic medical record. Progress notes reporting failed trials requested an electronic co-signature from the PCP. If the patient did not respond to the initial antidepressant, the pharmacist conducted a medication history and provided pharmacotherapy recommendations to PCPs via an electronic progress note (Step 2). The pharmacist also provided non-scripted medication management over the phone to patients experiencing severe side effects or problems with nonadherence. If the patient did not respond to 2 antidepressants trials, the protocol was to recommend a telepsychiatry consultation followed by additional treatment recommendations to the PCP (Step 3)

Control: USUAL CARE

Control groups received usual care. Usual care patients like the intervention group were provided with provider education and patient education. Also, the screening results were entered into the electronic medical record

Outcomes

The measures of adherence were assessed using an instrument specifically designed for the study. Prior to administering the follow-up survey, a study psychiatrist examined the patients VA electronic medical records to determine what antidepressants had been prescribed (or refilled) during the previous 6 months. The most recently prescribed/refilled antidepressant medication was recorded prior to the follow-up interview and the adherence questions referred to the antidepressant explicitly by name. Research assistants asked all patients with an active prescription if they were currently taking the medication. If the patient was currently taking the medication, the interviewers asked how frequently they took the medication in the previous month and if they took the dosage prescribed. Patients were classified as adherent if item responses indicated they took the full dosage $>=80 \%$ of the days in the previous month

The patient outcomes were treatment response, remission, health status, and quality of life. Treatment response and remission were measured using the Hopkins Symptom Checklist. Response is measured dichotomously as a 50\% improvement in depression severity between baseline and follow-up. Remission is defined dichotomously as SCL-20 $<0.5$. Health status was measured by the change in the physical health and mental health component scores (PCS and MCS) of the Short Form (SF12V) between baseline and follow-up. Improvement in health-related quality of life was measured by the change in the Quality of Well Being (QWB) score. Measures were taken at 6 months and 12 months follow-up.

\section{Notes}

-

\section{Risk of bias}

\begin{tabular}{lll}
\hline Bias & Authors' judgement & Support for judgement \\
\hline $\begin{array}{l}\text { Random sequence genera- } \\
\text { tion (selection bias) }\end{array}$ & $\begin{array}{l}\text { Unclear risk } \\
\text { Allocation concealment }\end{array}$ & $\begin{array}{l}\text { The article gives no details on the randomization process. Protocol paper does } \\
\text { not provide any additional information. (pg 1087) The } 7 \text { eligible CBOCs in the } \\
\text { South Central Veterans Healthcare Network were matched by parent VAMC, } \\
\text { and one CBOC within each pair was randomized to the intervention }\end{array}$ \\
\hline Unclear risk & $\begin{array}{l}\text { Insufficient information to permit judgment of 'Low risk' or 'High risk' of bias. } \\
\text { (pg 1087) "The } 7 \text { eligible CBOCs in the South Central Veterans Healthcare Net- } \\
\text { work were matched by parent VAMC, and one CBOC within each pair was ran- } \\
\text { domized to the intervention. Five of the CBOCs had on-site midlevel mental } \\
\text { health specialists (e.g. social workers)." }\end{array}$
\end{tabular}

Selective reporting (re- Low risk $\quad$ All relevant results from the methods paper seem to be reported
porting bias)
porting bias)

\begin{tabular}{ll}
\hline Other bias $\quad$ Unclear risk $\quad$ None noted but insufficient information provided to judge \\
\hline
\end{tabular}


Fortney 2007 (Continued)

Blinding of outcome as- Low risk (PRIMARY) SELF REPORT - INTERVIEW - "Data were collected via blinded telesessment (detection bias) phone interview." (pg 1087)

Adherence measure

\begin{tabular}{|c|c|c|}
\hline $\begin{array}{l}\text { Blinding of outcome as- } \\
\text { sessment (detection bias) }\end{array}$ & Low risk & $\begin{array}{l}\text { (PRIMARY) SELF REPORT - QUESTIONNAIRES - "Data were collected via blinded } \\
\text { telephone interview." (pg 1087) }\end{array}$ \\
\hline
\end{tabular}

Patient outcome

\begin{tabular}{|c|c|c|}
\hline $\begin{array}{l}\text { Blinding of participants } \\
\text { (performance bias) }\end{array}$ & High risk & $\begin{array}{l}\text { (PRIMARY) SELF REPORT - INTERVIEW - Patients were not blinded to the inter- } \\
\text { vention. This is a subjective measure }\end{array}$ \\
\hline
\end{tabular}

Adherence measure

Unclear risk

Blinding of participants

(performance bias)

Patient outcome
(PRIMARY) SELF REPORT - QUESTIONNAIRES - Insufficient information about patient blinding to permit judgment of 'Low risk' or 'High risk'. Patients would have been aware if they received the intervention; might have affected their questionnaire responses

(PRIMARY) SELF REPORT - INTERVIEW - "Data were collected via blinded telephone interview." (pg 1087)

formance bias)

Low risk

Adherence measure

(PRIMARY) SELF REPORT - QUESTIONNAIRES - Author note: due to the nature

Blinding of personnel (per- Low risk

formance bias) of the intervention, it was not possible to blind primary care providers to ran-

Patient outcome domization status. However, I do not believe that this introduces bias because the care management intervention was specifically designed to support primary care providers treating depression (e.g. alerting them to side effects and non-adherence)

\begin{tabular}{lll}
$\begin{array}{l}\text { Incomplete outcome data } \\
\text { (attrition bias) } \\
\text { Adherence measure }\end{array}$ & Low risk & $\begin{array}{l}\text { (PRIMARY) SELF REPORT - INTERVIEW - Author indicated that this is low risk of } \\
\text { bias }\end{array}$ \\
\hline $\begin{array}{l}\text { Incomplete outcome data } \\
\text { (attrition bias) }\end{array}$ & Low risk & $\begin{array}{l}\text { (PRIMARY) SELF REPORT - QUESTIONNAIRES - Missing outcome data approx- } \\
\text { imately balanced in numbers across intervention groups, with similar rea- } \\
\text { sons for missing data across groups. Refer to Figure } 1 \text { in the article. Plus author } \\
\text { note: missing data from completed follow-up interviews were imputed using } \\
\text { multiple imputation }\end{array}$
\end{tabular}

\section{Friedman 1996}

Methods Random allocation using a paired randomization protocol

Participants

Patients were 60 years or older, under the care of a physician for hypertension, and prescribed an antihypertensive medication. They needed to have systolic blood pressure greater than or equal to $160 \mathrm{~mm}$ $\mathrm{Hg}$ or a diastolic blood pressure greater than or equal to $90 \mathrm{~mm} \mathrm{Hg}$ based on an average of 2 determinations taken 5 minutes apart. Individuals were excluded if they had a life-threatening illness, were not English-speaking, did not have a telephone or could not use one, or refused to consent to participate

Interventions

Control patients received regular medical care. The intervention group received regular medical care plus the telephone-linked computer system (TLC). TLC is an interactive computer-based telecommunications system that converses with patients in their homes, using computer-controlled speech, between office visits to their physicians. The intervention patients would call the TLC on a weekly basis. Before calling, subjects would record their own blood pressure using an automated sphygmomanometer with a digital readout. During the conversation, subjects would answer a standard series of questions and the TLC would provide education and motivational counseling to improve medication adherence. The TLC then transmitted the reported information to the subject's physician 
Friedman 1996 (Continued)

Outcomes

Antihypertensive medication adherence was assessed by home pill count conducted by the field technicians

Clinical outcome measures included change in systolic and diastolic blood pressure. Outcome mea-

sures were recorded by the field technicians, at the 2 home visits performed 6 months apart. The mea-

sures were also reported on a weekly basis by the participant

Notes

\section{Risk of bias}

\begin{tabular}{lll}
\hline Bias & Authors' judgement & Support for judgement \\
\hline $\begin{array}{l}\text { Random sequence genera- } \\
\text { tion (selection bias) }\end{array}$ & Unclear risk & $\begin{array}{l}\text { No description regarding random sequence generation. (pg 286) "after which } \\
\text { participants were randomly assigned to either the TLC or usual care groups us- } \\
\text { ing a paired randomization protocol" }\end{array}$ \\
\hline
\end{tabular}

\begin{tabular}{ll}
\hline $\begin{array}{l}\text { Allocation concealment } \\
\text { (selection bias) }\end{array}$ & Unclear risk \\
& $\begin{array}{l}\text { No description of allocation concealment. (pg 286) "... after which participants } \\
\text { were randomly assigned to either the TLC or usual care groups using a paired } \\
\text { randomization protocol. The field technicians were blinded to the group as- } \\
\text { signments..." }\end{array}$ \\
\hline
\end{tabular}

\begin{tabular}{lll}
\hline $\begin{array}{l}\text { Selective reporting (re- } \\
\text { porting bias) }\end{array}$ & Unclear risk & Protocol not available \\
\hline Other bias & Unclear risk & $\begin{array}{l}\text { No major biases noted in the discussion but insufficient information provided } \\
\text { to make a judgment }\end{array}$ \\
\hline
\end{tabular}

\begin{tabular}{|c|c|c|}
\hline $\begin{array}{l}\text { Blinding of outcome as- } \\
\text { sessment (detection bias) } \\
\text { Adherence measure }\end{array}$ & Unclear risk & $\begin{array}{l}\text { (PRIMARY) PILL COUNT - Unclear if data collectors were blinded the entire } \\
\text { study. (pg 286) "The field technicians were blinded to the group assignments } \\
\text { until after baseline measurements were complete..." }\end{array}$ \\
\hline
\end{tabular}

\begin{tabular}{|c|c|c|}
\hline $\begin{array}{l}\text { Blinding of outcome as- } \\
\text { sessment (detection bias) } \\
\text { Patient outcome }\end{array}$ & Unclear risk & $\begin{array}{l}\text { (PRIMARY) BLOOD PRESSURE - Unclear if data collectors blinded the entire } \\
\text { study. (pg 286) "The field technicians were blinded to the group assignments } \\
\text { until after baseline measurements were completed" }\end{array}$ \\
\hline $\begin{array}{l}\text { Blinding of participants } \\
\text { (performance bias) } \\
\text { Adherence measure }\end{array}$ & High risk & $\begin{array}{l}\text { (PRIMARY) PILL COUNT - Patients not likely to be blind due to the nature of the } \\
\text { intervention }\end{array}$ \\
\hline $\begin{array}{l}\text { Blinding of participants } \\
\text { (performance bias) } \\
\text { Patient outcome }\end{array}$ & Low risk & $\begin{array}{l}\text { (PRIMARY) BLOOD PRESSURE - Lack of blinding of the study participant is un- } \\
\text { likely to affect this outcome }\end{array}$ \\
\hline
\end{tabular}

Blinding of personnel (per- Unclear risk

(PRIMARY) PILL COUNT - No mention of blinding of other study staff

formance bias)

Adherence measure

\begin{tabular}{|c|c|c|}
\hline $\begin{array}{l}\text { Blinding of personnel (per- } \\
\text { formance bias) } \\
\text { Patient outcome }\end{array}$ & Unclear risk & (PRIMARY) BLOOD PRESSURE - No mention of blinding study personnel \\
\hline $\begin{array}{l}\text { Incomplete outcome data } \\
\text { (attrition bias) } \\
\text { Adherence measure }\end{array}$ & Unclear risk & $\begin{array}{l}\text { (PRIMARY) PILL COUNT - The attrition rate for the TLC group was } 15 \%(n=23) \text {, } \\
\text { and for the usual care group it was } 8 \%(n=11) \text {. TLC group lost double patients } \\
\text { to attrition than usual care. Not sure if that could have induced a change in the } \\
\text { result }\end{array}$ \\
\hline $\begin{array}{l}\text { Incomplete outcome data } \\
\text { (attrition bias) }\end{array}$ & Unclear risk & $\begin{array}{l}\text { (PRIMARY) BLOOD PRESSURE - The attrition rate for the TLC group was } 15 \% \text { ( } n \\
=23 \text { ), and for the usual care group it was } 8 \%(n=11) \text {. TLC group lost double pa- }\end{array}$ \\
\hline
\end{tabular}


Friedman 1996 (Continued)

Patient outcome tients to attrition than usual care. Not sure if that could have induced a change

in the result

\section{Gallefoss 1999}

Methods

At inclusion, patients signed a written consent and were then randomized to an intervention group or a control group. Concealment of allocation was unclear. Technical staff assessing bronchodilator spirometry were blinded to control and intervention patients. (Study reported in 2 papers)

Participants

Eligible subjects were patients with bronchial asthma or chronic obstructive pulmonary disease (COPD) between 18 and 70 years of age, not suffering from any serious disease such as unstable coronary heart disease, heart failure, serious hypertension, diabetes mellitus, or kidney or liver failure. Participants with stable asthma were to have a pre-bronchodilator FEV1 equal to or higher than $80 \%$ of predicted value "in stable phase". Furthermore, either a positive reversibility test, a documented $20 \%$ spontaneous variability (PEF or FEV1) or a positive methacholine test (provocative dose causing a $20 \%$ decrease in FEV1 (PD20) was required. A positive reversibility test required at least a 20\% increase (FEV1 or PEF) after inhalation of $400 \mu \mathrm{g}$ salbutamol. Subjects with COPD were to have a pre-bronchodilator FEV1 equal to or higher than $40 \%$ and lower than $80 \%$ of predicted

Interventions The control group participants were followed by their GPs and the intervention group received an education program and were then also transferred to a 1-year follow-up by their GPS

The educational intervention consisted of a specially constructed 19-page patient booklet with essential information about asthma/COPD, medication, compliance, self care, and self management plan. Instructions in the recoding of PEF and symptoms in a diary were given to both asthmatics and patients with COPD. There were also two 2 -hour group sessions (separate groups for asthmatics and patients with COPD) of 5 to 8 people on 2 separate days. The COPD group received more information about tobacco weaning, but besides this the educational interventions were comparable

The first session was given by a medical doctor, concentrating on pathophysiology, symptom awareness, prevention of attacks and factors causing exacerbations, especially smoking. The second group session was given by a pharmacist, focusing on drugs and their appropriate use. One or two 40-minute individual sessions were then supplied by a nurse, and another one or two 40-minute individual sessions, by a physiotherapist. With regard to anti-obstructive medication the following was emphasized: the components of obstruction were explained together with the site of action of the actual medication. The patient's pulmonary symptoms were registered and discussed with emphasis on the early symptoms experienced at exacerbations. The individual factors causing attacks/exacerbations and concerns regarding adverse effects of medication were discussed and inhalation technique was checked. At the final teaching the patients received an individual treatment plan on the basis of the acquired personal information and 2 weeks of peak flow monitoring. The personal understanding of the treatment plan with regard to changes in PEF and symptoms was discussed and tested

Outcomes

One paper reported compliance of regular medication, calculated as a \% age: (dispensed Defined Daily Dosage/Prescribed Defined Daily Dosage) x 100 during the 1-year follow-up. Patients were defined as compliant when dispensed regular medication was greater than $75 \%$ of prescribed regular medication during the study period. Pre-bronchodilator spirometry was performed before randomization and at 12-month follow-up by standard methods

The other paper reported that 4 simple health-related quality of life (HRQoL) questions were asked at baseline. HRQoL as measured by the St George's Respiratory Questionnaire (SGRQ) at 12 months plus the same 4 questions asked at baseline. FEV measured via spirometry prior to randomization and at 12 months

Notes

Patients who failed to attend all group sessions or who failed to meet at individual sessions were withdrawn. There was no similar "faintness of heart" procedure for the control group. Thus, 38 of 39 control asthma patients were included in the compliance assessment but only 30 of 39 intervention group patients 
Gallefoss 1999 (Continued)

Risk of bias

\begin{tabular}{|c|c|c|}
\hline Bias & Authors' judgement & Support for judgement \\
\hline $\begin{array}{l}\text { Random sequence genera- } \\
\text { tion (selection bias) }\end{array}$ & Unclear risk & $\begin{array}{l}\text { No information given in article. "We performed a randomized, controlled inter- } \\
\text { vention study in patients with mild to moderate asthma or COPD using a stan- } \\
\text { dardized education program and a self management plan." }\end{array}$ \\
\hline $\begin{array}{l}\text { Allocation concealment } \\
\text { (selection bias) }\end{array}$ & Unclear risk & $\begin{array}{l}\text { No information given in article. "We performed a randomized, controlled inter- } \\
\text { vention study in patients with mild to moderate asthma or COPD using a stan- } \\
\text { dardized education program and a self management plan." }\end{array}$ \\
\hline $\begin{array}{l}\text { Selective reporting (re- } \\
\text { porting bias) }\end{array}$ & Unclear risk & No protocol available \\
\hline Other bias & Unclear risk & $\begin{array}{l}\text { No other biases noted or obvious but insufficient information provided to } \\
\text { make a judgment }\end{array}$ \\
\hline $\begin{array}{l}\text { Blinding of outcome as- } \\
\text { sessment (detection bias) } \\
\text { Adherence measure }\end{array}$ & Unclear risk & $\begin{array}{l}\text { (PRIMARY) PHARMACY FILL RECORD - No mention of blinding of personnel. (pg } \\
\text { 2001) "Dispensed medication was reported from all local pharmacies through } \\
\text { monthly print-outs from the pharmacy data registers. At the 1-yr follow-up all } \\
\text { patients were asked whether they had received medication elsewhere." }\end{array}$ \\
\hline $\begin{array}{l}\text { Blinding of outcome as- } \\
\text { sessment (detection bias) } \\
\text { Patient outcome }\end{array}$ & Low risk & $\begin{array}{l}\text { (PRIMARY) SPIROMETRY - (pg 2002) "The technical staff did not know whether } \\
\text { the patients belonged to the control or intervention groups." }\end{array}$ \\
\hline $\begin{array}{l}\text { Blinding of participants } \\
\text { (performance bias) } \\
\text { Adherence measure }\end{array}$ & High risk & $\begin{array}{l}\text { (PRIMARY) PHARMACY FILL RECORD - Patients would have known if they re- } \\
\text { ceived the educational intervention }\end{array}$ \\
\hline $\begin{array}{l}\text { Blinding of participants } \\
\text { (performance bias) } \\
\text { Patient outcome }\end{array}$ & Low risk & $\begin{array}{l}\text { (PRIMARY) SPIROMETRY - Unlikely that lack of patient blinding would affect } \\
\text { this outcome }\end{array}$ \\
\hline $\begin{array}{l}\text { Blinding of personnel (per- } \\
\text { formance bias) } \\
\text { Adherence measure }\end{array}$ & Unclear risk & $\begin{array}{l}\text { (PRIMARY) PHARMACY FILL RECORD - No mention of blinding of personnel } \\
\text { collecting data. (pg 2001) "Dispensed medication was reported from all local } \\
\text { pharmacies through monthly print-outs from the pharmacy data registers. At } \\
\text { the 1-yr follow-up all patients were asked whether they had received medica- } \\
\text { tion elsewhere." }\end{array}$ \\
\hline $\begin{array}{l}\text { Blinding of personnel (per- } \\
\text { formance bias) } \\
\text { Patient outcome }\end{array}$ & Unclear risk & (PRIMARY) SPIROMETRY - No mention of study personnel blinding \\
\hline $\begin{array}{l}\text { Incomplete outcome data } \\
\text { (attrition bias) } \\
\text { Adherence measure }\end{array}$ & Unclear risk & $\begin{array}{l}\text { (PRIMARY) PHARMACY FILL RECORD - Reasons for missing data are noted but } \\
\text { unclear whether unequal missing data effects outcome }\end{array}$ \\
\hline $\begin{array}{l}\text { Incomplete outcome data } \\
\text { (attrition bias) } \\
\text { Patient outcome }\end{array}$ & Unclear risk & (PRIMARY) SPIROMETRY - Not enough information provided \\
\hline
\end{tabular}


Gamble 2011

\begin{tabular}{|c|c|}
\hline Methods & Randomized controlled trial \\
\hline \multirow[t]{4}{*}{ Participants } & The study location was Northern Ireland Regional Difficult Asthma Service, Northern Ireland \\
\hline & $\begin{array}{l}9 \text { participants were randomized to the intervention group and } 11 \text { participants were randomized to the } \\
\text { control group }\end{array}$ \\
\hline & $\begin{array}{l}\text { The inclusion criteria were } 18 \text { years of age, attending the Difficult Asthma Service, a Juniper Asthma } \\
\text { Control Score }=317 \text { and remained non-adherent despite participating in Phase } 1\end{array}$ \\
\hline & $\begin{array}{l}\text { The exclusion criteria were current tobacco smoking or significant other co-morbidity, which con- } \\
\text { tributed to persisting respiratory symptoms }\end{array}$ \\
\hline \multirow[t]{2}{*}{ Interventions } & $\begin{array}{l}\text { Intervention: INTERVENTION } \\
\text { The intervention was individualized, provided psycho-education and led by experienced registered } \\
\text { nurse with basic level psycho }\end{array}$ \\
\hline & $\begin{array}{l}\text { therapy training for } 12 \text { months to improve adherence to medication. In addition to standard asthma } \\
\text { care, intervention group subjects were offered up to } 8 \text { months of individual visits within a } 12 \text {-week peri- } \\
\text { od. Although the proposed intervention was unique in its design, to increase the internal validity of the } \\
\text { study, the Compliance Therapy Model was used to provide the underpinning theoretical framework. } \\
\text { This model encompassed the Transtheoretical Model of Change, Motivational Interviewing and Cog- } \\
\text { nitive Behavioral Therapy principles, providing a flexible short-term intervention using patient's indi- } \\
\text { vidual reasons for non-adherence as a guide to plan intervention content. The model used a non-con- } \\
\text { frontational technique which elicited self motivation and provided a process to resolve ambivalence } \\
\text { towards medication taking }\end{array}$ \\
\hline
\end{tabular}

Control: STANDARD ASTHMA CARE

All participants received standard asthma care at the difficult asthma service but the control group did not receive any further intervention. Subsequent follow-up visits for the control group was conducted at 6 months and 12 months post-recruitment scription from a single General Practitioner (GP) and prescription refills for inhaled combination therapy (ICT) were obtained for the previous 6 months and expressed as a percentage of prescribed medication. Non-adherence was defined as prescription filling of $>=50 \%$. Data were collected at 6 and 12 months

The patient outcomes were daily prescribed dose of inhaled corticosteroid (ICS), courses of rescue oral corticosteroids, total inhaled and nebulised beta-agonist doses, hospital admissions, and lung function (spirometry), as well as Asthma Control Questionnaire (ACQ), Asthma Quality of Life Score (AQLQ) and Hospital Anxiety and Depression Scale/State Trait Anxiety Scale (HADS). Outcomes for follow-up visits were obtained from the patient or medical notes, and lung function, questionnaires were obtained during the patient visit

\begin{tabular}{lll}
\hline Notes & - \\
\hline Risk of bias & Authors' judgement & Support for judgement \\
\hline Bias & Unclear risk & $\begin{array}{l}\text { Not enough information to judge. (pg 1309) Patients were randomly allocated } \\
\text { to either the intervention or control group }\end{array}$ \\
\hline $\begin{array}{l}\text { Random sequence genera- } \\
\text { tion (selection bias) }\end{array}$ & $\begin{array}{l}\text { Author's note: patients were randomly allocated using pre-sealed, sequentially } \\
\text { numbered, opaque envelopes }\end{array}$ \\
\hline $\begin{array}{l}\text { Allocation concealment } \\
\text { (selection bias) }\end{array}$ & Low risk & \begin{tabular}{l} 
No protocol available \\
\hline $\begin{array}{l}\text { Selective reporting (re- } \\
\text { porting bias) }\end{array}$
\end{tabular} \\
\hline
\end{tabular}


Gamble 2011 (Continued)

\begin{tabular}{lll} 
Other bias & Low risk & None noted \\
\hline $\begin{array}{l}\text { Blinding of outcome as- } \\
\text { sessment (detection bias) }\end{array}$ & Low risk & $\begin{array}{l}\text { (PRIMARY) PRESCRIPTION REFILL RECORDS - Appear to be low risk of bias. (pg } \\
\text { Adherence measure }\end{array}$ \\
$\begin{array}{l}\text { 1309) Adherence was measured as previously described and validated, using } \\
\text { prescription refill records. In Northern Ireland, all prescribed medication is ob- } \\
\text { tained via prescription from a single General Practitioner (GP) and prescription } \\
\text { refills for inhaled combination therapy (ICT) were obtained for the previous } 6 \\
\text { months and expressed as a percentage of prescribed medication }\end{array}$
\end{tabular}

Blinding of outcome as-
sessment (detection bias) $\quad$ Low risk $\quad$ (PRIMARY) SPIROMETRY - Objective measure of outcome

Patient outcome

Blinding of participants Unclear risk (PRIMARY) PRESCRIPTION REFILL RECORDS - Appear to be low risk of bias
(performance bias)
Adherence measure

Blinding of participants Low risk $\quad$ (PRIMARY) SPIROMETRY - Objective measure of outcome
$\begin{aligned} & \text { (performance bias) } \\ & \text { Patient outcome }\end{aligned}$

Blinding of personnel (per- Low risk
formance bias)
Adherence measure

\begin{tabular}{lll}
\hline $\begin{array}{l}\text { Blinding of personnel (per- } \\
\text { formance bias) } \\
\text { Patient outcome }\end{array}$ & Low risk & (PRIMARY) SPIROMETRY - Objective measure of outcome \\
\hline $\begin{array}{l}\text { Incomplete outcome data } \\
\text { (attrition bias) } \\
\text { Adherence measure }\end{array}$ & Low risk & (PRIMARY) PRESCRIPTION REFILL RECORDS - Only 2 withdrawals \\
\hline $\begin{array}{l}\text { Incomplete outcome data } \\
\text { (attrition bias) } \\
\text { Patient outcome }\end{array}$ & Low risk & (PRIMARY) SPIROMETRY - Only 2 withdrawals \\
\hline
\end{tabular}

Gani 2001

\begin{tabular}{ll}
\hline Methods & $\begin{array}{l}101 \text { patients were randomized into } 3 \text { groups: } A(n=30) \text { with drug therapy alone, B ( } n=35) \text { with drug } \\
\text { therapy plus training on the use of nasal spray, and C ( } n=36) \text { the same as B plus a lesson on rhinitis and } \\
\text { asthma. All patients received mometasone furoate nasal spray for } 8 \text { weeks as regular therapy, plus res- } \\
\text { cue medications on demand. Symptoms and drug consumption were evaluated during the pollen sea- } \\
\text { son }\end{array}$ \\
\hline Participants & 101 patients ( 62 male, 39 female, age range 12 to 60 years) had suffered for at least 2 years from sea- \\
sonal asthma and rhinitis (SAR) solely due to pollens (grasses, birch, Parietaria, and Compositae). Pa- \\
tients with sensitization to multiple pollens were included, whereas sensitization to cat dander, mites, \\
or mold was a reason for exclusion. Exclusion criteria were as follows: anatomical abnormalities of the \\
upper respiratory airways (septal deviation, polyposis), previous or ongoing immunotherapy, pregnan- \\
cy/lactation, chronic treatment with systemic corticosteroids, malignancies, and major psychiatric dis- \\
orders
\end{tabular}

Interventions

The first group of patients (group A $=30$ patients) was given only the drug with the instructions provided by the manufacturer. The second group (group $B=35$ patients) received a brief training on how to use the nasal spray and were given simplified written instructions on the use of the device. The third 
Gani 2001 (Continued)

group (group $C=36$ patients) also attended a 1-hour informal lesson on the clinical and pathogenic aspects of SAR, the treatment strategy, the correct use of medications, and the possible side effects of drugs. A trained allergist (1 per clinic) gave the lesson to patients, and the set of slides used was the same in the 3 clinics

Outcomes All patients completed a symptom diary, recording the presence and severity of their symptoms (self reported). The compliance with therapy was evaluated on the basis of the returned diaries and canisters. Symptoms were subdivided as follows: nasal (itching, sneezing, rhinorrhea, and blockage), ocular (itching, redness, lacrimation, and swelling), and respiratory (cough, wheezing, and chest tightness). The severity of symptoms was graded on a $10 \mathrm{~cm}$ visual analog scale (0: no symptoms, 10: severe symptoms). Patients were also required to record carefully each dose of each drug taken, in addition to the nasal corticosteroid

Notes 8-week follow-up during the whole pollen season is satisfactory for the seasonal disease

\section{Risk of bias}

Bias Authors' judgement Support for judgement

Random sequence genera- Unclear risk tion (selection bias)

Not stated - no details given. The study was designed to use 3 randomized, open-controlled parallel groups. "One hundred and one patients suffering from SAR were randomly allocated into three groups receiving a written prescription of drug therapy alone, or training on how to use the nasal spray, or a detailed lesson on the nature of their disease." The presence and severity of symptoms were assessed during the whole pollen season, as was the intake of drugs(pg 66)

$\begin{array}{ll}\begin{array}{l}\text { Allocation concealment } \\ \text { (selection bias) }\end{array} & \text { Unclear risk }\end{array} \quad \begin{aligned} & \text { (pg 66) Allocation concealment technique not mentioned "One hundred and } \\ & \text { one patients suffering from SAR were randomly allocated into } 3 \text { groups receiv- } \\ & \text { ing a written prescription of drug therapy alone, or training on how to use the } \\ & \text { nasal spray, or a detailed lesson on the nature of their disease." }\end{aligned}$

Selective reporting (re- Unclear risk No information given, no protocol available
porting bias)

\begin{tabular}{lll}
\hline Other bias & Unclear risk & Nothing noted but insufficient data provided to make a judgment \\
\hline $\begin{array}{l}\text { Blinding of outcome as- } \\
\text { sessment (detection bias) }\end{array}$ & Unclear risk & $\begin{array}{l}\text { (PRIMARY) SELF REPORT - DIARY - intervention does not mention blinding. (pg } \\
\text { Adherence measure }\end{array}$ \\
$\begin{array}{l}\text { with the instructions provided by the manufacturer. The second group (group } \\
\text { B }=35 \text { patients) received a brief training on how to use the nasal spray and } \\
\text { were given simplified written instructions on the use of the device. The third } \\
\text { group (group C }=36 \text { patients) also attended a 1-h informal lesson on the clini- } \\
\text { cal and pathogenic aspects of SAR, the treatment strategy, the correct use of } \\
\text { medications, and the possible side-effects of drugs. A trained allergist (one per } \\
\text { clinic) gave the lesson to patients, and the set of slides used was the same in } \\
\text { the three clinics". }\end{array}$
\end{tabular}

Blinding of outcome as- Unclear risk sessment (detection bias)

Patient outcome

\begin{abstract}
(PRIMARY) SELF REPORTED SYMPTOMS - Blinding not mentioned. (pg 66) "The first group of patients (group $A=30$ patients) was given only the drug with the instructions provided by the manufacturer. The second group (group $B=35$ patients) received a brief training on how to use the nasal spray and were given simplified written instructions on the use of the device. The third group (group $\mathrm{C}=36$ patients) also attended a 1-h informal lesson on the clinical and pathogenic aspects of SAR, the treatment strategy, the correct use of medications, and the possible side-effects of drugs. A trained allergist (one per clinic) gave the lesson to patients, and the set of slides used was the same in the three clinics."
\end{abstract}


Gani 2001 (Continued)

Blinding of participants High risk (PRIMARY) SELF REPORT - DIARY - Subjective measure and patients likely were (performance bias) not blind

Adherence measure

\begin{tabular}{|c|c|c|}
\hline $\begin{array}{l}\text { Blinding of participants } \\
\text { (performance bias) }\end{array}$ & High risk & $\begin{array}{l}\text { (PRIMARY) SELF REPORTED SYMPTOMS - Subjective measure; patients likely } \\
\text { were not blind }\end{array}$ \\
\hline
\end{tabular}

Patient outcome were not blind

Blinding of personnel (per- Unclear risk formance bias)

Adherence measure
(PRIMARY) SELF REPORT - DIARY - Intervention does not mention blinding. (pg 66) "The first group of patients (group $A=30$ patients) was given only the drug with the instructions provided by the manufacturer. The second group (group $B=35$ patients) received a brief training on how to use the nasal spray and were given simplified written instructions on the use of the device. The third group (group $\mathrm{C}=36$ patients) also attended a 1-h informal lesson on the clinical and pathogenic aspects of SAR, the treatment strategy, the correct use of medications, and the possible side-effects of drugs. A trained allergist (one per clinic) gave the lesson to patients, and the set of slides used was the same in the three clinics."

Blinding of personnel (per- Unclear risk formance bias)

Patient outcome
(PRIMARY) SELF REPORTED SYMPTOMS - Blinding not mentioned. (pg 66) "The first group of patients (group $A=30$ patients) was given only the drug with the instructions provided by the manufacturer. The second group (group $B=35$ patients) received a brief training on how to use the nasal spray and were given simplified written instructions on the use of the device. The third group (group $\mathrm{C}=36$ patients) also attended a 1 -h informal lesson on the clinical and pathogenic aspects of SAR, the treatment strategy, the correct use of medications, and the possible side-effects of drugs. A trained allergist (one per clinic) gave the lesson to patients, and the set of slides used was the same in the three clinics."
Incomplete outcome data Unclear risk

(attrition bias)

Adherence measure
(PRIMARY) SELF REPORT - DIARY - Unclear if amount of missing data would alter event rates. 6 patients dropped out because they did not attend the final visit(pg 66)

Incomplete outcome data Unclear risk

(attrition bias)

(PRIMARY) SELF REPORTED SYMPTOMS - Unclear if missing data will impact

Patient outcome the event rates

Gensichen 2009

\begin{tabular}{ll}
\hline Methods & Randomized controlled trial \\
\hline
\end{tabular}

\section{Participants}

The study location was 74 small primary care practices in Hesse, Germany

35 practices, 310 participants were randomized to the intervention group and 39 practices, 316 participants were randomized to the control group

The inclusion criteria were diagnosis of major depression with indication for any antidepressive treatment, age 18 to 80 years, access to a private telephone, ability to give informed consent, and ability to communicate in German

The exclusion criteria were confirmed pregnancy, severe alcohol or illicit drug consumption, or acute suicidal ideation assessed by the family physician

\footnotetext{
Interventions
}

Intervention: CASE MANAGEMENT

The intervention was in accordance with Chronic Care Model, which emphasizes proactive support for the patient by the entire practice team. One healthcare assistant from each practice assigned to the in- 
tervention group in 2 workshops (an 11-hour and a 6-hour workshop). This interactive training included information on depression, communication skills, telephone monitoring, and behavioral activation for the patient. The healthcare assistants contacted their patients by telephone twice a week in the first month and then once a month for the following 11 months. They monitored depression symptoms and adherence to medication by using the Depression Monitoring Context List. Healthcare assistants also encouraged patients to follow self management activities, such as medication adherence and activation for pleasant or social activities. The assistants provided this information to the family physician in a structured report that stratified the urgency of the contact by a robot scheme. Family physicians in both the intervention and control groups received training on evidence-based depression treatment guidelines

Control: USUAL CARE

Patients in the control group were given usual care

Outcomes

The measures of adherence were a modified Morisky patient self report scale, in which patients are scored from 0 to 3 on the basis of their answers to the following 3 questions (coded higher values indicate higher adherence): Did you ever forget to take your medicine during the last 2 weeks? During the last 2 weeks, did you sometimes stop taking your medicine when you felt better? During the last 2 weeks, did you stop taking your medicine when you felt worse? This questionnaire was given to patients at 6 and 12 months

The patient outcome was depression symptoms as the primary outcome, which was assessed by using the primary care-validated PHQ-9. Each item is scored from 0 (not at all) to 3 (nearly every day), for a total score that ranges from 0 to 27 (high scores indicate more severe depression). Response (50\% improvement in PHQ-9 score) and remission status (PHQ-9 score=5) were secondary outcomes. Data for the following secondary outcomes were also recorded: quality of life, patient assessment of chronic illness care, and medication adherence. Health-related quality of life was measured by using the Medical Outcomes Study Short Form 36 (SF-36) and the EuroQol-5D. The SF-36 allows the calculation of scores for physical health and mental health (range, 0 to 100; higher scores indicate better status). The EuroQol-5D is a generic instrument that measures health-related quality of life with a visual analog scale (range, 0 to 100; higher ratings indicate higher quality of life). The number of physical comorbid conditions was determined by counting the documented diagnoses from different diagnostic groups listed in the Diagnostic and Statistical Manual of Mental Disorders, 4th Edition, and International Classification of Diseases, 10th Edition, excluding all psychiatric diagnoses in the patient record. Severity of chronic physical diseases was assessed by using the Chronic Disease Score, on the basis of prescription data from the patient record. All outcomes were assessed at 6 and 12 months

Notes -

\section{Risk of bias}

Bias Authors' judgement Support for judgement

Random sequence genera- Low risk tion (selection bias)
Computer randomized. (pg 370) "The data safety and monitoring board stratified the practices according to the size of the city and performed computer-based randomization. Patient random assignment status was nested within the practice status. The data safety and monitoring board was responsible for allocation concealment by keeping the randomization results in a secure database."

\begin{tabular}{lll}
\hline $\begin{array}{l}\text { Allocation concealment } \\
\text { (selection bias) }\end{array}$ & Low risk & $\begin{array}{l}\text { Allocation concealment done. (pg 370) "The data safety and monitoring board } \\
\text { stratified the practices according to the size of the city and performed comput- } \\
\text { er-based randomization. Patient random assignment status was nested within } \\
\text { the practice status. The data safety and monitoring board was responsible for } \\
\text { allocation concealment by keeping the randomization results in a secure data- } \\
\text { base." }\end{array}$ \\
\hline $\begin{array}{l}\text { Selective reporting (re- } \\
\text { porting bias) }\end{array}$ & Unclear risk & $\begin{array}{l}\text { Did not report some prespecified outcomes from the protocol of Beck Depres- } \\
\text { sion Inventory and days out of work }\end{array}$ \\
\hline
\end{tabular}


Gensichen 2009 (Continued)

Other bias Unclear risk Some risk of bias noted by the author - (pg 369) "Patients, health care assistants, family physicians, and researchers were not blinded to group assignment, and 12-month follow-up of patients was incomplete". However, overall risk of bias is unclear

Blinding of outcome as- $\quad$ High risk
sessment (detection bias)

(PRIMARY) SELF REPORT - QUESTIONNAIRE - Outcome assessors were not Adherence measure blind. (pg 370) "Because of the practice staff training required for the behavioral intervention, patients, health care assistants, family physicians, and researchers were not blinded to assignment once the trial was started."

$\begin{array}{lll}\text { Blinding of outcome as- } & \text { High risk } & \text { (PRIMARY) DEPRESSION SYMPTOMS AND QUALITY OF LIFE QUESTIONNAIRES } \\ \text { sessment (detection bias) } & & \text { - Outcome assessors were not blinded. (pg 370) "Because of the practice staff } \\ \text { Patient outcome } & \text { training required for the behavioral intervention, patients, health care assis- } \\ & \text { tants, family physicians, and researchers were not blinded to assignment once } \\ & \text { the trial was started." }\end{array}$

\begin{tabular}{|c|c|c|}
\hline $\begin{array}{l}\text { Blinding of participants } \\
\text { (performance bias) } \\
\text { Adherence measure }\end{array}$ & High risk & $\begin{array}{l}\text { (PRIMARY) SELF REPORT - QUESTIONNAIRE - Patients were not blind. (pg 370) } \\
\text { "Because of the practice staff training required for the behavioral intervention, } \\
\text { patients, health care assistants, family physicians, and researchers were not } \\
\text { blinded to assignment once the trial was started." }\end{array}$ \\
\hline
\end{tabular}

Blinding of participants High risk
(performance bias) (PRIMARY) DEPRESSION SYMPTOMS AND QUALITY OF LIFE QUESTIONNAIRES

Patient outcome - Patients were not blinded. (pg 370) "Because of the practice staff training required for the behavioral intervention, patients, health care assistants, family physicians, and researchers were not blinded to assignment once the trial was started."

Blinding of personnel (per- High risk
formance bias)
Adherence measure

(PRIMARY) SELF REPORT - QUESTIONNAIRE - Study staff were not blind. (pg 370) "Because of the practice staff training required for the behavioral intervention, patients, health care assistants, family physicians, and researchers were not blinded to assignment once the trial was started."

\begin{tabular}{|c|c|c|}
\hline $\begin{array}{l}\text { Blinding of personnel (per- } \\
\text { formance bias) } \\
\text { Patient outcome }\end{array}$ & High risk & $\begin{array}{l}\text { (PRIMARY) DEPRESSION SYMPTOMS AND QUALITY OF LIFE QUESTIONNAIRES - } \\
\text { Study staff were not blinded. (pg 370) "Because of the practice staff training re- } \\
\text { quired for the behavioral intervention, patients, health care assistants, family } \\
\text { physicians, and researchers were not blinded to assignment once the trial was } \\
\text { started." }\end{array}$ \\
\hline
\end{tabular}

\begin{tabular}{|c|c|c|}
\hline $\begin{array}{l}\text { Incomplete outcome data } \\
\text { (attrition bias) } \\
\text { Adherence measure }\end{array}$ & Unclear risk & $\begin{array}{l}\text { (PRIMARY) SELF REPORT - QUESTIONNAIRE - Reasons for dropouts not noted, } \\
\text { dropouts were not balanced across - but not clear how this would have affect- } \\
\text { ed the results }\end{array}$ \\
\hline
\end{tabular}

\begin{tabular}{|c|c|c|}
\hline $\begin{array}{l}\text { Incomplete outcome data } \\
\text { (attrition bias) } \\
\text { Patient outcome }\end{array}$ & Unclear risk & $\begin{array}{l}\text { (PRIMARY) DEPRESSION SYMPTOMS AND QUALITY OF LIFE QUESTIONNAIRES } \\
\text { - Reasons for dropouts not noted; dropouts were not balanced across groups, } \\
\text { but unclear how this would have affected the results }\end{array}$ \\
\hline
\end{tabular}

\begin{tabular}{ll} 
Ginde 2003 & $\begin{array}{l}\text { Randomized controlled trial: consenting patients were randomized to the ED (intervention) or pharma- } \\
\text { cy (control) group }\end{array}$ \\
\hline Participants & $\begin{array}{l}\text { The study was conducted from November } 2001 \text { to May 2002. During the 6-month study period, all adult } \\
\text { patients ( }>18 \text { years old) presenting to the ED for whom an outpatient prescription for a macrolide an- } \\
\text { tibiotic was being considered in discharge planning were eligible for the study. The need for outpatient } \\
\text { treatment with an antibiotic was determined by the attending Emergency Physician who was primarily } \\
\text { responsible for the patient. Patients who were unwilling or unable to give informed consent or were un- } \\
\text { available for telephone follow-up were excluded from the study. In addition, all females of childbearing }\end{array}$ \\
\hline
\end{tabular}


Ginde 2003 (Continued)

potential were given urine pregnancy tests, and pregnant or breast-feeding females were excluded. 77 patients were recruited

Interventions

Patients in the ED group were provided a full course of azithromycin $(6 \times 250 \mathrm{mg})$ at no charge and given instructions on the proper dose and frequency before discharge from the ED. Patients in the pharmacy group received a written prescription for a full course of azithromycin before discharge from the ED. To minimize the potential for economic bias, the patients were able to fill their prescriptions free of charge at a 24-hour pharmacy located 8 blocks from the hospital

\section{Outcomes}

The primary outcome was compliance of obtaining medication as determined by pharmacy records. A secondary outcome was compliance in completing the course of medication as determined by a telephone survey

Measurement of clinical health outcomes: return visits to the ED and hospitalization

The prescription filling rate for the control group is based on the assumption that control patients used
a participating pharmacy 8 blocks away that provided the drug free of charge and patients were ap-
parently not asked if they filled their prescription elsewhere. The prescription filling rates could have
been clarified for the control group. The "course completed" rate is based on self report on a telephone
call and there was no indication that interviewers were blinded to group or if the exact question given.
Technically, this study qualified for the review, but the reliability and credibility of these measures is
suspect. This intervention may be impractical in any setting where giving drugs out for free is not possi-
ble

\section{Risk of bias}

\begin{tabular}{|c|c|c|}
\hline Bias & Authors' judgement & Support for judgement \\
\hline $\begin{array}{l}\text { Random sequence genera- } \\
\text { tion (selection bias) }\end{array}$ & Low risk & $\begin{array}{l}\text { Author's note: patients were randomized by random sequence generation } \\
\text { through pharmacy who opened the envelope to determine if the subject was } \\
\text { in the intervention or control group }\end{array}$ \\
\hline $\begin{array}{l}\text { Allocation concealment } \\
\text { (selection bias) }\end{array}$ & Unclear risk & $\begin{array}{l}\text { No mention of allocation concealment. (pg 313) "Patients who were enrolled } \\
\text { in the study were randomized into the ED (intervention) or pharmacy (control) } \\
\text { group." }\end{array}$ \\
\hline $\begin{array}{l}\text { Selective reporting (re- } \\
\text { porting bias) }\end{array}$ & Low risk & $\begin{array}{l}\text { Author's note: We reported all outcomes that we measured: compliance by self } \\
\text { report, compliance by pharmacy records, return ED visits, or hospitalization } \\
\text { within } 2 \text { weeks }\end{array}$ \\
\hline Other bias & Unclear risk & $\begin{array}{l}\text { Limitations in discussion note other risks of bias. (pg } 315 \text { ) "The most impor- } \\
\text { tant limitation of this study is the poor reliability of patient self reported com- } \\
\text { pliance. This makes it difficult to draw conclusions on patient compliance be- } \\
\text { yond filling the prescription. Another limitation was the choice of a study med- } \\
\text { ication, which is often prescribed for relatively benign, self limiting conditions, } \\
\text { because spontaneous improvement in the patient's condition could further } \\
\text { decrease compliance. The benign nature of disease in this population could } \\
\text { have also limited the ability to find differences in patient morbidity and use } \\
\text { of hospital resources as a result of noncompliance. Finally, small sample size } \\
\text { and our urban setting limit the ability to generalize the results to larger popu- } \\
\text { lations or other ED settings." Author note: these limitations present an unclear } \\
\text { risk of bias }\end{array}$ \\
\hline $\begin{array}{l}\text { Blinding of outcome as- } \\
\text { sessment (detection bias) } \\
\text { Adherence measure }\end{array}$ & Unclear risk & $\begin{array}{l}\text { (PRIMARY) PHARMACY RECORD - No mention of blinding of outcome assessors } \\
\text { - not possible given the groups in this study (only one group received medi- } \\
\text { cine from the pharmacy). (pg 313) "Pharmacy records were reviewed to deter- } \\
\text { mine whether patients in the pharmacy group had filled their prescriptions". } \\
\text { No mention of other details like whether the records were electronic or pa- } \\
\text { per-based }\end{array}$ \\
\hline
\end{tabular}


Ginde 2003 (Continued)

Blinding of outcome as- Low risk (PRIMARY) RETURN VISIT TO ED/HOSPITAL ADMISSION - No mention of blindsessment (detection bias) ing of outcome assessors, though this is unlikely to impact this outcome givPatient outcome en its objective nature. (pg 313-4) "The hospital's computerized record system was searched to identify enrolled patients who returned to the ED or were admitted to the hospital within 2 weeks of the index visit.....as well as return visits to the ED and hospital admissions within 2 weeks of the index visit."

$\begin{array}{ll}\begin{array}{l}\text { Blinding of participants } \\ \text { (performance bias) }\end{array} & \text { (PRIMARY) PHARMACY RECORD - No explicit statement on blinding. Pharmacy } \\ \text { Adherence measure } & \text { group patients were required to fill their prescriptions at a pharmacy } 8 \text { blocks } \\ & \text { away and ED patients from ED itself. It is not known whether the fact that some } \\ & \text { of the patients were obtaining medicines from ED was concealed from the } \\ \text { pharmacy group, a fact which could alter the outcome; hence unclear }\end{array}$

$\begin{array}{ll}\begin{array}{l}\text { Blinding of participants } \\ \text { (performance bias) }\end{array} & \text { Low risk } \\ \begin{array}{l}\text { Patient outcome } \\ \text { (PRIMARY) RETURN VISIT TO ED/HOSPITAL ADMISSION - No mention of blind- } \\ \text { ing of outcome assessors, though this is unlikely to impact this outcome given } \\ \text { its objective nature }\end{array}\end{array}$

\begin{tabular}{|c|c|c|}
\hline $\begin{array}{l}\text { Blinding of personnel (per- } \\
\text { formance bias) } \\
\text { Adherence measure }\end{array}$ & Unclear risk & $\begin{array}{l}\text { (PRIMARY) PHARMACY RECORD - True blinding impossible because medicines } \\
\text { were dispensed from } 2 \text { different sites. There is no statement regarding the } \\
\text { blinding; hence adjudged uncertain }\end{array}$ \\
\hline
\end{tabular}

\begin{tabular}{|c|c|c|}
\hline Adherence measure & & blinding; hence adjudged uncertain \\
\hline $\begin{array}{l}\text { Blinding of personnel (per- } \\
\text { formance bias) } \\
\text { Patient outcome }\end{array}$ & Low risk & $\begin{array}{l}\text { (PRIMARY) RETURN VISIT TO ED/HOSPITAL ADMISSION - No mention of blind- } \\
\text { ing of outcome assessors, though this is unlikely to impact this outcome given } \\
\text { its objective nature }\end{array}$ \\
\hline
\end{tabular}

\begin{tabular}{lll}
\hline $\begin{array}{l}\text { Incomplete outcome data } \\
\text { (attrition bias) } \\
\text { Adherence measure }\end{array}$ & Low risk & $\begin{array}{l}\text { (PRIMARY) PHARMACY RECORD - Incomplete data is evenly spread across the } \\
\text { groups - } 4 \text { in the ED group and } 3 \text { in the pharmacy group }\end{array}$ \\
\hline $\begin{array}{l}\text { Incomplete outcome data } \\
\text { (attrition bias) } \\
\begin{array}{l}\text { Patient outcome } \\
\hline\end{array}\end{array}$ & $\begin{array}{l}\text { Unclear risk } \\
\text { (PRIMARY) RETURN VISIT TO ED/HOSPITAL ADMISSION - Incomplete data is } \\
\text { evenly spread across the groups - } 4 \text { in the ED group and } 3 \text { in the pharmacy } \\
\text { group }\end{array}$ \\
\hline
\end{tabular}

\section{Girvin 1999}

$\begin{array}{ll}\text { Methods } & \text { Randomization was conducted by an independent advisor by resampling without replacement after } \\ \text { the placebo run-in period. The study was not double-blind because one outcome was the difference in } \\ \text { compliance between once-daily and twice-daily regimens. However, the investigator responsible for } \\ \text { analyzing the results was blinded as to the treatment phase }\end{array}$

Participants
$\begin{aligned} & 27 \text { patients with a history of mild hypertension (well controlled on monotherapy), with a diastolic BP } \\ & \text { between } 90 \text { to } 110 \mathrm{~mm} \mathrm{Hg} \text { were included. Patients were excluded if they had secondary hypertension } \\ & \text { or significant end organ damage, were pregnant or lactating mothers, had cardiovascular complica- } \\ & \text { tions in addition to hypertension (e.g. MI within the past } 6 \text { months), stroke, congestive heart failure, } \\ & \text { angina pectoris, had poor renal function, a history of renal artery stenosis, were obese (weighing over } \\ & 125 \% \text { of ideal body weight), had hyperkalemia, had a history of angioneurotic edema, had any con- } \\ & \text { traindication or hypersensitivity to ACE inhibitors, or if they were taking non-steroidal anti-inflammato- } \\ & \text { ry drugs, corticosteroids or any other medication that would significantly alter blood pressure }\end{aligned}$

Interventions

Patients were randomly assigned to a sequence of enalapril $20 \mathrm{mg}$ once daily or $10 \mathrm{mg}$ twice daily in 3 4-week periods following a 4-week run-in period. Treatment A comprised enalapril $20 \mathrm{mg}$ once daily, and treatment $B$ comprised enalapril $10 \mathrm{mg}$ twice daily. The first 2 periods in each group constituted a conventional 2-period cross-over design. The third treatment period was included to detect any carryover effects between the periods without having to incorporate a washout phase between treatments. The 4 study arms were organized as follows (each period lasted 4 weeks): ABB BAA ABA BAB 
Girvin 1999 (Continued)

Outcomes

Measurement of compliance: patient compliance was measured via pill counts and electronic monitoring using medication electronic monitoring system (MEMS), which record the exact date and time of each opening and closing of the drug container. Measurement of clinical health outcomes: blood pressure reduction was measured at each visit. Patients were asked not to take their blood pressure tablet on the morning of the clinical visit until after the investigator had measured their blood pressure so that the blood pressure (BP) readings were trough values. 2 readings were taken after 10 minutes rest in the seated position. The arm was supported at heart level and the diastolic blood pressure taken as the disappearance of the Korotkoff sounds (phase V). Ambulatory blood pressure was measured at the end of the placebo run-in period and at the end of periods 1 and 2

Notes

\section{Risk of bias}

\begin{tabular}{lll}
\hline Bias & Authors' judgement & Support for judgement \\
\hline $\begin{array}{l}\text { Random sequence genera- } \\
\text { tion (selection bias) }\end{array}$ & Unclear risk & $\begin{array}{l}\text { No mention of method of randomization. (pg 1628) "Randomization was con- } \\
\text { ducted by an independent advisor (by resampling without replacement) after } \\
\text { the placebo run-in period." }\end{array}$ \\
\hline
\end{tabular}

\begin{tabular}{|c|c|c|}
\hline $\begin{array}{l}\text { Allocation concealment } \\
\text { (selection bias) }\end{array}$ & Unclear risk & $\begin{array}{l}\text { No mention of allocation concealment, though reference to an "independent } \\
\text { advisor" may have meant allocation was concealed from study staff. (pg 1628) } \\
\text { "Randomization was conducted by an independent advisor (by resampling } \\
\text { without replacement) after the placebo run-in period." }\end{array}$ \\
\hline
\end{tabular}

\begin{tabular}{lll}
\hline $\begin{array}{l}\text { Selective reporting (re- } \\
\text { porting bias) }\end{array}$ & Unclear risk & No protocol available \\
\hline Other bias & Unclear risk & No biases noted in discussion, no other obvious risks of bias in study \\
\hline $\begin{array}{l}\text { Blinding of outcome as- } \\
\text { sessment (detection bias) } \\
\text { Adherence measure }\end{array}$ & High risk & $\begin{array}{l}\text { (PRIMARY) PILL COUNT - (pg 1628) "The study could not be double-blind since } \\
\text { an important outcome was the difference in compliance between the once } \\
\text { daily and twice daily regimens. However, the investigator responsible for } \\
\text { analysing the results was blinded as to the treatment phase." }\end{array}$
\end{tabular}

\section{Blinding of outcome as- High risk} sessment (detection bias) Adherence measure

(PRIMARY) MEMS - No mention of blinding outcomes assessors, but (pg 1628) "The study could not be double-blind since an important outcome was the difference in compliance between the once daily and twice daily regimens. However, the investigator responsible for analysing the results was blinded as to the treatment phase."

\begin{tabular}{|c|c|c|}
\hline $\begin{array}{l}\text { Blinding of outcome as- } \\
\text { sessment (detection bias) } \\
\text { Patient outcome }\end{array}$ & Low risk & $\begin{array}{l}\text { (PRIMARY) BLOOD PRESSURE - (pg 1628-9) "Blood pressure was measured at } \\
\text { each visit using the Hawksley Random-Zero Sphygmomanometer (Lancing, } \\
\text { UK)" }\end{array}$ \\
\hline
\end{tabular}

\begin{tabular}{|c|c|c|}
\hline $\begin{array}{l}\text { Blinding of participants } \\
\text { (performance bias) } \\
\text { Adherence measure }\end{array}$ & High risk & $\begin{array}{l}\text { (PRIMARY) MEMS - Patients would have been aware that their pills were being } \\
\text { tracked }\end{array}$ \\
\hline $\begin{array}{l}\text { Blinding of participants } \\
\text { (performance bias) } \\
\text { Adherence measure }\end{array}$ & High risk & $\begin{array}{l}\text { (PRIMARY) PILL COUNT - Patients would have been aware that their pills were } \\
\text { being counted }\end{array}$ \\
\hline $\begin{array}{l}\text { Blinding of participants } \\
\text { (performance bias) } \\
\text { Patient outcome }\end{array}$ & Low risk & $\begin{array}{l}\text { (PRIMARY) BLOOD PRESSURE - (pg 1628-9) "Blood pressure was measured at } \\
\text { each visit using the Hawksley Random-Zero Sphygmomanometer (Lancing, } \\
\text { UK)" }\end{array}$ \\
\hline
\end{tabular}


Girvin 1999 (Continued)

Blinding of personnel (per- High risk formance bias)

Adherence measure
(PRIMARY) MEMS - (pg 1628) "The study could not be double-blind since an important outcome was the difference in compliance between the once daily and twice daily regimens. However, the investigator responsible for analysing the results was blinded as to the treatment phase."

\section{Blinding of personnel (per- High risk} formance bias)

Adherence measure
(PRIMARY) PILL COUNT - (pg 1628) "The study could not be double-blind since an important outcome was the difference in compliance between the once daily and twice daily regimens. However, the investigator responsible for analysing the results was blinded as to the treatment phase."

$\begin{array}{ll}\begin{array}{ll}\text { Blinding of personnel (per- } & \text { Low risk }\end{array} & \text { (PRIMARY) BLOOD PRESSURE - (pg 1628) "Blood pressure was measured at } \\ \text { formance bias) } & \text { each visit using the Hawksley Random-Zero Sphygmomanometer (Lancing, } \\ \text { Patient outcome } & \text { UK)." }\end{array}$
each visit using the Hawksley Random-Zero Sphygmomanometer (Lancing, (PRIMARY) MEMS - No mention of groups missing data were from. (pg 1629) "Twenty-seven patients were recruited into the study, two of whom had to be withdrawn after experiencing headache, nausea and dizziness upon commencing enalapril therapy. The remaining 25 patients completed".

Incomplete outcome data Unclear risk

(attrition bias)

Adherence measure

(PRIMARY) PILL COUNT - No mention of groups missing data were from. (pg

Incomplete outcome data Unclear risk

(attrition bias) 1629) "Twenty-seven patients were recruited into the study, two of whom had

Adherence measure to be withdrawn after experiencing headache, nausea and dizziness upon commencing enalapril therapy. The remaining 25 patients completed."

Incomplete outcome data Unclear risk
(attrition bias)

(PRIMARY) BLOOD PRESSURE - No mention of groups missing data were from.

Patient outcome (pg 1629) "Twenty-seven patients were recruited into the study, two of whom had to be withdrawn after experiencing headache, nausea and dizziness upon commencing enalapril therapy. The remaining 25 patients completed."

\title{
Gould 2009
}

\begin{tabular}{ll}
\hline Methods & Randomized controlled trial \\
\hline Participants & The study location was not specified \\
& 64 participants were randomized to the intervention group and 65 participants were randomized to the \\
control group & \\
The inclusion criteria were adult male and female patients between the ages of 30 and 80 years treated \\
for an acute cardiac event with percutaneous coronary intervention (PCI) and discharged from a hospi- \\
tal setting within 72 hours of the procedure \\
The exclusion criteria were if the patients were not accessible by telephone, had conditions that may \\
impair telephone communication, or were enrolled in clinical trials or other research activity requiring \\
telephone follow-up
\end{tabular}

Interventions

\begin{abstract}
Intervention: DISCHARGE NURSING INTERVENTION (DNI)
The discharge nursing intervention consisted of written discharge materials and telephone follow-up by an expert cardiovascular nurse. Expert nurses were defined as those having advanced education and clinical expertise in the care and management of this population. Delivery of the intervention was time-sensitive. The intervention was offered at discharge and continued within 24 hours of discharge. DNI group received a packet containing group instructions, medication review materials, a medication pocket card, suggested Internet sites, copies of the interview tools, and the Revised Illness Perception Questionnaire (IPQ-R) instrument
\end{abstract}

Control: USUAL CARE 
Gould 2009 (Continued)

Control group patients received routine discharge materials and usual care. Subjects in the control group received an envelope containing group instructions, copies of interview tools, and the IPQ-R

Outcomes

The measures of adherence were the Self-Reported Medication Taking Scale and the Machtinger and Bansberg visual analog scale. They were given the patients at discharge, with responses collected 1 to 3 days later via telephone

The patient outcome was urgent care visits. This was measured via questions in a telephone interview 3 days after hospital discharge. Patients were asked if they had placed an urgent call to their physician or to the hospital or visited an ER since discharge

\section{Notes}

The authors got consent from 154 patients but only 129 were included in the analysis. It is not clear whether the 154 patients were randomized and then they dropped out or whether they dropped out prior to randomization

\section{Risk of bias}

\begin{tabular}{lll}
\hline Bias & Authors' judgement & Support for judgement \\
\hline $\begin{array}{l}\text { Random sequence genera- } \\
\text { tion (selection bias) }\end{array}$ & Unclear risk & $\begin{array}{l}\text { Insufficient information to judge. (pg 120) Following consent, patients were } \\
\text { randomly assigned into } 2 \text { groups: control and experimental, determined by se- } \\
\text { lection of sealed envelopes containing group assignment and study materials }\end{array}$ \\
\hline $\begin{array}{l}\text { Allocation concealment } \\
\text { (selection bias) }\end{array}$ & Low risk & $\begin{array}{l}\text { Additional info provided by author: the Pl completed the consent process and } \\
\text { delivered the intervention. Allocation concealment was done as patients were } \\
\text { assigned to groups using a sealed envelope technique. The envelopes were } \\
\text { identical visually and physically. Envelopes were prepared by the primary in- } \\
\text { vestigator but were shuffled and placed in a container by } 2 \text { adults without the } \\
\text { Pl present. The PI had no knowledge of group assignment until the patient } \\
\text { opened the envelope. At that point both patient and PI became aware of group } \\
\text { assignment. The staff caring for the patient was not aware of group assign- } \\
\text { ment }\end{array}$ \\
\hline
\end{tabular}

\begin{tabular}{lll}
\hline $\begin{array}{l}\text { Selective reporting (re- } \\
\text { porting bias) }\end{array}$ & Unclear risk & No protocol available \\
\hline Other bias & Unclear risk & None noted but unclear \\
\hline $\begin{array}{l}\text { Blinding of outcome as- } \\
\text { sessment (detection bias) } \\
\text { Adherence measure }\end{array}$ & Low risk & $\begin{array}{l}\text { (PRIMARY) SELF REPORT - QUESTIONNAIRE - Additional info provided by au- } \\
\text { thor: the PI completed the consent process and delivered the intervention. Al- } \\
\text { location concealment was done as patients were assigned to groups using a } \\
\text { sealed envelope technique. The envelopes were identical visually and physi- } \\
\text { cally. Envelopes were prepared by the primary investigator but were shuffled } \\
\text { and placed in a container by } 2 \text { adults without the PI present. The PI had no } \\
\text { knowledge of group assignment until the patient opened the envelope. At that } \\
\text { point both patient and PI became aware of group assignment. The staff caring } \\
\text { for the patient was not aware of group assignment }\end{array}$ \\
\hline
\end{tabular}

\begin{tabular}{lll}
\hline $\begin{array}{l}\text { Blinding of outcome as- } \\
\text { sessment (detection bias) }\end{array}$ & High risk & (PRIMARY) USE OF URGENT CARE - Author's note: the staff in the cardiovascu- \\
$\begin{array}{l}\text { Patient outcome } \\
\text { lar department, caring for the patients, were not aware of group assignment. } \\
\text { The PI was aware of patient assignment during the interviews and patients } \\
\text { were aware of assignment during interview }\end{array}$
\end{tabular}

Blinding of participants High risk (performance bias) Adherence measure

Blinding of participants High risk
(performance bias)

(PRIMARY) SELF REPORT - QUESTIONNAIRE - Author's note: the PI and patients were blinded only during the enrollment stage. Following consent, both patients and PI became aware of group assignment ment during interviews 
Gould 2009 (Continued)

Patient outcome formance bias)

Adherence measure
Blinding of personnel (per- High risk

(PRIMARY) SELF REPORT - QUESTIONNAIRE - Author's note: the PI and patients were blinded only during the enrollment stage. Following consent, both patients and PI became aware of group assignment

(PRIMARY) USE OF URGENT CARE - Author's note: the PI was aware of patient assignment during the interviews

Blinding of personnel (per- High risk formance bias)

Patient outcome

Incomplete outcome data Unclear risk

(attrition bias)

Adherence measure

(PRIMARY) SELF REPORT - QUESTIONNAIRE - No information given about the group membership of the dropouts, or if they were disproportionate in one group over the other

Incomplete outcome data Low risk

(attrition bias)

Patient outcome

(PRIMARY) USE OF URGENT CARE - There is a low risk of bias; there seems to be no missing information. Refer to Table 3, 4 and 5: there seems to be no data missing for use of urgent care data, and patient satisfaction. 1 participant's data are missing from the control group for illness perception (because there are only 64/65)

Gray 2012

\begin{tabular}{ll}
\hline Methods & Randomized controlled trial \\
\hline Participants & The study location was Manchester Royal Eye Hospital (MREH) clinics in Manchester, UK \\
& $\begin{array}{l}64 \text { participants were randomized to the intervention group and } 63 \text { participants were randomized to the } \\
\text { control group }\end{array}$
\end{tabular}

The inclusion criteria were patients with newly diagnosed ocular hypertension $(\mathrm{OHT})$, open-angle glaucoma (POAG), normal tension glaucoma (NTG), pigment dispersion, or pseudo-exfoliation glaucoma

The exclusion criteria were inability to make an informed decision about participating in the study and having a co-existing eye condition requiring a drop regimen

Interventions

\section{Intervention: INDIVIDUALIZED PATIENT CARE}

Patients in the individualized care group received standard care plus an individualized care plan implemented by a glaucoma trained nurse. This included a 45-minute assessment of healthcare needs and beliefs with supplied booklets and drop diaries, a 20-minute educational session, and a 10-minute training session on instilling eye drops. A 1-year follow-up care plan was designed and implemented according to healthcare needs, based on education and support, which was tailored to gaps in glaucoma knowledge, pre-existing beliefs, and ability to manage an eye drop regimen. Patients were given the nurse's contact telephone for advice or assistance between consultation. Follow-up involved ongoing training and support by both face-to-face and telephone consultations. This incorporated a review of drop diaries in the initial weeks of therapy (these were continued if found beneficial as a reminder tool), reminders to collect and use drops, and repetition of information as required. Needs were reassessed and the level of support adjusted accordingly at the end of each consultation. The intervention nurse was the same throughout, and the intervention was guided by prescriptive documentation

\section{Control: STANDARD CARE}

Standard of care is not definitively described. Education, advice, and support varies from clinic to clinic within Manchester Royal Eye Hospital but is limited for many patients. No further contact after initial consultation

Outcomes pharmacists for prescription dispensing information during the 1-year follow-up period, and self report adherence using the Revised Glaucoma Adherence Questionnaire (GAQ-R) 


\section{Risk of bias}

\begin{tabular}{lll}
\hline Bias & Authors' judgement & Support for judgement \\
\hline $\begin{array}{l}\text { Random sequence genera- } \\
\text { tion (selection bias) }\end{array}$ & Low risk & $\begin{array}{l}\text { (pg 408) Computer-generated randomization was conducted by a statistician } \\
\text { with no involvement in data collection }\end{array}$ \\
\hline $\begin{array}{l}\text { Allocation concealment } \\
\text { selection bias) }\end{array}$ & Low risk & $\begin{array}{l}\text { (pg 409, Figure 1) Allocations were concealed in opaque, sealed envelopes by } \\
\text { personnel with no involvement in the study, and opened by a research co-ordi- } \\
\text { nator with no other involvement in the study }\end{array}$ \\
\hline $\begin{array}{l}\text { Selective reporting (re- } \\
\text { porting bias) }\end{array}$ & Low risk & $\begin{array}{l}\text { The study protocol is not available but it is clear that the published reports in- } \\
\text { clude all expected outcomes, including those that were pre-specified }\end{array}$ \\
\hline $\begin{array}{l}\text { Other bias } \\
\text { Unclear risk }\end{array}$ & $\begin{array}{l}\text { Author noted limitations in the article. (pg 415) "...refill adherence does not } \\
\text { capture all aspects of refill behavior" - refilling does not necessarily mean the } \\
\text { previous bottle was used; could have been lost - changes in visual field or optic } \\
\text { nerve head not likely to reach significance during study length }\end{array}$
\end{tabular}

$\begin{array}{ll}\begin{array}{l}\text { Blinding of outcome as- } \\ \text { sessment (detection bias) }\end{array} & \text { Low risk }\end{array} \quad \begin{aligned} & \text { (PRIMARY) REFILL ADHERENCE - "The researcher and outcome assessor were } \\ & \text { masked to allocations until study completion." (pg 409, Figure 1) }\end{aligned}$

Adherence measure

\begin{tabular}{lll}
\hline $\begin{array}{l}\text { Blinding of outcome as- } \\
\text { sessment (detection bias) }\end{array}$ & Low risk & (PRIMARY) MEAN IOP, IOP FLUCTUATION, AND CHANGE IN CLINICAL MANAGE- \\
Patient outcome & MENT - IOP level recordings and decisions regarding clinical management \\
& were made at routine clinic visits and were the responsibility of clinicians with \\
& no involvement in the study
\end{tabular}

$\begin{array}{ll}\text { Blinding of participants } & \text { Low risk } \\ \text { (performance bias) } & \text { (PRIMARY) REFILL ADHERENCE - The lack of blinding of participants is not like- } \\ \text { Adherence measure } & \text { ly to affect the outcome }\end{array}$

Adherence measure

$\begin{array}{ll}\begin{array}{l}\text { Blinding of participants } \\ \text { (performance bias) }\end{array} & \text { Low risk } \\ \begin{array}{l}\text { Patient outcome } \\ \text { (PRIMARY) MEAN IOP, IOP FLUCTUATION, AND CHANGE IN CLINICAL MANAGE- } \\ \text { is not likely to affect the outcome }\end{array}\end{array}$

\begin{tabular}{|c|c|c|}
\hline $\begin{array}{l}\text { Blinding of personnel (per- } \\
\text { formance bias) } \\
\text { Adherence measure }\end{array}$ & Low risk & $\begin{array}{l}\text { (PRIMARY) REFILL ADHERENCE - "The researcher and outcome assessor were } \\
\text { masked to allocations until study completion." (pg 409, Figure 1) }\end{array}$ \\
\hline $\begin{array}{l}\text { Blinding of personnel (per- } \\
\text { formance bias) } \\
\text { Patient outcome }\end{array}$ & Low risk & $\begin{array}{l}\text { (PRIMARY) MEAN IOP, IOP FLUCTUATION, AND CHANGE IN CLINICAL MANAGE- } \\
\text { MENT - The data were collected from the hospital records. The researcher and } \\
\text { outcome assessor were masked to allocations until study completion }\end{array}$ \\
\hline
\end{tabular}

\begin{tabular}{|c|c|c|}
\hline $\begin{array}{l}\text { Incomplete outcome data } \\
\text { (attrition bias) } \\
\text { Adherence measure }\end{array}$ & Low risk & $\begin{array}{l}\text { (PRIMARY) REFILL ADHERENCE - } 10 \text { in intervention group did not receive full in- } \\
\text { tervention but an ITT analysis was done; } 9 \text { intervention arm patients who did } \\
\text { not receive the full intervention were classed as having poor refill adherence }\end{array}$ \\
\hline
\end{tabular}

$\begin{array}{ll}\begin{array}{l}\text { Incomplete outcome data } \\ \text { (attrition bias) }\end{array} & \text { Low risk } \\ \begin{array}{l}\text { Patient } \\ \text { (PRIMARY) MEAN IOP, IOP FLUCTUATION, AND CHANGE IN CLINICAL MANAGE- }\end{array} \\ \text { MENT - Few dropouts and balanced across intervention and control }\end{array}$

Patient outcome 
Hamann 2007

\begin{tabular}{ll}
\hline Methods & Randomized controlled trial \\
\hline Participants & $\begin{array}{l}\text { The study location was } 12 \text { acute psychiatric wards of } 2 \text { German state hospitals (Bezirkskrankenhaus } \\
\text { Haar, Klinikum Agatharied) } \\
54 \text { participants were randomized to the intervention group and } 59 \text { participants were randomized to the } \\
\text { control group }\end{array}$
\end{tabular}

The inclusion criteria were all men and women aged 18 to 65 years who had an ICD-10 diagnosis of schizophrenia or schizophreniform disorder (F20/F23)

The exclusion criteria were (i) severe mental retardation, (ii) lack of fluency in German, and (iii) refusal to give written informed consent

Interventions

Intervention: SHARED DECISION MAKING (SDM)

The intervention was designed to inform patients about their treatment options and to prepare them for a planning talk with their physicians. A printed 16-page booklet covering the pros and cons of oral versus depot formulation, first versus second generation antipsychotics, psychoeducation, and type of socio-therapeutic intervention was presented to the patients through the head nurse of the ward as soon as the psychiatrist in charge considered them able to co-operate. Trained nurses assisted the patient to work trough the booklet. Within the decision aid, patients were asked to write down their experiences with previous antipsychotic medication and to indicate their preferences regarding the different options on each topic. Nurses were advised to answer any questions of the patients and to encourage them to state any point of view contrary to that of the doctor. They were also instructed to postpone the participation of patients in the study if serious thought disturbances or delusional misinterpretations were detected while working through the booklet. The average time for working through the booklet was 30 to 60 minutes. Patients met their physicians within 24 hours after having worked through the decision aid with their nurse. The aim of these meetings (planning talks) was to reach an agreement between patient and psychiatrist on the further treatment according to the preferences indicated by the patient in the booklet. Like nurses, physicians were also trained about the SDM and required communication skills

Control: USUAL CARE

"Patients in the control group were treated "as usual", thus they did not receive the decision aid and there was no arrangement for an extra planning talk

Outcomes

The measures of adherence were the Medication Adherence Rating Scale (MARS) adherence questionnaire and a measurement of plasma levels. Patients were followed-up at 6 and 18 months. To rate compliance with medication, patients were requested to fill in a questionnaire on their compliance (MARS). MARS is a previously validated 10 -item questionnaire derived from the Drug Attitude Inventory (DAI) and the MAQ (Medical Adherence Questionnaire). Physicians were requested to rate compliance of their patients on a 4-point scale ranging from "poor compliance" to "very good compliance". MARS rating below the median score of 8 were considered to indicate poor compliance; rating of 8 or above were considered to indicate good compliance. Physicians were requested to rate compliance of their patients on a 4-point scale ranging from "poor compliance" to "very good compliance". Physicians were requested to make unannounced measurements of plasma levels of the prescribed antipsychotics at 6 months and 18 months after discharge. The estimates of compliance by patients and physicians as well as results of the plasma levels were dichotomized into good and poor compliance. A "conservative" algorithm was applied in order to obtain an overall measure of compliance for every patient and point in time. Overall compliance was considered "good" if patients and physicians agreed in their (positive) estimates. In all other cases (incongruence of ratings, both rating poor compliance), compliance was rated as "poor". Results were corrected in the direction toward the results of the plasma evaluation if plasma levels indicated compliance or noncompliance difference from that derived from self rating/physicians' rating (in 2 cases)

The patient outcome was rehospitalization due to schizophrenia, which was recorded for the periods of 0 to 6 and 6 to 18 months after discharge from the hospital. Rehospitalization within 18 months after discharge was defined as the main outcome measure. The variable was dichotomized into scores of 1 (rehospitalization occurred with in 18 months after discharge) and 0 (no rehospitalization occurred within 18 months after discharge). At 6 and 18 months after discharge, patients' global functioning 

assessed

\begin{tabular}{|c|c|c|}
\hline Notes & - & \\
\hline \multicolumn{3}{|l|}{ Risk of bias } \\
\hline Bias & Authors' judgement & Support for judgement \\
\hline $\begin{array}{l}\text { Random sequence genera- } \\
\text { tion (selection bias) }\end{array}$ & Unclear risk & $\begin{array}{l}\text { No mention of randomization method. (pg. 993) "... were randomly included in } \\
\text { a decision aid program or received usual care" }\end{array}$ \\
\hline $\begin{array}{l}\text { Allocation concealment } \\
\text { (selection bias) }\end{array}$ & Unclear risk & $\begin{array}{l}\text { No mention of allocation concealment. (pg. 993) "... were randomly included in } \\
\text { a decision aid program or received usual care" }\end{array}$ \\
\hline $\begin{array}{l}\text { Selective reporting (re- } \\
\text { porting bias) }\end{array}$ & Low risk & $\begin{array}{l}\text { No protocol available, refers to another study (ref } 11 \text { ) for details on the inter- } \\
\text { vention but that does not appear to be a protocol for this study }\end{array}$ \\
\hline Other bias & High risk & 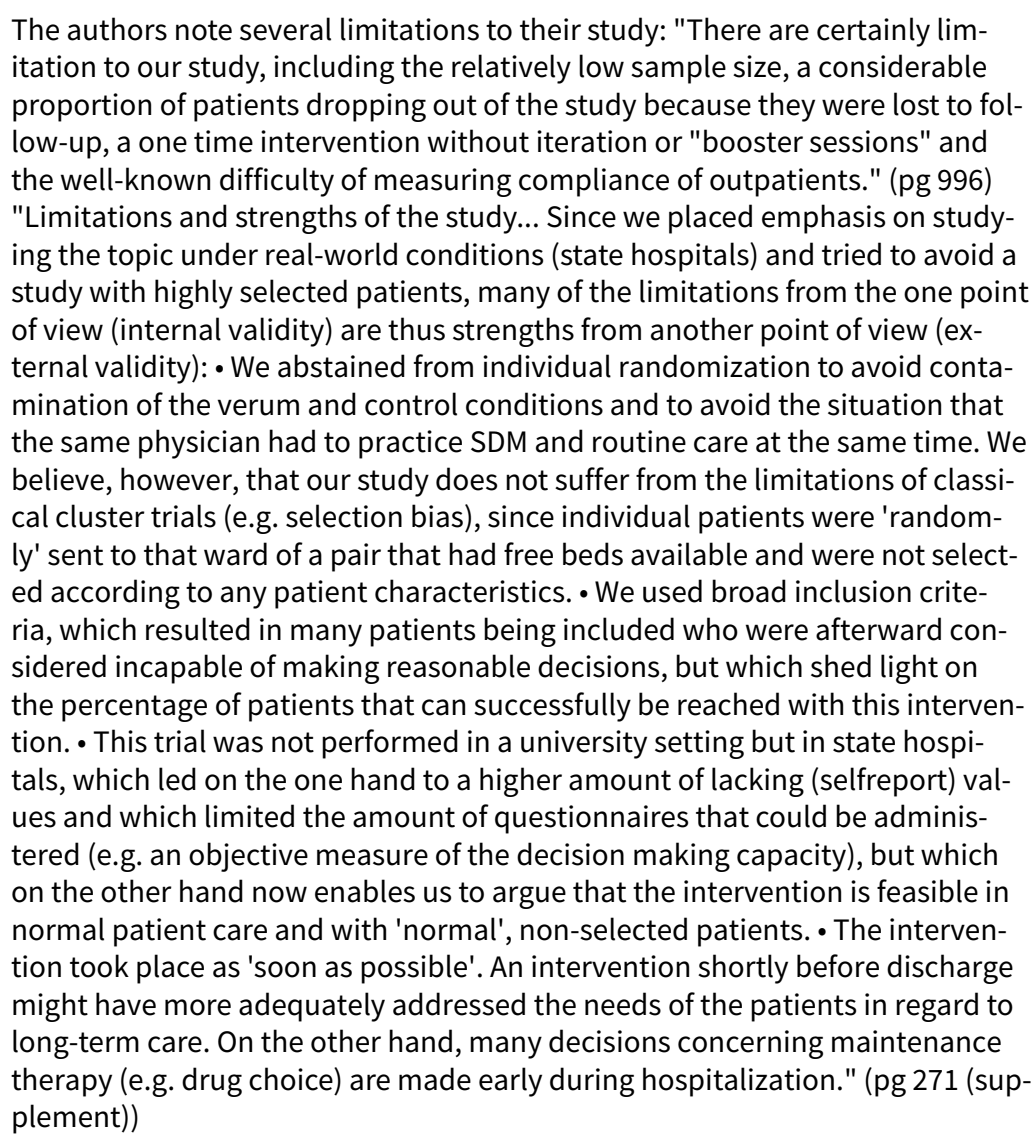 \\
\hline
\end{tabular}

\begin{tabular}{|c|c|c|}
\hline $\begin{array}{l}\text { Blinding of outcome as- } \\
\text { sessment (detection bias) }\end{array}$ & Unclear risk & $\begin{array}{l}\text { (PRIMARY) SELF REPORT - QUESTIONNAIRE - No mention of blinding of out- } \\
\text { come assessors }\end{array}$ \\
\hline
\end{tabular}
Adherence measure

\begin{tabular}{ll}
$\begin{array}{l}\text { Blinding of outcome as- } \\
\text { sessment (detection bias) } \\
\begin{array}{l}\text { Patient outcome }\end{array}\end{array} \quad$ Low risk & $\begin{array}{l}\text { (PRIMARY) REHOSPITALIZATIONS - No mention of blinding of outcome asses- } \\
\text { sors but an objective outcome }\end{array}$ \\
\hline
\end{tabular}

\begin{tabular}{|c|c|c|}
\hline $\begin{array}{l}\text { Blinding of participants } \\
\text { (performance bias) }\end{array}$ & High risk & $\begin{array}{l}\text { (PRIMARY) SELF REPORT - QUESTIONNAIRE - No mention of blinding of pa- } \\
\text { tients and subjective outcome }\end{array}$ \\
\hline
\end{tabular}


Hamann 2007 (Continued)

Adherence measure

$\begin{array}{ll}\begin{array}{l}\text { Blinding of participants } \\ \text { (performance bias) }\end{array} & \text { Low risk } \\ \begin{array}{l}\text { Patient } \\ \text { objective outcome }\end{array}\end{array}$

Patient outcome

(PRIMARY) SELF REPORT - QUESTIONNAIRE - No mention of blinding of study staff

formance bias)

Unclear risk

Adherence measure

Blinding of personnel (per- Low risk

formance bias)

Patient outcome

Incomplete outcome data High risk

(attrition bias)

Adherence measure

Incomplete outcome data High risk

(attrition bias)

Patient outcome
(PRIMARY) REHOSPITALIZATIONS - No mention of blinding of study staff but an objective outcome

(PRIMARY) SELF REPORT - QUESTIONNAIRE - Reasons for incomplete data unclear and high losses to follow-up by 18 months

Haynes 1976

Methods Random allocation by 'minimization', a method stated to be impervious to bias

Participants

This was the second phase of a 2 phase study. Male steel company employees with high blood pressure (when sitting quietly on 3 separate days, a standard series of fifth phase diastolic blood-pressures were $>95 \mathrm{~mm} \mathrm{Hg}$ ) who were treated with antihypertensive medications during the first phase of the study were included in the second phase if they were non-adherent with prescribed antihypertensive therapy (pill counts less than $80 \%$ ), and not at goal blood pressures (fifth phase $<90 \mathrm{~mm} \mathrm{Hg}$ ) in the 6th month of treatment of phase 1.

Interventions

Patients in the experimental group were all taught the correct method to measure their own blood pressures, were asked to chart their home blood pressures and pill taking, and taught how to tailor pill taking to their daily habits and rituals. These men also visited fortnightly at the work site a high-school graduate with no formal health professional training who reinforced the experimental maneuvers and rewarded improvements in adherence and blood pressure. Rewards included allowing participants to earn credit, for improvements in adherence and blood pressure, that could be applied towards the eventual purchase of the blood pressure apparatus they had been loaned for the trial. Control patients received none of these interventions

Outcomes An unobtrusive pill count done in the patient's home by a home visitor was the method of determining medication adherence. Adherence rates are reported as the proportion of pills prescribed for the 12th month of therapy which were removed from their containers and, presumably, swallowed by the patients. In the 12th month of treatment, patients were evaluated for adherence and blood pressure both at home and at the mill by examiners who were 'blind' to their experimental group allocation

Notes -

\section{Risk of bias}

\begin{tabular}{lll}
\hline Bias & Authors' judgement & Support for judgement \\
\hline $\begin{array}{ll}\text { Random sequence genera- } \\
\text { tion (selection bias) }\end{array}$ & Low risk & $\begin{array}{l}\text { Minimization used. (pg 1265) "39 such men were allocated by "minimisation" } \\
\text { either to a control group or to an experimental group. Minimisation allows } \\
\text { the simultaneous consideration of a large series of matching characteristics }\end{array}$ \\
\hline
\end{tabular}


Haynes 1976 (Continued)

when allocating subjects to experimental and control groups, thereby minimising (using randomisation in the case of ties) between-group differences. The method is immune to experimenter bias and has been shown to substantially outperform simple randomisation in reducing the imbalance between treatment groups that has troubled several earlier randomised trials."

Allocation concealment Low risk
(selection bias)

(selection bias)
Minimization used. (pg 1265) "39 such men were allocated by "minimisation" either to a control group or to an experimental group. Minimisation allows the simultaneous consideration of a large series of matching characteristics when allocating subjects to experimental and control groups, thereby minimising (using randomisation in the case of ties) between-group differences. The method is immune to experimenter bias and has been shown to substantially outperform simple randomisation in reducing the imbalance between treatment groups that has troubled several earlier randomised trials."

\begin{tabular}{|c|c|c|}
\hline $\begin{array}{l}\text { Selective reporting (re- } \\
\text { porting bias) }\end{array}$ & Unclear risk & No protocol available \\
\hline Other bias & High risk & $\begin{array}{l}\text { Possible confounding bias identified by the authors in the Discussion portion } \\
\text { of the paper. (pg 1268) "We are not satisfied, however, that this investigation } \\
\text { is free from a fourth potential source of bias, and this is the confounding of } \\
\text { the compliance-improving strategies with the amount of attention shown to } \\
\text { these patients. By design, phase-Il experimental patients received more atten- } \\
\text { tion (five hours, spread over six months) than phase-II controls, and our review } \\
\text { of the compliance literature suggests that simply spending more time with } \\
\text { patients, regardless of the content of the interchange, is associated with in- } \\
\text { creased compliance." }\end{array}$ \\
\hline
\end{tabular}

\begin{tabular}{|c|c|c|}
\hline $\begin{array}{l}\text { Blinding of outcome as- } \\
\text { sessment (detection bias) } \\
\text { Adherence measure }\end{array}$ & Low risk & $\begin{array}{l}\text { (PRIMARY) PILL COUNT - Blinding was accounted for. (pg 1266) "At the end of } \\
\text { phase } 2 \text { (in the twelfth month of treatment) patients were evaluated both at } \\
\text { home and at the mill by examiners who were "blind" to their experimental } \\
\text { group allocation." }\end{array}$ \\
\hline $\begin{array}{l}\text { Blinding of outcome as- } \\
\text { sessment (detection bias) } \\
\text { Patient outcome }\end{array}$ & Low risk & $\begin{array}{l}\text { (PRIMARY) BLOOD PRESSURE - Outcome assessors were blinded to treatment } \\
\text { group. (pg 1266) "At the end of phase II (in the twelfth month of treatment) pa- } \\
\text { tients were evaluated both at home and at the mill by examiners who were } \\
\text { "blind" to their experimental group allocation." }\end{array}$ \\
\hline $\begin{array}{l}\text { Blinding of participants } \\
\text { (performance bias) } \\
\text { Adherence measure }\end{array}$ & Low risk & $\begin{array}{l}\text { (PRIMARY) PILL COUNT - Pill count done unobtrusively once, while patient not } \\
\text { in room. (pg 1266) "...The home visitor verified each patient's doses while the } \\
\text { patient was supplying a urine specimen (requested without prior warning), } \\
\text { did an unobtrusive pill- count and compared it with a baseline established one } \\
\text { month earlier." }\end{array}$ \\
\hline
\end{tabular}

\begin{tabular}{ll}
\hline Blinding of participants & Unclear risk \\
(performance bias) & (PRIMARY) BLOOD PRESSURE - Patient blinding is not reported
\end{tabular}

Patient outcome

Blinding of personnel (per- Unclear risk (PRIMARY) PILL COUNT - No mention of blinding other study personnel formance bias) Adherence measure

$\begin{array}{ll}\begin{array}{l}\text { Blinding of personnel (per- } \\ \text { formance bias) }\end{array} & \text { (PRIMARY) BLOOD PRESSURE - Blinding of the outcome assessor is account- } \\ \text { Patient outcome } & \text { ed for. (pg 1266) "At the end of phase II (in the twelfth month of treatment) pa- } \\ & \text { tients were evaluated both at home and at the mill by examiners who were } \\ \text { "blind" to their experimental group allocation." }\end{array}$

$\begin{array}{ll}\begin{array}{l}\text { Incomplete outcome data } \\ \text { (attrition bias) }\end{array} & \text { (PRIMARY) PILL COUNT - There are few missing outcome data; reason for miss- } \\ & \text { ing data unrelated to intervention. (pg 1266) "1 control developed deep vein }\end{array}$


Haynes 1976 (Continued)

Adherence measure thrombosis and his hypotensive drugs were stopped; this patient was removed from the study, leaving 20 experimental patients and 18 controls."

\section{Incomplete outcome data Low risk}

(attrition bias)

Patient outcome
(PRIMARY) BLOOD PRESSURE - There are few missing outcome data; reason for missing data unrelated to intervention. (pg 1266) "1 control developed deep vein thrombosis and his hypotensive drugs were stopped; this patient was removed from the study, leaving 20 experimental patients and 18 controls."

Hederos 2005

Methods The parents of the 60 children were randomized consecutively in groups of 4 to either the intervention or the control group by the nurses. This resulted in 32 children in the intervention group and 28 children in the control group. The 3 doctors that were involved in the group sessions also performed the follow-up visits. Blinding could not be completed since the intervention was led by their physicians

Participants

Patients were 60 children aged between 3 months to 6 years and had been given a diagnosis of asthma in the region, 1 to 2 months earlier. Asthma was defined by 3 or more episodes of wheezing before 2 years of age, or the first wheezing episode after the age of 2, or the first episode of wheezing in a child with other atopic diseases. The patients also had fulfilled the following criteria implying high risk for permanent asthma: wheezing without symptoms of upper respiratory tract infection (URTI) and/or proven allergy and/or atopic heredity

Interventions

The intervention consisted of meetings in a group setting with the parents. The sessions took place in the afternoon and lasted about 1.5 hours. Shortly after the children were diagnosed as an asthmatic, 3 meetings (one every week for 3 weeks) took place and a follow-up meeting took place 6 months later. 3 pediatricians, 3 nurses and 2 psychologists were involved in these sessions: one nurse was present on all occasions, and the doctors and psychologists on 3 each. The goal of all the meetings was to reach the parents' "main worry" and, apart from teaching about asthma, the following key question was asked: "What is asthma to you?" The use of dialogue and peer education, whereby the group was encouraged to share personal experiences was emphasized. The control group, as well as the intervention group, received basic education about asthma and its treatment, including how to use the Nebunette, and information on environmental control at the first visit to the clinic. They received a written treatment plan where the principle was high dose ( $0.2 \mathrm{mg} \times 4$ of budesonide for 3 days) initially and then, in association with URTI, stepping down the therapy to the lowest possible dose according to the status of the child. The treatment was stopped if the child had no asthma for 6 months

Outcomes

Compliance was measured in the following ways: 1) parents and doctors estimated adherence on a visual analog scale (VAS) at inclusion, at 6 months, and after 18 months; 2) adherence was measured between the 12- and 18-month follow-up visits using a diary in which the parents recorded the consumption of medicines, asthma symptoms, and other illnesses; 3 ) all the Metered Dose Inhalers (MDIs) with budesonide used during this period were weighed and the real consumption was estimated; and 4) the adherence according to parents was calculated as the number of doses given according to the diaries/the number of doses prescribed ${ }^{*} 100$. The verified adherence was defined as the real number of doses/the number of doses prescribed ${ }^{*} 100$. The verified adherence was considered acceptable if the index was 50 to 150 and poor if the index was $<50$

The following clinical outcomes were assessed: 1) parents estimated their children's asthma problems during the last 6 months, after 6 months and after 18 months on another VAS; 2) 3 doctors classified the children according to GINA guidelines including medication in 4 groups: mild, moderate, rather severe, and severe at inclusion, after 6 months and after 18 months; 3 ) during the first 6 and last 6 months of the 18-month-long study, the parents noted how many days the child was hospitalized and how many times they had to seek emergency help due to asthma; and 4) frequency of exacerbations, defined by the need for parents to stay at home to take care of their child due to asthma symptoms

\section{Risk of bias}


Hederos 2005 (Continued)

\begin{tabular}{|c|c|c|}
\hline Bias & Authors' judgement & Support for judgement \\
\hline $\begin{array}{l}\text { Random sequence genera- } \\
\text { tion (selection bias) }\end{array}$ & Unclear risk & $\begin{array}{l}\text { (pg 603) "The parents of the } 60 \text { children were randomized consecutively in } \\
\text { groups of four to either the intervention or the control group." No mention of } \\
\text { random sequence generation process }\end{array}$ \\
\hline $\begin{array}{l}\text { Allocation concealment } \\
\text { (selection bias) }\end{array}$ & Unclear risk & $\begin{array}{l}\text { Insufficient information provided; no mention of allocation concealment (pg } \\
603 \text { ) "The parents of the } 60 \text { children were randomized consecutively in groups } \\
\text { of four to either the intervention or the control group." }\end{array}$ \\
\hline $\begin{array}{l}\text { Selective reporting (re- } \\
\text { porting bias) }\end{array}$ & Unclear risk & Insufficient information provided. No protocol was found \\
\hline Other bias & Unclear risk & No other obvious risks of bias and no limitation section of the paper to consult \\
\hline
\end{tabular}

Blinding of outcome as- High risk

Patient outcome ization and the 3 doctors that were involved in the group sessions also performed the follow-up visits. Therefore, a complete blinding procedure could not be established

Blinding of participants High risk
(performance bias)

(PRIMARY) SELF REPORT - DIARY - (pg 603) The nurses carried out the randomAdherence measure ization and the 3 doctors that were involved in the group sessions also performed the follow-up visits. Therefore, a complete blinding procedure could not be established

Blinding of participants High risk

(performance bias)

(PRIMARY) HOSPITALIZATIONS - (pg 603) The nurses carried out the random-

Patient outcome ization and the 3 doctors that were involved in the group sessions also performed the follow-up visits. Therefore, a complete blinding procedure could not be established

Blinding of personnel (per- High risk formance bias)

(PRIMARY) SELF REPORT - DIARY - (pg 603) The nurses carried out the randomAdherence measure ization and the 3 doctors that were involved in the group sessions also performed the follow-up visits. Therefore, a complete blinding procedure could not be established

Blinding of personnel (per- High risk formance bias)

Patient outcome

(PRIMARY) HOSPITALIZATIONS - (pg 603) The nurses carried out the randomization and the 3 doctors that were involved in the group sessions also performed the follow-up visits. Therefore, a complete blinding procedure could not be established

Incomplete outcome data Low risk (attrition bias)

Adherence measure
(PRIMARY) SELF REPORT - DIARY - Reasons for missing data. (pg 605) "All families included were evaluated after 6 mo. After $18 \mathrm{mo}, 29$ of 32 in the intervention group and 24 of 28 in the control group were followed up. The dropouts in the control group consisted of a family who moved away after 6 mo. One girl was diagnosed as suffering from cystic fibrosis and left the study after $1 \mathrm{y}$. Another two families dropped out between the 12- and 18-mo follow-ups. In the intervention group, the parents of one girl did not visit any group session, another girl was diagnosed as ciliary dysfunction and yet another girl did not return for the 18 -mo control. The follow-up rate was thus $86 \%$ in the control group, $91 \%$ in the intervention group and $88 \%$ for the total cohort after $18 \mathrm{mo}$. After 12 mo, 55 children remained in the study, but three of them used other nebulizers or types of steroids than those recommended. Thus, 52 children entered the 6-mo adherence study. Four children did not need any inhaled steroids during the last 6 mo of the study, and the diaries for two patients were 
Hederos 2005 (Continued)

missing. The follow-up rate for adherence data is thus $85 \%$." Missing data have been accounted for

Incomplete outcome data Unclear risk

(attrition bias)

Patient outcome
(PRIMARY) HOSPITALIZATIONS - Groups slightly unbalanced for incomplete data - not sure how this impacts the outcomes

Heisler 2010

\begin{tabular}{ll}
\hline Methods & Randomized controlled trial \\
\hline Participants & Thestudy location was Midwest, United States
\end{tabular}

Participants The study location was Midwest, United States

126 participants were randomized to the intervention group and 119 participants were randomized to the control group

The inclusion criteria were veterans with diabetes and poor glycemic control, who were receiving care at 2 Midwestern US Department of Veterans Affairs (VA) facilities and a most recent recorded hemoglobin A1c (HbA1c) level greater than $7.5 \%$ within the past 6 months

The exclusion criteria were an International Classification of Diseases, Ninth Edition, diagnosis of posttraumatic stress disorder, bipolar disorder, dementia, schizophrenia, or personality disorder; active substance abuse, severe depression, hearing loss, terminal illnesses, or participation in other diabetes studies

Interventions Intervention: RECIPROCAL PEER SUPPORT (RPS)

After the baseline assessment, patients in the RPS group attended a 3-hour group session facilitated by a care manager and a research associate. In the first half of the session, patients' laboratory and blood pressure results were reviewed and action planning was introduced. In the second half, patients received brief training in basic peer communication skills and were paired with another age-matched patient in their cohort. Peer partners were encouraged to call each other at least once a week using an interactive, voice-response-facilitated telephone platform that recorded call initiation, frequency, and duration; enabled partners to contact each other without exchanging telephone numbers and to set periods during which calls could be blocked; and generated automated reminders every 7 days if no peer calls were attempted. During a reminder call, patients could be transferred automatically to their peer partner's number. The system also allowed patients to leave voice messages for research staff or care managers. At the end of the initial session, patients were given a DVD that demonstrated peer communication skills and a diabetes self management workbook that they could use to help guide their peer telephone calls. Patients were also offered 3 optional 1.5-hour group sessions at months 1 , 3 , and 6 . These were completely patient-driven sessions at which patients were encouraged to share concerns, questions, strategies, and progress on their action plans. Sessions were facilitated by a care manager and a research associate. Research associates were present to help maintain intervention fidelity by encouraging nondirective facilitation of group discussions and to complete a checklist of key areas covered and communication skills used in each session

Control: NURSE CARE MANAGEMENT (NCM)

At baseline and 6-month follow-up, all study patients had their HbA1c level and blood pressure checked and were informed of the results and the most recent cholesterol values were in their medical record. Patients in the NCM group then attended a 1.5-hour session, led by a care manager, to review their laboratory and blood pressure results, ask questions, and receive information on VA care management services. They were provided their assigned care manager's contact information and encouraged to schedule follow-up telephone calls or face-to-face visits with that care manager. Each patient was also provided with diabetes self-management educational materials. Patients in the NCM group thus received enhanced usual care, because even though they would all be eligible for nurse care manager support at the study sites, many patients are not aware of and do not avail themselves of this service unless referred by their physician 
Heisler 2010 (Continued)

The patient outcomes were change in $\mathrm{HbA1c}$, blood pressure, changes in medication, and self reported diabetes related emotional distress. All measures were collected at baseline and at 6 months

\section{Notes}

$-$

\section{Risk of bias}

\begin{tabular}{|c|c|c|}
\hline Bias & Authors' judgement & Support for judgement \\
\hline $\begin{array}{l}\text { Random sequence genera- } \\
\text { tion (selection bias) }\end{array}$ & Unclear risk & $\begin{array}{l}\text { Do not specify method used for random sequence generation. (pg 508) "Ran- } \\
\text { dom sequence generation and treatment group assignment were determined } \\
\text { centrally just before the initial session. The sequence was concealed until in- } \\
\text { terventions were assigned. Patients, research staff, and care managers were } \\
\text { blinded to randomization results until after the baseline surveys and physio- } \\
\text { logic measures were completed. Data assessors remained blinded to group } \\
\text { assignment throughout the study. Because the RPS group needed to have an } \\
\text { even number of patients to pair all members, randomization algorithms en- } \\
\text { sured allocation of an even number to that group. On the basis of evidence } \\
\text { that peers closer in age have an increased likelihood of providing effective } \\
\text { peer support (6), patients in the RPS group were paired by age, after random } \\
\text { assignment, with a peer partner who attended the same initial session." }\end{array}$ \\
\hline
\end{tabular}

Allocation concealment Unclear risk
(selection bias)

The sequence was concealed until interventions were assigned - does not (selection bias) specify how. "At the initial group session, participants completed written informed consent and a self-administered survey, had their blood pressure measured, had their HbA1c level measured with a Bayer DCA2000x Analyzer (Bayer, Keverkusen, Germany) (24), and were randomly assigned to either the RPS or NCM group." "Random sequence generation and treatment group assignment were determined centrally just before the initial session. The sequence was concealed until interventions were assigned. Patients, research staff, and care managers were blinded to randomization results until after the baseline surveys and physiologic measures were completed." (pg 508)

Selective reporting (re- Unclear risk
porting bias)

No protocol available. Also, "...we had intended to include change in point of service cholesterol levels, but we dropped this measure after the trial began because we determined (from comparisons of a subsample of assays with results from VA laboratories) that the quality of measurement was poor." (pg 509)

Other bias Unclear risk

\begin{abstract}
Authors noted several limitations: "Our study has limitations. First, we included only male patients. Although peer-support interventions have been found to be more acceptable to women than men, research also suggests that similar peers are more likely to have mutually supportive peer relationships. Peersupport initiatives may thus be especially effective among patients with common identity bonds, such as shared experiences, cultural and ethnic backgrounds, or religious faith. We targeted veterans in the same age cohort, who often have a common sense of identity because of their shared military experience within a specific sociohistorical context. Future studies should attempt to replicate this study in other, sex-mixed samples of patients and examine the effectiveness of different peer-support models among patients with a range of self-management challenges. The success of our intervention can help guide other efforts to combine periodic group sessions, care management support, and peer communication to initiate and support other behavior changes in diabetes or other conditions that require high levels of self-management (such as obesity, heart failure, chronic pain, or physical inactivity). Second, our intervention lasted only 6 months; future studies should test peer-support interventions over longer periods. One advantage of peer-support interventions is their potential to provide flexible, longer-term selfmanagement support. Third, although the nurse care managers and all other providers were blinded to the study's hypotheses, the nature of the intervention prevented blinding
\end{abstract}


Heisler 2010 (Continued)

to treatment group. We also cannot exclude treatment bias, because the same care managers provided care to patients in both groups. However, we would expect that the nurse care managers would want to show their current provision of care to be superior to between-patient support, so the most likely effect of any treatment bias would be toward the null. Of note, this intervention focused exclusively on activating patients to improve their self-management. A more powerful intervention would also target provider behavior, such as by encouraging providers to initiate or intensify medication. Finally, our intervention had a relatively low rate of uptake. Peer-based programs, such as ours, would need to be part of a menu of options available to patients." (pg 512)

\begin{tabular}{|c|c|c|}
\hline $\begin{array}{l}\text { Blinding of outcome as- } \\
\text { sessment (detection bias) }\end{array}$ & Low risk & $\begin{array}{l}\text { (PRIMARY) SELF REPORTED ADHERENCE - "Data assessors remained blinded to } \\
\text { group assignment throughout the study." (pg 509) }\end{array}$ \\
\hline
\end{tabular}

Adherence measure

Blinding of outcome as- Low risk sessment (detection bias) Patient outcome

Blinding of participants (performance bias)

Adherence measure
High risk

(1)
(PRIMARY) HBA1C LEVEL - This is an objective measure of outcome. The outcome is not likely to be affected by lack of blinding
(PRIMARY) SELF REPORTED ADHERENCE - "Patients, research staff, and care managers were blinded to randomization results until after the baseline surveys and physiologic measures were completed. Data assessors remained blinded to group assignment throughout the study." - (pg 509) Participants were not blinded after randomization. The outcome was self reported. Lack of blinding of participants could affect the outcome

$\begin{array}{ll}\begin{array}{l}\text { Blinding of participants } \\ \text { (performance bias) }\end{array} & \text { Low risk } \\ \begin{array}{l}\text { Patient outcome } \\ \text { come is not likely to be affected by lack of blinding. "Patients, research staff, } \\ \text { and care managers were blinded to randomization results until after the base- } \\ \text { line surveys and physiologic measures were completed. Data assessors re- } \\ \text { mained blinded to group assignment throughout the study." (pg 509) This is an } \\ \text { objective measure of outcome. The outcome is not likely to be affected by lack } \\ \text { of blinding }\end{array}\end{array}$

Blinding of personnel (per- Low risk

formance bias)

Adherence measure
(PRIMARY) SELF REPORTED ADHERENCE - Author's note: all research staff who conducted surveys, drew labs and other clinical measures and had research contact with participants were blinded to study group. Separate assessors were blinded to study group and had no contact with participants, so no risk of inadvertently hearing what activities they performed (revealing group)
Blinding of personnel (per- Low risk formance bias)

Patient outcome
(PRIMARY) HBA1C LEVEL - This is an objective measure of outcome. The outcome is not likely to be affected by lack of blinding
Incomplete outcome data Low risk (attrition bias)

Adherence measure
(PRIMARY) SELF REPORTED ADHERENCE - Of the 26 people, 8 were excluded in the RPS group because they died, discontinued intervention, or were lost to follow-up and 5 were excluded in the NCM group because they died or were lost to follow-up. Refer to Figure 1. "Of the 244 enrolled, 231 (95\%) completed the survey assessments at 6 months." (pg 510) Approximately equal number of participants are missing from both groups and the reasons for missing information are not due to intervention effects
Incomplete outcome data Low risk

(attrition bias)

Patient outcome
(PRIMARY) HBA1C LEVEL - "Six-month HbA1c data were missing for 28 randomly assigned patients (11\%). We therefore conducted a second analysis that imputed missing data. A third sensitivity analysis examined the worst-case scenario, in which baseline $\mathrm{HbA1c}$ levels of patients who lacked 6-month $\mathrm{HbA1c}$ data remained unchanged at 6 months. The results remained unchanged in both analyses." (pg 510). Of the 26 people, 8 were excluded in the RPS group because they died, discontinued intervention, or were lost to follow-up and 5 were excluded in the NCM group because they died or were lost to follow-up. 

single-blinded in that, although patients were aware of the names of the study medication and the fact the study was an $\mathrm{H}$. Pylori treatment trial, they were unaware of either the differences between the treatment groups or the compliance enhancing purpose of the trial

Participants

All adult patients over the age of 18 years with $H$. Pylori infection were screened for eligibility. Patient exclusion criteria included inability or refusal to give informed consent, contraindication to the study medication, consultant's recommendation not to treat patient, consultant wish to use an $\mathrm{H}$. pylori therapy other than the study medication, and inpatient status as patient compliance is imposed in this situation

Interventions

All patients received 10 days of omeprazole $20 \mathrm{mg}$ twice a day, amoxycillin $500 \mathrm{mg} 3$ times a day, and metronidazole $400 \mathrm{mg} 3$ times a day, as well as verbal advice on medication use and possible side effects, in an initial 20-minute consultation. In addition, patients in the intervention group received medication in dose-dispensing units, an information sheet on $\mathrm{H}$. Pylori treatment, and a medication chart. Compliance in intervention group patients was also encouraged by a phone call 2 days after the start of therapy

Outcomes

Measurement of compliance: compliance was assessed by phone interview on day 10 of therapy, and by returned tablet count at the follow-up C-urea breath test (C-UBT) visit. Patients were defined as compliant if they were assessed by both pill count and interview as taking $=80 \%$ of study medications. Total percentage of tablets taken in both groups was assessed by taking the lower of the 2 estimates of tablet consumption (pill count or interview data) for each patient. Measurement for healthcare outcomes: Patients were considered $\mathrm{H}$. Pylori-positive if the CLO-test, histopathology, or 13C-UBT was positive. 13C-UBT test using kits sent to a single central laboratory for analysis was performed for more than one month after cessation of $H$. pylori treatment and any other antimicrobial therapy (including bismuth), 2 weeks after cessation of proton-pump inhibitor therapy and 1 week after cessation of histamine-receptor antagonists. An increase of 5 per million in the $\mathrm{CO} 230$ minutes after ingestion of C-urea compared with baseline measurements was considered positive for $\mathrm{H}$. Pylori. Treatment was considered successful if 13C-UBT was negative. Side effects were assessed by phone interview on day 10 of therapy and by returned side effects form. Patients were asked to rate specific side effects and give an overall rating where none $=0$, mild $=1$ (does not limit daily activities), moderate $=2$ (interferes with daily activities), and severe $=3$ (incapacitating, stops normal daily activities)

Notes

\section{Risk of bias}

\begin{tabular}{lll}
\hline Bias & Authors' judgement & Support for judgement \\
\hline $\begin{array}{l}\text { Random sequence genera- } \\
\text { tion (selection bias) }\end{array}$ & Unclear risk & $\begin{array}{l}\text { No information in the article. (pg 811) "...were prospectively recruited from } \\
\text { the endoscopy unit and outpatient gastroenterological clinic of our teaching } \\
\text { hospital and randomized to one of two treatment groups. All adult patients } \\
\text { (age .18 yr) were screened for eligibility." }\end{array}$ \\
\hline $\begin{array}{l}\text { Allocation concealment } \\
\text { (selection bias) }\end{array}$ & Unclear risk & $\begin{array}{l}\text { Insufficient information provided in the article. (pg 811) "...were prospective- } \\
\text { ly recruited from the endoscopy unit and outpatient gastroenterological clin- } \\
\text { ic of our teaching hospital and randomized to one of two treatment groups. All } \\
\text { adult patients (age .18 yr) were screened for eligibility." }\end{array}$ \\
\hline
\end{tabular}


Henry 1999 (Continued)

Selective reporting (re- Unclear risk $\quad$ No protocol available
porting bias)

\begin{tabular}{ll}
\hline Other bias $\quad$ Unclear risk & $\begin{array}{l}\text { No biases other than measurement bias noted in discussion; no other clear } \\
\text { risks of bias }\end{array}$
\end{tabular}

\begin{tabular}{|c|c|c|}
\hline $\begin{array}{l}\text { Blinding of outcome as- } \\
\text { sessment (detection bias) } \\
\text { Adherence measure }\end{array}$ & High risk & $\begin{array}{l}\text { (PRIMARY) TELEPHONE INTERVIEW - (pg 812) "The trial was single-blinded" } \\
\text { with respect to patients, so no other blinding was done }\end{array}$ \\
\hline
\end{tabular}

\begin{tabular}{|c|c|c|}
\hline $\begin{array}{l}\text { Blinding of outcome as- } \\
\text { sessment (detection bias) } \\
\text { Patient outcome }\end{array}$ & High risk & $\begin{array}{l}\text { (PRIMARY) CURE RATE - (pg 812) "The trial was single-blinded" with respect to } \\
\text { patients, so no other blinding was done }\end{array}$ \\
\hline
\end{tabular}

\begin{tabular}{ll}
\hline $\begin{array}{l}\text { Blinding of participants } \\
\text { (performance bias) }\end{array}$ & Low risk \\
$\begin{array}{l}\text { Adherence measure } \\
\text { that, although patients were aware of the names of the study medication and } \\
\text { the fact that the study was an H. pylori treatment trial, they were unaware of } \\
\text { either the differences between the treatment groups or the compliance en- } \\
\text { hancing purpose of the trial". }\end{array}$ \\
\hline
\end{tabular}

$\begin{array}{ll}\begin{array}{l}\text { Blinding of participants Low risk } \\ \text { (performance bias) }\end{array} & \begin{array}{l}\text { (PRIMARY) CURE RATE - Patients were blinded. (pg 812) "The trial was sin- } \\ \text { gatient outcome }\end{array} \\ & \begin{array}{l}\text { gle-blinded in that, although patients were aware of the names of the study } \\ \text { medication and the fact that the study was antipylori treatment trial, they } \\ \text { were unaware of either the differences between the treatment groups or the } \\ \text { compliance enhancing purpose of the trial." }\end{array}\end{array}$

\begin{tabular}{|c|c|c|}
\hline $\begin{array}{l}\text { Blinding of personnel (per- } \\
\text { formance bias) }\end{array}$ & High risk & $\begin{array}{l}\text { (PRIMARY) TELEPHONE INTERVIEW - (pg 812) "The trial was single-blinded" } \\
\text { with respect to patients, so no other blinding was done }\end{array}$ \\
\hline
\end{tabular}

Adherence measure
Blinding of personnel (per- High risk (PRIMARY) CURE RATE - (pg 812) "The trial was single-blinded" with respect to formance bias) patients, so no other blinding was done
Patient outcome

$\begin{array}{ll}\begin{array}{l}\text { Incomplete outcome data } \\ \text { (attrition bias) }\end{array} & \text { Low risk } \\ \text { Adherence measure } & \text { (PRIMARY) TELEPHONE INTERVIEW - Few incomplete data and handled conser- } \\ \end{array}$

Adherence measure

Incomplete outcome data Low risk
(attrition bias)

Patient outcome

\section{Hill 2001}

Methods

Patients were stratified into bands of low, medium, or high knowledge of their rheumatoid arthritis (RA) by means of a validated patient knowledge questionnaire. 21 patients in each band were randomly allocated to the Education Group and Control Group using a separate computer-generated code for each band. This was done to ensure that the 2 groups had comparable levels of initial knowledge. Allocation was carried out by a clerk who had no study input or patient contact

Participants

Rheumatologists referred 100 patients with active RA; all were deemed to require D-penicillamine (DPA) as their slow-acting antirheumatic drugs (SAARD). Entry criteria required that all patients were aged 18 years or above, had a positive diagnosis of RA using the American Rheumatism Association criteria, a plasma viscosity $(\mathrm{PV})>1.75 \mathrm{mPa}$. or a $\mathrm{C}$ reactive protein $(\mathrm{CRP})>10 \mathrm{mg} / \mathrm{l}$. In addition, they should have 2 out of 3 clinical features: an articular index $>15$, morning stiffness $>45$ minutes, a minimum of moderate levels of pain. Patients were excluded if they had received DPA previously, had a con- 
Hill 2001 (Continued)

traindication such as kidney impairment or pregnancy, or were receiving incompatible concomitant drugs. Patients who were awaiting hospital admission were excluded as the nursing staff often give drugs during their stay

Interventions

The chosen intervention was a Patient Education program taught by a rheumatology nurse practitioner. Where practicable, variables that could confound the results were eliminated. All patients took the same SAARD, were given the same number and length of appointments, and were seen by the same rheumatology nurse practitioner. All patients were seen by the rheumatology nurse practitioner for a 30 minute appointment at monthly intervals over a 6 -month period comprising 7 visits. The Education Group received a comprehensive program of patient education based on the theory of self efficacy: a person's confidence in their ability to perform a specific task or achieve a certain objective. The noneducation cohort received the same DPA drug information leaflet as the intervention group. This was in question and answer format and supplied information about DPA, how and when to take it, unwanted side effects, and described safety monitoring

Outcomes Clinical health outcomes included: PV, CRP, 3 clinical assessments - articular index (AI), morning stiffness, pain score

Notes

\section{Risk of bias}

\begin{tabular}{lll}
\hline Bias & Authors' judgement & Support for judgement \\
\hline $\begin{array}{l}\text { Random sequence genera- } \\
\text { tion (selection bias) }\end{array}$ & Unclear risk & $\begin{array}{l}\text { No information on sequence generation. (pg 869) "The study was a ran- } \\
\text { domised controlled design comparing an experimental group (EG) receiving a } \\
\text { full programme of patient education (PE) with a control group (CG)." }\end{array}$ \\
\hline $\begin{array}{l}\text { Allocation concealment } \\
\text { (selection bias) }\end{array}$ & Unclear risk & $\begin{array}{l}\text { No mention of allocation concealment. (pg 869) "The study was a randomised } \\
\text { controlled design comparing an experimental group (EG) receiving a full pro- } \\
\text { gramme of PE with a control group (CG)." }\end{array}$
\end{tabular}

\begin{tabular}{lll}
\hline $\begin{array}{l}\text { Selective reporting (re- } \\
\text { porting bias) }\end{array}$ & Unclear risk & $\begin{array}{l}\text { All pre-specified outcomes seem to be reported; no protocol available to con- } \\
\text { firm }\end{array}$ \\
\hline Other bias & Unclear risk & No obvious bias detected but unclear \\
\hline $\begin{array}{l}\text { Blinding of outcome as- } \\
\text { sessment (detection bias) }\end{array}$ & Low risk & $\begin{array}{l}\text { (PRIMARY) PHARMACOLOGICAL MARKER - (pg 870) "An independent blind as- } \\
\text { sessor carried out all clinical assessments. Withdrawal criteria were ( a ) any } \\
\text { patient who requested withdrawal was immediately removed from the study; } \\
\text { (b) decisions on withdrawal from the trial owing to adverse drug events were } \\
\text { made by an impartial observer (HB), who was unaware of the group alloca- } \\
\text { tion." }\end{array}$
\end{tabular}

\begin{tabular}{lll}
\hline $\begin{array}{l}\text { Blinding of outcome as- } \\
\text { sessment (detection bias) }\end{array}$ & Low risk & (PRIMARY) PLASMA VISCOSITY - (pg 870) "An independent blind assessor car- \\
Patient outcome & ried out all clinical assessments." "However, bias was minimised by ensuring \\
& that clinical assessments and all data collection were undertaken by the blind- \\
ed observer."
\end{tabular}

Blinding of participants Low risk (performance bias)

Adherence measure

\begin{abstract}
(PRIMARY) PHARMACOLOGICAL MARKER - (pg 870) "The independent assessor invited patients to take part in the research but did not mention PE or adherence. Patients were advised that their DPA would contain a small dose of phenobarbitone to assess the efficacy of the drug. All patients agreed to participate. It has been suggested that former educational level is a predictor of prognosis, behavioral variables, and knowledge of disease. Patients were therefore stratified into bands of low, medium, or high knowledge of their RA by means of a validated patient knowledge questionnaire. Patients in each band were allocated to the EG and CG using a separate computer generated code for each band. This was done to ensure that the 2 groups had compara-
\end{abstract}


Hill 2001 (Continued)

ble levels of initial knowledge. Allocation was carried out by a clerk who had no study input or patient contact."

Blinding of participants Low risk

(performance bias)

Patient outcome MENT AND BLINDING The independent assessor invited patients to take part in the research but did not mention PE or adherence. Patients were advised
(PRIMARY) PLASMA VISCOSITY - Objective outcome. (pg 871) "GROUP ASSIGNthat their DPA would contain a small dose of phenobarbitone to assess the efficacy of the drug. All patients agreed to participate. It has been suggested that former educational level is a predictor of prognosis, behavioral variables, and knowledge of disease. Patients were therefore stratified into bands of low, medium, or high knowledge of their RA by means of a validated patient knowledge questionnaire. Patients in each band were allocated to the EG and CG using a separate computer generated code for each band. This was done to ensure that the two groups had comparable levels of initial knowledge. Allocation was carried out by a clerk who had no study input or patient contact".

Blinding of personnel (per- Low risk formance bias)

Adherence measure
(PRIMARY) PHARMACOLOGICAL MARKER - (pg 870) "The independent assessor invited patients to take part in the research but did not mention PE or adherence. Patients were advised that their DPA would contain a small dose of phenobarbitone to assess the efficacy of the drug. All patients agreed to participate. It has been suggested that former educational level is a predictor of prognosis, behavioral variables, and knowledge of disease. Patients were therefore stratified into bands of low, medium, or high knowledge of their RA by means of a validated patient knowledge questionnaire. Patients in each band were allocated to the EG and CG using a separate computer generated code for each band. This was done to ensure that the 2 groups had comparable levels of initial knowledge. Allocation was carried out by a clerk who had no study input or patient contact".

Blinding of personnel (per- Unclear risk (PRIMARY) PLASMA VISCOSITY - No mention of blinding of other staff formance bias)

Patient outcome

Incomplete outcome data Unclear risk

(attrition bias)

Adherence measure
(PRIMARY) PHARMACOLOGICAL MARKER - Reasons for dropouts recorded but dropouts not even across groups

Incomplete outcome data Unclear risk

(attrition bias)

(PRIMARY) PLASMA VISCOSITY - Reasons for withdrawals reported but

Patient outcome

dropouts not even across groups

\section{Holland 2007}

Methods Randomized controlled trial

Participants The study location was UK

149 participants were randomized to the intervention group and 144 participants were randomized to the control group

The inclusion criteria were adults (aged over 18 years), admitted as an emergency in which heart failure was an important ongoing clinical condition, and prescribed 2 or more drugs (from any drug class) on discharge

The exclusion criteria were living in a residential or nursing home, awaiting surgery for ischemic or valvular heart disease or heart transplantation, or had terminal malignancy 
Holland 2007 (Continued)

The pharmacist arranged a home visit, within 2 weeks of hospital discharge, at a time when they could meet the patient and any carer(s). Where appropriate, pharmacists educated the patient/carer about heart failure and their drugs and gave basic exercise, dietary, and smoking cessation advice. They also encouraged completion of simple sign and symptom monitoring diary cards (including monitoring body weight), removed discontinued drugs (with the patient's consent), fed back recommendations to the general practitioner, and fed back to the local pharmacist any need for a drug adherence aid (for example, a Medidos or Dosett container). We provided all pharmacists with a detailed manual describing the expected components of their visit and asked them to deliver education in line with advice given in the British Heart Foundation's booklet Living with Heart Failure, which they left with patients after the first visit. Pharmacists completed a standardized visit form during each visit. One follow-up visit occurred at 6 to 8 weeks after discharge to review progress and reinforce original advice. We also recorded a selection of pharmacists' visits to investigate the intervention's delivery and the pharmacists' communication skills

Control: USUAL CARE

The nature of the intervention meant that no clear "placebo" could be provided. Participants were told after randomization which group they were in. Those in the control group received usual care

Outcomes The measures of adherence were a mailed questionnaire that measures drug adherence (medication adherence report scale or MARS) at baseline and 2 years

The patient outcomes were emergency admissions and mortality (data obtained from hospital records) and quality of life (Minnesota living with heart failure questionnaire and EQ 5D). Measures were performed at baseline and at 2 years

\footnotetext{
Notes
}

\section{Risk of bias}

Bias Authors' judgement Support for judgement

Random sequence genera- Low risk tion (selection bias)

Computer-generated random number. (pg 2) "We used third party telephone randomisation based on a computer generated random allocation sequence. We stratified randomisation by New York Heart Association class (class I/II-no or mild limitation, III-moderate limitation, or IV- severe limitation) and recruitment site."

\begin{tabular}{ll}
\hline $\begin{array}{l}\text { Allocation concealment } \\
\text { (selection bias) }\end{array}$ & Low risk \\
& $\begin{array}{l}\text { Third party allocation, assumed this is concealed. (pg 2) "We used third party } \\
\text { telephone randomisation based on a computer generated random allocation } \\
\text { sequence. We stratified randomisation by New York Heart Association class } \\
\text { (class I/II-no or mild limitation, III-moderate limitation, or IV- severe limita- } \\
\text { tion) and recruitment site." }\end{array}$ \\
\hline
\end{tabular}

\begin{tabular}{lll}
\hline $\begin{array}{l}\text { Selective reporting (re- } \\
\text { porting bias) }\end{array}$ & Unclear risk & No protocol available
\end{tabular}

\begin{tabular}{|c|c|c|}
\hline Other bias & Low risk & None noted \\
\hline $\begin{array}{l}\text { Blinding of outcome as- } \\
\text { sessment (detection bias) } \\
\text { Adherence measure }\end{array}$ & High risk & $\begin{array}{l}\text { (PRIMARY) SELF REPORT - QUESTIONNAIRE - Self report is subjective and no } \\
\text { mention of blinding outcomes assessors }\end{array}$ \\
\hline $\begin{array}{l}\text { Blinding of outcome as- } \\
\text { sessment (detection bias) } \\
\text { Patient outcome }\end{array}$ & Unclear risk & $\begin{array}{l}\text { (PRIMARY) HOSPITAL READMISSIONS - No mention of blinding and not clear } \\
\text { how these data were collected }\end{array}$ \\
\hline $\begin{array}{l}\text { Blinding of participants } \\
\text { (performance bias) } \\
\text { Adherence measure }\end{array}$ & High risk & $\begin{array}{l}\text { (PRIMARY) SELF REPORT - QUESTIONNAIRE - Patients were not blinded to } \\
\text { treatment group. (pg 5) "However, patients could not be blinded to treatment } \\
\text { group, which may have biased their responses to questionnaires." }\end{array}$ \\
\hline
\end{tabular}


Holland 2007 (Continued)

$\begin{array}{ll}\begin{array}{l}\text { Blinding of participants } \\ \text { (performance bias) }\end{array} & \text { Low risk } \\ \text { Patient } \text { affect this outcome }\end{array}$

Patient outcome affect this outcome
Blinding of personnel (per- Unclear risk formance bias)
Adherence measure
(PRIMARY) SELF REPORT - QUESTIONNAIRE - Insufficient information to permit judgment of 'Low risk' or 'High risk'

\begin{tabular}{|c|c|c|}
\hline $\begin{array}{l}\text { Blinding of personnel (per- } \\
\text { formance bias) }\end{array}$ & Unclear risk & $\begin{array}{l}\text { (PRIMARY) HOSPITAL READMISSIONS - No mention of blinding and not clear } \\
\text { how these data were collected }\end{array}$ \\
\hline
\end{tabular}

Patient outcome

\section{Incomplete outcome data Unclear risk}

(attrition bias)

Adherence measure

\begin{tabular}{ll}
$\begin{array}{l}\text { Incomplete outcome data } \\
\text { (attrition bias) }\end{array}$ & Unclear risk \\
$\begin{array}{l}\text { Patient outcome } \\
\text { (PRIMARY) HOSPITAL READMISSIONS - Reasons for dropouts not provided; un- } \\
\end{array}$ & \\
\hline
\end{tabular}

\section{Holstad 2011}

\begin{tabular}{|c|c|}
\hline Methods & Randomized controlled trial \\
\hline \multirow[t]{4}{*}{ Participants } & The study location was 5 HIV clinical sites in a large south eastern metropolitan city, USA \\
\hline & $\begin{array}{l}104 \text { participants were randomized to the intervention group and } 103 \text { participants were randomized to } \\
\text { the control group }\end{array}$ \\
\hline & The inclusion criteria were (1) HIV infected; (2) female by birth; (3) prescribed antiretroviral therapy; (4) \\
\hline & $\begin{array}{l}18 \text { years of age or older; (5) English speaking; (6) mentally stable as determined by a screening assess- } \\
\text { ment; ( } 7 \text { ) willing to participate by completing computerized assessments, use electronic drug monitor- } \\
\text { ing (EDM) caps, be randomly assigned and participate in group sessions }\end{array}$ \\
\hline
\end{tabular}

Interventions

Intervention: KHARMA INTERVENTION

The KHARMA intervention consisted of 8 group sessions using motivational interviewing delivered in a group format. It was designed to empower women to make decisions and develop strategies about taking ART as prescribed and consistently using risk reduction behaviors, such as condom use and to overcome resistance/ambivalence to both. The sessions lasted about 1.5 to 2 hours, and were led by trained MI nurses. The first and last session focused on both adherence and risk behavior, 3 sessions were devoted to adherence only and 3 to risk reduction behaviors only, including a session on disclosure which is important to risk reduction as well as adherence. Each session included a discussion of goals and goal setting related to the topic. MI techniques were incorporated into every session. In keeping with the autonomy support spirit of MI, participants as a group chose which topic they wanted to address first. The majority of groups $(n=14)$ chose medication adherence as the first topic

\section{Control: HEALTH PROMOTION PROGRAM}

The control group sessions were equivalent in length and time to the MI group and were led by trained nurses and a health educator. This group used health education techniques of lecture/discussion/educational games and focused on nutrition, exercise, stress recognition, and women's health issues tailored to the HIV positive woman. Participants received a manual containing content and supplementary materials for each session. Adherence and risk reduction behaviours (RRB) were not addressed in the health promotion program (HPP) and facilitators were instructed to redirect the group if these issues came up

Outcomes

The measures of adherence were Electronic Drug Monitoring (EDM). One medication from the regimen was electronically monitored using the $\mathrm{MEMS}^{\circledR}$ cap and an algorithm was used to determine which 
Holstad 2011 (Continued)

medication would receive the cap. In general, that medication was the primary protease inhibitor (PI), or the non-nucleoside reverse transcriptase inhibitor (NNRTI) if a PI was not prescribed. A sticker was placed on the monitored medication bottle and the participant was instructed to write dates and times on the sticker when the medication was pocketed, or if the cap was opened by mistake. At each download, information on this sticker was reviewed and an EDM questionnaire was completed. The information collected on the questionnaire included changes in medication regimen, problems with the cap, if someone else had administered the medication, and if the medication had been stopped. If the medication had been stopped, the participant was asked who stopped it and the reason, and if it had been restarted. If the participant was taken off the medication and brought the cap to the study office, it was stored until the participant re-started medication and those days were marked as 'non-monitored.' EDM data were adjusted by setting certain days as 'non-monitored' on which the following events occurred: cap malfunction, lost cap, medication stopped by healthcare provider, someone else administered the medication (e.g. hospital, group home), incarceration, pocketing pills, reported exclusive use of pill box, and excessive openings (a form of cap malfunction defined as more than twice the dose plus one). The EDM data were captured over time in phases consistent with the 5 assessment periods. Data from the MEMS report on the Percentage (\%) of Prescribed Doses Taken and Percentage (\%) of Pre-

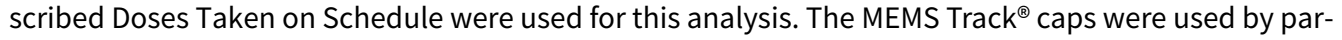
ticipants during the entire study period (about 13 months) including 2 weeks prior to the baseline to obtain an estimate of baseline adherence

The patient outcomes were CD4 counts and viral loads. Data were extracted from participants' medical records during the time they were enrolled in the study. Dates that the laboratory tests were drawn were grouped according to proximity with the study assessment periods. For example, laboratory tests drawn as close as possible and prior to or on the day of the baseline assessment were classified as the baseline CD4 and viral load results. The median was about 27 days prior to the baseline. Participants did not always have both tests performed on the same date and therefore may have only had one test result available during an assessment period. The standard of care is to order these tests every 3 to 4 months once a patient has stabilized. Consequently, by the end of the follow-up period, participants had fewer laboratory tests available that corresponded to study time points

Notes

Low attendance rates to the intervention. Also, not all the participants' viral loads were calculated by the same method

\section{Risk of bias}

\begin{tabular}{lll}
\hline Bias & Authors' judgement & Support for judgement \\
\hline $\begin{array}{l}\text { Random sequence genera- } \\
\text { tion (selection bias) }\end{array}$ & Low risk & $\begin{array}{l}\text { (pg 3) The study was a randomized controlled behavioral clinical trial in which } \\
\text { participants were randomized within sites to the intervention or control condi- } \\
\text { tion using a computer-generated randomization scheme }\end{array}$ \\
\hline
\end{tabular}

\begin{tabular}{lll}
\hline $\begin{array}{l}\text { Allocation concealment } \\
\text { (selection bias) }\end{array}$ & Unclear risk & No information given on allocation concealment \\
\hline $\begin{array}{l}\text { Selective reporting (re- } \\
\text { porting bias) }\end{array}$ & Low risk & $\begin{array}{l}\text { Author's note: "We report on page 7: CESD scores were significantly but mildly } \\
\text { correlated }(r<0.2) \text { with adherence measures, but not significantly different be- } \\
\text { tween treatment groups at baseline, thus we chose not to control for depres- } \\
\text { sive symptoms" }\end{array}$ \\
\hline
\end{tabular}

Other bias High risk From discussion (pg 10): "In 2006, our main recruitment site implemented
an ongoing "Prevention for Positives" initiative where all providers were re-
quired to elicit and document discussion about risky behaviors with each pa-
tient every 12 months. When indicated, patients were referred for risk reduc-
tion education and counseling. Our results may be impacted by the addition of
this program. Given this occurred for women in both groups, it might have di-
luted between group differences. In addition, risk behaviors in this study were
measured by self-report, and could be subject to bias from poor recall or social
desirability. Due to cost constraints, laboratory results were extracted from
medical records and dates of lab tests did not always correspond in time to fol-
low-up assessments. As the study progressed, there were fewer lab data for 


\begin{tabular}{|c|c|c|}
\hline Blinding of outcome as- & Low risk & $\begin{array}{l}\text { (PRIMARY) MEMS - MEMS not likely to be affected by lack of blinding of out- } \\
\text { come assessors }\end{array}$ \\
\hline
\end{tabular}

Blinding of outcome as- Unclear risk sessment (detection bias)

Patient outcome

(PRIMARY) CD4 COUNT AND VIRAL LOAD - Unclear if extractor was blind. "Because of their high cost, we used data extracted from participants' medical records during the time they were enrolled in the study. Dates that the laboratory tests were drawn were grouped according to proximity with the study assessment periods. For example, labs drawn as close as possible and prior to or on the day of the baseline assessment were classified as the baseline CD4 and viral load results."

Blinding of participants High risk (performance bias) Adherence measure
(PRIMARY) MEMS - Author's note: patients were not blind. Also, the article suggests patients may have taken medication out of MEMS bottle to use other devices, and were then asked to remember to open the bottle when they took medication. (pg 10) "We monitored adherence primarily using the MEMS ${ }^{\circledR}$ Track Cap for electronic drug monitoring. Participants were asked to use this cap during the 13 months while enrolled in the study. The cap is cumbersome to use, and affects the portability of one's medications. Therefore, participants may have skipped using their caps for periods of time during the study. In addition, caps can malfunction, rendering data unavailable. Since many patients use pill boxes or pill trays to facilitate their adherence, it is difficult to remember to open the cap when removing pills from the pill box. For these reasons, future researchers who choose to use EDM might consider shortening the time for EDM, or using newer more user-friendly technology available to conduct EDM."

Blinding of participants Low risk
(performance bias)
Patient outcome

(PRIMARY) CD4 COUNT AND VIRAL LOAD - Lack of blinding of the patients not likely to affect this outcome

Blinding of personnel (per- High risk

formance bias)

Adherence measure study groups. Also, the article outlines complicated method for determining adherence based on MEMS results. "Electronic Drug Monitoring (EDM)-One medication from the regimen was electronically monitored using the MEMS ${ }^{\circledR}$ cap and an algorithm was used to determine which medication would receive the cap. In general, that medication was the primary protease inhibitor (PI), or the non-nucleoside reverse transcriptase inhibitor (NNRTI) if a PI was not prescribed. A sticker was placed on the monitored medication bottle and the participant was instructed to write dates and times on the sticker when the medication was pocketed, or if the cap was opened by mistake. At each download, information on this sticker was reviewed and an EDM questionnaire was completed. The information collected on the questionnaire included changes in medication regimen, problems with the cap, if someone else had administered the medication, and if the medication had been stopped. If the medication had been stopped, the participant was asked who stopped it and the reason, and if it had been restarted. If the participant was taken off the medication and brought the cap to the study office, it was stored until the participant re-started medication and those days were marked as 'non-monitored.' EDM data were adjusted by setting certain days as 'non-monitored' on which the following events occurred: cap malfunction, lost cap, medication stopped by healthcare provider, someone else administered the medication (e.g., hospital, group home), incarceration, pocketing pills, reported exclusive use of pill box, and excessive openings (a form of cap malfunction defined as more than twice the dose plus one). The EDM data were captured over time in phases consistent with the five assessment periods. Data from the MEMS report on the Percentage (\%) of Prescribed Doses Taken and Percentage (\%) of Prescribed 
Holstad 2011 (Continued)

Doses Taken on Schedule were used for this analysis. The MEMS Track ${ }^{\circledR}$ caps were used by participants during the entire study period (about 13 months) including 2 weeks prior to the baseline to obtain an estimate of baseline adherence."

Blinding of personnel (per- Low risk formance bias)

Patient outcome
(PRIMARY) CD4 COUNT AND VIRAL LOAD - Unclear if key study staff were the extractors and if they were blind. "Because of their high cost, we used data extracted from participants' medical records during the time they were enrolled in the study. Dates that the laboratory tests were drawn were grouped according to proximity with the study assessment periods. For example, labs drawn as close as possible and prior to or on the day of the baseline assessment were classified as the baseline CD4 and viral load results."

(PRIMARY) MEMS - Withdrawal fairly balanced, but wide variation in attendance. However, results also have been reported by taking only the participants with high attendance rates

(attrition bias)

Adherence measure

(PRIMARY) CD4 COUNT AND VIRAL LOAD - Withdrawal fairly balanced, but wide variation in attendance. However, results also have been reported by taking only the participants with high attendance rates

Hou 2010

Methods Randomized controlled trial

Participants

The study location was Boston, Massachusetts, USA

41 participants were randomized to the intervention group and 41 participants were randomized to the control group

The inclusion criteria were women seeking care at Planned Parenthood League of Massachusetts who were sexually active, had voluntarily chosen the pill as their contraceptive method, and were new users of the method. The criteria also included having a personal mobile phone with text-messaging capabilities and desire to use oral contraceptive pills for at least 6 months

The exclusion criteria were contraindications to oral contraceptive pill use, the use of oral contraceptive pills primarily for non-contraceptive indications, current use of oral contraceptive pills for more than 1 month, intent of pregnancy in the subsequent 12 months, plans to travel outside the cell phone networks of the United States and Canada during the duration of the study, inability to complete the study, and being in situations in which receipt of a text message reminder to take an oral contraceptive pill would endanger the safety and privacy of the woman

Interventions Intervention: TEXT MESSAGING

Participants received daily text-message reminders. During the 3-month study period, each participant assigned the intervention received a daily text message, "Please remember to take your birth control pill", sent at a designated time chosen by the participant

Control: USUAL CARE

Patients in the control group received usual care and were not offered additional medication reminders

Outcomes

The measures of adherence were electronic monitoring and diary self report. The pill packs were modified so that each pack could be inserted into the electronic monitoring device, and each pack was placed in a separate envelope and labeled for the participant to place into the device at the beginning of its cycle. Each woman received an electronic monitoring device called SIMPill (Clinical Technology Advisors, Inc., Acton, MA) for adherence data collection. Each time the participant opened the electronic monitoring device to remove a pill, a short message service signal was sent wirelessly to a main server and a second server. As proof of pill-taking, each day was examined for at least one record of elec- 
Hou 2010 (Continued)

tronic monitoring device opening on either server. All participants were asked to recharge the electronic monitoring device once a month and received a text message on approximately the 15th of every month of the study reminding them to do so. devices and pill diaries. Each day was examined for at least one electronic monitoring device opening on either server. If 7 or more electronic monitoring device openings in a cycle were recorded, we assumed that the device was functioning for the cycle. If 4 to 6 openings in a cycle were recorded and the patient assessed herself as non-adherent (missing 3 or more pills a month) on the final questionnaire, then we assumed the device was functioning. However, if 4 to 6 openings were recorded in a cycle but the patient assessed herself as adherent (missing 2 or fewer pills per month), we assumed that the electronic monitoring device was malfunctioning for the cycle and the cycle was dropped from analysis. If 3 openings or less were recorded in a given cycle, it was assumed that the electronic monitoring device was malfunctioning and the cycle was dropped from analysis. The operational definition of a pill-taking day was from 3:00 AM to 2:59 AM. Only events during the first 21 active pill days of a cycle were used in the analysis. Patients kept a diary of their daily pill taking, which were returned to the clinic at the end of 3 months

The patient outcome was pregnancy. It seems that a self reported questionnaire at 3 months was used to obtain information about pregnancy

Notes -

\section{Risk of bias}

\begin{tabular}{lll}
\hline Bias & Authors' judgement & Support for judgement \\
\hline $\begin{array}{l}\text { Random sequence genera- } \\
\text { tion (selection bias) }\end{array}$ & Low risk & $\begin{array}{l}\text { "Randomization was computer-generated with varying blocks of four and } \\
\text { six." (pg 634) }\end{array}$ \\
\hline $\begin{array}{l}\text { Allocation concealment } \\
\text { (selection bias) }\end{array}$ & Low risk & $\begin{array}{l}\text { (pg 634) "Randomization was computer-generated with varying blocks of four } \\
\text { and six". Randomization sequences were concealed within opaque, sequen- } \\
\text { tially numbered envelopes until interventions were assigned by a research as- } \\
\text { sistant who did not participate in data analysis }\end{array}$ \\
\hline $\begin{array}{l}\text { Selective reporting (re- } \\
\text { porting bias) }\end{array}$ & Unclear risk & Protocol not available \\
\hline
\end{tabular}

Other bias High risk

Authors noted the following limitations: "The lack of a significant difference between the arms could be attributed to the frequent use of alternative reminder systems in the control arm. At the beginning of the study, all women were given routine contraceptive counseling, including the possibility of using reminder methods to help them to remember to take their pill. The high rate of reminder system use in the control arm, particularly electronic systems such as cell phone alarms that mimicked the study intervention, could contribute to the lack of difference between the arms." - (pg 639) "Possible reasons for the lack of pregnancies may be that our participants had a low frequency of sexual activity or correctly used backup methods like condoms when they had poor adherence with oral contraceptive pills. Coital activity and condom use with each sexual act was not assessed. The text-message arm also reported more frequent condom and emergency contraception use during the study, so the text-message reminders may have had an unintended effect of reinforcing use of backup methods for women at risk." - (pg 639) "Our study cohort was mostly white, well-educated, and nulliparous, which may limit the generalizability of these findings to a more diverse population." - (pg 639) "Because we cannot exclude the possibility that participants may open and close the electronic monitoring device without taking their oral contraceptive pill, the electronic monitoring device may be underestimating the actual missed pill rate in the cohort." - (pg 639) "Our wireless technology was limited by mechanical and technological issues as described, but only 42 of the possible 246 cycles (17\%) could not be included in analysis compared with 220 of a possible 507 cycles (43\%) that could not be analyzed in the study by Potter et al." - (pg 640) "An electronic monitoring device with an embedded memory chip has been test- 
Hou 2010 (Continued)

ed among oral contraceptive pill users, but data collection was limited by unreturned devices or erased memory chips." - (pg 634)

\begin{tabular}{|c|c|c|}
\hline $\begin{array}{l}\text { Blinding of outcome as- } \\
\text { sessment (detection bias) }\end{array}$ & Low risk & $\begin{array}{l}\text { (PRIMARY) ELECTRONIC MONITORING DEVICE - The information was collected } \\
\text { by the sending automatic messages to the server }\end{array}$ \\
\hline
\end{tabular}

\begin{tabular}{|c|c|c|}
\hline $\begin{array}{l}\text { Blinding of outcome as- } \\
\text { sessment (detection bias) }\end{array}$ & Unclear risk & $\begin{array}{l}\text { (PRIMARY) PREGNANCY - It appears that the questionnaire may have been } \\
\text { completed by the patient but this is unclear }\end{array}$ \\
\hline
\end{tabular}

Patient outcome

\begin{tabular}{lll}
\hline $\begin{array}{l}\text { Blinding of participants } \\
\text { (performance bias) } \\
\text { Adherence measure }\end{array}$ & High risk & $\begin{array}{l}\text { (PRIMARY) ELECTRONIC MONITORING DEVICE - "Women were told that the de- } \\
\text { vice would monitor their pill taking during the study." (pg 635) }\end{array}$ \\
\hline $\begin{array}{l}\text { Blinding of participants } \\
\text { (performance bias) }\end{array}$ & High risk & $\begin{array}{l}\text { (PRIMARY) PREGNANCY - Blinding is impossible as oral contraceptives and } \\
\text { pregnancy are linked. Also, this was a subjective questionnaire without the use } \\
\text { of an objective measure i.e. blood test/urine test pregnancy confirmation at 3 } \\
\text { months }\end{array}$
\end{tabular}

\begin{tabular}{ll}
\hline $\begin{array}{l}\text { Blinding of personnel (per- } \\
\text { formance bias) }\end{array}$ & Low risk \\
Adherence measure & (PRIMARY) ELECTRONIC MONITORING DEVICE - Investigators involved in da- \\
& ta analysis were blinded to group assignment until primary data analysis was \\
completed (pg 634)
\end{tabular}

\begin{tabular}{|c|c|c|}
\hline $\begin{array}{l}\text { Blinding of personnel (per- } \\
\text { formance bias) } \\
\text { Patient outcome }\end{array}$ & Unclear risk & $\begin{array}{l}\text { (PRIMARY) PREGNANCY - It appears that the questionnaire may have been } \\
\text { completed by the patient but this is unclear }\end{array}$ \\
\hline $\begin{array}{l}\text { Incomplete outcome data } \\
\text { (attrition bias) } \\
\text { Adherence measure }\end{array}$ & Low risk & $\begin{array}{l}\text { (PRIMARY) ELECTRONIC MONITORING DEVICE - } 9 \text { participants do not have } \\
\text { any usable data. But it not clear which study group they come from. "Fifteen } \\
\text { women had data for two cycles as a result of a presumed nonfunctioning de- } \\
\text { vice for one cycle (nbeta11), dropping from the study (nbeta3), or stopping } \\
\text { oral contraceptive pills during the third cycle (nbeta1). The final } 10 \text { women had } \\
\text { data for only one cycle either because of a presumed nonfunctioning device } \\
\text { for two cycles (nbeta8) or because she stopped her pills during the second cy- } \\
\text { cle (nbeta2)." - (pg 637) According to Figure } 1,1 \text { patient had non-functioning } \\
\text { electronic monitoring device, } 3 \text { stopped OCPs, and } 1 \text { violated protocol in inter- } \\
\text { vention group. } 1 \text { stopped OCPs and } 1 \text { violated protocol in control group. How- } \\
\text { ever, } 21 \text { from the intervention group and } 24 \text { from control were presumed to } \\
\text { have non-functioning electronic device during the cycle. Therefore data from } \\
26 \text { participants in the intervention group and } 26 \text { from the control group have } \\
\text { missing information. Missing outcome data are balanced in numbers across in- } \\
\text { tervention groups, with similar reasons for missing data across groups }\end{array}$ \\
\hline
\end{tabular}

Incomplete outcome data Unclear risk (PRIMARY) PREGNANCY - Article contains no information about this measure (attrition bias) other than the result; impossible to judge

Patient outcome 
Howe 2005 (Continued)

Participants

Patients had 2 consecutive glycosylated hemoglobin $(\mathrm{HbA1c}$ ) results of $8.5 \%$ or higher, were aged 1 to 16 years, and had been diagnosed with Type 1 diabetes for at least 1 year

Interventions

Patients in the SC group received standard care from a nurse practitioner and endocrinologist, typically every quarter. During the 30-minute office visits, $\mathrm{HbAlc}$ value was obtained, blood glucose records were reviewed, problems were identified, target goals were determined, and education was provided as needed. Patients in the ED group received the standard care in the clinic. They also participated in a one-time education session with the study co-ordinator, a nurse, with the goal of providing families with basic diabetes management skills such as insulin administration and carbohydrate counting. Children older than 8 years were asked to participate in the education sessions. Families were given customized written guidelines including insulin doses for hyperglycemia and for varying carbohydrate loads. At the completion of the program, parents were expected to identify problems and to know when to call their nurse practitioner for assistance in insulin dose adjustment, for sick-day management, or for advice in co-ordination of the diabetes regimen. Patients in the ED + TCM group received both the standard care in clinic and the education program described above. They also received weekly telephone calls for 3 months or until the first clinic visit and then bimonthly calls for 3 months from the study co-ordinator. At the time of enrolment, subjects were given an appointment 3 months after the start of study. For children younger than 13 years, telephone calls were between the study co-ordinator and a designated parent. Some teens did elect to be involved in telephone calls as well. The study co-ordinator talked with both the teen and parent to ascertain that plans were clear between child and parent. The study co-ordinator followed a standardized telephone protocol to review blood sugars, safety issues related to hypoglycemia and hyperglycemia, problem-solving skills, diet and meal planning, and changing insulin dose. The study co-ordinator also discussed parenting and behavior management skills with parents as needed. Telephone calls were typically 5 to 15 minutes

Outcomes

The ADH (an adherence questionnaire) was used to evaluate child/family behaviors related to diabetes safety and control. ADH was obtained at baseline and at the end of study. The HbAlc values were used as clinical measures and their levels were obtained at baseline, at 3 to 6 months, and at end of study

\section{Notes}

$-$

\section{Risk of bias}

\section{Bias}

Random sequence genera- Low risk

tion (selection bias)

\section{Authors' judgement Support for judgement}

Computer-generated random sequence. (pg 87) "A randomization schedule was produced using Statistical Analysis System (SAS) program with subjects blocked by race, age group, sex, and family structure (single vs. two parents). Within each block, subjects were randomly assigned to one of the three treatment groups."

\begin{tabular}{|c|c|c|}
\hline $\begin{array}{l}\text { Allocation concealment } \\
\text { (selection bias) }\end{array}$ & Unclear risk & $\begin{array}{l}\text { No mention of allocation concealment. (pg } 87 \text { ) "A randomization schedule } \\
\text { was produced using Statistical Analysis System (SAS) program with subjects } \\
\text { blocked by race, age group, sex, and family structure (single vs. two parents). } \\
\text { Within each block, subjects were randomly assigned to one of the three treat- } \\
\text { ment groups." }\end{array}$ \\
\hline
\end{tabular}

\begin{tabular}{|c|c|c|}
\hline $\begin{array}{l}\text { Selective reporting (re- } \\
\text { porting bias) }\end{array}$ & Unclear risk & No protocol available \\
\hline Other bias & High risk & $\begin{array}{l}\text { Authors note the following(pg 91): "Recruiting } 135 \text { subjects from a single cen- } \\
\text { ter became more difficult than was expected. Initially, the research team an- } \\
\text { ticipated that approximately } 10 \text { subjects per week could be recruited for the } \\
\text { study. In reality, less than half of these eligible subjects actually kept their } \\
\text { scheduled visit. Further, because of the time constraints of a busy clinic, some } \\
\text { subjects were not approached. Of those approached, less than half of these } \\
\text { subjects followed up with the enrollment process (paper- work returned) or } \\
\text { with the initial study intervention (education session). In the end, the research } \\
\text { team recruited one to three subjects per month, with } 89 \text { subjects recruited }\end{array}$ \\
\hline
\end{tabular}


Howe 2005 (Continued)

over a 3-year period. The attrition rate was $16 \%$, with 14 subjects failing to complete the study protocol. One subject requested to leave the study. The remainder were dropped from the study after repeated attempts by the study coordinator to have the family complete the protocol with its required clinic visits, $\mathrm{HbA1c}$ blood work, and paperwork. Although the research design with its original sample size accounted for differences in subjects' ages, the smaller sample size could not. Because there was a big difference in diabetes management and parent and child interactions around diabetes depending on age, without the power of the original sample size, our results may not reflect accurate comparisons. As well, the subjects completing the study may have represented a biased sample because they were not necessarily representative of patients and families in poor control. Another limitation of the study was using unstandardized assessment tools versus standardized assessment tools. The research team elected to use the ADH, TEAM, and KNOW as they were assessment tools already integrated into the clinical practice of the Diabetes Center for Children. Data collection was simplified, however; these tools do not have the psychometric properties established for standardized tools. Obtaining data points at the times specified in the protocol proved to be difficult when done in real-life terms with subjects and their families. The study was designed to obtain data at baseline and then in two 3-month intervals. Although the study coordinator was very flexible in meeting families' scheduling needs, there were frequent $b$ no-shows $Q$ in the clinic, thus, requiring rescheduling of appointments. The 3-month interval at times stretched to 4- to 6-month intervals between data points. Finally, the study design did not control for telephone contacts between clinicians and families in the ED or SC groups. Because all subjects were in relatively poor control, clinicians often elected to have families call in to review blood sugars. Whether and how much this occurred was not followed for this study. It is possible that the failure to see larger between-group differences was because the interventions may not have been different enough."

$\begin{array}{lll}\text { Blinding of outcome as- } & \text { Unclear risk } & \begin{array}{l}\text { (PRIMARY) CLINICIAN CHECKLIST (ADH) - No mention of blinding of outcome } \\ \text { sessment (detection bias) }\end{array}\end{array}$

Adherence measure

\begin{tabular}{|c|c|c|}
\hline $\begin{array}{l}\text { Blinding of outcome as- } \\
\text { sessment (detection bias) }\end{array}$ & Low risk & $\begin{array}{l}\text { (PRIMARY) HBA1C MEASUREMENT - Objective measure - unlikely that blinding } \\
\text { will affect outcome }\end{array}$ \\
\hline
\end{tabular}

\begin{tabular}{|c|c|c|}
\hline $\begin{array}{l}\text { Blinding of participants } \\
\text { (performance bias) } \\
\text { Adherence measure }\end{array}$ & High risk & $\begin{array}{l}\text { (PRIMARY) CLINICIAN CHECKLIST (ADH) - No mention of blinding of patients; } \\
\text { subjective outcome }\end{array}$ \\
\hline $\begin{array}{l}\text { Blinding of participants } \\
\text { (performance bias) } \\
\text { Patient outcome }\end{array}$ & Low risk & $\begin{array}{l}\text { (PRIMARY) HBA1C MEASUREMENT - Objective measure - unlikely that blinding } \\
\text { will affect outcome }\end{array}$ \\
\hline $\begin{array}{l}\text { Blinding of personnel (per- } \\
\text { formance bias) } \\
\text { Adherence measure }\end{array}$ & Unclear risk & $\begin{array}{l}\text { (PRIMARY) CLINICIAN CHECKLIST (ADH) - No mention of blinding of study per- } \\
\text { sonnel }\end{array}$ \\
\hline $\begin{array}{l}\text { Blinding of personnel (per- } \\
\text { formance bias) } \\
\text { Patient outcome }\end{array}$ & Low risk & $\begin{array}{l}\text { (PRIMARY) HBA1C MEASUREMENT - Objective measure - unlikely that blinding } \\
\text { will affect outcome }\end{array}$ \\
\hline $\begin{array}{l}\text { Incomplete outcome data } \\
\text { (attrition bias) } \\
\text { Adherence measure }\end{array}$ & Unclear risk & $\begin{array}{l}\text { (PRIMARY) CLINICIAN CHECKLIST (ADH) - Rate of attrition is less than } 20 \% \text { but } \\
\text { no mention of which group the dropouts were from or the reasons for drop- } \\
\text { ping out }\end{array}$ \\
\hline
\end{tabular}


Howe 2005 (Continued)

Incomplete outcome data Unclear risk (attrition bias)

Patient outcome
(PRIMARY) HBA1C MEASUREMENT - Rate of attrition is less than $20 \%$. However, sample size has only a 55\% power calculation

Howland 1990

\begin{tabular}{ll}
\hline Methods & $\begin{array}{l}\text { Method of randomization not stated. The physician educating the patients was not blinded, whereas } \\
\text { the office nurse questioning patients in the follow-up period was blinded as to which patient was in } \\
\text { which group }\end{array}$ \\
\hline Participants & $\begin{array}{l}\text { All patients over } 18 \text { years treated with erythromycin for an acute illness were included, while patients } \\
\text { with a history of allergy/intolerance to erythromycin were excluded }\end{array}$ \\
\hline Interventions & $\begin{array}{l}\text { Informed patients were told of } 6 \text { possible side effects of treatment with erythromycin, while control } \\
\text { (uninformed) patients were not made aware of potential side effects of treatment }\end{array}$ \\
\hline Outcomes & The occurrence of side effects both before and after treatment \\
\hline Notes & $\begin{array}{l}\text { Adherence was measured using the following methods: the mean number of erythromycin pills taken } \\
\text { per day, patients reporting that they missed at least one pill, and the mean number of pills taken out of } \\
40 \text { pills }\end{array}$
\end{tabular}

\section{Risk of bias}

\begin{tabular}{|c|c|c|}
\hline Bias & Authors' judgement & Support for judgement \\
\hline $\begin{array}{l}\text { Random sequence genera- } \\
\text { tion (selection bias) }\end{array}$ & Unclear risk & $\begin{array}{l}\text { Randomization process not described. (pg 62) "Patients were randomized to } \\
\text { informed (study) and UP informed (control) groups." }\end{array}$ \\
\hline $\begin{array}{l}\text { Allocation concealment } \\
\text { (selection bias) }\end{array}$ & Unclear risk & $\begin{array}{l}\text { No mention of allocation concealment. (pg 62) "Patients were randomized to } \\
\text { informed (study) and UP informed (control) groups." }\end{array}$ \\
\hline $\begin{array}{l}\text { Selective reporting (re- } \\
\text { porting bias) }\end{array}$ & Unclear risk & No protocol available \\
\hline Other bias & Unclear risk & $\begin{array}{l}\text { Hawthorne effect possible. Physician not blinded. Small sample size. However, } \\
\text { unclear }\end{array}$ \\
\hline $\begin{array}{l}\text { Blinding of outcome as- } \\
\text { sessment (detection bias) } \\
\text { Adherence measure }\end{array}$ & Low risk & $\begin{array}{l}\text { (PRIMARY) SELF REPORT - INTERVIEW - Outcome assessor was blind. (pg 63) } \\
\text { "The nurse did not know the identity of informed and uninformed patients." }\end{array}$ \\
\hline $\begin{array}{l}\text { Blinding of outcome as- } \\
\text { sessment (detection bias) } \\
\text { Patient outcome }\end{array}$ & Low risk & $\begin{array}{l}\text { (PRIMARY) SIDE EFFECTS - Outcome assessor was blind. (pg 63) "The nurse did } \\
\text { not know the identity of informed and uninformed patients." }\end{array}$ \\
\hline $\begin{array}{l}\text { Blinding of participants } \\
\text { (performance bias) } \\
\text { Adherence measure }\end{array}$ & Low risk & $\begin{array}{l}\text { (PRIMARY) SELF REPORT - INTERVIEW - Patients were blinded to group. Au- } \\
\text { thor's note: "To prevent bias, patients were blinded regarding the study. This } \\
\text { was felt to be reasonable, as treatment decisions were not affected by inclu- } \\
\text { sion, and all patients were treated within generally accepted standards of } \\
\text { care." }\end{array}$ \\
\hline $\begin{array}{l}\text { Blinding of participants } \\
\text { (performance bias) }\end{array}$ & Low risk & $\begin{array}{l}\text { (PRIMARY) SIDE EFFECTS - Patients were blinded to group. Authors report that: } \\
\text { "To prevent bias, patients were blinded regarding the study. This was felt to be }\end{array}$ \\
\hline
\end{tabular}

Patient outcome 
Blinding of personnel (per- High risk

formance bias)

Adherence measure

Blinding of personnel (per- High risk

formance bias)

Patient outcome
(PRIMARY) SELF REPORT - INTERVIEW - Physician was not blind (pg 64)

(PRIMARY) SIDE EFFECTS - Physician not blind. All the patients in the study were seen by the same physician

(PRIMARY) SELF REPORT - INTERVIEW - Low rate of missing data. However, the

distribution is not known, therefore uncertain

Incomplete outcome data Unclear risk

(attrition bias)

Adherence measure

Incomplete outcome data Unclear risk

(attrition bias)

(PRIMARY) SIDE EFFECTS - Low rate of missing data. However, the distribution

Patient outcome

is not known, therefore uncertain

Huguelet 2011

Methods Randomized controlled trial

Participants

The study location was the Department of Psychiatry at the University Hospitals of Geneva

42 participants were randomized to the intervention group and 42 participants were randomized to the control group

The inclusion criteria were no hospitalization in the previous 6 months (stability) and treated by their current psychiatrist for at least 3 months (familiarity)

The exclusion criterion was inability to participate in the intervention due to their clinical condition

Interventions

Intervention: RELIGIOUS AND SPIRITUAL ASSESSMENT

The intervention was delivered by psychiatrists who were trained by the researchers. Psychiatrist attended a 90-minute training session during which they were informed about the rationale for taking into account the spiritual dimension in the treatment of patients with schizophrenia and how to conduct a spiritual assessment. They were made aware of how their own religious and spiritual experiences could influence their identity and world view, as well as how their attitudes toward such experiences might introduce biases into clinical assessment and treatment. Finally, psychiatrists were reminded to show respect for patients with different religious and spiritual backgrounds. Psychiatrists used a semi-structured interview guided by the following topics: religious and spiritual history, effects of illness on spirituality or religiousness, current spiritual or religious beliefs and practices, subjective importance of religion in general, subjective importance of religion in coping with the illness, synergy of religion with psychiatric care. After each assessment the psychiatrist met with 2 of the authors, a psychiatrist and a psychologist of religion. In these sessions the individual patient was discussed for 10 to 40 minutes, depending on the clinical context. The participating psychiatrist reported the outcome of his or her spiritual assessment and was given guidance and advice, similar to clinical coaching; when needed, a more thorough discussion from a psychotherapeutic perspective was undertaken

Control: USUAL CARE

"For the control group, psychiatrists were instructed to avoid speaking about religious issues during the three-month follow-up period unless patients spontaneously brought up the subject." (pg 81)

Outcomes

The measures of adherence were Medication Adherence Rating Scale. It was administered at baseline and at the 3-month assessment 
The patient outcomes were psychosocial adaptation measured with Global Assessment Function, Social Functioning Questionnaire and World Health Organization Quality of Life Instrument; satisfaction with care measured with Client Satisfaction Questionnaire and Working Alliance Inventory; change in symptoms as measured with Positive Negative Scale and Recovery Assessment Scale. All measurements were carried out at baseline and at completion of the 3-month intervention by trained and blinded psychologists

Notes -

\section{Risk of bias}

\begin{tabular}{lll}
\hline Bias & Authors' judgement & Support for judgement \\
\hline $\begin{array}{l}\text { Random sequence genera- } \\
\text { tion (selection bias) }\end{array}$ & Unclear risk & $\begin{array}{l}\text { The authors state that they assigned the patients a random number but it is } \\
\text { not clear how they came up with these random numbers (e.g. coin tossing, } \\
\text { random number etc?). "To ensure random selection, all eligible patients of } \\
\text { each psychiatrist were assigned a random number and then listed in numeri- } \\
\text { cal order. Up to } 14 \text { patients per clinician were selected. The first seven patients } \\
\text { on the numerical list were assigned to the intervention group, which receive } \\
\text { standard treatment plus a spiritual assessment by their psychiatrist. The last } \\
\text { seven patients on the list were assigned to the control group, which received } \\
\text { only standard treatment." (pg 80) }\end{array}$ \\
\hline
\end{tabular}

\begin{tabular}{|c|c|c|}
\hline $\begin{array}{l}\text { Allocation concealment } \\
\text { (selection bias) }\end{array}$ & High risk & $\begin{array}{l}\text { Their method of allocating patients to treatment groups is not concealed: "To } \\
\text { ensure random selection, all eligible patients of each psychiatrist were as- } \\
\text { signed a random number and then listed in numerical order. Up to } 14 \text { patients } \\
\text { per clinician were selected. The first seven patients on the numerical list were } \\
\text { assigned to the intervention group, which receive standard treatment plus a } \\
\text { spiritual assessment by their psychiatrist. The last seven patients on the list } \\
\text { were assigned to the control group, which received only standard treatmen- } \\
\text { t." (pg } 80 \text { ) }\end{array}$ \\
\hline
\end{tabular}

Selective reporting (re- Unclear risk $\quad$ Protocol not available
porting bias)

Other bias Unclear risk Several limitations have been listed by the authors but how they might have influenced the result is unknown. (pg 84) "The study had some limitations. First, cultural context is likely to have influenced the results, and the study should be replicated in other areas. Only patients in the intervention group received additional attention from the psychiatrists, who explored and discussed patients' personal beliefs, which may have introduced significant bias. The additional time invested by the psychiatrists could have made a difference, an effect having little to do with the focus on spiritual issues. Furthermore, psychiatrists received supervision only for patients in the intervention group, and supervision itself could have altered patients' outcomes. Patients signed an informed consent form to participate in the study and then were randomly assigned to the intervention or control group. The latter patients might have been disappointed at not having received a spiritual assessment, which may have altered their evaluations. Other limitations were noted above: the short training session and the lack of commitment among some clinicians."

\begin{tabular}{|c|c|c|}
\hline $\begin{array}{l}\text { Blinding of outcome as- } \\
\text { sessment (detection bias) } \\
\text { Adherence measure }\end{array}$ & Unclear risk & $\begin{array}{l}\text { (PRIMARY) MEDICATION ADHERENCE RATING SCALE - It is not clear who admin- } \\
\text { istered and collected the questionnaire data }\end{array}$ \\
\hline $\begin{array}{l}\text { Blinding of outcome as- } \\
\text { sessment (detection bias) } \\
\text { Patient outcome }\end{array}$ & Low risk & $\begin{array}{l}\text { (PRIMARY) CLIENT SATISFACTION QUESTIONNAIRE - (pg 81) "Assessment was } \\
\text { performed by trained psychologists blind to the patient's group assignment." }\end{array}$ \\
\hline
\end{tabular}


Huguelet 2011 (Continued)

Blinding of participants (performance bias)

Adherence measure
High risk

(PRIMARY) MEDICATION ADHERENCE RATING SCALE - This is a subjective measure of adherence. The following quote suggests that the patients probably knew their group assignment: "Patients signed an informed consent form to participate in the study and then were randomly assigned to the intervention or control group. The latter patients might have been disappointed at not having received a spiritual assessment, which may have altered their evaluations."

\section{Blinding of participants High risk} (performance bias)

Patient outcome
(PRIMARY) CLIENT SATISFACTION QUESTIONNAIRE - The questionnaires were a subjective measure, answered by the patients. The following quote suggests that the patients probably knew their group assignment: "Patients signed an informed consent form to participate in the study and then were randomly assigned to the intervention or control group. The latter patients might have been disappointed at not having received a spiritual assessment, which may have altered their evaluations."

(PRIMARY) MEDICATION ADHERENCE RATING SCALE - No information is provided about the blinding of key personnel
Blinding of personnel (per- Unclear risk formance bias) Adherence measure
(PRIMARY) CLIENT SATISFACTION QUESTIONNAIRE - Insufficient information for judgment

Blinding of personnel (per- Unclear risk formance bias)

Patient outcome

(PRIMARY) MEDICATION ADHERENCE RATING SCALE - Missing data not balanced across the groups. Reason for missing is not given
Incomplete outcome data High risk (attrition bias)

Adherence measure
Incomplete outcome data High risk (attrition bias)

Patient outcome
(PRIMARY) CLIENT SATISFACTION QUESTIONNAIRE - Missing data not balanced across the groups. Reason for missing data is not given

\begin{tabular}{ll}
\hline Methods & Randomized controlled trial \\
\hline Participants & The study location was San Francisco, California, USA \\
& 45 participants were randomized to the intervention group and 39 participants were randomized to the \\
& control group \\
& The inclusion criteria were non-smokers (5 or fewer pack-years of smoking history) who were aged 18 \\
& to 55 years with moderate-to-severe asthma (i.e. FEV1 < $80 \%$ of predicted value, daily symptoms, and \\
& 1 night-time awakening per week), and had spirometric evidence of reversible airflow obstruction or \\
bronchial reactivity to inhaled methacholine & \\
& The exclusion criteria were: had received systemic steroids within 4 weeks of study enrollment, an up- \\
per respiratory tract infection within 6 weeks of enrollment, pregnancy, cardiac, gastrointestinal, or \\
psychiatric disease, or other lung disease, previous participation in a formal asthma education pro- \\
gram, mild or intermittent asthma, smoker, or non-reversible airflow obstruction
\end{tabular}
trol group plus an individualized self management component. Self management sessions were held by a certified asthma educator and respiratory therapist. The sessions consisted of asthma facts and medication actions and individualized components such as verbal and graphic interpretation of spirometric results, peak flow trends, metered dose inhaler technique error, and skin allergen results (with 
Janson 2009 (Continued)

strategies to control specific personal environmental exposures). The peak flow monitor was modified for the intervention group to use a traffic light analogy and correlated to a simple written action plan

Control: SELF MONITORING ALONE

Control patients attended the same number of visits as intervention patients, but control visits were only for data collection. During each phase of the trial, all participants measured morning peak flow with an electronic peak flowmeter (Airwatch; iMetrikus, Carlsbad, Calif) and also recorded their daily values in a diary. All participants were told that higher peak flow numbers meant their airways were more open and lower numbers meant their airways were more closed. An electronic medication monitor, which concealed readings from the subject (Doser CT; MediTrack, Hudson, Mass), was placed on each ICS inhaler. Participants also monitored daily symptoms, night-time awakenings, and tabulated ICS and inhaled b-agonist (IBA) use in the diary. Data from the electronic monitors and diary pages were collected at each study visit

Outcomes

The measures of adherence were an electronic medication monitor on each ICS inhaler. Data from the electronic monitors were collected at each study visit. ICS adherence was calculated as the percentage of prescribed doses taken each week as measured by the electronic device validated for monitoring metered dose inhaler use. The numerator was capped at the prescribed doses per day to avoid overestimation of adherence to greater than $100 \%$ per day

The patient outcomes were pulmonary function assessed by spirometry before bronchodilator use and after withholding short-acting b-agonists for 6 or more hours and long-acting beta-agonists for 24 or more hours. FEV1 per cent predicted was used as a proxy variable for overall lung function; induced sputum samples were collected at the end of the run-in phase, the end of the intervention, and the end of the study to assess the degree of airway inflammation. Inflammation markers were eosinophils, neutrophils, eosinophil cationic protein (ECP), and tryptase; quality of life and perceived asthma control were assessed by using validated and self completed questionnaires; morning peak flow (measured by using the electronic peak flowmeter by participant), asthma symptoms (rated daily by participants on validated 10-point numeric rating scales), symptom-free days, night-time awakenings, and inhaled beta-agonist use were all recorded daily in participant diary and summed weekly for analysis

Notes -

\section{Risk of bias}

\section{Bias \\ Authors' judgement Support for judgement}

Random sequence genera- Low risk tion (selection bias)

(pg 841) Participants were randomized using a computer-generated method

\begin{tabular}{|c|c|c|}
\hline $\begin{array}{l}\text { Allocation concealment } \\
\text { (selection bias) }\end{array}$ & Unclear risk & $\begin{array}{l}\text { Allocation concealment not mentioned. At the end of the run-in phase, partici- } \\
\text { pants (n584) were randomized using a computer-generated method to individ- } \\
\text { ualized asthma self management education with self monitoring of symptoms, } \\
\text { peak flow, and night-time awakenings (intervention group) or self monitoring } \\
\text { alone (control group) }\end{array}$ \\
\hline
\end{tabular}

Selective reporting (re- High risk
porting bias)
porting bias)

Self report data on adherence were collected but not reported. (pg 842) Electronic and diary adherence and peak flow data were compared to look for concurrence, but only the electronic data for both were used in the analysis

Other bias Unclear risk

The authors note the following: (pg 845) data dumping just before a research visit; loss of data with failed or lost inhalers - self reporting for some outcomes (loss of diary, incomplete entries, errors in entries, not completed)

Blinding of outcome as- Low risk sessment (detection bias)

Adherence measure

(PRIMARY) ELECTRONIC MEDICATION MONITOR - (pg 841) Except for the study co-ordinator, who had no role in data management or assessment, the investigators were blinded to group assignment 
Janson 2009 (Continued)

Blinding of outcome as- Low risk (PRIMARY) SYMPTOM CONTROL - Except for the study co-ordinator, who had sessment (detection bias) no role in data management or assessment, the investigators were blinded to Patient outcome group assignment

$\begin{array}{ll}\begin{array}{l}\text { Blinding of participants } \\ \text { (performance bias) }\end{array} & \text { (PRIMARY) ELECTRONIC MEDICATION MONITOR - Author's comment: patients } \\ \text { Adherence measure } & \text { were aware of the monitor but could not see any data or counts. So even if } \\ & \text { they knew it was being monitored over the course of } 6 \text { months they had no } \\ & \text { feedback. Risk of bias is very low }\end{array}$

Blinding of participants Low risk (performance bias)

Patient outcome
(PRIMARY) SYMPTOM CONTROL - Author's note: I believe there is a low risk of bias as all subjects in both groups followed the same protocol. Complete blinding was not possible due to the nature of the intervention. However, both groups were told the same information about the study verbally and in the consent form. All subjects were told we were studying 2 kinds of monitoring for asthma management. Subjects in the control group had no contact or knowledge of the intervention group

$\begin{array}{ll}\begin{array}{l}\text { Blinding of personnel (per- } \\ \text { formance bias) }\end{array} & \text { Low risk } \\ \text { Adherence measure } & \begin{array}{l}\text { (PRIMARY) ELECTRONIC MEDICATION MONITOR - (pg 841) Except for the study } \\ \text { gators were blinded to group assignment }\end{array}\end{array}$

(PRIMARY) SYMPTOM CONTROL - Except for the study co-ordinator, who had no role in data management or assessment, the investigators were blinded to group assignment

\section{Blinding of personnel (per- Low risk}

formance bias)

Patient outcome

Incomplete outcome data Low risk

(attrition bias)

Adherence measure
(PRIMARY) ELECTRONIC MEDICATION MONITOR - Author's note: 3 subjects from each group had some days of incomplete adherence data due to either lost or failed medication monitors. For these subjects we used all data available

Incomplete outcome data Unclear risk
(attrition bias)

Patient outcome

(PRIMARY) SYMPTOM CONTROL - Not enough information to judge. (pg 841) "We enrolled 95 subjects and randomized 84 subjects. Intention-to-treat analyses included all participants randomized, 78 with completed data and 6 with incomplete data."

\section{Jarab 2012 a}

\begin{tabular}{ll}
\hline Methods & Randomized controlled trial \\
\hline Participants & $\begin{array}{l}\text { The study location was an outpatient diabetes clinic at Royal Medical Services Hospital, Amman, Jor- } \\
\text { dan }\end{array}$
\end{tabular}

85 participants were randomized to the intervention group and 86 participants were randomized to the control group

The inclusion criteria were 18 years of age or older, treated at RMS Hospital and diagnosed with type 2 diabetes at least 1 year previously, took at least 1 prescribed medication for diabetes, and had an A1c level exceeding $7.5 \%$

The exclusion criteria were diagnosed with convulsive disorder, diabetic proliferative retinopathy, or diabetic neuropathy as reported in their medical files

Interventions

Intervention: PHARMACIST INTERVENTION

Patients in the pharmacist intervention group received structured patient education and discussion about type 2 diabetes, risks and complications from diabetes, the prescribed drug therapy, proper dosage, side effects, and the importance of medication adherence. The pharmacist also emphasized lifestyle management (changing unhealthy dietary habits that affect blood glucose, blood pressure 
Jarab 2012 a (Continued)

and lipid levels; regular physical activity; and monitoring and record blood glucose levels). Smokers were referred to a hospital-run smoking cessation program. A special booklet on diabetes and lifestyle changes was given to each patient. 8 weekly telephone calls were made by the pharmacist to discuss and review prescribed therapy, emphasize the importance of adherence, and to answer patient questions or address concerns. Each call average 20 minutes

Control: USUAL CARE

Control patients $(n=85)$ received usual care by medical and nursing staff (patient assessment; 3- or 6month blood glucose and blood pressure measurements; advice on self monitoring blood glucose, and nutrition counseling)

Outcomes

The measures of adherence were self reported, as measured by Morisky Scale. This simple, validated 4question survey assessed the likelihood that patients take their medications as prescribed. To score the questionnaire, each "yes" response is given a score of 1 , and each "no" response is given a score of 0 (range 0 to 4). According to the Morisky classification, adherence is divided into 3 groups: high for those scoring 0 , medium for those scoring 1 or 2 , and low for those scoring 3 or 4 , when scoring one point for each "yes" answer. For the purpose of the present analysis, the patients were divided into 2 groups: those scoring 0 were considered adherent, and those scoring 1 to 4 were deemed non-adherent

The patient outcome was A1c and the secondary outcomes were systolic and diastolic blood pressure, lipid values, and BMI as measured by the patient's physician at 6-month follow-up

Notes -

\section{Risk of bias}

\begin{tabular}{lll}
\hline Bias & Authors' judgement & Support for judgement \\
\hline $\begin{array}{ll}\text { Random sequence genera- } \\
\text { tion (selection bias) }\end{array}$ & Low risk & "Patients were randomly assigned to intervention and control groups via \\
& & $\begin{array}{l}\text { a minimization technique using Minim software (available for free down- } \\
\text { load)." (pg 518) This software helps to minimize imbalances between interven- } \\
\text { tion and control groups }\end{array}$ \\
\hline
\end{tabular}

\begin{tabular}{|c|c|c|}
\hline $\begin{array}{l}\text { Allocation concealment } \\
\text { (selection bias) }\end{array}$ & Unclear risk & $\begin{array}{l}\text { Allocation concealment not described. "Study participants were randomly as- } \\
\text { signed to intervention and control groups via a minimization technique using } \\
\text { Minim software (available for free download). The patients were recruited over } \\
\text { a period of } 4 \text { months from January through April } 2011 \text {, and the last follow-up } \\
\text { was performed on October } 27,2011 \text {. The study received approval from the In- } \\
\text { stitutional Review Board, King Hussein Hospital, Royal Medical Services, Jor- } \\
\text { dan." (pg 518) }\end{array}$ \\
\hline
\end{tabular}

Selective reporting (re- Unclear risk
porting bias)

No protocol and study objective (pg 518) is vague regarding what outcomes porting bias) were sought: "The objective of the present study was to evaluate the impact of a clinical pharmacist-led pharmaceutical care program on different clinical outcomes and self management behavior in outpatients with type 2 diabetes in Jordan."

\begin{tabular}{ll}
\hline Other bias & Limitations noted by the authors: First, this study used a patient-reported \\
& measure of medical adherence, and the results may be affected by social de- \\
& sirability and recall bias. Second, although the study outcomes were statisti- \\
cally more favorable in the intervention group compared with usual care, the & study was underpowered because the trial enrolled a small number of patients \\
due to limited availability of a single investigator
\end{tabular}

\begin{tabular}{lll}
\hline $\begin{array}{l}\text { Blinding of outcome as- } \\
\text { sessment (detection bias) }\end{array}$ & Unclear risk & $\begin{array}{l}\text { (PRIMARY) SELF REPORT - QUESTIONNAIRE - Insufficient information about } \\
\text { blinding of data collectors to permit judgment of 'Low risk' or 'High risk' of } \\
\text { bias }\end{array}$ \\
\hline $\begin{array}{l}\text { Blinding of outcome as- } \\
\text { sessment (detection bias) }\end{array}$ & Unclear risk & (PRIMARY) A1C - Blinding not mentioned \\
\hline
\end{tabular}


Jarab 2012 a (Continued)

Patient outcome

\begin{tabular}{|c|c|c|}
\hline $\begin{array}{l}\text { Blinding of participants } \\
\text { (performance bias) }\end{array}$ & Unclear risk & $\begin{array}{l}\text { (PRIMARY) SELF REPORT - QUESTIONNAIRE - Insufficient information about } \\
\text { blinding of participants to permit judgment of 'Low risk' or 'High risk' of bia }\end{array}$ \\
\hline
\end{tabular}

Adherence measure

$\begin{aligned} & \text { Blinding of participants } \\ & \text { (performance bias) }\end{aligned} \quad$ Unclear risk (PRIMARY) A1C - Blinding not mentioned
Patient

Patient outcome

Blinding of personnel (per- Unclear risk

formance bias)

(PRIMARY) SELF REPORT - QUESTIONNAIRE - Insufficient information about

Adherence measure blinding of key personnel to permit judgment of 'Low risk' or 'High risk' of bias

Blinding of personnel (per- Unclear risk

(PRIMARY) A1C - Blinding not mentioned

formance bias)

Patient outcome

$\begin{array}{ll}\begin{array}{l}\text { Incomplete outcome data } \\ \text { (attrition bias) }\end{array} & \text { Low risk } \\ \begin{array}{ll}\text { Adherence measure } & \text { in numbers across intervention groups, with similar reasons for missing data } \\ \text { across groups }\end{array}\end{array}$

Incomplete outcome data Low risk

(attrition bias)

(PRIMARY) A1C - Missing outcome data balanced in numbers across interven-

Patient outcome tion groups, with similar reasons for missing data across groups

Jarab 2012 b

\begin{tabular}{ll}
\hline Methods & Randomized controlled trial \\
\hline Participants & The study location was an outpatient COPD clinic at the Royal Medical Services, Jordan \\
& 66 participants were randomized to the intervention group and 67 participants were randomized to the \\
control group & \\
& The inclusion criteria were patients attend only the outpatient COPD clinic at the Royal Medical Ser- \\
vices, confirmed diagnosis of COPD by the hospital consultant for at least 1 year, over 35 years old, hav- & ing forced expiratory volume in 1 second (FEV1) of $30 \%$ to $80 \%$ of the predicted normal value and hos- \\
pital consultant agreement that the patient is suitable for entering the trial & \\
& The exclusion criteria were moderate to severe learning difficulties, mobility problems, confusion, dis- \\
orientation or terminal illness, congestive heart failure or if they attended a pulmonary rehabilitation \\
program or had consulted a pulmonary nurse or clinical pharmacist in the last 6 months
\end{tabular}

Interventions

\begin{abstract}
Intervention: PHARMACIST INTERVENTION
Intervention participants received structured education about chronic obstructive pulmonary disease (COPD) and management of its symptoms from a clinical pharmacist in a separate room at the outpatient clinic. The pharmacist also completed a medication table designed specifically to discuss types, indications, doses, frequency of administration, and possible side effects for each prescribed medication. The importance of simple exercises symptoms control and the technique for expectoration were discussed with the intervention patients. A booklet on these techniques was prepared to assist in the education session and the patients were given a copy to take home with them. The clinical pharmacist used the motivational interviewing technique with the aim of improving adherence to the prescribed treatment. Patients who still smoked were referred to a special smoking cessation program within the hospital
\end{abstract}

Control: TREATMENT AS USUAL 
Jarab 2012 b (Continued)

Controls did not receive pharmacists care

Outcomes The measures of adherence were the Morisky scale. The measure was administered at baseline and at 6 months by the researcher. This simple 4-question survey assesses the likelihood that patients take their medications as prescribed. On scoring of the questionnaire, each 'yes' response is given a score of 1 and each 'no' response is given a score of 0 . Adherence scores can therefore range between 0 and 4 . For the purpose of the present analysis, the patients were divided into 2 groups: those scoring 0 were considered adherent and those scoring 1 to 4 were considered non-adherent

The patient outcomes were health-related quality of life (St George's Respiratory Questionnaire), and healthcare utilization. Arabic version of the questionnaires were administered at baseline and 6 months by the researcher

Notes

Insufficient information about how long or how many sessions pharmacist care was given to intervention participants. Not enough information about the controls. The FEV1 and BMI data are reported as outcomes but it is not clear where these data were collected

\title{
Risk of bias
}

Bias Authors' judgement Support for judgement

\begin{tabular}{lll}
\hline $\begin{array}{l}\text { Random sequence genera- } \\
\text { tion (selection bias) }\end{array}$ & Low risk & $\begin{array}{l}\text { Minimization. (pg 55) "Study participants were randomly assigned to interven- } \\
\text { tion and control groups via a minimisation technique using MINIM software" }\end{array}$
\end{tabular}

Allocation concealment Unclear risk

(selection bias)

Insufficient information to permit judgment of 'Low risk' or 'High risk' of bias. "The patients were asked to sign a consent form if they were willing to participate in the study. Study participants were randomly assigned to intervention and control groups via a minimisation technique using MINIM software." (pg 55)

Selective reporting (re- Unclear risk None detected but protocol unavailable
porting bias)

Other bias Unclear risk

\begin{abstract}
The authors noted the following: (pg 60) "The study was limited in that the length of time required to complete the battery of questionnaires used in the present study may have encouraged bias in the responses gained from the participants, as in an effort to finish quickly, participants may have selected answers without giving due consideration to the questions posed. Furthermore, social desirability and recall bias associated with the use of a selfreport method to assess medications adherence could have affected the results. Another limitation was that the target sample size was not attained because the capacity for inclusion was limited in this trial with a single investigator. However, increasing the sample size therefore may allow more robust conclusions to be drawn about the findings."
\end{abstract}

\begin{tabular}{|c|c|c|}
\hline $\begin{array}{l}\text { Blinding of outcome as- } \\
\text { sessment (detection bias) } \\
\text { Adherence measure }\end{array}$ & Unclear risk & $\begin{array}{l}\text { (PRIMARY) SELF REPORT - QUESTIONNAIRE - Insufficient information about } \\
\text { the blinding of data collectors to permit judgment of 'Low risk' or 'High risk' of } \\
\text { bias }\end{array}$ \\
\hline $\begin{array}{l}\text { Blinding of outcome as- } \\
\text { sessment (detection bias) } \\
\text { Patient outcome }\end{array}$ & Unclear risk & $\begin{array}{l}\text { (PRIMARY) HEALTH-RELATED QUALITY OF LIFE (SGRQ) - This is a subjective out- } \\
\text { come. Insufficient information about the blinding of the data collectors to per- } \\
\text { mit judgment of 'Low risk' or 'High risk' of bias }\end{array}$ \\
\hline
\end{tabular}

Blinding of participants High risk

(performance bias)

(PRIMARY) SELF REPORT - QUESTIONNAIRE - Patients likely to be aware of intervention, due to its nature. The authors also note that one of the limitations of study was social desirability as a possible bias signaling that patients may not have been blinded or blinding could have been broken 
Jarab 2012 b (Continued)

Blinding of participants High risk (PRIMARY) HEALTH-RELATED QUALITY OF LIFE (SGRQ) - Patients likely to be (performance bias) aware of intervention, due to its nature. The limitations also notes social desirPatient outcome ability as a possible bias signaling that patients may not have been blinded or blinding could have been broken

Blinding of personnel (per- Unclear risk formance bias)

(PRIMARY) SELF REPORT - QUESTIONNAIRE - Insufficient information about Adherence measure the blinding of key personnel to permit judgment of 'Low risk' or 'High risk' of bias

Blinding of personnel (per- Unclear risk formance bias) (PRIMARY) HEALTH-RELATED QUALITY OF LIFE (SGRQ) - This is a subjective outPatient outcome come. Insufficient information about the blinding of the key personnel to permit judgment of 'Low risk' or 'High risk' of bias

Incomplete outcome data Low risk

(PRIMARY) SELF REPORT - QUESTIONNAIRE - Missing data are balanced

(attrition bias)

Adherence measure

Incomplete outcome data Low risk (attrition bias)

Patient outcome

(PRIMARY) HEALTH-RELATED QUALITY OF LIFE (SGRQ) - Missing data are balanced

Jiang 2007

Methods $\quad$ Randomized controlled trial

Participants

The study location was Chengdu, Sichuan Province, China

83 participants were randomized to the intervention group and 84 participants were randomized to the control group

The inclusion criteria were first hospitalization with either angina pectoris or myocardial infarction, willing to participate in this study, able to speak, read and write Chinese, living at home with family after hospital discharge, living in Chengdu and available for telephone follow-up, with fasting blood sample taken for lipid test within 24 hours of hospitalization

The exclusion criteria were planning for surgical treatment, pre-existing mobility problems, hypothyroidism or nephrotic syndrome, diagnosed psychosis or currently undergoing antipsychosis treatment or with terminal illness

Interventions

Intervention: CARDIAC REHABILITATION PROGRAM

Patients in the intervention group received a 12 -week, hospital-initiated, home-based, multifaceted cardiac rehabilitation intervention led by a nurse. Phase I of the intervention involved in-hospital individual and family education about CHD and self management principles, medication management, angina prevention and management, physical exercise, dietary management, smoking cessation, and family support. All sessions employed principles of adult learning and were short to facilitate time for discussion. All participants received a self help practical workbook. In Phase II of the intervention provided home-based supervision, coaching and support by a experienced cardiac nurse over 12 weeks using home visits and telephone calls that included goal setting, practice, monitoring, problem solving and reinforcement, with iteration of this process to ensure the achievement of mutually set behavioral goals on a daily basis and used a log record for goal-directed self reporting, self monitoring and self reinforcement of daily rehabilitative behaviors and mobilization of the family to join the behavioral change and provide appropriate support

Control: ROUTINE CARE

Control patients received conventional care and were not offered any additional interventions 
Jiang 2007 (Continued)

Outcomes
The measures of adherence were self reported drug compliance scale was selected to assess the patients' level of medication adherence. The measure is a 5-point Likert scale ranging from 1 (totally drug refusal) to 5 (about 100\% drug compliance). The assessment span was 1 week

The patient outcomes were body weight examined using a balance scale, with patients in light clothing, shoes removed, and after urination. Arterial BP on the right arm in a sitting position was measured by the auscultatory method. Lipid testing was carried out in the Blood Biochemistry Laboratory of the 2 hospitals. All plasma samples were taken before 9 am. Subjects were instructed to take nothing orally except water and medication for 12 hours before the test. Measurements were made by a trained research assistant at baseline, 3 , and 6 months

\begin{tabular}{ll}
\hline Notes & - \\
\hline Risk of bias &
\end{tabular}

\begin{tabular}{|c|c|c|}
\hline Bias & Authors' judgement & Support for judgement \\
\hline $\begin{array}{l}\text { Random sequence genera- } \\
\text { tion (selection bias) }\end{array}$ & Low risk & $\begin{array}{l}\text { (pg 2) The research design used in this study is a 2-group randomized interven- } \\
\text { tion design, involving randomized assignment of subjects into an intervention } \\
\text { group and a control group according to a computer-generalized random table }\end{array}$ \\
\hline $\begin{array}{l}\text { Allocation concealment } \\
\text { (selection bias) }\end{array}$ & Unclear risk & $\begin{array}{l}\text { Allocation concealment not described. Insufficient information to permit judg- } \\
\text { ment of 'Low risk' or 'High risk' }\end{array}$ \\
\hline $\begin{array}{l}\text { Selective reporting (re- } \\
\text { porting bias) }\end{array}$ & Unclear risk & None detected but protocol not available \\
\hline Other bias & Unclear risk & $\begin{array}{l}\text { They do not report the details of standard/routine care, so we are unsure of } \\
\text { how different the intervention is from what the control group received. They } \\
\text { also do not report the intensity (frequency and duration) of each contact by } \\
\text { the study registered nurse (RN) with the patient }\end{array}$ \\
\hline $\begin{array}{l}\text { Blinding of outcome as- } \\
\text { sessment (detection bias) } \\
\text { Adherence measure }\end{array}$ & Low risk & $\begin{array}{l}\text { (PRIMARY) SELF REPORT - QUESTIONNAIRE - (pg 1888) "Before proceeding to } \\
\text { data collection in the pilot study, two research assistants underwent the fol- } \\
\text { lowing training...They were blinded to patient group assignment. One was re- } \\
\text { sponsible for the face-to-face interview according to the questionnaire. The } \\
\text { other was responsible for conducting the health assessment for body weight } \\
\text { and BP and for taking blood samples for lipid testing." }\end{array}$ \\
\hline
\end{tabular}

$\begin{array}{lll}\text { Blinding of outcome as- Low risk (PRIMARY) SERUM LIPIDS - Objective measure } & \text { L }\end{array}$

sessment (detection bias)

Patient outcome

\begin{tabular}{|c|c|c|}
\hline $\begin{array}{l}\text { Blinding of participants } \\
\text { (performance bias) } \\
\text { Adherence measure }\end{array}$ & High risk & $\begin{array}{l}\text { (PRIMARY) SELF REPORT - QUESTIONNAIRE - Pa } \\
\text { which group they are assigned. Subjective mea }\end{array}$ \\
\hline $\begin{array}{l}\text { Blinding of participants } \\
\text { (performance bias) } \\
\text { Patient outcome }\end{array}$ & Low risk & (PRIMARY) SERUM LIPIDS - Objective measure \\
\hline
\end{tabular}

\begin{tabular}{|c|c|c|}
\hline $\begin{array}{l}\text { Blinding of personnel (per- } \\
\text { formance bias) } \\
\text { Adherence measure }\end{array}$ & Unclear risk & $\begin{array}{l}\text { (PRIMARY) SELF REPORT - QUESTIONNAIRE - Insufficient information to permit } \\
\text { judgment of 'Low risk' or 'High risk' }\end{array}$ \\
\hline
\end{tabular}

Blinding of personnel (per- Low risk (PRIMARY) SERUM LIPIDS - Objective measure


Jiang 2007 (Continued)

Incomplete outcome data Unclear risk (attrition bias)

Adherence measure
(PRIMARY) SELF REPORT - QUESTIONNAIRE - During the course of this study, 4 subjects in the intervention group and 12 subjects in the control group dropped out at 3 months; 10 ( 5 in the intervention group and 5 in the control group) dropped out at 6 months. A total of 151 and 141 patients completed the study at 3 and 6 months, respectively. This means of 167 participants, 83 in intervention, 75 completed data at 6 months, while of 84 in control group, 67 completed data at 6 months. They never suggest how this was accounted for in analysis. Randomized 167 participants

(PRIMARY) SERUM LIPIDS - 9 lost in the intervention groups and 17 in control; thus an imbalance in dropouts; but unclear in terms of bias

(attrition bias)

Unclear risk

Patient outcome

\section{Johnson 1978}

\begin{tabular}{ll}
\hline Methods & Random allocation in a $2 \times 2$ factorial design. No statement concerning concealment of randomization \\
\hline Participants & $\begin{array}{l}\text { Volunteers from shopping center blood pressure screening in Canada, with follow-up by usual family } \\
\text { doctors. Men and women aged } 35 \text { to } 65 \text { who had been receiving antihypertensive medications for at } \\
\text { least } 1 \text { year, but whose diastolic blood pressure had remained elevated }\end{array}$
\end{tabular}

Interventions

The interventions consisted of (1) self recording and monthly home visits, (2) self recording only, (3) monthly home visits, and the control group consisted of (4) neither self recording nor home visits. Subjects in groups (1) and (2) received a blood pressure kit and instruction in self recording. Patients in the self recording groups were to keep charts of their daily blood pressure readings and were instructed to bring these charts to their physician at each appointment. Subjects in groups (1) and (3) had their blood pressure measured in their homes every 4 weeks, and the results were reported to both the patient and the physician

Outcomes Adherence with therapy was assessed by interview and pill counts (the percentage of prescribed pills that had been consumed was estimated by comparing pills on hand at a home visit with prescription records of pills dispensed and the regimen prescribed). Changes in mean diastolic blood pressure $(\mathrm{mm} \mathrm{Hg})$ were assessed. Since the initial blood pressure bears an important relation to the change in blood pressure over time, the change scores were adjusted for differences in entry values by covariance analysis. Outcome assessors were blinded to study group

\section{Notes}

\section{Risk of bias}

\begin{tabular}{lll}
\hline Bias & Authors' judgement & Support for judgement \\
\hline $\begin{array}{l}\text { Random sequence genera- } \\
\text { tion (selection bias) }\end{array}$ & Unclear risk & $\begin{array}{l}\text { Not enough information given in the article. (pg 1035) Once their informed } \\
\text { consent was obtained the subjects were stratified for age (less than } 45 \text { years } \\
\text { old and 45 or older) and sex, then assigned at random to one of } 4 \text { groups in a 2 } \\
\text { x 2 factorial design: (1) self recording and monthly home visits; (2) self record- } \\
\text { ing only; (3) monthly home visits; and (4) neither self recording nor monthly } \\
\text { home visits }\end{array}$ \\
\hline $\begin{array}{l}\text { Allocation concealment } \\
\text { (selection bias) }\end{array}$ & Unclear risk & $\begin{array}{l}\text { Not enough information given in the article. (pg 1035) Once their informed } \\
\text { consent was obtained the subjects were stratified for age (less than 45 years } \\
\text { old and 45 or older) and sex, then assigned at random to one of 4 groups in a 2 } \\
\text { x 2 factorial design: (1) self recording and monthly home visits; (2) self record- } \\
\text { ing only; (3) monthly home visits; and (4) neither self recording nor monthly } \\
\text { home visits }\end{array}$ \\
&
\end{tabular}


Johnson 1978 (Continued)

Selective reporting (re- Unclear risk No protocol available porting bias)

\begin{tabular}{lll}
\hline Other bias & Unclear risk & None noted but unclear \\
\hline $\begin{array}{l}\text { Blinding of outcome as- } \\
\text { sessment (detection bias) }\end{array}$ & Unclear risk & $\begin{array}{l}\text { (PRIMARY) SELF REPORT - INTERVIEW - Adherence data were collected at } \\
\text { sdherence measure }\end{array}$ \\
& $\begin{array}{l}\text { months later all subjects were visited twice within } 1 \text { to } 3 \text { days by the visitor } \\
\text { who had previously seen them. Standardized blood pressure measurements } \\
\text { were made and compliance with therapy was assessed by interview and pill } \\
\text { count (the percentage of prescribed pills that had been consumed was esti- } \\
\text { mated by comparing pills on hand with prescription records of pills dispensed } \\
\text { and the regimen prescribed)." }\end{array}$ \\
\hline
\end{tabular}

\begin{tabular}{|c|c|c|}
\hline $\begin{array}{l}\text { Blinding of outcome as- } \\
\text { sessment (detection bias) }\end{array}$ & Unclear risk & (PRIMARY) BLOOD PRESSURE - No mention of blinding \\
\hline
\end{tabular}

\begin{tabular}{|c|c|c|}
\hline $\begin{array}{l}\text { Blinding of participants } \\
\text { (performance bias) } \\
\text { Adherence measure }\end{array}$ & High risk & $\begin{array}{l}\text { (PRIMARY) SELF REPORT - INTERVIEW - Participants would have been aware o } \\
\text { their group membership }\end{array}$ \\
\hline $\begin{array}{l}\text { Blinding of participants } \\
\text { (performance bias) } \\
\text { Patient outcome }\end{array}$ & Low risk & $\begin{array}{l}\text { (PRIMARY) BLOOD PRESSURE - Blood pressure unlikely to be influenced by pa } \\
\text { tient blinding }\end{array}$ \\
\hline $\begin{array}{l}\text { Blinding of personnel (per- } \\
\text { formance bias) } \\
\text { Adherence measure }\end{array}$ & Unclear risk & $\begin{array}{l}\text { (PRIMARY) SELF REPORT - INTERVIEW - Blinding measures not described ex- } \\
\text { cept for the independent investigator measuring BP. Other personnel may be } \\
\text { unblinded }\end{array}$ \\
\hline
\end{tabular}

Blinding of personnel (per- Unclear risk
formance bias)

Patient outcome

\begin{tabular}{ll}
\hline $\begin{array}{l}\text { Incomplete outcome data } \\
\text { (attrition bias) }\end{array}$ & Low risk \\
Adherence measure & (PRIMARY) SELF REPORT - INTERVIEW - Small rate of attrition - 4/140. Reasons \\
\end{tabular}

Adherence measure

$\begin{array}{ll}\begin{array}{l}\text { Incomplete outcome data } \\ \text { (attrition bias) }\end{array} & \text { (PRIMARY) BLOOD PRESSURE - Small rate of attrition - 4/140. Reasons for the } \\ \text { Patient outcome } & \text { missing data unlikely to be connected with outcome }\end{array}$

Patient outcome

\begin{tabular}{ll}
\hline Johnson 2011 & Randomized controlled trial \\
\hline Participants & The study location was San Francisco, CA, USA \\
& 128 participants were randomized to the intervention group and 121 participants were randomized to \\
the control group & \\
& $\begin{array}{l}\text { The inclusion criteria were at least 18 years of age, provide written informed consent, be taking a rec- } \\
\text { ognized ART regimen (verified by documentation from pharmacy, letter from provider, or examination } \\
\text { of prescription bottles) for at least the prior } 30 \text { days, and report not being currently involved in another } \\
\text { behavioral intervention study related to HIV. Participants were eligible for enrollment in the trial if they }\end{array}$
\end{tabular}


The intervention was 5 60-minute individual counseling sessions with each session designed around topics relevant to ART side effects coping. Intervention sessions followed a standard structure and set of activities, but were individually tailored to participants' specific life contexts, stressors, and goals. Participants received USD 30 at the 3-month assessment if they completed all 5 sessions prior to that assessment interview. The intervention was delivered between months 3 and 6 of the study

Control: USUAL CARE

Control group participants received treatment as usual and received no active psychosocial interventions prior to the final trial assessment interview

Outcomes

The measures of adherence were self reported Adult AIDS Clinical Trials Group and visual analog scale. Adult AIDS Clinical Trials Group assesses missed pills over the prior 3 days. This measure has been used widely with diverse samples and the short-term recall period has been associated with long-term clinical outcomes. The measure was computerized for ACASI administration to minimize the social desirability associated with adherence reporting. Mean 3-day adherence was calculated by dividing the number of pills reported as being taken by the number of pills that were prescribed in the regimen. Secondly, visual analog scale assesses 30-day adherence, reporting separately for each drug along a continuum anchored by "0\%" to "100\%".This measure has shown to be correlated with other measures of adherence, such as medication event monitoring systems and a 30-day time frame has recently been supported as preferable to other approaches of self report. For the visual analog scale, the mean per cent adherence was calculated across all drugs in the participant's regimen. Assessments were completed at 1 week (baseline) and at 3, 6, 9, and 15 months for both intervention and control groups

The patient outcomes were the extent to which patients took side effect medication, as measured by the SECope. Follow-up assessment interviews were scheduled at 3 (second baseline interview), 6, 9, and 15 months for both the intervention and control groups. Interviews were conducted using laptop computers in private settings in research offices. Procedures involved a combination of audio computer-assisted self interviewing (ACASI) and computer-assisted personal interviewing (CAPI) using the Questionnaire Development System. The SECope is a 20-item measure that assesses strategies for coping with HIV treatment side effects, and includes a scale for Taking Side Effect Medications

\section{Notes} $-$

\section{Risk of bias}

Bias Authors' judgement Support for judgement

Random sequence genera- Low risk tion (selection bias)
"Simple randomization was implemented immediately following the second baseline interview using the SAS System's random number generator under the uniform distribution, aligning treatments in order with consecutive partici- pant ID." (pg 84)

Insufficient information to permit judgment of 'Low risk' or 'High risk' of bias. Information about randomization is available but nothing about allocation concealment. "Simple randomization was implemented immediately following the second baseline interview using the SAS System's random number generator under the uniform distribution, aligning treatments in order with consecutive participant ID." (pg 84)

\begin{tabular}{|c|c|c|}
\hline $\begin{array}{l}\text { Selective reporting (re- } \\
\text { porting bias) }\end{array}$ & Unclear risk & No protocol is available \\
\hline Other bias & Unclear risk & $\begin{array}{l}\text { The authors note the following: "There are several noteworthy limitations in } \\
\text { the current study. First, the experimental design used a treatment as usual } \\
\text { comparison rather than a matched attention control condition, so it is impos- } \\
\text { sible to determine the potential confounding effects of increased attention by }\end{array}$ \\
\hline
\end{tabular}


trial staff in the experimental condition rather than the control condition. Further, the assessment did not capture comprehensive data on access and use of adherence resources outside of the trial, a construct that is gaining attention in adherence research. Second, the use of self reported adherence data, while supported by validity studies has been questioned in HIV research as being inflated because of recall, social desirability, and other biases. To minimize the biases inherent in self reported data, we employed several techniques. We used conservative cut-offs of validated measures of adherence that have demonstrated meaningful relationships with important outcomes, such as viral load, in other studies. ACASI interviewing for the adherence portion of the interview was used, thereby removing the interviewer's presence and minimizing social desirability bias. Such approaches to computerized adherence assessment have shown favorable effects in other studies. Despite these strategies, it should be noted that the use of self reported adherence outcomes remains a limitation of the study, and results may have differed if other adherence assessment approaches had been used. Third, because the study used a convenience sample rather than a probability based sample, there are limits of the degree to which findings are generalizable to other populations. Related, the sample was predominately male, and thus caution should be exercised when generalizing the findings to women. Finally, because the eligibility criteria did not select based on levels of adherence at baseline, there was a limit of the degree to which patients could improve on their adherence, as some reported perfect adherence at study entry. However, even with the potential ceiling effect of adherence scores in the sample, the intervention was shown to significantly protect against the likelihood of subsequent nonadherence." (pg 89)

\begin{tabular}{|c|c|c|}
\hline $\begin{array}{l}\text { Blinding of outcome as- } \\
\text { sessment (detection bias) } \\
\text { Adherence measure }\end{array}$ & Low risk & $\begin{array}{l}\text { (PRIMARY) SELF REPORT - QUESTIONNAIRE - Data were collected via comput- } \\
\text { erized interview. The lack of blinding of outcome assessors is not likely to af- } \\
\text { fect the outcome }\end{array}$ \\
\hline
\end{tabular}

\begin{tabular}{|c|c|c|}
\hline $\begin{array}{l}\text { Blinding of outcome as- } \\
\text { sessment (detection bias) } \\
\text { Patient outcome }\end{array}$ & Low risk & $\begin{array}{l}\text { (PRIMARY) SECOPE QUESTIONNAIRE - The outcome is self reported by partici- } \\
\text { pants. The lack of blinding of data collectors is not likely to affect the outcome }\end{array}$ \\
\hline
\end{tabular}

\begin{tabular}{|c|c|c|}
\hline $\begin{array}{l}\text { Blinding of participants } \\
\text { (performance bias) } \\
\text { Adherence measure }\end{array}$ & Unclear risk & $\begin{array}{l}\text { (PRIMARY) SELF REPORT - QUESTIONNAIRE - it is not clear whether partic- } \\
\text { ipants were blinded to the intervention (not explicitly stated in the paper). } \\
\text { Therefore, insufficient information to permit judgment of 'Low risk' or 'High } \\
\text { risk' of bias }\end{array}$ \\
\hline
\end{tabular}

\begin{tabular}{|c|c|c|}
\hline $\begin{array}{l}\text { Blinding of participants } \\
\text { (performance bias) } \\
\text { Patient outcome }\end{array}$ & Unclear risk & $\begin{array}{l}\text { (PRIMARY) SECOPE QUESTIONNAIRE - it is not clear whether participants were } \\
\text { blinded to the intervention (not explicitly stated in the paper). Therefore, in- } \\
\text { sufficient information to permit judgment of 'Low risk' or 'High risk' of bias }\end{array}$ \\
\hline
\end{tabular}

\begin{tabular}{ll}
\hline $\begin{array}{l}\text { Blinding of personnel (per- } \\
\text { formance bias) }\end{array}$ & Low risk \\
Adherence measure & $\begin{array}{l}\text { (PRIMARY) SELF REPORT - QUESTIONNAIRE - Data were collected via comput- } \\
\text { erized interview. The lack of blinding of key personnel is not likely to affect the } \\
\text { outcome }\end{array}$
\end{tabular}

$\begin{array}{ll}\text { Blinding of personnel (per- } & \text { Low risk } \\ \text { formance bias) } & \text { (PRIMARY) SECOPE QUESTIONNAIRE - The outcome is self reported by partic- } \\ \text { Patient outcome } & \begin{array}{l}\text { ipants. The lack of blinding of study personnel is not likely to affect the out- } \\ \text { come }\end{array}\end{array}$

Incomplete outcome data Low risk

(attrition bias)

Adherence measure 
Johnson 2011 (Continued)

Patient outcome

Kalichman 2011

\begin{tabular}{ll}
\hline Methods & Randomized controlled trial \\
\hline Participants & The study location was AIDS service providers in Atlanta, Georgia, USA \\
& 217 participants were randomized to the intervention group and 219 participants were randomized to \\
& the control group \\
& The inclusion criteria were (1) aged 18 years or older and (2) name-matching proof of positive HIV sta- \\
& tus and photo identification
\end{tabular}

Interventions

Intervention: INTEGRATED INTERVENTION

Intervention was an integrated risk reduction and adherence intervention based on the conflict theory of decision making. It consisted of a 45-minute one to one orientation and goal setting with 1 of the group facilitators before 5 120-minute group sessions and a 60 -minute post group one to one counseling session, conducted by facilitators/interventionists. Assessment was done at baseline, 3, 6, and 9 month intervals for a total of 12 months of follow-up

\section{Control: ATTENTION CONTROL CONDITION}

Comparison intervention group received 45-minute one-on-one orientation (with 1 facilitator), 5 120minute group sessions (with male-female facilitator pairs containing 8 to 10 participants of mixed gender and sexual orientation) and a 60-minute one-on-one post-group counseling session. The first group session focused on building group cohesion and discussed how to access quality health information. The remaining 4 group sessions covered detecting early warning signs of cancer, breast and testicular self examination, nutrition decision making, healthy food selection, planning exercise, and relaxation. The final individual counseling session set personalized health improvement goals

Outcomes

The measures of adherence were unannounced pill counts. Participants were called at unscheduled times by a telephone assessor. Participants were given training on pill counting procedure and were asked count pills during the call. Pill counts were taken over 21- to 35-day intervals and for each antiretroviral medication the participants were taking. Pharmacy information from pill bottles were collected to verify the number of pills dispensed between calls. Adherence was calculated as the ratio of pills counted to pills prescribed, taking into account the number of pills dispensed. 2 consecutive pill counts were necessary for computing adherence. This information was collected by telephone assessors who were blind to the assigned treatment condition.

The patient outcomes were patient-reported monthly viral load collected by telephone assessors, sexual risk behaviors and STIs measured by questionnaire and adherence and prevention strategies and risk compensation beliefs measured by a 5 -point scale

In the results section(pg 536) there is a reference to table 3; there is no table 3 in the manuscript

\section{Risk of bias}

\begin{tabular}{lll}
\hline Bias & Authors' judgement & Support for judgement \\
\hline $\begin{array}{l}\text { Random sequence genera- } \\
\text { tion (selection bias) }\end{array}$ & Unclear risk & No information about how the randomization was performed is reported \\
\hline $\begin{array}{l}\text { Allocation concealment } \\
\text { (selection bias) }\end{array}$ & Low risk & $\begin{array}{l}\text { "The project director performed the allocation, manually drawing equal num- } \\
\text { bers of condition-coded markers without replacement." (pg 534) }\end{array}$ \\
\hline $\begin{array}{l}\text { Selective reporting (re- } \\
\text { porting bias) }\end{array}$ & Unclear risk & No obvious reporting bias. No protocol available, hence judged as unclear \\
\hline
\end{tabular}


Kalichman 2011 (Continued)

Other bias Unclear risk
The authors noted the following: (pg 537) "Although adherence improvements were relatively stable over the 9 months of followup, the sexual risk reduction outcomes were shorter lived, dissipating before 9 months after the intervention. The durability of behavioral outcomes may prove more optimistic when the intervention is delivered in clinical care given the opportunities for ongoing support. Another limitation of this trial was its reliance on self reported measures for sexual risk and biological outcomes. Although the consistency of findings supports the study's internal validity, further testing of this intervention should be undertaken with biological endpoints. We emphasized ecological validity in designing the intervention, focusing on simple and lowcost strategies for reducing risk and improving adherence. Although we strived to maintain implementation simplicity, the intervention included 2 individual and 5 group sessions. Operations research is needed to examine whether the intervention can be shortened and whether it can be infused within existing clinical services, such as support groups, medication adherence groups, and case management." Also the final individual session was attended by 62 and 63 per cent of participants from the intervention and control groups respectively

\begin{tabular}{lll}
\hline Blinding of outcome as- & Low risk & (PRIMARY) UNANNOUNCED PILL COUNTS - Telephone assessors were blind to \\
sessment (detection bias) & & assigned treatment condition (pg 532). Blinding of outcome assessment en- \\
Adherence measure & sured and unlikely that the blinding could have been broken
\end{tabular}

\begin{tabular}{ll}
\hline $\begin{array}{l}\text { Blinding of outcome as- } \\
\text { sessment (detection bias) }\end{array}$ & Low risk \\
$\begin{array}{ll}\text { Patient outcome } & \text { (PRIMARY) ADHERENCE AND PREVENTION STRATEGIES AND RISK COM- } \\
& \text { PENSATION BELIEFS - Participants were asked these questions at 3-, 6-, and 9- } \\
\text { month follow-ups using audio computer-assisted self interviews. Blinding of } \\
\text { outcome assessment ensured and unlikely that the blinding could have been } \\
\text { broken }\end{array}$
\end{tabular}

Blinding of participants Low risk
(performance bias)

(performance bias)

(PRIMARY) UNANNOUNCED PILL COUNTS - They state that "unannounced pill counts are reliable and valid in assessing HIV treatment adherence when conducted in participants' home and on the telephone." Further, "they collected pharmacy information from pill bottles to verify the number of pills dispensed between calls."(pg 532). Although the paper does not explicitly state that the participants were blinded, the structure of intervention received by participants in integrated intervention and comparison intervention were very similar. "We implemented the 2 conditions in this trial using the same operational procedures" (pg 532). No blinding or incomplete blinding, but the review authors judge that the outcome is not likely to be influenced by lack of blinding

\begin{tabular}{|c|c|c|}
\hline $\begin{array}{l}\text { Blinding of participants } \\
\text { (performance bias) }\end{array}$ & Unclear risk & $\begin{array}{l}\text { (PRIMARY) ADHERENCE AND PREVENTION STRATEGIES AND RISK COM- } \\
\text { PENSATION BELIEFS - Participant blinding not described }\end{array}$ \\
\hline
\end{tabular}

(PRIMARY) UNANNOUNCED PILL COUNTS - (pg 534) "Recruitment, screening, office-based assessment, and telephone assessment staff remained blinded to condition throughout the study, and interventionists never conducted assessments."
Blinding of personnel (per- Low risk

formance bias)

Adherence measure
(PRIMARY) ADHERENCE AND PREVENTION STRATEGIES AND RISK COMPENSATION BELIEFS - Participants were asked these questions at 3-, 6-, and 9month follow-ups using audio computer-assisted self interviews. Blinding of outcome assessment ensured and unlikely that the blinding could have been broken

(PRIMARY) UNANNOUNCED PILL COUNTS - Reasons for missing data unlikely to be related to outcome. Low attrition rate, balanced across groups at all time points except 9 months 
Kalichman 2011 (Continued)

Incomplete outcome data (attrition bias)

Patient outcome
Unclear risk

(PRIMARY) ADHERENCE AND PREVENTION STRATEGIES AND RISK COMPENSATION BELIEFS - Reasons for missing data unlikely to be related to outcome. Low attrition rate, balanced across groups at all time points except 9 months

Kato 2008

\begin{tabular}{ll} 
Methods & Randomized controlled trial \\
\hline Participants & $\begin{array}{l}\text { The study location was } 34 \text { academic medical centers and community practices in the United States, } \\
\text { Canada and Australia }\end{array}$
\end{tabular}

197 participants were randomized to the intervention group and 178 participants were randomized to the control group

The inclusion criteria were ages 13 to 29 years, had a malignancy diagnosis (newly diagnosed or relapsed), and were undergoing treatment (chemotherapy, radiation, or stem cell transplantation) that was expected to last at least 4 months after enrollment

The exclusion criteria were a history of seizures as a result of photosensitivity (e.g. flashing lights); inability to communicate with study personnel in English, French, or Spanish; or inability to follow the study schedule or directions

Interventions Intervention: CANCER TARGETED VIDEO GAME

The intervention participants were given a mini-computer containing commercial game plus the intervention game, which was a video PC game called Re-Mission47. In this game, players control a nanobot, "Roxxi", in 3-dimensional environments within the bodies of young patients with cancers that commonly are diagnosed in AYA. Game content was engineered to address behavioral issues that were identified in literature reviews and preproduction targeting studies as critical for optimal AYA patient participation in cancer treatment. Video-game play includes destroying cancer cells and managing common treatment-related adverse effects such as bacterial infections, nausea, and constipation by using chemotherapy, antibiotics, antiemetics, and a stool softener as ammunition. To win, players control the nanobot, Roxxi, to ensure strategically that virtual patients engage in positive self care behaviors, such as taking oral chemotherapy to fight cancer cells, taking antibiotics to fight infection, taking stool softeners to prevent bowel perforations, practicing good mouth care to combat mucositis, using relaxation techniques to reduce stress, and eating food to gain energy. Neither the nanobot nor any of the virtual patients "die" in the game. If players "fail" at any point in the game, then the nanobot powers down and players are given the opportunity to try the mission again. Players had to complete missions successfully before moving on to the next level. Participants were instructed to play for at least 1 hour per week during the 3-month period

Control: COMMERCIAL VIDEO GAME

The control patients were provided a commercial video game - a PC version of Indiana Jones and the Emperor's Tomb served as the control game because the play structure and controller interface closely resembled that of Re-Mission

Outcomes The adherence measures were CDCL (Chronic Disease Compliance Instrument), MAS (medication adherence scale), plasma assessment of 6MP by HPLC and MEMS. The measurements were made at 1 and 3 months.

Patient outcomes were self efficacy to manage cancer, knowledge about cancer, health locus of control, stress, and quality of life. All the outcomes were measured by self report at 1 and 3 months

\section{Notes}

\section{Risk of bias}


Kato 2008 (Continued)

\section{Bias Authors' judgement Support for judgement}

Random sequence genera- Low risk tion (selection bias)

Allocation concealment Low risk
(selection bias)

Computerized randomization. (pg e306) "Computer allocation was randomized within sites (as blocks) on the basis of a computerized random-number generator."
Allocation concealment Low risk
(selection bias)
After baseline assessments, a site associate contacted a study co-ordinator at a central office, who gave the associate a number indicating a specific computer to be distributed to the participant (i.e. a computer implementing the control or experimental condition). Computer allocation was randomized within sites (as blocks) on the basis of a computerized random-number generator. Condition assignment of each participant was concealed from study personnel, but participants became aware of their treatment assignment once they logged onto their assigned computers

Selective reporting (re- Low risk
porting bias)

The study protocol is not available but it is clear that the published reports include all expected outcomes, including those that were pre-specified

Other bias Unclear risk

\begin{abstract}
Authors note the following limitations: (pg e314) "Limitations include the heterogeneity of cancer diagnoses and treatment regimens and the nonuniform trial entry at varying treatment stages. Although this heterogeneity may reduce statistical power, it may improve generalizability of the findings for application in a broad array of AYA patients with cancer. Direct measures of adherence to TMP/SMX and oral 6-MP were obtained from the subset of the sample who were prescribed these medications, thus making it impossible to determine whether patients who are prescribed other medications would show similar patterns of adherence to their medications if exposed to the intervention game. Male patients were overrepresented among study participants, perhaps because of greater appeal of video games to that audience; however, intervention effects were similar for both genders but with a somewhat greater impact on oral TMP/SMX adherence for female patients. A final limitation involves suboptimal adherence to the video game intervention, which was used less than the requested amount by most participants in this study."
\end{abstract}

\begin{tabular}{|c|c|c|}
\hline $\begin{array}{l}\text { Blinding of outcome as- } \\
\text { sessment (detection bias) } \\
\text { Adherence measure }\end{array}$ & Low risk & (PRIMARY) MEMS - MEMS not likely to be affected by outcome assessors \\
\hline $\begin{array}{l}\text { Blinding of outcome as- } \\
\text { sessment (detection bias) }\end{array}$ & Low risk & $\begin{array}{l}\text { (PRIMARY) FACT-G - Condition assignment of each participant was concealed } \\
\text { from study personnel (pg e306) }\end{array}$ \\
\hline
\end{tabular}

(PRIMARY) FACT-G - Condition assignment of each participant was concealed (PRIMARY) MEMS - Participants aware of the measure due to the nature of intervention and obtrusive nature of MEMS

\begin{tabular}{lll}
\hline $\begin{array}{l}\text { Blinding of participants } \\
\text { (performance bias) } \\
\text { Adherence measure }\end{array}$ & High risk & $\begin{array}{l}\text { (PRIMARY) MEMS - Participants aware of the measure due to the nature of in- } \\
\text { tervention and obtrusive nature of MEMS }\end{array}$ \\
\hline $\begin{array}{l}\text { Blinding of participants } \\
\text { (performance bias) }\end{array}$ & High risk & $\begin{array}{l}\text { (PRIMARY) FACT-G - Patients aware of group allocation and intervention; sub- } \\
\text { jective outcome }\end{array}$ \\
\hline
\end{tabular}

Blinding of personnel (per- Low risk

(PRIMARY) MEMS - MEMS not likely to be affected by key study personnel

formance bias)

Adherence measure

Blinding of personnel (per- Low risk formance bias)

Patient outcome

(PRIMARY) FACT-G - Condition assignment of each participant was concealed from study personnel (pg e306) 
Kato 2008 (Continued)
Incomplete outcome data
Low risk
(PRIMARY) MEMS - Missing data balanced across groups
(attrition bias)

Adherence measure

Incomplete outcome data Low risk
(attrition bias)
Patient outcome

Patient outcome

Katon 2001

Patients were randomized to the relapse prevention intervention versus usual care in blocks of 8 . With-
in each block, the randomization sequence was computer-generated. The telephone survey team con-
ducting the follow-up assessments (at $3,6,9$, and 12 months) were blinded to randomization status.
Patients could not be blinded due to the nature of the intervention (i.e. patient education, visits with
depression specialist, telephone monitoring and follow-up). The primary care physicians were also not
blinded

Participants

Patients between the ages of 18 and 80 years who received a new antidepressant prescription (no prior prescriptions within the previous 120 days) from a primary care physician for the diagnosis of depression or anxiety were eligible for the study. Inclusion criteria for the relapse prevention study obtained during the baseline interview included patients with fewer than 4 DSM-IV major depressive symptoms and a history or 3 or more episodes of major depression or dysthymia or 4 residual depressive symptoms but with a mean Symptom Checklist 20 (SCL-20) depression score of less than 1.0 and a history a major depression/dysthymia. Exclusion criteria included having a screening score of 2 or more on the CAGE alcohol screening questionnaire, pregnancy or currently nursing, planning to disenroll from the Group Health Cooperative of Puget Sound (GHC) within the next 12 months, currently seeing a psychiatrist, limited command of English, or recently using lithium or antipsychotic medication

Interventions The intervention included patient education, 2 visits with a depression specialist, and telephone monitoring and follow-up. Before the first study visit, the intervention patients were provided a book and videotape developed by the study team that was aimed at increasing patient education and enhancing self treatment of their depression. They were also scheduled for 2 visits with a depression specialist (one 90-minute initial session and one 60-minute follow-up session) in the primary care clinic. 3 addition telephone visits at 1,4 , and 8.5 months from session 2 with the depression specialist and 4 personalized mailings $(2,6,10$, and 12 months) were scheduled over the following year. The mailed personalized feedback contained a graph of patients' Beck Depression scores over the course of the intervention program and checklists for patients to send back to the depression specialist, including early warning signs of depression and whether they were still adhering to their medication plan. The depression specialist reviewed monthly automated pharmacy data on antidepressant refills and alerted the primary care physician and telephoned the patients when mailed feedback or automated data indicated they were symptomatic and/or had discontinued medication. The ultimate aim of the intervention was to have each patient complete and follow a 2-page written personal relapse prevention plan, which was also shared with his/her primary care provider. Follow-up telephone calls and mailings were geared toward monitoring progress and adherence to each patient's plan. Usual care for most patients was provided by the GHC family physicians in the 4 primary care clinics and involved prescription of an antidepressant medication, 2 to 4 visits over the first 6 months of treatment, and an option to refer to $\mathrm{GHC}$ mental health services. Both intervention and control patients could also self refer to a GHC mental health provider

Outcomes

Measurement of compliance: patients' adherence to antidepressant medication was measured at 3, 6, 9 , and 12 months after randomization by a telephone interviewer. Based on computerized automated data from prescription refills, patients were rated as adherent at the 3-, 6-, 9-, and 12-month follow-up periods as well as whether they received adequate dosage of antidepressant medication for 90 days or more during the 1-year period. The lowest dosages in the ranges recommended in the Agency for Healthcare Policy and Research guidelines developed for newer agents were used to define a minimum dosage standard. Measurement of clinical health outcomes: baseline and follow-up interviews assessing depressive symptoms (at 3-, 6-, 9-, and 12-months) included the SCL-20 depression items (scored on 
Katon 2001 (Continued)

a 0 to 4 scale), the dysthymia and current depression modules of the SCID, the NEO Personality Inventory Neuroticism Scale and the Longitudinal Interval Follow-up Evaluation to measure incidence and duration of episodes within each 3-month block of time

\begin{tabular}{ll}
\hline Notes & - \\
\hline Risk of bias &
\end{tabular}

\begin{tabular}{lll}
\hline Bias & Authors' judgement & Support for judgement \\
\hline $\begin{array}{l}\text { Random sequence genera- } \\
\text { tion (selection bias) }\end{array}$ & Low risk & $\begin{array}{l}\text { Patients were randomized to the relapse prevention intervention (I) versus } \\
\text { usual care (UC) in blocks of 8. Within each block, the randomization sequence } \\
\text { was computer-generated(pg 242) }\end{array}$ \\
\hline $\begin{array}{l}\text { Allocation concealment } \\
\text { (selection bias) }\end{array}$ & Unclear risk & $\begin{array}{l}\text { Allocation concealment is not described; we only know that it followed the } \\
\text { baseline interview to assess eligibility, and that a substantial proportion re- } \\
\text { fused randomization at that point (pg 242). Of the 480 patients completing } \\
\text { baseline interviews for the relapse study, 386 patients (80.4\%) were success- } \\
\text { fully randomized to the relapse prevention study; } 69 \text { patients (14.4\%) accept- } \\
\text { ed randomization to a separate persistence study based on having 4 DSM-IV } \\
\text { symptoms and an SCL-20 depression score greater than 1.0; and 25 (5.2\%) re- } \\
\text { fused randomization }\end{array}$ \\
\hline
\end{tabular}

\begin{tabular}{|c|c|c|}
\hline $\begin{array}{l}\text { Selective reporting (re- } \\
\text { porting bias) }\end{array}$ & High risk & $\begin{array}{l}\text { Longitudinal interval follow-up evaluation was only reported at baseline and } \\
\text { not as outcome }\end{array}$ \\
\hline
\end{tabular}

\begin{tabular}{ll}
\hline Other bias & Selection bias is not excluded(pg 242). Baseline interviews were completed \\
& with 480 patients (68.4\%). Patients refusing baseline interviews or who were \\
ineligible for participation in the trial did not differ on age, sex, medical comor- & bidity, number of current depressive symptoms on the SCID, or prior mental \\
health utilization compared with those successfully randomized. Some bias & noted in 'Limitations' but unclear if these substantially effect results. (pg 246) \\
& "Limitations of this research included the sample studied and our ability to ac- \\
curately adjust our findings for missing data. We relied on imputation models & that assumed that we could reasonably predict non-response using baseline \\
data. Although these assumptions are untestable, we believe they are reason- & able and that our results offer a more realistic estimate of intervention effects \\
than analyses that completely ignore missing data."
\end{tabular}

\begin{tabular}{|c|c|c|}
\hline $\begin{array}{l}\text { Blinding of outcome as- } \\
\text { sessment (detection bias) }\end{array}$ & Low risk & $\begin{array}{l}\text { (PRIMARY) SELF REPORT - INTERVIEW - (pg 243) "...by a telephone interviewer } \\
\text { blinded to the patients' randomization status" }\end{array}$ \\
\hline
\end{tabular}

Adherence measure

Blinding of outcome as- Low risk sessment (detection bias)

Patient outcome
(PRIMARY) SCL-20 - (pg 243) "...by a telephone interviewer blinded to the patients' randomization status."

(PRIMARY) SELF REPORT - INTERVIEW - No mention of blinding of patients; subjective measure

\begin{tabular}{|c|c|c|}
\hline $\begin{array}{l}\text { Blinding of participants } \\
\text { (performance bias) } \\
\text { Adherence measure }\end{array}$ & High risk & $\begin{array}{l}\text { (PRIMARY) SELF REPORT - INTERVIEW - No mention of blinding of patients; } \\
\text { subjective measure }\end{array}$ \\
\hline
\end{tabular}

Adherence measure

Blinding of participants High risk

(PRIMARY) SCL-20 - No blinding, and this could have affected the outcome

(performance bias)

Patient outcome

Blinding of personnel (per- Unclear risk

formance bias)

Adherence measure

(PRIMARY) SELF REPORT - INTERVIEW - No information is provided on how adherence is actually measured by phone, and the outcome is not further reported 
Katon 2001 (Continued)

Blinding of personnel (per- Unclear risk $\quad$ (PRIMARY) SCL-20 - No mention of blinding of study staff formance bias)

Patient outcome

\begin{tabular}{|c|c|c|}
\hline $\begin{array}{l}\text { Incomplete outcome data } \\
\text { (attrition bias) } \\
\text { Adherence measure }\end{array}$ & Unclear risk & $\begin{array}{l}\text { (PRIMARY) SELF REPORT - INTERVIEW - No information is provided on how ad- } \\
\text { herence is actually measured by phone, and the outcome is not further report- } \\
\text { ed. Unclear how missing data impacts results }\end{array}$ \\
\hline
\end{tabular}

Adherence measure ed. Unclear how missing data impacts results

\section{Incomplete outcome data Unclear risk}

(attrition bias)

(PRIMARY) SCL-20 - Dropouts are likely to be linked to the severity of the out-

Patient outcome come (depression) but unclear how missing data impacts results

Kemp 1996

\begin{tabular}{|c|c|}
\hline Methods & Random allocation by means of a table of random numbers \\
\hline Participants & $\begin{array}{l}\text { Patients between the ages of } 18 \text { and } 65 \text { who were admitted to hospital with acute psychosis over } 8 \\
\text { months. Diagnostic and Statistical Manual of Mental Disorders, Third Edition, Revised (DSM III-R) diag- } \\
\text { noses of subjects included schizophrenia, severe affective disorders, schizophreniform, schizoaffective } \\
\text { disorder, delusional disorders, and psychotic disorder not otherwise classified. Non-English speakers } \\
\text { and subjects with low IQ scores, deafness, or organic brain disease were excluded }\end{array}$ \\
\hline
\end{tabular}

Interventions

Control group treatment consisted of 4 to 6 supportive counseling sessions with the same therapist. Therapists listened to patient concerns but declined to discuss treatment. Experimental intervention treatment consisted of 4 to 6 sessions of "compliance therapy" - a strategy that borrows from motivational interviewing. During session 1 and session 2, patients reviewed their illness and conceptualized the problem. In the next 2 sessions, patients focused on symptoms and the side effects of treatment. In the last 2 sessions, the stigma of drug treatment was addressed

Adherence scores were measured using a 7-point scale $(1=$ complete refusal to $7=$ active participa-
tion and ready acceptance). Measures were obtained preintervention, postintervention, at 3-month
follow-up and at 6-month follow-up. Outcome measures included ratings on a brief psychiatric rating
scale, global functioning assessment, and dose of antipsychotic drug

Notes

\section{Risk of bias}

\begin{tabular}{lll}
\hline Bias & Authors' judgement & Support for judgement \\
\hline $\begin{array}{l}\text { Random sequence genera- } \\
\text { tion (selection bias) }\end{array}$ & Low risk & $\begin{array}{l}\text { Used random number table. (pg 346) "Patients were randomly assigned by } \\
\text { means of a table of random numbers to compliance therapy or control treat- } \\
\text { ment." }\end{array}$ \\
\hline $\begin{array}{l}\text { Allocation concealment } \\
\text { (selection bias) }\end{array}$ & Unclear risk & $\begin{array}{l}\text { No mention of allocation concealment. (pg 346) "Patients were randomly as- } \\
\text { signed by means of a table of random numbers to compliance therapy or con- } \\
\text { trol treatment." }\end{array}$ \\
\hline $\begin{array}{l}\text { Selective reporting (re- } \\
\text { porting bias) }\end{array}$ & Unclear risk & $\begin{array}{l}\text { No protocol available } \\
\text { Other bias }\end{array}$ \\
\hline
\end{tabular}


Kemp 1996 (Continued)

Blinding of outcome as- Low risk $\quad$ (PRIMARY) SELF REPORTED SCALE - (pg 346) "Initial compliance was rated sessment (detection bias) blind to intervention by the patients' primary nurses on a seven point rating Adherence measure scale."

\begin{tabular}{|c|c|c|}
\hline $\begin{array}{l}\text { Blinding of outcome as- } \\
\text { sessment (detection bias) } \\
\text { Patient outcome }\end{array}$ & Low risk & $\begin{array}{l}\text { (PRIMARY) PSYCHIATRIC SYMPTOMS - (pg 346) "6 month evaluation was con- } \\
\text { ducted by an independent investigator blinded to intervention" "Initial com- } \\
\text { pliance was rated blind to intervention by the patients' primary nurses on a } \\
\text { seven point rating scale." }\end{array}$ \\
\hline
\end{tabular}

\begin{tabular}{|c|c|c|}
\hline $\begin{array}{l}\text { Blinding of participants } \\
\text { (performance bias) } \\
\text { Adherence measure }\end{array}$ & Unclear risk & $\begin{array}{l}\text { (PRIMARY) SELF REPORTED SCALE - Control group were given non-specific } \\
\text { counseling - same duration as intervention. No other effort to ensure blinding } \\
\text { is not mentioned }\end{array}$ \\
\hline
\end{tabular}

\begin{tabular}{|c|c|c|}
\hline $\begin{array}{l}\text { Blinding of participants } \\
\text { (performance bias) } \\
\text { Patient outcome }\end{array}$ & Unclear risk & $\begin{array}{l}\text { (PRIMARY) PSYCHIATRIC SYMPTOMS - Control group were given non-specific } \\
\text { counseling - same duration as intervention. No other effort to ensure blinding } \\
\text { is mentioned, therefore marked uncertain }\end{array}$ \\
\hline
\end{tabular}

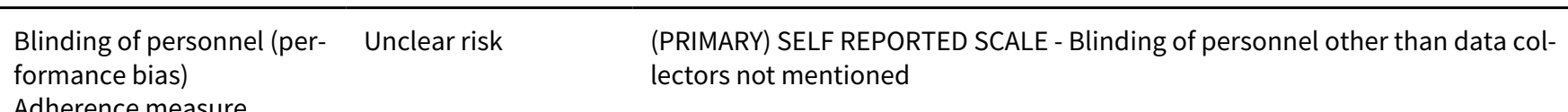

Adherence measure

\begin{tabular}{|c|c|c|}
\hline $\begin{array}{l}\text { Blinding of personnel (per- } \\
\text { formance bias) }\end{array}$ & Unclear risk & $\begin{array}{l}\text { (PRIMARY) PSYCHIATRIC SYMPTOMS - Blinding of personnel other than data } \\
\text { collectors not mentioned }\end{array}$ \\
\hline
\end{tabular}

Patient outcome

\begin{tabular}{|c|c|c|}
\hline $\begin{array}{l}\text { Incomplete outcome data } \\
\text { (attrition bias) } \\
\text { Adherence measure }\end{array}$ & Unclear risk & $\begin{array}{l}\text { (PRIMARY) SELF REPORTED SCALE - Missing data uniform in } 2 \text { groups. Missing } \\
\text { data for each outcome measure at different time points not included in the } \\
\text { postintervention analysis. For example, compliance data were measured at } \\
6 \text { months in the control group for } 18 / 22(19 \%) \text { subjects and } 22 / 25(12 \%) \text { sub- } \\
\text { jects. Not known whether this could have changed the results }\end{array}$ \\
\hline
\end{tabular}

\begin{tabular}{|c|c|c|}
\hline $\begin{array}{l}\text { Incomplete outcome data } \\
\text { (attrition bias) } \\
\text { Patient outcome }\end{array}$ & Low risk & $\begin{array}{l}\text { (PRIMARY) PSYCHIATRIC SYMPTOMS - Psychiatric rating scale data for } 4 \text { sub- } \\
\text { jects (19\%) from control group missing and } 3(12 \%) \text { from intervention group. } \\
\text { Reasons for dropouts provided and dropouts were low }\end{array}$ \\
\hline
\end{tabular}

\begin{tabular}{ll} 
Kemp 1998 & \\
\hline Methods & Random allocation by means of a table of random numbers \\
\hline Participants & $\begin{array}{l}\text { Patients between the ages of } 18 \text { and } 65 \text { who were admitted to hospital with acute psychosis over } 14 \\
\text { months. DSM III-R diagnoses of subjects included schizophrenia, severe affective disorders, schizo- } \\
\text { phreniform, schizoaffective disorder, delusional disorders, and psychotic disorder not otherwise classi- } \\
\text { fied. Non-English speakers and subjects with low IQ scores, deafness, or organic brain disease were ex- } \\
\text { cluded }\end{array}$ \\
\hline $\begin{array}{l}\text { Control group treatment consisted of } 4 \text { to } 6 \text { supportive counseling sessions with the same therapist. } \\
\text { Therapists listened to patients' concerns but when medication issues were broached, patients were di- } \\
\text { rected to discuss such issues with their treatment teams. Experimental intervention treatment consist- } \\
\text { ed of } 4 \text { to } 6 \text { sessions of "compliance therapy" - a strategy that borrows from motivational interviewing. } \\
\text { During session } 1 \text { and session 2, patients reviewed their illness and conceptualized the problem. In the } \\
\text { next } 2 \text { sessions, patients focused on symptoms and the side effects of treatment. In the last } 2 \text { sessions, } \\
\text { the stigma of drug treatment was addressed }\end{array}$
\end{tabular}
\begin{tabular}{ll}
\hline Outcomes & $\begin{array}{l}\text { Adherence scores were measured using a } 7 \text {-point scale }(1=\text { complete refusal to } 7=\text { active participation } \\
\text { and ready acceptance of regimen })\end{array}$
\end{tabular} 

sessment, schedule for assessment of insight, drug attitudes inventory, attitude to medication questionnaire, Simpson-Angus Scale for extrapyramidal side effects. Measures were obtained in-hospital preintervention and postintervention. Following discharge, measurements were made at 3, 6, 12, and 18 months

Notes Initial compliance was rated by the patient's primary nurse. Follow-up compliance ratings were obtained using the 7-point scale, based on corroboration from as many sources as possible (mean number of sources was approximately 2 )

\section{Risk of bias}

\begin{tabular}{lll}
\hline Bias & Authors' judgement & Support for judgement \\
\hline $\begin{array}{l}\text { Random sequence genera- } \\
\text { tion (selection bias) }\end{array}$ & Unclear risk & $\begin{array}{l}\text { Random sequence generation is not explained. (pg 414) "Patients were ran- } \\
\text { domly assigned to the intervention consisting of 4-6 sessions (mean = 4.7) of } \\
\text { compliance therapy, lasting 20-60 minutes" }\end{array}$ \\
\hline
\end{tabular}

$\begin{array}{lll}\begin{array}{l}\text { Allocation concealment } \\ \text { (selection bias) }\end{array} & \text { Unclear risk } & \begin{array}{l}\text { No mention of method of allocation concealment. (pg 414) "Patients were ran- } \\ \text { domly assigned to the intervention consisting of 4-6 sessions (mean }=4.7) \text { of } \\ \text { compliance therapy, lasting 20-60 minutes, approximately twice weekly, or the } \\ \text { control treatment consisting of an equal number" }\end{array}\end{array}$

Selective reporting (re- Unclear risk No protocol available
porting bias)

Other bias High risk

The authors note the following: (pg 417) "A weakness of the study is the drop-
out rate over follow-up; the statistical method used to deal with the subsequent missing values has already been discussed. A high rate of patient refusal and drop-out would not be unexpected with this relatively unselected and highly disturbed patient sample, of which $59.5 \%$ were admitted involuntarily. In fact, the actual initial refusal rate was $15 \%$, and subsequent attrition by onethird included only 11 overt refusers. The therapy sessions were very well accepted by patients, with all those recruited completing the course of therapy. Substantial follow-up drop-out rates have been re- ported in: (a) drug studies; (b) prospective studies of inner-city samples where at least $10 \%$ relocate beyond catchment area boundaries each year; and (c) studies of psychosocial interventions in similar populations (Tarrier et al, 1993). Longer follow- up periods inevitably lead to greater attrition. A practical issue is that of tracking subjects for follow-up in a highly mobile inner-city sample. Another methodological issue concerns the measure of compliance. This was an indirect composite measure based on information from a number of sources, which correlated strongly at each time point with measures of treatment attitudes, lending it concurrent validity. A mean advantage for the compliance therapy group of between one and two points on the observer-rated compliance scale is a clinically meaningful difference (for example it could amount to the difference between a patient with a bipolar disorder accepting lithium with some supervision rather than being reluctantly maintained on a less appropriate depot medication schedule). However, it may be argued that lack of a direct compliance measure is a weakness in this study, though all these measures have their drawbacks. Pill counts have been widely used in the past even though despite the well-recognised potential for inaccuracy (Rudd, 1976; Kane, 1983; Pullar et $\mathrm{a}[$, 1989). Furthermore, they are time-consuming, demanding of manpower, and ultimately not particularly suitable for: (a) in-patient studies where medication is largely administered by staff; (b) studies involving patients on depot medication; (c) patients with individually tailored regimes. Serum assays are expensive, invasive and are not available for the full range of antipsychotics; we believe their use in this study would have further adversely affected the drop-out rate. Urine tests for a drug or its metabolite may overestimate compliance with drugs like antipsychotics with a long half-life (Churchill, 1985); al- 
so currently available assays may not detect some antipsychotics at the lower dose range. Both serum and urine assays are of limited value in assessing partial compliance (Babiker, 1986). While simple self report compliance measures are poorly predictive of behavior, Hogan et a1 (1983) found that DAI ratings could accurately assign $89 \%$ of a large out-patient sample to compliant and non-compliant groupings. Observer bias Observer bias was another potential problem. The initial ratings and most of the three-month follow-up ratings of functioning and compliance were made by the research psychiatrist (R.K.) who was not blind to treatment status, though the compliance ratings were based on information from impartial sources including community psychiatric nurses and out-patient doctors on the clinical teams. However, all sixmonth, 12-month and 18-month ratings on the other hand were carried out by two researchers trained in their use, who were blind to treatment status. Inspection of the results shows consistency between ratings over the serial points, and satisfactory inter-rater reliability coefficients were obtained. Despite these shortcomings, the findings suggest that compliance therapy does have a measurable and positive effect on treatment adherence."

$\begin{array}{lll}\begin{array}{l}\text { Blinding of outcome as- } \\ \text { sessment (detection bias) }\end{array} & \text { Low risk } & \text { (PRIMARY) GLOBAL ASSESSMENT OF FUNCTIONING SCALE - All ratings except } \\ \text { Patient outcome } & \text { for the initial and 3-month rating were carried out by blinded researchers. (pg } \\ & 415): \text { "All six-month, 12-month and 18-month ratings on the other hand were } \\ & \text { carried out by two researchers trained in their use, who were blind to treat- } \\ \text { ment status." }\end{array}$

Blinding of participants High risk (performance bias) Adherence measure

Blinding of outcome as- Unclear risk sessment (detection bias)

Adherence measure
(PRIMARY) NURSE ASSESSMENT - 7 POINT SCALE - (pg 414) "Compliance. Initial compliance was rated blind to intervention status by the patients' primary nurse according to a seven-point rating scale." However, the following is also indicated in the article: "The initial ratings and most of the three-month follow-up ratings of functioning and compliance were made by the research psychiatrist (R.K.) who was not blind to treatment status" (pg 418) cause of the nature of the intervention

(PRIMARY) GLOBAL ASSESSMENT OF FUNCTIONING SCALE - Patients likely to be unblinded due to the nature of the intervention
(PRIMARY) NURSE ASSESSMENT - 7-POINT SCALE - Likely to be unblinded be-
Blinding of participants High risk (performance bias)

Patient outcome
(PRIMARY) NURSE ASSESSMENT - 7-POINT SCALE - Insufficient information and a bit unclear. "The initial ratings and most of the three-month follow-up ratings of functioning and compliance were made by the research psychiatrist (R.K.) who was not blind to treatment status" (pg 418)

(PRIMARY) GLOBAL ASSESSMENT OF FUNCTIONING SCALE - There is insufficient information available regarding other personnel, if any

Blinding of personnel (per- Unclear risk formance bias)

Patient outcome

(PRIMARY) NURSE ASSESSMENT - 7-POINT SCALE - As noted in limitations, dropouts lead to high risk of bias

Incomplete outcome data High risk

(attrition bias)

Adherence measure

Incomplete outcome data High risk
(attrition bias)

Patient outcome

(PRIMARY) GLOBAL ASSESSMENT OF FUNCTIONING SCALE - High loss to follow-up during the study 
Khdour 2009

\begin{tabular}{ll}
\hline Methods & Randomized controlled trial \\
\hline Participants & The study location was outpatient COPD clinic at the Mater Hospital, Belfast, Northern Ireland \\
& $\begin{array}{l}86 \text { participants were randomized to the intervention group and } 87 \text { participants were randomized to the } \\
\text { control group }\end{array}$
\end{tabular}

The inclusion criteria were confirmed diagnosis of COPD for at least 1 year, having a forced expiratory volume in 1 second (FEV1) of $30 \%$ to $80 \%$ of the predicted normal value and $>45$ years old

The exclusion criteria were having congestive heart failure, moderate to severe learning difficulties, attended a pulmonary rehabilitation program in the last 6 months, and severe mobility problems or terminal illness

The intervention was individualized and tailored for each patient by the clinical pharmacist based on disease knowledge, smoking status, medication adherence, self efficacy in managing breathing difficulty, and exercise and diet habits. Intervention patients were educated individually by the clinical pharmacist (in a structured fashion) on COPD, their prescribed medication, the importance of adherence, inhaler technique (written information was provided) and the management of COPD symptoms. The clinical pharmacist ensured that the patient knew the indications and doses of each medicine, and was able and willing to use the inhaler devices prescribed. The clinical pharmacist also discussed with the intervention patients the importance of simple exercises that patients can do at home (e.g. upper and lower limb exercises and relaxation techniques), symptom control (pursed lip technique) and the technique for expectoration (huff and puff technique). The pharmacist demonstrated these techniques and then asked the patients to carry out the techniques to ensure that they fully understood how to perform them. A booklet on these techniques was prepared to assist in the education session and the patients were given a copy to take home with them. Advice, using the motivational interviewing technique, was provided to the patients who still smoked and referral to a special smoking cessation program run within the hospital was made. A customized action plan for acute exacerbations, including advice to GPs to provide a prescription for an antibiotic (amoxicillin/clavulanic acid) and an oral corticosteroid to be initiated promptly by patients for exacerbations, was developed for each patient. The clinical pharmacist through motivational interviewing attempted to increase the intervention patients' self efficacy to manage or avoid breathing difficulty while participating in certain activities. The interventions were tailored according to the preliminary assessment, i.e. checklists of patients' needs were prepared by the research pharmacist and forwarded to the clinical pharmacist to discuss with the patients. The initial intervention lasted for approximately 1 hour for nonsmoker patients and slightly longer for patients who currently smoked. At each outpatient clinic visit (every 6 months arranged by the hospital consultant), intervention group patients received reinforcement of the education on COPD and its treatment from the clinical pharmacist. In addition, follow-up telephone calls by the clinical pharmacist to reinforce the education and motivate the patients to achieve their goals were made at 3 and 9 months, i.e. between outpatient clinic appointments

Control: USUAL CARE

Control patients received usual hospital outpatient care from medical and nursing staff

The measures of adherence were self reported Morisky adherence scale, which measures adherence through 4 Yes/No response items, reflects the number of ways medication omission can occur: forgetting, carelessness, stopping when feeling better, and stopping when feeling worse.On scoring of the questionnaire, each 'yes' response is given a score of 1 and each 'no' response is given a score of 0 . Adherence scores can therefore range between 0 and 4 . In the present study, 2 adherence classifications were used. The Morisky self report adherence scale has been shown to have good validity (a reliability = $0.61)$

The patient outcomes were utilization of health resources, disease-specific health-related quality of life, BMI, and FEV1. Patients charts were consulted to determine their use of health resources over the 12 months of the study (ED visits, hospital admissions), their BMI, and the FEV1. The SGRQ was administered by the research pharmacist at baseline, 6 months, and 12 months to measure QOL. A change in the mean total score of 4 units was used as a clinically significant threshold. If a patient could not self complete the questionnaire, a strict protocol was used to read the questions to the patients 
Khdour 2009 (Continued)

Notes

\section{Risk of bias}

\begin{tabular}{lll}
\hline Bias & Authors' judgement & Support for judgement \\
\hline $\begin{array}{ll}\text { Random sequence genera- } \\
\text { tion (selection bias) }\end{array}$ & Low risk & $\begin{array}{l}\text { The randomization was carried out using the minimization method described } \\
\text { by Gore. The software used in the minimization process can be accessed on: } \\
\text { http://www-users.york.ac.uk/ } / \mathrm{mb} 55 / \text { guide/minim.htm }\end{array}$ \\
\end{tabular}

\begin{tabular}{ll}
\hline $\begin{array}{l}\text { Allocation concealment } \\
\text { (selection bias) }\end{array}$ & $\begin{array}{l}\text { Not enough information given. The randomization was carried out using the } \\
\text { minimization method described by Gore. The software used in the minimiza- } \\
\text { tion process can be accessed on: http://www-users.york.ac.uk/ } / \text { mb55/guide/ } \\
\text { minim.htm }\end{array}$
\end{tabular}

Selective reporting (re- Unclear risk No protocol available

porting bias)

\begin{tabular}{lll}
\hline Other bias & Unclear risk & The manuscript does not explicitly give any limitations \\
\hline $\begin{array}{l}\text { Blinding of outcome as- } \\
\text { sessment (detection bias) }\end{array}$ & Low risk & $\begin{array}{l}\text { (PRIMARY) SELF REPORT - QUESTIONNAIRE - "Patients who had difficulty self- } \\
\text { completing questionnaires, e.g. forgot reading glasses, had the questionnaires } \\
\text { read to them. If this occurred, a strict protocol was followed, i.e.the questions } \\
\text { were read to the patients and their answers sought without any interpretation } \\
\text { of the questions being given. This helped minimize potential bias related to } \\
\text { the fact that, for operational reasons, the researcher could not be blinded to } \\
\text { the group to which the patient belonged." (pg 590) }\end{array}$ \\
\hline
\end{tabular}

Blinding of outcome as- Low risk (PRIMARY) ST GEORGE'S RESPIRATORY QUESTIONNAIRE - "Patients who had sessment (detection bias) difficulty self-completing questionnaires, e.g. forgot reading glasses, had the Patient outcome questionnaires read to them. If this occurred, a strict protocol was followed, i.e.the questions were read to the patients and their answers sought without any interpretation of the questions being given. This helped minimize potential bias related to the fact that, for operational reasons, the researcher could not be blinded to the group to which the patient belonged." (pg 590). This outcome is self reported by the participant. The lack of blinding is not likely to affect the outcome

\begin{tabular}{|c|c|c|}
\hline $\begin{array}{l}\text { Blinding of outcome as- } \\
\text { sessment (detection bias) } \\
\text { Patient outcome }\end{array}$ & Low risk & $\begin{array}{l}\text { (PRIMARY) HEALTH RESOURCES UTILIZATION - Objective measure, unlikely to } \\
\text { be biased; obtained data from computerized hospital records }\end{array}$ \\
\hline $\begin{array}{l}\text { Blinding of participants } \\
\text { (performance bias) } \\
\text { Adherence measure }\end{array}$ & High risk & $\begin{array}{l}\text { (PRIMARY) SELF REPORT - QUESTIONNAIRE - The manuscript does not explic- } \\
\text { itly state whether participants were blinded. The outcome is self reported and } \\
\text { therefore the lack of blinding will interfere with the outcome }\end{array}$ \\
\hline $\begin{array}{l}\text { Blinding of participants } \\
\text { (performance bias) } \\
\text { Patient outcome }\end{array}$ & Low risk & $\begin{array}{l}\text { (PRIMARY) HEALTH RESOURCES UTILIZATION - This is an objective measure of } \\
\text { outcome. The lack of blinding is not likely to affect the outcome }\end{array}$ \\
\hline $\begin{array}{l}\text { Blinding of participants } \\
\text { (performance bias) } \\
\text { Patient outcome }\end{array}$ & Unclear risk & $\begin{array}{l}\text { (PRIMARY) ST GEORGE'S RESPIRATORY QUESTIONNAIRE - Insufficient informa- } \\
\text { tion to permit judgment }\end{array}$ \\
\hline $\begin{array}{l}\text { Blinding of personnel (per- } \\
\text { formance bias) } \\
\text { Adherence measure }\end{array}$ & Low risk & $\begin{array}{l}\text { (PRIMARY) SELF REPORT - QUESTIONNAIRE - "The researcher could not be } \\
\text { blinded to the group to which the patient belonged." (pg 590). However, the } \\
\text { questionnaire was answered by the participant }\end{array}$ \\
\hline
\end{tabular}


Khdour 2009 (Continued)

Blinding of personnel (per- Unclear risk formance bias)

Patient outcome
(PRIMARY) ST GEORGE'S RESPIRATORY QUESTIONNAIRE - Insufficient information to permit judgment

(PRIMARY) HEALTH RESOURCES UTILIZATION - This is an objective measure of outcome. The lack of blinding is not likely to affect the outcome
Blinding of personnel (per- Low risk formance bias)

Patient outcome
Incomplete outcome data Low risk

(attrition bias)

Adherence measure
(PRIMARY) SELF REPORT - QUESTIONNAIRE - Equal number of participants discontinued the study from both groups at the end of 12 months for the same reasons. Refer to Figure 1. "During the study period, three patients from the intervention group and five from the control group died and a total of 22 patients withdrew from the study; 12 patients from the intervention group and 10 from the control group (Figure 1). Therefore, the total number of patients lost to follow-up over the complete study was 30, leaving 72 patients in the control group and 71 participants in the intervention group at the end of the study." (pg 591)
Incomplete outcome data Low risk

(attrition bias)

Patient outcome
(PRIMARY) HEALTH RESOURCES UTILIZATION - Equal number of participants discontinued the study from both groups at the end of 12 months for the same reasons. Refer to Figure 1. "During the study period, three patients from the intervention group and five from the control group died and a total of 22 patients withdrew from the study; 12 patients from the intervention group and 10 from the control group (Figure 1). Therefore, the total number of patients lost to follow-up over the complete study was 30 , leaving 72 patients in the control group and 71 participants in the intervention group at the end of the study." (pg 591)

(PRIMARY) ST GEORGE'S RESPIRATORY QUESTIONNAIRE - Equal number of participants discontinued the study from both groups at the end of 12 months for the same reasons. Refer to Figure 1. "During the study period, three patients from the intervention group and five from the control group died and a total of 22 patients withdrew from the study; 12 patients from the intervention group and 10 from the control group (Figure 1). Therefore, the total number of patients lost to follow-up over the complete study was 30, leaving 72 patients in the control group and 71 participants in the intervention group at the end of the study." (pg 591)

Kimmel 2012

\begin{tabular}{ll} 
Methods & Randomized controlled trial \\
\hline Participants & $\begin{array}{l}\text { The study location was an outpatient hospital of the University of Pennsylvania Anticoagulation Man- } \\
\text { agement Center }\end{array}$
\end{tabular}

53 participants were randomized to the intervention group and 48 participants were randomized to the control group

The inclusion criteria were age over 21 years, attending the out-patient clinic at University of Pennsylvania Anticoagulation Management center, INR between 2 and 3.5, and had, at any time in the past, achieved stable warfarin anticoagulation, defined as 2 INRs within their target range over 2 consecutive clinic visits

The exclusion criteria were no access to a telephone line (which was required to use the Med-eMonitor (Informedix, Rockville, MD), as discussed below), unwillingness to participate or to sign a consent form, dementia or any other impairment affecting ability to provide informed consent and/or use the MedeMonitor, illness with anticipated life expectancy of 6 months or less, INR over the upper limit for the individual's range at the time of enrollment (to avoid possibly exacerbating this overanticoagulation if 
a patient's adherence improved during the study), and antiphospholipid antibody syndrome or abnormal INR before starting warfarin

Interventions

Intervention: LOTTERY-BASED INCENTIVES

Patients in the intervention group were offered financial incentives to remain adherent. All patients were provided with an Informedix Med-eMonitor System, which has a display screen and separate medication compartments in which to place their warfarin. The monitor connects to an analog telephone line. They were enrolled in a daily lottery, administered via the Med-eMonitor, with an expected daily value of USD 3, or no lottery intervention. Participants had a 1 in 5 chance of a USD 10 reward and 1 in 100 chance of a USD 100 reward each day if they opened the monitor's pill compartment and confirmed that they took their warfarin as prescribed that day. If patients were told to not take warfarin on a particular day, they would only be eligible for the lottery if they did not take a pill that day

Control: CONTROL

Patients in the control arm were set up with the Med-eMonitor in order to measure medication adherence. Participants were also seen by their anticoagulation clinic practitioner as they normally would and by the study staff at baseline, 2 weeks, 3 months, and 6 months

Outcomes

The measures of adherence were measured with the Informedix Med-emonitor system. If the patient opened the monitor's pill compartment and confirmed that they took their warfarin as prescribed that day they were deemed adherent. The device was programmed to communicate by telephone with a central database at 3 AM each night.The system was automated so that there were no personnel required to run the lotteries. All other reminder systems and feedback from the Med-eMonitor were disabled for both groups

The patient outcomes were anticoagulation control, bleeding events, and thromboembolism. Study staff collected the clinical outcome data at baseline, 2 weeks, 3 months, and 6 months (corresponding to times when patients were returning for regular clinic visits). Instrument or technique of data collection not explicitly mentioned in the article

\section{Notes}

$-$

\section{Risk of bias}

\begin{tabular}{lll}
\hline Bias & Authors' judgement & Support for judgement \\
\hline $\begin{array}{l}\text { Random sequence genera- } \\
\text { tion (selection bias) }\end{array}$ & Low risk & $\begin{array}{l}\text { Randomization was carried out using a random-number generator (pg 269). } \\
\text { (pg 2) "Randomization was carried out using a random-number generator and } \\
\text { via permuted block randomization with variable block sizes of 2, 4, and 6. Be- } \\
\text { cause of the a priori hypothesis that patients within therapeutic INR range at } \\
\text { the time of randomization might benefit less from the intervention than those } \\
\text { with an INR below the target range, randomization was stratified by INR below } \\
\text { range and INR within range at enrollment." }\end{array}$
\end{tabular}

\begin{tabular}{|c|c|c|}
\hline $\begin{array}{l}\text { Allocation concealment } \\
\text { (selection bias) }\end{array}$ & Unclear risk & No mention of allocation concealment \\
\hline Other bias & Unclear risk & $\begin{array}{l}\text { Author notes the following: (pg } 271 \text { ) "...degree of anticoagulation control in } \\
\text { the cohort was better than anticipated, both limiting the study's power and } \\
\text { the opportunity for the intervention to improve adherence" (pg 272) "Other } \\
\text { limitations of the study include its inability to discern if patients took the cor- } \\
\text { rect number of pills from the Med-eMonitor compartment, use of a single anti- } \\
\text { coagulation clinic, and the potential for gaming of the system by opening pill } \\
\text { doors but not taking the drug (which, although unlikely that patients would } \\
\text { not go ahead and take the pill at that point, is why our primary outcome was } \\
\text { INR control, not adherence)." }\end{array}$ \\
\hline
\end{tabular}


Kimmel 2012 (Continued)

Blinding of outcome as- Low risk sessment (detection bias)

Adherence measure
(PRIMARY) MED-EMONITOR - (pg 269) "Neither field staff nor study participants could be blinded to study arm because of the nature of the intervention; study investigators and analysts, however, remained blinded to intervention assignments until all follow-ups and data cleaning were completed." Data collectors were blinded

\begin{tabular}{lll}
\hline $\begin{array}{l}\text { Blinding of outcome as- } \\
\text { sessment (detection bias) } \\
\text { Patient outcome }\end{array}$ & Low risk & $\begin{array}{l}\text { (PRIMARY) ANTICOAGULATION CONTROL - INR analyses is an objective mea- } \\
\text { sure, unlikely to be biased due to lack of blinding }\end{array}$ \\
\hline $\begin{array}{l}\text { Blinding of participants } \\
\text { (performance bias) }\end{array}$ & High risk & $\begin{array}{l}\text { (PRIMARY) MED-EMONITOR - No mention that patients were blinded and they } \\
\text { whould be aware of the intervention. (pg 269) "Neither field staff nor study par- } \\
\text { ticipants could be blinded to study arm because of the nature of the interven- } \\
\text { tion; study investigators and analysts, however, remained blinded to interven- } \\
\text { tion assignments until all follow-ups and data cleaning were completed." }\end{array}$ \\
\hline
\end{tabular}

\begin{tabular}{lll}
\hline $\begin{array}{l}\text { Blinding of participants } \\
\text { (performance bias) } \\
\text { Patient outcome }\end{array}$ & Low risk & $\begin{array}{l}\text { (PRIMARY) ANTICOAGULATION CONTROL - INR analyses is an objective mea- } \\
\text { sure, unlikely to be biased due to lack of blinding }\end{array}$ \\
\hline $\begin{array}{l}\text { Blinding of personnel (per- } \\
\text { formance bias) }\end{array}$ & Low risk & $\begin{array}{l}\text { (PRIMARY) MED-EMONITOR - (pg 269) "Neither field staff nor study participants } \\
\text { could be blinded to study arm because of the nature of the intervention; study } \\
\text { investigators and analysts, however, remained blinded to intervention assign- } \\
\text { ments until all follow-ups and data cleaning were completed." Lack of blinding } \\
\text { unlikely to affect results }\end{array}$ \\
\hline
\end{tabular}

\begin{tabular}{lll}
$\begin{array}{l}\text { Blinding of personnel (per- } \\
\text { formance bias) } \\
\text { Patient outcome }\end{array}$ & Low risk & $\begin{array}{l}\text { (PRIMARY) ANTICOAGULATION CONTROL - INR analyses is an objective mea- } \\
\text { sure, unlikely to be biased due to lack of blinding }\end{array}$ \\
\hline $\begin{array}{l}\text { Incomplete outcome data } \\
\text { (attrition bias) } \\
\text { Adherence measure }\end{array}$ & Unclear risk & $\begin{array}{l}\text { (PRIMARY) MED-EMONITOR - No statistically significant difference between } \\
\text { groups in primary outcome. However, missing data not uniformly distributed. } \\
\text { Reasons for missing data provided but unclear the impact incomplete data } \\
\text { would have }\end{array}$ \\
\hline $\begin{array}{l}\text { Incomplete outcome data } \\
\text { (attrition bias) }\end{array}$ & Low risk & $\begin{array}{l}\text { (PRIMARY) ANTICOAGULATION CONTROL - No statistically significant differ- } \\
\text { ence between groups in primary outcome. Missing data not uniformly distrib- } \\
\text { uted. } \text { Reasons for missing data provided, but unclear how this may have im- } \\
\text { pacted the results }\end{array}$ \\
\hline
\end{tabular}

Klein 2009

\begin{tabular}{ll}
\hline Methods & Randomized controlled trial \\
\hline Participants & The study location was University Hospital Mainz, Langenbeckstrasse, Mainz, Germany \\
& 26 participants were randomized to the intervention group and 24 participants were randomized to the \\
control group & \\
The inclusion criteria were 18 years of age or over, first organ transplant, follow-up care at University \\
Hospital Mainz for the first year after transplantation, and administration of oral immunosuppressive \\
therapy as a capsule or tablet
\end{tabular}

Interventions

Intervention: PHARMACEUTICAL CARE

In addition to routine clinical care, patients in the intervention group received pharmaceutical care services provided by a dedicated hospital pharmacist. The pharmaceutical care program usually started about 1 week before discharge from the transplant surgery unit. The hospital pharmacist met with 
Klein 2009 (Continued)

the patient 3 to 4 times and educated him on different issues regarding immunosuppressive medication, for example, action of the drugs, side effects, interactions, vital signs, laboratory data, and discharge medication. On discharge, the hospital pharmacist handed out and explained written information, including a discharge medication plan, information regarding the immunosuppressive therapy, and a diary for documenting vital signs and laboratory data. During the first year after transplantation, the patient met the pharmacist at least once per quarter year and at maximum once per month. During these meetings the pharmacist discussed with the patient changes in medication, laboratory values, and drug-related problems. Preferably, family members were involved. In addition, the hospital pharmacist reviewed the patients' drug therapy, to minimize drug-related problems, and simplify drug regimens

Control: CONTROL

Patients in the control group did not receive pharmaceutical care but they received routine clinical care from the same hospital pharmacist as the intervention group

Outcomes

The measures of adherence were medication event monitoring systems (MEMS), pill count, immunosuppressant drug concentrations, Morisky score, and self reported adherence questionnaires. Compliance with the immunosuppressive therapy was measured by MEMS. Compliance was defined as dosing compliance (DC), which describes the percentage of days with the correct number of bottle openings. For patients of both groups the immunosuppressive drug was distributed in MEMS bottles. The bottles were filled in the pharmacy department of the University Hospital Mainz. During each visit, remaining capsules/tablets were counted. During hospital stays electronic monitoring was discontinued. All data collected during the study were analyzed after the study was closed. If the patient's overall DC was less than $80 \%$, the patient was characterized as noncompliant. To get the pill counts, tablets/capsules remaining in MEMS bottles were counted during each visit of the patient. These data were used to calculate the compliance rate at each visit for each patient. Blood samples were routinely collected from all liver transplant patients for immunosuppressant drug monitoring. Serum concentrations were assayed in house by the department of clinical chemistry. Results were used for assessment of compliance. Serum drug concentrations were classified into 2 categories, "target" or "not target". The Morisky score was determined by evaluating the answers to 4 questions concerning medication taking behavior. The Morisky score questionnaire was given to the patient upon discharge, at 6 and 12 months after transplantation. In the self report questionnaire, patients were asked how often they forgot to take a dose of their immunosuppressant during the last 4 weeks. This questionnaire was monitored at 6 and 12 months after transplantation

The patient outcome was rejection episodes assessed by histologic diagnosis based on percutaneous liver biopsy. The number of biopsy-proven rejection episodes were documented during the entire study period and compared for both groups

\begin{tabular}{lll}
\hline Notes & - & \\
\hline Risk of bias & Authors' judgement & Support for judgement \\
\hline Bias & Unclear risk & $\begin{array}{l}\text { No information on randomization procedure. (pg 840) "...this study was de- } \\
\text { signed as a prospective randomized controlled trial..." }\end{array}$ \\
\hline $\begin{array}{l}\text { Random sequence genera- } \\
\text { tion (selection bias) }\end{array}$ & Unclear risk & $\begin{array}{l}\text { No information on allocation concealment. (pg 840) "...this study was designed } \\
\text { as a prospective randomized controlled trial..." }\end{array}$ \\
\hline $\begin{array}{l}\text { Allocation concealment } \\
\text { (selection bias) }\end{array}$ & $\begin{array}{l}\text { No protocol available } \\
\text { Selective reporting (re- } \\
\text { porting bias) }\end{array}$ & $\begin{array}{l}\text { Unclear risk } \\
\text { Other bias }\end{array}$ \\
\hline $\begin{array}{l}\text { The authors noted several limitations: "Although the prospective, random- } \\
\text { ized, controlled study design was chosen according to research standards in } \\
\text { clinical trials, blinding is still a problem in intervention studies. Patients who } \\
\text { participate in clinical studies benefit regardless of the treatment and whether } \\
\text { they are assigned to the control or intervention group. This is probably be- } \\
\text { cause they receive special attention. This makes it more difficult to demon- }\end{array}$
\end{tabular}


Klein 2009 (Continued)

strate the effect of an intervention, such as pharmaceutical care, because patients belonging to the control group are more likely to have better outcomes than the overall population. However, even in a small study population, results showing a statistical significance probably resulted from the pharmaceutical care provided. Because of the randomized design, patients of the intervention and control group visited the outpatient clinic at the same time and were able to exchange written and oral information. Moreover, patients in the control group received the basic immunosuppressant from the same hospital pharmacist as the intervention group. If those patients had questions or problems, not caring for them would have been unethical. Finally, it has to be discussed if it is necessary and justifiable not to tell the patients that we will be examining their compliance? Apart from the ethical problem, the high dropout rate caused by using pill boxes results from not informing the patients how the MEMS system works. However, this method is essential to receive valid data. Otherwise, patients could easily manipulate the results. To protect the patients' privacy, all data were coded and documented anonymously. Physicians and staff who cared for the patients had no access to the data, and the study design was approved by the ethical committee. Pill counts proved to be unfeasible, especially during the first weeks following transplantation, when the dose of the immunosuppressive drug was changed frequently. Therefore, documentation was time consuming and probably incomplete. However, this method was helpful for confirming the electronic data. Results of serum concentration measures also confirmed the MEMS results, especially because this method is a direct method of measuring compliance and proves ingestion of the drug. The questionnaire designed by Morisky was easy to administer and analyze. The biggest disadvantage is that the results are subjective. The number of patients assessed as compliant was much higher with the survey than with electronic compliance measurement. However, the questionnaire might be helpful in detecting compliance problems in daily clinical practice. Patients reporting to have forgotten their drug intake, or to have stopped their drug intake when feeling better, can be instructed especially on these issues. We were not surprised that only few patients reported to have forgotten to take their immunosuppressants. Our study reaffirms the previously reported findings that self reports are not reliable measures of compliance." (pg 846)

\begin{tabular}{|c|c|c|}
\hline $\begin{array}{l}\text { Blinding of outcome as- } \\
\text { sessment (detection bias) } \\
\text { Adherence measure }\end{array}$ & Low risk & $\begin{array}{l}\text { (PRIMARY) MEMS - No blinding mentioned but outcome unlikely to be affected } \\
\text { by outcome assessor }\end{array}$ \\
\hline $\begin{array}{l}\text { Blinding of outcome as- } \\
\text { sessment (detection bias) } \\
\text { Patient outcome }\end{array}$ & Low risk & $\begin{array}{l}\text { (PRIMARY) REJECTION EPISODES - Objective outcome. Rejection episodes: his- } \\
\text { tologic diagnosis of rejection episodes was based on percutaneous liver biop- } \\
\text { sy. "The number of biopsy-proven rejection episodes were documented during } \\
\text { the entire study period and compared for both groups." (pg 842) }\end{array}$ \\
\hline
\end{tabular}

\begin{tabular}{|c|c|c|}
\hline $\begin{array}{l}\text { Blinding of participants } \\
\text { (performance bias) } \\
\text { Adherence measure }\end{array}$ & High risk & (PRIMARY) MEMS - No mention of patient blinding \\
\hline $\begin{array}{l}\text { Blinding of participants } \\
\text { (performance bias) } \\
\text { Patient outcome }\end{array}$ & Low risk & $\begin{array}{l}\text { (PRIMARY) REJECTION EPISODES - Objective outcome. Rejection episodes: his- } \\
\text { tologic diagnosis of rejection episodes was based on percutaneous liver biop- } \\
\text { sy. "The number of biopsy-proven rejection episodes were documented during } \\
\text { the entire study period and compared for both groups." (pg 842) }\end{array}$ \\
\hline
\end{tabular}

Blinding of personnel (per- Low risk formance bias) (PRIMARY) MEMS - Insufficient information about who the key personnel are Adherence measure but outcome unlikely to be affected

Blinding of personnel (per- Low risk formance bias) (PRIMARY) REJECTION EPISODES - Objective outcome. Rejection episodes: hisPatient outcome tologic diagnosis of rejection episodes was based on percutaneous liver biop- 
Klein 2009 (Continued)

sy. "The number of biopsy-proven rejection episodes were documented during the entire study period and compared for both groups." (pg 842)

\section{Incomplete outcome data Low risk \\ (attrition bias)}

Adherence measure
(PRIMARY) MEMS - Low risk of bias: "Two patients in the intervention group died before compliance data could be downloaded for the first time. Four patients in the intervention group and three patients in the control group used additional pill containers besides MEMS. Excluding these nine patients, the intervention group consisted of 20 patients and the control group of 21 patients." (pg 843)

(PRIMARY) REJECTION EPISODES - No incomplete data for this outcome are identified, but from the MEMS data it seems that "Two patients in the intervention group died before compliance data could be downloaded for the first time." Thus, probably no data were collected from these 2 patients

Knobel 1999

Methods Patients were randomly allocated using a 2:1 (control:intervention) ratio. There are no details about the randomization procedure or whether it allowed for concealment of allocation. The study was not blinded

There are no exclusion criteria. Inclusion criteria: all patients with HIV infection demonstrated by plas-
ma viral load $>5000$ copies/ml and CD4+ lymphocyte count $<600 \mathrm{X} 106 / \mathrm{L}$ initiating treatment with indi-
navir $(800 \mathrm{mg} / 8 \mathrm{~h})$, zidovudine ( $300 \mathrm{mg} / 12 \mathrm{~h})$, and lamivudine $(150 \mathrm{mg} / 12 \mathrm{~h})$. They included all patients
with HIV infection receiving prescription for this combination of agents from July 1996 to December
1997

All patients were treated with zidovudine + lamivudine + indinavir. Control patients $(n=110)$ received
conventional care in addition to the drug regimen (new refill every 2 months). Intervention patients $(n=$
60) received individualized counseling/assessments which consisted of adaptation of treatment to the
patient's lifestyle, detailed information about highly active antiretroviral therapy, phone support (for
questions or medication-related problems), and monthly visits to the HIV day clinic

Outcomes Measurement of compliance: compliance was estimated every 2 months using a structured interview and by pill counts. The same person conducted all compliance evaluations blind to viral load (not to allocation). Patients were considered to be compliant when: (1) they took more than $90 \%$ of their drugs; AND (2) $>90 \%$ of pill intakes should be according to a pre-specified schedule (hours between doses, relation between doses and meals); AND (3) fewer than 2 mistakes in pill intake per day Measurement of clinical health outcomes: undetectable viral load was measured, as was reduction in viral load and increase in CD4+ lymphocyte count

\begin{tabular}{lll}
\hline Notes & - \\
\hline Risk of bias & Authors' judgement & Support for judgement \\
\hline Bias & Randomization process not described \\
\hline $\begin{array}{l}\text { Random sequence genera- } \\
\text { tion (selection bias) }\end{array}$ & Unclear risk & Allocation concealment was not mentioned \\
\hline $\begin{array}{l}\text { Allocation concealment } \\
\text { (selection bias) }\end{array}$ & Unclear risk & There is not protocol; insufficient information provided to permit judgment \\
\hline $\begin{array}{l}\text { Selective reporting (re- } \\
\text { porting bias) }\end{array}$ & Unclear risk & \\
\hline
\end{tabular}


Knobel 1999 (Continued)

Other bias High risk This was an open study with self reported adherence measures - measurement bias

Blinding of outcome as- High risk

(PRIMARY) SELF REPORT - INTERVIEW - interviewers were not blind sessment (detection bias)

Adherence measure

\begin{tabular}{|c|c|c|}
\hline $\begin{array}{l}\text { Blinding of outcome as- } \\
\text { sessment (detection bias) }\end{array}$ & Low risk & $\begin{array}{l}\text { (PRIMARY) VIRAL LOAD - The study was open but the outcome is not likely to be } \\
\text { influenced by lack of blinding; objective measure }\end{array}$ \\
\hline
\end{tabular}

Patient outcome

\begin{tabular}{|c|c|c|}
\hline g of participants & High risk & (PRIMARY) SELF REPORT - INTERVIEW - Open study - subjective measure \\
\hline
\end{tabular}

(performance bias)

Adherence measure

Blinding of participants Low risk
(performance bias)
Patient outcome

Blinding of personnel (per- Unclear risk

formance bias)

Adherence measure

(PRIMARY) VIRAL LOAD - The study was open but the outcome is not likely to be influenced by lack of blinding; objective measure

$\begin{array}{ll}\begin{array}{l}\text { Blinding of personnel (per- } \\ \text { formance bias) }\end{array} & \text { Low risk } \\ \text { Patient outcome } & \begin{array}{l}\text { (PRIMARY) VIRAL LOAD - The study was open but the outcome is not likely to be } \\ \text { influenced by lack of blinding; objective measure }\end{array}\end{array}$

\begin{tabular}{|c|c|c|}
\hline $\begin{array}{l}\text { Incomplete outcome data } \\
\text { (attrition bias) } \\
\text { Adherence measure }\end{array}$ & Unclear risk & $\begin{array}{l}\text { (PRIMARY) SELF REPORT - INTERVIEW - The dropouts seem balanced among } \\
\text { the } 2 \text { groups. However, it is difficult to establish the effect on the results }\end{array}$ \\
\hline $\begin{array}{l}\text { Incomplete outcome data } \\
\text { (attrition bias) } \\
\text { Patient outcome }\end{array}$ & Unclear risk & $\begin{array}{l}\text { (PRIMARY) VIRAL LOAD - The dropouts seem balanced among the } 2 \text { groups. } \\
\text { However, it is difficult to establish the effect on the results }\end{array}$ \\
\hline
\end{tabular}

Kunutsor 2011

\begin{tabular}{ll}
\hline Methods & Randomized controlled trial \\
\hline Participants & The study location was Jinja Hospital HIV clinic, Jinja District, Uganda \\
& 87 participants were randomized to the intervention group and 87 participants were randomized to the \\
control group & \\
The inclusion criteria were adults (at least 18 years old), currently receiving ART, receiving the standard \\
adherence intervention package including the existing routine adherence counseling support and edu- \\
cation provided by the HIV clinic, and if they were all agreeable to have a treatment supporter
\end{tabular}

Interventions

Intervention: TREATMENT SUPPORTER (TS) INITIATIVE

Patients in the TS arm received both the TS intervention and the standard adherence intervention package. Elements of the standard intervention package consisted of self monitoring of medication taking using adherence diaries; regular individual and group education by peer-workers using patient education leaflets and tabletop flip-charts; and late attendee tracing. The treatment supporters were usually family members-usually a partner, mother, daughter, sister, brother, friend, or neighbor/friend-who were chosen by the patient with the assistance of the health workers, had accepted the patient's HIV status and were confidantes. These individuals were committed to support the patient with ART for a long time, had gained the patient's trust over time, and commanded respect. Pa- 
Kunutsor 2011 (Continued)

tients were asked to bring their chosen treatment supporter to the ART clinic for the health worker to explain about ART, adherence and treatment support. This includes commitment, confidentiality, knowledge on HIV and ART related needs, and perhaps emergency resource needs such as money, help with household, and children. Treatment supporters were educated with the following WHO Integrated Management of Adolescent and Adult Illness (IMAI) educational materials: Patient Education Flipchart, Patient Education Cards, and Caregiver Booklets. They were also educated on how to remind the patient to take their medicine, be present at the follow-up appointments, remember all important test results and clinic history over time, and to accompany patient to support group meetings if possible. Treatment supporter meetings were also held at the clinic every 2 or more weeks to deal with issues of burn out, patient non-adherence and other barriers to treatment and adherence

\section{Control: STANDARD ADHERENCE INTERVENTION}

Patients randomized to the control arm did not have a treatment supporter but otherwise received the same standard adherence intervention package including the ongoing existing health education and adherence counseling support that all patients received during routine monthly clinic visits. These existing interventions are typical for HIV/ AIDS treatment programs in Uganda and the rest of sub-Saharan Africa

Outcomes

The measures of adherence were an adherence assessment. Each client who reported to the health facility for their 4-weekly refill of ARV drugs had a clinic-based pill count conducted. Clients also answered an adherence assessment form. Zero adherence was awarded to patients who missed visits and were known not to have collected medications from the pharmacy, and those patients who were incapacitated or sick and were known not to have taken their medications

The patient outcome was confirmed deaths

Notes -

\section{Risk of bias}

Bias Authors' judgement Support for judgement

Random sequence genera- Low risk tion (selection bias)
Patients were randomized to a standard adherence intervention package plus treatment supporter (TS) intervention group versus the standard intervention package (non-TS) control group at a 1:1 allocation ratio (see Figure 1, trial profile). Randomization was performed using a computer-generated allocated sequence

Allocation concealment Unclear risk
(selection bias)

Not mentioned of allocation concealment in the article. (pg 1796) Patients were randomized to a standard adherence intervention package plus treatment supporter (TS) intervention group versus the standard intervention package (non-TS) control group at a 1:1 allocation ratio (see Figure 1, trial profile). Randomization was performed using a computer-generated allocated sequence

\begin{tabular}{|c|c|c|}
\hline $\begin{array}{l}\text { Selective reporting (re- } \\
\text { porting bias) }\end{array}$ & Unclear risk & No protocol available \\
\hline Other bias & Unclear risk & $\begin{array}{l}\text { The author indicate the following limitations: (pg1800) "Though informative, } \\
\text { our study had some limitations which merit consideration. Our study was orig- } \\
\text { inally powered to detect a 15\% increase in adherence after the intervention, } \\
\text { but then adherence levels were higher than anticipated for the control group } \\
\text { thereby rendering the small but 'real' increase in adherence between the two } \\
\text { groups statistically non-significant. It is possible this study was likely under- } \\
\text { powered for adherence outcomes. Considering the fact that very high levels } \\
\text { of adherence were exhibited by both treatment groups, any small difference } \\
\text { could be of clinical and substantive importance. We were not able to corrob- } \\
\text { orate attendance and adherence monitoring with more objective indicators } \\
\text { such as immunological, virological or clinical outcomes because of financial } \\
\text { constraints particularly the cost of additional laboratory monitoring in this set- }\end{array}$ \\
\hline
\end{tabular}


ting. The clinic-based pill count measure though less objective compared to Medication Event Monitoring System (MEMS) caps and HIV viral loads, it has been reported to be correlated with viral loads. Considering the fact that all participants were willing to identify treatment supporters, i.e. they all reported disclosure before enrollment, it is possible this could have attenuated potential benefits of treatment supporters since disclosure alone is a major predictor of adherence; it may be that we collected data from a cohort of highly motivated people who were prepared to gain the most from ART. The data was derived from a single site and so the results may not be generalizable to the whole country. Despite the various limitations, our study findings are very important and lend support to the results reported by Taiwo et al. in their randomized trial on treatment partners, that the use of patient-selected treatment supports is associated with improved adherence."

\begin{tabular}{|c|c|c|}
\hline $\begin{array}{l}\text { Blinding of outcome as- } \\
\text { sessment (detection bias) } \\
\text { Adherence measure }\end{array}$ & Unclear risk & (PRIMARY) PILL COUNT - Blinding not mentioned \\
\hline $\begin{array}{l}\text { Blinding of outcome as- } \\
\text { sessment (detection bias) } \\
\text { Patient outcome }\end{array}$ & High risk & $\begin{array}{l}\text { (PRIMARY) CLINIC ATTENDANCE - Author's note: adherence assessors were not } \\
\text { blinded. Quite impossible to blind in such operational research studies where } \\
\text { patients receive usual care }\end{array}$ \\
\hline
\end{tabular}

\begin{tabular}{|c|c|c|}
\hline $\begin{array}{l}\text { Blinding of participants } \\
\text { (performance bias) } \\
\text { Adherence measure }\end{array}$ & High risk & $\begin{array}{l}\text { (PRIMARY) PILL COUNT - Participants not blinded due to the nature of the in- } \\
\text { tervention }\end{array}$ \\
\hline
\end{tabular}

\begin{tabular}{|c|c|c|}
\hline $\begin{array}{l}\text { Blinding of participants } \\
\text { (performance bias) }\end{array}$ & High risk & $\begin{array}{l}\text { (PRIMARY) CLINIC ATTENDANCE - Patients aware of intervention and measure- } \\
\text { ment due to the nature of intervention }\end{array}$ \\
\hline
\end{tabular}

Blinding of personnel (per- High risk formance bias)

Patient outcome
Incomplete outcome data Unclear risk (attrition bias)

Adherence measure
(PRIMARY) CLINIC ATTENDANCE - Author's note: high risk of bias as key study personnel were not blinded

\section{Incomplete outcome data Unclear risk} (attrition bias)

Patient outcome

(PRIMARY) PILL COUNT - Missing data matched between the groups but reasons for missing data are not the same, therefore marked unclear

\section{Lai 2011}

\begin{tabular}{ll}
\hline Methods & Randomized controlled trial \\
\hline Participants & $\begin{array}{l}\text { The study location was University Malaya Medical Centre, Malaya Medical Centre, Kuala Lumpur, } \\
\text { Malaysia }\end{array}$ \\
& $\begin{array}{l}100 \text { participants were randomized to the intervention group and } 98 \text { participants were randomized to } \\
\text { the control group }\end{array}$
\end{tabular}


Lai 2011 (Continued)

The inclusion criteria were postmenopausal women who had just been diagnosed with osteoporosis, never on any active osteoporosis therapy within the past 6 months, and just been prescribed onceweekly alendronate. Patients who were either on alendronate or risedronate were included

The exclusion criteria were metabolic bone disease or any other medical conditions or treatment likely to affect bone metabolism, history of chronic renal, hepatic, or gastrointestinal disease or traumatic lumbar compression fracture

Interventions

Intervention: PHARMACIST COUNSELING

The intervention was enhanced pharmacist care. Patients were followed over a 12-month period that included 4 visits. All participants were given a 3-month supply of their drugs at each visit, and instructed on how to take their medications. Intervention participants received an explanation on osteoporosis, risk factors, lifestyle modifications, goals of osteoporosis therapy, side effects and the importance of medication adherence. Verbal counseling was reinforced with an osteoporosis booklet. The pharmacist also reviewed participant's medications and conducted monthly follow-up via telephone calls for the first 6 months, then every 3 months until month 12

Control: USUAL CARE

Participants were dispensed 3 months' supply of bisphosphonate and instructed on how to take their medications. Received no counseling

Outcomes

The measures of adherence were direct reporting, pill counts, and self recording. For direct reporting, patients were asked by a research assistant how many doses had been missed since the last meeting. This was assessed at month 3, 6, and 12 . Pill counts were taken at months 3, 6, and 12 by counting the number of pills left at each visit. Patients were asked to self record the date they took their medication

The patient outcomes were bone turnover markers (BTM). BTMs were measured 2 ways, serum C-terminal cross-linking telopeptide of type I collagen (CTX-I), a bone resorption marker and serum osteocalcin (OC), a bone formation marker. 6 tests were performed for each BTM over a 10-day period. Serum for BTM was collected at baseline, month 3 , and month 6 of the study

\section{Notes}

\section{Risk of bias}

\section{Bias Authors' judgement Support for judgement}

Random sequence genera- Low risk tion (selection bias)
Random number table used, so low risk of bias. (pg 559 sheet) "This study used a stratified block randomization design to ensure that the number of participants on alendronate and risedronate in the control and intervention group were the same. Therefore, participants were first divided into whether they were on alendronate or risedronate, then randomly allocated to the intervention group using the random digits table while the rest were allocated to the control group."

Allocation concealment Unclear risk
(selection bias)

No information about allocation concealment. "This study used a stratified block randomization design to ensure that the number of participants on alendronate and risedronate in the control and intervention group were the same. Therefore, participants were first divided into whether they were on alendronate or risedronate, then randomly allocated to the intervention group using the random digits table while the rest were allocated to the control group." (pg 557)

\begin{tabular}{|c|c|c|}
\hline $\begin{array}{l}\text { Selective reporting (re- } \\
\text { porting bias) }\end{array}$ & Unclear risk & No protocol available \\
\hline Other bias & Unclear risk & $\begin{array}{l}\text { The author notes the following: "...one of the limitations in this study is that } \\
\text { data were collected from only one site and hence cannot be considered as } \\
\text { population-based." (pg 565) "There was no significant difference between } \\
\text { the BTMs of the control and intervention participants in this study at } 3 \text { and }\end{array}$ \\
\hline
\end{tabular}


Lai 2011 (Continued)

6 months. The lack of significant correlation may be due to the already high medication adherence observed in both the control and intervention group and hence did not affect the BTMs. In addition, the half-life of bisphosphonates is very long and its serum levels are only transiently elevated after each dose. As a result, if adherence is interrupted at weekly intervals, most of the active sites will be only a few days old on an average and relatively little resorption will occur and hence, this small change will not be detected by the BTMs. Changes in the BTMs will only be detected if the patient stops bisphosphonate therapy for more than a month." (pg 565)

Blinding of outcome as- Low risk sessment (detection bias) (PRIMARY) DIRECT REPORTING - "An independent research assistant collected the data on medication adherence to minimize pharmacist interaction with Adherence measure control participants and to reduce intervention bias" (pg 559)

\begin{tabular}{|c|c|c|}
\hline $\begin{array}{l}\text { Blinding of outcome as- } \\
\text { sessment (detection bias) }\end{array}$ & Low risk & $\begin{array}{l}\text { (PRIMARY) BONE TURNOVER MARKER - This outcome is unlikely to be subject } \\
\text { to bias (objective outcome) }\end{array}$ \\
\hline
\end{tabular}

Patient outcome

Blinding of participants High risk
(performance bias)

Adherence measure

(PRIMARY) DIRECT REPORTING - No blinding or incomplete blinding, and the outcome is likely to be influenced by lack of blinding. Also there is potential for recall bias in this type of measure ( $p g$ 560)

Blinding of participants Low risk

(performance bias)

(PRIMARY) BONE TURNOVER MARKER - This outcome is unlikely to be subject

Patient outcome to bias (objective outcome)

Blinding of personnel (per- Low risk

formance bias)

(PRIMARY) DIRECT REPORTING - Self recorded by patients; unlikely other per-

Adherence measure sonnel could bias this outcome

Blinding of personnel (per- Low risk

formance bias)

(PRIMARY) BONE TURNOVER MARKER - This outcome is unlikely to be subject

Patient outcome to bias (objective outcome)

Incomplete outcome data Low risk

(attrition bias)

(PRIMARY) DIRECT REPORTING - Refer to Figure 2 for details. Adverse events:

Adherence measure 10 ; withdrew consent: 2 ; did not start biophosphate treatment 1 ; lost to follow-up: 6; deceased: 1 ; diagnosed with thalassemia: 1 . Missing outcome data balanced in numbers across intervention groups, with similar reasons for missing data across groups

Incomplete outcome data Low risk (attrition bias)

(PRIMARY) BONE TURNOVER MARKER - Refer to Figure 2 for details. Adverse Patient outcome events: 10; withdrew consent: 2; did not start biophosphate treatment 1; lost to follow-up: 6 ; deceased: 1 ; diagnosed with thalassemia: 1 . Missing outcome data balanced in numbers across intervention groups, with similar reasons for missing data across groups

\section{Laporte 2003}

\begin{tabular}{ll}
\hline Methods & $\begin{array}{l}\text { A } 2 \text { by } 2 \text { factorial design with patients randomly allocated to warfarin (long half-life) or acenocoumarol } \\
\text { (short-half life) and to either intensive education or standard education. Allocation concealment was } \\
\text { achieved by central computerized randomization balanced in blocks of 2, 4, and } 6 \text { patients }\end{array}$ \\
\hline Participants & $\begin{array}{l}\text { Patients over } 18 \text { years old were enrolled if they needed at least 3-month oral anticoagulant therapy } \\
\text { (OAT) following IV infusion for a thromboembolic disease. Patients were excluded if they were preg- } \\
\text { nant, had any contra-indication to anticoagulant therapy, recent surgery (<4 days) or progressive } \\
\text { bleeding }\end{array}$
\end{tabular}


Laporte 2003 (Continued)

Interventions

Patients assigned to warfarin received a dose of $6 \mathrm{mg}$ (up to 70 years old) or $4 \mathrm{mg}$ (over 70 years) those assigned to acenocoumarol received a dose of $4 \mathrm{mg}$ (up to 70 years old) or $3 \mathrm{mg}$ (over 70 years). Subsequent doses were adjusted to maintain the international normalized ratio (INR) within the target range of 2 to 3. Patients took a single dose of the oral anticoagulant (OA) daily at $8 \mathrm{pm}$. The standard education group received the minimum information consistent with ethical OAT with no particular emphasis on the necessity of strict compliance. Patients in the intensive education group received information about the causes of anticoagulation instability and the importance of strict adherence. The intensive education group were provided information through visual material, were visited daily by nurses and physicians to repeat some items, and were tested daily about their education. The education, either standard or intensive was given until hospital discharge

The number of tablets left in the bottle were recorded at follow-up at 1, 2, and 3 months
Measurement of clinical health outcomes: laboratory INR measurements were made in the morning
and recorded in the patient's diary. The raw INR levels, the \% of INRs in target range, the \% of time in
target range and \%age of dose adjustments were recorded. Follow-up visits were scheduled at 1,2 , and
3 months. During each visit patients were asked about their symptoms or bleeding events

Notes

The follow-up period was only 3 months but since the results proved to be negative it still meets the criteria for inclusion in the review

\section{Risk of bias}

\begin{tabular}{|c|c|c|}
\hline Bias & Authors' judgement & Support for judgement \\
\hline $\begin{array}{l}\text { Random sequence genera- } \\
\text { tion (selection bias) }\end{array}$ & Low risk & $\begin{array}{l}\text { Computer-generated. Centralized in the Clinical Pharmacology Unit. A tele- } \\
\text { phone call was needed to randomize the patients }\end{array}$ \\
\hline $\begin{array}{l}\text { Allocation concealment } \\
\text { (selection bias) }\end{array}$ & Low risk & $\begin{array}{l}\text { Allocation concealment described and appropriate. (pg 460) "Concealment of } \\
\text { allocation was received by central computerised randomisation. balanced in } \\
\text { groups of 2, } 4 \text { or } 6 \text { patients." }\end{array}$ \\
\hline $\begin{array}{l}\text { Selective reporting (re- } \\
\text { porting bias) }\end{array}$ & Low risk & $\begin{array}{l}\text { Author's note: the primary outcome was not a clinical endpoint, but the stabil- } \\
\text { ity of INR. All endpoints are reported in the paper }\end{array}$ \\
\hline Other bias & Low risk & No other risks of bias noted in discussion; no other clear risks of bias in article \\
\hline $\begin{array}{l}\text { Blinding of outcome as- } \\
\text { sessment (detection bias) } \\
\text { Adherence measure }\end{array}$ & Low risk & $\begin{array}{l}\text { (PRIMARY) MEMS - Although study personnel were not blinded (pg 459), this is } \\
\text { not likely to affect this outcome measure }\end{array}$ \\
\hline
\end{tabular}

\begin{tabular}{|c|c|c|}
\hline $\begin{array}{l}\text { Blinding of outcome as- } \\
\text { sessment (detection bias) } \\
\text { Patient outcome }\end{array}$ & Low risk & $\begin{array}{l}\text { (PRIMARY) INR VALUES - Author note: the primary endpoint was the stability of } \\
\text { INR. INR levels were blindly assessed }\end{array}$ \\
\hline $\begin{array}{l}\text { Blinding of participants } \\
\text { (performance bias) } \\
\text { Adherence measure }\end{array}$ & High risk & $\begin{array}{l}\text { (PRIMARY) MEMS - (pg 459) A } 2 \text { by } 2 \text { open randomized factorial design was } \\
\text { used. Patients were not told of the purpose of the pill cap but it is likely they } \\
\text { inferred the purpose of the cap. (pg 459) "The patients were not informed } \\
\text { about the full purpose of the pill bottle;only told that it recorded the number } \\
\text { of openings." }\end{array}$ \\
\hline $\begin{array}{l}\text { Blinding of participants } \\
\text { (performance bias) } \\
\text { Patient outcome }\end{array}$ & Low risk & $\begin{array}{l}\text { (PRIMARY) INR VALUES - Unclear if patients were blinded but IVT values are de- } \\
\text { termined by a blood test and difficult for patients to impact the outcome }\end{array}$ \\
\hline $\begin{array}{l}\text { Blinding of personnel (per- } \\
\text { formance bias) } \\
\text { Adherence measure }\end{array}$ & Low risk & $\begin{array}{l}\text { (PRIMARY) MEMS - Although study personnel were not blinded (pg 459), this is } \\
\text { not likely to affect this outcome measure }\end{array}$ \\
\hline
\end{tabular}


Laporte 2003 (Continued)

Blinding of personnel (per- Low risk $\quad$ (PRIMARY) INR VALUES - Author's note: the primary endpoint was the stability formance bias) of INR. INR levels were blindly assessed

Patient outcome

(PRIMARY) MEMS - Follow-up is balanced across groups. Reasons for loss to fol-

Incomplete outcome data Low risk

(attrition bias)

low-up provided and unlikely to affect study outcomes

Adherence measure

Incomplete outcome data Low risk

(attrition bias)

(PRIMARY) INR VALUES - Follow-up is balanced across groups. Reasons for loss

Patient outcome

to follow-up provided and unlikely to affect study outcomes

Larrey 2011

Methods Randomized controlled trial

Participants

The study location was Montpellier, Nimes, Bagnols/ceze, Beziers, Ales, Narbonne, Avignon, Arles, Perpignan, and Aix en Provence, France

123 participants were randomized to the intervention group and 121 participants were randomized to the control group

The inclusion criteria were age 18 to 65 years; chronic infection with either genotype 2 or genotype 3 $\mathrm{HCV}$; absolute neutrophil count $>=1500 \mathrm{~mm}^{3}$ and platelet count $>=100,000 \mathrm{~mm}^{3}$; no prior treatment for HCV

The exclusion criteria were any relevant concomitant medical condition; decompensated liver disease or cirrhosis, or other significant liver disease; human immunodeficiency virus or hepatitis B virus coinfection; peginterferon (Peg-IFN) or ribavirin (RBV) contraindication; a history of alcohol or illicit drug use; pregnancy/breast-feeding

Interventions

Intervention: NURSE EDUCATION

The nurse used a standardized questionnaire to evaluate the patient's understanding of the disease and the side effects of treatment. The nurse responded to any questions and informed the patient as thoroughly as possible with the means at his/her disposal, including by using explanatory texts and drawings. The nurse's goal during the consultation was to improve adherence. The following points were systematically covered: a) evaluation of the reasons for any eventual change in adherence; $b$ ) improvement of the quality of the patient-medical team relationship; c) explanation of para-clinical tests on therapeutic follow-up and discussion of the positive aspects of the results; d) facilitation of the quality of the patient's relationship with his/her family and/or professional milieu; e) increasing if necessary social service support for the patient. This consultation with the nurse took place in a standardized fashion, which was set out in a document to guide the consultation. All the nurses involved in these consultations had received prior training in the field of viral hepatitis and its treatment, and on the details of this study. The consultation lasted between 30 and 45 minutes. At the end of the consultation, the nurse filled out a standardized questionnaire build for this study and comprising 34 items in 8 groups. The patient could call the nurse free-of-charge if necessary outside the standard consultation dates

Control: USUAL CARE

The control group received conventional clinical follow-up. These patients did not receive consultation from the nurses

Outcomes

The measures of adherence were defined as the continuation of treatment as normally scheduled. Patients with early discontinuation were classified as non-adherent. These visits were systematic at the beginning of treatment day 0 , week 4 , week 8 , week 12 , week 24 , and in patients with 48 weeks of treatment at week 36 
Larrey 2011 (Continued)

The patient outcome was sustained virologic response (SVR). SVR was evaluated at 12 and 24 weeks after the end of treatment

\begin{tabular}{|c|c|c|}
\hline Notes & \multicolumn{2}{|c|}{ Substantial discontinuation of treatment. See table 3 in the article } \\
\hline \multicolumn{3}{|l|}{ Risk of bias } \\
\hline Bias & Authors' judgement & Support for judgement \\
\hline $\begin{array}{l}\text { Random sequence genera- } \\
\text { tion (selection bias) }\end{array}$ & Unclear risk & $\begin{array}{l}\text { Insufficient information about the sequence generation process to permit } \\
\text { judgment of 'Low risk' or 'High risk' }\end{array}$ \\
\hline $\begin{array}{l}\text { Allocation concealment } \\
\text { (selection bias) }\end{array}$ & Unclear risk & $\begin{array}{l}\text { Insufficient information about allocation concealment to permit judgment of } \\
\text { 'Low risk' or 'High risk' }\end{array}$ \\
\hline $\begin{array}{l}\text { Selective reporting (re- } \\
\text { porting bias) }\end{array}$ & Unclear risk & No protocol available \\
\hline Other bias & Unclear risk & $\begin{array}{l}\text { The authors noted: (pg.785) "The limitations of this study were the relatively } \\
\text { low number of participating patients and the choice to centralize therapeutic } \\
\text { education only to specialized nurse care. Other methods also probably would } \\
\text { be beneficial. Multidisciplinary protocols probably would improve results even } \\
\text { more. These avenues must be explored in controlled studies to validate the } \\
\text { notion of multidisciplinary management." }\end{array}$ \\
\hline
\end{tabular}

$\begin{array}{ll}\text { Blinding of outcome as- } & \text { High risk }\end{array}$ (PRIMARY) INTERVIEW WITH THE NURSE - Open-label trial

Adherence measure

\begin{tabular}{|c|c|c|}
\hline $\begin{array}{l}\text { Blinding of outcome as- } \\
\text { sessment (detection bias) } \\
\text { Patient outcome }\end{array}$ & Low risk & (PRIMARY) SUSTAINED VIROLOGICAL RESPONSE - Objective measure \\
\hline $\begin{array}{l}\text { Blinding of participants } \\
\text { (performance bias) } \\
\text { Adherence measure }\end{array}$ & High risk & (PRIMARY) INTERVIEW WITH THE NURSE - Open-label trial \\
\hline $\begin{array}{l}\text { Blinding of participants } \\
\text { (performance bias) } \\
\text { Patient outcome }\end{array}$ & Low risk & (PRIMARY) SUSTAINED VIROLOGICAL RESPONSE - Objective measure \\
\hline
\end{tabular}

Blinding of personnel (per- High risk
formance bias)

formance bias)

Adherence measure

\begin{tabular}{|c|c|c|}
\hline $\begin{array}{l}\text { Blinding of personnel (per- } \\
\text { formance bias) } \\
\text { Patient outcome }\end{array}$ & Low risk & (PRIMARY) SUSTAINED VIROLOGICAL RESPONSE - Objective measure \\
\hline $\begin{array}{l}\text { Incomplete outcome data } \\
\text { (attrition bias) } \\
\text { Adherence measure }\end{array}$ & Unclear risk & $\begin{array}{l}\text { (PRIMARY) INTERVIEW WITH THE NURSE - } 6 \text { patients refused treatment in } \\
\text { group B. Large number of discontinuations }\end{array}$ \\
\hline
\end{tabular}

Adherence measure

$\begin{array}{ll}\begin{array}{l}\text { Incomplete outcome data } \\ \text { (attrition bias) }\end{array} & \text { Unclear risk } \\ \begin{array}{l}\text { (PRIMARY) SUSTAINED VIROLOGICAL RESPONSE - } 6 \text { patients refused treatment } \\ \text { in group B. Large number of discontinuations }\end{array}\end{array}$


Lee 2006

\begin{tabular}{|c|c|}
\hline Methods & $\begin{array}{l}\text { Patients ( } n=159) \text { were randomized to either usual care }(n=76) \text { or continued pharmacy care }(n=83) \text { in } \\
\text { a 1:1 ratio using a computer-generated random number sequence. Patients were randomized in blocks } \\
\text { based on the level of baseline medication adherence (above or below } 55 \% \text { baseline adherence). Nei- } \\
\text { ther the participants nor the clinical pharmacists assessing the outcomes were blind to the study group } \\
\text { assignment }\end{array}$ \\
\hline
\end{tabular}

$\begin{array}{ll}\text { Participants } & \text { Patients were from the Walter Reed Army Medical Center and were elderly men and women (> } 65 \text { years) } \\ \text { taking } 4 \text { or more chronic medications daily. Patients were excluded from the study if they did not live } \\ \text { independently or in the presence of any serious medical condition for which 1-year survival was expect- } \\ \text { ed to be unlikely }\end{array}$

Interventions

The intervention entailed a comprehensive pharmacy care program that consisted of 3 elements, including individualized medication education (using standardized scripts), medications dispensed using an adherence aid (blister packs) and regular follow-up with clinical pharmacists every 2 months. All medications were provided to patients in customized blister packs filled by pharmacy technicians and checked by clinical pharmacists. Patients were instructed to tape any medications not taken back into the blister pack, to account for any selective adherence. Usual care was defined as returning to their baseline (pre-study) status of medication provision; however, medication education and blister-packed medications were not provided. For the usual care group in phase 2, all medications were provided in new pill bottles with a 90-day supply and 1 refill prescription

Outcomes Compliance for the randomized stage was measured by the persistence of mean medication adherence. The clinical endpoints of the randomized stage were the changes in BP and LDL-C at study month 14

Notes -1

\section{Risk of bias}

Bias Authors' judgement Support for judgement

Random sequence genera- Low risk tion (selection bias)

Computerized random number generation employed. (pg 2565) "Patients were randomized to either usual care or continued pharmacy care in a 1:1 ratio using a computer generated random number sequence."

\begin{tabular}{|c|c|c|}
\hline $\begin{array}{l}\text { Allocation concealment } \\
\text { (selection bias) }\end{array}$ & Low risk & $\begin{array}{l}\text { "Allocation was concealed to both patients and the study personnel who en- } \\
\text { rolled participants by central control of the randomization sequence." (pg } \\
2565 \text { ) }\end{array}$ \\
\hline
\end{tabular}

$\begin{array}{ll}\begin{array}{l}\text { Selective reporting (re- } \\ \text { porting bias) }\end{array} & \begin{array}{l}\text { There is no obvious selective reporting bias. Protocol not available therefore } \\ \text { marked as uncertain }\end{array}\end{array}$

Other bias $\quad$ Unclear risk The authors note the following limitations: 1 . Study subjects were receiving drugs without financial constraints - military personnel. (pg 2570) "within the military health care system, all medications are provided at no cost to the patient, thereby removing financial constraints as a barrier to adherence. This characteristic of the military health care system created an optimal environment for this study, but potentially limits the generalizability of our findings to clinical populations in which financial barriers to medication acquisition are present." 2. Study population excluded those living in assisted care facilities

\begin{tabular}{|c|c|c|}
\hline $\begin{array}{l}\text { Blinding of outcome as- } \\
\text { sessment (detection bias) } \\
\text { Adherence measure }\end{array}$ & High risk & $\begin{array}{l}\text { (PRIMARY) PILL COUNT - "Because of the nature of the intervention, it was not } \\
\text { possible to blind either the participants or the clinical pharmacists assessing } \\
\text { the outcomes to the study group assignment." (pg 2566) }\end{array}$ \\
\hline
\end{tabular}


Lee 2006 (Continued)

Blinding of outcome as- Unclear risk $\quad$ (PRIMARY) BLOOD PRESSURE MEASURE - "Because of the nature of the intersessment (detection bias) vention, it was not possible to blind either the participants or the clinical pharPatient outcome macists assessing the outcomes to the study group assignment." (pg 2566)

$\begin{array}{ll}\begin{array}{l}\text { Blinding of participants } \\ \text { (performance bias) }\end{array} & \text { High risk } \\ \text { Adherence measure } & \begin{array}{l}\text { (PRIMARY) PILL COUNT - "Because of the nature of the intervention, it was not } \\ \text { possible to blind either the participants or the clinical pharmacists assessing } \\ \text { the outcomes to the study group assignment." (pg 2566) }\end{array}\end{array}$

Adherence measure

(PRIMARY) BLOOD PRESSURE MEASURE - Objective outcome, automated

Blinding of participants Low risk

(performance bias) sphygmomanometer was used to obtain the BPs

Patient outcome

Blinding of personnel (per- High risk

formance bias)

Adherence measure

Blinding of personnel (per- Low risk

formance bias)

Patient outcome
(PRIMARY) PILL COUNT - "Because of the nature of the intervention, it was not possible to blind either the participants or the clinical pharmacists assessing the outcomes to the study group assignment." (pg 2566)

$\begin{array}{ll}\begin{array}{l}\text { Incomplete outcome data } \\ \text { (attrition bias) }\end{array} & \text { Low risk } \\ \text { Adherence measure } & \text { (PRIMARY) PILL COUNT - } 7 \text { from control and } 6 \text { from intervention missing, simi- } \\ \text { lar reasons - uniform. ITT analysis done }\end{array}$

(PRIMARY) BLOOD PRESSURE MEASURE - Objective outcome, automated sphygmomanometer was used to obtain the BPS

(PRIMARY) PILL COUNT - 7 from control and 6 from intervention missing, simi(PRIMARY) BLOOD PRESSURE MEASURE - 7 from control and 6 from interven-

tion missing, similar reasons - uniform. ITT analysis done

Incomplete outcome data Low risk

(attrition bias)

Patient outcome

\section{Lester 2010}

\begin{tabular}{|c|c|}
\hline Methods & Randomized controlled trial \\
\hline \multirow[t]{3}{*}{ Participants } & $\begin{array}{l}\text { The study location was The University of Nairobi Pumwani Clinic, Coptic Hope Center for Infectious Dis- } \\
\text { eases, The Kajiado Clinic, Kenya }\end{array}$ \\
\hline & $\begin{array}{l}273 \text { participants were randomized to the intervention group and } 265 \text { participants were randomized to } \\
\text { the control group }\end{array}$ \\
\hline & $\begin{array}{l}\text { The inclusion criteria were over } 18 \text { years old, initiating ART for the first time, and able to access a mo- } \\
\text { bile phone on a near-daily basis and communicate via short message service (SMS). People who did } \\
\text { not own mobile phones were eligible if they had shared access (with corroborative agreement by the } \\
\text { phone owner), and illiterate patients were eligible if assisted by a literate partner. Participants used ex- } \\
\text { isting mobile phone services; phones and network airtime credit were not provided }\end{array}$ \\
\hline
\end{tabular}

All intervention group participants were given brief training about the use of SMS intervention by the study clinicians. On Monday morning of each week, the site nurse or clinical officer sent a text message via SMS to patients in the intervention group to inquire about their status and thus to remind them about the availability of phone-based support. Regular, structured mobile phone communication between healthcare workers and patients could improve patient outcomes by both reminding patients to take their ART and by providing support to the patients. Patients in the intervention group were instructed to respond within 48 hours that either they were doing well or that they had a problem. The clinician then called patients who said they had a problem or who failed to respond within 2 days. Participants were instructed that healthcare workers were available to respond during clinic hours only

Control: USUAL CARE 
Lester 2010 (Continued)

Control group is standard care. Standard care at Kijaiado study site included providing one counseling session at ART initiation and at the 2 Nairobi sites included providing 2 counseling sessions before and one session 1 month after ART initiation. Disclosure of HIV status, pairing up with a treatment adherence partner, and participation in support groups was encouraged but not insisted upon. Additional brief counseling was provided at each site during dispensation of the drugs in the clinic or pharmacy. Patients did not receive weekly SMS

Outcomes

The measures of adherence were self reported adherence, measured at 6 and 12 months followed. Participants were asked how many pills they missed in the past 30 days, and classified as adherent if they reported that they had taken more than $95 \%$ of the provided pills

The patient outcome was suppression of plasma HIV-1 viral load. Participants were classed as virologically suppressed if their plasma HIV-1 RNA load at their 12-month visit was 400 copies per ml or less. Patients who did not achieve this outcome were classed as virologic failures. Plasma was taken from patients at the 12-month visit for assessment of HIV-1 RNA viral load (Amplicor, Roche Diagnostics, Mannheim, Germany) and was stored and analyzed at a later time point in batches. Laboratory assays (CD4 count and HIV-1 RNA load) were all done at a central laboratory (University of Nairobi Institutes for Tropical and Infectious Diseases). CD4 count testing (FACScan, Becton Dickinson, Sunnyvale, CA, USA) was part of routine care at the urban sites and was provided for study purposes at the rural site

Notes -

\section{Risk of bias}

Bias Authors' judgement Support for judgement

Random sequence genera- Low risk tion (selection bias)
"Patients were randomised (1:1) by simple randomisation with a random number generating program to a mobile phone short message service (SMS) intervention or standard care." (pg 1838. "WelTel Kenya1 was an individually randomised, parallel, multisite controlled trial. Patients were randomly assigned (1:1) by simple randomisation 15 to the SMS intervention or to standard care (control group). A project statistician generated the randomisation numbers with a random number generating program." (pg 1839)

\begin{tabular}{|c|c|c|}
\hline $\begin{array}{l}\text { Allocation concealment } \\
\text { (selection bias) }\end{array}$ & Low risk & $\begin{array}{l}\text { "Written allocation of assignment was sealed in individual opaque envelopes } \\
\text { marked with study identification numbers, which were distributed to all three } \\
\text { study clinics." (pg 1839) }\end{array}$ \\
\hline
\end{tabular}

Selective reporting (re- Unclear risk porting bias)

They do not report on all of the predefined secondary outcomes, but they state that "Other predefined secondary endpoints, including quality of life and social and economic outcomes, will be reported separately." (pg 1840). CD4 cell count is reported for baseline but no results from follow-up is reported. "CD4 count testing (FACScan, Becton Dickinson, Sunnyvale, CA, USA) was part of routine care at the urban sites and was provided for study purposes at the rural site." (pg 1840)

\begin{tabular}{|c|c|c|}
\hline Other bias & Unclear risk & $\begin{array}{l}\text { Author's note: risk of bias is unclear because contamination would have to be } \\
\text { quite substantial for it to pose a high risk of bias }\end{array}$ \\
\hline
\end{tabular}

Blinding of outcome as- Unclear risk sessment (detection bias) Adherence measure (PRIMARY) SELF REPORT - INTERVIEW - Not blinded (pg 1839), but probably would not have influenced patient responses

\begin{tabular}{lll}
\hline $\begin{array}{l}\text { Blinding of outcome as- } \\
\text { sessment (detection bias) } \\
\text { Patient outcome }\end{array}$ & Low risk & $\begin{array}{l}\text { (PRIMARY) VIRAL LOAD - Objective outcome. Also, all analysis "...were done by } \\
\text { investigators masked to treatment allocation." }\end{array}$ \\
\hline $\begin{array}{l}\text { Blinding of participants } \\
\text { (performance bias) }\end{array}$ & High risk & $\begin{array}{l}\text { (PRIMARY) SELF REPORT - INTERVIEW - The authors indicate this measure may } \\
\text { Adherence measure }\end{array}$ \\
\hline
\end{tabular}


ported in the intervention group contributed to the positive intervention effect for the primary outcomes. When only available data were included in the complete-case analyses, a significant reduction was preserved in viral suppression but not in self reported adherence. This could be because of a recall or social desirability bias in self reporting adherence among those who were followed up. Alternatively, patients might have been less likely to respond to follow-up if they had not adhered to ART. Nonetheless, we chose an intention-to-treat analysis for the primary outcome because contributions of loss to follow-up are important indicators for the durable implementation of ART programs

$\begin{array}{ll}\begin{array}{l}\text { Blinding of participants } \\ \text { (performance bias) }\end{array} & \text { Low risk } \\ \begin{array}{l}\text { Patient outcome } \\ \text { (PRIMARY) VIRAL LOAD - Study participants were not masked to treatment; but } \\ \text { this is an measure of outcome. Thus the outcome measurement is not likely to } \\ \text { be influenced by lack of blinding }\end{array}\end{array}$

Blinding of personnel (per- Low risk formance bias)

(PRIMARY) SELF REPORT - INTERVIEW - Not blinded (pg 1839), but probably Adherence measure would not have influenced patient responses

\begin{tabular}{lll}
\hline $\begin{array}{l}\text { Blinding of personnel (per- } \\
\text { formance bias) } \\
\text { Patient outcome }\end{array}$ & Low risk & $\begin{array}{l}\text { (PRIMARY) VIRAL LOAD - Objective outcome. Also, all analysis "...were done by } \\
\text { investigators masked to treatment allocation" }\end{array}$ \\
\hline $\begin{array}{l}\text { Incomplete outcome data } \\
\text { (attrition bias) }\end{array}$ & Low risk & $\begin{array}{l}\text { (PRIMARY) SELF REPORT - INTERVIEW - Total attrition (missing) from SMS } \\
\text { gdherence measure }\end{array}$ \\
& $\begin{array}{l}\text { low-up, mortality, withdrawal, transfer out. Refer to Table } 2 . \text { Missing outcome } \\
\text { data balanced in numbers across intervention groups, with similar reasons for } \\
\text { missing data across groups }\end{array}$
\end{tabular}

\begin{tabular}{|c|c|c|}
\hline $\begin{array}{l}\text { Incomplete outcome data } \\
\text { (attrition bias) } \\
\text { Patient outcome }\end{array}$ & Low risk & $\begin{array}{l}\text { (PRIMARY) VIRAL LOAD - Total attrition (missing) from SMS group is } 53(19 \%) \\
\text { and standard care is } 61 \text { (23\%). The reasons are loss to follow-up, mortality, } \\
\text { withdrawal, transfer out. Refer to Table } 2 . \text { Missing outcome data balanced in } \\
\text { numbers across intervention groups, with similar reasons for missing data } \\
\text { across groups }\end{array}$ \\
\hline
\end{tabular}

Levy 2000

Methods Patients were randomized consecutively into intervention and control groups using equal blocks of 4 generated using the Clinstat program. This was done by the 2 nurses at their respective hospitals, by first producing 2 patient lists, by date order of receipt of their consent forms i) completed when attending or ii) returned by post. 108 patients were randomly allocated into the control group, and 103 patients were randomly allocated into the intervention group. Study nurses were not blinded to allocation after randomization occurred

Participants

211 patients over 18 years old attending the emergency room department for asthma were included. Exclusion criteria were not specified, except that patients with a previously recorded diagnosis of chronic obstructive pulmonary disease were excluded

Interventions The intervention group was invited to attend a 1-hour consultation with one of the nurses beginning
2 weeks after entry to the study, followed by 2 or more lasting half an hour, at 6 -weekly intervals. The
second and third could be substituted by a telephone call. Patients were phoned, by the nurse before
each appointment in order to improve attendance rates. Patient's asthma control and management
were assessed followed by education on recognition and self treatment of episodes of asthma. The pa-
tients were taught to step-up medication when they recognized uncontrolled asthma using peak ex-
piratory flow (PEF) or symptoms. The advice was in accordance with national guideline. Prescriptions
were obtained from one of the doctors in the clinic or by providing the patient with a letter to their gen-
eral practitioner. Patients presenting with severe asthma (severe symptoms of PEF below $60 \%$ of their 
Levy 2000 (Continued)

best/normal) were referred immediately to the consultant. Patients in the control group continued with their usual medical treatment and were not offered any intervention during the study period

\section{Outcomes}

Measurement of compliance: the primary outcome was the patients' reported, appropriate adherence to self management of mild attacks within the previous 2 weeks or severe attacks in the previous 6 weeks

Measurement for clinical health outcomes: home peak flow and symptom diaries. Patients recorded the best of 3 PEF readings in the morning and evening, and also recorded symptom scores daily for 7 days. Quality of life was also assessed using the St. George's Respiratory Questionnaire (SGRQ), and patients use of medical services was assessed

Notes -

\section{Risk of bias}

\begin{tabular}{lll} 
Bias & Authors' judgement & Support for judgement \\
\hline $\begin{array}{l}\text { Random sequence genera- } \\
\text { tion (selection bias) }\end{array}$ & Low risk & $\begin{array}{l}\text { Computer-generated randomization schedule. (pg 901) "Patients were ran- } \\
\text { domized consecutively into intervention and control groups using equal } \\
\text { blocks of four generated using the Clinstat program developed by Martin }\end{array}$ \\
& $\begin{array}{l}\text { Bland (http://www.sghms.ac.uk/depts/phs/sta?/ jmb). This was done by the } \\
\text { two nurses at their respective hospitals, by first producing two patient lists, } \\
\text { by date order of receipt of their consent forms (i) completed when attending } \\
\text { or (ii) returned by post. Patients who had a previously recorded diagnosis of } \\
\text { chronic obstructive pulmonary disease were excluded." }\end{array}$
\end{tabular}

\begin{tabular}{lll}
\hline $\begin{array}{l}\text { Allocation concealment } \\
\text { (selection bias) }\end{array}$ & Unclear risk & $\begin{array}{l}\text { The authors state (pg 901) that "The nurses had no idea which group the pa- } \\
\text { tients would be randomized into". However, the technique used is not stated. } \\
\text { Also randomization was not central - was done at the } 2 \text { study centres by nurses }\end{array}$ \\
\hline $\begin{array}{l}\text { Selective reporting (re- } \\
\text { porting bias) }\end{array}$ & Unclear risk & No protocol available \\
\hline Other bias & Unclear risk & $\begin{array}{l}\text { The authors note the following: (pg 907) "We could be criticized that our sam- } \\
\text { ple is not representative of the population at large". No other bias noted }\end{array}$ \\
\hline
\end{tabular}

Blinding of outcome as- Low risk sessment (detection bias) Adherence measure

(PRIMARY) SELF REPORT - QUESTIONNAIRE - Outcome assessors were blinded - (pg 901) "An interviewer (MR), blinded to the patients randomization status, conducted four structured telephone interviews using the St George's Respiratory Questionnaire (SGRQ) (6) and an assessment questionnaire, described below. The first, third and fourth interviews included the SGRQ and the complete assessment questionnaire and the second only included the self management sections of the assessment questionnaire. Interviews took place at about 2 weeks after randomization (baseline), 6 weeks, 3 and 6 months after randomization".

\begin{tabular}{|c|c|c|}
\hline $\begin{array}{l}\text { Blinding of outcome as- } \\
\text { sessment (detection bias) } \\
\text { Patient outcome }\end{array}$ & Low risk & $\begin{array}{l}\text { (PRIMARY) SYMPTOM DIARY CARD - Outcome assessors were blinded - (pg 901) } \\
\text { "An interviewer (MR), blinded to the patients randomization status, conducted } \\
\text { four structured telephone interviews using the St George's Respiratory Ques- } \\
\text { tionnaire (SGRQ) (6) and an assessment questionnaire, described below. The } \\
\text { first, third and fourth interviews included the SGRQ and the complete assess- } \\
\text { ment questionnaire and the second only included the self management sec- } \\
\text { tions of the assessment questionnaire. Interviews took place at about } 2 \text { weeks } \\
\text { after randomization (baseline), } 6 \text { weeks, } 3 \text { and } 6 \text { months after randomization" }\end{array}$ \\
\hline
\end{tabular}

\begin{tabular}{|c|c|c|}
\hline $\begin{array}{l}\text { Blinding of participants } \\
\text { (performance bias) }\end{array}$ & High risk & $\begin{array}{l}\text { (PRIMARY) SELF REPORT - QUESTIONNAIRE - No mention of patient blinding; } \\
\text { subjective outcome }\end{array}$ \\
\hline
\end{tabular}


Levy 2000 (Continued)

Blinding of participants High risk $\quad$ (PRIMARY) SYMPTOM DIARY CARD - No mention of patient blinding; subjective (performance bias) outcome

Patient outcome

Blinding of personnel (per- High risk formance bias)

Adherence measure
(PRIMARY) SELF REPORT - QUESTIONNAIRE - Nurses were not blind to groups: "The nurses had no idea which group the patients would be randomized into, however, once randomized they became aware in order to proceed and invite intervention group patients to attend."

Blinding of personnel (per- Unclear risk

formance bias)

(PRIMARY) SYMPTOM DIARY CARD - Nurses were unblinded but were likely not

Patient outcome involved in outcome measurement

Incomplete outcome data Unclear risk

(PRIMARY) SELF REPORT - QUESTIONNAIRE - Reasons for dropouts unclear

(attrition bias)

Adherence measure

Incomplete outcome data Low risk

(attrition bias)

Patient outcome

\begin{abstract}
(PRIMARY) SYMPTOM DIARY CARD - There was some loss of subjects returning diary cards during the study, but the loss was similar in the 2 groups (Table 3). We considered that selective dropout of patients during the study may explain the significant results at 6 months, however Table 7 shows data at 3 months for those subjects having data at 6 months only. The differences are very similar to those for the whole group at 3 months, and not like those at 6 months. Thus we cannot ascribe the differences between treatment and control subjects at 6 months to selective dropout (pg 904)
\end{abstract}

\title{
Maitland 2008
}

Methods Randomized controlled trial

Participants

The study location was not reported

48 participants were randomized to the intervention group and 48 participants were randomized to the control group

The inclusion criteria were HIV-1 infected patients with established viral load below the limits of assay detection (< 50 HIV-1 RNA copies/ml), taking separate abacavir (ABC) $300 \mathrm{mg}$ and lamivudine (3TC) 150 $\mathrm{mg}$ bid in combination with any other antiretroviral agent(s) suitable for once daily dosing, and be stable for 16 weeks prior to screening

The exclusion criteria were pregnancy or declined the use of effective contraception, had a proven or suspected active opportunistic infection, weighed less than $40 \mathrm{~kg}$ or had a creatinine clearance $<50 \mathrm{ml} /$ $\min$

Interventions Intervention: ONCE DAILY DOSING

Patients were switched to a fixed-dose combination tablet of $A B C$ and 3TC dosed once-daily. All other antiretroviral agent(s) in the patient's regimen were dosed once-daily from or before screening

Control: USUAL DOSING (TWICE DAILY)

Patients remained on $A B C$ and 3TC twice daily. All other antiretroviral agent(s) in the patient's regimen were dosed once daily from or before screening

\section{Outcomes}

The measures of adherence were drug monitoring via MEMS. At baseline patients in arm 1 had the fixed-dose combination tablet of ABC and 3TC dispensed in a bottle with a MEMS cap, while patients in arm 2 had their 3TC dispensed in a bottle with a MEMS cap. Data were collected at week 4 . Patients were advised only to open the bottle at the time of dosing and were aware of the function of the MEMS cap. MEMS data were calculated in 3 ways. Taking compliance (TAC) (the percentage of prescribed number of doses taken); correct dosing compliance (COD) (the percentage of days with correct number 
of doses taken); and timing compliance (TIC) (the percentage of doses taken within beta 3 hours of the prescribed dosing interval)

The patient outcomes were viral load and hospital anxiety and depression (HAD). Viral load was measured at baseline and at 4 weeks. HAD was measured with a questionnaire at baseline and 4 weeks

Notes Only looking at results at 4 weeks - before the control group got switched to treatment

\section{Risk of bias}

\begin{tabular}{lll}
\hline Bias & Authors' judgement & Support for judgement \\
\hline $\begin{array}{l}\text { Random sequence genera- } \\
\text { tion (selection bias) }\end{array}$ & Unclear risk & $\begin{array}{l}\text { Sequence generation not specified. Eligible patients were randomized (using } \\
\text { shuffled opaque envelopes in a 1:1 ratio) at baseline to either switch immedi- } \\
\text { ately to the fixed-dose combination tablet of ABC and } 3 T C \text { dosed once daily } \\
\text { (arm 1) or to remain on ABC and 3TC twice daily until week } 4 \text { before switching } \\
\text { to the fixed-dose combination tablet of the } 2 \text { agents for the final } 4 \text { weeks of the } \\
\text { study (arm 2) }\end{array}$ \\
&
\end{tabular}

\begin{tabular}{ll}
\hline $\begin{array}{l}\text { Allocation concealment } \\
\text { (selection bias) }\end{array}$ & $\begin{array}{l}\text { Sealed, opaque envelopes. Eligible patients were randomized (using shuffled } \\
\text { opaque envelopes in a 1:1 ratio) at baseline to either switch immediately to } \\
\text { the fixed-dose combination tablet of ABC and 3TC dosed once daily (arm 1) } \\
\text { or to remain on ABC and 3TC twice daily until week } 4 \text { before switching to the } \\
\text { fixed-dose combination tablet of the } 2 \text { agents for the final } 4 \text { weeks of the study } \\
\text { (arm 2) }\end{array}$ \\
\hline
\end{tabular}

Selective reporting (re- Unclear risk No protocol available
porting bias)

\begin{tabular}{|c|c|c|}
\hline Other bias & Low risk & None noted \\
\hline $\begin{array}{l}\text { Blinding of outcome as- } \\
\text { sessment (detection bias) } \\
\text { Adherence measure }\end{array}$ & Low risk & (PRIMARY) MEMS - The lack of blinding is not likely to affect the outcome \\
\hline $\begin{array}{l}\text { Blinding of outcome as- } \\
\text { sessment (detection bias) } \\
\text { Patient outcome }\end{array}$ & High risk & $\begin{array}{l}\text { (PRIMARY) HAD SCORE - Open-label study - staff not blinded; therefore high } \\
\text { risk of bias }\end{array}$ \\
\hline
\end{tabular}

\begin{tabular}{|c|c|c|}
\hline $\begin{array}{l}\text { Blinding of participants } \\
\text { (performance bias) } \\
\text { Adherence measure }\end{array}$ & High risk & $\begin{array}{l}\text { (PRIMARY) MEMS - Patients could open bottle and not take medication (or take } \\
\text { medication out and then not open bottle later when actually taken) }\end{array}$ \\
\hline
\end{tabular}

\begin{tabular}{|c|c|c|}
\hline $\begin{array}{l}\text { Blinding of participants } \\
\text { (performance bias) } \\
\text { Patient outcome }\end{array}$ & High risk & $\begin{array}{l}\text { (PRIMARY) HAD SCORE - Open-label study - staff not blinded; therefore high } \\
\text { risk of bias }\end{array}$ \\
\hline
\end{tabular}

Blinding of personnel (per- Low risk
formance bias)
Adherence measure

\begin{tabular}{|c|c|c|}
\hline $\begin{array}{l}\text { Blinding of personnel (per- } \\
\text { formance bias) } \\
\text { Patient outcome }\end{array}$ & High risk & $\begin{array}{l}\text { (PRIMARY) HAD SCORE - Open-label study - staff not blinded; therefore high } \\
\text { risk of bias }\end{array}$ \\
\hline $\begin{array}{l}\text { Incomplete outcome data } \\
\text { (attrition bias) } \\
\text { Adherence measure }\end{array}$ & Low risk & $\begin{array}{l}\text { (PRIMARY) MEMS - "No randomized patients were lost to follow-up or failed to } \\
\text { complete all study visits." (pg 669) }\end{array}$ \\
\hline
\end{tabular}


Maitland 2008 (Continued)

Incomplete outcome data (attrition bias)

Patient outcome
Low risk

(PRIMARY) HAD SCORE - "No randomized patients were lost to follow-up or failed to complete all study visits." (pg 669)

Margolius 2012

\begin{tabular}{ll}
\hline Methods & Randomized controlled trial \\
\hline Participants & The study location was the Family Health Center in San Francisco General Hospital, San Francisco, USA \\
& $\begin{array}{l}129 \text { participants were randomized to the intervention group and } 108 \text { participants were randomized to } \\
\text { the control group }\end{array}$
\end{tabular}

The inclusion criteria were patients with blood pressures of at least 145 systolic or at least 90 diastolic $\mathrm{mmHg}$, measured by the medical assistant at the enrollment visit and at least 1 previous visit in the last 12 months (based on chart review)

The exclusion criteria were an age of younger than 30 years; not speaking English, Spanish, Cantonese, or Vietnamese; a creatinine level of greater than $1.5 \mathrm{mg} / \mathrm{dl}$; New York Heart Association class III or IV heart failure; a life expectancy of less than 1 year; or being identified by one's primary care clinician as unable to follow instructions because of physical or cognitive disability, psychiatric illness, or other reasons

Clinicians of patients in the home-titration arm completed an algorithm of antihypertensive medication adjustments. Health coaches made weekly telephone calls to participants in both study arms to discuss overall well-being, adherence to action plans, and blood pressure values. Patients in the hometitration arm who reported blood pressure greater than $140 \mathrm{mmHg}$ systolic or greater than $90 \mathrm{mmHg}$ diastolic and excellent medication adherence could choose to increase their antihypertensive medication regimen according to the algorithm without a clinician appointment. In those cases, health coaches notified a physician investigator to fax the prescription to the pharmacy. Clinicians were notified of medication changes by e-mail, and health coaches entered the change in the electronic health record. The duration of the intervention was 6 months

\section{Control: NO HOME TITRATION}

Home monitoring and health coaching alone (no home-titration arm), included health coaches made weekly telephone calls to participants in both study arms to discuss overall well-being, adherence to action plans, and blood pressure values. The duration of the intervention was 6 months

\section{Outcomes}

The measures of adherence were self reported medication adherence. Health coaches recorded the number of days in the past week patient reported having missed taking a blood pressure medication. 6 months after study completion, patients' electronic health records were reviewed for the number of blood pressure medications at enrollment and at 6 months

The patient outcomes were blood pressure and number of visits at primary care office. Systolic blood pressure was the primary outcome. Blood pressure was measured at baseline and 6 months. Patients were asked to come to the clinic, and blood pressure was measured by the medical assistant using the standard procedures: patients were seated at the nurse station for at least 5 minutes before blood pressures were measured with an automated machine on $1 \mathrm{arm}$. Electronic records were used to obtain information about the number of primary care visits made by each patient in the 6 month before, during and after the study.

Notes -

\section{Risk of bias}

Bias Authors' judgement Support for judgement


Margolius 2012 (Continued)

Random sequence genera- Unclear risk tion (selection bias)
Unclear method of randomization - (pg 200) "Study arm assignments were randomly ordered and enclosed in sealed, consecutively numbered envelopes. After enrollment, participants were assigned to one of the study arms by opening the next sealed envelope."

Allocation concealment Low risk
(selection bias)
(selection bias)

Selective reporting (re- Unclear risk
porting bias)

Selective reporting (re-
Low bias method of allocation concealment - (pg 200) "Study arm assignments were randomly ordered and enclosed in sealed, consecutively numbered envelopes. After enrollment, participants were assigned to one of the study arms by opening the next sealed envelope."

\begin{tabular}{|c|c|c|}
\hline Other bias & High risk & $\begin{array}{l}\text { The authors note the following limitations: the use of control, outcome mea- } \\
\text { surement noted as limitations. (pg 204) "This study had several limitations. A } \\
\text { usual-care arm would have been helpful to further substantiate the improve- } \\
\text { ment in SBP found in both intervention arms. In recent studies involving pa- } \\
\text { tients with elevated baseline SBP levels, however, levels dropped by } 2,6,7,10 \text {, } \\
\text { 12, and } 14 \mathrm{~mm} \mathrm{Hg} \text { with usual care, reductions considerably smaller than the } \\
\text { approximately } 20 \text {-mm Hg SBP reduction in both groups of our study. In an ef- } \\
\text { fort to pattern our study intervention to standard clinical care, we used blood } \\
\text { pressures measured by medical assistants at the office visit. This approach } \\
\text { may have introduced more random error creating a bias toward not finding a } \\
\text { difference between study arms. It is unlikely that it affected the result to the } \\
\text { point of masking a true significant difference, however. The potential impact } \\
\text { on the before-after analysis would be toward the null hypothesis, making our } \\
\text { results a conservative estimate of actual change from baseline to } 6 \text { months. } \\
\text { The association between number of coaching encounters and SBP reduction, } \\
\text { while supportive of a true effect of health coaching, relied on observational } \\
\text { data and could reflect confounding by unmeasured variables. Although we ex- } \\
\text { pected health coaching to improve medication adherence, self reported ad- } \\
\text { herence decreased over the course of the study. Two factors may explain this } \\
\text { seemingly paradoxic finding. First, on the basis of coaches' reports, many pa- } \\
\text { tients at baseline did not know their medications well enough to accurately } \\
\text { report adherence. Second, patients may have become more truthful as they } \\
\text { developed trusting relationships with their coaches. Also, self reported adher- } \\
\text { ence correlates poorly with more objective adherence measures." }\end{array}$ \\
\hline
\end{tabular}

In the protocol most outcomes other than adherence measure were mentioned (ref 20 - Bennett H, Laird K, Margolius D, Ngo V, Thom DH, Bodenheimer T. BMC Public Health 2009;9:456-61). The effectiveness of health coaching, home blood pressure monitoring, and home-titration in controlling hypertension among low-income patients: protocol for a randomized controlled trial
Blinding of outcome as- Low risk sessment (detection bias) Adherence measure
(PRIMARY) SELF REPORT - INTERVIEW - The outcome was self reported by the participants. The outcome was not likely to be affected by the lack of blinding of data collectors

\begin{tabular}{lll}
\hline $\begin{array}{l}\text { Blinding of outcome as- } \\
\text { sessment (detection bias) }\end{array}$ & Low risk & (PRIMARY) BLOOD PRESSURE - No mention of blinding of outcome assessors \\
Patient outcome & $\begin{array}{l}\text { but objective outcome - "...blood pressures were measured with an automated } \\
\text { machine on } 1 \text { arm." }\end{array}$
\end{tabular}

Patient outcome but objective outcome - "...blood pressures were measured with an automated machine on 1 arm."

Blinding of participants High risk (performance bias)

Adherence measure (PRIMARY) SELF REPORT - INTERVIEW - Subjective outcome; no mention of blinding of patients

Blinding of participants Low risk (performance bias)

(PRIMARY) BLOOD PRESSURE - No mention of blinding but objective outcome Patient outcome

"...blood pressures were measured with an automated machine on 1 arm."

Blinding of personnel (per- Unclear risk formance bias)

(PRIMARY) SELF REPORT - INTERVIEW - No mention of blinding or of role of other study personnel in outcome assessment 
Margolius 2012 (Continued)

Adherence measure

Blinding of personnel (per- Low risk formance bias)

Patient outcome
(PRIMARY) BLOOD PRESSURE - No mention of blinding of outcome assessors but objective outcome - "...blood pressures were measured with an automated machine on 1 arm."

\section{Incomplete outcome data Low risk}

(attrition bias)

(PRIMARY) SELF REPORT - INTERVIEW - There were no significant differences in

Adherence measure attrition rates between the 2 groups. Patients who dropped out or were lost to follow-up did not differ significantly from patients who completed the study

Incomplete outcome data Low risk

(attrition bias)

(PRIMARY) BLOOD PRESSURE - There were no significant differences in attri-

Patient outcome tion rates between the 2 groups. Patients who dropped out or were lost to follow-up did not differ significantly from patients who completed the study

\section{Marquez Contreras 2004}

\begin{tabular}{ll}
\hline Methods & $\begin{array}{l}\text { A controlled, randomized clinical trial was conducted in } 6 \text { primary care centers in the Huelva province } \\
\text { of Spain }\end{array}$
\end{tabular}
of Spain

\section{Participants}

126 people diagnosed with hypercholesterolemia according to Spanish Consensus criteria were chosen: 63 in control group and 63 in intervention group. Recruitment took place from January to June 2001

Interventions

The control group (CG) of 63 patients, who received the doctor's normal treatment, which included oral information about hypercholesterolemia, advice about its control, brochures about dietary recommendations, 3 month-long prescriptions for a cholesterol-lowering medication, and titration of that medication if indicated at 3 months

The intervention group (IG) of 63 patients received this care, and in addition, received a telephone call at 7 to 10 days, 2 months, and 4 months. The goal of the intervention was to establish the level of compliance, categorize this as adequate or inadequate, and make recommendations based on that. Level of compliance was determined by comparing the number of pills consumed to the number that should have been consumed (calculated using self reported information about the number of pills remaining, number of pills dispensed, and fill date of the prescription). Compliance was defined as taking $80 \%$ to $110 \%$ of the pills that should have been taken thus far. Compliant patients were congratulated and encouraged to continue their good level of compliance as it would lower their risk of heart disease. Noncompliant patients were notified their behavior was considered noncompliant and encouraged to better comply with therapy as it would lower their risk of heart disease

Outcomes Pills were counted in person at 3 and 6-month follow-up visits to estimate compliance over the previous 3 months. Cholesterol, triglycerides, HDL-C and LDL-C were measured at the start, and at the $3 r d$ and 6 th months

Notes -

\section{Risk of bias}

\begin{tabular}{lll}
\hline Bias & Authors' judgement & Support for judgement \\
\hline $\begin{array}{l}\text { Random sequence genera- } \\
\text { tion (selection bias) }\end{array}$ & Low risk & Used random number tables (pg 88) \\
\hline $\begin{array}{l}\text { Allocation concealment } \\
\text { (selection bias) }\end{array}$ & Unclear risk & Allocation concealment not mentioned (pg 88) \\
\hline
\end{tabular}


Marquez Contreras 2004 (Continued)

\begin{tabular}{|c|c|c|}
\hline $\begin{array}{l}\text { Selective reporting (re- } \\
\text { porting bias) }\end{array}$ & Unclear risk & No protocol available \\
\hline Other bias & Low risk & No other bias noted \\
\hline $\begin{array}{l}\text { Blinding of outcome as- } \\
\text { sessment (detection bias) } \\
\text { Adherence measure }\end{array}$ & Low risk & (PRIMARY) PILL COUNT - Double-blinding is present (pg 449) \\
\hline $\begin{array}{l}\text { Blinding of outcome as- } \\
\text { sessment (detection bias) } \\
\text { Patient outcome }\end{array}$ & Low risk & $\begin{array}{l}\text { (PRIMARY) BLOOD PRESSURE MEASUREMENT - Double-blinding is mentioned } \\
\text { (pg 449) }\end{array}$ \\
\hline $\begin{array}{l}\text { Blinding of participants } \\
\text { (performance bias) } \\
\text { Adherence measure }\end{array}$ & High risk & $\begin{array}{l}\text { (PRIMARY) PILL COUNT - Patients took medication in to be counted so they are } \\
\text { aware of this measure }\end{array}$ \\
\hline $\begin{array}{l}\text { Blinding of participants } \\
\text { (performance bias) } \\
\text { Patient outcome }\end{array}$ & Low risk & $\begin{array}{l}\text { (PRIMARY) BLOOD PRESSURE MEASUREMENT - Double-blinding is mentioned } \\
\text { (pg 449) }\end{array}$ \\
\hline
\end{tabular}

Patient outcome

(PRIMARY) PILL COUNT - Key personnel blinding is not mentioned in the article

Blinding of personnel (per- Unclear risk

formance bias)

Adherence measure

Blinding of personnel (per- Low risk

formance bias)

Patient outcome
(PRIMARY) BLOOD PRESSURE MEASUREMENT - Double-blinding is mentioned (pg 449)

\section{Incomplete outcome data Unclear risk}

(attrition bias)

Adherence measure

(PRIMARY) PILL COUNT - Although follow-up seems balanced it is difficult to say whether this had an effect on results

Incomplete outcome data Unclear risk

(attrition bias)

Unclear risk

(PRIMARY) BLOOD PRESSURE MEASUREMENT - Although the dropouts seem balanced, it is hard to tell if this had an effect on results

Patient outcome

\section{Marquez Contreras 2005}

Methods

Patients $(n=636)$ were randomly allocated to receive 1 of the 2 interventions, the telephone intervention $(n=216)$ or the mail intervention $(n=212)$, or usual care $(n=212)$. Allocation concealment was not specified

Participants

Patients were eligible for participation in the trial if the following criteria were met: (i) Outpatients of either sex and between 18 and 80 years of age; (ii) newly diagnosed or uncontrolled phase I and II hypertension (JNC-VI criteria) requiring antihypertensive treatment; (iii) provision of patient informed consent in writing

Patients were excluded if they met any of the following criteria: (i) Patients who at the start of the study required 2 or more antihypertensive drugs for hypertension control; (ii) acute myocardial infarction; (iii) secondary hypertension; (iv) known side effects and contraindications to the use of angiotensin AT1 inhibitors; (v) pregnant or breastfeeding women; (vi) patients with conditions capable of interfering with the study; (vii) patients planning to donate blood; (viii) participants in other research studies; (ix) patients cohabiting with another person taking the same antihypertensive medication Study withdrawal criteria were as follows: (i) Inadequate therapeutic effect requiring an increase of more than $20 \%$ in the scheduled number of visits; (ii) patient decision not to continue with the study 
Marquez Contreras 2005 (Continued)

and/or schedule follow-up visits; (iii) concomitant illnesses or adverse effects that in investigator opinion, the patient needs be withdrawn from the study

Interventions

Participants allocated to the telephone intervention group (TIG) received a controlled intervention in the form of 3 telephone calls: the first 15 days after the inclusion visit; the second and third being one week after visits 3 and 4 . The telephone intervention was made by 2 expert nurses in this type of interventions. During the calls to patients in this group, the patients were reminded of scheduled visits and asked about the name, dosage, and timing of their antihypertensive medication, and the number of remaining tablets. Patients were informed, according to the number of tablets in their possession, if they had good or poor compliance. In the event of good compliance, the patients were congratulated and encouraged to continue adhering to therapy. In the event of noncompliance, the patients were encouraged to comply, and the associated benefits were explained. For participants who were allocated to the mail intervention group (MIG), they received 3 mailed communications at home: the first 15 days after the inclusion visits; the second and third, being one week after visits 3 and 4; in order to promote compliance through health education in hypertension, reinforce compliance, and remind the subjects of the scheduled visits. The mailed messages included information about the following hypertension aspects: what is hypertension?; diagnosis of hypertension; symptoms; related risk factors; why is necessary to treat the hypertension?; what is the hypertension treatment?; and information about the correct taking of medication. Patients who were allocated to the control group (CG) received the center's routine primary care intervention and did not receive any additional intervention to improve adherence

Outcomes

Compliance was assessed using a pill count. Percentage compliance (PC) was calculated from the following formula: $\mathrm{PC}=$ (total no. of presumably consumed tablets/total no. that should have been consumed $)^{\star} 100$. Compliance was accepted if it was in the range of $80 \%$ to $110 \%$. The study final PC for each patient was defined as the cumulative PC at the end of follow-up (at the end of the last visit or at the time of withdrawal), while the monthly PC was taken to be the PC recorded between one follow-up visit and the next. Blood pressure was measured as the clinical endpoint during the scheduled visits by the primary care physician. The final blood pressure reading was taken as the mean of the 2 measurements made

\begin{tabular}{|c|c|c|}
\hline Notes & - & \\
\hline \multicolumn{3}{|l|}{ Risk of bias } \\
\hline Bias & Authors' judgement & Support for judgement \\
\hline $\begin{array}{l}\text { Random sequence genera- } \\
\text { tion (selection bias) }\end{array}$ & Low risk & The author notes that they used a random numbers table \\
\hline $\begin{array}{l}\text { Allocation concealment } \\
\text { (selection bias) }\end{array}$ & Low risk & $\begin{array}{l}\text { Centralized allocation. The "intervention group designation was carried out by } \\
\text { two investigators not included as field investigators, and on a centralized ba- } \\
\text { sis." No other description of allocation concealment is described. But marked } \\
\text { low because the process of randomization was centralized, performed by } 2 \text { in- } \\
\text { vestigators not included as field investigators, away from the study sites }\end{array}$ \\
\hline $\begin{array}{l}\text { Selective reporting (re- } \\
\text { porting bias) }\end{array}$ & Low risk & $\begin{array}{l}\text { The author notes, "...study explores whether the intervention is targeted to } \\
\text { patients with hypertension, based on two strategies adapted to our setting } \\
\text { ("telephone intervention" and "mail intervention"), is effective in improving } \\
\text { compliance. This question answered in the study." }\end{array}$ \\
\hline Other bias & Low risk & $\begin{array}{l}\text { The author notes that the population included in this study consists of new- } \\
\text { ly diagnosed and uncontrolled hypertensive patients. These } 2 \text { populations } \\
\text { are different, and indeed there is a high percentage of uncontrolled hyperten- } \\
\text { sive patients that could not be controlled because of poor adherence. Also, we } \\
\text { should bear in mind that the generalization of these study findings excludes } \\
\text { patients with previous acute myocardial infarction seen in primary care cen- } \\
\text { ters }\end{array}$ \\
\hline
\end{tabular}




\section{Marquez Contreras 2005 (Continued)}

Blinding of outcome as- Low risk sessment (detection bias)

Adherence measure
(PRIMARY) PILL COUNT - Those collecting the data were stated to be blinded. "The field technicians were blinded to the group assignments until after the baseline measurements were completed. Subjects assigned to the TLC intervention group were trained to use TLC and an automated sphygmomanometer. All participants received a final home visit 6 months after entry into the study when all study measurements were re-administered by technicians blinded to the study assignments." (pg 286)

\begin{tabular}{|c|c|c|}
\hline $\begin{array}{l}\text { Blinding of outcome as- } \\
\text { sessment (detection bias) } \\
\text { Patient outcome }\end{array}$ & Unclear risk & $\begin{array}{l}\text { (PRIMARY) BLOOD PRESSURE - Blinding of primary health physician not men- } \\
\text { tioned in the article. "The field technicians were blinded to the group assign- } \\
\text { ments until after the baseline measurements were completed." (pg 286) }\end{array}$ \\
\hline
\end{tabular}

\begin{tabular}{|c|c|c|}
\hline $\begin{array}{l}\text { Blinding of participants } \\
\text { (performance bias) } \\
\text { Adherence measure }\end{array}$ & Unclear risk & $\begin{array}{l}\text { (PRIMARY) PILL COUNT - Patients would have been aware of the intervention. } \\
\text { However, "at the follow-up and final visits, BP, weight and tablet count were } \\
\text { recorded - the investigator being required to show discretion in counting the } \\
\text { tablets, in order to avoid patient bias." }\end{array}$ \\
\hline
\end{tabular}

$\begin{array}{ll}\begin{array}{l}\text { Blinding of participants } \\ \text { (performance bias) }\end{array} & \text { (PRIMARY) BLOOD PRESSURE - This is an objective measure of outcome }\end{array}$

(performance bias)

Patient outcome
Blinding of personnel (per- Unclear risk formance bias)

Adherence measure
(PRIMARY) PILL COUNT - No information on blinding given. There is insufficient information to permit judgment of 'Low risk' or 'High risk'

Blinding of personnel (per- Unclear risk

formance bias)

(PRIMARY) BLOOD PRESSURE - No information on blinding given. There is in-

Patient outcome sufficient information to permit judgment of 'Low risk' or 'High risk'

\begin{tabular}{|c|c|c|}
\hline $\begin{array}{l}\text { Incomplete outcome data } \\
\text { (attrition bias) }\end{array}$ & Unclear risk & $\begin{array}{l}\text { (PRIMARY) PILL COUNT - No information given about why the dropouts oc- } \\
\text { curred }\end{array}$ \\
\hline
\end{tabular}

Adherence measure

Incomplete outcome data Unclear risk
(attrition bias)
Patient outcome

Patient outcome

\section{Marquez Contreras 2006}

Methods The patients $(n=250)$ were randomly assigned to one of the 2 groups, stratified by age and sex: a control group (CG) and an intervention group (IG). The randomization process was centralized and blind, performed using random number tables and by a person not involved in the follow-up

Participants

Patients were ambulatory patients between 18 and 80 years of age, newly diagnosed hypertensive patients or those already on antihypertensive treatment but not controlled and who did not have an electronic monitor for home blood pressure measurement (HBPM), patients with phase I or II arterial hypertension (AHT) according to the JNC-VI criteria, and patients who had given their written consent. Patients were excluded from the study if they were requiring 2 or more antihypertensive drugs at the start of the study, secondary AHT, pregnant or breast-feeding women, patients with diseases that could interfere with the study, patients who intended to donate blood, patients who were unable to give their consent, patients participating in other studies, and patients co-habiting with other individuals taking the same antihypertensive medication

Interventions

Patients in this intervention, apart from receiving the usual care, also received an OMRON automatic monitor for home blood pressure measurement (HBPM). The patients received a kit in their home containing the monitor, an instruction manual, a summary of the functions, and a card on which to note the measurements. They were advised to follow the HBPM program, which consisted of measuring the 
Marquez Contreras 2006 (Continued)

BP 3 days a week (Tuesdays, Thursdays, and Saturdays), twice before breakfast (0800 to 1000 hours) and twice before supper (2000 to 2200 hours) and record these results on the card ( 4 times a day). The patients received a phone call to explain how to use the monitor and follow the HBPM program. The control intervention involved patients receiving the care usually provided by their general practitioners

Outcomes Compliance was measured using Medication Event Monitoring System (MEMS) and the percentage compliance (PC) was calculated by dividing the total number of tablets the patients were assumed to have taken by the total number of tablets that the patients should have taken and multiplying by 100 to obtain a percentage. Compliance was considered to be present in patients with a percentage compliance between $80 \%$ and $100 \%$

Blood pressure (taken as the mean of 2 measurements) was the clinical outcome used

\author{
Notes
}

\title{
Risk of bias
}

\begin{tabular}{lll}
\hline Bias & Authors' judgement & Support for judgement \\
\hline $\begin{array}{ll}\text { Random sequence genera- } \\
\text { tion (selection bias) }\end{array}$ & Low risk & $\begin{array}{l}\text { Randomization done using random number table. (pg 170) "The patients were } \\
\text { randomly assigned to one of the two groups, stratified by age and sex. The ran- } \\
\text { domization process was centralized and blind, performed using random num- } \\
\text { ber tables and by a person not involved in the follow-up." }\end{array}$
\end{tabular}

\begin{tabular}{ll}
\hline $\begin{array}{l}\text { Allocation concealment } \\
\text { (selection bias) }\end{array}$ & Low risk \\
& $\begin{array}{l}\text { Allocation concealment completed. (pg 170) "The patients were randomly as- } \\
\text { signed to one of the two groups, stratified by age and sex. The randomization } \\
\text { process was centralized and blind, performed using random number tables } \\
\text { and by a person not involved in the follow-up." }\end{array}$ \\
\hline
\end{tabular}

\begin{tabular}{lll}
\hline $\begin{array}{l}\text { Selective reporting (re- } \\
\text { porting bias) }\end{array}$ & Unclear risk & No protocol available
\end{tabular}

\begin{tabular}{|c|c|c|}
\hline Other bias & Unclear risk & No mention of limitations in discussion or other clear biases \\
\hline $\begin{array}{l}\text { Blinding of outcome as- } \\
\text { sessment (detection bias) } \\
\text { Adherence measure }\end{array}$ & Unclear risk & $\begin{array}{l}\text { (PRIMARY) MEMS - No mention of blinding of outcome assessors. (pg 174) "The } \\
\text { methodology has been correct: a randomized, double-blind trial" }\end{array}$ \\
\hline $\begin{array}{l}\text { Blinding of outcome as- } \\
\text { sessment (detection bias) } \\
\text { Patient outcome }\end{array}$ & Unclear risk & $\begin{array}{l}\text { (PRIMARY) BLOOD PRESSURE MEASUREMENT - Method of blinding not de- } \\
\text { scribed but less likely to affect BP reading - electronic measurement. (pg 174) } \\
\text { "The methodology has been correct: a randomized, double-blind trial" }\end{array}$ \\
\hline $\begin{array}{l}\text { Blinding of participants } \\
\text { (performance bias) } \\
\text { Adherence measure }\end{array}$ & Unclear risk & $\begin{array}{l}\text { (PRIMARY) MEMS - No mention of blinding of patients. MEMS is obtrusive but } \\
\text { objective measure. (pg 174) "The methodology has been correct: a random- } \\
\text { ized, double-blind trial" }\end{array}$ \\
\hline $\begin{array}{l}\text { Blinding of participants } \\
\text { (performance bias) } \\
\text { Patient outcome }\end{array}$ & Low risk & $\begin{array}{l}\text { (PRIMARY) BLOOD PRESSURE MEASUREMENT - Objective outcome but no } \\
\text { mention of blinding of patient }\end{array}$ \\
\hline $\begin{array}{l}\text { Blinding of personnel (per- } \\
\text { formance bias) } \\
\text { Adherence measure }\end{array}$ & Unclear risk & $\begin{array}{l}\text { (PRIMARY) MEMS - Uncertain mention of blinding of study personnel. (pg 174) } \\
\text { "The methodology has been correct: a randomized, double-blind trial" }\end{array}$ \\
\hline $\begin{array}{l}\text { Blinding of personnel (per- } \\
\text { formance bias) } \\
\text { Patient outcome }\end{array}$ & Unclear risk & $\begin{array}{l}\text { (PRIMARY) BLOOD PRESSURE MEASUREMENT - Method of blinding not de- } \\
\text { scribed but less likely to affect BP reading - electronic measurement. (pg 174) } \\
\text { "The methodology has been correct: a randomized, double-blind trial" }\end{array}$ \\
\hline $\begin{array}{l}\text { Incomplete outcome data } \\
\text { (attrition bias) }\end{array}$ & Unclear risk & $\begin{array}{l}\text { (PRIMARY) MEMS - Usable sample size did not meet power calculations - } 200 \\
\text { versus } 250 \text { ( } 80 \% \text { of power calculation). Missing data uniform across groups - } 13\end{array}$ \\
\hline
\end{tabular}


Marquez Contreras 2006 (Continued)

Adherence measure each. Statistically significant difference only in diastolic BP. Not sure whether the missing data and reduced sample size could have affected the result. (pg 171) "A total of 250 patients were included, with data being obtained from 226. Of these, compliance data were obtained in 200 subjects $(88.49 \%$ of the sample), with 26 subjects withdrawing from the study, 13 from the GC and 13 from the IG (P 1/4 NS). Four of these were as a result of adverse events, 10 because of travel or change of address, one because of the intention to become pregnant, one because of the detection of secondary AHT (CG), four did not attend the scheduled visits, and six withdrew as a result of the malfunctioning of the MEMS."

\section{Incomplete outcome data Unclear risk} (attrition bias)

Patient outcome
(PRIMARY) BLOOD PRESSURE MEASUREMENT - Usable sample size did not meet power calculations - 200 versus 250 ( $80 \%$ of power calculation). Missing data uniform across groups - 13 each. Statistically significant difference only in diastolic BP. Not sure whether the missing data and reduced sample size could have affected the result. (pg 171) "A total of 250 patients were included, with data being obtained from 226. Of these, compliance data were obtained in 200 subjects ( $88.49 \%$ of the sample), with 26 subjects withdrawing from the study, 13 from the GC and 13 from the IG (P $1 / 4 \mathrm{NS})$. Four of these were as a result of adverse events, 10 because of travel or change of address, one because of the intention to become pregnant, one because of the detection of secondary AHT (CG), four did not attend the scheduled visits, and six withdrew as a result of the malfunctioning of the MEMS."

\section{Marquez Contreras 2007}

\begin{tabular}{ll}
\hline Methods & Randomized controlled trial \\
\hline Participants & The study location was Huelva-Costa, Spain \\
& 110 participants were randomized to the intervention group and 110 participants were randomized to \\
the control group & \\
The inclusion criteria were ambulatory patients of both sexes between the ages of 18 and 80, pre- \\
scribed lipid-lowering medication, consented to participate in the study, receiving lipid-lowering med- \\
ication in accordance with Spanish recommendations \\
The exclusion criteria were patients taking more than one lipid-lowering medication, having secondary \\
hyper-cholesterol, pregnant or lactating women, with disorders that could compromise the results of \\
the study, participating in other studies, patients residing with others on the same medication
\end{tabular}

Interventions Intervention: CALENDAR REMINDER

The patients in the intervention group were mailed a calendar as a reminder of medication taking. The calendar was double-sided. On one side, there was a calendar where the patient could mark with an $x$ the days of the months when they should be taking their medication. On the other side, there was information about the next visits, treatment recommendations, and a place to insert lipid analysis info

Control: USUAL TREATMENT

Patients received treatment as usual as provided by a family physician

Outcomes

The measures of adherence were MEMS containers. The MEMS containers were filled at baseline and 12 weeks. Patients were asked to bring MEMS in to sessions at 12 and 24 weeks. This was the primary adherence measure

The patient outcomes were biochemical measures obtained via blood tests. Lipid measurements were calculated. The degree of control of dyslipidemia was measured according to the therapeutic guidelines 
Marquez Contreras 2007 (Continued)

Notes

\section{Risk of bias}

\begin{tabular}{|c|c|c|}
\hline Bias & Authors' judgement & Support for judgement \\
\hline $\begin{array}{l}\text { Random sequence genera- } \\
\text { tion (selection bias) }\end{array}$ & Low risk & A random numbers table was used (pg 662) \\
\hline $\begin{array}{l}\text { Allocation concealment } \\
\text { (selection bias) }\end{array}$ & Unclear risk & $\begin{array}{l}\text { Insufficient information to permit judgment of 'Low risk' or 'High risk'; method } \\
\text { of allocation not specified }\end{array}$ \\
\hline $\begin{array}{l}\text { Selective reporting (re- } \\
\text { porting bias) }\end{array}$ & Unclear risk & Study protocol is not available \\
\hline Other bias & Low risk & The study appears to be free of other sources of bias \\
\hline $\begin{array}{l}\text { Blinding of outcome as- } \\
\text { sessment (detection bias) } \\
\text { Adherence measure }\end{array}$ & Low risk & $\begin{array}{l}\text { (PRIMARY) MEMS - This is an open study but MEMs is unlikely to be affected by } \\
\text { outcome assessors }\end{array}$ \\
\hline
\end{tabular}

Blinding of outcome as- Low risk

(PRIMARY) LIPID LEVELS - Open study but this is an objective measure sessment (detection bias)

Patient outcome

Blinding of participants $\quad$ High risk
(performance bias)

Adherence measure

Blinding of participants Low risk (PRIMARY) LIPID LEVELS - Open study but this is an objective measure
(performance bias)
Patient outcome

\begin{tabular}{|c|c|c|}
\hline $\begin{array}{l}\text { Blinding of personnel (per- } \\
\text { formance bias) } \\
\text { Adherence measure }\end{array}$ & Low risk & $\begin{array}{l}\text { (PRIMARY) MEMS - This is an open study but MEMs is unlikely to be affected by } \\
\text { key study personnel }\end{array}$ \\
\hline
\end{tabular}

Adherence measure

(PRIMARY) LIPID LEVELS - Open study but this is an objective measure

Blinding of personnel (per- Low risk

formance bias)

Patient outcome

Incomplete outcome data Low risk

(attrition bias)

(PRIMARY) MEMS - Missing data have been imputed using appropriate meth-

Adherence measure ods. Missing data relatively balanced across groups

Incomplete outcome data Low risk (attrition bias)

(PRIMARY) LIPID LEVELS - Missing data have been imputed using appropriate

Patient outcome methods. Number of dropouts is relatively balanced across both groups

Martins 2009

Methods Randomized controlled trial


137 participants were randomized to the intervention group and 133 participants were randomized to the control group

The inclusion criteria were patients with newly diagnosed pulmonary tuberculosis, 18 years of age or older, and who agreed to receive tuberculosis treatment at the clinic for 8 months

The exclusion criteria were pregnancy and previous treatment for tuberculosis for more than 1 month

Intervention: FOOD INCENTIVE
The intervention was a food incentive program in which the intervention group patients were provided
with midday meals every time they attended the clinic. Patients were to report to the clinic 5 or 6 morn-
ings a week to receive directly observed treatment in the intensive phase and fortnightly in the contin-
uation phase
Control: NUTRITIONAL ADVICE
Control participants received usual care. They were also given nutritional advice (verbal and written)
about the types of locally available food that would constitute a balanced diet and would be likely to
assist cure of tuberculosis

Outcomes

The measures of adherence were clinical attendance, directly observed treatment, interview, and pill counts. Clinic attendance and direct observation were performed daily in the intensive phase and fortnightly in the continuation phase while interview and pill counts were performed in the continuation phase

The patient outcomes were treatment completion (in terms of either completion of 8 months or treatment or clearance of acid fast bacilli from the sputum) and clinical improvement (in terms of improvement in weight gain, cough clearance, and adverse events). Weight gain was measured at 8 and 32 weeks while cough clearance was measured at 4,8 , and 32 weeks

Notes

The authors note that "...the civil conflict dramatically increased the default rate of those patients $(68,25 \%)$ still receiving treatment after 28 April 2006 and led to a significant decrease in treatment completion (168/199 (84\%) before conflict vs 35/66 (53\%) after conflict; $1.58,1.26$ to 2.01 ; $\mathrm{P}<0.001)$."

\section{Risk of bias}

Bias Authors' judgement Support for judgement

Random sequence genera- Low risk tion (selection bias)

Computerized randomization was used. "At each study site a research assistant randomly allocated study participants to the intervention group (supplementary food) or control group (nutritional advice). An independent statistician computer generated a random allocation sequence with randomly varying block sizes in Stata (version 8)." (pg 2)

$\begin{array}{ll}\begin{array}{l}\text { Allocation concealment } \\ \text { (selection bias) }\end{array} & \text { "Tow risk } \\ & \text { bered opaque sealed envelopes prepared distant from the study site. Alloca- } \\ & \text { tion was stratified by community health clinic and by diagnosis of tubercu- } \\ & \text { losis (smear positive and smear negative). Both participants and treatment } \\ \text { providers were aware of an individual's allocation status after randomisa- } \\ \text { tion." (pg 2) }\end{array}$

\begin{tabular}{lll}
\hline $\begin{array}{l}\text { Selective reporting (re- } \\
\text { porting bias) }\end{array}$ & Low risk & $\begin{array}{l}\text { No protocol available; although it appears that everything was reported it is } \\
\text { difficult to determine this without a protocol }\end{array}$ \\
\hline Other bias & Low risk & The study seems to be free of other types of bias \\
\hline $\begin{array}{l}\text { Blinding of outcome as- } \\
\begin{array}{l}\text { sessment (detection bias) } \\
\text { Adherence measure }\end{array}\end{array}$ & Unclear risk & $\begin{array}{l}\text { (PRIMARY) COMPOSITE ADHERENCE MEASURES - No explicit information was } \\
\text { given regarding who collected the data and how. There is insufficient informa- } \\
\text { tion to permit judgment of 'Low risk' or 'High risk' }\end{array}$ \\
\hline
\end{tabular}


Martins 2009 (Continued)

Blinding of outcome as- Low risk $\quad$ (PRIMARY) TREATMENT COMPLETION - "An independent observer (PM, based sessment (detection bias) in Darwin), who was blinded to the intervention received by the patients, howPatient outcome ever, determined the primary outcome (treatment completion)." (pg 2)

\begin{tabular}{|c|c|c|}
\hline $\begin{array}{l}\text { Blinding of participants } \\
\text { (performance bias) } \\
\text { Adherence measure }\end{array}$ & Unclear risk & $\begin{array}{l}\text { (PRIMARY) COMPOSITE ADHERENCE MEASURES - Patients were aware of allo } \\
\text { cation after randomization; not enough details are given about the methods } \\
\text { for this measure to judge }\end{array}$ \\
\hline
\end{tabular}

\begin{tabular}{ll}
\hline $\begin{array}{l}\text { Blinding of participants } \\
\text { (performance bias) }\end{array}$ & Low risk \\
$\begin{array}{l}\text { Patient outcome } \\
\text { (PRIMARY) TREATMENT COMPLETION - Outcome is unlikely to be affected by } \\
\text { patient's lack of blinding }\end{array}$
\end{tabular}

Patient outcome

Blinding of personnel (per- Unclear risk
formance bias)

Adherence measure
(PRIMARY) COMPOSITE ADHERENCE MEASURES - Providers were unblinded. No information on how the data were converted into a \% adherent. (pg 2) "Both participants and treatment providers were aware of an individual's allocation status after randomisation."

\begin{tabular}{|c|c|c|}
\hline $\begin{array}{l}\text { Blinding of personnel (per- } \\
\text { formance bias) } \\
\text { Patient outcome }\end{array}$ & Unclear risk & $\begin{array}{l}\text { (PRIMARY) TREATMENT COMPLETION - Providers and patients were aware of } \\
\text { allocation after randomization but it is unclear whether this would have an ef- } \\
\text { fect on this measure }\end{array}$ \\
\hline
\end{tabular}

\begin{tabular}{|c|c|c|}
\hline $\begin{array}{l}\text { Incomplete outcome data } \\
\text { (attrition bias) } \\
\text { Adherence measure }\end{array}$ & Unclear risk & $\begin{array}{l}\text { (PRIMARY) COMPOSITE ADHERENCE MEASURES - There is a high rate of data } \\
\text { loss for the measure. ITT analysis was done; it is not clear if any imputation } \\
\text { method was employed }\end{array}$ \\
\hline
\end{tabular}

\begin{tabular}{ll}
\hline $\begin{array}{l}\text { Incomplete outcome data } \\
\text { (attrition bias) }\end{array}$ & Low risk \\
Patient outcome & $\begin{array}{l}\text { (PRIMARY) TREATMENT COMPLETION - Few data points missing for this out- } \\
\text { come }\end{array}$ \\
\hline
\end{tabular}

\section{Matsumura 2012}

\begin{tabular}{ll}
\hline Methods & Randomized controlled trial \\
\hline Participants & The study location was 29 hospitals or clinics in Japan \\
& 103 participants were randomized to the intervention group and 104 participants were randomized to \\
the control group & The inclusion criteria were 20 years or older, hypertension, who could be treated with angiotensin II re- \\
ceptor blockers (ARBs) and diuretics (thiazides or related sulphonamide compounds) & The exclusion criteria were extremely high blood pressure (= 200 mm Hg in systolic or $=120$ mm Hg in \\
diastolic blood pressure), or a serious renal or liver dysfunction, taking more than 4 tablets excluding \\
the study drugs \\
$\begin{array}{l}\text { Intervention: COMBINATION PILL } \\
\text { The intervention was a combination pill instead of multiple pills. Patients assigned to the intervention } \\
\text { group received a combination pill (losartan } 50 \text { mg/hydrochlorothiazide } 12.5 \text { mg). Follow-up was done } \\
\text { at } 1,3 \text {, and } 6 \text { months } \\
\text { Control: MULTIPLE PILLS } \\
\text { Control patients were provided with an angiotensin receptor blocker and a diuretic. Follow-up was } \\
\text { done at } 1,3 \text {, and } 6 \text { months. Adherence outcomes and blood pressure were measured at the } 1,3 \text {, and } 6- \\
\text { month appointments; patient outcomes at before and } 6 \text { months after randomization }\end{array}$ \\
$\begin{array}{l}\text { The measures of adherence were pill counts performed at } 1,3 \text {, and } 6 \text { months. Adherence rates were cal- } \\
\text { culated for each visit using the following formula: adherence rate (\%) }=[(\text { number of prescribed pills - }\end{array}$ \\
\hline Outcomes
\end{tabular}


Matsumura 2012 (Continued)

number of residual pills)/number of prescribed pills] $\times 100$. Non-adherence was defined as an adherence rate of less than $90 \%$

The patient outcomes were blood pressure, adverse events, and blood variables. After resting for at least 5 minutes, blood pressures were measured twice in a sitting position using a standard sphygmomanometer. The mean of 2 measurements was used in the present analysis. Blood variables including hematocrit, serum creatinine, serum sodium, serum potassium and serum uric acid were measured before and 6 months after randomization. Secondary outcomes were achieved follow-up blood pressure, adverse events, and blood variables

Notes

\section{Risk of bias}

\begin{tabular}{lll}
\hline Bias & Authors' judgement & Support for judgement \\
\hline $\begin{array}{l}\text { Random sequence genera- } \\
\text { tion (selection bias) }\end{array}$ & Low risk & $\begin{array}{l}\text { Computerized randomization was used. (pg 1416) "Study treatments were al- } \\
\text { located using a central, computer-based, randomization service accessible by } \\
\text { the internet and telephone" }\end{array}$ \\
\hline
\end{tabular}

$\begin{array}{lll}\begin{array}{l}\text { Allocation concealment } \\ \text { (selection bias) }\end{array} & \text { Low risk } & \begin{array}{l}\text { Central randomization was used. "Study treatments were allocated using a } \\ \text { central, computer-based, randomization service accessible by the internet and } \\ \text { telephone" (pg 1416) }\end{array}\end{array}$

\begin{tabular}{|c|c|c|}
\hline $\begin{array}{l}\text { Selective reporting (re- } \\
\text { porting bias) }\end{array}$ & Unclear risk & $\begin{array}{l}\text { No protocol available; although it appears that everything was reported it is } \\
\text { difficult to determine this without a protocol }\end{array}$ \\
\hline
\end{tabular}

Other bias High risk

\begin{abstract}
The authors note that "...the present study was limited by the facts that there were not enough subjects and that the study period might not be sufficiently long enough to detect the small difference in adherence rates between the combination pill and control groups. In the present study, the patients were treated over 6 months. If the treatment period is to be longer, medication adherence might be improved in the combination pill group compared with the control group. Moreover, the present study provides little information regarding medication persistence. In order to achieve optimal outcomes in the treatment of hypertension, patients were required to take their medications not only properly (medication adherence) but also to continue to do so throughout long-term treatment (persistence)." adherence rate is the selection bias of the patients participating in the present study, because all patients were screened for run-in phases 1 and 2 . The patients with a low adherence rate might be excluded during run-in periods. Therefore, this excellent medication adherence rate observed in the present study might not be applicable to general Japanese hypertensive patients. In addition, many participants were not newly diagnosed hypertensive patients, but rather had been treated with antihypertensive drugs for several years.25 Furthermore, a recent study demonstrated that merely participating in a clinical trial significantly increases adherence. 26 Even considering these limitations, however, the findings of the present study are largely new and provide important information on medication adherence regarding a combination pill of antihypertensive drugs" - p.1420-1421 "Electronic monitoring seems to be the most accurate method to evaluate medication adherence. 27 Unfortunately, however, the cost of this device precluded its use in the present study. Accordingly, the indirect method of pill counts was applied in the present study. This method can be applied to estimate the quantities of medications a patient presumably takes". (pg 1421)
\end{abstract}

\begin{tabular}{|c|c|c|}
\hline $\begin{array}{l}\text { Blinding of outcome as- } \\
\text { sessment (detection bias) } \\
\text { Adherence measure }\end{array}$ & Unclear risk & $\begin{array}{l}\text { (PRIMARY) PILL COUNT - No information on whether pill count was computer- } \\
\text { ized. There is insufficient information to permit judgment of 'Low risk' or 'High } \\
\text { risk' }\end{array}$ \\
\hline
\end{tabular}


Matsumura 2012 (Continued)

Blinding of outcome as- Unclear risk $\quad$ (PRIMARY) BLOOD PRESSURE - No information on whether the method of taksessment (detection bias) ing blood pressure was computerized. There is insufficient information to perPatient outcome mit judgment of 'Low risk' or 'High risk'. Open trial

\begin{tabular}{|c|c|c|}
\hline $\begin{array}{l}\text { Blinding of participants } \\
\text { (performance bias) }\end{array}$ & High risk & $\begin{array}{l}\text { (PRIMARY) PILL COUNT - Open trial. Patients aware of allocation due to the na- } \\
\text { ture of the intervention }\end{array}$ \\
\hline
\end{tabular}

Adherence measure

(PRIMARY) BLOOD PRESSURE - This is an objective measure of outcome. Lack

Blinding of participants Low risk

(performance bias)

of blinding of patients is not likely to affect the end results

Patient outcome

Blinding of personnel (per- Unclear risk

formance bias)

(PRIMARY) PILL COUNT - No information on blinding given. There is insufficient

Adherence measure information to permit judgment of 'Low risk' or 'High risk'

Blinding of personnel (per- Unclear risk

formance bias)

(PRIMARY) BLOOD PRESSURE - No information on blinding given. There is in-

Patient outcome sufficient information to permit judgment of 'Low risk' or 'High risk'

Incomplete outcome data Low risk

(attrition bias)

(PRIMARY) PILL COUNT - All patients were included in ITT analysis irrespective

Adherence measure

of completion. Overall, there was a high rate of completion

Incomplete outcome data Low risk

(attrition bias)

(PRIMARY) BLOOD PRESSURE - All patients were included in ITT analysis irre-

Patient outcome

spective of completion. Overall, there was a high rate of completion

Mehuys 2011

Methods $\quad$ Randomized controlled trial

Participants

The study location was 66 community pharmacies located in Flanders, Belgium

35 pharmacies and 153 participants were randomized to the intervention group and 31 pharmacies and 135 participants were randomized to the control group

The inclusion criteria were: have a prescription for oral hypoglycemic medication, age between 45 years and 75 years, BMI over $25 \mathrm{~kg} / \mathrm{m}^{2}$, treatment with oral hypoglycemic medication for at least 12 months, and a regular visitor of the pharmacy

The exclusion criteria were age above 45 , solely on insulin (no oral hypoglycemic)

Interventions Intervention: COMMUNITY PHARMACIST INTERVENTION

Patients in the intervention group received pharmacist-led, individual education about type 2 diabetes and its complications, education about the correct use of oral hypoglycemic agents, facilitation of medication adherence, healthy lifestyle education (diet, physical exercise and smoking cessation), and reminders about annual eye and foot examinations. These elements were implemented at the first visit and at each prescription-refill visit of the patient during the 6-month intervention period

Control: USUAL PHARMACIST CARE

Patients in the control group received usual pharmacist care

Outcomes

The measures of adherence were prescription refill rate used to calculated adherence rate (\%) using the following formula: (total days supplied during the study - days of last supply in the study) divided by (last claim date in the study - first claim date in the study) $x 100$. Self reported adherence was assessed at the end of the study by asking patients: How often do you not take your oral hypoglycemic 
Mehuys 2011 (Continued)

medication as prescribed? with permitted answers of (i) never, (ii) 1 to 2 times/year, (iii) 1 to 2 times/ month, (iv) 1 to 2 times/week, or (v) daily

The patient outcomes were (1) Fasting plasma glucose (FPG) based an average of 3 days' glucose day curve (i.e. 4 FPG measurements/day for 3 days, which was then averaged), at the start and at the end (24 weeks) of the study for control participants and at the start, 6, 12, 18, and 24 weeks for the intervention participants. (2) Glycosylated hemoglobin (HbA1c) provided by the participant's GP for the previous 6 to 9 months

Notes -1

\section{Risk of bias}

\begin{tabular}{lll}
\hline Bias & Authors' judgement & Support for judgement \\
\hline $\begin{array}{l}\text { Random sequence genera- } \\
\text { tion (selection bias) }\end{array}$ & Low risk & $\begin{array}{l}\text { Randomization was performed at the pharmacy level. Each participating phar- } \\
\text { macy was randomly assigned to either the control group or the intervention } \\
\text { group. The sequence of allocation to control or intervention group was prede- } \\
\text { termined by the investigators based on a randomization table generated using } \\
\text { SPS 14.0 software (pg 603) }\end{array}$ \\
&
\end{tabular}

\begin{tabular}{ll}
\hline $\begin{array}{l}\text { Allocation concealment } \\
\text { (selection bias) }\end{array}$ & Unclear risk
\end{tabular}$\quad \begin{aligned} & \text { The sequence of allocation to control or intervention group was predeter- } \\
& \text { mined by the investigators based on a randomization table generated using } \\
& \text { SPSS } 14.0 \text { software (pg 603) }\end{aligned}$

\begin{tabular}{|c|c|c|}
\hline $\begin{array}{l}\text { Selective reporting (re- } \\
\text { porting bias) }\end{array}$ & Unclear risk & $\begin{array}{l}\text { No protocol available; although it appears that everything was reported it is } \\
\text { difficult to determine this without a protocol }\end{array}$ \\
\hline
\end{tabular}

\begin{tabular}{|c|c|c|}
\hline Other bias & Low risk & The study seems to be free of other types of bias \\
\hline $\begin{array}{l}\text { Blinding of outcome as- } \\
\text { sessment (detection bias) } \\
\text { Adherence measure }\end{array}$ & Low risk & $\begin{array}{l}\text { (PRIMARY) PRESCRIPTION REFILL RATES - This is an objective measure of out- } \\
\text { come }\end{array}$ \\
\hline $\begin{array}{l}\text { Blinding of outcome as- } \\
\text { sessment (detection bias) } \\
\text { Patient outcome }\end{array}$ & Low risk & $\begin{array}{l}\text { (PRIMARY) FASTING BLOOD GLUCOSE - This is an objective measure of out- } \\
\text { come }\end{array}$ \\
\hline $\begin{array}{l}\text { Blinding of outcome as- } \\
\text { sessment (detection bias) } \\
\text { Patient outcome }\end{array}$ & Low risk & $\begin{array}{l}\text { (PRIMARY) HBA1C - Objective measure not likely to be influenced by lack of } \\
\text { blinding }\end{array}$ \\
\hline $\begin{array}{l}\text { Blinding of participants } \\
\text { (performance bias) } \\
\text { Adherence measure }\end{array}$ & Low risk & $\begin{array}{l}\text { (PRIMARY) PRESCRIPTION REFILL RATES - This is an objective measure of out- } \\
\text { come }\end{array}$ \\
\hline $\begin{array}{l}\text { Blinding of participants } \\
\text { (performance bias) } \\
\text { Patient outcome }\end{array}$ & Low risk & $\begin{array}{l}\text { (PRIMARY) FASTING BLOOD GLUCOSE - Objective measure not likely to be in- } \\
\text { fluenced by lack of blinding }\end{array}$ \\
\hline $\begin{array}{l}\text { Blinding of participants } \\
\text { (performance bias) } \\
\text { Patient outcome }\end{array}$ & Low risk & $\begin{array}{l}\text { (PRIMARY) HBA1C - Objective measure not likely to be influenced by lack of } \\
\text { blinding }\end{array}$ \\
\hline $\begin{array}{l}\text { Blinding of personnel (per- } \\
\text { formance bias) } \\
\text { Adherence measure }\end{array}$ & Low risk & $\begin{array}{l}\text { (PRIMARY) PRESCRIPTION REFILL RATES - This is an objective measure of out- } \\
\text { come }\end{array}$ \\
\hline
\end{tabular}


Mehuys 2011 (Continued)

Blinding of personnel (per- Low risk (PRIMARY) HBA1C - Objective measure not likely to be influenced by lack of formance bias) blinding

Patient outcome

(PRIMARY) FASTING BLOOD GLUCOSE - This is an objective measure of out-

Blinding of personnel (per- Low risk

formance bias) come

Patient outcome

\begin{tabular}{|c|c|c|}
\hline ncomplete outcome data & Low risk & $\begin{array}{l}\text { (PRIMARY) PRESCRIPTION REFILL RATES - Very few missing outcome data ar } \\
\text { provided }\end{array}$ \\
\hline
\end{tabular}

(attrition bias) provided

Adherence measure

Incomplete outcome data Low risk

(attrition bias)

Patient outcome

Incomplete outcome data Low risk

(attrition bias)

Patient outcome
(PRIMARY) FASTING BLOOD GLUCOSE - Reasons for non-completion were: hospitalization (2), cancer diagnosis (1), cardiovascular accident (1), objection of the GP (1), patient no longer motivated (1) and lost to follow-up (2)

tion patients (see 2.5)

\section{Merinder 1999}

$\begin{array}{ll}\text { Methods } & \text { Patients were block-randomized, stratified for gender and for illness duration. The randomization was } \\ \text { carried out by an independent institution. Due to the nature of the intervention, patients could not be } \\ \text { blinded. Ratings of psychopathology and psychosocial function were performed by researchers who } \\ \text { were not informed of treatment allocation. Relapse and compliance outcomes were assessed by re- } \\ \text { searchers blind to the allocation of the patients }\end{array}$

Participants

Patients aged 18 to 49 years and a clinical ICD-10 diagnosis of schizophrenia and in treatment at the time of recruitment were included. Patients were included based on a clinical diagnosis, validated by the use of operational criteria checklist for psychotic and affective illness (OPCRIT) on case records

Interventions

The control group received usual treatment provided in community psychiatry. The experimental group received an 8-session intervention using a mainly didactic interactive method. The program was standardized with a manual for group leaders, overhead presentations, and a booklet for participants. Patient and relative interventions were conducted separately, with group sizes in both patient and relative groups of 5 to 8 participants. The program was the same for both patients and relatives, and sessions were conducted weekly

Outcomes Compliance measurements: compliance measures were made at baseline and at follow-up (12 months after start of intervention). A non-compliance episode was rated if the case notes indicated that the patient did not receive medication for a period of 14 days

Measurement of clinical health outcomes: patient outcome measures included knowledge, relapse, psychosocial function, insight and satisfaction. The following scales were used: OPCRIT - operational criteria checklist for psychotic illness; BPRS- brief psychiatric rating scale; GAF - global assessment of function; IS - insight scale; VSS - Vern service satisfaction scale. Also, knowledge of schizophrenia was evaluated

Notes -

\section{Risk of bias}

Bias

Authors' judgement Support for judgement 
Merinder 1999 (Continued)

Random sequence genera- Unclear risk The authors note that the randomization was carried out by an independent tion (selection bias) institution (Department of Biostatistics at the University of Aarhus, Denmark)

$\begin{array}{ll}\begin{array}{l}\text { Allocation concealment } \\ \text { (selection bias) }\end{array} & \text { Low risk }\end{array} \quad \begin{aligned} & \text { The authors note that the randomization was carried out by an independent } \\ & \text { institution (Department of Biostatistics at the University of Aarhus, Denmark) }\end{aligned}$

\begin{tabular}{|c|c|c|}
\hline $\begin{array}{l}\text { Selective reporting (re- } \\
\text { porting bias) }\end{array}$ & Unclear risk & $\begin{array}{l}\text { No protocol available; although it appears that everything was reported it is } \\
\text { difficult to determine this without a protocol }\end{array}$ \\
\hline
\end{tabular}

Other bias Unclear risk
difficult to determine this without a protocol

Other bias Unclear risk
Authors note in the discussion that the study used mainly validated and reli- able instruments, tested inter-rater reliability, and included control of medica- tion dose. However, a blind assessment of psychopathology (BPRS) and psy- chosocial function (GAF) was not attained. The use of a non-validated ad hoc instrument to measure knowledge and a compliance measure based on case records, which did not include urine testing or pill count, to some extent al- so limits the validity of findings. Furthermore, the power of the study and the generalizability of the findings are limited by the low eligibility of patients to the study and the resulting small sample size. The represent activity analysis indicated that the sample was skewed in the direction of more self destructive behavior diagnoses, fewer substance abuse diagnoses and towards shorter ill- ness duration (pg 291)

\begin{tabular}{|c|c|c|}
\hline $\begin{array}{l}\text { Blinding of outcome as- } \\
\text { sessment (detection bias) } \\
\text { Adherence measure }\end{array}$ & Low risk & $\begin{array}{l}\text { (PRIMARY) NON COMPLIANCE EPISODES - The methods state these data were } \\
\text { obtained from case records and the researchers were blinded. "Case records } \\
\text { were used at baseline to obtain information on OPCRIT diagnosis and at base- } \\
\text { line and at the end of FU to obtain information on relapse, compliance and } \\
\text { medication before and after the intervention. The rating was done by re- } \\
\text { searchers blind to the allocation of the patients. A non-compliance episode } \\
\text { was rated if case notes indicated that the patient did not receive medication } \\
\text { for a period of } 14 \text { days. This "unit" of non-compliance enabled a comparison } \\
\text { of compliance between patients receiving depot medication and those tak- } \\
\text { ing daily oral medication, and was the basis of the analysis of the effectiveness } \\
\text { of the programme on non-compliance reduction. The comparison of baseline } \\
\text { medication in allocation groups was based on transformation of medication } \\
\text { data to DDD." (pg 289) }\end{array}$ \\
\hline
\end{tabular}

Blinding of outcome as- High risk sessment (detection bias)

Patient outcome
(PRIMARY) PSYCHOPATHOLOGY AND PSYCHOSOCIAL FUNCTION RATINGS - The authors indicate blinding was broken: however, it was not possible to maintain blindness to the treatment allocation. After the PI and FU interviews, the raters guessed the allocation of the patients and guessed wrong in only $17 \%$ of the cases

\begin{tabular}{ll}
\hline $\begin{array}{l}\text { Blinding of participants } \\
\text { (performance bias) }\end{array}$ & Low risk \\
$\begin{array}{l}\text { Adherence measure } \\
\text { of their own group membership, but it would not have influenced their case } \\
\text { records. This is an objective measure of outcome }\end{array}$
\end{tabular}

\begin{tabular}{ll}
\hline $\begin{array}{l}\text { Blinding of participants } \\
\text { (performance bias) }\end{array}$ & High risk \\
$\begin{array}{l}\text { Patient outcome } \\
\text { (PRIMARY) PSYCHOPATHOLOGY AND PSYCHOSOCIAL FUNCTION RATINGS - Pa- } \\
\text { tients likely to be unblinded due to the nature of the intervention }\end{array}$
\end{tabular}

\begin{tabular}{|c|c|c|}
\hline $\begin{array}{l}\text { Blinding of personnel (per- } \\
\text { formance bias) } \\
\text { Adherence measure }\end{array}$ & Low risk & $\begin{array}{l}\text { (PRIMARY) NON COMPLIANCE EPISODES - The author notes that these da- } \\
\text { ta were collected from records so unlikely to be influenced by knowledge of } \\
\text { study group }\end{array}$ \\
\hline $\begin{array}{l}\text { Blinding of personnel (per- } \\
\text { formance bias) } \\
\text { Patient outcome }\end{array}$ & Unclear risk & $\begin{array}{l}\text { (PRIMARY) PSYCHOPATHOLOGY AND PSYCHOSOCIAL FUNCTION RATINGS - The } \\
\text { ratings of psychopathology and psychosocial function were performed by re- } \\
\text { searchers not involved in the intervention and not informed of the treatment } \\
\text { allocation of the patient. However, it was not possible to maintain blindness to }\end{array}$ \\
\hline
\end{tabular}


Incomplete outcome data Unclear risk

(attrition bias)

Adherence measure
(PRIMARY) NON COMPLIANCE EPISODES - Not enough information given on the reasons for drop out or which groups the patients were in pg 288.8 patients (17.4\%; 4 intervention and 4 control patients) were partly lost to follow-up of compliance or relapse data, as they were referred to private practitioners for further treatment $(n=5)$ or moved to another county $(n=2) .1$ patient in the control group committed suicide during the follow-up period

(PRIMARY) PSYCHOPATHOLOGY AND PSYCHOSOCIAL FUNCTION RATINGS Dropout reasons are not given for the specific groups; not enough information to judge
Incomplete outco
(attrition bias)

Patient outcome
Unclear risk

\section{Morgado 2011}

\begin{tabular}{ll}
\hline Methods & Randomized controlled trial \\
\hline Participants & The study location was University Hospital of Cova da Beira, Covilha, Portugal \\
& $\begin{array}{l}98 \text { participants were randomized to the intervention group and } 99 \text { participants were randomized to the } \\
\text { control group }\end{array}$
\end{tabular}

The inclusion criteria were all adults of 18 years or more with established diagnosis and under treatment for arterial hypertension regardless of BP control

The exclusion criteria were dementia, pregnancy, and breastfeeding

\section{Interventions Intervention: PHARMACIST INTERVENTION PROGRAM}

In sessions at baseline ( 30 minutes) and 3 and 6 months follow-up (20 minutes) the clinical pharmacist thoroughly interviewed the patient to identify problems with medication adherence, provided patient education and counseling, and provided advice to physicians regarding pharmaceutical care. Pharmacists could schedule additional visits as needed, and patients were encouraged to bring all empty medication blisters and boxes to visits

\section{Control: USUAL CARE}

Control group patients received usual care through the hospital clinic. Pharmacists were not involved in their care

The measures of adherence were a validated 5-item adherence scale, derived from the Morisky 4-item scale, which was measured at baseline and end of study ( 9 months) by clinical pharmacists (not blinded to study allocation). Low adherence was defined as answering Yes to at least 3 of the 5 questions

The patient outcomes were the proportion of patients achieving blood pressure control according to the JNC 7 guidelines, reduction in systolic blood pressure, and reduction in diastolic blood pressure at 9 months. These outcomes were based on the mean of 2 consecutive measurements, measured by trained nurses blinded to group allocation, according to the published guidelines on proper blood pressure measurement issued by the Portuguese Society of Hipertension using a validated automatic blood pressure measuring devices (Omron M4-I) and appropriate cuffs. Patient knowledge of target BP values and of hypertension risks were also evaluated. Patients were considered knowledgeable of target BP values if they knew both target BP figures $(140 / 90 \mathrm{~mm} \mathrm{Hg}$ for hypertensive patients without diabetes and CKD and 130/80 mm Hg for hypertensive patients with diabetes or CKD). They were considered knowledgeable of the negative impacts of hypertension to health if they mentioned at least 2 potential major negative consequences of uncontrolled hypertension to health 
Morgado 2011 (Continued)

Bias Authors' judgement Support for judgement

Random sequence genera- Low risk tion (selection bias)

Allocation concealment Low risk
(selection bias)
(selection bias)
Computer-generated random numbers were used. "Participants were allocated following simple randomisation procedures (equal allocation and without restrictions) using a computer- generated list of random numbers." (pg 133)
Selective reporting (reporting bias)
Low risk

The allocation sequence was concealed from the clinical pharmacist enrolling and assessing participants in sequentially numbered, opaque, sealed envelopes. The computer-generated the allocation sequence and the envelopes were prepared by a researcher with no clinical involvement in the trial
The primary outcome measures with respect to pharmaceutical care efficacy were the proportion of patients achieving BP control and reduction in baseline SBP and DBP. The secondary outcome measure was antihypertensive medication adherence, which was determined in both arms by a pharmacist using a validated 5 -item adherence scale, derived from the 4-item scale developed by Morisky et al

\begin{tabular}{lll}
\hline Other bias & Low risk & The study seems to be free of other types of bias \\
\hline $\begin{array}{l}\text { Blinding of outcome as- } \\
\text { sessment (detection bias) } \\
\begin{array}{l}\text { Adherence measure } \\
\text { High risk }\end{array}\end{array}$ & $\begin{array}{l}\text { (PRIMARY) 5-ITEM VALIDATED QUESTIONNAIRE - The pharmacist was not } \\
\text { blinded. "Pharmacists and physicians were aware of the patient allocated } \\
\text { arm". (pg 133) }\end{array}$ \\
\hline
\end{tabular}

$\begin{array}{lll}\text { Blinding of outcome as- } & \text { Low risk } & \text { (PRIMARY) PROPORTION OF PATIENTS WITH CONTROLLED BP - Nurses who } \\ \text { sessment (detection bias) } & \text { were measuring blood pressure were blinded to group allocation }\end{array}$

Patient outcome

Blinding of participants High risk
(performance bias)

Adherence measure

(PRIMARY) 5-ITEM VALIDATED QUESTIONNAIRE - "Based on the nature of the intervention, it is not feasible to blind hypertensive patients in pharmaceutical intervention models. Thus, whereas patients, pharmacists and physicians were aware of the patient allocated arm, nurses assessing BP were kept blinded to the allocation." (pg 133)

$\begin{array}{ll}\begin{array}{l}\text { Blinding of participants } \\ \text { (performance bias) }\end{array} & \text { Low risk } \\ \begin{array}{l}\text { Patient outcome } \\ \text { (PRIMARY) PROPORTION OF PATIENTS WITH CONTROLLED BP - Lack of patient } \\ \text { blinding unlikely to affect this outcome }\end{array}\end{array}$

Patient outcome

(PRIMARY) PROPORTION OF PATIENTS WITH CONTROLLED BP - Lack of patient

Blinding of personnel (per- High risk

formance bias)

Adherence measure

(PRIMARY) 5-ITEM VALIDATED QUESTIONNAIRE - The pharmacist was not blinded. "Pharmacists and physicians were aware of the patient allocated arm". (pg 133)

Blinding of personnel (per- Unclear risk

formance bias)

(PRIMARY) PROPORTION OF PATIENTS WITH CONTROLLED BP - All person-

Patient outcome nel except nurses were unblinded. "Based on the nature of the intervention, it is not feasible to blind hypertensive patients in pharmaceutical intervention models. Thus, whereas patients, pharmacists and physicians were aware of the patient allocated arm, nurses assessing BP were kept blinded to the allocation." (pg 133)

\begin{tabular}{lll}
\hline $\begin{array}{l}\text { Incomplete outcome data } \\
\text { (attrition bias) } \\
\text { Adherence measure }\end{array}$ & Low risk & $\begin{array}{l}\text { (PRIMARY) 5-ITEM VALIDATED QUESTIONNAIRE - Analysis with most 'pes- } \\
\text { simistic' outcome values for patients dropping out was done, conclusions did } \\
\text { not change }\end{array}$ \\
\hline $\begin{array}{l}\text { Incomplete outcome data } \\
\begin{array}{l}\text { (attrition bias) } \\
\text { Patient outcome }\end{array}\end{array}$ & Low risk & $\begin{array}{l}\text { (PRIMARY) PROPORTION OF PATIENTS WITH CONTROLLED BP - Only 3.6\% of } \\
\text { patients dropped out; intention-to-treat analyses did not change conclusions } \\
\text { based on on-treatment analyses }\end{array}$ \\
\hline
\end{tabular}


Morice 2001

The subjects were randomized into 2 groups: one receiving subsequent visits from the asthma nurse
until discharge from hospital $(n=35)$ and a control group $(n=30)$, which received 'routine care' from
medical and nursing staff but no further intervention from the asthma nurse

Participants

A group of 80 patients (53 women), with an age range of 16 to 72 years (mean 36.1 years) was recruited. Patients who had been admitted on the general medical take to a large teaching hospital with a documented primary diagnosis of acute asthma were recruited for the study. Patients were not permitted to participate if they: (1) had underlying chronic obstructive pulmonary disease; (2) had previously participated in an educational program from a hospital-based asthma nurse; (3) were unable or unwilling to complete a series of follow-up questionnaires

Interventions

The education program took place over a minimum of 2 separate sessions, lasting on average 30 minutes each, and was carried out on an individual basis. The first session involved discussion on the basic mechanisms of asthma, including common triggers and an explanation of the changes which occur to the airways resulting in the symptoms experienced by the patient. This was supported by illustrations in the 'Regular Therapy with Asthma' booklet, which was given to each intervention group patient. Lifestyle influences, such as occupation and leisure activities were discussed where appropriate to the individual. The need for 'preventer' and 'reliever' medication was also emphasized during this session. Patients were encouraged to actively participate in the session and relatives were included at the patients' request. The second session took place on the following day. Previously given information was briefly summarized with input from the patient as a means of checking understanding. An agreed individualized self-management plan was determined, with written instructions using the 'Sheffield Asthma Card'. This also contained a telephone contact number. Each patient was given a peak low meter to take home and instructions on monitoring, with documentation of predicted peak low measurement and parameters for altering treatment, as well as clear written guidelines on when to seek emergency care. Home intervention was based upon a combination of symptoms and peak low recordings and all guidance offered throughout the educational program was based on the British Thoracic Society (BTS) guidelines for the management of asthma in adults. A final visit was made to each patient where possible prior to discharge at which they were encouraged to express any fears or anxieties relating to their home managements

\section{Outcomes}

Compliance was measured by questionnaire at 6 months

Clinical health outcomes included: (1) Occasions of GP call-outs and re-admission; (2) Patients percentage of claiming to have a writing management plan; (3) Percentage of the compliance of using beta-agonist inhaler regularly everyday; (4) first line action and (5) BPRS and GAS scores

Notes

\section{Risk of bias}

Bias Authors' judgement Support for judgement

Random sequence genera- Unclear risk tion (selection bias)
No details were given in the article. "The subjects were then randomized into two groups: one receiving subsequent visits from the asthma nurse until discharge from hospital (women $=62.5 \%$ ) and a control group which received 'routine care' from medical and nursing staff but no further intervention from the asthma nurse (women $=67.5 \%) "(p g$ 852)

\begin{tabular}{lll}
\hline $\begin{array}{l}\text { Allocation concealment } \\
\text { (selection bias) }\end{array}$ & Unclear risk & No information was provided about how allocation was handled \\
\hline $\begin{array}{l}\text { Selective reporting (re- } \\
\text { porting bias) }\end{array}$ & Unclear risk & $\begin{array}{l}\text { No protocol available; although it appears that everything was reported it is } \\
\text { difficult to determine this without a protocol }\end{array}$ \\
\hline Other bias & Unclear risk & $\begin{array}{l}\text { No objective criteria for measuring outcomes - even hospital utilization is mea- } \\
\text { sured by questionnaire to GPs. Written consent was obtained from GPs, verbal } \\
\text { from patients }\end{array}$ \\
\hline
\end{tabular}


Morice 2001 (Continued)

Blinding of outcome as- Unclear risk $\quad$ (PRIMARY) SELF REPORT - QUESTIONNAIRE - No information on blinding given. sessment (detection bias) There is insufficient information to permit judgment of 'Low risk' or 'High risk'

Adherence measure

\begin{tabular}{|c|c|c|}
\hline $\begin{array}{l}\text { Blinding of outcome as- } \\
\text { sessment (detection bias) }\end{array}$ & Unclear risk & $\begin{array}{l}\text { (PRIMARY) FIRST-LINE ACTION - No information on blinding given. There is in- } \\
\text { sufficient information to permit judgment of 'Low risk' or 'High risk' }\end{array}$ \\
\hline
\end{tabular}

Patient outcome

$\begin{array}{ll}\begin{array}{l}\text { Blinding of participants } \\ \text { (performance bias) }\end{array} & \text { High risk }\end{array} \quad \begin{aligned} & \text { (PRIMARY) SELF REPORT - QUESTIONNAIRE - Patient would have been aware } \\ & \text { of their own group, subjective outcome }\end{aligned}$

Adherence measure

\begin{tabular}{|c|c|c|}
\hline $\begin{array}{l}\text { Blinding of participants } \\
\text { (performance bias) } \\
\text { Patient outcome }\end{array}$ & Unclear risk & $\begin{array}{l}\text { (PRIMARY) FIRST-LINE ACTION - This is a subjective measure; there is no infor- } \\
\text { mation on blinding }\end{array}$ \\
\hline
\end{tabular}

Blinding of personnel (per- Unclear risk (PRIMARY) SELF REPORT - QUESTIONNAIRE - No information on blinding given. formance bias) There is insufficient information to permit judgment of 'Low risk' or 'High risk'

Adherence measure

\begin{tabular}{|c|c|c|}
\hline $\begin{array}{l}\text { Blinding of personnel (per- } \\
\text { formance bias) }\end{array}$ & Unclear risk & $\begin{array}{l}\text { (PRIMARY) FIRST-LINE ACTION - No information on blinding given. There is in- } \\
\text { sufficient information to permit judgment of 'Low risk' or 'High risk' }\end{array}$ \\
\hline
\end{tabular}

Patient outcome

(PRIMARY) SELF REPORT - QUESTIONNAIRE - No information was given about

reasons for dropouts

(attrition bias)

Adherence measure

Incomplete outcome data Unclear risk
(attrition bias)

(PRIMARY) FIRST-LINE ACTION - No information was given about reasons for

Patient outcome dropouts. Number of questionnaires were not similar between the groups

Moshkovska 2011

\begin{tabular}{ll}
\hline Methods & Randomized controlled trial \\
\hline Participants & The study location was a gastroenterology outpatient clinic at Leicester General Hospital, UK \\
& $\begin{array}{l}43 \text { participants were randomized to the intervention group and } 41 \text { participants were randomized to the } \\
\text { control group }\end{array}$
\end{tabular}

The inclusion criteria were patients aged 18 to 80 years, with ulcerative colitis, and on maintenance oral 5-ASA therapy

The exclusion criteria were those who were unwilling or unable to provide informed consent

Intervention: PERCEPTUAL (MOTIVATIONAL) INTERVENTIONS

Participants who were assigned to the intervention group attended a one-on-one education and motivation session conducted by the researcher. First, this session aimed to identify perceptual and practical barriers to 5-ASA medication adherence and, second, to motivate, convince, and educate. The session was designed as a structured dialog allowing the patient to comment and ask questions. Educational topics included ulcerative colitis, 5-ASA medication, and adherence. Participants were also encouraged to identify practical barriers to 5-ASA medication use, as well as perceived barriers to adherence. Strategies for overcoming these barriers were also discussed. Sessions lasted for 20 to 30 minutes and were intended to deliver individualized support to each patient. At the end of the session patients were offered an educational leaflet to take away. Patients had the option of being accompanied to these educational sessions by a relative or friend and any accompanying person was also offered 
a leaflet specifically written for relatives and friends. During the session patients were offered a free choice of up to 3 practical adherence enhancing interventions; simplifying of dosing regime, medication reminder charts, visual medication reminders for refrigerators and bedside cabinets, daily electronic pill box organizers with alarms, weekly electronic pill box organizers, weekly non-electronic pill box organizers, mobile telephone alarm set-up, taking into consideration that practical problems and adherence may change over time. Participants had the option of changing these interventions at any time during the study and at weeks 4 and 24 they were formally asked whether they wished to change the interventions. One brief follow-up telephone call was made to patients in the intervention group at week 4. During the mid-study visit a 10-minute reinforcement session was held during which the importance of adherence to prescribed 5-ASA medication was reiterated, beliefs regarding medicine-taking were reassessed, and any practical problems were discussed. All intervention group patients were given a telephone number which enabled them to obtain advice at specified times or leave a message for a return call

\section{Control: USUAL CARE}

Patients in the control group received standard prescribed care from their clinical team. The treatment regime for these patients was not changed in any way as a result of involvement in the study and no reminders or other additional adherence support was offered by the research team. Participants in the control group provided 3 urine samples at 0,24 , and 48 weeks and completed questionnaires during baseline and end-of-study visits. At the end of the study, control group participants were given the educational leaflets that intervention group participants received at the beginning of study

Outcomes

The measures of adherence were the concentration of the drug in the urine of participants, which involves the use of high performance liquid chromatography (HPLC) for determination of 5-ASA and its metabolites in the urine. Samples were collected at baseline, mid-study (24 weeks), and at the end of the study ( 48 weeks)

The patient outcomes were disease activity (flare ups), for which data were collected from medical records during the study period. A flare-up was defined as an unscheduled hospital admissions or appointment related to ulcerative colitis

Notes -

\section{Risk of bias}

\section{Authors' judgement Support for judgement}

Random sequence genera- Low risk tion (selection bias)
A computer-generated randomization schedule was used to assign each subject to an intervention or control arm. Preparation of the randomization sequence involved blocking to ensure comparable final numbers in the intervention and control groups and also stratification by gender, duration of disease, and ethnicity to ensure comparable participant characteristics in the 2 groups (pg 1875)

$\begin{array}{ll}\begin{array}{l}\text { Allocation concealment } \\ \text { (selection bias) }\end{array} & \text { Low risk } \\ & \begin{array}{l}\text { Sequentially numbered, opaque, sealed envelopes containing a comput- } \\ \text { er-generated randomization sequence were prepared by a member of the re- } \\ \text { search team (M.A.S.) not involved in any way in patient recruitment or delivery } \\ \text { of the intervention }\end{array}\end{array}$

Selective reporting (re- Unclear risk
porting bias)

\section{No protocol available; although it appears that everything was reported it is} difficult to determine this without a protocol

Other bias Unclear risk


agreed or did not agree to take part resulted in recruitment bias due to patient characteristics. This was an exploratory study for which the sample size was not powered to detect a clinical difference relating to flare-ups. We acknowledge that our definition of a flareup is based on the unscheduled hospital appointment or admission, which is open to challenge. In addition, the sample recruited contained a low proportion of people assessed as nonadherent at baseline. However, our findings suggest a useful area for future research involving a larger sample size of people with lower baseline adherence levels and collection of more detailed data relating to flare-ups in order to further investigate the question of clinical impact. Additionally, a general problem with evaluating complex interventions is that it is difficult to accurately assess the contribution made by the various components. Nevertheless, our findings suggested that combining adherence enhancing interventions tailored to individual patients was an effective way of improving persistence with 5-ASA medication. The difficulty of accurately measuring adherence to 5-ASA medication has been previously confirmed in our program of work; however, the objective measure used was probably the most appropriate method available for evaluating the intervention. We are unable to confirm whether the positive trend, but lack of significance, for results relating to changes in health beliefs was due to the small sample size or to the limited effectiveness of those aspects of the intervention aimed at addressing patient perceptions; further studies exploring methods of modifying health beliefs are therefore required. It could be suggested that our study does not take account of the potential impact of once-daily dosing regimes for patients with UC. Simplification of treatment can lead to improved patient adherence in a variety of disorders, and similar results have been reported in the treatment of UC. While we acknowledge that once-daily regimes were not available to patients in our study, we do not believe that this reduces the validity of our findings. A range of factors influence the prescribing decisions made by clinicians, including national and local guidelines, cost, and availability. Moreover, a survey of 100 Canadian patients with UC revealed that factors such as medication efficacy and safety were rated as being more important than those related to the dosing regime or cost. In this survey, speed of symptom relief and infrequency of side effects were rated as the most important factors when considering UC medication. 37 It may also be pertinent to note that changing to a once-daily dosing schedule could potentially lead to an actual decrease in adherence, as a single missed dose would equate to a full 24 hours of missed therapy. Finally, the need to consider cost-effectiveness in the evaluation of adherence interventions has been suggested. 13 While formal assessment of cost-effectiveness was not within the scope of the present study, the actual costs could be described as relatively low since the intervention involved only a brief educational session and provision of inexpensive leaflets and practical reminders. It would therefore seem reasonable to suggest that the intervention could be implemented in routine clinical care at relatively low cost". (pg 1880)

\begin{tabular}{lll}
\hline $\begin{array}{l}\text { Blinding of outcome as- } \\
\text { sessment (detection bias) } \\
\text { Adherence measure }\end{array}$ & Low risk & $\begin{array}{l}\text { (PRIMARY) HIGH - PERFORMANCE LIQUID CHROMATOGRAPHY - This is an ob- } \\
\text { jective measure of outcome }\end{array}$ \\
\hline $\begin{array}{l}\text { Blinding of outcome as- } \\
\text { sessment (detection bias) } \\
\text { Patient outcome }\end{array}$ & Unclear risk & $\begin{array}{l}\text { (PRIMARY) DISEASE ACTIVITY - No blinding; as a secondary outcome measure, } \\
\text { disease activity (flare-up) data were collected from medical records during the } \\
\text { study period }\end{array}$ \\
\hline
\end{tabular}

\begin{tabular}{|c|c|c|}
\hline $\begin{array}{l}\text { Blinding of participants } \\
\text { (performance bias) } \\
\text { Adherence measure }\end{array}$ & Low risk & $\begin{array}{l}\text { (PRIMARY) HIGH - PERFORMANCE LIQUID CHROMATOGRAPHY - This is an ob- } \\
\text { jective measure of outcome }\end{array}$ \\
\hline $\begin{array}{l}\text { Blinding of participants } \\
\text { (performance bias) } \\
\text { Patient outcome }\end{array}$ & Low risk & $\begin{array}{l}\text { (PRIMARY) DISEASE ACTIVITY - Patient lack of blinding unlikely to affect this } \\
\text { outcome }\end{array}$ \\
\hline
\end{tabular}


Moshkovska 2011 (Continued)

Blinding of personnel (per- Low risk (PRIMARY) HIGH - PERFORMANCE LIQUID CHROMATOGRAPHY - This is an obformance bias) jective measure of outcome

Adherence measure

Blinding of personnel (per- Unclear risk formance bias)

Patient outcome
(PRIMARY) DISEASE ACTIVITY - No information on blinding given. There is insufficient information to permit judgment of 'Low risk' or 'High risk'

\begin{tabular}{|c|c|c|}
\hline $\begin{array}{l}\text { Incomplete outcome data } \\
\text { (attrition bias) }\end{array}$ & Unclear risk & $\begin{array}{l}\text { (PRIMARY) HIGH - PERFORMANCE LIQUID CHROMATOGRAPHY - Reasons for } \\
\text { withdrawals were not noted }\end{array}$ \\
\hline
\end{tabular}

Adherence measure

withdrawals were not noted

\begin{tabular}{|c|c|c|}
\hline $\begin{array}{l}\text { Incomplete outcome data } \\
\text { (attrition bias) }\end{array}$ & Unclear risk & (PRIMARY) DISEASE ACTIVITY - Reasons for withdrawals were not noted \\
\hline
\end{tabular}

Patient outcome

\section{Mullan 2009}

\begin{tabular}{ll}
\hline Methods & Randomized controlled trial \\
\hline Participants & $\begin{array}{l}\text { The study location was } 11 \text { primary care and family medicine sites within the Mayo Clinic Health System } \\
\text { and Olmsted Medical Center, all in southeast Minnesota, USA }\end{array}$ \\
& 48 participants were randomized to the intervention group and 37 participants were randomized to the \\
control group & \\
& The inclusion criteria were adults with a diagnosis of type 2 diabetes mellitus for at least 1 year who \\
had a scheduled appointment with an enrolled clinician and were able and willing to give informed \\
consent to participate in the trial. Patients with incomplete glycemic control who had remaining anti- \\
hyperglycemic medication options were included based on HbAlc tests conducted less than 6 months \\
prior to enrollment and results between $7.0 \%$ and $9.5 \%$ while taking 3 or fewer antihyperglycemic med- \\
ications and not using insulin
\end{tabular}

Interventions Intervention: DIABETES MEDICATION CHOICE DECISION AID TOOL

The intervention was the use of a decision aid tool in one appointment with the patient. The tool was designed to enable clinicians to discuss with patients the potential advantages and disadvantages of adding an agent from 1 of the following antihyperglycemic classes to their regimen: metformin, insulin, thiazolidinediones, exenatide, and sulfonylureas. The tool consists of 6 cards that describe the possible effects of the medications on 6 outcomes: "weight change," "low blood sugar," "blood sugar," "daily routine," "daily sugar testing," and "side effects". After reviewing and discussing the cards that the patient and the clinician chose to discuss, they arrived at the medication that best matched the patient's circumstances and preferences. The patient received a copy of the cards in the form of a take-home pamphlet

\section{Control: USUAL CARE}

Participants in the usual care arm discussed antihyperglycemic medication in the usual manner. In addition, patients received a professionally produced (by the Mayo Clinic Patient Education Center) 12page general pamphlet on oral antihyperglycemic medications to take home

Outcomes

The measures of adherence were self reported interviews wherein research staff telephoned patients at 1,3 , and 6 months after the visit to assess adherence to diabetes medications. Patients were asked a single question: "People often have difficulty taking their pills for one reason or another. How many times do you think you may have missed taking your pills in the last week?" Any patient reporting a missed dose was considered to be non-adherent. We collected the patients' pharmacy records for all diabetes medications 6 months after their clinical visit as another measure of adherence to prescribed antihyperglycemic regimens. Patients continuing to take the medications that they were using before the visit were presumed to have enough medication to cover the time until their first prescription fill 
Mullan 2009 (Continued)

after the visit, up to a 100-day supply. A gap of longer than 90 days was considered discontinuation, rather than a temporary suspension, of the medication regimen

The patient outcomes were $\mathrm{HbAlc}$ and self reported health. $\mathrm{HbA1c}$ was obtained from patient health records for the appointment closest to the end of the study (after 6 months). Self reported health was measured via a telephone call at the end of the study that asked patients to rate their health as excellent, very good, good, fair, or poor

Notes -

\section{Risk of bias}

Bias Authors' judgement Support for judgement

Random sequence genera- Low risk tion (selection bias)
Computer-generated sequence was used. "We randomized clinicians to either use the decision aid with all of their eligible patients (intervention) or discuss antihyperglycemic medications in their usual manner (control) during a regularly scheduled clinical visit. A computer-generated allocation sequence, unavailable to personnel enrolling patients or clinicians, randomized clinicians to intervention (decision aid) or usual care and was accessed by the study coordinators via telephone. The sequence was stratified by practice type (eg, family medicine or primary care) and practice location, with a block size of 4 . Consequently, patient eligibility was assessed prior to randomization for the first patient a clinician saw while enrolled in the trial, but any subsequent patients the clinician saw were assessed for eligibility without being blind to the study arm". (pg 1562)

Allocation concealment Low risk
(selection bias)

Allocation was concealed. "We randomized clinicians to either use the decision aid with all of their eligible patients (intervention) or discuss antihyperglycemic medications in their usual manner (control) during a regularly scheduled clinical visit. A computer-generated allocation sequence, unavailable to personnel enrolling patients or clinicians, randomized clinicians to intervention (decision aid) or usual care and was accessed by the study coordinators via telephone. The sequence was stratified by practice type (eg, family medicine or primary care) and practice location, with a block size of 4 . Consequently, patient eligibility was assessed prior to randomization for the first patient a clinician saw while enrolled in the trial, but any subsequent patients the clinician saw were assessed for eligibility without being blind to the study arm". (pg 1562)

\begin{tabular}{lll}
\hline $\begin{array}{l}\text { Selective reporting (re- } \\
\text { porting bias) }\end{array}$ & Unclear risk & $\begin{array}{l}\text { No protocol is available. On pg 1563, it states that the phone calls to partici- } \\
\text { pants were made at 1, 3, and 6 months to assess adherence and self reported } \\
\text { health. Only 6-month results are reported on }\end{array}$ \\
\hline Other bias & Low risk & The study seems to be free of other types of bias \\
\hline $\begin{array}{l}\text { Blinding of outcome as- } \\
\begin{array}{l}\text { sessment (detection bias) } \\
\text { Adherence measure }\end{array}\end{array}$ & Unclear risk & $\begin{array}{l}\text { (PRIMARY) PHARMACY RECORD - No mention of blinding of outcome assessors. } \\
\text { There is insufficient information to permit judgment of 'Low risk' or 'High risk' }\end{array}$ \\
\hline
\end{tabular}

\begin{tabular}{|c|c|c|}
\hline $\begin{array}{l}\text { Blinding of outcome as- } \\
\text { sessment (detection bias) } \\
\text { Patient outcome }\end{array}$ & Unclear risk & $\begin{array}{l}\text { (PRIMARY) HBA1C - No mention of outcome assessor blinding. Review of med- } \\
\text { ical records provided information about the baseline glycemic control (HBA1C } \\
\text { levels) }\end{array}$ \\
\hline $\begin{array}{l}\text { Blinding of participants } \\
\text { (performance bias) } \\
\text { Adherence measure }\end{array}$ & Low risk & $\begin{array}{l}\text { (PRIMARY) PHARMACY RECORD - Patients were not told the goal of the study. } \\
\text { Pharmacy records unlikely to be influenced }\end{array}$ \\
\hline $\begin{array}{l}\text { Blinding of participants } \\
\text { (performance bias) }\end{array}$ & Low risk & (PRIMARY) HBA1C - it is unlikely patient could influence their HBA1C measure \\
\hline
\end{tabular}


Mullan 2009 (Continued)

Patient outcome

Blinding of personnel (per- Unclear risk formance bias)

Adherence measure
(PRIMARY) PHARMACY RECORD - No mention of blinding. There is insufficient information to permit judgment of 'Low risk' or 'High risk'
Blinding of personnel (per- Low risk formance bias)

Patient outcome
(PRIMARY) HBA1C - No mention of research staff blinding. This is unlikely to influence outcome measure
Incomplete outcome data Low risk (attrition bias)

Adherence measure
(PRIMARY) PHARMACY RECORD - There is a small amount of missing data but it is balanced across the conditions

Incomplete outcome data Low risk

(PRIMARY) HBA1C - Complete data for this measure

(attrition bias)

Patient outcome

Muniz 2010

\begin{tabular}{ll}
\hline Methods & Randomized controlled trial \\
\hline Participants & The study location was 64 hospitals throughout Spain \\
& 867 participants were randomized to the intervention group and 890 participants were randomized to \\
the control group & \\
& The inclusion criteria were male and female patients admitted for acute coronary syndrome with or \\
without ST-segment elevation, discharged with a diagnosis of Q-wave or non-Q-wave acute myocardial & infarction (AMI) or unstable angina with sufficient cultural level to be able to understand the interven- \\
& tion and the ability to fulfill the schedule of proposed further visits (at 2 and 6 months) \\
& The exclusion criteria were under 18 or above 80 years of age, those presenting accompanying illnesses \\
which would cause unfavorable prognosis in the following months or which would prevent their partic- \\
ipation
\end{tabular}

Interventions

Intervention: POST DISCHARGE EDUCATIONAL INTERVENTION

Intervention is an educational intervention consisting of a signed agreement between patient and physician on the objectives to be reached. The intervention includes a personalized interview at discharge with patient and nearest next-of-kin, in which physician and patient discuss and sign an agreement with the patient-specific secondary prevention procedures and therapeutic aims. Both physician and patient keep a copy of the signed agreement. Written back-up information (about heart attack, controlling cholesterol, body weight, and blood pressure, and effects of smoking) and a phone number as to where to call in case of questions were given. Intervention also included an interview with the patient 2 months after discharge in order to review the agreement, adapt treatment if needed and reinforce the intervention. Informative materials are given once again.The visits took an average of 30 to 40 minutes each

Control: USUAL CARE

Control group participants received usual care. Follow-up was at 6 months

Outcomes The measures of adherence were self report at baseline and at 6 months

The patient outcomes were blood pressure, BMI, and lipid levels measured at baseline and 6 months. Lipid levels were sourced from hospital data 
Muniz 2010 (Continued)

\section{Risk of bias}

\begin{tabular}{lll}
\hline Bias & Authors' judgement & Support for judgement \\
\hline $\begin{array}{l}\text { Random sequence genera- } \\
\text { tion (selection bias) }\end{array}$ & Low risk & $\begin{array}{l}\text { "1,757 patients were assigned to the Intervention Group }(\mathrm{n}=867) \text { or the Con- } \\
\text { trol Group }(\mathrm{n}=890) \text { by means of stratified randomization by centre and with } \\
\text { concealment of allocation sequence. The unit of randomization was the pa- } \\
\text { tient and the stratification by centre was done to remove the effect of the hos- } \\
\text { pital by obtaining groups of equal size (intervention and control) in every hos- } \\
\text { pital." (pg 2) }\end{array}$ \\
\hline
\end{tabular}

\begin{tabular}{lll}
\hline $\begin{array}{l}\text { Allocation concealment } \\
\text { (selection bias) }\end{array}$ & Low risk & $\begin{array}{l}\text { The author notes that very center had a sequence prepared for 30 patients. } \\
\text { Every sequence was hospital-specific and randomly ordered }\end{array}$ \\
\hline $\begin{array}{l}\text { Selective reporting (re- } \\
\text { porting bias) }\end{array}$ & Low risk & The author has provided the protocol \\
\hline Other bias & Low risk & The study seems to be free of other types of bias \\
\hline $\begin{array}{l}\text { Blinding of outcome as- } \\
\text { sessment (detection bias) } \\
\text { Adherence measure }\end{array}$ & High risk & $\begin{array}{l}\text { (PRIMARY) SELF REPORT - INTERVIEW - This is a subjective measure; there is no } \\
\text { information on blinding. This is an open-label study }\end{array}$ \\
\hline
\end{tabular}

\begin{tabular}{lll}
\hline $\begin{array}{l}\text { Blinding of outcome as- } \\
\text { sessment (detection bias) }\end{array}$ & Unclear risk & (PRIMARY) BLOOD PRESSURE - This is an open-label study. No information on \\
Patient outcome & whether the method of taking blood pressure was computerized. There is in- \\
& sufficient information to permit judgment of 'Low risk' or 'High risk'
\end{tabular}

\begin{tabular}{ll}
\hline $\begin{array}{l}\text { Blinding of participants } \\
\text { (performance bias) }\end{array}$ & High risk \\
Adherence measure & $\begin{array}{l}\text { (PRIMARY) SELF REPORT - INTERVIEW - The study was open-labeled. This is a } \\
\text { subjective measure of adherence }\end{array}$
\end{tabular}

\begin{tabular}{|c|c|c|}
\hline $\begin{array}{l}\text { Blinding of participants } \\
\text { (performance bias) } \\
\text { Patient outcome }\end{array}$ & Low risk & $\begin{array}{l}\text { (PRIMARY) BLOOD PRESSURE - Although this is an open-label study, the out- } \\
\text { come is objective. Therefore lack of blinding is not likely to affect the outcome }\end{array}$ \\
\hline $\begin{array}{l}\text { Blinding of personnel (per- } \\
\text { formance bias) } \\
\text { Adherence measure }\end{array}$ & Low risk & $\begin{array}{l}\text { (PRIMARY) SELF REPORT - INTERVIEW - The author notes that there were no } \\
\text { "key study personnel" who might have affected data quality }\end{array}$ \\
\hline $\begin{array}{l}\text { Blinding of personnel (per- } \\
\text { formance bias) } \\
\text { Patient outcome }\end{array}$ & Unclear risk & $\begin{array}{l}\text { (PRIMARY) BLOOD PRESSURE - No information on blinding given. There is in- } \\
\text { sufficient information to permit judgment of 'Low risk' or 'High risk' }\end{array}$ \\
\hline $\begin{array}{l}\text { Incomplete outcome data } \\
\text { (attrition bias) } \\
\text { Adherence measure }\end{array}$ & Low risk & $\begin{array}{l}\text { (PRIMARY) SELF REPORT - INTERVIEW - The author notes that the absolute pro- } \\
\text { portion of those who refused to come to the final visit is equal in the } 2 \text { groups } \\
(4 \%) \text { (figure } 1 \text { ) }\end{array}$ \\
\hline $\begin{array}{l}\text { Incomplete outcome data } \\
\text { (attrition bias) } \\
\text { Patient outcome }\end{array}$ & Low risk & $\begin{array}{l}\text { (PRIMARY) BLOOD PRESSURE - The author notes that the absolute proportion } \\
\text { of those who refused to come to the final visit is equal in the } 2 \text { groups ( } 4 \% \text { ) (fig- } \\
\text { ure } 1 \text { ) }\end{array}$ \\
\hline
\end{tabular}

Murray 2007

Methods Randomized controlled trial


Murray 2007 (Continued)

Participants
The study location was the general medicine and cardiology practices of Wishard Health Services, Indianapolis, Indiana, USA

122 participants were randomized to the intervention group and 192 participants were randomized to the control group

The inclusion criteria were clinically stable patients from general internal medicine practices, a cardiology clinic, and Wishard Memorial Hospital (at discharge) to participate in the study. Patients were eligible if they were 50 years of age or older; planned to receive all of their care, including prescribed medications, at Wishard Health Services; had a diagnosis of heart failure confirmed by their primary care physician; regularly used at least 1 cardiovascular medication for heart failure (angiotensin-converting enzyme (ACE) inhibitor or angiotensin-receptor blocker, beta-adrenergic antagonist, diuretic, digoxin, or aldosterone antagonist); were not using or were not planning to use a medication container adherence aid (for example, a pill box); had access to a working telephone; and could hear within the range of normal conversation

The exclusion criteria were patients with dementia
Interventions
Intervention: PHARMACIST INTERVENTION

A pharmacist delivered the intervention by using a protocol that included a baseline medication history of all prescription and over-the-counter drugs and dietary supplements taken by patients, which patients brought with them to the baseline interview, and the results of an assessment of patient medication knowledge and skills. The pharmacist dispensed enough of the patient's medications to last approximately 2 months. The intervention lasted 9 months. When medications were dispensed, the pharmacist provided patient-centered verbal instructions and written materials about the medications. Each medication category had an icon associated with it. The same icon appeared on the container label and lid and on the written patient instructions. The pharmacist monitored patients' medication use, health care encounters, body weight, and other relevant data by using a study database. Information about patients was communicated as needed to clinic nurses and primary care physicians by faceto-face visits, telephone, paging (physician only), and e-mail (physician only). An interdisciplinary team of investigators trained the intervention pharmacist. The intervention pharmacist also studied guidelines for treating heart failure, key concepts in the pharmaceutical care of older adults, communication techniques, and the pharmacotherapy of the cardiovascular drugs for heart failure

\section{Control: USUAL CARE}

Control groups received usual care. Usual care participants were aware of the purpose of the study. They received their prescription services from the same pharmacy as the intervention participants, but the pharmacists who attended the usual care participants were not trained by the interdisciplinary team

Outcomes
The measures of adherence were Medication Event Monitoring System (MEMS), prescription records, and self reported adherence. MEMS is a prescription container lid and all prescribed cardiovascular medications were dispensed with MEMS lids that recorded the time and date of each opening and closing onto a digital chip. Data retrieved from the lids were used to compute taking adherence and scheduling adherence. Taking adherence is the percentage of prescribed medication taken and measures deviation from the physician's prescription. Scheduling adherence measures the day-to-day deviation in the timing of administration. A medication prescribed for once-daily administration would need to be administered within 24 hours of the previous dose, whereas medications prescribed for twice-daily administration would need to be administered within 12 hours of the previous dose. Scheduling adherence measures the reliability or consistency of dosing over time. Refill adherence as the medication possession ratio by using prescription records from the Regenstrief Medical Record System. Results for 1 year, incorporating the 9-month intervention period and the 3-month postintervention period was computed. Patients came for refills at approximately 2 -month intervals. Considering the carry-over effect of the intervention that stopped at 9 months, the intervention effect on medication supplies would extend to 11 to 12 months. Hence, the 12 -month period adequately reflects the effect of the intervention. Self reported adherence was determined for the previous month at baseline and 9 months by using validated questionnaires. Using these questionnaire scores, a composite score of self reported adherence was computed

The patient outcomes were exacerbations by using hospital admission data from emergency department visits. We extracted data for heart failure-specific, all cardiovascular, and all-cause reasons for 
Murray 2007 (Continued)

emergency visits and hospitalizations; these were adjudicated by a registered nurse abstractor who used a previously validated method, from the Regenstrief Medical Record System

Secondary outcomes included health-related quality of life. We analyzed disease-specific quality of life by using the Chronic Heart Failure Questionnaire, which performs well in the clinical setting of our study. This validated questionnaire has 4 dimensions: fatigue, dyspnea, emotion, and mastery. We averaged the scores on each scale, ranging from 1 (worst function) to 7 (best function), across items within each dimension

Notes -

\section{Risk of bias}

\begin{tabular}{|c|c|c|}
\hline Bias & Authors' judgement & Support for judgement \\
\hline $\begin{array}{l}\text { Random sequence genera- } \\
\text { tion (selection bias) }\end{array}$ & Low risk & $\begin{array}{l}\text { A pseudo-random number generator was used. "A trained interviewer con- } \\
\text { ducted a baseline interview at enrollment. Interviewers were blinded to pa- } \\
\text { tients' study status and played no role in the delivery of the intervention. In- } \\
\text { terviewers contacted a centralized data manager at the end of each interview } \\
\text { to determine the patient's study assignment, which was otherwise concealed. } \\
\text { We randomly assigned patients, without blocking or stratification, to receive } \\
\text { the pharmacy intervention or usual care by using a univariate discrete distrib- } \\
\text { ution from the IMSL Fortran Library's subroutine RNGDA pseudorandom num- } \\
\text { ber generator (Absoft Corp., Rochester Hills, Michigan) (16). We randomly as- } \\
\text { signed more patients to the usual care group so that this group could also be a } \\
\text { prospective cohort for studying risk factors associated with the clinical deteri- } \\
\text { oration of heart failure. Of the } 314 \text { patients included in the study, } 229 \text { were re- } \\
\text { cruited from the general internal medicine practices, } 15 \text { from the cardiology } \\
\text { clinic, and } 70 \text { on discharge from the Wishard Memorial Hospital. The numbers } \\
\text { of patients assigned to the intervention and usual care groups did not differ by } \\
\text { recruitment site" (pg } 715 \text { ) }\end{array}$ \\
\hline
\end{tabular}

\begin{tabular}{ll}
\hline $\begin{array}{l}\text { Allocation concealment } \\
\text { (selection bias) }\end{array}$ & Low risk \\
& $\begin{array}{l}\text { Allocation concealment was noted. "Interviewers contacted a centralized data } \\
\text { manager at the end of each interview to determine the patient's study assign- } \\
\text { ment, which was otherwise concealed" (pg 715) }\end{array}$
\end{tabular}

\begin{tabular}{lll}
\hline $\begin{array}{l}\text { Selective reporting (re- } \\
\text { porting bias) }\end{array}$ & Low risk & Protocol is available. All pre-specified outcomes are reported on \\
\hline Other bias & Low risk & The study seems to be free of other types of bias \\
\hline $\begin{array}{l}\text { Blinding of outcome as- } \\
\text { sessment (detection bias) } \\
\begin{array}{l}\text { Adherence measure } \\
\text { L }\end{array}\end{array}$ & Low risk & $\begin{array}{l}\text { (PRIMARY) MEMS - Outcome unlikely influenced by outcome assessor. "Inter- } \\
\text { viewers were blinded to patients' study status and played no role in the deliv- } \\
\text { ery of the intervention" (pg 717) }\end{array}$
\end{tabular}

\begin{tabular}{|c|c|c|}
\hline $\begin{array}{l}\text { Blinding of outcome as- } \\
\text { sessment (detection bias) }\end{array}$ & Low risk & $\begin{array}{l}\text { (PRIMARY) HOSPITAL VISIT RECORDS - Lack of staff blinding unlikely to affect } \\
\text { this outcome }\end{array}$ \\
\hline
\end{tabular}

\begin{tabular}{|c|c|c|}
\hline $\begin{array}{l}\text { Blinding of participants } \\
\text { (performance bias) } \\
\text { Adherence measure }\end{array}$ & High risk & $\begin{array}{l}\text { (PRIMARY) MEMS - There is no information on blinding. Any blinding could } \\
\text { have been broken due to the nature of the intervention }\end{array}$ \\
\hline $\begin{array}{l}\text { Blinding of participants } \\
\text { (performance bias) } \\
\text { Patient outcome }\end{array}$ & Low risk & $\begin{array}{l}\text { (PRIMARY) HOSPITAL VISIT RECORDS - Lack of patient blinding unlikely to af- } \\
\text { fect this outcome }\end{array}$ \\
\hline
\end{tabular}

Blinding of personnel (per- Low risk (PRIMARY) MEMS - This is an objective measure of outcome


Murray 2007 (Continued)

Blinding of personnel (per- Low risk formance bias)

(PRIMARY) HOSPITAL VISIT RECORDS - Lack of staff blinding unlikely to affect

Patient outcome this outcome

\begin{tabular}{lll}
\hline $\begin{array}{l}\text { Incomplete outcome data } \\
\text { (attrition bias) } \\
\text { Adherence measure }\end{array}$ & Unclear risk & $\begin{array}{l}\text { (PRIMARY) MEMS - it is unclear whether the reasons for dropouts are related to } \\
\text { the intervention; the number of dropouts are not balanced }\end{array}$ \\
\hline $\begin{array}{l}\text { Incomplete outcome data } \\
\text { (attrition bias) }\end{array}$ & Unclear risk & $\begin{array}{l}\text { (PRIMARY) HOSPITAL VISIT RECORDS - it is unclear whether the reasons for } \\
\text { dropouts are related to the intervention; the number of dropouts are not bal- } \\
\text { anced }\end{array}$
\end{tabular}

Nazareth 2001

$\begin{array}{ll}\text { Methods } & \text { Patients were independently randomized by the health authority's central community pharmacy office } \\ \text { using computer-generated random numbers. } 165 \text { patients were eligible at baseline in the intervention } \\ \text { group and } 151 \text { patients were eligible in the control group. They used blocked randomization, stratified } \\ \text { by trial center, to ensure equal numbers of participants in each randomized group }\end{array}$

Participants

From June 1995 to March 1997, patients discharged from elderly care wards were asked by the hospital pharmacist to give informed consent. 362 patients were recruited. Patients over 75 years who were taking 4 or more medicines at discharge were asked to join the study. Patients who could not speak English or were too ill were excluded

Interventions

Between 7 and 14 days after discharge, community pharmacists visited the patients at home. This visit allowed the pharmacist to check for discrepancies between the medicines the patient was taking and those prescribed on discharge. The pharmacist assessed the patient's understanding of and adherence to the medication regimen and intervened when appropriate. Interventions included counseling patients or carers on the purpose and appropriate doses of the medication, disposing of excess medicines and liaising with general practitioners. The pharmacists arranged further community visits at their discretion. All assessments and interventions were sent to the hospital-based liaison pharmacist. A revised care plan was issued if a patient was re-admitted to hospital during the 6-month study period. Patients randomized to the control group were discharged from hospital following standard procedures. These included a discharge letter to the general practitioner who indicated the diagnosis, investigations and current medications. The pharmacists did not provide a review of discharge medication or follow-up in the community

Outcomes Compliance measures were made at baseline and at follow-up ( 3 and 6 months after start of intervention). The primary outcome was re-admission to hospital in the follow-up period. Secondary outcomes were number of deaths, attendances at hospital outpatient clinics and general practice (at home or in the surgery) and days in hospital as a percentage of days of follow-up

\begin{tabular}{lll}
\hline Notes & - \\
\hline Risk of bias & & \\
\hline Bias & Authors' judgement & Support for judgement \\
\hline $\begin{array}{l}\text { Random sequence genera- } \\
\text { tion (selection bias) }\end{array}$ & Low risk & $\begin{array}{l}\text { Random number generation used for randomization. "computer generat- } \\
\text { ed random numbers. We used blocked randomization, stratified by trial cen- } \\
\text { tre..." (pg 34) }\end{array}$ \\
\hline $\begin{array}{l}\text { Allocation concealment } \\
\text { (selection bias) }\end{array}$ & Low risk & $\begin{array}{l}\text { Central center was used for allocation. "The health authority's central com- } \\
\text { munity pharmacy office using computer-generated random numbers..." "allo- } \\
\text { cation code held by randomization centre was revealed only at the end of the } \\
\text { study" (pg 34) }\end{array}$ \\
\hline
\end{tabular}


Nazareth 2001 (Continued)

Selective reporting (re- Unclear risk No protocol available; although it appears that everything was reported it is porting bias) difficult to determine this without a protocol
There seems to be some lack of uniformity in the intervention delivery - 15/19 pharmacists conducted a second visit and 2 went on a third visit - exact reasons for the extra visits not reported. There is a small chance that some pharmacists were more keen so they went on more visits

\begin{tabular}{|c|c|c|}
\hline $\begin{array}{l}\text { Blinding of outcome as- } \\
\text { sessment (detection bias) } \\
\text { Adherence measure }\end{array}$ & Low risk & $\begin{array}{l}\text { (PRIMARY) PRESCRIBED MEDICATION INTERVIEW - Outcome assessors were } \\
\text { blind. "These data were assessed by an independent blinded hospital pharma- } \\
\text { cist. Each item was rated } 0 \text { (none) or } 1 \text { (highest level) and mean scores calcu- } \\
\text { lated" (pg 35) }\end{array}$ \\
\hline
\end{tabular}

\begin{tabular}{|c|c|c|}
\hline $\begin{array}{l}\text { Blinding of outcome as- } \\
\text { sessment (detection bias) } \\
\text { Patient outcome }\end{array}$ & Low risk & $\begin{array}{l}\text { (PRIMARY) READMISSION TO HOSPITALS - The outcome assessors blind. } \\
\text { "These data were assessed by an independent blinded hospital pharmacist. } \\
\text { Each item was rated } 0 \text { (none) or } 1 \text { (highest level) and mean scores calculat- } \\
\text { ed" (pg 35) }\end{array}$ \\
\hline
\end{tabular}

\begin{tabular}{|c|c|c|}
\hline $\begin{array}{l}\text { Blinding of participants } \\
\text { (performance bias) } \\
\text { Adherence measure }\end{array}$ & High risk & $\begin{array}{l}\text { (PRIMARY) PRESCRIBED MEDICATION INTERVIEW - This is a subjective mea- } \\
\text { sure; there is no information on blinding }\end{array}$ \\
\hline
\end{tabular}

Adherence measure

\begin{tabular}{ll}
$\begin{array}{l}\text { Blinding of participants } \\
\text { (performance bias) }\end{array}$ & Low risk \\
Patient outcome & come \\
\hline
\end{tabular}

Blinding of personnel (per- Low risk formance bias)

Adherence measure
(PRIMARY) PRESCRIBED MEDICATION INTERVIEW - The author has noted that the research assistant remained blinded to allocation of patient

$\begin{array}{ll}\text { Blinding of personnel (per- } & \text { Low risk } \\ \text { formance bias) } & \text { (PRIMARY) READMISSION TO HOSPITALS - This is an objective measure of out- } \\ \text { Patient } & \text { come }\end{array}$

formance bias) come

Incomplete outcome data Unclear risk

(attrition bias)

(PRIMARY) PRESCRIBED MEDICATION INTERVIEW - Missing data are somewhat

Adherence measure uniform across time points for adherence measure. Unable to predict whether the numbers could affect the results; therefore, marked unclear

\begin{tabular}{|c|c|c|}
\hline $\begin{array}{l}\text { Incomplete outcome data } \\
\text { (attrition bias) } \\
\text { Patient outcome }\end{array}$ & Unclear risk & $\begin{array}{l}\text { (PRIMARY) READMISSION TO HOSPITALS - Unable to determine the potential } \\
\text { effect of missing data for this outcome on results }\end{array}$ \\
\hline
\end{tabular}

\begin{tabular}{ll}
\hline Nguyen 2008 & Randomized controlled trial \\
\hline Participants & The study location was The Hospital for Sick Children, Toronto, ON, Canada \\
& 92 participants were randomized to the intervention group and 75 participants were randomized to the \\
& control group \\
& The inclusion criteria were pregnant women who had not started any multivitamin due to adverse \\
events such as nausea, vomiting, constipation, diarrhea, calling the Motherisk program at The Hospital \\
for Sick Kids in Toronto
\end{tabular}


The exclusion criteria were pregnancy progressed past 20 gestational weeks, hypersensitivity to any of the ingredients in the study drugs, hemochromatosis, hemosiderosis or hemolytic anemia

Interventions

Intervention: SMALL LOW IRON DOSE TABLET

Small low-dose iron tablets were used as the intervention in this study. PregVit a prenatal multivitamin that contains $35 \mathrm{mg}$ elemental iron, as ferrous fumarate was prescribed for intervention group patients. The multiple vitamins and minerals are formulated into 2 small tablets, and is taken as 2 tablets per day. After enrolment, subjects received a 1-week follow-up telephone call and then were interviewed by telephone on a monthly basis until the end of pregnancy. Each interview documented obstetrical and medical information, adherence based on pill intake recall, and any reported adverse events. The date(s) of discontinuation at any time(s) during study participation was documented as the date(s) reported by the subject during the monthly interview

Control: SMALL 60 MG MULTIVITAMIN TABLET

A small-sized high-dose $(60 \mathrm{mg})$ multivitamin administered once daily was used as the control in this study

Outcomes

The measures of adherence were measured by monthly telephone interview until the end of pregnancy. The date and time of discontinuation of the drug was documented by the interviewer

The patient outcomes were adverse events. Data were collected by making telephone calls to the patients on a monthly basis until the end of the pregnancy

\begin{tabular}{ll}
\hline Notes & - \\
\hline Risk of bias &
\end{tabular}

\section{Risk of bias}

\begin{tabular}{lll}
\hline Bias & Authors' judgement & Support for judgement \\
\hline $\begin{array}{l}\text { Random sequence genera- } \\
\text { tion (selection bias) }\end{array}$ & Low risk & $\begin{array}{l}\text { A computer-generated randomization table was used. "Based on a comput- } \\
\text { er-generated randomization table, women were randomized to one of two } \\
\text { groups" (pg 3) }\end{array}$ \\
\hline
\end{tabular}

\begin{tabular}{lll}
\hline $\begin{array}{l}\text { Allocation concealment } \\
\text { (selection bias) }\end{array}$ & Unclear risk & No information was provided about how allocation was handled \\
\hline $\begin{array}{l}\text { Selective reporting (re- } \\
\text { porting bias) }\end{array}$ & Unclear risk & $\begin{array}{l}\text { No protocol available; although it appears that everything was reported it is } \\
\text { difficult to determine this without a protocol }\end{array}$ \\
\hline
\end{tabular}

\begin{tabular}{|c|c|c|}
\hline Other bias & Low risk & The study seems to be free of other types of bias \\
\hline $\begin{array}{l}\text { Blinding of outcome as- } \\
\text { sessment (detection bias) } \\
\text { Adherence measure }\end{array}$ & Unclear risk & $\begin{array}{l}\text { (PRIMARY) SELF REPORT - INTERVIEW - No information on blinding given. } \\
\text { There is insufficient information to permit judgment of 'Low risk' or 'High risk' }\end{array}$ \\
\hline
\end{tabular}

\begin{tabular}{ll}
\hline $\begin{array}{l}\text { Blinding of outcome as- } \\
\text { sessment (detection bias) } \\
\begin{array}{l}\text { Patient outcome }\end{array}\end{array} \quad$ Unclear risk & $\begin{array}{l}\text { (PRIMARY) ADVERSE EFFECTS - No information on blinding given. There is in- } \\
\text { sufficient information to permit judgment of 'Low risk' or 'High risk' }\end{array}$
\end{tabular}

\begin{tabular}{|c|c|c|}
\hline $\begin{array}{l}\text { Blinding of participants } \\
\text { (performance bias) } \\
\text { Adherence measure }\end{array}$ & High risk & $\begin{array}{l}\text { (PRIMARY) SELF REPORT - INTERVIEW - This is a subjective measure; there is no } \\
\text { information on blinding }\end{array}$ \\
\hline
\end{tabular}

\begin{tabular}{ll}
\hline $\begin{array}{l}\text { Blinding of participants } \\
\text { (performance bias) }\end{array}$ & High risk \\
$\begin{array}{l}\text { Patient outcome } \\
\text { (PRIMARY) ADVERSE EFFECTS - This is a subjective measure; there is no infor- } \\
\text { mation on blinding }\end{array}$
\end{tabular}

\begin{tabular}{|c|c|c|}
\hline $\begin{array}{l}\text { Blinding of personnel (per- } \\
\text { formance bias) }\end{array}$ & Unclear risk & $\begin{array}{l}\text { (PRIMARY) SELF REPORT - INTERVIEW - No information on blinding given. } \\
\text { There is insufficient information to permit judgment of 'Low risk' or 'High risk' }\end{array}$ \\
\hline
\end{tabular}


Nieuwkerk 2012 (Continued)

The patient outcomes were lipid levels and anxiety. A fasting lipid profile was analyzed from capillary finger-stick whole blood using the Cholestech LDX Lipid Analyzer, which measures total cholesterol, triglycerides, and high-density lipoprotein cholesterol. Low-density lipoprotein (LDL) cholesterol was calculated. Anxiety was assessed using the Hospital Anxiety and Depression Scale. Higher scores indicate higher levels of anxiety. Quality of life (QoL) was measured using the Medical Outcomes Study Short-Form 12-Item Health Survey. 2 subscale scores can be obtained, a physical health score and a mental health score. Higher scores indicate better physical and mental health. Symptoms related to the use of lipid-lowering medication were assessed using a symptom checklist containing 20 items that were derived from the item bank of the European Organisation for Research and Treatment of Cancer QoL group. The checklist includes the most frequently occurring side effects observed by statin users. The presence of a symptom during the past 4 weeks was scored on a 4-point scale. A summary score was calculated. The self reported questionnaires were completed at baseline and then before subsequent consultations. Carotid IMT and FMD were measured at baseline and at month 18. B-mode ultrasound IMT measurements were performed in the far walls of the carotid arteries. The mean of 3 measurements was used to calculate IMT. FMD was determined in terms of the percentage change in diameter relative to the baseline measurement. Baseline vessel diameter was calculated as the average of the 3 baseline measurements. Each of the imaging operations was performed by a single highly skilled sonographer

Notes -

\section{Risk of bias}

\begin{tabular}{lll}
\hline Bias & Authors' judgement & Support for judgement \\
\hline $\begin{array}{ll}\text { Random sequence genera- } \\
\text { tion (selection bias) }\end{array}$ & Low risk & $\begin{array}{l}\text { Computer program was used for randomization. "After inclusion, patients } \\
\text { were randomly assigned to RC or extended care (EC), using a randomization } \\
\text { computer program, to obtain an equal distribution of primary and secondary } \\
\text { prevention patients, hospital origin, and gender in the 2 groups." (pg 666) }\end{array}$
\end{tabular}

\begin{tabular}{lll}
\hline $\begin{array}{l}\text { Allocation concealment } \\
\text { (selection bias) }\end{array}$ & Unclear risk & No information was provided about how allocation was handled \\
\hline $\begin{array}{l}\text { Selective reporting (re- } \\
\text { porting bias) }\end{array}$ & Unclear risk & $\begin{array}{l}\text { No protocol available; although it appears that everything was reported it is } \\
\text { difficult to determine this without a protocol }\end{array}$ \\
\hline
\end{tabular}

\begin{tabular}{lll}
\hline Other bias & Low risk & The study seems to be free of other types of bias \\
\hline $\begin{array}{l}\text { Blinding of outcome as- } \\
\text { sessment (detection bias) } \\
\begin{array}{l}\text { Adherence measure } \\
\text { Adhe }\end{array}\end{array}$ & High risk & $\begin{array}{l}\text { (PRIMARY) SELF REPORT - QUESTIONNAIRE - The study nurse was not blinded } \\
\text { to the purpose of the study (pg 668) }\end{array}$
\end{tabular}

$\begin{array}{ll}\begin{array}{l}\text { Blinding of outcome as- } \\ \text { sessment (detection bias) }\end{array} & \text { Low risk } \\ \begin{array}{l}\text { Patient outcome } \\ \text { (PRIMARY) FASTING LIPID LEVEL - Although the study nurse was not blinded to } \\ \text { the purpose of the study (pg 668), this is an objective measure }\end{array}\end{array}$

\begin{tabular}{|c|c|c|}
\hline $\begin{array}{l}\text { Blinding of outcome as- } \\
\text { sessment (detection bias) } \\
\text { Patient outcome }\end{array}$ & High risk & $\begin{array}{l}\text { (PRIMARY) ANXIETY (HAS SCORE) - The study nurse was not blinded to the pur- } \\
\text { pose of the study; this is a subjective measure }\end{array}$ \\
\hline $\begin{array}{l}\text { Blinding of participants } \\
\text { (performance bias) } \\
\text { Adherence measure }\end{array}$ & High risk & $\begin{array}{l}\text { (PRIMARY) SELF REPORT - QUESTIONNAIRE - The author notes that patients } \\
\text { were not blinded to the study. They were aware that enhancing adherence was } \\
\text { a study aim. They were informed that responses to questions about adherence } \\
\text { were handled confidential and anonymously making use of code numbers, } \\
\text { and that their responses were not communicated to their treating physician }\end{array}$ \\
\hline $\begin{array}{l}\text { Blinding of participants } \\
\text { (performance bias) } \\
\text { Patient outcome }\end{array}$ & High risk & $\begin{array}{l}\text { (PRIMARY) ANXIETY (HAS SCORE) - The author notes that patients were not } \\
\text { blinded to the study. They were aware that enhancing adherence was a study } \\
\text { aim. They were informed that responses to questions about adherence were }\end{array}$ \\
\hline
\end{tabular}


handled confidential and anonymously making use of code numbers, and that their responses were not communicated to their treating physician; this is a subjective measure

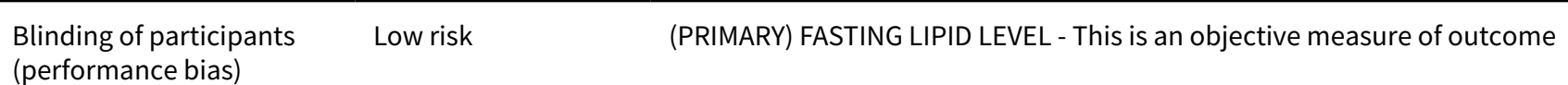

Patient outcome

Blinding of personnel (per- Unclear risk formance bias)

Adherence measure

(PRIMARY) SELF REPORT - QUESTIONNAIRE - No information on blinding given. There is insufficient information to permit judgment of 'Low risk' or 'High risk'

\begin{tabular}{|c|c|c|}
\hline $\begin{array}{l}\text { Blinding of personnel (per- } \\
\text { formance bias) }\end{array}$ & Unclear risk & $\begin{array}{l}\text { (PRIMARY) ANXIETY (HAS SCORE) - No information on blinding given. There is } \\
\text { insufficient information to permit judgment of 'Low risk' or 'High risk' }\end{array}$ \\
\hline
\end{tabular}

Patient outcome

Blinding of personnel (per- Low risk

formance bias)

Patient outcome

(PRIMARY) FASTING LIPID LEVEL - This is an objective measure of outcome

Incomplete outcome data Unclear risk

(attrition bias)

Adherence measure

\begin{tabular}{lll}
\hline $\begin{array}{l}\text { Incomplete outcome data } \\
\text { (attrition bias) }\end{array}$ & Unclear risk & (PRIMARY) FASTING LIPID LEVEL - Attrition rates were not balanced \\
Patient outcome & \\
\hline $\begin{array}{l}\text { Incomplete outcome data } \\
\text { (attrition bias) }\end{array}$ & Unclear risk & (PRIMARY) ANXIETY (HAS SCORE) - Attrition rates were not balanced \\
Patient outcome & \\
\hline
\end{tabular}

\section{O'Donnell 2003}

Methods Random allocation of consenting patients to compliance therapy or control groups using odd and even digits from a standard random numbers table. The researcher obtaining outcome measures was blinded to the intervention

\section{Participants}

54 of 96 consecutive people with psychosis, who had been admitted to St. John of God Hospital, Dublin, agreed to join the study. Patients aged 18 to 65 years, an IQ greater then 80, fluent in English, with no evidence of organic disturbance and diagnosed with schizophrenia. Each person who signed for informed consent took part in a structured clinical interview to determine their diagnosis according to the Diagnostic and Statistical Manual of Mental Disorders

Interventions The control group received non-specific counseling compromising of 5 sessions lasting 30 to 60 minutes. The experimental group received 5 sessions of compliance therapy, each session lasting 30 to 60 minutes. The sessions covered a review of the patient's illness history, understanding of the illness and his or her ambivalence to treatment, maintenance medication, and stigma. Compliance therapy is a cognitive behavior intervention with techniques adapted from motivational interviewing, other cognitive therapies, and psychoeducation

Outcomes A structured clinical interview was used to assess compliance 1 month before the intervention and 1
year post-intervention. Patient outcome measures included attitude towards medication, symptoma-
tology, insight, functioning, quality of life, and psychiatric hospital bed occupancy. The following scales
were used: DAI - Drug attitude inventory; PANSS - positive and negative symptom scale; SAI - Schedule
for assessment of insight; GAF - global assessment of function; QLS- Heinrich's quality of life scale 
O'Donnell 2003 (Continued)

Notes

\section{Risk of bias}

\begin{tabular}{lll}
\hline Bias & Authors' judgement & Support for judgement \\
\hline $\begin{array}{ll}\text { Random sequence genera- } \\
\text { tion (selection bias) }\end{array}$ & Low risk & $\begin{array}{l}\text { Random number table was used to generate sequence. "We randomly allocat- } \\
\text { ed consenting patients to compliance therapy or control groups using odd and } \\
\text { even digits from a standard table of random numbers." (pg 2) }\end{array}$ \\
\hline
\end{tabular}

\begin{tabular}{lll}
\hline $\begin{array}{l}\text { Allocation concealment } \\
\text { (selection bias) }\end{array}$ & Unclear risk & No information was provided about how allocation was handled \\
\hline $\begin{array}{l}\text { Selective reporting (re- } \\
\text { porting bias) }\end{array}$ & Unclear risk & $\begin{array}{l}\text { No protocol available; although it appears that everything was reported it is } \\
\text { difficult to determine this without a protocol }\end{array}$ \\
\hline Other bias & Unclear risk & $\begin{array}{l}\text { The authors note that they may have overestimated compliance. "Like Kemp } \\
\text { et al, we relied on the reports of patients and their relatives and healthcare } \\
\text { professionals for our measure of compliance. This is not ideal and, like pill } \\
\text { counts and serum drug levels, probably overestimates compliance. Electronic } \\
\text { measurement is methodologically superior but is expensive, is not foolproof, } \\
\text { and can be difficult to use.We have no reason to believe that using a self report } \\
\text { method led to a systematic bias." (pg 3) }\end{array}$ \\
\hline
\end{tabular}

\begin{tabular}{|c|c|c|}
\hline $\begin{array}{l}\text { Blinding of outcome as- } \\
\text { sessment (detection bias) } \\
\text { Adherence measure }\end{array}$ & Low risk & $\begin{array}{l}\text { (PRIMARY) STRUCTURED CLINICAL INTERVIEW - "One year after the interven- } \\
\text { tion a researcher who was blind to the type of intervention delivered repeated } \\
\text { the assessments of participants' compliance, attitudes to treatment, insight, } \\
\text { symptomatology, overall functioning, and quality of life" (pg 2) }\end{array}$ \\
\hline
\end{tabular}

Blinding of outcome as- $\quad$ Low risk
sessment (detection bias)

(PRIMARY) SYMPTOMATOLOGY (PANSS) - "One year after the intervention a researcher who was blind to the type of intervention delivered repeated the assessments of participants' compliance, attitudes to treatment, insight, symptomatology, overall functioning, and quality of life." (pg 2)

$\begin{array}{ll}\begin{array}{l}\text { Blinding of outcome as- } \\ \text { sessment (detection bias) }\end{array} & \text { Low risk } \\ \begin{array}{l}\text { Patient outcome } \\ \text { (PRIMARY) INSIGHT (SAI) - "One year after the intervention a researcher who } \\ \text { was blind to the type of intervention delivered repeated the assessments of } \\ \text { participants' compliance, attitudes to treatment, insight, symptomatology, } \\ \text { overall functioning, and quality of life." (pg 2) }\end{array}\end{array}$

\begin{tabular}{|c|c|c|}
\hline $\begin{array}{l}\text { Blinding of participants } \\
\text { (performance bias) } \\
\text { Adherence measure }\end{array}$ & Unclear risk & $\begin{array}{l}\text { (PRIMARY) STRUCTURED CLINICAL INTERVIEW - This is a subjective measure; } \\
\text { there is no information on blinding }\end{array}$ \\
\hline
\end{tabular}

\begin{tabular}{ll}
\hline $\begin{array}{l}\text { Blinding of participants } \\
\text { (performance bias) }\end{array}$ & High risk \\
$\begin{array}{l}\text { Patient outcome } \\
\text { no information on blinding }\end{array}$
\end{tabular}

\begin{tabular}{|c|c|c|}
\hline $\begin{array}{l}\text { Blinding of participants } \\
\text { (performance bias) } \\
\text { Patient outcome }\end{array}$ & Unclear risk & $\begin{array}{l}\text { (PRIMARY) INSIGHT (SAI) - This is a subjective measure; there is no information } \\
\text { on blinding }\end{array}$ \\
\hline
\end{tabular}

\begin{tabular}{|c|c|c|}
\hline $\begin{array}{l}\text { Blinding of personnel (per- } \\
\text { formance bias) } \\
\text { Adherence measure }\end{array}$ & Unclear risk & $\begin{array}{l}\text { (PRIMARY) STRUCTURED CLINICAL INTERVIEW - No information on blinding } \\
\text { given. There is insufficient information to permit judgment of 'Low risk' or } \\
\text { 'High risk' }\end{array}$ \\
\hline
\end{tabular}

Adherence measure 'High risk'

Blinding of personnel (per- Unclear risk formance bias) 


\section{O'Donnell 2003 (Continued)}

Blinding of personnel (per- Unclear risk formance bias)

Patient outcome
(PRIMARY) INSIGHT (SAI) - No information on blinding given. There is insufficient information to permit judgment of 'Low risk' or 'High risk'

\section{Incomplete outcome data Unclear risk (attrition bias)}

Adherence measure
(PRIMARY) STRUCTURED CLINICAL INTERVIEW - "Six patients were lost to follow up: two dropped out during therapy (both controls); three (two controls, one compliance therapy) refused follow up, and one (compliance therapy) died in the follow up period. More than $80 \%$ follow up reported in both group$s^{\prime \prime}$ (pg 2). It is not known whether the missing data could have changed the result

Incomplete outcome data Unclear risk
(attrition bias)

Patient outcome
(PRIMARY) INSIGHT (SAI) - "Six patients were lost to follow up: two dropped out during therapy (both controls); three (two controls, one compliance therapy) refused follow up, and one (compliance therapy) died in the follow up period. More than $80 \%$ follow up reported in both groups". It is not known whether the missing data could have changed the result

Incomplete outcome data Unclear risk
(attrition bias)

Patient outcome
(PRIMARY) SYMPTOMATOLOGY (PANSS) - "Six patients were lost to follow up: two dropped out during therapy (both controls); three (two controls, one compliance therapy) refused follow up, and one (compliance therapy) died in the follow up period. More than $80 \%$ follow up reported in both groups" (pg 2). Not known whether the missing data could have changed the result

\section{Odegard 2005}

$\begin{array}{ll}\text { Methods } & \text { A total of } 77 \text { patients were randomized, with } 34 \text { in the usual care group and } 43 \text { in the pharma- } \\ \text { cist-provider intervention group }\end{array}$

Participants

Eligible patients included all adults at least 18 years of age and older with type 2 diabetes, taking at least 1 oral diabetes medication, with a glycosylated hemoglobin (HbA1c) result $>$ or $=$ to $9 \%$. Non-English speaking subjects, those with unstable psychiatric conditions, or patients with a terminal prognosis within 6 months were not eligible

Interventions

The pharmacist intervention entailed the development of a diabetes care plan (DCP), regular pharmacist-patient communication on diabetes care progress, and pharmacist-provider communication on the subject's diabetes care progress. Medication-related problems requiring intervention were identified as part of the DCP. The pharmacist intervention was initiated 1 week after the baseline interview with an in-person appointment to develop the DCP that was then communicated to the primary care provider using electronic notation in the medical record. The pharmacist maintained regular contact with the subjects with weekly in-person or telephone meetings. Once the patient and pharmacist determined that the diabetes care needs were progressing as outlined in the DCP, follow-up phone call frequency was reduced to monthly through the 6-month intervention period. Patients in the usual care group were instructed to continue normal care with their primary care provider

\section{Outcomes}

$\mathrm{HbA1c}$ was used as the clinical endpoint and assessed at baseline, 6 months, and 12 months. Diabetes knowledge and quality of life with diabetes were assessed using a brief sample of questions used for identifying opportunities for diabetes care support and developing the DCP. Diabetes care history, adherence challenges, self management skills, and diabetes knowledge were assessed at baseline during an in-person interview. Medication appropriateness of all prescribed drugs was assessed from the medical record by the Medication Appropriateness Index (MAI). Adherence was assessed at baseline, 6 months, and 12 months using a self reported, 2-question recall technique. Medication use history was collected at baseline, 6 months, and 12 months

Notes -

\section{Risk of bias}


Odegard 2005 (Continued)

\begin{tabular}{|c|c|c|}
\hline Bias & Authors' judgement & Support for judgement \\
\hline $\begin{array}{l}\text { Random sequence genera- } \\
\text { tion (selection bias) }\end{array}$ & Unclear risk & $\begin{array}{l}\text { Randomization was not described in detail. "Subjects were enrolled in blocks } \\
\text { of } 4 \text { from each of the } 8 \text { clinics until achievement of the target sample." (pg 434) }\end{array}$ \\
\hline $\begin{array}{l}\text { Allocation concealment } \\
\text { (selection bias) }\end{array}$ & Unclear risk & No information was provided about how allocation was handled \\
\hline $\begin{array}{l}\text { Selective reporting (re- } \\
\text { porting bias) }\end{array}$ & Unclear risk & $\begin{array}{l}\text { No protocol available; although it appears that everything was reported it is } \\
\text { difficult to determine this without a protocol }\end{array}$ \\
\hline Other bias & Low risk & The study seems to be free of other types of bias \\
\hline $\begin{array}{l}\text { Blinding of outcome as- } \\
\text { sessment (detection bias) } \\
\text { Adherence measure }\end{array}$ & Unclear risk & $\begin{array}{l}\text { (PRIMARY) SELF REPORT - QUESTIONNAIRE - The authors do not report who } \\
\text { conducted the questionnaire interview. "A pharmacist trained in the use of the } \\
\text { MAI and not working directly with the study subjects assessed the MAl at base- } \\
\text { line and } 6 \text { months (end of the intervention), with follow-up evaluation by the } \\
\text { intervention pharmacist at } 12 \text { months" (pg 434) }\end{array}$ \\
\hline
\end{tabular}

\begin{tabular}{|c|c|c|}
\hline $\begin{array}{l}\text { Blinding of outcome as- } \\
\text { sessment (detection bias) } \\
\text { Patient outcome }\end{array}$ & Low risk & (PRIMARY) HBA1C - This is an objective measure of outcome \\
\hline $\begin{array}{l}\text { Blinding of participants } \\
\text { (performance bias) } \\
\text { Adherence measure }\end{array}$ & High risk & $\begin{array}{l}\text { (PRIMARY) SELF REPORT - QUESTIONNAIRE - Patients unblin } \\
\text { ture of the intervention; this is a subjective measure }\end{array}$ \\
\hline $\begin{array}{l}\text { Blinding of participants } \\
\text { (performance bias) } \\
\text { Patient outcome }\end{array}$ & Low risk & (PRIMARY) HBA1C - This is an objective measure of outcome \\
\hline
\end{tabular}

\begin{tabular}{ll}
\hline $\begin{array}{l}\text { Blinding of personnel (per- } \\
\text { formance bias) }\end{array}$ & High risk \\
Adherence measure & (PRIMARY) SELF REPORT - QUESTIONNAIRE - intervention pharmacist main- \\
tained regular contact with the subjects and with the primary care physicians; \\
therefore, both were not blinded
\end{tabular}

Blinding of personnel (per- Low risk (PRIMARY) HBA1C - This is an objective measure of outcome
formance bias)

Patient outcome

\begin{tabular}{|c|c|c|}
\hline $\begin{array}{l}\text { Incomplete outcome data } \\
\text { (attrition bias) } \\
\text { Adherence measure }\end{array}$ & Unclear risk & $\begin{array}{l}\text { (PRIMARY) SELF REPORT - QUESTIONNAIRE - At } 6 \text { months missing data equal } \\
\text { across groups, imbalance at } 12 \text { months. ITT using GEE (generalized estimating } \\
\text { equations) was used. "The GEE method does not require imputation of missing } \\
\text { data" (pg 435) }\end{array}$ \\
\hline $\begin{array}{l}\text { Incomplete outcome data } \\
\text { (attrition bias) } \\
\text { Patient outcome }\end{array}$ & Unclear risk & $\begin{array}{l}\text { (PRIMARY) HBA1C - There is not enough information given on the reasons for } \\
\text { dropouts }\end{array}$ \\
\hline
\end{tabular}

Ogedegbe 2012

\begin{tabular}{ll}
\hline Methods & Randomized controlled trial \\
\hline Participants & $\begin{array}{l}\text { The study location was a primary care practice within the ambulatory care network of New York Pres- } \\
\text { byterian Hospital, New York, New York, USA }\end{array}$
\end{tabular}


125 participants were randomized to the intervention group and 131 participants were randomized to the control group

The inclusion criteria were self identification as African American or black, fluency in the English language, a diagnosis of hypertension, and the use of at least 1 antihypertensive medication

The exclusion criteria were (i) had a diagnosis of cognitive impairment or serious medical condition as determined by their primary care physician, (ii) were unable to provide informed consent, or (iii) refused to participate

Interventions

Intervention: POSITIVE AFFECT INTERVENTION

Patients in the Positive Education (PE) control group received a culturally tailored educational workbook designed (1) to enhance patients' knowledge about hypertension, (2) to improve self management behaviors, and (3) to support goal-setting. Patients randomized to the Positive Affect (PA) intervention group were given the same workbook as those in the PE group but with an additional chapter that addresses the benefits of positive moments in overcoming obstacles to medication adherence. Also, these patients received 2 forms of PA during bimonthly telephone calls. First, they were asked to identify small things in their lives that invoke positive feelings in them and were then instructed to incorporate these positive thoughts into their daily routine. The positive thoughts were further reinforced during subsequent bimonthly telephone calls. Second, the patients received unexpected small gifts mailed to them before each telephone call. This strategy was based on the potential of the receipt of unexpected gifts to induce positive feelings. For self affirmation induction, the patients were asked to remember their core values and proud moments in their lives whenever they encounter situations that make it difficult for them to take their medications

\section{Control: PATIENT EDUCATION}

Patient Education (PE) control group received a culturally tailored educational workbook designed (1) to enhance patients' knowledge about hypertension, (2) to improve self management behaviors, and (3) to support goal-setting. On receipt of the workbook, trained Research Assistants (RAs) reviewed each chapter with the patients and then asked them to sign a behavioral contract that asked them to make a commitment to taking their medications as prescribed. Subsequent to this session, each patient received bimonthly telephone calls, during which the RAs assessed the patient's behavioral contract and confidence to take their medications as prescribed. These assessments served as the basis for reviewing and counseling the patient on perceived barriers to medication adherence. The intervention lasted for 12 months

Outcomes

The measures of adherence were self report questionnaire for baseline adherence measurement and an electronic pill monitor. Patients taking more than 1 medication could select the medication they wanted to put in the monitor. Monitors were returned to research assistants to have data downloaded or were sent in for downloading at 12 months. Electronic pill monitors are the accepted gold standard for adherence assessment

The patient outcomes were change in blood pressure (BP) from baseline to 12 months. BP data were extracted from patients' electronic medical records log of office BP readings taken by nurses or certified medical assistants using standard mercury sphygmomanometers. Blood pressure control was defined as a BP greater than $130 / 80 \mathrm{~mm} \mathrm{Hg}$ for patients with diabetes or chronic kidney disease and a BP less than $140 / 90 \mathrm{~mm} \mathrm{Hg}$ for all other patients

\begin{tabular}{lll}
\hline Notes & - & \\
\hline Risk of bias & Authors' judgement & Support for judgement \\
\hline Bias & Low risk & $\begin{array}{l}\text { Used a computer random-number generator. "Separate randomization sched- } \\
\text { ules were developed from a computerized random-number generator, bal- } \\
\text { anced at set intervals, using permutated blocks in order to assure equal num- } \\
\text { bers in each arm. Randomization assignment was carried out by the study sta- } \\
\text { tistician using sealed envelopes. Upon randomization, each patient was en- } \\
\text { tered into the study and included in the intention-to-treat analysis. A total of } \\
95 \text { patients were randomly assigned to each study group. As is typical for most }\end{array}$ \\
\hline
\end{tabular}


behavioral interventions, neither the patient nor the RA delivering the motivational interviewing could be blinded to the intervention assignment. However, the primary-care physician did not know the randomization group to which his or her patient belonged." (pg 172s)

Allocation concealment Unclear risk
(selection bias)

There is no mention of sequential allocation but opaque and sealed envelopes used. "On completion of the baseline assessments, the study biostatistician randomly assigned patients to either the PE control group or the PA intervention group in a 1:1 ratio. Patient assignments were placed in sealed opaque envelopes. As is typical for most behavioral interventions, neither the patients nor the RAs were blinded to the intervention. The primary care providers did not know their patients' group assignment." (pg 323)

\begin{tabular}{|c|c|c|}
\hline $\begin{array}{l}\text { Selective reporting (re- } \\
\text { porting bias) }\end{array}$ & Low risk & $\begin{array}{l}\text { The same measures were noted in the protocol. "Study measures included the } \\
\text { Morisky self-report medication adherence questionnaire, the CES-D measure } \\
\text { of depression, the Duke Social Support and Stress Scale (DUSOCS), the Charl- } \\
\text { son comorbidity index, the medication adherence self-efficacy scale (MASES), } \\
\text { and the Treatment Self-Regulation questionnaire (TSRQ) measure of intrinsic } \\
\text { motivation." (pg 173) }\end{array}$ \\
\hline
\end{tabular}

\begin{tabular}{lll}
\hline Other bias & Low risk & The study seems to be free of other types of bias \\
\hline $\begin{array}{l}\text { Blinding of outcome as- } \\
\text { sessment (detection bias) } \\
\begin{array}{l}\text { Adherence measure } \\
\text { L }\end{array}\end{array}$ & Low risk & $\begin{array}{l}\text { (PRIMARY) ELECTRONIC PILL MONITOR - This is an objective measure of out- } \\
\text { come }\end{array}$ \\
\hline
\end{tabular}

\begin{tabular}{|c|c|c|}
\hline $\begin{array}{l}\text { Blinding of outcome as- } \\
\text { sessment (detection bias) } \\
\text { Patient outcome }\end{array}$ & Low risk & $\begin{array}{l}\text { (PRIMARY) BLOOD PRESSURE MEASUREMENT - "The primary care providers } \\
\text { did not know their patients' group assignments." (pg 323) }\end{array}$ \\
\hline $\begin{array}{l}\text { Blinding of participants } \\
\text { (performance bias) } \\
\text { Adherence measure }\end{array}$ & High risk & $\begin{array}{l}\text { (PRIMARY) ELECTRONIC PILL MONITOR - No patient blinding but blinding may } \\
\text { have been broken due to the nature of the intervention }\end{array}$ \\
\hline $\begin{array}{l}\text { Blinding of participants } \\
\text { (performance bias) } \\
\text { Patient outcome }\end{array}$ & Low risk & $\begin{array}{l}\text { (PRIMARY) BLOOD PRESSURE MEASUREMENT - The lack of blinding is not likely } \\
\text { to affect the outcome. Information is also taken from patient records }\end{array}$ \\
\hline
\end{tabular}

Blinding of personnel (per- Low risk formance bias) (PRIMARY) ELECTRONIC PILL MONITOR - This is an objective measure of outAdherence measure come

Blinding of personnel (per- Unclear risk formance bias)

Patient outcome

(PRIMARY) BLOOD PRESSURE MEASUREMENT - No information on blinding given. There is insufficient information to permit judgment of 'Low risk' or 'High risk'

Incomplete outcome data Low risk (attrition bias)

Adherence measure

(PRIMARY) ELECTRONIC PILL MONITOR - After randomization, 2 withdrew, 7 were unavailable to follow-up, and 3 died from the positive affect group, therefore 113 completed the trial from the intervention group. From the control group, 11 withdrew, and 5 were unavailable for follow-up. 115 completed the trial at 12 months from the control group. Refer to Figure, CONSORT diagram. Approximately same number of missing information is there from both groups and the follow-up at 12 months is greater than $80 \%$

Incomplete outcome data Low risk

(attrition bias)

Patient outcome
(PRIMARY) BLOOD PRESSURE MEASUREMENT - After randomization, 2 withdrew, 7 were unavailable to follow-up, and 3 died from the positive affect group, therefore 113 completed the trial from the intervention group. From the control group, 11 withdrew, and 5 were unavailable for follow-up. 115 completed the trial at 12 months from the control group. Refer to Figure, CONSORT 
Okeke 2009

\begin{tabular}{|c|c|}
\hline Methods & Randomized controlled trial \\
\hline Participants & $\begin{array}{l}\text { The study location was Wilmer Eye Institute, Baltimore, Maryland; and Scheie Eye Institute, Philadel- } \\
\text { phia, Pennsylvania, USA }\end{array}$ \\
\hline & $\begin{array}{l}35 \text { participants were randomized to the intervention group and } 31 \text { participants were randomized to the } \\
\text { control group }\end{array}$ \\
\hline
\end{tabular}

The inclusion criteria were one of open-angle glaucoma, angle-closure glaucoma, glaucoma suspect, or ocular hypertension. Patients were 18 years of age or older, using or prescribed a topical prostaglandin analog, and able to return for 3- and 6-month follow-up visits. No laser or surgical glaucoma therapy within the 3 months before enrollment. Used $75 \%$ or fewer administered doses of topical prostaglandin analog in Phase 1

The exclusion criteria were: unable to understand the study, did not instill their own drops, or were incapable of using the Dosing Aid (DA) after a brief demonstration

\title{
Interventions
}

\begin{abstract}
Intervention: INTERVENTION
The intervention consisted of 4 components. (1). a 10-minute educational video created through Alcon, Inc. marketing branch for the DA device, which stressed the importance of regular drop-taking, its rationale and expected effects, alternatives to eyedrops, and methods to maximize co-operation, such as linking drops to a daily activity, keeping a drop-taking calendar diary, and using family members to help in reminding them; (2) a structured discussion with the study co-ordinator to develop a strategy for improving adherence that included finding the best time of day to take the medication, distributing a blank calendar diary and going over details of how to keep it, and discussing individual patient barriers to taking the medication; (3) reminder telephone calls from the co-ordinator, including administration of a questionnaire about drop-taking behavior, difficulty with drops, side effects, and eliciting questions about therapy (this call was made once per week for the first follow-up month and then every other week for the next 2 months); and (4) activation of the audible and visible alarms on the DA
\end{abstract}

Control: USUAL CARE

Usual care group were told that it is important to take their eyedrops as prescribed but had no other intervention domization). The data from the DA were downloaded onto computer-based software at the 3-month and 6-month visits

The patient outcome was intraocular pressure (IOP), measured at baseline, 3 , and 6 months

Notes -

\section{Risk of bias}

\section{Bias}

Authors' judgement Support for judgement

Random sequence genera- Low risk tion (selection bias)

\begin{abstract}
Participants were randomized using random numbers placed in serially marked, sealed envelopes that were opened at the time of randomization. To perform the randomization procedure, a string of random numbers was selected from a random numbers table. The numbers were placed into envelopes and then sealed and initialed across the seal. The envelopes were numbered consecutively starting with 1 . When an eligible patient was identified, an enve-
\end{abstract}


Okeke 2009 (Continued)

lope was opened; if the envelope contained an even number then the participant received the intervention (pg 2287)

Allocation concealment Unclear risk
(selection bias)

Does not indicate the envelopes were opaque. "Participants were randomized using random numbers placed in serially marked, sealed envelopes that were opened at the time of randomization. To perform the randomization procedure, a string of random numbers was selected from a random numbers table. The numbers were placed into envelopes and then sealed and initialed across the seal. The envelopes were numbered consecutively starting with 1 . When an eligible patient was identified, an envelope was opened; if the envelope contained an even number then the participant received the intervention." (pg 2287)

\begin{tabular}{|c|c|c|}
\hline $\begin{array}{l}\text { Selective reporting (re- } \\
\text { porting bias) }\end{array}$ & Low risk & $\begin{array}{l}\text { No protocol available but the only outcome measure is "...change in drop use } \\
\text { adherence as determined by the DA device." }\end{array}$ \\
\hline
\end{tabular}

\begin{tabular}{ll}
\hline Other bias & $\begin{array}{l}\text { The author notes that the intervention group had more veteran eyedrop tak- } \\
\text { ers. This may have increased the magnitude of the intervention effect, because } \\
\text { our univariate analysis showed lower adherence among less experienced eye- } \\
\text { drop takers. Some patients took their drops without placing the bottle in the } \\
\text { devices, which decreased the measured adherence rate in the intervention } \\
\text { group, but not significantly. When excluding those who took drops without the } \\
\text { DA, the measured adherence improved slightly in the control group, but still } \\
\text { the difference in magnitude of improved adherence between the intervention } \\
\text { group and the control group remained large. Also, the findings were limited to } \\
\text { the use of } 1 \text { prostaglandin analog, because only its bottle fits in the device (pg } \\
\text { 2291) }\end{array}$
\end{tabular}

\begin{tabular}{|c|c|c|}
\hline $\begin{array}{l}\text { Blinding of outcome as- } \\
\text { sessment (detection bias) } \\
\text { Adherence measure }\end{array}$ & Unclear risk & $\begin{array}{l}\text { (PRIMARY) DOSING AID - The information was downloaded directly from the DA } \\
\text { to computer software, which has a low risk for bias. However, the data were } \\
\text { manipulated somewhat: "In phase } 2 \text {, participants with } 75 \% \text { or fewer admin- } \\
\text { istered doses were randomized to either intervention or usual care. The da- } \\
\text { ta used for this determination included values obtained during the } 8 \text { weeks } \\
\text { starting } 2 \text { weeks after enrollment and ending } 2 \text { weeks before the follow-up vis- } \\
\text { it. Only these data were used because we detected that there was significant- } \\
\text { ly greater adherence just after a visit and just before a visit. A dose was con- } \\
\text { sidered taken if the lever of the DA was depressed and recorded beta4 hours } \\
\text { from that patient's median dosing hour (as determined from the DA data). Be- } \\
\text { cause we recognized from our previous study that the device has the potential } \\
\text { to make extra recordings when the lever is depressed erroneously, we did not } \\
\text { count more than } 1 \text { dose taken per eye per day in our adherence rate calcula- } \\
\text { tion. When the lever was depressed outside the time window it was assumed } \\
\text { that a dose was not taken, and when the lever was depressed multiple times } \\
\text { in the time window only a single dose for } 1 \text { or both eyes was assumed to have } \\
\text { been delivered." (pg 2288) }\end{array}$ \\
\hline
\end{tabular}

\begin{tabular}{|c|c|c|}
\hline $\begin{array}{l}\text { Blinding of outcome as- } \\
\text { sessment (detection bias) } \\
\text { Patient outcome }\end{array}$ & Low risk & $\begin{array}{l}\text { (PRIMARY) INTRAOCULAR PRESSURE - No mention of who took the IOP mea- } \\
\text { surements and whether that person was blinded to the study groups; but this } \\
\text { is an objective measure }\end{array}$ \\
\hline
\end{tabular}

\begin{tabular}{|c|c|c|}
\hline $\begin{array}{l}\text { Blinding of participants } \\
\text { (performance bias) } \\
\text { Adherence measure }\end{array}$ & Unclear risk & $\begin{array}{l}\text { (PRIMARY) DOSING AID - No mention of blinding of participants to the study } \\
\text { group }\end{array}$ \\
\hline
\end{tabular}

Blinding of participants Low risk
$\begin{aligned} & \text { (performance bias) } \\ & \text { Patient outcome }\end{aligned}$

Blinding of personnel (per- Unclear risk (PRIMARY) DOSING AID - No information on blinding given. There is insufficient formance bias) information to permit judgment of 'Low risk' or 'High risk' 
Okeke 2009 (Continued)

Adherence measure

Blinding of personnel (per- Unclear risk

(PRIMARY) INTRAOCULAR PRESSURE - This is an objective measure of outcome formance bias)

Patient outcome

Incomplete outcome data Low risk

(attrition bias)

Adherence measure
(PRIMARY) DOSING AID - The authors report on how many people participated in the intervention. There is no information about missing data for results. In Table 3 and Figure 1 also, they list intervention $n=35$ and control $n=31$, which are the original sample sizes at baseline. This suggests that data from all the participants were collected

(PRIMARY) INTRAOCULAR PRESSURE - No mention of whether the outcome data are complete or not. Only baseline IOP reported
Incomplete outcome data Unclear risk (attrition bias)

Patient outcome

\section{Otsuki 2009}

Methods Randomized controlled trial

Participants

The study location was the pediatric emergency department, Johns Hopkins, Baltimore, MD, USA

84 in Asthma Basic Care and 83 in Adherence Monitoring with Feedback. 84 participants were randomized to the intervention group and 83 participants were randomized to the control group

The inclusion criteria were children between 2 and 12 years of age who had physician-diagnosed asthma, 2 ED visits or 1 hospitalization for asthma in the preceding year, resided in Baltimore city, and were prescribed an asthma controller medication

\begin{abstract}
Intervention: ASTHMA BASIC CARE (ABC)
$A B C$ intervention received 530 - to 45-minute home visits by trained asthma educators (AES) 1, 2, 3, 4, and 8 weeks after randomization. The $A B C$ intervention is a home-based asthma education program with 5 core components: (1) review of the prescribed asthma regimen and training in medication, spacer, and peak flow technique; (2) development of an asthma action plan; (3) identification of barriers to accessing health care and problem-solving to reduce barriers; (4) discussion of beliefs and concerns about asthma and medications; and (5) provision of written asthma education materials
\end{abstract}

Intervention: ADHERENCE MONITORED FEEDBACK (AMF)

The intervention included $A B C+A M F$. AMF stands for adherence monitoring with feedback and $A B C$ stands for asthma basic care. These patients received 1. Objective feedback of medication adherence: electronic medication feedback. The AEs were trained to provide non-threatening, supportive feedback on adherence to encourage a partnership with the family; 2 . Goal-setting: families were encouraged to set asthma control goals (e.g. no coughing at night) and weekly adherence goals. The AEs assisted families in setting age-appropriate expectations regarding the child's ability to self manage asthma; 3 . Reinforcement for attaining adherence goals: the importance of positive reinforcement. When the child attained the adherence goal, the AE provided a small reward (e.g. crayons). When it was not achieved, the AE worked with the family to identify barriers and taught problem-solving skills. 4. Strategies for self monitoring medication use: families were taught to monitor adherence and asthma symptoms by using behavioral charts and symptom diaries. When possible, the AE highlighted the relationship between improvements in adherence and asthma outcomes

Control: USUAL CARE

Patients received an asthma education booklet and resource guide that provided information about low-cost asthma care providers, social services, legal services, and other resources. Participants were encouraged to receive care from their primary care provider

Outcomes
Adherence was measured by means of self reported adherence and pharmacy refill data. Trained research assistants who were blinded to study assignments conducted surveys by telephone. Pharma- 
Otsuki 2009 (Continued)

cy refill data were requested at baseline and 12 months from all pharmacies identified by the caregiver. Self reported adherence was collected from caregivers. Caregivers reported how the child administered the medication (e.g. 2 puffs twice a day), then estimated how often the child missed doses in the previous 7 days. Percentage self reported adherence was calculated as use/prescribed use $\times 100 \%$. For pharmacy-based adherence, by using a protocol described by Butz et al, the number of inhaled corticosteroid (ICS) refills per quarter was abstracted from pharmacy records for the year before and after randomization. The number of canisters dispensed was converted to therapeutically equivalent values so that 1 canister represented a 1-month supply of ICS. The quarterly ICS refill rates were defined as the number of ICS canisters dispensed quarterly. These analyses included the quarter before enrollment (the baseline value) through the 4th quarter after randomization. An ICS refill rate of 3.0 is equivalent to $100 \%$ adherence for the quarter. Self reported adherence data were collected at baseline, 6,12 , and 18 months, while pharmacy records were requested at baseline and 12 months and data for baseline, 3, 6 , 9 , and 12 months obtained

The clinical outcomes were caregiver reports of asthma symptoms (cough, wheeze, shortness of breath, or chest tightness/discomfort), night-time awakenings, ED visits, hospitalizations, and courses of oral corticosteroids in the previous 6 months. Total numbers of days and nights (combining day and night symptoms) were calculated for each child with a range of 0 to 60 for day or night symptom counts reported during the previous 30 days for an asthma symptom frequency variable. The data were collected by blinded research staff at 1,6,12, and 18-month intervals

\section{Notes}

Self reported adherence was not included in the analysis. (pg 1516) "Because of lack of change over time, we were unable to model self-reported ICS adherence."

\section{Risk of bias}

\begin{tabular}{lll}
\hline Bias & Authors' judgement & Support for judgement \\
\hline $\begin{array}{l}\text { Random sequence genera- } \\
\text { tion (selection bias) }\end{array}$ & Unclear risk & $\begin{array}{l}\text { Source of random sequence is not explicitly stated. "To mask staff to group } \\
\text { assignment during recruitment, the statistician created block randomization } \\
\text { schema and placed the randomization assignments into sealed envelopes, } \\
\text { which were opened after families completed baseline surveys." (pg 1514) }\end{array}$ \\
\hline
\end{tabular}

Allocation concealment Low risk

(selection bias)
Sealed envelopes were used. "To mask staff to group assignment during recruitment, the statistician created block randomization schema and placed the randomization assignments into sealed envelopes, which were opened after families completed baseline surveys." (pg 1514)

\begin{tabular}{|c|c|c|}
\hline $\begin{array}{l}\text { Selective reporting (re- } \\
\text { porting bias) }\end{array}$ & Unclear risk & $\begin{array}{l}\text { No protocol available; although it appears that everything was reported it is } \\
\text { difficult to determine this without a protocol }\end{array}$ \\
\hline Other bias & Unclear risk & $\begin{array}{l}\text { The author notes, "...we did not use Bonferroni correction for interpreting the } \\
\text { outcomes; as a result, we may risk committing type I error." (pg 1520) }\end{array}$ \\
\hline $\begin{array}{l}\text { Blinding of outcome as- } \\
\text { sessment (detection bias) } \\
\text { Adherence measure }\end{array}$ & Low risk & $\begin{array}{l}\text { (PRIMARY) PHARMACY REFILL RECORD - The author notes that research assis- } \\
\text { tants requesting the pharmacy data and data managers and coders were not } \\
\text { aware of study group }\end{array}$ \\
\hline $\begin{array}{l}\text { Blinding of outcome as- } \\
\text { sessment (detection bias) } \\
\text { Patient outcome }\end{array}$ & Low risk & $\begin{array}{l}\text { (PRIMARY) ASTHMA MORBIDITY MEASURES - Trained research assistants who } \\
\text { were blinded to study assignments conducted surveys by telephone (pg 1514) }\end{array}$ \\
\hline $\begin{array}{l}\text { Blinding of participants } \\
\text { (performance bias) } \\
\text { Adherence measure }\end{array}$ & Low risk & $\begin{array}{l}\text { (PRIMARY) PHARMACY REFILL RECORD - Patients not blinded but loss of blind- } \\
\text { ing not likely to bias the result }\end{array}$ \\
\hline $\begin{array}{l}\text { Blinding of participants } \\
\text { (performance bias) } \\
\text { Patient outcome }\end{array}$ & High risk & $\begin{array}{l}\text { (PRIMARY) ASTHMA MORBIDITY MEASURES - This is a subjective measure; there } \\
\text { is no information on blinding. Since participants are children under the age of } \\
12 \text {, data are reported by their caregiver }\end{array}$ \\
\hline
\end{tabular}


Otsuki 2009 (Continued)

Blinding of personnel (per- Unclear risk $\quad$ (PRIMARY) PHARMACY REFILL RECORD - No information on blinding given. formance bias) There is insufficient information to permit judgment of 'Low risk' or 'High risk'

Adherence measure

\begin{tabular}{|c|c|c|}
\hline $\begin{array}{l}\text { Blinding of personnel (per- } \\
\text { formance bias) } \\
\text { Patient outcome }\end{array}$ & Low risk & $\begin{array}{l}\text { (PRIMARY) ASTHMA MORBIDITY MEASURES - The author notes that research } \\
\text { assistant and data managers involved with data entry and management were } \\
\text { not aware of group assignment }\end{array}$ \\
\hline
\end{tabular}

Patient outcome

(PRIMARY) PHARMACY REFILL RECORD - There is above $80 \%$ completion of all

Incomplete outcome data Low risk

(attrition bias) surveys in all groups, missing numbers are fairly even but it is likely that the

Adherence measure reason fro missing could be related to the outcome - they may not have been adherent. ITT analysis was used

Incomplete outcome data Low risk

(attrition bias)

(PRIMARY) ASTHMA MORBIDITY MEASURES - An ITT analysis was performed.

Patient outcome

The author also notes that missing data for all groups were primarily due to failure to reach the family at either their primary or secondary phone number or by letter

Parienti 2007

\begin{tabular}{ll}
\hline Methods & Randomized controlled trial \\
\hline Participants & The study location was 4 French academic medical centers, France \\
& 31 participants were randomized to the intervention group and 31 participants were randomized to the \\
control group & \\
& The inclusion criteria were chronically HIV-1-infected adults, receiving nevirapine-based antiretroviral \\
therapy with RNA-HIV levels less than 400 copies/ml for more than 6 months and without liver enzyme & abnormality (aspartate aminotransferase or alanine aminotransferase $>2.5 \mathrm{~N}$ and $>1.25 \mathrm{~N}$ if hepatitis \\
virus B or C were negative and positive, respectively)
\end{tabular}

Interventions

Intervention: ONCE A DAY DOSING

Patients were switched from 2 a day nevirapine to a 1 a day formula

Control: TWICE A DAY DOSAGE

Control participants continued to take nevirapine twice a day

Outcomes The measures of adherence were Medication Event Monitoring System (MEMS) and nevirapine plasma level at the end of each phase. MEMS is a electronic monitoring device. Electronic adherence data showing no event within the 14 preceding days of a plasma sample with detectable nevirapine levels were considered invalid and the overall phase was suppressed. In addition, electronic data were validated by patient's self report to detect pocket-dose and box-filling in order to adjust events.

The patient outcomes were viral control (RNA-HIV level $<400$ copies $/ \mathrm{ml}$ ), measured at the end of the RCT portion of the trial

Notes It is not clear what the patient clinical outcomes were and how they were measured

\section{Risk of bias}

\begin{tabular}{lll}
\hline Bias & Authors' judgement & Support for judgement \\
\hline $\begin{array}{l}\text { Random sequence genera- } \\
\text { tion (selection bias) }\end{array}$ & Low risk & $\begin{array}{l}\text { The author stated that permutated blocks of size } 4 \text { stratified by centers were } \\
\text { used in randomization }\end{array}$ \\
\hline
\end{tabular}


Parienti 2007 (Continued)

\begin{tabular}{|c|c|c|}
\hline $\begin{array}{l}\text { Allocation concealment } \\
\text { (selection bias) }\end{array}$ & Unclear risk & $\begin{array}{l}\text { No information was provided about how allocation was handled. "At the end } \\
\text { of month 3, patients were } 1: 1 \text { randomly allocated to continue nevirapine } \\
\text { twice a day or switch to nevirapine once-daily for a 4-month period (phase 2, } \\
\text { randomized controlled trial)." (pg 2218) }\end{array}$ \\
\hline
\end{tabular}

\begin{tabular}{lll}
\hline $\begin{array}{l}\text { Selective reporting (re- } \\
\text { porting bias) }\end{array}$ & Unclear risk & The efficacy data only given in total, not between groups \\
\hline Other bias & Low risk & The study seems to be free of other types of bias \\
\hline $\begin{array}{l}\text { Blinding of outcome as- } \\
\text { sessment (detection bias) } \\
\text { Adherence measure }\end{array}$ & Unclear risk & $\begin{array}{l}\text { (PRIMARY) MEMS - As data were adjusted based on patient self report, the ob- } \\
\text { jectivity of the MEMS measure is somewhat questionable. No information giv- } \\
\text { en about the personnel or the methods that were used to collect the patient } \\
\text { self reports }\end{array}$ \\
\hline
\end{tabular}

$\begin{array}{ll}\text { Blinding of outcome as- } & \text { (PRIMARY) VIRAL CONTROL - This is an objective measure of outcome } \\ \text { sessment (detection bias) } & \text { Latient }\end{array}$
(detection bias)

Patient outcome

\section{Blinding of participants High risk}

(performance bias)

Adherence measure

Blinding of participants Low risk $\quad$ (PRIMARY) VIRAL CONTROL - This is an objective measure of outcome
(performance bias)
$\begin{aligned} & \text { Patient outcome }\end{aligned}$
jectively of the MEMS measure is somewhat questionable
(PRIMARY) MEMS - As data were adjusted based on patient self report, the ob-

(PRIMARY) MEMS - As data were adjusted based on patient self report, the objectively of the MEMS measure is somewhat questionable. Not enough detail given on how the patient's MEMS records were adjusted based on their self report

(PRIMARY) VIRAL CONTROL - This is an objective measure of outcome

Blinding of personnel (per- Low risk

formance bias)

Patient outcome

Incomplete outcome data Unclear risk

(attrition bias)

Adherence measure

Incomplete outcome data Unclear risk

(attrition bias)

Patient outcome

(PRIMARY) MEMS - No detail given about which dropouts were in which group

Patient outcome

Parsons 2007

\begin{tabular}{ll}
\hline Methods & Randomized controlled trial \\
\hline Participants & The study location was Behavioral Research Center, New York, USA \\
& 65 participants were randomized to the intervention group and 78 participants were randomized to the \\
control group & \\
The inclusion criteria were HIV-positive, at least 18 years of age, English speaking, currently taking a \\
HAART regimen, and had scored 8 or greater on the Alcohol Use Disorder Identification Test (AUDIT),
\end{tabular}

(PRIMARY) VIRAL CONTROL - Not enough information was given on which missing data are from which groups

HAART regimen, and had scored 8 or greater on the Alcohol Use Disorder Identification Test (AUDIT), 
Parsons 2007 (Continued)

met criteria for hazardous drinking ( $>16$ standard drinks per week for men or $>12$ standard drinks per week for women) and having alcohol problems greater than those associated with other drugs

Interventions

Intervention: PROJECT PLUS INTERVENTION

Intervention was 8, 60-minute individual sessions based on Information Motivation Behavioral Skills model delivered by delivered by master's degree-prepared counselors. Two complementary techniques-motivational interviewing (MI) and cognitive-behavioral skills training (CBST) - were integrated, allowing trained counselors to match targeted information and skill-building techniques to the particulars of each client's motivation for change. The first session was delivered immediately on completion of the baseline assessment, thereby ensuring that each participant has a minimum dose of 1 session. Follow-ups were conducted at 3 and 6 months

Control: EDUCATION CONDITION

8 education sessions of 60 minutes facilitated by a health educator was the intervention. Sessions were designed to be completed weekly, but participants had 12 weeks to complete all 8 sessions. The first session was delivered immediately on completion of the baseline assessment, thereby ensuring that each participant had a minimum dose of 1 session. The sessions were video taped to ensure that motivational interview or cognitive-behavioral skills training was not used

Outcomes The measures of adherence were self reported adherence measured with timeline follow-back interview. The participants were asked to explain their HAART regimen and the number of schedules doses of each medication and then required to recall, day by day, all medication doses taken and missed during the past 2 weeks. For each participant, an adherent day was defined as a day in which the participant missed none of his or her scheduled doses. Per cent day adherence was calculated as the per cent of days with perfect adherence in the past 2 weeks

The patient outcomes were viral load and CD4 count calculated from laboratory blood tests conducted at 3 and 6 months. All blood draws were conducted on-site by a certified phlebotomist and were analyzed by Specialty Laboratories. HIV viral load was measured by reverse transcriptase polymerase chain reaction (RT-PCR) using the HIV-1 Ultraquant assay, and results were log transformed to adjust for skew. CD4 cell counts were measured by flow cytometry.

Notes -

\section{Risk of bias}

Bias Authors' judgement Support for judgement

Random sequence genera- Low risk tion (selection bias)
Urn randomization procedure was used. "Eligible participants were assigned to the 8-session intervention or to an 8-session educational comparison condition, using urn randomization procedures, which are systematically biased in favor of balancing groups. This procedure preserves randomization as the primary basis for assignment to condition, is less susceptible to experimenter bias or manipulation of the assignment process by staff, allows matching on several variables (in this study, viral load and AUDIT score), and most efficiently ensures multivariate equivalence of treatment groups.34 Although it is always possible to control statistically for differences between groups in later analyses, the potential removal of such differences in the randomization process increases power by reducing the number of covariates included in primary analyses." (pg 444)

\begin{tabular}{lll}
\hline $\begin{array}{l}\text { Allocation concealment } \\
\text { (selection bias) }\end{array}$ & Unclear risk & No information was provided about how allocation was handled \\
\hline $\begin{array}{l}\text { Selective reporting (re- } \\
\text { porting bias) }\end{array}$ & Low risk & $\begin{array}{l}\text { No protocol available; although it appears that everything was reported it is } \\
\text { difficult to determine this without a protocol }\end{array}$ \\
\hline
\end{tabular}


Parsons 2007 (Continued)

Other bias Unclear risk "Because participants were required to have alcohol problems as part of the eligibility criteria, it is possible that perceived demands to report decreased alcohol use were stronger than those for reporting adherence changes". (pg 449)

\begin{tabular}{|c|c|c|}
\hline $\begin{array}{l}\text { Blinding of outcome as- } \\
\text { sessment (detection bias) } \\
\text { Adherence measure }\end{array}$ & Low risk & $\begin{array}{l}\text { (PRIMARY) SELF REPORT - INTERVIEW - The author notes that interviews con- } \\
\text { ducted by research staff not involved in the intervention }\end{array}$ \\
\hline $\begin{array}{l}\text { Blinding of outcome as- } \\
\text { sessment (detection bias) } \\
\text { Patient outcome }\end{array}$ & Low risk & (PRIMARY) CD4 CELL COUNT - This is an objective measure of outcome \\
\hline $\begin{array}{l}\text { Blinding of outcome as- } \\
\text { sessment (detection bias) } \\
\text { Patient outcome }\end{array}$ & Low risk & (PRIMARY) VIRAL LOAD - This is an objective measure of outcome \\
\hline $\begin{array}{l}\text { Blinding of participants } \\
\text { (performance bias) } \\
\text { Adherence measure }\end{array}$ & High risk & $\begin{array}{l}\text { (PRIMARY) SELF REPORT - INTERVIEW - The author notes that participants } \\
\text { were informed that they would be randomized to } 1 \text { of } 2 \text { groups. This outcome } \\
\text { is subject to recall bias }\end{array}$ \\
\hline
\end{tabular}

Adher

$\begin{aligned} & \text { Blinding of participants } \\ & \text { (performance bias) }\end{aligned}$
Patient outcome

Patient outcome

\begin{tabular}{|c|c|c|}
\hline $\begin{array}{l}\text { Blinding of participants } \\
\text { (performance bias) } \\
\text { Patient outcome }\end{array}$ & Low risk & (PRIMARY) VIRAL LOAD - This is an objective measure of outcome \\
\hline $\begin{array}{l}\text { Blinding of personnel (per- } \\
\text { formance bias) } \\
\text { Adherence measure }\end{array}$ & Low risk & $\begin{array}{l}\text { (PRIMARY) SELF REPORT - INTERVIEW - The author notes that key study per- } \\
\text { sonnel were blind }\end{array}$ \\
\hline
\end{tabular}

Blinding of personnel (per- Low risk
formance bias)
Patient outcome

Blinding of personnel (per- Low risk (PRIMARY) CD4 CELL COUNT - This is an objective measure of outcome formance bias)

Patient outcome

\begin{tabular}{|c|c|c|}
\hline $\begin{array}{l}\text { Incomplete outcome data } \\
\text { (attrition bias) } \\
\text { Adherence measure }\end{array}$ & Low risk & $\begin{array}{l}\text { (PRIMARY) SELF REPORT - INTERVIEW - 3-month follow-up was not completed } \\
\text { by } 12 \text { participants from the intervention group and } 10 \text { from the control group. } \\
\text { At } 6 \text {-month follow-up, } 11 \text { did not complete the follow-up from the intervention } \\
\text { group and } 16 \text { from the control group. Refer to Figure } 1 \text {. The reasons are similar } \\
\text { across the different groups }\end{array}$ \\
\hline $\begin{array}{l}\text { Incomplete outcome data } \\
\text { (attrition bias) } \\
\text { Patient outcome }\end{array}$ & Low risk & $\begin{array}{l}\text { (PRIMARY) CD4 CELL COUNT - 3-month follow-up was not completed by } 12 \\
\text { participants from the intervention group and } 10 \text { from the control group. At } \\
6 \text {-month follow-up, } 11 \text { did not complete the follow-up from the intervention } \\
\text { group and } 16 \text { from the control group. Refer to Figure } 1 \text {. The reasons are similar } \\
\text { across the different groups }\end{array}$ \\
\hline $\begin{array}{l}\text { Incomplete outcome data } \\
\text { (attrition bias) } \\
\text { Patient outcome }\end{array}$ & Low risk & $\begin{array}{l}\text { (PRIMARY) VIRAL LOAD - 3-month follow-up was not completed by } 12 \text { partici- } \\
\text { pants from the intervention group and } 10 \text { from the control group. At } 6 \text {-month } \\
\text { follow-up, } 11 \text { did not complete the follow-up from intervention group and } 16 \\
\text { from the control group. Refer to Figure } 1 \text {. The reasons are similar across the } \\
\text { different groups }\end{array}$ \\
\hline
\end{tabular}


Pearson 2007

\begin{tabular}{ll}
\hline Methods & Randomized controlled trial \\
\hline Participants & The study location was HIV care clinic in the Beira Central Hospital, Mozambique \\
& 175 participants were randomized to the intervention group and 175 participants were randomized to \\
the control group & \\
The inclusion criteria were at least 18 years of age, living near the HIV clinic in the Beira Central Hospi- \\
tal, and free of severe mental illness or dementia
\end{tabular}

Interventions

Intervention: PEER DELIVERED MODIFIED DIRECTLY OBSERVED THERAPY (MDOT)

The participants in the MDOT intervention group received both the standard of care and a 6-week peer intervention to monitor their morning weekday dose. Peers also provided daily social support, information about the benefits and side effects of HAART, and help to address barriers to adherence. Peers were also a link between participants and other members of the HIV clinic team and the community

\section{Control: STANDARD CARE}

It includes no-cost medications, clinical and laboratory follow-up, psychosocial adherence support by a trained social worker, and referral to community-based peer support groups. Mandatory pre-HAART counseling involves education about dosing, side effects, nutritional requirements, and the importance of adherence. Patients were encouraged to identify a treatment partner to help with adherence, provided with information on community-based support groups and nutritional resources, and instructed to contact their medical provider, nurse, pharmacist, or peer if they have any difficulties or concerns about their medication regimen. Peers were HIV-positive, chosen from among patients at the clinic and participants in community-based groups through self nomination or nominations by clinic staff, and were paid a small stipend for their work. Patients met with the pharmacist and peer for pharmacy refills at week 2, 4, and 6 for the first 2 months and monthly thereafter

Outcomes The measures of adherence were self reported and assessed at 6- and 12-month interviews where 2 adherence questions were asked

The patient outcomes were CD4 cell count at 6 and 12 months. Participants provided a 4 to $5 \mathrm{ml}$ blood sample for a CD4 cell count as part of standard care immediately before and 4 and 10 months after initiating HAART. The absolute CD4 cell count was determined through flow cytometry. A chart review was conducted to record the CD4 test result closest to the assessment point but within 2 months. If a CD4 result was not available during this time frame, the participant was excluded from the intent-to-treat (ITT) and change-score analyses of CD4 outcome. Mortality was verified by either medical records or by a family member who witnessed the death. If death was not verified by either of these 2 methods, then participants were assumed alive. Both measures were conducted as close to the 2 assessment points of 6 months and 12 months

Notes -

\section{Risk of bias}

\begin{tabular}{lll}
\hline Bias & Authors' judgement & Support for judgement \\
\hline $\begin{array}{l}\text { Random sequence genera- } \\
\text { tion (selection bias) }\end{array}$ & Low risk & $\begin{array}{l}\text { Random assignment to condition was based on a computer-generated alloca- } \\
\text { tion sequence prepared by an external statistician (pg 239) }\end{array}$ \\
\hline $\begin{array}{l}\text { Allocation concealment } \\
\text { (selection bias) }\end{array}$ & Low risk & $\begin{array}{l}\text { Allocation concealment involved the use of sequentially numbered, opaque, } \\
\text { sealed envelopes containing the group assignment, which the research man- } \\
\text { ager opened at the moment of randomization after enrolling participants (pg } \\
\text { 239) }\end{array}$ \\
\hline $\begin{array}{l}\text { Selective reporting (re- } \\
\text { porting bias) }\end{array}$ & Unclear risk & $\begin{array}{l}\text { No protocol available; although it appears that everything was reported it is } \\
\text { difficult to determine this without a protocol }\end{array}$ \\
\hline
\end{tabular}


Pearson 2007 (Continued)

Other bias Low risk The study seems to be free of other types of bias

\begin{tabular}{|c|c|c|}
\hline $\begin{array}{l}\text { Blinding of outcome as- } \\
\text { sessment (detection bias) } \\
\text { Adherence measure }\end{array}$ & High risk & $\begin{array}{l}\text { (PRIMARY) SELF REPORT - INTERVIEW - No blinding of staff. "Due to the nature } \\
\text { of the intervention, participants and the study team could not be blinded to in- } \\
\text { tervention." (pg 239) }\end{array}$ \\
\hline
\end{tabular}

\begin{tabular}{lll}
\hline Blinding of outcome as- & High risk & (PRIMARY) CD4 CELL COUNT - A chart review was conducted to record the CD4 \\
sessment (detection bias) & test result closest to the assessment point but within 2 months. Study person- \\
Patient outcome & nel not blinded
\end{tabular}

\begin{tabular}{|c|c|c|}
\hline $\begin{array}{l}\text { Blinding of participants } \\
\text { (performance bias) } \\
\text { Adherence measure }\end{array}$ & High risk & $\begin{array}{l}\text { (PRIMARY) SELF REPORT - INTERVIEW - This is a subjective measure; there is no } \\
\text { information on blinding }\end{array}$ \\
\hline
\end{tabular}

\begin{tabular}{ll}
\hline $\begin{array}{l}\text { Blinding of participants } \\
\text { (performance bias) }\end{array}$ & Low risk \\
$\begin{array}{l}\text { Patient outcome } \\
\text { (PRIMARY) CD4 CELL COUNT - Patient unblinding unlikely to affect the out- } \\
\text { come }\end{array}$ \\
\hline
\end{tabular}

\begin{tabular}{|c|c|c|}
\hline $\begin{array}{l}\text { Blinding of personnel (per- } \\
\text { formance bias) }\end{array}$ & Unclear risk & $\begin{array}{l}\text { (PRIMARY) SELF REPORT - INTERVIEW - No information on blinding given. } \\
\text { There is insufficient information to permit judgment of 'Low risk' or 'High risk' }\end{array}$ \\
\hline
\end{tabular}

Adherence measure

Blinding of personnel (per- High risk $\quad$ (PRIMARY) CD4 CELL COUNT - Not blinded
formance bias)

Patient outcome

\begin{tabular}{lll}
\hline $\begin{array}{l}\text { Incomplete outcome data } \\
\text { (attrition bias) } \\
\text { Adherence measure }\end{array}$ & Unclear risk & $\begin{array}{l}\text { (PRIMARY) SELF REPORT - INTERVIEW - There were fewer participants in the } \\
\text { control group than in intervention group at both } 6 \text { and } 12 \text { months }\end{array}$ \\
\hline $\begin{array}{l}\text { Incomplete outcome data } \\
\text { (attrition bias) }\end{array}$ & Unclear risk & $\begin{array}{l}\text { (PRIMARY) CD4 CELL COUNT - The author notes that they reported that MDOT } \\
\text { participants were more likely than those in the standard care arm to get a CD4 } \\
\text { cell count (at } 6 \text { months post HAART: } 90 \% \text { versus } 79 \%, \text { OR }=2.5,95 \% \mathrm{Cl} 1.3 \text { to } \\
5.3 ; \text { at } 12 \text { months post HAART: } 96 \% \text { versus } 83 \%, \mathrm{OR}=5.3,95 \% \mathrm{Cl} 2.0 \text { to } 16.2) . \\
\text { However, mean CD4 count among those with CD4 data did not differ between } \\
\text { arms at baseline (Table } 1 \text { ) or at } 6 \text { and } 12 \text { months (Table } 2)\end{array}$ \\
\hline
\end{tabular}

Perrin 2010

\begin{tabular}{ll}
\hline Methods & Randomized controlled trial \\
\hline Participants & The study location was Medical Research Institute of New Zealand and the P3 Research Clinical Trials \\
Unit at Bowen Hospital, Wellington, New Zealand \\
57 participants were randomized to the intervention group and 54 participants were randomized to the \\
control group \\
The inclusion criteria were adults in the Wellington region age 16 to 65 years with a diagnosis of asth- \\
ma, recruited from existing research volunteer databases, newspaper advertisements, and letters via \\
family doctors with a diagnosis of asthma and to be currently taking ICS at a stable dose with or with- \\
out a separate LABA inhaler \\
$\begin{array}{l}\text { The exclusion criteria were a diagnosis of chronic obstructive pulmonary disease, current use of a com- } \\
\text { bination ICS/LABA inhaler, women who were pregnant or lactating, a history of other clinically signifi- } \\
\text { cant disease, or a significant exacerbation of asthma in the previous month requiring a clinic or hospi- } \\
\text { tal attendance }\end{array}$ \\
\hline
\end{tabular}


Perrin 2010 (Continued)

Interventions

Intervention: COMBINATION METERED DOSE INHALER (MDI)

Subjects received the intervention treatment regimen for a duration of 24 weeks that involved $125 \mathrm{mg}$ FP and $25 \mathrm{mg}$ salmeterol in a combination Smartinhaler, 2 actuations twice daily. Participants were seen in the clinic on 5 occasions. At the first visit, subjects were randomized and issued the appropriate Smartinhalers, and inhaler technique was checked. Subjects were instructed to take 2 actuations of the study medications twice daily, resulting in a daily dose of $500 \mathrm{mg}$ FP and $100 \mathrm{mg}$ salmeterol with both regimens. Subjects were advised that the study was designed to compare the efficacy of the 2 regimens but were not informed that adherence would be monitored. They were told that the MDI casing looked different because it was possible to program it with a reminder alarm, but that this function would not be used in this study

Control: SEPARATE METERED DOSE INHALER (MDI)

Subjects received a treatment regimens for a duration of 24 weeks of $125 \mathrm{mg}$ FP and $25 \mathrm{mg}$ salmeterol in separate Smartinhalers, 2 actuations twice daily. Participants were seen in the clinic on 5 occasions. At the first visit, subjects were randomized and issued the appropriate Smartinhalers, and inhaler technique was checked. Subjects were instructed to take 2 actuations of the study medications twice daily, resulting in a daily dose of $500 \mathrm{mg}$ FP and $100 \mathrm{mg}$ salmeterol with both regimens. Subjects were advised that the study was designed to compare the efficacy of the 2 regimens but were not informed that adherence would be monitored

Outcomes

The measures of adherence were 1 ) the number of doses taken as a percentage of those prescribed during the final (4th) 6-week period of the study; 2 ) adherence in the first, second, and third 6-week periods of the study; 3 ) number of adherent days in which the prescribed 2 doses were taken twice daily in each 6 -week period of the study; 4 ) and the proportion of patients who took $>50 \%,>80 \%$, and $>90 \%$ of doses in each of the 6 -week periods of the study. At 4 clinic visits after randomization, adherence data were uploaded from the Smartinhaler to a computer

The patient outcomes were results from the Asthma Control Questionnaire and FEV1

\author{
Notes
}

$-$

\title{
Risk of bias
}

\begin{tabular}{lll}
\hline Bias & Authors' judgement & Support for judgement \\
\hline $\begin{array}{l}\text { Random sequence genera- } \\
\text { tion (selection bias) }\end{array}$ & Low risk & $\begin{array}{l}\text { Random code computer was used. "Randomization was by computer-gener- } \\
\text { ated random code supplied by a statistician. The sequence was imbedded in } \\
\text { a Microsoft Access Database (Microsoft Corp, Redmond, Wash) by a third par- } \\
\text { ty and concealed from the researchers until the time the subject was enrolled } \\
\text { and entered into the database." (pg 507) }\end{array}$ \\
\hline $\begin{array}{l}\text { Allocation concealment } \\
\text { (selection bias) }\end{array}$ & Low risk & $\begin{array}{l}\text { The allocation code was code was concealed. "Randomization was by com- } \\
\text { puter-generated random code supplied by a statistician. The sequence was } \\
\text { imbedded in a Microsoft Access Database (Microsoft Corp, Redmond, Wash) } \\
\text { by a third party and concealed from the researchers until the time the subject } \\
\text { was enrolled and entered into the database." (pg 507) }\end{array}$ \\
\hline $\begin{array}{l}\text { Selective reporting (re- } \\
\text { porting bias) }\end{array}$ & Unclear risk & $\begin{array}{l}\text { No protocol available; although it appears that everything was reported it is } \\
\text { difficult to determine this without a protocol }\end{array}$ \\
\hline $\begin{array}{l}\text { Other bias } \\
\text { Unclear risk }\end{array}$ & $\begin{array}{l}\text { Other possible sources of bias are: } 1 . \text { Drug sponsored study (GlaxoSmithK- } \\
\text { line) (pg 505). 2. Subjects were informed that the purpose of the study was to } \\
\text { compare single with combination inhaler therapy (pg 508). } 3 \text { Because subjects } \\
\text { were recruited from an existing volunteer trial participant list, some may have } \\
\text { become aware that the inhaler device was monitoring their drug use (pg 509). } \\
\text { 4. Having been enrolled in a previous study, some may have been more com- } \\
\text { pliant (pg 509). 5. The authors state the study may have been underpowered to } \\
\text { detect small but clinically important differences in compliance (pg 509) }\end{array}$ \\
\hline
\end{tabular}


Perrin 2010 (Continued)

Blinding of outcome as- Unclear risk $\quad$ (PRIMARY) METERED DOSE INHALER - Blinding of staff collecting the data not sessment (detection bias) mentioned (the inhalers had different colors and the control group would have Adherence measure 2 inhalers rather than 1 for the intervention group). The data from the Smartinhalers were uploaded to a computer. Data were somewhat manipulated because doses were excluded that had 10 or more actuations within a 3-hour period

\begin{tabular}{lll}
$\begin{array}{l}\text { Blinding of outcome as- } \\
\text { sessment (detection bias) } \\
\text { Patient outcome }\end{array}$ & Unclear risk & $\begin{array}{l}\text { (PRIMARY) ASTHMA CONTROL QUESTIONNAIRE - Subjective questionnaire, no } \\
\text { mention of blinding, unclear if this might influence outcome }\end{array}$ \\
\hline $\begin{array}{l}\text { Blinding of participants } \\
\text { (performance bias) } \\
\text { Adherence measure }\end{array}$ & Unclear risk & $\begin{array}{l}\text { (PRIMARY) METERED DOSE INHALER - Patients were not told their dose taking } \\
\text { was being monitored but because they were in a previous study, some may } \\
\text { have guessed that the unique inhaler was a monitor }\end{array}$ \\
\hline
\end{tabular}

Blinding of participants High risk
(performance bias) Patient outcome (PRIMARY) ASTHMA CONTROL QUESTIONNAIRE - Subjective questionnaire, no mention of blinding, unclear if this might influence outcome

Blinding of personnel (per- Unclear risk formance bias) Adherence measure

(PRIMARY) METERED DOSE INHALER - No information on blinding given. There is insufficient information to permit judgment of 'Low risk' or 'High risk'

\begin{tabular}{|c|c|c|}
\hline $\begin{array}{l}\text { Blinding of personnel (per- } \\
\text { formance bias) } \\
\text { Patient outcome }\end{array}$ & Unclear risk & $\begin{array}{l}\text { (PRIMARY) ASTHMA CONTROL QUESTIONNAIRE - Subjective questionnaire, no } \\
\text { mention of blinding, unclear if this might influence outcome }\end{array}$ \\
\hline $\begin{array}{l}\text { Incomplete outcome data } \\
\text { (attrition bias) } \\
\text { Adherence measure }\end{array}$ & Unclear risk & $\begin{array}{l}\text { (PRIMARY) METERED DOSE INHALER - Attrition reported but there were al- } \\
\text { most } 10 \% \text { fewer subjects in the control group at study's end but reasons for } \\
\text { dropouts were similar in intervention and control; however, the authors state } \\
\text { that the study was likely underpowered. Bias unclear }\end{array}$ \\
\hline $\begin{array}{l}\text { Incomplete outcome data } \\
\text { (attrition bias) } \\
\text { Patient outcome }\end{array}$ & Unclear risk & $\begin{array}{l}\text { (PRIMARY) ASTHMA CONTROL QUESTIONNAIRE - Attrition reported but there } \\
\text { were almost 10\% fewer subjects in the control group at study's end. Reasons } \\
\text { for dropouts were similar in intervention and control groups; however, the au- } \\
\text { thors state that the study was likely underpowered. Bias unclear }\end{array}$ \\
\hline
\end{tabular}

\section{Peterson 1984}

\begin{tabular}{ll}
\hline Methods & Coin toss randomization \\
\hline Participants & $\begin{array}{l}\text { Adult and teenage epileptic patients, who were consecutive attenders at outpatient clinics during a 4- } \\
\text { month period, who were responsible for their own medication, and who possessed a hospital pharma- } \\
\text { cy prescription book, were included in the study }\end{array}$ \\
\hline Interventions & $\begin{array}{l}\text { Patients in the intervention group received several adherence-improving strategies: patients were } \\
\text { counseled on the goals of anticonvulsant therapy and the importance of good adherence in achiev- } \\
\text { ing these goals, a schedule of medication taking was devised that corresponded with the patient's } \\
\text { everyday habits, patients were given a copy of an educational leaflet, each patient was provided with } \\
\text { a 'Dosett' medication container and counseled on its utility, patients were instructed to use a medica- } \\
\text { tion/seizure diary, and patients were reminded by mail of upcoming appointments and of missed pre- } \\
\text { scription refills. The control group received none of these interventions. The mean daily dosages of the } \\
\text { most commonly prescribed anticonvulsant drugs (phenytoin, carbamazepine, and sodium valproate) } \\
\text { were not significantly different between the } 2 \text { groups }\end{array}$ \\
\hline
\end{tabular}


Peterson 1984 (Continued)

Outcomes
Each patient had plasma anticonvulsant levels measured (provided that the patient's medication regimen had not been altered in the preceding 2 weeks), the patient's prescription record book was checked to assess prescription refill frequency (if the refill frequency was 1 or more weeks later than expected at least once during the previous 6 months, the patient was considered non-adherent), and patient appointment-keeping frequency (patients who had attended all their scheduled appointments in the previous 6 months were considered compliant) were assessed. The median number of self recorded seizures experienced by each patient was compared between the control and intervention groups

Notes Physicians were blinded to the intervention group of their patients

\section{Risk of bias}

\begin{tabular}{|c|c|c|}
\hline Bias & Authors' judgement & Support for judgement \\
\hline $\begin{array}{l}\text { Random sequence genera- } \\
\text { tion (selection bias) }\end{array}$ & Low risk & $\begin{array}{l}\text { Coin toss was used. "The patients were randomly allocated (by toss of a coin) } \\
\text { to either a control or an intervention group" (pg 412) }\end{array}$ \\
\hline $\begin{array}{l}\text { Allocation concealment } \\
\text { (selection bias) }\end{array}$ & Unclear risk & No information was provided about how allocation was handled \\
\hline $\begin{array}{l}\text { Selective reporting (re- } \\
\text { porting bias) }\end{array}$ & Unclear risk & $\begin{array}{l}\text { No protocol available; although it appears that everything was reported it is } \\
\text { difficult to determine this without a protocol }\end{array}$ \\
\hline Other bias & Unclear risk & Insufficient information provided to assess this \\
\hline $\begin{array}{l}\text { Blinding of outcome as- } \\
\text { sessment (detection bias) } \\
\text { Adherence measure }\end{array}$ & Low risk & $\begin{array}{l}\text { (PRIMARY) PLASMA ANTICONVULSANT LEVELS - The author notes that the clini- } \\
\text { cal chemistry staff were blinded, and in fact unaware of the study's details }\end{array}$ \\
\hline $\begin{array}{l}\text { Blinding of outcome as- } \\
\text { sessment (detection bias) } \\
\text { Patient outcome }\end{array}$ & Low risk & $\begin{array}{l}\text { (PRIMARY) MEDIAN NUMBER OF SEIZURES - The author notes that all hospital } \\
\text { personnel were blinded }\end{array}$ \\
\hline $\begin{array}{l}\text { Blinding of participants } \\
\text { (performance bias) } \\
\text { Adherence measure }\end{array}$ & Low risk & $\begin{array}{l}\text { (PRIMARY) PLASMA ANTICONVULSANT LEVELS - No mention of blinding of pa- } \\
\text { tients; likely not done but measurement of drug levels in blood may be part of } \\
\text { routine care }\end{array}$ \\
\hline
\end{tabular}

\begin{tabular}{ll}
\hline $\begin{array}{l}\text { Blinding of participants } \\
\text { (performance bias) }\end{array}$ & High risk \\
$\begin{array}{l}\text { Patient outcome } \\
\text { (PRIMARY) MEDIAN NUMBER OF SEIZURES - Any blinding could have been bro- } \\
\text { ken due to the nature of the intervention }\end{array}$
\end{tabular}

\begin{tabular}{|c|c|c|}
\hline $\begin{array}{l}\text { Blinding of personnel (per- } \\
\text { formance bias) } \\
\text { Adherence measure }\end{array}$ & Low risk & $\begin{array}{l}\text { (PRIMARY) PLASMA ANTICONVULSANT LEVELS - The author notes that all hos- } \\
\text { pital personnel were blinded }\end{array}$ \\
\hline $\begin{array}{l}\text { Blinding of personnel (per- } \\
\text { formance bias) } \\
\text { Patient outcome }\end{array}$ & Low risk & $\begin{array}{l}\text { (PRIMARY) MEDIAN NUMBER OF SEIZURES - The author notes that all hospital } \\
\text { personnel were blinded }\end{array}$ \\
\hline $\begin{array}{l}\text { Incomplete outcome data } \\
\text { (attrition bias) } \\
\text { Adherence measure }\end{array}$ & Unclear risk & $\begin{array}{l}\text { (PRIMARY) PLASMA ANTICONVULSANT LEVELS - No mention of reasons for } \\
\text { missing data though missing data are nearly balanced across groups }\end{array}$ \\
\hline $\begin{array}{l}\text { Incomplete outcome data } \\
\text { (attrition bias) } \\
\text { Patient outcome }\end{array}$ & Unclear risk & $\begin{array}{l}\text { (PRIMARY) MEDIAN NUMBER OF SEIZURES - No mention of reasons for missing } \\
\text { data though missing data are nearly balanced across groups }\end{array}$ \\
\hline
\end{tabular}


Peterson 2004

\begin{tabular}{ll}
\hline Methods & Random allocation, not otherwise specified \\
\hline Participants & $\begin{array}{l}\text { 210 eligible patients with established cardiovascular disease and an acute cardiovascular/cerebrovas- } \\
\text { cular-related admission, and discharged from the hospital between April and October } 2001 \text { on statin } \\
\text { therapy, were invited to participate in the study. Patients were excluded if they had dementia, lived in a } \\
\text { domiciliary care facility or lived beyond the greater Hobart area. } 94 \text { provided informed consent. } 13 \text { pa- } \\
\text { tients were subsequently lost to follow-up; } 6 \text { from the control group and } 7 \text { from the intervention group }\end{array}$ \\
\hline Interventions & $\begin{array}{l}\text { Patients in the intervention group were visited at home monthly by a pharmacist, who educated the } \\
\text { patients on the goals of lipid-lowering treatment and the importance of lifestyle issues in dyslipidemia } \\
\text { chompliance with therapy, assessed patients for drug-related problems, and measured total blood } \\
\text { ical care. There was no further contact with patients in the control group after the initial collection of } \\
\text { baseline data, until } 6 \text { months had lapsed. At that time, their final total blood cholesterol level was mea- } \\
\text { sured, and the current medication regimen and self reported compliance were recorded }\end{array}$
\end{tabular}

\begin{tabular}{ll}
\hline Outcomes & $\begin{array}{l}\text { Self reported compliance at } 6 \text { months } \\
\text { Measurement of clinical health outcomes: total cholesterol levels }\end{array}$ \\
\hline Notes & - \\
\hline
\end{tabular}

\section{Risk of bias}

\begin{tabular}{|c|c|c|}
\hline Bias & Authors' judgement & Support for judgement \\
\hline $\begin{array}{l}\text { Random sequence genera- } \\
\text { tion (selection bias) }\end{array}$ & Low risk & $\begin{array}{l}\text { A random number generator was used. "Patients who provided written, in- } \\
\text { formed consent were allocated to either the intervention or control group, us- } \\
\text { ing a computer-generated list of random numbers." (pg 24) }\end{array}$ \\
\hline $\begin{array}{l}\text { Allocation concealment } \\
\text { (selection bias) }\end{array}$ & Unclear risk & No information was provided about how allocation was handled \\
\hline $\begin{array}{l}\text { Selective reporting (re- } \\
\text { porting bias) }\end{array}$ & Unclear risk & $\begin{array}{l}\text { No protocol available; although it appears that everything was reported it is } \\
\text { difficult to determine this without a protocol }\end{array}$ \\
\hline Other bias & Low risk & The study seems to be free of other types of bias \\
\hline $\begin{array}{l}\text { Blinding of outcome as- } \\
\text { sessment (detection bias) } \\
\text { Adherence measure }\end{array}$ & Unclear risk & $\begin{array}{l}\text { (PRIMARY) SELF REPORT QUESTIONNAIRE - No mention of blinding of outcome } \\
\text { assessor }\end{array}$ \\
\hline
\end{tabular}

\begin{tabular}{|c|c|c|}
\hline $\begin{array}{l}\text { Blinding of outcome as- } \\
\text { sessment (detection bias) }\end{array}$ & Low risk & $\begin{array}{l}\text { (PRIMARY) BLOOD CHOLESTEROL LEVEL - This is an objective measure of out- } \\
\text { come }\end{array}$ \\
\hline
\end{tabular}

\begin{tabular}{|c|c|c|}
\hline $\begin{array}{l}\text { Blinding of participants } \\
\text { (performance bias) } \\
\text { Adherence measure }\end{array}$ & High risk & $\begin{array}{l}\text { (PRIMARY) SELF REPORT QUESTIONNAIRE - This is a subjective measure; there } \\
\text { is no information on blinding }\end{array}$ \\
\hline
\end{tabular}

\begin{tabular}{ll}
\hline $\begin{array}{l}\text { Blinding of participants } \\
\text { (performance bias) } \\
\begin{array}{l}\text { Patient outcome } \\
\hline\end{array}\end{array}$ & $\begin{array}{l}\text { (PRIMARY) BLOOD CHOLESTEROL LEVEL - This is an objective measure of out- } \\
\text { come }\end{array}$ \\
\hline
\end{tabular}
Blinding of personnel (per- Unclear risk formance bias) (PRIMARY) SELF REPORT QUESTIONNAIRE - No mention of study personnel blinding Adherence measure


Peterson 2004 (Continued)

Blinding of personnel (per- Low risk (PRIMARY) BLOOD CHOLESTEROL LEVEL - This is an objective measure of outformance bias) come

Patient outcome

(PRIMARY) SELF REPORT QUESTIONNAIRE - Sample size at baseline was 94.13

Incomplete outcome data Low risk

(attrition bias)

patients lost to follow-up; uniform distribution of missing data

Adherence measure

Incomplete outcome data Unclear risk

(attrition bias)

Patient outcome

(PRIMARY) BLOOD CHOLESTEROL LEVEL - Sample size at baseline was 94.13

patients lost to follow-up; uniform distribution of missing data

Peveler 1999

Methods Immediately after referral patients were individually randomized in blocks of 8 to one of 4 treatment groups by prearranged random number sequence, stratified by drug type, in a factorial design. Patients were unaware of their allocation at first interview and were asked not to reveal drug-counseling sessions to the interviewer subsequently

Participants

Patients were included if they were aged 18 or over and starting new courses of treatment with dothiepin or amitriptyline. Inclusion was based on clinical diagnosis of depressive illness. Patients were excluded if they had received either drug within 3 months, had a contraindication (allergy, heart disease, glaucoma, or pregnancy) or were receiving other incompatible drugs. Any patients at high risk of suicide were also excluded

Interventions

The 4 treatment groups were as follows: treatment as usual, leaflet, drug counseling, or both interventions. The information leaflet contained information about the drug, unwanted side effects, and what to do in the event of a missing dose. Patients were given drug counseling by a nurse at weeks 2 and 8 , according to a written protocol. Sessions included assessment of daily routine and lifestyle, attitudes to treatment, and understanding of the reasons for treatment. Education was given about depressive illness and related problems, self help, and local resources. The importance of drug treatment was emphasized, and side effects and their management discussed. Advice was given about the use of reminders and cues, the need to continue treatment for up to 6 months, and what to do in the event of forgetting a dose, and the feasibility of involving family or friends with medicine taking was explored

Outcomes

Measurement of compliance: at 6 weeks, self reported adherence was assessed and was reassessed at the final visit. To check the reliability of self reported adherence, adherence was measured in a subgroup using a Medication Event Monitoring System (MEMS) monitor. Patients were seen at 3 weeks to resupply drugs and pills were counted. At 6 weeks the container was collected and the cap data were downloaded

Measurement of clinical health outcomes: depressive symptoms were measured by the hospital anxiety and depression scale and functional status was measured by the SF-36 health survey. Interviews were conducted at baseline, 6 weeks, and when drugs were discontinued at 12 weeks (whichever was sooner). Also, at 6 weeks depressive symptoms and unwanted effects of treatment were assessed. At the final visit, satisfaction with treatment and unwanted effects were reassessed and the SF-36 repeated

Notes -

\section{Risk of bias}

\begin{tabular}{lll}
\hline Bias & Authors' judgement & Support for judgement \\
\hline $\begin{array}{ll}\text { Random sequence genera- } \\
\text { tion (selection bias) }\end{array}$ & Low risk & "Immediately after referral, patients were individually randomised in blocks of \\
& & eight to one of four treatment groups (treatment as usual, leaflet, drug coun-
\end{tabular}


Peveler 1999 (Continued)

selling, or both interventions) by prearranged random number sequence, stratified by drug type, in a factorial design." (pg 612)

\begin{tabular}{ll}
\hline $\begin{array}{l}\text { Allocation concealment } \\
\text { (selection bias) }\end{array}$ & "Tow risk \\
& ers. Leaflets were included in an opaque sealed envelope with study informa- \\
& tion. Patients were unaware of their allocation at first interview and asked not \\
to reveal drug counselling sessions to the interviewer subsequently." (pg 613)
\end{tabular}

\begin{tabular}{|c|c|c|}
\hline $\begin{array}{l}\text { Selective reporting (re- } \\
\text { porting bias) }\end{array}$ & Unclear risk & $\begin{array}{l}\text { No protocol available; although it appears that everything was reported it is } \\
\text { difficult to determine this without a protocol }\end{array}$ \\
\hline
\end{tabular}

Other bias High risk The authors admit and try to account for patient selection bias by gener-
al practitioners. "The main weakness of this design is that it is important to know whether there was significant bias in patient selection by general physicians. Our attempt to evaluate bias retrospectively suggests that patients with chronic depression, concurrent physical illness or postnatal depression may have been under represented." (pg 615)

\begin{tabular}{|c|c|c|}
\hline $\begin{array}{l}\text { Blinding of outcome as- } \\
\text { sessment (detection bias) } \\
\text { Adherence measure }\end{array}$ & Unclear risk & $\begin{array}{l}\text { (PRIMARY) SELF REPORT QUESTIONNAIRE - Although patients were asked not } \\
\text { to reveal drug counseling session to the interviewer, there was no formal test } \\
\text { of blindness conducted and so it possible that the blinding was not effective. } \\
\text { A randomization key was concealed from interviewers to maintain blinding, } \\
\text { however. "To maintain blinding the randomisation key was concealed from in- } \\
\text { terviewers. Leaflets were included in an opaque sealed envelope with study } \\
\text { information. Patients were unaware of their allocation at first interview and } \\
\text { asked not to reveal drug counselling sessions to the interviewer subsequent- } \\
\text { ly." (pg 613) }\end{array}$ \\
\hline
\end{tabular}

\begin{tabular}{|c|c|c|}
\hline $\begin{array}{l}\text { Blinding of outcome as- } \\
\text { sessment (detection bias) } \\
\text { Patient outcome }\end{array}$ & Low risk & $\begin{array}{l}\text { (PRIMARY) DEPRESSION SYMPTOMS - "To maintain blinding the randomisa- } \\
\text { tion key was concealed from interviewers. Leaflets were included in an opaque } \\
\text { sealed envelope with study information. Patients were unaware of their alloca- } \\
\text { tion at first interview and asked not to reveal drug counselling sessions to the } \\
\text { interviewer subsequently." (pg 613) }\end{array}$ \\
\hline
\end{tabular}

\begin{tabular}{|c|c|c|}
\hline $\begin{array}{l}\text { Blinding of participants } \\
\text { (performance bias) }\end{array}$ & High risk & $\begin{array}{l}\text { (PRIMARY) SELF REPORT QUESTIONNAIRE - This is a subjective measure; blind- } \\
\text { ing could have been broken }\end{array}$ \\
\hline
\end{tabular}

Blinding of participants Unclear risk

Patient outcome (performance bias)

(PRIMARY) DEPRESSION SYMPTOMS - This is a subjective measure. To maintain blinding the randomization key was concealed from interviewers. Leaflets were included in an opaque sealed envelope with study information. Patients were unaware of their allocation at first interview and asked not to reveal drug counseling sessions to the interviewer subsequently." (pg 613); "Depressive symptoms were measured by the hospital anxiety and depression scale and functional status was measured by the SF 36 health survey. Interviews were conducted at baseline, 6 weeks, and when drugs were discontinued or at 12 weeks, whichever was sooner. A postal questionnaire was sent at 12 weeks to all those who discontinued. At 6 weeks self reported adherence depressive symptoms and unwanted effects of treatment were assessed. At the final visit, reported adherence, satisfaction with treatment and unwanted effects were reassessed and the depression scale and SF 36 repeated." (pg 613)

(PRIMARY) SELF REPORT QUESTIONNAIRE - No information on blinding given. There is insufficient information to permit judgment of 'Low risk' or 'High risk'

Blinding of personnel (per- Unclear risk formance bias)

Adherence measure

Blinding of personnel (per- Unclear risk

formance bias)

(PRIMARY) DEPRESSION SYMPTOMS - No information on blinding given. There is insufficient information to permit judgment of 'Low risk' or 'High risk'

Patient outcome 
Peveler 1999 (Continued)

Incomplete outcome data Unclear risk (PRIMARY) SELF REPORT QUESTIONNAIRE - Reasons for missing data were not (attrition bias) provided

Adherence measure

Incomplete outcome data Unclear risk

(attrition bias)

Patient outcome

Phumipamorn 2008

\begin{tabular}{ll}
\hline Methods & Randomized controlled trial \\
\hline Participants & The study location was Krabi Province, Thailand \\
& $\begin{array}{l}67 \text { participants were randomized to the intervention group and } 68 \text { participants were randomized to the } \\
\text { control group }\end{array}$
\end{tabular}
control group

The inclusion criteria were Muslim diabetic patients, literate in Thai, over 18 years of age, and had A1C > $7 \% 3$ months prior to the study

Interventions

\begin{abstract}
Intervention: EXTRA PHARMACIST SERVICE
Patients received their usual scheduled care by a primary care physician every 4 to 8 weeks. At each visit, fasting blood glucose was checked by the laboratory. Blood pressure and weight were recorded by a qualified nurse. A research pharmacist checked the pill count. Each patient then met a physician who assessed the patient and issued a repeat or modified prescription which the dispensing pharmacist filled and they also gave general advice on the medication uses. This was done over the dispensary counter on a routine basis. In addition to the usual care, each patient of the study group had a scheduled meeting with the research pharmacist for 4 consecutive visits at 2 -month intervals. Each visit was on the same date as the physician's appointment and in addition, to avoid a missed appointment, a health personnel co-ordinator attached to the primary health care center in the area, where a patient was living, reminded the patients of the scheduled visit 3 days prior to each visit date. At each visit, the research pharmacist refilled prescriptions, discussed the uses of medication, and checked the pill count. Education on diabetes which included appropriate lifestyles and correct diet was also provided apart from a companion diabetic pamphlet which covered the diabetic complications, the targets of treating diabetes, lifestyle change, and antidiabetic medications
\end{abstract}

Control: USUAL CARE

The control group received their usual scheduled care by a primary care physician every 4 to 8 weeks. At each visit, fasting blood glucose was checked by the laboratory. Blood pressure and weight were recorded by a qualified nurse. A research pharmacist checked the pill count. Each patient then met a physician who assessed the patient and issued a repeat or modified prescription, which the dispensing pharmacist filled and they also gave general advice on the medication uses. This was done over the dispensary counter on a routine basis

Outcomes

The measure of adherence was per cent pill count. It was measured at baseline and then by a research pharmacist at each follow-up appointment the patient had with their primary care physician, every 4 to 8 weeks. Patients were asked to bring their medications with them to appointments to facilitate pill counts

The patient outcomes were changes in A1C level and changes in lipid profiles. Patients fasting blood glucose was checked at each appointment by the laboratory. A patient's A1C level was measured using NycoCard ${ }^{\circledast}$, manufactured by Rapport Company Limited, USA. The hospital laboratory employed a DataPro ${ }^{\circledR}$ Random Access Clinical Analyser, from the U.S. Summit Oversea Company, to determine fasting glucose, total cholesterol, triglyceride and HDL-C. No specific reagent for measuring LDL-C was available at the setting studied. The albuminuria status level was identified using urine test strips. It should be noted here that the $\mathrm{A} 1 \mathrm{C}$ and albuminuria measurements are not routinely performed in the 
Phumipamorn 2008 (Continued)

setting studied and, as required by the study, these tests and results were performed specifically to collect these data

Notes - -

\section{Risk of bias}

\begin{tabular}{|c|c|c|}
\hline Bias & Authors' judgement & Support for judgement \\
\hline $\begin{array}{l}\text { Random sequence genera- } \\
\text { tion (selection bias) }\end{array}$ & Unclear risk & $\begin{array}{l}\text { Random numbers were used. "They were selected randomly by drawing num- } \\
\text { bers from a container that included "1" for the study group }(\mathrm{N}=67) \text { and "2" } \\
\text { for the control group }(\mathrm{N}=68) . " \text { (pg } 32) \text {. "The randomization method used was } \\
\text { apparently not optimal as more women were drawn into the study group and } \\
\text { more patients in the control group took single antidiabetic agent and tended } \\
\text { to have higher pill count.The randomization method used was apparently not } \\
\text { optimal as more women were drawn into the study group and more patients in } \\
\text { the control group took single antidiabetic agent and tended to have higher pill } \\
\text { count." (pg 36) }\end{array}$ \\
\hline
\end{tabular}

\begin{tabular}{|c|c|c|}
\hline $\begin{array}{l}\text { Allocation concealment } \\
\text { (selection bias) }\end{array}$ & Unclear risk & $\begin{array}{l}\text { It does not specify that an opaque container was used. "They were selected } \\
\text { randomly by drawing numbers from a container that included "1" for the study } \\
\text { group }(N=67) \text { and "2" for the control group }(N=68) . "(\operatorname{pg} 32)\end{array}$ \\
\hline
\end{tabular}

\begin{tabular}{|c|c|c|}
\hline $\begin{array}{l}\text { Selective reporting (re- } \\
\text { porting bias) }\end{array}$ & Unclear risk & $\begin{array}{l}\text { No protocol available; although it appears that everything was reported it is } \\
\text { difficult to determine this without a protocol }\end{array}$ \\
\hline
\end{tabular}

\begin{tabular}{|c|c|c|}
\hline Other bias & Unclear risk & $\begin{array}{l}\text { As noted by the authors, "...some contaminations between the control and the } \\
\text { study groups in the single site as in this study, as well as their close proximity } \\
\text { of living in confined Muslim community could have diluted the effect of the in- } \\
\text { tervention. The Hawthorn effect could not also be excluded. In addition, there } \\
\text { might also be an increase in the overall patient care by other care providers } \\
\text { due to a lack of blinding in the pharmacist's activities." - (pg } 34 \text { "This study has } \\
\text { a number of limitations. Expectations and needs of this specific group of pa- } \\
\text { tients were not considered while planning for the interventions. The random- } \\
\text { ization method used was apparently not optimal as more women were drawn } \\
\text { into the study group and more patients in the control group took single antidi- } \\
\text { abetic agent and tended to have higher pill count. Net AlC reduction set in the } \\
\text { study may be too large to be obtained with the interventions. We measured } \\
\text { two points of A1C, i.e., at the baseline and at the end, and as a consequence } \\
\text { there was a lack of observation that could have possibly led to a more accu- } \\
\text { rate trend of A1C change. The pill count method to gauge medication adher- } \\
\text { ence may be inadequate. Though blinding to the randomization groups, the } \\
\text { physicians and nurses were aware of pharmacist carrying out the study thus } \\
\text { increases in overall care might be possible. Our intention was not to affect or } \\
\text { evaluate the process of physician care for diabetes but it would be useful to } \\
\text { measure changes in their diabetes management that may also have an impact } \\
\text { on the outcome measures. The pharmacist's extra input involved combined } \\
\text { strategies. Thus, it was impossible to label which component was associated } \\
\text { with the improvements although multifaceted interventions were proved to } \\
\text { enhance patient outcomes in diabetes care. It should be borne in mind that } \\
\text { the management of diabetes mellitus in real practice is life-long and com- } \\
\text { plex in nature. The results may not be conclusively generalisable, but they im- } \\
\text { ply that similar strategies employed for general diabetes patients might have } \\
\text { favourable effects on cardiovascular risks in this specific group." (pg 36) }\end{array}$ \\
\hline
\end{tabular}

Blinding of outcome as-
sessment (detection bias)

Adherence measure
(PRIMARY) PILL COUNT - Pharmacist was not blinded. As noted by the author, "In addition, there might also be an increase in the overall patient care by other care providers due to a lack of blinding in the pharmacist's activities" (pg 34) 
Phumipamorn 2008 (Continued)
Blinding of outcome as-
Low risk
(PRIMARY) A1C - This is an objective laboratory test sessment (detection bias)

Patient outcome

\begin{tabular}{lll}
\hline $\begin{array}{l}\text { Blinding of participants } \\
\text { (performance bias) } \\
\text { Adherence measure }\end{array}$ & High risk & (PRIMARY) PILL COUNT - Participants were not blinded \\
\hline $\begin{array}{l}\text { Blinding of participants } \\
\text { (performance bias) }\end{array}$ & Low risk & (PRIMARY) A1C - This is an objective laboratory test \\
Patient outcome & & \\
\hline
\end{tabular}

\section{Blinding of personnel (per- Unclear risk}

formance bias)

(PRIMARY) PILL COUNT - No information on blinding given. There is insufficient

Adherence measure information to permit judgment of 'Low risk' or 'High risk'

Blinding of personnel (per- Low risk

(PRIMARY) A1C - This is an objective laboratory test.

formance bias)

Patient outcome

\begin{tabular}{|c|c|c|}
\hline $\begin{array}{l}\text { Incomplete outcome data } \\
\text { (attrition bias) } \\
\text { Adherence measure }\end{array}$ & Unclear risk & $\begin{array}{l}\text { (PRIMARY) PILL COUNT - Few dropouts, but they were not evenly spread across } \\
\text { the } 2 \text { groups }\end{array}$ \\
\hline
\end{tabular}

(attrition bias) the 2 groups

Incomplete outcome data Unclear risk

(attrition bias)

Patient outcome

(PRIMARY) A1C - Only 5 dropouts but they were unbalanced across the groups

\section{Portsmouth 2005}

Methods Patients $(n=43)$ were randomized at baseline to receive treatment in 1 of 2 dosing regimens: patients in the intervention (or PRC) group $(n=22)$ were assigned to take Stavudine d4T PRC/3TC/EFV all once daily (24 hours apart) and patients in the usual care group $(n=21)$ were assigned to continue the twice daily version of $\mathrm{d} 4 \mathrm{~T}$ (IR/3TC/EFV or Combivirs/EFV) as per their screening regimen

Participants

Patients were over 18 years of age and weighed over 40 kilograms. Patients were excluded from this study if they were pregnant (in women of childbearing potential, consent was obtained to ensure they used 2 effective forms of contraception and regularly underwent urinary pregnancy testing), they had proven or suspected hepatitis, an active AIDS-defining disease, a history of bilateral peripheral neuropathy or signs of bilateral peripheral neuropathy of grade 2 or higher

Interventions

This intervention involved simplifying the dosage for a nucleoside reverse transcriptase inhibitor (NRTI) from twice daily to once daily. Patients in the intervention group were assigned to take Stavudine d4T $\mathrm{PRC} / 3 \mathrm{TC} / \mathrm{EFV}$ all once daily (24 hours apart). Control group patients continued either $\mathrm{d} 4 \mathrm{~T}$ IR/3TC/EFV or Combivirs/EFV as per their screening regimen

Outcomes

Compliance was measured using the information obtained from Medication Event Monitoring System (MEMS) caps given with the medication and downloaded at baseline, week 12 and week 24 visits. 3 compliance summary variables were computed: 1) taking compliance, the percentage of prescribed number of doses taken; 2) correct dosing compliance, the percentage of days with correct number of doses taken; and 3) timing compliance, the percentage of doses taken within +3 hours of the prescribed dosing intervals. At each visit, a clinical history was taken and a clinical examination was performed that entailed searching for symptoms of peripheral neuropathy, an examination of peripheral sensation, motor power and reflexes, checking viral load, total lymphocyte and subset analysis, full blood counts and measurements of serum transaminases (including gamma glutamyl transferase ( $g$ GT), serum amylase, lactate and anion gap), total cholesterol, triglycerides, low-density lipoproteins $(\mathrm{LDL})$, high-density lipoproteins (HDL), serum electrolytes, and urea and creatinine. At baseline, week 
Portsmouth 2005 (Continued)

12 and week 24, a quality of life assessment was made using a Medical Outcomes Study HIV Health Survey (MOS-HIV) questionnaire

\section{Notes}

\section{Risk of bias}

\begin{tabular}{lll}
\hline Bias & Authors' judgement & Support for judgement \\
\hline $\begin{array}{ll}\text { Random sequence genera- } \\
\text { tion (selection bias) }\end{array}$ & $\begin{array}{l}\text { Unclear risk } \\
\text { Randomization was not described in detail. "A screening visit 4 weeks prior to } \\
\text { randomization; a baseline visit where 1:1 randomization to switch to d4T PRC } \\
100 \mathrm{mg} \text { and once-daily therapy or to continue their current therapy took place; } \\
\text { and follow-up at weeks } 12 \text { and 24. Subjects were randomly allocated at base- } \\
\text { line to receive treatment in one of two dosing regimens." (pg 186) }\end{array}$ \\
\hline
\end{tabular}

\begin{tabular}{lll}
\hline $\begin{array}{l}\text { Allocation concealment } \\
\text { (selection bias) }\end{array}$ & Unclear risk & No information was provided about how allocation was handled \\
\hline $\begin{array}{l}\text { Selective reporting (re- } \\
\text { porting bias) }\end{array}$ & Unclear risk & $\begin{array}{l}\text { No protocol available; although it appears that everything was reported it is } \\
\text { difficult to determine this without a protocol }\end{array}$ \\
\hline
\end{tabular}

Other bias Unclear risk Study population already had $98.5 \%$ adherence - raises doubts regarding se-
lection of subjects. There is no mention of the study site, whether all patients were offered participation. Also, adherence level is not included as an inclusion criterion

\begin{tabular}{|c|c|c|}
\hline $\begin{array}{l}\text { Blinding of outcome as- } \\
\text { sessment (detection bias) } \\
\text { Adherence measure }\end{array}$ & Unclear risk & $\begin{array}{l}\text { (PRIMARY) MEMS - Open-label study. Not clear who were involved in collect- } \\
\text { ing data, but the data download was done remotely. Insufficient information. } \\
\text { There is insufficient information to permit judgment of 'Low risk' or 'High risk' }\end{array}$ \\
\hline
\end{tabular}

\begin{tabular}{|c|c|c|}
\hline $\begin{array}{l}\text { Blinding of outcome as- } \\
\text { sessment (detection bias) } \\
\text { Patient outcome }\end{array}$ & Low risk & (PRIMARY) VIRAL LOAD - This is an objective measure of outcome \\
\hline $\begin{array}{l}\text { Blinding of participants } \\
\text { (performance bias) } \\
\text { Adherence measure }\end{array}$ & High risk & $\begin{array}{l}\text { (PRIMARY) MEMS - No mention of patient blinding. Blinding of patient/partici- } \\
\text { pant attempted, but likely that the blinding could have been broken, and the } \\
\text { outcome is likely to be influenced by lack of blinding }\end{array}$ \\
\hline
\end{tabular}

\begin{tabular}{ll}
\hline $\begin{array}{l}\text { Blinding of participants } \\
\text { (performance bias) }\end{array}$ & Low risk \\
$\begin{array}{l}\text { Patient outcome } \\
\text { (PRIMARY) VIRAL LOAD - This is an objective measure of outcome }\end{array}$ \\
$\begin{array}{l}\text { Blinding of personnel (per- } \\
\text { formance bias) } \\
\begin{array}{l}\text { Adherence measure } \\
\text { Unclear risk }\end{array}\end{array}$ & $\begin{array}{l}\text { (PRIMARY) MEMS - No information on blinding given. There is insufficient infor- } \\
\text { mation to permit judgment of 'Low risk' or 'High risk' }\end{array}$ \\
\hline
\end{tabular}

\begin{tabular}{ll}
\hline $\begin{array}{l}\text { Blinding of personnel (per- Low risk } \\
\text { formance bias) } \\
\text { Patient outcome }\end{array}$ & (PRIMARY) VIRAL LOAD - This is an objective measure of outcome \\
\hline $\begin{array}{l}\text { Incomplete outcome data Low risk } \\
\text { (attrition bias) } \\
\text { Adherence measure }\end{array}$ & (PRIMARY) MEMS - Missing outcome balanced across groups \\
\hline $\begin{array}{l}\text { Incomplete outcome data } \\
\text { (attrition bias) } \\
\text { Patient outcome }\end{array}$ & (PRIMARY) VIRAL LOAD - Missing outcome balanced across groups \\
\hline
\end{tabular}


Powell 2010

Methods Randomized controlled trial

Participants

The study location was 10 recruiting hospitals, Chicago metropolitan area, Illinois, USA

451 participants were randomized to the intervention group and 451 participants were randomized to the control group

The inclusion criteria were HF for not less than the prior 3 months defined as either: (1) left ventricular ejection fraction $=40 \%$ by echocardiography, radiographic ventriculography, or radionuclide ventriculography; or (2) diuretic therapy for at least 3 months and 1 previous hospitalization for HF

The exclusion criteria were (1) New York Heart Association (NYHA) class IV, owing to low likelihood of benefiting from behavioral treatment; (2) NYHA class I, owing to low likelihood of having a primary endpoint; (3) heart failure symptoms that may be eliminated by surgery (e.g. severe aortic stenosis); (4) uncertain 12-month prognosis; (5) severe medical or psychiatric comorbid condition; (6) patient unwillingness to make lifestyle changes; (7) logistical barriers; (8) physician refusal; and (9) patient refusal

Interventions Intervention: SELF MANAGEMENT PLUS EDUCATION In the self management plus education treatment, patients received group base heart failure education plus counseling to help patients develop mastery in problem-solving skills and in 5 self management skills. 18 2-hour group meetings of approximately 10 patients were spread over the course of 1 year. At each meeting, education in the form of 18 heart failure tip sheets summarized basic elements of patient management. A problem-solving format was used. Groups were led by health professionals

Control: EDUCATION ONLY

Patients randomized to receive education received the same 18 Heart Failure Tip Sheets, on the same schedule as the self management group meetings but delivered by mail. To ensure receipt and check comprehension, a study co-ordinator contacted the patient by telephone within 2 to 3 days of each mailing. If the tip sheet had not been read, the call was rescheduled. All questions about the tip sheets were answered. For concerns unrelated to the tip sheets, the patient was referred to his or her primary care clinician

Outcomes The adherence measure was assessed using MEMS for 1 month after a patient's annual exam. At the conclusion of each exam, the patient was asked to put a month's supply of an ACE inhibitor (or beta-blocker if the patient was not taking an ACE inhibitor) into a MEMS container and was taught to use it for the ensuing month.

The patient outcomes were 1) death or heart failure hospitalization during follow-up, 2) quality of life, and 3) psychosocial function. Death or heart failure was assessed in blinded fashion by a team of cardiologists. All patients, or in the case of death, their family members, were contacted every 3 months by telephone to ascertain occurrence of a death or hospitalization. Reports of death were confirmed by medical record, death certificate, emergency medical services record, or queries from the Social Security Death Index. Heart failure admissions were adjudicated by the presence of shortness of breath, peripheral edema, or chest radiographic evidence of pulmonary edema without evidence of another disease process accounting for symptoms or signs. Heart failure admissions were confirmed if the patient responded to heart failure therapy or had a documented decrease in left ventricular function. Quality of life was assessed as (1) physical function, using the 10-item subscale from the RAND 36-Item ShortForm Health Survey (>=0.93); (2) vitality, using the 4-item subscale from the RAND survey (>=0.86); (3) satisfaction with health and function, using the 11-item subscale from the Quality of Life Index-Cardiac $(>=0.93$ ); and (4) satisfaction with psychological/spiritual function, using the 11-item subscale from the Quality of Life Index-Cardiac ( $>=0.89$ ). Psychosocial function was assessed as (1) major depressive symptoms, using the Geriatric Depression Scale (for which a score greater than 10 is a sensitive and specific screen for major depressive symptoms); (2) social support-emotional, using the 8-item subscale of the Medical Outcomes Study Social Support Scale ( $>=0.90)$; and (3) purpose in life, using the 14-item subscale of the Psychological Well-Being Scale. Quality of life and psychosocial function were assessed at the patient's annual follow-up

Notes Re. cluster question: HART featured a cluster design within the self management group only, in which patients were treated in 42 groups of approximately 10 patients each. The effect of group assignment 
Powell 2010 (Continued) and group leader on the primary outcome was found to be non-significant, therefore clustering was not considered further

\section{Risk of bias}

\begin{tabular}{lll}
\hline Bias & Authors' judgement & Support for judgement \\
\hline $\begin{array}{l}\text { Random sequence genera- } \\
\text { tion (selection bias) }\end{array}$ & Low risk & $\begin{array}{l}\text { Automated randomization method was used. "At the conclusion of the base- } \\
\text { line examination, the nurse coordinator called the automated randomization } \\
\text { service (Moffitt Cancer Center, University of South Florida)" (pg 1333) }\end{array}$ \\
\hline $\begin{array}{l}\text { Allocation concealment } \\
\text { (selection bias) }\end{array}$ & Unclear risk & $\begin{array}{l}\text { "At the conclusion of the baseline examination, the nurse coordinator called } \\
\text { the automated randomization service (Moffitt Cancer Center, University of } \\
\text { South Florida) and treatment assignment was sent to an unblinded staff mem- } \\
\text { ber, who mailed a letter of notification to the patient." (pg 1333) }\end{array}$
\end{tabular}

\begin{tabular}{|c|c|c|}
\hline $\begin{array}{l}\text { Selective reporting (re- } \\
\text { porting bias) }\end{array}$ & Low risk & $\begin{array}{l}\text { The study protocol is available and all of the study's pre-specified (primary } \\
\text { and secondary) outcomes that are of interest in the review have been reported } \\
\text { in the pre-specified way }\end{array}$ \\
\hline
\end{tabular}

\begin{tabular}{lll}
\hline Other bias & Low risk & The study seems to be free of other types of bias \\
\hline $\begin{array}{l}\text { Blinding of outcome as- } \\
\text { sessment (detection bias) }\end{array}$ & Low risk & $\begin{array}{l}\text { (PRIMARY) MEMS - "All investigators and staff, except for } 2 \text { biostatisticians and } \\
\text { the recruiting nurses, were blinded to the randomization status of the partic- } \\
\text { ipant. Treatment teams within each trial arm had no contact with patients in } \\
\text { the other arm." (pg 3s) }\end{array}$
\end{tabular}

\begin{tabular}{|c|c|c|}
\hline $\begin{array}{l}\text { Blinding of outcome as- } \\
\text { sessment (detection bias) } \\
\text { Patient outcome }\end{array}$ & Low risk & $\begin{array}{l}\text { (PRIMARY) SURVIVAL AND HOSPITALIZATION - "All investigators and staff, ex- } \\
\text { cept for the data management team, were blinded to the randomization status } \\
\text { of the patient." (pg 3s) }\end{array}$ \\
\hline
\end{tabular}

\begin{tabular}{ll}
\hline $\begin{array}{l}\text { Blinding of participants } \\
\text { (performance bias) }\end{array}$ & High risk \\
$\begin{array}{l}\text { Adherence measure } \\
\text { (PRIMARY) MEMS - Although patients were not blinded to group, they were } \\
\text { blinded to the purpose of the study. However, the blinding could have been } \\
\text { broken due to the nature of the intervention }\end{array}$
\end{tabular}

\begin{tabular}{ll}
\hline $\begin{array}{l}\text { Blinding of participants } \\
\text { (performance bias) }\end{array}$ & Low risk \\
$\begin{array}{l}\text { Patient outcome } \\
\text { ticipants were blinded to trial hypotheses by providing neutral names for the } \\
\text { randomized treatment arms." }\end{array}$
\end{tabular}

\begin{tabular}{ll}
\hline $\begin{array}{l}\text { Blinding of personnel (per- } \\
\text { formance bias) }\end{array}$ & Low risk \\
$\begin{array}{l}\text { Adherence measure } \\
\text { key personnel are, "All investigators and staff, except for } 2 \text { biostatisticians and } \\
\text { the recruiting nurses, were blinded to the randomization status of the partic- } \\
\text { ipant. Treatment teams within each trial arm had no contact with patients in } \\
\text { the other arm." (pg 3s) }\end{array}$ \\
\hline
\end{tabular}

\begin{tabular}{|c|c|c|}
\hline $\begin{array}{l}\text { Blinding of personnel (per- } \\
\text { formance bias) } \\
\text { Patient outcome }\end{array}$ & Unclear risk & $\begin{array}{l}\text { (PRIMARY) SURVIVAL AND HOSPITALIZATION - The study seems to be free of } \\
\text { other types of bias }\end{array}$ \\
\hline
\end{tabular}

\begin{tabular}{|c|c|c|}
\hline $\begin{array}{l}\text { Incomplete outcome data } \\
\text { (attrition bias) } \\
\text { Adherence measure }\end{array}$ & Low risk & $\begin{array}{l}\text { (PRIMARY) MEMS - Dropouts appear balanced across the } 2 \text { conditions with sim- } \\
\text { ilar reasons for data missing }\end{array}$ \\
\hline $\begin{array}{l}\text { Incomplete outcome data } \\
\text { (attrition bias) } \\
\text { Patient outcome }\end{array}$ & Low risk & $\begin{array}{l}\text { (PRIMARY) SURVIVAL AND HOSPITALIZATION - incomplete data were balanced } \\
\text { across groups }\end{array}$ \\
\hline
\end{tabular}


Powers 2011

\begin{tabular}{ll}
\hline Methods & Randomized controlled trial \\
\hline Participants & The study location was Durham, North Carolina, USA
\end{tabular}

\section{Participants}

The study location was Durham, North Carolina, USA

45 participants were randomized to the intervention group and 44 participants were randomized to the control group

The inclusion criteria were enrolled in primary care for at least 1 year; age $=55$ years; had a diagnosis of hypertension based on International Classification of Diseases 401.0, 401.1, or 401.9; received a prescription for hypertensive medication in the previous year; had systolic blood pressure N140 or diastolic blood pressure $\mathrm{N} 90$ based on their most recent blood pressure measurement within the last 12 months; and had an electrocardiogram within the last 5 years to evaluate the absence or presence of left ventricular hypertrophy

The exclusion criteria were hospitalized for a myocardial infarction or coronary artery revascularization or had a diagnosis of metastatic cancer in the past 6 months; had a history of stroke; had active diagnosis of psychosis or dementia documented in medical record; were participating in another chronic disease self management study; were resident of a nursing home; or did not have access to a telephone

Interventions Intervention: PERSONALIZED RISK COMMUNICATION Patients in the personalized risk communication arm received standard risk factor education (control) as well as personalized information based on their Framingham CHD and stroke risk score, presented verbally and in graphic form as vertical bar charts. Patients' average and optimal CHD and stroke risks based on published estimates for their 5-year age group were also presented in graphical form alongside their estimated risk. To achieve optimal risk, patients were presented with potential strategies to improve their risk through risk factor modification such as medication and patient lifestyle factors. A copy of the patient's personal risk information was also provided to the primary care provider

\section{Control: STANDARD RISK FACTOR EDUCATION}

Control patients received written patient education materials from the American Heart Association/American Stroke Association entitled "Are You at Risk of Heart Attack or Stroke?", which reviewed risk factors and how these factors can be improved but did not provide personalized estimates of individual risk. The research assistant verbally reviewed the information with all patients and answered any questions at the initial visit

The measures of adherence were measured at baseline and 3 months by means of the Morisky test. The questionnaire was administered by research assistants

The patient outcome was knowledge of cardiovascular risk factors and measured by asking patients to name as many risk factors as they could. Results are reported as the number of correctly identified risk factors. Patients were masked to their calculated risk scores and asked to estimate their 10-year stroke risk, 10-year risk for a CHD event, as well as their level of worry for each type of event on a continuous scale ranging from 1 to 100 . The interview was conducted by research assistants at baseline and 3 months postintervention. The patient outcomes were risk factor knowledge, perceived stroke risk, perceived CHD risk, stroke worry, CHD worry SBP and DBP, 10-year CHD risk estimate, 10-year stroke risk estimate. All the measurements were conducted by research assistants at baseline and 3 months post intervention. Patients' resting blood pressure was measured twice using a digital blood pressure monitor, and the mean was used for the longitudinal analysis. A patient's Framingham stroke and CHD risk estimates were calculated at baseline and 3 months postintervention based on their risk factors with the most recent clinic blood pressure and cholesterol measurements used for communication

Notes -

\section{Risk of bias}

Bias Authors' judgement Support for judgement

Random sequence genera- Unclear risk Method of random sequence generation not described

tion (selection bias) 
Powers 2011 (Continued)

Allocation concealment Unclear risk No information was provided about how allocation was handled
(selection bias)

\begin{tabular}{ll}
\hline $\begin{array}{l}\text { Selective reporting (re- } \\
\begin{array}{l}\text { porting bias) } \\
\text { Low risk }\end{array}\end{array}$ \\
$\begin{array}{l}\text { No protocol available; although it appears that everything was reported it is } \\
\text { difficult to determine this without a protocol }\end{array}$
\end{tabular}

\begin{tabular}{|c|c|c|}
\hline Other bias & Low risk & The study appears to be free of other sources of bias \\
\hline $\begin{array}{l}\text { Blinding of outcome as- } \\
\text { sessment (detection bias) } \\
\text { Adherence measure }\end{array}$ & High risk & $\begin{array}{l}\text { (PRIMARY) SELF REPORT - QUESTIONNAIRE - Blinding of outcome assessors } \\
\text { not described. The study is an open-label trial, however. This is a subjective } \\
\text { measure }\end{array}$ \\
\hline $\begin{array}{l}\text { Blinding of outcome as- } \\
\text { sessment (detection bias) } \\
\text { Patient outcome }\end{array}$ & Unclear risk & $\begin{array}{l}\text { (PRIMARY) BLOOD PRESSURE - it is unclear if a computerized method was used } \\
\text { to take blood pressure }\end{array}$ \\
\hline
\end{tabular}

\begin{tabular}{|c|c|c|}
\hline $\begin{array}{l}\text { Blinding of participants } \\
\text { (performance bias) } \\
\text { Adherence measure }\end{array}$ & High risk & $\begin{array}{l}\text { (PRIMARY) SELF REPORT - QUESTIONNAIRE - Blinding of outcome assessors } \\
\text { not described. The study is an open-label trial, however. This is a subjective } \\
\text { measure }\end{array}$ \\
\hline
\end{tabular}

\begin{tabular}{ll}
\hline $\begin{array}{l}\text { Blinding of participants } \\
\text { (performance bias) }\end{array}$ & Low risk \\
Patient outcome & $\begin{array}{l}\text { (PRIMARY) BLOOD PRESSURE - Outcome measurement not likely influenced by } \\
\text { lack of blinding }\end{array}$ \\
\hline
\end{tabular}

\begin{tabular}{ll}
\hline $\begin{array}{l}\text { Blinding of personnel (per- } \\
\text { formance bias) }\end{array}$ & High risk \\
$\begin{array}{ll}\text { Adherence measure } & \text { (PRIMARY) SELF REPORT - QUESTIONNAIRE - Blinding of outcome assessors } \\
\text { not described. The study is an open-label trial, however. This is a subjective } \\
\text { measure }\end{array}$ \\
\hline
\end{tabular}

\begin{tabular}{|c|c|c|}
\hline Blinding of personnel (per- & Unclear risk & $\begin{array}{l}\text { (PRIMARY) BLOOD PRESSURE - No information on blinding given. There is in- } \\
\text { sufficient information to permit judgment of 'Low risk' or 'High risk' }\end{array}$ \\
\hline
\end{tabular}

Patient outcome

Incomplete outcome data Low risk
(attrition bias)

Adherence measure

Incomplete outcome data Low risk
(attrition bias)

Patient outcome

\section{Pradier 2003}

\begin{tabular}{ll}
\hline Methods & Randomized controlled trial. Patients were randomized into the intervention group (IG) and the control \\
& group (CG) \\
\hline Participants & $\begin{array}{l}\text { All HIV-infected patients who had medical follow-up at the Nice University Hospital between Septem- } \\
\text { ber } 1999 \text { and December } 1999 \text { were approached for study participation. Patients were included if they } \\
\text { were: } 1 \text { ) over } 18 \text { years of age; } 2 \text { ) being treated for at least } 1 \text { month by a combination of at least } 1 \text { pro- } \\
\text { tease inhibitor (PI) or } 1 \text { nonnucleoside reverse transcriptase inhibitor (NNRTI) or abacavir with } 2 \text { nucle- } \\
\text { oside reverse transcriptase inhibitors (NRTIs); 3) not having required hospitalization in the prior month } \\
\text { or requiring it at the time of consultation; 4) not previously included in another protocol }\end{array}$
\end{tabular}

Interventions

The intervention combined an educational and counseling approach that was founded on the principles of motivational psychology, client centered therapy and the use of an "empathic therapeutic to enhance participants' self efficacy". The intervention focused on cognitive, emotional, social and behavioral determinants affecting adherence. The intervention consisted of 3 individually delivered ses- 
Pradier 2003 (Continued)

sions by nurses lasting 45 to 60 minutes. To standardize the intervention, intervention group manuals for the nurses were prepared and the nurses attended a 5-day intensive training course given by psychologists. Some flexibility was allowed for the nurses to tailor the intervention based on the needs of the individual patient. To ensure the quality of the intervention each nurse had supervision sessions with a psychologist and a clinical supervisor to review written material filled out by the nurses. No mention was made of the care that was provided for the control group

\begin{tabular}{ll} 
Outcomes & $\begin{array}{l}\text { This data were collected using a self administered questionnaire at month } 0 \text { (M0) and month } 6 \text { (M6) } \\
\text { Measurement of clinical health outcomes: } 1 \text { ) Change in Viral Load between M0 and M6; 2) Percentage } \\
\text { of patients achieving plasma HIV-1 RNA levels < } 40 \text { copies ml at M6; 3) 16-item HAART related symptom } \\
\text { scale; 4) Proportion of patients with reported toxic events; 5) Depressive mood using CES-D scale }\end{array}$ \\
\hline Notes & $\begin{array}{l}\text { The clinical significance of these findings is unclear - adherence rate was on self report in an unblinded } \\
\text { trial, the mean HIV RNA was no different at } 6 \text { months for the } 2 \text { groups and no actual clinical outcomes } \\
\text { were reported }\end{array}$
\end{tabular}

\section{Risk of bias}

\begin{tabular}{|c|c|c|}
\hline Bias & Authors' judgement & Support for judgement \\
\hline $\begin{array}{l}\text { Random sequence genera- } \\
\text { tion (selection bias) }\end{array}$ & Unclear risk & $\begin{array}{l}\text { No mention of randomization method. "Patients were randomized in an inter- } \\
\text { vention group (IG) and a control group (CG)" (pg 122) }\end{array}$ \\
\hline $\begin{array}{l}\text { Allocation concealment } \\
\text { (selection bias) }\end{array}$ & Unclear risk & No information was provided about how allocation was handled \\
\hline $\begin{array}{l}\text { Selective reporting (re- } \\
\text { porting bias) }\end{array}$ & Unclear risk & $\begin{array}{l}\text { No protocol available; although it appears that everything was reported it is } \\
\text { difficult to determine this without a protocol }\end{array}$ \\
\hline Other bias & Low risk & The study seems to be free of other types of bias \\
\hline $\begin{array}{l}\text { Blinding of outcome as- } \\
\text { sessment (detection bias) } \\
\text { Adherence measure }\end{array}$ & Low risk & $\begin{array}{l}\text { (PRIMARY) SELF REPORT - QUESTIONNAIRE - According to the author, the risk } \\
\text { of bias has been minimized since several questions were used in order to in- } \\
\text { crease the sensitivity of the detection of non-adherence }\end{array}$ \\
\hline
\end{tabular}

\begin{tabular}{|c|c|c|}
\hline $\begin{array}{l}\text { Blinding of outcome as- } \\
\text { sessment (detection bias) }\end{array}$ & Unclear risk & $\begin{array}{l}\text { (PRIMARY) TOXICITY AND SYMPTOM QUESTIONNAIRE - This is a subjective } \\
\text { measure; there is no information on blinding }\end{array}$ \\
\hline
\end{tabular}
Patient outcome

\begin{tabular}{|c|c|c|}
\hline $\begin{array}{l}\text { Blinding of participants } \\
\text { (performance bias) }\end{array}$ & High risk & $\begin{array}{l}\text { (PRIMARY) SELF REPORT - QUESTIONNAIRE - This is a subjective measure; } \\
\text { there is no information on blinding }\end{array}$ \\
\hline
\end{tabular}

\begin{tabular}{|c|c|c|}
\hline $\begin{array}{l}\text { Blinding of participants } \\
\text { (performance bias) } \\
\text { Patient outcome }\end{array}$ & High risk & $\begin{array}{l}\text { (PRIMARY) TOXICITY AND SYMPTOM QUESTIONNAIRE - This is a subjective } \\
\text { measure; there is no information on blinding }\end{array}$ \\
\hline $\begin{array}{l}\text { Blinding of personnel (per- } \\
\text { formance bias) } \\
\text { Adherence measure }\end{array}$ & Low risk & $\begin{array}{l}\text { (PRIMARY) SELF REPORT - QUESTIONNAIRE - According to the author, the ad- } \\
\text { herence score was computed after data entry by the research team, which was } \\
\text { totally independent from the clinical staff }\end{array}$ \\
\hline
\end{tabular}

\begin{tabular}{|c|c|c|}
\hline $\begin{array}{l}\text { Blinding of personnel (per- } \\
\text { formance bias) } \\
\text { Patient outcome }\end{array}$ & Unclear risk & $\begin{array}{l}\text { (PRIMARY) TOXICITY AND SYMPTOM QUESTIONNAIRE - This is a subjective } \\
\text { measure; there is no information on blinding }\end{array}$ \\
\hline $\begin{array}{l}\text { Incomplete outcome data } \\
\text { (attrition bias) } \\
\text { Adherence measure }\end{array}$ & Low risk & $\begin{array}{l}\text { (PRIMARY) SELF REPORT - QUESTIONNAIRE - There is a relatively high rate of } \\
\text { missing data but similar distribution across groups ( } 16 \% \text { and } 19 \%)\end{array}$ \\
\hline
\end{tabular}


Pradier 2003 (Continued)

Incomplete outcome data Low risk (PRIMARY) TOXICITY AND SYMPTOM QUESTIONNAIRE - There is a relatively (attrition bias) high rate of missing data but similar distribution across groups (16\% and $19 \%)$

Patient outcome

\section{Purcell 2007}

\begin{tabular}{ll}
\hline Methods & Randomized controlled trial \\
\hline Participants & The study location was community venues in Baltimore, Miami, New York, and San Francisco, USA \\
& $\begin{array}{l}486 \text { participants were randomized to the intervention group and } 480 \text { participants were randomized to } \\
\text { the control group }\end{array}$
\end{tabular}

The inclusion criteria were confirmed HIV-positive patients over 18 years old, who used injected drugs in the past year, had at least 1 opposite-sex sexual partner in the past 3 months, who agreed to a blood draw, had not been enrolled in the cross-site pilot study or an intervention study conducted by a principal investigator, lived within the study area and were willing to provide contact information, were English speaking, and were available for the first intervention session

Interventions Intervention: PEER MENTORING INTERVENTION

The peer mentoring intervention sessions were delivered twice a week for 5 weeks and included 7 group sessions, 2 individual sessions, and 1 "peer volunteer activity" (PVA), during which participants went to a local service organization for 2 to 4 hours to observe, participate, and practice peer mentoring skills. The first session focused on setting group rules and the power of peer mentoring, 2 group sessions and 1 individual session focused on utilization of HIV primary care and adherence, and 3 group sessions and 1 individual session focused on sex and drug risk behaviors. Risk messages were communicated using posters and handouts with risk hierarchies that helped to form individualized risk plans discussed during the individual session focusing on sex and injection behaviors. The final group session focused on review and reinforcement of motivation and skills for behavior change and ended with a graduation ceremony. For both treatment groups, a resource table that provided information about local services available for medical care, support groups, drug treatment, and prevention resources such as pamphlets and male and female condoms was available during and after every session

Control: VIDEO DISCUSSION INTERVENTION

Control participants had similar access to general information resources and risk reduction information and resources as intervention participants, and received equal attention during the study regarding groups sessions, but not the 2 individual sessions as did the intervention participants. Participants in the control group took part in 8 group sessions over 5 weeks. For all but session 1 , the control sessions were led by the same 2 facilitators who led the intervention sessions. Participants in the control group watched documentary or self help videos focused on issues relevant to HIV-positive intravenous drug users, followed by facilitated discussion. Topics directly related to the intervention outcomes were avoided or minimized. Community resources and risk reduction information and tools were available at every control session adherence was defined as having taken $90 \%$ of antiretroviral medications in the prior 7 days

The patient outcomes were sexual behavior, injection behavior, and utilization of HIV care ( 2 times or more in the past 6 months) assessed at baseline, 3 months (not care utilization), 6 months, and 12 months by means of audio computer-assisted self interviewing (A-CASI)

\section{Notes}

$$
-
$$

\section{Risk of bias}

Bias Authors' judgement Support for judgement


Purcell 2007 (Continued)

Random sequence genera- Low risk Computer randomization was used. "One staff member at each site who was tion (selection bias) not an intervention facilitator used a computer program to assign participants to 1 of the 2 intervention conditions." (pg s36)

\begin{tabular}{lll}
\hline $\begin{array}{l}\text { Allocation concealment } \\
\text { (selection bias) }\end{array}$ & Unclear risk & No information was provided about how allocation was handled \\
\hline $\begin{array}{l}\text { Selective reporting (re- } \\
\text { porting bias) }\end{array}$ & Unclear risk & $\begin{array}{l}\text { MEMS results are not reported, only self reported adherence, but since all re- } \\
\text { sults are negative it is assumed that it is unlikely MEMS was positive and thus } \\
\text { low risk of bias }\end{array}$ \\
\hline Other bias & Low risk & The study seems to be free of other types of bias \\
\hline $\begin{array}{l}\text { Blinding of outcome as- } \\
\text { sessment (detection bias) } \\
\text { Adherence measure }\end{array}$ & Low risk & $\begin{array}{l}\text { (PRIMARY) SELF REPORT - QUESTIONNAIRE - No mentioning of (not) blinding } \\
\text { data collection personnel to the group allocation. But A-CASI is used to admin- } \\
\text { ister the interviews - objective measure }\end{array}$ \\
\hline
\end{tabular}

\begin{tabular}{ll}
$\begin{array}{l}\text { Blinding of outcome as- } \\
\text { sessment (detection bias) } \\
\begin{array}{l}\text { Patient outcome }\end{array}\end{array} \quad$ Low risk & $\begin{array}{l}\text { (PRIMARY) SEXUAL BEHAVIOR - A-CASI used to administer the interviews. This } \\
\text { is an objective measure of outcome }\end{array}$ \\
\hline
\end{tabular}

Patient outcome

\begin{tabular}{|c|c|c|}
\hline $\begin{array}{l}\text { Blinding of participants } \\
\text { (performance bias) }\end{array}$ & High risk & $\begin{array}{l}\text { (PRIMARY) SELF REPORT - QUESTIONNAIRE - Patients likely not blind due to } \\
\text { the nature of the intervention }\end{array}$ \\
\hline
\end{tabular}

Adherence measure

$\begin{array}{ll}\begin{array}{l}\text { Blinding of participants } \\ \text { (performance bias) }\end{array} & \text { High risk } \\ \begin{array}{l}\text { (Patient outcome } \\ \text { the intervention }\end{array}\end{array}$

\begin{tabular}{|c|c|c|}
\hline $\begin{array}{l}\text { Blinding of personnel (per- } \\
\text { formance bias) } \\
\text { Adherence measure }\end{array}$ & Low risk & $\begin{array}{l}\text { (PRIMARY) SELF REPORT - QUESTIONNAIRE - No mentioning of blinding of key } \\
\text { personnel noted. However, A-CASI is used to administer the interviews - objec- } \\
\text { tive measure }\end{array}$ \\
\hline $\begin{array}{l}\text { Blinding of personnel (per- } \\
\text { formance bias) } \\
\text { Patient outcome }\end{array}$ & Low risk & $\begin{array}{l}\text { (PRIMARY) SEXUAL BEHAVIOR - A-CASI used to administer the interviews. This } \\
\text { is an objective measure of outcome }\end{array}$ \\
\hline $\begin{array}{l}\text { Incomplete outcome data } \\
\text { (attrition bias) } \\
\text { Adherence measure }\end{array}$ & Unclear risk & $\begin{array}{l}\text { (PRIMARY) SELF REPORT - QUESTIONNAIRE - Attrition for measuring adher- } \\
\text { ence was higher in the intervention group. Although the authors state that } \\
\text { they repeated the models with imputation of missing data, which showed no } \\
\text { differences, no details are provided }\end{array}$ \\
\hline $\begin{array}{l}\text { Incomplete outcome data } \\
\text { (attrition bias) } \\
\text { Patient outcome }\end{array}$ & Low risk & $\begin{array}{l}\text { (PRIMARY) SEXUAL BEHAVIOR - Missing data are balanced between groups, } \\
\text { but on the border of significant ( } 20 \%) \text {. However, percentage of missing data is } \\
\text { somewhat lower at the other visits }\end{array}$ \\
\hline
\end{tabular}

Pyne 2011

\begin{tabular}{ll}
\hline Methods & Randomized controlled trial \\
\hline Participants & The study location was 3 Veteran's Administration (VA) HIV treatment facilities, Little Rock, Arkansas, \\
USA \\
$\begin{array}{l}138 \text { participants were randomized to the intervention group and } 138 \text { participants were randomized to } \\
\text { the control group }\end{array}$
\end{tabular}


Pyne 2011 (Continued)

The inclusion criteria were (1) a current 9-item Patient Health Questionnaire (PHQ-9) depression score of 10 or higher and (2) current treatment in the VA HIV clinic

The exclusion criteria were (1) no access to a telephone, (2) current acute suicidal ideation, (3) significant cognitive impairment as indicated by a score higher than 10 on the Blessed Orientation-Memory-Concentration Test and (4) history of bipolar disorder or schizophrenia

Interventions

Intervention: HIV TRANSLATING INITIATIVES FOR DEPRESSION INTO EFFECTIVE SOLUTIONS (HITIDES) The purpose of the HITIDES intervention was to support HIV and mental health clinicians in delivering evidence-based depression treatment. The HIV depression care team consisted of a registered nurse depression care manager, a clinical pharmacist, and a psychiatrist. This team was located offsite and convened once a week and as needed by telephone or in person. The depression care team communicated with treating clinicians via electronic medical record progress notes. The DCM communicated with patients via telephone. The HITIDES depression care team made treatment suggestions. Treatment decisions were made by the HIV or mental health clinicians at each site. The DCM delivered the following intervention components: participant education and activation, assessment of treatment barriers and possible resolutions, depression symptom and treatment monitoring, substance abuse monitoring, and instruction in self management. The DCM used prewritten scripts, which are standardized instruments that were supported by the web-based decision support system during these telephone encounters. The intervention used a stepped-care model for depression treatment. At any time, HIV health care providers were free to refer participants directly to specialty mental health care. The DCM conducted telephone-based monitoring every 2 weeks during acute treatment and every 4 weeks during watchful waiting or continuation treatment. The NetDSS system identified potential treatment non-response as (1) antidepressant regimen adherence of less than $80 \%$ during the past 14 days, (2) counseling non-adherence of less than $75 \%$ during the past month, (3) participant report of severe adverse effects during 2 consecutive DCM encounters, (4) participant report of a 5-point increase in depression severity from the enrollment PHQ-9 score based on 2 consecutive DCM encounters, or (5) lack of participant response during an 8-week antidepressant or 12-week counseling trial

Control: USUAL CARE

Usual care depression treatment was provided by HIV or mental health clinicians without involvement of the HITIDES depression care team. Before starting the study, all HIV health care providers received 1 hour of HIV and depression training

Outcomes The measures of adherence were using the AIDS Clinical Trial Group assessment, which asks participants to report the number of pills per day they are supposed to take and the number of pills they skipped taking for each medication for each of the past 4 days. Both HIV and depression medication adherence were measured using this assessment. The data were collected at baseline, 6 months, and 12 months by telephone interviewers who were blinded to treatment assignment

The patient outcomes were 1) depression severity during the past 2 weeks, measured using the 20 -item Hopkins Symptom Checklist; 2) health status measured using the physical and mental health component summary scores from the Medical Outcomes Study Veterans 12-Item short form health survey; 3 ) health-related quality of life measured using the Quality of Well Being Self-administered Scale; 4) severity of HIV symptoms using the 20-item symptoms distress module which summarizes the degree to which each symptom bothered the participant in the past 4 weeks. All measures were collected by telephone interview at baseline, 6 , and 12 months by telephone interviewers who were blinded to treatment assignment

Notes -

\section{Risk of bias}

\begin{tabular}{lll}
\hline Bias & Authors' judgement & Support for judgement \\
\hline $\begin{array}{l}\text { Random sequence genera- } \\
\text { tion (selection bias) }\end{array}$ & Low risk & $\begin{array}{l}\text { Computer-generated random assignment was used. "Participants were ran- } \\
\text { domized to the intervention or to usual care in a 1:1 ratio according to a com- } \\
\text { puter-generated random assignment sequence stratified by clinic and gener- } \\
\text { ated in advance. Research assistants at each clinic were provided envelopes }\end{array}$
\end{tabular}


Pyne 2011 (Continued)

labeled by participant number and containing randomized assignment." (pg 24)

\begin{tabular}{ll}
\hline $\begin{array}{l}\text { Allocation concealment } \\
\text { (selection bias) }\end{array}$ & Unclear risk
\end{tabular}$\quad \begin{aligned} & \text { The study does not specify opaque envelopes. "Research assistants at each } \\
& \text { clinic were provided envelopes labeled by participant number and containing } \\
& \text { randomized assignment." (pg 24) }\end{aligned}$

\begin{tabular}{|c|c|c|}
\hline $\begin{array}{l}\text { Selective reporting (re- } \\
\text { porting bias) }\end{array}$ & Unclear risk & $\begin{array}{l}\text { It indicates there are results not reported in this paper. "The primary out- } \\
\text { comes listed in clinicaltrials.gov were depression severity, implementation } \\
\text { process, and quality of care. Implementation process and quality of care will } \\
\text { be addressed in separate reports." (pg 25) }\end{array}$ \\
\hline
\end{tabular}

\begin{tabular}{lll}
\hline Other bias & Low risk & The study seems to be free of other types of bias \\
\hline $\begin{array}{l}\text { Blinding of outcome as- } \\
\text { sessment (detection bias) }\end{array}$ & Low risk & (PRIMARY) AIDS CLINICAL TRIAL GROUP ASSESSMENT - QUESTIONNAIRE - \\
Adherence measure & $\begin{array}{l}\text { States personnel were blinded to study group. "The assessments were done at } \\
6 \text { and } 12 \text { months by telephone interviewers who were blinded to treatment as- } \\
\text { signment and used scripted computer-based assessments" (pg 25) }\end{array}$
\end{tabular}

\begin{tabular}{|c|c|c|}
\hline $\begin{array}{l}\text { Blinding of outcome as- } \\
\text { sessment (detection bias) } \\
\text { Patient outcome }\end{array}$ & Low risk & $\begin{array}{l}\text { (PRIMARY) DEPRESSION SYMPTOM SEVERITY - The assessments were blinded. } \\
\text { "Baseline and 6- and 12-month data were collected by telephone interview- } \\
\text { ers who were blinded to treatment assignment and used scripted comput- } \\
\text { er-based assessments." (pg 25) }\end{array}$ \\
\hline
\end{tabular}

\begin{tabular}{|c|c|c|}
\hline $\begin{array}{l}\text { Blinding of participants } \\
\text { (performance bias) } \\
\text { Adherence measure }\end{array}$ & High risk & $\begin{array}{l}\text { (PRIMARY) AIDS CLINICAL TRIAL GROUP ASSESSMENT - QUESTIONNAIRE - This } \\
\text { is a subjective measure; there is no information on blinding }\end{array}$ \\
\hline $\begin{array}{l}\text { Blinding of participants } \\
\text { (performance bias) } \\
\text { Patient outcome }\end{array}$ & High risk & $\begin{array}{l}\text { (PRIMARY) DEPRESSION SYMPTOM SEVERITY - This is a subjective measure; } \\
\text { there is no information on blinding }\end{array}$ \\
\hline $\begin{array}{l}\text { Blinding of personnel (per- } \\
\text { formance bias) } \\
\text { Adherence measure }\end{array}$ & Unclear risk & $\begin{array}{l}\text { (PRIMARY) AIDS CLINICAL TRIAL GROUP ASSESSMENT - QUESTIONNAIRE - No } \\
\text { information on blinding given. There is insufficient information to permit judg- } \\
\text { ment of 'Low risk' or 'High risk' }\end{array}$ \\
\hline
\end{tabular}

Blinding of personnel (per- Unclear risk

formance bias)

Patient outcome

(PRIMARY) DEPRESSION SYMPTOM SEVERITY - No information on blinding given. There is insufficient information to permit judgment of 'Low risk' or 'High risk'

$\begin{array}{ll}\begin{array}{l}\text { Incomplete outcome data } \\ \text { (attrition bias) }\end{array} & \text { (PRIMARY) AIDS CLINICAL TRIAL GROUP ASSESSMENT - QUESTIONNAIRE - } \\ \text { Adherence measure } & \text { Missing data are relatively balanced across groups and were imputed in the } \\ & \text { analysis (pg 26) }\end{array}$

Incomplete outcome data Low risk (PRIMARY) DEPRESSION SYMPTOM SEVERITY - Missing data are relatively bal(attrition bias) anced across the groups; missing data were imputed (pg 26)

Patient outcome

Rawlings 2003

\begin{tabular}{ll}
\hline Methods & $\begin{array}{l}\text { Consenting patients were randomized 1:1 to receive either: an EI (4 modules of the Tools for Health Em- } \\
\text { powerment course) plus routine counseling (RC) (EI + RC); or RC alone }\end{array}$ \\
\hline Participants & $\begin{array}{l}\text { A 24-week open-label clinical trial was conducted in } 195 \text { HIV-infected adults commonly under-repre- } \\
\text { sented in research (35\% female, 71\% African American, 21\% Hispanic, and 20\% injection drug users } \\
\text { (IDUs)) }\end{array}$
\end{tabular}


Rawlings 2003 (Continued)

Interventions
The course is an 11-module educational program for HIV-infected patients and their informal caregivers in which there are interactive small arm sessions facilitated by a healthcare professional trained in the principles of adult learning, skills-building exercises aimed at behavior change in participants, flip charts, videotapes, patient logbooks, and patient workbooks. Program materials are designed at a fifth-grade reading level (English only). The goal of the THE course is to empower people living with HIV/AIDS and their informal caregivers with the knowledge, skills, attitudes, and resources to improve self care, adherence, quality of life, and satisfaction with care, leading to improved quality of care. The following 4 modules focusing on patient empowerment, HIV pathogenesis and treatment, and medication management and adherence were delivered ( 1 session per week) during weeks 1 through 4 of this clinical trial. "The RC consisted of provision of the following information at each study visit: names and physical descriptions of the study drugs; instructions on how best to take the study drugs, including dosage and dosage schedules (taking the patient's daily routine into account) as well as how/when to remove the medications from bottles using Medication Event Monitoring System (MEMS) TrackCaps (APREX Corporation, Union City, CA); importance of taking the study drugs exactly as prescribed; and potential adverse events as well as actions to take if study participants experienced any of these."

Outcomes Adherence was measured using MEMS track caps which monitored and electronically recorded the date and time each medication was removed from the bottle. The primary efficacy measure was the proportion of patients attaining plasma HIV-1 RNA levels below the 40-copy/ml lower limit of quantitation (LLOQ) of the NucliSens assay and below the 400-copy/ml LLOQ of the HIV-1 MONITOR version 1.0 polymerase chain reaction (PCR) assay (Roche, Nutley, $\mathrm{NJ}$ ) at 24 weeks after starting treatment with $\mathrm{COM}+\mathrm{ABC}$. Viral load response (HIV-1 RNA in plasma) was the primary study endpoint. A secondary efficacy measure was an assessment of changes in the number of CD4 lymphocyte counts (immunologic response). Patients were also monitored for adverse events, laboratory abnormalities and HIV-related illnesses at week $5,8,12,16$, and 24

Notes -

\section{Risk of bias}

\begin{tabular}{lll}
\hline Bias & Authors' judgement & Support for judgement \\
\hline $\begin{array}{l}\text { Random sequence genera- } \\
\text { tion (selection bias) }\end{array}$ & Unclear risk & $\begin{array}{l}\text { Randomization was not described in detail. "In addition to their medication, } \\
\text { patients were randomized } 1: 1 \text { to receive either an El (4 modules of the THE } \\
\text { course) plus RC (El + RC) or RC alone" (pg 175) }\end{array}$ \\
\hline
\end{tabular}

\begin{tabular}{lll}
\hline $\begin{array}{l}\text { Allocation concealment } \\
\text { (selection bias) }\end{array}$ & Unclear risk & No information was provided about how allocation was handled \\
\hline $\begin{array}{l}\text { Selective reporting (re- } \\
\text { porting bias) }\end{array}$ & Unclear risk & $\begin{array}{l}\text { No protocol available; although it appears that everything was reported it is } \\
\text { difficult to determine this without a protocol }\end{array}$ \\
\hline
\end{tabular}

\begin{tabular}{lll}
\hline Other bias & Low risk & The study seems to be free of other types of bias \\
\hline $\begin{array}{l}\text { Blinding of outcome as- } \\
\text { sessment (detection bias) } \\
\begin{array}{l}\text { Adherence measure } \\
\hline\end{array}\end{array}$ & Low risk & (PRIMARY) MEMS - This is an objective measure of outcome \\
\hline
\end{tabular}

\begin{tabular}{lll}
\hline $\begin{array}{l}\text { Blinding of outcome as- } \\
\text { sessment (detection bias) } \\
\text { Patient outcome }\end{array}$ & Low risk & (PRIMARY) VIRAL LOAD - This is an objective measure of outcome \\
\hline $\begin{array}{l}\text { Blinding of participants } \\
\text { (performance bias) } \\
\text { Adherence measure }\end{array}$ & High risk & $\begin{array}{l}\text { (PRIMARY) MEMS - No mention of patient blinding. Blinding of patient/partici- } \\
\text { pant attempted, but likely that the blinding could have been broken, and the } \\
\text { outcome is likely to be influenced by lack of blinding }\end{array}$ \\
\hline
\end{tabular}

\begin{tabular}{ll}
\hline $\begin{array}{l}\text { Blinding of participants } \\
\text { (performance bias) }\end{array} \quad$ (PRIMARY) VIRAL LOAD - This is an objective measure of outcome
\end{tabular}


Rawlings 2003 (Continued)

Patient outcome

Blinding of personnel (per- Low risk $\quad$ (PRIMARY) MEMS - This is an objective measure of outcome
formance bias)

Adherence measure

Blinding of personnel (per- Low risk (PRIMARY) VIRAL LOAD - This is an objective measure of outcome

formance bias)

Patient outcome

Incomplete outcome data Unclear risk

(attrition bias)

Adherence measure

Incomplete outcome data Unclear risk

(attrition bias)

Patient outcome
(PRIMARY) MEMS - High proportion of dropouts (31 (32\%) and $23(23 \%))$ in the $\mathrm{RC}$ and control arm. Reasons provided. Missing data per outcome - not provided, unequal distribution. Possibly, this may be large enough to affect outcome

\title{
Razali 2000
}

The selected patients were randomly assigned to the study group ( $\mathrm{n}=80$ ), which received the culturally
modified family therapy (CMFT), or control group $(n=86)$, which received the behavioral family therapy
(BFT). Allocation was unblinded for treating psychiatrist and patient; outcome assessments were done
by independent, blinded psychiatrists

Participants Recently discharged patients from the University Hospital with the diagnosis of schizophrenia (DSMIV). Inclusion criteria included: at least 2 previous psychiatric admissions (including the latest admission), aged between 17 to 55 years, staying with a responsible relative who is willing to be involved in the study, stabilized for at least 4 weeks (stabilization was defined as rating of 4 or less on the Brief Psychiatric Rating Scale (BPRS) psychotic items). Exclusion criteria not specified

Interventions

The CMFT consists of a sociocultural approach of family education, drug intervention program and problem-solving skills. The sociocultural approaches to family education include explanations of the concept of schizophrenia from a cultural perspective and an attempt to correct negative attitudes toward modern treatment. The family education and drug intervention was delivered as a package. The drug intervention program includes drug counseling [from Table 1] clear instruction about dose, frequency and possible side effects, the role of carers in supervision of medication at home, and close monitoring of compliance by a drug intake check-list presented in every follow-up visit. Both groups of patients received routine prescription of medication. It should be noted that 1 psychiatrist treated the intervention group throughout the study, and a 2nd psychiatrist treated the control group throughout the study. Patients in each group were followed up on the same schedule; monthly for the first 3 months and then every 6 weeks in the next 9 months

\section{Outcomes}

\begin{abstract}
Measurement of compliance: measured at the end of 6 months and 1 year after initiation of the intervention. Medication compliance was assessed through a semi-structured interview with the carer and examination of the amount of unused medication. A home visit was made to assess unused medication "in doubtful cases". Drug compliance was measured globally as a percentage of the total prescribed drug dosage actually taken during the previous 6 months. The compliance was reported on a 6-point ordinal scale, with 1 indicating non-compliant, 2: 25\% compliant, 3: 50\% compliant, 4: 75\% compliant, 5: $90 \%$ compliant and 6: $100 \%$ compliant. $90 \%$ compliance was considered to be an ideal level Measurement of clinical health outcomes: measured at the end of 6 months and 1 year after initiation of the intervention. Frequency of symptoms exacerbation, psychosocial functioning and behavioral difficulties were measured. Symptomatic exacerbation was determined by BPRS ratings. A rating of 5 or above in one or more of the psychoticism scales indicated an exacerbation. Overall psychosocial function was rated using the Global Assessment of Function (GAF) of DSM-IV, while the Social Behavior Schedule (SBS) measured the behavioral difficulties
\end{abstract}


Razali 2000 (Continued)

Notes

\section{Risk of bias}

\begin{tabular}{|c|c|c|}
\hline Bias & Authors' judgement & Support for judgement \\
\hline $\begin{array}{l}\text { Random sequence genera- } \\
\text { tion (selection bias) }\end{array}$ & Unclear risk & $\begin{array}{l}\text { Randomization was not described in detail. "The selected patients were ran- } \\
\text { domly assigned to the study or control group" (pg 284) }\end{array}$ \\
\hline $\begin{array}{l}\text { Allocation concealment } \\
\text { (selection bias) }\end{array}$ & Unclear risk & No information was provided about how allocation was handled \\
\hline $\begin{array}{l}\text { Selective reporting (re- } \\
\text { porting bias) }\end{array}$ & Unclear risk & $\begin{array}{l}\text { No protocol available; although it appears that everything was reported it is } \\
\text { difficult to determine this without a protocol }\end{array}$ \\
\hline Other bias & Low risk & The study seems to be free of other types of bias \\
\hline $\begin{array}{l}\text { Blinding of outcome as- } \\
\text { sessment (detection bias) } \\
\text { Adherence measure }\end{array}$ & Low risk & $\begin{array}{l}\text { (PRIMARY) SEMI-STRUCTURED INTERVIEW WITH CARER - "Two independent } \\
\text { psychiatrists (UAK and MS) who were blind to the treatment assignment car- } \\
\text { ried out the assessments" (pg 285) }\end{array}$ \\
\hline $\begin{array}{l}\text { Blinding of outcome as- } \\
\text { sessment (detection bias) } \\
\text { Patient outcome }\end{array}$ & Low risk & $\begin{array}{l}\text { (PRIMARY) EXACERBATIONS, PSYCHOSOCIAL FUNCTIONING AND BEHAVIORAL } \\
\text { DIFFICULTIES - "Two independent psychiatrists (UAK and MS) who were blind } \\
\text { to the treatment assignment carried out the assessments" (pg 285) }\end{array}$ \\
\hline $\begin{array}{l}\text { Blinding of participants } \\
\text { (performance bias) } \\
\text { Adherence measure }\end{array}$ & High risk & $\begin{array}{l}\text { (PRIMARY) SEMI-STRUCTURED INTERVIEW WITH CARER - Patients could not be } \\
\text { blinded; this is a subjective measure }\end{array}$ \\
\hline $\begin{array}{l}\text { Blinding of participants } \\
\text { (performance bias) } \\
\text { Patient outcome }\end{array}$ & High risk & $\begin{array}{l}\text { (PRIMARY) EXACERBATIONS, PSYCHOSOCIAL FUNCTIONING AND BEHAVIORAL } \\
\text { DIFFICULTIES - This is a subjective measure }\end{array}$ \\
\hline $\begin{array}{l}\text { Blinding of personnel (per- } \\
\text { formance bias) } \\
\text { Adherence measure }\end{array}$ & High risk & $\begin{array}{l}\text { (PRIMARY) SEMI-STRUCTURED INTERVIEW WITH CARER - Therapists were not } \\
\text { blind to groups. "The two research psychiatrists treated the patients separate- } \\
\text { ly. The same psychiatrist throughout the study treated each group of patients. } \\
\text { They were followed-up on the same schedule; monthly for the first } 3 \text { months } \\
\text { and then every } 6 \text { weeks in the next } 9 \text { months. SMR dealt with the study group } \\
\text { while CIH treated the control group" (pg 285) }\end{array}$ \\
\hline
\end{tabular}

Blinding of personnel (per- High risk formance bias)

Patient outcome
(PRIMARY) EXACERBATIONS, PSYCHOSOCIAL FUNCTIONING AND BEHAVIORAL DIFFICULTIES - Therapists were not blind to groups. "The two research psychiatrists treated the patients separately. The same psychiatrist throughout the study treated each group of patients. They were followed-up on the same schedule; monthly for the first 3 months and then every 6 weeks in the next 9 months. SMR dealt with the study group while $\mathrm{CIH}$ treated the control group" (pg 285)

Incomplete outcome data High risk

(attrition bias)

(PRIMARY) SEMI-STRUCTURED INTERVIEW WITH CARER - There is a greater dropout rate in the control group. Authors address this in the discussion. "It could be argued that the significantly greater number of drop-outs in the control group would bias the results but the bias would probably be to produce worse outcomes in the study group. The most likely reason for a drop out is a poor outcome" (pg 287)

Incomplete outcome data High risk
(attrition bias)
Patient outcome

(PRIMARY) EXACERBATIONS, PSYCHOSOCIAL FUNCTIONING AND BEHAVIORAL DIFFICULTIES - There is a greater dropout rate in control group. The authors address this in the discussion. "It could be argued that the significantly greater 

program $(n=106)$, or usual care through the medical provider of the HIV-sero-positive partner $(n=109)$. A randomization table was constructed from a random numbers list and stratified by couple type. Randomization was conducted by the study's project director while assessors and all other personnel (except for intervention facilitators) were blind to study arm assignment throughout the trial

Participants

Patients were eligible if they were an HIV-sero-discordant couple (self report) with a relationship duration of 6 months or more, and both partners were English-speaking adults (over 18 years of age). The HIV-sero-positive partner needed to be in primary care and taking antiretroviral therapy (ART) for at least 1 month. Couples meeting these criteria were scheduled for an in-person main screening appointment where the couple's relationship status was confirmed by independently asking each partner when and how they met, whether they considered themselves to be in a 'committed' relationship, and whether they expected to be in this relationship for at least another year. Couples returned 2 weeks later and were eligible for the study if less than $80 \%$ of prescribed doses were taken within specified time windows during the 2-week Medication Event Monitoring System (MEMS) observation period

Interventions

The intervention, a 4-session couple-focused adherence program, aimed to improve patients' adherence to HIV/AIDS medical care regimens by fostering the support of their partners; in addition, to help couples address their issues of sex and intimacy. The intervention was individually administered to each couple by a nurse practitioner through 4 45- to 60-minute sessions held over 5 weeks. The session content included structured discussions and instruction, as well as specific problem-solving and couple-communication exercises. Key components included education about the importance of adherence to avoid viral resistance and maintain health, identifying patterns of non-adherence, developing communication and problem-solving strategies to overcome adherence barriers, optimizing partner support, and building confidence in the couple for achieving and maintaining improved adherence. Standard care patients received attention to adherence-related issues from a multidisciplinary treatment team. Dosing, common side effects, and the importance of adherence to the regimen as prescribed were discussed. Patients were instructed to contact the clinic to speak with either their medical provider or a nurse if they had difficulties with the regimen. Follow-up with the patient's medical provider usually occurred within 2 to 4 weeks after initiating a new regimen. Any adherence problems were assessed in order to find the underlying causes and the appropriate manner to address them

Outcomes The primary measure of adherence was the MEMS cap. MEMS data were downloaded into computer software to calculate adherence summary scores for the percentage of prescribed doses taken (without regard to timing) and the percentage of prescribed doses taken within specified time windows (e.g. for twice-a-day regimens, intended dosage times were set 12 hours apart, with +- 2-hour windows around each intended dosage time). The adherence summary scores were adjusted through participant self reports of errors in MEMS use. Viral HIV RNA load and CD4 cell count assays at baseline and at week 8 were used as clinical measures. If a blood sample was not given, the patient's medical chart was examined for clinical outcomes within appropriate time intervals. If neither a blood sample nor medical chart data were provided, self reported biomarkers were used

\begin{tabular}{lll}
\hline Notes & - \\
\hline Risk of bias & \\
\hline Bias & Authors' judgement & Support for judgement \\
\hline $\begin{array}{l}\text { Random sequence genera- } \\
\text { tion (selection bias) }\end{array}$ & Low risk & $\begin{array}{l}\text { The study explicitly refers to a random table. "A randomization table was con- } \\
\text { structed from a random numbers list and stratified by couple type." (pg 809) }\end{array}$ \\
\hline
\end{tabular}


Remien 2005 (Continued)

$\begin{array}{ll}\begin{array}{l}\text { Allocation concealment } \\ \text { (selection bias) }\end{array} & \text { Unclear risk }\end{array} \quad \begin{aligned} & \text { Randomization was not centralized but done by study director. Although as- } \\ & \text { sessors were blinded, it is not clear who were the recruiters and if they were } \\ & \text { blinded. "Each partner of eligible couples was separately administered the } \\ & \text { baseline interview prior to randomization." (pg 809) }\end{aligned}$

\begin{tabular}{lll}
\hline $\begin{array}{l}\text { Selective reporting (re- } \\
\text { porting bias) }\end{array}$ & Unclear risk & $\begin{array}{l}\text { No protocol available; although it appears that everything was reported it is } \\
\text { difficult to determine this without a protocol }\end{array}$ \\
\hline Other bias & Low risk & The study seems to be free of other types of bias \\
\hline $\begin{array}{l}\text { Blinding of outcome as- } \\
\begin{array}{l}\text { sessment (detection bias) } \\
\text { Adherence measure }\end{array}\end{array}$ & Low risk & $\begin{array}{l}\text { (PRIMARY) MEMS - Assessors and all other personnel (except for intervention } \\
\text { facilitators) were blind to study arm assignment throughout the trial (pg 809) }\end{array}$
\end{tabular}

\begin{tabular}{|c|c|c|}
\hline $\begin{array}{l}\text { Blinding of outcome as- } \\
\text { sessment (detection bias) } \\
\text { Patient outcome }\end{array}$ & Low risk & $\begin{array}{l}\text { (PRIMARY) VIRAL LOAD - This is an objective measure and assessors were blind- } \\
\text { ed. "Assessors and all other personnel were blind to study arm assignment } \\
\text { throughout the trial" (pg 809) }\end{array}$ \\
\hline
\end{tabular}

$\begin{array}{ll}\begin{array}{l}\text { Blinding of participants } \\ \text { (performance bias) }\end{array} & \text { High risk } \\ \text { Adherence measure } & \begin{array}{l}\text { (PRIMARY) MEMS - Patient could not be blinded to the adherence intervention, } \\ \text { and likely they are aware of the purpose of the MEMS cap }\end{array}\end{array}$

\begin{tabular}{ll} 
Adherence measure & \\
\hline $\begin{array}{l}\text { Blinding of participants } \\
\text { (performance bias) }\end{array}$ & (PRIMARY) VIRAL LOAD - This is an objective measure of outcome
\end{tabular}

Patient outcome

\begin{tabular}{ll}
\hline $\begin{array}{l}\text { Blinding of personnel (per- } \quad \text { Low risk } \\
\text { formance bias) }\end{array}$ & (PRIMARY) MEMS - Assessors and all other personnel (except for intervention \\
Adherence measure & facilitators) were blind to study arm assignment throughout the trial (pg 809)
\end{tabular}

\begin{tabular}{|c|c|c|}
\hline $\begin{array}{l}\text { Blinding of personnel (per- } \\
\text { formance bias) } \\
\text { Patient outcome }\end{array}$ & Low risk & $\begin{array}{l}\text { (PRIMARY) VIRAL LOAD - This is an objective measure and assessors were blind- } \\
\text { ed. "Assessors and all other personnel were blind to study arm assignment } \\
\text { throughout the trial" (pg 809) }\end{array}$ \\
\hline $\begin{array}{l}\text { Incomplete outcome data } \\
\text { (attrition bias) } \\
\text { Adherence measure }\end{array}$ & Low risk & $\begin{array}{l}\text { (PRIMARY) MEMS - Dropout rates are similar between study arms at } 8 \text { weeks } \\
\text { (primary outcome assessment) }\end{array}$ \\
\hline $\begin{array}{l}\text { Incomplete outcome data } \\
\text { (attrition bias) } \\
\text { Patient outcome }\end{array}$ & High risk & $\begin{array}{l}\text { (PRIMARY) VIRAL LOAD - A blood sample could not be taken for dropouts at } 8 \\
\text { weeks (see snapshot figure 1) We cannot know if the others did. Self reporting } \\
\text { of biomarkers could have been biased. Reasons for missing data not reported }\end{array}$ \\
\hline
\end{tabular}

\section{Rickles 2005}

$\begin{array}{ll}\text { Methods } & \text { Randomization involved the researcher preparing } 10 \text { pieces of paper with sequential numbers for each } \\ \text { participating pharmacist at the site. Each of the } 8 \text { pharmacies had a different cluster of numbers. When } \\ \text { a patient was enrolled from a site, the researcher would randomly select a number out of the envelope. } \\ \text { Selection of an odd or even number meant the patient was assigned to the control group or the inter- } \\ \text { vention group, respectively. A total of } 63 \text { patients were randomized to either the intervention group ( } \mathrm{n} \\ =31 \text { ) or the control group }(\mathrm{n}=32)\end{array}$

Participants

Patients were 18 years of age or older, willing to pick up their medication from a study pharmacy during the next 4 months, having no hearing impairment, having no antidepressant use in the last 4 months and planning to be in the local area in the next 4 months. Patients excluded from the study were those with a Beck Depression Inventory Second Edition (BDI-II) score below 16, requiring a translator, preg- 
Rickles 2005 (Continued)

nant or nursing, receiving medications for a psychotic or bipolar disorder, and/or having physical conditions requiring additional caution with their antidepressant

Interventions

Patients in the intervention group received 3 monthly calls from the pharmacists providing pharmacist-guided education and monitoring (PGEM). On average, the first telephone call took place within the first 3 weeks of the patient picking up their initial antidepressant prescription from the pharmacy and took 19 minutes to complete. During the first call, the pharmacist assessed the patient's antidepressant knowledge and beliefs and clarified or explained issues that were not understood by the patients. Pharmacists rated the severity of their concerns and made suggestions on how to handle adverse effects, difficulties remembering or paying for medications, and other concerns. Also, the pharmacists accessed the patient's treatment goals or areas in which they hoped the medication would help, and how the medication was being used during the week before the telephone call. Pharmacists were expected to follow-up on any indication of medication non-adherence, inquire on why the doses were missed and make recommendations to increase medication compliance. The second and third telephone calls took place approximately 1 and 2 months after the initial call and on average, required 12 and 11 minutes to complete. During these calls, study pharmacists used the monitoring tool to guide their follow-up on any concerns identified in earlier calls and made new recommendations as needed. Pharmacists reviewed current adherence, whether any new adverse effects or concerns had developed, and evaluated the patient's progress in their medication goals. Patients in the control group received 3 monthly calls from the pharmacists providing usual pharmacist's care - defined as that education and monitoring which pharmacists may typically provide patients at the study pharmacies

Outcomes Medication adherence was recorded after the first 3 months after enrollment and again after another 3 months. The number of missed doses was calculated by multiplying the number of prescribed doses per day times the number of days late between refills for the first 3-month period and second 3month period. Results were multiplied by 100 to yield the percentage of missed doses for each period. The pharmacy records used for this method of compliance measurement were validated in 2 ways. First, the pharmacy records were compared with prescription insurance claims for 49 of 63 patients for whom claims data were available from the participating managed care organization. Inconsistencies were resolved by the research pharmacist after case-by-case analysis. Second, the patient's self reported antidepressant adherence was measured as part of the outcomes survey, "In the past 7 days ending yesterday, how many times did you miss taking a pill?" The BDI-Il was used to measure depression symptoms

Notes

While pharmacist-guided education and monitoring had no significant impact on adherence at 3 months, a per-protocol analysis revealed significantly improved adherence at 6 months for those who completed the study. When the 3 patients who withdrew from the study were included in the analysis, the difference did not reach significance at the 0.05 level

\section{Risk of bias}

Bias Authors' judgement Support for judgement

Random sequence genera- Low risk tion (selection bias)

Randomization involved the researcher preparing 10 pieces of paper with sequential numbers for each participating pharmacist at the site. Each of the 8 pharmacies had a different cluster of numbers; the first site had numbers beginning with 100 , the second site had numbers with 200 , and so forth. Since the first site had 3 participating study pharmacists, 30 slips of paper numbered from 100 to 130 were prepared and placed into an envelope. When a patient was enrolled from that site, the researcher would randomly select a number out of the envelope. Selection of an odd or even number meant the patient was assigned to the usual care or PGEM group, respectively (pg 346)

\begin{tabular}{|c|c|c|}
\hline $\begin{array}{l}\text { Allocation concealment } \\
\text { (selection bias) }\end{array}$ & Unclear risk & $\begin{array}{l}\text { The study does not specify sequentially numbered, opaque, sealed envelopes. } \\
\text { "Researcher: - Contacts patient to confirm eligibility and answers questions } \\
\text { - Notifies pharmacist of eligible patients randomized to pharmacist-guided } \\
\text { education and monitoring." (pg 347) }\end{array}$ \\
\hline
\end{tabular}


Rickles 2005 (Continued)

Selective reporting (re- Unclear risk No protocol available; although it appears that everything was reported it is porting bias)

difficult to determine this without a protocol

Other bias Unclear risk

States that a "...fifth study limitation pertains to randomization procedures. Since we randomized by patient and not by site, patients in the usual care group may have been exposed to improved antidepressant education and monitoring when they returned for refills. Thus, it is possible that the usual care group received enhanced care by study pharmacists." "Indeed, the invitation to participate in this study may have biased results in several ways due to the Hawthorne effect. Both study groups may have reported greater clinical improvement since they wanted to meet the expectations of interested pharmacists (especially since patients were unblinded to group assignment). This phenomenon may explain why study groups had greater antidepressant adherence than has been reported in the literature" (pg 352)

Blinding of outcome as- High risk sessment (detection bias)

Adherence measure
(PRIMARY) PHARMACY RECORD - The author noted that the researcher was not blinded to study group

(PRIMARY) DEPRESSION SYMPTOMS - BDI-II - Procedures are unclear as to how the $\mathrm{BDI}-$ II was returned to researchers

sessment (detection bias)

Unclear risk

Patient outcome

$\begin{array}{ll}\begin{array}{l}\text { Blinding of participants } \\ \text { (performance bias) }\end{array} & \text { High risk } \\ \text { Adherence measure } & \text { not blinded to study group }\end{array}$

Adherence measure

High risk

Blinding of participants

(performance bias)

Patient outcome
(PRIMARY) DEPRESSION SYMPTOMS - BDI-II - intent of BDI-II would be obvious to patients. Any blinding could have been broken

Blinding of personnel (per- High risk

formance bias)

(PRIMARY) PHARMACY RECORD - The author noted that the researcher was not

Adherence measure blinded to study group

Blinding of personnel (per- Unclear risk

formance bias)

(PRIMARY) DEPRESSION SYMPTOMS - BDI-II - Procedures are unclear as to how

Patient outcome the $\mathrm{BDI}-\mathrm{II}$ was returned to researchers

\begin{tabular}{lll}
$\begin{array}{l}\text { Incomplete outcome data } \\
\text { (attrition bias) } \\
\text { Adherence measure }\end{array}$ & High risk & $\begin{array}{l}\text { (PRIMARY) PHARMACY RECORD - inclusion of the } 3 \text { dropouts reversed the } \\
\text { results: "...we performed an intention-to-treat analysis that includes the } \\
\text { three patient dropouts, this 6-month difference was not significant (data not } \\
\text { shown)." }\end{array}$ \\
\hline $\begin{array}{l}\text { Incomplete outcome data } \begin{array}{l}\text { (attrition bias) } \\
\text { Patient outcome }\end{array} \\
\text { Unclear risk }\end{array} \quad \begin{array}{l}\text { (PRIMARY) DEPRESSION SYMPTOMS - BDI-II - ITT analysis reversed results to } \\
\text { not significant improvement in case of at least } 1 \text { outcome measure - adher- } \\
\text { ence. It is not known whether the incomplete data had any effect in the case of } \\
\text { depression scores. (See table 2, pg 351) }\end{array}$
\end{tabular}

Riesen 2008

\begin{tabular}{ll}
\hline Methods & Randomized controlled trial \\
\hline Participants & The study location was Switzerland \\
& $\begin{array}{l}527 \text { participants were randomized to the intervention group and } 601 \text { participants were randomized to } \\
\text { the control group }\end{array}$ \\
\hline
\end{tabular}


Riesen 2008 (Continued)

The inclusion criteria were patients over 18 years attending primary care physician practices for treatment of primary hypercholesterolemia with a 10 -year $\mathrm{CHD}$ risk $>20 \%$, CHD or other atherosclerotic disease, either statin naïve or on an accepted starting dose of lipid-lowering medication, which had proved ineffective in reaching the target level of LDL-C for that dose. Statin-naive patients (with an LDL$C>3.5 \mathrm{mmol} / \mathrm{L}$ fasting level) were required to complete dietary counseling before entering the study. Patients who switched from accepted starting doses of other lipid-lowering medication (with an LDL-C $>3.1 \mathrm{mmol} / \mathrm{L}$ fasting level) were directly enrolled in the study. Another inclusion criterion was a fasting triglyceride (TG) level of $94.52 \mathrm{mmol} / \mathrm{L}$

The exclusion criteria were heterozygous or homozygous familial hypercholesterolemia, type III hyperlipoproteinemia (familial dysbetalipoproteinemia), or secondary hypercholesterolemia; hypersensitivity reactions or serious adverse effects (e.g. myopathy) in relation to other statins were also excluded, pregnant or breastfeeding women; women of childbearing potential were asked to use adequate contraception during the study; unstable cardiovascular disease, uncontrolled diabetes, active liver disease, renal impairment as defined by a serum creatinine level $>220 \mathrm{mmol} / \mathrm{L}$, any medical condition requiring cyclosporine therapy, and a history of alcohol and/or drug abuse

Interventions

Intervention: 10 MG PLUS

Patients received a daily oral treatment with rosuvastatin and access to compliance enhancement tools (10 mg Plus group) for 24 weeks. Patients were assessed at week 4 and at week 12 to review fasting levels of TC, LDL-C, HDL-C, and triglycerides. For patients not achieving the 1998 European target for LDL-C at week 12, the daily dose of rosuvastatin was increased to $20 \mathrm{mg}$ for the remainder of the study. Patients in the $10 \mathrm{mg}$ Plus group received a starter pack containing a videotape and educational leaflets concerning their condition. These patients also received newsletters at regular intervals and had access to both a telephone helpline and an Internet website, all designed to reinforce the initial message in the starter pack

Control: $10 \mathrm{MG}$

Patients received a daily oral treatment with rosuvastatin alone (10 mg group) for 24 weeks. Patients were assessed at week 4 and at week 12 to review fasting levels of TC, LDL-C, HDL-C, and triglycerides. For patients not achieving the 1998 European target for LDL-C at week 12 the daily dose of rosuvastatin was increased to $20 \mathrm{mg}$ for the remainder of the study

Outcomes

The measures of adherence was the difference between dispensed and returned tablets in comparison with the number of days between visits. Patients were asked to return unused medication to the study investigator at week 12 and week 24.

The patient outcomes were the number and percentage of patients in both treatment groups who reached the 1998 European goal for LDL-C $(<3.0 \mathrm{mmol} / \mathrm{L})$ after 24 weeks of therapy; the number and percentage of patients within the 1998 European goal for LDL-C at week 12, the number and percentage of patients within the 1998 European goal for TC $(<5.0 \mathrm{mmol} / \mathrm{l})$ at week 12 and week 24 , and the number and percentage of patients within the 2003 European goal for LDL-C $(<2.5 \mathrm{mmol} / \mathrm{L})$ and for TC $(<4.5 \mathrm{mmol} / \mathrm{L})$ at week 12 and week 24 . Other secondary efficacy endpoints were the number of patients with a dose increase to $20 \mathrm{mg}$ rosuvastatin at week 12; and the percentage change in LDL-C, TC, HDL-C, and TG between baseline and week 24

Notes

Non-compliant with blood test have been excluded, so that adherence even without intervention is very high $97 \%$

\section{Risk of bias}

Bias Authors' judgement Support for judgement

Random sequence genera- Unclear risk tion (selection bias)
Randomization was not described in detail. "This was a cluster-randomised, multicentre, open label, parallel group study of 24 weeks' duration and conducted throughout Switzerland. A cluster randomisation procedure was used and all patients in each centre were assigned to the same treatment group." (pg 421) 
Riesen 2008 (Continued)

$\begin{aligned} & \text { Allocation concealment } \quad \text { Unclear risk No information was provided about how allocation was handled } \\ & \text { (selection bias) }\end{aligned}$

\begin{tabular}{|c|c|c|}
\hline $\begin{array}{l}\text { Selective reporting (re- } \\
\text { porting bias) }\end{array}$ & Unclear risk & $\begin{array}{l}\text { No protocol available; although it appears that everything was reported it is } \\
\text { difficult to determine this without a protocol }\end{array}$ \\
\hline Other bias & Low risk & The study seems to be free of other types of bias \\
\hline $\begin{array}{l}\text { Blinding of outcome as- } \\
\text { sessment (detection bias) } \\
\text { Adherence measure }\end{array}$ & Unclear risk & $\begin{array}{l}\text { (PRIMARY) PILL COUNT - Patients were asked to return all unused rosuvastatin } \\
\text { tablets and containers to the investigator at week } 12 \text { and week } 24 \text {. The pa- } \\
\text { tient's compliance was determined by the difference between the dispensed } \\
\text { and the returned tablets in comparison with the number of days between the } \\
\text { visits. No mention of blinding the outcome assessors }\end{array}$ \\
\hline
\end{tabular}

\begin{tabular}{|c|c|c|}
\hline $\begin{array}{l}\text { Blinding of outcome as- } \\
\text { sessment (detection bias) } \\
\text { Patient outcome }\end{array}$ & Low risk & (PRIMARY) BLOOD TESTS - This is an objective measure of outcome \\
\hline $\begin{array}{l}\text { Blinding of participants } \\
\text { (performance bias) } \\
\text { Adherence measure }\end{array}$ & Unclear risk & $\begin{array}{l}\text { (PRIMARY) PILL COUNT - The results may have been reliable if it was conduct- } \\
\text { ed in an unannounced manner. If participants knew that their pill were being } \\
\text { counted, then they could take away some drugs before returning the contain- } \\
\text { ers. Insufficient information about the how much participants knew about this } \\
\text { outcome measure }\end{array}$ \\
\hline
\end{tabular}

$\begin{aligned} & \text { Blinding of participants } \quad \text { Low risk } \\ & \text { (performance bias) } \\ & \text { Patient outcome }\end{aligned}$

Patient outcome

(PRIMARY) PILL COUNT - No information on blinding given. There is insufficient information to permit judgment of 'Low risk' or 'High risk'

Blinding of personnel (per- Unclear risk formance bias)

Adherence measure

Blinding of personnel (per- Low risk

(PRIMARY) BLOOD TESTS - This is an objective measure of outcome

formance bias)

Patient outcome

Incomplete outcome data Unclear risk

(attrition bias)

Adherence measure

(PRIMARY) PILL COUNT - information in the study about missing data is too confusing to make a judgment. There are different numbers in different parts of the paper, and it is unclear just how many missing data there are

Incomplete outcome data Unclear risk (attrition bias)

Patient outcome

Rosen 2007

\begin{tabular}{ll}
\hline Methods & Randomized controlled trial \\
\hline Participants & The study location was HIV clinics in the greater Hartford, Connecticut, area, USA \\
& 28 participants were randomized to the intervention group and 28 participants were randomized to the \\
control group & \\
The inclusion criteria were: prescribed antiretroviral medication, able and willing to use MEMS-compat- \\
ible bottles, had ever used an illicit drug weekly for 1 year, and had a score on the Mini Mental Status \\
Exam 22 of 23 or higher
\end{tabular}


Rosen 2007 (Continued)

Interventions
Intervention: CONTINGENCY MANAGEMENT (CM)

The intervention group participants were provided with 16 weeks of weekly CM-based counseling followed by 16 additional weeks of data collection and adherence feedback to providers followed by 16 additional weeks of data collection and adherence feedback to providers. The CM intervention provided by bachelor's level staff involved review of data generated by electronic pill-bottle caps that record bottle opening (MEMS) and brief substance abuse counseling. CM participants were reinforced for MEMS measured adherence with drawings from a bowl for prizes and bonus drawings for consecutive weeks of perfect adherence

\section{Control: SUPPORTIVE COUNSELING CONDITION}

The supportive counseling condition was an attention control condition. Participants were encouraged to meet with counselors weekly. In these sessions, participants were asked about their adherence, and offered support for their efforts to improve adherence. However, the counselors did not review MEMS data with the participants or conduct urine toxicology testing. There was an initial review of self reported substance abuse and referral to available treatment. In addition, providers were sent monthly letters stating the participant's self reported adherence. The same staff members delivered both interventions

\section{Outcomes}

The measures of adherence were MicroElectronic Monitoring Systems (MEMS) and self reported adherence. MEMS are electronic pill-bottle caps that record bottle opening. The data were collected at baseline and every 4 weeks thereafter for a total of 9 assessments. The MEMS recorded the date and time the pill bottle was opened. Participants in were also directly asked each month to report how many times they had opened their pill bottles without taking their medication. To test the possibility that the CM intervention was associated with opening pill bottles to obtain reinforcement but not taking the medications in the pill bottle, blood samples were drawn at week 4 to assess antiretroviral levels. Participants were not told that assessment of antiretroviral levels was the purpose of these blood draws. Samples were processed at a commercial laboratory

The patient outcomes were viral load and side effects. Viral load was measured from drawing blood samples at baseline, 16 weeks, and 32 weeks. The standard assay was run using the Roche Cobas Amplicor HIV-1 Monitor Test, Version 1.5. When the laboratory switched to an ultra-sensitive assay sensitive to 50 HIV-RNA copies per milliliter, viral loads below 400 were scored as 399 to be consistent with the earlier assay not having been ultra-sensitive. Side effects was assessed using a questionnaire used by the AIDS Clinical Trial Group every 4 weeks. This questionnaire elicits ratings of 20 potential side effects rated on a Likert scale from 0 ("I do not have this symptom") to 4 ("bothers me a lot")

Notes

\section{Risk of bias}

\section{Bias \\ Authors' judgement Support for judgement}

Random sequence genera- Unclear risk tion (selection bias)
No information about the way randomization was performed is given: "Fiftysix participants with histories of illicit substance use who were prescribed antiretroviral medication but evidenced suboptimal adherence during a baseline assessment were randomly assigned to 16 weeks of weekly CM-based counseling or supportive counseling, followed by 16 additional weeks of data collection and adherence feedback to providers." (pg 30 "Randomization, with baseline adherence as a stratifying variable, was used to maximize the likelihood that baseline adherence would not differ between the two groups." (pg 31)

\begin{tabular}{|c|c|c|}
\hline $\begin{array}{l}\text { Allocation concealment } \\
\text { (selection bias) }\end{array}$ & Unclear risk & $\begin{array}{l}\text { No information about the allocation concealment is provided: No information } \\
\text { about the way randomization was performed is given: "Fifty-six participants } \\
\text { with histories of illicit substance use who were prescribed antiretroviral med- } \\
\text { ication but evidenced suboptimal adherence during a baseline assessment } \\
\text { were randomly assigned to } 16 \text { weeks of weekly CM-based counseling or sup- } \\
\text { portive counseling, followed by } 16 \text { additional weeks of data collection and ad- } \\
\text { herence feedback to providers." (pg } 30 \text { "Randomization, with baseline adher- }\end{array}$ \\
\hline
\end{tabular}


Rosen 2007 (Continued)

ence as a stratifying variable, was used to maximize the likelihood that baseline adherence would not differ between the two groups." (pg 31)

Selective reporting (re- Unclear risk
porting bias)

No reporting of CD4 cell count at 16 and 32 weeks: "The CD4 counts were reported by providers." (pg 33) Who are the providers? For the level of antiretroviral therapy in blood, they randomly selected only 4 people. In the results, they only state that "...all four participants had plasma levels consistent with having actually taken the medication, as determined by an infectious disease specialist." (pg 36). They could provide more details of the results

\begin{tabular}{lll}
\hline Other bias & Unclear risk & Insufficient information to assess whether an important risk of bias exists \\
\hline $\begin{array}{l}\text { Blinding of outcome as- } \\
\text { sessment (detection bias) } \\
\text { Adherence measure }\end{array}$ & Low risk & (PRIMARY) MEMS - This is an objective measure of outcome \\
\end{tabular}

\begin{tabular}{lll}
\hline $\begin{array}{l}\text { Blinding of outcome as- } \\
\text { sessment (detection bias) } \\
\text { Patient outcome }\end{array}$ & Low risk & (PRIMARY) VIRAL LOAD - This is an objective measure of outcome \\
\hline $\begin{array}{l}\text { Blinding of participants } \\
\text { (performance bias) } \\
\text { Adherence measure }\end{array}$ & High risk & $\begin{array}{l}\text { (PRIMARY) MEMS - Although this is typically considered objective data, MEMS } \\
\text { activity was tied to rewards thus patients could be opening the bottle solely to } \\
\text { obtain the reward. Patients were also warned that a physical measure would } \\
\text { be used to back up MEMS data }\end{array}$
\end{tabular}

Blinding of participants Low risk $\quad$ (PRIMARY) VIRAL LOAD - This is an objective measure of outcome
(performance bias)

Patient outcome

Blinding of personnel (per- Low risk

formance bias)

(PRIMARY) MEMS - This is an objective measure of outcome

Adherence measure

Blinding of personnel (per- Low risk
formance bias)
Patient outcome

\begin{tabular}{ll}
\hline $\begin{array}{l}\text { Incomplete outcome data } \\
\text { (attrition bias) }\end{array}$ & Low risk \\
Adherence measure & \\
\hline $\begin{array}{l}\text { Incomplete outcome data } \\
\text { (attrition bias) }\end{array}$ & Low risk \\
Patient outcome & (PRIMARY) VIRAL LOAD - Similar attrition numbers across both groups \\
\hline
\end{tabular}

Rubak 2011

\begin{tabular}{ll}
\hline Methods & Randomized controlled trial \\
\hline Participants & The study location was Denmark \\
& $\begin{array}{l}37 \text { practices and } 307 \text { participants were randomized to the intervention group and } 41 \text { practices and } 321 \\
\text { participants were randomized to the control group }\end{array}$
\end{tabular}

The inclusion criteria were 40- to 69-year-old people with screen-detected type 2 diabetes. 
Rubak 2011 (Continued)

The exclusion criteria were contraindications or intolerance to study medication; a history of alcoholism, drug abuse, psychosis, or other emotional problems likely to invalidate informed consent or adherence to treatment; malignant disease with a poor prognosis; pregnant or lactating

Interventions Intervention: MOTIVATIONAL INTERVIEWING

The courses in "motivational interviewing" (MI) for the GPs in the I-group were conducted by a trained teacher introducing a manual which together with "Motivational interviewing, preparing people to change addictive behaviour" constituted the theoretical part of the course curriculum. The intervention group was coached in the key points of MI. The training also included the use of specific skills, e.g. empowerment, ambivalence, the decisional balance schedule, the visual analog scale, stage of change, and reflective listening, all of which are described in detail in the book MI. The intervention group courses consisted of a $1 \frac{1}{2}$-day training sessions with a half-day follow-up twice during the first year. None of the GPs in intervention and control group had previously participated in an MI course. All GPs in the intervention and the control group participated in the same half-day course on intensive treatment of type 2 diabetes. During these diabetes training sessions, it was stressed that GPs should act as counselors for the patients, allowing treatment decisions to be based on mutual understanding between the patient and the GP. In Denmark, GPs' consultation encounters average 15 minutes and the County Health Insurance has agreed to one longer preventive consultation encounter of 45 minutes per patient. In this study the County Health Insurance agreed to allow the GPs in the intervention and control group to undertake 3 consultations of 45 minutes per patient, in which the intervention group could use MI

Control: CONTROL

None of the GPs in the control group had previously participated in an MI course. All GPs in the control group participated in the same half-day course on intensive treatment of type 2 diabetes. During these diabetes training sessions, it was stressed that GPs should act as counselors for the patients, allowing treatment decisions to be based on mutual understanding between the patient and the GP. In Denmark, GPs' consultation encounters average 15 minutes and the County Health Insurance has agreed to one longer preventive consultation encounter of 45 minutes per patient. In this study the County Health Insurance agreed to allow the GPs in the control group to undertake 3 consultations of 45 minutes per patient

Outcomes The measures of adherence were based on the number of prescriptions cashed in at the pharmacy by the patient, drawn from the National Health Service Registry

The patient outcomes were data obtained at baseline and at the 1-year follow-up. Outcomes included a risk profile that included $\mathrm{HbA1c}$, analyzed using a BioRad Variant, and serum cholesterol/HDL-cholesterol/triglycerides analyzed using a Hitachi 912. LDL-cholesterol was calculated using Fridewald's formula. All blood samples were analyzed according to the Danish quality assurance for laboratories. $\mathrm{BMI}$ and blood pressure (systolic and diastolic) was measured at rest at the GP's surgery. The number of encounters and blood samples was obtained from register data files from the National Health Service Registry. Data on smoking and exercise in leisure time and at work were obtained from patient questionnaires. The questions on physical activity had previously been validated in the "International Physical Activity Questionnaire (IPAQ)", the questions on smoking had previously been validated in the "Summary of Diabetes Self Care Activities" (SDSCA) questionnaire. The questionnaires were designed and processed in Teleform. This study included the "intermediate endpoints" and "process-ofcare endpoints" from the ADDITION trial

\begin{tabular}{lll}
\hline Notes & - & \\
\hline Risk of bias & Authors' judgement & Support for judgement \\
\hline Bias & Low risk & $\begin{array}{l}\text { "This study included practices/GPs from the intensive arm of ADDITION Den- } \\
\text { mark from two counties in DK (Figure 1) randomized by the project manager } \\
\text { using the method " drawing lots " into an intervention group (I-group) com- } \\
\text { pandom sequence genera- } \\
\text { prion (selection bias) } \\
\text { group) of GPs who received no formal training in MI. Randomization was strati- } \\
\text { fied by county, size of practices, and by numbers of full-time GPs." (pg 93) }\end{array}$ \\
\hline
\end{tabular}


Rubak 2011 (Continued)

$\begin{array}{ll}\begin{array}{l}\text { Allocation concealment } \\ \text { (selection bias) }\end{array} & \text { Unclear risk } \\ & \text { included practices/GPs from the intensive arm of ADDITION Denmark from } \\ \text { two counties in DK (Figure 1) randomized by the project manager using the } & \text { method " drawing lots " into an intervention group (I-group) comprising GPs } \\ \text { who completed an MI training course and a control group (C-group) of GPs } \\ \text { who received no formal training in MI. Randomization was stratified by county, } \\ \text { size of practices, and by numbers of full-time GPs." (pg 93) }\end{array}$

\begin{tabular}{|c|c|c|}
\hline $\begin{array}{l}\text { Selective reporting (re- } \\
\text { porting bias) }\end{array}$ & Unclear risk & $\begin{array}{l}\text { The study on which this study is based (ADDITION) reports more outcomes and } \\
\text { measures more outcomes than this study }\end{array}$ \\
\hline Other bias & Low risk & The study seems to be free of other types of bias \\
\hline $\begin{array}{l}\text { Blinding of outcome as- } \\
\text { sessment (detection bias) } \\
\text { Adherence measure }\end{array}$ & Low risk & $\begin{array}{l}\text { (PRIMARY) PHARMACY REFILL DATA - No information about blinding of person- } \\
\text { nel who collected these data. However, this is an objective measure of adher- } \\
\text { ence; numbers drawn from national health service registry }\end{array}$ \\
\hline
\end{tabular}

\begin{tabular}{lll}
\hline $\begin{array}{l}\text { Blinding of outcome as- } \\
\text { sessment (detection bias) } \\
\text { Patient outcome }\end{array}$ & Low risk & $\begin{array}{l}\text { (PRIMARY) RISK PROFILE - No mention of blinding but objective outcomes } \\
\text { should not be influenced by blinding }\end{array}$ \\
\hline $\begin{array}{l}\text { Blinding of participants } \\
\text { (performance bias) }\end{array}$ & Low risk & $\begin{array}{l}\text { (PRIMARY) PHARMACY REFILL DATA - No information about blinding of pa- } \\
\text { tients. However, this is an objective measure of adherence; numbers drawn } \\
\text { from national health service registry }\end{array}$ \\
\hline
\end{tabular}

\begin{tabular}{ll}
\hline $\begin{array}{l}\text { Blinding of participants } \\
\text { (performance bias) }\end{array}$ & Low risk \\
$\begin{array}{ll}\text { Patient outcome } \\
\text { Blinding of personnel (per- }\end{array}$ & $\begin{array}{l}\text { (PRIMARY) RISK PROFILE - No mention of blinding but objective outcomes } \\
\text { should not be influenced by blinding }\end{array}$ \\
$\begin{array}{l}\text { formance bias) } \\
\text { Adherence measure }\end{array}$ & $\begin{array}{l}\text { (PRIMARY) PHARMACY REFILL DATA - No information on blinding given. There } \\
\text { is insufficient information to permit judgment of 'Low risk' or 'High risk' }\end{array}$ \\
\hline
\end{tabular}

\begin{tabular}{|c|c|c|}
\hline $\begin{array}{l}\text { Blinding of personnel (per- } \\
\text { formance bias) } \\
\text { Patient outcome }\end{array}$ & Low risk & $\begin{array}{l}\text { (PRIMARY) RISK PROFILE - No mention of blinding but objective outcomes } \\
\text { should not be influenced by blinding }\end{array}$ \\
\hline $\begin{array}{l}\text { Incomplete outcome data } \\
\text { (attrition bias) } \\
\text { Adherence measure }\end{array}$ & Low risk & $\begin{array}{l}\text { (PRIMARY) PHARMACY REFILL DATA - No missing data: "acquisition of a 100\% } \\
\text { data rate from the National Health Service Registry." (pg 95) }\end{array}$ \\
\hline $\begin{array}{l}\text { Incomplete outcome data } \\
\text { (attrition bias) } \\
\text { Patient outcome }\end{array}$ & Unclear risk & $\begin{array}{l}\text { (PRIMARY) RISK PROFILE - it only seems to include patients who completed the } \\
12 \text {-month study; no mention of baseline number of patients included }\end{array}$ \\
\hline
\end{tabular}

\section{Rudd 2004}

Methods $\begin{aligned} & \text { Eligible patients underwent randomization using computer-generated assignment to receive either } \\ & \text { usual medical care only (UC; } \mathrm{n}=76 \text { ) or usual care plus nurse care management intervention (INT; } \mathrm{n}= \\ & \text { 74). At } 3 \text { and } 6 \text { months after randomization, a research assistant blinded to group assignment mea- } \\ & \text { sured clinic blood pressure (BP) and interviewed patients about medications taken since the previous } \\ & \text { visit }\end{aligned}$

\begin{tabular}{ll}
\hline Participants & Patients had an elevation of BP to levels greater than $150 \mathrm{mmHg}$ systolic, $95 \mathrm{mmHg}$ diastolic, or both. \\
This was confirmed by the mean of $2 \mathrm{BP}$ values being greater than $150 / 95 \mathrm{mmHg}$ on $2 \mathrm{screening}$ visits \\
conducted on separate days at least 1 week apart
\end{tabular}


Rudd 2004 (Continued)

Interventions
The intervention consisted of the nurse care manager conducting baseline counseling on the correct use of the automated BP device, regular return of the automatically printed BP reports, tips for enhancing drug adherence, and recognition of potential drug side effects. The nurse initiated follow-up phone contacts at 1 week and at 1,2 , and 4 months that averaged 10 minutes in duration. During the phone calls, the nurse asked the patients about each medication dosage and any problems experienced since the previous contact. Patients were encouraged to telephone anytime during regular hours with questions or concerns. The nurse care manager contacted physicians to obtain permission to initiate any new BP drug but did not contact physicians regarding changes in medication dosage. Usual care in both groups consisted of patients continuing to receive the routine care that they had received before the study

Outcomes

Compliance was measured in both groups from the data downloaded using the electronic drug event monitors (eDEMs). The same semi-automated portable device was used to measure BP at home and during each clinic visits. At home, patients recorded BP twice daily at the same times each day and each week; the device generated a printed report of up to 14 measurements

Notes -

\section{Risk of bias}

\begin{tabular}{lll}
\hline Bias & Authors' judgement & Support for judgement \\
\hline $\begin{array}{l}\text { Random sequence genera- } \\
\text { tion (selection bias) }\end{array}$ & Low risk & $\begin{array}{l}\text { Used a computer-generated random number randomization method. "After } \\
\text { establishing eligibility, patients gave written informed consent and underwent } \\
\text { randomization using computer- generated assignment." (pg 922) }\end{array}$ \\
\hline
\end{tabular}

\begin{tabular}{lll}
\hline $\begin{array}{l}\text { Allocation concealment } \\
\text { (selection bias) }\end{array}$ & Unclear risk & No information was provided about how allocation was handled \\
\hline $\begin{array}{l}\text { Selective reporting (re- } \\
\text { porting bias) }\end{array}$ & Unclear risk & $\begin{array}{l}\text { No protocol available; although it appears that everything was reported it is } \\
\text { difficult to determine this without a protocol }\end{array}$ \\
\hline
\end{tabular}

\begin{tabular}{lll}
\hline Other bias & Low risk & The study seems to be free of other types of bias \\
\hline $\begin{array}{l}\text { Blinding of outcome as- } \\
\begin{array}{l}\text { sessment (detection bias) } \\
\text { Adherence measure }\end{array}\end{array}$ & Unclear risk & $\begin{array}{l}\text { (PRIMARY) ELECTRONIC DRUG EVENT MONITOR - Notes blinding of data collec- } \\
\text { tors for other measures but not for MEMS }\end{array}$ \\
\hline $\begin{array}{l}\text { Blinding of outcome as- } \\
\text { sessment (detection bias) }\end{array}$ & Low risk & $\begin{array}{l}\text { (PRIMARY) BLOOD PRESSURE - Outcome assessors blinded and semi-automat- } \\
\text { ed portable device used to measure BP. "Patients in both groups returned to } \\
\text { the clinic at } 3 \text { and } 6 \text { months for BP measurements, which were performed by } \\
\text { study staff blinded to group assignment." (pg 922) }\end{array}$ \\
\hline
\end{tabular}

\begin{tabular}{|c|c|c|}
\hline $\begin{array}{l}\text { Blinding of participants } \\
\text { (performance bias) } \\
\text { Adherence measure }\end{array}$ & High risk & $\begin{array}{l}\text { (PRIMARY) ELECTRONIC DRUG EVENT MONITOR - Patients were probably un- } \\
\text { blinded due to the nature of intervention }\end{array}$ \\
\hline
\end{tabular}

\begin{tabular}{ll}
\hline $\begin{array}{l}\text { Blinding of participants } \\
\text { (performance bias) }\end{array}$ & Low risk \\
Patient outcome & $\begin{array}{l}\text { (PRIMARY) BLOOD PRESSURE - Objective measure unlikely to be influenced by } \\
\text { lack of patient blinding }\end{array}$
\end{tabular}

\begin{tabular}{|c|c|c|}
\hline $\begin{array}{l}\text { Blinding of personnel (per- } \\
\text { formance bias) } \\
\text { Adherence measure }\end{array}$ & Unclear risk & $\begin{array}{l}\text { (PRIMARY) ELECTRONIC DRUG EVENT MONITOR - Notes blinding of study per- } \\
\text { sonnel for baseline and BP measures but not MEMS }\end{array}$ \\
\hline
\end{tabular}

Adherence measure

Blinding of personnel (per- Unclear risk

formance bias)

Patient outcome

(PRIMARY) BLOOD PRESSURE - No information on blinding given. There is insufficient information to permit judgment of 'Low risk' or 'High risk' 
Rudd 2004 (Continued)

Incomplete outcome data Low risk (attrition bias)

Adherence measure
(PRIMARY) ELECTRONIC DRUG EVENT MONITOR - Reasons for dropouts provided; dropouts fairly similar across groups

(PRIMARY) BLOOD PRESSURE - Reasons for dropouts provided and dropouts

similar in number across groups

Incomplete outcome data Low risk

(attrition bias)

Patient outcome

Sabin 2010

\begin{tabular}{ll}
\hline Methods & Randomized controlled trial \\
\hline Participants & The study location was Dali Second People's Hospital (DSPH) in Dali, Yunnan province, China \\
& $\begin{array}{l}34 \text { participants were randomized to the intervention group and } 34 \text { participants were randomized to the } \\
\text { control group } \\
\text { The inclusion criteria were: on ART and aged } 18 \text { years or above }\end{array}$
\end{tabular}

Interventions

Intervention: COUNSELING BASED ON ELECTRONIC DRUG MONITORING DATA

When intervention participants came to the clinic monthly, a study member downloaded and reviewed the subject's previous month's electronic drug monitoring device (EDM) data. Each subject found to be less than $95 \%$ adherent according to the EDM data was 'flagged' for counseling with a clinic physician or nurse utilizing the EDM information immediately following regular clinic visit activities. The data were provided to both the subject and his/her clinician as a printout summarizing the per cent of doses taken, the per cent of doses taken on time, and a visual display of doses taken by time. This process of flagging and counseling was specific to each clinic visit. In each counseling session, the clinician reviewed the EDM printout with the subject, explored reasons for missed or off-time doses, and inquired about problems or challenges the subject might be having. Beyond this, counseling sessions did not follow a script. This was designed to accommodate each clinician's counseling style, allow for an individually focused discussion of adherence behavior, and encourage each subject-clinician pair to devise personalized strategies to improving adherence. In this regard, the EDM feedback provided data to inform and thereby enhance the counseling, but did not dictate precisely how the counseling should be performed. In the event that subjects did not immediately offer reasons for missed or off-time doses, clinicians were advised to say: "Let's talk more about any problems that you had last month." Most counseling sessions were completed within 10 to 15 minutes. The intervention period was 7 to 12 months

\section{Control: STANDARD CARE}

Control group participants provided their electronic drug monitors (EDM) data at their monthly visits to the study team members and received standard care. Standard care in China included completing self reports of adherence and attending counseling session with clinician if self reported adherence indicated less than 95\% adherence. In the counseling sessions with control subjects, which were guided by self reported adherence and clinicians inquired about recent problems that might have affected dose-taking od and self reported adherence during the intervention. Self reported adherence, used to identify low adherers in the control group during the intervention period, was assessed from subjects' written responses to questions on the monthly form. These included: (1) a visual analog scale (VAS) of proportion of ART medications taken in the previous month; (2) a series of 6 yes/no questions about medication-taking behavior in the previous month (being careless, forgetting, stopping treatment due to feeling better, not taking medications while at work, taking pills early or late, sharing medications); and (3) 2 quantitative questions on the number of days medications were not taken and number of days medications were taken early or late. A subject in the control arm was flagged as a 'low adherer' if he/she reported $<95 \%$ on the VAS, answered 'yes' to any one of the 6 behavioral questions, or reported more than 0 days for either of the quantitative questions. During the intervention period (months 7 to 12 ), patients visited the clinic monthly. The adherence measure was calculated at 6 and 12 months. Addi- 
Sabin 2010 (Continued)

tionally, adherence was also calculated as the proportion of patients achieving high $(>/=95 \%)$ adherence. The adherence self report measure was administered by study team members.

The patient outcomes were CD4 count and HIV viral load tested at baseline, randomization (month 6), and post-intervention (month 12). CD4 counts were measured at a local laboratory by flow cytometry. We calculated change in CD4 count for each subject by subtracting month 6 CD4 from month 12 CD4 count. HIV viral loads were measured with an Organon Teknica NucliSens analyzer, at the Center for Disease Control laboratory in Kunming, the provincial capital. The lower limit of the viral load assay was 400 copies per $\mathrm{ml}$

Notes -

\section{Risk of bias}

\begin{tabular}{|c|c|c|}
\hline Bias & Authors' judgement & Support for judgement \\
\hline $\begin{array}{l}\text { Random sequence genera- } \\
\text { tion (selection bias) }\end{array}$ & Low risk & $\begin{array}{l}\text { Randomization was performed on site, through a block randomization } \\
\text { process. "Subjects within each adherence group were then randomized to } \\
\text { the intervention or control arm, ensuring that equal numbers of high and low } \\
\text { adherers were allocated to each arm. This was performed on site, through a } \\
\text { block randomization process as follows: at each subject's month } 6 \text { visit, the } \\
\text { subject pulled an unmarked allocation envelope, the inside of which had a sin- } \\
\text { gle paper stamped with either "intervention" or "control", from a larger enve- } \\
\text { lope that had originally held ten such allocation envelopes, five for each arm. } \\
\text { When each large envelope was empty, it was replaced with another large enve- } \\
\text { lope, similarly containing ten allocation envelopes." (pg 583) }\end{array}$ \\
\hline
\end{tabular}

\begin{tabular}{|c|c|c|}
\hline $\begin{array}{l}\text { Allocation concealment } \\
\text { (selection bias) }\end{array}$ & High risk & $\begin{array}{l}\text { Envelopes used were not sealed, described as opaque, or sequentially num- } \\
\text { bered }\end{array}$ \\
\hline
\end{tabular}

\begin{tabular}{lll}
\hline $\begin{array}{l}\text { Selective reporting (re- } \\
\text { porting bias) }\end{array}$ & Unclear risk & $\begin{array}{l}\text { No protocol available; although it appears that everything was reported it is } \\
\text { difficult to determine this without a protocol }\end{array}$ \\
\hline Other bias & Low risk & The study seems to be free of other types of bias \\
\hline $\begin{array}{l}\text { Blinding of outcome as- } \\
\begin{array}{l}\text { sessment (detection bias) } \\
\text { Adherence measure }\end{array}\end{array}$ & Low risk & $\begin{array}{l}\text { (PRIMARY) EDM (MED-IC PILL BOTTLE) - This is an objective measure of out- } \\
\text { come }\end{array}$
\end{tabular}

\begin{tabular}{|c|c|c|}
\hline $\begin{array}{l}\text { Blinding of outcome as- } \\
\text { sessment (detection bias) } \\
\text { Patient outcome }\end{array}$ & Low risk & (PRIMARY) CD4 CELL COUNT - This is an objective measure of outcome \\
\hline $\begin{array}{l}\text { Blinding of participants } \\
\text { (performance bias) } \\
\text { Adherence measure }\end{array}$ & High risk & $\begin{array}{l}\text { (PRIMARY) EDM (MED-IC PILL BOTTLE) - Adherence for Life was a non-blinded } \\
\text { randomized controlled intervention trial (pg 581) }\end{array}$ \\
\hline
\end{tabular}

\begin{tabular}{|c|c|c|}
\hline $\begin{array}{l}\text { Blinding of participants } \\
\text { (performance bias) } \\
\text { Patient outcome }\end{array}$ & Low risk & (PRIMARY) CD4 CELL COUNT - This is an objective measure of outcome \\
\hline $\begin{array}{l}\text { Blinding of personnel (per- } \\
\text { formance bias) } \\
\text { Adherence measure }\end{array}$ & Low risk & $\begin{array}{l}\text { (PRIMARY) EDM (MED-IC PILL BOTTLE) - This is an objective measure of out- } \\
\text { come }\end{array}$ \\
\hline
\end{tabular}

\footnotetext{
Blinding of personnel (per- Low risk (PRIMARY) CD4 CELL COUNT - This is an objective measure of outcome formance bias)

Patient outcome
} 
Sabin 2010 (Continued)
Incomplete outcome data Low risk
(attrition bias)
(PRIMARY) EDM (MED-IC PILL BOTTLE) - Balanced dropout rates; reasons for
dropouts were similar

Adherence measure

\begin{tabular}{ll}
\hline $\begin{array}{l}\text { Incomplete outcome data } \\
\text { (attrition bias) }\end{array}$ & (PRIMARY) CD4 CELL COUNT - Similar rate of attrition \\
Patient outcome &
\end{tabular}

Patient outcome

\section{Sackett 1975}

\begin{tabular}{ll} 
Methods & Random allocation, $2 \times 2$ factorial design, no indication of concealment \\
\hline Participants & Male steel company employees who exhibited persistently elevated diastolic blood pressure on repeat- \\
& ed examination (at or above $95 \mathrm{mmHg}(5$ th phase)), were free of secondary forms of hypertension, were \\
taking no daily medication, and had not been prescribed antihypertensive medications for at least 6 \\
months before the trial were eligible for the study
\end{tabular}

Interventions Subjects in augmented convenience saw company physicians, rather than their family physicians, for hypertensive and follow-up care during paid working hours. The second intervention, mastery learning, was designed to give the facts about hypertension, its effects upon target organs, health, and life expectancy, the benefits of antihypertensive therapy, the need for adherence with medications and some simple reminders for taking pills (this information was provided in a slide-tape format, and reinforced by a secondary-school graduate 'patient educator')

Adherence was calculated by comparing the number of tablets prescribed with medications still on
hand, by the semi-quantitative identification of drugs and metabolites in the urine, by the identifica-
tion of characteristic changes in serum potassium and uric acid in men on thiazide drugs. Adherence is
reported in terms of the per cent of medication prescribed for the 6th month which was removed from
the bottle and, presumably, consumed by the patient. Patients whose pill counts were consistent with
adherence levels of $80 \%$ or more were considered 'compliant'. Blood pressure control was assessed
by trained observers. Only patients whose diastolic blood pressure was below 90 mm Hg at 6 months
would be designated as being 'at goal blood pressure'. Outcome assessors were blinded to study group

Notes

\section{Risk of bias}

\begin{tabular}{|c|c|c|}
\hline Bias & Authors' judgement & Support for judgement \\
\hline $\begin{array}{l}\text { Random sequence genera- } \\
\text { tion (selection bias) }\end{array}$ & Unclear risk & $\begin{array}{l}\text { Method of sequence generation not described: "After stratification for factors } \\
\text { likely to influence either compliance or the probability that their blood-pres- } \\
\text { sure could be controlled (prior antihypertensive therapy, age, other illness, } \\
\text { and severity of hypertension), they were randomly allocated into a factorial } \\
\text { design which permitted the simultaneous evaluation of the ability of two in- } \\
\text { dependent strategies to enhance compliance with antihypertensive thera- } \\
\text { py." (pg 1205) }\end{array}$ \\
\hline $\begin{array}{l}\text { Allocation concealment } \\
\text { (selection bias) }\end{array}$ & Low risk & The author indicated allocation was concealed \\
\hline $\begin{array}{l}\text { Selective reporting (re- } \\
\text { porting bias) }\end{array}$ & Unclear risk & $\begin{array}{l}\text { No protocol available; although it appears that everything was reported it is } \\
\text { difficult to determine this without a protocol }\end{array}$ \\
\hline Other bias & Low risk & The study seems to be free of other types of bias \\
\hline
\end{tabular}


Sackett 1975 (Continued)

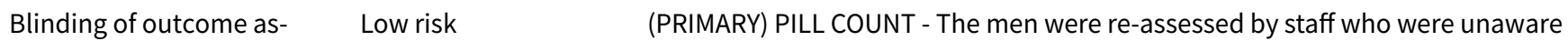
sessment (detection bias) of the experimental group allocation (pg 1206)

Adherence measure

$\begin{aligned} & \text { Blinding of outcome as- } \\ & \text { sessment (detection bias) }\end{aligned} \quad$ Low risk

Patient outcome

Blinding of participants High risk
(performance bias)

(performance bias)

Adherence measure

\begin{tabular}{ll}
\hline $\begin{array}{l}\text { Blinding of participants } \\
\text { (performance bias) }\end{array}$ & Low risk \\
$\begin{array}{l}\text { Patient outcome } \\
\text { (PRIMARY) BLOOD PRESSURE - The author has noted that the patients were } \\
\text { not blinded but blinding would likely not impact outcome }\end{array}$
\end{tabular}

\begin{tabular}{|c|c|c|}
\hline $\begin{array}{l}\text { Blinding of personnel (per- } \\
\text { formance bias) } \\
\text { Adherence measure }\end{array}$ & Low risk & $\begin{array}{l}\text { (PRIMARY) PILL COUNT - The men were re-assessed by staff who were unaware } \\
\text { of the experimental group allocation (pg 1206) }\end{array}$ \\
\hline $\begin{array}{l}\text { Blinding of personnel (per- } \\
\text { formance bias) } \\
\text { Patient outcome }\end{array}$ & Unclear risk & $\begin{array}{l}\text { (PRIMARY) BLOOD PRESSURE - No information on whether the method of tak- } \\
\text { ing blood pressure was computerized. There is insufficient information to per- } \\
\text { mit judgment of 'Low risk' or 'High risk' }\end{array}$ \\
\hline
\end{tabular}

\begin{tabular}{lll}
\hline $\begin{array}{l}\text { Incomplete outcome data } \\
\text { (attrition bias) }\end{array}$ & Unclear risk & (PRIMARY) PILL COUNT - Reasons for dropouts were not provided \\
Adherence measure & \\
\hline $\begin{array}{l}\text { Incomplete outcome data } \\
\text { (attrition bias) }\end{array}$ & Unclear risk & (PRIMARY) BLOOD PRESSURE - Reasons for missing data were not provided \\
Patient outcome & \\
\hline
\end{tabular}

Sadik 2005

Methods Patients $(n=221)$ were randomized to either the intervention group $(n=109)$ or control group $(n=112)$ using the minimization method. Both groups were matched as closely as possible, for the following parameters: severity of heart failure (HF) (NYHA Grade I- IV), renal function (serum creatinine > or $=$ to 200

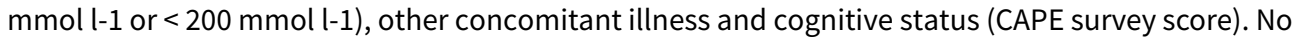
method of allocation concealment was mentioned

$\begin{array}{ll}\text { Participants } & \text { Patients had a diagnosis of heart failure, a score of more than } 6 \text { on the Clifton Assessments Procedures } \\ \text { for the Elderly (CAPE) survey used to assess cognitive status, and the consent of a hospital consultant } \\ \text { for the trial. Patients were excluded from the trial if they had significant airways disease and severe mo- } \\ \text { bility problems due to other causes }\end{array}$

Interventions Patients receiving the intervention were 1) educated on heart failure (HF), their prescribed medication
and the management of HF symptoms by the research pharmacist; 2) given a printed booklet devel-
oped for this type of education program, which contained information on HF, its symptoms, the aims
of treatment, the types of medication used and their possible side effects, diet and lifestyle changes,
advice to stick to one brand of digoxin (it having a narrow therapeutic index) and information on the
action to take if doses of medication were missed; 3) instructed on a self monitoring program (signs
and symptoms of HF; compliance with prescribed medication) in which they were asked to become en-
gaged and involved a monitoring diary card (covering 1 month); 4) asked to record their weight daily
in their diary card because they had been instructed to take an extra dose of their diuretic and to con-
tact their physician immediately if their weight increased by 3 kilograms over 48 hours or if there was a
marked deterioration in their HF signs/symptoms; 5) asked to perform daily exercise (walking); and 6)
given rationalization of drug therapy or simplification of dosage regimens, when deemed appropriate. 
Sadik 2005 (Continued)

Control group patients received usual care, i.e. excluding counseling and education by the research pharmacist, self monitoring, pharmacist liaison with physicians, etc.

Outcomes

At the 3-monthly outpatient clinics patients were assessed as per initial baseline assessments as follows: 2-minute walk test (including time to walk 25 and 50 meters), blood pressure, body weight, pulse, forced expiratory vital capacity (FVC), quality of life questionnaires (MLHF questionnaire and the SF-36), questionnaire on symptoms and knowledge of, and compliance with, prescribed medication and lifestyle advice

\section{Notes}

\section{Risk of bias}

\begin{tabular}{|c|c|c|}
\hline Bias & Authors' judgement & Support for judgement \\
\hline $\begin{array}{l}\text { Random sequence genera- } \\
\text { tion (selection bias) }\end{array}$ & Low risk & $\begin{array}{l}\text { Minimization was used. "After recruitment, patients were randomly assigned } \\
\text { to one of two groups: intervention group or control group. The randomization } \\
\text { was carried out using the minimization method described by Gore [20]." (pg } \\
\text { 185) }\end{array}$ \\
\hline $\begin{array}{l}\text { Allocation concealment } \\
\text { (selection bias) }\end{array}$ & Unclear risk & Method of concealment was not described \\
\hline $\begin{array}{l}\text { Selective reporting (re- } \\
\text { porting bias) }\end{array}$ & Unclear risk & $\begin{array}{l}\text { No protocol available; although it appears that everything was reported it is } \\
\text { difficult to determine this without a protocol }\end{array}$ \\
\hline Other bias & Unclear risk & $\begin{array}{l}\text { "The research pharmacist delivered the pharmaceutical care programme and } \\
\text { was also involved in some aspects of data collection. The possible bias that } \\
\text { this could have introduced to the study was minimized, in those cases where } \\
\text { the outcome questionnaires could not be self completed by patients, by ensur- } \\
\text { ing that a strict protocol for questionnaire administration was adhered to, as } \\
\text { designated in the SF36 manual." (pg 191) }\end{array}$ \\
\hline
\end{tabular}

Blinding of outcome as- Low risk sessment (detection bias) Adherence measure

(PRIMARY) SELF REPORT - QUESTIONNAIRE - Outcome assessors were blinded. "Baseline measurements were performed by a research pharmacist (A.S.) with the exception of the 2-min walk test and the FVC test, which were performed by nursing staff or a pharmacy technician. They were blinded regarding the group to which individual patients had been assigned and received training on test administration." (pg 185)

\begin{tabular}{|c|c|c|}
\hline $\begin{array}{l}\text { Blinding of outcome as- } \\
\text { sessment (detection bias) } \\
\text { Patient outcome }\end{array}$ & Low risk & $\begin{array}{l}\text { (PRIMARY) QUALITY OF LIFE QUESTIONNAIRE - The outcome assessors were } \\
\text { blinded. "Baseline measurements were performed by a research pharma- } \\
\text { cist (A.S.) with the exception of the 2-min walk test and the FVC test, which } \\
\text { were performed by nursing staff or a pharmacy technician. They were blind- } \\
\text { ed regarding the group to which individual patients had been assigned and re- } \\
\text { ceived training on test administration." (pg 185) }\end{array}$ \\
\hline
\end{tabular}

\begin{tabular}{|c|c|c|}
\hline $\begin{array}{l}\text { Blinding of participants } \\
\text { (performance bias) }\end{array}$ & High risk & $\begin{array}{l}\text { (PRIMARY) SELF REPORT - QUESTIONNAIRE - This is a subjective measure; } \\
\text { there is no information on blinding }\end{array}$ \\
\hline
\end{tabular}

Adherence measure

High risk

Blinding of participants (performance bias)

Patient outcome
(PRIMARY) QUALITY OF LIFE QUESTIONNAIRE - This is a subjective measure; there is no information on blinding
Blinding of personnel (per- Unclear risk

formance bias)

Adherence measure
(PRIMARY) SELF REPORT - QUESTIONNAIRE - No information on blinding given. There is insufficient information to permit judgment of 'Low risk' or 'High risk' 
Sadik 2005 (Continued)

Blinding of personnel (per- Unclear risk $\quad$ (PRIMARY) QUALITY OF LIFE QUESTIONNAIRE - No information on blinding givformance bias)

Patient outcome en. There is insufficient information to permit judgment of 'Low risk' or 'High risk'

Incomplete outcome data Unclear risk (attrition bias)

Adherence measure

(PRIMARY) SELF REPORT - QUESTIONNAIRE - A total of $221 \mathrm{HF}$ patients (109 intervention; 112 control) were recruited into the study. 2 patients in each group died during the study; in addition, 3 patients withdrew from the intervention group and 6 from the control group during the study, meaning that a total of 104 patients in each group completed the 12-month follow-up study. Unlikely that the missing data would have changed the outcome, but since it is not clear, it is marked unclear

Incomplete outcome data Unclear risk

(attrition bias)

(PRIMARY) QUALITY OF LIFE QUESTIONNAIRE - Reasons for withdrawals were

Patient outcome not provided

\section{Samet 2005}

Methods

Patients $(n=151)$ were randomly assigned to either the control $(n=77)$ or intervention group $(n=74)$ and balance between groups was ensured every 4 subjects that were enrolled

Participants

Patients were HIV-infected and had a history of alcohol problems. HIV status was confirmed by laboratory tests and alcohol problems were defined as current or lifetime history of alcohol abuse or dependence and were determined by 2 or more positive responses to the CAGE alcohol screening questionnaire. Those who did not meet the CAGE criteria were eligible if one of 2 attending physicians made a clinical diagnosis of alcohol abuse. Patients also were fluent in English or Spanish, had a Mini-Mental State Examination score of at least 21 or greater and had no plans to move from Boston area in the following 2 years

Interventions

The intervention (called ADHERE) incorporated 4 distinct components: 1 ) assessment and discussion of the patient's alcohol and other substance use based on stage of readiness for behavioral change; 2 ) use of a watch as a medication timing device to improve adherence; 3) enhancement of perceived efficacy of medications; and 4) individualized HIV counseling and exploration of ways to tailor medication use to specific circumstances. Visits for the intervention group was scheduled for an initial 60-minute appointment (within 2 weeks of randomization), a follow-up home visit within the first 3 weeks and 2 subsequent 15- to 30-minute appointments at 1 month and 3 months with the nurse interventionist who delivered the adherence enhancement intervention. Patients in the control group received standard care for HIV infection, which included verbal or written instructions about optimal medication strategies and regular medical care for HIV infection

Outcomes Adherence to antiretroviral therapy (ART) was measured using the AIDS Clinical Trials Group (ACTG) scale for both the previous 3 days and 30 days. Self reported adherence was measured using the ACTG scale. Adherence was defined as $>95 \%$ adherence over the previous 30 days and $100 \%$ adherence over the previous 3 days. In addition to the dichotomous measure of adherence, a continuous measure of adherence for the past 30 days was measured using the actual proportion of doses taken verses doses prescribed. Both adherence outcomes were assessed at 6 months (short-term) and at 13 months or 12 months (long-term). Self reported adherence assessment was verified with the MEMS caps of certain patients - ones who reported no change in HIV medications during the assessed interval and did not use a pill-organizing container. At 12 months, the following clinical outcomes were assessed: 1) CD4 cell count; 2) Log HIV RNA; and 3) Alcohol severity and consumption (using both the Addiction Severity Index and quantity and frequency questions assessing the previous 30 days), which was used to calculate the average number of drinks per day

\section{Notes}

\section{Risk of bias}


Samet 2005 (Continued)

\section{Bias Authors' judgement Support for judgement}

Random sequence genera- Unclear risk tion (selection bias)

Randomization was not described in detail. "Subjects were randomly assigned to either the control or intervention group and balance between groups was ensured after every four subjects were enrolled." (pg 84)

\begin{tabular}{|c|c|c|}
\hline $\begin{array}{l}\text { Allocation concealment } \\
\text { (selection bias) }\end{array}$ & Unclear risk & No information was provided about how allocation was handled \\
\hline Other bias & Low risk & The study seems to be free of other types of bias \\
\hline $\begin{array}{l}\text { Blinding of outcome as- } \\
\text { sessment (detection bias) } \\
\text { Adherence measure }\end{array}$ & High risk & $\begin{array}{l}\text { (PRIMARY) SELF REPORT - INTERVIEW - The author has noted that the research } \\
\text { assistants were not concealed to treatment group as previously stated. They } \\
\text { facilitated getting the subjects connected with the nurse }\end{array}$ \\
\hline
\end{tabular}

\begin{tabular}{ll}
\hline Blinding of outcome as- & Low risk
\end{tabular} (PRIMARY) CD4 CELL COUNT - This is an objective measure of outcome

Patient outcome

\begin{tabular}{|c|c|c|}
\hline $\begin{array}{l}\text { Blinding of participants } \\
\text { (performance bias) }\end{array}$ & High risk & $\begin{array}{l}\text { (PRIMARY) SELF REPORT - INTERVIEW - The author notes that subjects could } \\
\text { not be blinded to the intervention }\end{array}$ \\
\hline
\end{tabular}

Adherence measure

\begin{tabular}{ll}
\hline $\begin{array}{l}\text { Blinding of participants } \\
\text { (performance bias) }\end{array}$ (PRIMARY) CD4 CELL COUNT - This is an objective measure of outcome
\end{tabular}

Patient outcome

Blinding of personnel (per- Low risk

formance bias)

(PRIMARY) SELF REPORT - INTERVIEW - The author has noted that key study

Adherence measure personnel were not made aware of the group assignments

Blinding of personnel (per- Low risk

formance bias)

Patient outcome

(PRIMARY) CD4 CELL COUNT - This is an objective measure of outcome

\begin{tabular}{lll}
\hline $\begin{array}{l}\text { Incomplete outcome data } \\
\text { (attrition bias) }\end{array}$ & Unclear risk & $\begin{array}{l}\text { (PRIMARY) SELF REPORT - INTERVIEW - Long-term (12-month) data are avail- } \\
\text { able for 58\% and 66\% of subjects only }\end{array}$ \\
\hline $\begin{array}{l}\text { Incomplete outcome data } \\
\text { (attrition bias) } \\
\begin{array}{l}\text { Patient outcome } \\
\text { Unclear risk }\end{array}\end{array}$ & $\begin{array}{l}\text { (PRIMARY) CD4 CELL COUNT - Long-term (12-month) data are available for 58\% } \\
\text { and 66\% of subjects only }\end{array}$ \\
\hline
\end{tabular}

Sarna 2008

\begin{tabular}{ll}
\hline Methods & Randomized controlled trial \\
\hline Participants & The study location was outpatient HIV treatment clinics in Mombasa, Kenya \\
& $\begin{array}{l}116 \text { participants were randomized to the intervention group and } 118 \text { participants were randomized to } \\
\text { the control group }\end{array}$
\end{tabular}


Sarna 2008 (Continued)

The inclusion criteria were ART-naive adults (> 18 years) residing in Mombasa who were eligible for ART (CD4 cell count $<200$ cells $/ \mathrm{mm}^{3}$ or WHO clinical stage 3 or 4 )

Patients in the intervention arm received M-DOT services for the first 24 weeks of ART, in addition to standard care. Although consideration was given to provision of home-based M-DOT, formative research revealed that patients were concerned this would undermine their privacy and confidentiality. They also believed that clinic visits would provide beneficial access to healthcare workers, so M-DOT services were provided during twice-weekly clinic visits. To enhance convenience, participants could select 1 of 6 health centers for their M-DOT visits. At each visit, participants met with M-DOT observers (nurses) who observed ingestion of the patient's ART dose, inquired about difficulties encountered, and provided individualized adherence support. Used medication containers were also collected, pill counts recorded, and medication dispensed for the subsequent 3 or 4 days. During the monthly clinic visits, efforts were made to ensure that participants in the M-DOT and control group received equal contact time with study staff to minimize the likelihood that any differences observed would be due to nonspecific effects of increased attention given to the intervention group. CHW traced M-DOT participants who missed visits and brought medications to participants who were unable to visit the facility. After cessation of M-DOT at week 24, patients had no further contact with M-DOT observation centers. Like the control group, they collected monthly medication refills at recruitment clinics and received standard adherence support during weeks 25 to 72 . No compensation was given for study participation, though travel costs were reimbursed for $21 \mathrm{M}$-DOT participants with financial constraints (USD 0.65 per visit)

\section{Control: STANDARD CARE}

As standard care, all participants attended 3 one-on-one adherence counseling sessions before initiating ART. In these, trained nurse counselors emphasized the importance of adherence; educated patients on the treatment regimen, dosing instructions, side effects, and dietary considerations; tailored the regimen to daily activities; and identified social issues like living conditions and family support. After ART initiation, patients visited treatment centers every 4 weeks for follow-up. At the first 2 follow-up visits, general adherence counseling was provided, as was discussion of specific emerging problems with side effects or medication intake; thereafter, counseling was tailored to individual needs. All patients were encouraged to bring a family member or friend to clinic visits and counseling sessions ed adherence (4-day recall) was assessed 7.0 times ( 8 weekly from 1 to 48 weeks plus at week 72 ) and was dichotomized into those having missed or not having missed doses in the past 4 days. Pill counts were made at each M-DOT visit between weeks 4 and 24 when used medication containers were returned (twice weekly). These counts were aggregated to produce a 4-week measure. From weeks 25 to 48 and for participants in the control arm (weeks 4 to 48), pill counts were measured every 4 weeks and at week 72 (a total of 13 data points for both groups). Pill counts, measured as a percentage and dichotomized to $<95 \%$ and $>95 \%$ adherence, were calculated as: number of pills taken/number of pills expected to have taken ${ }^{\star} 100$

The patient outcome was depression, assessed at baseline and weeks 24,48 , and 72 using a culturally adapted 21-item Beck's Depression Inventory (BDI), translated into Swahili. Depression was categorized as none (0 to 9), mild (10 to 18), moderate (19 to 29), and severe (30 to 63) as per BDI guidelines. Body weight was collected monthly and body mass index (BMI) is presented. CD4 cell counts were determined at baseline and weeks 24,48 , and 72 using PARTEC and FACS counters. CD4 measures were extracted from medical records by nurses and the study co-ordinator. For analysis, cell counts at baseline and week 24 were dichotomized above and below the median. Plasma viral load was measured at 48 and 72 weeks. Viral load was dichotomized to those with, and those without, viral suppression

Notes -

\section{Risk of bias}

\begin{tabular}{lll}
\hline Bias & Authors' judgement & Support for judgement \\
\hline $\begin{array}{l}\text { Random sequence genera- } \\
\text { tion (selection bias) }\end{array}$ & Low risk & $\begin{array}{l}\text { A computer-generated random number sequence was used. "Computer-gen- } \\
\text { erated random number assignment was used, allocating an equal number of }\end{array}$
\end{tabular}


Sarna 2008 (Continued)

participants to treatment and control groups. Allocation concealment was maintained with sequentially numbered, opaque sealed envelopes. Before ART initiation, participants were randomly assigned to study groups, in blocks of 40 . Only laboratory personnel were blinded to study group allocation. Standardized data collection tools, staff training, and regular supervision by the study coordinator aimed to ensure that study activities were uniform across sites" (pg 612)

\begin{tabular}{lll}
\hline $\begin{array}{l}\text { Allocation concealment } \\
\text { (selection bias) }\end{array}$ & Low risk & $\begin{array}{l}\text { "Computer-generated random number assignment was used, allocating an } \\
\text { equal number of participants to treatment and control groups. Allocation con- } \\
\text { cealment was maintained with sequentially numbered, opaque sealed en- } \\
\text { velopes." (pg 612) }\end{array}$ \\
\hline $\begin{array}{l}\text { Selective reporting (re- } \\
\text { porting bias) }\end{array}$ & Unclear risk & $\begin{array}{l}\text { No protocol available; although it appears that everything was reported it is } \\
\text { difficult to determine this without a protocol }\end{array}$ \\
\hline Other bias & Unclear risk & $\begin{array}{l}\text { "As the study began when ART programs were first introduced in Kenya, treat- } \\
\text { ment was available for a limited number of patients. With this constraint, the } \\
\text { study lacks power to detect smaller but nevertheless clinically important dif- } \\
\text { ferences in outcomes. Differences in the way pill counts were measured for the } \\
2 \text { groups during the first 24 weeks could have introduced bias in these mea- } \\
\text { sures." (pg 613) }\end{array}$
\end{tabular}

\begin{tabular}{|c|c|c|}
\hline $\begin{array}{l}\text { Blinding of outcome as- } \\
\text { sessment (detection bias) } \\
\text { Adherence measure }\end{array}$ & Unclear risk & $\begin{array}{l}\text { (PRIMARY) PILL COUNT - "Only laboratory personnel were blinded to study } \\
\text { group allocation" (pg 612). However, there is insufficient information about } \\
\text { who did the pill count }\end{array}$ \\
\hline
\end{tabular}

\begin{tabular}{|c|c|c|}
\hline $\begin{array}{l}\text { Blinding of outcome as- } \\
\text { sessment (detection bias) } \\
\text { Patient outcome }\end{array}$ & Unclear risk & $\begin{array}{l}\text { (PRIMARY) VIRAL LOAD AND CD4 COUNTS - CD4 cell counts were determined at } \\
\text { baseline and weeks } 24,48 \text {, and } 72 \text { using PARTEC and FACS counters. CD4 mea- } \\
\text { sures were extracted from medical records by nurses and the study co-ordina- } \\
\text { tor. No mention of blinding }\end{array}$ \\
\hline
\end{tabular}

\begin{tabular}{|c|c|c|}
\hline $\begin{array}{l}\text { Blinding of participants } \\
\text { (performance bias) } \\
\text { Adherence measure }\end{array}$ & High risk & $\begin{array}{l}\text { (PRIMARY) PILL COUNT - Patients not blinded and pill count may be altered by } \\
\text { patients. "Some came back with fewer pills than expected due to misplaced } \\
\text { pills, repeated ingestion if pills had been vomited, or "pill dumping" (as occa- } \\
\text { sionally admitted to counsellors and CHW)." }\end{array}$ \\
\hline
\end{tabular}

\begin{tabular}{ll}
\hline $\begin{array}{l}\text { Blinding of participants } \\
\text { (performance bias) } \\
\begin{array}{l}\text { Patient outcome } \\
\hline\end{array}\end{array}$ & $\begin{array}{l}\text { (PRIMARY) VIRAL LOAD AND CD4 COUNTS - This is an objective measure of out- } \\
\text { come }\end{array}$ \\
\hline
\end{tabular}

Blinding of personnel (per- Unclear risk

formance bias)

Adherence measure

(PRIMARY) PILL COUNT - No information on blinding given. There is insufficient information to permit judgment of 'Low risk' or 'High risk'

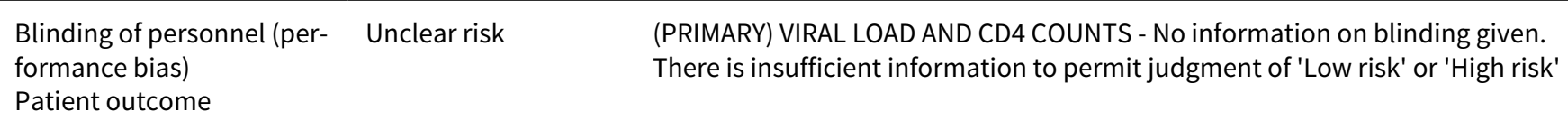

\begin{tabular}{lll}
$\begin{array}{l}\text { Incomplete outcome data } \\
\text { (attrition bias) } \\
\text { Adherence measure }\end{array}$ & Unclear risk & $\begin{array}{l}\text { (PRIMARY) PILL COUNT - Reasons for discontinuation are unclear; unclear how } \\
\text { this may have affected results }\end{array}$ \\
\hline $\begin{array}{l}\text { Incomplete outcome data } \\
\text { (attrition bias) }\end{array}$ & Low risk & $\begin{array}{l}\text { (PRIMARY) VIRAL LOAD AND CD4 COUNTS - Missing outcome data balanced } \\
\text { in numbers across intervention groups, with similar reasons for missing data } \\
\text { across groups; from M-DOT group, a total of } 89 / 116 \text { lasted in the intervention; } \\
7 \text { discontinued the intervention, } 15 \text { died and } 2 \text { were lost to follow-up. From the } \\
\text { standard care, a total of } 94 / 118 \text { lasted until the end; } 10 \text { discontinued the inter- } \\
\text { vention, } 12 \text { died, and } 4 \text { were lost to follow-up(Figure } 1)\end{array}$
\end{tabular}


Schaffer 2004

Methods

Participants were recruited using flyers posted throughout the health science center campus, within the university student health center, and in health departments within the county. In an effort to approximate the ethnicity of the surrounding county, which is 19\% African American, the principal investigator also recruited participants personally in an African American church. There were 46 participants at the beginning of the study. A computerized randomization protocol was used to assign participants to one of 4 treatment groups

Participants

There were 46 participants at the beginning of the study. English-speaking adults aged 18 to 65 , whose reported use of preventive medication for asthma during the 3 months prior to the study indicated that they had mild persistent to moderate persistent asthma according to the US NAEPP (2002) guidelines. Individuals were excluded if they reported daily oral steroid use, diagnosis of chronic obstructive pulmonary disorder (COPD), or symptomatic cardiac disease

Interventions

4 treatment groups: (a) standard provider education (control) $(n=13) ;(b)$ audiotape alone $(n=10) ;(c)$ National Heart Lung and Blood Institute (NHLBI) booklet alone $(n=12)$; and (d) audiotape plus NHLBI booklet $(n=11)$

$\begin{array}{ll}\text { Outcomes } & \text { Compliance measurements: self reported and pharmacy-verified adherence to preventive medication } \\ \text { Measurement of clinical health outcomes: asthma control measured with the Asthma Control Ques- } \\ \text { tionnaire (ACQ), asthma quality of life measured with the Mini Asthma Quality of Life Questionnaire } \\ \text { (MiniAQLQ), and asthma self efficacy assessed using the Perceived Control of Asthma Questionnaire } \\ \text { (PCAQ). Asthma knowledge was measured with the Asthma Knowledge Scale, developed for this study }\end{array}$

\section{Risk of bias}

\begin{tabular}{lll}
\hline Bias & Authors' judgement & Support for judgement \\
\hline $\begin{array}{l}\text { Random sequence genera- } \\
\text { tion (selection bias) }\end{array}$ & Low risk & $\begin{array}{l}\text { Computerized randomization method. "A research assistant then consulted a } \\
\text { computerized randomization protocol and provided participants with the au- } \\
\text { diotape and headphones, educational brochure, or both." (pg 79) }\end{array}$ \\
\hline
\end{tabular}

\begin{tabular}{lll}
\hline $\begin{array}{l}\text { Allocation concealment } \\
\text { (selection bias) }\end{array}$ & Unclear risk & No information was provided about how allocation was handled \\
\hline $\begin{array}{l}\text { Selective reporting (re- } \\
\text { porting bias) }\end{array}$ & Unclear risk & $\begin{array}{l}\text { No protocol available; although it appears that everything was reported it is } \\
\text { difficult to determine this without a protocol }\end{array}$ \\
\hline
\end{tabular}

\begin{tabular}{|c|c|c|}
\hline Other bias & Low risk & The study seems to be free of other types of bias \\
\hline $\begin{array}{l}\text { Blinding of outcome as- } \\
\text { sessment (detection bias) } \\
\text { Adherence measure }\end{array}$ & Low risk & $\begin{array}{l}\text { (PRIMARY) SELF REPORT - QUESTIONNAIRE - "The researcher remained blind } \\
\text { to group assignment until the data collection was completed." (pg 79) }\end{array}$ \\
\hline $\begin{array}{l}\text { Blinding of outcome as- } \\
\text { sessment (detection bias) } \\
\text { Patient outcome }\end{array}$ & Low risk & $\begin{array}{l}\text { (PRIMARY) ACQ, AQLQ, PCAQ AND ASTHMA KNOWLEDGE SCALE - There is an } \\
\text { explicit statement regarding blinding the researcher who collected the data } \\
\text { and conducted the spirometry. "The researcher remained blind to group as- } \\
\text { signment until the data collection was completed." (pg 79) }\end{array}$ \\
\hline
\end{tabular}

\begin{tabular}{|c|c|c|}
\hline $\begin{array}{l}\text { Blinding of participants } \\
\text { (performance bias) }\end{array}$ & High risk & $\begin{array}{l}\text { (PRIMARY) SELF REPORT - QUESTIONNAIRE - This is a subjective measure; } \\
\text { there is no information on blinding }\end{array}$ \\
\hline
\end{tabular}


Schaffer 2004 (Continued)

Blinding of participants (performance bias)

Patient outcome
High risk

(PRIMARY) ACQ, AQLQ, PCAQ AND ASTHMA KNOWLEDGE SCALE - This is a subjective measure; there is no information on blinding

(PRIMARY) SELF REPORT - QUESTIONNAIRE - No information on blinding given. There is insufficient information to permit judgment of 'Low risk' or 'High risk'
Unclear risk

formance bias)

Adherence measure

Blinding of personnel (per- Unclear risk formance bias)

Patient outcome
(PRIMARY) ACQ, AQLQ, PCAQ AND ASTHMA KNOWLEDGE SCALE - No information on blinding given. There is insufficient information to permit judgment of 'Low risk' or 'High risk'

\section{Incomplete outcome data Unclear risk}

(attrition bias)

(PRIMARY) SELF REPORT - QUESTIONNAIRE - Not enough detail given on the Adherence measure dropouts to judge

Incomplete outcome data Unclear risk

(attrition bias)

Patient outcome

(PRIMARY) ACQ, AQLQ, PCAQ AND ASTHMA KNOWLEDGE SCALE - Detail not given on the dropouts

\section{Schroeder 2005}

Methods

An author not involved in the practice and patient recruitment randomized eligible patients $(n=245)$ stratified by age and sex to the intervention $(n=128)$ and control $(n=117)$ groups, using computer-generated random numbers that were assigned to an anonymized list of participants. The principal investigator passed the randomization schedule on to the practice nurses shortly before the appointment for delivering the intervention. The study participants and the practice nurses were aware of the group assignment

Participants

Patients had hypertension and a latest blood pressure recording of $>$ or $=$ to $150 \mathrm{~mm} \mathrm{Hg}$ systolic and/or $90 \mathrm{~mm} \mathrm{Hg}$ diastolic in the past 6 months. Patients were excluded from the study if they did not control their medication intake (such as some nursing home patients), had secondary hypertension, severe dementia or other reasons for not approaching them, such as recent bereavement

Interventions Patients in the intervention group received, in addition to usual care, a nurse-led adherence support session lasting a maximum of 20 minutes, followed by a shorter reinforcement session (10 minutes) 2 months later. The intervention was aimed to provide an opportunity for patients to talk about any problems with their blood pressure-lowering medication. Practice nurses investigated whether patients understood their diagnosis and agreed with the treatment process. They also addressed patient concerns with their medication and to agree to tailored strategies to resolve any medication problems. The control group received standard care delivered at their respective practices, apart from blood pressure checks at similar intervals as the participants in the intervention group. Wherever possible, these checks were carried out by another practice nurse who was not involved in delivering the intervention but all practice nurses were made aware of the risk of contamination and encouraged not to change their 'usual practice' for the control patients

Outcomes

The primary adherence outcome was measured by Medication Event Monitoring System (MEMS) in the 6 months period following the intervention. Adherence was defined as 'timing compliance', which is the number of doses taken at $24 \pm 6$-hour intervals for a once daily regimen or $12 \pm 3$ hours for twice daily doses, divided by the total number of days and multiplied by $100 \% .2$ additional measures of adherence were taken: 1) 'correct dosing', which was the percentage of days on which the correct number of doses was taken; and 2) 'taking compliance', was defined as the percentage of prescribed number of doses taken, equivalent to a 'pill count'. Systolic and diastolic blood pressure was measured at baseline as well as 1, 2, and 6 months after randomization 
Schroeder 2005 (Continued)

Risk of bias

Bias Authors' judgement Support for judgement

Random sequence genera- Low risk

tion (selection bias)

Central randomization; computer-generated numbers were used for randomization. "One of the authors (TJP) who was not involved in practice and patient recruitment randomized eligible patients stratified by age and sex to the intervention and control groups using computer-generated random numbers, which were assigned to an anonymized list of participants. The principal investigator (KS) passed the randomization schedule on to the practice nurses shortly before the appointment for delivering the intervention." (pg 146)

Allocation concealment Low risk
(selection bias)

One author not involved in the rest of the study completed randomization. "One of the authors (TJP) who was not involved in practice and patient recruitment randomized eligible patients stratified by age and sex to the intervention and control groups using computer-generated random numbers, which were assigned to an anonymized list of participants. The principal investigator (KS) passed the randomization schedule on to the practice nurses shortly before the appointment for delivering the intervention." (pg 146)

\begin{tabular}{|c|c|c|}
\hline $\begin{array}{l}\text { Selective reporting (re- } \\
\text { porting bias) }\end{array}$ & Unclear risk & $\begin{array}{l}\text { No protocol available; although it appears that everything was reported it is } \\
\text { difficult to determine this without a protocol }\end{array}$ \\
\hline
\end{tabular}

\begin{tabular}{|c|c|c|}
\hline Other bias & High risk & $\begin{array}{l}\text { "There is also a possibility that MEMS }{ }^{\circledR} \text { may have altered patient behaviour, } \\
\text { although it is unlikely that this effect would have persisted throughout the } \\
\text { whole study period." "We do not know if the high adherence levels observed in } \\
\text { this RCT were due to a self selected population, or whether the results reflect } \\
\text { generally higher adherence levels in the UK." (pg 150) "Baseline blood pres- } \\
\text { sures in both groups were close to our chosen cut-off point of >=150/90, and } \\
\text { only } 94 \text { out of } 245 \text { participants ( } 39 \% \text { ) were 'uncontrolled'." "Lastly, with this } \\
\text { study design there was potential for contamination." (pg 149) }\end{array}$ \\
\hline
\end{tabular}

\begin{tabular}{|c|c|c|}
\hline $\begin{array}{l}\text { Blinding of outcome as- } \\
\text { sessment (detection bias) } \\
\text { Adherence measure }\end{array}$ & Low risk & $\begin{array}{l}\text { (PRIMARY) MEMS - Open RCT; practice nurses were aware of the group alloca- } \\
\text { tion. However, low risk proposed because it appears that practice nurses were } \\
\text { not involved in data collection and unaware of results until completion of the } \\
\text { study }\end{array}$ \\
\hline
\end{tabular}

Blinding of outcome as- Unclear risk sessment (detection bias) (PRIMARY) BLOOD PRESSURE MEASUREMENT - No information on whether the Patient outcome method of taking blood pressure was automated. There is insufficient information to permit judgment of 'Low risk' or 'High risk'

Blinding of participants High risk (performance bias) (PRIMARY) MEMS - No patient blinding. "In this open RCT both the study particAdherence measure ipants and the practice nurses were aware of the group assignment at completion of the baseline period". (pg 146)

\begin{tabular}{|c|c|c|}
\hline $\begin{array}{l}\text { Blinding of participants } \\
\text { (performance bias) }\end{array}$ & Unclear risk & $\begin{array}{l}\text { (PRIMARY) BLOOD PRESSURE MEASUREMENT - There is insufficient informa- } \\
\text { tion to permit judgment of 'Low risk' or 'High risk' }\end{array}$ \\
\hline
\end{tabular}

Patient outcome

(PRIMARY) MEMS - No information on blinding given. There is insufficient infor-

Blinding of personnel (per- Unclear risk formance bias) mation to permit judgment of 'Low risk' or 'High risk'

Adherence measure

(PRIMARY) BLOOD PRESSURE MEASUREMENT - No information on blinding given. There is insufficient information to permit judgment of 'Low risk' or 'High risk' 
Schroeder 2005 (Continued)

Incomplete outcome data Unclear risk (PRIMARY) MEMS - 85\% follow-up in intervention group; 80.3\% in the control. (attrition bias) Actual sample size (245) is less than power calculations (330). No significant

Adherence measure

difference in outcome between groups

Incomplete outcome data Unclear risk

(attrition bias)

(PRIMARY) BLOOD PRESSURE MEASUREMENT - Dropouts not equal across

Patient outcome

groups and reasons not given for all dropouts

Sherrard 2009

\begin{tabular}{|c|c|}
\hline Methods & Randomized controlled trial \\
\hline \multirow[t]{3}{*}{ Participants } & The study location was University of Ottawa Heart Institute (UOHI), Ontario, Canada \\
\hline & $\begin{array}{l}164 \text { participants were randomized to the intervention group and } 167 \text { participants were randomized to } \\
\text { the control group }\end{array}$ \\
\hline & $\begin{array}{l}\text { The inclusion criteria were over the age of } 18 \text {, discharged from the UOHI, underwent coronary artery } \\
\text { bypass grafts and/or valvular surgery, had telephone service to their home, and spoke either English or } \\
\text { French }\end{array}$ \\
\hline
\end{tabular}

The exclusion criteria were: underwent other surgeries such as cardiac transplantation and/or they were discharged to a care facility or other institution

Interventions

Intervention: INTERACTIVE VOICE RESPONSE (IVR)

Patients in the IVR follow-up group received automated telephone calls for 6 months, at 1, 2, 3, 4, 6, $8,10,12,16,20$, and 24 weeks after discharge. The telephone interview contained an algorithm of 11 questions addressing medication compliance, reporting of adverse events, providing information on common medications, and offering general medication safety tips. The intent of the IVR algorithm was to provide early identification of issues permitting timely intervention, provide a mechanism for tracking medication compliance, and provide medication information at the time deemed most valuable by the patient at his or her request and to provide longer term follow-up as the patient transitioned from hospital to home. Patients were asked questions about medication compliance such as, "Did you fill the prescriptions given to you at discharge?" and were offered additional information on 8 common medications prescribed to cardiac surgical patients on discharge. The answers to the questions were captured in a database. Depending on the response, a colored flag appears in the database next to the question indicating no action is needed, the call was not answered, or alerting the nurse to intervene by calling the patient to provide education and counseling

Control: USUAL CARE

Patients in the control group received the standard of care provided to all patients discharged from post-cardiac surgery. This included receiving an IVR call on day 3 and 10 after discharge to screen common symptoms. This current surgical follow-up algorithm does not contain questions or information on medications. They were contacted at 6 months to answer questions on medication compliance and outcomes

Outcomes

The measure of adherence was contacting of patients at 6 months via telephone to answer questions on medication compliance

The patient outcomes were hospitalizations and emergency room visits, assessed via questionnaire during IVR follow-up

Notes -

\section{Risk of bias}


Sherrard 2009 (Continued)

Random sequence genera- Unclear risk tion (selection bias)

Randomization was not described in detail. "Allocation to the treatment group was blinded by using a sealed envelope identified by study number and containing the random allocation. Randomization occurred once consent to participate was obtained." (pg 11)

Allocation concealment Unclear risk

(selection bias)

Allocation concealed through use of sealed envelopes but there is no mention of opaque envelopes. "Allocation to the treatment group was blinded by using a sealed envelope identified by study number and containing the random allocation. Randomization occurred once consent to participate was obtained." (pg 11)

\begin{tabular}{|c|c|c|}
\hline $\begin{array}{l}\text { Selective reporting (re- } \\
\text { porting bias) }\end{array}$ & Unclear risk & $\begin{array}{l}\text { No protocol available; although it appears that everything was reported it is } \\
\text { difficult to determine this without a protocol }\end{array}$ \\
\hline Other bias & Unclear risk & $\begin{array}{l}\text { There are limitations to this study. "The six month surveys were conducted by } \\
\text { telephone interview by the research nurse coordinator who had intervened } \\
\text { with the patients during the study. The lack of anonymity may have caused a } \\
\text { favorable response bias. Recall was required for questions on emergency visits } \\
\text { and hospitalization. The interview schedule was not pre-tested. Close-ended, } \\
\text { forced choice dichotomous questions limited the potential responses of the } \\
\text { patients." (pg 15) }\end{array}$ \\
\hline
\end{tabular}

\begin{tabular}{lll}
\hline $\begin{array}{l}\text { Blinding of outcome as- } \\
\text { sessment (detection bias) }\end{array}$ & High risk & $\begin{array}{l}\text { (PRIMARY) SELF REPORT - QUESTIONNAIRE - "The six-month surveys were con- } \\
\text { ducted by telephone interview by the research nurse coordinator who had in- } \\
\text { tervened with the patients during the study" (pg 15) }\end{array}$
\end{tabular}

\begin{tabular}{lll}
\hline $\begin{array}{l}\text { Blinding of outcome as- } \\
\text { sessment (detection bias) }\end{array}$ & High risk & $\begin{array}{l}\text { (PRIMARY) COMPOSITE OUTCOME (HOSPITALIZATIONS, ER VISITS) - "The six- } \\
\text { month surveys were conducted by telephone interview by the research nurse } \\
\text { coordient outcome }\end{array}$ \\
\hline
\end{tabular}

\begin{tabular}{|c|c|c|}
\hline $\begin{array}{l}\text { Blinding of participants } \\
\text { (performance bias) }\end{array}$ & High risk & $\begin{array}{l}\text { (PRIMARY) SELF REPORT - QUESTIONNAIRE - This is a subjective measure; } \\
\text { there is no information on blinding }\end{array}$ \\
\hline
\end{tabular}

\begin{tabular}{|c|c|c|}
\hline $\begin{array}{l}\text { Blinding of participants } \\
\text { (performance bias) } \\
\text { Patient outcome }\end{array}$ & Unclear risk & $\begin{array}{l}\text { (PRIMARY) COMPOSITE OUTCOME (HOSPITALIZATIONS, ER VISITS) - No men- } \\
\text { tion of patient blinding; it is unclear if blinding might impact outcome report- } \\
\text { ing }\end{array}$ \\
\hline
\end{tabular}

Blinding of personnel (per- Unclear risk formance bias)

Adherence measure

(PRIMARY) SELF REPORT - QUESTIONNAIRE - No information on blinding given. There is insufficient information to permit judgment of 'Low risk' or 'High risk'

\begin{tabular}{|c|c|c|}
\hline $\begin{array}{l}\text { Blinding of personnel (per- } \\
\text { formance bias) } \\
\text { Patient outcome }\end{array}$ & Unclear risk & $\begin{array}{l}\text { (PRIMARY) COMPOSITE OUTCOME (HOSPITALIZATIONS, ER VISITS) - No infor- } \\
\text { mation on blinding given. There is insufficient information to permit judgment } \\
\text { of 'Low risk' or 'High risk' }\end{array}$ \\
\hline $\begin{array}{l}\text { Incomplete outcome data } \\
\text { (attrition bias) } \\
\text { Adherence measure }\end{array}$ & Unclear risk & $\begin{array}{l}\text { (PRIMARY) SELF REPORT - QUESTIONNAIRE - The survey response rates were } \\
84 \% \text { and } 86 \% \text { for the IVR and UC group respectively. The response rate is bal- } \\
\text { anced across both groups but not reasons given for missing data }\end{array}$ \\
\hline $\begin{array}{l}\text { Incomplete outcome data } \\
\text { (attrition bias) } \\
\text { Patient outcome }\end{array}$ & Unclear risk & $\begin{array}{l}\text { (PRIMARY) COMPOSITE OUTCOME (HOSPITALIZATIONS, ER VISITS) - The survey } \\
\text { response rates were } 84 \% \text { and } 86 \% \text { for the IVR and UC group respectively. The } \\
\text { numbers are balanced across the groups but no reason for missing data is giv- } \\
\text { en }\end{array}$ \\
\hline
\end{tabular}


Simon 2011

\begin{tabular}{ll}
\hline Methods & Randomized controlled trial \\
\hline Participants & $\begin{array}{l}\text { The study location was } 9 \text { primary care clinics in Bellevue, Burien, Everett, Olympia, Renton, Seattle, and } \\
\text { Spokane, Washington, USA } \\
106 \text { participants were randomized to the intervention group and } 102 \text { participants were randomized to } \\
\text { the control group } \\
\text { The inclusion criteria were age } 18 \text { or older, filled a new antidepressant prescription from a participating } \\
\text { primary care physician; did not fill any prescription for antidepressant medication in the prior } 270 \text { days; } \\
\text { had a diagnosis of a depressive disorder associated with the prescription; was registered to use online } \\
\text { messaging; and received no diagnosis of bipolar disorder or psychotic disorder nor any prescription for } \\
\text { mood stabilizer or antipsychotic medication in the prior } 2 \text { years }\end{array}$ \\
\hline
\end{tabular}

Interventions

Intervention: CARE MANAGEMENT

Intervention group received care management intervention in addition to usual care by the treating physician. The intervention was delivered online but the structure was similar to the telephone programs tested in earlier studies. After randomization, participants received a welcome letter describing the program and it contained general advice about the antidepressants medication and self care for depression. Monitoring contacts were scheduled 2, 6, and 10 weeks later. At each monitoring contact, there was an outreach message from the nurse containing a link to an online assessment. The assessment included the PHQ depression questionnaire and questions regarding use of antidepressant medication, side effects, and reasons for medication discontinuation. Those not responding were sent up to 2 reminder messages. For each assessment completed, an algorithm generated a suggested response based on PHQ depression score, current antidepressant use, and side effects. The care manager could tailor this suggested response using information in the medical record or in messages since the last contact. The care manager communicated with the treating physician using an electronic messaging system within the electronic medical record. In consultation with the physician, the care manager might facilitate follow-up visits, support changes in medication, or facilitate referral for specialty care (including urgent referrals in case of suicidal ideation or severe symptoms). Each of the 3 care management contacts included this cycle: outreach message from the care manager, patient completion of online assessment, structured response from the care manager, and follow-up communication with the patient and physician as needed. The care manager's messages to patients included brief support but no formal psychotherapy. Patients were free to send additional messages or telephone the care manager if needed. The care manager was expected to make outreach telephone calls in case of suicidal ideation or other urgent clinical need. All outgoing messages were in English. The care manager in this trial was a registered nurse with added certification in psychiatry and 15 years of experience in mental health

Control: USUAL CARE

Controls received usual care and did not receive any additional care other than what was normally available, which included follow-up in primary care or specialty referral for psychotherapy or medication management. Online patient-provider messaging was available to all patients in the usual care

The measures of adherence were electronic medical records checks for filled antidepressant prescriptions. Prescription refill data were used to assess 2 measures of antidepressant use: the total days dispensed AND receipt of a second antidepressant (indicating medication switch or combination)

The patient outcomes were the SCL depression score and a single-item rating of satisfaction with depression care on a 7-point scale ranging from "very dissatisfied" to "very satisfied". Consistent with previous trials, comparison of satisfaction ratings considered the proportion "very satisfied". For all potential participants, computerized membership and medical records were used to examine demographic characteristics, and overall medical morbidity

\section{Notes} $-$

\section{Risk of bias}


Simon 2011 (Continued)

Random sequence genera- Low risk tion (selection bias)
Random number generated. (pg 699) "Following the survey, each participant was randomly assigned to continued usual care or to the intervention program and was immediately notified of her/his assignment. Assignments were automatically generated by the survey database using a random number generator with no blocking or stratification. Treating physicians were not notified regarding study participation or group assignment, but (as described below) physicians of intervention group patients were later contacted by the care manager."

Allocation concealment Unclear risk
(selection bias)

Allocation concealment Unclear risk (selection bias)
No clear mention of allocation concealment. (pg 699) "Following the survey, each participant was randomly assigned to continued usual care or to the intervention program and was immediately notified of her/his assignment. Assignments were automatically generated by the survey database using a random number generator with no blocking or stratification. Treating physicians were not notified regarding study participation or group assignment, but (as described below) physicians of intervention group patients were later contacted by the care manager."

\begin{tabular}{lll}
\hline $\begin{array}{l}\text { Selective reporting (re- } \\
\text { porting bias) }\end{array}$ & Unclear risk & No protocol available
\end{tabular}

Other bias

Unclear risk

(pg 703) "We should emphasize that these findings only apply to patients able and willing to communicate by online messaging. Nearly $80 \%$ of Americans have home internet access, 29 and surveys find high interest in e-mail communication with health care providers. 30 Financial incentives authorized by the 2009 Recovery Act may further increase availability of online health communication, especially if those incentives define meaningful use of electronic records to include online patient-provider communication. 31 Nevertheless, disadvantaged populations may have less access to online health services. In our sample of patients starting antidepressant treatment, those not registered for online services more often lived in disadvantaged neighborhoods. Approximately half of those registered to use online services enrolled in this trial, compared to $60 \%$ to $65 \%$ participation in similar trials of telephone care management. Non-participation may have reflected reservations about online depression follow-up or reservations about participation in a clinical trial. Participation may have been greater if (as in previous trials of telephone interventions) the initial invitation had come from the patient's health care team rather than a researcher and was followed by vigorous telephone outreach. The overall completion rate for care management contacts was approximately $85 \% \mathrm{com}$ pared to $95 \%$ in previous telephone programs. Despite these lower completion rates, clinical benefits (considering all patients randomized) were similar. This study was conducted in an integrated health care system with shared records of medical and mental health care as well as established collaborative relationships between primary care and mental health providers. The efficiency and clinical benefit of this program might be difficult to replicate outside of an integrated system. Follow-up in the usual care group was more intensive than in typical primary care practice, probably reflecting both above average follow-up rates in this setting 2,5 and a greater likelihood of research participants to return for follow-up. Testing this intervention among patients receiving above-average follow-up care could create a conservative bias (i.e. reduce the likelihood of showing a benefit)".

\begin{tabular}{lll}
\hline $\begin{array}{l}\text { Blinding of outcome as- } \\
\text { sessment (detection bias) } \\
\text { Adherence measure }\end{array}$ & Unclear risk & $\begin{array}{l}\text { (PRIMARY) PHARMACY REFILL DATA - No mention of blinding, unclear if lack of } \\
\text { blinding would influence outcome }\end{array}$ \\
\hline $\begin{array}{l}\text { Blinding of outcome as- } \\
\begin{array}{l}\text { sessment (detection bias) } \\
\text { Patient outcome }\end{array}\end{array}$ & Low risk & $\begin{array}{l}\text { (PRIMARY) SCL DEPRESSION SCORE - The surveys were filled out by the partic- } \\
\text { ipants. "Approximately five months after randomization each participant in } \\
\text { the care management and usual care groups received a message inviting par- }\end{array}$ \\
\hline
\end{tabular}


Simon 2011 (Continued)

ticipation in a research follow-up survey" (pg 700). Thus, the data collectors would not influence this outcome measure

\begin{tabular}{|c|c|c|}
\hline $\begin{array}{l}\text { Blinding of participants } \\
\text { (performance bias) } \\
\text { Adherence measure }\end{array}$ & Low risk & $\begin{array}{l}\text { (PRIMARY) PHARMACY REFILL DATA - No mention of blinding; pharmacy refill } \\
\text { objective and should not be influenced by patient blinding }\end{array}$ \\
\hline $\begin{array}{l}\text { Blinding of participants } \\
\text { (performance bias) } \\
\text { Patient outcome }\end{array}$ & High risk & $\begin{array}{l}\text { (PRIMARY) SCL DEPRESSION SCORE - Participants were not blinded to the } \\
\text { study groups; subjective measure. "Following the survey, each participant was } \\
\text { randomly assigned to continued usual care or to the intervention program and } \\
\text { was immediately notified of her/his assignment." (pg 699) }\end{array}$ \\
\hline
\end{tabular}

Blinding of personnel (per- Unclear risk $\quad$ (PRIMARY) PHARMACY REFILL DATA - No mention of blinding; unclear if lack of formance bias) blinding would influence outcome

Adherence measure

Blinding of personnel (per- Unclear risk

formance bias)

(PRIMARY) SCL DEPRESSION SCORE - The surveys were filled out by the partic-

Patient outcome ipants. "Approximately five months after randomization each participant in the care management and usual care groups received a message inviting participation in a research follow-up survey" (pg 700). Thus, the data collectors would not influence this outcome measure

Incomplete outcome data Low risk
(attrition bias)

Adherence measure

(PRIMARY) PHARMACY REFILL DATA - No incomplete data were identified. Figure 1 shows that all 106 from the intervention group and 102 from the control group were included in data analysis for health utilization. This could be because this outcome was measured from the electronic medical records, thus there might not have been any missing data

\begin{tabular}{|c|c|c|}
\hline $\begin{array}{l}\text { Incomplete outcome data } \\
\text { (attrition bias) }\end{array}$ & Unclear risk & $\begin{array}{l}\text { (PRIMARY) SCL DEPRESSION SCORE - Unequal dropouts across groups; no rea- } \\
\text { sons provided for dropouts }\end{array}$ \\
\hline
\end{tabular}

\section{Simoni 2007}

\begin{tabular}{|c|c|}
\hline Methods & Randomized controlled trial \\
\hline \multirow[t]{4}{*}{ Participants } & The study location was The study location was Jacobi Medical Center, Bronx, New York, USA \\
\hline & $\begin{array}{l}71 \text { participants were randomized to the intervention group and } 65 \text { participants were randomized to the } \\
\text { control group }\end{array}$ \\
\hline & $\begin{array}{l}\text { The inclusion criteria were } 18 \text { years or older, proficient in English, on prescribed HAART regimen and } \\
\text { without dementia or psychosis }\end{array}$ \\
\hline & The exclusion criteria were dementia or psychosis \\
\hline \multirow[t]{4}{*}{ Interventions } & Intervention: PEER SUPPORT \\
\hline & $\begin{array}{l}\text { Patients in the peer support group had } 6 \text { twice-monthly meetings during the 3-month peer support in- } \\
\text { tervention where peers and participants met with other peers and participants to discuss shared ex- } \\
\text { periences, barriers to HAART adherence, life issues, etc. The group meetings were facilitated by an A } \\
\text { but were predominately peer-led. Between group meetings, peers were instructed to call each of their } \\
\text { study participants } 3 \text { times weekly to provide more in-depth one-on-one attention and feedback }\end{array}$ \\
\hline & Control: STANDARD CARE \\
\hline & $\begin{array}{l}\text { Standard of care (control) patients received no additional adherence assistance beyond the clinic's } \\
\text { typical offerings (consultation with primary providers and social and mental health referrals when re- } \\
\text { quested) }\end{array}$ \\
\hline
\end{tabular}


Simoni 2007 (Continued)

Outcomes
The measures of adherence were by EDM use with the most frequently dosed medication. The EDM data were uploaded at the 3- and 6-month interviews. At baseline and 3 and 6 months, participants were administered the Adult AIDS Clinical Trials Group Adherence to Antiretrovirals Instrument. For each medication prescribed, patients reported for each of the last 3 days the number of doses taken. We computed an adherence variable that consisted of the percentage of doses taken (according to self report) over those prescribed (according to medical record) for the past 3 days

The patient outcomes were HIV-1 RNA viral load, taken from the patient records, and depressive symptomatology using the 20-item Centers for Epidemiological Studies Depression Scale administered by the research assistant during follow-up interviews

\begin{tabular}{ll}
\hline Notes & - \\
\hline Risk of bias &
\end{tabular}

\begin{tabular}{lll}
\hline Bias & Authors' judgement & Support for judgement \\
\hline $\begin{array}{l}\text { Random sequence genera- } \\
\text { tion (selection bias) }\end{array}$ & Low risk & $\begin{array}{l}\text { A computer random number generator was used for randomization. "Random } \\
\text { assignment to condition was based on a computer-generated allocation se- } \\
\text { quence prepared by an external statistician." (pg 489) }\end{array}$ \\
\hline $\begin{array}{l}\text { Allocation concealment } \\
\text { (selection bias) }\end{array}$ & Low risk & $\begin{array}{l}\text { "Allocation concealment involved the use of sequentially numbered, opaque, } \\
\text { sealed envelopes containing the group assignment, which the RAs opened } \\
\text { at the moment of randomization after participants were consented and en- } \\
\text { rolled." (pg 489) }\end{array}$ \\
\hline
\end{tabular}

Selective reporting (re- Low risk
porting bias)

No protocol but expected outcomes clearly stated. "In the present study, we evaluated a peer support intervention grounded in our social support model of adherence that posits a central role for depressive symptomatology in nonadherence. The randomized controlled trial (RCT) involved men and women living with HIV/AIDS in the Bronx, New York, and included an a priori primary clinical outcome and the secondary outcomes of adherence, social support, and depressive symptomatology." (pg 489)

\begin{tabular}{ll}
\hline Other bias & (pg 489) Study may have been underpowered according to authors - "Initial \\
calculations, based on .83 power to detect a significant difference ( $\mathrm{p}$ beta .05, & two-tailed), had indicated 75 patients were required for each study group." (pg \\
& 491) "Although the trial was moderately underpowered, the size of the differ- \\
ence in the outcomes between conditions suggests that power was not an is- & sue." (pg 492) When EDM is not opened, cannot determine whether the partic- \\
ipant missed a dose of medication or was not using the device: 3-month inter- & vention too short for participants to develop comfortable rapport with peer \\
support - low attendance at intervention meetings and phone call contact by & peers (many barriers to attending and fear of having their HIV status exposed \\
to others) - sample had high substance abuse that would lead to less compli- & ance - high number had previous use of unsuccessful regimens of HAART that \\
may have made them resistant to meds
\end{tabular}

\begin{tabular}{|c|c|c|}
\hline $\begin{array}{l}\text { Blinding of outcome as- } \\
\text { sessment (detection bias) }\end{array}$ & Low risk & $\begin{array}{l}\text { (PRIMARY) SELF REPORT - QUESTIONNAIRE - "RAs conducting the follow-up } \\
\text { assessments were blinded to the study condition of the interviewees." (pg 490) }\end{array}$ \\
\hline
\end{tabular}

\begin{tabular}{lll}
\hline $\begin{array}{l}\text { Blinding of outcome as- } \\
\begin{array}{l}\text { sessment (detection bias) } \\
\text { Patient outcome }\end{array}\end{array}$ & Low risk & $\begin{array}{l}\text { (PRIMARY) HIV-1 RNA VIRAL LOAD - "RAs conducting the follow-up assessments } \\
\text { were blinded to the study condition of the interviewees." (pg 490) }\end{array}$ \\
\hline $\begin{array}{l}\text { Blinding of participants } \\
\begin{array}{l}\text { (performance bias) } \\
\text { Adherence measure }\end{array}\end{array}$ & High risk & $\begin{array}{l}\text { (PRIMARY) SELF REPORT - QUESTIONNAIRE - "Due to the nature of the inter- } \\
\text { vention, participants could not be uninformed of the study condition" (pg 490) }\end{array}$ \\
\hline
\end{tabular}


Simoni 2007 (Continued)

Blinding of participants

Patient outcome

\begin{tabular}{|c|c|c|}
\hline $\begin{array}{l}\text { Blinding of personnel (per- } \\
\text { formance bias) }\end{array}$ & Unclear risk & $\begin{array}{l}\text { (PRIMARY) SELF REPORT - QUESTIONNAIRE - No information on blinding given. } \\
\text { There is insufficient information to permit judgment of 'Low risk' or 'High risk' }\end{array}$ \\
\hline
\end{tabular}

Adherence measure

(PRIMARY) HIV-1 RNA VIRAL LOAD - This is an objective measure of outcome

Blinding of personnel (per- Low risk

formance bias)

Patient outcome

\begin{tabular}{lll}
\hline $\begin{array}{l}\text { Incomplete outcome data } \\
\text { (attrition bias) } \\
\text { Adherence measure }\end{array}$ & Unclear risk & $\begin{array}{l}\text { (PRIMARY) SELF REPORT - QUESTIONNAIRE - Attrition rates not balanced; rea- } \\
\text { sons for attrition not known }\end{array}$ \\
\hline $\begin{array}{l}\text { Incomplete outcome data } \\
\text { (attrition bias) }\end{array}$ & Unclear risk & $\begin{array}{l}\text { (PRIMARY) HIV-1 RNA VIRAL LOAD - Attrition rates not similar; reasons not avail- } \\
\text { Patient outcome }\end{array}$ \\
\hline
\end{tabular}

\section{Simoni 2009}

\begin{tabular}{ll}
\hline Methods $\quad$ Randomized controlled trial \\
\hline
\end{tabular}

Participants The study location was Harborview Medical Center, Seattle, Washington, USA

57 participants were randomized to peer support; 56 to pager messaging; 56 to pager messaging and peer support; and 57 to the control group

The inclusion criteria were (a) at least 18 years of age, (b) proficient in English, (c) living within the service area of the pager, and (d) initiating or changing at least 2 medications of a HAART regimen

The exclusion criteria were cognitively impaired, actively psychotic, or had a known history of harming others

\footnotetext{
Interventions
}

\begin{abstract}
Intervention: PEER SUPPORT
The 3-month peer support intervention consisted of 2 parts: (a) 6 twice-monthly, 1-hour gatherings held at the clinic, consisting of all peers and actively enrolled participants in the peer support arm and (b) weekly phone calls from peers to participants. At the time of enrollment, participants were assigned to individual peers by study staff based on peer availability and presumed compatibility. In the group setting, participants had the opportunity to interact face-to-face with their assigned peer and meet the other peers and participants, with the goal of benefiting from the discussion of the shared experiences of the group. The meetings were designed to identify barriers to HAART adherence and generate problem-solving strategies to overcome them. Other emerging themes included life issues that impact adherence, including HIV status disclosure, dating, substance use, and struggles with mental health issues. One of several research staff members co-ordinated the groups by making reminder phone calls, preparing the meeting room, and providing refreshments. With assistance from the peers, they facilitated the meetings by refocusing the discussion on adherence-related topics when appropriate. Otherwise, they refrained from interfering with the group process and the exchange of support among peers and participants, resulting in predominantly peer led groups. Participants received a USD 15 incentive for attending each of the 6 sessions. All were welcomed to continue attending thereafter but were provided neither reminder phone calls nor monetary incentives for additional meetings. Between group meetings, peers were instructed to call each of their study participants weekly to provide more in-depth one-on-one attention and feedback. Phone calls also were better suited for participants with confidentiality concerns and those who had difficulty traveling to the clinic or had scheduling conflicts with the set meeting times. Peers were instructed not to initiate contact with participants after the 3month intervention period, but they were allowed to respond to requests for contact from the participants at their own discretion.
\end{abstract}


Simoni 2009 (Continued)

Intervention: PAGER MESSAGING

The 3-month pager intervention consisted of a customized pager system that combined the communicating abilities of the world-wide web and 2-way pagers. A computer program allowed for the timing of all text messages to be specified up front and then sent automatically without any further intervention from study staff. At randomization, the study co-ordinator distributed a 2-way pager and customized a message schedule to the participant's daily medication regimen, which was confirmed by the clinic pharmacist. In addition to dose reminders, 3 other types of text messages were sent: (1) educational; (2) entertainment (jokes or thoughts for the day); and (3) adherence assessments. There was some flexibility in the frequency and content of messages to accommodate participants' differing needs and schedules, but there was a minimum of 3 pager messages sent daily to participants for the first 2 months. Pages gradually tapered in the last month of the 3-month intervention to avoid a rebound in non-adherence. A confirmation return page was requested for every message sent. Project staff periodically reviewed the return page log and if no responses were received, the participant could be called to determine if they were having any problems with the pager. Between the first contact and the end of the 3-month intervention, the participants were asked to wear the pager at all waking moments. Participants had to use the study pagers and could not substitute with their own pager or cell phone. They were instructed not to use the devices for personal use. Participants could select from a variety of auditory alarms or a vibrate-only option if desired. If the pager was lost or failed, it was promptly replaced at no cost to the subject

Control: USUAL CARE

Before initiation of HAART, all clinic patients who are naive patients or off HAART for more than 6 months are required to complete the HAART protocol, a clinic-based program designed to provide education regarding HAART and adherence and to identify and correct adherence barriers before HAART initiation. The HAART protocol involves a series of 3 separate appointments with a pharmacist, nutritionist, and case manager after an initial meeting with a provider and before a final meeting when the provider decides whether to prescribe HAART. During these preliminary interviews, patients are given social and mental health referrals as appropriate, a daily medication schedule, and information on medication side effects and techniques to help manage them. All participants in each of the study's 4 arms participated in the HAART protocol if they had not received it in the last 6 months. There were no time or attention-control activities

Outcomes

The measures of adherence were self reported adherence and Electronic Drug Monitor-based adherence, measured at 3 months, 6 months, and 9 months. Self reported adherence was measured with 1 item from the Simplified Medication Adherence Questionnaire assessing the number of doses missed during the previous week. The measure was taken via a computer-assisted self interview. Participants were provided with an EDM for the duration of the trial. Each participant was given one EDM to use with the most frequently dosed antiretroviral. The EDM adherence was calculated by the number of bottle openings recorded during the prior 7 days before each assessment divided by the number of prescribed doses

The patient outcomes were HIV-1 RNA viral load (VL) and CD4 lymphocyte count. Patients were assessed at 3, 6, and 9 months. At each assessment, blood was drawn to determine HIV-1 RNA viral load (VL) and CD4 lymphocyte count. Study staff abstracted VL and CD4 lymphocyte counts from patient medical records if they were available within 30 days of the baseline, 3-month, 6-month, and 9-month interviews; otherwise, blood draws for VL and CD4 counts were conducted the day of the interview. Clinical outcomes were analyzed as continuous variables and as dichotomous variables with cut offs for VL of undetectable, 1000, and 10,000 and for CD4 of 350 at each assessment point and across all 3 follow-up assessments

\begin{tabular}{lll}
\hline Notes & - \\
\hline Risk of bias & \\
\hline Bias & Authors' judgement & Support for judgement \\
\hline $\begin{array}{l}\text { Random sequence genera- } \\
\text { tion (selection bias) }\end{array}$ & Low risk & $\begin{array}{l}\text { "An external statistician had used a computerized random number generator } \\
\text { to select random permuted blocks of 4." (pg 466) }\end{array}$ \\
\hline
\end{tabular}


Simoni 2009 (Continued)

$\begin{array}{ll}\begin{array}{l}\text { Allocation concealment Low risk } \\ \text { (selection bias) }\end{array} & \begin{array}{l}\text { "Allocation concealment involved the use of sequentially numbered, opaque, } \\ \text { sealed envelopes containing the study arm assignment, which the study staff } \\ \text { opened at the moment of randomization." (pg 466) }\end{array}\end{array}$

\begin{tabular}{|c|c|c|}
\hline $\begin{array}{l}\text { Selective reporting (re- } \\
\text { porting bias) }\end{array}$ & Unclear risk & $\begin{array}{l}\text { No protocol available; although it appears that everything was reported it is } \\
\text { difficult to determine this without a protocol }\end{array}$ \\
\hline
\end{tabular}

\begin{tabular}{lll}
\hline Other bias & Low risk & The study seems to be free of other types of bias \\
\hline $\begin{array}{l}\text { Blinding of outcome as- } \\
\text { sessment (detection bias) } \\
\text { Adherence measure }\end{array}$ & Low risk & (PRIMARY) EDM - MEMS type measure, unlikely staff would bias the results \\
\end{tabular}

\begin{tabular}{|c|c|c|}
\hline $\begin{array}{l}\text { Blinding of outcome as- } \\
\text { sessment (detection bias) } \\
\text { Adherence measure }\end{array}$ & Low risk & $\begin{array}{l}\text { (PRIMARY) SELF REPORT - QUESTIONNAIRE - Self interview, staff unlikely to } \\
\text { bias responses }\end{array}$ \\
\hline
\end{tabular}

\begin{tabular}{|c|c|c|}
\hline $\begin{array}{l}\text { Blinding of outcome as- } \\
\text { sessment (detection bias) } \\
\text { Patient outcome }\end{array}$ & Low risk & (PRIMARY) VIRAL LOAD - This is an objective measure of outcome \\
\hline $\begin{array}{l}\text { Blinding of participants } \\
\text { (performance bias) } \\
\text { Adherence measure }\end{array}$ & High risk & $\begin{array}{l}\text { (PRIMARY) EDM - "Due to the nature of the intervention, participants, study } \\
\text { staff, and data analysts could not be completely blinded to study arm assign- } \\
\text { ment." (pg 466) }\end{array}$ \\
\hline $\begin{array}{l}\text { Blinding of participants } \\
\text { (performance bias) } \\
\text { Adherence measure }\end{array}$ & High risk & $\begin{array}{l}\text { (PRIMARY) SELF REPORT - QUESTIONNAIRE - "Due to the nature of the inter- } \\
\text { vention, participants, study staff, and data analysts could not be completely } \\
\text { blinded to study arm assignment." (pg 466) This is a subjective outcome mea- } \\
\text { sure }\end{array}$ \\
\hline
\end{tabular}

Blinding of participants Low risk
(performance bias)

Patient outcome

\begin{tabular}{|c|c|c|}
\hline $\begin{array}{l}\text { Blinding of personnel (per- } \\
\text { formance bias) } \\
\text { Adherence measure }\end{array}$ & Low risk & (PRIMARY) EDM - This is an objective measure of outcome \\
\hline $\begin{array}{l}\text { Blinding of personnel (per- } \\
\text { formance bias) } \\
\text { Adherence measure }\end{array}$ & Low risk & $\begin{array}{l}\text { (PRIMARY) SELF REPORT - QUESTIONNAIRE - Self interview, staff unlikely to } \\
\text { bias responses }\end{array}$ \\
\hline
\end{tabular}

Adherence measure

Blinding of personnel (per- Low risk

formance bias)

Patient outcome

(PRIMARY) VIRAL LOAD - This is an objective measure of outcome

\begin{tabular}{|c|c|c|}
\hline $\begin{array}{l}\text { Incomplete outcome data } \\
\text { (attrition bias) } \\
\text { Adherence measure }\end{array}$ & Low risk & $\begin{array}{l}\text { (PRIMARY) SELF REPORT - QUESTIONNAIRE - "To assess for differences be- } \\
\text { tween participants with complete self report data ( } 79 \%) \text {, those who missed a } \\
\text { single assessment (13\%), and those who missed } 2 \text { or more assessments ( } 9 \%) \text {, } \\
\text { x2 tests and one-way analysis of variances were conducted on categorical and } \\
\text { continuous sociodemographic characteristics, respectively. No significant dif- } \\
\text { ferences were found among these } 3 \text { groups." (pg 469) }\end{array}$ \\
\hline
\end{tabular}

\begin{tabular}{|c|c|c|}
\hline $\begin{array}{l}\text { Incomplete outcome data } \\
\text { (attrition bias) } \\
\text { Adherence measure }\end{array}$ & Low risk & $\begin{array}{l}\text { (PRIMARY) EDM - "Missing EDM adherence data were tabulated separately as } \\
\text { this data could be available even if a self report assessment was missing. For } \\
\text { EDM adherence, } 88 \% \text { of participants had complete data, } 5 \% \text { were missing a } \\
\text { single assessment, and } 8 \% \text { were missing } 2 \text { or more assessments. No significant } \\
\text { differences were found among these } 3 \text { groups." (pg 469) }\end{array}$ \\
\hline
\end{tabular}


Simoni 2009 (Continued)

Incomplete outcome data Unclear risk (PRIMARY) VIRAL LOAD - Not enough information given on the reasons for (attrition bias)

dropouts. These were not evenly spread across groups

Patient outcome

Simoni 2011

\begin{tabular}{ll}
\hline Methods & Randomized controlled trial \\
\hline Participants & The study location was Ditan hospital, Beijing, China \\
& $\begin{array}{l}36 \text { participants were randomized to the intervention group and } 34 \text { participants were randomized to the } \\
\text { control group }\end{array}$
\end{tabular}

The inclusion criteria were mandarin speaking, above 18 years of age, CD4 counts lower than 350 cells / $\mathrm{mm}^{3}$,otherwise eligible for ART, willing to or capable of attending follow-up visits at the hospital

The exclusion criteria were cognitive impairment, actively psychotic

Interventions
Intervention: ENHANCED INTERVENTION ARM

Patients assigned to the intervention arm could choose an alarm device, counseling, or both. The alarm device was either a cell phone (if the patient so chose) or a small battery-powered electronic alarm device. In either case, the project staff helped the patient set up the device of their choice. Counseling was delivered by a bachelor level nurse. In accordance with a manualized protocol, the counseling sessions involved a cognitive-behavioral and problem-solving approach to: (1) enhancing motivation for treatment continuation, (2) learning about antiretroviral medication and the prescribed regimen, (3) keeping appointments, (4) communicating with healthcare providers, (5) formulating a daily medication schedule, (6) storing medications, (7) setting reminder strategies, (8) coping with side effects, (9) securing family and social support, (10) handing adherence lapses, and (11) addressing additional barriers. Participants could also invite a treatment partner to attend the counseling sessions with them. A "treatment partner" was defined as someone to whom the participant had already disclosed their HIV status and who was available to assist the participant on a daily basis. Participants who opted to have counseling, either individually or with a treatment adherence partner, had 3 counseling sessions of up to 1 hour each with the study nurse. The first session occurred either at the enrollment interview or within the first 2 weeks of initiating ART; additional counseling sessions occurred at 5 and 9 weeks. If necessary, the later sessions were replaced with counseling provided over the telephone

\section{Control: MINIMAL INTERVENTION ARM}

At the baseline appointment and before initiation of ART, all participants completed a 1-hour interviewer-administered paper-and-pencil baseline survey. They then participated in a 30-minute educational session facilitated with a flip-chart, which was designed to provide information regarding their treatment plans, likely side effects, and the importance of adherence. All patients also were given a daily medication schedule, a plastic pill box to organize daily doses, and a referral card to the hospital-based peer support group. Participants assigned to the minimal intervention were to receive no further adherence-promotion intervention beyond the usual care at the clinic, which involved monthly medication pick-ups and any conversations patients initiated with their healthcare providers. All participants continued to receive medical care as usual at the clinic

Outcomes

The measures of adherence were self reported and electronic drug monitoring device (EDM), using 7day and 30-day assessment intervals. Adherence outcomes were computed for 7 weeks, 13 weeks, and 19 and 25 weeks. Self reported 7-day adherence was based on a single item "How many of your HIV medication doses did you miss in the last 7 days?" for which we computed a dichotomous outcome of $100 \%$ versus less than $100 \%$ adherence. A similar variable based on data covering a 30 day time frame was also calculated. An electronic drug monitoring device known as Medication Event Monitoring System or MEMS was provided to all participants for the duration of the trial. EDM technology consists of a plastic pill vial and modified cap containing a microprocessor capable of recording the precise date and time of each vial opening as a presumptive dose. Each participant was given one EDM to use with nevirapine or efavirenz. Based on EDM data, 2 continuous adherence variables for each assessment 
Simoni 2011 (Continued)

point, defined as the number of bottle openings recorded by the EDM cap during the 7 days and the 30 days before each assessment was computed date divided by the number of prescribed doses according to medical record review. Doses were spaced 12 hours apart and EDM openings 11 to 13 hours after the previous dose were counted for on-time adherence estimates.

The patient outcomes were CD4 lymphocyte count and viral load, which were assessed via blood draws at baseline, 13 weeks, and 25 weeks. As viral load data were not normally distributed, a log 10 transformation of viral load data were conducted and used the transformed values in all analyses. CD4 and viral load were analyzed as continuous variables to enhance power

Notes

\section{Risk of bias}

\begin{tabular}{lll}
\hline Bias & Authors' judgement & Support for judgement \\
\hline $\begin{array}{l}\text { Random sequence genera- } \\
\text { tion (selection bias) }\end{array}$ & Unclear risk & $\begin{array}{l}\text { Randomization was not described in detail. "...sequentially numbered, } \\
\text { opaque, sealed envelopes containing the intervention assignment, which the } \\
\text { staff member opened at the moment of randomization." (pg 921) }\end{array}$ \\
\hline $\begin{array}{l}\text { Allocation concealment } \\
\text { (selection bias) }\end{array}$ & Low risk & No information was provided about how allocation was handled \\
\hline $\begin{array}{l}\text { Selective reporting (re- } \\
\text { porting bias) }\end{array}$ & Unclear risk & $\begin{array}{l}\text { No protocol available; although it appears that everything was reported it is } \\
\text { difficult to determine this without a protocol }\end{array}$ \\
\hline Other bias & High risk & $\begin{array}{l}\text { Same nurses were involved in the care of both groups; therefore there was } \\
\text { a chance of diffusion of intervention. "The nurse intervener was supervised } \\
\text { twice a month by telephone by study investigators to ensure fidelity to the in- } \\
\text { tervention protocol, which included completion of a checklist and a progress } \\
\text { note after each session. Note that the study nurse as well as the other nurses, } \\
\text { all trained in the intervention, continued to see other patients at the hospital, } \\
\text { including those in the minimal intervention arm. It was difficult, therefore, to } \\
\text { limit the diffusion of the intervention." (pg 922) }\end{array}$ \\
\hline
\end{tabular}

Blinding of outcome as-
sessment (detection bias) $\quad$ (PRIMARY) MEMS - This is an objective measure of outcome

Adherence measure

\begin{tabular}{lll}
\hline $\begin{array}{l}\text { Blinding of outcome as- } \\
\begin{array}{l}\text { sessment (detection bias) } \\
\text { Adherence measure }\end{array}\end{array}$ & Unclear risk & $\begin{array}{l}\text { (PRIMARY) SELF REPORT - QUESTIONNAIRE - "Study staff administering sur- } \\
\text { veys, but not the participants and the intervention nurse, were generally blind- } \\
\text { ed to study arm assignment." (pg 921) }\end{array}$ \\
\hline $\begin{array}{l}\text { Blinding of outcome as- } \\
\begin{array}{l}\text { sessment (detection bias) } \\
\text { Patient outcome }\end{array}\end{array}$ & Low risk & $\begin{array}{l}\text { (PRIMARY) CD4 COUNT AND VIRAL LOAD DATA - This is an objective measure of } \\
\text { outcome. "Study staff administering surveys, but not the participants and in- } \\
\text { tervention nurse, were generally blinded to study arm assignment." (pg 921) }\end{array}$ \\
\hline
\end{tabular}

\begin{tabular}{|c|c|c|}
\hline $\begin{array}{l}\text { Blinding of participants } \\
\text { (performance bias) } \\
\text { Adherence measure }\end{array}$ & High risk & (PRIMARY) SELF REPORT - QUESTIONNAIRE - This is a subjective measure \\
\hline $\begin{array}{l}\text { Blinding of participants } \\
\text { (performance bias) } \\
\text { Adherence measure }\end{array}$ & High risk & $\begin{array}{l}\text { (PRIMARY) MEMS - No mention of patient blinding. Patients could have been } \\
\text { aware of the intervention }\end{array}$ \\
\hline $\begin{array}{l}\text { Blinding of participants } \\
\text { (performance bias) } \\
\text { Patient outcome }\end{array}$ & Low risk & $\begin{array}{l}\text { (PRIMARY) CD4 COUNT AND VIRAL LOAD DATA - This is an objective measure of } \\
\text { outcome }\end{array}$ \\
\hline
\end{tabular}


Simoni 2011 (Continued)

Blinding of personnel (per- Unclear risk formance bias)

Adherence measure
(PRIMARY) SELF REPORT - QUESTIONNAIRE - No information on blinding given. There is insufficient information to permit judgment of 'Low risk' or 'High risk'

\author{
Blinding of personnel (per- Low risk \\ formance bias) \\ (PRIMARY) MEMS - This is an objective measure of outcome
}

Adherence measure

Blinding of personnel (per- Low risk

formance bias)

Patient outcome
(PRIMARY) CD4 COUNT AND VIRAL LOAD DATA - This is an objective measure of outcome
Incomplete outcome data Unclear risk

(attrition bias)

Adherence measure

\begin{abstract}
(PRIMARY) SELF REPORT - QUESTIONNAIRE - It is unclear because there is a significant difference between the number of people who dropped out in the control group and the intervention group. However, the percentage retention in the minimal intervention group is above $8 \%$. One of the reasons for dropout is ceasing ART because of severe side effects. "During the course of the trial, 6 of 34 participants enrolled in the minimal intervention arm dropped out due to moving to other provinces, ceasing ART because of severe side effects, losing interest in the study, or transferring to another institution for HIV care. None of the participants in the enhanced arm of the study dropped out. This difference was statistically significant ( $18 \%$ vs. $0 \%)$, Fisher's exact v2 $(1)=6.95, P=$ 0.01 . According to $v 2$ tests and one-way ANOVAs, participants across arms with complete selfreport data (79\%) did not differ from those who missed one or more assessments $(21 \%)$ on any of the main sociodemographic, psychosocial, or biological variables as assessed at baseline." (pg 923)
\end{abstract}

Incomplete outcome data Unclear risk (attrition bias)

Adherence measure
(PRIMARY) MEMS - It is unclear because there is a significant difference between the number of people who dropped out in the control group and the intervention group. However, the percentage retention is the study is above $80 \%$ in the minimal intervention arm. One of the reasons for dropout is ceasing ART because of severe side effects. "During the course of the trial, 6 of 34 participants enrolled in the minimal intervention arm dropped out due to moving to other provinces, ceasing ART because of severe side effects, losing interest in the study, or transferring to another institution for HIV care. None of the participants in the enhanced arm of the study dropped out. This difference was statistically significant ( $18 \%$ vs. $0 \%$ ), Fisher's exact v2(1) $=6.95, P=0.01 . "$ (pg 923)

Incomplete outcome data Unclear risk
(attrition bias)

Patient outcome
(PRIMARY) CD4 COUNT AND VIRAL LOAD DATA - It is unclear because there is a significant difference between the number of people who dropped out in the control group and the intervention group. However, the percentage retention is the study is above $80 \%$ in the minimal intervention arm. One of the reasons for dropouts is ceasing ART because of severe side effects. "During the course of the trial, 6 of 34 participants enrolled in the minimal intervention arm dropped out due to moving to other provinces, ceasing ART because of severe side effects, losing interest in the study, or transferring to another institution for HIV care. None of the participants in the enhanced arm of the study dropped out. This difference was statistically significant ( $18 \%$ vs. $0 \%$ ), Fisher's exact v2 $(1)=6.95, \mathrm{P}=0.01 . "(\mathrm{pg} 923)$

Sirey 2010

\begin{tabular}{ll}
\hline Methods & Randomized controlled trial \\
\hline Participants & The study location was New York City, New York, USA
\end{tabular}

Participants

The study location was New York City, New York, USA 
Sirey 2010 (Continued)

33 participants were randomized to the intervention group and 37 participants were randomized to the control group

The inclusion criteria were adults aged 60 diagnosed with major depression; newly recommended antidepressant treatment by their primary care physicians; confirmed diagnosis via a structured diagnostic interview (Structured Clinical Interview for DSM Disroders [SCID] IV); and score of 14 or greater on the Hamilton Depression Rating Scale

The exclusion criteria were active suicidal ideation; psychotic depression; a history of mania; cognitive impairment (MMSE <24); or unable to communicate in English

\begin{abstract}
Interventions Intervention: TREATMENT INITIATION AND PARTICIPATION PROGRAM (TIP)

The Treatment Initiation and Participation Program (TIP) included 3 30-minute individual meetings between the TIP Counselor and older adult patient during the first 6 weeks of pharmacotherapy, followed by 2 follow-up telephone calls at 8 and 10 weeks after study entry. During these sessions the TIP Counselor and older adult would review symptoms and antidepressant therapy regimen, and conduct a barriers assessment, define a personal goal that could be achieved with adherence, provide education about depression and antidepressant therapy, collaborate to address barriers to treatment participation, create an adherence strategy and facilitate and empower the older adult to talk directly with the primary care physician (PCP) about the treatment. A "contact sheet" listed barriers in each domain and specific intervention techniques and served as the guide for sessions and a record of the interventions administered
\end{abstract}

Control: TREATMENT AS USUAL (TAU)

Patients in the control group continued with treatment as usual

Outcomes

The measure of adherence was the Medication and Nonmedication Treatment Compliance Data form, completed at entry, 6 weeks, 12 weeks, and 24 weeks after entry. It was assessed by trained Research Assistants. At study completion, a chart review recorded the duration of antidepressant treatment and verified a prescription was on record

The patient outcome was depression severity, measured by the Hamilton Depression Rating Scale at entry, 6 weeks, 12 weeks, and 24 weeks. Self report assessment administered by research associates

Notes -

\title{
Risk of bias
}

\begin{tabular}{|c|c|c|}
\hline Bias & Authors' judgement & Support for judgement \\
\hline $\begin{array}{l}\text { Random sequence genera- } \\
\text { tion (selection bias) }\end{array}$ & Unclear risk & $\begin{array}{l}\text { Randomization was not described in detail. "Participants who met study cri- } \\
\text { teria were randomly assigned to either pharmacotherapy as usual (TAU) or } \\
\text { pharmacotherapy with the Treatment Initiation and Participation (TIP) pro- } \\
\text { gram." (pg 3) }\end{array}$ \\
\hline $\begin{array}{l}\text { Selective reporting (re- } \\
\text { porting bias) }\end{array}$ & High risk & $\begin{array}{l}\text { Aside from adherence and HDRS, the WHODAS and use of mental health ser- } \\
\text { vices was assessed, but not reported in results and neither was chart verifi- } \\
\text { cation. "Overall functioning was assessed using the World Health Organiza- } \\
\text { tion Disability Assessment Schedule (WHODAS). At study completion, a chart } \\
\text { review recorded the duration of antidepressant treatment and verified a pre- } \\
\text { scription was on record for those clients who indicated they were taking anti- } \\
\text { depressant medication. Use of mental health services was recorded at } 12 \text { and } \\
24 \text { weeks using the Cornell Services Index. [32]" (pg 3) }\end{array}$ \\
\hline
\end{tabular}

Other bias

High risk

No co-intervention or sham intervention for TAU group. The attention alone could have an effect 
Sirey 2010 (Continued)

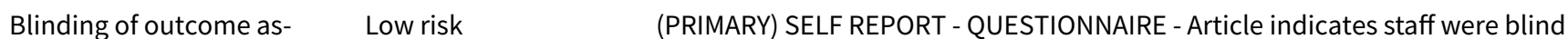
sessment (detection bias) to group. "Assessments were conducted by trained Research Assistants who Adherence measure were unaware of group assignment." (pg 3)
Low risk

Blinding of outcome assessment (detection bias)

Patient outcome
(PRIMARY) DEPRESSIVE SYMPTOMS - Assessments were conducted by trained Research Assistants who were unaware of group assignment

\begin{tabular}{|c|c|c|}
\hline $\begin{array}{l}\text { Blinding of participants } \\
\text { (performance bias) } \\
\text { Adherence masure }\end{array}$ & High risk & $\begin{array}{l}\text { (PRIMARY) SELF REPORT - QUESTIONNAIRE - This is a subjective measure; } \\
\text { there is no information on blinding }\end{array}$ \\
\hline
\end{tabular}

Adherence measure

(PRIMARY) SELF REPORT - QUESTIONNAIRE - This is a subjective measure;

\begin{tabular}{ll}
\hline $\begin{array}{l}\text { Blinding of participants } \\
\text { (performance bias) }\end{array}$ & High risk \\
$\begin{array}{l}\text { Patient outcome } \\
\text { (PRIMARY) DEPRESSIVE SYMPTOMS - This is a subjective measure; there is no } \\
\text { information on blinding }\end{array}$ \\
\hline
\end{tabular}

Blinding of personnel (per- Unclear risk

formance bias)

(PRIMARY) SELF REPORT - QUESTIONNAIRE - Unclear who did the comparisons

Adherence measure with the charts/prescription records and how those might have influenced the scoring of the self report, especially if those personnel were not blinded. Possible source of bias, but not described in article so it is unclear

\begin{tabular}{|c|c|c|}
\hline $\begin{array}{l}\text { Blinding of personnel (per- } \\
\text { formance bias) }\end{array}$ & Unclear risk & $\begin{array}{l}\text { (PRIMARY) DEPRESSIVE SYMPTOMS - No information on blinding given. There } \\
\text { is insufficient information to permit judgment of 'Low risk' or 'High risk' }\end{array}$ \\
\hline
\end{tabular}

Patient outcome

\begin{tabular}{lll}
\hline $\begin{array}{l}\text { Incomplete outcome data } \\
\text { (attrition bias) } \\
\text { Adherence measure }\end{array}$ & Unclear risk & $\begin{array}{l}\text { (PRIMARY) SELF REPORT - QUESTIONNAIRE - No reasons given for why the pa- } \\
\text { tients dropped out }\end{array}$ \\
\hline $\begin{array}{l}\text { Incomplete outcome data } \\
\begin{array}{l}\text { (attrition bias) } \\
\text { Patient outcome }\end{array}\end{array}$ & Unclear risk & $\begin{array}{l}\text { (PRIMARY) DEPRESSIVE SYMPTOMS - No information given on the reasons for } \\
\text { dropout }\end{array}$ \\
\hline
\end{tabular}

\section{Solomon 2012}

\begin{tabular}{ll}
\hline Methods & Randomized controlled trial \\
\hline Participants & The study location was Pennsylvania, USA \\
& $\begin{array}{l}1050 \text { participants were randomized to the intervention group and } 1047 \text { participants were randomized } \\
\text { to the control group } \\
\text { The inclusion criteria were } 65 \text { years or more in age; enrolled in PACE for at least } 12 \text { months, reside in a } \\
\text { non-institutional setting, and do not have a designated power of attorney }\end{array}$ \\
\hline
\end{tabular}

\footnotetext{
Interventions
}

Intervention: TELEPHONE-BASED COUNSELING

Subjects in both groups started receiving educational material regarding osteoporosis 30 days after randomization. In addition the intervention group subjects received motivational intervening based counseling administered by a health educator. 10 sessions were targeted per subject

Control: CONTROL

Approximately 30 days after randomization, all subjects received mailings regarding osteoporosis. During the study, all subjects received 7 informational mailings covering topics such as exercise, fall prevention, and recommended calcium intake

\section{Outcomes}

The measures of adherence were self reported medication adherence assessment and pharmacy fill record. Self reported medication adherence assessment were done through phone calls at 1, 3, 7, 11, 
$17,23,31,39$, and 52 weeks. Pharmacy fill records were collected from the pharmacy. They contain information about the name and dosage of the medication, the date dispensed, and the number of days supplied. Using this the days with available osteoporosis medication from the day supply field was calculated. Medication compliance will be measured as the medication possession ratio (MPR), calculated as the percentage of days in which the subject has an osteoporosis medication available for use during the follow-up period

The patient outcomes were self reported fractures, self reported falls, and general health. All of these outcome are self reported. Fractures assessment was done at 12 months, falls assessment at weeks 7 and 31 and general health assessments were done at weeks 0,11 , and 39

Notes

The large discrepancy between groups in missing data is unexplained and might be suggestive of logistic issues for intervention delivery. Also, note that the level of intervention participation is not reported. Depression and satisfaction are not reported although they have been mentioned as secondary outcomes. General health as a patient outcome is mentioned in the supplementary but not in the methods section of primary but results reported

\section{Risk of bias}

\begin{tabular}{|c|c|c|}
\hline Bias & Authors' judgement & Support for judgement \\
\hline $\begin{array}{l}\text { Random sequence genera- } \\
\text { tion (selection bias) }\end{array}$ & Low risk & $\begin{array}{l}\text { Randomization of subjects occurred centrally using a random number gener- } \\
\text { ator and was stratified by gender, allowing recruitment of similar numbers of } \\
\text { men and women in both treatment arms (pg } 137(\mathrm{~s} 1) \text { ) }\end{array}$ \\
\hline $\begin{array}{l}\text { Allocation concealment } \\
\text { (selection bias) }\end{array}$ & Low risk & $\begin{array}{l}\text { Randomization of subjects occurred centrally. Subjects were assigned into } \\
\text { treatment arm "A" or "B" (intervention or control) based on a randomization } \\
\text { schedule generated by a random number program. Only the study co-ordina- } \\
\text { tor was aware of intervention and control assignment. All study investigators } \\
\text { and biostatisticians remained blind to treatment assignment (pg } 139 \text { (s1)) }\end{array}$ \\
\hline $\begin{array}{l}\text { Selective reporting (re- } \\
\text { porting bias) }\end{array}$ & High risk & $\begin{array}{l}\text { They failed to report the health care utilization data from Medicare - these } \\
\text { were an indication of fracture rates(pg } 142(\mathrm{~s} 1))\end{array}$ \\
\hline Other bias & Unclear risk & $\begin{array}{l}\text { "Our follow-up may have been inadequate to detect a change in fracture rate } \\
\text { attributable to a modest change in medication use." Large imbalance be- } \\
\text { tween groups in dropouts. } 16 \text { in control versus } 204 \text { in intervention; no rea- } \\
\text { son given. (pg 481-2) "The use of routinely collected data presents important } \\
\text { methodologic challenges. We relied on pharmacy claims data to identify re- } \\
\text { cent initiators of an osteoporosis medication regimen. These data needed to } \\
\text { be processed, and then we allowed potential subjects to opt out of recruit- } \\
\text { ment. This meant that, by the time subjects were recruited and received their } \\
\text { first intervention call, a median of } 113 \text { days had passed since they filled their } \\
\text { first prescription. Although data shown in Figure } 3 \text { suggest that the interven- } \\
\text { tion's effect increased during the study, the lag period may have limited the } \\
\text { benefit of our intervention because many subjects had already discontinued } \\
\text { use of their osteoporosis medication at the time of their first telephone cal- } \\
\text { l." (pg 481) }\end{array}$ \\
\hline
\end{tabular}

\begin{tabular}{|c|c|c|}
\hline $\begin{array}{l}\text { Blinding of outcome as- } \\
\text { sessment (detection bias) } \\
\text { Adherence measure }\end{array}$ & Low risk & $\begin{array}{l}\text { (PRIMARY) PHARMACY FILL RECORD - Only the study co-ordinator is aware of } \\
\text { intervention and control assignment. All study investigators and biostatisti- } \\
\text { cians remain blind to treatment assignment (pg 138). "The investigators as- } \\
\text { sessing and analyzing the outcomes are blinded to the treatment assignmen- } \\
\text { t." (s1) }\end{array}$ \\
\hline $\begin{array}{l}\text { Blinding of outcome as- } \\
\text { sessment (detection bias) } \\
\text { Patient outcome }\end{array}$ & Low risk & $\begin{array}{l}\text { (PRIMARY) SELF REPORTED FALLS, GENERAL HEALTH - "The investigators as- } \\
\text { sessing and analyzing the outcomes are blinded to the treatment assignmen- } \\
\text { t." (pg 138) }\end{array}$ \\
\hline
\end{tabular}


Solomon 2012 (Continued)

Blinding of participants (performance bias)

Adherence measure

Low risk

(PRIMARY) PHARMACY FILL RECORD - pg 139 indicates that patients were blinded. Also, because all subjects in both arms received enhanced care, they were not aware of their treatment arm allocation (478, primary)

$\begin{array}{ll}\begin{array}{l}\text { Blinding of participants } \\ \text { (performance bias) }\end{array} & \text { Low risk } \\ \begin{array}{l}\text { Patient outcome } \\ \text { arms received enhanced care, therefore they were not aware of their treat- } \\ \text { ment arm allocation (478, primary); pg 138-9 says that subjects were also } \\ \text { blinded }\end{array}\end{array}$

Blinding of personnel (per- Unclear risk

formance bias)

(PRIMARY) PHARMACY FILL RECORD - Depending on who we consider to be the

Adherence measure key study personnel the risk of bias will vary. If the study co-ordinator, who was aware of intervention and control assignment, is the key personal then there will be a high risk of bias; on the other hand, if the investigators and biostatisticians are considered key personnel - then there would be a low risk of bias

\begin{tabular}{|c|c|c|}
\hline $\begin{array}{l}\text { Blinding of personnel (per- } \\
\text { formance bias) }\end{array}$ & Unclear risk & $\begin{array}{l}\text { (PRIMARY) SELF REPORTED FALLS, GENERAL HEALTH - No information regard- } \\
\text { ing other personnel other than the study co-ordinator }\end{array}$ \\
\hline
\end{tabular}

Patient outcome ing other personnel other than the study co-ordinator

\begin{tabular}{|c|c|c|}
\hline $\begin{array}{l}\text { Incomplete outcome data } \\
\text { (attrition bias) } \\
\text { Adherence measure }\end{array}$ & Low risk & $\begin{array}{l}\text { (PRIMARY) PHARMACY FILL RECORD - ITT analysis is used and as the author } \\
\text { notes, "...these are old people who died. We had more complete death data for } \\
\text { intervention participants than for controls. Controls who died were considered } \\
\text { loss to followup but not drop outs." }\end{array}$ \\
\hline
\end{tabular}

Incomplete outcome data Low risk

(attrition bias)

(PRIMARY) SELF REPORTED FALLS, GENERAL HEALTH - imbalance across the

Patient outcome groups. ITT analysis done

Sorensen 2007

\begin{tabular}{ll}
\hline Methods & Randomized controlled trial \\
\hline Participants & $\begin{array}{l}\text { The study location was } 2 \text { urban clinics in San Francisco, California, USA: the San Francisco General Hos- } \\
\text { pital Opiate Treatment Outpatient Program (OTOP) and Bay Area Addiction Research and Treatment } \\
\text { (BAART), Market Street Clinic }\end{array}$
\end{tabular}

34 participants were randomized to the intervention group and 32 participants were randomized to the control group

The inclusion criteria were for the initial baseline phase: (a) enrolled in outpatient methadone maintenance treatment, (b) HIV antibody seropositive as indicated by clinic records, and (c) prescribed an antiretroviral medication for treatment of HIV/AIDS for at least 1 month, evidenced by prescription or prescription bottle

The exclusion criteria were for the initial baseline phase: (a) participating in other adherence improvement research or clinical programs or (b) living in a controlled environment that dispensed residents' HIV medications. Before beginning the actual trial, participants who were $80 \%$ adherent or greater during the baseline phase were excluded from the study

Interventions

Intervention: VOUCHER INTERVENTION

Patients in the voucher intervention group began with a 4-week baseline phase, where they received a MEMS monitor for one of their HAART medications. Patients met with a registered nurse or trained research assistant who provided medication coaching once during the baseline phase and then every 2 weeks throughout the study. Patients were provided with a hard copy of their MEMS data throughout the study. During baseline, patients met a research assistant twice weekly to provide the MEMS data. At the end of the baseline phase, patients in the voucher phase continued to meet twice weekly with a re- 
search assistant, for a total of 24 visits. When patients opened their medication caps as scheduled, they received vouchers that were exchangeable for goods and services for each correctly taken medication dose. The value of the voucher increased for each correctly taken dose in a row, but reset to the original value if a dose was missed. Patients could earn up to USD 1172.40 if they took all their medication correctly throughout the study

Control: COMPARISON

Patients in the comparison group began with a 4-week baseline phase, where they received a MEMS monitor for one of their HAART medications. Patients met with a registered nurse or trained research assistant who provided medication coaching once during the baseline phase and then every 2 weeks throughout the study. Patients were provided with a hard copy of their MEMS data throughout the study. During baseline, patients met a research assistant twice weekly to provide the MEMS data. During the intervention phase, comparison group participants continued to meet twice weekly with the research assistant, for a total of 24 visits, and received medication coaching every 2 weeks. As several of the initial comparison group participants expressed dissatisfaction with their treatment compared to the voucher group, a reward system was implemented for the comparison group. A fishbowl prize system was used to reinforce attendance at scheduled interviews. Patients could pick a number from the fishbowl, which would give them either a small or large prize

Outcomes The measures of adherence were MEMS, a medication adherence and side effects questionnaire, and pill counts. For MEMS, one selected HAART medication was selected to monitor as the primary adherence outcome measure. On-time MEMS cap openings were expressed as the percentage of scheduled dosing times when the cap was opened "on-time", defined as taking place in a 4-hour window around the scheduled dosage time, that is, per cent observed openings/per cent expected openings. MEMS records were used to calculate on-time openings and the longest documented days of continuous on-time openings. The medication adherence questionnaire was a self report of patient's adherence for the previous day and the past 3 days for each medication. This measure was administered weekly throughout the study. Pills were counted for one selected HAART medication at baseline to reflect the initial stock, then weekly to track adherence, and after refills to account for new pills added to the bottle. All adherence measures were collected by research assistants during in-person meetings with participants

The patient outcome was the SF-36, a 36-item self administered instrument that evaluates health-related quality of life in 8 dimensions, including: physical functioning, role functioning, bodily pain, general health, vitality, social functioning, mental health, and reported health transition. It provides 2 summary measures; a Mental Health Summary Scale and a Physical Health Summary Scale, which were utilized as the primary outcome measures of self reported health. The SF-36 was administered monthly (baseline, weeks 4, 8, 12, 16, and 20). Plasma HIV-1 RNA (viral load) was quantified from monthly blood draws using the Quantiplex bDNA Assay. Viral load results typically are widely variable, therefore they present raw results and log-10 transformed values. A decrease of at least 0.5 in log 10 viral load is considered consistent with improvement and not within the range of laboratory error. CD4+ lymphocyte counts, a type of white blood cells or T-cells vital to immune function, was obtained at baseline, weeks 12 and 20 from blood samples sent to the hematology section of San Francisco General Hospital clinical laboratories. HIV infection leads to a progressive reduction in the number of T-cells with CD4 receptors, and the CD4 count is used as a staging indicator for treatment decisions. When there are fewer than 200 CD4+ T-cells per microliter of blood, a person is diagnosed with AIDS. Weight was measured in pounds on a physician mechanical balance beam scale at baseline and at 20-week follow-up. Urine specimens were collected monthly and analyzed by Quest Diagnostics Inc., using enzyme multiplied immunoassay technique (EMIT), and positive screens were re-analyzed using thin-layer chromatography (TLC). Reported results included alcohol, amphetamines, barbiturates, benzodiazepines, cannabinoids, cocaine, and opiates; however, due to low frequencies of positive tests for most substances only cocaine and opiates were analyzed in the current report

Notes - -

\section{Risk of bias}




\section{Sorensen 2007 (Continued)}

Random sequence genera- Low risk tion (selection bias)
A computer-generated random sequence was used for randomization. "Eligible participants were randomly assigned to receive vouchers or a comparison intervention (medication coaching only) according to a computer generated list. Assignment was stratified by baseline CD4 lymphocyte count (i.e., greater than or equal to 200 cells/UL versus less than 200 cells/UL) because more medically compromised patients were likely to have more severe medical problems during the study. The research assistant opened a sealed envelope of intervention group assignments generated by the project statistician." (pg 56)

It does not specify opaque envelopes. "The research assistant opened a sealed envelope of intervention group assignments generated by the project statistician." (pg 56)

Allocation concealment Unclear risk (selection bias)

No protocol available; although it appears that everything was reported it is difficult to determine this without a protocol porting bias)

Unclear risk The study seems to be free of other types of bias

\begin{tabular}{lll}
\hline Other bias & Low risk & The study seems to be free of other types of bias \\
\hline $\begin{array}{l}\text { Blinding of outcome as- } \\
\text { sessment (detection bias) } \\
\begin{array}{l}\text { Adherence measure } \\
\text { L }\end{array}\end{array}$ & Low risk & $\begin{array}{l}\text { (PRIMARY) MEMS - unlikely to be affected by the blinding status of the RA col- } \\
\text { lecting the data }\end{array}$
\end{tabular}

Blinding of outcome as- Unclear risk sessment (detection bias)

Patient outcome

Blinding of participants High risk
(performance bias)

(performance bias)

Adherence measure
Blinding of participants Unclear risk (performance bias)

Patient outcome
(PRIMARY) SELF REPORTED HEALTH (SF 36) - This is a subjective measure; there is no information on blinding
Blinding of personnel (per- Low risk formance bias) Adherence measure
(PRIMARY) MEMS - Participants in the intervention group were given vouchers based on opening their medication caps. Participants could have opened the caps without actually taking any medication

\begin{tabular}{ll}
\hline Blinding of personnel (per- & Unclear risk \\
formance bias) & (PRIMARY) SELF REPORTED HEALTH (SF 36) - This is a subjective measure; \\
Patient outcome & there is no information on blinding
\end{tabular}

(PRIMARY) SELF REPORTED HEALTH (SF 36) - This is a subjective measure; there is no information on blinding

Incomplete outcome data Unclear risk

(attrition bias)

(PRIMARY) MEMS - Reasons for dropout given but not which group they were

Adherence measure

(PRIMARY) MEMS - unlikely to be affected by the blinding status of the personnel in. Not completely balanced across the conditions

Incomplete outcome data Unclear risk (attrition bias)

Patient outcome

(PRIMARY) SELF REPORTED HEALTH (SF 36) - Dropouts uneven across groups; it does not indicate which dropouts were in each group

Staring 2010

\begin{tabular}{ll}
\hline Methods & Randomized controlled trial \\
\hline Participants & The study location was the Netherlands
\end{tabular}


Staring 2010 (Continued)

54 participants were randomized to the intervention group and 55 participants were randomized to the control group

The inclusion criteria were a DSM-IV diagnosis of schizophrenia or schizoaffective disorder; receiving out-patient treatment; mastery of the Dutch language; at least some problems with service engagement, as defined by an average item-score of 1.25 or higher on at least 2 subscales of the Service Engagement Scale (SES). Individuals were referred when the clinician believed them to meet the criteria. In order to classify individuals according to DSM-IV, they were interviewed using the lifetime Composite International Diagnostic Interview, version 2.1.The SES was used to determine whether an individual met the 4th criterion

Interventions Intervention: TREATMENT ADHERENCE THERAPY

Initial sessions assess individual determinants of non-adherence. According to the clusters of determinants detected, therapists fill out a decision form and chose from the 3 modules available for the subsequent patient appoints. Modules are motivational interviewing, medication optimization, and behavioral training. If more than one cluster of problems was present in an individual, the modules were completed in order. The duration and number of sessions varied per patient, in general taking no more than 6 months. Most of the therapists were psychiatric nurses who were not the patients own mental health professionals. All sessions were recorded and used in supervision

Control: TREATMENT AS USUAL

Treatment as usual generally consisted of sessions with a psychiatric nurse and a psychiatrist when indicated. The sessions varied in frequency and duration, but mostly consisted of 1 or 2 sessions per month. The contents reflected overall problems the participant might encounter such as symptoms, social participation, work, daily activities, and medication issues. Some participants received psychoeducation individually or in group sessions. This was recorded

Outcomes

The measures of adherence were a composite of the adherence subscale of the Service Engagement Scale (SES) and the results of a semi-structured interview with the participant. The SES was completed by the clinician most familiar with the participant. The interview was conducted by an independent rater who normalized non-adherence and the reasons for it, stressing that the obtained information would not be passed on to the participant's clinician. The interviewed inquired about the number of missed doses in the past days and weeks. These 2 measures were standardized, summed, and reversed, thereby creating a compiled measure of adherence in which null scores indicated the average adherence in our study and high scores indicated good adherence. Adherence measures were collected at baseline, after the 6 -month treatment period, and 6 months after treatment ended

The patient outcomes were admissions, symptoms, and quality of life. Admissions documented, at the time the study was conducted, if participants had been readmitted to a psychiatric hospital, and, if so, whether this had been voluntary or involuntary. Symptoms were measured with the PANSS25, a 30item rating scale that is completed by trained raters. It has 3 subscales: positive, negative, and general psychopathology. Quality of life was measured with the self report EQ-5D, which has been validated in people with schizophrenia. All measured were obtained at baseline, after 6 months of treatment, and 6 months after treatment ended

Notes -

\section{Risk of bias}

Bias Authors' judgement Support for judgement

Random sequence genera- Low risk tion (selection bias)

Randomized according to a lottery system, executed by the main researcher. "Participants were randomly assigned to one of the treatment conditions. This was done according to a lottery system, executed by the main researcher." (pg 449)

\begin{tabular}{l}
$\begin{array}{l}\text { Allocation concealment } \\
\text { (selection bias) }\end{array} \quad$ Unclear risk No information was provided about how allocation was handled \\
\hline
\end{tabular}


Staring 2010 (Continued)

Selective reporting (re- Low risk The protocol is available in the Dutch Trial Registry: NTR1159. All outcomes are porting bias) accounted for

\begin{tabular}{lll}
\hline Other bias & Low risk & The study seems to be free of other types of bias \\
\hline $\begin{array}{l}\text { Blinding of outcome as- } \\
\text { sessment (detection bias) } \\
\begin{array}{l}\text { Adherence measure } \\
\text { (PRIMARY) SERVICE ENGAGEMENT SCALE - Clinician ratings - clinicians were } \\
\text { aware of the patient's group membership and this might have biased their re- } \\
\text { sponses }\end{array}\end{array} \quad$ High risk &
\end{tabular}

Blinding of outcome as- $\quad$ Low risk
sessment (detection bias)

(PRIMARY) ADMISSIONS - The author notes that they had close contact with

Patient outcome the patients and health professionals, and access to their psychiatric institute files. It was very easy to collect data on whether the patients were admitted to a psychiatric inpatient clinic or not, how many days this was, and whether it was voluntary or not

\begin{tabular}{ll}
\hline $\begin{array}{l}\text { Blinding of participants } \\
\text { (performance bias) }\end{array}$ & Low risk \\
(PRIMARY) SERVICE ENGAGEMENT SCALE - Ratings were done by the clinician, \\
not the patient
\end{tabular}

Adherence measure

(PRIMARY) SERVICE ENGAGEMENT SCALE - Ratings were done by the clinician,

Blinding of participants Low risk

$\begin{array}{ll}\text { (performance bias) } & \text { measure } \\ \text { Patient outcome } & \end{array}$

Patient outcome

\begin{tabular}{|c|c|c|}
\hline $\begin{array}{l}\text { Blinding of personnel (per- } \\
\text { formance bias) } \\
\text { Adherence measure }\end{array}$ & Unclear risk & $\begin{array}{l}\text { (PRIMARY) SERVICE ENGAGEMENT SCALE - it is unclear how the data were } \\
\text { combined from the interview with the other results - possible introduction of } \\
\text { bias? }\end{array}$ \\
\hline
\end{tabular}

formance bias)

Adherence measure

(PRIMARY) ADMISSIONS - No information on blinding given. There is insuffi-

Blinding of personnel (per- Unclear risk

formance bias)

Patient outcome cient information to permit judgment of 'Low risk' or 'High risk'

Incomplete outcome data Low risk
(attrition bias)

(attrition bias)

Adherence measure

Incomplete outcome data Low risk
(attrition bias)

Patient outcome

\section{Stevens 2002}

\begin{tabular}{ll} 
Methods & $\begin{array}{l}\text { Patients who tested positive for } H \text {. pylori were randomly assigned to either usual care or special coun- } \\
\text { seling using a computer-generated random sequence. The participating pharmacies were provided } \\
\text { with a supply of opaque randomization envelopes, and the pharmacists were trained to open the top } \\
\text { envelope to determine the treatment assignment for each research participant }\end{array}$ \\
\hline Participants & 325 adult dyspeptic patients positive for $H$. pylori participated in the study \\
\hline Interventions & $\begin{array}{l}\text { All the patients were provided a standard antibiotic regimen and randomly assigned to receive either } \\
\text { usual care counseling from a pharmacist (the control group participants met with the dispensing phar- } \\
\text { macist for } 5 \text { minutes. The pharmacist described the proper protocol for taking the medication. This is } \\
\text { consistent with standard care.) or a longer adherence counseling session and a follow-up phone call } \\
\text { from the pharmacist during drug treatment (patients received a 15-minute counseling session with the } \\
\text { pharmacist, including a detailed review of possible side effects, emphasis on the importance about } \\
\text { possible barriers to adherence and coping strategies, and encouragement to call the pharmacist in the } \\
\text { event of any problems. The pharmacist also scheduled a follow-up telephone call with the patient } 2\end{array}$
\end{tabular}


to 3 days after the start of therapy to check on adherence to the drug regimen.). All subjects were given the same 7-day course of omeprazole, bismuth subsalicylate, metronidazole, and tetracycline hydrochloride (OBMT)

\begin{tabular}{ll}
\hline Outcomes & $\begin{array}{l}\text { All the patients were contacted by telephone and were asked to report their adherence to the regimen } \\
\text { and their current symptoms }\end{array}$ \\
\hline Notes & $\begin{array}{l}\text { The major problems with this study are that a) both groups received blister packs with daily doses } \\
\text { clearly marked; b) both groups received counseling, although this was longer and more detailed for the } \\
\text { intervention group than the control group; and c) self report was used for measuring adherence (insen- } \\
\text { sitive). All these factors would bias towards no difference }\end{array}$
\end{tabular}

\title{
Risk of bias
}

\begin{tabular}{lll}
\hline Bias & Authors' judgement & Support for judgement \\
\hline $\begin{array}{l}\text { Random sequence genera- } \\
\text { tion (selection bias) }\end{array}$ & Low risk & $\begin{array}{l}\text { A computer-generated random sequence used. "Participants who tested pos- } \\
\text { itive for } H \text { pylori were randomly assigned to either usual care or special coun- } \\
\text { seling using a computer-generated random sequence." (pg 94) }\end{array}$ \\
\hline
\end{tabular}

Allocation concealment Low risk
(selection bias)

\begin{abstract}
Sealed envelopes and computer-generated random numbers were used. "Participants who tested positive for $\mathrm{H}$ pylori were randomly assigned to either usual care or special counseling using a computer-generated random sequence. The participating pharmacies were provided with a supply of opaque randomization envelopes, and the pharmacists were trained to open the top envelope to determine the treatment assignment for each new research participant." (pg 94)
\end{abstract}

\begin{tabular}{|c|c|c|}
\hline $\begin{array}{l}\text { Selective reporting (re- } \\
\text { porting bias) }\end{array}$ & Unclear risk & $\begin{array}{l}\text { No protocol available; although it appears that everything was reported it is } \\
\text { difficult to determine this without a protocol }\end{array}$ \\
\hline
\end{tabular}

\begin{tabular}{|c|c|c|}
\hline Other bias & High risk & $\begin{array}{l}\text { Another limitation of our study is that the same pharmacists delivered both in- } \\
\text { terventions and, therefore, may have mixed some elements of the counseling } \\
\text { treatments. Occasional observation checks for quality control did not show ev- } \\
\text { idence of this problem, but some contamination between treatments cannot } \\
\text { be ruled out (pg 96) }\end{array}$ \\
\hline
\end{tabular}

\begin{tabular}{|c|c|c|}
\hline $\begin{array}{l}\text { Blinding of outcome as- } \\
\text { sessment (detection bias) } \\
\text { Adherence measure }\end{array}$ & Low risk & $\begin{array}{l}\text { (PRIMARY) SELF REPORT - INTERVIEW - Staff were blinded. All data collectors } \\
\text { were masked to treatment assignments(pg 93) }\end{array}$ \\
\hline $\begin{array}{l}\text { Blinding of outcome as- } \\
\text { sessment (detection bias) } \\
\text { Patient outcome }\end{array}$ & Low risk & (PRIMARY) UREA BREATH TEST (UBT) - This is an objective measure of outcome \\
\hline
\end{tabular}

\begin{tabular}{|c|c|c|}
\hline $\begin{array}{l}\text { Blinding of participants } \\
\text { (performance bias) } \\
\text { Adherence measure }\end{array}$ & High risk & $\begin{array}{l}\text { (PRIMARY) SELF REPORT - INTERVIEW - This is a subjective measure; there is no } \\
\text { information on blinding }\end{array}$ \\
\hline
\end{tabular}

Blinding of participants Low risk (PRIMARY) UREA BREATH TEST (UBT) - This is an objective measure of outcome (performance bias)

Patient outcome

\begin{tabular}{lll}
\hline $\begin{array}{l}\text { Blinding of personnel (per- } \\
\text { formance bias) } \\
\begin{array}{l}\text { Adherence measure } \\
\text { High risk }\end{array}\end{array}$ & $\begin{array}{l}\text { (PRIMARY) SELF REPORT - INTERVIEW - Pharmacists were not blind because it } \\
\text { appears that both groups were seen by the same pharmacist }\end{array}$ \\
\hline $\begin{array}{l}\text { Blinding of personnel (per- } \\
\text { formance bias) }\end{array}$ & Low risk & (PRIMARY) UREA BREATH TEST (UBT) - This is an objective measure of outcome \\
\hline
\end{tabular}


Stevens 2002 (Continued)

Patient outcome

\begin{tabular}{|c|c|c|}
\hline $\begin{array}{l}\text { Incomplete outcome data } \\
\text { (attrition bias) } \\
\text { Adherence measure }\end{array}$ & Unclear risk & $\begin{array}{l}\text { (PRIMARY) SELF REPORT - INTERVIEW - Insufficient reporting of missing data } \\
\text { for the outcome. No information provided regarding how many patients were } \\
\text { contacted for adherence assessment - 8th day phone call }\end{array}$ \\
\hline
\end{tabular}

Adherence measure

contacted for adherence assessment - 8th day phone call

\begin{tabular}{|c|c|c|}
\hline $\begin{array}{l}\text { Incomplete outcome data } \\
\text { (attrition bias) }\end{array}$ & Unclear risk & $\begin{array}{l}\text { (PRIMARY) UREA BREATH TEST (UBT) - The article gives no information on who } \\
\text { dropped out of which group or why }\end{array}$ \\
\hline
\end{tabular}

Patient outcome

\section{Strang 1981}

\begin{tabular}{ll}
\hline Methods & Random allocation, not otherwise specified \\
\hline Participants & $\begin{array}{l}\text { Recently discharged patients with Present State Examination/CATEGO diagnoses of schizophrenia who } \\
\text { were living with at least } 1 \text { parent, who exhibited high 'expressed emotion' on the Camberwell Family In- } \\
\text { terview }\end{array}$ \\
\hline
\end{tabular}

$\begin{array}{ll}\text { Interventions } & \text { All patients had scheduled therapy and monthly medication appointments. Patients were allocated to } \\ \text { family therapy or individual support sessions. All patients received oral neuroleptic medication (usually } \\ \text { chlorpromazine) }\end{array}$

Outcomes patients were seen monthly by the prescribing psychiatrist, blinded to the group assignment, where
medication status and adherence were assessed. Medication was adjusted based on mental status,
side effects, and blood plasma levels. Patients with poor compliance for oral medications were given
fluphenazine decanoate injections. Adherence was defined in 6 ways: number of missed appointments
with psychiatrist; number of patients change to intramuscular depot medication; tablet-taking compli-
ance (pill counts, self reports by patient or family, and blood plasma levels); variability in plasma levels;
mean and modal doses prescribed for each treatment group; mean plasma level in each group. Relapse
was the treatment outcome (no information on how measured)

Notes

\section{Risk of bias}

\begin{tabular}{|c|c|c|}
\hline Bias & Authors' judgement & Support for judgement \\
\hline $\begin{array}{l}\text { Random sequence genera- } \\
\text { tion (selection bias) }\end{array}$ & Unclear risk & Randomization was not described in detail \\
\hline $\begin{array}{l}\text { Allocation concealment } \\
\text { (selection bias) }\end{array}$ & Unclear risk & No information was provided about how allocation was handled \\
\hline $\begin{array}{l}\text { Selective reporting (re- } \\
\text { porting bias) }\end{array}$ & High risk & $\begin{array}{l}6 \text { measures of compliance were reported in the method section; only a select- } \\
\text { ed few were reported in the results section }\end{array}$ \\
\hline Other bias & Unclear risk & $\begin{array}{l}\text { Discussion notes results were confounded by pharmacotherapy, otherwise un- } \\
\text { clear }\end{array}$ \\
\hline $\begin{array}{l}\text { Blinding of outcome as- } \\
\text { sessment (detection bias) } \\
\text { Adherence measure }\end{array}$ & Unclear risk & $\begin{array}{l}\text { (PRIMARY) NUMBER OF MISSED APPOINTMENTS WITH PSYCHIATRIST - No in- } \\
\text { formation on blinding given. There is insufficient information to permit judg- } \\
\text { ment of 'Low risk' or 'High risk' }\end{array}$ \\
\hline
\end{tabular}

Blinding of outcome as- Unclear risk sessment (detection bias)

Patient outcome

(PRIMARY) PLASMA LEVEL/PRESCRIBED DOSE RATIO - No description of how the outcome was measured/calculated 
Strang 1981 (Continued)

Blinding of participants High risk (PRIMARY) NUMBER OF MISSED APPOINTMENTS WITH PSYCHIATRIST - No (performance bias) mention of blinding of participants; although it should be very clear to the par-

Adherence measure ticipants receiving a family therapy session. This may affect the number of appointments attended

Blinding of participants Unclear risk
(performance bias)

(PRIMARY) PLASMA LEVEL/PRESCRIBED DOSE RATIO - No description of how

Patient outcome the outcome was measured/calculated

Blinding of personnel (per- Low risk

formance bias)

(PRIMARY) NUMBER OF MISSED APPOINTMENTS WITH PSYCHIATRIST - Pre-

Adherence measure scribing psychiatrist was blinded. "The prescribing psychiatrist, who was blind to the therapy assignment adjusted medication monthly on the basis of assessments of mental status..." (pg 88)

Blinding of personnel (per- Unclear risk formance bias)

(PRIMARY) PLASMA LEVEL/PRESCRIBED DOSE RATIO - No description of how Patient outcome the outcome was measured/calculated

\begin{tabular}{|c|c|c|}
\hline $\begin{array}{l}\text { Incomplete outcome data } \\
\text { (attrition bias) }\end{array}$ & Unclear risk & $\begin{array}{l}\text { (PRIMARY) NUMBER OF MISSED APPOINTMENTS WITH PSYCHIATRIST - No in- } \\
\text { complete outcome data were identified }\end{array}$ \\
\hline
\end{tabular}

(1) measure

Incomplete outcome data Unclear risk

(attrition bias)

(PRIMARY) PLASMA LEVEL/PRESCRIBED DOSE RATIO - No description of how

Patient outcome the outcome was measured/calculated

Taiwo 2010

\begin{tabular}{ll}
\hline Methods $\quad$ Randomized controlled trial \\
\hline
\end{tabular}

Participants The study location was JUTH, Jos, Nigeria

248 participants were randomized to the intervention group and 251 participants were randomized to the control group

The inclusion criteria were HIV-1-infected, treatment-naive adults ( $>15$ years of age) at the JUTH ART clinic who were eligible for treatment based on a clinical diagnosis of AIDS, CD4 cell count $<350$ cells per cubic millimeter with HIV-related symptoms, or CD4 cell count $<200$ cells per cubic millimeter regardless of symptoms were invited to participate. Willingness and ability to select a treatment partner were required

The exclusion criteria were individuals with severe illness such as advanced malignancy or active opportunistic infection, including tuberculosis

Interventions

\begin{abstract}
Intervention: TREATMENT PARTNER INTERVENTION
In addition to standard care, patients randomized to the treatment partner intervention (TPA) arm chose a treatment partner who was aware of the patient's HIV infection and resided in the same house or in close proximity. Treatment partners attended 1 adherence education session similar to that for study participants. They were asked to observe the ingestion of HIV drugs at least once daily, assist with the reporting and management of adverse effects, and remind participants of drug pickup. No compensation was provided for participation, but treatment partners with financial constraints received travel stipends of USD 2 to 14 (total)
\end{abstract}

\title{
Control: STANDARD CARE
}

All participants were given a 2-hour interactive adherence session in English and local language conducted by a nurse who was openly HIV-positive, trained as an adherence counselor. Content included information on ART, HIV drug resistance, symptom management, and emphasis on the importance of adherence and benefits of disclosure. Each patient was given a pillbox and educated on proper use. 
Taiwo 2010 (Continued)

The study pharmacist, who was blinded to treatment arm, provided one-on-one reinforcement of the education provided by the adherence counselor plus information specific to each participant's regimen. The pharmacist had formal training in adherence counseling and more than 3 years experience at study clinic. At each drug pickup visit, the pharmacist provided targeted counseling based on the participant's self report of adherence and adverse effects. Patients who had detectable viremia at week 24 underwent intensive adherence retraining with the adherence counselor. This retraining was aimed at identifying individualized obstacles to adherence and practical tips for overcoming them. Follow-ups were conducted at 12, 24, and 48 weeks after baseline

Outcomes

The measures of adherence were drug pickup adherence to the regime, calculated from pharmacy records at 24 and 48 weeks and dichotomized as $>=95 \%$ and $<95 \%$ adherent. Per cent adherence $=$ total number of days - \% of days alive without medication (e.g. if 6 days late picking up prescriptions through week 24 was $100 \%$ - $[((168-6) / 168) \times 100]=96.4 \%$ adherent $)$. For participants who died during the course of the study, adherence was computed through the day of death. For patients who were lost to follow-up, we assigned the maximum number of possible days without medication

The patient outcomes were plasma viral load and CD4 cell count measured at baseline and weeks 12 , 24 , and 48 and mortality determined from hospital records, clinic charts, social contacts, treatment partners, study staff, and social workers

Notes -

\section{Risk of bias}

\begin{tabular}{|c|c|c|}
\hline Bias & Authors' judgement & Support for judgement \\
\hline $\begin{array}{l}\text { Random sequence genera- } \\
\text { tion (selection bias) }\end{array}$ & Low risk & $\begin{array}{l}\text { Computer-generated random numbers were used for randomization. "Using } \\
\text { a computer-generated allocation sequence, randomization was performed } \\
\text { in a 1:1 ratio to treatment partner-assisted (TPA) ART (treatment arm) or pa- } \\
\text { tient-administered standard of care (SOC) ART (control arm)." (pg 86) }\end{array}$ \\
\hline $\begin{array}{l}\text { Allocation concealment } \\
\text { (selection bias) }\end{array}$ & Unclear risk & No information was provided about how allocation was handled \\
\hline $\begin{array}{l}\text { Selective reporting (re- } \\
\text { porting bias) }\end{array}$ & Unclear risk & $\begin{array}{l}\text { No protocol available; although it appears that everything was reported it is } \\
\text { difficult to determine this without a protocol }\end{array}$ \\
\hline Other bias & Low risk & The study seems to be free of other types of bias \\
\hline $\begin{array}{l}\text { Blinding of outcome as- } \\
\text { sessment (detection bias) } \\
\text { Adherence measure }\end{array}$ & Low risk & $\begin{array}{l}\text { (PRIMARY) PHARMACY FILL RECORD - The study pharmacist, who was blinded } \\
\text { to treatment arm, provided one-on-one reinforcement of the education pro- } \\
\text { vided by the adherence counselor plus information specific to each partici- } \\
\text { pant's regimen }\end{array}$ \\
\hline
\end{tabular}

Blinding of outcome as- Low risk sessment (detection bias) Patient outcome (PRIMARY) PLASMA VIRAL LOAD - Objective outcome measurement not likely to be influenced by lack of blinding

\begin{tabular}{|c|c|c|}
\hline $\begin{array}{l}\text { Blinding of participants } \\
\text { (performance bias) } \\
\text { Adherence measure }\end{array}$ & High risk & $\begin{array}{l}\text { (PRIMARY) PHARMACY FILL RECORD - Patients likely to be aware of both the in- } \\
\text { tervention and measure }\end{array}$ \\
\hline
\end{tabular}

$\begin{array}{ll}\begin{array}{l}\text { Blinding of participants } \\ \text { (performance bias) }\end{array} & \text { Low risk } \\ \begin{array}{l}\text { Patient outcome } \\ \text { (PRIMARY) PLASMA VIRAL LOAD - Objective outcome measurement not likely to } \\ \text { be influenced by lack of blinding }\end{array}\end{array}$


Taiwo 2010 (Continued)

Blinding of personnel (per- Low risk formance bias)

Patient outcome
(PRIMARY) PLASMA VIRAL LOAD - Objective outcome measurement not likely to be influenced by lack of blinding

Incomplete outcome data Low risk $\quad$ (PRIMARY) PHARMACY FILL RECORD - Missing data fairly balanced
(attrition bias)

Adherence measure

Incomplete outcome data Low risk (PRIMARY) PLASMA VIRAL LOAD - Missing data fairly balanced

(attrition bias)

Patient outcome

Tuldra 2000

Methods $\quad 116$ patients were randomly allocated (no statement of allocation concealment) to 1 of 2 arms. 61 patients were randomized to the control group and 55 were randomized to the "psychoeducative intervention" group. There is no statement in the report about blinding of physicians. Patients and psychologists were not blinded and, if there was a separate outcome assessor, it is not stated

Participants

116 patients who initiated their first or second-line highly active antiretroviral treatment (HAART) at a general university hospital's HIV-outpatient unit were included. Exclusion criteria were not specified

Interventions

The experimental group received a psychoeducative assessment in addition to the regular clinical follow-up. The individual(s) who delivered the intervention is not identified, but is apparently, a psychologist, rather than the treating physician. The intervention was intended "primarily to improve patients' knowledge and customs in handling medication to increase self efficacy". Patients in this arm received explanations about the reasons for starting treatment and the relevance of appropriate adherence to prevent replication of viral mutations and the development of antiretroviral drug resistance. Patients' doubts about medication intake were solved and a dosage schedule was developed with the patients' input. Study subjects were also taught to manage medication and tackle problems such as forgetting, delays, side effects and changes in the daily routine. A phone number was also given should any questions arise before the next interview. During follow-up visits, adherence was verbally reinforced and strategies were developed to deal with problems that had appeared to that point, including rescheduling dose schedules to overcome adherence problems, providing skills to deal with minor adverse effects. Patients in the control group received a standard assessment consisting of an interview with a psychologist following the regular medical visit, in which only variables related to adherence were recorded. The control group received only normal clinical follow-up. Both groups were interviewed for data collection at $0,4,24$, and 48 weeks of follow-up

Outcomes

Measurement of compliance: self reported adherence was registered at each visit. The proportion of compliance was calculated by dividing the number of pills taken during the month before by the number of pills prescribed during the same period. Patients who consumed more than $95 \%$ of medication prescribed were considered "adherent patients". Randomized blood analyses were also performed without warning in $40 \%$ of the patients to measure plasma levels of protease inhibitors (PI). Plasma levels of $\mathrm{PI}>0.01 \mathrm{mg} / \mathrm{L}$ indicated adequate compliance, $\mathrm{PI}$ levels $<0.01 \mathrm{mg} / \mathrm{dl}$ indicated noncompliance

Measurement for clinical health outcomes: HIV-1 RNA levels (copies/ml)

Notes

\section{Risk of bias}

\begin{tabular}{lll}
\hline Bias & Authors' judgement & Support for judgement \\
\hline $\begin{array}{l}\text { Random sequence genera- } \\
\text { tion (selection bias) }\end{array}$ & Unclear risk & $\begin{array}{l}\text { No mention of randomization process. "...prospective, two-arm randomized } \\
\text { controlled study was designed" (pg 222) }\end{array}$ \\
\hline
\end{tabular}


Tuldra 2000 (Continued)

\begin{tabular}{|c|c|c|}
\hline $\begin{array}{l}\text { Allocation concealment } \\
\text { (selection bias) }\end{array}$ & Unclear risk & $\begin{array}{l}\text { No information was provided about how allocation was handled. "...prospec- } \\
\text { tive, two-arm randomized controlled study was designed" (pg 222) }\end{array}$ \\
\hline
\end{tabular}

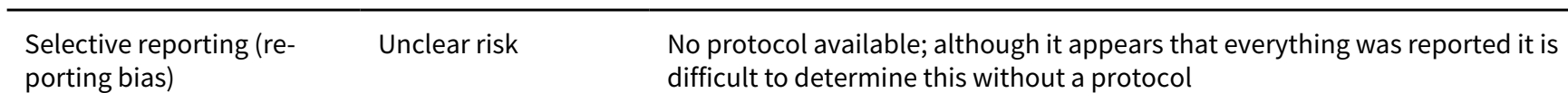

\begin{tabular}{lll}
\hline Other bias & Low risk & The study seems to be free of other types of bias \\
\hline $\begin{array}{l}\text { Blinding of outcome as- } \\
\text { sessment (detection bias) } \\
\begin{array}{l}\text { Adherence measure } \\
\text { Blinding of outcome as- }\end{array}\end{array}$ & High risk & $\begin{array}{l}\text { (PRIMARY) SELF REPORT - INTERVIEW - This is a subjective measure; there is no } \\
\text { information on blinding }\end{array}$ \\
$\begin{array}{l}\text { sessment (detection bias) } \\
\text { Patient outcome }\end{array}$ & Low risk & (PRIMARY) PLASMA RNA COUNT - This is an objective measure of outcome \\
\end{tabular}

\begin{tabular}{|c|c|c|}
\hline $\begin{array}{l}\text { Blinding of participants } \\
\text { (performance bias) } \\
\text { Adherence measure }\end{array}$ & High risk & $\begin{array}{l}\text { (PRIMARY) SELF REPORT - INTERVIEW - This is a subjective measure; there is no } \\
\text { information on blinding }\end{array}$ \\
\hline
\end{tabular}

Blinding of participants Low risk

(PRIMARY) PLASMA RNA COUNT - This is an objective measure of outcome

(performance bias)

Patient outcome

\begin{tabular}{ll}
\hline $\begin{array}{l}\text { Blinding of personnel (per- } \\
\text { formance bias) }\end{array}$ & High risk \\
$\begin{array}{ll}\text { Adherence measure } & \text { (PRIMARY) SELF REPORT - INTERVIEW - This is a subjective measure; there is no } \\
\end{array}$
\end{tabular}

Blinding of personnel (per- Low risk (PRIMARY) PLASMA RNA COUNT - This is an objective measure of outcome formance bias)

Patient outcome

Incomplete outcome data High risk

(attrition bias)

Adherence measure
(PRIMARY) SELF REPORT - INTERVIEW - Only at 48 weeks groups differed in adherence in as-treated analysis. In ITT the difference was less significant, again at 48 weeks only. $16 \%$ did not complete the 48 -week follow-up. It is also reported that $11 \%$ discontinued therapy due to toxicity, 4 patients abandoned medication, $5 \%$ interrupted medical follow-up, 2 patients in control group were switched to other therapies
Incomplete outcome data High risk

(attrition bias)

Patient outcome
(PRIMARY) PLASMA RNA COUNT - Only at 48 weeks groups differed in adherence in as-treated analysis. In ITT the difference was less significant, again at 48 weeks only. $16 \%$ did not complete the 48 -week follow-up. It is also reported that $11 \%$ discontinued therapy due to toxicity, 4 patients abandoned medication, $5 \%$ interrupted medical follow-up, 2 patients in control group were switched to other therapies

\section{Udelson 2009}

\begin{tabular}{ll}
\hline Methods & Randomized controlled trial \\
\hline Participants & The study location was the USA \\
& $\begin{array}{l}136 \text { participants on once-daily medication were randomized to the intervention group and } 133 \text { partic- } \\
\text { ipants on twice-daily medication, and } 136 \text { on once-daily medication + placebo participants were ran- } \\
\text { domized to the control group }\end{array}$
\end{tabular}


Udelson 2009 (Continued)

The inclusion criteria were patients currently taking carvedilol IR twice-daily with stable HF, who had mild, moderate, or severe symptoms and LV dysfunction. Patients were required to have been on stable dosing for at least 2 months without plans for further up-titration. Stability of HF was defined as the absence of either a change in New York Heart Association class or a hospitalization for HF or administration of IV diuretics, vasodilators, or positive inotrope therapy during the 2 weeks before the screening/baseline visit; and a stable medical regimen receiving background HF medications as noted

The exclusion criteria were patients with a history of symptomatic or sustained ventricular tachycardia or ventricular fibrillation within 3 months before screening

Intervention: ONCE-DAILY DOSING
The intervention was an open-label, once-daily regimen of controlled-release carvedilol CR
Control: TWICE A DAY DOSAGE
Participants received their usual twice-daily dose of carvedilol IR, but in a double-blinded fashion
Control: ONCE A DAY DOSING PLUS PLACEBO
Participants received a once-daily dose of controlled release carvedilol CR in the morning with a place-
bo substituted for the second daily dose in a double-blinded manner

Outcomes The measures of adherence were MEMS electronic measurement. Data were downloaded at months 1
and 5

The patient outcomes were evaluation and comparison of quality of life (QOL) measured by the Kansas City Cardiomyopathy Questionnaire (KCCQ), PHQ-8 Depressive Symptoms Questionnaire (PHQ-8), and Treatment Satisfaction Questionnaire with Medication. In addition, data were collected on BNP levels and hospital and emergency services utilization. After randomization, patients were seen at 1 month and again for the final visit at 5 months. Testing and administration of questionnaires were repeated at each of these visits

Notes $\quad-\quad$

\section{Risk of bias}

\begin{tabular}{|c|c|c|}
\hline Bias & Authors' judgement & Support for judgement \\
\hline $\begin{array}{l}\text { Random sequence genera- } \\
\text { tion (selection bias) }\end{array}$ & Unclear risk & $\begin{array}{l}\text { Randomization was not described in detail. Eligible subjects were randomized } \\
\text { in a 1:1:1 distribution to receive their usual twice-daily dose of carvedilol IR, } \\
\text { but in a double-blinded fashion ( } \operatorname{Arm} A \text { ) or (b) }\end{array}$ \\
\hline $\begin{array}{l}\text { Allocation concealment } \\
\text { (selection bias) }\end{array}$ & Unclear risk & $\begin{array}{l}\text { No information was provided about how allocation was handled. Eligible sub- } \\
\text { jects were randomized in a 1:1:1 distribution to receive their usual twice-daily } \\
\text { dose of carvedilol IR, but in a double-blinded fashion (Arm A) or (b) }\end{array}$ \\
\hline $\begin{array}{l}\text { Selective reporting (re- } \\
\text { porting bias) }\end{array}$ & Unclear risk & $\begin{array}{l}\text { No protocol available; although it appears that everything was reported it is } \\
\text { difficult to determine this without a protocol }\end{array}$ \\
\hline Other bias & Unclear risk & $\begin{array}{l}\text { High level of baseline adherence use of MEMS; this obvious measure might } \\
\text { have negated the blinding of control groups }\end{array}$ \\
\hline $\begin{array}{l}\text { Blinding of outcome as- } \\
\text { sessment (detection bias) } \\
\text { Adherence measure }\end{array}$ & Low risk & $\begin{array}{l}\text { (PRIMARY) MEMS - unlikely to be affected by lack of blinding of outcome asses- } \\
\text { sors }\end{array}$ \\
\hline $\begin{array}{l}\text { Blinding of outcome as- } \\
\text { sessment (detection bias) } \\
\text { Patient outcome }\end{array}$ & Unclear risk & $\begin{array}{l}\text { (PRIMARY) QUALITY OF LIFE (KCCQ) - } 2 \text { of the } 3 \text { conditions were double-blind- } \\
\text { ed, but the other was not }\end{array}$ \\
\hline $\begin{array}{l}\text { Blinding of participants } \\
\text { (performance bias) }\end{array}$ & High risk & $\begin{array}{l}\text { (PRIMARY) MEMS - MEMS is an obvious measure; patients are likely to be aware } \\
\text { of measurement of adherence }\end{array}$ \\
\hline
\end{tabular}


Udelson 2009 (Continued)

Adherence measure

$\begin{array}{ll}\begin{array}{l}\text { Blinding of participants } \\ \text { (performance bias) }\end{array} & \text { High risk } \\ \begin{array}{l}\text { Patient } \\ \text { (PRIMARY) QUALITY OF LIFE (KCCQ) - This is a subjective measure; } 2 \text { of the } 3 \\ \text { conditions were double-blinded, but the other was not }\end{array}\end{array}$

Patient outcome

(PRIMARY) MEMS - Unlikely to be affected by lack of blinding of key study per-

sonnel

formance bias)

Adherence measure

Blinding of personnel (per- Unclear risk

formance bias)

(PRIMARY) QUALITY OF LIFE (KCCQ) - 2 of the 3 conditions were double-blinded, but the other was not

Patient outcome

Incomplete outcome data Low risk

(attrition bias)

Adherence measure

(PRIMARY) MEMS - Missing data are relatively balanced across the groups, with similar reasons (see table 2)

\begin{tabular}{|c|c|c|}
\hline $\begin{array}{l}\text { Incomplete outcome data } \\
\text { (attrition bias) }\end{array}$ & Low risk & $\begin{array}{l}\text { (PRIMARY) QUALITY OF LIFE (KCCQ) - Dropouts are relatively balanced across } \\
\text { groups with similar reasons }\end{array}$ \\
\hline
\end{tabular}

(PRIMARY) QUALITY OF LIFE (KCCQ) - Dropouts are relatively balanced across

Valencia 2007

\begin{tabular}{|c|c|}
\hline Methods & Randomized controlled trial \\
\hline \multirow[t]{3}{*}{ Participants } & $\begin{array}{l}\text { The study location was hospital of the INPRF, National Institute of Health of the Ministry of Health, Mex- } \\
\text { ico }\end{array}$ \\
\hline & $\begin{array}{l}49 \text { participants were randomized to the intervention group and } 49 \text { participants were randomized to the } \\
\text { control group }\end{array}$ \\
\hline & $\begin{array}{l}\text { The inclusion criteria were outpatients who were taking anti-psychotic (AP) medication and were clini- } \\
\text { cally stable in terms of their psychotic symptoms, men or women aged } 16 \text { to } 50 \text { who had completed at } \\
\text { least } 6 \text { years of elementary education, lived with their families and resided in Mexico City or the metro- } \\
\text { politan area, and who had provided written informed consent to participate in the research project. }\end{array}$ \\
\hline
\end{tabular}

Interventions

Intervention: PSYCHOSOCIAL SKILLS TRAINING (PSST)

PSST is psychosocial skills training. It is composed of 7 treatment areas: (1) symptom management, (2) medication management, (3) social relations, (4) occupational, (5) money management, (6) couple relations, and (7) family relations. A therapist's manual describes all the areas, the skills corresponding to each area, and the training strategies for each session. The trainers were 2 psychologists who used 6 learning activities to teach patients skills acquisition: (1) introduction and explanation of the skills to be taught, including preparing and motivating patients to participate actively in the learning activities; (2) demonstration of the skills by one of the therapists, followed by a question-and-answer segment that allowed for clarification; (3) role playing: patients practiced the skills by role playing during sessions; (4) role playing feedback to allow patients to identify the resources needed to perform the skills in the real world; (5) practice of skills in their natural environment; and (6) at the beginning of the following session a segment was dedicated to verifying the practice of the skills in the community; this information was registered in a skills learning check-up list. The learning activities were similar to the 7 instructional techniques proposed for teaching social and instrumental skills to the severely mentally ill. These were modified to 6 learning activities for the participants of the present study. Patients participated in group sessions, 8 patients per group, with a time limit of 1 hour 15 minutes, once a week for a total of 48 sessions during 1 year of PSST. To verify that each treatment area was being covered systematically and adequately, a therapist fidelity evaluation form was used. Family therapy (FT) consists of 2 parts: the first was psychoeducation, which included 8 group sessions where all the patients' relatives received information about the illness, symptoms and medication management. The second part consisted of 4 sessions for each family, including the patient, oriented to problem solving as needed 
Valencia 2007 (Continued)

by each family to improve communication skills, the recognition and management of warning signs of relapse, the importance of medication and its side-effects, compliance with AP medication, and keeping appointments with physicians. 2 family therapists conducted the FT. Recreational activities for the patients, conducted by an arts teacher, included singing, musical games, creative movement, and arts and crafts, once a week for 2 hours. Recreational activities were not considered as a therapeutic modality

Control: TREATMENT AS USUAL

Control group was treatment as usual, which was provided at the Schizophrenia Clinic of the INPRF by 2 clinical psychiatrists, who were blind to the 2 treatment conditions. They provided 20-minute monthly appointments during a 1-year period, controlled the prescription of their AP medication based upon the assessment of their psychotic symptoms, checked their medication compliance, recorded their attendance to the consultations, and registered all this information in their clinical files

The measures of adherence were self report, psychiatrist verification, and medical records. To obtain these data, patients were asked if they had taken their AP medication during treatment according to their psychiatrist's instructions. This information was verified using 2 sources: the patients' psychiatrist and the patients' medical records. Compliance occurred when patients took their AP medication in the full prescribed dose by their treating psychiatrist. A criterion of adequate compliance was determined when patients had taken at least $80 \%$ of the prescribed AP medication verified by all 3 sources.

The patient outcomes were symptomatology, psychosocial functioning, global functioning, relapse, rehospitalization and adherence to intervention therapy. Symptomatology was assessed using the PANSS, which is a validated 30-item scale. The Spanish adaptation consists of 3 subscales: positive ( 7 items), negative (7 items) and general psychopathology (GPS) (16 items). Each item is scored from 1 (absence of psychopathology) to 7 (extremely severe). Psychosocial functioning (PSF) was measured using the Psychosocial Functioning Scale (PSFS). Functioning was assessed in 5 areas (occupational, social, money management, marital, and familial), and the patient's global psychosocial functioning (GPSF) was also assessed. PSF evaluates role performance through the level of satisfaction reported by the patient in the above-mentioned areas of functioning. The instrument is composed of a total of 35 items. Each item is scored from 1 (very satisfied) to 5 (very unsatisfied). A low score indicates better psychosocial functioning. Global functioning was evaluated using the Global Assessment of Functioning (GAF) scale in DSM-IV, which measures the combination of 2 elements: (1) symptom severity, and (2) any serious impairment in psychological, social and occupational functioning on a mental healthillness continuum (level of functioning). To evaluate intervention adherence, 2 elements were considered: (1) patients' attendance at sessions was registered to measure their percentage of attendance during the intervention, and (2) the level of therapeutic adherence was obtained by considering the number of patients who completed the intervention, compared with those who dropped out. To determine the corresponding therapeutic adherence, the levels of therapeutic adherence must be verified. The percentage of desertion (non-adherence) was obtained by considering the number of patients who dropped out in comparison with the number of patients who initiated the intervention. Independent interviewers, properly trained in all research instruments and unaware of which study group the patients belonged to, evaluated the 2 groups under study: initial and final ( 12 months) assessments. To ensure blindness the interviewers were instructed to remind all patients to abstain from mentioning what type of treatment they were receiving.

Notes

$-$

Risk of bias

\begin{tabular}{lll}
\hline Bias & Authors' judgement & Support for judgement \\
\hline $\begin{array}{l}\text { Random sequence genera- } \\
\text { tion (selection bias) }\end{array}$ & Unclear risk & $\begin{array}{l}\text { Randomization was not described in detail. "Clinic were randomly assigned to } \\
\text { two groups: } 49 \text { patients to the PSST programme (experimental treatment) and } \\
49 \text { to TAU alone (control treatment)." (pg 1394) }\end{array}$ \\
\hline $\begin{array}{l}\text { Allocation concealment } \\
\text { (selection bias) }\end{array}$ & Unclear risk & $\begin{array}{l}\text { No information was provided about how allocation was handled. "Clinic were } \\
\text { randomly assigned to two groups: 49 patients to the PSST programme (experi- } \\
\text { mental treatment) and 49 to TAU alone (control treatment)." (pg 1394) }\end{array}$ \\
\hline
\end{tabular}


Valencia 2007 (Continued)

Selective reporting (re- Unclear risk No protocol available; although it appears that everything was reported it is porting bias) difficult to determine this without a protocol

\begin{tabular}{lll}
\hline Other bias & Low risk & The study seems to be free of other types of bias \\
\hline $\begin{array}{l}\text { Blinding of outcome as- } \\
\text { sessment (detection bias) }\end{array}$ & Low risk & $\begin{array}{l}\text { (PRIMARY) SELF REPORT - INTERVIEW - Blinded staff. "Independent interview- } \\
\text { ers, properly trained in all research instruments and unaware of which study } \\
\text { gdherence measure }\end{array}$ \\
$\begin{array}{l}\text { group the patients belonged to, evaluated the two groups under study: initial } \\
\text { and final assessments. To ensure blindness the interviewers were instructed } \\
\text { to remind all patients to abstain from mentioning what type of treatment they } \\
\text { were receiving. The independent interviewers did not participate in the treat- } \\
\text { ment team and had no knowledge of the research project." (pg 1396) }\end{array}$
\end{tabular}

Blinding of outcome as- Low risk sessment (detection bias)

Patient outcome
(PRIMARY) SYMPTOMATOLOGY (PANSS) - Blind assessment. "Independent interviewers, properly trained in all research instruments and unaware of which study group the patients belonged to, evaluated the two groups under study: initial and final assessments. To ensure blindness the interviewers were instructed to remind all patients to abstain from mentioning what type of treatment they were receiving. The independent interviewers did not participate in the treatment team and had no knowledge of the research project." (pg 1396)

\begin{tabular}{|c|c|c|}
\hline $\begin{array}{l}\text { Blinding of participants } \\
\text { (performance bias) } \\
\text { Adherence measure }\end{array}$ & High risk & $\begin{array}{l}\text { (PRIMARY) SELF REPORT - INTERVIEW - This is a subjective measure; there is no } \\
\text { information on blinding }\end{array}$ \\
\hline $\begin{array}{l}\text { Blinding of participants } \\
\text { (performance bias) } \\
\text { Patient outcome }\end{array}$ & High risk & $\begin{array}{l}\text { (PRIMARY) SYMPTOMATOLOGY (PANSS) - This is a subjective measure; there is } \\
\text { no information on blinding }\end{array}$ \\
\hline $\begin{array}{l}\text { Blinding of personnel (per- } \\
\text { formance bias) } \\
\text { Adherence measure }\end{array}$ & Unclear risk & $\begin{array}{l}\text { (PRIMARY) SELF REPORT - INTERVIEW - No information on blinding given. } \\
\text { There is insufficient information to permit judgment of 'Low risk' or 'High risk' }\end{array}$ \\
\hline $\begin{array}{l}\text { Blinding of personnel (per- } \\
\text { formance bias) } \\
\text { Patient outcome }\end{array}$ & Unclear risk & $\begin{array}{l}\text { (PRIMARY) SYMPTOMATOLOGY (PANSS) - No information on blinding given. } \\
\text { There is insufficient information to permit judgment of 'Low risk' or 'High risk' }\end{array}$ \\
\hline $\begin{array}{l}\text { Incomplete outcome data } \\
\text { (attrition bias) } \\
\text { Adherence measure }\end{array}$ & Unclear risk & $\begin{array}{l}\text { (PRIMARY) SELF REPORT - INTERVIEW - Attrition rate was not similar between } \\
\text { groups }\end{array}$ \\
\hline $\begin{array}{l}\text { Incomplete outcome data } \\
\text { (attrition bias) } \\
\text { Patient outcome }\end{array}$ & Unclear risk & $\begin{array}{l}\text { (PRIMARY) SYMPTOMATOLOGY (PANSS) - Attrition rate was not similar between } \\
\text { groups }\end{array}$ \\
\hline
\end{tabular}

\section{Valenstein 2011}

\begin{tabular}{ll}
\hline Methods & Randomized controlled trial \\
\hline Participants & $\begin{array}{l}\text { The study location was 4 Departments of Veterans Affairs: San Diego California; Hines, Illinois; Ann Ar- } \\
\text { bor, Michigan; and Detroit, Michigan, USA }\end{array}$ \\
& $\begin{array}{l}58 \text { participants were randomized to the intervention group and } 60 \text { participants were randomized to the } \\
\text { control group }\end{array}$
\end{tabular}


Valenstein 2011 (Continued)

The inclusion criteria were clinical diagnoses of schizophrenia, schizoaffective, or bipolar disorder; a treatment plan that included long-term antipsychotic treatment, antipsychotic medication possession ratios (MPRs) of $<0.8$ in the prior 12 months; and no clinical contraindications to study participation

The exclusion criteria were no longer active in VA care, receiving antipsychotics outside of VA system, life expectancy of less than 1 year, receiving "stronger interventions" to promote adherence (e.g. the VA adaptation of Assertive Community Treatment, staff administration of medications, depot antipsychotics, or clozapine with its attendant close supervision), medications being administered by either paid staff or a care giver

Interventions

Intervention: MEDS-HELP INTERVENTION

A composite intervention consisting of: 1) unit-of-use packaging that included all patients' medications for psychiatric and general medical conditions; 2) a medication and packaging education session; 3) refill reminders mailed 2 weeks before scheduled refill dates; and 4) notification of clinicians when patients failed to fill antipsychotic prescriptions within 7 to 10 days of a fill date. The medication education session was conducted by a pharmacist, usually in person, but occasionally by telephone. During this session, the pharmacist reviewed patients' prescribed medications, including treatment indications. The pharmacist also explained unit-of-use medication packaging and plans for interim use of pill boxes when medication changes were made by clinicians before the next shipment of medication packages

Control: USUAL CARE

Usual care was treatment in Veterans Affairs outpatient mental health clinics and included psychiatrist visits, non-MD mental health visits, and group visits. During the study period, patients completed an average of 8 visits with psychiatrists; $49 \%$ had visits with non-MD mental health clinicians and $23 \%$ had group visits

Outcomes The measures of adherence were Medication Possession Ratio (MPR) and a Composite Adherence Measure (CAM). MPR was the primary adherence measure. It was based on pharmacy data and was calculated for 3 periods: baseline, 0 to 6 months, and 6 to 12 months. Patients were considered adherent on the CAM only if: (1) their MPR during the study time periods was $<0.8$, (2) they reported they "always" took their antipsychotics or only missed antipsychotics "a couple of times" in response to questions from Schizophrenia Outcomes Module, and (3) their blood test indicated the presence of some antipsychotic medication.

The patient outcomes were psychiatric symptoms as measured by the Positive and Negative Symptom Scale (PANSS), quality of life as measured by the Quality of Well-Being Scale (QWB), and patient satisfaction as measured by Client Satisfaction Questionnaire (CSQ-8) scale. The PANSS and QWB were completed by the research associates at each of the study sites. All these scales are widely used and have demonstrated reliability and validity. Exploratory outcomes included VA psychiatric hospitalizations, ascertained through chart reviews

Notes -

\section{Risk of bias}

Bias Authors' judgement Support for judgement

Random sequence genera- Low risk tion (selection bias)
Central randomization. (pg.729) "Randomization was completed centrally at the coordinating site, using a blocked randomization scheme by site based on the patient's level of adherence in the prior 12 months (MPR of $<0.4,0.4-0.59$, or $0.6-0.79$ ) and the presence of concurrent substance use."

Allocation concealment Unclear risk
(selection bias)

Insufficient information to permit judgment of 'Low risk' or 'High risk'. "In all, 118 patients were randomized to UC alone or UC plus Meds-Help. Randomization was completed centrally at the coordinating site, using a blocked randomization scheme by site based on the patient's level of adherence in the prior 12 months (MPR of $<0.4,0.4-0.59$, or 0.6-0.79) and the presence of concurrent substance use. Site research associates (RAs) called into the central research 
Valenstein 2011 (Continued)

coordinator to receive newly enrolling patients' treatment assignment." (pg 729)

Selective reporting (re- Low risk None detected
porting bias)

Other bias Unclear risk

\begin{abstract}
"Potentially, patients may have refilled their medications more regularly with Meds-Help but failed to increase their medication ingestion. However, our a priori CAM included components related to ingestion and still showed robust increases with the intervention. In addition to patients with schizophrenia, we included patients with bipolar disorder on long-term antipsychotics. These patients had lower levels of psychotic symptoms at baseline, which could potentially limit our ability to detect symptomatic changes. However, decreases in PANSS scores from baseline to 12 months were similar for patients with schizophrenia and bipolar disorder. We note that the increase in overall dose from improved adherence may simply have been too small to impact symptoms ( $25 \%$ more outpatient days with medications "on hand"), the follow-up period may have been too short to fully capture the benefits of increased adherence, or the relatively stable outpatients enrolling in this study may have been receiving the maximum benefit from their antipsychotic medications despite incomplete adherence. Patients with SMI may need broader- based interventions than those focused on medication adherence if their outcomes are to be improved. Other Limitations Measures of adherence in this study are approximations of actual adherence behaviors. A direct measure of patients' medication taking behavior would be the ultimate gold standard but is seldom achievable in adherence research.33 Although our participation rate is similar to that of most RCTs, patients recruited into a randomized trial may not be typical of all patients with SMI. More paranoid patients or those who were completely unwilling to take medications may have been underrepresented in the study sample-and this should be considered when generalizing study results to clinical populations. However, study participants' reported attitudes toward antipsychotic medications were similar to those reported for another population of patients with schizophrenia.25 Our study was not double blind, and a blinded assessment of outcomes would have been desirable. However, primary study outcomes were based on longer term patterns of medication filling which may be less susceptible to subtle biases on the part of interviewers or patients." (pg 734)
\end{abstract} Blinding of outcome as- $\quad$ Unclear risk
sessment (detection bias) Adherence measure

Blinding of outcome assessment (detection bias)

Patient outcome
(PRIMARY) MEAN POSSESSION RATE - No information on whether pill count was computerized. There is insufficient information to permit judgment of 'Low risk' or 'High risk'

\begin{tabular}{ll} 
& would be "unblinded" by patient comm \\
\hline $\begin{array}{l}\text { Blinding of participants } \\
\text { (performance bias) }\end{array}$ & (PRIMARY) MEAN POSSESSION RATE - No information on whether pill count \\
Adherence measure & was computerized. There is insufficient information to permit judgment of \\
\hline
\end{tabular}

(PRIMARY) PSYCHIATRIC SYMPTOMS - Research assistants were not blinded. (pg 730) "Research associates were also not blinded due to the costs and logistics of hiring blinded assessors for each site and the likelihood that assessors would be "unblinded" by patient comments." 'Low risk' or 'High risk'

Blinding of participants High risk (performance bias) (PRIMARY) PSYCHIATRIC SYMPTOMS - "As with many health services interven-

Patient outcome tions, patients could not be blinded to study assignment."(pg 730)

Blinding of personnel (per- Unclear risk formance bias) Adherence measure

(PRIMARY) MEAN POSSESSION RATE - No information on whether pill count was computerized. There is insufficient information to permit judgment of 'Low risk' or 'High risk' 
Valenstein 2011 (Continued)

Blinding of personnel (per- Unclear risk (PRIMARY) PSYCHIATRIC SYMPTOMS - Insufficient information to permit judgformance bias) ment of 'Low risk' or 'High risk'

Patient outcome

(PRIMARY) MEAN POSSESSION RATE - There was a similar rate of completion

Incomplete outcome data Low risk

(attrition bias)

for both groups

Adherence measure

Incomplete outcome data Unclear risk

(attrition bias)

Patient outcome

(PRIMARY) PSYCHIATRIC SYMPTOMS - "Unlike adherence measures, the secondary outcomes of the PANSS,QWB, and CSQ-8 required that patients complete in-person interviews within the appropriate time frame. These outcomes were calculated for $56(97 \%)$ of intervention patients and $50(83 \%)$ of UC patients at 6 months and for 49 (84\%) of intervention patients and $49(82 \%)$ of UC patients at 12 months. Patients missed in-person interviews for a variety of reasons including the deaths noted above, no shows or interview refusals, loss to follow-up, geographic moves, or jail time." (pg 731). At 6 months there is more missing data in the UC (83\%) group than MedHelps (97\%) group. It is not clear whether this difference is significant or not

van der Meer 2009

\begin{tabular}{ll}
\hline Methods & Randomized controlled trial \\
\hline Participants & $\begin{array}{l}\text { The study location was } 37 \text { general practices (69 general practitioners) in the Leiden and The Hague area } \\
\text { and the Outpatient Clinic of the Department of Pulmonology at the Leiden University Medical Center, } \\
\text { Leiden, the Netherlands }\end{array}$
\end{tabular}

101 participants were randomized to the intervention group and 99 participants were randomized to the control group

The inclusion criteria were physician-diagnosed asthma coded according to the International Classification of Primary Care in the electronic medical record, age 18 to 50 years, prescription of inhaled corticosteroids for at least 3 months in the previous year, no serious comorbid conditions that interfered with asthma treatment, access to the Internet at home, and mastery of the Dutch language

The exclusion criteria were receiving maintenance oral glucocorticosteroid treatment

Interventions

\begin{abstract}
Intervention: INTERNET-BASED SELF MANAGEMENT
An internet based self management program consisting of a specially designed website, which allowed monitoring through the website or text messaging, use of an internet-based treatment plan, online education and web communications with a specialized asthma nurse was administered to the intervention group. Patients monitored their asthma weekly by completing an electronic version of the Asthma Control Questionnaire on the website and instantly received feedback on the current state of their asthma control along with advice on how to adjust their treatment according to a predefined algorithm and treatment plan. Self management education consisted of both web-based and face-to-face, group-based education. Web-based education included asthma information, news, frequently asked questions, and interactive communication with a respiratory nurse specialist. All patients were offered 2 group-based education sessions, which lasted 45 to 60 minutes, for patients in the Internet-based self management group within 6 weeks after entering the trial. Both sessions included exploration of a patient's interests and previous knowledge, personalized feedback, and empowerment of self management. The first educational session also included pathophysiology of asthma, information on the web-based action plan, and information and review of inhalation technique. The second educational session gave information about the mechanisms and side effects of medication and explained trigger avoidance
\end{abstract}

Control: USUAL CARE 
van der Meer 2009 (Continued)

Website access for usual care patients was restricted to a diary page for patients to keep during assessments

\section{Outcomes}

The measure of adherence was self reported medication adherence assessed at baseline and 12 months

The patient outcome was asthma-related quality of life, as the primary outcome, measured by the 32-item Asthma Quality of Life Questionnaire. 5 secondary clinical outcomes: asthma control, symptom-free days, prebronchodilator FEV1, daily inhaled corticosteroid dose, and exacerbations. All outcomes except for exacerbations were assessed over 2 weeks, at 3 months, after the baseline period, and again at 12 months. During these assessments, all patients kept Internet-based daily diaries as they had during the baseline period. Calculated daily inhaled corticosteroid dose as fluticasone equivalents. Exacerbations were defined as deterioration in asthma that required emergency treatment or hospitalization or the need for oral steroids for 3 days or more, as judged by the attending physician, and assessed them over the whole year. Participants provided the Asthma Control Questionnaires, symptom-free days, and prebronchodilator FEV1 through the Internet. Other outcomes were collected by written questionnaire

Notes -

\section{Risk of bias}

\begin{tabular}{lll}
\hline Bias & Authors' judgement & Support for judgement \\
\hline $\begin{array}{ll}\text { Random sequence genera- } \\
\text { tion (selection bias) }\end{array}$ & Low risk & Used computer-generated sequences. "After the 2-week baseline period, \\
& & we randomly assigned participants to either the Internet group or the usual \\
& care group. We stratified according to care provider (primary vs. subspecial- \\
& ty care) and asthma control at baseline (15). We randomly assigned patients \\
& to the 2 groups (1:1 ratio) by using a computer-generated, permuted-block \\
scheme." (pg 111)
\end{tabular}

\begin{tabular}{ll}
\hline $\begin{array}{l}\text { Allocation concealment } \\
\text { (selection bias) }\end{array}$ & Low risk
\end{tabular} $\begin{aligned} & \text { The allocation was concealed. "Allocation took place by computer after collec- } \\
& \text { tion of the baseline data, ensuring concealment of allocation." (pg 111) }\end{aligned}$

\begin{tabular}{lll}
\hline $\begin{array}{l}\text { Selective reporting (re- } \\
\text { porting bias) }\end{array}$ & Unclear risk & $\begin{array}{l}\text { No protocol available; although it appears that everything was reported it is } \\
\text { difficult to determine this without a protocol }\end{array}$ \\
\hline Other bias & Unclear risk & $\begin{array}{l}\text { (pg 117) "A potential limitation of our study was that the patients and physi- } \\
\text { cians were aware of the allocation group". This might have introduced biased } \\
\text { reporting by patients and clinicians }\end{array}$ \\
\hline
\end{tabular}

\begin{tabular}{|c|c|c|}
\hline $\begin{array}{l}\text { Blinding of outcome as- } \\
\text { sessment (detection bias) } \\
\text { Adherence measure }\end{array}$ & High risk & $\begin{array}{l}\text { (PRIMARY) SELF REPORT - QUESTIONNAIRE - This is a subjective measure; } \\
\text { there is no blinding }\end{array}$ \\
\hline
\end{tabular}

\begin{tabular}{|c|c|c|}
\hline $\begin{array}{l}\text { Blinding of outcome as- } \\
\text { sessment (detection bias) } \\
\text { Patient outcome }\end{array}$ & High risk & $\begin{array}{l}\text { (PRIMARY) ASTHMA-RELATED QUALITY OF LIFE QUESTIONNAIRE - This is a sub- } \\
\text { jective measure; there is no blinding }\end{array}$ \\
\hline $\begin{array}{l}\text { Blinding of participants } \\
\text { (performance bias) } \\
\text { Adherence measure }\end{array}$ & High risk & $\begin{array}{l}\text { (PRIMARY) SELF REPORT - QUESTIONNAIRE - This is a subjective measure; } \\
\text { there is no blinding }\end{array}$ \\
\hline $\begin{array}{l}\text { Blinding of participants } \\
\text { (performance bias) } \\
\text { Patient outcome }\end{array}$ & High risk & $\begin{array}{l}\text { (PRIMARY) ASTHMA-RELATED QUALITY OF LIFE QUESTIONNAIRE - This is a sub- } \\
\text { jective measure; there is no blinding }\end{array}$ \\
\hline $\begin{array}{l}\text { Blinding of personnel (per- } \\
\text { formance bias) }\end{array}$ & High risk & $\begin{array}{l}\text { (PRIMARY) SELF REPORT - QUESTIONNAIRE - This is a subjective measure; } \\
\text { there is no blinding }\end{array}$ \\
\hline
\end{tabular}


van der Meer 2009 (Continued)

Adherence measure

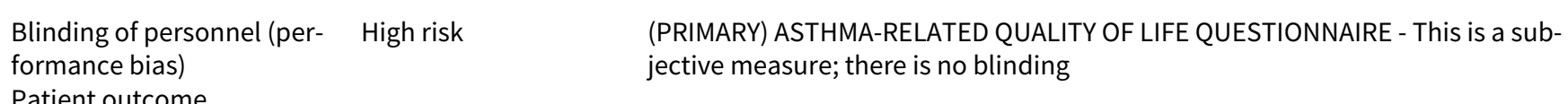

Patient outcome

$\begin{array}{ll}\begin{array}{l}\text { Incomplete outcome data } \\ \text { (attrition bias) }\end{array} & \text { Low risk } \\ \begin{array}{l}\text { (PRIMARY) SELF REPORT - QUESTIONNAIRE - ITT analysis done and missing } \\ \text { values were not imputed; missing data fairly balanced }\end{array}\end{array}$

Adherence measure values were not imputed; missing data fairly balanced

Incomplete outcome data Low risk

(attrition bias)

(PRIMARY) ASTHMA-RELATED QUALITY OF LIFE QUESTIONNAIRE - ITT analysis

Patient outcome done and missing values were not imputed; missing data fairly balanced

\section{Velligan 2008}

Methods Randomized controlled trial

Participants The study location was San Antonio and Austin, Texas, USA

36 patients were randomized to the Cognitive Adaptation Training (PharmCAT), which was focused only on medication and appointment adherence; 37 were randomized to the Cognitive Adaptation Training (Full-CAT), which focused on many aspects of community adaptation; 32 participants were randomized to the control group

The inclusion criteria were: 1) diagnosis of schizophrenia or schizoaffective disorder utilizing the Structured Clinical Interview for Diagnosis, 2) ages of 18 to 60 years, receiving treatment with an oral atypical antipsychotic with the treating physician's recommendation to continue the medication and participate in follow-up at the Center for Health Care Services, (3) have primary responsibility for taking their own medications, have a stable residence, and 4) able to understand and complete rating scales and neuropsychological testing

The exclusion criteria were 1) on clozapine or depot medication, 2) documented history of significant head trauma, seizure disorder, or mental retardation, 3) a history of substance abuse or dependence in the past month, or 4) a history of violence in the past 6 months

Cognitive Adaptation Training (CAT) uses manual-driven compensatory strategies and supports such as pill containers with alarms, organization of belongings, and activity checklists to prompt and sequence adaptive behaviors in an individual's home environment. CAT strategies are tailored to the specific cognitive impairments and behavioral approaches to goal-directed activity exhibited by each participant. Environmental supports in Full-CAT treatment were based upon an assessment of neurocognitive function, behavior, adaptive functioning, and the environment. Interventions for each functional deficit were based on 2 dimensions, (1) level of impairment in executive functions and (2) whether the overt behavior of the individual during performance of goal-directed activity was characterized more by apathy, disinhibition, or a combination of these styles. According to the CAT model, individuals with poor executive functioning need high levels of structure and more obviously placed environmental cues, while those with somewhat better executive functioning need less structure and more subtle cues. Individuals with apathetic behavior benefit from environmental supports that cue and sequence behavior, those with disinhibition benefit most from the removal of distracting stimuli, and those with mixed behavior benefit from a combination of these strategies. Assessment results yield one of 6 CAT classifications for which interventions can be targeted. Once an individual's CAT classification was determined, strategies for specific functional problems were chosen from the manual. CAT interventions were established, trained, and maintained in the home during weekly visits from a CAT therapist/trainer. Patients in Full-CAT were seen once weekly for 30 to 45 minutes. The treatment lasted for 9 months and then the patients were followed up for 6 months after the withdrawal of home visits. CAT therapists were individuals with bachelor's or master's degrees in psychology or related fields trained using a combination of didactic and in vivo strategies 
Pharm-CAT is a subset of the Full-CAT program, which is a manual-driven treatment using environmental supports. Patients received assessments of neurocognitive function, behavior, adaptive functioning, and the environment. Interventions in Pharm-CAT are individualized in the same manner as those in Full-CAT treatment. However, only interventions that specifically target adherence are used. Additional issues such as transportation were addressed only if they related to taking medication or making it to clinic appointments. Patients in Full-CAT and Pharm-CAT were seen once weekly for 30 to 45 minutes. Visits in Pharm-CAT were necessarily shorter in duration because the focus of treatment was circumscribed around the issue of adherence. Pharm-CAT is a subset of the Full-CAT program, which is a manual-driven treatment using environmental supports. Patients received assessments of neurocognitive function, behavior, adaptive functioning, and the environment. Interventions in Pharm-CAT were individualized in the same manner as those in Full-CAT treatment. However, only interventions that specifically targeted adherence were used. Additional issues such as transportation were addressed only if they related to taking medication or making it to clinic appointments. Patients in Full-CAT and Pharm-CAT were seen once weekly for 30 to 45 minutes. Visits in Pharm-CAT were necessarily shorter in duration because the focus of treatment was circumscribed around the issue of adherence. Pharm-CAT therapists were individuals with bachelor's or master's degrees in psychology or related fields trained using a combination of didactic and in vivo strategies

Control: TAU

Patients were seen monthly to every 3 months for brief medication visits. They had case managers with high case loads who had little ongoing contact with patients not in crisis

Outcomes

The measures of adherence were per cent adherence from unannounced pill counts conducted in the participants' homes twice during each 3 months in the study. The researcher making the visit requested that he or she be given all pills available to be counted. An adherence per cent was (the number of pills missing from the bottle and assumed taken/number of pills prescribed) $x 100$. The method required some initial preparation including asking patients to save all empty medication bottles (providing a sign and empty box) and bagging and stapling old bottles of medication so that the researcher would know when pills were taken from multiple bottles. Pill counts could not be blinded due to the obvious nature of environmental supports. Pharmacy records were examined as a secondary measure of adherence that would not be impacted by the obvious nature of environmental supports in the participants' homes. Pharmacy per cent adherence [(number of pills supplied/number days in period) $x$ $100]$ was calculated. Pharmacy records that overlapped assessment periods were included in the assessment period in which the majority of prescription days fell

The patient outcomes were symptomatology, relapse, and functional outcomes. Symptomatology was assessed using an expanded version of BPRS. The psychosis factor score was used to measure positive symptoms; the higher the score, the higher the levels of symptomatology. Relapse was assessed using BPRS. Patients were considered to be relapsed if a score on any of the 4 items increased 2 points to a score of 5 or higher, or if the patient was suicidal, hospitalized, or unable to care for themselves without continual supervision. Functional outcomes were assessed using SOFAS scores conducted during a lengthy semi-structured interview. Higher scores indicated better adaptive functioning. To further increase validity, collateral information was collected from caregivers and relatives

Notes -

\section{Risk of bias}

\section{Bias \\ Authors' judgement Support for judgement}

Random sequence genera- Low risk tion (selection bias)

Allocation concealment (selection bias)
Author's note: statistician created randomization tables and informed staff of the randomization after baseline assessments were completed. Staff dealing with patients were not in charge of randomization

Unclear risk

Insufficient information to permit judgment of 'Low risk' or 'High risk'. "Participants received a baseline assessment and were then randomized into one of 3 treatment conditions for a period of 9 months" "Randomization was stratified by recruitment site (hospital vs community clinic), gender, and age." (pg 484) 
Velligan 2008 (Continued)

Selective reporting (re- Low risk The study protocol is not available but it is clear that the published reports inporting bias)

Unclear risk clude all expected outcomes, including those that were pre-specified
Other bias

\begin{abstract}
"These results must be examined within the context of the study's methodological limitations. A significant number of inpatient recruits did not make it to the point of randomization into treatment for this outpatient treatment study. Results can only apply to those individuals treated as outpatients or inpatients who have successfully negotiated the transition from inpatient to outpatient status. Participants in the study had been ill on average for more than a decade. The extent to which these techniques would be helpful to individuals with a more recent onset of schizophrenia should be examined in future research. In future studies including a baseline period of assessment for medication adherence prior to randomization would be important. In-home pill counts could not be conducted by blinded observers given the nature of environmental supports. However, pharmacy records were not subject to observer bias. It is also likely that more adherent individuals agreed to participate in the study; a common problem in adherence research. Moreover, assessments of medication adherence involve error that may overestimate or underestimate actual adherence. Methodological problems with pill counts and pharmacy records are outlined elsewhere. 29 The fact that medication adherence improved, while psychotic symptoms did not suggests that our notions about adequate adherence and optimal dosing may have been formed in the ambiguous environment of partial adherence or negotiation and may need to be altered to maximize the outcomes of our patients. Despite these methodological limitations, the study provides strong support for the benefits of CAT and Pharm-CAT with respect to improving medication adherence and for the benefits of CAT for improving functional outcomes." (pg 491)
\end{abstract}

Blinding of outcome as-
sessment (detection bias)

Adherence measure
(PRIMARY) PILL COUNT - "Pill counts could not be blinded due to the obvious nature of environmental supports." As the personnel had to visit the homes of the participants, they had the opportunity to see if the participants were in a certain intervention or control group." (pg 5)
High risk

(PRIMARY) SYMPTOMATOLOGY - (pg 5) "In an effort to maintain treatment blinds, all subjects and collaterals were asked at the beginning of each assessment neither to divulge information about any visits made by staff of the research project nor to refer to any items they may have received as part of the study. If blinds were broken, alternative raters blind to group assignment completed the remaining assessments."
Blinding of outcome as- Low risk sessment (detection bias)

Patient outcome
(PRIMARY) PILL COUNT - Given the method of intervention, it would be easy for the study participants to become unblinded
Blinding of participants High risk (performance bias) Adherence measure
(PRIMARY) SYMPTOMATOLOGY - This is a subjective measure; there is no information on blinding
Blinding of participants High risk (performance bias)

Patient outcome
(PRIMARY) PILL COUNT - No information on blinding given. There is insufficient information to permit judgment of 'Low risk' or 'High risk'

(PRIMARY) SYMPTOMATOLOGY - No information on blinding given. There is insufficient information to permit judgment of 'Low risk' or 'High risk'

Blinding of personnel (per- Unclear risk

formance bias)

Adherence measure

Blinding of personnel (per- Unclear risk

formance bias)

Patient outcome

(PRIMARY) PILL COUNT - More information is needed about the how many patients from each group had missing information and the reasons for missing

Incomplete outcome data Unclear risk (attrition bias)

Adherence measure 
Velligan 2008 (Continued)

information. "For pill count and pharmacy records, respectively, 90 and 83 subjects had available data at baseline and at least one follow-up." (pg 488)

Incomplete outcome data Unclear risk

(attrition bias)

Patient outcome
(PRIMARY) SYMPTOMATOLOGY - Reasons for missing outcome data after randomization are not discussed

\section{Vergouwen 2005}

\section{Methods}

\begin{abstract}
In this study the general practitioners (GPs; $n=30$ ) were randomly assigned to either the Depression Care Program (DCP; $n=16$ ), or the Standard Follow-Up Program (SFP; $n=14$ ). Random treatment assignment was placed in advance in a set of sealed, opaque envelopes by an individual who was not involved in the opening of the envelopes. When a GP was randomized, the GP's name and the number of the envelope were recorded before the envelope was opened. There were a total of 211 patients, 101 from the DCP and 110 from the SFP. The number of patients analyzed were $n=81$ in the DCP group and $\mathrm{n}=96$ for the SFU group
\end{abstract}

Patients were eligible for the study if they met the following criteria: primary diagnosis of depression fulfilling the criteria of a major depressive episode according to DSM-IV; at least 18 years of age; no renal or hepatic dysfunction. Subjects had to give written informed consent prior to participation and the MINI International Neuropsychiatric Interview was used for the diagnostic psychiatric screening. Exclusion criteria were: benzodiazepines not stabilized at a maximum level of $10 \mathrm{mg}$ diazepam or equivalent rate at least 4 weeks prior to start of treatment; use of other psychopharmacological medication; a history of schizophrenia or bipolar disorder; previously unresponsive to selective serotonin reuptake inhibitor (SSRI) therapy (for depression or other indications); women who were pregnant, lactating or not using adequate contraception; a history of seizures (except for febrile seizures in childhood); meeting DSM-IV criteria for substance abuse within 3 months prior to the start of the trial, respectively substance dependence within 6 months; any serious medical condition that would, in the opinion of the GP, preclude the administration of a SSRI; a current serious suicidal or homicidal risk in the GP's judgment; and current psychological or psychotherapeutic treatment
Interventions
Depression care program: prior to every scheduled visit ( 7 visits in 26 weeks), the DCP patients received a newsletter by mail, which reviewed the biology and symptoms for depression, as well as the importance of antidepressant medication, and its effects and side effects. In addition, the need to continue treatment for up to 6 months, the value of social support, social stigmas, and common misconceptions about depression were explained. Patients also were asked to complete homework assignments that involved: (1) filling out a questionnaire addressing the perceived costs and benefits of antidepressant medication, (2) planning activities, and (3) discussing their illness and treatment with significant others. Before each visit, the GPs received a summary of the content of the newsletter and the homework assignments and both patients and GPs were encouraged to discuss the topics and homework assignments during the visits. In particular, the GPs clarified the benefits of and perceived costs of taking antidepressant medication Systematic follow-up program: patients and GPs in the SFP received no letters, homework, nor instructions. The SFP targeted only the structure of care: follow-up visits were scheduled and structured, and patients were assessed with the same frequency and with the same instruments as the patients in the DCP group

Outcomes
Adherence with antidepressant medication was assessed during the visits at weeks 2, 6, 10, 14, 18, 22, and 26 , by pill counts. When a patient did not return pills, the patient's self reports were used. Early adherence was defined as $>70 \%$ medication intake during the first 10 weeks. Late adherence was defined as $>70 \%$ medication intake during the full 26 weeks

Clinical outcomes were measured using: (a) The MINI at baseline and week 26; (b) Clinical Global Impression (CGI) at baseline and all the following visits; (c) The Beck Depression Inventory (BDI) at weeks 2, 6, 10, 18, and 26; and (d) The Symptom Checklist-90-Revised (SCL-90 R) at weeks 2, 10, 18, and 26. The GPs did assessments of adherence, MINI, and CGI and the BDI and SCL-90 R were self rating questionnaires 
Vergouwen 2005 (Continued)

Notes

\section{Risk of bias}

Bias Authors' judgement Support for judgement

Random sequence genera- Unclear risk tion (selection bias)

Randomization was not described in detail. "After agreement to participate, GPs were randomly assigned to either the DCP, or the SFP. Random treatment assignment was placed in advance in a set of sealed, opaque envelopes by an individual who was not involved in the opening of the envelopes. When a GP was randomized, the GP's name and the number of the envelope were recorded before the envelope was opened." (pg 26)

\begin{tabular}{ll}
\hline $\begin{array}{l}\text { Allocation concealment } \\
\text { (selection bias) }\end{array}$ & Low risk \\
& $\begin{array}{l}\text { Opaque, sealed envelopes used. "After agreement to participate, GPs were } \\
\text { randomly assigned to either the DCP, or the SFP. Random treatment assign- } \\
\text { ment was placed in advance in a set of sealed, opaque envelopes by an indi- } \\
\text { vidual who was not involved in the opening of the envelopes. When a GP was } \\
\text { randomized, the GP's name and the number of the envelope were recorded } \\
\text { before the envelope was opened." (pg 26) }\end{array}$
\end{tabular}

\begin{tabular}{|c|c|c|}
\hline $\begin{array}{l}\text { Selective reporting (re- } \\
\text { porting bias) }\end{array}$ & Unclear risk & $\begin{array}{l}\text { No protocol available; although it appears that everything was reported it is } \\
\text { difficult to determine this without a protocol }\end{array}$ \\
\hline
\end{tabular}

\begin{tabular}{lll}
\hline Other bias & Low risk & The study seems to be free of other types of bias \\
\hline $\begin{array}{l}\text { Blinding of outcome as- } \\
\text { sessment (detection bias) } \\
\begin{array}{l}\text { Adherence measure } \\
\text { (PRIMARY) PILL COUNT - Open-label trial - the GPs did assessments of adher- }\end{array}\end{array}$ & High risk & $\begin{array}{l}\text { ence, MINI, and CGI. This is a subjective measure } \\
\end{array}$
\end{tabular}

\begin{tabular}{|c|c|c|}
\hline $\begin{array}{l}\text { Blinding of outcome as- } \\
\text { sessment (detection bias) } \\
\text { Patient outcome }\end{array}$ & High risk & $\begin{array}{l}\text { (PRIMARY) MINI INTERNATIONAL NEUROPSYCHIATRIC INTERVIEW - Open-la- } \\
\text { bel trial - the GPs did assessments of adherence, MINI, and CGI. The BDI and } \\
\text { SCL- } 90 \text { R are self rating questionnaires }\end{array}$ \\
\hline $\begin{array}{l}\text { Blinding of participants } \\
\text { (performance bias) } \\
\text { Adherence measure }\end{array}$ & High risk & $\begin{array}{l}\text { (PRIMARY) PILL COUNT - This is a subjective measure; there is no information } \\
\text { on blinding }\end{array}$ \\
\hline
\end{tabular}

\begin{tabular}{|c|c|c|}
\hline $\begin{array}{l}\text { Blinding of participants } \\
\text { (performance bias) } \\
\text { Patient outcome }\end{array}$ & High risk & $\begin{array}{l}\text { (PRIMARY) MINI INTERNATIONAL NEUROPSYCHIATRIC INTERVIEW - An open-la- } \\
\text { bel trial; this is a subjective measure; there is no information on blinding }\end{array}$ \\
\hline $\begin{array}{l}\text { Blinding of personnel (per- } \\
\text { formance bias) } \\
\text { Adherence measure }\end{array}$ & High risk & $\begin{array}{l}\text { (PRIMARY) PILL COUNT - This is a subjective measure; there is no information } \\
\text { on blinding }\end{array}$ \\
\hline $\begin{array}{l}\text { Blinding of personnel (per- } \\
\text { formance bias) } \\
\text { Patient outcome }\end{array}$ & High risk & $\begin{array}{l}\text { (PRIMARY) MINI INTERNATIONAL NEUROPSYCHIATRIC INTERVIEW - An open-la- } \\
\text { bel trial; this is a subjective measure; there is no information on blinding }\end{array}$ \\
\hline $\begin{array}{l}\text { Incomplete outcome data } \\
\text { (attrition bias) } \\
\text { Adherence measure }\end{array}$ & High risk & $\begin{array}{l}\text { (PRIMARY) PILL COUNT - Dropouts are not equal across groups but the reasons } \\
\text { are provided for some of them; less than } 80 \% \text { of patients followed up at } 26 \\
\text { weeks }\end{array}$ \\
\hline $\begin{array}{l}\text { Incomplete outcome data } \\
\text { (attrition bias) } \\
\text { Patient outcome }\end{array}$ & High risk & $\begin{array}{l}\text { (PRIMARY) MINI INTERNATIONAL NEUROPSYCHIATRIC INTERVIEW - Dropouts } \\
\text { are not equal across groups but the reasons are provided for some of them; } \\
\text { less than } 80 \% \text { of patients followed up at } 26 \text { weeks }\end{array}$ \\
\hline
\end{tabular}


Volume 2001

Methods

Cluster-randomized trial with pharmacies as the unit of randomization. 2 of the 16 pharmacies were located 2 blocks apart in the same rural community. To minimize the risk of sample contamination between these 2 pharmacies, they were included in the same study group. One pair from the same community were assigned as a block. 8 pharmacies were randomly placed in the treatment group and 8 pharmacies were randomly to be in the control group. Pharmacists from 5 of the 8 treatment pharmacies completed the practice enhancement program and began enrolling patients into the study

Participants

Ambulatory elderly ( $>$ or $=65$ years of age) patients $(n=60)$ covered under Alberta Health \& Wellness's senior drug benefit plan and who were concurrently using 3 or more medications according to pharmacy profiles

Interventions

In intervention group, pharmacists used the Pharmacist's Management of Drug-Related Problems (PM$\mathrm{DRP}$ ) instrument to summarize the information collected during the patient interview and prepared a "SOAP" record (Subjective, Objective, Assessment, and Plan) to document actions and follow-up. Pharmacists at control pharmacies continued to provide traditional pharmacy care

\section{Outcomes}

Adherence to medication regimens was assessed using a 4-item self report measure. Health-related quality of life was assessed using the SF-36 health survey. The SF-36 has been used extensively to evaluate the success of clinical interventions

Notes -

\section{Risk of bias}

\begin{tabular}{|c|c|c|}
\hline Bias & Authors' judgement & Support for judgement \\
\hline $\begin{array}{l}\text { Random sequence genera- } \\
\text { tion (selection bias) }\end{array}$ & Unclear risk & $\begin{array}{l}\text { Randomization of pharmacies were done by the study statistician, blinded. Se- } \\
\text { quence generation not described }\end{array}$ \\
\hline $\begin{array}{l}\text { Allocation concealment } \\
\text { (selection bias) }\end{array}$ & Low risk & Allocation was centrally performed, but by the statistician, who was blinded \\
\hline $\begin{array}{l}\text { Selective reporting (re- } \\
\text { porting bias) }\end{array}$ & Unclear risk & $\begin{array}{l}\text { No protocol available; although it appears that everything was reported it is } \\
\text { difficult to determine this without a protocol }\end{array}$ \\
\hline Other bias & Low risk & The study seems to be free of other types of bias \\
\hline $\begin{array}{l}\text { Blinding of outcome as- } \\
\text { sessment (detection bias) } \\
\text { Adherence measure }\end{array}$ & Unclear risk & $\begin{array}{l}\text { (PRIMARY) SELF REPORT - SURVEY - This is a subjective measure; there is no in- } \\
\text { formation on blinding }\end{array}$ \\
\hline $\begin{array}{l}\text { Blinding of outcome as- } \\
\text { sessment (detection bias) } \\
\text { Patient outcome }\end{array}$ & Unclear risk & $\begin{array}{l}\text { (PRIMARY) HEALTH-RELATED QUALITY OF LIFE (HRQOL) - The article does not } \\
\text { state if the telephone survey personnel were blinded. (pg 4) A telephone sur- } \\
\text { vey of patients was administered by the Population Research Lab at the Uni- } \\
\text { versity of Alberta at baseline (time } 1 \text {; before the intervention); mid-point (time } \\
2 ; 6 \text { to } 7 \text { months after the intervention); and the conclusion of the study (time } \\
3 ; 12 \text { to } 13 \text { months after baseline). Respondents were asked to provide such in- } \\
\text { formation as demographics, self reported adherence, expectations, satisfac- } \\
\text { tion with pharmacy services, and patient HRQOL }\end{array}$ \\
\hline
\end{tabular}

\section{Blinding of participants High risk}

(performance bias)

Adherence measure

Blinding of participants High risk
(performance bias)

(PRIMARY) SELF REPORT - SURVEY - Patients would have been aware of the additional attention paid by the intervention group pharmacists

(PRIMARY) HEALTH-RELATED QUALITY OF LIFE (HRQOL) - This is a subjective measure; there is no information on blinding 
Volume 2001 (Continued)

Patient outcome

$\begin{array}{ll}\begin{array}{l}\text { Blinding of personnel (per- } \\ \text { formance bias) }\end{array} & \text { High risk } \\ \text { Adherence measure } & \text { (PRIMARY) SELF REPORT - SURVEY - Pharmacists would have been aware of } \\ \end{array}$
Adherence measure

(PRIMARY) HEALTH-RELATED QUALITY OF LIFE (HRQOL) - Pharmacists would have been aware of group memberships

Blinding of personnel (per- High risk formance bias)

Patient outcome

Incomplete outcome data Unclear risk

(attrition bias)

Adherence measure

Incomplete outcome data Unclear risk

(attrition bias)

Unclear risk

Patient outcome
(PRIMARY) SELF REPORT - SURVEY - Reasons for the patients who did not complete all 3 interviews are not given

(PRIMARY) HEALTH-RELATED QUALITY OF LIFE (HRQOL) - Reasons for the patients who did not complete all 3 interviews are not given

Wakefield 2011

\begin{tabular}{ll}
\hline Methods & Randomized controlled trial \\
\hline
\end{tabular}

Participants The study location was lowa City VA Medical Center (ICVAMC), lowa, USA

93 participants were randomized to the high intervention group, 102 participants were randomized to the low intervention group and 107 participants were randomized to the control group

The inclusion criteria were coexisting diabetes mellitus and hypertension, a land-line telephone in the home, receipt of primary care from the VA in the previous 12 months, and anticipation of receiving primary care for the duration of study enrollment

The exclusion criteria were legally blind, resided in a long-term care facility, or who had diagnoses indicating dementia or psychosis

In the high-intensity group, subjects were instructed to measure BP daily and blood glucose (BG) as directed by their physician, that is, frequency of home $B G$ monitoring was not changed. The study team developed a branching disease management algorithm based on DM and HTN guidelines from the VA, American Diabetes Association, and the American Heart Association. The algorithm was programmed into the device and focused on diet, exercise, smoking cessation, foot care, advice for sick days, medications, weight management, preventive care, and behavior modification and lifestyle adjustments. A schedule was established for each prompt set so that subjects received both standard prompts each day and a rotation of questions and educational content. Follow-up was for a period of 12 months

Intervention: LOW-INTENSITY GROUP

In the low-intensity group, subjects were instructed to measure BP daily and BG as directed by their physician. Subjects in this group responded to a small subset of questions from the larger set of questions used with the high-intensity group. Every day, subjects in this group were asked, "Have you taken all your medications as prescribed?" In addition, subjects were prompted with one additional question each day focused on diet, exercise, foot care, or medication side effects. These questions did not use the branching algorithm used for the high-intensity group, rather they used yes/no or multiple choice responses

Control: USUAL CARE

Usual care subjects scheduled follow-up appointments with the primary care clinic in the usual manner. Subjects had access to their nurse care manager employed by the medical center 
Wakefield 2011 (Continued)

Outcomes

The measures of adherence were the Self Reported Medication Taking scale. It includes 4 items addressing medication-taking behavior in patients with hypertension. The scale has been shown to have acceptable reliability, with individuals scoring high on the scale are significantly more likely to have their blood pressure under control compared with individuals who scored low $(r=0.58$; P value $<0.01)$ at 42-month follow-up. For diabetes mellitus, a validated regimen adherence scale was used, which addresses medication, diet, exercise, and BG testing. Data were collected at baseline, and 6 and 12 months

The patient outcomes were hemoglobin A1c level and systolic blood pressure. Blood was drawn and analyzed for A1c by the ICVAMC Laboratory. BP was measured by study staff using an automated BP machine according to recommended standards. Data were collected at baseline, 6 months, and 12 months. Data were collected by scheduling clinic visits for all subjects

Notes -

\section{Risk of bias}

\section{Bias}

Random sequence genera- Unclear risk tion (selection bias)

\section{Authors' judgement Support for judgement}

Randomization method is not stated. "We targeted patients who had an upcoming Primary Care Clinic appointment, with a goal of sending letters to a maximum of 10 patients per day. Although it occurred infrequently, if there were more than 10 patients from our pool with a clinic appointment on a given day, we randomly selected 10 potential subjects, using a random number generator to select patients." "This study was a single-center, randomized, controlled clinical trial design comparing three treatments, two remote monitoring intensity levels and usual care, with respect to improvement in outcomes in patients with comorbid DM and HTN. Primary outcome measures were Alc and SBP." (pg 254). Insufficient information about participant randomization to the different study groups: "Randomization occurred after consent and collection of baseline data. Group assignments were made by the study nurses using sequentially numbered, sealed, opaque envelopes prepared in advance by the project director." (pg 255)

Allocation concealment Low risk
(selection bias)

"Randomization occurred after consent and collection of baseline data. Group assignments were made by the study nurses using sequentially numbered, sealed, opaque envelopes prepared in advance by the project director." (pg 255)

\begin{tabular}{|c|c|c|}
\hline $\begin{array}{l}\text { Selective reporting (re- } \\
\text { porting bias) }\end{array}$ & Unclear risk & None detected; protocol unavailable \\
\hline Other bias & Unclear risk & $\begin{array}{l}\text { "Limitations: On average, subjects who enrolled in this study had relatively } \\
\text { good baseline control for A1c and SBP; thus, this sample may represent pa- } \\
\text { tients who were more highly motivated to manage their chronic illness. Be- } \\
\text { cause these data were collected in a Midwestern VA Medical Center, minorities } \\
\text { and women were underrepresented. Patients without telephones could not } \\
\text { participate; this may have excluded the most economically disadvantaged pa- } \\
\text { tients for whom the intervention would be the most effective. The study was } \\
\text { not designed to measure outcomes beyond the 12-month follow-up period, } \\
\text { so longer-term effects were not measured." (pg 259). "Subjects had relatively } \\
\text { good baseline control for A1c and SBP; minorities and women were underrep- } \\
\text { resented." (pg 254) }\end{array}$ \\
\hline
\end{tabular}

\begin{tabular}{|c|c|c|}
\hline $\begin{array}{l}\text { Blinding of outcome as- } \\
\text { sessment (detection bias) } \\
\text { Adherence measure }\end{array}$ & Unclear risk & $\begin{array}{l}\text { (PRIMARY) SELF REPORTED MEDICATION TAKING SCALE - No information on } \\
\text { blinding given. There is insufficient information to permit judgment of 'Low } \\
\text { risk' or 'High risk' }\end{array}$ \\
\hline
\end{tabular}


Wakefield 2011 (Continued)

Blinding of outcome as- Low risk $\quad$ (PRIMARY) BLOOD SAMPLE - This is an objective measure of outcome sessment (detection bias)

Patient outcome

\begin{tabular}{|c|c|c|}
\hline $\begin{array}{l}\text { Blinding of outcome as- } \\
\text { sessment (detection bias) } \\
\text { Patient outcome }\end{array}$ & Low risk & $\begin{array}{l}\text { (PRIMARY) BLOOD PRESSURE (BP) - This is an objective measure of outcome. } \\
\text { Used an automatic BP machine }\end{array}$ \\
\hline $\begin{array}{l}\text { Blinding of participants } \\
\text { (performance bias) } \\
\text { Adherence measure }\end{array}$ & High risk & $\begin{array}{l}\text { (PRIMARY) SELF REPORTED MEDICATION TAKING SCALE - This is a subjective } \\
\text { measure; there is no information on blinding }\end{array}$ \\
\hline $\begin{array}{l}\text { Blinding of participants } \\
\text { (performance bias) } \\
\text { Patient outcome }\end{array}$ & Low risk & (PRIMARY) BLOOD SAMPLE - This is an objective measure of outcome \\
\hline $\begin{array}{l}\text { Blinding of participants } \\
\text { (performance bias) } \\
\text { Patient outcome }\end{array}$ & Low risk & $\begin{array}{l}\text { (PRIMARY) BLOOD PRESSURE (BP) - This is an objective measure of outcome. } \\
\text { Used an automatic BP machine }\end{array}$ \\
\hline $\begin{array}{l}\text { Blinding of personnel (per- } \\
\text { formance bias) } \\
\text { Adherence measure }\end{array}$ & Unclear risk & $\begin{array}{l}\text { (PRIMARY) SELF REPORTED MEDICATION TAKING SCALE - No information on } \\
\text { blinding given. There is insufficient information to permit judgment of 'Low } \\
\text { risk' or 'High risk' }\end{array}$ \\
\hline
\end{tabular}
Blinding of personnel (per- Low risk (PRIMARY) BLOOD SAMPLE - This is an objective measure of outcome formance bias)

Patient outcome

Blinding of personnel (per- Low risk formance bias)

Patient outcome

Incomplete outcome data Unclear risk (attrition bias)

Adherence measure

Incomplete outcome data Unclear risk

(attrition bias)

Patient outcome

Incomplete outcome data Unclear risk (attrition bias)

Patient outcome
(PRIMARY) BLOOD PRESSURE (BP) - This is an objective measure of outcome. Used an automatic BP machine
(PRIMARY) SELF REPORTED MEDICATION TAKING SCALE - imbalance in attrition rates

(PRIMARY) BLOOD SAMPLE - imbalance in attrition rates

(PRIMARY) BLOOD SAMPLE - imbalance in attrition rates

(PRIMARY) SELF REPORTED MEDICATION TAKING SCALE - This is a subjective 
Walley 2001 (Continued)

that no treatment for tuberculosis had been taken previously, and that the patient lived in one of the trial catchment areas. Urban Rawalpindi was a WHO-sponsored "demonstration" site, patients in the demonstration site catchment area were excluded

Interventions

170 were assigned DOTS with direct observation of treatment by health workers; 165 were assigned DOTS with direct observation of treatment by family members; and 162 were assigned self administered treatment. The first, and prevailing, strategy was self administered treatment, in which each patient collects drugs fortnightly from the most convenient health facility. The second was health worker direct observation of treatment, i.e. supervision by a health worker at a health facility when the patient met criteria for access to the facility, and by a community health worker at or near the patient's home otherwise. The access criteria, determined from the exploratory studies, were that the return journey from the patient's home to the health facility was a distance of less than 2 kilometers, a duration of less than 2 hours, and a cost of less than 10 rupees; and for unmarried women, an accompanying relative was to be available. The patient nominated the health facility most convenient for him or her. If the access criteria were met, a health worker at that facility was identified to supervise treatment; otherwise, a community health worker local to the patient's home and acceptable to the patient was chosen as supervisor. The supervisor was oriented on his or her role by a visiting field officer. The patient was then expected to attend the health facility or community health worker 6 times per week in the initial 2-month intensive phase to take the drugs. In the 6-month continuation phase, patients continued on self administered treatment, collecting drugs fortnightly from the most convenient health facility or community health worker. The third strategy was family-member direct observation of treatment, that is, supervision by a family member. The patient was assisted in the selection of a concerned and influential family member as supervisor. The family member was oriented on his or her role. The patient (or family member) collected drugs fortnightly from the health facility most convenient for him or her. In both strategies involving direct observation of treatment, the supervisor was taught how to record drug-taking using a specially designed form, and was made aware of the importance of observing drugtaking and of encouraging the patient to complete treatment

Outcomes

"Defaulted" in Table 2 used as a proxy for "noncompliant". Default was defined as failing to collect treatment from the health center for 2 consecutive months during the course of treatment. The outcome measures used were cure, and cure plus treatment completion

Notes

$-$

\section{Risk of bias}

\begin{tabular}{|c|c|c|}
\hline Bias & Authors' judgement & Support for judgement \\
\hline $\begin{array}{l}\text { Random sequence genera- } \\
\text { tion (selection bias) }\end{array}$ & Low risk & $\begin{array}{l}\text { Method of randomization appropriate and well described. "Method of ran- } \\
\text { domisation of individual patients was by telephone through a third party (who } \\
\text { was unaware of any information about the patient) at the research-team office } \\
\text { in Islamabad, with a list of random allocations computer-generated by the re- } \\
\text { search team. To allow for the possibility of failed telephone contact, we also } \\
\text { provided facilities with preprepared allocations sealed in opaque envelopes. } \\
\text { As it happened, there were many problems with telephone contacts, and the } \\
\text { envelope method of allocation was used for most cases. However, we are con- } \\
\text { fident that this had no effect on the quality of randomisation." (pg 665) }\end{array}$ \\
\hline
\end{tabular}

$\begin{array}{ll}\begin{array}{l}\text { Allocation concealment } \\ \text { (selection bias) }\end{array} & \text { Low risk } \\ & \begin{array}{l}\text { Allocation concealment described and appropriate. "...by telephone through } \\ \text { a third party (who was unaware of any information about the patient) at the } \\ \text { research-team office in Islamabad, with a list of random allocations comput- } \\ \text { er-generated by the research team." (pg 665) }\end{array}\end{array}$

\begin{tabular}{|c|c|c|}
\hline $\begin{array}{l}\text { Selective reporting (re- } \\
\text { porting bias) }\end{array}$ & Unclear risk & $\begin{array}{l}\text { No protocol available; although it appears that everything was reported it is } \\
\text { difficult to determine this without a protocol }\end{array}$ \\
\hline
\end{tabular}

Other bias Low risk The study seems to be free of other types of bias


Walley 2001 (Continued)

Blinding of outcome as- Low risk (PRIMARY) TREATMENT COMPLETED RATE - Outcomes assessors were blindsessment (detection bias) ed. "Outcome assessment was by laboratory examination of sputum by techAdherence measure nicians unaware of treatment allocation". (pg 666)

\begin{tabular}{|c|c|c|}
\hline $\begin{array}{l}\text { Blinding of outcome as- } \\
\text { sessment (detection bias) } \\
\text { Patient outcome }\end{array}$ & Low risk & $\begin{array}{l}\text { (PRIMARY) CURE RATE - Outcome assessors were blinded. "Outcome assess- } \\
\text { ment was by laboratory examination of sputum by technicians unaware of } \\
\text { treatment allocation" (pg 666) }\end{array}$ \\
\hline
\end{tabular}

(PRIMARY) TREATMENT COMPLETED RATE - Patients were aware of treatment

Blinding of participants Unclear risk

(performance bias) allocation but unclear if this would bias outcome. "After randomisation, the

Adherence measure enrollment officer and the patient discussed and agreed the details of the selected treatment protocol" (pg 665)

Blinding of participants Unclear risk

(performance bias)

(PRIMARY) CURE RATE - Patients were aware of allocation but unclear if this

Patient outcome would impact outcome. "After randomisation, the enrolment officer and the patient discussed and agreed the details of the selected treatment protocol" (pg 665)

Blinding of personnel (per- Low risk formance bias)

(PRIMARY) TREATMENT COMPLETED RATE - Study personnel were blinded. Adherence measure

"The doctor, health educator, laboratory technicians, and other regular staff of the diagnostic centre provided health education, and monitored the clinical aspects of care, side effects, sputum conversion, \&c, following the same procedure for all patients. These staff were unaware of the trial group of the patients. The enrolment officer had no role in care provision." (pg 666)

Blinding of personnel (per- Low risk

formance bias)

(PRIMARY) CURE RATE - Study personnel were blinded. "The doctor, health ed-

Patient outcome ucator, laboratory technicians, and other regular staff of the diagnostic centre provided health education, and monitored the clinical aspects of care, side effects, sputum conversion, \&c, following the same procedure for all patients. These staff were unaware of the trial group of the patients. The enrolment officer had no role in care provision." (pg 666)

$\begin{array}{ll}\begin{array}{l}\text { Incomplete outcome data } \\ \text { (attrition bias) }\end{array} & \begin{array}{l}\text { (PRIMARY) TREATMENT COMPLETED RATE - Reasons for missing data are not } \\ \text { reported }\end{array}\end{array}$

Adherence measure

(PRIMARY) TREATMENT COMPLETED RATE - Reasons for missing data are not

Incomplete outcome data Unclear risk $\quad$ (PRIMARY) CURE RATE - Reasons for missing data are not reported
(attrition bias)
Patient outcome

Wang 2010 a

\begin{tabular}{ll} 
Methods & Randomized controlled trial \\
\hline Participants & The study location was Hengyang, Chenzhou and Yueyang in Hunan Province, China \\
& 58 participants were randomized to the intervention group and 58 participants were randomized to the \\
control group & \\
& The inclusion criteria were 1) a confirmed diagnosis of HIV infection, active or past heroin addicts, 2) 18 \\
& years or older, 3) received ART for at least 1 month prior to commencement of this study and continu- \\
ing ART at study commencement, and 5) mentally competent to answer questions
\end{tabular}

Interventions

Intervention: NURSE-DELIVERED HOME VISITS

4 home visits (every 2 months) were delivered by a qualified nurse and included 1 ) the provision of information about HIV/AIDS, 2) ART medication and adherence, and 3) skills to facilitate adherence, reinforcing motivation, mobilizing family support. Patients were provided with a pamphlet, electric pill- 
Wang 2010 a (Continued)

box with alarm, drug rehabilitation, methadone therapy, and stress management. In addition, tailored interventions were made based on the previous home visit and addressed barriers identified. Similarly, telephone calls were every 2 weeks including following each home visit to reinforce the effect of home visit and varied from 10 to 20 minutes to 1 hour during which adherence level, barriers and general emotional, sleeping and eating conditions were discussed.

Control: USUAL CARE

As part of the Chinese national ART management program, patients are seen twice in the first month of ART and receive medication for half a month at each visit and in the absence of side effects and presence of normal liver and renal function, visits are reduced to once a month. The clinic's pharmacy dispenses medication monthly. Clients on ART also receive free laboratory test for CD4+ T cell counts every 3- 6 months for evaluating the effectiveness of the treatment. HIV viral load test is not routinely provided in the national treatment program because of the limited fund. The patients visit the clinic once they have side effects or other health problems and need a laboratory test. The service of home visits or phone calls from health care providers are not routinely provided

Outcomes

The measures of adherence were the Community Programs for Clinical Research on AIDS (CPCRA) Antiretroviral Medication Self Report questionnaire and included the timing of doses by asking how often they took pills on time at study initiation and at 8 months follow-up

The patient outcomes were quality of life, measured by the Chinese version of WHO Quality of life (WHOQOL-BREF) and symptoms of depression measured by the Chinese version of Self rating Depression Scale (SDS) developed by Zung in 1965. Data were collected at baseline and 8 months

\section{Notes}

$-$

\section{Risk of bias}

\begin{tabular}{lll}
\hline Bias & Authors' judgement & Support for judgement \\
\hline $\begin{array}{l}\text { Random sequence genera- } \\
\text { tion (selection bias) }\end{array}$ & Unclear risk & $\begin{array}{l}\text { Unclear. No details provided in article. (pg 2) "Study design" "Randomised trial } \\
\text { and pretests and postintervention tests were used in this study." }\end{array}$ \\
\hline $\begin{array}{l}\text { Allocation concealment } \\
\text { (selection bias) }\end{array}$ & Unclear risk & $\begin{array}{l}\text { Unclear. No details provided in article. (pg 2) "Study design" "Randomised trial } \\
\text { and pretests and postintervention tests were used in this study." }\end{array}$ \\
\hline $\begin{array}{l}\text { Selective reporting (re- } \\
\text { porting bias) }\end{array}$ & Unclear risk & None detected; protocol not available \\
\hline $\begin{array}{l}\text { Other bias } \\
\text { High risk }\end{array}$ & $\begin{array}{l}\text { Co-intervention. Participants in the home visit group were given "an electric } \\
\text { pillbox with an alarm" along with other strategies. The control group received } \\
\text { standard care. The intervention itself is very complex with multiple compo- } \\
\text { nents, so it seems inappropriately biased towards finding an effect }\end{array}$ \\
\hline
\end{tabular}

\begin{tabular}{|c|c|c|}
\hline $\begin{array}{l}\text { Blinding of outcome as- } \\
\text { sessment (detection bias) }\end{array}$ & Unclear risk & $\begin{array}{l}\text { (PRIMARY) SELF REPORT - QUESTIONNAIRE - No information on blinding given. } \\
\text { There is insufficient information to permit judgment of 'Low risk' or 'High risk' }\end{array}$ \\
\hline
\end{tabular}

Adherence measure

\begin{tabular}{|c|c|c|}
\hline $\begin{array}{l}\text { Blinding of outcome as- } \\
\text { sessment (detection bias) } \\
\text { Patient outcome }\end{array}$ & Unclear risk & $\begin{array}{l}\text { (PRIMARY) QUALITY OF LIFE (WHOQOL-BREF) - No information on blinding giv- } \\
\text { en. There is insufficient information to permit judgment of 'Low risk' or 'High } \\
\text { risk' }\end{array}$ \\
\hline
\end{tabular}

Blinding of participants High risk

(performance bias)

Adherence measure

Blinding of participants Unclear risk (performance bias) (PRIMARY) SELF REPORT - QUESTIONNAIRE - This is a subjective measure; there is no information on blinding

Patient outcome 
Wang 2010 a (Continued)

Blinding of personnel (per- Unclear risk formance bias)

Adherence measure
(PRIMARY) SELF REPORT - QUESTIONNAIRE - No information on blinding given. There is insufficient information to permit judgment of 'Low risk' or 'High risk'

\footnotetext{
Blinding of personnel (per- Unclear risk formance bias)

Patient outcome

(PRIMARY) QUALITY OF LIFE (WHOQOL-BREF) - No information on blinding given. There is insufficient information to permit judgment of 'Low risk' or 'High risk'
}

\begin{tabular}{|c|c|c|}
\hline $\begin{array}{l}\text { Incomplete outcome data } \\
\text { (attrition bias) }\end{array}$ & High risk & $\begin{array}{l}\text { LF REPORT - QUESTIONNAIRE - Attrition rate is not balan } \\
\text { is for dropouts are given }\end{array}$ \\
\hline
\end{tabular}

Adherence measure

Incomplete outcome data High risk

(attrition bias)

(PRIMARY) QUALITY OF LIFE (WHOQOL-BREF) - Attrition numbers are not bal-

Patient outcome anced; dissimilar reasons for dropouts are given

Wang $2010 \mathrm{~b}$

\begin{tabular}{ll}
\hline Methods & Randomized controlled trial \\
\hline Participants & $\begin{array}{l}\text { The study location was Pulmonary Medicine outpatient clinic, Tri-Service General Hospital, Taipei, Tai- } \\
\text { wan }\end{array}$
\end{tabular}

35 in the Asthma Education Program and 34 in the Asthma Education and Pharmacist Counseling Program participants were randomized to the intervention group and 35 participants were randomized to the control group

The inclusion criteria were 1) outpatient aged 18 to 80 years, 2) good cognitive function, 3) able to understand Chinese, 4) confirmed diagnosis of bronchial asthma as determined by clinical features before treatment, 5) clinically stable, and 6) willing to participate

The exclusion criteria were other medical conditions that could impact quality of life, including psychiatric illness or cognitive impairment

Interventions

\begin{abstract}
Intervention: PHARMACIST COUNSELING
Patients participated in the standard nurse administered asthma education program with additional pharmacist counseling with the pharmacist. A detailed workbook prepared by chest physicians was used for each session. The asthma education program covered 4 topics taught in sequence in 31 -hour sessions offered during monthly clinic visits (at months 1, 2, and 3). Topics covered were: (1) definition, etiology, diagnosis, disease progress, and complications of asthma; (2) instruction to monitor disease severity, especially skills needed to use the peak expiratory flow (PEF) meter and the format to record symptoms in a diary; (3) introduction on medications for asthma therapy, including protocol of a stepwise treatment plan, pharmacology of leading asthma drugs and correct inhaler techniques; and (4) guidelines for self management, including understanding potential environmental triggers and irritant factors, environmental control and standard procedure for coping with asthma attacks. Pharmacist counseling covered information related to the action and side effects of asthma medications, treatment plans for individualized medication, and modification of medications in response to progressive asthma
\end{abstract}

Intervention: NURSE-ADMINISTERED ASTHMA EDUCATION PROGRAM

Patients participated in the standard nurse-administered asthma education program. A detailed workbook prepared by chest physicians was used for each session. The asthma education program covered 4 topics taught in sequence in 31 -hour sessions offered during monthly clinic visits (at months 1, 2, and 3). Topics covered were: (1) definition, etiology, diagnosis, disease progress, and complications of asthma; (2) instruction to monitor disease severity, especially skills needed to use the peak expiratory flow (PEF) meter and the format to record symptoms in a diary; (3) introduction on medications for asthma therapy, including protocol of a stepwise treatment plan, pharmacology of leading asthma drugs and correct inhaler techniques; and (4) guidelines for self management, including understanding potential 
Wang 2010 b (Continued)

environmental triggers and irritant factors, environmental control and standard procedure for coping with asthma attacks

Control: CONTROL

Patients in the control group received only routine asthma care

Outcomes

The measures of adherence were the Self Assessment of Medication Adherence questionnaire, which includes 4 items on specific self management behavior in use of asthma medication within the past month, and was measured at baseline, 3 and 6 months

The patient outcome was one questionnaire, used to measure participants' HRQOL pre- and post-intervention. Acceptable validity and reliability of the instruments had been previously determined. Asthma patients' quality of life was measured with the AQLQ, a 32-item questionnaire with 4 subscales of activity limitations, symptoms, emotional status, and exposure to environmental triggers. The instrument's reliability has been validated after 7 years of use in clinical trials

Notes -

\section{Risk of bias}

\begin{tabular}{lll}
\hline Bias & Authors' judgement & Support for judgement \\
\hline $\begin{array}{ll}\text { Random sequence genera- } \\
\text { tion (selection bias) }\end{array}$ & Unclear risk & $\begin{array}{l}\text { Randomization was not described in detail. "The study is a random block de- } \\
\text { sign. The investigator randomly assigned patients to one of three groups: } 35\end{array}$ \\
& & were assigned to the nurse-administered asthma education program (Group \\
& 1), 34 to the education program combined with pharmacist counseling (Group \\
& 2), and 35 received routine asthma care only (Control group). " (pg 724)
\end{tabular}

Allocation concealment Unclear risk No information was provided about how allocation was handled

(selection bias)

\begin{tabular}{|c|c|c|}
\hline $\begin{array}{l}\text { Selective reporting (re- } \\
\text { porting bias) }\end{array}$ & Unclear risk & $\begin{array}{l}\text { No protocol available; although it appears that everything was reported it is } \\
\text { difficult to determine this without a protocol }\end{array}$ \\
\hline
\end{tabular}

\begin{tabular}{lll}
\hline Other bias & Low risk & The study seems to be free of other types of bias \\
\hline $\begin{array}{l}\text { Blinding of outcome as- } \\
\text { sessment (detection bias) } \\
\begin{array}{l}\text { Adherence measure } \\
\text { (PRIMARY) SELF REPORT - QUESTIONNAIRE - No mention of blinding of out- }\end{array}\end{array}$ & High risk & $\begin{array}{l}\text { come assessors; subjective outcome } \\
\end{array}$ \\
\hline
\end{tabular}

Blinding of outcome as- High risk
sessment (detection bias) Patient outcome (PRIMARY) HEALTH-RELATED QUALITY OF LIFE QUESTIONNAIRE - This is a subjective measure; there is no information on blinding

\begin{tabular}{|c|c|c|}
\hline $\begin{array}{l}\text { Blinding of participants } \\
\text { (performance bias) } \\
\text { Adherence measure }\end{array}$ & High risk & $\begin{array}{l}\text { (PRIMARY) SELF REPORT - QUESTIONNAIRE - No mention of blinding of pa- } \\
\text { tients; subjective outcome }\end{array}$ \\
\hline
\end{tabular}

\begin{tabular}{ll}
\hline $\begin{array}{l}\text { Blinding of participants } \\
\text { (performance bias) }\end{array}$ & High risk \\
$\begin{array}{l}\text { Patient outcome } \\
\text { (PRIMARY) HEALTH-RELATED QUALITY OF LIFE QUESTIONNAIRE - This is a sub- }\end{array}$ & jective measure; there is no information on blinding
\end{tabular}

Blinding of personnel (per- High risk
formance bias)


Wang 2010 b (Continued)

Incomplete outcome data Low risk (PRIMARY) SELF REPORT - QUESTIONNAIRE - Fairly equal dropouts across (attrition bias) groups; reasons for dropouts provided

Adherence measure

Incomplete outcome data Low risk

(attrition bias)

(PRIMARY) HEALTH-RELATED QUALITY OF LIFE QUESTIONNAIRE - Fairly equal

Patient outcome

dropouts across groups; reasons for dropouts provided

Weber 2004

\begin{tabular}{ll}
\hline Methods & Random allocation, not otherwise specified \\
\hline Participants & $\begin{array}{l}60 \text { HIV patients were randomized by the researchers after giving informed consent. Inclusion and ex- } \\
\text { clusion criteria: therapy containing a combination of at least } 3 \text { different antiretroviral drugs of at least } \\
2 \text { different drug classes, viral load below } 50 \text { copies/ml documented within the previous } 3 \text { months and } \\
\text { at screening visit, participation in the Swiss HIV cohort study, no intravenous drug use or on stable } \\
\text { methadone maintenance in case of drug addiction }\end{array}$ \\
\hline $\begin{array}{l}\text { Participants were randomly assigned to a psychotherapist and given the contact information to sched- } \\
\text { Interventions their own first appointment. Protocol defined a minimum of } 3 \text { and a maximum of } 25 \text { sessions with- } \\
\text { in the 1-year study period. Participant and psychotherapist determined the frequency of appointments } \\
\text { and set their own goals for future interventions. The method of intervention had to be based on con- } \\
\text { cepts of cognitive behavior therapy. Both intervention and control groups continued to receive stan- } \\
\text { dard care. Standard care included monthly visits for } 12 \text { months with assessments of clinical and labora- } \\
\text { tory data, course of treatment, drug adverse events and HIV-1 RNA }\end{array}$ \\
\hline
\end{tabular}

Outcomes An electronic medication exposure monitoring system was used to measure adherence. Outcome measures included virological and immunological outcomes, CD4 lymphocyte end-points, change in antiretroviral therapy during study, and psychosocial measures

Notes

\section{Risk of bias}

\begin{tabular}{lll}
\hline Bias & Authors' judgement & Support for judgement \\
\hline $\begin{array}{ll}\text { Random sequence genera- } \\
\text { tion (selection bias) }\end{array}$ & Low risk & The allocation schedule for 2 treatment arms and 3 different CD4 strata $(0-$ \\
& & $0.05 \times 109 / l, 0.051-0.2 \times 109 / /$ or $>0.2 \times 109 / /)$ with randomly permuted block sizes \\
& of 2 and 4, was generated in advance with the program RANCODE V 3.0 (IDV \\
& Datenanalyse und Versuchsplanung, Gauting, Germany) and properly con- \\
& cealed from care providers (pg 86)
\end{tabular}

Allocation concealment Low risk (selection bias)

Allocation concealment detailed. The allocation schedule for 2 treatment arms and 3 different CD4 strata $(0-0.05 \times 109 / /, 0.051-0.2 \times 109 / \mathrm{l}$ or $>0.2 \times 109 / \mathrm{l})$ with randomly permuted block sizes of 2 and 4 , was generated in advance with the program RANCODE V 3.0 and properly concealed from care providers (pg 86)

\begin{tabular}{|c|c|c|}
\hline $\begin{array}{l}\text { Selective reporting (re- } \\
\text { porting bias) }\end{array}$ & Unclear risk & $\begin{array}{l}\text { No protocol available; although it appears that everything was reported it is } \\
\text { difficult to determine this without a protocol }\end{array}$ \\
\hline
\end{tabular}

\begin{tabular}{lll}
\hline Other bias & Low risk & The study seems to be free of other types of bias \\
\hline $\begin{array}{l}\text { Blinding of outcome as- } \\
\text { sessment (detection bias) }\end{array}$ & High risk & $\begin{array}{l}\text { (PRIMARY) SELF REPORT - STRUCTURED QUESTIONNAIRE - This is a subjective } \\
\text { measure; there is no information on blinding }\end{array}$ \\
\end{tabular}


Weber 2004 (Continued)

Blinding of outcome as- Low risk (PRIMARY) VIRAL LOAD - HIV-1 RNA - This is an objective measure of outcome sessment (detection bias)

Patient outcome

\begin{tabular}{|c|c|c|}
\hline $\begin{array}{l}\text { Blinding of participants } \\
\text { (performance bias) } \\
\text { Adherence measure }\end{array}$ & High risk & $\begin{array}{l}\text { (PRIMARY) SELF REPORT - STRUCTURED QUESTIONNAIRE - This is a subjective } \\
\text { measure; there is no information on blinding }\end{array}$ \\
\hline $\begin{array}{l}\text { Blinding of participants } \\
\text { (performance bias) } \\
\text { Patient outcome }\end{array}$ & Low risk & (PRIMARY) VIRAL LOAD - HIV-1 RNA - This is an objective measure of outcome \\
\hline
\end{tabular}

\begin{tabular}{ll}
\hline Blinding of personnel (per- & High risk \\
$\begin{array}{l}\text { formance bias) } \\
\text { Adherence measure }\end{array}$ & (PRIMARY) SELF REPORT - STRUCTURED QUESTIONNAIRE - This is a subjective \\
& measure; there is no information on blinding
\end{tabular}

Blinding of personnel (per- Low risk

(PRIMARY) VIRAL LOAD - HIV-1 RNA - This is an objective measure of outcome

formance bias)

Patient outcome

\begin{tabular}{|c|c|c|}
\hline $\begin{array}{l}\text { Incomplete outcome data } \\
\text { (attrition bias) } \\
\text { Adherence measure }\end{array}$ & Unclear risk & $\begin{array}{l}\text { (PRIMARY) SELF REPORT - STRUCTURED QUESTIONNAIRE - No information giv- } \\
\text { en on reasons for dropouts }\end{array}$ \\
\hline
\end{tabular}

\begin{tabular}{|c|c|c|}
\hline $\begin{array}{l}\text { Incomplete outcome data } \\
\text { (attrition bias) }\end{array}$ & Unclear risk & $\begin{array}{l}\text { (PRIMARY) VIRAL LOAD - HIV-1 RNA - No information given about dropout rea- } \\
\text { sons }\end{array}$ \\
\hline
\end{tabular}

Patient outcome

\section{Weinberger 2002}

A cluster-RCT: the 36 drugstores were divided into 12 clusters of 3 geographically proximal drugstores
("triplets"). The 3 drugstores within each triplet were matched on percentage of Medicaid-insured
adults with reactive airways disease (to control for customers' socioeconomic status) and number of
prescriptions filled (high versus low-volume). Within each triplet, a random number chart was used to
assign drugstores to 1 of 3 study groups

Participants 1113 eligible patients were enrolled. 453 were chronic obstructive pulmonary disease (COPD) patients and 660 people with asthma. Patients were censored from the study if they died, were placed in a nursing home, moved away permanently from Indianapolis, their insurance no longer covered using these drugstores, or they lost telephone access. Customers were eligible if they: (1) filled a prescription for methylxanthines, inhaled corticosteroids, inhaled or oral sympathomimetics, inhaled parasympathetic antagonists, or inhaled cromolyn sodium during the preceding 4 months; (2) reported having COPD or asthma as an active problem; (3) were 18 years or older; (4) received $70 \%$ or more of their medications from a single study drugstore; (5) reported no significant impairment in vision, hearing, or speech that precluded participation; (6) did not reside in an institution (e.g. nursing home); and (7) provided written informed consent

Interventions

Components of intervention in pharmaceutical care program group (Group 1) included: 1) Computer Display of Patient-Specific Data. When a study patient filled any prescription (not only breathing medications), the drugstore computer alerted pharmacists to review patient-specific data contained in a separate study computer behind the counter. To safeguard patients' confidentiality, access to patient-specific data required pharmacists' individualized passwords. Study computers contained: (1) contact information for patients and 1 to 2 physicians caring for their breathing problem; (2) graphical display of all Peak Expiratory Flow Rate (PEFR) data gathered during monthly interviews; (3) dates and locations of recent emergency department visits and hospitalizations; and (4) breathing medications (including compliance rates and refill histories). These data were obtained during monthly telephone interviews. Pharmacists were encouraged to document their pharmaceutical care activities at the bot- 
Weinberger 2002 (Continued)

tom of the screen. 2). Written Patient Educational Materials. One-page handouts were developed corresponding to specific problems associated with clinical data stored in the study computer. Handouts, designed to be easily understood by patients, used mnemonic devices and color coding to facilitate distribution by pharmacists. 3). Resource Guide. Attached to the study computer, guides contained laminated pages with practical suggestions to help pharmacists implement the program in a busy practice. 4). Pragmatic Strategies to Facilitate Pharmaceutical Care. To reinforce pharmacist training and facilitate program implementation: (1) pharmacists were encouraged to page the on-call investigator with questions; (2) an investigator made personal visits to each intervention drugstore every 1 to 2 months; (3) periodic newsletters containing information about reactive airways disease and suggestions on implementing the program were distributed; (4) weekly lists were faxed of recent patient activity (e.g. medication refill, ED or hospital visit) and pharmacists' documented activities; and (5) pharmacists were provided with telephone appointment scheduling cards to facilitate interactions with patients at a mutually convenient time. During the final year of the study, pharmacists were paid USD 50 per month for high rates of compliance with the pharmaceutical care protocol (viewing data on the study computer for $90 \%$ of patients and documenting actions for $75 \%$ of patients). Patients in the pharmaceutical care group received a peak flow meter, instruction about its use, and monthly calls from research personnel to obtain current PEFR results. The peak flow meter monitoring control group (group 2) also received a peak flow meter, instructions about its use, and monthly calls to elicit PEFRs. However, PEFR data were not provided to the pharmacist. Patients in the usual care group received neither peak flow meters nor instructions in their use; during monthly telephone interviews, PEFR rates were not elicited. Pharmacists in both control groups also had a 4-hour training session although the topics were different and they received no components of the pharmaceutical care program

Outcomes

Compliance measures were made at baseline, at 6 month and 12 months by face-to-face interview using 2 validated measures: a single-item indicator (proportion of noncompliance), and a 4-item scale ranging from 0 (low) to 4 (high) noncompliance. Self report had been found to be valid when inquiries were made in a non-threatening manner

Clinical health outcomes included: peak expiratory flow rates, breathing-related emergency department or hospital visits, health-related quality of life (HRQOL), medication compliance, and patient satisfaction

Notes -

\section{Risk of bias}

\begin{tabular}{lll}
\hline Bias & Authors' judgement & Support for judgement \\
\hline $\begin{array}{ll}\text { Random sequence genera- } \\
\text { tion (selection bias) }\end{array}$ & Low risk & $\begin{array}{l}\text { Randomization done using random number table."... Within each triplet, we } \\
\text { used a random-number chart to assign drugstores to } 1 \text { of } 3 \text { study groups." (pg } \\
1595)\end{array}$ \\
\hline
\end{tabular}

\begin{tabular}{|c|c|c|}
\hline $\begin{array}{l}\text { Allocation concealment } \\
\text { (selection bias) }\end{array}$ & Unclear risk & $\begin{array}{l}\text { Cluster-randomized "...Within each triplet, we used a random-number chart to } \\
\text { assign drugstores to } 1 \text { of } 3 \text { study groups." (pg 1595) }\end{array}$ \\
\hline Other bias & Low risk & The study seems to be free of other types of bias \\
\hline $\begin{array}{l}\text { Blinding of outcome as- } \\
\text { sessment (detection bias) } \\
\text { Adherence measure }\end{array}$ & Unclear risk & $\begin{array}{l}\text { (PRIMARY) SELF REPORT - INTERVIEW - Baseline, 6-, and 12-month interviews } \\
\text { were conducted by blinded interviewers "Interviewers, blinded to study group } \\
\text { assignment, obtained informed consent and conducted baseline interviews". } \\
\text { "After completing an interview, the laptop computer used to administer inter- } \\
\text { views revealed the patient's study group assignment." "in-person follow-up } \\
\text { interviews at } 6 \text { and } 12 \text { months to assess outcomes by individuals blinded to } \\
\text { study group." Possible loss of blinding because group assignments were re- } \\
\text { vealed in the laptop after the baseline interview(pg 1597) }\end{array}$ \\
\hline
\end{tabular}


Weinberger 2002 (Continued)

Blinding of outcome as- Unclear risk $\quad$ (PRIMARY) PEAK FLOW RATE MEASUREMENT - There is a report of blinding of sessment (detection bias) interviewers conducting face to face interviews at baseline, 6-, and 12 months. Patient outcome However there is no statement of blinding of those conducting the monthly telephone interviews

Blinding of participants High risk (performance bias)

Adherence measure
(PRIMARY) SELF REPORT - INTERVIEW - This is a subjective measure; there is no information on blinding
Blinding of participants Low risk (performance bias)

Patient outcome
(PRIMARY) PEAK FLOW RATE MEASUREMENT - This is an objective measure of outcome

Blinding of personnel (per- Unclear risk

formance bias)

Adherence measure

(PRIMARY) SELF REPORT - INTERVIEW - Interviewers reported to be blind. Pharmacists not blind - cluster design. Insufficient information regarding other personnel blinding

Blinding of personnel (per- Unclear risk formance bias)

Patient outcome

(PRIMARY) PEAK FLOW RATE MEASUREMENT - No information on blinding given. There is insufficient information to permit judgment of 'Low risk' or 'High risk'

Incomplete outcome data Low risk

(attrition bias)

(PRIMARY) SELF REPORT - INTERVIEW - Missing data - 76 and 91 (20\%) in the pharma care group at 6 months and 12 months; 48 and 67 (18\%) in the peak flow monitoring group; 42 and 57 (18\%) in the usual care group - possibility of the relatively high missing data affecting result. No statistical difference between groups on adherence outcome. Reasons for missing fairly uniform, probably unrelated to outcome. (pg 1597) "Patients were censored from the study if they died, were placed in a nursing home, moved away permanently from Indianapolis, their insurance no longer covered using these drugstores, or they lost telephone access".

Incomplete outcome data Low risk

(attrition bias)

Patient outcome
(PRIMARY) PEAK FLOW RATE MEASUREMENT - Missing data - 76 and 91 (20\%) in the pharma care group at 6 months and 12 months; 48 and 67 (18\%) in the peak flow monitoring group; 42 and $57(18 \%)$ in the usual care group - possibility of the relatively high missing data affecting result. No statistical difference between groups on adherence outcome. Reasons for missing fairly uniform, probably unrelated to outcome. (pg 1597) "Patients were censored from the study if they died, were placed in a nursing home, moved away permanently from Indianapolis, their insurance no longer covered using these drugstores, or they lost telephone access"

\section{Wiggins 2009}

\begin{tabular}{ll}
\hline Methods & Randomized controlled trial \\
\hline Participants & The study location was 2 different ambulatory settings in the Midwest, USA \\
& $\begin{array}{l}7 \text { participants were randomized to the intervention group and } 6 \text { participants were randomized to the } \\
\text { control group }\end{array}$ \\
& The inclusion criteria were patients aged 12 through 18 years and admitted for a tonsillectomy or T \& A; \\
with no risks or complications due to the surgical procedure and no history of bleeding disorders; dis- \\
charged home with analgesia prescription that included instructions for administration every 4 hours \\
for moderate to severe pain; discharged the same day as the surgery; both parent and child are able to \\
speak, read, and write using the English language; and access to a telephone in the home for purpose \\
of 2 follow-up interviews.
\end{tabular}


Wiggins 2009 (Continued)

Interventions

Intervention: AROUND-THE-CLOCK INTERVENTION

The intervention was alarms to remind administering analgesic 4 hours after going to bed on the night of surgery and next 2 postoperative nights as instructed by the research nurse. In addition to the study procedure, all children and families received discharge education from their ear, nose, and throat (ENT) physician/clinic and from the professional nurses in each of the ambulatory centers. Discharge education in both ambulatory settings included use of around-the-clock prescribed analgesia for pain during the early days of recovery; increased fluid intake; monitoring for infection and bleeding; and returning to their specialist at a designated time in the recovery process. In addition, all ENT specialists encouraged families to contact them with concerns. All families received a phone call from a registered nurse from their ambulatory surgery center 24 hours after discharge

Control: USUAL CARE

The usual care group (UCG) was not given any specific intervention, but was offered the same discharge education as the intervention group. Discharge education materials included information about ear pain and the length of the recovery, mothers and children expressed self doubt about their ability to provide adequate symptom management when painful experiences continued

Outcomes The measures of adherence were a diary. Each child recorded daily pain and symptom information in a diary from the day of surgery (after returning home) through the second postoperative day

The patient outcomes were pain intensity, fluid intake, and night-time awakenings by as self report diary. Pain intensity was recorded for the night of the surgery and postoperative day one and 2 using the Poker chip tool (PCT). Each child was given 4 red poker chips prior to discharge from the ambulatory setting. Both the parent and child were instructed by the research nurse that zero poker chips indicated no pain and 4 poker chips was the worst pain. Fluid intake and awakening were also recorded in the diary. Children were instructed record the number of awakening they remembered through the night. Fluid intake was measured per 8 ounce glass. Night time sleep was also measured using an Actigraph wrist device, which the patient had to wear from the time of discharge through the second postoperative day

Notes Clinical outcomes reported as median only

\section{Risk of bias}

\begin{tabular}{lll}
\hline Bias & Authors' judgement & Support for judgement \\
\hline $\begin{array}{l}\text { Random sequence genera- } \\
\text { tion (selection bias) }\end{array}$ & Low risk & $\begin{array}{l}\text { Computer-generated random numbers used. "The research nurse used a com- } \\
\text { puter-generated random numbers table to assign children to either the RTC } \\
\text { group or the UCG at the time of discharge." (pg 167) }\end{array}$ \\
\hline
\end{tabular}

\begin{tabular}{lll}
\hline $\begin{array}{l}\text { Allocation concealment } \\
\text { (selection bias) }\end{array}$ & Unclear risk & No information was provided about how allocation was handled \\
\hline $\begin{array}{l}\text { Selective reporting (re- } \\
\text { porting bias) }\end{array}$ & Unclear risk & $\begin{array}{l}\text { No protocol available; although it appears that everything was reported it is } \\
\text { difficult to determine this without a protocol }\end{array}$ \\
\hline Other bias & Low risk & The study seems to be free of other types of bias \\
\hline $\begin{array}{l}\text { Blinding of outcome as- } \\
\text { sessment (detection bias) } \\
\text { Adherence measure }\end{array}$ & High risk & $\begin{array}{l}\text { (PRIMARY) SELF REPORT - DIARY - No blinding of outcome assessment is men- } \\
\text { tioned in the article. Patients entered the data themselves. They were unblind- } \\
\text { ed. "Children and parent(s) were informed during the consent/assent process } \\
\text { that there were two different group assignments and after the final interview } \\
\text { they would be told about the differences." }\end{array}$ \\
\hline
\end{tabular}

Blinding of outcome assessment (detection bias) Patient outcome
High risk

(PRIMARY) DIARY RECORDING: PAIN AND SLEEP - Measurements were recorded by the patient who was instructed by the research nurse how to use the Poker chip tool. There is no information as to blinding of the nurse but any blinding could have been broken due to the nature of the intervention. "Children and parent(s) were informed during the consent/assent process that there were 
Wiggins 2009 (Continued)

two different group assignments and after the final interview they would be told about the differences." It is possible that patients and families were aware of the groups - not clear in the manuscript" (pg 167)

$\begin{array}{ll}\begin{array}{l}\text { Blinding of participants } \\ \text { (performance bias) }\end{array} & \text { High risk } \\ \text { Adherence measure } & \text { (PRIMARY) SELF REPORT - DIARY - Children and parent(s) were informed during } \\ \text { the consent/assent process that there were } 2 \text { different group assignments and } \\ \text { after the final interview they would be told about the differences }\end{array}$

\begin{tabular}{|c|c|c|}
\hline $\begin{array}{l}\text { Blinding of participants } \\
\text { (performance bias) } \\
\text { Patient outcome }\end{array}$ & High risk & $\begin{array}{l}\text { (PRIMARY) DIARY RECORDING: PAIN AND SLEEP - Measure was recorded by pa- } \\
\text { tient themselves. Children and parent(s) were informed during the consent/as- } \\
\text { sent process that there were } 2 \text { different group assignments and after the final } \\
\text { interview they would be told about the differences." (pg 167) }\end{array}$ \\
\hline
\end{tabular}

Blinding of personnel (per- Low risk

formance bias)

(PRIMARY) SELF REPORT - DIARY - Research nurse is aware of group assign-

Adherence measure ment. Other health care providers were blinded. "Allhealth care providers in the ambulatory setting were blinded to group assignment." (pg 167)

Blinding of personnel (per- Low risk

formance bias)

(PRIMARY) DIARY RECORDING: PAIN AND SLEEP - "All health care providers in

Patient outcome the ambulatory setting were blinded to group assignment" (pg 167)

$\begin{array}{ll}\begin{array}{l}\text { Incomplete outcome data Low risk } \\ \text { (attrition bias) }\end{array} & \text { (PRIMARY) SELF REPORT - DIARY - 1 child in the RTC group did not choose to } \\ \text { Adherence measure } & \begin{array}{l}\text { use the alarm intervention. This child reported having minimal pain and ad- } \\ \text { ministering only a few doses of the prescribed pain medication during the } \\ \text { postoperative recovery. (pg 170) If this child did not adhere to the interven- } \\ \text { tion, he/she should have been removed from the analysis. The reason for miss- } \\ \text { ing data does not introduce any bias }\end{array}\end{array}$

Incomplete outcome data Low risk

(attrition bias)

Patient outcome
(PRIMARY) DIARY RECORDING: PAIN AND SLEEP - 1 child in the RTC group did not choose to use the alarm intervention. This child reported having minimal pain and administering only a few doses of the prescribed pain medication during the postoperative recovery. (pg 170) If this child did not adhere to the intervention, he/she should have been removed from the analysis. The reason for missing data does not introduce any bias

Wilson 2010

\begin{tabular}{ll}
\hline Methods & Randomized controlled trial \\
\hline Participants & The study location was Kaiser Permanente (KP) Center for Health Research in Portland, Oregon; Hon- \\
olulu, Hawaii; Oakland/Richmond, California; San Francisco, California, USA \\
204 participants were randomized to the Shared Treatment Decision Making (SDM) intervention group \\
and 204 participants were randomized to the Clinician Decision Making (CDM) control group \\
The inclusion criteria were KP members aged 18 to 70 years with evidence suggestive of poorly con- \\
trolled asthma, who used rescue medications and had at least 3 beta-agonist dispensings in the past \\
year, or were recently admitted to the ED or hospital for asthma-related reasons \\
The exclusion criteria were intermittent asthma, primary diagnosis of chronic obstructive pulmonary \\
disease or emphysema, insufficient pulmonary function reversibility, regular use of oral corticos- \\
teroids, and current asthma care management \\
$\begin{array}{l}\text { Intervention: SHARED DECISION MAKING } \\
\text { Session } 1 \text { involved setting the stage, gathering patient information, providing information and nego- } \\
\text { tiating a treatment plan. In session } 2 \text { (1 month after session 1), and in } 3 \text { brief phone calls 3, 6, and } 9 \\
\text { months later, patient progress was assessed and medications were adjusted, as necessary, using the } \\
\text { assigned care management approach. Researchers used identical standardized interventionist scripts }\end{array}$ \\
\hline Interventions
\end{tabular}


and materials. The patient's asthma history was elicited using a standardized patient information form, the patient's level of asthma control was classified, and asthma education was provided. Once treatment was negotiated, patients were instructed in the correct use of the relevant inhaler medication devices using methods previously shown by this team to improve inhaler technique and eliminate common usage errors. At the end of session 1, a written asthma management and action plan was created, and potential barriers to medication adherence were elicited and addressed using motivational interviewing techniques. Any subsequent changes made at session 2 or in a follow-up phone call were documented in the plan. The SDM model implemented the 4 key defining features. The care manager elicited the patient's goals for treatment and relative priorities regarding symptom control, regimen convenience, avoidance of side effects, and cost. The patient was then shown a list of the full range of regimen options for all levels of asthma severity, based on the then-current national asthma guidelines and KP pharmacopeia. These options differed with respect to the number and type(s) of medications, dosing, and schedule. Using a simple worksheet, the patient and clinician then compared the pros and cons of all of the options the patient wished to consider, which included the option of continuing the patient's current regimen to arrive at a treatment that best accommodated the patient's and care manager's goals. A SABA was always prescribed for rescue use as needed. If indicated, treatment of allergic rhinitis and/or gastroesophageal reflux disease was negotiated

\section{Intervention: CLINICIAN DECISION MAKING}

Session 1 of the intervention involved prescribing the patient a therapy rather than negotiating a therapy. In session 2 ( 1 month after session 1), and in 3 brief phone calls 3, 6, and 9 months later, patient progress was assessed and medications were adjusted, as necessary, using the assigned care management approach. Researchers used identical standardized interventionist scripts and materials. The patient's asthma history was elicited using a standardized patient information form, the patient's level of asthma control was classified, and asthma education was provided. Once treatment was decided (CDM), patients were instructed in the correct use of the relevant inhaler medication devices using methods previously shown by this team to improve inhaler technique and eliminate common usage errors. At the end of session 1, a written asthma management and action plan was created, and potential barriers to medication adherence were elicited and addressed using motivational interviewing techniques. Any subsequent changes made at session 2 or in a follow-up phone call were documented in the plan. In the CDM model, the care manager prescribed an appropriate regimen based on the patient's level of asthma control, and explained that decision to the patient. A SABA was always prescribed for rescue use as needed. If indicated, treatment of allergic rhinitis and/or gastroesophageal reflux disease was prescribed

\section{Control: USUAL CARE}

Usual asthma care at KP medical centers was based on a stepped-care approach to pharmacotherapy with the aim of long-term asthma control, as recommended by the National Asthma Education Prevention Program's Expert Panel Report 2. At some KP sites, physicians also had the option to refer patients to an asthma care management program, typically of less than 6 months' duration, in which a licensed health professional (non-physician) provided asthma education and addressed adherence and other medication use and self management issues in a manner similar to, but less structured than, the CDM intervention. However, asthma care management was neither a required aspect of usual care nor necessarily available at all BOAT sites, and current participation in that program was an exclusion criterion for the study. Once enrolled in BOAT, usual care and SDM or CDM patients (after the intervention phase) still had access to KP's existing care management services, if available, based on their physician's referral

The measure of adherence was pharmacy data. These data provided information about medication acquisition and were extracted from KP dispensing records 1 year pre-randomization and 2 years postrandomization. Fill/refill adherence was measured using a continuous medication acquisition (CMA) index for each year, calculated as the total days' supply acquired in a given year divided by 365 days. The index represents the proportion of the prescribed medication supply acquired by the patient during each 365-day period, and may potentially overestimate, but not underestimate, actual use.

The patient outcomes were pharmacy data. These data provided information about medication acquisition and were extracted from KP dispensing records 1 year pre-randomization and 2 years post-randomization. Fill/refill adherence was measured using a continuous medication acquisition (CMA) index for each year, calculated as the total days' supply acquired in a given year divided by 365 days. The index represents the proportion of the prescribed medication supply acquired by the patient during each 365-day period, and may potentially overestimate, but not underestimate, actual use 
Wilson 2010 (Continued)

Notes

\section{Risk of bias}

\begin{tabular}{|c|c|c|}
\hline Bias & Authors' judgement & Support for judgement \\
\hline $\begin{array}{l}\text { Random sequence genera- } \\
\text { tion (selection bias) }\end{array}$ & Low risk & $\begin{array}{l}\text { Randomization sequence computer-generated. "A computer-based adaptive } \\
\text { randomization algorithm (25) was used to ensure concealment from random- } \\
\text { ization staff and better-than chance balance among the } 3 \text { groups on age (18- } \\
34,35-50 \text {, and } 51-70 \mathrm{yr} \text { ), sex, race/ethnicity, hospitalization in the prior two } \\
\text { years (yes/ no), and frequency of asthma controller use in the past week (none, } \\
1-3,>4 d) . " \text { (pg 567) }\end{array}$ \\
\hline
\end{tabular}

Allocation concealment Low risk
(selection bias)

Randomization sequence kept separate from those involved in the study and done using a computer sequence. "A computer-based adaptive randomization algorithm (25) was used to ensure concealment from randomization staff and better than chance balance among the three groups on age (18-34, 35-50, and 51-70 yr), sex, race/ethnicity, hospitalization in the prior two years (yes/ no), and frequency of asthma controller use in the past week (none, 1-3,>4d)". "Allocation was concealed from staff randomizing patients. Randomization was implemented by having a designated, non-blinded re search staff member at the site enter the relevant patient descriptors into the randomization module on the BOAT website, which immediately performed the randomization, stored the result, and return ed the patient's study assignment for implementation of the experimental assignment as indicated (e.g., referral to the designated care manager). All other study personnel, with the exception of the care managers, were blinded to patient's study assignment." (protocol).

\begin{tabular}{lll}
\hline $\begin{array}{l}\text { Selective reporting (re- } \\
\text { porting bias) }\end{array}$ & Low risk & All outcomes specified in the protocol were reported \\
\hline Other bias & Low risk & The study seems to be free of other types of bias \\
\hline $\begin{array}{l}\text { Blinding of outcome as- } \\
\begin{array}{l}\text { sessment (detection bias) } \\
\text { Adherence measure }\end{array}\end{array}$ & Low risk & $\begin{array}{l}\text { (PRIMARY) PHARMACY RECORD - Blinded assessors. "All other study personnel, } \\
\text { with the exception of the care managers, were blinded to patient's study as- } \\
\text { signment." (pg 3, suppl) }\end{array}$ \\
\hline $\begin{array}{l}\text { Blinding of outcome as- } \\
\text { sessment (detection bias) } \\
\begin{array}{l}\text { Patient outcome } \\
\text { (PRIMARY) ASTHMA-RELATED QUALITY OF LIFE - Blinded assessors. "All other }\end{array}\end{array}$ & Low risk & $\begin{array}{l}\text { (Ptudy personnel, with the exception of the care managers, were blinded to pa- } \\
\text { tient's study assignment." (pg 3, suppl) }\end{array}$
\end{tabular}

\begin{tabular}{lll}
\hline $\begin{array}{l}\text { Blinding of participants } \\
\text { (performance bias) }\end{array}$ & Low risk & (PRIMARY) PHARMACY RECORD - This is an objective measure of outcome \\
$\begin{array}{ll}\text { Adherence measure } \\
\text { Blinding of participants }\end{array}$ & High risk & $\begin{array}{l}\text { (PRIMARY) ASTHMA-RELATED QUALITY OF LIFE - This is a subjective measure; } \\
\text { (performance bias) } \\
\begin{array}{l}\text { Patient outcome } \\
\text { there is no information on blinding }\end{array}\end{array}$ \\
\hline
\end{tabular}
Blinding of personnel (per- Unclear risk (PRIMARY) PHARMACY RECORD - No information on blinding given. There is in- formance bias) sufficient information to permit judgment of 'Low risk' or 'High risk'

Adherence measure

\begin{tabular}{|c|c|c|}
\hline $\begin{array}{l}\text { Blinding of personnel (per- } \\
\text { formance bias) } \\
\text { Patient outcome }\end{array}$ & Unclear risk & $\begin{array}{l}\text { (PRIMARY) ASTHMA-RELATED QUALITY OF LIFE - No information on blinding } \\
\text { given. There is insufficient information to permit judgment of 'Low risk' or } \\
\text { 'High risk' }\end{array}$ \\
\hline
\end{tabular}

\begin{tabular}{|c|c|c|}
\hline $\begin{array}{l}\text { Incomplete outcome data } \\
\text { (attrition bias) }\end{array}$ & Unclear risk & $\begin{array}{l}\text { (PRIMARY) PHARMACY RECORD - Missing outcome data only for ICS canister } \\
\text { equivalents and LABA acquisition. Missing data for ICS canister acquisition is }\end{array}$ \\
\hline
\end{tabular}


Wilson 2010 (Continued)

Adherence measure fairly similar across the groups but no reasons are given. There are a lot of data missing for the LABA acquisition and there is a large discrepancy between the groups. The number of patients per group at pre-randomization and follow-up Year 2 is: SDM, $n=204 ; C D M, n=202 ; U C, n=204$; and at follow-up Year 1 is: SDM, $n=204 ; C D M, n=202 ; U C, n=203$ for ICS canister equivalents. The number of patients per group at each time point is: pre-randomization, SDM, $\mathrm{n}$ $=40 ;$ CDM, $n=44 ;$ UC, $n=52$; follow-up Year 1: SDM, $n=112 ;$ CDM, $n=108 ; U C, n$ $=59$ for $L A B A$ acquisition

Incomplete outcome data Unclear risk

(attrition bias)

Patient outcome

(PRIMARY) ASTHMA-RELATED QUALITY OF LIFE - Missing outcome data are fairly balanced in numbers across intervention groups but no reasons given for missing data. Refer to Figure 2. "The number of patients per group with no missing values at either time point is SDM $n=182, \operatorname{CDM} n=180, \mathrm{UC} n=189$ for quality of life measure." (pg 574)

Wolever 2010

\begin{tabular}{ll}
\hline Methods & Randomized controlled trial \\
\hline Participants & The study location was Duke University Medical Center, Durham, North Carolina, USA \\
& $\begin{array}{l}30 \text { participants were randomized to the intervention group and } 26 \text { participants were randomized to the } \\
\text { control group }\end{array}$
\end{tabular}

The inclusion criteria were English speaking, at least 18 years of age, have a diagnosis of type 2 diabetes for at least 1 year, be taking oral diabetes medication for at least 1 year, and have medical and pharmacy benefits available to the study team

The exclusion criteria were dementia, Alzheimer disease, schizophrenia, or other cognitive impairment that would preclude informed consent

\title{
Interventions
}

\begin{abstract}
Intervention: INTEGRATIVE HEALTH (IH) COACHING
2 coaches provided the coaching intervention. Both had substantial training in coaching methods as well as masters-level degrees in social work or psychology. Coaches each had over 100 hours of experience of individualized coaching with type 2 diabetes patients and had previously facilitated diabetes coaching groups. Participants randomized to the coaching condition had an initial telephone session with their coach within 2 weeks of the baseline visit. They were then offered 30 -minute coaching sessions by telephone ( 8 weekly calls, 4 biweekly calls, and a final call 1 month later) for a total of 14 sessions. Participants were paired with the same coach throughout the intervention. During the initial telephone call, participants were asked what was important to them in terms of diabetes care, how well they were managing their health, and what they perceived to be their challenges or areas of required support. Patients were guided in creating a vision of health, and long-term goals were discussed that aligned with that vision. To facilitate learning, participants randomized to $\mathrm{IH}$ coaching received a binder of educational materials at the initial assessment visit. Contents included materials from GlaxoSmithKline's Adherence Starts with Knowledge ${ }^{\circledR}$ (ASK-20) and Essential Connections ${ }^{\circledR}$ as well as information from Duke Integrative Medicine. These were referenced throughout the interactions of the study. The ASK-20 is a brief survey that helps practitioners quickly identify and target reasons patients may not be adhering to prescribed medication regimens. It is accompanied by materials on topics relevant to self management such as symptom recognition, self care, and disease risk factors. Duke Integrative Medicine provided information regarding nutrition, stress management, and tips on how to best utilize time with the coach. Additional materials came from Essential Connections, a resource of tools for coaches to facilitate motivational interviewing techniques and behavior change, linking topics of interest with patients' readiness to change and relevant education content
\end{abstract}

Control: USUAL CARE

Control group participants received usual care, with no additional materials or correspondence 
Wolever 2010 (Continued)

The patient outcomes were A1C, perceived stress, and quality of life. Measures were collected by blinded study staff at baseline and again after the 6-month intervention. Perceived stress was measured by the PSS-4 scale (self report) and quality of life by the Shot-Form Health Survey (SF-12)

\begin{tabular}{ll}
\hline Notes & - \\
\hline Risk of bias &
\end{tabular}

\begin{tabular}{|c|c|c|}
\hline Bias & Authors' judgement & Support for judgement \\
\hline $\begin{array}{l}\text { Random sequence genera- } \\
\text { tion (selection bias) }\end{array}$ & Unclear risk & $\begin{array}{l}\text { Randomization was not described in detail. "Procedure and randomization } \\
\text { at the baseline visit, participants provided informed consent; filled out demo- } \\
\text { graphic, medical history, and psychosocial questionnaires; reported current } \\
\text { medications; and had blood drawn." (pg 631) }\end{array}$ \\
\hline $\begin{array}{l}\text { Allocation concealment } \\
\text { (selection bias) }\end{array}$ & Unclear risk & No information was provided about how allocation was handled \\
\hline $\begin{array}{l}\text { Selective reporting (re- } \\
\text { porting bias) }\end{array}$ & Unclear risk & $\begin{array}{l}\text { No protocol available; although it appears that everything was reported it is } \\
\text { difficult to determine this without a protocol }\end{array}$ \\
\hline Other bias & Low risk & The study seems to be free of other types of bias. \\
\hline $\begin{array}{l}\text { Blinding of outcome as- } \\
\text { sessment (detection bias) } \\
\text { Adherence measure }\end{array}$ & Low risk & $\begin{array}{l}\text { (PRIMARY) SELF REPORT - QUESTIONNAIRE - "Preassessments and postassess- } \\
\text { ments were administered by blinded study staff." (pg 631) }\end{array}$ \\
\hline $\begin{array}{l}\text { Blinding of outcome as- } \\
\text { sessment (detection bias) } \\
\text { Patient outcome }\end{array}$ & Low risk & $\begin{array}{l}\text { (PRIMARY) A1C - This is an objective outcome and "Preassessments and } \\
\text { postassessments were administered by blinded study staff." (pg 632) }\end{array}$ \\
\hline $\begin{array}{l}\text { Blinding of participants } \\
\text { (performance bias) } \\
\text { Adherence measure }\end{array}$ & High risk & $\begin{array}{l}\text { (PRIMARY) SELF REPORT - QUESTIONNAIRE - This is a subjective measure; } \\
\text { there is no information on blinding }\end{array}$ \\
\hline $\begin{array}{l}\text { Blinding of participants } \\
\text { (performance bias) } \\
\text { Patient outcome }\end{array}$ & Low risk & (PRIMARY) A1C - This is an objective measure of outcome \\
\hline $\begin{array}{l}\text { Blinding of personnel (per- } \\
\text { formance bias) } \\
\text { Adherence measure }\end{array}$ & Unclear risk & $\begin{array}{l}\text { (PRIMARY) SELF REPORT - QUESTIONNAIRE - No information on blinding given } \\
\text { There is insufficient information to permit judgment of 'Low risk' or 'High risk' }\end{array}$ \\
\hline $\begin{array}{l}\text { Blinding of personnel (per- } \\
\text { formance bias) } \\
\text { Patient outcome }\end{array}$ & Low risk & (PRIMARY) A1C - This is an objective measure of outcome \\
\hline $\begin{array}{l}\text { Incomplete outcome data } \\
\text { (attrition bias) } \\
\text { Adherence measure }\end{array}$ & Low risk & $\begin{array}{l}\text { (PRIMARY) SELF REPORT - QUESTIONNAIRE - There was a small number of } \\
\text { dropouts, evenly spread across the groups }\end{array}$ \\
\hline $\begin{array}{l}\text { Incomplete outcome data } \\
\text { (attrition bias) } \\
\text { Patient outcome }\end{array}$ & Low risk & (PRIMARY) A1C - There are few dropouts, evenly spread across the conditions \\
\hline
\end{tabular}




\begin{tabular}{ll}
\hline Methods & Randomized controlled trial \\
\hline
\end{tabular}

The study location was Prince of Wales Hospital, Shatin, Hong Kong

$\begin{array}{ll}219 \text { participants were randomized to the intervention group and } 223 \text { participants were randomized to } \\ \text { the control group }\end{array}$

The inclusion criteria were patients receiving polypharmacy defined as 5 or more chronic medications on at least 2 consecutive visits to the clinic who were found to be non-compliant upon first assessment by pharmacist

The exclusion criteria were patients who spoke non-Cantonese dialects or a different language, had conditions that prevented effective communication or patients who lived in nursing homes with supervised treatment

Interventions Intervention: INCREASED SUPERVISION BY PHARMACIST

Patients in the intervention group received 10 to 15 -minute telephone calls from the pharmacist at the midpoint between clinic visits, normally scheduled at intervals of 2 to 4 months, throughout the study period. During the telephone calls the pharmacist asked about the patient's current medication regime, clarified misconceptions, explained the nature of side effects, reminded patients of next appointment, reinforced importance of compliance with medications and relevant aspects of self care and encouraged patients to share side effects, self initiated change in regimen, or other concerns with the doctors at next follow-up

Control: USUAL CARE

Patients in the control group continued with usual care, which for clinically stable patients meant follow-up at intervals of 2 to 4 months, with each consultation lasting 10 to 15 minutes

\title{
Outcomes
}

\begin{abstract}
The measures of adherence were assessed at the screening visit, screening visit, enrolment/randomization visit, and at the end of the 2-year study period. Adherence was assessed through a direct structured questionnaire by a pharmacist that asked the patient to describe their regimen by drug dosages, frequency, and number of pills taken at different times of the day. They were asked whether they had missed any doses; changed their regimens in terms of doses, frequency, and timing; or had drugs left over. This information was checked against the dispensing information on the Health Authority's clinical management system to calculate a Compliance Score $=$ (number of drugs that the patient was fully compliant with)/(total number of prescribed drugs) $x 100$ (\%). A patient who complied with all prescribed drugs had a compliance score of $100 \%$, whereas one who complied with only 3 of the 6 drugs had a compliance score of $50 \%$
\end{abstract}

The patient outcome was mortality. 2 senior doctors confirmed the causes of death by reviewing medical records and examining death certificates with an accountability of $100 \%$. Secondary outcomes were changes in the rate of admission to hospital, number of emergency room visits, hospital stay in the 2 years before and after the screening visit. Hospital admissions, emergency room attendance, and drug dispensing information were computerized and accessed through the clinical management system

\begin{tabular}{lll}
\hline Notes & - & \\
\hline Risk of bias & Authors' judgement & Support for judgement \\
\hline Bias & Low risk \\
tion (selection bias) & $\begin{array}{l}\text { Computer-generated randomization. "At the enrolment visit, we reassessed el- } \\
\text { igible patients for compliance. The pharmacist was blinded to the randomisa- } \\
\text { tion codes, which were computer generated by our statistician and sealed in } \\
\text { envelopes labelled with consecutive numbers. The envelopes were opened by } \\
\text { the clinic nurse in an ascending manner, and patients were allocated to the in- } \\
\text { tervention or control group." (pg 2) }\end{array}$ \\
\hline
\end{tabular}


Wu 2006 (Continued)

$\begin{array}{ll}\begin{array}{l}\text { Allocation concealment } \\ \text { (selection bias) }\end{array} & \text { "The pharmacist was blinded to the randomisation codes, which were com- } \\ & \text { puter generated by our statistician and sealed in envelopes labelled with con- } \\ & \text { secutive numbers. The envelopes were opened by the clinic nurse in an as- } \\ \text { cending manner, and patients were allocated to the intervention or control } & \text { group." (pg 2) }\end{array}$

\begin{tabular}{|c|c|c|}
\hline $\begin{array}{l}\text { Selective reporting (re- } \\
\text { porting bias) }\end{array}$ & Unclear risk & $\begin{array}{l}\text { No protocol available; although it appears that everything was reported it is } \\
\text { difficult to determine this without a protocol }\end{array}$ \\
\hline
\end{tabular}

\begin{tabular}{|c|c|c|}
\hline Other bias & Low risk & The study seems to be free of other types of bias \\
\hline $\begin{array}{l}\text { Blinding of outcome as- } \\
\text { sessment (detection bias) } \\
\text { Adherence measure }\end{array}$ & Low risk & $\begin{array}{l}\text { (PRIMARY) SELF REPORT - INTERVIEW - (pg 2) The pharmacist was blinded to } \\
\text { the randomization codes }\end{array}$ \\
\hline $\begin{array}{l}\text { Blinding of outcome as- } \\
\text { sessment (detection bias) } \\
\text { Patient outcome }\end{array}$ & Low risk & $\begin{array}{l}\text { (PRIMARY) MORTALITY - Outcome measurement not likely to be influenced by } \\
\text { lack of blinding }\end{array}$ \\
\hline
\end{tabular}

Blinding of participants High risk (performance bias) the nature of the intervention. Subjective measure

Adherence measure

\begin{tabular}{ll}
\hline $\begin{array}{l}\text { Blinding of participants } \\
\text { (performance bias) }\end{array}$ & Low risk \\
$\begin{array}{l}\text { Patient outcome } \\
\text { lack of blinding }\end{array}$
\end{tabular}

\begin{tabular}{|c|c|c|}
\hline $\begin{array}{l}\text { Blinding of personnel (per- } \\
\text { formance bias) } \\
\text { Adherence measure }\end{array}$ & Unclear risk & $\begin{array}{l}\text { (PRIMARY) SELF REPORT - INTERVIEW - No information on blinding given. } \\
\text { There is insufficient information to permit judgment of 'Low risk' or 'High risk' }\end{array}$ \\
\hline $\begin{array}{l}\text { Blinding of personnel (per- } \\
\text { formance bias) } \\
\text { Patient outcome }\end{array}$ & Low risk & $\begin{array}{l}\text { (PRIMARY) MORTALITY - Outcome measurement not likely to be influenced by } \\
\text { lack of blinding }\end{array}$ \\
\hline $\begin{array}{l}\text { Incomplete outcome data } \\
\text { (attrition bias) } \\
\text { Adherence measure }\end{array}$ & Low risk & $\begin{array}{l}\text { (PRIMARY) SELF REPORT - INTERVIEW - No loss to follow-up. The authors also } \\
\text { report the outcomes for } 60 \text { patients initially screened prior to randomization }\end{array}$ \\
\hline $\begin{array}{l}\text { Incomplete outcome data } \\
\text { (attrition bias) } \\
\text { Patient outcome }\end{array}$ & Low risk & (PRIMARY) MORTALITY - No loss to follow-up. Death rates were not similar \\
\hline
\end{tabular}

Wu 2012

\begin{tabular}{|c|c|}
\hline Methods & Randomized controlled trial \\
\hline \multirow[t]{3}{*}{ Participants } & The study location was a southern state, USA \\
\hline & $\begin{array}{l}27 \text { participants were randomized to the theory-based intervention plus MEMS (PLUS) group, } 27 \text { partic- } \\
\text { ipants were randomized to the theory-based intervention only (LITE) group and } 28 \text { participants were } \\
\text { randomized to the control group }\end{array}$ \\
\hline & $\begin{array}{l}\text { The inclusion criteria were } 1 \text { ) having a diagnosis of chronic heart failure (HF); } 2 \text { ) undergoing evaluation } \\
\text { of HF by a cardiologist and optimization of medical therapy; and 3) being able to read and speak Eng- } \\
\text { lish }\end{array}$ \\
\hline
\end{tabular}


Wu 2012 (Continued)

The exclusion criteria were 1) impaired cognition; 2) a coexisting imminently terminal illness such as cancer or chronic renal failure requiring dialysis; 3 ) a myocardial infarction within the past 3 months; or 4) a history of cerebral vascular accident within the past 3 months or with major sequelae

Interventions

Intervention: LITE

The intervention was delivered by a cardiovascular nurse expert in delivery of the education and counseling intervention. Patients received the counseling intervention individually every other week for a total of 4 sessions. The first and third sessions were face-to-face education and counseling lasting 1 hour. The second and 4th sessions were delivered by telephone and lasted 20 minutes each. The intervention was designed to influence medication adherence by creating a more positive attitude toward medication adherence, incorporating significant others into the patient education and counseling sessions to build a positive subjective norm, and providing needed information and skills to overcome barriers to adherence to increase the patient's perceived behavioral control

Intervention: PLUS

In addition to what was received by the LITE group, participants received feedback on their medication taking behavior from the MEMS at each of the 2 face-to-face sessions. MEMS feedback was used to show the patients their own medication taking behavior and identify problematic areas. A visual display was shared by the nurse with the participant

Control: USUAL CARE

Received usual care. Participants completed a baseline survey, were contacted monthly to collect outcome, and completed a 9-month questionnaire. In addition their MEMS data were downloaded at 1, 2 , and 9 months

Outcomes

The adherence measure was MEMS, used to collect information on one heart failure medication. Patients were given a diary to record unscheduled cap openings, such as those to refill the bottle, and those unscheduled events unrelated to adherence were removed from analysis. Participants were given the bottles at the start of the study by a trained nurse, including written and verbal instructions on how to use it. After 1 month, a research nurse downloaded the MEMS data. Patients used the bottle during the study and returned it at 9 months

The patient outcomes were cardiac event-free survival and quality of life. Cardiac event-free survival was the composite endpoint. This endpoint consisted of cardiac-related emergency department (ED) visit, cardiac-related hospitalization, or cardiac death. Monthly follow-up phone calls to patients collected these data, with confirmation via hospital records. Date and cause of death were collected from interviews with family members and physicians and confirmed by review of medical records and death certificates. Quality of life was measured using the Minnesota Living with Heart Failure Questionnaire (LHFQ). It consists of 21 questions rated on a scale from 0 (no effect) to 5 (very much). Item ratings are summed for a total score that can range from 0 to 105 . Higher scores reflect worse quality of life. Questions concern a variety of physical and psychologic aspects of living with HF and include activities of daily living, economic issues, ability to work, enjoyment of leisure time activities, relations with family and friends, sexual activity, side effects from medications, depression, and impact of HF symptoms

Notes -

\section{Risk of bias}

Random sequence genera- Unclear risk tion (selection bias)
Randomization was not described in detail. "This study was a randomized controlled trial to determine the effect of a theory-based intervention on medication adherence and cardiac event-free survival in patients with HF. All patients were randomly assigned to theory-based intervention plus feedback of medication-taking behavior from the MEMS (the PLUS group), theory-based intervention only (LITE), or usual care (control)." (pg 2)

Allocation concealment Unclear risk No information was provided about how allocation was handled

(selection bias) 
Wu 2012 (Continued)

\begin{tabular}{|c|c|c|}
\hline $\begin{array}{l}\text { Selective reporting (re- } \\
\text { porting bias) }\end{array}$ & Unclear risk & $\begin{array}{l}\text { No protocol available; although it appears that everything was reported it is } \\
\text { difficult to determine this without a protocol }\end{array}$ \\
\hline
\end{tabular}

\begin{tabular}{lll}
\hline Other bias & Low risk & The study seems to be free of other types of bias \\
\hline $\begin{array}{l}\text { Blinding of outcome as- } \\
\begin{array}{l}\text { sessment (detection bias) } \\
\text { Adherence measure }\end{array}\end{array}$ & Low risk & (PRIMARY) MEMS - MEMS is an objective measure of adherence \\
\hline $\begin{array}{l}\text { Blinding of outcome as- } \\
\text { sessment (detection bias) } \\
\begin{array}{l}\text { Patient outcome } \\
\text { (PRIMARY) CARDIAC EVENT-FREE SURVIVAL - Objective data; unlikely to be bi- }\end{array}\end{array} \quad$ Low risk & $\begin{array}{l}\text { (PRed. Patients were followed monthly by phone to obtain their hospitalization } \\
\text { data by a research associate blind to group assignment from baseline to the } \\
\text { end of the study }\end{array}$ \\
\hline
\end{tabular}

\begin{tabular}{|c|c|c|}
\hline $\begin{array}{l}\text { Blinding of participants } \\
\text { (performance bias) } \\
\text { Adherence measure }\end{array}$ & High risk & $\begin{array}{l}\text { (PRIMARY) MEMS - Although MEMS is an objective measure of adherence, it } \\
\text { does not indicate if patients were blind to study purpose. Patients were asked } \\
\text { to record unscheduled cap openings }\end{array}$ \\
\hline
\end{tabular}

\begin{tabular}{ll}
\hline $\begin{array}{l}\text { Blinding of participants } \\
\text { (performance bias) }\end{array}$ & Low risk \\
$\begin{array}{l}\text { Patient outcome } \\
\text { to the study but information was collected from the patients were confirmed } \\
\text { with medical records and death certificates }\end{array}$
\end{tabular}

\begin{tabular}{|c|c|c|}
\hline $\begin{array}{l}\text { Blinding of personnel (per- } \\
\text { formance bias) } \\
\text { Adherence measure }\end{array}$ & Unclear risk & $\begin{array}{l}\text { (PRIMARY) MEMS - No details on blinding are given, and the authors indicate } \\
\text { that adjustments were made to the MEMS data based on patient self report } \\
\text { record. Patients were given a MEMS diary to record unscheduled cap openings, } \\
\text { such as those to refill the bottle, so that those unscheduled events unrelated } \\
\text { to adherence were removed from analysis }\end{array}$ \\
\hline
\end{tabular}

$\begin{array}{ll}\begin{array}{l}\text { Blinding of personnel (per- } \\ \text { formance bias) }\end{array} & \text { Unclear risk } \\ \begin{array}{l}\text { Patient outcome } \\ \text { (PRIMARY) CARDIAC EVENT-FREE SURVIVAL - Insufficient information about } \\ \text { blinding to permit judgment of 'Low risk' or 'High risk' }\end{array}\end{array}$

Patient outcome

Incomplete outcome data Unclear risk

(attrition bias)

(PRIMARY) MEMS - There is insufficient information to permit judgment of 'Low

Adherence measure

Incomplete outcome data Unclear risk

(attrition bias)

(PRIMARY) CARDIAC EVENT-FREE SURVIVAL - Insufficient report
tion/exclusions to permit judgment of 'Low risk' or 'High risk' risk' or 'High risk'

Patient outcome

\section{Wysocki 2001}

Methods At the end of baseline evaluation, a research assistant randomly assigned each family to one of the 3 groups. Randomization was stratified by the adolescent's sex and by the treatment center. (No statement of concealment of allocation). It is also unclear whether outcomes assessors were blinded. Due to the nature of the intervention, patients could not be blinded. It should be noted that despite randomization the 3 treatment groups differed demographically at baseline. The BFST group included significantly fewer intact families and more single-parents families than did the other 2 groups

Participants

Inclusion criteria included the following: 12 to 17 years of age, having Type I diabetes for more than 1 year, no other major chronic diseases, no mental retardation, not incarcerated in foster care or in residential psychiatric treatment, no diagnoses of psychosis major depression or substance abuse disorder in adolescents or parents during the previous 6 months. Also, at least 1 family member had to obtain a score on the Diabetes Responsibility and Conflict scale $>24$ or a score $>5$ on the Conflict Behavior Questionnaire 
Wysocki 2001 (Continued)

Interventions
Families were randomized to 3 months of treatment with either Behavioral-Family Systems Therapy (BFST), an education and support (ES) group, or current therapy (CT). Current Therapy: patients in the CT group (as well as those in the other groups) received standard diabetes therapy from pediatric endocrinologists, including an examination by a physician and a $\mathrm{GHb}$ assay at least quarterly; 2 or more daily injection of mixed intermediate- and short-acting insulins; self monitoring of blood glucose and recording of test results; diabetes self management training; a prescribed diet; physical exercise and an annual evaluation for diabetic complications. Education and Support: in the first 3 months of the study, families attended 10 groups meetings that provided diabetes education and social support. A social worker at 1 center and a health educator at another center served as group facilitators. Panels of 2 to 5 families began and completed 10 sessions together; the parents and the adolescent with the diabetes attended the sessions. Family communication and conflict resolution skills were specifically excluded from session content, because these are the primary targets of BFST. Each session included a 45-minute educational presentation by a diabetes professional, followed by a 45-minute interaction among the families about a topic led by the facilitator. A monetary incentive, outlined below, was also provided to patients in this group. BFST: adolescents and caregivers in this group received 10 sessions of BFST. BFST consisted of 4 therapy components that were used in accordance with each family's treatment needs as identified by the project psychologists and was based on study data and family interaction during sessions. The 4 therapy components included problem-solving training, communication skills training, cognitive restructuring and functional and structural family therapy. A monetary incentive was also provided to patients in this group. Monetary incentive - to maximize completion of data collection, families were paid USD 100 (USD 50 for parent, USD 50 for adolescent) on completion of each evaluation. ES and BFST families could earn another USD 100 if they completed all 10 scheduled intervention sessions

Outcomes

Measurement of compliance: a 14-item, validated Self-Care Inventory (SCI) was used to measure diabetes treatment adherence during the preceding 3 months. Higher scores indicate better treatment adherence. Questionnaires were given at baseline, at post-treatment ( 3 months) and at 6 and 12 months after treatment ended

Measurement of clinical health outcomes: glycated hemoglobin $(\mathrm{GHb})$ assays were conducted using affinity chromatography to index recent glycemic control. General parent-adolescent relationships were assessed via the Parent-Adolescent Relationship Questionnaire (PARQ), and Type I diabetes-specific psychological adjustment was assessed via the Teen Adjustment to Diabetes Scale (TADS). Questionnaires were given at baseline, at post-treatment ( 3 months) and at 6 and 12 months after treatment ended

\begin{tabular}{|c|c|c|}
\hline Notes & - & \\
\hline \multicolumn{3}{|l|}{ Risk of bias } \\
\hline Bias & Authors' judgement & Support for judgement \\
\hline $\begin{array}{l}\text { Random sequence genera- } \\
\text { tion (selection bias) }\end{array}$ & Unclear risk & $\begin{array}{l}\text { Randomization was not described in detail. "At the end of the baseline evalu- } \\
\text { ation, a research assistant randomly assigned each family to one of the three } \\
\text { conditions described below." (pg 442) }\end{array}$ \\
\hline $\begin{array}{l}\text { Allocation concealment } \\
\text { (selection bias) }\end{array}$ & Unclear risk & No information was provided about how allocation was handled \\
\hline $\begin{array}{l}\text { Selective reporting (re- } \\
\text { porting bias) }\end{array}$ & Unclear risk & $\begin{array}{l}\text { No protocol available; although it appears that everything was reported it is } \\
\text { difficult to determine this without a protocol }\end{array}$ \\
\hline Other bias & Low risk & The study seems to be free of other types of bias \\
\hline $\begin{array}{l}\text { Blinding of outcome as- } \\
\text { sessment (detection bias) } \\
\text { Adherence measure }\end{array}$ & Unclear risk & $\begin{array}{l}\text { (PRIMARY) SELF CARE INVENTORY (SCI) - QUESTIONNAIRE - No information on } \\
\text { blinding given. There is insufficient information to permit judgment of 'Low } \\
\text { risk' or 'High risk' }\end{array}$ \\
\hline
\end{tabular}


Wysocki 2001 (Continued)

Blinding of outcome as- Unclear risk $\quad$ (PRIMARY) TEEN ADJUSTMENT TO DIABETES SCALE - No information on blindsessment (detection bias) ing given. There is insufficient information to permit judgment of 'Low risk' or Patient outcome 'High risk'

\begin{tabular}{|c|c|c|}
\hline $\begin{array}{l}\text { Blinding of participants } \\
\text { (performance bias) }\end{array}$ & High risk & $\begin{array}{l}\text { (PRIMARY) SELF CARE INVENTORY (SCI) - QUESTIONNAIRE - This is a subjective } \\
\text { measure; there is no information on blinding }\end{array}$ \\
\hline
\end{tabular}

Adherence measure measure; there is no information on blinding

\begin{tabular}{|c|c|c|}
\hline Blinding of participants & High risk & $\begin{array}{l}\text { (PRIMARY) TEEN ADJUSTMENT TO DIABETES SCALE - This is a subjective mea- } \\
\text { sure; there is no information on blinding }\end{array}$ \\
\hline
\end{tabular}

Patient outcome

\section{(PRIMARY) SELF CARE INVENTORY (SCI) - QUESTIONNAIRE - No information on blinding given. There is insufficient information to permit judgment of 'Low risk' or 'High risk' \\ Blinding of personnel (per- Unclear risk \\ formance bias) \\ Adherence measure}

(PRIMARY) TEEN ADJUSTMENT TO DIABETES SCALE - No information on blind-

Blinding of personnel (per- Unclear risk

formance bias)

Patient outcome ing given. There is insufficient information to permit judgment of 'Low risk' or 'High risk'

Incomplete outcome data Unclear risk

(attrition bias)

(PRIMARY) SELF CARE INVENTORY (SCI) - QUESTIONNAIRE - The distribution of

Adherence measure missing data across groups was not given. Insufficient reporting of attrition/exclusions to permit judgment of 'Low risk' or 'High risk' (e.g. number randomized not stated, no reasons for missing data provided)

Incomplete outcome data Unclear risk

(attrition bias)

(PRIMARY) TEEN ADJUSTMENT TO DIABETES SCALE - The distribution of miss-

Patient outcome ing data across groups was not given. Insufficient reporting of attrition/exclusions to permit judgment of 'Low risk' or 'High risk' (e.g. number randomized not stated, no reasons for missing data provided)

Xiong 1994

\begin{tabular}{ll}
\hline Methods & Random allocation, not otherwise specified \\
\hline Participants & 63 DSM-III-R Chinese schizophrenic patients living with family members \\
\hline Interventions & $\begin{array}{l}\text { Standard care (medication prescription at hospital discharge plus laissez faire follow-up on patient's } \\
\text { or family's initiative) versus a family-based intervention that included monthly 45-minute counseling } \\
\text { sessions focused on the management of social and occupational problems, medication management, } \\
\text { family education, family group meetings, and crisis intervention }\end{array}$
\end{tabular}

\section{Outcomes}

Medication usage was assessed by family member reports. Time for which the patient took more than $50 \%$ of prescribed dosage was the measure for comparison of groups. Psychiatric outcomes were assessed at 6,12 , and 18 months following hospital discharge by observers who were trained clinical researchers, blinded to study group allocation

Notes - -

\section{Risk of bias}

\section{Bias \\ Authors' judgement Support for judgement}

Random sequence genera- Unclear risk tion (selection bias)
Randomization was not described in detail. "...they were randomly assigned to family intervention (experimental) or the standard care (control) group." (pg 240) 
Xiong 1994 (Continued)

\begin{tabular}{lll}
$\begin{array}{l}\text { Allocation concealment } \\
\text { (selection bias) }\end{array}$ & Unclear risk & No information was provided about how allocation was handled \\
\hline $\begin{array}{l}\text { Selective reporting (re- } \\
\text { porting bias) }\end{array}$ & Unclear risk & $\begin{array}{l}\text { No protocol available; although it appears that everything was reported it is } \\
\text { difficult to determine this without a protocol }\end{array}$ \\
\hline Other bias & Low risk & The study seems to be free of other types of bias \\
\hline $\begin{array}{l}\text { Blinding of outcome as- } \\
\text { sessment (detection bias) } \\
\text { Adherence measure }\end{array}$ & Low risk & $\begin{array}{l}\text { (PRIMARY) SELF REPORT (BY FAMILY MEMBER) - Assessors were blind. At 6- } \\
\text { month intervals after discharge 2 experienced clinical researchers who were } \\
\text { blind to patients' treatment status conducted home interviews with patients } \\
\text { and family members to assess patients' clinical and social functioning over the } \\
\text { previous } 6 \text { months }\end{array}$ \\
\hline
\end{tabular}

\begin{tabular}{lll}
\hline Blinding of outcome as- & Low risk & (PRIMARY) BRIEF PSYCHIATRIC RATING SCALE (BPRS) - Assessors were blind. At \\
sessment (detection bias) & & 6 -month intervals after discharge 2 experienced clinical researchers who were \\
Patient outcome & blind to patients' treatment status conducted home interviews with patients \\
& and family members to assess patients' clinical and social functioning over the \\
& previous 6 months
\end{tabular}

Blinding of outcome as- Low risk sessment (detection bias)

(PRIMARY) SCALE OF ASSESSMENT (SANS) OF NEGATIVE SYMPTOMS - AssesPatient outcome sors were blind. At 6-month intervals after discharge 2 experienced clinical researchers who were blind to patients' treatment status conducted home interviews with patients and family members to assess patients' clinical and social functioning over the previous 6 months

\begin{tabular}{|c|c|c|}
\hline $\begin{array}{l}\text { Blinding of outcome as- } \\
\text { sessment (detection bias) } \\
\text { Patient outcome }\end{array}$ & Low risk & $\begin{array}{l}\text { (PRIMARY) SCALE FOR ASSESSMENT OF POSITIVE SYMPTOMS (SAPS) - Asses- } \\
\text { sors were blind. At } 6 \text {-month intervals after discharge } 2 \text { experienced clinical re- } \\
\text { searchers who were blind to patients' treatment status conducted home inter- } \\
\text { views with patients and family members to assess patients' clinical and social } \\
\text { functioning over the previous } 6 \text { months }\end{array}$ \\
\hline
\end{tabular}

Blinding of participants High risk (PRIMARY) SELF REPORT (BY FAMILY MEMBER) - Family members reported ad(performance bias) herence; therefore, a subjective measure. No mention of blinding

Adherence measure

\begin{tabular}{|c|c|c|}
\hline $\begin{array}{l}\text { Blinding of participants } \\
\text { (performance bias) } \\
\text { Patient outcome }\end{array}$ & High risk & $\begin{array}{l}\text { (PRIMARY) BRIEF PSYCHIATRIC RATING SCALE (BPRS) - This is a subjective } \\
\text { measure; there is no information on blinding }\end{array}$ \\
\hline $\begin{array}{l}\text { Blinding of participants } \\
\text { (performance bias) } \\
\text { Patient outcome }\end{array}$ & High risk & $\begin{array}{l}\text { (PRIMARY) SCALE OF ASSESSMENT (SANS) OF NEGATIVE SYMPTOMS - This is a } \\
\text { subjective measure; there is no information on blinding }\end{array}$ \\
\hline $\begin{array}{l}\text { Blinding of participants } \\
\text { (performance bias) } \\
\text { Patient outcome }\end{array}$ & High risk & $\begin{array}{l}\text { (PRIMARY) SCALE FOR ASSESSMENT OF POSITIVE SYMPTOMS (SAPS) - This is a } \\
\text { subjective measure; there is no information on blinding }\end{array}$ \\
\hline $\begin{array}{l}\text { Blinding of personnel (per- } \\
\text { formance bias) } \\
\text { Adherence measure }\end{array}$ & Unclear risk & $\begin{array}{l}\text { (PRIMARY) SELF REPORT (BY FAMILY MEMBER) - No information on blinding } \\
\text { given. There is insufficient information to permit judgment of 'Low risk' or } \\
\text { 'High risk' }\end{array}$ \\
\hline $\begin{array}{l}\text { Blinding of personnel (per- } \\
\text { formance bias) } \\
\text { Patient outcome }\end{array}$ & Unclear risk & $\begin{array}{l}\text { (PRIMARY) SCALE OF ASSESSMENT (SANS) OF NEGATIVE SYMPTOMS - No infor- } \\
\text { mation on blinding given. There is insufficient information to permit judgment } \\
\text { of 'Low risk' or 'High risk' }\end{array}$ \\
\hline
\end{tabular}


Xiong 1994 (Continued)

Blinding of personnel (per- Unclear risk formance bias)

Patient outcome
(PRIMARY) SCALE FOR ASSESSMENT OF POSITIVE SYMPTOMS (SAPS) - No information on blinding given. There is insufficient information to permit judgment of 'Low risk' or 'High risk'

\begin{tabular}{|c|c|c|}
\hline $\begin{array}{l}\text { Blinding of personnel (per- } \\
\text { formance bias) } \\
\text { Patient outcome }\end{array}$ & Unclear risk & $\begin{array}{l}\text { (PRIMARY) BRIEF PSYCHIATRIC RATING SCALE (BPRS) - No information on } \\
\text { blinding given. There is insufficient information to permit judgment of 'Low } \\
\text { risk' or 'High risk' }\end{array}$ \\
\hline
\end{tabular}

Incomplete outcome data High risk

(attrition bias)

(PRIMARY) SELF REPORT (BY FAMILY MEMBER) - Unclear number of dropouts/

Adherence measure losses to follow-up. As treated analysis was performed even though rate of compliance was low. The statistical plan was not described. $32 \%$ non-attendance rate in the intervention group. The rates of noncompliance with the individual family sessions in patients and family members were $23 \%$ and $27 \%$

\begin{tabular}{|c|c|c|}
\hline $\begin{array}{l}\text { Incomplete outcome data } \\
\text { (attrition bias) } \\
\text { Patient outcome }\end{array}$ & High risk & $\begin{array}{l}\text { (PRIMARY) SCALE OF ASSESSMENT (SANS) OF NEGATIVE SYMPTOMS - As treat- } \\
\text { ed analysis was performed even though rate of compliance was low. The sta- } \\
\text { tistical plan was not described. } 32 \% \text { non-attendance rate in the intervention } \\
\text { group. The rates of non-compliance with the individual family sessions in pa- } \\
\text { tients and family members were } 23 \% \text { and } 27 \%\end{array}$ \\
\hline
\end{tabular}

\begin{tabular}{lll}
\hline $\begin{array}{l}\text { Incomplete outcome data } \\
\text { (attrition bias) }\end{array}$ & High risk & (PRIMARY) BRIEF PSYCHIATRIC RATING SCALE (BPRS) - As treated analysis per- \\
Patient outcome & formed even though rate of compliance was low. Statistical plan was not de- \\
& scribed. $32 \%$ non-attendance rate in the intervention group. The rates of non- \\
compliance with the individual family sessions in patients and family mem- \\
bers were $23 \%$ and $27 \%$. Likely to be high risk of bias
\end{tabular}

\begin{tabular}{|c|c|c|}
\hline $\begin{array}{l}\text { Incomplete outcome data } \\
\text { (attrition bias) } \\
\text { Patient outcome }\end{array}$ & High risk & $\begin{array}{l}\text { (PRIMARY) SCALE FOR ASSESSMENT OF POSITIVE SYMPTOMS (SAPS) - As treat- } \\
\text { ed analysis was performed even though rate of compliance was low. The sta- } \\
\text { tistical plan was not described. } 32 \% \text { non-attendance rate in the intervention } \\
\text { group. The rates of noncompliance with the individual family sessions in pa- } \\
\text { tients and family members were } 23 \% \text { and } 27 \%\end{array}$ \\
\hline
\end{tabular}

Yopp 2004

$\begin{array}{ll}\text { Methods } & \text { Following completion of this baseline assessment, adolescents ( } n=53) \text { were randomly assigned to ei- } \\ \text { ther the standard care condition }(n=26) \text { or the multisystemic therapy (MST) plus standard care condi- } \\ \text { tion }(n=27) \text {. The data collection staff worked independently from the MST intervention staff, and were } \\ \text { blind to treatment conditions for the subjects }\end{array}$

Participants

Participating adolescents had: a) a diagnosis of type 1 diabetes for a minimum of 1 year; b) glycosylated hemoglobin ( $\mathrm{HbA1C}$ ) of at least $8 \%$ at the onset of the study; $\mathrm{c}$ ) an average $\mathrm{HbA} 1 \mathrm{c}$ of at least $8 \%$ for the previous year. Adolescents were excluded from the study if they: $a$ ) were unable to speak English; $b$ ) had been diagnosed with a thought disorder, such as schizophrenia; or c) suffered from an additional chronic illness that may interfere with conventional treatment for type 1 diabetes

Interventions

Standard care consisted of receiving treatment from a multidisciplinary team. Adolescents and their families attended clinic appointments every 3 months to monitor the adolescent's health and were provided with traditional diabetes education services and eligible to be referred to community-based mental health agencies for psychological or adherence concerns. In addition to the standard diabetes care described above, adolescents and their families assigned to the MST intervention received approximately 7 months of this family-based treatment. The initial goals of treatment were to understand and form hypotheses as to what factors are maintaining the adolescent's poor health status. Interventions were then implemented to address these problematic areas, including problems with general and diabetes-specific family interaction patterns negatively impacting the adolescent's treatment adherence. Overarching goals of MST interventions often included increasing family cohesion and structure, as they relate to completing diabetes management tasks. A variety of behaviorally-based, action-oriented interventions may have been used during MST including parent management training, problem-solv- 
Yopp 2004 (Continued)

ing skills training, and contingency management. Specifically, family-based interventions are designed to improve communication between family members regarding completion of adherence tasks, ensure adequate parental supervision of diabetes management behaviors, and provide family members with strategies to address general and diabetes-specific conflict situations. Overall, the goal of MST is to encourage parents to adopt an authoritative parenting style in which they are responsive to their adolescent's health needs, able to see clearly defined expectations for adherence behaviors, and able to enforce effective discipline strategies to address problematic behavior. Treatment was terminated when overarching goals were accomplished

\begin{tabular}{ll}
\hline Outcomes & Compliance was measured using the 1) Diabetes Management Scale (DMS) and 2) 24-Hour Recall In- \\
terview. Both were administered separately to the adolescent and parent. Glycosylated hemoglobin \\
(HbA1c) values were used as clinical endpoints
\end{tabular}

Notes -

\section{Risk of bias}

\begin{tabular}{|c|c|c|}
\hline Bias & Authors' judgement & Support for judgement \\
\hline $\begin{array}{l}\text { Random sequence genera- } \\
\text { tion (selection bias) }\end{array}$ & Unclear risk & Randomization was not described in detail \\
\hline $\begin{array}{l}\text { Allocation concealment } \\
\text { (selection bias) }\end{array}$ & Unclear risk & No information was provided about how allocation was handled \\
\hline $\begin{array}{l}\text { Selective reporting (re- } \\
\text { porting bias) }\end{array}$ & Unclear risk & $\begin{array}{l}\text { No protocol available; although it appears that everything was reported it is } \\
\text { difficult to determine this without a protocol }\end{array}$ \\
\hline Other bias & High risk & $\begin{array}{l}\text { Follow-up data were collected immediately following the completion - or at } \\
\text { the end - of treatment for families receiving MST intervention }\end{array}$ \\
\hline $\begin{array}{l}\text { Blinding of outcome as- } \\
\text { sessment (detection bias) } \\
\text { Adherence measure }\end{array}$ & Low risk & $\begin{array}{l}\text { (PRIMARY) DIABETES MANAGEMENT SCALE - Personnel were blinded to treat- } \\
\text { ment conditions }\end{array}$ \\
\hline $\begin{array}{l}\text { Blinding of outcome as- } \\
\text { sessment (detection bias) } \\
\text { Patient outcome }\end{array}$ & Low risk & $\begin{array}{l}\text { (PRIMARY) HBA1C - Objective measure, unlikely to be biased. The staff were } \\
\text { blinded }\end{array}$ \\
\hline $\begin{array}{l}\text { Blinding of participants } \\
\text { (performance bias) } \\
\text { Adherence measure }\end{array}$ & High risk & $\begin{array}{l}\text { (PRIMARY) DIABETES MANAGEMENT SCALE - This is a subjective measure; there } \\
\text { is no information on blinding }\end{array}$ \\
\hline $\begin{array}{l}\text { Blinding of participants } \\
\text { (performance bias) } \\
\text { Patient outcome }\end{array}$ & Low risk & (PRIMARY) HBA1C - This is an objective measure of outcome \\
\hline $\begin{array}{l}\text { Blinding of personnel (per- } \\
\text { formance bias) } \\
\text { Adherence measure }\end{array}$ & Unclear risk & $\begin{array}{l}\text { (PRIMARY) DIABETES MANAGEMENT SCALE - No information on blinding given. } \\
\text { There is insufficient information to permit judgment of 'Low risk' or 'High risk' }\end{array}$ \\
\hline
\end{tabular}

\begin{tabular}{|c|c|c|}
\hline $\begin{array}{l}\text { Blinding of personnel (per- } \\
\text { formance bias) } \\
\text { Patient outcome }\end{array}$ & Low risk & (PRIMARY) HBA1C - Objective measure, unlikely to be biased \\
\hline $\begin{array}{l}\text { Incomplete outcome data } \\
\text { (attrition bias) } \\
\text { Adherence measure }\end{array}$ & High risk & $\begin{array}{l}\text { (PRIMARY) DIABETES MANAGEMENT SCALE - There are more than } 20 \% \\
\text { dropouts. Unable to determine whether the reason for } 7 \text { families that dropped } \\
\text { is related to the outcome. Reason for missing outcome data likely to be related }\end{array}$ \\
\hline
\end{tabular}


Yopp 2004 (Continued)

to true outcome, with either imbalance in numbers or reasons for missing data across intervention groups

Incomplete outcome data Unclear risk
(attrition bias)

(attrition bias)

Patient outcome
(PRIMARY) HBA1C - There are more than 20\% dropouts. Unable to determine whether the reason for 7 families that dropped is related to the outcome. Reason for missing outcome data likely to be related to true outcome, with either imbalance in numbers or reasons for missing data across intervention groups

\section{Zhang 1994}

\begin{tabular}{ll}
\hline Methods & Random allocation not otherwise specified \\
\hline Participants & $\begin{array}{l}\text { Men discharged after their first admission to the hospital for schizophrenia. Schizophrenia was defined } \\
\text { according to the Chinese Medical Association criteria. Inclusion criteria were no serious concurrent } \\
\text { medical illnesses, living within commuting distance of the hospital, and willingness to attend regular } \\
\text { family intervention sessions. Mean age for the } 78 \text { men who were followed was } 24 \text { years. Occupation was } \\
\text { the only baseline characteristic that was not the same in each group }\end{array}$
\end{tabular}

Interventions Men in both groups came to the outpatient department by their own choice; no regular appointments were made and there was no routine follow-up. Medication was obtained at these visits. Families and patients in the family intervention group were assigned to one of 2 counselors for their ongoing care, were invited to come to a discharge session that focused on education about the management of the patient's treatment, asked to come to a family group counseling session with other families 3 months after discharge, and then attend 3-monthly group sessions with other families with similar patient problems. Non-attendance triggered a visit from study staff. Each family was contacted at least once during the 18-month follow-up. Control group patients received no family interventions

Outcomes $\quad$ All patients were seen every 3 months by staff physicians, blinded to the group assignment, where medication status and adherence were assessed. Adherence was defined as taking at least $33 \%$ of dose prescribed at the time of the index discharge for at least 6 days/week. Non-adherence was anything else. Readmission to hospital, the mean hospital-free period for those who were readmitted, and BPRS and GAS scores were the treatment outcomes assessed

Notes

\section{Risk of bias}

\begin{tabular}{|c|c|c|}
\hline Bias & Authors' judgement & Support for judgement \\
\hline $\begin{array}{l}\text { Random sequence genera- } \\
\text { tion (selection bias) }\end{array}$ & Unclear risk & Randomization was not described in detail \\
\hline $\begin{array}{l}\text { Allocation concealment } \\
\text { (selection bias) }\end{array}$ & Unclear risk & No information was provided about how allocation was handled is given \\
\hline $\begin{array}{l}\text { Selective reporting (re- } \\
\text { porting bias) }\end{array}$ & Unclear risk & $\begin{array}{l}\text { No protocol available; although it appears that everything was reported it is } \\
\text { difficult to determine this without a protocol }\end{array}$ \\
\hline Other bias & Low risk & The study seems to be free of other types of bias \\
\hline $\begin{array}{l}\text { Blinding of outcome as- } \\
\text { sessment (detection bias) } \\
\text { Adherence measure }\end{array}$ & Unclear risk & $\begin{array}{l}\text { (PRIMARY) SELF REPORT - INTERVIEW - Staff were blinded but, blinding may } \\
\text { have been broken as noted in the limitations section. "This is a source of bias } \\
\text { that we were not able to completely eliminate from this study; it may have had } \\
\text { some effect on the assessment of the severity of symptoms." }\end{array}$ \\
\hline $\begin{array}{l}\text { Blinding of outcome as- } \\
\text { sessment (detection bias) }\end{array}$ & Unclear risk & $\begin{array}{l}\text { (PRIMARY) BPRS AND GAS SURVEYS - Staff were blinded but, blinding may have } \\
\text { been broken as noted in the limitations section. "This is a source of bias that }\end{array}$ \\
\hline
\end{tabular}


Zhang 1994 (Continued)

Patient outcome we were not able to completely eliminate from this study; it may have had some effect on the assessment of the severity of symptoms."

\begin{tabular}{|c|c|c|}
\hline $\begin{array}{l}\text { Blinding of participants } \\
\text { (performance bias) } \\
\text { Adherence measure }\end{array}$ & High risk & $\begin{array}{l}\text { (PRIMARY) SELF REPORT - INTERVIEW - This is a subjective measure; there is no } \\
\text { information on blinding }\end{array}$ \\
\hline $\begin{array}{l}\text { Blinding of participants } \\
\text { (performance bias) } \\
\text { Patient outcome }\end{array}$ & High risk & $\begin{array}{l}\text { (PRIMARY) BPRS AND GAS SURVEYS - This is a subjective measure; there is no } \\
\text { information on blinding }\end{array}$ \\
\hline
\end{tabular}

\begin{tabular}{|c|c|c|}
\hline $\begin{array}{l}\text { Blinding of personnel (per- } \\
\text { formance bias) } \\
\text { Adherence measure }\end{array}$ & Unclear risk & $\begin{array}{l}\text { (PRIMARY) SELF REPORT - INTERVIEW - No information provided regarding the } \\
\text { blinding key members other than assessors. Psychiatrists seeing the patients } \\
\text { at their regular visits may have be unblinded }\end{array}$ \\
\hline $\begin{array}{l}\text { Blinding of personnel (per- } \\
\text { formance bias) } \\
\text { Patient outcome }\end{array}$ & Unclear risk & (PRIMARY) BPRS AND GAS SURVEYS - Status of other personnel not reported \\
\hline $\begin{array}{l}\text { Incomplete outcome data } \\
\text { (attrition bias) } \\
\text { Adherence measure }\end{array}$ & Unclear risk & $\begin{array}{l}\text { (PRIMARY) SELF REPORT - INTERVIEW - They imply that there are no missing } \\
\text { data for adherence measurement. It seems unlikely that all the patients were } \\
\text { interviewed for adherence because all interviews were conducted together; } \\
\text { however. Thus, the risk of bias is unclear }\end{array}$ \\
\hline $\begin{array}{l}\text { Incomplete outcome data } \\
\text { (attrition bias) } \\
\text { Patient outcome }\end{array}$ & High risk & $\begin{array}{l}\text { (PRIMARY) BPRS AND GAS SURVEYS - There is a high rate of missing data for } \\
\text { BPRS and GAF assessment. From tables } 5 \text { and } 6 \text {, it is clear that } 11 / 39 \text { were not } \\
\text { assessed }\end{array}$ \\
\hline
\end{tabular}

Zolfaghari 2012

\begin{tabular}{ll}
\hline Methods & Randomized controlled trial \\
\hline Participants & The study location was Tehran, Iran
\end{tabular}

Participants

The study location was Tehran, Iran

38 short message services (SMS) participants were randomized to the intervention group and 39 telephone follow-up participants were randomized to the control group

The inclusion criteria were to have telephone access in their homes and their own personal mobile phones, or have access to one belonging to a relative, age 18 or above. They could only used oral antidiabetic medications. The had to be able to read and write, had sufficient power vision, had no problem in hearing and vocalization and did not have a history of psychiatric diseases

The exclusion criteria were clinical history of an important illness such as renal insufficiency with a creatinine level $>1.5 \mathrm{mg} / \mathrm{dl}$, hepatic insufficiency, mentally ill or had $<7 \%$ of $\mathrm{HbAlc}$

\section{Interventions Intervention: SHORT MESSAGE SYSTEM (SMS) GROUP}

Participants in both groups received 3 days of diabetes self care education sessions. Before the intervention, the SMS group received 10 minutes of instruction on how to use their cell phones and check their ability to read the SMS. The intervention was provided for 3 months. Patients in the SMS group received about 6 messages every week (excluding holidays) that consisted information about taking a diet, exercising, diabetic medication taking, frequent self monitoring of blood glucose levels and stress management. Overall, 72 messages were sent to patients during intervention, and the length of each message was not more than 160 features. Participants in the SMS group could receive messages at any place where access was possible by cellular phone. The researcher sent optimal recommendations back to each patient, 6 times by SMSs of a cellular phone weekly.

\section{Control: TELEPHONE INTERVENTION GROUP}


The intervention for the telephone group was provided via telephone for 3 months. The intervention was provided by counseling scheduled appointments - whenever the time was convenient to the subject. The content of intervention consisted of counseling on the nature of the disease, risk factors, importance of maintaining blood glucose levels within a near-normal range, continuous education and reinforcement of diet, exercise, medications taking, hypoglycemia management, illness management, how to record daily blood glucose and frequent self monitoring of blood glucose levels. The researcher contacted the telephone group at least twice a week for the first month and then weekly for the second and third month. The total frequency of telephone counseling averaged 16 times per subject. The average length of these contacts was 20 minutes per call. The researcher asked questions about the diet: 'Did you eat salad and vegetable before every meal?', 'How many days did you follow your recommended diet over the past days?' 'Did you eat your meals at regular times?' and....some recommendations about exercising such as: 'How many times did you do physical exercising or walking during the last days?' 'When is the best time to exercise'? 'Did you feel better after exercising?' 'Do you know that exercising is as important as diabetic medication?' and....medication related questions were: 'Did you take your recommended diabetic medication?' 'When did you consume your prescribed tablet? 'Do you know how your consuming medications, act in your body?'... and so on

Outcomes

The measure of adherence was self reported adherence, which was measured by self care diabetes questionnaire during 3 stages of the study: at baseline, 3 , and 6 months. The questionnaire consisted of 3 items: demographic characteristics, disease characteristics and questions related to adherence therapeutic regimen namely diabetic diet, physical exercise, and diabetic medication taking. The score of ' 4 ' was given for an achieved goal and ' 0 ' for a non-achieved goal

The patient outcome was HbAlc, measured at baseline and at 3 months by a high-performance liquid chromatography technique

\begin{tabular}{ll}
\hline Notes & - \\
\hline Risk of bias &
\end{tabular}

\begin{tabular}{|c|c|c|}
\hline Bias & Authors' judgement & Support for judgement \\
\hline $\begin{array}{l}\text { Random sequence genera- } \\
\text { tion (selection bias) }\end{array}$ & Low risk & $\begin{array}{l}\text { They were randomized by random permuted block design using a random } \\
\text { number table and assigned to one of } 2 \text { groups: SMS group }(n=39) \text { or tele- } \\
\text { phone group }(n=41)\end{array}$ \\
\hline $\begin{array}{l}\text { Allocation concealment } \\
\text { (selection bias) }\end{array}$ & Unclear risk & $\begin{array}{l}\text { No information about how allocation was handled. "They were randomised by } \\
\text { random permuted block design using a random number table and assigned to } \\
\text { one of two groups: SMS group }(n=39) \text { or telephone group }(n=41) . "(p g \text { 1924) }\end{array}$ \\
\hline $\begin{array}{l}\text { Selective reporting (re- } \\
\text { porting bias) }\end{array}$ & Unclear risk & $\begin{array}{l}\text { No protocol available; although it appears that everything was reported it is } \\
\text { difficult to determine this without a protocol }\end{array}$ \\
\hline Other bias & Unclear risk & $\begin{array}{l}\text { There is insufficient rationale or evidence that an identified problem in the lim- } \\
\text { itations will introduce bias }\end{array}$ \\
\hline $\begin{array}{l}\text { Blinding of outcome as- } \\
\text { sessment (detection bias) } \\
\text { Adherence measure }\end{array}$ & Unclear risk & $\begin{array}{l}\text { (PRIMARY) SELF REPORT - QUESTIONNAIRE - No information on blinding given. } \\
\text { There is insufficient information to permit judgment of 'Low risk' or 'High risk' }\end{array}$ \\
\hline $\begin{array}{l}\text { Blinding of outcome as- } \\
\text { sessment (detection bias) } \\
\text { Patient outcome }\end{array}$ & Low risk & (PRIMARY) HBA1C LEVEL - This is an objective measure of outcome \\
\hline $\begin{array}{l}\text { Blinding of participants } \\
\text { (performance bias) } \\
\text { Adherence measure }\end{array}$ & High risk & $\begin{array}{l}\text { (PRIMARY) SELF REPORT - QUESTIONNAIRE - This is a subjective measure; } \\
\text { there is no information on blinding }\end{array}$ \\
\hline
\end{tabular}


Zolfaghari 2012 (Continued)

Blinding of participants Low risk (PRIMARY) HBA1C LEVEL - This is an objective measure of outcome (performance bias)

Patient outcome

\begin{tabular}{|c|c|c|}
\hline $\begin{array}{l}\text { Blinding of personnel (per- } \\
\text { formance bias) }\end{array}$ & Unclear risk & $\begin{array}{l}\text { (PRIMARY) SELF REPORT - QUESTIONNAIRE - No information on blinding. In- } \\
\text { sufficient information to permit judgment of 'Low risk' or 'High risk' }\end{array}$ \\
\hline
\end{tabular}

Adherence measure

Blinding of personnel (per- Low risk (PRIMARY) HBA1C LEVEL - This is an objective measure of outcome formance bias)

Patient outcome

\begin{tabular}{|c|c|c|}
\hline $\begin{array}{l}\text { Incomplete outcome data } \\
\text { (attrition bias) } \\
\text { Adherence measure }\end{array}$ & Unclear risk & $\begin{array}{l}\text { (PRIMARY) SELF REPORT - QUESTIONNAIRE - Fairly similar attrition, but there } \\
\text { was a small sample size so it is unclear }\end{array}$ \\
\hline $\begin{array}{l}\text { Incomplete outcome data } \\
\text { (attrition bias) } \\
\text { Patient outcome }\end{array}$ & Unclear risk & $\begin{array}{l}\text { (PRIMARY) HBA1C LEVEL - Fairly similar attrition, but there was a small sample } \\
\text { size so it is unclear }\end{array}$ \\
\hline
\end{tabular}

ACE: angiotensin-converting enzyme

ACR: American College of Rheumatology

ACTG: AIDS Clinical Trials Group

AHA: American Heart Association

AMI: acute myocardial infarction

AP: anti-psychotic

ARB: angiotensin receptor blocker

ART: antiretroviral therapy

ARV: antiretroviral

AT: adherence therapy

AVRF: audiovisual reminder function

BDI: Beck Depression Inventory

BG: blood glucose

BMI: body mass index

BP: blood pressure

BPRS: Brief Psychiatric Rating Scale

CDSMP: chronic disease self-management program

CES-D: Center for Epidemiologic Studies Depression Scale

CHD: coronary heart disease

CHF: chronic heart failure

$\mathrm{Cl}$ : confidence interval

COPD: chronic obstructive pulmonary disease

CRP: C-reactive protein

CV: cardiovascular

DBP: diastolic blood pressure

DKA: diabetic ketoacidosis

DMAS: Disease Management Assistance System

DSM-IV: Diagnostic and Statistical Manual of Mental Disorders - IV

ECG: electrocardiogram

ED: emergency department

ER: emergency room

EULAR: European League Against Rheumatism

FEV1: forced expiratory volume in one second

FVC: forced vital capacity

FP: fluticasone propionate

FRS: Framingham risk score

GAF: Global Assessment of Function

GP: general practitioner

HAART: highly active antiretroviral therapy 
HCV: hepatitis C virus

HCTZ: hydrochlorothiazide

HDL-C: high-density lipoprotein cholesterol

HF: heart failure

HPP: health promotion program

ICD-9, ICD-10: International Statistical Classification of Diseases and Related Health Problems (9th revision, 10th revision)

ICS: inhaled corticosteroids

INR: international normalized ratio

IOP: intraocular pressure

IPQ-R: Revised Illness Perception Questionnaire

ITT: intention-to-treat

IV: intravenous

JNC: Joint National Committee

LABA: long-acting beta-agonist

LDL-C: low-density lipoprotein cholesterol

LV: left ventricular

MARS: Medication Adherence Rating Scale

MDI: metered-dose inhaler

MGL: Morisky-Green-Levine Test

MEMS: medication event monitoring system

MI: myocardial infarction

MMSE: Mini Mental State Examination

NNRTI: nonnucleoside reverse transcriptase inhibitor

NYHA: New York Heart Association

OCP: oral contraceptive pill

OP: on protocol

OR: odds ratio

PANSS: Positive and Negative Syndrome Scale

PCP: primary care physician

PEF: peak expiratory flow

Peg-INF: peginterferon (Peg-IFN)

PEP: post-exposure prophylaxis

PI: primary investigator

PV: plasma viscosity

QLS: quality of life scale

QoL: quality of life

$\mathrm{RBV}$ : ribavirin

$\mathrm{RCT}$ : randomized controlled trial

$\mathrm{RN}$ : registered nurse

RRB: risk reduction behaviours

SABA: short-acting beta-agonist

SBP: systolic blood pressure

SCID: Structured Clinical Interview for DSM Disroders

SGRQ: St George's Respiratory Questionnaire

STOPS: Supevised Treatment in Out-patients for Schizophrenia

$T \& A$ : tonsillectomy and adenoidectomy

TAU: treatment as usual

URTI: upper respiratory tract infection

VA: Veterans Affairs

VAMCs: Veterans Affairs Medical Centers

WHO: World Health Organization

Characteristics of excluded studies [ordered by study ID]

\begin{tabular}{ll}
\hline Study & Reason for exclusion \\
\hline Adamian 2004 & Confounded comparison groups \\
\hline Adams 2000 & $\begin{array}{l}\text { No intervention intended to affect adherence with prescribed, self administered medications. No } \\
\text { measure of treatment outcome }\end{array}$ \\
\hline
\end{tabular}




\begin{tabular}{|c|c|}
\hline Study & Reason for exclusion \\
\hline Adams 2001 & No intervention intended to affect adherence with prescribed, self administered medications \\
\hline Adler 2004 & Follow-up rate $<80 \%$ \\
\hline Al Rashed 2002 & No measure of treatment outcome \\
\hline Al-Saffer 2005 & $\begin{array}{l}\text { Follow-up too short. Follow-up rate }<80 \% \text {. Pseudo-randomization method. No measure of treat- } \\
\text { ment outcome }\end{array}$ \\
\hline Alhalaiqa 2012 & Follow-up rate $<80 \%$ \\
\hline Allen 2002 & No intervention intended to affect adherence with prescribed, self administered medications \\
\hline Alves da Costa 2005 & Follow-up too short \\
\hline Antoni 2006 & Follow-up rate $<80 \%$ \\
\hline Armour 2007 & Missing data on adherence outcome \\
\hline Arthur 2002 & No intervention intended to affect adherence with prescribed, self administered medications \\
\hline Atherton-Naji 2001 & Follow-up rate $<80 \%$ \\
\hline Azrin 1998 & Only 2 months of follow-up \\
\hline Baker 2001 & No intervention intended to affect adherence with prescribed, self administered medications \\
\hline Ball 2006 & Follow-up rate $<80 \%$ \\
\hline Banet 1997 & No measure of compliance with medication at baseline \\
\hline Barbanel 2003 & No measure of medication adherence \\
\hline Barcelo 2001 & No intervention intended to affect adherence with prescribed, self administered medications \\
\hline Bass 1986 & Confounded comparison groups \\
\hline Begley 1997 & $\begin{array}{l}\text { No specific disease/disorder being treated. No specific medication. No specific measure of treat- } \\
\text { ment outcome }\end{array}$ \\
\hline Berg 1997 & Study duration too short \\
\hline Berg 2011 & Follow-up rate $<80 \%$ \\
\hline Bertakis 1986 & Follow-up too short or on less than $80 \%$ of participants \\
\hline Binstock 1986 & Missing data on adherence \\
\hline Birrer 1984 & Follow-up too short or on less than $80 \%$ of participants \\
\hline Birtwhistle 2004 & Confounded comparison groups \\
\hline Bisserbe 1997 & Study duration too short \\
\hline Bodsworth 1997 & No compliance data presented and $<80 \%$ follow-up \\
\hline
\end{tabular}




\begin{tabular}{|c|c|}
\hline Study & Reason for exclusion \\
\hline Bogner 2008 & Follow-up rate $<80 \%$ \\
\hline BonAdASIA 2009 & No measure of medication adherence \\
\hline Bonner 2002 & Follow-up too short or on less than $80 \%$ of participants \\
\hline Bouvy $2003 a$ & Follow-up too short or on less than $80 \%$ of participants \\
\hline Bouvy $2003 b$ & Follow-up too short or on less than $80 \%$ of participants \\
\hline Brodaty 1983 & Follow-up too short or on less than $80 \%$ of participants \\
\hline Brook 2002 & Confounded comparison groups \\
\hline Brook 2003 & No intervention intended to affect adherence with prescribed, self administered medications \\
\hline Brook 2005 & Follow-up rate $<80 \%$ \\
\hline Brotons 2005 & No measure of adherence outcome \\
\hline Brown 1987 & Missing description of disease outcome \\
\hline Brown 1997b & No measure of compliance with medications \\
\hline Browne 2002 & Confounded comparison groups \\
\hline Buchanan-Lee 2002 & No intervention intended to affect adherence with prescribed, self administered medications \\
\hline Bukstein 2003 & Confounded comparison groups \\
\hline Bungay 2004 & No measurement of adherence \\
\hline Burkhart 2002 & Only 5 weeks of follow-up \\
\hline Burnand 2002 & 10-week follow-up \\
\hline Bussmann 2009 & $\begin{array}{l}\text { Patients not randomized to intervention but to drug. Patients randomized to one drug were } \\
\text { crossed over to the other. Adherence was not described }\end{array}$ \\
\hline Caine 2002 & Confounded comparison groups \\
\hline Canto De Cetina 2001 & Not self administered medication \\
\hline Cantor 1985 & Follow-up too short or on less than $80 \%$ of participants \\
\hline Capoccia 2004 & Confounded comparison groups \\
\hline Cargill 1992 & Follow-up too short or on less than $80 \%$ of participants \\
\hline Carroll 2004 & No intervention intended to affect adherence with prescribed, self administered medications \\
\hline Celik 1997 & Follow-up $<80 \%$ \\
\hline Chaisson 2001 & No measure of treatment outcome \\
\hline
\end{tabular}




\begin{tabular}{|c|c|}
\hline Study & Reason for exclusion \\
\hline Chang 2010 & Follow-up rate $<80 \%$ \\
\hline Chang 2011 & Follow-up rate $<80 \%$ \\
\hline Cheng 2001 & No measure of treatment outcome \\
\hline Cheung 1988 & Confounded comparison groups \\
\hline Chien 2006 & No measure of adherence outcome \\
\hline Chiou-Tan 2003 & Confounded comparison groups \\
\hline Chisholm 2001 & No measure of treatment outcome \\
\hline Choi 2002 & Confounded comparison groups \\
\hline Clancy 2003 & No measure of medication adherence \\
\hline Clarkin 1998 & Follow-up rate $<80 \%$ \\
\hline Clifford 2002 & No intervention intended to affect adherence with prescribed, self administered medications \\
\hline Cochran 1984 & $\begin{array}{l}38 \text { patients were randomized before consent. When consent was requested, only } 28(74 \%) \text { agreed } \\
\text { so that the maximum follow-up was less than } 80 \% .2 \text { additional patients dropped out after giving } \\
\text { consent }\end{array}$ \\
\hline Cockburn 1997 & Follow-up rate $<80 \%$ \\
\hline Cohn 2002 & No intervention intended to affect adherence with prescribed, self administered medications \\
\hline Colom 2003 & No intervention intended to affect adherence with prescribed, self administered medications \\
\hline Cooper 2004 & No measurement of adherence \\
\hline Cordina 2001 & Follow-up rate $<80 \%$ \\
\hline Couturaud 2002 & Follow-up rate $<80 \%$ \\
\hline Cramer 2003 & No intervention intended to affect adherence with prescribed, self administered medications \\
\hline Crilly 2005 & No measure of adherence outcome \\
\hline Criswell 2010 & Follow-up rate $<80 \%$ \\
\hline Crockett 2006 & Follow-up too short \\
\hline Cukiernik 2007 & Effectiveness study \\
\hline Daley 1992 & Missing description of disease outcome \\
\hline Datto 2003 & Confounding of physician adherence intervention with patient adherence intervention \\
\hline de Bruin 2010 & $\begin{array}{l}\text { They combined the post-intervention ( } 3 \text { months) and follow-up ( } 7 \text { months) results and found sig- } \\
\text { nificant results }\end{array}$ \\
\hline
\end{tabular}




\begin{tabular}{|c|c|}
\hline Study & Reason for exclusion \\
\hline De Jonghe 2001 & Confounded comparison groups \\
\hline de Klerk 2001 & No measure of treatment outcome \\
\hline de Lusignan 2001 & No measure of medication adherence \\
\hline de Wit 2001 & Follow-up too short (8 weeks) \\
\hline Dehesa 2002 & Confounded comparison groups \\
\hline Deinzer 2006 & No measure of adherence outcome \\
\hline Delaronde 2005 & Follow-up rate $<80 \%$. Pseudo-randomization method \\
\hline Demiralay 2002 & Follow-up too short (only 2 months) \\
\hline Demyttenaere 1998 & Study too short duration \\
\hline Demyttenaere 2001 & Confounded comparison groups \\
\hline Dilorio 2003 & Follow-up too short (only 2 months) \\
\hline Dittrich 2002 & Confounded comparison groups \\
\hline Donadio 2001 & No measure of medication adherence \\
\hline Edworthy 1999 & Follow-up too short (only 8 weeks) \\
\hline Elixhauser 1990 & Follow-up too short or on less than $80 \%$ of participants \\
\hline Eron 2000 & Regimen/follow-up too short (only 16 weeks for HIV therapy) \\
\hline Eshelman 1976 & Follow-up too short or on less than $80 \%$ of participants \\
\hline Evers 2002 & Confounded comparison groups \\
\hline Falloon 1985 & Missing data on adherence \\
\hline Feaster 2010 & Follow-up rate $<80 \%$ at a time point for which they provide results \\
\hline Feinstein 1959 & Confounded comparison groups \\
\hline Fennell 1994 & Confounded comparison groups \\
\hline Ferrante 2010 & $\begin{array}{l}\text { Adherence is measured in the intervention group only. It is only available as part of a composite } \\
\text { outcome }\end{array}$ \\
\hline Finkelstein 2003 & Confounded comparison groups \\
\hline Finley 2003 & Confounded comparison groups \\
\hline Finney 1985 & Follow-up too short or on less than $80 \%$ of participants \\
\hline Fisher 2001 & No measure of treatment outcome \\
\hline
\end{tabular}




\begin{tabular}{|c|c|}
\hline Study & Reason for exclusion \\
\hline Franchini 2006 & Not randomized \\
\hline Francis 2001 & No measure of treatment outcome \\
\hline Frangou 2005 & Follow-up too short \\
\hline Freemantle 2002 & No intervention intended to affect adherence with prescribed, self administered medications \\
\hline Frick 2001 & No patients are prescribed medication for a medical (including psychological) disorder \\
\hline Fujioka 2003 & No intervention intended to affect adherence with prescribed, self administered medications \\
\hline Fumaz 2002 & Confounded comparison groups \\
\hline Gabriel 1977 & Missing description of disease outcome \\
\hline Gallefoss 2004 & Confounded comparison groups \\
\hline Garcao 2002 & The intervention is confounded \\
\hline Garety 2006 & Follow-up rate $<80 \%$. No measure of adherence outcome \\
\hline Garnett 1981 & Missing description of disease outcome \\
\hline Gibbs 1989 & Missing description of disease outcome \\
\hline Gilfillin 2002 & No measure of medication adherence \\
\hline Godemann 2003 & No measure of treatment outcome \\
\hline Goodyer 1995 & Follow-up too short or on less than $80 \%$ of participants \\
\hline Goujard 2003 & Follow-up rate $<80 \%$ \\
\hline Graham 2002a & Confounded comparison groups \\
\hline Graham 2002b & Only 4 months follow-up \\
\hline Grant 2003 & Follow-up rate $<80 \%$ \\
\hline Gray 2006 & $\mathrm{n} / \mathrm{a}$ \\
\hline Gupta 2001 & No intervention intended to affect adherence with prescribed, self administered medications \\
\hline Gustafson 2012 & Follow-up rate $<80 \%$ \\
\hline Guthrie 2001 & No measure of treatment outcome \\
\hline Gwadry-Sridhar 2005 & Follow-up rate $<80 \%$ \\
\hline Hamet 2003 & No measure of treatment outcome \\
\hline Hamilton 2003 & No measure of treatment outcome \\
\hline Hammond 2001 & No measure of medication adherence \\
\hline
\end{tabular}




\begin{tabular}{|c|c|}
\hline Study & Reason for exclusion \\
\hline Hampton 2001 & Confounded comparison groups \\
\hline Hardstaff 2003 & No measure of treatment outcome \\
\hline Haubrich 1999 & Less than $80 \%$ follow-up at 6 months \\
\hline Hayes 2003 & Patients are not prescribed a medication \\
\hline Heard 1999 & $\begin{array}{l}\text { In addition to } 3 \text { asthma clinic sessions, a GP consultation (where medications could be potentially } \\
\text { be altered) was added to the intervention group. Also, it is unclear whether medication adherence } \\
\text { is actually measured (i.e. paper only states that 'medication use' is assessed) }\end{array}$ \\
\hline Herschorn 2004 & Follow-up rate $<80 \%$. Follow-up too short \\
\hline Hertling 2003 & Confounded comparison groups \\
\hline Hesselink 2004 & Follow-up rate $<80 \%$ \\
\hline Hoffman 2003 & No measure of treatment outcome \\
\hline Holzemer 2006 & Follow-up rate $<80 \%$ \\
\hline Hommel 2012 & No patient outcome comparisons between treatment groups \\
\hline Hornung 1998a & $\begin{array}{l}\text { Patients initially randomized into treatment groups. However, these groups were re-arranged (not } \\
\text { randomly) for the purposes of analysis }\end{array}$ \\
\hline Hovell 2003 & No outcomes measured \\
\hline Insull 2001 & Confounded comparison groups \\
\hline Jameson 1995 & $\begin{array}{l}\text { Confounded intervention group (combined adherence intervention with adjustments to medica- } \\
\text { tions) }\end{array}$ \\
\hline Johnson 1997 & Study too short duration \\
\hline Johnson 2006 & No endpoints reported \\
\hline Jones 2003 & 10 weeks of follow-up \\
\hline Kakuda 2001 & No intervention intended to affect adherence with prescribed, self administered medications \\
\hline Kardas 2001 & Confounded comparison groups \\
\hline Katelaris 2002 & Confounded comparison groups \\
\hline Katon 2002 & Confounded comparison groups \\
\hline Katon 2004 & $\begin{array}{l}\text { Measured adherence outcomes but no results reported. Unclear whether all patients were on a } \\
\text { medication (some took insulin and some had antidepressants) }\end{array}$ \\
\hline Kelly 1988 & Follow-up too short or on less than $80 \%$ of participants \\
\hline Kelly 1990 & Follow-up too short or on less than $80 \%$ of participants \\
\hline
\end{tabular}




\begin{tabular}{|c|c|}
\hline Study & Reason for exclusion \\
\hline Kelly 1991 & Follow-up too short or on less than $80 \%$ of participants \\
\hline Kiarie 2003 & Confounded comparison groups \\
\hline Klein 2001 & No measure of adherence \\
\hline Kogos Jr. 2004 & $\begin{array}{l}\text { Not randomized. Patients are prescribed medication for a chronic condition but does not specify } \\
\text { the medical disorder (might be a range). Unknown follow-up status. Follow-up too short }\end{array}$ \\
\hline Krantz 2008 & Confounded comparison groups \\
\hline Krein 2004 & Confounded comparison groups \\
\hline Kritikos 2007 & Follow-up rate $<80 \%$ \\
\hline Kronish 2012 & No intervention intended to affect adherence with prescribed, self administered medications \\
\hline Krudsood 2002 & No measure of medication adherence \\
\hline Kumar 2002 & Confounded comparison groups \\
\hline Kutcher 2002 & Follow-up rate $<80 \%$ \\
\hline Lafeuillade 2001 & No intervention intended to affect adherence with prescribed, self administered medications \\
\hline Laffel 2003 & No measure of adherence \\
\hline Lam 2003 & Intervention was 12 to 18 sessions of cognitive therapy, which is a confounder \\
\hline Laramee 2003 & Confounded comparison groups \\
\hline Lawson 2005 & Intervention not tailored to improve adherence, only to adjust insulin levels \\
\hline Leal 2004 & No measurement of adherence \\
\hline Lee 2003 & No intervention intended to affect adherence with prescribed, self administered medications \\
\hline Leenan 1997 & Study too short duration \\
\hline Lemstra 2002 & No intervention intended to affect adherence with prescribed, self administered medications \\
\hline Lerman 2009 & No inter-group comparisons \\
\hline Leung 2003 & $\begin{array}{l}\text { Different medications in the } 2 \text { arms (rifampin + pyrazinamid versus isoniazid) as well as different } \\
\text { durations ( } 2 \text { months versus } 6 \text { months) }\end{array}$ \\
\hline Levesque 1983 & Confounded comparison groups \\
\hline Levine 1979 & Missing data on adherence \\
\hline Levy 2004 & Follow-up too short. Follow-up rate $<80 \%$ \\
\hline Lewis 1984 & Follow-up too short or on less than $80 \%$ of participants \\
\hline Lin 2003 & No measure of treatment outcome \\
\hline
\end{tabular}




\begin{tabular}{|c|c|}
\hline Study & Reason for exclusion \\
\hline Linkewich 1974 & Missing description of disease outcome \\
\hline Linszen 1996 & Follow-up too short or on less than $80 \%$ of participants \\
\hline Logan 1979 & Confounded comparison groups \\
\hline Lopez-Vina 2000 & Follow-up rate $<80 \%$ \\
\hline Lwilla 2003 & Follow-up rate $<80 \%$ \\
\hline Macalino 2007 & Follow-up too short or on less than $80 \%$ of participants \\
\hline Maclntyre 2003 & No measure of treatment outcome \\
\hline Maiman 1978 & Missing description of disease outcome \\
\hline Malotte 2001 & No measure of treatment outcome \\
\hline Manders 2001 & Follow-up too short or on less than $80 \%$ of participants \\
\hline Mann 2001 & No measure of treatment outcome \\
\hline Mannheimer 2002 & No intervention intended to affect adherence with prescribed, self administered medications \\
\hline Mannheimer 2006 & Follow-up rate $<80 \%$ \\
\hline Mantzaris 2002 & Confounded comparison groups \\
\hline Marquez Contreras 2004b & Follow-up rate $<80 \%$ \\
\hline Maslennikova 1998 & $\begin{array}{l}\text { Confounded: patients in education group also visited 'super-specialist' doctors, while the control } \\
\text { group received no education and also only visited regular primary doctors. Therefore, cannot sepa- } \\
\text { rate effects of the education from the effects of having different physicians }\end{array}$ \\
\hline Maspero 2001 & Confounded comparison groups \\
\hline Matsuyama 1993 & Follow-up too short or on less than $80 \%$ of participants \\
\hline Maxwell 2002 & No intervention intended to affect adherence with prescribed, self administered medications \\
\hline Mazzuca 1986 & Follow-up too short or on less than $80 \%$ of participants \\
\hline McCrindle 1997 & Study duration too short \\
\hline McFarlane 1995 & Follow-up too short or on less than $80 \%$ of participants \\
\hline Miklowitz 2000 & Follow-up rate $<80 \%$ \\
\hline Miklowitz 2003 & Follow-up rate $<80 \%$ \\
\hline Millard 2003 & No measure of medication adherence \\
\hline Miller 1990 & Follow-up too short or on less than $80 \%$ of participants \\
\hline Mita 2003 & Follow-up too short or on less than $80 \%$ of participants \\
\hline
\end{tabular}




\begin{tabular}{|c|c|}
\hline Study & Reason for exclusion \\
\hline Morisky 1980 & Follow-up too short or on less than $80 \%$ of participants \\
\hline Morisky 1983 & Missing data on adherence \\
\hline Morisky 1990 & Missing description of disease outcome \\
\hline Morisky 2001 & No measure of treatment outcome \\
\hline Moulding 2002 & No measure of treatment outcome \\
\hline Moya 2006 & Follow-up rate $<80 \%$. Not an RCT \\
\hline Muhlig 2001 & No measure of treatment outcome \\
\hline Mundt 2001 & Less than $80 \%$ follow-up at 6 months \\
\hline Murphy 2002 & No measure of treatment outcome \\
\hline Murphy 2007 & Unclear follow-up percentage \\
\hline Murray 1993 & Missing description of disease outcome \\
\hline Myers 1984 & Follow-up too short or on less than $80 \%$ of participants \\
\hline Myers 1992 & Follow-up too short or on less than $80 \%$ of participants \\
\hline Nachega 2010 & Follow-up rate $<80 \%$ \\
\hline Nansel 2007 & $\begin{array}{l}\text { Insufficient information about insulin administration. No inter-group comparison on adherence to } \\
\text { insulin administration }\end{array}$ \\
\hline Naunton 2003 & Follow-up too short or on less than $80 \%$ of participants \\
\hline Nessman 1980 & Follow-up too short or on less than $80 \%$ of participants \\
\hline Ngoh 1997 & No measure of treatment outcome reported \\
\hline Nides 1993 & Follow-up too short or on less than $80 \%$ of participants \\
\hline Noonan 2001 & Confounded comparison groups \\
\hline Nyomba 2004 & $76 \%$ follow-up rate \\
\hline O'Connor 1996 & Non-randomised trial \\
\hline O'Suilleabhain 2002 & Follow-up too short or on less than $80 \%$ of participants \\
\hline Obreli Neto 2011 & No between-group comparisons \\
\hline Ogedegbe 2008 & Follow-up rate $<80 \%$ \\
\hline Onyirimba 2003 & Follow-up rate $<80 \%$ \\
\hline Pearce 2008 & Follow-up rate $<80 \%$. Missing data on adherence outcome \\
\hline
\end{tabular}




\begin{tabular}{|c|c|}
\hline Study & Reason for exclusion \\
\hline Phan 1995 & Follow-up too short or on less than $80 \%$ of participants \\
\hline Piette 2001 & Confounded \\
\hline Pladevall 2010 & Follow-up rate $<80 \%$ \\
\hline Polonsky 2003 & Follow-up rate $<80 \%$ \\
\hline Ponnusankar 2004 & No measurement of treatment outcome \\
\hline Pop Eleches 2011 & No patient outcomes \\
\hline Poplawska 2004 & No measurement of adherence \\
\hline Portilla 2003 & Follow-up rate $<80 \%$ \\
\hline Purcell 2004 & No measure of treatment outcome. Not all participants taking medication \\
\hline Putnam 1994 & Follow-up too short or on less than $80 \%$ of participants \\
\hline Qazi 2002 & No intervention intended to affect adherence with prescribed, self administered medications \\
\hline Ran 2003 & Not self administered medication \\
\hline Rapoff 2002 & Follow-up rate $<80 \%$ \\
\hline Rathbun 2005 & Follow-up rate $<80 \%$ \\
\hline Raynor 1993 & Missing description of disease outcome \\
\hline Razali 1997 & Compliance measured to determine eligibility, but not measured through the course of the study \\
\hline Rehder 1980 & Follow-up too short or on less than $80 \%$ of participants \\
\hline Reid 2005 & Addiction study (alcoholism) \\
\hline Rettig 1986 & Follow-up too short or on less than $80 \%$ of participants \\
\hline Rich 1996 & Follow-up too short or on less than $80 \%$ of participants \\
\hline Rickheim 2002a & No measure of medication adherence \\
\hline Rickheim 2002b & No measure of medication adherence \\
\hline Rigsby 2000 & $\begin{array}{l}\text { Follow-up less than } 6 \text { months, and trial is not definitively negative since there are fewer than } 50 \text { pa- } \\
\text { tients per group }\end{array}$ \\
\hline Riis 2001 & Confounded comparison groups \\
\hline Rimer 1987 & Follow-up too short or on less than $80 \%$ of participants \\
\hline Robinson 1986 & Follow-up too short or on less than $80 \%$ of participants \\
\hline Rodriguez 2003 & No intervention intended to affect adherence with prescribed, self administered medications \\
\hline
\end{tabular}




\begin{tabular}{|c|c|}
\hline Study & Reason for exclusion \\
\hline Rosen 2004 & Follow-up time was only 4 months \\
\hline Ross 2004 & $78.5 \%$ follow-up rate \\
\hline Roy-Byrne 2001 & $\begin{array}{l}\text { Confounded: part of intervention included pharmacotherapy with a selective serotonin reuptake } \\
\text { inhibitor, whereas usual care patients received 'treatment as usual' from their physician. There- } \\
\text { fore, control and intervention groups may have different drug regimens }\end{array}$ \\
\hline Rudnicka 2003 & Confounded comparison groups \\
\hline Ruiz 2010 & Follow-up rate $<80 \%$ \\
\hline Ruoff 2005 & Follow-up rate $<80 \%$. No control group. Follow-up too short \\
\hline Rytter 2010 & No measure of medication adherence \\
\hline Safren 2003 & Follow-up too short or on less than $80 \%$ of participants \\
\hline Safren 2009 & Follow-up too short or on less than $80 \%$ of participants \\
\hline Sanchez 2002 & Confounded comparison groups \\
\hline Sanmarti 1993 & Missing description of disease outcome \\
\hline Santschi 2008 & Adherence measured in the intervention group only \\
\hline Saunders 1991 & Follow-up too short or on less than $80 \%$ of participants \\
\hline Sawicki 1999 & Confounded comparison groups \\
\hline Schmaling 2001 & Follow-up rate $<80 \%$ \\
\hline Schneider 2008 & Pseudo-randomization method \\
\hline Schoenbaum 2001 & No measure of medication adherence \\
\hline Schousboe 2005 & No clear measure of treatment outcome \\
\hline Schwartz 1981 & Confounded comparison groups \\
\hline Sclar 1991 & Missing description of disease outcome \\
\hline Seal 2003 & No intervention intended to affect adherence with prescribed, self administered medications \\
\hline Segador 2005 & Follow-up rate $<80 \%$ \\
\hline Seggev 1998 & Follow-up rate $<80 \%(78.8 \%)$ \\
\hline Sellors 1997 & No treatment outcome measured \\
\hline Sellwood 2001 & Confounded comparison groups \\
\hline Serfaty 2002 & No measure of treatment outcome \\
\hline Serfaty 2003 & Confounded comparison groups \\
\hline
\end{tabular}




\begin{tabular}{|c|c|}
\hline Study & Reason for exclusion \\
\hline Shames 2004 & Confounded comparison groups \\
\hline Sharpe 1974 & Missing description of disease outcome \\
\hline Shepard 1979 & Missing data on adherence \\
\hline Sherbourne 2001 & No measure of medication adherence \\
\hline Sherman 2001 & $\begin{array}{l}\text { Confounded comparison groups, and no intervention intended to affect adherence with pre- } \\
\text { scribed, self administered medications }\end{array}$ \\
\hline Shetty 1997 & No random assignment to treatment groups \\
\hline Silverman 2002 & No measure of medication adherence \\
\hline Simkins 1986 & Missing description of disease outcome \\
\hline Simmons 2001 & Follow-up too short or on less than $80 \%$ of participants \\
\hline Simon 2002 & No measure of medication adherence \\
\hline Simon 2005 & $\begin{array}{l}\text { Intervention aimed at changing prescribing behavior. No measure of adherence. Follow-up rate }< \\
80 \%\end{array}$ \\
\hline Simon 2006 & Follow-up rate $<80 \%$ \\
\hline Smith 1986 & Missing description of disease outcome \\
\hline Smith 2003 & Follow-up too short or on less than $80 \%$ of participants \\
\hline Solomon 1988 & Missing description of disease outcome. Follow-up too short or on less than $80 \%$ of participants \\
\hline Solomon 1997 & Study too short duration \\
\hline Stringer 2003 & No measure of treatment outcome \\
\hline Stuart 2003 & No measure of treatment outcome \\
\hline Sturgess 2003 & Follow-up too short or on less than $80 \%$ of participants \\
\hline Stuurman-Bieze 2005 & Follow-up too short. No data on control group. No measure of treatment outcome \\
\hline Suppapitiporn 2005 & No measure of adherence outcome. Unknown follow-up status \\
\hline Surwit 2002 & No measure of medication adherence \\
\hline Svoren 2003 & No measure of medication adherence \\
\hline Swartz 2001 & No measure of treatment outcome \\
\hline Sáez 2011 & Missing information about the intervention \\
\hline Taggart 1981 & Follow-up too short or on less than $80 \%$ of participants \\
\hline Takala 1979 & Missing data on adherence \\
\hline
\end{tabular}




\begin{tabular}{|c|c|}
\hline Study & Reason for exclusion \\
\hline Tan 2011 & Insufficient time to follow-up \\
\hline Tapanya 1997 & Study too short duration \\
\hline Taylor 2001 & Follow-up too short or on less than $80 \%$ of participants \\
\hline Taylor 2003 & $\begin{array}{l}\text { The interventions are mainly directed at enhancing therapy though reviewing patients' drug reg- } \\
\text { imens. Enhancing adherence is a secondary objective; for the outcomes measured, the indepen- } \\
\text { dent effects of the adherence part cannot be separated out }\end{array}$ \\
\hline Ting 2012 & Adherence to clinic visits not adherence to medications \\
\hline Tinkelman 1980 & Confounded comparison groups \\
\hline Tobari 2010 & Medication adherence not the main focus of the study \\
\hline Toyota 2003 & Follow-up too short or on less than $80 \%$ of participants \\
\hline Treiber 2002 & Confounded comparison groups \\
\hline Trienekens 1993 & Confounded comparison groups \\
\hline Unutzer 2001 & No measure of treatment outcome \\
\hline Unutzer 2002 & No intervention intended to affect adherence with prescribed, self administered medications \\
\hline Vale 2003 & No measure of medication adherence \\
\hline Valles 2003 & No measure of medication adherence \\
\hline Van der 2001 & No measure of treatment outcome \\
\hline Van Dyke 2002 & $\begin{array}{l}\text { Confounded comparison groups and no intervention intended to affect adherence with prescribed, } \\
\text { self administered medications }\end{array}$ \\
\hline van Es 2001 & No measure of treatment outcome \\
\hline Van Servellen 2005 & Follow-up rate $<80 \%$ \\
\hline Vander Stichele 1992 & Follow-up too short or on less than $80 \%$ of participants \\
\hline Velasco 2002 & No measure of medication adherence \\
\hline VeldhuizenScott 1995 & Follow-up too short or on less than $80 \%$ of participants \\
\hline Vestergaard 1997 & No treatment outcome reported \\
\hline Vetter 1999 & $\begin{array}{l}\text { No compliance intervention, since patients in control group received clarithromycin } 250 \mathrm{mg} \text { twice } \\
\text { daily, while patients in intervention group received clarithromycin 500mg (modified release) once } \\
\text { daily PLUS placebo }\end{array}$ \\
\hline Villeneuve 2010 & Follow-up rate $<80 \%$ \\
\hline Vivian 2002 & $\begin{array}{l}\text { Confounded: the intervention included both changing medications as needed and compliance } \\
\text { counseling }\end{array}$ \\
\hline
\end{tabular}




\begin{tabular}{|c|c|}
\hline Study & Reason for exclusion \\
\hline Vrijens 1997 & Study duration too short \\
\hline Wagner 2002 & No measure of treatment outcome \\
\hline Walker 2006 & $\begin{array}{l}\text { Confounded comparison groups. No specific disease/disorder being treated. Inadequate measure } \\
\text { of clinical outcome }\end{array}$ \\
\hline Walker 2011 & No inter-group comparisons for the adherence measures \\
\hline Wang 2011 & No inter-group comparisons \\
\hline Wasilewski 2000 & $\begin{array}{l}\text { Confounded: different medications and different medication schedule in intervention and control } \\
\text { groups }\end{array}$ \\
\hline Webb 1980 & Confounded comparison groups \\
\hline Weiss 2002 & Follow-up rate $<80 \%$ \\
\hline Wells 2004 & Confounded comparison groups \\
\hline Williams 1986 & Missing description of disease outcome \\
\hline Williams 2006 & Follow-up rate $<80 \%$ \\
\hline Williams 2012 & Follow-up rate $<80 \%$ \\
\hline Windsor 1990 & Missing description of disease outcome \\
\hline Wise 1986 & Follow-up too short or on less than $80 \%$ of participants \\
\hline Wohl 2006 & Follow-up rate $<80 \%$ \\
\hline Wong 1987 & Missing description of disease outcome \\
\hline Wright 2003 & No measure of medication adherence \\
\hline Wu 2006 & Follow-up rate $<80 \%$ \\
\hline Xiang 1994 & Follow-up too short or on less than $80 \%$ of participants \\
\hline Xiao 2001 & No intervention intended to affect adherence with prescribed, self administered medications \\
\hline Yeboah-Antwi 2001 & No measure of medication adherence \\
\hline Yuan 2003 & No measure of medication adherence \\
\hline Zarnke 1997 & Study too short duration \\
\hline Zermansky 2002 & Patients are not prescribed medication for a medical (including psychological) disorder \\
\hline Ziauddin Hyder 2002 & No measure of treatment outcome \\
\hline
\end{tabular}


Characteristics of studies awaiting assessment [ordered by study ID]

Andres 2007

\begin{tabular}{ll}
\hline Methods & Not yet assessed \\
\hline Participants & Not yet assessed \\
\hline Interventions & Not yet assessed \\
\hline Outcomes & Not yet assessed \\
\hline Notes & Translation of this article into English was not possible \\
\hline
\end{tabular}

\section{Clowes 2004}

\begin{tabular}{ll}
\hline Methods & Not yet assessed \\
\hline Participants & Not yet assessed \\
\hline Interventions & Not yet assessed \\
\hline Outcomes & Not yet assessed \\
\hline Notes & Not yet assessed \\
\hline
\end{tabular}

Gallefoss 2002

\begin{tabular}{ll}
\hline Methods & Not yet assessed \\
\hline Participants & Not yet assessed \\
\hline Interventions & Not yet assessed \\
\hline Outcomes & Not yet assessed \\
\hline Notes & Translation of this article into English was not possible \\
\hline
\end{tabular}

Hornung 1998b

\begin{tabular}{ll}
\hline Methods & Not yet assessed \\
\hline Participants & Not yet assessed \\
\hline Interventions & Not yet assessed \\
\hline Outcomes & Not yet assessed \\
\hline Notes & Not yet assessed \\
\hline
\end{tabular}


Kripalani 2006

\begin{tabular}{ll}
\hline Methods & Not yet assessed \\
\hline Participants & Not yet assessed \\
\hline Interventions & Not yet assessed \\
\hline Outcomes & Not yet assessed \\
\hline Notes & Not yet assessed \\
\hline
\end{tabular}

Marquez 2000

\begin{tabular}{ll}
\hline Methods & Not yet assessed \\
\hline Participants & Not yet assessed \\
\hline Interventions & Not yet assessed \\
\hline Outcomes & Not yet assessed \\
\hline Notes & Translation of this article into English was not possible
\end{tabular}

\section{Marquez 2009}

\begin{tabular}{ll} 
Methods & Not yet assessed \\
\hline Participants & Not yet assessed \\
\hline Interventions & Not yet assessed \\
\hline Outcomes & Not yet assessed \\
\hline Notes & Translation of this article into English was not possible
\end{tabular}

Shon 2002

\begin{tabular}{ll}
\hline Methods & Not yet assessed \\
\hline Participants & Not yet assessed \\
\hline Interventions & Not yet assessed \\
\hline Outcomes & Not yet assessed \\
\hline Notes & Not yet assessed \\
\hline
\end{tabular}


DATA AND ANALYSES

\section{Comparison 1. Studies that met criteria}

\begin{tabular}{lllll}
\hline Outcome or subgroup title & $\begin{array}{l}\text { No. of } \\
\text { studies }\end{array}$ & $\begin{array}{l}\text { No. of partici- } \\
\text { pants }\end{array}$ & Statistical method & Effect size \\
\hline 1 Adherence and outcome & & Other data & No numeric data \\
\hline
\end{tabular}

\section{Analysis 1.1. Comparison 1 Studies that met criteria, Outcome 1 Adherence and outcome.}

\begin{tabular}{|c|c|c|c|c|c|}
\hline \multicolumn{6}{|c|}{ Adherence and outcome } \\
\hline Study & Clinical problem & Intervention & Control & $\begin{array}{l}\text { Effect on adherence } \\
\text { (Yes means a statis- } \\
\text { tically significant ef- } \\
\text { fect in favor of the } \\
\text { intervention; No } \\
\text { means no effect or } \\
\text { a negative effect) }\end{array}$ & $\begin{array}{l}\text { Effect on clin- } \\
\text { ical outcome } \\
\text { (Yes means a statis- } \\
\text { tically significant ef- } \\
\text { fect in favor of the } \\
\text { intervention; No } \\
\text { means no effect or } \\
\text { a negative effect) }\end{array}$ \\
\hline Ahmadipour 2010 & Type 2 diabetes & $\begin{array}{l}\text { DIARY CHECKLIST: The } \\
\text { intervention group was } \\
\text { asked to complete a di- } \\
\text { ary checklist about how } \\
\text { they took their drugs } \\
\text { during the study peri- } \\
\text { od.The duration was } 12 \\
\text { weeks } \\
(\mathrm{n}=50)\end{array}$ & $\begin{array}{l}\text { COLLECTION OF MEDI- } \\
\text { CATION SHELLS: The } \\
\text { control group patients } \\
\text { were asked to collect } \\
\text { the shells of oral hypo- } \\
\text { glycemic agents after } \\
\text { taking in a pocket. Dura- } \\
\text { tion was } 12 \text { weeks. } \\
(\mathrm{n}=50)\end{array}$ & $\begin{array}{l}\text { Yes for improving med- } \\
\text { ication adherence in pa- } \\
\text { tients with type } 2 \text { dia- } \\
\text { betes with a diary check } \\
\text { list intervention }\end{array}$ & $\begin{array}{l}\text { No for improvement in } \\
\text { HbAlc levels }\end{array}$ \\
\hline
\end{tabular}




\begin{tabular}{|c|c|c|c|c|c|}
\hline \multicolumn{6}{|c|}{ Adherence and outcome } \\
\hline Study & Clinical problem & Intervention & Control & $\begin{array}{l}\text { Effect on adherence } \\
\text { (Yes means a statis- } \\
\text { tically significant ef- } \\
\text { fect in favor of the } \\
\text { intervention; No } \\
\text { means no effect or } \\
\text { a negative effect) }\end{array}$ & $\begin{array}{l}\text { Effect on clin- } \\
\text { ical outcome } \\
\text { (Yes means a statis- } \\
\text { tically significant ef- } \\
\text { fect in favor of the } \\
\text { intervention; No } \\
\text { means no effect or } \\
\text { a negative effect) }\end{array}$ \\
\hline Al Mazroui 2009 & Type 2 diabetes mellitus & 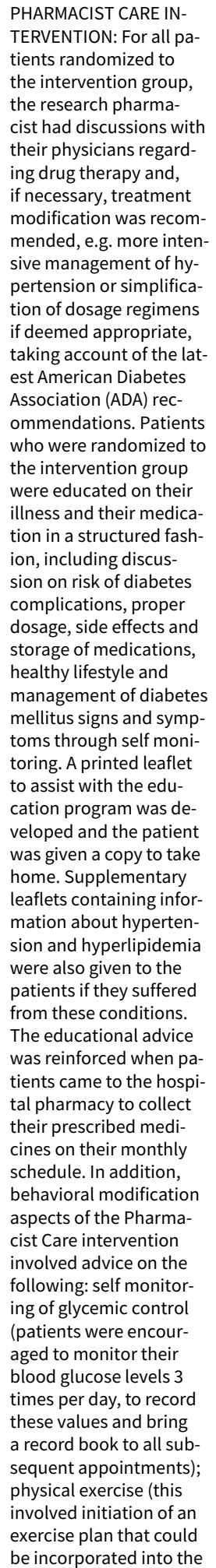 & $\begin{array}{l}\text { USUAL CARE: Control } \\
\text { group participants re- } \\
\text { ceived normal care from } \\
\text { medical and nursing } \\
\text { staff. They did not re- } \\
\text { ceive any pharmacy clin- } \\
\text { ical service but received } \\
\text { advice on self monitor- } \\
\text { ing their blood glucose } \\
\text { by medical or nursing } \\
\text { staff } \\
(\mathrm{n}=120)\end{array}$ & $\begin{array}{l}\text { Yes for improving adher- } \\
\text { ence to medication at } 12 \\
\text { months }\end{array}$ & $\begin{array}{l}\text { Yes for BMI, blood glu- } \\
\text { cose, HbAlc, blood pres- } \\
\text { sure, cholesterol, qual- } \\
\text { ity of life, Framingham } \\
\text { prediction scores, and } \\
\text { British National Formu- } \\
\text { lary risk prediction }\end{array}$ \\
\hline
\end{tabular}




\begin{tabular}{|c|c|c|c|c|c|}
\hline \multicolumn{6}{|c|}{ Adherence and outcome } \\
\hline Study & Clinical problem & Intervention & Control & $\begin{array}{l}\text { Effect on adherence } \\
\text { (Yes means a statis- } \\
\text { tically significant ef- } \\
\text { fect in favor of the } \\
\text { intervention; No } \\
\text { means no effect or } \\
\text { a negative effect) }\end{array}$ & $\begin{array}{l}\text { Effect on clin- } \\
\text { ical outcome } \\
\text { (Yes means a statis- } \\
\text { tically significant ef- } \\
\text { fect in favor of the } \\
\text { intervention; No } \\
\text { means no effect or } \\
\text { a negative effect) }\end{array}$ \\
\hline & & $\begin{array}{l}\text { patient's daily sched- } \\
\text { ule, after taking into } \\
\text { consideration their lev- } \\
\text { el of fitness, e.g. 1-hour } \\
\text { walk daily; diet (the pa- } \\
\text { tient was assisted with } \\
\text { the identification of di- } \\
\text { etary behavior that ad- } \\
\text { versely influences blood } \\
\text { glucose control, lipid } \\
\text { levels, weight manage- } \\
\text { ment, and of the times } \\
\text { of day when the patient } \\
\text { was most vulnerable to } \\
\text { overeating, and given } \\
\text { improved understanding } \\
\text { of the relative effects of } \\
\text { certain food choices on } \\
\text { blood glucose control); } \\
\text { medication adherence } \\
\text { (patients were asked } \\
\text { about any problems that } \\
\text { they had encountered } \\
\text { with regard to taking } \\
\text { their medication and } \\
\text { were offered education } \\
\text { and practical help to en- } \\
\text { courage them to take the } \\
\text { medicines prescribed for } \\
\text { them by their physician); } \\
\text { and smoking cessation } \\
\text { (patients were encour- } \\
\text { aged to stop smoking } \\
\text { by advising them about } \\
\text { the danger of smoking to } \\
\text { health, with emphasis on } \\
\text { the increased dangers of } \\
\text { smoking in diabetic pa- } \\
\text { tients) } \\
\text { ( } \mathrm{n}=120 \text { ) }\end{array}$ & & & \\
\hline Al-Eidan 2002 & Helicobacter pylori & $\begin{array}{l}\text { Intervention patients } \\
(\mathrm{n}=38) \text { received their } \\
\text { medicines via the hospi- } \\
\text { tal pharmacy and were } \\
\text { counseled (and followed } \\
\text { up) by a hospital phar- } \\
\text { macist }\end{array}$ & $\begin{array}{l}\text { Control patients ( } \mathrm{n}= \\
\text { 38) were given a stan- } \\
\text { dard advice sheet and } \\
\text { referred to their GP who } \\
\text { prescribed the same } \\
\text { therapy }\end{array}$ & $\begin{array}{l}\text { Yes for improving com- } \\
\text { pliance with a 1-week } \\
\text { course of triple therapy } \\
\text { to eradicate } H \text {. pylori }\end{array}$ & $\begin{array}{l}\text { Yes for improving clinical } \\
\text { outcomes for the inter- } \\
\text { vention group who had a } \\
\text { significantly higher rate } \\
\text { of } H \text {. pylori eradication }\end{array}$ \\
\hline Amado 2011 & Hypertension & $\begin{array}{l}\text { INTERVENTION (IG): Pa- } \\
\text { tients in the Intervention } \\
\text { Group (IG) had } 4 \text { visits } \\
\text { with specially trained } \\
\text { nurses who used stan- } \\
\text { dardized guidelines and } \\
\text { who had attended a 10- } \\
\text { hour workshop that fo- } \\
\text { cused on the antihyper- } \\
\text { tensive medications. } \\
\text { Each visit lasted for an } \\
\text { average of } 15 \text { minutes. } \\
\text { Information was person- } \\
\text { alized to the needs of the } \\
\text { patient. Schedule sheets } \\
\text { with the treatment plan } \\
\text { were provided which } \\
\text { contained information } \\
\text { on the prescribed drugs } \\
\text { and dosage schedule } \\
\text { as well as basic advice } \\
\text { on how to maximize the }\end{array}$ & $\begin{array}{l}\text { CONTROL GROUP (CG): } \\
\text { Control patients re- } \\
\text { ceived usual clinic care } \\
\text { without any standard- } \\
\text { ized intervention } \\
(\mathrm{n}=481)\end{array}$ & $\begin{array}{l}\text { Yes for Haynes-Sack- } \\
\text { ett test; no for Morisky- } \\
\text { Green test, self declared } \\
\text { 3-month adherence, and } \\
\text { pill count }\end{array}$ & $\begin{array}{l}\text { No for systolic and dias- } \\
\text { tolic blood pressure, hy- } \\
\text { pertension control, BMI, } \\
\text { and number of antihy- } \\
\text { pertensive drugs taken }\end{array}$ \\
\hline
\end{tabular}




\begin{tabular}{|c|c|c|c|c|c|}
\hline \multicolumn{6}{|c|}{ Adherence and outcome } \\
\hline Study & Clinical problem & Intervention & Control & $\begin{array}{l}\text { Effect on adherence } \\
\text { (Yes means a statis- } \\
\text { tically significant ef- } \\
\text { fect in favor of the } \\
\text { intervention; No } \\
\text { means no effect or } \\
\text { a negative effect) }\end{array}$ & $\begin{array}{l}\text { Effect on clin- } \\
\text { ical outcome } \\
\text { (Yes means a statis- } \\
\text { tically significant ef- } \\
\text { fect in favor of the } \\
\text { intervention; No } \\
\text { means no effect or } \\
\text { a negative effect) }\end{array}$ \\
\hline & & $\begin{array}{l}\text { treatment schedule. The } \\
\text { sheets were provided to } \\
\text { reinforce the nurse's ver- } \\
\text { bal instructions } \\
(\mathrm{n}=515)\end{array}$ & & & \\
\hline Anderson 2010 & Schizophrenia & $\begin{array}{l}\text { ADHERENCE TREAT- } \\
\text { MENT: The intervention } \\
\text { was 'Adherence Ther- } \\
\text { apy' a manualized, pa- } \\
\text { tient-centric approach } \\
\text { that seeks to address a } \\
\text { broad range of factors } \\
\text { known to affect adher- } \\
\text { ence. This individual } \\
\text { therapy focuses on the } \\
\text { needs, concerns, fears, } \\
\text { values, goals, and expe- } \\
\text { riences of the individ- } \\
\text { ual with the aim of en- } \\
\text { couraging people to take } \\
\text { their medications. It was } \\
\text { delivered by } 4 \text { therapists } \\
\text { with Master's degree in } \\
\text { social work. There were } \\
8 \text { one to one sessions of } \\
\text { between } 20 \text { to } 60 \text { min- } \\
\text { utes, over } 8 \text { weeks. Fol- } \\
\text { low-up was conducted } \\
\text { after the completion of } \\
\text { the therapy. All inter- } \\
\text { vention patients also re- } \\
\text { ceived treatment as usu- } \\
\text { al } \\
\text { ( } \mathrm{n}=12 \text { ) }\end{array}$ & $\begin{array}{l}\text { TREATMENT AS USUAL: } \\
\text { TAU included day treat- } \\
\text { ment, case manage- } \\
\text { ment, employment } \\
\text { placement, medication } \\
\text { monitoring, and indi- } \\
\text { vidual counseling. Dur- } \\
\text { ing the trial, AT partici- } \\
\text { pants did not see their } \\
\text { own therapist for ther- } \\
\text { apy sessions, but con- } \\
\text { tinued their other treat- } \\
\text { ment activities } \\
(n=14)\end{array}$ & $\begin{array}{l}\text { No for improving adher- } \\
\text { ence to antipsychotic } \\
\text { medication in schizo- } \\
\text { phrenia patients receiv- } \\
\text { ing adherence therapy } \\
\text { and treatment as usual } \\
\text { at } 8 \text { weeks }\end{array}$ & $\begin{array}{l}\text { No for improving the } \\
\text { PANSS positive, nega- } \\
\text { tive and general scores } \\
\text { in schizophrenia patients } \\
\text { receiving adherence } \\
\text { therapy and treatment } \\
\text { as usual at } 8 \text { weeks }\end{array}$ \\
\hline Andrade 2005 & HIV & $\begin{array}{l}\text { Disease Management As- } \\
\text { sistant System (DMAS) } \\
\text { device, programmed } \\
\text { with verbal reminder } \\
\text { messages and dosing } \\
\text { times for medications } \\
\text { in the highly active an- } \\
\text { tiretroviral treatment } \\
\text { (HAART) regimen with } \\
\text { monthly adherence } \\
\text { counseling and feedback } \\
\text { (see Control; } n=29 \text { ) }\end{array}$ & $\begin{array}{l}\text { Monthly adherence } \\
\text { counseling (education } \\
\text { about barriers to adher- } \\
\text { ence, hazards of non-ad- } \\
\text { herence, their prescribed } \\
\text { HAART regimen) and ad- } \\
\text { herence feedback ( } \mathrm{n}= \\
\text { 29) }\end{array}$ & $\begin{array}{l}\text { No for all adherence out- } \\
\text { comes }\end{array}$ & $\begin{array}{l}\text { No for CD4+ cell count. } \\
\text { Yes for plasma HIV RNA } \\
\text { (significant for } 2 \text { of } 4 \\
\text { measures) }\end{array}$ \\
\hline Ansah 2001 & Malaria & $\begin{array}{l}\text { The use of pre-packed } \\
\text { chloroquine tablets }(n= \\
155)\end{array}$ & $\begin{array}{l}\text { The use of chloroquine } \\
\text { syrup }(n=144)\end{array}$ & $\begin{array}{l}\text { Yes. The tablet form of } \\
\text { medicine resulted in } \\
\text { higher adherence rates, } \\
\text { but it is not established } \\
\text { whether this is due to the } \\
\text { formulation or the lack } \\
\text { of provision of a stan- } \\
\text { dard measuring device }\end{array}$ & $\begin{array}{l}\text { No, there was no differ- } \\
\text { ence in the clinical out- } \\
\text { comes }\end{array}$ \\
\hline Antonicelli 2008 & Congestive heart failure & $\begin{array}{l}\text { HOME TELEMONI- } \\
\text { TORING: Patients were } \\
\text { in a 12-month follow-up } \\
\text { period. Patients (or one } \\
\text { of their relatives) were } \\
\text { contacted by telephone } \\
\text { at least once a week by } \\
\text { the CHF team to obtain } \\
\text { information on symp- } \\
\text { toms and adherence to } \\
\text { prescribed treatment, as } \\
\text { well as blood pressure, } \\
\text { heart rate, bodyweight } \\
\text { and 24-hour urine out- }\end{array}$ & $\begin{array}{l}\text { STANDARD CARE: Pa- } \\
\text { tients (or one of their } \\
\text { relatives) in the con- } \\
\text { trol group were con- } \\
\text { tacted monthly for } 12 \\
\text { months of follow-up by } \\
\text { telephone to obtain da- } \\
\text { ta on new hospital ad- } \\
\text { missions, cardiovascu- } \\
\text { lar complications and } \\
\text { death. These patients } \\
\text { were also routinely seen } \\
\text { in the CHF outpatient } \\
\text { clinic every } 4 \text { months, }\end{array}$ & $\begin{array}{l}\text { Yes for improving adher- } \\
\text { ence to beta-blockers, } \\
\text { HMG-CoA reductase in- } \\
\text { hibitors and aldosterone } \\
\text { receptor agonists at } 12 \\
\text { months in elderly pa- } \\
\text { tients with CHF }\end{array}$ & $\begin{array}{l}\text { Yes for composite end- } \\
\text { point of mortality and } \\
\text { hospital readmission, } \\
\text { hospital readmission } \\
\text { (alone) and heart rate re- } \\
\text { duction. No for left ven- } \\
\text { tricular ejection fraction } \\
\text { change and mortality } \\
\text { (alone) }\end{array}$ \\
\hline
\end{tabular}




\begin{tabular}{|c|c|c|c|c|c|}
\hline \multicolumn{6}{|c|}{ Adherence and outcome } \\
\hline Study & Clinical problem & Intervention & Control & $\begin{array}{l}\text { Effect on adherence } \\
\text { (Yes means a statis- } \\
\text { tically significant ef- } \\
\text { fect in favor of the } \\
\text { intervention; No } \\
\text { means no effect or } \\
\text { a negative effect) }\end{array}$ & $\begin{array}{l}\text { Effect on clin- } \\
\text { ical outcome } \\
\text { (Yes means a statis- } \\
\text { tically significant ef- } \\
\text { fect in favor of the } \\
\text { intervention; No } \\
\text { means no effect or } \\
\text { a negative effect) }\end{array}$ \\
\hline & & $\begin{array}{l}\text { put data for the previ- } \\
\text { ous day. A weekly ECG } \\
\text { transmission was also } \\
\text { required. Evaluation of } \\
\text { these parameters was } \\
\text { followed by reassess- } \\
\text { ment of the therapeu- } \\
\text { tic regimen and modifi- } \\
\text { cation whenever need- } \\
\text { ed. In addition, clinic vis- } \\
\text { its were arranged as re- } \\
\text { quired on the basis of } \\
\text { the data provided by } \\
\text { telemonitoring or tele- } \\
\text { phone interviews. De- } \\
\text { cisions on hospital re- } \\
\text { admission during fol- } \\
\text { low-up in both groups } \\
\text { were made after consul- } \\
\text { tation with a CHF team } \\
\text { member } \\
\text { ( } \mathrm{n}=29 \text { ) }\end{array}$ & $\begin{array}{l}\text { with additional visits be- } \\
\text { ing arranged whenever } \\
\text { changes in clinical status } \\
\text { made this necessary } \\
(n=28)\end{array}$ & & \\
\hline Apter 2011 & Asthma & $\begin{array}{l}\text { PROBLEM-SOLVING IN- } \\
\text { TERVENTION: Partic- } \\
\text { ipants met with a re- } \\
\text { search co-ordinator for } \\
4 \text { sessions of a prob- } \\
\text { lem-solving (PS)inter- } \\
\text { vention. PS comprised } 4 \\
\text { 30-minute sessions. The } \\
\text { individualized interven- } \\
\text { tion involved } 4 \text { interac- } \\
\text { tive steps, usually } 1 \text { per } \\
\text { research session. For the } \\
\text { 158 participants who re- } \\
\text { ported missing doses of } \\
\text { inhaled corticosteroids } \\
\text { (ICS), the goal was to im- } \\
\text { prove adherence. For the } \\
7 \text { participants who de- } \\
\text { clared adherence to the } \\
\text { prescribed regimen, the } \\
\text { goal was to maintain ad- } \\
\text { herence. The first PS step } \\
\text { consisted of defining the } \\
\text { problem: improving or } \\
\text { preserving adherence } \\
\text { to ICS use within the pa- } \\
\text { tient's unique context } \\
\text { and orientation. Prob- } \\
\text { lem orientation facili- } \\
\text { tated the adoption of a } \\
\text { rational, positive, and } \\
\text { constructive appraisal } \\
\text { of how to achieve ad- } \\
\text { herence, with non-ad- } \\
\text { herence being present- } \\
\text { ed as a problem to be } \\
\text { solved. PS was present- } \\
\text { ed as a means of cop- } \\
\text { ing with problems more } \\
\text { generally and modify- } \\
\text { ing attitudes or beliefs } \\
\text { that inhibit or interfere } \\
\text { with attempts to solve } \\
\text { problems. It was a mo- } \\
\text { tivational technique to } \\
\text { help the participant view } \\
\text { the occurrence of prob- }\end{array}$ & $\begin{array}{l}\text { ASTHMA EDUCATION: } \\
\text { Patients attended } 4 \text { 30- } \\
\text { minute sessions, con- } \\
\text { ducted by a research } \\
\text { co-ordinator. Each ses- } \\
\text { sion was about an asth- } \\
\text { ma education (AE) top- } \\
\text { ic unrelated to self man- } \\
\text { agement, adherence, or } \\
\text { inhaled corticosteroid } \\
\text { (ICS) therapy. The topics } \\
\text { covered, } 1 \text { at each ses- } \\
\text { sion, were the following: } \\
\text { (1) the proper technique } \\
\text { for using an albuterol } \\
\text { rescue metered-dose } \\
\text { inhaler and a dry pow- } \\
\text { der inhaler or spacer, } \\
\text { depending on the pa- } \\
\text { tient's medications; ( } 2 \text { ) } \\
\text { the use of peak flow me- } \\
\text { ters; (3) common asth- } \\
\text { ma triggers; and (4) the } \\
\text { pathophysiology of asth- } \\
\text { ma. These sessions did } \\
\text { not involve discussion of } \\
\text { problem-solving or ad- } \\
\text { herence, only didactic } \\
\text { presentation of health } \\
\text { information } \\
\text { ( } \mathrm{n}=168 \text { ) }\end{array}$ & $\begin{array}{l}\text { No for improvement in } \\
\text { medication adherence }\end{array}$ & $\begin{array}{l}\text { No for improving asth- } \\
\text { ma control, spirometry, } \\
\text { emergency department } \\
\text { visits and hospitaliza- } \\
\text { tions, and asthma-relat- } \\
\text { ed quality of life }\end{array}$ \\
\hline
\end{tabular}




\begin{tabular}{|c|c|c|c|c|c|}
\hline \multicolumn{6}{|c|}{ Adherence and outcome } \\
\hline Study & Clinical problem & Intervention & Control & $\begin{array}{l}\text { Effect on adherence } \\
\text { (Yes means a statis- } \\
\text { tically significant ef- } \\
\text { fect in favor of the } \\
\text { intervention; No } \\
\text { means no effect or } \\
\text { a negative effect) }\end{array}$ & $\begin{array}{l}\text { Effect on clin- } \\
\text { ical outcome } \\
\text { (Yes means a statis- } \\
\text { tically significant ef- } \\
\text { fect in favor of the } \\
\text { intervention; No } \\
\text { means no effect or } \\
\text { a negative effect) }\end{array}$ \\
\hline & & $\begin{array}{l}\text { lems as inevitable, nor- } \\
\text { mal, and solvable. This } \\
\text { first step involved break- } \\
\text { ing problems into small } \\
\text { achievable pieces. The } \\
\text { second step was brain- } \\
\text { storming for alternative } \\
\text { solutions. The third step } \\
\text { was choosing the best } \\
\text { solution by weighing the } \\
\text { consequences, both de- } \\
\text { sirable and undesirable, } \\
\text { of each candidate solu- } \\
\text { tion. Between the third } \\
\text { and 4th meetings, the } \\
\text { solution was tried. For } \\
\text { the } 4 \text { th step, the chosen } \\
\text { solution was evaluated } \\
\text { and revised. As part of } \\
\text { this intervention, down- } \\
\text { loaded data from moni- } \\
\text { tored ICSs were shared } \\
\text { with the participant in } \\
\text { a nonjudgmental fash- } \\
\text { ion at each visit. At these } \\
\text { sessions, subjects fol- } \\
\text { lowed the same PS steps } \\
\text { for addressing an addi- } \\
\text { tional problem of their } \\
\text { own choosing, such as } \\
\text { increasing physical activ- } \\
\text { ity. The problems were } \\
\text { sometimes interrelat- } \\
\text { ed; for example, a father } \\
\text { wants to play sports with } \\
\text { his child, and improving } \\
\text { asthma management } \\
\text { makes this easier } \\
\text { (n = } 165 \text { ) }\end{array}$ & & & \\
\hline Bailey 1990 & Asthma & $\begin{array}{l}\text { Pamphlet, workbook, } \\
\text { counseling, phone fol- } \\
\text { low-up, support group, } \\
\text { and reinforcement of ad- } \\
\text { herence }(n=132)\end{array}$ & $\begin{array}{l}\text { Instructional pamphlet } \\
\text { alone }(n=135)\end{array}$ & Yes & Yes \\
\hline Bailey 1999 & Asthma & $\begin{array}{l}2 \text { intervention groups: } \\
\text { 1) Asthma Self Manage- } \\
\text { ment Program ( } n=78) \text { - } \\
\text { a skill-oriented self help } \\
\text { workbook, which pa- } \\
\text { tients were counseled } \\
\text { about in a one-on-one } \\
\text { session and during } 2 \\
\text { asthma support group } \\
\text { meetings. Patients were } \\
\text { also given peak flow me- } \\
\text { ters and trained to use } \\
\text { them for early detection } \\
\text { of impending asthma } \\
\text { attacks. They also re- } \\
\text { ceived } 2 \text { telephone calls } \\
\text { and a follow-up letter } \\
\text { at } 1,2 \text {, and } 4 \text { weeks, af- } \\
\text { ter the counseling ses- } \\
\text { sion. } 2 \text { ) Core-Elements } \\
\text { Program ( } n=76 \text { ) - a re- } \\
\text { vised, shortened work- } \\
\text { book that was reviewed } \\
\text { in a } 15 \text { to } 20 \text { minutes } \\
\text { one-to-one counseling }\end{array}$ & $\begin{array}{l}\text { Usual education from } \\
\text { their physician, as well } \\
\text { as a standardized set of } \\
\text { pamphlets containing in- } \\
\text { formation about asthma. } \\
\text { No steps were taken to } \\
\text { ensure that patients read } \\
\text { the pamphlets }(n=78)\end{array}$ & $\begin{array}{l}\text { No (medication adher- } \\
\text { ence and inhaler use) }\end{array}$ & $\begin{array}{l}\text { No for all clinical out- } \\
\text { comes (asthma symp- } \\
\text { toms, respiratory illness, } \\
\text { functional impairment, } \\
\text { use of health services }\end{array}$ \\
\hline
\end{tabular}




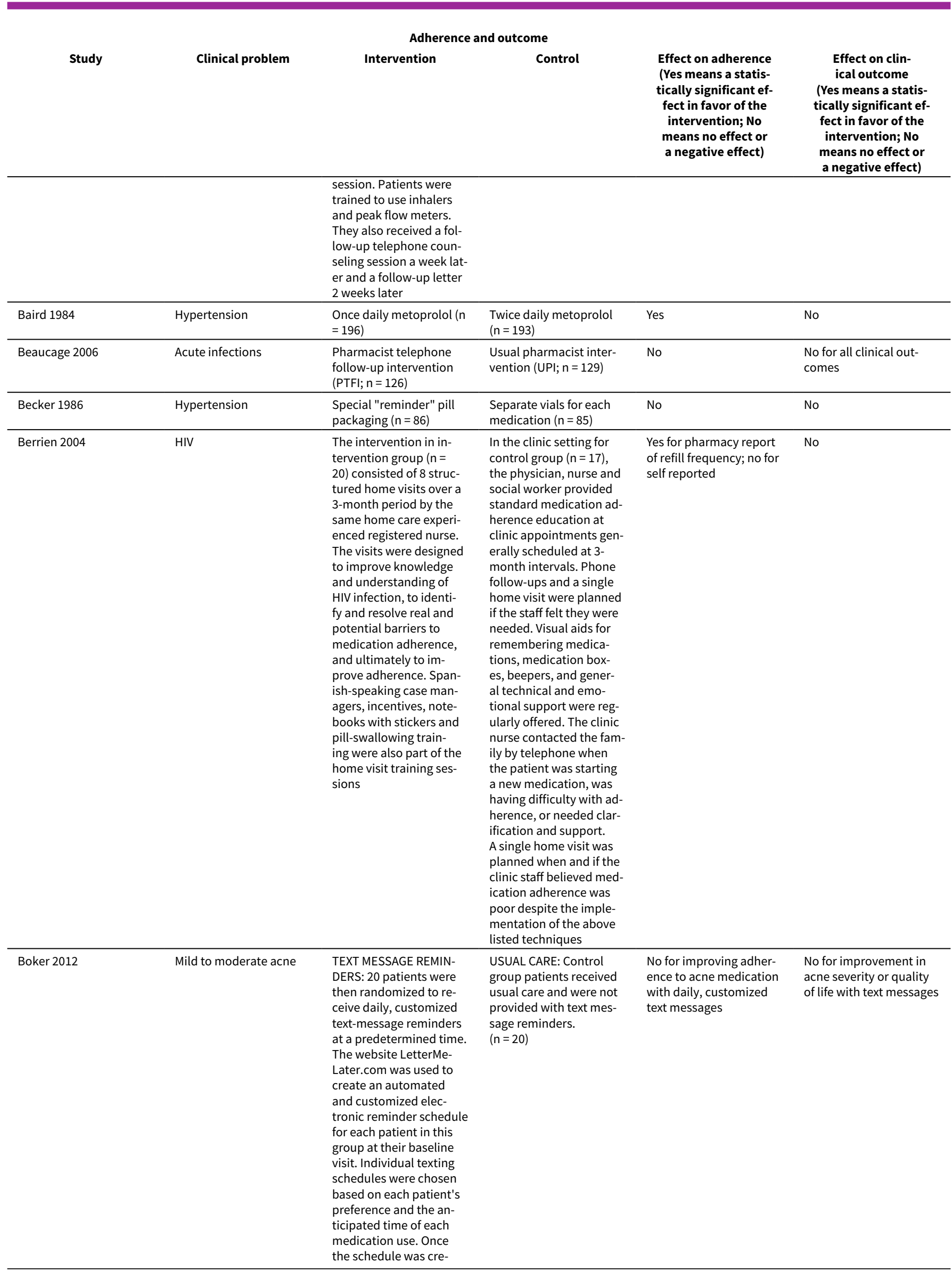




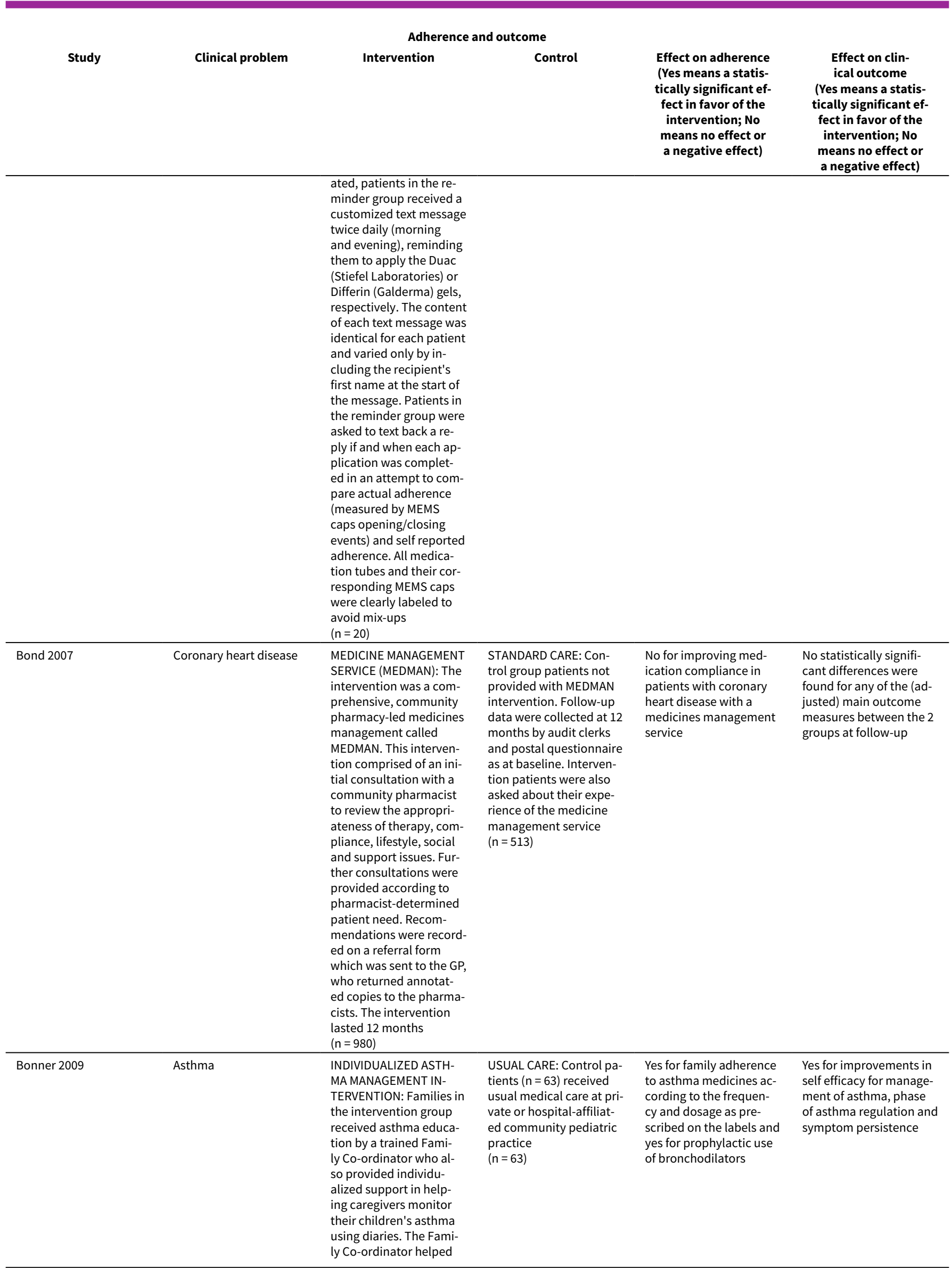




\begin{tabular}{|c|c|c|c|c|c|}
\hline \multicolumn{6}{|c|}{ Adherence and outcome } \\
\hline Study & Clinical problem & Intervention & Control & $\begin{array}{l}\text { Effect on adherence } \\
\text { (Yes means a statis- } \\
\text { tically significant ef- } \\
\text { fect in favor of the } \\
\text { intervention; No } \\
\text { means no effect or } \\
\text { a negative effect) }\end{array}$ & $\begin{array}{l}\text { Effect on clin- } \\
\text { ical outcome } \\
\text { (Yes means a statis- } \\
\text { tically significant ef- } \\
\text { fect in favor of the } \\
\text { intervention; No } \\
\text { means no effect or } \\
\text { a negative effect) }\end{array}$ \\
\hline & & $\begin{array}{l}\text { caregivers interpret the } \\
\text { diaries and communi- } \\
\text { cate the contents to their } \\
\text { doctors. } 3 \text { group edu- } \\
\text { cation workshops were } \\
\text { held at 1-month intervals } \\
\text { that followed the asth- } \\
\text { ma self regulation mod- } \\
\text { el. Families were trained } \\
\text { to use the diaries and } \\
\text { peak flow meters. Family } \\
\text { Co-ordinators regularly } \\
\text { called families to discuss } \\
\text { their diary records. The } \\
\text { second workshop used } \\
\text { patients' diary records } \\
\text { as illustrations of the } \\
\text { relative effectiveness } \\
\text { of controller medicines } \\
\text { over rescue/quick-re- } \\
\text { lief drugs in preventing } \\
\text { asthma symptoms over } \\
\text { time. Participants re- } \\
\text { viewed their own records } \\
\text { of medicines and symp- } \\
\text { toms. The third work- } \\
\text { shop described asthma } \\
\text { management as a two- } \\
\text { pronged effort of phar- } \\
\text { macotherapy and trigger } \\
\text { control. Between the 1st } \\
\text { and } 2 \text { nd workshops, the } \\
\text { Family Co-ordinator pre- } \\
\text { pared families for their } \\
\text { doctor visit. The Fami- } \\
\text { ly Co-ordinator accom- } \\
\text { panied families to the } \\
\text { doctor visit where he in- } \\
\text { tervened if the family } \\
\text { failed to communicate } \\
\text { a thorough asthma his- } \\
\text { tory. The children in the } \\
\text { intervention group were } \\
\text { tested for allergies by } \\
\text { an attending allergist at } \\
\text { the hospital if they had } \\
\text { not recently been tested } \\
\text { by their own physician. } \\
\text { Family Co-ordinator con- } \\
\text { ducted a home environ- } \\
\text { ment assessment and } \\
\text { suggested strategies for } \\
\text { reducing asthma triggers } \\
\text { ( } \mathrm{n}=56 \text { ) }\end{array}$ & & & \\
\hline Brown 1997a & $\begin{array}{l}\text { Hyperlipidemia and } \\
\text { coronary artery disease }\end{array}$ & $\begin{array}{l}\text { Controlled release niacin } \\
\text { twice daily }(n=31)\end{array}$ & $\begin{array}{l}\text { Regular niacin } 4 \text { times a } \\
\text { day }(n=31)\end{array}$ & Yes & Yes \\
\hline Brus 1998 & $\begin{array}{l}\text { Rheumatoid arthritis } \\
\text { (RA) }\end{array}$ & $\begin{array}{l}6 \text { patient education } \\
\text { meetings. The educa- } \\
\text { tion program focused } \\
\text { on compliance with sul- } \\
\text { phasalazine therapy, } \\
\text { physical exercises, en- } \\
\text { durance activities (walk- } \\
\text { ing, swimming, bicy- } \\
\text { cling), advice on energy } \\
\text { conservation, and joint } \\
\text { protection. } 4 \text { (2-hour) } \\
\text { meetings were offered } \\
\text { during the first months. }\end{array}$ & $\begin{array}{l}\text { The control group re- } \\
\text { ceived a brochure on RA, } \\
\text { as provided by the Dutch } \\
\text { League against Rheuma- } \\
\text { tism. This brochure gives } \\
\text { comprehensive infor- } \\
\text { mation on medication, } \\
\text { physical and occupation- } \\
\text { al therapy ( } n=31 \text { ) }\end{array}$ & No & No \\
\hline
\end{tabular}




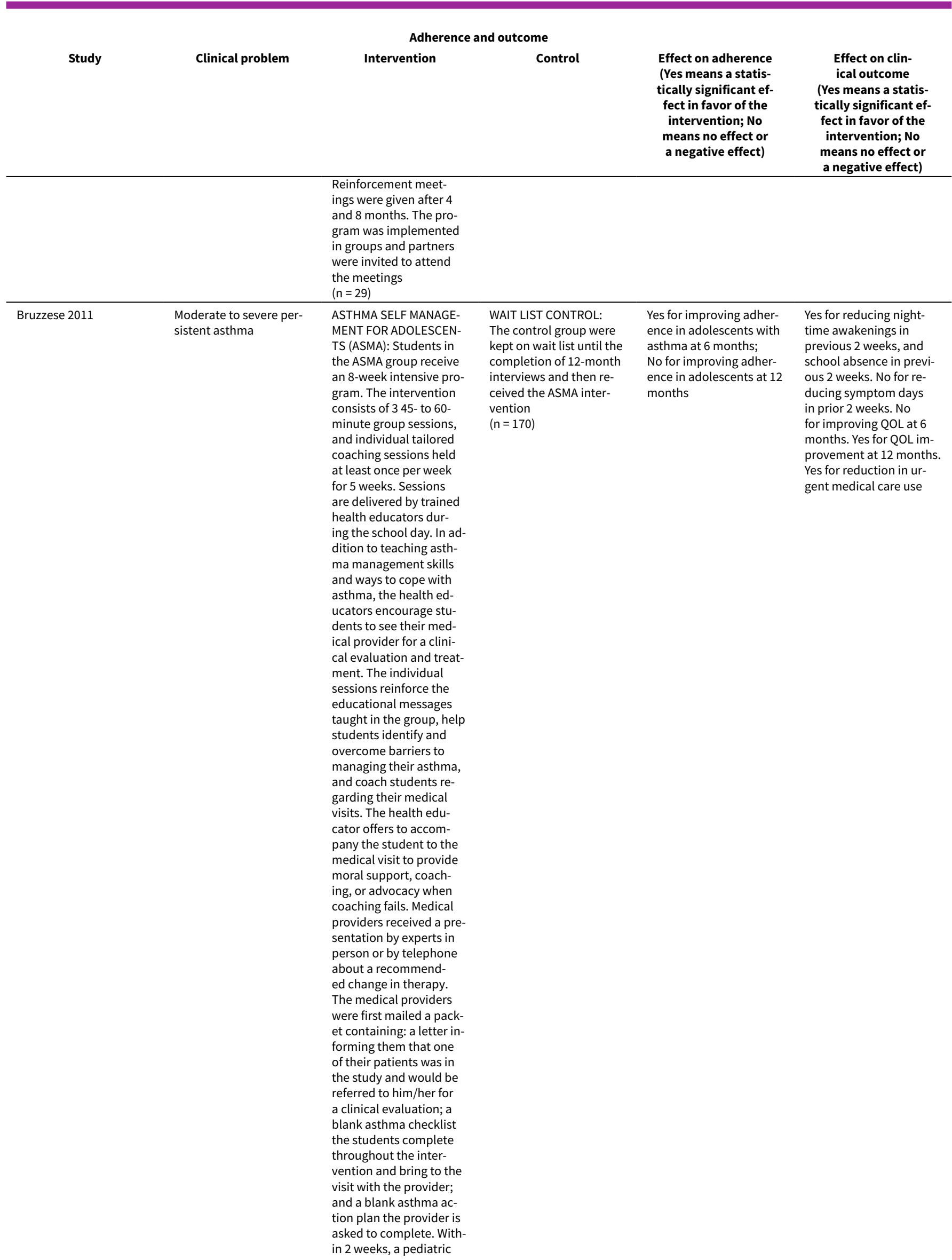




\begin{tabular}{|c|c|c|c|c|c|}
\hline \multicolumn{6}{|c|}{ Adherence and outcome } \\
\hline Study & Clinical problem & Intervention & Control & $\begin{array}{l}\text { Effect on adherence } \\
\text { (Yes means a statis- } \\
\text { tically significant ef- } \\
\text { fect in favor of the } \\
\text { intervention; No } \\
\text { means no effect or } \\
\text { a negative effect) }\end{array}$ & $\begin{array}{l}\text { Effect on clin- } \\
\text { ical outcome } \\
\text { (Yes means a statis- } \\
\text { tically significant ef- } \\
\text { fect in favor of the } \\
\text { intervention; No } \\
\text { means no effect or } \\
\text { a negative effect) }\end{array}$ \\
\hline & & $\begin{array}{l}\text { pulmonologist or adoles- } \\
\text { cent medicine special- } \\
\text { ist called the students' } \\
\text { medical providers to dis- } \\
\text { cuss the concepts pre- } \\
\text { sented in the program } \\
\text { and to answer any ques- } \\
\text { tions regarding NHLBI In- } \\
\text { stitute criteria for treat- } \\
\text { ing asthma } \\
(n=175)\end{array}$ & & & \\
\hline Burgess 2007 & Asthma & $\begin{array}{l}\text { FUNHALER: Patients re- } \\
\text { ceived a Funhaler for } \\
\text { their daily asthma med- } \\
\text { ication. The Funhaler } \\
\text { is a small volume spac- } \\
\text { er that incorporates an } \\
\text { incentive toy (spinning } \\
\text { disk and whistle) that is } \\
\text { driven by the child's ex- } \\
\text { pired breath } \\
(\mathrm{n}=26)\end{array}$ & $\begin{array}{l}\text { CONTROL SPACER: Pa- } \\
\text { tients received a stan- } \\
\text { dard spacer for admin- } \\
\text { istering asthma medica- } \\
\text { tion } \\
(\mathrm{n}=21)\end{array}$ & $\begin{array}{l}\text { No for improving adher- } \\
\text { ence to medication at } 3 \\
\text { months in asthma pa- } \\
\text { tients }\end{array}$ & $\begin{array}{l}\text { No for exacerbations of } \\
\text { asthma. No for reducing } \\
\text { the frequency of wheeze } \\
\text { or cough at } 3 \text { months }\end{array}$ \\
\hline Chamorro 2011 & $\begin{array}{l}\text { Hypertension, dyslipi- } \\
\text { demia, cardiovascular } \\
\text { disease, type } 2 \text { diabetes } \\
\text { and coronary heart dis- } \\
\text { ease }\end{array}$ & $\begin{array}{l}\text { PHARMACOTHERAPY } \\
\text { FOLLOW-UP: The inter- } \\
\text { vention consisted in fol- } \\
\text { low-up of the patients by } \\
\text { the pharmacist. He gave } \\
\text { written and oral informa- } \\
\text { tion about cardiovascu- } \\
\text { lar prevention and ad- } \\
\text { herence to the patients } \\
\text { in the first interview. } \\
\text { The pharmacist adopt- } \\
\text { ed a pharmacothera- } \\
\text { py follow-up program, } \\
\text { for } 4 \text { visits over } 16 \text { to } 18 \\
\text { weeks. The final assess- } \\
\text { ment was at } 32 \text { weeks } \\
(n=44)\end{array}$ & $\begin{array}{l}\text { EDUCATION: This proce- } \\
\text { dure consisted of health } \\
\text { education, written and } \\
\text { oral material all given in } \\
1 \text { session at enrollment } \\
(n=41)\end{array}$ & $\begin{array}{l}\text { No for adherence at } 8 \\
\text { months }\end{array}$ & $\begin{array}{l}\text { No for all clinical health } \\
\text { outcomes }\end{array}$ \\
\hline Chan 2007 & Persistent asthma & $\begin{array}{l}\text { INTERNET-BASED HOME } \\
\text { MONITORING AND ED- } \\
\text { UCATION: Both groups } \\
\text { had } 6 \text { visits scheduled } \\
\text { at } 0,2,6,12,26 \text {, and } 52 \\
\text { weeks, with the study } \\
\text { pediatrician and } 1 \text { of the } \\
4 \text { assigned nurse case } \\
\text { managers or the pedi- } \\
\text { atric clinical pharma- } \\
\text { cist case manager. The } \\
\text { intervention group re- } \\
\text { ceived } 3 \text { in-person visits, } \\
\text { at } 0,26 \text {, and } 52 \text { weeks, } \\
\text { and the rest as virtual } \\
\text { visits. Virtual visits in- } \\
\text { cluded asthma educa- } \\
\text { tion, a video recording } \\
\text { of peak flow meter and } \\
\text { inhaler use forwarded to } \\
\text { the website, daily asth- } \\
\text { ma diaries, and commu- } \\
\text { nication with the case } \\
\text { manager electronical- } \\
\text { ly via the website. Pa- } \\
\text { tients were provided a } \\
\text { home computer system, } \\
\text { camera, and Internet ac- } \\
\text { cess. On-site in-home in- } \\
\text { struction was provided }\end{array}$ & $\begin{array}{l}\text { OFFICE-BASED VISITS: } \\
\text { Patients were treated } \\
\text { with an ambulatory asth- } \\
\text { ma clinical pathway, } \\
\text { with } 6 \text { visits scheduled } 0 \text {, } \\
2,6,12,26 \text {, and } 52 \text { weeks } \\
\text { after enrollment. At each } \\
\text { visit, patients and their } \\
\text { parents received in- } \\
\text { depth asthma educa- } \\
\text { tion from the case man- } \\
\text { ager, with specific sub- } \\
\text { jects being determined } \\
\text { by an asthma education- } \\
\text { al pathway. Office-based } \\
\text { group patients received } \\
\text { all of their information } \\
\text { in person at the pedi- } \\
\text { atric clinic. Patients were } \\
\text { able to contact their case } \\
\text { manager by telephone } \\
\text { ( } \mathrm{n}=60 \text { ) }\end{array}$ & $\begin{array}{l}\text { No for improving asth- } \\
\text { ma controller medica- } \\
\text { tion adherence with in- } \\
\text { ternet-based patient ed- } \\
\text { ucation and home mon- } \\
\text { itoring for children with } \\
\text { asthma }\end{array}$ & $\begin{array}{l}\text { No for rescue medica- } \\
\text { tion use or emergency } \\
\text { visits, symptoms, asth- } \\
\text { ma knowledge and in- } \\
\text { haler technique }\end{array}$ \\
\hline
\end{tabular}




\begin{tabular}{|c|c|c|c|c|c|}
\hline \multicolumn{6}{|c|}{ Adherence and outcome } \\
\hline Study & Clinical problem & Intervention & Control & $\begin{array}{l}\text { Effect on adherence } \\
\text { (Yes means a statis- } \\
\text { tically significant ef- } \\
\text { fect in favor of the } \\
\text { intervention; No } \\
\text { means no effect or } \\
\text { a negative effect) }\end{array}$ & $\begin{array}{l}\text { Effect on clin- } \\
\text { ical outcome } \\
\text { (Yes means a statis- } \\
\text { tically significant ef- } \\
\text { fect in favor of the } \\
\text { intervention; No } \\
\text { means no effect or } \\
\text { a negative effect) }\end{array}$ \\
\hline & & 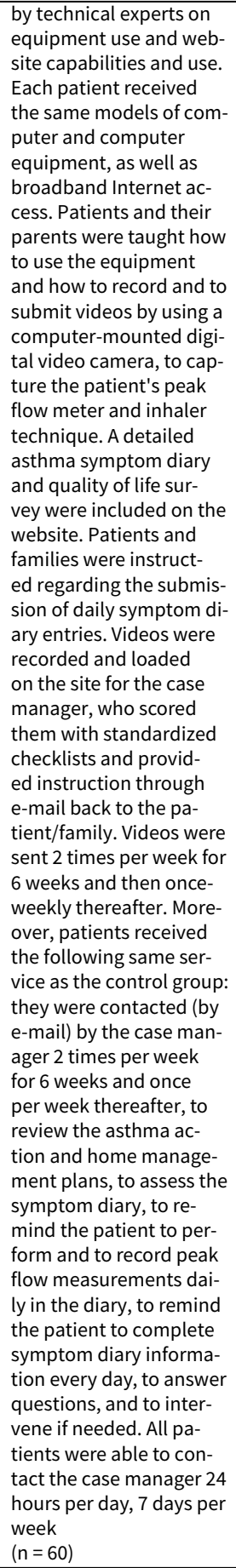 & & & \\
\hline Chaplin 1998 & Schizophrenia & $\begin{array}{l}\text { Individual semi-struc- } \\
\text { tured educational ses- } \\
\text { sions discussing the ben- } \\
\text { efits and adverse effects } \\
\text { of antipsychotic drugs, }\end{array}$ & Usual care $(\mathrm{n}=28)$ & No & No \\
\hline
\end{tabular}




\begin{tabular}{|c|c|c|c|c|c|}
\hline \multicolumn{6}{|c|}{ Adherence and outcome } \\
\hline Study & Clinical problem & Intervention & Control & $\begin{array}{l}\text { Effect on adherence } \\
\text { (Yes means a statis- } \\
\text { tically significant ef- } \\
\text { fect in favor of the } \\
\text { intervention; No } \\
\text { means no effect or } \\
\text { a negative effect) }\end{array}$ & $\begin{array}{l}\text { Effect on clin- } \\
\text { ical outcome } \\
\text { (Yes means a statis- } \\
\text { tically significant ef- } \\
\text { fect in favor of the } \\
\text { intervention; No } \\
\text { means no effect or } \\
\text { a negative effect) }\end{array}$ \\
\hline & & $\begin{array}{l}\text { including tardive dyski- } \\
\text { nesia }(n=28)\end{array}$ & & & \\
\hline Charles 2007 & Asthma & $\begin{array}{l}\text { AUDIOVISUAL REMIN- } \\
\text { DER: The intervention } \\
\text { was an audiovisual re- } \\
\text { minder attached to the } \\
\text { inhaler. When the alarm } \\
\text { was switched on, it gen- } \\
\text { erated a single beep, } \\
\text { which sounded once } \\
\text { every } 30 \text { seconds for } 60 \\
\text { minutes after the pre- } \\
\text { designated time, which } \\
\text { was programmed into } \\
\text { the device. The alarm } \\
\text { stopped if the MDI was } \\
\text { actuated or after } 60 \text { min- } \\
\text { utes if not taken. The de- } \\
\text { vice was programmed to } \\
\text { emit the alarm at prede- } \\
\text { termined times twice a } \\
\text { day. The AVRF also had a } \\
\text { colored light, which was } \\
\text { green before MDI use, } \\
\text { changing to red once } \\
\text { the MDI was taken. This } \\
\text { function served to re- } \\
\text { mind patients whether } \\
\text { they had taken the MDI } \\
\text { as scheduled. Follow-up } \\
\text { period was } 12 \text { weeks } \\
\text { ( } \mathrm{n}=55 \text { ) }\end{array}$ & $\begin{array}{l}\text { SMART INHALER: Control } \\
\text { participants received the } \\
\text { same Smartinhaler as in- } \\
\text { tervention participants, } \\
\text { but it did not have the } \\
\text { audiovisual reminder de- } \\
\text { vice } \\
(n=55)\end{array}$ & $\begin{array}{l}\text { Yes for improving adher- } \\
\text { ence to inhalers in adults } \\
\text { and adolescents with } \\
\text { asthma with an audiovi- } \\
\text { sual reminder }\end{array}$ & $\begin{array}{l}\text { No for improving clini- } \\
\text { cal outcomes with an au- } \\
\text { diovisual timer device } \\
\text { for inhalers in asthmatic } \\
\text { adults and adolescents }\end{array}$ \\
\hline Choudhry 2011 & $\begin{array}{l}\text { Myocardial infarction or } \\
\text { coronary artery disease }\end{array}$ & $\begin{array}{l}\text { FULL PRESCRIPTION } \\
\text { COVERAGE: The inter- } \\
\text { vention involved chang- } \\
\text { ing the pharmacy bene- } \\
\text { fits of the intervention } \\
\text { group patients so that } \\
\text { they had no cost sharing } \\
\text { for any brand or gener- } \\
\text { ic statin, beta-blocker, } \\
\text { ACE inhibitor or ARB for } \\
\text { every prescription after } \\
\text { randomization } \\
(\mathrm{n}=2845)\end{array}$ & $\begin{array}{l}\text { USUAL PRESCRIPTION } \\
\text { COVERAGE: Control pa- } \\
\text { tients received usual pre- } \\
\text { scription-drug coverage } \\
(\mathrm{n}=3010)\end{array}$ & $\begin{array}{l}\text { Yes for improving ad- } \\
\text { herence to prevention } \\
\text { medications after MI by } \\
\text { providing full coverage } \\
\text { pharmacy plans }\end{array}$ & $\begin{array}{l}\text { Yes for reduction in } \\
\text { health expenditure and } \\
\text { improving rates of first } \\
\text { major vascular events }\end{array}$ \\
\hline Chung 2011 & HIV & $\begin{array}{l}\text { COUNSELING: In the ad- } \\
\text { herence counseling in- } \\
\text { tervention, trained coun- } \\
\text { selors administered } 2 \\
\text { counseling sessions to } \\
\text { participants prior to } \\
\text { HAART initiation and a } \\
\text { third session } 1 \text { month } \\
\text { after HAART initiation. } \\
\text { Counseling sessions } \\
\text { around HAART initiation } \\
\text { were based on a model } \\
\text { of successful antiretro- } \\
\text { viral adherence promo- } \\
\text { tion at a large University } \\
\text { of Washington-affiliated } \\
\text { HIV treatment program } \\
\text { in Seattle, Washington. } \\
\text { All counseling sessions } \\
\text { followed a written stan- } \\
\text { dardized protocol and } \\
\text { lasted between } 30 \text { and } \\
45 \text { minutes. In the first } \\
\text { session, counselors ex- }\end{array}$ & $\begin{array}{l}\text { USUAL CARE: "At HAART } \\
\text { initiation, the study } \\
\text { pharmacist explained } \\
\text { the side effects of med- } \\
\text { ications and problems } \\
\text { associated with poor ad- } \\
\text { herence in a 15-min ses- } \\
\text { sion prior to dispensing } \\
\text { drugs. All participants, } \\
\text { including those in the } \\
\text { control arm, received } \\
\text { this educational mes- } \\
\text { sage. Participants ran- } \\
\text { domized to the control } \\
\text { group did not receive ad- } \\
\text { herence counseling or an } \\
\text { alarm device." (pg 2-3) } \\
\text { ( } \mathrm{n}=100 \text { ) }\end{array}$ & $\begin{array}{l}\text { Yes for improving adher- } \\
\text { ence to medication at } 1 \\
\text { month in the counsel- } \\
\text { ing group; No for improv- } \\
\text { ing adherence to med- } \\
\text { ication at } 18 \text { months in } \\
\text { counseling group; No for } \\
\text { improving adherence to } \\
\text { HAART in alarm group at } \\
\text { any time point }\end{array}$ & $\begin{array}{l}\text { Yes for reducing viral fail- } \\
\text { ure in counseling group. } \\
\text { No for improving mor- } \\
\text { tality and CD4 cell count } \\
\text { in counseling group. No } \\
\text { for reducing viral failure, } \\
\text { CD4 cell count and mor- } \\
\text { tality in alarm group }\end{array}$ \\
\hline
\end{tabular}


Adherence and outcome

Intervention

Control

\section{Effect on adherence \\ (Yes means a statis- tically significant ef- \\ fect in favor of the \\ intervention; No \\ means no effect or \\ a negative effect)}

Effect on clin-

ical outcome

(Yes means a statis-

tically significant ef

fect in favor of the

intervention; No

means no effect or a negative effect)

and taught participants about HIV, the virus that causes AIDS, antiretrovi-

ral medications, and the

risks of treatment failure

due to poor adherence.

The second session oc-

curred on a separate day

and involved a review

of a participant's un-

derstanding and readi-

ness to begin antiretro-

viral medications. The

third session allowed the

counselor to examine

practical and personal is

sues that the participant

may have encountered

on HAART. The adher-

ence counseling inter-

vention had been previ-

ously used and adapted

at the same site in Kenya

for over 2 years and was

delivered in English and

Kiswahili

$(\mathrm{n}=100)$

COUNSELING PLUS

ALARM: Participants in

counseling plus alarm

group received both ad-

herence counseling and

alarm reminders. 3 ad

herence counseling ses-

sions (2 prior to HAART

initiation and 1 after

HAART initiation) were

conducted. All counsel-

ing sessions followed

a written standardized

protocol and lasted be-

tween 30 and 45 min-

utes. In the first session,

counselors explored per-

sonal barriers to good

adherence and taught

participants about the

HIV, the virus that causes

AIDS, antiretroviral med-

ications, and the risks

of treatment failure due

to poor adherence. The

2nd session occurred on

a separate day and in-

volved a review of a par-

ticipant's understanding

and readiness to begin

antiretroviral medica-

tions. The 3rd session al-

lowed the counselor to

examine practical and

personal issues that the

participant may have

encountered on HAART.

The counseling session

was delivered in English

and Kiswahili. In addi- 


\begin{tabular}{|c|c|c|c|c|c|}
\hline \multicolumn{6}{|c|}{ Adherence and outcome } \\
\hline Study & Clinical problem & Intervention & Control & $\begin{array}{l}\text { Effect on adherence } \\
\text { (Yes means a statis- } \\
\text { tically significant ef- } \\
\text { fect in favor of the } \\
\text { intervention; No } \\
\text { means no effect or } \\
\text { a negative effect) }\end{array}$ & $\begin{array}{l}\text { Effect on clin- } \\
\text { ical outcome } \\
\text { (Yes means a statis- } \\
\text { tically significant ef- } \\
\text { fect in favor of the } \\
\text { intervention; No } \\
\text { means no effect or } \\
\text { a negative effect) }\end{array}$ \\
\hline & & $\begin{array}{l}\text { tion, participants were } \\
\text { given a small pocket dig- } \\
\text { ital alarm, which the in- } \\
\text { dividual was to carry at } \\
\text { all times for } 6 \text { months. } \\
\text { The device was pro- } \\
\text { grammed by the study } \\
\text { staff to beep and flash } \\
\text { twice a day at a time } \\
\text { convenient to the partic- } \\
\text { ipant when medications } \\
\text { were to be taken. The } \\
\text { digital alarm could not } \\
\text { be reprogrammed or in- } \\
\text { activated by the individ- } \\
\text { ual and was utilized for } 6 \\
\text { months after HAART ini- } \\
\text { tiation before being dis- } \\
\text { abled by study staff } \\
\text { ( } \mathrm{n}=100 \text { ) }\end{array}$ & & & \\
\hline & & $\begin{array}{l}\text { ALARM DEVICE: Partici- } \\
\text { pants in the alarm device } \\
\text { intervention received } \\
\text { a small pocket digital } \\
\text { alarm which the individ- } \\
\text { ual was to carry at all } \\
\text { times for } 6 \text { moths dura- } \\
\text { tion. The device was pro- } \\
\text { grammed by the study } \\
\text { staff to beep and flash } \\
\text { twice a day at a time } \\
\text { convenient to the partic- } \\
\text { ipant when medications } \\
\text { were to be taken. The } \\
\text { digital alarm could not } \\
\text { be reprogrammed or in- } \\
\text { activated by the individ- } \\
\text { ual and was utilized for } 6 \\
\text { months after HAART ini- } \\
\text { tiation before being dis- } \\
\text { abled by study staff } \\
\text { ( } \mathrm{n}=100 \text { ) }\end{array}$ & & & \\
\hline Colcher 1972 & Strep throat & $\begin{array}{l}\text { Special counseling and } \\
\text { written instructions on } \\
\text { need to take all pills ( } n= \\
100 \text { ) }\end{array}$ & Usual care $(n=100)$ & Yes & Yes \\
\hline Collier 2005 & HIV & $\begin{array}{l}\text { Serial, scripted, and sup- } \\
\text { portive telephone calls } \\
\text { from a nurse plus usu- } \\
\text { al adherence support } \\
\text { (same as control group; } \\
\mathrm{n}=142 \text { ) }\end{array}$ & $\begin{array}{l}\text { Usual support measures } \\
\text { including in-person } \\
\text { counseling by a nurse at } \\
\text { start of therapy and dis- } \\
\text { cretionary phone calls ( } \mathrm{n} \\
=140 \text { ) }\end{array}$ & No & No \\
\hline Cooper 2010 & HIV & $\begin{array}{l}\text { ONCE NIGHTLY REGI- } \\
\text { MEN: Patients in the } \\
\text { once nightly regimen } \\
\text { group received } 1 \times \text { di- } \\
\text { danosine (DDI) en- } \\
\text { teric-coated (EC) cap- } \\
\text { sule } 400 \mathrm{mg}(250 \mathrm{mg} \text { if } \\
\text { weight less than } 60 \mathrm{~kg} \text { ), } \\
2 \times \text { lamivudine (3TC) } 150 \\
\text { mg tablet, } 1 \times \text { efavirenz } \\
\text { (Sustiva) } 600 \mathrm{mg} \text { tablet } \\
\text { each evening } \\
(\mathrm{n}=44)\end{array}$ & $\begin{array}{l}\text { TWICE DAILY REGIMEN: } \\
\text { Patients in the control } \\
\text { group received Combivir } \\
\text { (zidovudine } 300 \mathrm{mg}+ \\
\text { 3TC } 150 \mathrm{mg} \text { ): } 1 \text { tablet } \\
\text { twice daily, } 1 \text { x efavirenz } \\
600 \mathrm{mg} \text { tablet taken } \\
\text { nightly } \\
(\mathrm{n}=43)\end{array}$ & $\begin{array}{l}\text { Yes for improving adher- } \\
\text { ence with HAART with } \\
\text { once nightly dosing ver- } \\
\text { sus twice daily dosing }\end{array}$ & $\begin{array}{l}\text { Yes for viral load unde- } \\
\text { tectable; No for HAART } \\
\text { beliefs and intrusiveness }\end{array}$ \\
\hline
\end{tabular}




\section{Adherence and outcome}

Intervention
Effect on adherence

(Yes means a statis-

tically significant ef-

fect in favor of the

intervention; No

means no effect or

a negative effect) disciplinary interven-

tion consisted of clini-

cal follow-up, smoking

cessation assistance,

dietary advice and life

style modification ad-

vice. The intervention

was delivered by a team

consisting of an endocri-

nologist, a cardiolo-

gist, a nurse and a dieti-

cian. There were 2 fol-

low-up assessment - at

60 to 90 days after MI

and 120 to 180 days after

MI. In diabetic patients,

capillary glycemia was

measured (Advantage

reagent strips, Roche, In

dianapolis, IN, USA), low-

er limbs were examined,

and adherence to pre-

scribed oral antidiabetic

agents and insulin was

reviewed. Those patients

who were still smokin

were advised to stop

smoking by the nurse

and also by the cardiolo-

gist. No oral medication

was prescribed in this re-

gard since these drugs

are not routinely provid-

ed by the Public Health

System in Brazil. After

the above-described

procedures, the dietitian

evaluated body weight

and performed a nutri-

tional review. This re-

view was followed by re-

inforcement of healthy

nutritional habits, which

included information

on the characteristics

and amount of healthy

meals according to each

case and also lifestyle

modification reinforce-

ment. The management

plan was formulated as

an individualized thera-

peutic alliance among

the patient and fami-

ly, the physician, and

other members of the

health care team. Final-

ly, patients were evalu-

ated by the cardiologist,

who completed the vis-

it with the specific med-

ical history, physical ex-

amination and specific

complementary tests.

Drug prescription by the

cardiologist followed

the AHA guidelines for

both groups (statins,

antiplatelet therapy,

beta-blockers and an- received regular care.

Before discharge, they

were visited by a dietit-

ian who prescribed a

post-discharge diet plan

after nutritional evalua-

tion. Then they were re-

ferred to the convention

al outpatient clinic for

heart care, where the pa-

tients were seen only by

the appointed cardiolo-

gist. Cardiologists kept

routine schedule with

the patients and were

seen for no more than 15

minutes. Then these par-

ticipants were asked to

be present at the clinic

180 days after AMI to per-

form a clinical examina-

tion and to obtain blood

samples

$(n=75)$

patients after myocardial

infarction

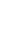

index; No for reduction

in rate of hospitaliza-

tion and deaths; Yes for increasing compliance with diet; Yes for improving compliance with visits 


\begin{tabular}{|c|c|c|c|c|c|}
\hline \multicolumn{6}{|c|}{ Adherence and outcome } \\
\hline Study & Clinical problem & Intervention & Control & $\begin{array}{l}\text { Effect on adherence } \\
\text { (Yes means a statis- } \\
\text { tically significant ef- } \\
\text { fect in favor of the } \\
\text { intervention; No } \\
\text { means no effect or } \\
\text { a negative effect) }\end{array}$ & $\begin{array}{l}\text { Effect on clin- } \\
\text { ical outcome } \\
\text { (Yes means a statis- } \\
\text { tically significant ef- } \\
\text { fect in favor of the } \\
\text { intervention; No } \\
\text { means no effect or } \\
\text { a negative effect) }\end{array}$ \\
\hline & & $\begin{array}{l}\text { giotensin-converting en- } \\
\text { zyme inhibitors). Diabet- } \\
\text { ic patients were evalu- } \\
\text { ated by an endocrinolo- } \\
\text { gist. Drug prescription } \\
\text { by the endocrinologist } \\
\text { followed the American } \\
\text { Diabetes Association } \\
\text { (ADA) guidelines for both } \\
\text { groups } \\
\text { ( } n=78)\end{array}$ & & & \\
\hline Cote 1997 & Asthma & $\begin{array}{l}\text { Extensive asthma educa- } \\
\text { tion program plus writ- } \\
\text { ten self managed action } \\
\text { plan based on peak ex- } \\
\text { piratory flow (PEF) ( } \mathrm{n}= \\
50 \text { ) or based on asthma } \\
\text { symptom monitoring ( } \mathrm{n} \\
=45 \text { ) }\end{array}$ & $\begin{array}{l}\text { Basic information pro- } \\
\text { vided plus verbal action } \\
\text { plan could be given by } \\
\text { physician }(n=54)\end{array}$ & No for each intervention & No for each intervention \\
\hline Cote 2001 & Asthma & $\begin{array}{l}\text { Patients in Group Lim- } \\
\text { ited Education (LE) (n } \\
=30 \text { ) were given a self } \\
\text { action plan that was ex- } \\
\text { plained by the on call } \\
\text { physician. The action } \\
\text { plan used "traffic light- } \\
\text { s" (green, yellow, red) to } \\
\text { describe specific states } \\
\text { of asthma control based } \\
\text { on peak expiratory flow } \\
\text { and symptoms and ac- } \\
\text { tions that the patient } \\
\text { should take for each } \\
\text { state. Subjects were all } \\
\text { instructed by a respira- } \\
\text { tory therapist or study } \\
\text { nurse in the proper use } \\
\text { of an inhaler. In addi- } \\
\text { tion to what patients in } \\
\text { Group LE received, the } \\
\text { patients in Group Struc- } \\
\text { tured Education (SE } n \\
=33 \text { ) participated in a } \\
\text { structured asthma edu- } \\
\text { cational program based } \\
\text { on the PRECEDE mod- } \\
\text { el of health education } \\
\text { within } 2 \text { weeks after their } \\
\text { randomization }\end{array}$ & $\begin{array}{l}\text { The patients in Group } \mathrm{C} \\
\text { (control, } \mathrm{n}=35 \text { ) received } \\
\text { the usual treatment giv- } \\
\text { en for an acute asthma } \\
\text { exacerbation }\end{array}$ & No & No \\
\hline Coull 2004 & Ischemic heart disease & $\begin{array}{l}\text { Intervention consist- } \\
\text { ed of participation in a } \\
\text { mentor-led group ( } \mathrm{n}= \\
\text { 165), through attend- } \\
\text { ing monthly 2-hour long } \\
\text { meetings in communi- } \\
\text { ty facilities over a 1-year } \\
\text { period. There was an } \\
\text { average of } 10 \text { patients } \\
\text { per group, each led by } 2 \\
\text { mentors. The core activ- } \\
\text { ities covered in the pro- } \\
\text { gram were lifestyle risk } \\
\text { factors of smoking, di- } \\
\text { et and exercise; blood } \\
\text { pressure and choles- } \\
\text { terol; understanding of } \\
\text { and ability to cope with } \\
\text { IHD; and drug concor- } \\
\text { dance. Each mentored }\end{array}$ & $\begin{array}{l}\text { Both intervention and } \\
\text { control groups }(n=154) \\
\text { continued to receive } \\
\text { standard care }\end{array}$ & Yes & No \\
\hline
\end{tabular}




\begin{tabular}{|c|c|c|c|c|c|}
\hline \multicolumn{6}{|c|}{ Adherence and outcome } \\
\hline Study & Clinical problem & Intervention & Control & $\begin{array}{l}\text { Effect on adherence } \\
\text { (Yes means a statis- } \\
\text { tically significant ef- } \\
\text { fect in favor of the } \\
\text { intervention; No } \\
\text { means no effect or } \\
\text { a negative effect) }\end{array}$ & $\begin{array}{l}\text { Effect on clin- } \\
\text { ical outcome } \\
\text { (Yes means a statis- } \\
\text { tically significant ef- } \\
\text { fect in favor of the } \\
\text { intervention; No } \\
\text { means no effect or } \\
\text { a negative effect) }\end{array}$ \\
\hline & & $\begin{array}{l}\text { group was also encour- } \\
\text { aged to develop its own } \\
\text { agenda. Input was pro- } \\
\text { vided from a pharma- } \\
\text { cist, cardiac rehabilita- } \\
\text { tion specialist nurse, di- } \\
\text { etician, welfare benefits } \\
\text { advisor and Recreation } \\
\text { Services. Volunteer lay } \\
\text { health mentors, aged } 54 \\
\text { to } 74 \text { recruited from the } \\
\text { local community led the } \\
\text { groups }\end{array}$ & & & \\
\hline Dejesus 2009 & HIV/AIDS & $\begin{array}{l}\text { SINGLE TABLET REGI- } \\
\text { MEN (EFV/FTC/TDF): In- } \\
\text { tervention group pa- } \\
\text { tients were prescribed } \\
\text { a single-tablet regimen } \\
\text { consisting of efavirenz/ } \\
\text { emtricitabine/tenofovir } \\
\text { disoproxil fumarate } \\
\text { (EFV/FTC/TDF) } \\
\text { ( } n=203)\end{array}$ & $\begin{array}{l}\text { ART: Control group pa- } \\
\text { tients were prescribed } \\
\text { regular multi-drug ART } \\
(n=97)\end{array}$ & $\begin{array}{l}\text { No for change in adher- } \\
\text { ence to medication in } \\
\text { EFV/FTC/TDF arm and } \\
\text { SBR arm at } 48 \text { weeks }\end{array}$ & $\begin{array}{l}\text { No for improving QOL; } \\
\text { Yes for improving prefer- } \\
\text { ence of medication and } \\
\text { ease of the regimen; Yes } \\
\text { for HIV symptom index }\end{array}$ \\
\hline Dilorio 2008 & HIV & $\begin{array}{l}\text { MOTIVATIONAL INTER- } \\
\text { VIEWING: Intervention } \\
\text { group receives usual ad- } \\
\text { herence education and } \\
\text { motivational interview. } \\
\text { Participants received } 5 \\
\text { individual MI counsel- } \\
\text { ing sessions with a study } \\
\text { nurse counselor over a 3- } \\
\text { month period. The goal } \\
\text { of these sessions was to } \\
\text { help participants gain an } \\
\text { understanding of their } \\
\text { medication-taking be- } \\
\text { haviors and the actions } \\
\text { necessary to successful- } \\
\text { ly maintain a high level } \\
\text { of adherence. The coun- } \\
\text { selor used a MI script to } \\
\text { guide the interaction } \\
\text { with the participants. } \\
\text { During the session par- } \\
\text { ticipants were encour- } \\
\text { aged to identify and dis- } \\
\text { cuss barriers to adher- } \\
\text { ence, to express and re- } \\
\text { solve ambivalence about } \\
\text { taking medications, and } \\
\text { to support motivation } \\
\text { to attain or maintain ad- } \\
\text { herence. After each med- } \\
\text { ication was discussed } \\
\text { and an action plan de- } \\
\text { veloped, the counselor } \\
\text { ended each session by } \\
\text { summarizing the discus- } \\
\text { sion and the action plan } \\
\text { agreed upon by the par- } \\
\text { ticipant and counselor. } \\
\text { Session } 1 \text { was complet- } \\
\text { ed in-person for all par- } \\
\text { ticipants. Telephone } \\
\text { sessions (for sessions } 2 \\
\text { though 5) were conduct- } \\
\text { ed as needed for par- } \\
\text { ticipants who were un- }\end{array}$ & $\begin{array}{l}\text { CONTROL: Participants } \\
\text { randomized to the con- } \\
\text { trol group received the } \\
\text { usual adherence educa- } \\
\text { tion provided at the clin- } \\
\text { ic. } 3 \text { nurse educators em- } \\
\text { ployed at the HIV clin- } \\
\text { ic provided comprehen- } \\
\text { sive adherence educa- } \\
\text { tion to patients who are } \\
\text { initiating or changing } \\
\text { ART. They use a variety of } \\
\text { teaching methods that } \\
\text { were tailored for each in- } \\
\text { dividual based on factors } \\
\text { such as education level, } \\
\text { culture, type of regimen } \\
\text { and time schedule. Pa- } \\
\text { tients were referred to } \\
\text { the Get Busy Living staff } \\
\text { when the nurse educa- } \\
\text { tors cleared them to be- } \\
\text { gin taking their medica- } \\
\text { tions. Participants could } \\
\text { continue to meet with } \\
\text { the nurse educators for } \\
\text { adherence assistance as } \\
\text { needed after the initial } \\
\text { education sessions } \\
\text { ( } \mathrm{n}=122 \text { ) }\end{array}$ & $\begin{array}{l}\text { Yes for the per cent of } \\
\text { prescribed doses taken } \\
\text { on schedule; No for the } \\
\text { per cent of doses taken }\end{array}$ & $\begin{array}{l}\text { No for viral load and CD4 } \\
\text { count }\end{array}$ \\
\hline
\end{tabular}




\begin{tabular}{|c|c|c|c|c|c|}
\hline \multicolumn{6}{|c|}{ Adherence and outcome } \\
\hline Study & Clinical problem & Intervention & Control & $\begin{array}{l}\text { Effect on adherence } \\
\text { (Yes means a statis- } \\
\text { tically significant ef- } \\
\text { fect in favor of the } \\
\text { intervention; No } \\
\text { means no effect or } \\
\text { a negative effect) }\end{array}$ & $\begin{array}{l}\text { Effect on clin- } \\
\text { ical outcome } \\
\text { (Yes means a statis- } \\
\text { tically significant ef- } \\
\text { fect in favor of the } \\
\text { intervention; No } \\
\text { means no effect or } \\
\text { a negative effect) }\end{array}$ \\
\hline & & $\begin{array}{l}\text { able to meet the coun- } \\
\text { selor in the clinic. Par- } \\
\text { ticipants were paid USD } \\
10 \text { for completing the } \\
\text { first MI session and USD } \\
5 \text { for each of the remain- } \\
\text { ing } 4 \text { sessions. Partici- } \\
\text { pants in the intervention } \\
\text { group also received a } \\
\text { copy of the Get Busy Liv- } \\
\text { ing video, a journal and } \\
\text { a calendar } \\
\text { ( } \mathrm{n}=125 \text { ) }\end{array}$ & & & \\
\hline Druss 2010 & Serious mental illness & 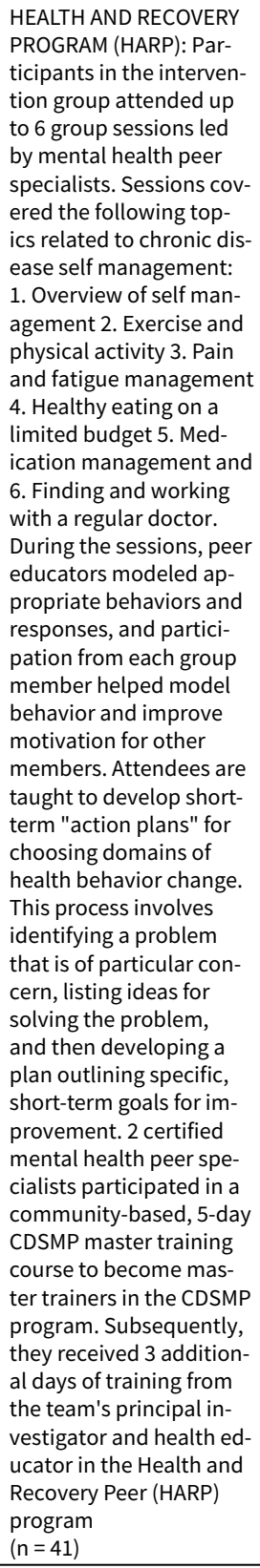 & $\begin{array}{l}\text { USUAL CARE: Subjects } \\
\text { assigned to usual care } \\
\text { continued to receive all } \\
\text { medical, mental health, } \\
\text { and peer-based services } \\
\text { that they were otherwise } \\
\text { receiving prior to entry } \\
\text { into the study } \\
(n=39)\end{array}$ & $\begin{array}{l}\text { No for improving ad- } \\
\text { herence to medica- } \\
\text { tion in patients with se- } \\
\text { vere mental illness at } 6 \\
\text { months }\end{array}$ & $\begin{array}{l}\text { Yes for improving patient } \\
\text { activation and primary } \\
\text { care medical services } \\
\text { use at } 6 \text { months. No for } \\
\text { improving physical ac- } \\
\text { tivity, physical health- } \\
\text { related quality of life, } \\
\text { and mental health-re- } \\
\text { lated quality of life at } 6 \\
\text { months }\end{array}$ \\
\hline
\end{tabular}




\begin{tabular}{|c|c|c|c|c|c|}
\hline \multicolumn{6}{|c|}{ Adherence and outcome } \\
\hline Study & Clinical problem & Intervention & Control & $\begin{array}{l}\text { Effect on adherence } \\
\text { (Yes means a statis- } \\
\text { tically significant ef- } \\
\text { fect in favor of the } \\
\text { intervention; No } \\
\text { means no effect or } \\
\text { a negative effect) }\end{array}$ & $\begin{array}{l}\text { Effect on clin- } \\
\text { ical outcome } \\
\text { (Yes means a statis- } \\
\text { tically significant ef- } \\
\text { fect in favor of the } \\
\text { intervention; No } \\
\text { means no effect or } \\
\text { a negative effect) }\end{array}$ \\
\hline Duncan 2012 & HIV & 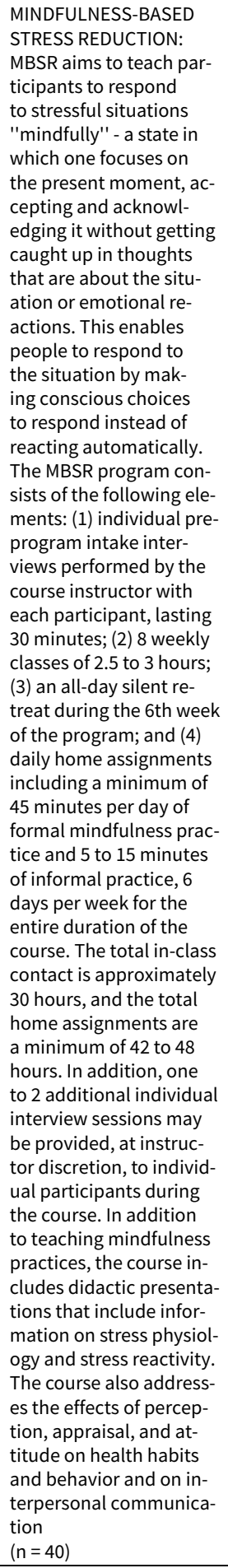 & $\begin{array}{l}\text { STANDARD CARE: Con- } \\
\text { trol group received stan- } \\
\text { dard care and went } \\
\text { through the same as- } \\
\text { sessment procedure as } \\
\text { the intervention group } \\
(n=36)\end{array}$ & $\begin{array}{l}\text { No for improving med- } \\
\text { ication adherence in HIV } \\
\text { patients with Mindful- } \\
\text { ness Based Stress reduc- } \\
\text { tion Therapy at } 3 \text { or } 6 \\
\text { months }\end{array}$ & $\begin{array}{l}\text { Yes for reducing frequen- } \\
\text { cy of symptoms attrib- } \\
\text { utable to ARTs at } 3 \text { and } \\
6 \text { months and distress } \\
\text { associated with those } \\
\text { symptoms at } 3 \text { months. } \\
\text { No for reduction in per- } \\
\text { ceived stress, depres- } \\
\text { sion, and positive and } \\
\text { negative affect, at } 3 \text { and } \\
6 \text { months }\end{array}$ \\
\hline Dusing 2009 & Hypertension & $\begin{array}{l}\text { MULTIFACTORIAL INTER- } \\
\text { VENTION: The set of sup- } \\
\text { portive measures provid- } \\
\text { ed for selected centers }\end{array}$ & $\begin{array}{l}\text { STANDARD CARE: At the } \\
\text { baseline visit, all eligible } \\
\text { patients were started on } \\
\text { study treatment with val- }\end{array}$ & $\begin{array}{l}\text { No for improving ad- } \\
\text { herence outcome in pa- } \\
\text { tients with essential hy- }\end{array}$ & No for reduction in BP \\
\hline
\end{tabular}




\begin{tabular}{|c|c|c|c|c|c|}
\hline \multicolumn{6}{|c|}{ Adherence and outcome } \\
\hline Study & Clinical problem & Intervention & Control & $\begin{array}{l}\text { Effect on adherence } \\
\text { (Yes means a statis- } \\
\text { tically significant ef- } \\
\text { fect in favor of the } \\
\text { intervention; No } \\
\text { means no effect or } \\
\text { a negative effect) }\end{array}$ & $\begin{array}{l}\text { Effect on clin- } \\
\text { ical outcome } \\
\text { (Yes means a statis- } \\
\text { tically significant ef- } \\
\text { fect in favor of the } \\
\text { intervention; No } \\
\text { means no effect or } \\
\text { a negative effect) }\end{array}$ \\
\hline & & $\begin{array}{l}\text { and all patients recruit- } \\
\text { ed in these centers is list- } \\
\text { ed below. It was up to } \\
\text { the patients to select the } \\
\text { tools they would like to } \\
\text { use on an individual ba- } \\
\text { sis. For the patient: (a) } \\
\text { 24-hour timer: the timer } \\
\text { can be set to an individ- } \\
\text { ual time and provides } \\
\text { an acoustic signal every } \\
24 \text { hours at this point } \\
\text { of time. (b) Set of } 10 \text { re- } \\
\text { minding stickers to be } \\
\text { positioned at prominent } \\
\text { places at home (e.g. re- } \\
\text { frigerator and bathroom } \\
\text { mirror). (c) Information } \\
\text { brochure for patients } \\
\text { with hypertension pub- } \\
\text { lished by the German Hy- } \\
\text { pertension Society. (d) } \\
\text { Information letter for } \\
\text { the patient. (e) Informa- } \\
\text { tion letter the patient } \\
\text { can give to next of kin to } \\
\text { receive support or his } \\
\text { therapy (e.g. spouse re- } \\
\text { minding of drug intake). } \\
\text { (f) Home BP measure- } \\
\text { ment device. (g) Booklet } \\
\text { to document home BP } \\
\text { measurements } \\
\text { ( } \mathrm{n}=101 \text { ) }\end{array}$ & $\begin{array}{l}\text { sartan } 160 \text { mg daily for } \\
4 \text { weeks. Patients with } \\
\text { controlled BP were con- } \\
\text { tinued on treatment with } \\
\text { valsartan } 160 \text { mg. Pa- } \\
\text { tients not achieving BP } \\
\text { values less than } 140 / 90 \\
\text { mmHg by week } 4 \text { were } \\
\text { then up-titrated to val- } \\
\text { sartan } 160 \text { mg and HCTZ } \\
12.5 \text { mg as a fixed-dose } \\
\text { combination. Follow-up } \\
\text { visits were scheduled af- } \\
\text { ter } 2 \text { (third visit), } 4 \text { (4th } \\
\text { visit), } 8 \text { (fifth visit), } 14 \\
\text { (6th visit), } 24 \text { weeks (7th } \\
\text { visit), and at the end of } \\
\text { the observation period } \\
\text { at } 34 \text { weeks ( } 8 \text { h visit). } \\
\text { Dispensing of the study } \\
\text { drugs was as follows. } \\
\text { At baseline, patients re- } \\
\text { ceived MEMS bottles } \\
\text { containing } 48 \text { tablets of } \\
160 \text { mg valsartan. At } 4 \text { th } \\
\text { and } 5 \text { th visits, that is, af- } \\
\text { ter } 4 \text { and } 8 \text { weeks, pa- } \\
\text { tients received further } \\
\text { MEMS bottles contain- } \\
\text { ing } 48 \text { tablets of either } \\
160 \text { mg valsartan or } 160 \\
\text { mg valsartan and } 12.5 \\
\text { mg of HCTZ depending } \\
\text { on their BP. At } 6 \text { th and } \\
7 \text { th visits, that is, after } \\
14 \text { and } 24 \text { weeks of treat- } \\
\text { ment, patients received } \\
\text { MEMS bottles containing } \\
76 \text { tablets. Patients were } \\
\text { instructed to take their } \\
\text { medication per mouth } \\
\text { with water in the morn- } \\
\text { ing between } 0700 \text { and } \\
1100 \text { hours, regardless } \\
\text { of meals. No supportive } \\
\text { measures were given to } \\
\text { patients } \\
\text { (n = } 105 \text { ) }\end{array}$ & $\begin{array}{l}\text { pertension with the use } \\
\text { of supportive measures }\end{array}$ & \\
\hline El Miedany 2011 & Rheumatoid arthritis & $\begin{array}{l}\text { VISUAL FEEDBACK: The } \\
\text { active group consisted } \\
\text { of a visual feedback fa- } \\
\text { cility (visualization of } \\
\text { computer charts show- } \\
\text { ing the disease progres- } \\
\text { sion) that was added to } \\
\text { their management pro- } \\
\text { tocol. Visual feedback is } \\
\text { a relatively new tool that } \\
\text { enables the patient to vi- } \\
\text { sualize as well as mon- } \\
\text { itor a real-time change } \\
\text { of their disease activity } \\
\text { parameters as well as } \\
\text { the patient's reported } \\
\text { outcome measures. In- } \\
\text { tegrating electronic da- } \\
\text { ta recording in the stan- } \\
\text { dard rheumatology clin- } \\
\text { ical practice facilitated }\end{array}$ & $\begin{array}{l}\text { ROUTINE MANAGEMENT: } \\
\text { Control group patients } \\
\text { continued their routine } \\
\text { standard management } \\
\text { and assessment every } 3 \\
\text { months. All the patient's } \\
\text { disease activity para- } \\
\text { meters, patient-report- } \\
\text { ed outcome measures } \\
\text { (PROMs), medications, } \\
\text { scores of falls, and car- } \\
\text { diovascular risks were } \\
\text { recorded and discussed } \\
\text { verbally with the pa- } \\
\text { tient. Each patient was } \\
\text { allowed to view his for- } \\
\text { mer completed forms } \\
\text { and compare between } \\
\text { his/her current scores in } \\
\text { comparison to the earlier } \\
\text { records }\end{array}$ & $\begin{array}{l}\text { Yes for adherence to } \\
\text { medication }\end{array}$ & $\begin{array}{l}\text { Yes for improving pain } \\
\text { score, patient global } \\
\text { assessment, function- } \\
\text { al disability, quality of } \\
\text { life, and disease activity } \\
\text { score }\end{array}$ \\
\hline
\end{tabular}




\begin{tabular}{|c|c|c|c|c|c|}
\hline \multicolumn{6}{|c|}{ Adherence and outcome } \\
\hline Study & Clinical problem & Intervention & Control & $\begin{array}{l}\text { Effect on adherence } \\
\text { (Yes means a statis- } \\
\text { tically significant ef- } \\
\text { fect in favor of the } \\
\text { intervention; No } \\
\text { means no effect or } \\
\text { a negative effect) }\end{array}$ & $\begin{array}{l}\text { Effect on clin- } \\
\text { ical outcome } \\
\text { (Yes means a statis- } \\
\text { tically significant ef- } \\
\text { fect in favor of the } \\
\text { intervention; No } \\
\text { means no effect or } \\
\text { a negative effect) }\end{array}$ \\
\hline & & $\begin{array}{l}\text { the introduction of visual } \\
\text { feedback into the stan- } \\
\text { dard rheumatology prac- } \\
\text { tice. During their visit, } \\
\text { the patients were given } \\
\text { the chance to view the } \\
\text { progression of their dis- } \\
\text { ease on the computer, } \\
\text { discuss the changes in } \\
\text { their disease activity pa- } \\
\text { rameters, comorbidity } \\
\text { risks, functional disabili- } \\
\text { ty, and quality of life. The } \\
\text { patients were assessed } \\
\text { at 3-month intervals for } \\
\text { another } 6 \text { months (un- } \\
\text { less they sustained a } \\
\text { flare up of their condi- } \\
\text { tion, at which time they } \\
\text { would be reviewed earli- } \\
\text { er). Before every assess- } \\
\text { ment in the clinic, every } \\
\text { patient completed the } \\
\text { multidimensional pa- } \\
\text { tient reported outcome } \\
\text { measures questionnaire } \\
\text { ( } \mathrm{n}=55 \text { ) }\end{array}$ & $(n=56)$ & & \\
\hline Ellis 2005 & $\begin{array}{l}\text { Adolescents with type } 1 \\
\text { diabetes }\end{array}$ & $\begin{array}{l}\text { Standard medical care } \\
\text { plus Multisystematic } \\
\text { Therapy (MST), an inten- } \\
\text { sive, family-centered, } \\
\text { community-based psy- } \\
\text { chotherapy treatment } \\
\text { with tailored treatment } \\
\text { goals and interventions } \\
\text { for each family to best } \\
\text { treat the adherence } \\
\text { problem. MST interven- } \\
\text { tions targeted adher- } \\
\text { ence-related problems } \\
\text { within the family system, } \\
\text { peer network, and the } \\
\text { broader community sys- } \\
\text { tems within which the } \\
\text { family was embedded (n } \\
=64 \text { ) }\end{array}$ & $\begin{array}{l}\text { Standard medical care } \\
\text { at a hospital-based en- } \\
\text { docrine clinic where ado- } \\
\text { lescents were cared for } \\
\text { consisted of quarter- } \\
\text { ly medical visits with a } \\
\text { multidisciplinary med- } \\
\text { ical team composed } \\
\text { of an endocrinologist, } \\
\text { nurse, dietician, social } \\
\text { worker, and psychologist } \\
(\mathrm{n}=63)\end{array}$ & No & $\begin{array}{l}\text { No for all clinical out- } \\
\text { comes }\end{array}$ \\
\hline Ellis 2012 & Type 1 or 2 diabetes & $\begin{array}{l}\text { MULTISYSTEMIC THERA- } \\
\text { PY: Patients in the MST } \\
\text { group received both } \\
\text { standard medical care } \\
\text { and treatment sessions } \\
\text { by } 5 \text { masters-level ther- } \\
\text { apists trained to have } \\
\text { sufficient knowledge re- } \\
\text { garding diabetes to en- } \\
\text { able them to conduct di- } \\
\text { abetes adherence inter- } \\
\text { ventions with families. } \\
\text { Treatment included 1- } \\
\text { hour family treatment } \\
\text { sessions, skills practice } \\
\text { (e.g. spending } 15 \text { min- } \\
\text { utes in home to observe } \\
\text { a caregiver implement- } \\
\text { ing a reward or conse- } \\
\text { quence as part of a be- } \\
\text { havior plan), attending } \\
\text { school meetings to pro- } \\
\text { vide information to staff }\end{array}$ & $\begin{array}{l}\text { TELEPHONE SUPPORT: } \\
\text { Control patients (tele- } \\
\text { phone support) received } \\
\text { an initial home visit } \\
\text { where the program was } \\
\text { explained to the adoles- } \\
\text { cent and primary care- } \\
\text { giver by either a master } \\
\text { level therapists or doc- } \\
\text { toral students in clini- } \\
\text { cal psychology or social } \\
\text { work. Weekly phone calls } \\
\text { (approximately } 30 \text { min- } \\
\text { utes each) focused on } \\
\text { emotional support for di- } \\
\text { abetes care using client- } \\
\text { centered, nondirective } \\
\text { counseling, assessing } \\
\text { adherence to diabetes } \\
\text { for the previous week, } \\
\text { reviewing readings in } \\
\text { the blood glucose meter, } \\
\text { and helping the adoles- }\end{array}$ & $\begin{array}{l}\text { Yes for parent-reported } \\
\text { adherence at } 7 \text { and } 12 \\
\text { months; No for youth- } \\
\text { reported adherence at } 7 \\
\text { and } 12 \text { months }\end{array}$ & $\begin{array}{l}\text { Yes for reduction in } \\
\text { HB1AC }\end{array}$ \\
\hline
\end{tabular}




\begin{tabular}{|c|c|c|c|c|c|}
\hline \multicolumn{6}{|c|}{ Adherence and outcome } \\
\hline Study & Clinical problem & Intervention & Control & $\begin{array}{l}\text { Effect on adherence } \\
\text { (Yes means a statis- } \\
\text { tically significant ef- } \\
\text { fect in favor of the } \\
\text { intervention; No } \\
\text { means no effect or } \\
\text { a negative effect) }\end{array}$ & $\begin{array}{l}\text { Effect on clin- } \\
\text { ical outcome } \\
\text { (Yes means a statis- } \\
\text { tically significant ef- } \\
\text { fect in favor of the } \\
\text { intervention; No } \\
\text { means no effect or } \\
\text { a negative effect) }\end{array}$ \\
\hline & & $\begin{array}{l}\text { regarding diabetes care } \\
\text { (e.g. } 1-2 \text { hour staff train- } \\
\text { ing), and attending clin- } \\
\text { ic visits with families ( } 2 \\
\text { hours or more) } \\
(\mathrm{n}=74)\end{array}$ & $\begin{array}{l}\text { cent identify solutions } \\
\text { to any barriers in their } \\
\text { diabetes care. Non-dia- } \\
\text { betes-related problems } \\
\text { such as peer, school, } \\
\text { or family relationship } \\
\text { problems were also ad- } \\
\text { dressed during the call } \\
\text { if desired by the adoles- } \\
\text { cent. Telephone support } \\
\text { therapists completed the } \\
\text { same formal diabetes } \\
\text { education training com- } \\
\text { pleted by MST therapists } \\
(\mathrm{n}=72)\end{array}$ & & \\
\hline Evans 2010 & $\begin{array}{l}\text { Coronary artery disease } \\
\text { risk/cardiovascular risk }\end{array}$ & $\begin{array}{l}\text { PHARMACIST FOL- } \\
\text { LOW-UP: The pharma- } \\
\text { cist established goals for } \\
\text { the patient. Goals were } \\
\text { documented in the pa- } \\
\text { tient records. When any } \\
\text { of the risk factors were } \\
\text { uncontrolled, the phar- } \\
\text { macist alerted the pa- } \\
\text { tient by telephone and } \\
\text { mail, and the physician } \\
\text { was notified through the } \\
\text { patient's medical record } \\
\text { and face to face (when } \\
\text { possible). Patients re- } \\
\text { ceived continuous fol- } \\
\text { low-up by the pharma- } \\
\text { cist at a minimum of } \\
\text { every } 8 \text { weeks by tele- } \\
\text { phone, mail, electronic } \\
\text { mail, or face to face ap- } \\
\text { pointments. Mailed let- } \\
\text { ters were reserved for } \\
\text { patients who were suc- } \\
\text { cessfully controlled or } \\
\text { had been recently con- } \\
\text { tacted. Information de- } \\
\text { livered during follow-up } \\
\text { was patient-specific and } \\
\text { did not require that a } \\
\text { standard content be cov- } \\
\text { ered. Reasons for fol- } \\
\text { low-up included } 1 \text { ) To } \\
\text { communicate relevant } \\
\text { laboratory results, in- } \\
\text { cluding proximity to in- } \\
\text { dividual targets; } 2 \text { )To } \\
\text { monitor clinical status } \\
\text { within } 7 \text { to } 10 \text { days after } \\
\text { the initiation or change } \\
\text { of a drug; } 3 \text { ) To moni- } \\
\text { tor clinical status with- } \\
\text { in } 7 \text { to } 10 \text { days after ex- } \\
\text { periencing an adverse } \\
\text { event 4) To ensure that } \\
\text { the patient was able to } \\
\text { procure necessary fol- } \\
\text { low-up appointments } 5 \text { ) } \\
\text { To provide patients with } \\
\text { clinical goal reminders, } \\
\text { disease-specific infor- } \\
\text { mation, or timely topics } \\
\text { using periodic mailers. } \\
\text { Emphasis was placed }\end{array}$ & $\begin{array}{l}\text { SINGLE-CONTACT } \\
\text { GROUP: Patients met } \\
\text { at the beginning of the } \\
\text { study with the study } \\
\text { pharmacist, and re- } \\
\text { ceived a booklet about } \\
\text { cardiovascular disease. } \\
\text { After that meeting they } \\
\text { received usual care and } \\
\text { had no more contact } \\
\text { with the study pharma- } \\
\text { cist } \\
\text { ( } n=88 \text { ) }\end{array}$ & $\begin{array}{l}\text { No for improving adher- } \\
\text { ence to statin therapy }\end{array}$ & $\begin{array}{l}\text { No for improving Fram- } \\
\text { ingham risk score (FRS), } \\
\text { blood pressure, lipid } \\
\text { profile (total cholesterol, } \\
\text { HDL and triglycerides) } \\
\text { and hemoglobin A1C val- } \\
\text { ue }\end{array}$ \\
\hline
\end{tabular}




\begin{tabular}{|c|c|c|c|c|c|}
\hline \multicolumn{6}{|c|}{ Adherence and outcome } \\
\hline Study & Clinical problem & Intervention & Control & $\begin{array}{l}\text { Effect on adherence } \\
\text { (Yes means a statis- } \\
\text { tically significant ef- } \\
\text { fect in favor of the } \\
\text { intervention; No } \\
\text { means no effect or } \\
\text { a negative effect) }\end{array}$ & $\begin{array}{l}\text { Effect on clin- } \\
\text { ical outcome } \\
\text { (Yes means a statis- } \\
\text { tically significant ef- } \\
\text { fect in favor of the } \\
\text { intervention; No } \\
\text { means no effect or } \\
\text { a negative effect) }\end{array}$ \\
\hline & & $\begin{array}{l}\text { on conducting short fol- } \\
\text { low-up contacts that re- } \\
\text { minded and reinforced } \\
\text { the importance of drug } \\
\text { adherence and clinical } \\
\text { targets. All patients were } \\
\text { followed for a minimum } \\
\text { of } 6 \text { months } \\
(\mathrm{n}=88)\end{array}$ & & & \\
\hline Farber 2004 & Asthma & $\begin{array}{l}\text { Subjects in the inter- } \\
\text { vention group ( } n=28 \text { ) } \\
\text { received basic asth- } \\
\text { ma education; instruc- } \\
\text { tions on use of a me- } \\
\text { tered-dose inhaler with } \\
\text { holding chamber; a writ- } \\
\text { ten asthma self manage- } \\
\text { ment plan illustrated by } \\
\text { zones colored green, yel- } \\
\text { low, and red; a sample } \\
\text { age-appropriate hold- } \\
\text { ing chamber; and pre- } \\
\text { scriptions for medica- } \\
\text { tion needed to imple- } \\
\text { ment the plan. This med- } \\
\text { ication included an in- } \\
\text { haled corticosteroid } \\
\text { drug for everyday use } \\
\text { and a quick-acting bron- } \\
\text { chodilator for use as } \\
\text { needed. The importance } \\
\text { of seeking urgent med- } \\
\text { ical care in the red zone } \\
\text { was emphasized. } 3 \text { brief } \\
\text { follow-up phone calls } \\
\text { were placed to patients } \\
\text { in the intervention group } \\
\text { at } 1 \text { to } 2 \text { weeks, } 4 \text { to } 6 \\
\text { weeks and } 3 \text { months af- } \\
\text { ter enrollment }\end{array}$ & $\begin{array}{l}\text { The control group ( } n= \\
28 \text { ) received routine care }\end{array}$ & $\begin{array}{l}\text { Yes (based on dispens- } \\
\text { ing) }\end{array}$ & No \\
\hline
\end{tabular}




\begin{tabular}{|c|c|c|c|c|c|}
\hline \multicolumn{6}{|c|}{ Adherence and outcome } \\
\hline Study & Clinical problem & Intervention & Control & $\begin{array}{l}\text { Effect on adherence } \\
\text { (Yes means a statis- } \\
\text { tically significant ef- } \\
\text { fect in favor of the } \\
\text { intervention; No } \\
\text { means no effect or } \\
\text { a negative effect) }\end{array}$ & $\begin{array}{l}\text { Effect on clin- } \\
\text { ical outcome } \\
\text { (Yes means a statis- } \\
\text { tically significant ef- } \\
\text { fect in favor of the } \\
\text { intervention; No } \\
\text { means no effect or } \\
\text { a negative effect) }\end{array}$ \\
\hline Farooq 2011 & Schizophrenia & $\begin{array}{l}\text { STOPS: Participants in } \\
\text { the STOPS arm received } \\
\text { usual care plus specific } \\
\text { education given to a key } \\
\text { care supervisor about } \\
\text { the illness and the im- } \\
\text { portance of adherence; } \\
\text { medications were pro- } \\
\text { vided } 1 \text { month at a time } \\
\text { free of charge } \\
(n=55)\end{array}$ & $\begin{array}{l}\text { TAU: Psychiatrists pro- } \\
\text { vided treatment as they } \\
\text { would normally deliv- } \\
\text { er in routine out-pa- } \\
\text { tient settings. These in- } \\
\text { cluded prescribing evi- } \\
\text { dence-based pharmaco- } \\
\text { logical treatments, out- } \\
\text { patient attendance in } \\
\text { the psychiatry depart- } \\
\text { ment as deemed appro- } \\
\text { priate by the consultant } \\
\text { and brief counseling } \\
\text { about the treatment and } \\
\text { outcome. Participants } \\
\text { who could not afford to } \\
\text { buy medication had the } \\
\text { option to seek free drug } \\
\text { treatment from the so- } \\
\text { cial welfare department } \\
\text { of the hospital } \\
\text { ( } \mathrm{n}=55 \text { ) }\end{array}$ & $\begin{array}{l}\text { Yes for improving adher- } \\
\text { ence to antipsychotic } \\
\text { drugs at the end of } 1 \text { year }\end{array}$ & $\begin{array}{l}\text { Yes for PANSS total } \\
\text { scores, positive symp- } \\
\text { toms, and GAF scores }\end{array}$ \\
\hline Fisher 2011 & HIV & $\begin{array}{l}\text { LIFEWINDOWS: The in- } \\
\text { tervention was com- } \\
\text { puter-based, interac- } \\
\text { tive ARV adherence pro- } \\
\text { motion called LifeWin- } \\
\text { dows developed based } \\
\text { on the Information-Moti- } \\
\text { vation-Behavioral skills } \\
\text { (IMB) model. The nature } \\
\text { of this intervention is } \\
\text { to identify and address, } \\
\text { through interventions, } \\
\text { an individual's deficits in } \\
\text { adherence-related infor- } \\
\text { mation, motivation, and } \\
\text { behavioral skills. The in- } \\
\text { tervention activities con- } \\
\text { sisted of } 20 \text { different in- } \\
\text { teractive activities that } \\
\text { would be selected by the } \\
\text { participants according } \\
\text { to their goals. Patients } \\
\text { on average spent } 26 \text { min- } \\
\text { utes to complete the full } \\
\text { intervention with an av- } \\
\text { erage of } 8 \text { min dedicat- } \\
\text { ed to adherence inter- } \\
\text { vention modules. Partic- } \\
\text { ipants received USD } 20 \\
\text { for completion of each } \\
\text { session. Participants } \\
\text { completed } 1 \text { session per } \\
\text { month over } 18 \text { months } \\
\text { ( } \mathrm{n}=277 \text { ) }\end{array}$ & $\begin{array}{l}\text { STANDARD OF CARE: } \\
\text { Control patients re- } \\
\text { ceived standard of care } \\
\text { at the clinic they attend- } \\
\text { ed. Average total time } \\
\text { spent to complete the } \\
\text { full control session was } \\
14 \text { min. Participants re- } \\
\text { ceived USD } 20 \text { for com- } \\
\text { pletion of the session per } \\
\text { month over } 18 \text { months } \\
(\mathrm{n}=287)\end{array}$ & $\begin{array}{l}\text { Yes for increasing adher- } \\
\text { ence to ARV in on proto- } \\
\text { col patients at the end } \\
\text { of } 18 \text { months; No for in- } \\
\text { creasing adherence to } \\
\text { ARV in intent to treat at } \\
\text { the end of } 18 \text { months }\end{array}$ & $\begin{array}{l}\text { No for improving viral } \\
\text { load at } 18 \text { months of in- } \\
\text { tervention }\end{array}$ \\
\hline Fortney 2007 & Depression & $\begin{array}{l}\text { TELEMEDICINE-EN- } \\
\text { HANCED ANTIDE- } \\
\text { PRESSANT MANAGE- } \\
\text { MENT (TEAM): Patients } \\
\text { at intervention sites re- } \\
\text { ceived a stepped-care } \\
\text { model of depression } \\
\text { treatment for up to } 12 \\
\text { months. Treatment in- } \\
\text { tensity was increased } \\
\text { for patients failing to re- } \\
\text { spond to lower levels } \\
\text { of care by involving a }\end{array}$ & $\begin{array}{l}\text { USUAL CARE: Control } \\
\text { groups received usu- } \\
\text { al care. Usual care pa- } \\
\text { tients like the interven- } \\
\text { tion group were provid- } \\
\text { ed with provider educa- } \\
\text { tion and patient educa- } \\
\text { tion. Also, the screening } \\
\text { results were entered in- } \\
\text { to the electronic medical } \\
\text { record } \\
(\mathrm{n}=218 \text { patients ( } 4 \text { prac- } \\
\text { tices)) }\end{array}$ & $\begin{array}{l}\text { Yes for improving ad- } \\
\text { herence to antidepres- } \\
\text { sant medication in de- } \\
\text { pressed patients at } 6 \text { and } \\
12 \text { months }\end{array}$ & $\begin{array}{l}\text { Yes for increased re- } \\
\text { sponse and no for remit- } \\
\text { tance in the intervention } \\
\text { group at } 6 \text { months. Yes } \\
\text { for improving odds of } \\
\text { remittance and no for } \\
\text { response in interven- } \\
\text { tion group at } 12 \text { months. } \\
\text { Yes for improving satis- } \\
\text { faction in intervention } \\
\text { group at } 12 \text { months. No } \\
\text { for improving physical } \\
\text { health score at } 6 \text { and } 12\end{array}$ \\
\hline
\end{tabular}


Adherence and outcome

Intervention
Effect on adherence

(Yes means a statis

tically significant ef-

fect in favor of the

intervention; No

means no effect or

a negative effect)
Effect on clin-

ical outcome

(Yes means a statis-

tically significant ef-

fect in favor of the

intervention; No

means no effect or

a negative effect)

months. Yes for improv-

ing mental health score

at 12 months and not at

6 months

$\begin{array}{ll}\text { vention personnel with } & \text { ing mental } \\ \text { increasing mental health } & \text { at } 12 \text { months } \\ \text { expertise. The interven- } & 6 \text { months }\end{array}$

tion involved 5 types of

providers: (1) PCPs locat-

ed at CBOCs; 2) consult

telepsychiatrists located

at parent VAMCs; (3) an

off-site depression nurse

care manager (RN); (4)

an off-site clinical phar-

macist (PharmD); and

5) an off-site supervis-

ing psychiatrist. The con-

sult-telepsychiatrist ac-

cepted consultations or

referrals from PCPs. The

supervising psychiatrist

provided clinical supervi-

sion to the care manager

and clinical pharmacist

via weekly face-to-face

meetings. Patients and

providers could choose

either watchful waiting

or antidepressant treat-

ment (Step 1). Nurse care

manager encounters

were conducted via tele-

phone and were script-

ed to enhance standard

ization and reproducibil-

ity. During the initial care

management encounter,

patients were: (1) admin-

istered the PHQ9 symp-

tom monitoring tool; (2)

educated and activated

using a semi-structured

script4; and 3) assessed

for treatment barriers

using semi-structured

scripts for endorsed bar-

riers. Follow-up encoun-

ters to monitor symp-

toms, medication adher-

ence, and side effects

were scheduled every

2 weeks during acute

treatment and every 4

weeks during watchful

waiting or continuation

treatment. Non-adher-

ent patients or those ex-

periencing severe side

effects were adminis-

tered semi-structured

scripts. 3 A trial was con-

sidered to have failed in

the acute phase if the pa-

tient: (1) was non-adher-

ent to the medication,

(2) experienced severe

side effects, (3) experi-

enced 5-point increase

in their PHO9 score, or

(4) did not respond (50\%

decrease in PHQ9 score)

after 8 weeks of antide- 


\begin{tabular}{|c|c|c|c|c|c|}
\hline \multicolumn{6}{|c|}{ Adherence and outcome } \\
\hline Study & Clinical problem & Intervention & Control & $\begin{array}{l}\text { Effect on adherence } \\
\text { (Yes means a statis- } \\
\text { tically significant ef- } \\
\text { fect in favor of the } \\
\text { intervention; No } \\
\text { means no effect or } \\
\text { a negative effect) }\end{array}$ & $\begin{array}{l}\text { Effect on clin- } \\
\text { ical outcome } \\
\text { (Yes means a statis- } \\
\text { tically significant ef- } \\
\text { fect in favor of the } \\
\text { intervention; No } \\
\text { means no effect or } \\
\text { a negative effect) }\end{array}$ \\
\hline & & $\begin{array}{l}\text { pressant therapy. All } \\
\text { feedback was provided } \\
\text { to PCPs using the elec- } \\
\text { tronic medical record. } \\
\text { Progress notes report- } \\
\text { ing failed trials request- } \\
\text { ed an electronic co-sig- } \\
\text { nature from the PCP. If } \\
\text { the patient did not re- } \\
\text { spond to the initial anti- } \\
\text { depressant, the pharma- } \\
\text { cist conducted a med- } \\
\text { ication history and pro- } \\
\text { vided pharmacothera- } \\
\text { py recommendations } \\
\text { to PCPs via an electron- } \\
\text { ic progress note (Step } \\
\text { 2). The pharmacist al- } \\
\text { so provided non-script- } \\
\text { ed medication manage- } \\
\text { ment over the phone to } \\
\text { patients experiencing se- } \\
\text { vere side effects or prob- } \\
\text { lems with non-adher- } \\
\text { ence. If the patient did } \\
\text { not respond to } 2 \text { antide- } \\
\text { pressants trials, the pro- } \\
\text { tocol was to recommend } \\
\text { a telepsychiatry consul- } \\
\text { tation followed by addi- } \\
\text { tional treatment recom- } \\
\text { mendations to the PCP } \\
\text { (Step } 3 \text { ) } \\
\text { (n = } 177 \text { patients ( } 3 \text { prac- } \\
\text { tices)) }\end{array}$ & & & \\
\hline Friedman 1996 & Hypertension & $\begin{array}{l}\text { Telephone-linked com- } \\
\text { puter system (TLC) - } \\
\text { an interactive comput- } \\
\text { er-based telecommuni- } \\
\text { cations system that con- } \\
\text { verses with patients in } \\
\text { their homes between of- } \\
\text { fice visits to their physi- } \\
\text { cians ( } n=156)\end{array}$ & $\begin{array}{l}\text { Regular medical care }(\mathrm{n} \\
=145)\end{array}$ & Yes & Yes \\
\hline Gallefoss 1999 & $\begin{array}{l}\text { Asthma or chronic ob- } \\
\text { structive pulmonary dis- } \\
\text { ease (COPD) }\end{array}$ & $\begin{array}{l}\text { An educational interven- } \\
\text { tion consisting of a spe- } \\
\text { cially constructed pa- } \\
\text { tient brochure, } 22 \text {-hour } \\
\text { group sessions (separate } \\
\text { groups for asthmatics } \\
\text { and patients with COPD) } \\
\text { concentrating on patho- } \\
\text { physiology, anti-obstruc- } \\
\text { tive medication, symp- } \\
\text { tom awareness, treat- } \\
\text { ment plans, and phys- } \\
\text { iotherapy. One or } 240- \\
\text { minute individual ses- } \\
\text { sions were supplied by } \\
\text { both a nurse and a phys- } \\
\text { iotherapist. At the final } \\
\text { teaching the patients } \\
\text { received an individual } \\
\text { treatment plan on the } \\
\text { basis of the acquired } \\
\text { personal information } \\
\text { and } 2 \text { weeks of peak flow } \\
\text { monitoring ( } \mathrm{n}=39 \text { asth- }\end{array}$ & $\begin{array}{l}\text { Usual care from GP ( } \mathrm{n} \\
=39 \text { asthmatics, } \mathrm{n}=32 \\
\text { COPD patients) }\end{array}$ & No & No \\
\hline
\end{tabular}




\begin{tabular}{|c|c|c|c|c|c|}
\hline \multicolumn{6}{|c|}{ Adherence and outcome } \\
\hline Study & Clinical problem & Intervention & Control & $\begin{array}{l}\text { Effect on adherence } \\
\text { (Yes means a statis- } \\
\text { tically significant ef- } \\
\text { fect in favor of the } \\
\text { intervention; No } \\
\text { means no effect or } \\
\text { a negative effect) }\end{array}$ & $\begin{array}{l}\text { Effect on clin- } \\
\text { ical outcome } \\
\text { (Yes means a statis- } \\
\text { tically significant ef- } \\
\text { fect in favor of the } \\
\text { intervention; No } \\
\text { means no effect or } \\
\text { a negative effect) }\end{array}$ \\
\hline & & $\begin{array}{l}\text { matics, } \mathrm{n}=32 \text { COPD pa- } \\
\text { tients) }\end{array}$ & & & \\
\hline Gamble 2011 & Asthma & $\begin{array}{l}\text { INTERVENTION: The in- } \\
\text { tervention was individ- } \\
\text { ualized, provided psy- } \\
\text { cho-education and was } \\
\text { led by an experienced } \\
\text { registered nurse with ba- } \\
\text { sic level psychotherapy } \\
\text { training for } 12 \text { months } \\
\text { to improve adherence } \\
\text { to medication. In addi- } \\
\text { tion to standard asth- } \\
\text { ma care, intervention } \\
\text { group subjects were of- } \\
\text { fered up to } 8 \text { months of } \\
\text { individual visits with- } \\
\text { in a } 12 \text {-week period. Al- } \\
\text { though the proposed in- } \\
\text { tervention was unique } \\
\text { in its design, to increase } \\
\text { the internal validity of } \\
\text { the study, the Compli- } \\
\text { ance Therapy Model was } \\
\text { used to provide the un- } \\
\text { derpinning theoretical } \\
\text { framework. This model } \\
\text { encompassed the Trans- } \\
\text { theoretical Model of } \\
\text { Change, Motivational In- } \\
\text { terviewing and Cognitive } \\
\text { Behavioral Therapy prin- } \\
\text { ciples, providing a flexi- } \\
\text { ble short-term interven- } \\
\text { tion using patient's indi- } \\
\text { vidual reasons for non- } \\
\text { adherence as a guide to } \\
\text { plan intervention con- } \\
\text { tent. The model used } \\
\text { a non-confrontational } \\
\text { technique which elicit- } \\
\text { ed self motivation and } \\
\text { provided a process to } \\
\text { resolve ambivalence to- } \\
\text { wards medication taking } \\
\text { (n=9) }\end{array}$ & $\begin{array}{l}\text { STANDARD ASTHMA } \\
\text { CARE: All participants } \\
\text { received standard asth- } \\
\text { ma care at the difficult } \\
\text { asthma service but the } \\
\text { control group did not re- } \\
\text { ceive any further inter- } \\
\text { vention. Subsequent fol- } \\
\text { low-up visits for the con- } \\
\text { trol group was conduct- } \\
\text { ed at } 6 \text { months and } 12 \\
\text { months post-recruitment } \\
\text { ( } n=11 \text { ) }\end{array}$ & $\begin{array}{l}\text { Yes for percentage of } \\
\text { prescriptions filled. Yes } \\
\text { for number of partici- } \\
\text { pants in intervention } \\
\text { group filling prescrip- } \\
\text { tions }\end{array}$ & $\begin{array}{l}\text { Yes for reducing the daily } \\
\text { prescribed dose of main- } \\
\text { tenance prednisolone. } \\
\text { No for improving hospi- } \\
\text { tal admissions, FEV \% } \\
\text { predicted, quality of life, } \\
\text { asthma control score, } \\
\text { anxiety, and depression }\end{array}$ \\
\hline Gani 2001 & $\begin{array}{l}\text { Seasonal rhinitis and } \\
\text { asthma }\end{array}$ & $\begin{array}{l}\text { B group }(n=35) \text { with } \\
\text { drug therapy plus train- } \\
\text { ing on the use of nasal } \\
\text { spray, and C group ( } n= \\
\text { 36) the same as B plus } \\
\text { a lesson on rhinitis and } \\
\text { asthma }\end{array}$ & $\begin{array}{l}\text { A group }(n=30) \text { with } \\
\text { drug therapy alone }\end{array}$ & Yes for $A$ versus $B+C$ & $\begin{array}{l}\text { Yes: between group A } \\
\text { and group C in respirato- } \\
\text { ry symptoms. Yes, in the } \\
\text { use of inhaled albuterol } \\
\text { (Fisher test) among the } \\
\text { groups was observed (A } \\
\text { versus B plus C: } P \text { value }= \\
0.005 ; \text { A versus C: } P \text { value } \\
=0.005 \text { ) }\end{array}$ \\
\hline Gensichen 2009 & Major depression & $\begin{array}{l}\text { CASE MANAGEMENT: The } \\
\text { intervention was in ac- } \\
\text { cordance with Chronic } \\
\text { Care Model, which em- } \\
\text { phasizes proactive sup- } \\
\text { port for the patient by } \\
\text { the entire practice team. } \\
1 \text { healthcare assistant } \\
\text { from each practice as- } \\
\text { signed to the interven- } \\
\text { tion group in } 2 \text { work- } \\
\text { shops (an } 11 \text {-hour and a } \\
6 \text {-hour workshop). This } \\
\text { interactive training in- }\end{array}$ & $\begin{array}{l}\text { USUAL CARE: Patients in } \\
\text { the control group were } \\
\text { given usual care } \\
\text { ( } n=39 \text { practices, } 316 \text { pa- } \\
\text { tients) }\end{array}$ & $\begin{array}{l}\text { Yes for improving adher- } \\
\text { ence to medication at } 12 \\
\text { months }\end{array}$ & $\begin{array}{l}\text { Yes for reducing depres- } \\
\text { sion symptoms score } \\
\text { and increased response } \\
\text { and remission in in- } \\
\text { tervention group at } 12 \\
\text { months. No for quality of } \\
\text { life scores and number of } \\
\text { family physician or men- } \\
\text { tal health specialist con- } \\
\text { tacts at } 12 \text { months }\end{array}$ \\
\hline
\end{tabular}




\begin{tabular}{|c|c|c|c|c|c|}
\hline \multicolumn{6}{|c|}{ Adherence and outcome } \\
\hline Study & Clinical problem & Intervention & Control & $\begin{array}{l}\text { Effect on adherence } \\
\text { (Yes means a statis- } \\
\text { tically significant ef- } \\
\text { fect in favor of the } \\
\text { intervention; No } \\
\text { means no effect or } \\
\text { a negative effect) }\end{array}$ & $\begin{array}{l}\text { Effect on clin- } \\
\text { ical outcome } \\
\text { (Yes means a statis- } \\
\text { tically significant ef- } \\
\text { fect in favor of the } \\
\text { intervention; No } \\
\text { means no effect or } \\
\text { a negative effect) }\end{array}$ \\
\hline & & $\begin{array}{l}\text { cluded information on } \\
\text { depression, communi- } \\
\text { cation skills, telephone } \\
\text { monitoring, and behav- } \\
\text { ioral activation for the } \\
\text { patient. The healthcare } \\
\text { assistants contacted } \\
\text { their patients by tele- } \\
\text { phone twice a week in } \\
\text { the first month and then } \\
\text { once a month for the fol- } \\
\text { lowing } 11 \text { months. They } \\
\text { monitored depression } \\
\text { symptoms and adher- } \\
\text { ence to medication by } \\
\text { using the Depression } \\
\text { Monitoring Context List. } \\
\text { Healthcare assistants al- } \\
\text { so encouraged patients } \\
\text { to follow self manage- } \\
\text { ment activities, such } \\
\text { as medication adher- } \\
\text { ence and activation for } \\
\text { pleasant or social ac- } \\
\text { tivities. The assistants } \\
\text { provided this informa- } \\
\text { tion to the family physi- } \\
\text { cian in a structured re- } \\
\text { port that stratified the } \\
\text { urgency of the contact } \\
\text { by a robot scheme. Fami- } \\
\text { ly physicians in both the } \\
\text { intervention and control } \\
\text { groups received train- } \\
\text { ing on evidence-based } \\
\text { depression treatment } \\
\text { guidelines } \\
\text { ( } \mathrm{n}=35 \text { practices, } 310 \text { pa- } \\
\text { tients) }\end{array}$ & & & \\
\hline Ginde 2003 & $\begin{array}{l}\text { Macrolide antibiotic } \\
\text { treatment }\end{array}$ & $\begin{array}{l}\text { Patients in the ED } \\
\text { group ( } n=38) \text { were pro- } \\
\text { vided a full course of } \\
\text { azithromycin }(6 \times 250 \\
\mathrm{mg}) \text { at no charge and } \\
\text { given instructions on } \\
\text { the proper dose and fre- } \\
\text { quency before discharge } \\
\text { from the ED }\end{array}$ & $\begin{array}{l}\text { Patients in the phar- } \\
\text { macy group }(n=36) \text { re- } \\
\text { ceived a written pre- } \\
\text { scription for a full course } \\
\text { of azithromycin before } \\
\text { discharge from the ED }\end{array}$ & No & $\begin{array}{l}\text { No. The prescription fill- } \\
\text { ing rate for the control } \\
\text { group is based on the } \\
\text { assumption that con- } \\
\text { trol patients used a par- } \\
\text { ticipating pharmacy } 8 \\
\text { blocks away that pro- } \\
\text { vided the drugs free of } \\
\text { charge - patients were } \\
\text { apparently not asked } \\
\text { if they filled their pre- } \\
\text { scription elsewhere. } \\
\text { The "course completed" } \\
\text { rate is based on self re- } \\
\text { port on a telephone call } \\
\text { - no indication that in- } \\
\text { terviewers were blind- } \\
\text { ed to group; nor was the } \\
\text { exact question given (if } \\
\text { there was one). Techni- } \\
\text { cally, this study quali- } \\
\text { fied for the review, but } \\
\text { the reliability and cred- } \\
\text { ibility of the measures } \\
\text { are suspect. At least the } \\
\text { question of the control } \\
\text { group's filling of pre- } \\
\text { scriptions could have } \\
\text { been cleared up. The } \\
\text { intervention is also im- }\end{array}$ \\
\hline
\end{tabular}




\begin{tabular}{|c|c|c|c|c|c|}
\hline \multicolumn{6}{|c|}{ Adherence and outcome } \\
\hline Study & Clinical problem & Intervention & Control & $\begin{array}{l}\text { Effect on adherence } \\
\text { (Yes means a statis- } \\
\text { tically significant ef- } \\
\text { fect in favor of the } \\
\text { intervention; No } \\
\text { means no effect or } \\
\text { a negative effect) }\end{array}$ & $\begin{array}{l}\text { Effect on clin- } \\
\text { ical outcome } \\
\text { (Yes means a statis- } \\
\text { tically significant ef- } \\
\text { fect in favor of the } \\
\text { intervention; No } \\
\text { means no effect or } \\
\text { a negative effect) }\end{array}$ \\
\hline & & & & & $\begin{array}{l}\text { practical in any setting } \\
\text { where giving drugs out } \\
\text { for free is not possible }\end{array}$ \\
\hline Girvin 1999 & Hypertension & $\begin{array}{l}\text { Enalapril } 20 \mathrm{mg} \text { once dai- } \\
\text { ly }(\mathrm{n}=27) . \text { Cross-over } \\
\text { study, with 4-week study } \\
\text { periods }\end{array}$ & $\begin{array}{l}\text { Enalapril } 10 \text { mg twice } \\
\text { daily }(n=27) \text {. Cross-over } \\
\text { study }\end{array}$ & Yes & No \\
\hline Gould 2009 & Acute cardiac event & $\begin{array}{l}\text { DISCHARGE NURSING } \\
\text { INTERVENTION (DNI): } \\
\text { The discharge nursing } \\
\text { intervention consisted } \\
\text { of written discharge ma- } \\
\text { terials and telephone } \\
\text { follow-up by an expert } \\
\text { cardiovascular nurse. } \\
\text { Expert nurses were de- } \\
\text { fined as those having ad- } \\
\text { vanced education and } \\
\text { clinical expertise in the } \\
\text { care and management } \\
\text { of this population. Deliv- } \\
\text { ery of the intervention } \\
\text { was time-sensitive. The } \\
\text { intervention was offered } \\
\text { at discharge and contin- } \\
\text { ued within } 24 \text { hours of } \\
\text { discharge. DNI group re- } \\
\text { ceived a packet contain- } \\
\text { ing group instructions, } \\
\text { medication review mate- } \\
\text { rials, a medication pock- } \\
\text { et card, suggested Inter- } \\
\text { net sites, copies of the } \\
\text { interview tools, and the } \\
\text { Revised Illness Percep- } \\
\text { tion Questionnaire (IPQ- } \\
\text { R) instrument } \\
\text { ( } \mathrm{n}=64 \text { ) }\end{array}$ & $\begin{array}{l}\text { USUAL CARE: Control } \\
\text { group patients received } \\
\text { routine discharge ma- } \\
\text { terials and usual care. } \\
\text { Subjects in the control } \\
\text { group received an enve- } \\
\text { lope containing group } \\
\text { instructions, copies of } \\
\text { interview tools, and the } \\
\text { IPQ-R } \\
(n=65)\end{array}$ & $\begin{array}{l}\text { No for improving adher- } \\
\text { ence to medication in } \\
\text { early discharge inter- } \\
\text { ventional cardiology pa- } \\
\text { tients }\end{array}$ & No for use of urgent care \\
\hline Gray 2012 & $\begin{array}{l}\text { Ocular hypertension } \\
\text { (OHT), open-angle glau- } \\
\text { coma (OAG) }\end{array}$ & $\begin{array}{l}\text { INDIVIDUALIZED PATIENT } \\
\text { CARE: Patients in the in- } \\
\text { dividualized care group } \\
\text { received standard care } \\
\text { plus an individualized } \\
\text { care plan implemented } \\
\text { by a glaucoma trained } \\
\text { nurse. This included a } \\
\text { 45-minute assessment } \\
\text { of health care needs and } \\
\text { beliefs with supplied } \\
\text { booklets and drop di- } \\
\text { aries, a } 20 \text {-minute educa- } \\
\text { tional session, and a 10- } \\
\text { minute training session } \\
\text { on instilling eye drops. } \\
\text { A 1-year follow-up care } \\
\text { plan was designed and } \\
\text { implemented accord- } \\
\text { ing to healthcare needs, } \\
\text { based on education and } \\
\text { support, which was tai- } \\
\text { lored to gaps in glauco- } \\
\text { ma knowledge, pre-ex- } \\
\text { isting beliefs, and abil- } \\
\text { ity to manage an eye } \\
\text { drop regimen. Patients } \\
\text { were given the nurse's } \\
\text { contact telephone for } \\
\text { advice or assistance be- } \\
\text { tween consultation. Fol- }\end{array}$ & $\begin{array}{l}\text { STANDARD CARE: Stan- } \\
\text { dard of care is not defin- } \\
\text { itively described. Edu- } \\
\text { cation, advice, and sup- } \\
\text { port varies from clinic to } \\
\text { clinic within Manchester } \\
\text { Royal Eye Hospital but } \\
\text { is limited for many pa- } \\
\text { tients. No further contact } \\
\text { after initial consultation } \\
(\mathrm{n}=63)\end{array}$ & $\begin{array}{l}\text { Yes for improving refill } \\
\text { adherence at } 12 \text { months. } \\
\text { Yes for improving self re- } \\
\text { ported adherence at } 12 \\
\text { month follow-up }\end{array}$ & $\begin{array}{l}\text { No for mean IOP, IOP } \\
\text { fluctuation, and clini- } \\
\text { cal management at } 12 \\
\text { months and mean IOP } \\
\text { at } 24 \text { months; Yes for IOP } \\
\text { fluctuations and clini- } \\
\text { cal management at } 24 \\
\text { months }\end{array}$ \\
\hline
\end{tabular}




\begin{tabular}{|c|c|c|c|c|c|}
\hline \multicolumn{6}{|c|}{ Adherence and outcome } \\
\hline Study & Clinical problem & Intervention & Control & $\begin{array}{l}\text { Effect on adherence } \\
\text { (Yes means a statis- } \\
\text { tically significant ef- } \\
\text { fect in favor of the } \\
\text { intervention; No } \\
\text { means no effect or } \\
\text { a negative effect) }\end{array}$ & $\begin{array}{l}\text { Effect on clin- } \\
\text { ical outcome } \\
\text { (Yes means a statis- } \\
\text { tically significant ef- } \\
\text { fect in favor of the } \\
\text { intervention; No } \\
\text { means no effect or } \\
\text { a negative effect) }\end{array}$ \\
\hline & & $\begin{array}{l}\text { low-up involved ongo- } \\
\text { ing training and support } \\
\text { by both face-to-face and } \\
\text { telephone consultations. } \\
\text { This incorporated a re- } \\
\text { view of drop diaries in } \\
\text { the initial weeks of ther- } \\
\text { apy (these were contin- } \\
\text { ued if found beneficial } \\
\text { as a reminder tool), re- } \\
\text { minders to collect and } \\
\text { use drops, and repeti- } \\
\text { tion of information as re- } \\
\text { quired. Needs were re- } \\
\text { assessed and the level } \\
\text { of support adjusted ac- } \\
\text { cordingly at the end of } \\
\text { each consultation. The } \\
\text { intervention nurse was } \\
\text { the same throughout, } \\
\text { and the intervention was } \\
\text { guided by prescriptive } \\
\text { documentation } \\
\text { (n=64) }\end{array}$ & & & \\
\hline Hamann 2007 & $\begin{array}{l}\text { Schizophrenia or schizo- } \\
\text { phreniform disorder }\end{array}$ & $\begin{array}{l}\text { SHARED DECISION- } \\
\text { MAKING (SDM): The in- } \\
\text { tervention was designed } \\
\text { to inform patients about } \\
\text { their treatment options } \\
\text { and to prepare them } \\
\text { for a planning talk with } \\
\text { their physicians. A print- } \\
\text { ed 16-page booklet cov- } \\
\text { ering the pros and cons } \\
\text { of oral versus depot for- } \\
\text { mulation, first- versus } \\
\text { second-generation an- } \\
\text { tipsychotics, psychoe- } \\
\text { ducation, and type of } \\
\text { socio-therapeutic inter- } \\
\text { vention was presented } \\
\text { to the patients through } \\
\text { the head nurse of the } \\
\text { ward as soon as the psy- } \\
\text { chiatrist in charge con- } \\
\text { sidered them able to co- } \\
\text { operate. Trained nurses } \\
\text { assisted the patient to } \\
\text { work through the book- } \\
\text { let. Within the decision } \\
\text { aid, patients were asked } \\
\text { to write down their ex- } \\
\text { periences with previ- } \\
\text { ous antipsychotic med- } \\
\text { ication and to indicate } \\
\text { their preferences regard- } \\
\text { ing the different options } \\
\text { on each topic. Nurses } \\
\text { were advised to answer } \\
\text { any questions of the pa- } \\
\text { tients and to encourage } \\
\text { them to state any point } \\
\text { of view contrary to that } \\
\text { of the doctor. They were } \\
\text { also instructed to post- } \\
\text { pone the participation } \\
\text { of patients in the study } \\
\text { if serious thought dis- } \\
\text { turbances or delusional }\end{array}$ & $\begin{array}{l}\text { USUAL CARE: "Patients } \\
\text { in the control group were } \\
\text { treated "as usual", thus } \\
\text { they did not receive the } \\
\text { decision aid and there } \\
\text { was no arrangement for } \\
\text { an extra planning talk" } \\
(n=59)\end{array}$ & $\begin{array}{l}\text { No for improving adher- } \\
\text { ence to antipsychotic } \\
\text { medication at } 6 \text { and } 18 \\
\text { months }\end{array}$ & $\begin{array}{l}\text { No for reducing rehos- } \\
\text { pitalizations within } 6 \\
\text { and } 18 \text { months after dis- } \\
\text { charge. No for improving } \\
\text { CGI and GAF scores at } 18 \\
\text { months }\end{array}$ \\
\hline
\end{tabular}




\begin{tabular}{|c|c|c|c|c|c|}
\hline \multicolumn{6}{|c|}{ Adherence and outcome } \\
\hline Study & Clinical problem & Intervention & Control & $\begin{array}{l}\text { Effect on adherence } \\
\text { (Yes means a statis- } \\
\text { tically significant ef- } \\
\text { fect in favor of the } \\
\text { intervention; No } \\
\text { means no effect or } \\
\text { a negative effect) }\end{array}$ & $\begin{array}{l}\text { Effect on clin- } \\
\text { ical outcome } \\
\text { (Yes means a statis- } \\
\text { tically significant ef- } \\
\text { fect in favor of the } \\
\text { intervention; No } \\
\text { means no effect or } \\
\text { a negative effect) }\end{array}$ \\
\hline & & $\begin{array}{l}\text { misinterpretations were } \\
\text { detected while working } \\
\text { through the booklet. The } \\
\text { average time for work- } \\
\text { ing through the booklet } \\
\text { was } 30 \text { to } 60 \text { minutes. } \\
\text { Patients met their physi- } \\
\text { cians within } 24 \text { hours } \\
\text { after having worked } \\
\text { through the decision aid } \\
\text { with their nurse. The aim } \\
\text { of these meetings, "plan- } \\
\text { ning talks", was to reach } \\
\text { an agreement between } \\
\text { patient and psychiatrist } \\
\text { on the further treatment } \\
\text { according to the prefer- } \\
\text { ences indicated by the } \\
\text { patient in the booklet. } \\
\text { Like nurses, physicians } \\
\text { were also trained about } \\
\text { the SDM and required } \\
\text { communication skills } \\
\text { ( } \mathrm{n}=54 \text { ) }\end{array}$ & & & \\
\hline Haynes 1976 & Hypertension & $\begin{array}{l}\text { Tailoring, self monitoring } \\
\text { of pills and blood pres- } \\
\text { sure, rewards for high- } \\
\text { er adherence and lower } \\
\text { blood pressure }(n=20)\end{array}$ & Usual care $(n=18)$ & Yes & No \\
\hline Heisler 2010 & Diabetes & $\begin{array}{l}\text { RECIPROCAL PEER SUP- } \\
\text { PORT: After the baseline } \\
\text { assessment, patients in } \\
\text { the RPS group attended } \\
\text { a 3-hour group session } \\
\text { facilitated by a care man- } \\
\text { ager and a research as- } \\
\text { sociate. In the first half } \\
\text { of the session, patients' } \\
\text { laboratory and blood } \\
\text { pressure results were re- } \\
\text { viewed and action plan- } \\
\text { ning was introduced. In } \\
\text { the } 2 \text { nd half, patients } \\
\text { received brief training } \\
\text { in basic peer communi- } \\
\text { cation skills and were } \\
\text { paired with another age } \\
\text { matched patient in their } \\
\text { cohort. Peer partners } \\
\text { were encouraged to call } \\
\text { each other at least once } \\
\text { a week using an interac- } \\
\text { tive, voice-response-fa- } \\
\text { cilitated telephone plat- } \\
\text { form that recorded call } \\
\text { initiation, frequency, } \\
\text { and duration; enabled }\end{array}$ & $\begin{array}{l}\text { NURSE CARE MANAGE- } \\
\text { MENT: At baseline and } \\
6 \text {-month follow-up, all } \\
\text { study patients had their } \\
\text { HbA1c level and blood } \\
\text { pressure checked and } \\
\text { were informed of the re- } \\
\text { sults and the most re- } \\
\text { cent cholesterol values } \\
\text { were in their medical } \\
\text { record. Patients in the } \\
\text { NCM group then attend- } \\
\text { ed a 1.5-hour session, } \\
\text { led by a care manager, } \\
\text { to review their laborato- } \\
\text { ry and blood pressure } \\
\text { results, ask questions, } \\
\text { and receive information } \\
\text { on VA care management } \\
\text { services. They were pro- } \\
\text { vided their assigned care } \\
\text { manager's contact infor- } \\
\text { mation and encouraged } \\
\text { to schedule follow-up } \\
\text { telephone calls or face- } \\
\text { to-face visits with that } \\
\text { care manager. Each pa- } \\
\text { tient was also provided }\end{array}$ & $\begin{array}{l}\text { No for improving adher- } \\
\text { ence to medication at } 6 \\
\text { months }\end{array}$ & $\begin{array}{l}\text { Yes for reducing the } \\
\text { mean HbA1c level and } \\
\text { increasing social support } \\
\text { score at } 6 \text { months. No } \\
\text { for reducing blood pres- } \\
\text { sure and diabetes-relat- } \\
\text { ed emotional distress at } \\
6 \text { months }\end{array}$ \\
\hline
\end{tabular}




\begin{tabular}{|c|c|c|c|c|c|}
\hline \multicolumn{6}{|c|}{ Adherence and outcome } \\
\hline Study & Clinical problem & Intervention & Control & $\begin{array}{l}\text { Effect on adherence } \\
\text { (Yes means a statis- } \\
\text { tically significant ef- } \\
\text { fect in favor of the } \\
\text { intervention; No } \\
\text { means no effect or } \\
\text { a negative effect) }\end{array}$ & $\begin{array}{l}\text { Effect on clin- } \\
\text { ical outcome } \\
\text { (Yes means a statis- } \\
\text { tically significant ef- } \\
\text { fect in favor of the } \\
\text { intervention; No } \\
\text { means no effect or } \\
\text { a negative effect) }\end{array}$ \\
\hline & & $\begin{array}{l}\text { partners to contact each } \\
\text { other without exchang- } \\
\text { ing telephone numbers } \\
\text { and to set periods dur- } \\
\text { ing which calls could be } \\
\text { blocked; and generated } \\
\text { automated reminders } \\
\text { every } 7 \text { days if no peer } \\
\text { calls were attempted. } \\
\text { During a reminder call, } \\
\text { patients could be trans- } \\
\text { ferred automatically to } \\
\text { their peer partner's num- } \\
\text { ber. The system also al- } \\
\text { lowed patients to leave } \\
\text { voice messages for re- } \\
\text { search staff or care man- } \\
\text { agers. At the end of the } \\
\text { initial session, patients } \\
\text { were given a DVD that } \\
\text { demonstrated peer com- } \\
\text { munication skills and a } \\
\text { diabetes self manage- } \\
\text { ment workbook that } \\
\text { they could use to help } \\
\text { guide their peer tele- } \\
\text { phone calls. Patients } \\
\text { were also offered } 3 \text { op- } \\
\text { tional } 1.5 \text {-hour group } \\
\text { sessions at months } 1,3 \text {, } \\
\text { and } 6 \text {. These were com- } \\
\text { pletely patient-driven } \\
\text { sessions at which pa- } \\
\text { tients were encouraged } \\
\text { to share concerns, ques- } \\
\text { tions, strategies, and } \\
\text { progress on their action } \\
\text { plans. Sessions were fa- } \\
\text { cilitated by a care man- } \\
\text { ager and a research as- } \\
\text { sociate. Research asso- } \\
\text { ciates were present to } \\
\text { help maintain interven- } \\
\text { tion fidelity by encour- } \\
\text { aging nondirective facil- } \\
\text { itation of group discus- } \\
\text { sions and to complete } \\
\text { a checklist of key areas } \\
\text { covered and communi- } \\
\text { cation skills used in each } \\
\text { session } \\
\text { (n= } 126 \text { ) }\end{array}$ & $\begin{array}{l}\text { with diabetes self man- } \\
\text { agement educational } \\
\text { materials. Patients in the } \\
\text { NCM group thus received } \\
\text { enhanced usual care, be- } \\
\text { cause even though they } \\
\text { would all be eligible for } \\
\text { nurse care manager sup- } \\
\text { port at the study sites, } \\
\text { many patients are not } \\
\text { aware of and do not avail } \\
\text { themselves of this ser- } \\
\text { vice unless referred by } \\
\text { their physician } \\
\text { ( } n=119 \text { ) }\end{array}$ & & \\
\hline Henry 1999 & H. Pylori infection & $\begin{array}{l}10 \text { days of omeprazole } \\
20 \text { mg twice daily, amox- } \\
\text { icillin } 500 \text { mg } 3 \text { times a } \\
\text { day and metronidazole } \\
400 \text { mg } 3 \text { times a day, } \\
\text { verbal advice on medica- } \\
\text { tion use and its possible } \\
\text { side effects in an initial } \\
\text { 20-minute consultation. } \\
\text { Patients also received } \\
\text { medication in dose-dis- } \\
\text { pensing units, an infor- } \\
\text { mation sheet on } H \text {. Py- } \\
\text { lori treatment, and a } \\
\text { medication chart. Com- } \\
\text { pliance in intervention } \\
\text { group patients was also }\end{array}$ & $\begin{array}{l}10 \text { days of omeprazole } \\
20 \mathrm{mg} \text { twice daily, amox- } \\
\text { icillin } 500 \mathrm{mg} 3 \text { times a } \\
\text { day and metronidazole } \\
400 \mathrm{mg} 3 \text { times a day, } \\
\text { verbal advice on medica- } \\
\text { tion use and its possible } \\
\text { side effects in an initial } \\
20 \text {-minute consultation } \\
(\mathrm{n}=59)\end{array}$ & No & No \\
\hline
\end{tabular}




\begin{tabular}{|c|c|c|c|c|c|}
\hline \multicolumn{6}{|c|}{ Adherence and outcome } \\
\hline Study & Clinical problem & Intervention & Control & $\begin{array}{l}\text { Effect on adherence } \\
\text { (Yes means a statis- } \\
\text { tically significant ef- } \\
\text { fect in favor of the } \\
\text { intervention; No } \\
\text { means no effect or } \\
\text { a negative effect) }\end{array}$ & $\begin{array}{l}\text { Effect on clin- } \\
\text { ical outcome } \\
\text { (Yes means a statis- } \\
\text { tically significant ef- } \\
\text { fect in favor of the } \\
\text { intervention; No } \\
\text { means no effect or } \\
\text { a negative effect) }\end{array}$ \\
\hline & & $\begin{array}{l}\text { encouraged by a phone } \\
\text { call } 2 \text { days after the start } \\
\text { of therapy }(n=60)\end{array}$ & & & \\
\hline Hill 2001 & Rheumatoid arthritis & $\begin{array}{l}\text { The intervention group } \\
(\mathrm{n}=51) \text { received } 7 \times 30 \\
\text { minute one to one ses- } \\
\text { sions of patient educa- } \\
\text { tion }\end{array}$ & $\begin{array}{l}\text { The control group }(n= \\
\text { 49) received standard } \\
\text { management }\end{array}$ & $\begin{array}{l}\text { Yes for improving adher- } \\
\text { ence to D-penicillamine } \\
\text { (DPA) for rheumatoid } \\
\text { arthritis }\end{array}$ & $\begin{array}{l}\text { No for improving clin- } \\
\text { ical outcomes of plas- } \\
\text { ma viscosity, c-reactive } \\
\text { protein, articular index, } \\
\text { morning stiffness and } \\
\text { pain score }\end{array}$ \\
\hline Holland 2007 & Heart failure & 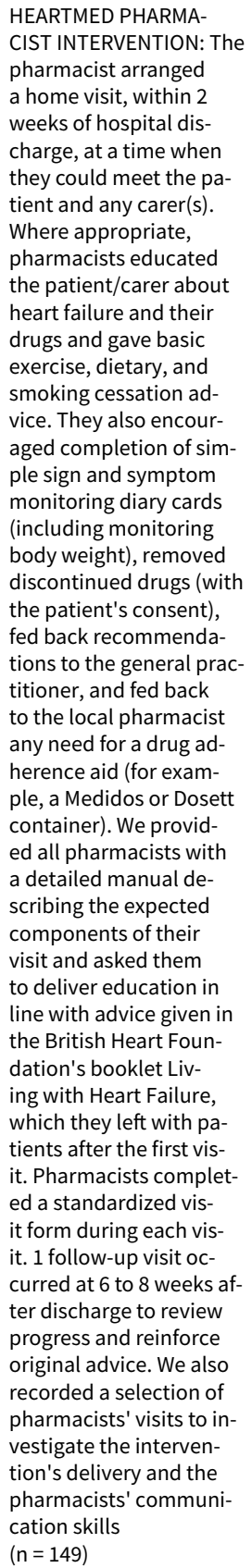 & $\begin{array}{l}\text { USUAL CARE: The na- } \\
\text { ture of the interven- } \\
\text { tion meant that no clear } \\
\text { "placebo" could be pro- } \\
\text { vided. Participants were } \\
\text { told after randomization } \\
\text { which group they were } \\
\text { in. Those in the control } \\
\text { group received usual } \\
\text { care } \\
(n=144)\end{array}$ & $\begin{array}{l}\text { No for improving med- } \\
\text { ication adherence }\end{array}$ & $\begin{array}{l}\text { No for improving quality } \\
\text { of life and reducing ED } \\
\text { visits and admissions }\end{array}$ \\
\hline
\end{tabular}




\begin{tabular}{|c|c|c|c|c|c|}
\hline \multicolumn{6}{|c|}{ Adherence and outcome } \\
\hline Study & Clinical problem & Intervention & Control & $\begin{array}{l}\text { Effect on adherence } \\
\text { (Yes means a statis- } \\
\text { tically significant ef- } \\
\text { fect in favor of the } \\
\text { intervention; No } \\
\text { means no effect or } \\
\text { a negative effect) }\end{array}$ & $\begin{array}{l}\text { Effect on clin- } \\
\text { ical outcome } \\
\text { (Yes means a statis- } \\
\text { tically significant ef- } \\
\text { fect in favor of the } \\
\text { intervention; No } \\
\text { means no effect or } \\
\text { a negative effect) }\end{array}$ \\
\hline Holstad 2011 & HIV & $\begin{array}{l}\text { KHARMA INTERVENTION: } \\
\text { The KHARMA interven- } \\
\text { tion consisted of } 8 \text { group } \\
\text { sessions using motiva- } \\
\text { tional interviewing deliv- } \\
\text { ered in a group format. It } \\
\text { was designed to empow- } \\
\text { er women to make deci- } \\
\text { sions and develop strate- } \\
\text { gies about taking ART as } \\
\text { prescribed and consis- } \\
\text { tently using risk reduc- } \\
\text { tion behaviors, such as } \\
\text { condom use and to over- } \\
\text { come resistance/am- } \\
\text { bivalence to both. The } \\
\text { sessions lasted about } \\
\text { 1.5 to } 2 \text { hours, and were } \\
\text { led by trained MI nurs- } \\
\text { es. The first and last ses- } \\
\text { sion focused on both ad- } \\
\text { herence and risk behav- } \\
\text { ior, } 3 \text { sessions were de- } \\
\text { voted to adherence only } \\
\text { and } 3 \text { to risk reduction } \\
\text { behaviors only, including } \\
\text { a session on disclosure } \\
\text { which is important to } \\
\text { risk reduction as well as } \\
\text { adherence. Each session } \\
\text { included a discussion of } \\
\text { goals and goal setting } \\
\text { related to the topic. MI } \\
\text { techniques were incor- } \\
\text { porated into every ses- } \\
\text { sion. In keeping with } \\
\text { the autonomy support } \\
\text { spirit of MI, participants } \\
\text { as a group chose which } \\
\text { topic they wanted to ad- } \\
\text { dress first. The majority } \\
\text { of groups ( } n=14 \text { ) chose } \\
\text { medication adherence as } \\
\text { the first topic } \\
\text { (n= } 104 \text { ) }\end{array}$ & $\begin{array}{l}\text { HEALTH PROMOTION } \\
\text { PROGRAM: The control } \\
\text { group sessions were } \\
\text { equivalent in length and } \\
\text { time to the MI group and } \\
\text { were led by trained nurs- } \\
\text { es and a health educator. } \\
\text { This group used health } \\
\text { education techniques of } \\
\text { lecture/discussion/edu- } \\
\text { cational games and fo- } \\
\text { cused on nutrition, exer- } \\
\text { cise, stress recognition, } \\
\text { and women's health is- } \\
\text { sues tailored to the HIV- } \\
\text { positive woman. Partici- } \\
\text { pants received a manual } \\
\text { containing content and } \\
\text { supplementary materi- } \\
\text { als for each session. Ad- } \\
\text { herence and RRB were } \\
\text { not addressed in the HPP } \\
\text { and facilitators were in- } \\
\text { structed to redirect the } \\
\text { group if these issues } \\
\text { came up } \\
\text { ( } \mathrm{n}=103 \text { ) }\end{array}$ & $\begin{array}{l}\text { No for improved adher- } \\
\text { ence to ART }\end{array}$ & $\begin{array}{l}\text { Yes for CD4 counts at } 9 \\
\text { months. No for all other } \\
\text { outcomes }\end{array}$ \\
\hline Hou 2010 & oral contraceptive use & $\begin{array}{l}\text { TEXT MESSAGING: Par- } \\
\text { ticipants received daily } \\
\text { text-message reminders. } \\
\text { During the 3-month } \\
\text { study period, each par- } \\
\text { ticipant assigned the } \\
\text { intervention received } \\
\text { a daily text message, } \\
\text { "Please remember to } \\
\text { take your birth control } \\
\text { pill," sent at a designated } \\
\text { time chosen by the par- } \\
\text { ticipant. } \\
\text { (n=41) }\end{array}$ & $\begin{array}{l}\text { USUAL CARE: Patients } \\
\text { in the control group re- } \\
\text { ceived usual care and } \\
\text { were not offered addi- } \\
\text { tional medication re- } \\
\text { minders. } \\
(n=41)\end{array}$ & $\begin{array}{l}\text { No for improving adher- } \\
\text { ence to oral contracep- } \\
\text { tives. }\end{array}$ & $\begin{array}{l}\text { No for pregnancy at } 3 \\
\text { months. }\end{array}$ \\
\hline Howe 2005 & $\begin{array}{l}\text { Children with type } 1 \text { dia- } \\
\text { betes }\end{array}$ & $\begin{array}{l}2 \text { intervention groups, } \\
\text { standard care (see Con- } \\
\text { trol) plus: } 1 \text { ) Education } \\
(E D) \text { - One-time session } \\
\text { by the study co-ordina- } \\
\text { tor that aimed to pro- } \\
\text { vide families with basic } \\
\text { diabetes management } \\
\text { skills ( } n=21) .2 \text { ) Edu- } \\
\text { cation and telephone }\end{array}$ & $\begin{array}{l}\text { Standard care }(\mathrm{SC}) \text { from } \\
\text { a nurse practitioner and } \\
\text { endocrinologist }(n=28)\end{array}$ & $\begin{array}{l}\text { Yes for the adherence } \\
\text { questionnaire }(A D H) \text {, in } \\
\text { comparison between the } \\
\text { ED and TCM group ver- } \\
\text { sus the SC group }\end{array}$ & $\begin{array}{l}\text { No for both intervention } \\
\text { groups }\end{array}$ \\
\hline
\end{tabular}




\begin{tabular}{|c|c|c|c|c|c|}
\hline \multicolumn{6}{|c|}{ Adherence and outcome } \\
\hline Study & Clinical problem & Intervention & Control & $\begin{array}{l}\text { Effect on adherence } \\
\text { (Yes means a statis- } \\
\text { tically significant ef- } \\
\text { fect in favor of the } \\
\text { intervention; No } \\
\text { means no effect or } \\
\text { a negative effect) }\end{array}$ & $\begin{array}{l}\text { Effect on clin- } \\
\text { ical outcome } \\
\text { (Yes means a statis- } \\
\text { tically significant ef- } \\
\text { fect in favor of the } \\
\text { intervention; No } \\
\text { means no effect or } \\
\text { a negative effect) }\end{array}$ \\
\hline & & $\begin{array}{l}\text { case management group } \\
\text { (ED and TCM) -TCM con- } \\
\text { sisted of standardized } \\
\text { telephone calls which } \\
\text { reviewed blood sug- } \\
\text { ars, safety issues, prob- } \\
\text { lem-solving skills, diet } \\
\text { and meal planning, and } \\
\text { changing insulin dose, } \\
\text { as well as parenting and } \\
\text { behavior management } \\
\text { skills with parents as } \\
\text { needed ( } \mathrm{n}=26 \text { ) }\end{array}$ & & & \\
\hline Howland 1990 & Acute infections & $\begin{array}{l}\text { Warnings about poten- } \\
\text { tial adverse effects of } \\
\text { drugs }(n=50)\end{array}$ & $\begin{array}{l}\text { No warnings about ad- } \\
\text { verse effects of drugs ( } n \\
=48 \text { ) }\end{array}$ & No & No \\
\hline Huguelet 2011 & $\begin{array}{l}\text { Schizophrenia or other } \\
\text { non-affective psychoses }\end{array}$ & $\begin{array}{l}\text { RELIGIOUS AND SPIRI- } \\
\text { TUAL ASSESSMENT: The } \\
\text { intervention was deliv- } \\
\text { ered by psychiatrists } \\
\text { who were trained by the } \\
\text { researchers. Psychiatrist } \\
\text { attended a 90-minute } \\
\text { training session dur- } \\
\text { ing which they were in- } \\
\text { formed about the ratio- } \\
\text { nale for taking into ac- } \\
\text { count the spiritual di- } \\
\text { mension in the treat- } \\
\text { ment of patients with } \\
\text { schizophrenia and how } \\
\text { to conduct a spiritual } \\
\text { assessment. They were } \\
\text { made aware of how their } \\
\text { own religious and spiri- } \\
\text { tual experiences could } \\
\text { influence their identity } \\
\text { and world view, as well } \\
\text { as how their attitudes to- } \\
\text { ward such experiences } \\
\text { might introduce biases } \\
\text { into clinical assessment } \\
\text { and treatment. Finally, } \\
\text { psychiatrists were re- } \\
\text { minded to show respect } \\
\text { for patients with differ- } \\
\text { ent religious and spiritu- } \\
\text { al backgrounds. Psychia- } \\
\text { trists used a semi-struc- } \\
\text { tured interview guided } \\
\text { by the following topics: } \\
\text { religious and spiritual } \\
\text { history, effects of illness } \\
\text { on spirituality or reli- } \\
\text { giousness, current spiri- } \\
\text { tual or religious beliefs } \\
\text { and practices, subjective } \\
\text { importance of religion } \\
\text { in general, subjective im- } \\
\text { portance of religion in } \\
\text { coping with the illness, } \\
\text { synergy of religion with } \\
\text { psychiatric care. After } \\
\text { each assessment the } \\
\text { psychiatrist met with } 2 \\
\text { of the authors, a psychi- } \\
\text { atrist and a psycholo- } \\
\text { gist of religion. In these } \\
\text { sessions the individual }\end{array}$ & $\begin{array}{l}\text { USUAL CARE: "For the } \\
\text { control group, psychia- } \\
\text { trists were instructed to } \\
\text { avoid speaking about re- } \\
\text { ligious issues during the } \\
\text { 3-month follow-up peri- } \\
\text { od unless patients spon- } \\
\text { taneously brought up } \\
\text { the subject." (pg 81) } \\
\text { (n=42) }\end{array}$ & $\begin{array}{l}\text { No for improving med- } \\
\text { ication adherence }\end{array}$ & $\begin{array}{l}\text { No for improving posi- } \\
\text { tive and negative syn- } \\
\text { drome scale, global as- } \\
\text { sessment of function- } \\
\text { ing, WHO quality of life } \\
\text { instrument, recovery as- } \\
\text { sessment scale, and so- } \\
\text { cial functioning ques- } \\
\text { tionnaire. Yes for improv- } \\
\text { ing the willingness to ask } \\
\text { for help at } 3 \text { months fol- } \\
\text { low-up }\end{array}$ \\
\hline
\end{tabular}




\begin{tabular}{|c|c|c|c|c|c|}
\hline \multicolumn{6}{|c|}{ Adherence and outcome } \\
\hline Study & Clinical problem & Intervention & Control & $\begin{array}{l}\text { Effect on adherence } \\
\text { (Yes means a statis- } \\
\text { tically significant ef- } \\
\text { fect in favor of the } \\
\text { intervention; No } \\
\text { means no effect or } \\
\text { a negative effect) }\end{array}$ & $\begin{array}{l}\text { Effect on clin- } \\
\text { ical outcome } \\
\text { (Yes means a statis- } \\
\text { tically significant ef- } \\
\text { fect in favor of the } \\
\text { intervention; No } \\
\text { means no effect or } \\
\text { a negative effect) }\end{array}$ \\
\hline & & $\begin{array}{l}\text { patient was discussed } \\
\text { for } 10 \text { to } 40 \text { minutes, de- } \\
\text { pending on the clinical } \\
\text { context. The participat- } \\
\text { ing psychiatrist reported } \\
\text { the outcome of his or her } \\
\text { spiritual assessment and } \\
\text { was given guidance and } \\
\text { advice, similar to clinical } \\
\text { coaching; when needed, } \\
\text { a more thorough discus- } \\
\text { sion from a psychother- } \\
\text { apeutic perspective was } \\
\text { undertaken } \\
\text { ( } \mathrm{n}=42 \text { ) }\end{array}$ & & & \\
\hline Janson 2009 & $\begin{array}{l}\text { Moderate-to-severe per- } \\
\text { sistent asthma }\end{array}$ & $\begin{array}{l}\text { SELF MANAGEMENT ED- } \\
\text { UCATIONAL INTERVEN- } \\
\text { TION: Participants in the } \\
\text { individualized self man- } \\
\text { agement group received } \\
\text { both the self monitoring } \\
\text { of the control group plus } \\
\text { an individualized self } \\
\text { management compo- } \\
\text { nent. Self management } \\
\text { sessions were held by a } \\
\text { certified asthma educa- } \\
\text { tor and respiratory ther- } \\
\text { apist. The sessions con- } \\
\text { sisted of asthma facts } \\
\text { and medication actions } \\
\text { and individualized com- } \\
\text { ponents such as verbal } \\
\text { and graphic interpreta- } \\
\text { tion of spirometric re- } \\
\text { sults, peak flow trends, } \\
\text { metered dose inhaler } \\
\text { technique error, and skin } \\
\text { allergen results (with } \\
\text { strategies to control spe- } \\
\text { cific personal environ- } \\
\text { mental exposures). The } \\
\text { peak flow monitor was } \\
\text { modified for the inter- } \\
\text { vention group to use a } \\
\text { traffic light analogy and } \\
\text { correlated to a simple } \\
\text { written action plan } \\
\text { ( } \mathrm{n}=45 \text { ) }\end{array}$ & $\begin{array}{l}\text { SELF-MONITORING } \\
\text { ALONE: Control patients } \\
\text { attended the same num- } \\
\text { ber of visits as interven- } \\
\text { tion patients, but con- } \\
\text { trol visits were only for } \\
\text { data collection. During } \\
\text { each phase of the tri- } \\
\text { al, all participants mea- } \\
\text { sured morning peak flow } \\
\text { with an electronic peak } \\
\text { flowmeter (Airwatch; } \\
\text { iMetrikus, Carlsbad, } \\
\text { Calif) and also recorded } \\
\text { their daily values in a di- } \\
\text { ary. All participants were } \\
\text { told that higher peak } \\
\text { flow numbers meant } \\
\text { their airways were more } \\
\text { open and lower num- } \\
\text { bers meant their air- } \\
\text { ways were more closed. } \\
\text { An electronic medica- } \\
\text { tion monitor, which con- } \\
\text { cealed readings from the } \\
\text { subject (Doser CT; Med- } \\
\text { iTrack, Hudson, Mass), } \\
\text { was placed on each ICS } \\
\text { inhaler. Participants also } \\
\text { monitored daily symp- } \\
\text { toms, night-time awak- } \\
\text { enings, and tabulated } \\
\text { ICS and inhaled b-ago- } \\
\text { nist (IBA) use in the di- } \\
\text { ary. Data from the elec- } \\
\text { tronic monitors and di- } \\
\text { ary pages were collected } \\
\text { at each study visit } \\
\text { (n = 39) }\end{array}$ & $\begin{array}{l}\text { Yes for maintaining > } \\
60 \% \text { adherence during } \\
\text { the intervention period; } \\
\text { No for mean adherence, } \\
\text { mean change in adher- } \\
\text { ence, and for maintain- } \\
\text { ing }>60 \% \text { adherence at } \\
\text { the end of the study }\end{array}$ & $\begin{array}{l}\text { Yes for night-time awak- } \\
\text { enings during the study } \\
\text { period, beta-agonist } \\
\text { use during the interven- } \\
\text { tion period, and mean } \\
\text { neutrophil count over } \\
\text { the study period. No for } \\
\text { FEV1, morning peak flow, } \\
\text { perceived asthma con- } \\
\text { trol, quality of life, symp- } \\
\text { tom score, ECP, symp- } \\
\text { tom-free days, night- } \\
\text { time awakenings dur- } \\
\text { ing the intervention, be- } \\
\text { ta-agonist use over the } \\
\text { entire study period, neu- } \\
\text { trophil counts during } \\
\text { the intervention, and } \\
\text { eosinophils and tryptase } \\
\text { counts }\end{array}$ \\
\hline Jarab 2012 a & Type 2 diabetes & $\begin{array}{l}\text { PHARMACIST INTER- } \\
\text { VENTION: Patients in } \\
\text { the pharmacist inter- } \\
\text { vention group received } \\
\text { structured patient edu- } \\
\text { cation and discussion } \\
\text { about type } 2 \text { diabetes, } \\
\text { risks and complications } \\
\text { from diabetes, the pre- } \\
\text { scribed drug therapy, } \\
\text { proper dosage, side ef- } \\
\text { fects, and the impor- } \\
\text { tance of medication ad- } \\
\text { herence. The pharmacist } \\
\text { also emphasized lifestyle }\end{array}$ & $\begin{array}{l}\text { USUAL CARE: Control pa- } \\
\text { tients ( } \mathrm{n}=85 \text { ) received } \\
\text { usual care by medical } \\
\text { and nursing staff (pa- } \\
\text { tient assessment; } 3 \text { - or } \\
6 \text {-month blood glucose } \\
\text { and blood pressure mea- } \\
\text { surements; advice on } \\
\text { self monitoring blood } \\
\text { glucose, and nutrition } \\
\text { counseling) } \\
(\mathrm{n}=86)\end{array}$ & $\begin{array}{l}\text { Yes for improving med- } \\
\text { ication adherence at } 6 \\
\text { months }\end{array}$ & $\begin{array}{l}\text { Yes for A1c values, sys- } \\
\text { tolic and diastolic blood } \\
\text { pressure, and LDL-C lev- } \\
\text { els; No for HDL-C levels } \\
\text { and BMI }\end{array}$ \\
\hline
\end{tabular}




\begin{tabular}{|c|c|c|c|c|c|}
\hline \multicolumn{6}{|c|}{ Adherence and outcome } \\
\hline Study & Clinical problem & Intervention & Control & $\begin{array}{l}\text { Effect on adherence } \\
\text { (Yes means a statis- } \\
\text { tically significant ef- } \\
\text { fect in favor of the } \\
\text { intervention; No } \\
\text { means no effect or } \\
\text { a negative effect) }\end{array}$ & $\begin{array}{l}\text { Effect on clin- } \\
\text { ical outcome } \\
\text { (Yes means a statis- } \\
\text { tically significant ef- } \\
\text { fect in favor of the } \\
\text { intervention; No } \\
\text { means no effect or } \\
\text { a negative effect) }\end{array}$ \\
\hline & & $\begin{array}{l}\text { management (changing } \\
\text { unhealthy dietary habits } \\
\text { that affect blood glu- } \\
\text { cose, blood pressure and } \\
\text { lipid levels; regular phys- } \\
\text { ical activity; and moni- } \\
\text { toring and record blood } \\
\text { glucose levels). Smokers } \\
\text { were referred to a hos- } \\
\text { pital-run smoking ces- } \\
\text { sation program. A spe- } \\
\text { cial booklet on diabetes } \\
\text { and lifestyle changes was } \\
\text { given to each patient. } 8 \\
\text { weekly telephone calls } \\
\text { were made by the phar- } \\
\text { macist to discuss and } \\
\text { review prescribed ther- } \\
\text { apy, emphasize the im- } \\
\text { portance of adherence, } \\
\text { and to answer patient } \\
\text { questions or address } \\
\text { concerns. Each call aver- } \\
\text { age } 20 \text { minutes } \\
\text { (n= } 85 \text { ) }\end{array}$ & & & \\
\hline Jarab 2012 b & $\begin{array}{l}\text { Chronic obstructive pul- } \\
\text { monary disease }\end{array}$ & $\begin{array}{l}\text { PHARMACIST INTERVEN- } \\
\text { TION: Intervention par- } \\
\text { ticipants received struc- } \\
\text { tured education about } \\
\text { chronic obstructive pul- } \\
\text { monary disease (COPD) } \\
\text { and management of its } \\
\text { symptoms from a clinical } \\
\text { pharmacist in a separate } \\
\text { room at the outpatient } \\
\text { clinic. The pharmacist } \\
\text { also completed a med- } \\
\text { ication table designed } \\
\text { specifically to discuss } \\
\text { types, indications, dos- } \\
\text { es, frequency of admin- } \\
\text { istration, and possible } \\
\text { side effects for each pre- } \\
\text { scribed medication. The } \\
\text { importance of simple ex- } \\
\text { ercises symptoms con- } \\
\text { trol and the technique } \\
\text { for expectoration were } \\
\text { discussed with the in- } \\
\text { tervention patients. A } \\
\text { booklet on these tech- } \\
\text { niques was prepared } \\
\text { to assist in the educa- } \\
\text { tion session and the pa- } \\
\text { tients were given a copy } \\
\text { to take home with them. } \\
\text { The clinical pharmacist } \\
\text { used the motivational } \\
\text { interviewing technique } \\
\text { with the aim of improv- } \\
\text { ing adherence to the pre- } \\
\text { scribed treatment. Pa- } \\
\text { tients who still smoked } \\
\text { were referred to a special } \\
\text { smoking cessation pro- } \\
\text { gram within the hospital } \\
\text { (n = 66) }\end{array}$ & $\begin{array}{l}\text { TREATMENT AS USUAL: } \\
\text { Controls did not receive } \\
\text { pharmacists care } \\
(\mathrm{n}=67)\end{array}$ & $\begin{array}{l}\text { Yes for improving adher- } \\
\text { ence to medication at } 6 \\
\text { months }\end{array}$ & $\begin{array}{l}\text { No for change in forced } \\
\text { expiratory volume in } 1 \\
\text { second (FEV1) and BMI } \\
\text { at } 6 \text { months. No for dif- } \\
\text { ference in health-related } \\
\text { quality of life and emer- } \\
\text { gency department visit } \\
\text { for acute exacerbation } \\
\text { of COPD at } 6 \text { months. Yes } \\
\text { for reducing hospital ad- } \\
\text { missions for acute exac- } \\
\text { erbation of COPD at } 6 \\
\text { months }\end{array}$ \\
\hline
\end{tabular}




\begin{tabular}{|c|c|c|c|c|c|}
\hline \multicolumn{6}{|c|}{ Adherence and outcome } \\
\hline Study & Clinical problem & Intervention & Control & $\begin{array}{l}\text { Effect on adherence } \\
\text { (Yes means a statis- } \\
\text { tically significant ef- } \\
\text { fect in favor of the } \\
\text { intervention; No } \\
\text { means no effect or } \\
\text { a negative effect) }\end{array}$ & $\begin{array}{l}\text { Effect on clin- } \\
\text { ical outcome } \\
\text { (Yes means a statis- } \\
\text { tically significant ef- } \\
\text { fect in favor of the } \\
\text { intervention; No } \\
\text { means no effect or } \\
\text { a negative effect) }\end{array}$ \\
\hline Jiang 2007 & $\begin{array}{l}\text { Coronary heart disease } \\
\text { (angina pectoris or my- } \\
\text { ocardial infarction) }\end{array}$ & $\begin{array}{l}\text { CARDIAC REHABILI- } \\
\text { TATION PROGRAM: Pa- } \\
\text { tients in the interven- } \\
\text { tion group received a 12- } \\
\text { week, hospital-initiated, } \\
\text { home-based multifac- } \\
\text { eted cardiac rehabilita- } \\
\text { tion intervention led by } \\
\text { a nurse. Phase I of the in- } \\
\text { tervention involved in- } \\
\text { hospital individual and } \\
\text { family education about } \\
\text { CHD and self manage- } \\
\text { ment principles, medica- } \\
\text { tion management, angi- } \\
\text { na prevention and man- } \\
\text { agement, physical ex- } \\
\text { ercise, dietary manage- } \\
\text { ment, smoking cessa- } \\
\text { tion, and family support. } \\
\text { All sessions employed } \\
\text { principles of adult learn- } \\
\text { ing and were short to fa- } \\
\text { cilitate time for discus- } \\
\text { sion. All participants re- } \\
\text { ceived a self help practi- } \\
\text { cal workbook. In Phase } \\
\text { Il of the intervention } \\
\text { provided home-based } \\
\text { supervision, coaching } \\
\text { and support by a experi- } \\
\text { enced cardiac nurse over } \\
12 \text { weeks using home vis- } \\
\text { its and telephone calls } \\
\text { that included goal set- } \\
\text { ting, practice, monitor- } \\
\text { ing, problem-solving and } \\
\text { reinforcement, with iter- } \\
\text { ation of this process to } \\
\text { ensure the achievement } \\
\text { pof mutually set behav- } \\
\text { ioral goals on a daily ba- } \\
\text { (n } 83 \text { ) } \\
\text { sis and used a log record } \\
\text { for goal-directed self re- } \\
\text { porting, self monitoring } \\
\text { and self reinforcement } \\
\text { of daily rehabilitative be- } \\
\text { haviors and mobilization } \\
\text { of the family to join the } \\
\text { pehavioral change and } \\
\text { apropriate sup- }\end{array}$ & $\begin{array}{l}\text { ROUTINE CARE: Control } \\
\text { patients received con- } \\
\text { ventional care and were } \\
\text { not offered any addition- } \\
\text { al interventions } \\
(\mathrm{n}=84)\end{array}$ & $\begin{array}{l}\text { Yes for improving adher- } \\
\text { ence to medication at } 3 \\
\text { months. No for improv- } \\
\text { ing adherence to med- } \\
\text { ication at } 6 \text { months }\end{array}$ & $\begin{array}{l}\text { Yes for reducing serum } \\
\text { lipids (TG, TC, LDL - ex- } \\
\text { cept for HDL) and sys- } \\
\text { tolic and diastolic BP at } \\
3 \text { months. No for body } \\
\text { weight at any point } \\
\text { and blood pressure at } 6 \\
\text { months }\end{array}$ \\
\hline Johnson 1978 & Hypertension & $\begin{array}{l}\text { (a) Self monitoring of } \\
\text { blood pressure at home } \\
(n=34) ;(b) \text { Monthly } \\
\text { home visits by a research } \\
\text { assistant }(n=33) ;(c) \\
\text { Both a and } b(n=35)\end{array}$ & $\begin{array}{l}\text { Neither intervention ( } \mathrm{n} \\
=34 \text { ) }\end{array}$ & No for each intervention & No for each intervention \\
\hline Johnson 2011 & HIV/AIDS & $\begin{array}{l}\text { BALANCE PROJECT EX- } \\
\text { PERIMENTAL INTERVEN- } \\
\text { TION: The intervention } \\
\text { was } 5 \text { 60-minute indi- } \\
\text { vidual counseling ses- } \\
\text { sions with each session } \\
\text { designed around topics } \\
\text { relevant to ART side ef- } \\
\text { fects coping. Interven- } \\
\text { tion sessions followed a }\end{array}$ & $\begin{array}{l}\text { USUAL CARE: Control } \\
\text { group participants re- } \\
\text { ceived treatment as usu- } \\
\text { al and received no active } \\
\text { psychosocial interven- } \\
\text { tions prior to the final tri- } \\
\text { al assessment interview } \\
(n=121)\end{array}$ & $\begin{array}{l}\text { Yes for improving adher- } \\
\text { ence to ART medication } \\
\text { at } 15 \text { months }\end{array}$ & $\begin{array}{l}\text { No for change in SECope } \\
\text { Positive Emotion Fo- } \\
\text { cused Coping, Taking } \\
\text { Side Effect Medications, } \\
\text { and Non-Adherence sub- } \\
\text { scales }\end{array}$ \\
\hline
\end{tabular}




\begin{tabular}{|c|c|c|c|c|c|}
\hline \multicolumn{6}{|c|}{ Adherence and outcome } \\
\hline Study & Clinical problem & Intervention & Control & $\begin{array}{l}\text { Effect on adherence } \\
\text { (Yes means a statis- } \\
\text { tically significant ef- } \\
\text { fect in favor of the } \\
\text { intervention; No } \\
\text { means no effect or } \\
\text { a negative effect) }\end{array}$ & $\begin{array}{l}\text { Effect on clin- } \\
\text { ical outcome } \\
\text { (Yes means a statis- } \\
\text { tically significant ef- } \\
\text { fect in favor of the } \\
\text { intervention; No } \\
\text { means no effect or } \\
\text { a negative effect) }\end{array}$ \\
\hline & & $\begin{array}{l}\text { standard structure and } \\
\text { set of activities, but were } \\
\text { individually tailored to } \\
\text { participants' specific } \\
\text { life contexts, stressors, } \\
\text { and goals. Participants } \\
\text { received USD } 30 \text { at the } \\
\text { 3-month assessment if } \\
\text { they completed all } 5 \text { ses- } \\
\text { sions prior to that as- } \\
\text { sessment interview. The } \\
\text { intervention was deliv- } \\
\text { ered between months } 3 \\
\text { and } 6 \text { of the study } \\
(\mathrm{n}=128)\end{array}$ & & & \\
\hline Kalichman 2011 & HIV & $\begin{array}{l}\text { INTEGRATED INTERVEN- } \\
\text { TION: Intervention was } \\
\text { an integrated risk reduc- } \\
\text { tion and adherence in- } \\
\text { tervention based on the } \\
\text { conflict theory of deci- } \\
\text { sion-making. It consist- } \\
\text { ed of a } 45 \text {-minute one } \\
\text { to one orientation and } \\
\text { goal setting with } 1 \text { of the } \\
\text { group facilitators before } \\
5120 \text {-minute group ses- } \\
\text { sions and a } 60 \text {-minute } \\
\text { post group one to one } \\
\text { counseling session, con- } \\
\text { ducted by facilitators/in- } \\
\text { terventionists. Assess- } \\
\text { ment was done at base- } \\
\text { line, } 3,6 \text {, and } 9 \text {-month } \\
\text { intervals for a total of } 12 \\
\text { months of follow-up } \\
\text { ( } \mathrm{n}=217 \text { ) }\end{array}$ & $\begin{array}{l}\text { ATTENTION CONTROL } \\
\text { CONDITION: Compari- } \\
\text { son intervention group } \\
\text { received 45-minute one- } \\
\text { on-one orientation (with } \\
1 \text { facilitator), 120-minute } \\
5 \text { group sessions (with } \\
\text { male-female facilitator } \\
\text { pairs containing } 8 \text { to } 10 \\
\text { participants of mixed } \\
\text { gender and sexual orien- } \\
\text { tation) and a 60-minute } \\
\text { one-on-one post-group } \\
\text { counseling session. The } \\
\text { first group session fo- } \\
\text { cused on building group } \\
\text { cohesion and discussed } \\
\text { how to access quality } \\
\text { health information. The } \\
\text { remaining } 4 \text { group ses- } \\
\text { sions covered detecting } \\
\text { early warning signs of } \\
\text { cancer, breast and tes- } \\
\text { ticular self examination, } \\
\text { nutrition decision-mak- } \\
\text { ing, healthy food selec- } \\
\text { tion, planning exercise, } \\
\text { and relaxation. The fi- } \\
\text { nal individual counsel- } \\
\text { ing session set personal- } \\
\text { ized health improvement } \\
\text { goals } \\
\text { ( } \mathrm{n}=219 \text { ) }\end{array}$ & $\begin{array}{l}\text { Yes improved adherence } \\
\text { to ART over } 12 \text { months }\end{array}$ & $\begin{array}{l}\text { Yes for sexual risk behav- } \\
\text { ior and STI. Yes for ad- } \\
\text { herence and prevention } \\
\text { strategies and risk com- } \\
\text { pensation beliefs. No for } \\
\text { viral load }\end{array}$ \\
\hline Kato 2008 & Cancer & $\begin{array}{l}\text { CANCER TARGETED } \\
\text { VIDEO GAME: The inter- } \\
\text { vention participants } \\
\text { were given a mini-com- } \\
\text { puter containing com- } \\
\text { mercial game plus the in- } \\
\text { tervention game, which } \\
\text { was a video PC game } \\
\text { called Re-Mission47. In } \\
\text { this game, players con- } \\
\text { trol a nanobot, "Rox- } \\
\text { xi", in 3-dimensional en- } \\
\text { vironments within the } \\
\text { bodies of young patients } \\
\text { with cancers that com- } \\
\text { monly are diagnosed in } \\
\text { AYA. Game content was } \\
\text { engineered to address } \\
\text { behavioral issues that } \\
\text { were identified in litera- } \\
\text { ture reviews and prepro- }\end{array}$ & $\begin{array}{l}\text { COMMERCIAL VIDEO } \\
\text { GAME: The control pa- } \\
\text { tients were provided a } \\
\text { commercial video game } \\
\text { - A PC version of Indiana } \\
\text { Jones and the Emperor's } \\
\text { Tomb served as the con- } \\
\text { trol game because the } \\
\text { play structure and con- } \\
\text { troller interface closely } \\
\text { resembled that of Re- } \\
\text { Mission } \\
\text { ( } \mathrm{n}=178)\end{array}$ & $\begin{array}{l}\text { No for self reported } \\
\text { adherence. Yes for im- } \\
\text { proving adherence to } \\
\text { chemotherapy as evi- } \\
\text { dence by } 6 \mathrm{MMP} \text { concen- } \\
\text { tration alone or com- } \\
\text { bined 6MMP and } 6 \mathrm{TG} \\
\text { concentrations }\end{array}$ & $\begin{array}{l}\text { Yes for improving cancer } \\
\text { knowledge and self effi- } \\
\text { cacy; No for improving } \\
\text { QOL, stress and control }\end{array}$ \\
\hline
\end{tabular}




\begin{tabular}{|c|c|c|c|c|c|}
\hline \multicolumn{6}{|c|}{ Adherence and outcome } \\
\hline Study & Clinical problem & Intervention & Control & $\begin{array}{l}\text { Effect on adherence } \\
\text { (Yes means a statis- } \\
\text { tically significant ef- } \\
\text { fect in favor of the } \\
\text { intervention; No } \\
\text { means no effect or } \\
\text { a negative effect) }\end{array}$ & $\begin{array}{l}\text { Effect on clin- } \\
\text { ical outcome } \\
\text { (Yes means a statis- } \\
\text { tically significant ef- } \\
\text { fect in favor of the } \\
\text { intervention; No } \\
\text { means no effect or } \\
\text { a negative effect) }\end{array}$ \\
\hline & & $\begin{array}{l}\text { duction targeting stud- } \\
\text { ies as critical for optimal } \\
\text { AYA patient participa- } \\
\text { tion in cancer treatment. } \\
\text { Video-game play in- } \\
\text { cludes destroying cancer } \\
\text { cells and managing com- } \\
\text { mon treatment-related } \\
\text { adverse effects such as } \\
\text { bacterial infections, nau- } \\
\text { sea, and constipation } \\
\text { by using chemothera- } \\
\text { py, antibiotics, antiemet- } \\
\text { ics, and a stool soften- } \\
\text { er as ammunition. To } \\
\text { win, players control the } \\
\text { nanobot, Roxxi, to en- } \\
\text { sure strategically that } \\
\text { virtual patients engage } \\
\text { in positive self care be- } \\
\text { haviors, such as taking } \\
\text { oral chemotherapy to } \\
\text { fight cancer cells, taking } \\
\text { antibiotics to fight infec- } \\
\text { tion, taking stool soft- } \\
\text { eners to prevent bowel } \\
\text { perforations, practicing } \\
\text { good mouth care to com- } \\
\text { bat mucositis, using re- } \\
\text { laxation techniques to } \\
\text { reduce stress, and eating } \\
\text { food to gain energy. Nei- } \\
\text { ther the nanobot nor any } \\
\text { of the virtual patients } \\
\text { "die" in the game. If play- } \\
\text { ers "fail" at any point } \\
\text { in the game, then the } \\
\text { nanobot powers down } \\
\text { and players are given } \\
\text { the opportunity to try } \\
\text { the mission again. Play- } \\
\text { ers had to complete mis- } \\
\text { sions successfully before } \\
\text { moving on to the next } \\
\text { level. Participants were } \\
\text { instructed to play for at } \\
\text { least } 1 \text { hour per week } \\
\text { during the 3-month peri- } \\
\text { od } \\
\text { (n= } 197 \text { ) }\end{array}$ & & & \\
\hline Katon 2001 & Depression & $\begin{array}{l}\text { Patient education, } 2 \text { vis- } \\
\text { its with a depression } \\
\text { specialist, telephone } \\
\text { monitoring and fol- } \\
\text { low-up }(n=194)\end{array}$ & Usual care $(n=192)$ & Yes & $\begin{array}{l}\text { Yes for SCL-20 scores and } \\
\text { depressive symptoms. } \\
\text { No for episodes of re- } \\
\text { lapse/recurrence }\end{array}$ \\
\hline Kemp 1996 & Acute psychosis & $\begin{array}{l}4 \text { to } 6 \text { sessions of com- } \\
\text { pliance therapy that fo- } \\
\text { cused on illness, concep- } \\
\text { tualization of the prob- } \\
\text { lem, symptoms, side ef- } \\
\text { fects of treatment, and } \\
\text { the stigma of drug treat- } \\
\text { ment }(n=25)\end{array}$ & $\begin{array}{l}4 \text { to } 6 \text { session non-specif- } \\
\text { ic counseling }(n=22)\end{array}$ & Yes & $\begin{array}{l}\text { Yes for global function- } \\
\text { ing assessment. Yes for } \\
\text { full version of the brief } \\
\text { psychiatric rating scale. } \\
\text { No for the abridged ver- } \\
\text { sion of the brief psychi- } \\
\text { atric rating scale. No for } \\
\text { dose of antipsychotic } \\
\text { drug }\end{array}$ \\
\hline Kemp 1998 & Psychotic disorders & $\begin{array}{l}4 \text { to } 6 \text { sessions of com- } \\
\text { pliance therapy that fo- } \\
\text { cused on illness, concep- } \\
\text { tualization of the prob- } \\
\text { lem, symptoms, side ef- }\end{array}$ & $\begin{array}{l}4 \text { to } 6 \text { session non-specif- } \\
\text { ic counseling }(n=35)\end{array}$ & Yes, at 12 months. & $\begin{array}{l}\text { No, at } 12 \text { months, for } \\
\text { the } 7 \text {-item version of the } \\
\text { Brief Psychiatric Rating } \\
\text { Scale. Yes, at } 12 \text { months, } \\
\text { for the Global Assess- }\end{array}$ \\
\hline
\end{tabular}




\begin{tabular}{|c|c|c|c|c|c|}
\hline \multicolumn{6}{|c|}{ Adherence and outcome } \\
\hline Study & Clinical problem & Intervention & Control & $\begin{array}{l}\text { Effect on adherence } \\
\text { (Yes means a statis- } \\
\text { tically significant ef- } \\
\text { fect in favor of the } \\
\text { intervention; No } \\
\text { means no effect or } \\
\text { a negative effect) }\end{array}$ & $\begin{array}{l}\text { Effect on clin- } \\
\text { ical outcome } \\
\text { (Yes means a statis- } \\
\text { tically significant ef- } \\
\text { fect in favor of the } \\
\text { intervention; No } \\
\text { means no effect or } \\
\text { a negative effect) }\end{array}$ \\
\hline & & $\begin{array}{l}\text { fects of treatment, and } \\
\text { the stigma of drug treat- } \\
\text { ment }(n=39)\end{array}$ & & & $\begin{array}{l}\text { ment of Function. Yes, at } \\
6 \text { months, for the Sched- } \\
\text { ule for Assessment of In- } \\
\text { sight }\end{array}$ \\
\hline Khdour 2009 & $\begin{array}{l}\text { Chronic obstructive pul- } \\
\text { monary disease }\end{array}$ & 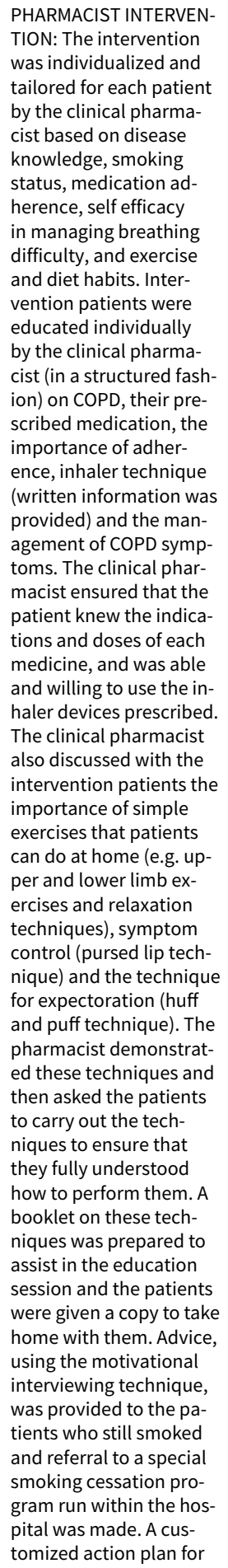 & $\begin{array}{l}\text { USUAL CARE: Control } \\
\text { patients received usual } \\
\text { hospital outpatient care } \\
\text { from medical and nurs- } \\
\text { ing staff } \\
(\mathrm{n}=87)\end{array}$ & $\begin{array}{l}\text { Yes for improving adher- } \\
\text { ence to medication at } 6 \\
\text { and } 12 \text { months }\end{array}$ & $\begin{array}{l}\text { Yes for reducing the } \\
\text { number of exacerbations } \\
\text { of COPD and hospitaliza- } \\
\text { tions at } 12 \text { months. Yes } \\
\text { for improving symptoms } \\
\text { and impact but no for } \\
\text { improving activity at } 6 \\
\text { and } 12 \text { months. No for } \\
\text { change in forced expira- } \\
\text { tory volume in } 1 \text { second } \\
\text { and body mass index at } \\
12 \text { months }\end{array}$ \\
\hline
\end{tabular}




\begin{tabular}{|c|c|c|c|c|c|}
\hline \multicolumn{6}{|c|}{ Adherence and outcome } \\
\hline Study & Clinical problem & Intervention & Control & $\begin{array}{l}\text { Effect on adherence } \\
\text { (Yes means a statis- } \\
\text { tically significant ef- } \\
\text { fect in favor of the } \\
\text { intervention; No } \\
\text { means no effect or } \\
\text { a negative effect) }\end{array}$ & $\begin{array}{l}\text { Effect on clin- } \\
\text { ical outcome } \\
\text { (Yes means a statis- } \\
\text { tically significant ef- } \\
\text { fect in favor of the } \\
\text { intervention; No } \\
\text { means no effect or } \\
\text { a negative effect) }\end{array}$ \\
\hline & & $\begin{array}{l}\text { acute exacerbations, in- } \\
\text { cluding advice to GPs } \\
\text { to provide a prescrip- } \\
\text { tion for an antibiotic } \\
\text { (amoxicillin/clavulanic } \\
\text { acid) and an oral corti- } \\
\text { costeroid to be initiat- } \\
\text { ed promptly by patients } \\
\text { for exacerbations,was } \\
\text { developed for each pa- } \\
\text { tient. The clinical phar- } \\
\text { macist through motiva- } \\
\text { tional interviewing at- } \\
\text { tempted to increase the } \\
\text { intervention patients' } \\
\text { self efficacy to manage } \\
\text { or avoid breathing dif- } \\
\text { ficulty while participat- } \\
\text { ing in certain activities. } \\
\text { The interventions were } \\
\text { tailored according to } \\
\text { the preliminary assess- } \\
\text { ment, i.e. checklists of } \\
\text { patients' needs were } \\
\text { prepared by the research } \\
\text { pharmacist and forward- } \\
\text { ed to the clinical phar- } \\
\text { macist to discuss with } \\
\text { the patients. The initial } \\
\text { intervention lasted for } \\
\text { approximately } 1 \text { hour } \\
\text { for non-smoker patients } \\
\text { and slightly longer for } \\
\text { patients who currently } \\
\text { smoked. At each outpa- } \\
\text { tient clinic visit (every } \\
6 \text { months arranged by } \\
\text { the hospital consultant), } \\
\text { intervention group pa- } \\
\text { tients received reinforce- } \\
\text { ment of the education } \\
\text { on coPD and its treat- } \\
\text { ment from the clinical } \\
\text { pharmacist. In addition, } \\
\text { follow-up telephone } \\
\text { calls by the clinical phar- } \\
\text { macist to reinforce the } \\
\text { education and motivate } \\
\text { the patients to achieve } \\
\text { their goals were made at } \\
\text { tween outpatient clinic } \\
\text { appointments } \\
\text { (n = } 86 \text { ) }\end{array}$ & & & \\
\hline Kimmel 2012 & $\begin{array}{l}\text { No specific clinical prob- } \\
\text { lems; patients just need- } \\
\text { ed to be on warfarin }\end{array}$ & $\begin{array}{l}\text { LOTTERY-BASED INCEN- } \\
\text { TIVES: Patients in the in- } \\
\text { tervention group were } \\
\text { offered financial incen- } \\
\text { tives to remain adher- } \\
\text { ent. All patients were } \\
\text { provided with an In- } \\
\text { formedix Med-eMoni- } \\
\text { tor System, which has a } \\
\text { display screen and sep- } \\
\text { arate medication com- } \\
\text { partments in which to } \\
\text { place their warfarin. The } \\
\text { monitor connects to an } \\
\text { analog telephone line. }\end{array}$ & $\begin{array}{l}\text { CONTROL: Patients in } \\
\text { the control arm were set } \\
\text { up with the Med-eMoni- } \\
\text { tor in order to measure } \\
\text { medication adherence. } \\
\text { Participants were also } \\
\text { seen by their anticoagu- } \\
\text { lation clinic practitioner } \\
\text { as they normally would } \\
\text { and by the study staff } \\
\text { at baseline, } 2 \text { weeks, } 3 \\
\text { months, and } 6 \text { months } \\
\text { ( } \mathrm{n}=48 \text { ) }\end{array}$ & $\begin{array}{l}\text { No for improving over- } \\
\text { all adherence. No for im- } \\
\text { proving adherence in } \\
\text { a priori group with INR } \\
\text { above target range }\end{array}$ & $\begin{array}{l}\text { No for overall anticoag- } \\
\text { ulation control. Yes for } \\
\text { anticoagulation control } \\
\text { in subjects below target } \\
\text { range and no for subjects } \\
\text { above target range }\end{array}$ \\
\hline
\end{tabular}




\begin{tabular}{|c|c|c|c|c|c|}
\hline \multicolumn{6}{|c|}{ Adherence and outcome } \\
\hline Study & Clinical problem & Intervention & Control & $\begin{array}{l}\text { Effect on adherence } \\
\text { (Yes means a statis- } \\
\text { tically significant ef- } \\
\text { fect in favor of the } \\
\text { intervention; No } \\
\text { means no effect or } \\
\text { a negative effect) }\end{array}$ & $\begin{array}{l}\text { Effect on clin- } \\
\text { ical outcome } \\
\text { (Yes means a statis- } \\
\text { tically significant ef- } \\
\text { fect in favor of the } \\
\text { intervention; No } \\
\text { means no effect or } \\
\text { a negative effect) }\end{array}$ \\
\hline & & $\begin{array}{l}\text { They were enrolled in } \\
\text { a daily lottery in a daily } \\
\text { lottery, administered via } \\
\text { the Med-eMonitor, with } \\
\text { an expected daily value } \\
\text { of USD } 3 \text {, or (2) no lot- } \\
\text { tery intervention. partici- } \\
\text { pants had a } 1 \text { in } 5 \text { chance } \\
\text { of a USD } 10 \text { reward and } \\
1 \text { in } 100 \text { chance of a USD } \\
100 \text { reward each day if } \\
\text { they opened the moni- } \\
\text { tor's pill compartment } \\
\text { and confirmed that they } \\
\text { took their warfarin as } \\
\text { prescribed that day. If } \\
\text { patients were told to not } \\
\text { take warfarin on a partic- } \\
\text { ular day, they would only } \\
\text { be eligible for the lottery } \\
\text { if they did not take a pill } \\
\text { that day } \\
\text { ( } \mathrm{n}=53 \text { ) }\end{array}$ & & & \\
\hline Klein 2009 & $\begin{array}{l}\text { Rejection episodes in liv- } \\
\text { er transplanted patients }\end{array}$ & $\begin{array}{l}\text { PHARMACEUTICAL CARE: } \\
\text { In addition to routine } \\
\text { clinical care, patients in } \\
\text { the intervention group } \\
\text { received pharmaceuti- } \\
\text { cal care services provid- } \\
\text { ed by a dedicated hos- } \\
\text { pital pharmacist. The } \\
\text { pharmaceutical care } \\
\text { program usually started } \\
\text { about } 1 \text { week before dis- } \\
\text { charge from the trans- } \\
\text { plant surgery unit. The } \\
\text { hospital pharmacist met } \\
\text { with the patient } 3 \text { to } 4 \\
\text { times and educated him } \\
\text { on different issues re- } \\
\text { garding immunosup- } \\
\text { pressive medication, for } \\
\text { example, action of the } \\
\text { drugs, side effects, in- } \\
\text { teractions, vital signs, } \\
\text { laboratory data, and dis- } \\
\text { charge medication. On } \\
\text { discharge, the hospi- } \\
\text { tal pharmacist handed } \\
\text { out and explained writ- } \\
\text { ten information, includ- } \\
\text { ing a discharge medica- } \\
\text { tion plan, information } \\
\text { regarding the immuno- } \\
\text { suppressive therapy, and } \\
\text { a diary for document- } \\
\text { ing vital signs and labo- } \\
\text { ratory data. During the } \\
\text { first year after transplan- } \\
\text { tation, the patient met } \\
\text { the pharmacist at least } \\
\text { once per quarter year } \\
\text { and at maximum once } \\
\text { per month. During these } \\
\text { meetings the pharmacist } \\
\text { discussed with the pa- } \\
\text { tient changes in medica- } \\
\text { tion, laboratory values, } \\
\text { and drug-related prob- }\end{array}$ & $\begin{array}{l}\text { CONTROL: Patients in } \\
\text { the control group did } \\
\text { not receive pharmaceu- } \\
\text { tical care but they re- } \\
\text { ceived routine clinical } \\
\text { care. from the same hos- } \\
\text { pital pharmacist as the } \\
\text { intervention group } \\
(n=24)\end{array}$ & Yes for adherence & No for rejection episodes \\
\hline
\end{tabular}




\begin{tabular}{|c|c|c|c|c|c|}
\hline \multicolumn{6}{|c|}{ Adherence and outcome } \\
\hline Study & Clinical problem & Intervention & Control & $\begin{array}{l}\text { Effect on adherence } \\
\text { (Yes means a statis- } \\
\text { tically significant ef- } \\
\text { fect in favor of the } \\
\text { intervention; No } \\
\text { means no effect or } \\
\text { a negative effect) }\end{array}$ & $\begin{array}{l}\text { Effect on clin- } \\
\text { ical outcome } \\
\text { (Yes means a statis- } \\
\text { tically significant ef- } \\
\text { fect in favor of the } \\
\text { intervention; No } \\
\text { means no effect or } \\
\text { a negative effect) }\end{array}$ \\
\hline & & $\begin{array}{l}\text { lems. Preferably, family } \\
\text { members were involved. } \\
\text { In addition, the hospital } \\
\text { pharmacist reviewed the } \\
\text { patients' drug therapy, } \\
\text { to minimize drug-related } \\
\text { problems, and simplify } \\
\text { drug regimens } \\
(\mathrm{n}=26)\end{array}$ & & & \\
\hline Kunutsor 2011 & HIV & $\begin{array}{l}\text { TREATMENT SUPPORT- } \\
\text { ER INITIATIVE: Patients } \\
\text { in the TS arm received } \\
\text { both the TS interven- } \\
\text { tion and the standard } \\
\text { adherence intervention } \\
\text { package. Elements of the } \\
\text { standard intervention } \\
\text { package consisted of self } \\
\text { monitoring of medica- } \\
\text { tion taking using adher- } \\
\text { ence diaries; regular in- } \\
\text { dividual and group edu- } \\
\text { cation by peer-workers } \\
\text { using patient education } \\
\text { leaflets and tabletop flip- } \\
\text { charts; and late attendee } \\
\text { tracing. The treatment } \\
\text { supporters were usu- } \\
\text { ally family members- } \\
\text { usually a partner, moth- } \\
\text { er, daughter, sister, } \\
\text { brother, friend, or neigh- } \\
\text { bor/friend-who were } \\
\text { chosen by the patient } \\
\text { with the assistance of } \\
\text { the health workers, had } \\
\text { accepted the patient's } \\
\text { HIV status and were } \\
\text { confidantes. These in- } \\
\text { dividuals were com- } \\
\text { mitted to support the } \\
\text { patient with ART for a } \\
\text { long time, had gained } \\
\text { the patient's trust over } \\
\text { time, and commanded } \\
\text { respect. Patients were } \\
\text { asked to bring their cho- } \\
\text { sen treatment support- } \\
\text { er to the ART clinic for } \\
\text { the health worker to ex- } \\
\text { plain about ART, adher- } \\
\text { ence and treatment sup- } \\
\text { port. This includes com- } \\
\text { mitment, confidential- } \\
\text { ity, knowledge on HIV } \\
\text { and ART related needs, } \\
\text { and perhaps emergency } \\
\text { resource needs such } \\
\text { as money, help with }\end{array}$ & $\begin{array}{l}\text { STANDARD ADHERENCE } \\
\text { INTERVENTION: Patients } \\
\text { randomized to the con- } \\
\text { trol arm did not have a } \\
\text { treatment supporter but } \\
\text { otherwise received the } \\
\text { same standard adher- } \\
\text { ence intervention pack- } \\
\text { age including the ongo- } \\
\text { ing existing health ed- } \\
\text { ucation and adherence } \\
\text { counseling support that } \\
\text { all patients received dur- } \\
\text { ing routine monthly clin- } \\
\text { ic visits. These existing } \\
\text { interventions are typical } \\
\text { for HIV/ AIDS treatment } \\
\text { programs in Uganda and } \\
\text { the rest of sub-Saharan } \\
\text { Africa } \\
\text { ( } \mathrm{n}=87 \text { ) }\end{array}$ & $\begin{array}{l}\text { No for mean adherence. } \\
\text { Yes for proportion of pa- } \\
\text { tients who were at least } \\
95 \% \text { adherent }\end{array}$ & $\begin{array}{l}\text { No for clinical atten- } \\
\text { dance. No for number of } \\
\text { deaths }\end{array}$ \\
\hline
\end{tabular}




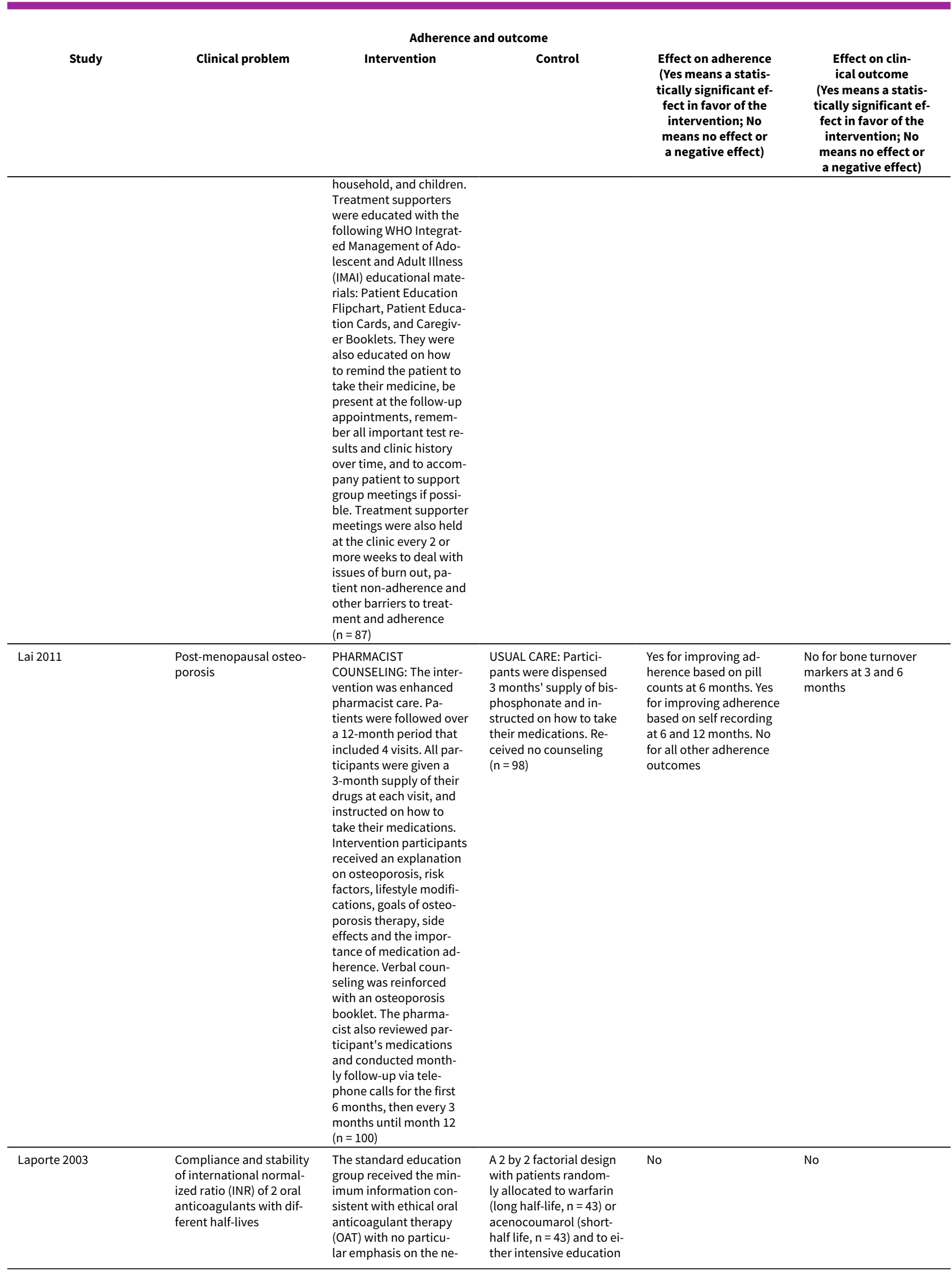




\begin{tabular}{|c|c|c|c|c|c|}
\hline \multicolumn{6}{|c|}{ Adherence and outcome } \\
\hline Study & Clinical problem & Intervention & Control & $\begin{array}{l}\text { Effect on adherence } \\
\text { (Yes means a statis- } \\
\text { tically significant ef- } \\
\text { fect in favor of the } \\
\text { intervention; No } \\
\text { means no effect or } \\
\text { a negative effect) }\end{array}$ & $\begin{array}{l}\text { Effect on clin- } \\
\text { ical outcome } \\
\text { (Yes means a statis- } \\
\text { tically significant ef- } \\
\text { fect in favor of the } \\
\text { intervention; No } \\
\text { means no effect or } \\
\text { a negative effect) }\end{array}$ \\
\hline & & $\begin{array}{l}\text { cessity of strict compli- } \\
\text { ance. Patients in the in- } \\
\text { tensive education group } \\
\text { received information } \\
\text { about the causes of an- } \\
\text { ticoagulation instability } \\
\text { and the importance of } \\
\text { strict adherence. The in- } \\
\text { tensive education group } \\
\text { were provided informa- } \\
\text { tion through visual ma- } \\
\text { terial, were visited daily } \\
\text { by nurses and physicians } \\
\text { to repeat some items, } \\
\text { and were tested daily } \\
\text { about their education. } \\
\text { The education, either } \\
\text { standard or intensive, } \\
\text { was given until hospital } \\
\text { discharge }\end{array}$ & $\begin{array}{l}(n=43) \text { or standard edu- } \\
\text { cation }(n=43)\end{array}$ & & \\
\hline Larrey 2011 & Genotype 1 hepatitis C & $\begin{array}{l}\text { NURSE EDUCATION: The } \\
\text { nurse used a standard- } \\
\text { ized questionnaire to } \\
\text { evaluate the patient's } \\
\text { understanding of the } \\
\text { disease and the side ef- } \\
\text { fects of treatment. The } \\
\text { nurse responded to any } \\
\text { questions and informed } \\
\text { the patient as thorough- } \\
\text { ly as possible with the } \\
\text { means at his/her dispos- } \\
\text { al, including by using } \\
\text { explanatory texts and } \\
\text { drawings. The nurse's } \\
\text { goal during the consulta- } \\
\text { tion was to improve ad- } \\
\text { herence. The following } \\
\text { points were systemati- } \\
\text { cally covered: a) evalu- } \\
\text { ation of the reasons for } \\
\text { any eventual change in } \\
\text { adherence; b) improve- } \\
\text { ment of the quality of } \\
\text { the patient-medical } \\
\text { team relationship; c) ex- } \\
\text { planation of para-clinical } \\
\text { tests on therapeutic fol- } \\
\text { low-up and discussion } \\
\text { of the positive aspects } \\
\text { of the results; d) facili- } \\
\text { tation of the quality of } \\
\text { the patient's relationship } \\
\text { with his/her family and/ } \\
\text { or professional milieu; e) } \\
\text { increasing if necessary } \\
\text { social service support } \\
\text { for the patient. This con- } \\
\text { sultation with the nurse } \\
\text { took place in a standard- } \\
\text { ized fashion, which was } \\
\text { set out in a document to } \\
\text { guide the consultation. } \\
\text { All the nurses involved } \\
\text { in these consultations } \\
\text { had received prior train- } \\
\text { ing in the field of viral he- } \\
\text { patitis and its treatment, } \\
\text { and on the details of this }\end{array}$ & $\begin{array}{l}\text { USUAL CARE: The con- } \\
\text { trol group received con- } \\
\text { ventional clinical fol- } \\
\text { low-up. These patients } \\
\text { did not receive consulta- } \\
\text { tion from the nurses } \\
(\mathrm{n}=121)\end{array}$ & $\begin{array}{l}\text { No for improving adher- } \\
\text { ence }\end{array}$ & $\begin{array}{l}\text { Yes for improving viro- } \\
\text { logical response }\end{array}$ \\
\hline
\end{tabular}




\begin{tabular}{|c|c|c|c|c|c|}
\hline \multicolumn{6}{|c|}{ Adherence and outcome } \\
\hline Study & Clinical problem & Intervention & Control & $\begin{array}{l}\text { Effect on adherence } \\
\text { (Yes means a statis- } \\
\text { tically significant ef- } \\
\text { fect in favor of the } \\
\text { intervention; No } \\
\text { means no effect or } \\
\text { a negative effect) }\end{array}$ & $\begin{array}{l}\text { Effect on clin- } \\
\text { ical outcome } \\
\text { (Yes means a statis- } \\
\text { tically significant ef- } \\
\text { fect in favor of the } \\
\text { intervention; No } \\
\text { means no effect or } \\
\text { a negative effect) }\end{array}$ \\
\hline & & $\begin{array}{l}\text { study. The consultation } \\
\text { lasted between } 30 \text { and } \\
45 \text { minutes. At the end } \\
\text { of the consultation, the } \\
\text { nurse filled out a stan- } \\
\text { dardized questionnaire } \\
\text { build for this study and } \\
\text { comprising } 34 \text { items in } 8 \\
\text { groups The patient could } \\
\text { call the nurse free-of- } \\
\text { charge if necessary out- } \\
\text { side the standard con- } \\
\text { sultation dates } \\
\text { ( } n=123 \text { ) }\end{array}$ & & & \\
\hline Lee 2006 & $\begin{array}{l}\text { Hypertension and hyper- } \\
\text { lipidemia }\end{array}$ & $\begin{array}{l}\text { Comprehensive phar- } \\
\text { macy care program con- } \\
\text { sisting of } 3 \text { elements ( } \mathrm{n}= \\
\text { 83): individualized med- } \\
\text { ication education; med- } \\
\text { ications dispensed using } \\
\text { blister packs; follow-ups } \\
\text { every } 2 \text { months by clini- } \\
\text { cal pharmacists }\end{array}$ & $\begin{array}{l}\text { Usual care }(n=76) \text {; fol- } \\
\text { lowed a } 6 \text {-month com- } \\
\text { prehensive care period; } \\
\text { patients were then given } \\
\text { a 90-day supply of their } \\
\text { medications with one re- } \\
\text { peat) }\end{array}$ & Yes & $\begin{array}{l}\text { Yes for systolic blood } \\
\text { pressure. No for diastolic } \\
\text { blood pressure and LDL- } \\
\text { C }\end{array}$ \\
\hline Lester 2010 & HIV & $\begin{array}{l}\text { SMS GROUP: All inter- } \\
\text { vention group partici- } \\
\text { pants were given brief } \\
\text { training about the use } \\
\text { of SMS intervention by } \\
\text { the study clinicians. On } \\
\text { Monday morning of each } \\
\text { week, the site nurse or } \\
\text { clinical officer sent a text } \\
\text { message via SMS to pa- } \\
\text { tients in the intervention } \\
\text { group to inquire about } \\
\text { their status and thus to } \\
\text { remind them about the } \\
\text { availability of phone- } \\
\text { based support. Regular, } \\
\text { structured mobile phone } \\
\text { communication between } \\
\text { healthcare workers and } \\
\text { patients could improve } \\
\text { patient outcomes by } \\
\text { both reminding patients } \\
\text { to take their ART and by } \\
\text { providing support to the } \\
\text { patients. Patients in the } \\
\text { intervention group were } \\
\text { instructed to respond } \\
\text { within } 48 \text { hours that ei- } \\
\text { ther they were doing } \\
\text { well or that they had a } \\
\text { problem. The clinician } \\
\text { then called patients who } \\
\text { said they had a prob- } \\
\text { lem or who failed to re- } \\
\text { spond within } 2 \text { days. Par- } \\
\text { ticipants were instruct- } \\
\text { ed that healthcare work- } \\
\text { ers were available to } \\
\text { respond during clinic } \\
\text { hours only } \\
\text { ( } \mathrm{n}=273 \text { ) }\end{array}$ & $\begin{array}{l}\text { USUAL CARE: Control } \\
\text { group is standard care. } \\
\text { Standard care at Kija- } \\
\text { iado study site includ- } \\
\text { ed providing } 1 \text { counsel- } \\
\text { ing session at ART initi- } \\
\text { ation and at the } 2 \text { Nairo- } \\
\text { bi sites included provid- } \\
\text { ing } 2 \text { counseling sessions } \\
\text { before and } 1 \text { session } 1 \\
\text { month after ART initia- } \\
\text { tion. Disclosure of HIV } \\
\text { status, pairing up with } \\
\text { a treatment adherence } \\
\text { partner, and participa- } \\
\text { tion in support groups } \\
\text { was encouraged but not } \\
\text { insisted upon. Addition- } \\
\text { al brief counseling was } \\
\text { provided at each site } \\
\text { during dispensation of } \\
\text { the drugs in the clinic or } \\
\text { pharmacy. Patients did } \\
\text { not receive weekly SMS } \\
\text { (n=265) }\end{array}$ & $\begin{array}{l}\text { Yes for improving adher- } \\
\text { ence to ART medication } \\
\text { at } 6 \text { and } 12 \text { months }\end{array}$ & $\begin{array}{l}\text { Yes for viral loads at } 12 \\
\text { months }\end{array}$ \\
\hline Levy 2000 & Acute asthma & $\begin{array}{l}\text { 1-hour structured asth- } \\
\text { ma consultation with } \\
\text { study nurse } 2 \text { weeks af- } \\
\text { ter entry into study, fol- } \\
\text { lowed by } 2 \text { or more } 30 \text { - }\end{array}$ & Usual care $(n=108)$ & $\begin{array}{l}\text { Yes for use of inhaled } \\
\text { topical steroids and res- } \\
\text { cue medication for se- } \\
\text { vere attacks. Not sta- } \\
\text { tistically significant for }\end{array}$ & Yes \\
\hline
\end{tabular}




\begin{tabular}{|c|c|c|c|c|c|}
\hline \multicolumn{6}{|c|}{ Adherence and outcome } \\
\hline Study & Clinical problem & Intervention & Control & $\begin{array}{l}\text { Effect on adherence } \\
\text { (Yes means a statis- } \\
\text { tically significant ef- } \\
\text { fect in favor of the } \\
\text { intervention; No } \\
\text { means no effect or } \\
\text { a negative effect) }\end{array}$ & $\begin{array}{l}\text { Effect on clin- } \\
\text { ical outcome } \\
\text { (Yes means a statis- } \\
\text { tically significant ef- } \\
\text { fect in favor of the } \\
\text { intervention; No } \\
\text { means no effect or } \\
\text { a negative effect) }\end{array}$ \\
\hline & & $\begin{array}{l}\text { minute consultations at } \\
6 \text {-weekly intervals }(n= \\
103 \text { ) }\end{array}$ & & $\begin{array}{l}\text { use of inhaled topical } \\
\text { steroids and rescue med- } \\
\text { ication for mild attacks }\end{array}$ & \\
\hline Maitland 2008 & HIV/AIDS & $\begin{array}{l}\text { ONCE DAILY DOSING } \\
\text { (QD): Patients were } \\
\text { switched to a fixed-dose } \\
\text { combination tablet of } \\
\text { ABC and 3TC dosed once } \\
\text { a day. All other antiretro- } \\
\text { viral agent(s) in the pa- } \\
\text { tient's regimen were } \\
\text { dosed once a day from or } \\
\text { before screening } \\
(\mathrm{n}=48)\end{array}$ & $\begin{array}{l}\text { USUAL DOSING (TWICE A } \\
\text { DAY): Patients remained } \\
\text { on ABC and } 3 T C \text { twice a } \\
\text { day. All other antiretro- } \\
\text { viral agent(s) in the pa- } \\
\text { tient's regimen were } \\
\text { dosed once a day from or } \\
\text { before screening } \\
(n=48)\end{array}$ & $\begin{array}{l}\text { Yes for adherence at } 4 \\
\text { weeks }\end{array}$ & $\begin{array}{l}\text { No for viral load at } 4 \\
\text { weeks. No for HAD at } 4 \\
\text { weeks }\end{array}$ \\
\hline Margolius 2012 & Hypertension & $\begin{array}{l}\text { HOME TITRATION } \\
\text { GROUP: Clinicians of pa- } \\
\text { tients in the home titra- } \\
\text { tion arm completed an } \\
\text { algorithm of antihyper- } \\
\text { tensive medication ad- } \\
\text { justments. Health coach- } \\
\text { es made weekly tele- } \\
\text { phone calls to partici- } \\
\text { pants in both study arms } \\
\text { to discuss overall well- } \\
\text { being, adherence to ac- } \\
\text { tion plans, and blood } \\
\text { pressure values. Patients } \\
\text { in the home titration } \\
\text { arm who reported blood } \\
\text { pressure greater than } \\
140 \text { mm Hg systolic or } \\
\text { greater than } 90 \text { mm Hg } \\
\text { diastolic and excellent } \\
\text { medication adherence } \\
\text { could choose to increase } \\
\text { their antihypertensive } \\
\text { medication regimen ac- } \\
\text { cording to the algorithm } \\
\text { without a clinician ap- } \\
\text { pointment. In those cas- } \\
\text { es, health coaches noti- } \\
\text { fied a physician investi- } \\
\text { gator to fax the prescrip- } \\
\text { tion to the pharmacy. } \\
\text { Clinicians were notified } \\
\text { of medication changes } \\
\text { by e-mail, and health } \\
\text { coaches entered the } \\
\text { change in the electronic } \\
\text { health record. The dura- } \\
\text { tion of the intervention } \\
\text { was } 6 \text { months } \\
\text { ( } \mathrm{n}=129 \text { ) }\end{array}$ & $\begin{array}{l}\text { NO HOME TITRATION: } \\
\text { Home monitoring and } \\
\text { health coaching alone } \\
\text { (no home titration arm), } \\
\text { included health coach- } \\
\text { es made weekly tele- } \\
\text { phone calls to partici- } \\
\text { pants in both study arms } \\
\text { to discuss overall well- } \\
\text { being, adherence to ac- } \\
\text { tion plans, and blood } \\
\text { pressure values. The du- } \\
\text { ration of the intervention } \\
\text { was } 6 \text { months } \\
\text { ( } \mathrm{n}=108 \text { ) }\end{array}$ & $\begin{array}{l}\text { No for adherence at } 6 \\
\text { months }\end{array}$ & $\begin{array}{l}\text { No for blood pressure at } \\
6 \text { months. No for change } \\
\text { in number of primary } \\
\text { care office visits }\end{array}$ \\
\hline Marquez Contreras 2004 & Hypercholesterolemia & $\begin{array}{l}\text { The intervention group } \\
\text { (IG) of } 63 \text { patients re- } \\
\text { ceived the standard care } \\
\text { given to control group, } \\
\text { and in addition received } \\
\text { a telephone call at } 7 \text { to } \\
10 \text { days, } 2 \text { months, and } 4 \\
\text { months. The goal of the } \\
\text { intervention was to es- } \\
\text { tablish the level of com- } \\
\text { pliance, categorize this } \\
\text { as adequate or inade- } \\
\text { quate, and make rec- } \\
\text { ommendations based } \\
\text { on that. Level of compli- }\end{array}$ & $\begin{array}{l}\text { The control group (CG) } \\
\text { of } 63 \text { patients, who re- } \\
\text { ceived the doctor's nor- } \\
\text { mal treatment, which } \\
\text { included oral informa- } \\
\text { tion about hypercholes- } \\
\text { terolemia, advice about } \\
\text { its control, brochures } \\
\text { about dietary recom- } \\
\text { mendations, } 3 \text { month- } \\
\text { long prescriptions for } \\
\text { a cholesterol-lowering } \\
\text { medication, and titration } \\
\text { of that medication if in- } \\
\text { dicated at } 3 \text { months }\end{array}$ & Yes & $\begin{array}{l}\text { Yes for the 6-month de- } \\
\text { crease in total choles- } \\
\text { terol and LDL-C was sig- } \\
\text { nificantly different be- } \\
\text { tween IG and CG (Table } \\
\text { 3). No for the 6-month } \\
\text { decrease in triglycerides } \\
\text { and HDL-C }\end{array}$ \\
\hline
\end{tabular}




\begin{tabular}{|c|c|c|c|c|c|}
\hline \multicolumn{6}{|c|}{ Adherence and outcome } \\
\hline Study & Clinical problem & Intervention & Control & $\begin{array}{l}\text { Effect on adherence } \\
\text { (Yes means a statis- } \\
\text { tically significant ef- } \\
\text { fect in favor of the } \\
\text { intervention; No } \\
\text { means no effect or } \\
\text { a negative effect) }\end{array}$ & $\begin{array}{l}\text { Effect on clin- } \\
\text { ical outcome } \\
\text { (Yes means a statis- } \\
\text { tically significant ef- } \\
\text { fect in favor of the } \\
\text { intervention; No } \\
\text { means no effect or } \\
\text { a negative effect) }\end{array}$ \\
\hline & & $\begin{array}{l}\text { ance was determined } \\
\text { by comparing the num- } \\
\text { ber of pills consumed to } \\
\text { the number that should } \\
\text { have been consumed } \\
\text { (calculated using self } \\
\text { reported information } \\
\text { about the number of } \\
\text { pills remaining, number } \\
\text { of pills dispensed, and } \\
\text { fill date of the prescrip- } \\
\text { tion). Compliance was } \\
\text { defined as taking } 80 \% \\
\text { to } 110 \% \text { of the pills that } \\
\text { should have been tak- } \\
\text { en thus far. Compliant } \\
\text { patients were congrat- } \\
\text { ulated and encouraged } \\
\text { to continue their good } \\
\text { level of compliance as it } \\
\text { would lower their risk of } \\
\text { heart disease. Non-com- } \\
\text { pliant patients were no- } \\
\text { tified their behavior was } \\
\text { considered non-compli- } \\
\text { ant and encouraged to } \\
\text { better comply with ther- } \\
\text { apy as it would lower } \\
\text { their risk of heart disease }\end{array}$ & & & \\
\hline Marquez Contreras 2006 & Hypertension & $\begin{array}{l}\text { Usual care plus OMRON } \\
\text { automatic monitor for } \\
\text { home blood pressure } \\
\text { monitoring (HBPM), a } \\
\text { card to record pressures, } \\
\text { with an instruction book } \\
\text { and phone call to go over } \\
\text { instructions ( } n=100)\end{array}$ & $\begin{array}{l}\text { Usual care in a primary } \\
\text { care setting at } 40 \text { sites ( } \mathrm{n} \\
=100 \text { ) }\end{array}$ & Yes & $\begin{array}{l}\text { No for all clinical out- } \\
\text { comes except the } \\
\text { change in diastolic blood } \\
\text { pressure from baseline } \\
\text { to } 6 \text { months between } \\
\text { groups }\end{array}$ \\
\hline Marquez Contreras 2007 & Hypercholesterolemia & $\begin{array}{l}\text { CALENDAR REMINDER: } \\
\text { The patients in the in- } \\
\text { tervention group were } \\
\text { mailed a calendar as a } \\
\text { reminder of medication } \\
\text { taking. The calendar is } \\
\text { double sided. On one }\end{array}$ & $\begin{array}{l}\text { USUAL TREATMENT: Pa- } \\
\text { tients received treat- } \\
\text { ment as usual as provid- } \\
\text { ed by a family physician } \\
(n=110)\end{array}$ & $\begin{array}{l}\text { Yes for adherence to lipid } \\
\text { medication }\end{array}$ & $\begin{array}{l}\text { Yes for cholesterol count } \\
\text { at } 24 \text { weeks. Yes for } \\
\text { triglyceride count at } 24 \\
\text { weeks. No for HDL-C } \\
\text { count at } 24 \text { weeks; Yes } \\
\text { for LDL-C count at } 24 \\
\text { weeks }\end{array}$ \\
\hline
\end{tabular}




\begin{tabular}{|c|c|c|c|c|c|}
\hline \multicolumn{6}{|c|}{ Adherence and outcome } \\
\hline Study & Clinical problem & Intervention & Control & $\begin{array}{l}\text { Effect on adherence } \\
\text { (Yes means a statis- } \\
\text { tically significant ef- } \\
\text { fect in favor of the } \\
\text { intervention; No } \\
\text { means no effect or } \\
\text { a negative effect) }\end{array}$ & $\begin{array}{l}\text { Effect on clin- } \\
\text { ical outcome } \\
\text { (Yes means a statis- } \\
\text { tically significant ef- } \\
\text { fect in favor of the } \\
\text { intervention; No } \\
\text { means no effect or } \\
\text { a negative effect) }\end{array}$ \\
\hline & & $\begin{array}{l}\text { side, there is a calendar } \\
\text { where the patient can } \\
\text { make with an } x \text { the days } \\
\text { of the months when they } \\
\text { should be taking their } \\
\text { medication. On the oth- } \\
\text { er side, there is informa- } \\
\text { tion about the next visits, } \\
\text { treatment recommenda- } \\
\text { tions and a place to in- } \\
\text { sert lipid analysis info } \\
(\mathrm{n}=110)\end{array}$ & & & \\
\hline Martins 2009 & Tuberculosis & $\begin{array}{l}\text { FOOD INCENTIVE: The } \\
\text { intervention was a food } \\
\text { incentive program in } \\
\text { which the intervention } \\
\text { group patients were pro- } \\
\text { vided with midday meals } \\
\text { every time they attended } \\
\text { the clinic. Patients were } \\
\text { to report to the clinic } 5 \\
\text { or } 6 \text { mornings a week to } \\
\text { receive directly observed } \\
\text { treatment in the inten- } \\
\text { sive phase and fortnight- } \\
\text { ly in the continuation } \\
\text { phase } \\
(\mathrm{n}=137)\end{array}$ & $\begin{array}{l}\text { NUTRITIONAL ADVICE: } \\
\text { Control participants re- } \\
\text { ceived usual care. They } \\
\text { were also given nutri- } \\
\text { tional advice (verbal and } \\
\text { written) about the types } \\
\text { of locally available food } \\
\text { that would constitute a } \\
\text { balanced diet and would } \\
\text { be likely to assist cure of } \\
\text { tuberculosis } \\
\text { ( } n=133 \text { ) }\end{array}$ & $\begin{array}{l}\text { No for improvement of } \\
\text { adherence in patients re- } \\
\text { ceiving directly observed } \\
\text { treatment for TB with } \\
\text { food incentives }\end{array}$ & $\begin{array}{l}\text { No for completion of } \\
\text { treatment. No for symp- } \\
\text { toms. No for cough clear- } \\
\text { ance. Yes for weight gain }\end{array}$ \\
\hline Matsumura 2012 & Hypertension & $\begin{array}{l}\text { COMBINATION PILL: } \\
\text { The intervention was } \\
\text { a combination pill in- } \\
\text { stead of multiple pills. } \\
\text { Patients assigned to the } \\
\text { intervention group re- } \\
\text { ceived a combination } \\
\text { pill (losartan } 50 \mathrm{mg} / \text { hy- } \\
\text { drochlorothiazide } 12.5 \\
\text { mg). Follow-up was done } \\
\text { at } 1,3 \text {, and } 6 \text { months } \\
\text { ( } \mathrm{n}=103 \text { ) }\end{array}$ & $\begin{array}{l}\text { MULTIPLE PILLS: Control } \\
\text { patients were provid- } \\
\text { ed with an angiotensin } \\
\text { receptor blocker and } \\
\text { a diuretic. Follow-up } \\
\text { was done at } 1,3 \text {, and } 6 \\
\text { months. Adherence out- } \\
\text { comes and blood pres- } \\
\text { sure were measured at } \\
\text { the } 1,3 \text {, and } 6 \text {-month ap- } \\
\text { pointments; patient out- } \\
\text { comes at before and } 6 \\
\text { months after randomiza- } \\
\text { tion } \\
(\mathrm{n}=104)\end{array}$ & $\begin{array}{l}\text { No for improving adher- } \\
\text { ence to medication at } 1 \text {, } \\
3 \text {, and } 6 \text { months in pa- } \\
\text { tients with hypertension }\end{array}$ & $\begin{array}{l}\text { No for improving blood } \\
\text { pressure at } 1,3 \text {, and } 6 \\
\text { months in patients with } \\
\text { hypertension. No for } \\
\text { difference in adverse } \\
\text { events and blood vari- } \\
\text { ables (hematocrit, serum } \\
\text { creatinine, serum sodi- } \\
\text { um, serum potassium } \\
\text { and serum uric acid) ob- } \\
\text { served in } 2 \text { groups }\end{array}$ \\
\hline Mehuys 2011 & Type 2 diabetes & $\begin{array}{l}\text { COMMUNITY PHARMA- } \\
\text { CIST INTERVENTION: Pa- } \\
\text { tients in the intervention } \\
\text { group received pharma- } \\
\text { cist-led, individual edu- } \\
\text { cation about type } 2 \text { dia- } \\
\text { betes and its complica- } \\
\text { tions, education about } \\
\text { the correct use of oral } \\
\text { hypoglycemic agents, } \\
\text { facilitation of medica- } \\
\text { tion adherence, healthy } \\
\text { lifestyle education (diet, } \\
\text { physical exercise, and } \\
\text { smoking cessation), and } \\
\text { reminders about annu- } \\
\text { al eye and foot examina- } \\
\text { tions. These elements } \\
\text { were implemented at } \\
\text { the first visit and at each } \\
\text { prescription-refill visit of } \\
\text { the patient during the 6- } \\
\text { month intervention peri- } \\
\text { od }\end{array}$ & $\begin{array}{l}\text { USUAL PHARMACIST } \\
\text { CARE: Patients in the } \\
\text { control group received } \\
\text { usual pharmacist care } \\
\text { ( } n=31 \text { pharmacies and } \\
135 \text { patients) }\end{array}$ & $\begin{array}{l}\text { No for adherence to oral } \\
\text { hyperglycemics with } \\
\text { high refill rates and self } \\
\text { reported adherence in } \\
\text { both groups }\end{array}$ & $\begin{array}{l}\text { Yes for reduction in } \\
\text { HbAlc. No for FPG. Yes } \\
\text { for FPG and HbAlc in } \\
\text { high risk group (FPG > } \\
\text { 10.7) }\end{array}$ \\
\hline
\end{tabular}




\begin{tabular}{|c|c|c|c|c|c|}
\hline \multicolumn{6}{|c|}{ Adherence and outcome } \\
\hline Study & Clinical problem & Intervention & Control & $\begin{array}{l}\text { Effect on adherence } \\
\text { (Yes means a statis- } \\
\text { tically significant ef- } \\
\text { fect in favor of the } \\
\text { intervention; No } \\
\text { means no effect or } \\
\text { a negative effect) }\end{array}$ & $\begin{array}{l}\text { Effect on clin- } \\
\text { ical outcome } \\
\text { (Yes means a statis- } \\
\text { tically significant ef- } \\
\text { fect in favor of the } \\
\text { intervention; No } \\
\text { means no effect or } \\
\text { a negative effect) }\end{array}$ \\
\hline & & $\begin{array}{l}\text { ( } \mathrm{n}=35 \text { pharmacies and } \\
153 \text { patients) }\end{array}$ & & & \\
\hline Merinder 1999 & Schizophrenia & $\begin{array}{l}\text { 8-session psychoeduca- } \\
\text { tional program for schiz- } \\
\text { ophrenic patients and } \\
\text { their relatives, conduct- } \\
\text { ed using a mainly didac- } \\
\text { tic interactive method (n } \\
=23 \text { ) }\end{array}$ & $\begin{array}{l}\text { Usual treatment provid- } \\
\text { ed in community psychi- } \\
\text { atry }(n=23)\end{array}$ & No & $\begin{array}{l}\text { Yes for knowledge of } \\
\text { schizophrenia and for } \\
\text { VSSS subscore satisfac- } \\
\text { tion with relatives' in- } \\
\text { volvement. There was } \\
\text { also a trend towards re- } \\
\text { duced BPRS score in in- } \\
\text { tervention group (P val- } \\
\text { ue }=0.07 \text { ). No for time } \\
\text { to relapse or insight into } \\
\text { psychosis or psychoso- } \\
\text { cial function (GAF) }\end{array}$ \\
\hline Morgado 2011 & Essential hypertension & $\begin{array}{l}\text { PHARMACIST INTER- } \\
\text { VENTION PROGRAM: In } \\
\text { sessions at baseline ( } 30 \\
\text { minutes) and } 3 \text { and } 6 \\
\text { months follow-up ( } 20 \\
\text { minutes) the clinical } \\
\text { pharmacist thoroughly } \\
\text { interviewed the patient } \\
\text { to identify problems with } \\
\text { medication adherence, } \\
\text { provided patient educa- } \\
\text { tion and counseling, and } \\
\text { provided advice to physi- } \\
\text { cians regarding pharma- } \\
\text { ceutical care. Pharma- } \\
\text { cists could schedule ad- } \\
\text { ditional visits as need- } \\
\text { ed, and patients were } \\
\text { encouraged to bring all } \\
\text { empty medication blis- } \\
\text { ters and boxes to visits } \\
\text { ( } \mathrm{n}=98 \text { ) }\end{array}$ & $\begin{array}{l}\text { USUAL CARE: Control } \\
\text { group patients received } \\
\text { usual care through the } \\
\text { hospital clinic. Pharma- } \\
\text { cists were not involved in } \\
\text { their care } \\
(\mathrm{n}=99)\end{array}$ & $\begin{array}{l}\text { Yes for improving adher- } \\
\text { ence to antihypertensive } \\
\text { medication at } 9 \text { months }\end{array}$ & $\begin{array}{l}\text { Yes for patient knowl- } \\
\text { edge of target BP values. } \\
\text { Yes for proportion of pa- } \\
\text { tients achieving BP con- } \\
\text { trol. Yes for reduction in } \\
\text { baseline SBP and DBP }\end{array}$ \\
\hline Morice 2001 & Asthma & $\begin{array}{l}\text { Subsequent visits from } \\
\text { the asthma nurse until } \\
\text { discharge from hospital } \\
(\mathrm{n}=35)\end{array}$ & $\begin{array}{l}\text { 'Routine care' from med- } \\
\text { ical and nursing staff but } \\
\text { no further intervention } \\
\text { from the asthma nurse ( } \mathrm{n} \\
=30 \text { ) }\end{array}$ & $\begin{array}{l}\text { No (on the contrary, } \\
\text { medication compliance } \\
\text { of beta-agonist inhaler } \\
\text { in intervention group } \\
\text { was lower than in con- } \\
\text { trol group) }\end{array}$ & $\begin{array}{l}\text { No for the total occa- } \\
\text { sions of GP call-out and } \\
\text { re-admission. Yes for } \\
\text { patients percentage of } \\
\text { claiming to have a writ- } \\
\text { ing management plan } \\
\text { and self management }\end{array}$ \\
\hline Moshkovska 2011 & Ulcerative colitis & $\begin{array}{l}\text { PERCEPTUAL (MOTI- } \\
\text { VATIONAL) INTERVEN- } \\
\text { TIONS: Participants who } \\
\text { were assigned to the } \\
\text { intervention group at- } \\
\text { tended a one-on-one } \\
\text { education and motiva- } \\
\text { tion session conduct- } \\
\text { ed by the researcher. } \\
\text { First, this session aimed } \\
\text { to identify perceptual } \\
\text { and practical barriers } \\
\text { to 5-ASA medication ad- } \\
\text { herence and, second, } \\
\text { to motivate, convince, } \\
\text { and educate. The ses- } \\
\text { sion was designed as a } \\
\text { structured dialog allow- } \\
\text { ing the patient to com- } \\
\text { ment and ask questions. } \\
\text { Educational topics in- } \\
\text { cluded ulcerative colitis, } \\
\text { 5-ASA medication, and } \\
\text { adherence. Participants } \\
\text { were also encouraged to }\end{array}$ & $\begin{array}{l}\text { USUAL CARE: Patients } \\
\text { in the control group } \\
\text { received standard } \\
\text { prescribed care from } \\
\text { their clinical team. The } \\
\text { treatment regime for } \\
\text { these patients was not } \\
\text { changed in any way as } \\
\text { a result of involvement } \\
\text { in the study and no re- } \\
\text { minders or other addi- } \\
\text { tional adherence sup- } \\
\text { port was offered by the } \\
\text { research team. Partic- } \\
\text { ipants in the control } \\
\text { group provided } 3 \text { urine } \\
\text { samples at } 0,24 \text {, and } \\
48 \text { weeks and complet- } \\
\text { ed questionnaires dur- } \\
\text { ing baseline and end-of- } \\
\text { study visits. At the end of } \\
\text { the study, control group } \\
\text { participants were given } \\
\text { the educational leaflets } \\
\text { that intervention group }\end{array}$ & $\begin{array}{l}\text { Yes for improving ad- } \\
\text { herence to 5-ASA at } 12 \\
\text { months to reduce the } \\
\text { risk of disease flare-ups. }\end{array}$ & $\begin{array}{l}\text { No difference for disease } \\
\text { flare-ups at } 12 \text { months. }\end{array}$ \\
\hline
\end{tabular}


Adherence and outcome

Intervention

Control

\section{Effect on adherence \\ (Yes means a statis- \\ tically significant ef- \\ fect in favor of the \\ intervention; No \\ means no effect or \\ a negative effect)}

Effect on clin-

ical outcome

(Yes means a statis-

tically significant ef

fect in favor of the

intervention; No

means no effect or a negative effect) identify practical barriers to 5-ASA medication

use, as well as perceived

barriers to adherence.

Strategies for overcom-

ing these barriers were

also discussed. Sessions

lasted for 20 to $30 \mathrm{~min}$ -

utes and were intended

to deliver individualized

support to each patient.

At the end of the session

patients were offered

an educational leaflet to

take away. Patients had

the option of being ac-

companied to these ed-

ucational sessions by a

relative or friend and any

accompanying person

was also offered a leaflet

specifically written for

relatives and friends.

During the session pa-

tients were offered a free

choice of up to 3 practi-

cal adherence enhanc-

ing interventions; simpli-

fying of dosing regime,

medication reminder

charts, visual medication

reminders for refriger-

ators and bedside cab-

inets, daily electronic

pill box organizers with

alarms, weekly electron-

ic pill box organizers,

weekly non-electronic

pill box organizers, mo-

bile telephone alarm set-

up, taking into consider-

ation that practical prob-

lems and adherence may

change over time. Partic

ipants had the option of

changing these interven-

tions at any time during

the study and at weeks 4

and 24 they were formal-

ly asked whether they

wished to change the in-

terventions. 1 brief fol-

low-up telephone call

was made to patients in

the intervention group at

week 4. During the mid-

study visit a 10-minute

reinforcement session

was held during which

the importance of adher-

ence to prescribed 5-ASA

medication was reiter-

ated, beliefs regarding

medicine-taking were re-

assessed, and any prac-

tical problems were dis-

cussed. All intervention

group patients were giv-

en a telephone number

which enabled them to participants received at

the beginning of study.

$(n=41)$ 


\begin{tabular}{|c|c|c|c|c|c|}
\hline \multicolumn{6}{|c|}{ Adherence and outcome } \\
\hline Study & Clinical problem & Intervention & Control & $\begin{array}{l}\text { Effect on adherence } \\
\text { (Yes means a statis- } \\
\text { tically significant ef- } \\
\text { fect in favor of the } \\
\text { intervention; No } \\
\text { means no effect or } \\
\text { a negative effect) }\end{array}$ & $\begin{array}{l}\text { Effect on clin- } \\
\text { ical outcome } \\
\text { (Yes means a statis- } \\
\text { tically significant ef- } \\
\text { fect in favor of the } \\
\text { intervention; No } \\
\text { means no effect or } \\
\text { a negative effect) }\end{array}$ \\
\hline & & $\begin{array}{l}\text { obtain advice at spec- } \\
\text { ified times or leave a } \\
\text { message for a return call } \\
(\mathrm{n}=43)\end{array}$ & & & \\
\hline Mullan 2009 & type 2 diabetes mellitus & $\begin{array}{l}\text { DIABETES MEDICATION } \\
\text { CHOICE DECISION AID } \\
\text { TOOL: The intervention } \\
\text { was the use of a decision } \\
\text { aid tool in one appoint- } \\
\text { ment with the patient. } \\
\text { The tool is designed to } \\
\text { enable clinicians to dis- } \\
\text { cuss with patients the } \\
\text { potential advantages } \\
\text { and disadvantages of } \\
\text { adding an agent from } \\
1 \text { of the following anti- } \\
\text { hyperglycemic classes } \\
\text { to their regimen: met- } \\
\text { formin, insulin, thiazo- } \\
\text { lidinediones, exenatide, } \\
\text { and sulfonylureas. The } \\
\text { tool consists of } 6 \text { cards } \\
\text { that describe the possi- } \\
\text { ble effects of the med- } \\
\text { ications on } 6 \text { outcomes: } \\
\text { "Weight Change," "Low } \\
\text { Blood Sugar," "Blood } \\
\text { Sugar," "Daily Routine," } \\
\text { "Daily Sugar Testing," } \\
\text { and "Side Effects". After } \\
\text { reviewing and discussing } \\
\text { the cards that the pa- } \\
\text { tient and the clinician } \\
\text { choose to discuss, they } \\
\text { arrive at the medication } \\
\text { that best matches the } \\
\text { patient's circumstances } \\
\text { and preferences. The pa- } \\
\text { tient receives a copy of } \\
\text { the cards in the form of a } \\
\text { take-home pamphlet. } \\
\text { (n = } 48 \text { ) }\end{array}$ & $\begin{array}{l}\text { USUAL CARE: Partici- } \\
\text { pants in the usual care } \\
\text { arm discussed anti-hy- } \\
\text { perglycemic medication } \\
\text { in the usual manner. In } \\
\text { addition, patients re- } \\
\text { ceived a professionally } \\
\text { produced (by the Mayo } \\
\text { Clinic Patient Education } \\
\text { Center) 12-page gener- } \\
\text { al pamphlet on oral an- } \\
\text { ti-hyperglycemic med- } \\
\text { ications to take home } \\
\text { ( } \mathrm{n}=37 \text { ) }\end{array}$ & $\begin{array}{l}\text { Yes for adherence judged } \\
\text { by pharmacy records. } \\
\text { Yes for self reported ad- } \\
\text { herence }\end{array}$ & No for HbA1c levels \\
\hline Muniz 2010 & $\begin{array}{l}\text { Acute coronary syn- } \\
\text { drome }\end{array}$ & $\begin{array}{l}\text { POST DISCHARGE ED- } \\
\text { UCATIONAL INTERVEN- } \\
\text { TION: Intervention is an } \\
\text { educational intervention } \\
\text { consisting of a signed } \\
\text { agreement between } \\
\text { patient and physician } \\
\text { on the objectives to be } \\
\text { reached. The interven- } \\
\text { tion includes a person- } \\
\text { alized interview at dis- } \\
\text { charge with patient and } \\
\text { nearest next-of-kin, in } \\
\text { which physician and pa- } \\
\text { tient discuss and sign an } \\
\text { agreement with the pa- } \\
\text { tient-specific secondary } \\
\text { prevention procedures } \\
\text { and therapeutic aims. } \\
\text { Both physician and pa- } \\
\text { tient keep a copy of the } \\
\text { signed agreement. Writ- } \\
\text { ten back-up informa- } \\
\text { tion (about heart attack, } \\
\text { controlling cholesterol, } \\
\text { body weight, and blood }\end{array}$ & $\begin{array}{l}\text { USUAL CARE: Control } \\
\text { group participants re- } \\
\text { ceived usual care. Fol- } \\
\text { low-up was at } 6 \text { months } \\
(\mathrm{n}=890)\end{array}$ & $\begin{array}{l}\text { Yes for significant differ- } \\
\text { ence between interven- } \\
\text { tion and control groups } \\
\text { at } 6 \text { month for improving } \\
\text { adherence to statins. No } \\
\text { for difference between } \\
\text { intervention and control } \\
\text { groups for medication } \\
\text { adherence to aspirin, } \\
\text { clopidogrel, beta-block- } \\
\text { ers, ACE-inhibitors, and } \\
\text { Angiotensin receptor } \\
\text { blocking agent Type II at } \\
6 \text { month }\end{array}$ & $\begin{array}{l}\text { Yes for reduction in BMI. } \\
\text { Yes for reduction in lipid } \\
\text { level and waist circum- } \\
\text { ference at } 6 \text { months in } \\
\text { intervention group with } \\
\text { an educational program } \\
\text { at discharge following } \\
\text { acute coronary episode. } \\
\text { No for blood pressure } \\
\text { control }\end{array}$ \\
\hline
\end{tabular}




\begin{tabular}{|c|c|c|c|c|c|}
\hline \multicolumn{6}{|c|}{ Adherence and outcome } \\
\hline Study & Clinical problem & Intervention & Control & $\begin{array}{l}\text { Effect on adherence } \\
\text { (Yes means a statis- } \\
\text { tically significant ef- } \\
\text { fect in favor of the } \\
\text { intervention; No } \\
\text { means no effect or } \\
\text { a negative effect) }\end{array}$ & $\begin{array}{l}\text { Effect on clin- } \\
\text { ical outcome } \\
\text { (Yes means a statis- } \\
\text { tically significant ef- } \\
\text { fect in favor of the } \\
\text { intervention; No } \\
\text { means no effect or } \\
\text { a negative effect) }\end{array}$ \\
\hline & & $\begin{array}{l}\text { pressure, and effects of } \\
\text { smoking), and a phone } \\
\text { number as to where to } \\
\text { call in case of questions } \\
\text { were given. Intervention } \\
\text { also included an inter- } \\
\text { view with the patient } 2 \\
\text { months after discharge } \\
\text { in order to review the } \\
\text { agreement, adapt treat- } \\
\text { ment if needed, and re- } \\
\text { inforce the intervention. } \\
\text { Informative materials } \\
\text { are given once again.The } \\
\text { visits took an average of } \\
30 \text { to } 40 \text { minutes each. } \\
\text { ( } \mathrm{n}=867 \text { ) }\end{array}$ & & & \\
\hline Murray 2007 & Heart failure & $\begin{array}{l}\text { PHARMACIST INTERVEN- } \\
\text { TION: A pharmacist de- } \\
\text { livered the intervention } \\
\text { by using a protocol that } \\
\text { included a baseline med- } \\
\text { ication history of all pre- } \\
\text { scription and over-the- } \\
\text { counter drugs and di- } \\
\text { etary supplements tak- } \\
\text { en by patients, which pa- } \\
\text { tients brought with them } \\
\text { to the baseline inter- } \\
\text { view, and the results of } \\
\text { an assessment of patient } \\
\text { medication knowledge } \\
\text { and skills. The pharma- } \\
\text { cist dispensed enough } \\
\text { of the patient's med- } \\
\text { ications to last approx- } \\
\text { imately } 2 \text { months. The } \\
\text { intervention lasted } 9 \\
\text { months. When medica- } \\
\text { tions were dispensed, } \\
\text { the pharmacist provid- } \\
\text { ed patient-centered ver- } \\
\text { bal instructions and writ- } \\
\text { ten materials about the } \\
\text { medications. Each med- } \\
\text { ication category had an } \\
\text { icon associated with it. } \\
\text { The same icon appeared } \\
\text { on the container label } \\
\text { and lid and on the writ- } \\
\text { ten patient instructions. } \\
\text { The pharmacist moni- } \\
\text { tored patients' medica- } \\
\text { tion use, health care en- } \\
\text { counters, body weight, } \\
\text { and other relevant da- } \\
\text { ta by using a study data- } \\
\text { base. Information about } \\
\text { patients was communi- } \\
\text { cated as needed to clin- } \\
\text { ic nurses and primary } \\
\text { care physicians by face- } \\
\text { to-face visits, telephone, } \\
\text { paging (physician only), } \\
\text { and e-mail (physician } \\
\text { only). An interdiscipli- } \\
\text { nary team of investiga- } \\
\text { tors trained the interven- } \\
\text { tion pharmacist. The in- }\end{array}$ & $\begin{array}{l}\text { USUAL CARE: Control } \\
\text { groups received usual } \\
\text { care. Usual care partici- } \\
\text { pants were aware of the } \\
\text { purpose of the study. } \\
\text { They received their pre- } \\
\text { scription services from } \\
\text { the same pharmacy as } \\
\text { the intervention partic- } \\
\text { ipants, but the pharma- } \\
\text { cists who attended the } \\
\text { usual care participants } \\
\text { were not trained by the } \\
\text { interdisciplinary team } \\
\text { ( } n=192 \text { ) }\end{array}$ & $\begin{array}{l}\text { Yes for adherence based } \\
\text { on MEMS and pharmacy } \\
\text { refill records. No for self } \\
\text { reported adherence }\end{array}$ & $\begin{array}{l}\text { Yes for exacerbations. No } \\
\text { for improving the quality } \\
\text { of life in heart failure pa- } \\
\text { tients receiving pharma- } \\
\text { cy intervention at } 6 \text { and } \\
12 \text { months compared to } \\
\text { usual care }\end{array}$ \\
\hline
\end{tabular}




\begin{tabular}{|c|c|c|c|c|c|}
\hline \multicolumn{6}{|c|}{ Adherence and outcome } \\
\hline Study & Clinical problem & Intervention & Control & $\begin{array}{l}\text { Effect on adherence } \\
\text { (Yes means a statis- } \\
\text { tically significant ef- } \\
\text { fect in favor of the } \\
\text { intervention; No } \\
\text { means no effect or } \\
\text { a negative effect) }\end{array}$ & $\begin{array}{l}\text { Effect on clin- } \\
\text { ical outcome } \\
\text { (Yes means a statis- } \\
\text { tically significant ef- } \\
\text { fect in favor of the } \\
\text { intervention; No } \\
\text { means no effect or } \\
\text { a negative effect) }\end{array}$ \\
\hline & & $\begin{array}{l}\text { tervention pharmacist } \\
\text { also studied guidelines } \\
\text { for treating heart failure, } \\
\text { key concepts in the phar- } \\
\text { maceutical care of old- } \\
\text { er adults, communica- } \\
\text { tion techniques, and the } \\
\text { pharmacotherapy of the } \\
\text { cardiovascular drugs for } \\
\text { heart failure } \\
(\mathrm{n}=122)\end{array}$ & & & \\
\hline Nazareth 2001 & $\begin{array}{l}\text { Complex regimens in the } \\
\text { elderly (aged } 75 \text { years } \\
\text { and older on } 4 \text { or more } \\
\text { medicines who had been } \\
\text { discharged) }\end{array}$ & $\begin{array}{l}\text { The hospital pharma- } \\
\text { cist developed discharge } \\
\text { plans which gave details } \\
\text { of medication and sup- } \\
\text { port required by the pa- } \\
\text { tient. A copy was given to } \\
\text { the patient and to all rel- } \\
\text { evant professionals and } \\
\text { carers. This was followed } \\
\text { by a domiciliary assess- } \\
\text { ment by a community } \\
\text { pharmacist. }(n=165)\end{array}$ & $\begin{array}{l}\text { In the control group, pa- } \\
\text { tients were discharged } \\
\text { from hospital follow- } \\
\text { ing standard proce- } \\
\text { dures that included a } \\
\text { discharge letter to the } \\
\text { general practitioner list- } \\
\text { ing current medications } \\
(n=151)\end{array}$ & No & No \\
\hline Nguyen 2008 & $\begin{array}{l}\text { Gastrointestinal irritabil- } \\
\text { ity due to prenatal multi- } \\
\text { vitamins }\end{array}$ & $\begin{array}{l}\text { SMALL LOW IRON DOSE } \\
\text { TABLET: Small low dose } \\
\text { iron tablets were used } \\
\text { as the intervention in } \\
\text { this study. PregVit a pre- } \\
\text { natal multivitamin that } \\
\text { contains } 35 \text { mg elemen- } \\
\text { tal iron, as ferrous fu- } \\
\text { marate was prescribed } \\
\text { for intervention group } \\
\text { patients. The multiple } \\
\text { vitamins and minerals } \\
\text { are formulated into } 2 \\
\text { small tablets, and is tak- } \\
\text { en as } 2 \text { tablets per day. } \\
\text { After enrolment, sub- } \\
\text { jects received a 1-week } \\
\text { follow-up telephone } \\
\text { call and then were in- } \\
\text { terviewed by telephone } \\
\text { on a monthly basis un- } \\
\text { til the end of pregnan- } \\
\text { cy. Each interview docu- } \\
\text { mented obstetrical and } \\
\text { medical information, ad- } \\
\text { herence based on pill in- } \\
\text { take recall, and any re- } \\
\text { ported adverse events. } \\
\text { The date(s) of discon- } \\
\text { tinuation at any time(s) } \\
\text { during study participa- } \\
\text { tion was documented as } \\
\text { the date(s) reported by } \\
\text { the subject during the } \\
\text { monthly interview } \\
\text { ( } \mathrm{n}=92 \text { ) }\end{array}$ & $\begin{array}{l}\text { SMALL } 60 \text { MG MULTIVI- } \\
\text { TAMIN TABLET: A small- } \\
\text { sized high-dose }(60 \mathrm{mg}) \\
\text { multivitamin adminis- } \\
\text { tered once daily was } \\
\text { used as the control in } \\
\text { this study } \\
(\mathrm{n}=75)\end{array}$ & $\begin{array}{l}\text { No for improving adher- } \\
\text { ence to multivitamin in } \\
\text { pregnant women }\end{array}$ & $\begin{array}{l}\text { No for reduced adverse } \\
\text { effects in pregnant } \\
\text { women }\end{array}$ \\
\hline Nieuwkerk 2012 & $\begin{array}{l}\text { Increased cardiovascular } \\
\text { risk }\end{array}$ & $\begin{array}{l}\text { EXTENDED CARE: Sub- } \\
\text { jects in Extended Care } \\
\text { (EC) received multifacto- } \\
\text { rial risk-factor counsel- } \\
\text { ing, in addition to Rou- } \\
\text { tine Care (RC). During } \\
\text { the counseling the nurse } \\
\text { practitioner explained } \\
\text { the presence of unmod- } \\
\text { ifiable risk factors, such }\end{array}$ & $\begin{array}{l}\text { ROUTINE CARE: Routine } \\
\text { care consisted of mea- } \\
\text { suring body weight and } \\
\text { blood pressure and per- } \\
\text { forming a capillary lipid } \\
\text { profile at each visit. Ini- } \\
\text { tially, all participants re- } \\
\text { ceived atorvastatin } 10 \\
\text { mg, unless baseline cho- } \\
\text { lesterol levels were se- }\end{array}$ & $\begin{array}{l}\text { Yes for improving adher- } \\
\text { ence to lipid-lowering } \\
\text { medication in patients } \\
\text { with increased cardio- } \\
\text { vascular risk }\end{array}$ & $\begin{array}{l}\text { Yes for lowering the low- } \\
\text { density lipoprotein cho- } \\
\text { lesterol, improving inti- } \\
\text { ma-media thickness and } \\
\text { anxiety. No for improv- } \\
\text { ing body weight, body } \\
\text { mass index, blood pres- } \\
\text { sure, adverse events and } \\
\text { quality of life }\end{array}$ \\
\hline
\end{tabular}




\begin{tabular}{|c|c|c|c|c|c|}
\hline \multicolumn{6}{|c|}{ Adherence and outcome } \\
\hline Study & Clinical problem & Intervention & Control & $\begin{array}{l}\text { Effect on adherence } \\
\text { (Yes means a statis- } \\
\text { tically significant ef- } \\
\text { fect in favor of the } \\
\text { intervention; No } \\
\text { means no effect or } \\
\text { a negative effect) }\end{array}$ & $\begin{array}{l}\text { Effect on clin- } \\
\text { ical outcome } \\
\text { (Yes means a statis- } \\
\text { tically significant ef- } \\
\text { fect in favor of the } \\
\text { intervention; No } \\
\text { means no effect or } \\
\text { a negative effect) }\end{array}$ \\
\hline & & $\begin{array}{l}\text { as age, gender, and fam- } \\
\text { ily history, and modifi- } \\
\text { able risk factors, such } \\
\text { as lipid levels, diabetes } \\
\text { mellitus, blood pressure, } \\
\text { overweight, smoking } \\
\text { habits, and physical ac- } \\
\text { tivity. The study nurse } \\
\text { was not blinded to the } \\
\text { purpose of the study. } \\
\text { The counseling focused } \\
\text { on changing modifiable } \\
\text { risk factors such as in- } \\
\text { creasing medication ad- } \\
\text { herence, reducing over- } \\
\text { weight, smoking ces- } \\
\text { sation, and increasing } \\
\text { physical activity. All ob- } \\
\text { tained data were sum- } \\
\text { marized in a personal } \\
\text { risk-factor passport: a } \\
\text { graphical presentation } \\
\text { of the patient's calculat- } \\
\text { ed } 10 \text {-year cardiovascu- } \\
\text { lar disease risk. It also } \\
\text { showed the target risk } \\
\text { that could be reached } \\
\text { if all the patient's mod- } \\
\text { ifiable risk factors were } \\
\text { optimally treated, as } \\
\text { well as the standard age- } \\
\text { and gender-related risk. } \\
10-y e a r \text { risk and target } \\
\text { risk were calculated us- } \\
\text { ing the Framingham } \\
\text { risk score. The risk-fac- } \\
\text { tor passport contained } \\
\text { the most recent ultra- } \\
\text { sound image of the pa- } \\
\text { tient's carotid artery, as } \\
\text { well as an example of a } \\
\text { healthy and an unfavor- } \\
\text { able image of the carotid } \\
\text { artery, which were both } \\
\text { explained and discussed } \\
\text { by the nurse practition- } \\
\text { er. This risk-factor pass- } \\
\text { port was updated during } \\
\text { each follow-up visit } \\
\text { (n = 101) }\end{array}$ & $\begin{array}{l}\text { vere and more aggres- } \\
\text { sive therapy was need- } \\
\text { ed. Dose escalation dur- } \\
\text { ing the study period was } \\
\text { allowed if deemed ap- } \\
\text { propriate by the treating } \\
\text { physician } \\
(n=100)\end{array}$ & & \\
\hline O'Donnell 2003 & Schizophrenia & $\begin{array}{l}\text { The experimental group } \\
(\mathrm{n}=28) \text { received } 5 \text { ses- } \\
\text { sions of compliance } \\
\text { therapy, each session } \\
\text { lasting } 30 \text { to } 60 \text { min- } \\
\text { utes. The sessions cov- } \\
\text { ered a review of the pa- } \\
\text { tient's illness history, } \\
\text { understanding of the ill- } \\
\text { ness and his or her am- } \\
\text { bivalence to treatment, } \\
\text { maintenance medication } \\
\text { and stigma. Compliance } \\
\text { therapy is a cognitive } \\
\text { behavior intervention } \\
\text { with techniques adapted } \\
\text { from motivational inter- } \\
\text { viewing, other cognitive }\end{array}$ & $\begin{array}{l}\text { The control group ( } n= \\
28) \text { received non-specific } \\
\text { counseling comprising of } \\
5 \text { sessions lasting } 30 \text { to } \\
60 \text { minutes }\end{array}$ & No & No \\
\hline
\end{tabular}




\begin{tabular}{|c|c|c|c|c|c|}
\hline \multicolumn{6}{|c|}{ Adherence and outcome } \\
\hline Study & Clinical problem & Intervention & Control & $\begin{array}{l}\text { Effect on adherence } \\
\text { (Yes means a statis- } \\
\text { tically significant ef- } \\
\text { fect in favor of the } \\
\text { intervention; No } \\
\text { means no effect or } \\
\text { a negative effect) }\end{array}$ & $\begin{array}{l}\text { Effect on clin- } \\
\text { ical outcome } \\
\text { (Yes means a statis- } \\
\text { tically significant ef- } \\
\text { fect in favor of the } \\
\text { intervention; No } \\
\text { means no effect or } \\
\text { a negative effect) }\end{array}$ \\
\hline & & $\begin{array}{l}\text { therapies and psychoed- } \\
\text { ucation }\end{array}$ & & & \\
\hline Odegard 2005 & $\begin{array}{l}\text { Poorly controlled type } \\
2 \text { diabetes, on oral med- } \\
\text { ications }\end{array}$ & $\begin{array}{l}\text { Usual care (see Control) } \\
\text { plus: Pharmacist-led } \\
\text { intervention }(n=43) \text { : } \\
\text { Pharmacist-patient } \\
\text { communication on di- } \\
\text { abetes progress; phar- } \\
\text { macist-provider com- } \\
\text { munication on the sub- } \\
\text { ject's progress; medica- } \\
\text { tion-related problems } \\
\text { - the pharmacists were } \\
\text { not formally affiliated } \\
\text { with the clinic }\end{array}$ & $\begin{array}{l}\text { Usual care (primary care, } \\
\text { university-based, med- } \\
\text { ical clinics) }(n=34)\end{array}$ & No & $\begin{array}{l}\text { No for all clinical out- } \\
\text { comes }\end{array}$ \\
\hline Ogedegbe 2012 & Hypertension & $\begin{array}{l}\text { POSITIVE AFFECT INTER- } \\
\text { VENTION: Patients in the } \\
\text { Positive Education (PE) } \\
\text { control group received } \\
\text { a culturally tailored ed- } \\
\text { ucational workbook de- } \\
\text { signed (1) to enhance pa- } \\
\text { tients' knowledge about } \\
\text { hypertension, (2) to im- } \\
\text { prove self management } \\
\text { behaviors, and (3) to } \\
\text { support goal-setting. Pa- } \\
\text { tients randomized to the } \\
\text { Positive Affect (PA) inter- } \\
\text { vention group were giv- } \\
\text { en the same workbook } \\
\text { as those in the PE group } \\
\text { but with an additional } \\
\text { chapter that addresses } \\
\text { the benefits of positive } \\
\text { moments in overcoming } \\
\text { obstacles to medication } \\
\text { adherence. Also, these } \\
\text { patients received } 2 \text { forms } \\
\text { of PA during bimonth- } \\
\text { ly telephone calls. First, } \\
\text { they were asked to iden- } \\
\text { tify small things in their } \\
\text { lives that invoke posi- } \\
\text { tive feelings in them and } \\
\text { were then instructed to } \\
\text { incorporate these posi- } \\
\text { tive thoughts into their } \\
\text { daily routine. The posi- } \\
\text { tive thoughts were fur- } \\
\text { ther reinforced during } \\
\text { sues whenever they en- } \\
\text { counter situations that } \\
\text { telephonene calls. Second, } \\
\text { the patients received } \\
\text { unexpected small gifts } \\
\text { mailed to them before } \\
\text { each telephone call. This } \\
\text { strategy was based on } \\
\text { the potential of the re- } \\
\text { ceipt of unexpected gifts } \\
\text { to induce positive feel- } \\
\text { ings. For self affirmation } \\
\text { induction, the patients } \\
\text { were asked to remem- }\end{array}$ & $\begin{array}{l}\text { PATIENT EDUCATION: } \\
\text { Patient Education (PE) } \\
\text { control group received } \\
\text { a culturally tailored ed- } \\
\text { ucational workbook de- } \\
\text { signed (1) to enhance } \\
\text { patients' knowledge } \\
\text { about hypertension, (2) } \\
\text { to improve self manage- } \\
\text { ment behaviors, and } \\
\text { (3) to support goal-set- } \\
\text { ting. On receipt of the } \\
\text { workbook, trained Re- } \\
\text { search Assistants (RAs) } \\
\text { reviewed each chapter } \\
\text { with the patients and } \\
\text { then asked them to sign } \\
\text { a behavioral contract } \\
\text { that asked them to make } \\
\text { a commitment to tak- } \\
\text { ing their medications as } \\
\text { prescribed. Subsequent } \\
\text { to this session, each pa- } \\
\text { tient received bimonthly } \\
\text { telephone calls, during } \\
\text { which the RAs assessed } \\
\text { the patient's behavioral } \\
\text { contract and confidence } \\
\text { to take their medications } \\
\text { as prescribed. These as- } \\
\text { sessments served as the } \\
\text { basis for reviewing and } \\
\text { counseling the patient } \\
\text { on perceived barriers to } \\
\text { medication adherence. } \\
\text { The intervention lasted } \\
\text { for } 12 \text { months } \\
\text { ( } \mathrm{n}=131 \text { ) }\end{array}$ & $\begin{array}{l}\text { Yes for improving adher- } \\
\text { ence to medication at } 12 \\
\text { months }\end{array}$ & $\begin{array}{l}\text { No for reducing systolic } \\
\text { and diastolic blood pres- } \\
\text { sure at } 12 \text { months }\end{array}$ \\
\hline
\end{tabular}




\begin{tabular}{|c|c|c|c|c|c|}
\hline \multicolumn{6}{|c|}{ Adherence and outcome } \\
\hline Study & Clinical problem & Intervention & Control & $\begin{array}{l}\text { Effect on adherence } \\
\text { (Yes means a statis- } \\
\text { tically significant ef- } \\
\text { fect in favor of the } \\
\text { intervention; No } \\
\text { means no effect or } \\
\text { a negative effect) }\end{array}$ & $\begin{array}{l}\text { Effect on clin- } \\
\text { ical outcome } \\
\text { (Yes means a statis- } \\
\text { tically significant ef- } \\
\text { fect in favor of the } \\
\text { intervention; No } \\
\text { means no effect or } \\
\text { a negative effect) }\end{array}$ \\
\hline & & $\begin{array}{l}\text { make it difficult for them } \\
\text { to take their medications } \\
(\mathrm{n}=125)\end{array}$ & & & \\
\hline Okeke 2009 & Glaucoma & $\begin{array}{l}\text { INTERVENTION: The in- } \\
\text { tervention consisted } \\
\text { of } 4 \text { components. (1) a } \\
\text { 10-minute educational } \\
\text { video created through } \\
\text { Alcon, Inc. marketing } \\
\text { branch for the DA device, } \\
\text { which stressed the im- } \\
\text { portance of regular drop- } \\
\text { taking, its rationale and } \\
\text { expected effects, alter- } \\
\text { natives to eyedrops, and } \\
\text { methods to maximize co- } \\
\text { operation, such as link- } \\
\text { ing drops to a daily activ- } \\
\text { ity, keeping a drop-tak- } \\
\text { ing calendar diary, and } \\
\text { using family members to } \\
\text { help in reminding them; } \\
\text { (2) a structured discus- } \\
\text { sion with the study co- } \\
\text { ordinator to develop a } \\
\text { strategy for improving } \\
\text { adherence that included } \\
\text { finding the best time of } \\
\text { day to take the medica- } \\
\text { tion, distributing a blank } \\
\text { calendar diary and go- } \\
\text { ing over details of how to } \\
\text { keep it, and discussing } \\
\text { individual patient barri- } \\
\text { ers to taking the medica- } \\
\text { tion; ( } 3 \text { ) reminder tele- } \\
\text { phone calls from the co- } \\
\text { ordinator, including ad- } \\
\text { ministration of a ques- } \\
\text { tionnaire about drop- } \\
\text { taking behavior, diffi- } \\
\text { culty with drops, side ef- } \\
\text { fects, and eliciting ques- } \\
\text { tions about therapy (this } \\
\text { call was made once per } \\
\text { week for the first fol- } \\
\text { low-up month and then } \\
\text { every other week for the } \\
\text { next } 2 \text { months); and (4) } \\
\text { activation of the audible } \\
\text { and visible alarms on the } \\
\text { DA } \\
\text { ( } \mathrm{n}=35 \text { ) }\end{array}$ & $\begin{array}{l}\text { USUAL CARE: Usual care } \\
\text { group were told that it is } \\
\text { important to take their } \\
\text { eyedrops as prescribed } \\
\text { but had no other inter- } \\
\text { vention } \\
(n=31)\end{array}$ & $\begin{array}{l}\text { Yes for improving eye- } \\
\text { drop adherence at } 6 \\
\text { months }\end{array}$ & $\begin{array}{l}\text { No for lowering intraoc- } \\
\text { ular pressure between } 3 \\
\text { and } 6 \text { months }\end{array}$ \\
\hline Otsuki 2009 & Asthma & $\begin{array}{l}\text { ASTHMA BASIC CARE } \\
\text { (ABC): ABC interven- } \\
\text { tion received } 530 \text { - to } 45- \\
\text { minute home visits by } \\
\text { trained asthma educa- } \\
\text { tors (AES) } 1,2,3,4, \text { and } \\
8 \text { weeks after random- } \\
\text { ization. The ABC inter- } \\
\text { vention is a home-based } \\
\text { asthma education pro- } \\
\text { gram with } 5 \text { core com- } \\
\text { ponents: (1) review of } \\
\text { the prescribed asthma } \\
\text { regimen and training in } \\
\text { medication, spacer, and } \\
\text { peak flow technique; ( } 2 \text { ) }\end{array}$ & $\begin{array}{l}\text { USUAL CARE: Patients } \\
\text { received an asthma ed- } \\
\text { ucation booklet and re- } \\
\text { source guide that pro- } \\
\text { vided information about } \\
\text { low-cost asthma care } \\
\text { providers, social ser- } \\
\text { vices, legal services, and } \\
\text { other resources. Partici- } \\
\text { pants were encouraged } \\
\text { to receive care from their } \\
\text { primary care provider } \\
(n=83)\end{array}$ & $\begin{array}{l}\text { Yes for pharmacy refills } \\
\text { both AMF versus UC and } \\
\text { Combined intervention } \\
\text { group versus UC were } \\
\text { significant but declined } \\
\text { after active intervention } \\
\text { was removed. No differ- } \\
\text { ence for ABC versus UC } \\
\text { or AMF versus ABC. No } \\
\text { for self report }\end{array}$ & $\begin{array}{l}\text { Yes for reduction of ED } \\
\text { visits between AMF and } \\
\text { UC group. No for reduc- } \\
\text { tion in oral corticos- } \\
\text { teroids between AMF } \\
\text { and UC groups. No for } \\
\text { asthma symptom fre- } \\
\text { quency and hospitaliza- } \\
\text { tions between AMF and } \\
\text { UC group. No for reduc- } \\
\text { tion of ED visits between } \\
\text { ABC and UC groups. Yes } \\
\text { for improvement in asth- } \\
\text { ma symptom frequen- } \\
\text { cy between ABC and UC } \\
\text { groups. Yes for decrease }\end{array}$ \\
\hline
\end{tabular}




\begin{tabular}{|c|c|c|c|c|c|}
\hline \multicolumn{6}{|c|}{ Adherence and outcome } \\
\hline Study & Clinical problem & Intervention & Control & $\begin{array}{l}\text { Effect on adherence } \\
\text { (Yes means a statis- } \\
\text { tically significant ef- } \\
\text { fect in favor of the } \\
\text { intervention; No } \\
\text { means no effect or } \\
\text { a negative effect) }\end{array}$ & $\begin{array}{l}\text { Effect on clin- } \\
\text { ical outcome } \\
\text { (Yes means a statis- } \\
\text { tically significant ef- } \\
\text { fect in favor of the } \\
\text { intervention; No } \\
\text { means no effect or } \\
\text { a negative effect) }\end{array}$ \\
\hline & & 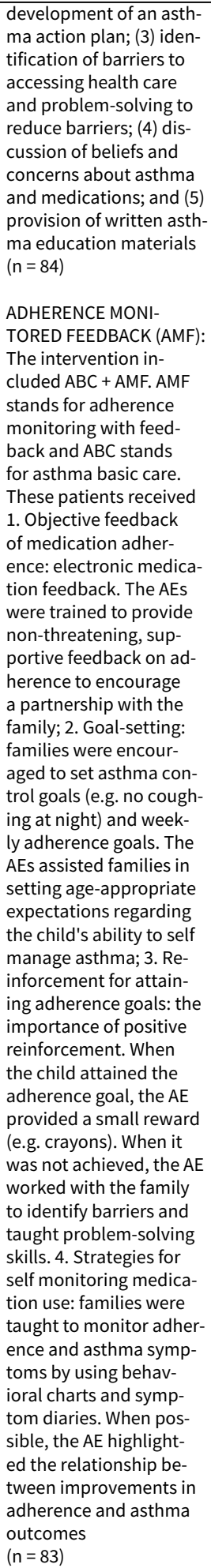 & & & $\begin{array}{l}\text { in oral corticosteroid } \\
\text { use between ABC and } \\
\text { UC group. No for hospi- } \\
\text { talization rate between } \\
\text { ABC and AMF groups. No } \\
\text { for improvement in any } \\
\text { clinical health outcome } \\
\text { between AMF and ABC } \\
\text { group. Yes for ED visit re- } \\
\text { duction and use of oral } \\
\text { corticosteroids between } \\
\text { combined intervention } \\
\text { groups and UC group. No } \\
\text { for asthma symptom fre- } \\
\text { quency and hospitaliza- } \\
\text { tion between combined } \\
\text { intervention groups and } \\
\text { UC }\end{array}$ \\
\hline
\end{tabular}




\begin{tabular}{|c|c|c|c|c|c|}
\hline \multicolumn{6}{|c|}{ Adherence and outcome } \\
\hline Study & Clinical problem & Intervention & Control & $\begin{array}{l}\text { Effect on adherence } \\
\text { (Yes means a statis- } \\
\text { tically significant ef- } \\
\text { fect in favor of the } \\
\text { intervention; No } \\
\text { means no effect or } \\
\text { a negative effect) }\end{array}$ & $\begin{array}{l}\text { Effect on clin- } \\
\text { ical outcome } \\
\text { (Yes means a statis- } \\
\text { tically significant ef- } \\
\text { fect in favor of the } \\
\text { intervention; No } \\
\text { means no effect or } \\
\text { a negative effect) }\end{array}$ \\
\hline Parienti 2007 & HIV & $\begin{array}{l}\text { ONCE A DAY DOSING: } \\
\text { Patients were switched } \\
\text { from } 2 \text { a day nevirapine } \\
\text { to a } 1 \text { a day formula } \\
(\mathrm{n}=31)\end{array}$ & $\begin{array}{l}\text { TWICE A DAY DOSAGE: } \\
\text { Control participants con- } \\
\text { tinued to take nevirapine } \\
\text { twice a day } \\
(\mathrm{n}=31)\end{array}$ & $\begin{array}{l}\text { No for adherence rates. } \\
\text { Yes for increased month- } \\
\text { ly days without dose. No } \\
\text { for monthly drug holi- } \\
\text { days }\end{array}$ & No for viral control \\
\hline Parsons 2007 & HIV & $\begin{array}{l}\text { PROJECT PLUS INTER- } \\
\text { VENTION: Intervention } \\
\text { was } 8,60 \text {-minute indi- } \\
\text { vidual sessions based } \\
\text { on Information Motiva- } \\
\text { tion Behavioral Skills } \\
\text { model delivered by de- } \\
\text { livered by master's de- } \\
\text { gree-prepared coun- } \\
\text { selors. } 2 \text { complementary } \\
\text { techniques-motivation- } \\
\text { al interviewing (MI) and } \\
\text { cognitive-behavioral } \\
\text { skills training (CBST)- } \\
\text { were integrated, allow- } \\
\text { ing trained counselors } \\
\text { to match targeted infor- } \\
\text { mation and skill-building } \\
\text { techniques to the partic- } \\
\text { ulars of each client's mo- } \\
\text { tivation for change.The } \\
\text { first session was deliv- } \\
\text { ered immediately on } \\
\text { completion of the base- } \\
\text { line assessment, thereby } \\
\text { ensuring that each par- } \\
\text { ticipant has a minimum } \\
\text { dose of } 1 \text { session. Fol- } \\
\text { low-ups were conducted } \\
\text { at } 3 \text { and } 6 \text { months } \\
\text { ( } \mathrm{n}=65 \text { ) }\end{array}$ & $\begin{array}{l}\text { EDUCATION CONDITION: } \\
8 \text { education sessions of } \\
60 \text { minutes facilitated by } \\
\text { a health educator was } \\
\text { the intervention. Ses- } \\
\text { sions were designed to } \\
\text { be completed weekly, } \\
\text { but participants had } 12 \\
\text { weeks to complete all } \\
8 \text { sessions. The first ses- } \\
\text { sion was delivered im- } \\
\text { mediately on comple- } \\
\text { tion of the baseline as- } \\
\text { sessment, thereby ensur- } \\
\text { ing that each participant } \\
\text { had a minimum dose } \\
\text { of } 1 \text { session. The ses- } \\
\text { sions were video taped } \\
\text { to ensure that motiva- } \\
\text { tional interview or cog- } \\
\text { nitive-behavioral skills } \\
\text { training was not used } \\
\text { ( } \mathrm{n}=78 \text { ) }\end{array}$ & $\begin{array}{l}\text { Yes for improving per- } \\
\text { centage dose adherence } \\
\text { and percentage day ad- } \\
\text { herence at } 3 \text { months. No } \\
\text { for improving percent- } \\
\text { age dose adherence and } \\
\text { percentage day adher- } \\
\text { ence at } 6 \text { months }\end{array}$ & $\begin{array}{l}\text { Yes for reducing viral } \\
\text { load and increasing CD4 } \\
\text { count at } 3 \text { months. No } \\
\text { for reducing viral load at } \\
6 \text { months and No for in- } \\
\text { creasing CD4 count at } 6 \\
\text { months }\end{array}$ \\
\hline Pearson 2007 & HIV & $\begin{array}{l}\text { PEER DELIVERED } \\
\text { MODIFIED DIRECTLY } \\
\text { OBSERVED THERAPY } \\
\text { (MDOT): The participants } \\
\text { in the MDot intervention } \\
\text { group received both the } \\
\text { standard of care and a 6- } \\
\text { week peer intervention } \\
\text { to monitor their morn- } \\
\text { ing weekday dose. Peers } \\
\text { also provided daily so- } \\
\text { cial support, information } \\
\text { about the benefits and } \\
\text { side effects of HAART, } \\
\text { and help to address bar- } \\
\text { riers to adherence. Peers } \\
\text { were also a link between } \\
\text { participants and other } \\
\text { members of the HIV clin- } \\
\text { ic team and the commu- } \\
\text { nity } \\
\text { ( } \mathrm{n}=175 \text { ) }\end{array}$ & $\begin{array}{l}\text { STANDARD CARE: In- } \\
\text { cludes no-cost medica- } \\
\text { tions, clinical and lab- } \\
\text { oratory follow-up, psy- } \\
\text { chosocial adherence } \\
\text { support by a trained so- } \\
\text { cial worker, and refer- } \\
\text { ral to community-based } \\
\text { peer support groups. } \\
\text { Mandatory pre-HAART } \\
\text { counseling involves edu- } \\
\text { cation about dosing, side } \\
\text { effects, nutritional re- } \\
\text { quirements, and the im- } \\
\text { portance of adherence. } \\
\text { Patients were encour- } \\
\text { aged to identify a treat- } \\
\text { ment partner to help } \\
\text { with adherence, provid- } \\
\text { ed with information on } \\
\text { community-based sup- } \\
\text { port groups and nutri- } \\
\text { tional resources, and in- } \\
\text { structed to contact their } \\
\text { medical provider, nurse, } \\
\text { pharmacist, or peer if } \\
\text { they have any difficulties } \\
\text { or concerns about their } \\
\text { medication regimen. } \\
\text { Peers were HIV-positive, } \\
\text { chosen from among pa- } \\
\text { tients at the clinic and } \\
\text { participants in com- }\end{array}$ & $\begin{array}{l}\text { Yes for improving } 7 \text { - and } \\
30 \text {-day adherence at } 6 \text { - } \\
\text { and } 12 \text {-month follow-up }\end{array}$ & $\begin{array}{l}\text { No for mean CD } 4 \text { cell } \\
\text { count at } 6 \text { and } 12 \\
\text { months. No for mortality } \\
\text { rate at } 6 \text { months }\end{array}$ \\
\hline
\end{tabular}




\begin{tabular}{|c|c|c|c|c|c|}
\hline \multicolumn{6}{|c|}{ Adherence and outcome } \\
\hline Study & Clinical problem & Intervention & Control & $\begin{array}{l}\text { Effect on adherence } \\
\text { (Yes means a statis- } \\
\text { tically significant ef- } \\
\text { fect in favor of the } \\
\text { intervention; No } \\
\text { means no effect or } \\
\text { a negative effect) }\end{array}$ & $\begin{array}{l}\text { Effect on clin- } \\
\text { ical outcome } \\
\text { (Yes means a statis- } \\
\text { tically significant ef- } \\
\text { fect in favor of the } \\
\text { intervention; No } \\
\text { means no effect or } \\
\text { a negative effect) }\end{array}$ \\
\hline & & & $\begin{array}{l}\text { munity-based groups } \\
\text { through self nomina- } \\
\text { tion or nominations by } \\
\text { clinic staff, and were } \\
\text { paid a small stipend for } \\
\text { their work. Patients met } \\
\text { with the pharmacist and } \\
\text { peer for pharmacy refills } \\
\text { at week } 2,4 \text {, and } 6 \text { for } \\
\text { the first } 2 \text { months and } \\
\text { monthly thereafter } \\
(\mathrm{n}=175)\end{array}$ & & \\
\hline Perrin 2010 & Asthma & $\begin{array}{l}\text { COMBINATION METERED } \\
\text { DOSE INHALER (MDI): } \\
\text { Subjects received the } \\
\text { intervention treatment } \\
\text { regimen for a duration of } \\
24 \text { weeks that involved } \\
125 \text { mg FP and } 25 \text { mg } \\
\text { salmeterol in a combi- } \\
\text { nation Smartinhaler, } 2 \\
\text { actuations twice daily. } \\
\text { Participants were seen } \\
\text { in the clinic on } 5 \text { occa- } \\
\text { sions. At the first visit, } \\
\text { subjects were random- } \\
\text { ized and issued the ap- } \\
\text { propriate Smartinhalers, } \\
\text { and inhaler technique } \\
\text { was checked. Subjects } \\
\text { were instructed to take } \\
2 \text { actuations of the study } \\
\text { medications twice daily, } \\
\text { resulting in a daily dose } \\
\text { of } 500 \text { mg FP and } 100 \\
\text { mg salmeterol with both } \\
\text { regimens. Subjects were } \\
\text { advised that the study } \\
\text { was designed to com- } \\
\text { pare the efficacy of the } \\
2 \text { regimens but were not } \\
\text { informed that adherence } \\
\text { would be monitored. } \\
\text { They were told that the } \\
\text { MDI casing looked differ- } \\
\text { ent because it was possi- } \\
\text { ble to program it with a } \\
\text { reminder alarm, but that } \\
\text { this function would not } \\
\text { be used in this study } \\
\text { ( } \mathrm{n}=57 \text { ) }\end{array}$ & $\begin{array}{l}\text { SEPARATE METERED } \\
\text { DOSE INHALER (MDI): } \\
\text { Subjects received a } \\
\text { treatment regimens for } \\
\text { a duration of } 24 \text { weeks } \\
\text { of } 125 \text { mg FP and } 25 \text { mg } \\
\text { salmeterol in separate } \\
\text { Smartinhalers, } 2 \text { actua- } \\
\text { tions twice daily. Partic- } \\
\text { ipants were seen in the } \\
\text { clinic on } 5 \text { occasions. At } \\
\text { the first visit, subjects } \\
\text { were randomized and } \\
\text { issued the appropriate } \\
\text { Smartinhalers, and in- } \\
\text { haler technique was } \\
\text { checked. Subjects were } \\
\text { instructed to take } 2 \text { actu- } \\
\text { ations of the study med- } \\
\text { ications twice daily, re- } \\
\text { sulting in a daily dose } \\
\text { of } 500 \text { mg FP and } 100 \\
\text { mg salmeterol with both } \\
\text { regimens. Subjects were } \\
\text { advised that the study } \\
\text { was designed to com- } \\
\text { pare the efficacy of the } \\
2 \text { regimens but were not } \\
\text { informed that adherence } \\
\text { would be monitored } \\
\text { ( } \mathrm{n}=54 \text { ) }\end{array}$ & $\begin{array}{l}\text { No for improving com- } \\
\text { pliance during the final } \\
6 \text { weeks of the study, for } \\
\text { the first } 36 \text {-week peri- } \\
\text { ods, percentages of days } \\
\text { that subjects were ad- } \\
\text { herent, or for the propor- } \\
\text { tion of subjects who took } \\
>50 \%, 80 \% \text {, or } 90 \% \text { of } \\
\text { their prescribed inhaler } \\
\text { medication }\end{array}$ & $\begin{array}{l}\text { No for Asthma Control } \\
\text { Questionnaire score and } \\
\text { lung function (FEV1) }\end{array}$ \\
\hline Peterson 1984 & Epilepsy & $\begin{array}{l}\text { Counseling, leaflet, self } \\
\text { monitoring of pill-tak- } \\
\text { ing and seizures, mailed } \\
\text { reminders for appoint- } \\
\text { ments and missed drugs } \\
\text { refills } \\
(\mathrm{n}=27)\end{array}$ & $\begin{array}{l}\text { Usual care } \\
(\mathrm{n}=26)\end{array}$ & Yes & No \\
\hline Peterson 2004 & Dyslipidemia & $\begin{array}{l}\text { Patients in the interven- } \\
\text { tion group }(n=45) \text { were } \\
\text { visited at home month- } \\
\text { ly by a pharmacist, who } \\
\text { educated the patients } \\
\text { on the goals of lipid-low- } \\
\text { ering treatment and the } \\
\text { importance of lifestyle is- } \\
\text { sues in dyslipidemia and } \\
\text { compliance with ther- } \\
\text { apy, assessed patients }\end{array}$ & $\begin{array}{l}\text { Patients in the control } \\
\text { group }(n=49) \text { received } \\
\text { standard medical care. } \\
\text { There was no further } \\
\text { contact with patients } \\
\text { in the control group af- } \\
\text { ter the initial collection } \\
\text { of baseline data, until } 6 \\
\text { months had lapsed. At } \\
\text { that time, their final total } \\
\text { blood cholesterol level }\end{array}$ & No & No \\
\hline
\end{tabular}




\begin{tabular}{|c|c|c|c|c|c|}
\hline \multicolumn{6}{|c|}{ Adherence and outcome } \\
\hline Study & Clinical problem & Intervention & Control & $\begin{array}{l}\text { Effect on adherence } \\
\text { (Yes means a statis- } \\
\text { tically significant ef- } \\
\text { fect in favor of the } \\
\text { intervention; No } \\
\text { means no effect or } \\
\text { a negative effect) }\end{array}$ & $\begin{array}{l}\text { Effect on clin- } \\
\text { ical outcome } \\
\text { (Yes means a statis- } \\
\text { tically significant ef- } \\
\text { fect in favor of the } \\
\text { intervention; No } \\
\text { means no effect or } \\
\text { a negative effect) }\end{array}$ \\
\hline & & $\begin{array}{l}\text { for drug-related prob- } \\
\text { lems, and measured to- } \\
\text { tal blood cholesterol lev- } \\
\text { els using point-of-care } \\
\text { testing }\end{array}$ & $\begin{array}{l}\text { was measured, and the } \\
\text { current medication reg- } \\
\text { imen and self reported } \\
\text { compliance were record- } \\
\text { ed }\end{array}$ & & \\
\hline Peveler 1999 & Depression & $\begin{array}{l}\text { Treatment information } \\
\text { leaflet }(n=53) \text {, drug } \\
\text { counseling }(n=52) \text { or } \\
\text { both leaflet and counsel- } \\
\text { ing }(n=53)\end{array}$ & Usual care $(n=55)$ & $\begin{array}{l}\text { Yes for counseling (at } 12 \\
\text { weeks). No for leaflet }\end{array}$ & $\begin{array}{l}\text { No for counseling. No for } \\
\text { leaflet }\end{array}$ \\
\hline Phumipamorn 2008 & Diabetes & 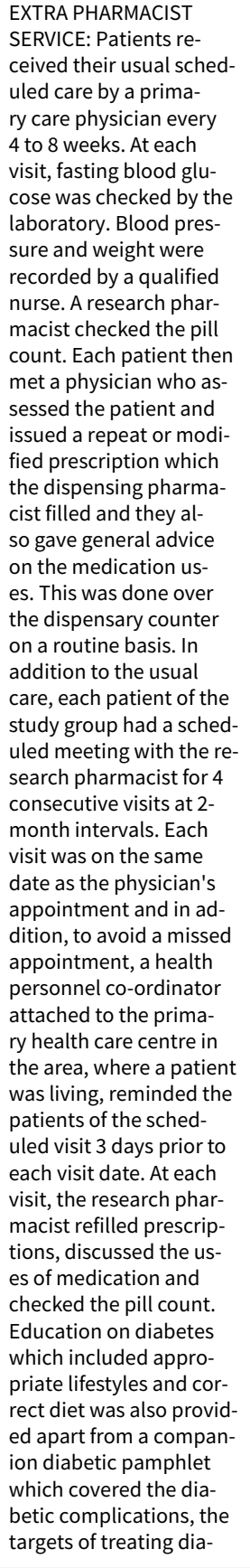 & $\begin{array}{l}\text { USUAL CARE: The control } \\
\text { group received their usu- } \\
\text { al scheduled care by a } \\
\text { primary care physician } \\
\text { every } 4 \text { to } 8 \text { weeks. At } \\
\text { each visit, fasting blood } \\
\text { glucose was checked by } \\
\text { the laboratory. Blood } \\
\text { pressure and weight } \\
\text { were recorded by a qual- } \\
\text { ified nurse. A research } \\
\text { pharmacist checked the } \\
\text { pill count. Each patient } \\
\text { then met a physician } \\
\text { who assessed the pa- } \\
\text { tient and issued a repeat } \\
\text { or modified prescription } \\
\text { which the dispensing } \\
\text { pharmacist filled and } \\
\text { they also gave gener- } \\
\text { al advice on the med- } \\
\text { ication uses. This was } \\
\text { done over the dispensary } \\
\text { counter on a routine ba- } \\
\text { sis } \\
\text { ( } \mathrm{n}=68 \text { ) }\end{array}$ & $\begin{array}{l}\text { Yes for improving adher- } \\
\text { ence to medication in } \\
\text { Muslim diabetic patients }\end{array}$ & $\begin{array}{l}\text { No for A1C. Yes for } \\
\text { change in total choles- } \\
\text { terol. No for changes } \\
\text { in triglycerides. Yes for } \\
\text { change in LDL. Yes for } \\
\text { change in HDL. No for } \\
\text { change in non HDL }\end{array}$ \\
\hline
\end{tabular}




\begin{tabular}{|c|c|c|c|c|c|}
\hline \multicolumn{6}{|c|}{ Adherence and outcome } \\
\hline Study & Clinical problem & Intervention & Control & $\begin{array}{l}\text { Effect on adherence } \\
\text { (Yes means a statis- } \\
\text { tically significant ef- } \\
\text { fect in favor of the } \\
\text { intervention; No } \\
\text { means no effect or } \\
\text { a negative effect) }\end{array}$ & $\begin{array}{l}\text { Effect on clin- } \\
\text { ical outcome } \\
\text { (Yes means a statis- } \\
\text { tically significant ef- } \\
\text { fect in favor of the } \\
\text { intervention; No } \\
\text { means no effect or } \\
\text { a negative effect) }\end{array}$ \\
\hline & & $\begin{array}{l}\text { betes, lifestyle change, } \\
\text { and antidiabetic medica- } \\
\text { tions } \\
(n=67)\end{array}$ & & & \\
\hline Portsmouth 2005 & HIV & $\begin{array}{l}\text { Participants were as- } \\
\text { signed to take Stavu- } \\
\text { dine (d4T), which is a } \\
\text { prolonged-release once- } \\
\text { daily formulation of a } \\
\text { thymidine-based nucle- } \\
\text { oside reverse transcrip- } \\
\text { tase inhibitor (NRTI). } \\
\text { Both groups continued } \\
\text { their other medications } \\
(\mathrm{n}=22)\end{array}$ & $\begin{array}{l}\text { Participants in the con- } \\
\text { trol group were assigned } \\
\text { to continue the twice } \\
\text { daily version of } d 4 T \\
\text { (IR/3TC/EFV or Com- } \\
\text { bivirs/EFV) as per their } \\
\text { screening regimen } \\
(n=21)\end{array}$ & $\begin{array}{l}\text { No for all adherence out- } \\
\text { comes }\end{array}$ & $\begin{array}{l}\text { No for all clinical out- } \\
\text { comes }\end{array}$ \\
\hline Powell 2010 & Heart failure & $\begin{array}{l}\text { SELF MANAGEMENT } \\
\text { PLUS EDUCATION: In the } \\
\text { self management plus } \\
\text { education treatment, } \\
\text { patients received group } \\
\text { base heart failure edu- } \\
\text { cation plus counseling } \\
\text { to help patients develop } \\
\text { mastery in problem-solv- } \\
\text { ing skills and in } 5 \text { self } \\
\text { management skills. } 18 \\
\text { 2-hour group meetings } \\
\text { of approximately } 10 \text { pa- } \\
\text { tients were spread over } \\
\text { the course of } 1 \text { year. At } \\
\text { each meeting, education } \\
\text { in the form of } 18 \text { heart } \\
\text { failure tip sheets sum- } \\
\text { marized basic elements } \\
\text { of patient management. } \\
\text { A problem-solving for- } \\
\text { mat was used. Groups } \\
\text { were led by health pro- } \\
\text { fessionals } \\
\text { ( } \mathrm{n}=451 \text { ) }\end{array}$ & $\begin{array}{l}\text { EDUCATION ONLY: Pa- } \\
\text { tients randomized to re- } \\
\text { ceive education received } \\
\text { the same } 18 \text { Heart Fail- } \\
\text { ure Tip Sheets, on the } \\
\text { same schedule as the } \\
\text { self management group } \\
\text { meetings but delivered } \\
\text { by mail. To ensure re- } \\
\text { ceipt and check compre- } \\
\text { hension, a study co-or- } \\
\text { dinator contacted the } \\
\text { patient by telephone } \\
\text { within } 2 \text { to } 3 \text { days of each } \\
\text { mailing. If the tip sheet } \\
\text { had not been read, the } \\
\text { call was rescheduled. All } \\
\text { questions about the tip } \\
\text { sheets were answered. } \\
\text { For concerns unrelated } \\
\text { to the tip sheets, the pa- } \\
\text { tient was referred to his } \\
\text { or her primary care clini- } \\
\text { cian } \\
\text { ( } \mathrm{n}=451 \text { ) }\end{array}$ & $\begin{array}{l}\text { No for adherence in pa- } \\
\text { tients with mild to mod- } \\
\text { erate heart failure }\end{array}$ & $\begin{array}{l}\text { No for reduction in death } \\
\text { or heart failure hospital- } \\
\text { ization in patients with } \\
\text { mild to moderate heart } \\
\text { failure. Yes for decreased } \\
\text { major depressive symp- } \\
\text { toms, restricting sodium } \\
\text { intake with time ( } 2 \text { to } 3 \\
\text { years). No for difference } \\
\text { in NYHA class, 6-minute } \\
\text { walk, heart rate, respira- } \\
\text { tory rate, blood pressure, } \\
\text { body mass index, quali- } \\
\text { ty of life, emotional sup- } \\
\text { port, or purpose in life }\end{array}$ \\
\hline Powers 2011 & $\begin{array}{l}\text { Coronary heart disease } \\
\text { and stroke }\end{array}$ & $\begin{array}{l}\text { PERSONALIZED RISK } \\
\text { COMMUNICATION: Pa- } \\
\text { tients in the personal- } \\
\text { ized risk communication } \\
\text { arm received standard } \\
\text { risk factor education } \\
\text { (control) as well as per- } \\
\text { sonalized information } \\
\text { based on their Framing- } \\
\text { ham CHD and stroke risk } \\
\text { score, presented verbal- } \\
\text { ly and in graphic form as } \\
\text { vertical bar charts. Pa- } \\
\text { tients' average and opti- } \\
\text { mal CHD and stroke risks } \\
\text { based on published es- } \\
\text { timates for their 5-year } \\
\text { age group were also pre- } \\
\text { sented in graphical form } \\
\text { alongside their estimat- } \\
\text { ed risk. To achieve opti- } \\
\text { mal risk, patients were } \\
\text { presented with poten- } \\
\text { tial strategies to improve } \\
\text { their risk through risk } \\
\text { factor modification such } \\
\text { as medication and pa- } \\
\text { tient lifestyle factors. A } \\
\text { copy of the patient's per- }\end{array}$ & $\begin{array}{l}\text { STANDARD RISK FAC- } \\
\text { TOR EDUCATION: Con- } \\
\text { trol patients received } \\
\text { written patient educa- } \\
\text { tion materials from the } \\
\text { American Heart Associ- } \\
\text { ation/American Stroke } \\
\text { Association entitled "Are } \\
\text { You at Risk of Heart At- } \\
\text { tack or Stroke?" which } \\
\text { reviewed risk factors and } \\
\text { how these factors can } \\
\text { be improved but did not } \\
\text { provide personalized } \\
\text { estimates of individual } \\
\text { risk. The research assis- } \\
\text { tant verbally reviewed } \\
\text { the information with all } \\
\text { patients and answered } \\
\text { any questions at the ini- } \\
\text { tial visit } \\
\text { ( } \mathrm{n}=44 \text { ) }\end{array}$ & $\begin{array}{l}\text { No for improving med- } \\
\text { ication adherence with } \\
\text { personalized stroke risk } \\
\text { communication in coro- } \\
\text { nary heart disease pa- } \\
\text { tients }\end{array}$ & $\begin{array}{l}\text { No for risk factor knowl- } \\
\text { edge, beliefs and health } \\
\text { behaviors, or estimated } \\
\text { vascular risk }\end{array}$ \\
\hline
\end{tabular}




\begin{tabular}{|c|c|c|c|c|c|}
\hline \multicolumn{6}{|c|}{ Adherence and outcome } \\
\hline Study & Clinical problem & Intervention & Control & $\begin{array}{l}\text { Effect on adherence } \\
\text { (Yes means a statis- } \\
\text { tically significant ef- } \\
\text { fect in favor of the } \\
\text { intervention; No } \\
\text { means no effect or } \\
\text { a negative effect) }\end{array}$ & $\begin{array}{l}\text { Effect on clin- } \\
\text { ical outcome } \\
\text { (Yes means a statis- } \\
\text { tically significant ef- } \\
\text { fect in favor of the } \\
\text { intervention; No } \\
\text { means no effect or } \\
\text { a negative effect) }\end{array}$ \\
\hline & & $\begin{array}{l}\text { sonal risk information } \\
\text { was also provided to the } \\
\text { primary care provider } \\
(\mathrm{n}=45)\end{array}$ & & & \\
\hline Pradier 2003 & HIV & $\begin{array}{l}\text { Patients ( } n=100 \text { ) in the } \\
\text { intervention group (IG) } \\
\text { were offered } 3 \text { individual } \\
\text { sessions by trained nurs- } \\
\text { es. }\end{array}$ & $\begin{array}{l}\text { No mention was made of } \\
\text { the care that was provid- } \\
\text { ed for the control group } \\
(n=102) \text {. }\end{array}$ & Yes & $\begin{array}{l}\text { No. The clinical signifi- } \\
\text { cance of these findings } \\
\text { is unclear - adherence } \\
\text { rate was on self report in } \\
\text { an unblinded trial, the } \\
\text { mean HIV RNA was no } \\
\text { different at } 6 \text { months for } \\
\text { the } 2 \text { groups and no ac- } \\
\text { tual clinical outcomes } \\
\text { were reported. }\end{array}$ \\
\hline Purcell 2007 & $\begin{array}{l}\text { HIV with injection drug } \\
\text { use }\end{array}$ & $\begin{array}{l}\text { PEER MENTORING IN- } \\
\text { TERVENTION: The peer } \\
\text { mentoring intervention } \\
\text { sessions were delivered } \\
\text { twice a week for } 5 \text { weeks } \\
\text { and included } 7 \text { group } \\
\text { sessions, } 2 \text { individual } \\
\text { sessions, and } 1 \text { "peer } \\
\text { volunteer activity" (P- } \\
\text { VA), during which par- } \\
\text { ticipants went to a lo- } \\
\text { cal service organization } \\
\text { for } 2 \text { to } 4 \text { hours to ob- } \\
\text { serve, participate, and } \\
\text { practice peer mentor- } \\
\text { ing skills. The first ses- } \\
\text { sion focused on setting } \\
\text { group rules and the pow- } \\
\text { er of peer mentoring, } \\
2 \text { group sessions and } \\
1 \text { individual session fo- } \\
\text { cused on utilization of } \\
\text { HIV primary care and ad- } \\
\text { herence, and } 3 \text { group } \\
\text { sessions and } 1 \text { individ- } \\
\text { ual session focused on } \\
\text { sex and drug risk behav- } \\
\text { iors. Risk messages were } \\
\text { communicated using } \\
\text { posters and handouts } \\
\text { with risk hierarchies that } \\
\text { helped to form individ- } \\
\text { ualized risk plans dis- } \\
\text { cussed during the indi- } \\
\text { vidual session focusing } \\
\text { on sex and injection be- } \\
\text { haviors. The final group } \\
\text { session focused on re- } \\
\text { view and reinforcement } \\
\text { of motivation and skills } \\
\text { able during and after } \\
\text { every session } \\
\text { for behavior change and } \\
\text { ended with a gradua- } \\
\text { tion ceremony. For both } \\
\text { treatment groups, a re- } \\
\text { source table that provid- } \\
\text { ed information about } \\
\text { local services available } \\
\text { for medical care, sup- } \\
\text { mort groups, drug treat- } \\
\text { resources such as pam- } \\
\text { malend male and fe- }\end{array}$ & $\begin{array}{l}\text { VIDEO DISCUSSION IN- } \\
\text { TERVENTION: Control } \\
\text { participants had similar } \\
\text { access to general infor- } \\
\text { mation resources and } \\
\text { risk reduction informa- } \\
\text { tion and resources Inter- } \\
\text { vention participants, and } \\
\text { received equal attention } \\
\text { during the study regard- } \\
\text { ing groups sessions, but } \\
\text { not the } 2 \text { individual ses- } \\
\text { sions as for Intervention. } \\
\text { Participants in the Con- } \\
\text { trol group took part in } \\
8 \text { group sessions over } 5 \\
\text { weeks. For all but ses- } \\
\text { sion } 1 \text {, the Control ses- } \\
\text { sions were led by the } \\
\text { same } 2 \text { facilitators who } \\
\text { led the Intervention ses- } \\
\text { sions. Participants in the } \\
\text { Control group watched } \\
\text { documentary or self help } \\
\text { videos focused on issues } \\
\text { relevant to HIV-positive } \\
\text { intravenous drug users, } \\
\text { followed by facilitated } \\
\text { discussion. Topics di- } \\
\text { rectly related to the in- } \\
\text { tervention outcomes } \\
\text { were avoided or mini- } \\
\text { mized. Community re- } \\
\text { sources and risk reduc- } \\
\text { tion information and } \\
\text { tools were available at } \\
\text { every Control session } \\
\text { ( } \mathrm{n}=480 \text { ) }\end{array}$ & $\begin{array}{l}\text { No for improving the } \\
\text { proportion of patients } \\
\text { adherent with HIV thera- } \\
\text { py after } 12 \text { months }\end{array}$ & $\begin{array}{l}\text { No for reduction in hos- } \\
\text { pital utilization, sexual } \\
\text { risk behavior, and injec- } \\
\text { tion drug risk behavior } \\
\text { with a peer mentoring } \\
\text { intervention }\end{array}$ \\
\hline
\end{tabular}




\begin{tabular}{|c|c|c|c|c|c|}
\hline \multicolumn{6}{|c|}{ Adherence and outcome } \\
\hline Study & Clinical problem & Intervention & Control & $\begin{array}{l}\text { Effect on adherence } \\
\text { (Yes means a statis- } \\
\text { tically significant ef- } \\
\text { fect in favor of the } \\
\text { intervention; No } \\
\text { means no effect or } \\
\text { a negative effect) }\end{array}$ & $\begin{array}{l}\text { Effect on clin- } \\
\text { ical outcome } \\
\text { (Yes means a statis- } \\
\text { tically significant ef- } \\
\text { fect in favor of the } \\
\text { intervention; No } \\
\text { means no effect or } \\
\text { a negative effect) }\end{array}$ \\
\hline & & $(n=486)$ & & & \\
\hline Pyne 2011 & HIV with depression & 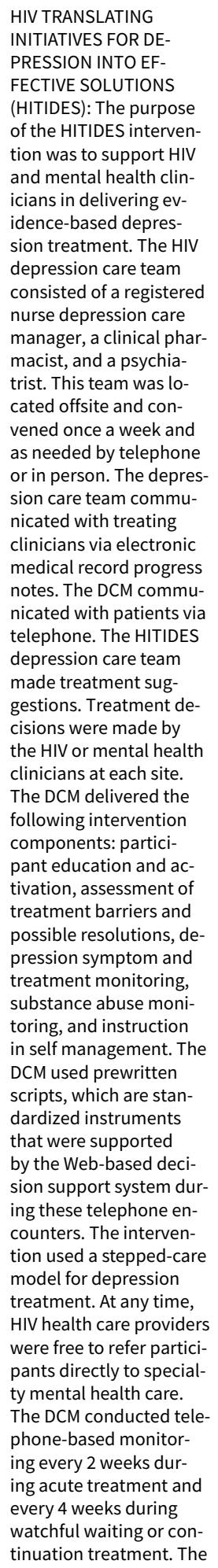 & $\begin{array}{l}\text { USUAL CARE: Usual care } \\
\text { depression treatment } \\
\text { was provided by HIV or } \\
\text { mental health clinicians } \\
\text { without involvement } \\
\text { of the HITIDES depres- } \\
\text { sion care team. Before } \\
\text { starting the study, all HIV } \\
\text { health care providers re- } \\
\text { ceived } 1 \text { hour of HIV and } \\
\text { depression training } \\
(\mathrm{n}=138)\end{array}$ & $\begin{array}{l}\text { No for improving adher- } \\
\text { ence to antidepressant } \\
\text { medication regime. No } \\
\text { for improving adherence } \\
\text { of HIV medications }\end{array}$ & $\begin{array}{l}\text { No for reduction of de- } \\
\text { pression severity score. } \\
\text { No for improvement in } \\
\text { health-related quality of } \\
\text { life. Yes for treatment re- } \\
\text { sponse improvement at } \\
6 \text { months. Yes for inter- } \\
\text { vention effect in remis- } \\
\text { sion rates at } 6 \text { months. } \\
\text { No for treatment re- } \\
\text { sponse at } 12 \text { months. No } \\
\text { for remission rates at } 12 \\
\text { months. Yes for depres- } \\
\text { sion free days }\end{array}$ \\
\hline
\end{tabular}




\begin{tabular}{|c|c|c|c|c|c|}
\hline \multicolumn{6}{|c|}{ Adherence and outcome } \\
\hline Study & Clinical problem & Intervention & Control & $\begin{array}{l}\text { Effect on adherence } \\
\text { (Yes means a statis- } \\
\text { tically significant ef- } \\
\text { fect in favor of the } \\
\text { intervention; No } \\
\text { means no effect or } \\
\text { a negative effect) }\end{array}$ & $\begin{array}{l}\text { Effect on clin- } \\
\text { ical outcome } \\
\text { (Yes means a statis- } \\
\text { tically significant ef- } \\
\text { fect in favor of the } \\
\text { intervention; No } \\
\text { means no effect or } \\
\text { a negative effect) }\end{array}$ \\
\hline & & $\begin{array}{l}\text { NetDSS system identi- } \\
\text { fied potential treatment } \\
\text { non-response as (1) anti- } \\
\text { depressant regimen ad- } \\
\text { herence of less than } 80 \% \\
\text { during the past } 14 \text { days, } \\
\text { (2) counseling non-ad- } \\
\text { herence of less than } 75 \% \\
\text { during the past month, } \\
\text { (3) participant report of } \\
\text { severe adverse effects } \\
\text { during } 2 \text { consecutive } \\
\text { DCM encounters, (4) par- } \\
\text { ticipant report of a 5- } \\
\text { point increase in depres- } \\
\text { sion severity from the } \\
\text { enrollment PHQ-9 score } \\
\text { based on } 2 \text { consecutive } \\
\text { DCM encounters, or (5) } \\
\text { lack of participant re- } \\
\text { sponse during an } 8 \text {-week } \\
\text { antidepressant or } 12- \\
\text { week counseling trial } \\
\text { (n = 138) }\end{array}$ & & & \\
\hline Rawlings 2003 & HIV & $\begin{array}{l}4 \text { modules of the Tools } \\
\text { for Health and Empow- } \\
\text { erment HIV education in- } \\
\text { tervention (EI) plus rou- } \\
\text { tine counseling (RC) } \\
(E I+R C ; n=96)\end{array}$ & $\begin{array}{l}\text { Routine counseling } \\
\text { alone }(R C) \\
(n=99)\end{array}$ & No & No \\
\hline Razali 2000 & Schizophrenia & $\begin{array}{l}\text { Culturally modified fami- } \\
\text { ly therapy (CMFT), which } \\
\text { consists of a sociocultur- } \\
\text { al approach of family ed- } \\
\text { ucation, drug interven- } \\
\text { tion program and prob- } \\
\text { lem-solving skills } \\
(n=80)\end{array}$ & $\begin{array}{l}\text { Behavior Family Therapy } \\
\text { (BFT) } \\
(n=86)\end{array}$ & Yes & $\begin{array}{l}\text { No at } 6 \text { months. Yes at } \\
12 \text { months for all vari- } \\
\text { ables (exacerbation, GAF } \\
\text { score, SBS score, rehos- } \\
\text { pitalization, family bur- } \\
\text { den) }\end{array}$ \\
\hline Remien 2005 & HIV & $\begin{array}{l}\text { Usual care (see Control) } \\
\text { plus a 4-session ( } 45 \text { to } \\
60 \text { minutes each, over } 5 \\
\text { weeks), couple-focused } \\
\text { adherence intervention } \\
\text { consisting of treatment } \\
\text { and adherence educa- } \\
\text { tion, identifying adher- } \\
\text { ence barriers, develop- } \\
\text { ing communication and } \\
\text { problem-solving strate- } \\
\text { gies, optimizing partner } \\
\text { support, and building } \\
\text { confidence for optimal } \\
\text { adherence, with each } \\
\text { partner receiving USD } 20 \\
\text { for each session attend- } \\
\text { ed } \\
\text { ( } \mathrm{n}=106)\end{array}$ & $\begin{array}{l}\text { Usual care from a multi- } \\
\text { disciplinary treatment } \\
\text { team, including month- } \\
\text { ly visits with provider if } \\
\text { nonadherent } \\
(\mathrm{n}=109)\end{array}$ & No & $\begin{array}{l}\text { No for all clinical out- } \\
\text { comes }\end{array}$ \\
\hline Rickles 2005 & Depression & $\begin{array}{l}\text { Usual care (see Control) } \\
\text { plus: Pharmacist-guided } \\
\text { education and monitor- } \\
\text { ing (PGEM) - to address } \\
\text { concerns, educate, and } \\
\text { help patients increase } \\
\text { adherence to medication } \\
(\mathrm{n}=31)\end{array}$ & $\begin{array}{l}\text { Usual care - no special } \\
\text { counseling or monitor- } \\
\text { ing of adherence } \\
(n=32)\end{array}$ & $\begin{array}{l}\text { No for all adherence out- } \\
\text { comes }\end{array}$ & No \\
\hline Riesen 2008 & $\begin{array}{l}\text { Primary hypercholes- } \\
\text { terolemia }\end{array}$ & $\begin{array}{l}10 \text { MG PLUS: Patients re- } \\
\text { ceived a daily oral treat- } \\
\text { ment with rosuvastatin }\end{array}$ & $\begin{array}{l}10 \mathrm{MG} \text { : Patients received } \\
\text { a daily oral treatment } \\
\text { with rosuvastatin alone }\end{array}$ & $\begin{array}{l}\text { No for improving ad- } \\
\text { herence to rosuvastatin }\end{array}$ & $\begin{array}{l}\text { Yes for reducing low- } \\
\text { density lipoprotein cho- } \\
\text { lesterol level at } 24 \text { weeks }\end{array}$ \\
\hline
\end{tabular}




\begin{tabular}{|c|c|c|c|c|c|}
\hline \multicolumn{6}{|c|}{ Adherence and outcome } \\
\hline Study & Clinical problem & Intervention & Control & $\begin{array}{l}\text { Effect on adherence } \\
\text { (Yes means a statis- } \\
\text { tically significant ef- } \\
\text { fect in favor of the } \\
\text { intervention; No } \\
\text { means no effect or } \\
\text { a negative effect) }\end{array}$ & $\begin{array}{l}\text { Effect on clin- } \\
\text { ical outcome } \\
\text { (Yes means a statis- } \\
\text { tically significant ef- } \\
\text { fect in favor of the } \\
\text { intervention; No } \\
\text { means no effect or } \\
\text { a negative effect) }\end{array}$ \\
\hline & & $\begin{array}{l}\text { and access to compli- } \\
\text { ance enhancement tools } \\
\text { (10 mg Plus group) for } 24 \\
\text { weeks. Patients were as- } \\
\text { sessed at week } 4 \text { and at } \\
\text { week } 12 \text { to review fast- } \\
\text { ing levels of TC, LDL-C, } \\
\text { HDL-C, and triglycerides. } \\
\text { For patients not achiev- } \\
\text { ing the } 1998 \text { European } \\
\text { target for LDL-C at week } \\
12 \text {, the daily dose of ro- } \\
\text { suvastatin was increased } \\
\text { to } 20 \text { mg for the remain- } \\
\text { der of the study. Patients } \\
\text { in the } 10 \text { mg Plus group } \\
\text { received a starter pack } \\
\text { containing a videotape } \\
\text { and educational leaflets } \\
\text { concerning their con- } \\
\text { dition. These patients } \\
\text { also received newslet- } \\
\text { ters at regular intervals } \\
\text { and had access to both a } \\
\text { telephone helpline and } \\
\text { an Internet website, all } \\
\text { designed to reinforce } \\
\text { the initial message in the } \\
\text { starter pack } \\
\text { ( } \mathrm{n}=527 \text { ) }\end{array}$ & $\begin{array}{l}\text { (10 mg group) for } 24 \\
\text { weeks. Patients were as- } \\
\text { sessed at week } 4 \text { and at } \\
\text { week } 12 \text { to review fast- } \\
\text { ing levels of TC, LDL-C, } \\
\text { HDL-C, and triglycerides. } \\
\text { For patients not achiev- } \\
\text { ing the } 1998 \text { European } \\
\text { target for LDL-C at week } \\
12 \text { the daily dose of rosu- } \\
\text { vastatin was increased to } \\
20 \text { mg for the remainder } \\
\text { of the study } \\
\text { ( } n=601 \text { ) }\end{array}$ & $\begin{array}{l}\text { medication at } 12 \text { and } 24 \\
\text { weeks }\end{array}$ & $\begin{array}{l}\text { below } 3.0 \mathrm{~mm} / \mathrm{mol} \text { (Eu- } \\
\text { ropean } 1998 \mathrm{goal} \text { ) and } \\
\text { not below } 2.5 \mathrm{~mm} / \mathrm{mol} \\
\text { (European } 2003 \text { goal). } \\
\text { No for reducing total } \\
\text { cholesterol and plasma } \\
\text { lipid levels at } 12 \text { and } 24 \\
\text { weeks. No for changes } \\
\text { in heart rate, blood pres- } \\
\text { sure, and body weight at } \\
24 \text { weeks }\end{array}$ \\
\hline Rosen 2007 & HIV & $\begin{array}{l}\text { CONTINGENCY MAN- } \\
\text { AGEMENT: The interven- } \\
\text { tion group participants } \\
\text { were provided with } 16 \\
\text { weeks of weekly CM- } \\
\text { based counseling fol- } \\
\text { lowed by } 16 \text { addition- } \\
\text { al weeks of data collec- } \\
\text { tion and adherence feed- } \\
\text { back to providers fol- } \\
\text { lowed by } 16 \text { additional } \\
\text { weeks of data collection } \\
\text { and adherence feedback } \\
\text { to providers. The CM in- } \\
\text { tervention provided by } \\
\text { bachelor's level staff in- } \\
\text { volved review of data } \\
\text { generated by electron- } \\
\text { ic pill-bottle caps that } \\
\text { record bottle opening } \\
\text { (MEMS) and brief sub- } \\
\text { stance abuse counseling. } \\
\text { CM participants were re- } \\
\text { inforced for MEMS mea- } \\
\text { sured adherence with } \\
\text { drawings from a bowl } \\
\text { for prizes and bonus } \\
\text { drawings for consecutive } \\
\text { weeks of perfect adher- } \\
\text { ence } \\
\text { ( } \mathrm{n}=28 \text { ) }\end{array}$ & $\begin{array}{l}\text { SUPPORTIVE } \\
\text { COUNSELING } \\
\text { CONDITION: The sup- } \\
\text { portive counseling con- } \\
\text { dition was an attention } \\
\text { control condition. Par- } \\
\text { ticipants were encour- } \\
\text { aged to meet with coun- } \\
\text { selors weekly. In these } \\
\text { sessions, participants } \\
\text { were asked about their } \\
\text { adherence, and offered } \\
\text { support for their efforts } \\
\text { to improve adherence. } \\
\text { However, the counselors } \\
\text { did not review MEMS da- } \\
\text { ta with the participants } \\
\text { or conduct urine toxi- } \\
\text { cology testing. There } \\
\text { was an initial review of } \\
\text { self reported substance } \\
\text { abuse and referral to } \\
\text { available treatment. In } \\
\text { addition, providers were } \\
\text { sent monthly letters stat- } \\
\text { ing the participant's self } \\
\text { reported adherence. The } \\
\text { same staff members de- } \\
\text { livered both interven- } \\
\text { tions } \\
\text { ( } \mathrm{n}=28 \text { ) }\end{array}$ & $\begin{array}{l}\text { Yes for improving adher- } \\
\text { ence to reinforced anti- } \\
\text { retroviral therapy during } \\
\text { the intervention period } \\
\text { ( } 1 \text { to } 16 \text { weeks) but no } \\
\text { during the follow-up pe- } \\
\text { riod ( } 17 \text { to } 32 \text { weeks). No } \\
\text { for improving adherence } \\
\text { to non-reinforced anti- } \\
\text { retroviral therapy during } \\
\text { the intervention and fol- } \\
\text { low-up period }\end{array}$ & $\begin{array}{l}\text { Yes for reducing viral } \\
\text { load at } 16 \text { weeks but not } \\
\text { at } 32 \text { weeks. No for re- } \\
\text { ducing the viral load be- } \\
\text { low } 400 \text { HIV-RNA copies } \\
\text { per milliliter at } 16 \text { and } 32 \\
\text { weeks }\end{array}$ \\
\hline Rubak 2011 & Type 2 diabetes & $\begin{array}{l}\text { MOTIVATIONAL INTER- } \\
\text { VIEWING: The courses } \\
\text { in "motivational inter- } \\
\text { viewing" (MI) for the } \\
\text { GPs in the intervention } \\
\text { group were conduct- } \\
\text { ed by a trained teacher } \\
\text { introducing a manu- }\end{array}$ & $\begin{array}{l}\text { CONTROL: None of the } \\
\text { GPs in the control group } \\
\text { had previously partici- } \\
\text { pated in an MI course. } \\
\text { All GPs in the control } \\
\text { group participated in the } \\
\text { same half-day course on } \\
\text { intensive treatment of }\end{array}$ & $\begin{array}{l}\text { No for improved ad- } \\
\text { herence to blood glu- } \\
\text { cose-lowering drugs, BP } \\
\text { or lipid-lowering drugs at } \\
1 \text { year in type } 2 \text { diabetes } \\
\text { patients }\end{array}$ & $\begin{array}{l}\text { Yes for improved blood } \\
\text { pressure, blood lipid } \\
\text { measurement, HbA1c, } \\
\text { and BMI at } 12 \text { months in } \\
\text { both controls and inter- } \\
\text { vention groups. No for } \\
\text { improvement in blood } \\
\text { pressure, blood lipid }\end{array}$ \\
\hline
\end{tabular}




\begin{tabular}{|c|c|c|c|c|c|}
\hline \multicolumn{6}{|c|}{ Adherence and outcome } \\
\hline Study & Clinical problem & Intervention & Control & $\begin{array}{l}\text { Effect on adherence } \\
\text { (Yes means a statis- } \\
\text { tically significant ef- } \\
\text { fect in favor of the } \\
\text { intervention; No } \\
\text { means no effect or } \\
\text { a negative effect) }\end{array}$ & $\begin{array}{l}\text { Effect on clin- } \\
\text { ical outcome } \\
\text { (Yes means a statis- } \\
\text { tically significant ef- } \\
\text { fect in favor of the } \\
\text { intervention; No } \\
\text { means no effect or } \\
\text { a negative effect) }\end{array}$ \\
\hline & & $\begin{array}{l}\text { al which together with } \\
\text { "Motivational interview- } \\
\text { ing, preparing people } \\
\text { to change addictive be- } \\
\text { haviour" constituted } \\
\text { the theoretical part of } \\
\text { the course curriculum. } \\
\text { The intervention group } \\
\text { was coached in the key } \\
\text { points of MI. The train- } \\
\text { ing also included the } \\
\text { use of specific skills, e.g. } \\
\text { empowerment, ambiva- } \\
\text { lence, the decisional bal- } \\
\text { ance schedule, the visu- } \\
\text { al analogue scale, stage } \\
\text { of change, and reflective } \\
\text { listening, all of which are } \\
\text { described in detail in the } \\
\text { book MI. The interven- } \\
\text { tion group courses con- } \\
\text { sisted of a } 11 \% 2 \text {-day train- } \\
\text { ing sessions with a half- } \\
\text { day follow-up twice dur- } \\
\text { ing the first year. None } \\
\text { of the GPs in I- and con- } \\
\text { trol group had previous- } \\
\text { ly participated in an MI } \\
\text { course. All GPs in the I- } \\
\text { and the control group } \\
\text { participated in the same } \\
\text { half-day course on inten- } \\
\text { sive treatment of type } 2 \\
\text { diabetes. During these } \\
\text { diabetes training ses- } \\
\text { sions, it was stressed } \\
\text { that GPs should act as } \\
\text { counselors for the pa- } \\
\text { tients, allowing treat- } \\
\text { ment decisions to be } \\
\text { based on mutual under- } \\
\text { standing between the } \\
\text { patient and the GP. In } \\
\text { Denmark, GPs' consul- } \\
\text { tation encounters aver- } \\
\text { age } 15 \text { minutes and the } \\
\text { County Health Insurance } \\
\text { has agreed to one longer } \\
\text { preventive consultation } \\
\text { encounter of } 45 \text { min- } \\
\text { utes per patient. In this } \\
\text { study the County Health } \\
\text { Insurance agreed to al- } \\
\text { low the GPs in the I- and } \\
\text { control group to under- } \\
\text { take } 3 \text { consultations of } \\
\text { 45 minutes per patient, } \\
\text { in which the intervention } \\
\text { group could use MI } 37 \text { practices and } 307 \\
\text { patients) }\end{array}$ & $\begin{array}{l}\text { type } 2 \text { diabetes. During } \\
\text { these diabetes training } \\
\text { sessions, it was stressed } \\
\text { that GPs should act as } \\
\text { counselors for the pa- } \\
\text { tients, allowing treat- } \\
\text { ment decisions to be } \\
\text { based on mutual under- } \\
\text { standing between the } \\
\text { patient and the GP. In } \\
\text { Denmark, GPs' consul- } \\
\text { tation encounters aver- } \\
\text { age } 15 \text { minutes and the } \\
\text { County Health Insurance } \\
\text { has agreed to one longer } \\
\text { preventive consultation } \\
\text { encounter of } 45 \text { min- } \\
\text { utes per patient. In this } \\
\text { study the County Health } \\
\text { Insurance agreed to al- } \\
\text { low the GPs in the con- } \\
\text { trol group to undertake } 3 \\
\text { consultations of } 45 \text { min- } \\
\text { utes per patient. } \\
\text { (n= } 41 \text { practices and } 321 \\
\text { patients) }\end{array}$ & & $\begin{array}{l}\text { measurement, } \mathrm{HbA1c}, \\
\text { and BMI in intervention } \\
\text { group compared to con- } \\
\text { trol groups }\end{array}$ \\
\hline Rudd 2004 & Hypertension & $\begin{array}{l}\text { A nurse care manag- } \\
\text { er conducted baseline } \\
\text { counseling on the cor- } \\
\text { rect use of the automat- } \\
\text { ed blood pressure (BP) } \\
\text { device, regular return of } \\
\text { the automatically print- } \\
\text { ed BP reports, tips for }\end{array}$ & Usual care $(n=76)$ & Yes & $\begin{array}{l}\text { Yes for changes in both } \\
\text { systolic and diastolic } \\
\text { blood pressure from } \\
\text { baseline to } 6 \text { months be- } \\
\text { tween groups }\end{array}$ \\
\hline
\end{tabular}




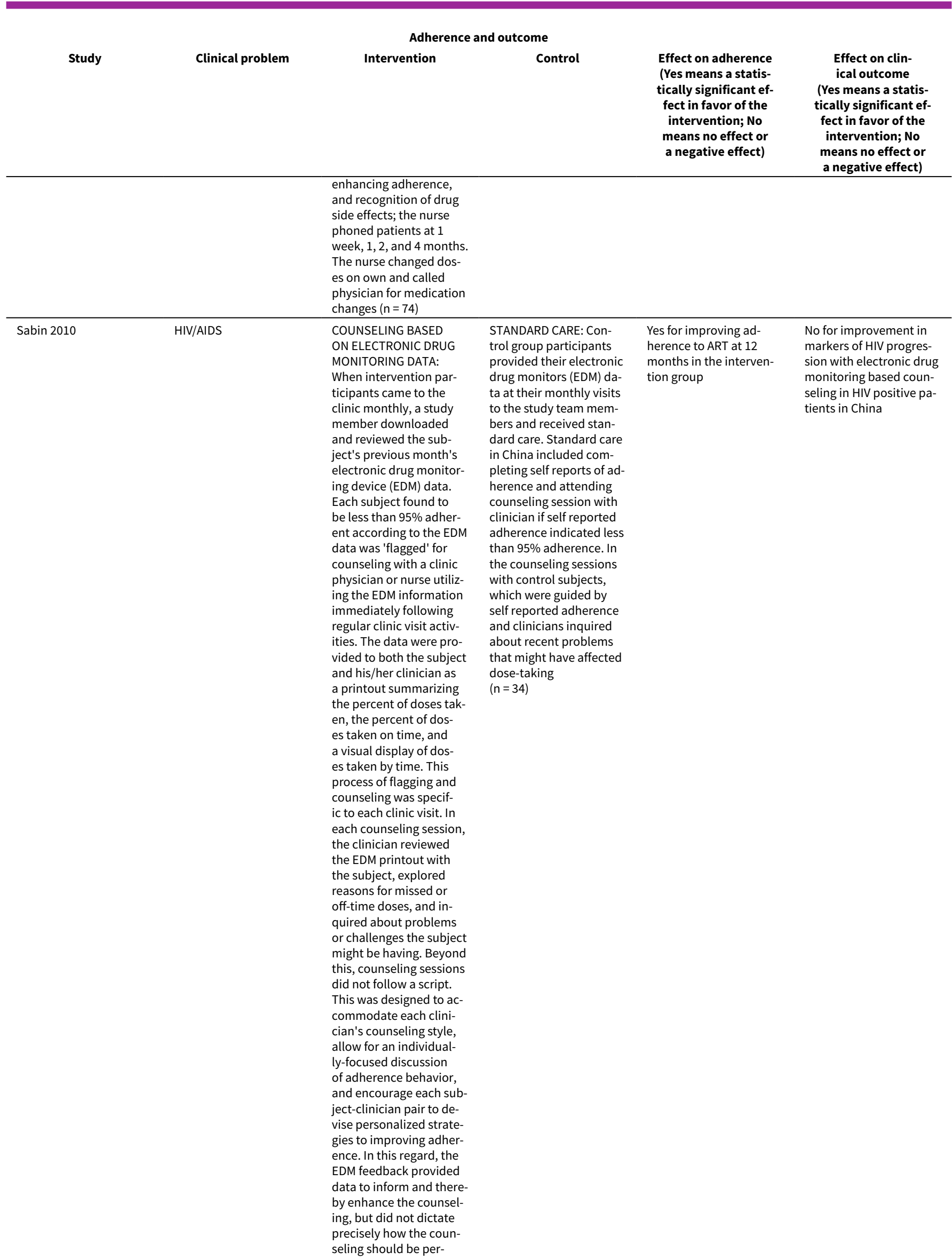




\begin{tabular}{|c|c|c|c|c|c|}
\hline \multicolumn{6}{|c|}{ Adherence and outcome } \\
\hline Study & Clinical problem & Intervention & Control & $\begin{array}{l}\text { Effect on adherence } \\
\text { (Yes means a statis- } \\
\text { tically significant ef- } \\
\text { fect in favor of the } \\
\text { intervention; No } \\
\text { means no effect or } \\
\text { a negative effect) }\end{array}$ & $\begin{array}{l}\text { Effect on clin- } \\
\text { ical outcome } \\
\text { (Yes means a statis- } \\
\text { tically significant ef- } \\
\text { fect in favor of the } \\
\text { intervention; No } \\
\text { means no effect or } \\
\text { a negative effect) }\end{array}$ \\
\hline & & $\begin{array}{l}\text { formed. In the event that } \\
\text { subjects did not imme- } \\
\text { diately offer reasons for } \\
\text { missed or off-time doses, } \\
\text { clinicians were advised } \\
\text { to say: "Let's talk more } \\
\text { about any problems that } \\
\text { you had last month".' } \\
\text { Most counseling sessions } \\
\text { were completed within } \\
10 \text { to } 15 \text { minutes. The in- } \\
\text { tervention period was } 7 \\
\text { to } 12 \text { months } \\
\text { ( } \mathrm{n}=34 \text { ) } \\
\end{array}$ & & & \\
\hline Sackett 1975 & Hypertension & $\begin{array}{l}\text { (a) Care at work site by } \\
\text { occupational health } \\
\text { physicians }(n=37) ;(b) \\
\text { Detailed 'programmed' } \\
\text { instructions about hy- } \\
\text { pertension and adher- } \\
\text { ence }(n=28) ;(c) \text { Both a } \\
\text { and b }(n=44)\end{array}$ & $\begin{array}{l}\text { Neither intervention }(n= \\
25)^{\star \star} \text { numbers provided } \\
\text { by author }\end{array}$ & No & No \\
\hline Sadik 2005 & Heart failure & $\begin{array}{l}\text { Usual care plus: Booklets } \\
\text { and education on heart } \\
\text { failure (HF) and training } \\
\text { on a self monitoring pro- } \\
\text { gram (daily weights and } \\
\text { symptom diary, to share } \\
\text { with physician and phar- } \\
\text { macist; extra dose of di- } \\
\text { uretic if weight rose). Re- } \\
\text { search pharmacist inter- } \\
\text { acted with physicians } \\
\text { to simplify drug regi- } \\
\text { mens, with patients on } \\
\text { follow-up visits to clinic } \\
\text { ( } \mathrm{n}=109 \text { ) }\end{array}$ & $\begin{array}{l}\text { Usual care in a medical } \\
\text { or cardiology clinic } \\
(n=112)\end{array}$ & Yes & $\begin{array}{l}\text { Yes for 2-minute walk } \\
\text { test, blood pressure and } \\
\text { pulse, HF symptoms, } \\
\text { forced vital capacity and } \\
\text { both quality of life mea- } \\
\text { sures - the MLHFQ and } \\
\text { SF36 }\end{array}$ \\
\hline Samet 2005 & HIV & $\begin{array}{l}\text { Usual medical care plus } \\
\text { nurse-led intervention } \\
\text { ( } 60 \text { minute session }+3 \\
\text { follow-up visits) with } 4 \\
\text { parts ( } n=74): \text { a) assess- } \\
\text { ment of the alcohol and } \\
\text { substance use b) a watch } \\
\text { to time medications and } \\
\text { improve adherence } c \text { ) } \\
\text { enhancement of per- } \\
\text { ceived efficacy of med- } \\
\text { ications d) individualized } \\
\text { HIV counseling }\end{array}$ & $\begin{array}{l}\text { Patients received regu- } \\
\text { lar medical care for HIV } \\
\text { infection. This includ- } \\
\text { ed verbal or written in- } \\
\text { structions about optimal } \\
\text { medication strategies } \\
(n=77)\end{array}$ & No & Yes for CD4 count \\
\hline Sarna 2008 & HIV & $\begin{array}{l}\text { MODIFIED DIRECTLY } \\
\text { OBSERVED THERAPY (M- } \\
\text { DOT): Patients in the in- } \\
\text { tervention arm received } \\
\text { M-DOT services for the } \\
\text { first } 24 \text { weeks of ART, } \\
\text { in addition to standard } \\
\text { care. Although consider- } \\
\text { ation was given to pro- } \\
\text { vision of home-based } \\
\text { M-DOT, formative re- } \\
\text { search revealed that pa- } \\
\text { tients were concerned } \\
\text { this would undermine } \\
\text { their privacy and confi- } \\
\text { dentiality. They also be- } \\
\text { lieved that clinic visits } \\
\text { would provide benefi- }\end{array}$ & $\begin{array}{l}\text { STANDARD CARE: As } \\
\text { standard care, all partic- } \\
\text { ipants attended } 3 \text { one- } \\
\text { on-one adherence coun- } \\
\text { seling sessions before } \\
\text { initiating ART. In these, } \\
\text { trained nurse counselors } \\
\text { emphasized the impor- } \\
\text { tance of adherence; ed- } \\
\text { ucated patients on the } \\
\text { treatment regimen, dos- } \\
\text { ing instructions, side ef- } \\
\text { fects, and dietary con- } \\
\text { siderations; tailored the } \\
\text { regimen to daily activi- } \\
\text { ties; and identified social } \\
\text { issues like living condi- } \\
\text { tions and family support. }\end{array}$ & $\begin{array}{l}\text { Yes for } 24 \text {-week adher- } \\
\text { ence. No for } 48 \text { and } 72 \text { - } \\
\text { week adherence }\end{array}$ & $\begin{array}{l}\text { No for suppression of vi- } \\
\text { ral load at } 48 \text { weeks. No } \\
\text { for increase in CD4 cell } \\
\text { count and immunolog- } \\
\text { ical improvements. Yes } \\
\text { for larger mean increase } \\
\text { in BMI during the inter- } \\
\text { vention period }\end{array}$ \\
\hline
\end{tabular}




\begin{tabular}{|c|c|c|c|c|c|}
\hline \multicolumn{6}{|c|}{ Adherence and outcome } \\
\hline Study & Clinical problem & Intervention & Control & $\begin{array}{l}\text { Effect on adherence } \\
\text { (Yes means a statis- } \\
\text { tically significant ef- } \\
\text { fect in favor of the } \\
\text { intervention; No } \\
\text { means no effect or } \\
\text { a negative effect) }\end{array}$ & $\begin{array}{l}\text { Effect on clin- } \\
\text { ical outcome } \\
\text { (Yes means a statis- } \\
\text { tically significant ef- } \\
\text { fect in favor of the } \\
\text { intervention; No } \\
\text { means no effect or } \\
\text { a negative effect) }\end{array}$ \\
\hline & & 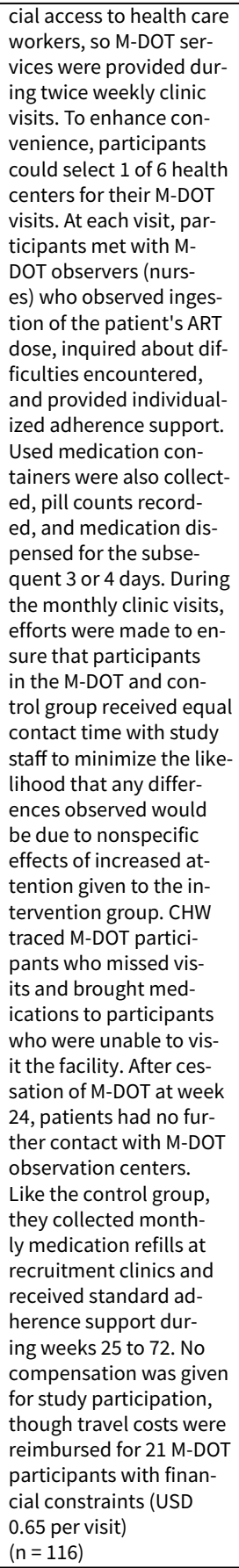 & $\begin{array}{l}\text { After ART initiation, pa- } \\
\text { tients visited treatment } \\
\text { centers every } 4 \text { weeks } \\
\text { for follow-up. At the first } \\
2 \text { follow-up visits, gen- } \\
\text { eral adherence counsel- } \\
\text { ing was provided, as was } \\
\text { discussion of specific } \\
\text { emerging problems with } \\
\text { side effects or medica- } \\
\text { tion intake; thereafter, } \\
\text { counseling was tailored } \\
\text { to individual needs. All } \\
\text { patients were encour- } \\
\text { aged to bring a family } \\
\text { member or friend to clin- } \\
\text { ic visits and counseling } \\
\text { sessions } \\
\text { ( } n=118 \text { ) }\end{array}$ & & \\
\hline Schaffer 2004 & Asthma & $\begin{array}{l}\text { (a) Audiotape alone ( } \mathrm{n} \\
=10) ;(\mathrm{b}) \text { National Heart } \\
\text { Lung and Blood Institute } \\
\text { (NHLBI) booklet alone ( } \mathrm{n} \\
=12) ;(\mathrm{c}) \text { Audiotape plus } \\
\text { NHLBI booklet ( } \mathrm{n}=11 \text { ) }\end{array}$ & $\begin{array}{l}\text { Standard provider edu- } \\
\text { cation (control) }(n=13)\end{array}$ & $\begin{array}{l}\text { Yes for positive effect } \\
\text { on adherence by phar- } \\
\text { macy-refill measure for } \\
\text { booklet versus control, } \\
\text { and for booklet + audio- } \\
\text { tape versus control, but } \\
\text { not for audiotape versus } \\
\text { control, at } 6 \text { months. No }\end{array}$ & No \\
\hline
\end{tabular}




\begin{tabular}{|c|c|c|c|c|c|}
\hline \multicolumn{6}{|c|}{ Adherence and outcome } \\
\hline Study & Clinical problem & Intervention & Control & $\begin{array}{l}\text { Effect on adherence } \\
\text { (Yes means a statis- } \\
\text { tically significant ef- } \\
\text { fect in favor of the } \\
\text { intervention; No } \\
\text { means no effect or } \\
\text { a negative effect) }\end{array}$ & $\begin{array}{l}\text { Effect on clin- } \\
\text { ical outcome } \\
\text { (Yes means a statis- } \\
\text { tically significant ef- } \\
\text { fect in favor of the } \\
\text { intervention; No } \\
\text { means no effect or } \\
\text { a negative effect) }\end{array}$ \\
\hline & & & & $\begin{array}{l}\text { for self reported adher- } \\
\text { ence }\end{array}$ & \\
\hline Schroeder 2005 & Hypertension & $\begin{array}{l}\text { Usual care (see Control) } \\
\text { plus nurse-led adher- } \\
\text { ence support sessions } \\
\text { ( } 20 \text { minutes initially, } 10 \\
\text { minutes } 2 \text { months lat- } \\
\text { er) with the following } \\
\text { goals ( } \mathrm{n}=128) \text { : patients } \\
\text { address problems with } \\
\text { blood pressure lower- } \\
\text { ing medication; explain } \\
\text { diagnosis and the treat- } \\
\text { ment process; address } \\
\text { patient concerns with } \\
\text { their medication and tai- } \\
\text { lor strategies to resolve } \\
\text { any problems }\end{array}$ & $\begin{array}{l}\text { Usual care at their doc- } \\
\text { tors' practices, other } \\
\text { than blood pressure } \\
\text { checks at similar inter- } \\
\text { vals as the intervention } \\
\text { group }(n=117)\end{array}$ & $\begin{array}{l}\text { No for all adherence out- } \\
\text { comes }\end{array}$ & $\begin{array}{l}\text { No for all clinical out- } \\
\text { comes }\end{array}$ \\
\hline Sherrard 2009 & $\begin{array}{l}\text { Adverse events post-car- } \\
\text { diac surgery (coronary } \\
\text { bypass grafts/valvular } \\
\text { surgery) }\end{array}$ & $\begin{array}{l}\text { INTERACTIVE VOICE } \\
\text { RESPONSE (IVR): Pa- } \\
\text { tients in the IVR fol- } \\
\text { low-up group received } \\
\text { automated telephone } \\
\text { calls for } 6 \text { months, at } 1 \text {, } \\
2,3,4,6,8,10,12,16,20 \text {, } \\
\text { and } 24 \text { weeks after dis- } \\
\text { charge. The telephone } \\
\text { interview contained an } \\
\text { algorithm of } 11 \text { ques- } \\
\text { tions addressing medica- } \\
\text { tion compliance, report- } \\
\text { ing of adverse events, } \\
\text { providing information } \\
\text { on common medica- } \\
\text { tions, and offering gener- } \\
\text { al medication safety tips. } \\
\text { The intent of the IVR al- } \\
\text { gorithm was to provide } \\
\text { early identification of } \\
\text { issues permitting time- } \\
\text { ly intervention, provide } \\
\text { a mechanism for track- } \\
\text { ing medication compli- } \\
\text { ance, and provide med- } \\
\text { ication information at } \\
\text { the time deemed most } \\
\text { valuable by the patient } \\
\text { at his or her request and } \\
\text { to provide longer-term } \\
\text { follow-up as the patient } \\
\text { transitioned from hos- } \\
\text { pital to home. Patients } \\
\text { were asked questions } \\
\text { about medication com- } \\
\text { pliance such as, "Did you } \\
\text { fill the prescriptions giv- } \\
\text { en to you at discharge?" } \\
\text { and were offered addi- } \\
\text { tional information on } 8 \\
\text { common medications } \\
\text { prescribed to cardiac } \\
\text { surgical patients on dis- } \\
\text { charge. The answers } \\
\text { to the questions were } \\
\text { captured in a database. } \\
\text { sponending on the re- } \\
\text { appears in the database } \\
\text { next to the question indi- }\end{array}$ & $\begin{array}{l}\text { USUAL CARE: Patients } \\
\text { in the control group re- } \\
\text { ceived the standard of } \\
\text { care provided to all pa- } \\
\text { tients discharged from } \\
\text { post-cardiac surgery. } \\
\text { This included receiving } \\
\text { an IVR call on day } 3 \text { and } \\
10 \text { after discharge to } \\
\text { screen common symp- } \\
\text { toms. This current surgi- } \\
\text { cal follow-up algorithm } \\
\text { does not contain ques- } \\
\text { tions or information on } \\
\text { medications. They were } \\
\text { contacted at } 6 \text { months } \\
\text { to answer questions on } \\
\text { medication compliance } \\
\text { and outcomes } \\
\text { ( } n=167 \text { ) }\end{array}$ & $\begin{array}{l}\text { Yes for improving com- } \\
\text { pliance at } 6 \text { months in } \\
\text { IVR group compared } \\
\text { to UC in post-cardiac } \\
\text { surgery patients }\end{array}$ & $\begin{array}{l}\text { Yes for composite out- } \\
\text { come. No for ER visits } \\
\text { and hospitalizations }\end{array}$ \\
\hline
\end{tabular}




\begin{tabular}{|c|c|c|c|c|c|}
\hline \multicolumn{6}{|c|}{ Adherence and outcome } \\
\hline Study & Clinical problem & Intervention & Control & $\begin{array}{l}\text { Effect on adherence } \\
\text { (Yes means a statis- } \\
\text { tically significant ef- } \\
\text { fect in favor of the } \\
\text { intervention; No } \\
\text { means no effect or } \\
\text { a negative effect) }\end{array}$ & $\begin{array}{l}\text { Effect on clin- } \\
\text { ical outcome } \\
\text { (Yes means a statis- } \\
\text { tically significant ef- } \\
\text { fect in favor of the } \\
\text { intervention; No } \\
\text { means no effect or } \\
\text { a negative effect) }\end{array}$ \\
\hline & & $\begin{array}{l}\text { cating no action is need- } \\
\text { ed, the call was not an- } \\
\text { swered, or alerting the } \\
\text { nurse to intervene by } \\
\text { calling the patient to } \\
\text { provide education and } \\
\text { counseling } \\
(\mathrm{n}=164)\end{array}$ & & & \\
\hline Simon 2011 & Depression & $\begin{array}{l}\text { CARE MANAGEMENT: } \\
\text { Intervention group re- } \\
\text { ceived care manage- } \\
\text { ment intervention in ad- } \\
\text { dition to usual care by } \\
\text { the treating physician. } \\
\text { The intervention was de- } \\
\text { livered online but the } \\
\text { structure was similar to } \\
\text { the telephone programs } \\
\text { tested in earlier stud- } \\
\text { ies. After randomization, } \\
\text { participants received a } \\
\text { welcome letter describ- } \\
\text { ing the program and it } \\
\text { contained general ad- } \\
\text { vice about the antide- } \\
\text { pressants medication } \\
\text { and self care for depres- } \\
\text { sion. Monitoring con- } \\
\text { tacts were scheduled } 2 \text {, } \\
6 \text {, and } 10 \text { weeks later. At } \\
\text { each monitoring contact, } \\
\text { there was an outreach } \\
\text { message from the nurse } \\
\text { containing a link to an } \\
\text { online assessment. The } \\
\text { assessment included the } \\
\text { PHQ depression ques- } \\
\text { tionnaire and questions } \\
\text { regarding use of antide- } \\
\text { pressant medication, } \\
\text { side effects, and reasons } \\
\text { for medication discon- } \\
\text { tinuation. Those not re- } \\
\text { sponding were sent up } \\
\text { to } 2 \text { reminder messages. } \\
\text { For each assessment } \\
\text { completed, an algorithm } \\
\text { generated a suggested } \\
\text { response based on PHQ } \\
\text { depression score, cur- } \\
\text { rent antidepressant use, } \\
\text { and side effects. The care } \\
\text { manager could tailor } \\
\text { this suggested response } \\
\text { using information in } \\
\text { the medical record or in } \\
\text { messages since the last } \\
\text { contact. The care man- } \\
\text { ager communicated with } \\
\text { ication, or facilitate re- } \\
\text { using an electronic mes- } \\
\text { saging system within } \\
\text { record. In consulth the physician, the } \\
\text { care manager might fa- } \\
\text { ilion }\end{array}$ & $\begin{array}{l}\text { USUAL CARE: Controls } \\
\text { received usual care and } \\
\text { did not receive any ad- } \\
\text { ditional care other than } \\
\text { what was normally avail- } \\
\text { able, which included fol- } \\
\text { low-up in primary care } \\
\text { or specialty referral for } \\
\text { psychotherapy or med- } \\
\text { ication management. } \\
\text { Online patient-provider } \\
\text { messaging was available } \\
\text { to all patients in the usu- } \\
\text { al care } \\
\text { ( } n=102 \text { ) }\end{array}$ & $\begin{array}{l}\text { Yes for increasing use of } \\
\text { antidepressant over } 90 \\
\text { days for patients with } \\
\text { depressive disorder }\end{array}$ & $\begin{array}{l}\text { Yes for improving SCL } \\
\text { depressive scores and } \\
\text { satisfaction with depres- } \\
\text { sion treatment. No for in- } \\
\text { creased hospitalization } \\
\text { or suicide attempts }\end{array}$ \\
\hline
\end{tabular}




\begin{tabular}{|c|c|c|c|c|c|}
\hline \multicolumn{6}{|c|}{ Adherence and outcome } \\
\hline Study & Clinical problem & Intervention & Control & $\begin{array}{l}\text { Effect on adherence } \\
\text { (Yes means a statis- } \\
\text { tically significant ef- } \\
\text { fect in favor of the } \\
\text { intervention; No } \\
\text { means no effect or } \\
\text { a negative effect) }\end{array}$ & $\begin{array}{l}\text { Effect on clin- } \\
\text { ical outcome } \\
\text { (Yes means a statis- } \\
\text { tically significant ef- } \\
\text { fect in favor of the } \\
\text { intervention; No } \\
\text { means no effect or } \\
\text { a negative effect) }\end{array}$ \\
\hline & & $\begin{array}{l}\text { ferral for specialty care } \\
\text { (including urgent refer- } \\
\text { rals in case of suicidal } \\
\text { ideation or severe symp- } \\
\text { toms). Each of the } 3 \text { care } \\
\text { management contacts } \\
\text { included this cycle: out- } \\
\text { reach message from the } \\
\text { care manager, patient } \\
\text { completion of online as- } \\
\text { sessment, structured } \\
\text { response from the care } \\
\text { manager, and follow-up } \\
\text { communication with the } \\
\text { patient and physician as } \\
\text { needed. The care man- } \\
\text { ager's messages to pa- } \\
\text { tients included brief sup- } \\
\text { port but no formal psy- } \\
\text { chotherapy. Patients } \\
\text { were free to send addi- } \\
\text { tional messages or tele- } \\
\text { phone the care manag- } \\
\text { er if needed. The care } \\
\text { manager was expected } \\
\text { to make outreach tele- } \\
\text { phone calls in case of } \\
\text { suicidal ideation or oth- } \\
\text { er urgent clinical need. } \\
\text { All outgoing messages } \\
\text { were in English. The care } \\
\text { manager in this trial was } \\
\text { a registered nurse with } \\
\text { added certification in } \\
\text { psychiatry and } 15 \text { years } \\
\text { of experience in mental } \\
\text { health } \\
\text { ( } \mathrm{n}=106 \text { ) }\end{array}$ & & & \\
\hline Simoni 2007 & HIV/AIDS & $\begin{array}{l}\text { PEER SUPPORT: Pa- } \\
\text { tients in the peer sup- } \\
\text { port group had } 6 \text { twice- } \\
\text { monthly meetings dur- } \\
\text { ing the 3-month peer } \\
\text { support intervention } \\
\text { where peers and partic- } \\
\text { ipants met with other } \\
\text { peers and participants } \\
\text { to discuss shared experi- } \\
\text { ences, barriers to HAART } \\
\text { adherence, life issues, } \\
\text { etc. The group meetings } \\
\text { were facilitated by an RA } \\
\text { but were predominately } \\
\text { peer-led. Between group } \\
\text { meetings, peers were in- } \\
\text { structed to call each of } \\
\text { their study participants } 3 \\
\text { times weekly to provide } \\
\text { more in-depth one-on- } \\
\text { one attention and feed- } \\
\text { back } \\
\text { (n=71) }\end{array}$ & $\begin{array}{l}\text { STANDARD CARE: Stan- } \\
\text { dard of care (control) pa- } \\
\text { tients received no addi- } \\
\text { tional adherence assis- } \\
\text { tance beyond the clinic's } \\
\text { typical offerings (con- } \\
\text { sultation with primary } \\
\text { providers and social and } \\
\text { mental health referrals } \\
\text { when requested) } \\
(\mathrm{n}=65)\end{array}$ & $\begin{array}{l}\text { No for medication adher- } \\
\text { ence by self report and } \\
\text { EDM at } 3 \text { and } 6 \text { months }\end{array}$ & $\begin{array}{l}\text { No for HIV-1 RNA viral } \\
\text { load and depressive } \\
\text { symptomatology }\end{array}$ \\
\hline Simoni 2009 & HIV/AIDS & $\begin{array}{l}\text { PEER SUPPORT: The 3- } \\
\text { month peer support in- } \\
\text { tervention consisted of } 2 \\
\text { parts: (a) } 6 \text { twice month- } \\
\text { ly 1-hour gatherings held } \\
\text { at the clinic, consisting } \\
\text { of all peers and active- }\end{array}$ & $\begin{array}{l}\text { USUAL CARE: Before ini- } \\
\text { tiation of HAART, all clin- } \\
\text { ic patients who are naive } \\
\text { patients or off HAART } \\
\text { for more than } 6 \text { months } \\
\text { are required to com- } \\
\text { plete the HAART proto- }\end{array}$ & $\begin{array}{l}\text { Yes for improving self re- } \\
\text { ported adherence at } 3 \\
\text { month in peer interven- } \\
\text { tion. No for improving } \\
\text { self reported adherence } \\
\text { at } 6 \text { and } 9 \text { months. No for } \\
\text { improving EDM adher- }\end{array}$ & $\begin{array}{l}\text { No for improvements } \\
\text { in viral loads and CD4 } \\
\text { cell counts at } 3,6 \text {, or } 9 \\
\text { months in the peer inter- } \\
\text { vention arm or pager in- } \\
\text { tervention arm }\end{array}$ \\
\hline
\end{tabular}




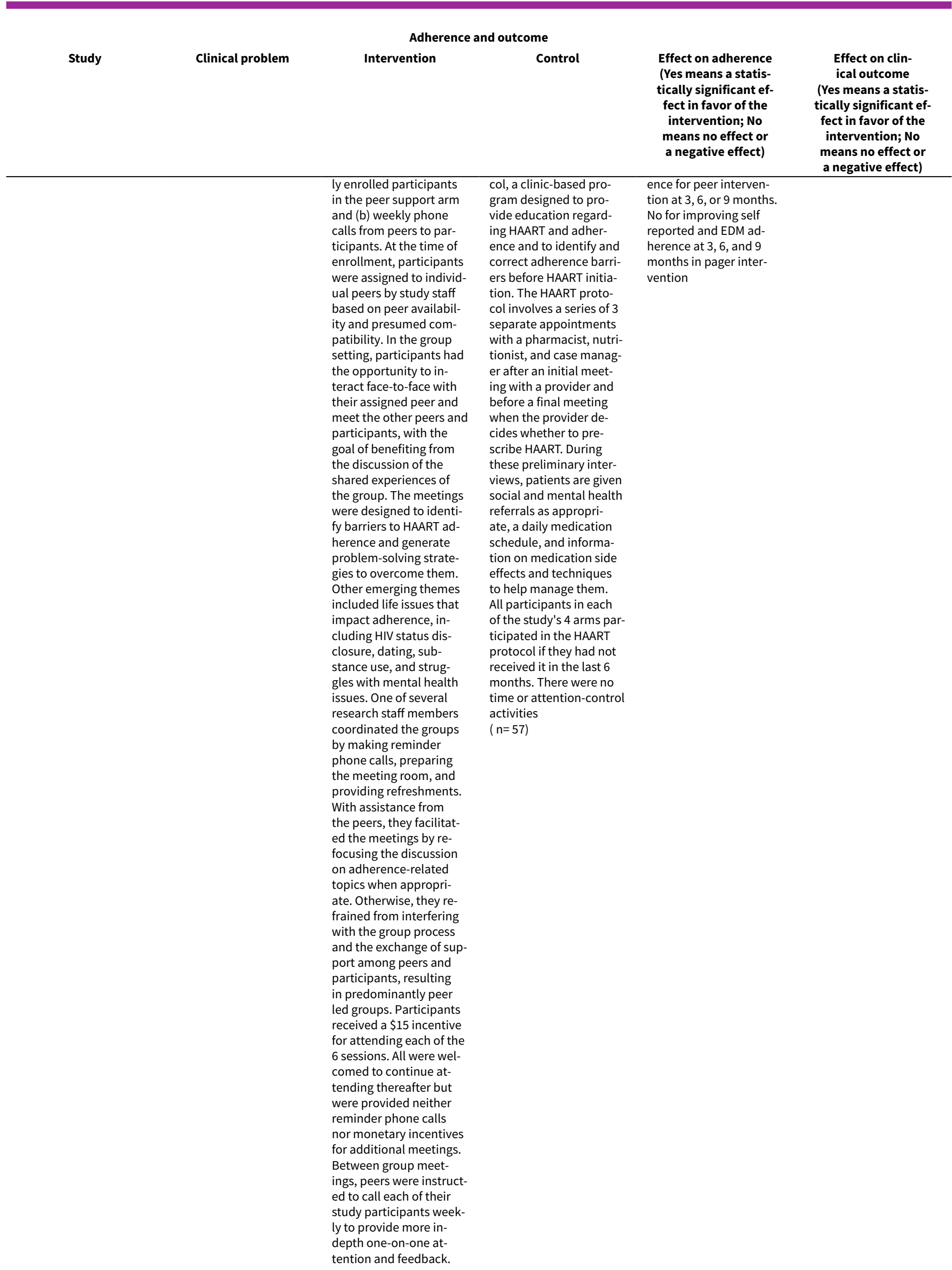


Adherence and outcome

Intervention

Control

\section{Effect on adherence \\ (Yes means a statis- \\ tically significant ef- \\ fect in favor of the \\ intervention; No \\ means no effect or \\ a negative effect)}

Effect on clin-

ical outcome

(Yes means a statis-

tically significant ef

fect in favor of the

intervention; No

means no effect or a negative effect)

Phone calls also were

better suited for partici-

pants with confidential-

ity concerns and those

who had difficulty trav-

eling to the clinic or had

scheduling conflicts with

the set meeting times.

Peers were instructed

not to initiate contact

with participants after

the 3-month interven-

tion period, but they

were allowed to respond

to requests for contact

from the participants at

their own discretion

$(\mathrm{n}=57)$

PAGER MESSAGING: The

3-month pager interven-

tion consisted of a cus-

tomized pager system

that combined the com

municating abilities of

the world-wide web and

2-way pagers. A com-

puter program allowed

for the timing of all text

messages to be speci-

fied up front and then

sent automatically with-

out any further inter

vention from study staff.

At randomization, the

study co-ordinator dis-

tributed a 2-way pager

and customized a mes-

sage schedule to the par-

ticipant's daily medica-

tion regimen, which was

confirmed by the clinic

pharmacist. In addition

to dose reminders, 3 oth-

er types of text messages

were sent: (1) education-

al; (2) entertainment

(jokes or thoughts for the

day); and (3) adherence

assessments. There was

some flexibility in the

frequency and content of

messages to accommo-

date participants' differ-

ing needs and schedules,

but there was a mini-

mum of 3 pager mes-

sages sent daily to par-

ticipants for the first 2

months. Pages gradu-

ally tapered in the last

month of the 3-month

intervention to avoid a

rebound in non-adher-

ence. A confirmation re-

turn page was requested

for every message sent.

Project staff periodically

reviewed the return page

$\log$ and if no responses 


\begin{tabular}{|c|c|c|c|c|c|}
\hline \multicolumn{6}{|c|}{ Adherence and outcome } \\
\hline Study & Clinical problem & Intervention & Control & $\begin{array}{l}\text { Effect on adherence } \\
\text { (Yes means a statis- } \\
\text { tically significant ef- } \\
\text { fect in favor of the } \\
\text { intervention; No } \\
\text { means no effect or } \\
\text { a negative effect) }\end{array}$ & $\begin{array}{l}\text { Effect on clin- } \\
\text { ical outcome } \\
\text { (Yes means a statis- } \\
\text { tically significant ef- } \\
\text { fect in favor of the } \\
\text { intervention; No } \\
\text { means no effect or } \\
\text { a negative effect) }\end{array}$ \\
\hline & & $\begin{array}{l}\text { were received, the par- } \\
\text { ticipant could be called } \\
\text { to determine if they were } \\
\text { having any problems } \\
\text { with the pager. Between } \\
\text { the first contact and the } \\
\text { end of the 3-month inter- } \\
\text { vention, the participants } \\
\text { were asked to wear the } \\
\text { pager at all waking mo- } \\
\text { ments. Participants had } \\
\text { to use the study pagers } \\
\text { and could not substitute } \\
\text { with their own pager or } \\
\text { cell phone. They were in- } \\
\text { structed not to use the } \\
\text { devices for personal use. } \\
\text { Participants could select } \\
\text { from a variety of audito- } \\
\text { ry alarms or a vibrate-on- } \\
\text { ly option if desired. If the } \\
\text { pager was lost or failed, } \\
\text { it was promptly replaced } \\
\text { at no cost to the subject } \\
\text { ( } \mathrm{n}=56 \text { ) } \\
56 \text { participants in Pager } \\
\text { Messaging and Peer Sup- } \\
\text { port }\end{array}$ & & & \\
\hline
\end{tabular}




\begin{tabular}{|c|c|c|c|c|c|}
\hline \multicolumn{6}{|c|}{ Adherence and outcome } \\
\hline Study & Clinical problem & Intervention & Control & $\begin{array}{l}\text { Effect on adherence } \\
\text { (Yes means a statis- } \\
\text { tically significant ef- } \\
\text { fect in favor of the } \\
\text { intervention; No } \\
\text { means no effect or } \\
\text { a negative effect) }\end{array}$ & $\begin{array}{l}\text { Effect on clin- } \\
\text { ical outcome } \\
\text { (Yes means a statis- } \\
\text { tically significant ef- } \\
\text { fect in favor of the } \\
\text { intervention; No } \\
\text { means no effect or } \\
\text { a negative effect) }\end{array}$ \\
\hline & & $\begin{array}{l}\text { barriers. Participants } \\
\text { could also invite a treat- } \\
\text { ment partner to attend } \\
\text { the counseling sessions } \\
\text { with them. A "treatment } \\
\text { partner" was defined as } \\
\text { someone to whom the } \\
\text { participant had already } \\
\text { disclosed their HIV sta- } \\
\text { tus and who was avail- } \\
\text { able to assist the partic- } \\
\text { ipant on a daily basis. } \\
\text { Participants who opted } \\
\text { to have counseling, ei- } \\
\text { ther individually or with } \\
\text { a treatment adherence } \\
\text { partner, had } 3 \text { counsel- } \\
\text { ing sessions of up to } 1 \\
\text { hour each with the study } \\
\text { nurse. The first session } \\
\text { occurred either at the } \\
\text { enrollment interview or } \\
\text { within the first } 2 \text { weeks } \\
\text { of initiating ART; addi- } \\
\text { tional counseling ses- } \\
\text { sions occurred at } 5 \text { and } 9 \\
\text { weeks. If necessary, the } \\
\text { later sessions were re- } \\
\text { placed with counseling } \\
\text { provided over the tele- } \\
\text { phone } \\
\text { (n = } 36 \text { ) }\end{array}$ & & & \\
\hline Sirey 2010 & Major depression & $\begin{array}{l}\text { TREATMENT INITIATION } \\
\text { AND PARTICIPATION } \\
\text { PROGRAM (TIP): The } \\
\text { Treatment Initiation } \\
\text { and Participation Pro- } \\
\text { gram (TIP) included } 3 \\
\text { 30-minute individual } \\
\text { meetings between the } \\
\text { TIP counselor and older } \\
\text { adult patient during the } \\
\text { first } 6 \text { weeks of pharma- } \\
\text { cotherapy, followed by } \\
2 \text { follow-up telephone } \\
\text { calls at } 8 \text { and } 10 \text { weeks } \\
\text { after study entry. Dur- } \\
\text { ing these sessions the } \\
\text { TIP counselor and old- } \\
\text { er adult would review } \\
\text { symptoms and antide- } \\
\text { pressant therapy regi- } \\
\text { men, and conduct a bar- } \\
\text { riers assessment, de- } \\
\text { fine a personal goal that } \\
\text { could be achieved with } \\
\text { adherence, provide ed- } \\
\text { ucation about depres- } \\
\text { sion and antidepressant } \\
\text { therapy, collaborate to } \\
\text { address barriers to treat- } \\
\text { ment participation, cre- } \\
\text { ate an adherence strate- } \\
\text { gy and facilitate and em- } \\
\text { power the older adult to } \\
\text { talk directly with the PCP } \\
\text { about the treatment. A } \\
\text { "contact sheet" listed } \\
\text { barriers in each domain }\end{array}$ & $\begin{array}{l}\text { TREATMENT AS USUAL } \\
\text { (TAU): Patients in the } \\
\text { control group continued } \\
\text { with treatment as usual } \\
(\mathrm{n}=37)\end{array}$ & $\begin{array}{l}\text { Yes for improved self re- } \\
\text { ported adherence to an- } \\
\text { tidepressant medica- } \\
\text { tion throughout all time } \\
\text { points }\end{array}$ & $\begin{array}{l}\text { Yes for reduction in de- } \\
\text { pressive symptoms }\end{array}$ \\
\hline
\end{tabular}




\begin{tabular}{|c|c|c|c|c|c|}
\hline \multicolumn{6}{|c|}{ Adherence and outcome } \\
\hline Study & Clinical problem & Intervention & Control & $\begin{array}{l}\text { Effect on adherence } \\
\text { (Yes means a statis- } \\
\text { tically significant ef- } \\
\text { fect in favor of the } \\
\text { intervention; No } \\
\text { means no effect or } \\
\text { a negative effect) }\end{array}$ & $\begin{array}{l}\text { Effect on clin- } \\
\text { ical outcome } \\
\text { (Yes means a statis- } \\
\text { tically significant ef- } \\
\text { fect in favor of the } \\
\text { intervention; No } \\
\text { means no effect or } \\
\text { a negative effect) }\end{array}$ \\
\hline & & $\begin{array}{l}\text { and specific intervention } \\
\text { techniques and served } \\
\text { as the guide for sessions } \\
\text { and a record of the inter- } \\
\text { ventions administered } \\
(n=33)\end{array}$ & & & \\
\hline Solomon 2012 & Osteoporosis & $\begin{array}{l}\text { TELEPHONE BASED } \\
\text { COUNSELING: Subjects } \\
\text { in both groups started } \\
\text { receiving educational } \\
\text { material regarding os- } \\
\text { teoporosis } 30 \text { days af- } \\
\text { ter randomization. In ad- } \\
\text { dition the intervention } \\
\text { group subjects received } \\
\text { motivational intervening } \\
\text { based counseling admin- } \\
\text { istered by a health edu- } \\
\text { cator. } 10 \text { sessions were } \\
\text { targeted per subject } \\
(\mathrm{n}=1050)\end{array}$ & $\begin{array}{l}\text { CONTROL: Approximate- } \\
\text { ly } 30 \text { days after random- } \\
\text { ization, all subjects re- } \\
\text { ceived mailings regard- } \\
\text { ing osteoporosis. During } \\
\text { the study, all subjects re- } \\
\text { ceived } 7 \text { informational } \\
\text { mailings covering top- } \\
\text { ics such as exercise, fall } \\
\text { prevention, and recom- } \\
\text { mended calcium intake } \\
(n=1047)\end{array}$ & $\begin{array}{l}\text { No for medication ad- } \\
\text { herence measured using } \\
\text { MPR during } 12 \text { months }\end{array}$ & $\begin{array}{l}\text { No for self reported falls. } \\
\text { No for poor or fair gener- } \\
\text { al health }\end{array}$ \\
\hline Sorensen 2007 & HIV & $\begin{array}{l}\text { VOUCHER INTERVEN- } \\
\text { TION: Patients in the } \\
\text { voucher intervention } \\
\text { group began with a } 4 \\
\text { week baseline phase, } \\
\text { where they received a } \\
\text { MEMS monitor for one } \\
\text { of their HAART med- } \\
\text { ications. Patients met } \\
\text { with a registered nurse } \\
\text { or trained research as- } \\
\text { sistant who provided } \\
\text { medication coaching } \\
\text { once during the baseline } \\
\text { phase and then every } 2 \\
\text { weeks throughout the } \\
\text { study. Patients were } \\
\text { provided with a hard } \\
\text { copy of their MEMS da- } \\
\text { ta throughout the study. } \\
\text { During baseline, patients } \\
\text { met a research assis- } \\
\text { tant twice weekly to pro- } \\
\text { vide the MEMS data. At } \\
\text { the end of the baseline } \\
\text { phase, patients in the } \\
\text { voucher phase contin- } \\
\text { ued to meet twice week- } \\
\text { ly with a research as- } \\
\text { sistant, for a total of } 24 \\
\text { visits. When patients } \\
\text { opened their medica- } \\
\text { tion caps as scheduled, } \\
\text { they received vouch- } \\
\text { ers that were exchange- } \\
\text { able for goods and ser- } \\
\text { vices for each correctly } \\
\text { taken medication dose. } \\
\text { The value of the vouch- } \\
\text { er increased for each } \\
\text { correctly taken dose in } \\
\text { a row, but reset to the } \\
\text { original value if a dose } \\
\text { was missed. Patients } \\
\text { could earn up to USD } \\
\text { 1172.40 if they took all } \\
\text { their medication correct- } \\
\text { ly throughout the study }\end{array}$ & $\begin{array}{l}\text { COMPARISON: Patients } \\
\text { in the comparison group } \\
\text { began with a 4-week } \\
\text { baseline phase, where } \\
\text { they received a MEMS } \\
\text { monitor for one of their } \\
\text { HAART medications. Pa- } \\
\text { tients met with a regis- } \\
\text { tered nurse or trained } \\
\text { research assistant who } \\
\text { provided medication } \\
\text { coaching once during } \\
\text { the baseline phase and } \\
\text { then every } 2 \text { weeks } \\
\text { throughout the study. } \\
\text { Patients were provided } \\
\text { with a hard copy of their } \\
\text { MEMS data throughout } \\
\text { the study. During base- } \\
\text { line, patients met a re- } \\
\text { search assistant twice } \\
\text { weekly to provide the } \\
\text { MEMS data. During the } \\
\text { intervention phase, com- } \\
\text { parison group partici- } \\
\text { pants continued to meet } \\
\text { twice weekly with the } \\
\text { research assistant, for } \\
\text { a total of } 24 \text { visits, and } \\
\text { received medication } \\
\text { coaching every } 2 \text { weeks. } \\
\text { As several of the initial } \\
\text { comparison group par- } \\
\text { ticipants expressed dis- } \\
\text { satisfaction with their } \\
\text { treatment compared to } \\
\text { the voucher group, a re- } \\
\text { ward system was imple- } \\
\text { mented for the compar- } \\
\text { ison group. A fishbowl } \\
\text { prize system was used } \\
\text { to reinforce attendance } \\
\text { at scheduled interviews. } \\
\text { Patients could pick a } \\
\text { number from the fish- } \\
\text { bowl which would give } \\
\text { them either a small or } \\
\text { large prize }\end{array}$ & $\begin{array}{l}\text { Yes for improving adher- } \\
\text { ence while intervention } \\
\text { was active. No for main- } \\
\text { taining that adherence } \\
\text { during the follow-up } \\
\text { phase }\end{array}$ & $\begin{array}{l}\text { No for all patient health } \\
\text { indices }\end{array}$ \\
\hline
\end{tabular}




\begin{tabular}{|c|c|c|c|c|c|}
\hline \multicolumn{6}{|c|}{ Adherence and outcome } \\
\hline Study & Clinical problem & Intervention & Control & $\begin{array}{l}\text { Effect on adherence } \\
\text { (Yes means a statis- } \\
\text { tically significant ef- } \\
\text { fect in favor of the } \\
\text { intervention; No } \\
\text { means no effect or } \\
\text { a negative effect) }\end{array}$ & $\begin{array}{l}\text { Effect on clin- } \\
\text { ical outcome } \\
\text { (Yes means a statis- } \\
\text { tically significant ef- } \\
\text { fect in favor of the } \\
\text { intervention; No } \\
\text { means no effect or } \\
\text { a negative effect) }\end{array}$ \\
\hline & & $(n=34)$ & $(n=32)$ & & \\
\hline Staring 2010 & Psychotic disorders & $\begin{array}{l}\text { TREATMENT ADHER- } \\
\text { ENCE THERAPY: Initial } \\
\text { sessions assess individ- } \\
\text { ual determinants of non- } \\
\text { adherence. According } \\
\text { to the clusters of deter- } \\
\text { minants detected, ther- } \\
\text { apists fill out a decision } \\
\text { form and chose from the } \\
3 \text { modules available for } \\
\text { the subsequent patient } \\
\text { appoints. Modules are } \\
\text { motivational interview- } \\
\text { ing, medication opti- } \\
\text { mization, and behavioral } \\
\text { training. If more than } \\
\text { one cluster of problems } \\
\text { was present in an indi- } \\
\text { vidual, the modules were } \\
\text { completed in order. The } \\
\text { duration and number of } \\
\text { sessions varied per pa- } \\
\text { tient, in general taking } \\
\text { no more than } 6 \text { months. } \\
\text { Most of the therapists } \\
\text { were psychiatric nurs- } \\
\text { es who were not the pa- } \\
\text { tients own mental health } \\
\text { professionals. All ses- } \\
\text { sions were recorded and } \\
\text { used in supervision } \\
\text { ( } \mathrm{n}=54 \text { ) }\end{array}$ & $\begin{array}{l}\text { TREATMENT AS USUAL: } \\
\text { Treatment as usual gen- } \\
\text { erally consisted of ses- } \\
\text { sions with a psychiatric } \\
\text { nurse and a psychiatrist } \\
\text { when indicated. The ses- } \\
\text { sions varied in frequency } \\
\text { and duration, but most- } \\
\text { ly consisted of one or } 2 \\
\text { sessions per month. The } \\
\text { contents reflected over- } \\
\text { all problems the partic- } \\
\text { ipant might encounter } \\
\text { such as symptoms, so- } \\
\text { cial participation, work, } \\
\text { daily activities, and med- } \\
\text { ication issues. Some par- } \\
\text { ticipants received psy- } \\
\text { choeducation individual- } \\
\text { ly or in group sessions. } \\
\text { This was recorded } \\
\text { ( } \mathrm{n}=55 \text { ) }\end{array}$ & $\begin{array}{l}\text { Yes for improving adher- } \\
\text { ence to antipsychotic } \\
\text { medications in the inter- } \\
\text { vention group at the end } \\
\text { of intervention and at 6- } \\
\text { month follow-up }\end{array}$ & $\begin{array}{l}\text { No for decrease in hos- } \\
\text { pital admissions and im- } \\
\text { provement in symptoms } \\
\text { and quality of life for par- } \\
\text { ticipants in TAT group } \\
\text { compared to controls at } \\
6 \text {-month follow-up }\end{array}$ \\
\hline Stevens 2002 & Helicobacter pylori & $\begin{array}{l}\text { A longer adherence } \\
\text { counseling session and } \\
\text { a follow-up phone call } \\
\text { from the pharmacist } \\
\text { during drug treatment } \\
\text { ( } \mathrm{n}=163 \text { ). All subjects } \\
\text { were given the same 7- } \\
\text { day course of omepra- } \\
\text { zole, bismuth subsalicy- } \\
\text { late, metronidazole, and } \\
\text { tetracycline hydrochlo- } \\
\text { ride (OBMT) }\end{array}$ & $\begin{array}{l}\text { A standard antibiotic } \\
\text { regimen and randomly } \\
\text { assigned to receive usu- } \\
\text { al care counseling from } \\
\text { a pharmacist ( } n=162 \text { ). } \\
\text { All subjects were given } \\
\text { the same } 7 \text {-day course } \\
\text { of omeprazole, bismuth } \\
\text { subsalicylate, metron- } \\
\text { idazole, and tetracycline } \\
\text { hydrochloride (OBMT) }\end{array}$ & No & $\begin{array}{l}\text { No. (The big problems } \\
\text { with this study are that } \\
\text { a) both groups got blister } \\
\text { packs with daily doses } \\
\text { clearly marked; b) both } \\
\text { groups got counseling, } \\
\text { although this was longer } \\
\text { and more detailed for } \\
\text { the IC than CG; c) self re- } \\
\text { port was used for mea- } \\
\text { suring adherence (insen- } \\
\text { sitive). All these factors } \\
\text { would bias towards no } \\
\text { difference) }\end{array}$ \\
\hline Strang 1981 & Schizophrenia & Family therapy $(n=17)$ & $\begin{array}{l}\text { Individual supportive } \\
\text { therapy }(\mathrm{n}=15)\end{array}$ & Yes & Yes \\
\hline Taiwo 2010 & HIV & $\begin{array}{l}\text { TREATMENT PARTNER } \\
\text { INTERVENTION: In ad- } \\
\text { dition to standard care, } \\
\text { patients randomized to } \\
\text { the treatment partner } \\
\text { intervention (TPA) arm } \\
\text { chose a treatment part- } \\
\text { ner who was aware of } \\
\text { the patient's HIV infec- } \\
\text { tion and resided in the } \\
\text { same house or in close } \\
\text { proximity. Treatment } \\
\text { partners attended one } \\
\text { adherence education } \\
\text { session similar to that } \\
\text { for study participants. } \\
\text { They were asked to ob- } \\
\text { serve the ingestion of } \\
\text { HIV drugs at least once }\end{array}$ & $\begin{array}{l}\text { STANDARD CARE: All par- } \\
\text { ticipants were given a } \\
\text { 2-hour interactive ad- } \\
\text { herence session in Eng- } \\
\text { lish and local language } \\
\text { conducted by a nurse } \\
\text { who was openly HIV pos- } \\
\text { itive trained as adher- } \\
\text { ence counselor. Content } \\
\text { included information } \\
\text { on ART, HIV drug resis- } \\
\text { tance, symptom man- } \\
\text { agement, and empha- } \\
\text { sis on the importance of } \\
\text { adherence and benefits } \\
\text { of disclosure. Each pa- } \\
\text { tient was given a pillbox } \\
\text { and educated on prop- } \\
\text { er use. The study phar- }\end{array}$ & $\begin{array}{l}\text { Yes for improving med- } \\
\text { ication adherence in HIV } \\
\text { patients undergoing ART } \\
\text { with Treatment Partner } \\
\text { Intervention at } 12 \text { and } 48 \\
\text { weeks }\end{array}$ & $\begin{array}{l}\text { No for viral load of HIV, } \\
\text { CD4 count, or mortality }\end{array}$ \\
\hline
\end{tabular}




\begin{tabular}{|c|c|c|c|c|c|}
\hline \multicolumn{6}{|c|}{ Adherence and outcome } \\
\hline Study & Clinical problem & Intervention & Control & $\begin{array}{l}\text { Effect on adherence } \\
\text { (Yes means a statis- } \\
\text { tically significant ef- } \\
\text { fect in favor of the } \\
\text { intervention; No } \\
\text { means no effect or } \\
\text { a negative effect) }\end{array}$ & $\begin{array}{l}\text { Effect on clin- } \\
\text { ical outcome } \\
\text { (Yes means a statis- } \\
\text { tically significant ef- } \\
\text { fect in favor of the } \\
\text { intervention; No } \\
\text { means no effect or } \\
\text { a negative effect) }\end{array}$ \\
\hline & & $\begin{array}{l}\text { daily, assist with the re- } \\
\text { porting and manage- } \\
\text { ment of adverse effects, } \\
\text { and remind participants } \\
\text { of drug pickup. No com- } \\
\text { pensation was provid- } \\
\text { ed for participation, but } \\
\text { treatment partners with } \\
\text { financial constraints re- } \\
\text { ceived travel stipends of } \\
\text { USD 2-14 (total) } \\
\text { (n=248) }\end{array}$ & $\begin{array}{l}\text { macist, who was blinded } \\
\text { to treatment arm, pro- } \\
\text { vided one-on-one rein- } \\
\text { forcement of the educa- } \\
\text { tion provided by the ad- } \\
\text { herence counselor plus } \\
\text { information specific to } \\
\text { each participant's reg- } \\
\text { imen. The pharmacist } \\
\text { had formal training in } \\
\text { adherence counseling } \\
\text { and more than } 3 \text { years } \\
\text { experience at study clin- } \\
\text { ic. At each drug pickup } \\
\text { visit, the pharmacist pro- } \\
\text { vided targeted counsel- } \\
\text { ing based on the partic- } \\
\text { ipant's self report of ad- } \\
\text { herence and adverse ef- } \\
\text { fects. Patients who had } \\
\text { detectable viremia at } \\
\text { week } 24 \text { underwent in- } \\
\text { tensive adherence re- } \\
\text { training with the adher- } \\
\text { ence counselor. This re- } \\
\text { training was aimed at } \\
\text { identifying individual- } \\
\text { ized obstacles to adher- } \\
\text { ence and practical tips } \\
\text { for overcoming them. } \\
\text { Follow-ups were con- } \\
\text { ducted at } 12,24 \text {, and } 48 \\
\text { weeks after baseline } \\
\text { ( } \mathrm{n}=251 \text { ) }\end{array}$ & & \\
\hline Tuldra 2000 & HIV & $\begin{array}{l}\text { Psychoeducative inter- } \\
\text { vention to implement } \\
\text { adherence, i.e. explana- } \\
\text { tions about reasons for } \\
\text { starting treatment and } \\
\text { the relevance of appro- } \\
\text { priate adherence, de- } \\
\text { velopment of a dosage } \\
\text { schedule with patients' } \\
\text { input, patients were } \\
\text { taught how to manage } \\
\text { various other aspects } \\
\text { of medication taking in } \\
\text { highly active antiretro- } \\
\text { viral treatment (HAART) } \\
\text { (i.e. forgetting, side ef- } \\
\text { fects, changes in daily } \\
\text { routine). Phone num- } \\
\text { ber was given should } \\
\text { patients have any ques- } \\
\text { tions before next inter- } \\
\text { view. Verbal reinforce- } \\
\text { ment of adherence at fol- } \\
\text { low-up visits } \\
\text { ( } \mathrm{n}=55 \text { ) }\end{array}$ & $\begin{array}{l}\text { Usual medical follow-up } \\
(n=61)\end{array}$ & No & No \\
\hline Udelson 2009 & $\begin{array}{l}\text { Chronic HF and left ven- } \\
\text { tricular (LV) dysfunction }\end{array}$ & $\begin{array}{l}\text { ONCE DAILY DOSING: } \\
\text { The intervention was an } \\
\text { open-label, once daily } \\
\text { regimen of controlled re- } \\
\text { lease carvedilol CR } \\
(\mathrm{n}=136)\end{array}$ & $\begin{array}{l}\text { TWICE A DAY DOSAGE: } \\
\text { Participants received } \\
\text { their usual twice daily } \\
\text { dose of carvedilol IR, but } \\
\text { in a double-blinded fash- } \\
\text { ion } \\
(\mathrm{n}=133) \\
\text { ONCE A DAY DOSING } \\
\text { PLUS PLACEBO: Partici- }\end{array}$ & $\begin{array}{l}\text { No for improving adher- } \\
\text { ence to carvedilol in pa- } \\
\text { tients with HF and LVF } \\
\text { with simplified dosing }\end{array}$ & $\begin{array}{l}\text { No improvement in qual- } \\
\text { ity of life (QOL), PHQ-8 } \\
\text { Depressive Symptoms } \\
\text { Questionnaire (PHQ-8), } \\
\text { and Treatment Satisfac- } \\
\text { tion Questionnaire with } \\
\text { Medication. No for BNP } \\
\text { levels and hospital and } \\
\text { emergency services uti- } \\
\text { lization }\end{array}$ \\
\hline
\end{tabular}




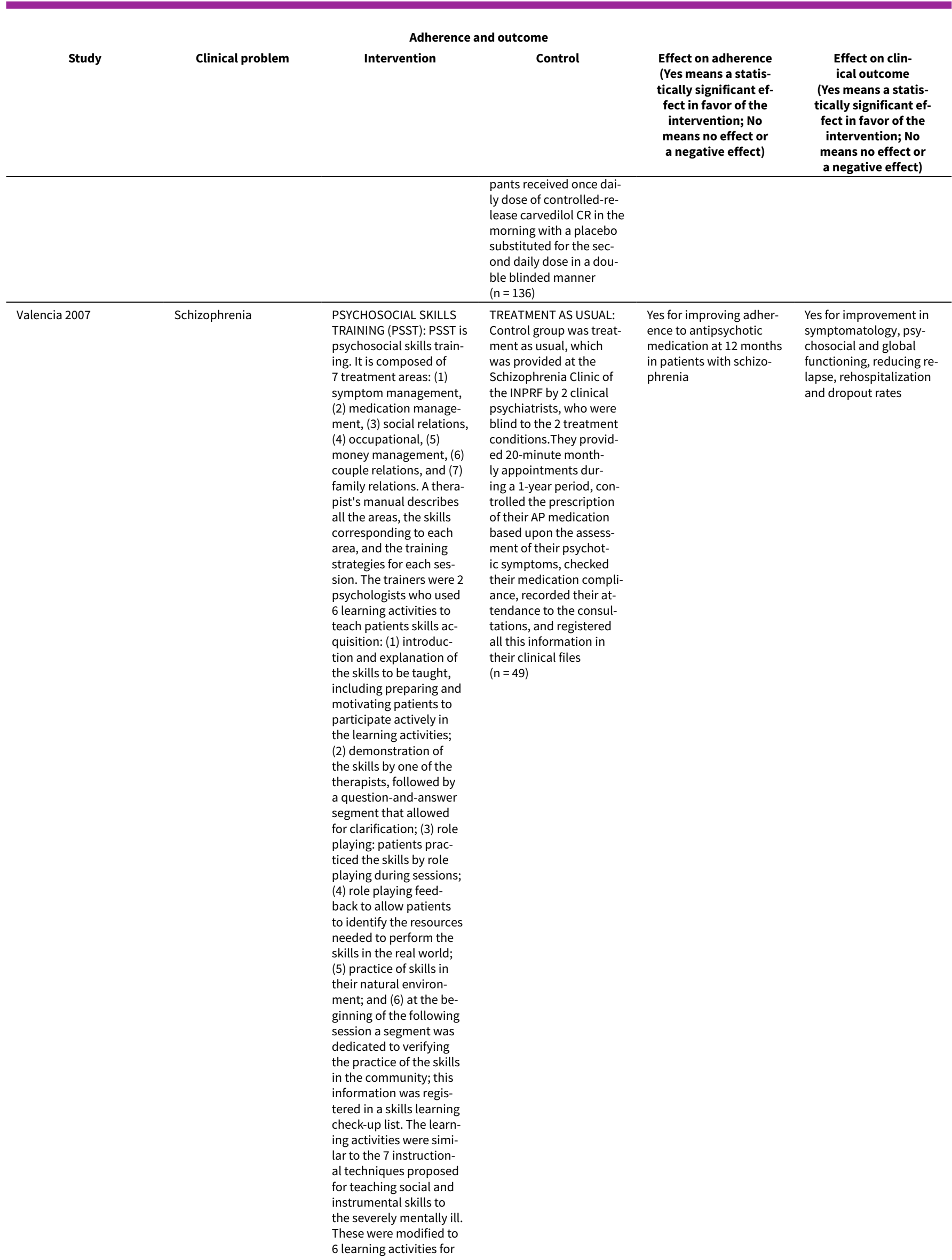




\begin{tabular}{|c|c|c|c|c|c|}
\hline \multicolumn{6}{|c|}{ Adherence and outcome } \\
\hline Study & Clinical problem & Intervention & Control & $\begin{array}{l}\text { Effect on adherence } \\
\text { (Yes means a statis- } \\
\text { tically significant ef- } \\
\text { fect in favor of the } \\
\text { intervention; No } \\
\text { means no effect or } \\
\text { a negative effect) }\end{array}$ & $\begin{array}{l}\text { Effect on clin- } \\
\text { ical outcome } \\
\text { (Yes means a statis- } \\
\text { tically significant ef- } \\
\text { fect in favor of the } \\
\text { intervention; No } \\
\text { means no effect or } \\
\text { a negative effect) }\end{array}$ \\
\hline & & $\begin{array}{l}\text { the participants of the } \\
\text { present study. Patients } \\
\text { participated in group } \\
\text { sessions, } 8 \text { patients per } \\
\text { group, with a time lim- } \\
\text { it of } 1 \text { hour } 15 \text { minutes, } \\
\text { once a week for a total of } \\
48 \text { sessions during } 1 \text { year } \\
\text { of PSST. To verify that } \\
\text { each treatment area was } \\
\text { being covered systemat- } \\
\text { ically and adequately, a } \\
\text { therapist fidelity evalua- } \\
\text { tion form was used. Fam- } \\
\text { ily therapy (FT) consists } \\
\text { of } 2 \text { parts: the first was } \\
\text { psychoeducation, which } \\
\text { included } 8 \text { group ses- } \\
\text { sions where all the pa- } \\
\text { tients' relatives received } \\
\text { information about the } \\
\text { illness, symptoms and } \\
\text { medication manage- } \\
\text { ment. The second part } \\
\text { consisted of } 4 \text { sessions } \\
\text { for each family, includ- } \\
\text { ing the patient, orient- } \\
\text { ed to problem-solving } \\
\text { as needed by each fami- } \\
\text { ly to improve communi- } \\
\text { cation skills, the recog- } \\
\text { nition and management } \\
\text { of warning signs of re- } \\
\text { lapse, the importance } \\
\text { of medication and its } \\
\text { side effects, compliance } \\
\text { with AP medication, and } \\
\text { keeping appointments } \\
\text { with physicians. } 2 \text { fam- } \\
\text { ily therapists conduct- } \\
\text { ed the FT. Recreation- } \\
\text { al activities for the pa- } \\
\text { tients, conducted by an } \\
\text { arts teacher, included } \\
\text { singing, musical games, } \\
\text { creative movement, and } \\
\text { arts and crafts, once a } \\
\text { week for } 2 \text { hours. Recre- } \\
\text { ational activities were } \\
\text { not considered as a ther- } \\
\text { apeutic modality } \\
\text { (n= } 49 \text { ) }\end{array}$ & & & \\
\hline Valenstein 2011 & $\begin{array}{l}\text { Serious mental illness } \\
\text { (SMI) including schizo- } \\
\text { phrenia, schizoaffective } \\
\text { and bipolar disorders }\end{array}$ & $\begin{array}{l}\text { MEDS-HELP INTERVEN- } \\
\text { TION: A composite inter- } \\
\text { vention consisting of: } \\
\text { 1) unit-of-use packag- } \\
\text { ing that included all pa- } \\
\text { tients' medications for } \\
\text { psychiatric and general } \\
\text { medical conditions; } 2 \text { ) a } \\
\text { medication and packag- } \\
\text { ing education session; } 3 \text { ) } \\
\text { refill reminders mailed } 2 \\
\text { weeks before scheduled } \\
\text { refill dates; and 4) notifi- } \\
\text { cation of clinicians when } \\
\text { patients failed to fill an- } \\
\text { tipsychotic prescriptions } \\
\text { within } 7 \text { to } 10 \text { days of a }\end{array}$ & $\begin{array}{l}\text { USUAL CARE: Usual care } \\
\text { was treatment in Veter- } \\
\text { ans Affairs outpatient } \\
\text { mental health clinics and } \\
\text { included psychiatrist } \\
\text { visits, non-MD mental } \\
\text { health visits, and group } \\
\text { visits. During the study } \\
\text { period, patients com- } \\
\text { pleted an average of } 8 \\
\text { visits with psychiatrists; } \\
49 \% \text { had visits with non- } \\
\text { MD mental health clini- } \\
\text { cians and } 23 \% \text { had group } \\
\text { visits } \\
(\mathrm{n}=60 \text { ) }\end{array}$ & $\begin{array}{l}\text { Yes for improving the } \\
\text { medication possession } \\
\text { ratio (MPR) of antipsy- } \\
\text { chotic drugs among pa- } \\
\text { tients with serious men- } \\
\text { tal illness }\end{array}$ & $\begin{array}{l}\text { No for improving psy- } \\
\text { chological symptoms, } \\
\text { quality of life, patient } \\
\text { satisfaction, and reduc- } \\
\text { ing hospitalizations at } \\
6 \text { and } 12 \text { months in pa- } \\
\text { tients with serious men- } \\
\text { tal illness }\end{array}$ \\
\hline
\end{tabular}




\begin{tabular}{|c|c|c|c|c|c|}
\hline \multicolumn{6}{|c|}{ Adherence and outcome } \\
\hline Study & Clinical problem & Intervention & Control & $\begin{array}{l}\text { Effect on adherence } \\
\text { (Yes means a statis- } \\
\text { tically significant ef- } \\
\text { fect in favor of the } \\
\text { intervention; No } \\
\text { means no effect or } \\
\text { a negative effect) }\end{array}$ & $\begin{array}{l}\text { Effect on clin- } \\
\text { ical outcome } \\
\text { (Yes means a statis- } \\
\text { tically significant ef- } \\
\text { fect in favor of the } \\
\text { intervention; No } \\
\text { means no effect or } \\
\text { a negative effect) }\end{array}$ \\
\hline 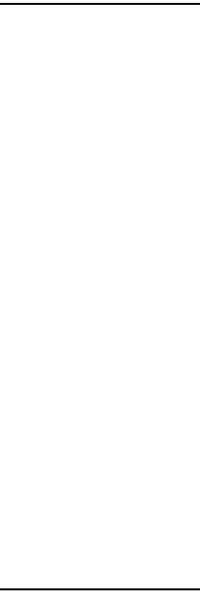 & & $\begin{array}{l}\text { fill date. The medication } \\
\text { education session was } \\
\text { conducted by a phar- } \\
\text { macist, usually in-per- } \\
\text { son, but occasionally by } \\
\text { telephone. During this } \\
\text { session, the pharmacist } \\
\text { reviewed patients' pre- } \\
\text { scribed medications, in- } \\
\text { cluding treatment indi- } \\
\text { cations. The pharmacist } \\
\text { also explained unit-of- } \\
\text { use medication packag- } \\
\text { ing and plans for interim } \\
\text { use of pill boxes when } \\
\text { medication changes } \\
\text { were made by clinicians } \\
\text { before the next shipment } \\
\text { of medication packages } \\
\text { ( } \mathrm{n}=58 \text { ) }\end{array}$ & & & \\
\hline van der Meer 2009 & Asthma & $\begin{array}{l}\text { INTERNET-BASED SELF } \\
\text { MANAGEMENT: An in- } \\
\text { ternet based self man- } \\
\text { agement program con- } \\
\text { sisting of a specially de- } \\
\text { signed website which } \\
\text { allowed monitoring } \\
\text { through the website or } \\
\text { text messaging, use of } \\
\text { an internet-based treat- } \\
\text { ment plan, online edu- } \\
\text { cation and web commu- } \\
\text { nications with a special- } \\
\text { ized asthma nurse was } \\
\text { administered to the in- } \\
\text { tervention group. Pa- } \\
\text { tients monitored their } \\
\text { asthma weekly by com- } \\
\text { pleting an electronic } \\
\text { version of the Asthma } \\
\text { Control Questionnaire } \\
\text { on the website and in- } \\
\text { stantly received feed- } \\
\text { back on the current state } \\
\text { of their asthma control } \\
\text { along with advice on } \\
\text { how to adjust their treat- } \\
\text { ment according to a pre- } \\
\text { defined algorithm and } \\
\text { treatment plan. Self- } \\
\text { management education } \\
\text { consisted of both web- } \\
\text { based and face-to-face, } \\
\text { group-based education. } \\
\text { Web-based education in- } \\
\text { cluded asthma informa- } \\
\text { tion, news, frequently } \\
\text { asked questions, and in- } \\
\text { teractive communication } \\
\text { with a respiratory nurse } \\
\text { specialist. All patients } \\
\text { were offered } 2 \text { group- } \\
\text { based education ses- } \\
\text { sions, which lasted } 45 \text { to } \\
60 \text { minutes, for patients } \\
\text { in the Internet-based } \\
\text { self management group } \\
\text { within } 6 \text { weeks after en- } \\
\text { tering the trial. Both ses- }\end{array}$ & $\begin{array}{l}\text { USUAL CARE: Website ac- } \\
\text { cess for usual care pa- } \\
\text { tients was restricted to a } \\
\text { diary page for patients to } \\
\text { keep during assessments } \\
(n=99)\end{array}$ & $\begin{array}{l}\text { No for improvement of } \\
\text { self reported adherence } \\
\text { with an internet-based } \\
\text { self management pro- } \\
\text { gram for asthma }\end{array}$ & $\begin{array}{l}\text { Yes for asthma control } \\
\text { and lung function. No for } \\
\text { other clinical outcomes } \\
\text { (exacerbations, inhaled } \\
\text { corticosteroid dose) }\end{array}$ \\
\hline
\end{tabular}




\begin{tabular}{|c|c|c|c|c|c|}
\hline \multicolumn{6}{|c|}{ Adherence and outcome } \\
\hline Study & Clinical problem & Intervention & Control & $\begin{array}{l}\text { Effect on adherence } \\
\text { (Yes means a statis- } \\
\text { tically significant ef- } \\
\text { fect in favor of the } \\
\text { intervention; No } \\
\text { means no effect or } \\
\text { a negative effect) }\end{array}$ & $\begin{array}{l}\text { Effect on clin- } \\
\text { ical outcome } \\
\text { (Yes means a statis- } \\
\text { tically significant ef- } \\
\text { fect in favor of the } \\
\text { intervention; No } \\
\text { means no effect or } \\
\text { a negative effect) }\end{array}$ \\
\hline & & $\begin{array}{l}\text { sions included explo- } \\
\text { ration of a patient's in- } \\
\text { terests and previous } \\
\text { knowledge, personal- } \\
\text { ized feedback, and em- } \\
\text { powerment of self man- } \\
\text { agement. The first edu- } \\
\text { cational session also in- } \\
\text { cluded pathophysiology } \\
\text { of asthma, information } \\
\text { on the web-based action } \\
\text { plan, and information } \\
\text { and review of inhalation } \\
\text { technique. The second } \\
\text { educational session gave } \\
\text { information about the } \\
\text { mechanisms and side ef- } \\
\text { fects of medication and } \\
\text { explained trigger avoid- } \\
\text { ance } \\
\text { ( } \mathrm{n}=101 \text { ) }\end{array}$ & & & \\
\hline Velligan 2008 & Schizophrenia & $\begin{array}{l}\text { FULL-CAT: Cognitive } \\
\text { Adaptation Training } \\
\text { (CAT) uses manual-dri- } \\
\text { ven compensatory } \\
\text { strategies and supports } \\
\text { such as pill containers } \\
\text { with alarms, organiza- } \\
\text { tion of belongings, and } \\
\text { activity checklists to } \\
\text { prompt and sequence } \\
\text { adaptive behaviors in } \\
\text { an individual's home en- } \\
\text { vironment. CAT strate- } \\
\text { gies are tailored to the } \\
\text { specific cognitive impair- } \\
\text { ments and behavioral } \\
\text { approaches to goal-di- } \\
\text { rected activity exhibit- } \\
\text { ed by each participant. } \\
\text { Environmental supports } \\
\text { in Full-CAT treatment } \\
\text { were based upon an as- } \\
\text { sessment of neurocog- } \\
\text { nitive function, behav- } \\
\text { ior, adaptive function- } \\
\text { ing, and the environ- } \\
\text { ment. Interventions for } \\
\text { each functional deficit } \\
\text { were based on } 2 \text { dimen- } \\
\text { sions, (1) level of impair- } \\
\text { ment in executive func- } \\
\text { tions and ( } 2 \text { ) whether the } \\
\text { overt behavior of the in- } \\
\text { dividual during perfor- } \\
\text { mance of goal-directed } \\
\text { activity was character- } \\
\text { ized more by apathy, dis- } \\
\text { inhibition, or a combina- } \\
\text { tion of these styles. Ac- } \\
\text { cording to the CAT mod- } \\
\text { el, individuals with poor } \\
\text { executive functioning } \\
\text { need high levels of struc- } \\
\text { ture and more obvious- } \\
\text { ly placed environmental } \\
\text { cues, while those with } \\
\text { somewhat better exec- } \\
\text { utive functioning need }\end{array}$ & $\begin{array}{l}\text { TAU: Patients are seen } \\
\text { monthly to every } 3 \\
\text { months for brief med- } \\
\text { ication visits. They have } \\
\text { case managers with high } \\
\text { case loads who have lit- } \\
\text { tle ongoing contact with } \\
\text { patients not in crisis } \\
\text { ( } n=32 \text { ) }\end{array}$ & $\begin{array}{l}\text { Yes for improving ad- } \\
\text { herence in Full-CAT and } \\
\text { Pharm-CAT compared } \\
\text { to TAU throughout treat- } \\
\text { ment and follow-up. No } \\
\text { difference between Full- } \\
\text { CAT and Pharm-CAT. Yes } \\
\text { for improving pill refill } \\
\text { rates in Full-CAT. No dif- } \\
\text { ference between Pharm- } \\
\text { CAT and TAU for improv- } \\
\text { ing pill refill rates }\end{array}$ & $\begin{array}{l}\text { No for improving symp- } \\
\text { toms. Yes for increased } \\
\text { percentage of partici- } \\
\text { pants with higher time } \\
\text { to relapse in Full-CAT } \\
\text { and Pharm-CAT com- } \\
\text { pared to TAU. Yes for im- } \\
\text { proved functional out- } \\
\text { come in CAT compared } \\
\text { to TAU and Pharm-CAT } \\
\text { at } 15 \text { months. Yes for } \\
\text { improved functional } \\
\text { outcome in Pharm-CAT } \\
\text { compared to TAU at } 6 \\
\text { months and not there- } \\
\text { after }\end{array}$ \\
\hline
\end{tabular}


Adherence and outcome

Intervention

Control

\section{Effect on adherence \\ (Yes means a statis- \\ tically significant ef- \\ fect in favor of the \\ intervention; No \\ means no effect or \\ a negative effect)}

Effect on clin-

ical outcome

(Yes means a statis-

tically significant ef

fect in favor of the

intervention; No

means no effect or a negative effect)

\section{less structure and more}

subtle cues. Individuals

with apathetic behav-

ior benefit from environ-

mental supports that cue

and sequence behavior,

those with disinhibition

benefit most from the

removal of distracting

stimuli, and those with

mixed behavior bene-

fit from a combination

of these strategies. As-

sessment results yield

one of 6 CAT classifica-

tions for which inter-

ventions can be target-

ed. Once an individual's

CAT classification was

determined, strategies

for specific functional

problems were chosen

from the manual. CAT

interventions were es-

tablished, trained, and

maintained in the home

during weekly visits from

a CAT therapist/train-

er. Patients in Full-CAT

were seen once week-

ly for 30 to 45 minutes.

The treatment lasted for

9 months and then the

patients were followed

up for 6 months after the

withdrawal of home vis-

its. CAT therapists were

individuals with bache-

lor's or master's degrees

in psychology or relat-

ed fields trained using a

combination of didactic

and in vivo strategies.

$(\mathrm{n}=37)$

PHARM-CAT: Pharm-CAT

is a subset of the Full-

CAT program, which is

a manual-driven treat-

ment using environmen-

tal supports. Patients

received assessments

of neurocognitive func-

tion, behavior, adaptive

functioning, and the en-

vironment. Interventions

in Pharm-CAT are indi-

vidualized in the same

manner as those in Full-

CAT treatment. Howev-

er, only interventions

that specifically target

adherence are used. Ad-

ditional issues such as

transportation are ad

dressed only if they re-

late to taking medication

or making it to clinic ap-

pointments. Patients in

Full-CAT and Pharm-CAT 


\begin{tabular}{|c|c|c|c|c|c|}
\hline \multicolumn{6}{|c|}{ Adherence and outcome } \\
\hline Study & Clinical problem & Intervention & Control & $\begin{array}{l}\text { Effect on adherence } \\
\text { (Yes means a statis- } \\
\text { tically significant ef- } \\
\text { fect in favor of the } \\
\text { intervention; No } \\
\text { means no effect or } \\
\text { a negative effect) }\end{array}$ & $\begin{array}{l}\text { Effect on clin- } \\
\text { ical outcome } \\
\text { (Yes means a statis- } \\
\text { tically significant ef- } \\
\text { fect in favor of the } \\
\text { intervention; No } \\
\text { means no effect or } \\
\text { a negative effect) }\end{array}$ \\
\hline & & $\begin{array}{l}\text { were seen once weekly } \\
\text { for } 30 \text { to } 45 \text { minutes. Vis- } \\
\text { its in Pharm-CAT were } \\
\text { necessarily shorter in du- } \\
\text { ration because the focus } \\
\text { of treatment was circum- } \\
\text { scribed around the issue } \\
\text { of adherence. Pharm- } \\
\text { CAT is a subset of the } \\
\text { Full-CAT program, which } \\
\text { is a manual-driven treat- } \\
\text { ment using environmen- } \\
\text { tal supports. Patients } \\
\text { received assessments } \\
\text { of neurocognitive func- } \\
\text { tion, behavior, adaptive } \\
\text { functioning, and the en- } \\
\text { vironment. Interventions } \\
\text { in Pharm-CAT are indi- } \\
\text { vidualized in the same } \\
\text { manner as those in Full- } \\
\text { CAT treatment. Howev- } \\
\text { er, only interventions } \\
\text { that specifically target } \\
\text { adherence are used. Ad- } \\
\text { ditional issues such as } \\
\text { transportation are ad- } \\
\text { dressed only if they re- } \\
\text { late to taking medication } \\
\text { or making it to clinic ap- } \\
\text { pointments. Patients in } \\
\text { Full-CAT and Pharm-CAT } \\
\text { were seen once weekly } \\
\text { for } 30 \text { to } 45 \text { minutes. Vis- } \\
\text { its in Pharm-CAT were } \\
\text { necessarily shorter in du- } \\
\text { ration because the focus } \\
\text { of treatment was circum- } \\
\text { scribed around the issue } \\
\text { of adherence. Pharm- } \\
\text { CAT therapists were in- } \\
\text { dividuals with bache- } \\
\text { lor's or master's degrees } \\
\text { in psychology or relat- } \\
\text { ed fields trained using a } \\
\text { combination of didactic } \\
\text { and in vivo strategies. } \\
\text { (n= } 36 \text { ) }\end{array}$ & & & \\
\hline Vergouwen 2005 & Depression & $\begin{array}{l}\text { Depression Care Pro- } \\
\text { gram targeted both pa- } \\
\text { tients and their GPs. } \\
\text { Participants received a } \\
\text { newsletter with informa- } \\
\text { tion about depression, } \\
\text { the need to continue an- } \\
\text { tidepressant medication } \\
\text { for } 6 \text { months, and the im- } \\
\text { portance of social sup- } \\
\text { port, and had homework } \\
\text { assignments. Their GPs } \\
\text { received newsletter sum- } \\
\text { maries and copies of the } \\
\text { homework and were to } \\
\text { use motivational inter- } \\
\text { viewing with patients } \\
(\mathrm{n}=81 \text { ) }\end{array}$ & $\begin{array}{l}\text { Patients and doctors did } \\
\text { not have the program, } \\
\text { but patient follow-ups } \\
\text { were scheduled at the } \\
\text { same frequency as for } \\
\text { the intervention group, } \\
\text { and GPs did the same as- } \\
\text { sessments for depres- } \\
\text { sion and compliance } \\
(n=96)\end{array}$ & No & $\begin{array}{l}\text { No for all clinical out- } \\
\text { comes }\end{array}$ \\
\hline Volume 2001 & $\begin{array}{l}\text { Ambulatory elderly (> or } \\
=65 \text { years of age) }\end{array}$ & $\begin{array}{l}\text { Pharmacists (in } \mathrm{n}=8 \\
\text { pharmacies, } 159 \text { pa- } \\
\text { tients) used the Pharma- }\end{array}$ & $\begin{array}{l}\text { Pharmacists at control } \\
\text { pharmacies ( } n=8 \text { phar- } \\
\text { macies, } 204 \text { patients) }\end{array}$ & No & No \\
\hline
\end{tabular}




\begin{tabular}{|c|c|c|c|c|c|}
\hline \multicolumn{6}{|c|}{ Adherence and outcome } \\
\hline Study & Clinical problem & Intervention & Control & $\begin{array}{l}\text { Effect on adherence } \\
\text { (Yes means a statis- } \\
\text { tically significant ef- } \\
\text { fect in favor of the } \\
\text { intervention; No } \\
\text { means no effect or } \\
\text { a negative effect) }\end{array}$ & $\begin{array}{l}\text { Effect on clin- } \\
\text { ical outcome } \\
\text { (Yes means a statis- } \\
\text { tically significant ef- } \\
\text { fect in favor of the } \\
\text { intervention; No } \\
\text { means no effect or } \\
\text { a negative effect) }\end{array}$ \\
\hline & & $\begin{array}{l}\text { cist's Management of } \\
\text { Drug-Related Problems } \\
\text { (PMDRP) instrument to } \\
\text { summarize the informa- } \\
\text { tion collected during the } \\
\text { patient interview and } \\
\text { the subjective, objective, } \\
\text { assessment, and plan } \\
\text { record to document ac- } \\
\text { tions and follow-up }\end{array}$ & $\begin{array}{l}\text { continued to provide tra- } \\
\text { ditional pharmacy care }\end{array}$ & & \\
\hline Wakefield 2011 & $\begin{array}{l}\text { Type } 2 \text { diabetes mellitus } \\
\text { and hypertension }\end{array}$ & $\begin{array}{l}\text { HIGH-INTENSITY GROUP: } \\
\text { In the high-intensity } \\
\text { group, subjects were in- } \\
\text { structed to measure BP } \\
\text { daily and BG as directed } \\
\text { by their physician, that } \\
\text { is, frequency of home } \\
\text { BG monitoring was not } \\
\text { changed. The study team } \\
\text { developed a branching } \\
\text { disease management } \\
\text { algorithm based on DM } \\
\text { and HTN guidelines from } \\
\text { the VA, American Dia- } \\
\text { betes Association, and } \\
\text { the American Heart As- } \\
\text { sociation. The algorithm } \\
\text { was programmed into } \\
\text { the device and focused } \\
\text { on diet, exercise, smok- } \\
\text { ing cessation, foot care, } \\
\text { advice for sick days, } \\
\text { medications, weight } \\
\text { management, preventive } \\
\text { care, and behavior mod- } \\
\text { ification and lifestyle ad- } \\
\text { justments. A schedule } \\
\text { was established for each } \\
\text { prompt set so that sub- } \\
\text { jects received both stan- } \\
\text { dard prompts each day } \\
\text { and a rotation of ques- } \\
\text { tions and educational } \\
\text { content. Follow-up was } \\
\text { for a period of } 12 \text { months } \\
\text { ( } \mathrm{n}=93 \text { ) }\end{array}$ & $\begin{array}{l}\text { USUAL CARE: Usual care } \\
\text { subjects scheduled fol- } \\
\text { low-up appointments } \\
\text { with the primary care } \\
\text { clinic in the usual man- } \\
\text { ner. Subjects had access } \\
\text { to their nurse care man- } \\
\text { ager employed by the } \\
\text { medical center } \\
(n=107)\end{array}$ & $\begin{array}{l}\text { No for improving adher- } \\
\text { ence to medication in di- } \\
\text { abetes patients with hy- } \\
\text { pertension with a nurse } \\
\text { management program }\end{array}$ & $\begin{array}{l}\text { Yes for decreasing A1c } \\
\text { at } 6 \text { months. No for } \\
\text { decreasing A1c at } 12 \\
\text { months. Yes for decreas- } \\
\text { ing SPB at } 6 \text { and } 12 \\
\text { months in high interven- } \\
\text { tion group }\end{array}$ \\
\hline & & $\begin{array}{l}\text { LOW-INTENSITY GROUP: } \\
\text { In the low-intensity } \\
\text { group, subjects were in- } \\
\text { structed to measure BP } \\
\text { daily and BG as direct- } \\
\text { ed by their physician. } \\
\text { Subjects in this group re- } \\
\text { sponded to a small sub- } \\
\text { set of questions from the } \\
\text { larger set of questions } \\
\text { used with the high-in- } \\
\text { tensity group. Every day, } \\
\text { subjects in this group } \\
\text { were asked, "Have you } \\
\text { taken all your medica- } \\
\text { tions as prescribed?" In } \\
\text { addition, subjects were } \\
\text { prompted with one addi- } \\
\text { tional question each day } \\
\text { focused on diet, exercise, } \\
\text { foot care, or medica- } \\
\text { tion side effects. These }\end{array}$ & & & \\
\hline
\end{tabular}




\begin{tabular}{|c|c|c|c|c|c|}
\hline \multicolumn{6}{|c|}{ Adherence and outcome } \\
\hline Study & Clinical problem & Intervention & Control & $\begin{array}{l}\text { Effect on adherence } \\
\text { (Yes means a statis- } \\
\text { tically significant ef- } \\
\text { fect in favor of the } \\
\text { intervention; No } \\
\text { means no effect or } \\
\text { a negative effect) }\end{array}$ & $\begin{array}{l}\text { Effect on clin- } \\
\text { ical outcome } \\
\text { (Yes means a statis- } \\
\text { tically significant ef- } \\
\text { fect in favor of the } \\
\text { intervention; No } \\
\text { means no effect or } \\
\text { a negative effect) }\end{array}$ \\
\hline & & $\begin{array}{l}\text { questions did not use } \\
\text { the branching algorithm } \\
\text { used for the high-inten- } \\
\text { sity group, rather they } \\
\text { used yes/no or multiple } \\
\text { choice responses } \\
(n=102)\end{array}$ & & & \\
\hline Walley 2001 & Tuberculosis & $\begin{array}{l}170 \text { were assigned DOTS } \\
\text { with direct observation } \\
\text { of treatment by health } \\
\text { workers; } 165 \text { were as- } \\
\text { signed DOTS with direct } \\
\text { observation of treatment } \\
\text { by family members }\end{array}$ & $\begin{array}{l}162 \text { were assigned self } \\
\text { administered treatment }\end{array}$ & No & No \\
\hline Wang $2010 \mathrm{a}$ & $\begin{array}{l}\text { HIV with substance ad- } \\
\text { diction }\end{array}$ & $\begin{array}{l}\text { NURSE-DELIVERED } \\
\text { HOME VISITS: } 4 \text { home } \\
\text { visits (every } 2 \text { months) } \\
\text { were delivered by a qual- } \\
\text { ified nurse and includ- } \\
\text { ed } 1 \text { ) the provision of in- } \\
\text { formation about HIV/ } \\
\text { AIDS, 2) ART medication } \\
\text { and adherence, and } 3 \text { ) } \\
\text { skills to facilitate adher- } \\
\text { ence, reinforcing motiva- } \\
\text { tion, mobilizing family } \\
\text { support. Patients were } \\
\text { provided with a pam- } \\
\text { phlet, electric pillbox } \\
\text { with alarm, drug rehabil- } \\
\text { itation, methadone ther- } \\
\text { apy, and stress manage- } \\
\text { ment. In addition, tai- } \\
\text { lored interventions were } \\
\text { made based on the pre- } \\
\text { vious home visit and ad- } \\
\text { dressed barriers identi- } \\
\text { fied. Similarly, telephone } \\
\text { calls were every } 2 \text { weeks } \\
\text { including following each } \\
\text { home visit to reinforce } \\
\text { the effect of home visit } \\
\text { and varied from } 10 \text { to } 20 \\
\text { minutes to } 1 \text { hour dur- } \\
\text { ing which adherence lev- } \\
\text { el, barriers and general } \\
\text { emotional, sleeping, and } \\
\text { eating conditions were } \\
\text { discussed } \\
\text { ( } \mathrm{n}=58 \text { ) }\end{array}$ & $\begin{array}{l}\text { USUAL CARE: As part } \\
\text { of the Chinese national } \\
\text { ART management pro- } \\
\text { gram, patients are seen } \\
\text { twice in the first month } \\
\text { of ART and receive med- } \\
\text { ication for half a month } \\
\text { at each visit and in the } \\
\text { absence of side effects } \\
\text { and presence of nor- } \\
\text { mal liver and renal func- } \\
\text { tion, visits are reduced to } \\
\text { once a month. The clin- } \\
\text { ic's pharmacy dispens- } \\
\text { es medication monthly. } \\
\text { Clients on ART also re- } \\
\text { ceive free laboratory test } \\
\text { for CD4+ T cell counts } \\
\text { every } 3-6 \text { months for } \\
\text { evaluating the effective- } \\
\text { ness of the treatment. } \\
\text { HIV viral load test is not } \\
\text { routinely provided in the } \\
\text { national treatment pro- } \\
\text { gram because of the lim- } \\
\text { ited fund. The patients } \\
\text { visit the clinic once they } \\
\text { have side effects or oth- } \\
\text { er health problems and } \\
\text { need a laboratory test. } \\
\text { The service of home vis- } \\
\text { its or phone calls from } \\
\text { health care providers are } \\
\text { not routinely provided } \\
\text { ( } \mathrm{n}=58 \text { ) }\end{array}$ & $\begin{array}{l}\text { Yes for improving adher- } \\
\text { ence to ART in heroin-ad- } \\
\text { dicted HIV-positive pa- } \\
\text { tients }\end{array}$ & $\begin{array}{l}\text { Yes for improving quali- } \\
\text { ty of life and depressive } \\
\text { symptoms in heroin-ad- } \\
\text { dicted HIV-positive pa- } \\
\text { tients }\end{array}$ \\
\hline Wang $2010 \mathrm{~b}$ & Asthma & $\begin{array}{l}\text { PHARMACIST } \\
\text { COUNSELING: Patients } \\
\text { participated in the stan- } \\
\text { dard nurse administered } \\
\text { asthma education pro- } \\
\text { gram with additional } \\
\text { pharmacist counseling } \\
\text { with the pharmacist. A } \\
\text { detailed workbook pre- } \\
\text { pared by chest physi- } \\
\text { cians was used for each } \\
\text { session. The asthma ed- } \\
\text { ucation program cov- } \\
\text { ered } 4 \text { topics taught in } \\
\text { sequence in } 31 \text {-hour } \\
\text { sessions offered during } \\
\text { monthly clinic visits (at } \\
\text { months } 1,2 \text {, and } 3 \text { ). Top- } \\
\text { ics covered were: (1) de- }\end{array}$ & $\begin{array}{l}\text { CONTROL: Patients in } \\
\text { the control group re- } \\
\text { ceived only routine asth- } \\
\text { ma care } \\
(n=35)\end{array}$ & $\begin{array}{l}\text { No for improving adher- } \\
\text { ence to asthma medica- } \\
\text { tion at } 6 \text { months }\end{array}$ & $\begin{array}{l}\text { No for quality of life at } 6 \\
\text { months }\end{array}$ \\
\hline
\end{tabular}


Adherence and outcome

Intervention

Control

\section{Effect on adherence \\ (Yes means a statis- \\ tically significant ef- \\ fect in favor of the \\ intervention; No \\ means no effect or \\ a negative effect)}

Effect on clin-

ical outcome

(Yes means a statis-

tically significant ef-

fect in favor of the

intervention; No

means no effect or a negative effect)

finition, etiology, diag-

nosis, disease progress,

and complications of

asthma; (2) instruction to

monitor disease severi-

ty, especially skills need-

ed to use the peak expi-

ratory flow (PEF) meter

and the format to record

symptoms in a diary; (3)

introduction on medica-

tions for asthma therapy,

including protocol of a

stepwise treatment plan,

pharmacology of leading

asthma drugs and cor-

rect inhaler techniques;

and (4) guidelines for self

management, including

understanding potential

environmental triggers

and irritant factors, envi-

ronmental control and

standard procedure for

coping with asthma at-

tacks. Pharmacist coun-

seling covered informa-

tion related to the action

and side effects of asth-

ma medications, treat-

ment plans for individu-

alized medication, and

modification of medica-

tions in response to pro-

gressive asthma

$(\mathrm{n}=34)$

NURSE ADMINISTERED

ASTHMA EDUCATION

PROGRAM: Patients par-

ticipated in the stan-

dard nurse administered

asthma education pro-

gram. A detailed work-

book prepared by chest

physicians was used for

each session. The asth-

ma education program

covered 4 topics taught

in sequence in 31 -hour

sessions offered during

monthly clinic visits (at

months 1 , 2, and 3). Top-

ics covered were: (1) de-

finition, etiology, diag-

nosis, disease progress,

and complications of

asthma; (2) instruction to

monitor disease severi-

ty, especially skills need-

ed to use the peak expi-

ratory flow (PEF) meter

and the format to record

symptoms in a diary; (3)

introduction on medica-

tions for asthma therapy,

including protocol of a

stepwise treatment plan,

pharmacology of leading

asthma drugs and cor- 


\begin{tabular}{|c|c|c|c|c|c|}
\hline \multicolumn{6}{|c|}{ Adherence and outcome } \\
\hline Study & Clinical problem & Intervention & Control & $\begin{array}{l}\text { Effect on adherence } \\
\text { (Yes means a statis- } \\
\text { tically significant ef- } \\
\text { fect in favor of the } \\
\text { intervention; No } \\
\text { means no effect or } \\
\text { a negative effect) }\end{array}$ & $\begin{array}{l}\text { Effect on clin- } \\
\text { ical outcome } \\
\text { (Yes means a statis- } \\
\text { tically significant ef- } \\
\text { fect in favor of the } \\
\text { intervention; No } \\
\text { means no effect or } \\
\text { a negative effect) }\end{array}$ \\
\hline & & $\begin{array}{l}\text { rect inhaler techniques; } \\
\text { and (4) guidelines for self } \\
\text { management, including } \\
\text { understanding potential } \\
\text { environmental triggers } \\
\text { and irritant factors, envi- } \\
\text { ronmental control and } \\
\text { standard procedure for } \\
\text { coping with asthma at- } \\
\text { tacks } \\
(\mathrm{n}=35)\end{array}$ & & & \\
\hline Weber 2004 & HIV & $\begin{array}{l}\text { Intervention group par- } \\
\text { ticipants ( } \mathrm{n}=32 \text { ) re- } \\
\text { ceived cognitive behav- } \\
\text { ior therapy in addition } \\
\text { to usual care, while con- } \\
\text { trol group participants } \\
(\mathrm{n}=28) \text { received usu- } \\
\text { al care alone. Interven- } \\
\text { tion group participants } \\
\text { were assigned to a psy- } \\
\text { chotherapist and given } \\
\text { the contact information } \\
\text { to schedule their own } \\
\text { first appointment. Proto- } \\
\text { col defined a minimum } \\
\text { of } 3 \text { and a maximum of } \\
25 \text { sessions within the } 1- \\
\text { year study period. Partic- } \\
\text { ipant and psychothera- } \\
\text { pist determined the fre- } \\
\text { quency of appointments } \\
\text { and set their own goals } \\
\text { for future interventions }\end{array}$ & $\begin{array}{l}\text { Both intervention and } \\
\text { control groups contin- } \\
\text { ued to receive standard } \\
\text { care. Standard care in- } \\
\text { cluded monthly visits for } \\
12 \text { months with assess- } \\
\text { ments of clinical and lab- } \\
\text { oratory data, course of } \\
\text { treatment, drug adverse } \\
\text { events and HIV-1 RNA }\end{array}$ & No & No \\
\hline Weinberger 2002 & $\begin{array}{l}\text { Asthma or chronic ob- } \\
\text { structive pulmonary dis- } \\
\text { ease (COPD) }\end{array}$ & $\begin{array}{l}\text { The pharmaceutical care } \\
\text { program provided phar- } \\
\text { macists with recent pa- } \\
\text { tient-specific clinical } \\
\text { data (peak expiratory } \\
\text { flow rates (PEFRs), emer- } \\
\text { gency department (ED) } \\
\text { visits, hospitalizations, } \\
\text { and medication com- } \\
\text { pliance), training, cus- } \\
\text { tomized patient educa- } \\
\text { tional materials, and re- } \\
\text { sources to facilitate pro- } \\
\text { gram implementation } \\
\text { ( } \mathrm{n}=447 \text { ) }\end{array}$ & $\begin{array}{l}\text { The PEFR monitoring } \\
\text { control group received a } \\
\text { peak flow meter, instruc- } \\
\text { tions about its use, and } \\
\text { monthly calls to elicit PE- } \\
\text { FRs. However, PEFR da- } \\
\text { ta were not provided to } \\
\text { the pharmacist. Patients } \\
\text { in the usual care group } \\
\text { ( } \mathrm{n}=303 \text { ) received nei- } \\
\text { ther peak flow meters } \\
\text { nor instructions in their } \\
\text { use; during monthly tele- } \\
\text { phone interviews, PEFR } \\
\text { rates were not elicited. } \\
\text { Pharmacists in both con- } \\
\text { trol groups had a train- } \\
\text { ing session but received } \\
\text { no components of the } \\
\text { pharmaceutical care in- } \\
\text { tervention } \\
\text { ( } \mathrm{n}=363 \text { ) }\end{array}$ & $\begin{array}{l}\text { Yes, for within-group at } \\
6 \text { and } 12 \text { months; no for } \\
\text { between-group }\end{array}$ & $\begin{array}{l}\text { Yes. At } 12 \text { months, pa- } \\
\text { tients receiving pharma- } \\
\text { ceutical care had signifi- } \\
\text { cantly higher peak flow } \\
\text { rates than the usual care } \\
\text { group ( } \mathrm{P} \text { value }=0.02 \text { ) } \\
\text { but not than PEFR moni- } \\
\text { toring controls ( } \mathrm{P} \text { value }= \\
0.28) \text {. There were no sig- } \\
\text { nificant between-group } \\
\text { differences in HRQOL, } \\
\text { but patients participat- } \\
\text { ing in the program were } \\
\text { significantly more satis- } \\
\text { fied with their pharma- } \\
\text { cists than the other } 2 \\
\text { groups }\end{array}$ \\
\hline Wiggins 2009 & $\begin{array}{l}\text { Postoperative pain after } \\
\text { tonsillectomy and ade- } \\
\text { noidectomy }\end{array}$ & $\begin{array}{l}\text { AROUND-THE-CLOCK IN- } \\
\text { TERVENTION: The inter- } \\
\text { vention was alarms to re- } \\
\text { mind administering anal- } \\
\text { gesic } 4 \text { hours after going } \\
\text { to bed on the night of } \\
\text { surgery and next } 2 \text { post- } \\
\text { operative nights as in- } \\
\text { structed by the research } \\
\text { nurse. In addition to the } \\
\text { study procedure, all chil- } \\
\text { dren and families re- } \\
\text { ceived discharge educa- }\end{array}$ & $\begin{array}{l}\text { USUAL CARE: The usual } \\
\text { care group (UCG) was not } \\
\text { given any specific inter- } \\
\text { vention, but was offered } \\
\text { the same discharge ed- } \\
\text { ucation as the interven- } \\
\text { tion group. Discharge ed- } \\
\text { ucation materials includ- } \\
\text { ed information about ear } \\
\text { pain and the length of } \\
\text { the recovery, mothers } \\
\text { and children expressed } \\
\text { self doubt about their }\end{array}$ & $\begin{array}{l}\text { Yes for improving adher- } \\
\text { ence to analgesic in chil- } \\
\text { dren after tonsillectomy } \\
\text { or adenoidectomy }\end{array}$ & $\begin{array}{l}\text { No for improved pain in- } \\
\text { tensity and fluid intake } \\
\text { until postoperative day } 2\end{array}$ \\
\hline
\end{tabular}




\begin{tabular}{|c|c|c|c|c|c|}
\hline \multicolumn{6}{|c|}{ Adherence and outcome } \\
\hline Study & Clinical problem & Intervention & Control & $\begin{array}{l}\text { Effect on adherence } \\
\text { (Yes means a statis- } \\
\text { tically significant ef- } \\
\text { fect in favor of the } \\
\text { intervention; No } \\
\text { means no effect or } \\
\text { a negative effect) }\end{array}$ & $\begin{array}{l}\text { Effect on clin- } \\
\text { ical outcome } \\
\text { (Yes means a statis- } \\
\text { tically significant ef- } \\
\text { fect in favor of the } \\
\text { intervention; No } \\
\text { means no effect or } \\
\text { a negative effect) }\end{array}$ \\
\hline & & $\begin{array}{l}\text { tion from their ear, nose, } \\
\text { and throat (ENT) physi- } \\
\text { cian/clinic and from the } \\
\text { professional nurses in } \\
\text { each of the ambulatory } \\
\text { centers. Discharge ed- } \\
\text { ucation in both ambu- } \\
\text { latory settings includ- } \\
\text { ed use of around-the- } \\
\text { clock prescribed analge- } \\
\text { sia for pain during the } \\
\text { early days of recovery; } \\
\text { increased fluid intake; } \\
\text { monitoring for infection } \\
\text { and bleeding; and re- } \\
\text { turning to their special- } \\
\text { ist at a designated time } \\
\text { in the recovery process. } \\
\text { In addition, all ENT spe- } \\
\text { cialists encouraged fami- } \\
\text { lies to contact them with } \\
\text { concerns. All families re- } \\
\text { ceived a phone call from } \\
\text { a registered nurse from } \\
\text { their ambulatory surgery } \\
\text { center } 24 \text { hours after dis- } \\
\text { charge } \\
\text { ( } \mathrm{n}=7 \text { ) }\end{array}$ & $\begin{array}{l}\text { ability to provide ade- } \\
\text { quate symptom manage- } \\
\text { ment when painful expe- } \\
\text { riences continued } \\
(n=6)\end{array}$ & & \\
\hline
\end{tabular}


Adherence and outcome

Intervention
Effect on adherence

(Yes means a statis

tically significant ef-

fect in favor of the

intervention; No

means no effect or

a negative effect)
Effect on clin-

ical outcome

(Yes means a statis-

tically significant ef

fect in favor of the

intervention; No

means no effect or a negative effect) action plan was creat-

ed, and potential barri-

ers to medication adher-

ence were elicited and

addressed using motiva-

tional interviewing tech-

niques. Any subsequent

changes made at ses-

sion 2 or in a follow-up

phone call were docu-

mented in the plan. The

SDM model implement-

ed the 4 key defining fea-

tures. The care manag-

er elicited the patient's

goals for treatment and

relative priorities regard-

ing symptom control,

regimen convenience,

avoidance of side effects,

and cost. The patient

was then shown a list of

the full range of regimen

options for all levels of

asthma severity, based

on the then-current na-

tional asthma guidelines

and KP pharmacopeia.

These options differed

with respect to the num-

ber and type(s) of med-

ications, dosing, and

schedule. Using a sim-

ple worksheet, the pa-

tient and clinician then

compared the pros and

cons of all of the options

the patient wished to

consider, which includ-

ed the option of contin-

uing the patient's cur-

rent regimen to arrive

at a treatment that best

accommodated the pa-

tient's and care manag-

er's goals. A SABA was al-

ways prescribed for res-

cue use as needed. If in-

dicated, treatment of al-

lergic rhinitis and/or gas-

troesophageal reflux dis-

ease was negotiated

$(\mathrm{n}=204)$

CLINICIAN DECISION-

MAKING: Session 1 of the

intervention involved

prescribing the patient

a therapy rather than ne-

gotiating a therapy. In

session 2 (1 month after

session 1 ), and in 3 brief

phone calls 3,6 , and 9

months later, patient

progress was assessed

and medications were

adjusted, as necessary,

using the assigned care

management approach.

Researchers used iden- had access to KP's exist-

ing care management

services, if available,

based on their physi-

cian's referral

$(n=204)$ 


\begin{tabular}{|c|c|c|c|c|c|}
\hline \multicolumn{6}{|c|}{ Adherence and outcome } \\
\hline Study & Clinical problem & Intervention & Control & $\begin{array}{l}\text { Effect on adherence } \\
\text { (Yes means a statis- } \\
\text { tically significant ef- } \\
\text { fect in favor of the } \\
\text { intervention; No } \\
\text { means no effect or } \\
\text { a negative effect) }\end{array}$ & $\begin{array}{l}\text { Effect on clin- } \\
\text { ical outcome } \\
\text { (Yes means a statis- } \\
\text { tically significant ef- } \\
\text { fect in favor of the } \\
\text { intervention; No } \\
\text { means no effect or } \\
\text { a negative effect) }\end{array}$ \\
\hline & & $\begin{array}{l}\text { tical standardized in- } \\
\text { terventionist scripts } \\
\text { and materials. The pa- } \\
\text { tient's asthma histo- } \\
\text { ry was elicited using a } \\
\text { standardized patient } \\
\text { information form, the } \\
\text { patient's level of asth- } \\
\text { ma control was classi- } \\
\text { fied, and asthma edu- } \\
\text { cation was provided. } \\
\text { Once treatment was de- } \\
\text { cided (CDM), patients } \\
\text { were instructed in the } \\
\text { correct use of the rele- } \\
\text { vant inhaler medication } \\
\text { devices using methods } \\
\text { previously shown by this } \\
\text { team to improve inhaler } \\
\text { technique and eliminate } \\
\text { common usage errors. } \\
\text { At the end of session } 1 \text {, } \\
\text { a written asthma man- } \\
\text { agement and action plan } \\
\text { was created, and po- } \\
\text { tential barriers to med- } \\
\text { ication adherence were } \\
\text { elicited and addressed } \\
\text { using motivational in- } \\
\text { terviewing techniques. } \\
\text { Any subsequent changes } \\
\text { made at session } 2 \text { or in } \\
\text { a follow-up phone call } \\
\text { were documented in the } \\
\text { plan. In the CDM model, } \\
\text { the care manager pre- } \\
\text { scribed an appropriate } \\
\text { regimen based on the } \\
\text { patient's level of asthma } \\
\text { control, and explained } \\
\text { that decision to the pa- } \\
\text { tient. A SABA was always } \\
\text { prescribed for rescue } \\
\text { use as needed. If indicat- } \\
\text { ed, treatment of allergic } \\
\text { rhinitis and/or gastroe- } \\
\text { sophageal reflux disease } \\
\text { was prescribed } \\
\text { (n= 204) }\end{array}$ & & & \\
\hline Wolever 2010 & Type 2 diabetes & $\begin{array}{l}\text { INTEGRATIVE HEALTH } \\
\text { (IH) COACHING: } 2 \text { coach- } \\
\text { es provided the coach- } \\
\text { ing intervention. Both } \\
\text { had substantial train- } \\
\text { ing in coaching methods } \\
\text { as well as masters-level } \\
\text { degrees in social work } \\
\text { or psychology. Coaches } \\
\text { each had over } 100 \text { hours } \\
\text { of experience of individ- } \\
\text { ualized coaching with } \\
\text { type } 2 \text { diabetes patients } \\
\text { and had previously facili- } \\
\text { tated diabetes coaching } \\
\text { groups. Participants ran- } \\
\text { domized to the coach- } \\
\text { ing condition had an ini- } \\
\text { tial telephone session } \\
\text { with their coach within }\end{array}$ & $\begin{array}{l}\text { USUAL CARE: Control } \\
\text { group participants re- } \\
\text { ceived usual care, with } \\
\text { no additional materials } \\
\text { or correspondence } \\
(n=26)\end{array}$ & $\begin{array}{l}\text { No for self reported ad- } \\
\text { herence on the Morisky } \\
\text { questionnaire }\end{array}$ & $\begin{array}{l}\text { No for A1C at } 6 \text { months. } \\
\text { No for stress at } 6 \\
\text { months. No for quality } \\
\text { of life between integra- } \\
\text { tive health coaching and } \\
\text { usual care patients at } 6 \\
\text { months }\end{array}$ \\
\hline
\end{tabular}


Adherence and outcome

Intervention

Control

\section{Effect on adherence \\ (Yes means a statis- \\ tically significant ef- \\ fect in favor of the \\ intervention; No \\ means no effect or \\ a negative effect)}

Effect on clin-

ical outcome

(Yes means a statis-

tically significant ef-

fect in favor of the

intervention; No

means no effect or a negative effect)

\section{2 weeks of the baseline}

visit. They were then of-

fered 30-minute coach-

ing sessions by tele-

phone (8 weekly calls,

4 biweekly calls, and a

final call 1 month later)

for a total of 14 sessions.

Participants were paired

with the same coach

throughout the interven-

tion. During the initial

telephone call, partici-

pants were asked what

was important to them

in terms of diabetes care,

how well they were man-

aging their health, and

what they perceived to

be their challenges or

areas of required sup-

port. Patients were guid-

ed in creating a vision of

health, and long-term

goals were discussed

that aligned with that vi-

sion. To facilitate learn-

ing, participants ran-

domized to IH coaching

received a binder of ed-

ucational materials at

the initial assessment

visit. Contents includ-

ed materials from Glax-

oSmithKline's Adher-

ence Starts with Knowl-

edge $^{\circledast}$ (ASK-20) and Es-

sential Connections ${ }^{\circledR}$ as

well as information from

Duke Integrative Medi-

cine. These were refer-

enced throughout the in

teractions of the study.

The ASK-20 is a brief sur-

vey that helps practition-

ers quickly identify and

target reasons patients

may not be adhering to

prescribed medication

regimens. It is accom-

panied by materials on

topics relevant to self

management such as

symptom recognition,

self care, and disease

risk factors. Duke Inte-

grative Medicine provid-

ed information regarding

nutrition, stress manage-

ment, and tips on how to

best utilize time with the

coach. Additional materi-

als came from Essential

Connections, a resource

of tools for coaches to fa-

cilitate motivational in-

terviewing techniques

and behavior change,

linking topics of interest

with patients' readiness 


\begin{tabular}{|c|c|c|c|c|c|}
\hline \multicolumn{6}{|c|}{ Adherence and outcome } \\
\hline Study & Clinical problem & Intervention & Control & $\begin{array}{l}\text { Effect on adherence } \\
\text { (Yes means a statis- } \\
\text { tically significant ef- } \\
\text { fect in favor of the } \\
\text { intervention; No } \\
\text { means no effect or } \\
\text { a negative effect) }\end{array}$ & $\begin{array}{l}\text { Effect on clin- } \\
\text { ical outcome } \\
\text { (Yes means a statis- } \\
\text { tically significant ef- } \\
\text { fect in favor of the } \\
\text { intervention; No } \\
\text { means no effect or } \\
\text { a negative effect) }\end{array}$ \\
\hline & & $\begin{array}{l}\text { to change and relevant } \\
\text { education content } \\
(n=30)\end{array}$ & & & \\
\hline Wu 2006 & $\begin{array}{l}\text { Chronic illnesses receiv- } \\
\text { ing polypharmacy }\end{array}$ & $\begin{array}{l}\text { INCREASED SUPER- } \\
\text { VISION BY PHARMACIST: } \\
\text { Patients in the interven- } \\
\text { tion group received 10- } \\
\text { to } 15 \text {-minute telephone } \\
\text { calls from the pharma- } \\
\text { cist at the midpoint be- } \\
\text { tween clinic visits, nor- } \\
\text { mally scheduled at in- } \\
\text { tervals of } 2 \text { to } 4 \text { months, } \\
\text { throughout the study } \\
\text { period. During the tele- } \\
\text { phone calls the phar- } \\
\text { macist asked about the } \\
\text { patient's current med- } \\
\text { ication regime, clari- } \\
\text { fied misconceptions, ex- } \\
\text { plained the nature of } \\
\text { side effects, reminded } \\
\text { patients of next appoint- } \\
\text { ment, reinforced impor- } \\
\text { tance of compliance with } \\
\text { medications and rele- } \\
\text { vant aspects of self care } \\
\text { and encouraged patients } \\
\text { to share side effects, self } \\
\text { initiated change in regi- } \\
\text { men, or other concerns } \\
\text { with the doctors at next } \\
\text { follow-up } \\
\text { ( } \mathrm{n}=219 \text { ) }\end{array}$ & $\begin{array}{l}\text { USUAL CARE: Patients } \\
\text { in the control group con- } \\
\text { tinued with usual care, } \\
\text { which for clinically sta- } \\
\text { ble patients meant fol- } \\
\text { low-up at intervals of } 2 \\
\text { to } 4 \text { months, with each } \\
\text { consultation lasting } 10 \\
\text { to } 15 \text { minutes } \\
\text { ( } n=223 \text { ) }\end{array}$ & $\begin{array}{l}\text { Yes for improving com- } \\
\text { pliance to polypharmacy } \\
\text { for chronic conditions }\end{array}$ & $\begin{array}{l}\text { Yes for mortality, ER vis- } \\
\text { its, and hospitalization }\end{array}$ \\
\hline Wu 2012 & Chronic heart failure & $\begin{array}{l}\text { LITE: The intervention } \\
\text { was delivered by a car- } \\
\text { diovascular nurse expert } \\
\text { in delivery of the educa- } \\
\text { tion and counseling in- } \\
\text { tervention. Patients re- } \\
\text { ceived the counseling in- } \\
\text { tervention individually } \\
\text { every other week for a } \\
\text { total of } 4 \text { sessions. The } \\
\text { first and third sessions } \\
\text { were face-to-face edu- } \\
\text { cation and counseling } \\
\text { lasting } 1 \text { hour. The } 2 \text { nd } \\
\text { and } 4 \text { th sessions were } \\
\text { delivered by telephone } \\
\text { and lasted } 20 \text { minutes } \\
\text { each. The intervention } \\
\text { was designed to influ- } \\
\text { ence medication adher- } \\
\text { ence by creating a more } \\
\text { positive attitude toward } \\
\text { medication adherence, } \\
\text { incorporating significant } \\
\text { others into the patient } \\
\text { education and counsel- } \\
\text { ing sessions to build a } \\
\text { positive subjective norm, } \\
\text { and providing needed in- } \\
\text { formation and skills to } \\
\text { overcome barriers to ad- } \\
\text { herence to increase the } \\
\text { patient's perceived be- } \\
\text { havioral control } \\
\text { ( } \mathrm{n}=27 \text { ) }\end{array}$ & $\begin{array}{l}\text { USUAL CARE: Received } \\
\text { usual care. Participants } \\
\text { completed a baseline } \\
\text { survey, were contacted } \\
\text { monthly to collect out- } \\
\text { come, and completed a } \\
\text { 9-month questionnaire. } \\
\text { In addition their MEMS } \\
\text { data were downloaded } \\
\text { at } 1,2 \text {, and } 9 \text { months } \\
(n=28)\end{array}$ & $\begin{array}{l}\text { Yes for improving ad- } \\
\text { herence to heart failure } \\
\text { medication at } 9 \text { months } \\
\text { in PLUS and LITE groups } \\
\text { compared to control. } \\
\text { Yes for improving ad- } \\
\text { herence at } 2 \text { months in } \\
\text { PLUS compared to con- } \\
\text { trol. No for improving } \\
\text { adherence at } 9 \text { months } \\
\text { in PLUS compared to } \\
\text { LITE }\end{array}$ & $\begin{array}{l}\text { Yes for improving cardiac } \\
\text { event-free survival in } \\
\text { both interventions com- } \\
\text { pared to controls at } 9 \\
\text { months. No for improved } \\
\text { quality of life over the 9- } \\
\text { month period }\end{array}$ \\
\hline
\end{tabular}




\begin{tabular}{|c|c|c|c|c|c|}
\hline \multicolumn{6}{|c|}{ Adherence and outcome } \\
\hline Study & Clinical problem & Intervention & Control & $\begin{array}{l}\text { Effect on adherence } \\
\text { (Yes means a statis- } \\
\text { tically significant ef- } \\
\text { fect in favor of the } \\
\text { intervention; No } \\
\text { means no effect or } \\
\text { a negative effect) }\end{array}$ & $\begin{array}{l}\text { Effect on clin- } \\
\text { ical outcome } \\
\text { (Yes means a statis- } \\
\text { tically significant ef- } \\
\text { fect in favor of the } \\
\text { intervention; No } \\
\text { means no effect or } \\
\text { a negative effect) }\end{array}$ \\
\hline & & $\begin{array}{l}\text { PLUS: In addition to } \\
\text { what was received by the } \\
\text { LITE group, participants } \\
\text { received feed-back on } \\
\text { their medication taking } \\
\text { behavior from the MEMS } \\
\text { at each of the } 2 \text { face- } \\
\text { to-face sessions. MEMS } \\
\text { feedback was used to } \\
\text { show the patients their } \\
\text { own medication-taking } \\
\text { behavior and identify } \\
\text { problematic areas. A vi- } \\
\text { sual display was shared } \\
\text { by the nurse with the } \\
\text { participant } \\
(\mathrm{n}=27)\end{array}$ & & & \\
\hline Wysocki 2001 & Diabetes & $\begin{array}{l}\text { Behavioral-Family Sys- } \\
\text { tems Therapy (BFST) } \\
\text {-10 sessions consist- } \\
\text { ing of } 4 \text { therapy compo- } \\
\text { nents: problem-solving } \\
\text { training, communica- } \\
\text { tion skills training, cog- } \\
\text { nitive restructuring and } \\
\text { functional and structural } \\
\text { family therapy, plus USD } \\
100 \text { monetary incentive } \\
\text { for attending all } 10 \text { inter- } \\
\text { vention sessions } \\
\text { ( } \mathrm{n}=38 \text { ) } \\
\text { Education and Support } \\
\text { (ES) - families attend- } \\
\text { ed } 10 \text { group diabetes } \\
\text { education and social } \\
\text { support meetings ( } 45- \\
\text { minute educational pre- } \\
\text { sentation by diabetes } \\
\text { professional + } 45-\text { minute } \\
\text { interaction among the } \\
\text { families), plus USD } 100 \\
\text { monetary incentive for } \\
\text { attending all } 10 \text { interven- } \\
\text { tion sessions } \\
\text { ( } \mathrm{n}=40 \text { ) }\end{array}$ & $\begin{array}{l}\text { Current therapy - stan- } \\
\text { dard pediatric en- } \\
\text { docrinology follow-up } \\
\text { and self management } \\
\text { training } \\
(\mathrm{n}=41)\end{array}$ & $\begin{array}{l}\text { No for BFST and ES at } \\
\text { post-treatment. Yes for } \\
\text { BFST at } 6 \text { and } 12 \text { months. } \\
\text { No for ES at } 6 \text { and } 12 \\
\text { months }\end{array}$ & $\begin{array}{l}\text { No for BFST in diabetic } \\
\text { control or adjustment } \\
\text { to diabetes. Yes for BFST } \\
\text { on PARQ scales at post- } \\
\text { treatment, } 6 \text {, and } 12 \\
\text { months. No for ES }\end{array}$ \\
\hline Xiong 1994 & Schizophrenia & $\begin{array}{l}\text { Family counseling and } \\
\text { close follow-up }(n=34)\end{array}$ & $\begin{array}{l}\text { Prescription of medica- } \\
\text { tion without formal fol- } \\
\text { low-up }(n=29)\end{array}$ & No & Yes \\
\hline Yopp 2004 & $\begin{array}{l}\text { Adolescents with type } 1 \\
\text { diabetes }\end{array}$ & $\begin{array}{l}\text { Usual care (see Con- } \\
\text { trol) plus Multisystemic } \\
\text { Therapy (MST; } n=27 \text { ) - a } \\
\text { home-based psychother- } \\
\text { apy, the goal of which } \\
\text { is to understand which } \\
\text { factors are maintaining } \\
\text { poor health status }\end{array}$ & $\begin{array}{l}\text { Usual care in a multidis- } \\
\text { ciplinary children's en- } \\
\text { docrinology clinic } \\
(n=26)\end{array}$ & $\begin{array}{l}\text { No for the Diabetes Man- } \\
\text { agement Scale. Yes for } \\
\text { the } 24 \text {-Hour Recall Inter- } \\
\text { view, specifically the in- } \\
\text { sulin adherence }\end{array}$ & No \\
\hline Zhang 1994 & Schizophrenia & $\begin{array}{l}\text { Family intervention }(n= \\
42)\end{array}$ & $\begin{array}{l}\text { Prescription of medica- } \\
\text { tion without formal fol- } \\
\text { low-up }(n=41)\end{array}$ & No & Yes \\
\hline Zolfaghari 2012 & Type 2 diabetes & $\begin{array}{l}\text { SHORT MESSAGE } \\
\text { SYSTEM (SMS) GROUP: } \\
\text { Participants in both } \\
\text { groups received } 3 \text { days } \\
\text { of diabetes self care ed- } \\
\text { ucation sessions. Be- } \\
\text { fore the intervention, the } \\
\text { SMS group received } 10\end{array}$ & $\begin{array}{l}\text { TELEPHONE INTERVEN- } \\
\text { TION GROUP: The in- } \\
\text { tervention for the Tele- } \\
\text { phone Group was pro- } \\
\text { vided via telephone for } \\
3 \text { months. The interven- } \\
\text { tion was provided by } \\
\text { counseling scheduled }\end{array}$ & $\begin{array}{l}\text { No for improving med- } \\
\text { ication adherence in di- } \\
\text { abetic patients with an } \\
\text { SMS intervention at } 6 \\
\text { months }\end{array}$ & $\begin{array}{l}\text { No for improving } \mathrm{HbA} 1 \mathrm{C} \\
\text { levels at } 6 \text { months. No } \\
\text { difference in HbAlc lev- } \\
\text { els between the groups }\end{array}$ \\
\hline
\end{tabular}




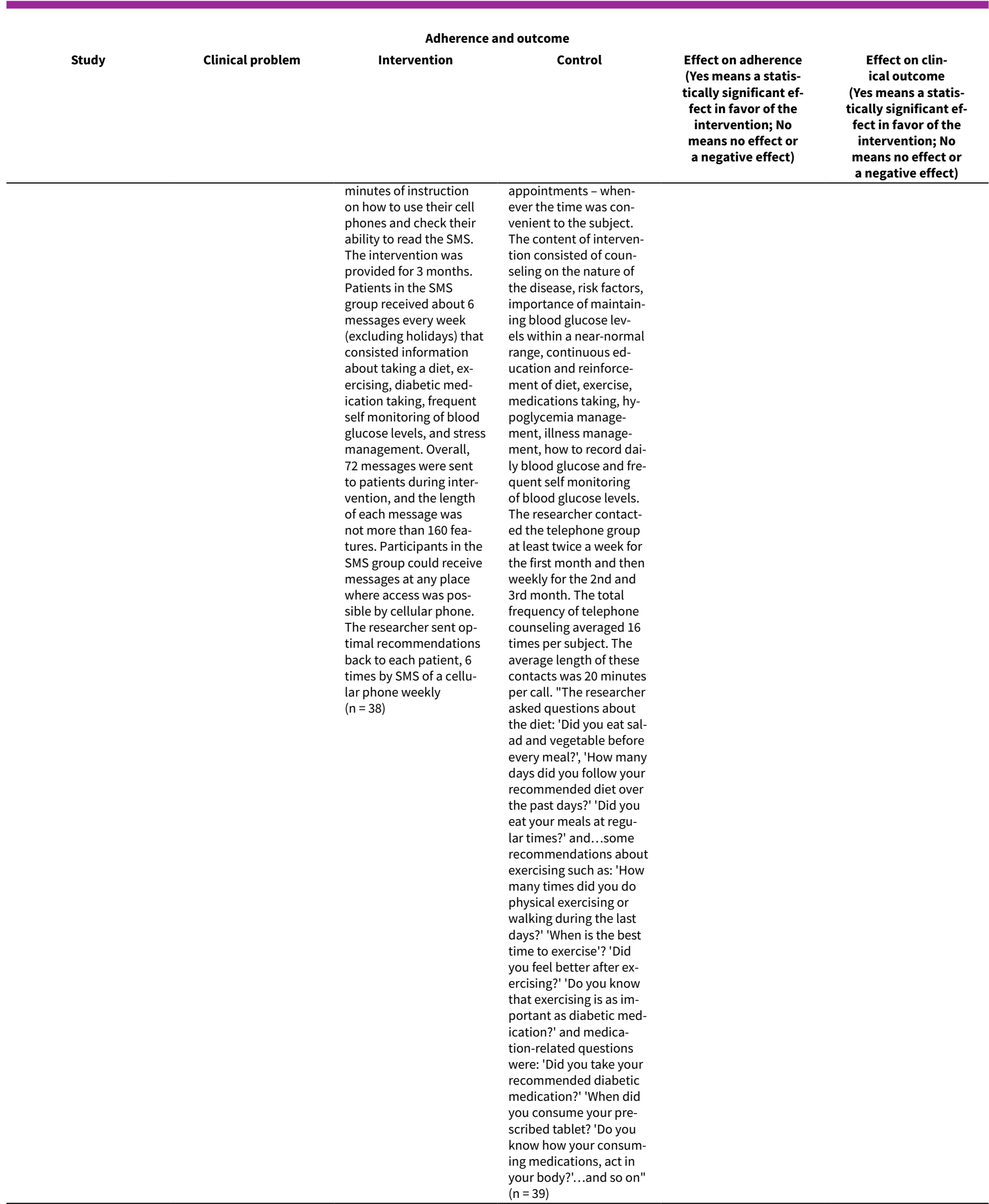




\section{AP PE N DICES}

\section{Appendix 1. Search filters used in the previous review and this update \\ MEDLINE and CINAHL database search filters used in the 2008 version of the review:}

1. ((patient compliance $(\mathrm{mh}) \mathrm{OR}$ patient adjacent to compliance (title and abstract) AND (clinical trials (pt) OR clinical trial (mh) OR all random: (textword))

2. ((random: or control:) AND (patient compliance/ or patient dropouts/ or psychotherapy or treatment refusal/ or patient education/ or regimen:.tw.) AND (intervention:.tw. or outcome:.tw.) AND (medicat:.tw. or drug therapy))

MEDLINE search filters used in this update using the Ovid interface:

1. ((exp patient compliance/ OR (patient adj compliance).tw. OR (patient adj adherence).tw. OR (medication adj compliance).tw. OR (medication adj adherence).tw.) AND ((clinical trial OR random:).mp. OR tu.xs.)) NOT ((qualitative OR retrospective OR mice OR rat OR rats).tw. OR editorial.pt. OR letter.pt. OR comment.pt.) NOT (animals NOT humans).sh. (Note: clinical trial.mp. picks up clinical trial.pt.)

2. ((random: OR control:).mp. AND (exp patient compliance/ OR patient dropouts/ OR psychotherapy/ OR treatment refusal/ OR patient education/ OR regimen:.tw.) AND (intervention: OR outcome:).tw. AND (medicat:.tw. OR drug therapy/)) NOT ((qualitative OR retrospective OR mice OR rat OR rats).tw. OR editorial.pt. OR letter.pt. OR comment.pt.) NOT (animals NOT humans).sh.

CINAHL search filters used in this update using the EBSCO interface:

1. MH patient compliance+ OR TI "patient compliance" OR AB "patient compliance" OR TI "patient adherence" OR AB "patient adherence" OR TI "medication compliance" OR AB "medication compliance" OR TI "medication adherence" OR AB "medication adherence" NOT $\mathrm{PT}$ editorial or $\mathrm{PT}$ letter or $\mathrm{TI}$ qualitative or $\mathrm{AB}$ qualitative or $\mathrm{TI}$ retrospective or $\mathrm{AB}$ retrospective or $\mathrm{TI}$ mice or $\mathrm{AB}$ mice or $\mathrm{TI}$ rat or $\mathrm{AB}$ rat or TI rats or AB rats (limited by Clinical Queries therapy sensitive search filter and date - 2007 to 2012 )

2. $\mathrm{MH}$ patient compliance OR MH medication compliance OR MH patient dropouts OR MH treatment refusal OR MH patient education OR TI psychotherapy OR AB psychotherapy AND TX ( (random* OR control $\left.{ }^{\star}\right)$ ) AND TX ( (medicat ${ }^{\star}$ OR drug therapy) ) NOT PT editorial or PT letter or $\mathrm{TI}$ qualitative or $\mathrm{AB}$ qualitative or $\mathrm{TI}$ retrospective or $\mathrm{AB}$ retrospective or $\mathrm{TI}$ mice or $\mathrm{AB}$ mice or $\mathrm{TI}$ rat or $\mathrm{AB}$ rat or $\mathrm{TI}$ rats or $\mathrm{AB}$ rats

EMBASE search filter used in the 2008 version of the review:

((random\$ or control\$) AND (patient adherence or patient dropouts or illness behavior or psychotherapy or treatment refusal or patient education or regimen\$) AND (intervention\$ or outcome\$ or treatment outcome) AND (medicat\$ or drug therapy) AND (clinical trial or controlled study or randomized controlled trial))

EMBASE search filter used in this update using the Ovid interface:

(random: or control:).mp. AND (patient compliance or patient dropouts or illness behavior or psychotherapy or treatment refusal or patient education or regimen:).mp. AND (intervention: or outcome: or treatment outcome).mp. AND (medicat: or drug therapy).mp. AND (clinical trial or controlled study or randomized controlled trial).mp.

PsycINFO search filter used in the 2008 version of the review:

((random\$ or clinical or control or trial) AND (adherence or compliance or noncompliance or dropouts or patient education) AND (drug therapy or drug or medicat\$ or treatment or regimen) AND (intervention or outcomes or treatment outcomes))

PsycINFO search filter used in this update using the Ovid interface:

(((control: or random:).tw. or exp treatment/) and (adherence or compliance or noncompliance or dropouts or patient education).mp. and (drug therapy or drug or medicat: or treatment or regimen).mp. and (intervention or outcomes or treatment outcomes).mp.) not (qualitative or retrospective or mice or rat or rats).tw.

The Cochrane Library search filter used in the 2008 version of the review:

((random\$) AND (complian\$ or adheren\$ or pharmacotherapy or regimen\$ or educat\$) AND (medicat\$)); patient adherence; patient adherence; medication adherence.

The Cochrane Library search filter used in this update (http://onlinelibrary.wiley.com/cochranelibrary/search/):

((random*) AND (complian* or adheren* or pharmacotherapy or regimen* or educat $\left.{ }^{\star}\right)$ AND (medicat $\left.\left.{ }^{\star}\right)\right)$ (Note: Searched using all text tag; Search by product: Cochrane Database of Systematic Reviews, DARE (Other Reviews), Central; Search by record: all)

Sociological Abstracts search filter used in the 2008 version of the review:

((patient or treatment or dropouts) AND (clinical trials or control) AND (drugs or medicine)) 
Sociological Abstracts search filter used in this update using the ProQuest interface (http://search.proquest.com/socabs/advanced):

((patient or treatment or dropouts) AND (clinical trials or control) AND (drugs or medicine or medication)) (Searched using all fields; all(medication) retrieves su(medication adherence)

ClinicalTrials.gov search filter used in this update (http://clinicaltrials.gov/ct2/search/advanced):

"patient compliance" OR "patient adherence" OR "medication compliance" OR "medication adherence" | Closed Studies | Studies With Results |

International Clinical Trials Registry Platform search filter used in this update (http://apps.who.int/trialsearch/AdvSearch.aspx):

patient compliance or patient adherence or medication compliance or medication adherence (Note: recruitment status all used)

International Pharmaceutical Abstracts (IPA) was searched during the previous review; however, this database is no longer available through McMaster University library services. We did not search this database for the update.

WHAT'S NEW

Date Event Description

18 December $2013 \quad$ New citation required but conclusions

The conclusions of the review have not changed. Characterishave not changed tics and effects of interventions to improve medication adherence varied among studies, with only 5 of the 17 highest quality trials providing convincing evidence for improvement. Current methods of improving adherence for chronic health problems are mostly complex and not very effective, so that the full benefits of treatment cannot be realized.

We added 15 new authors in addition to RB Haynes, who was an author on the previous version of the review. The research objectives and inclusion criteria remain the same as in the previous review. We added the assessment of the risk of bias to the outcome measures. We updated the search filters for detecting relevant studies. We added 109 new studies in this 2013 update from searches run in January 2013.

\section{H I S T O R Y}

Review first published: Issue 3, 1999

\begin{tabular}{lll}
\hline Date & Event & Description \\
\hline 14 February 2008 & New search has been performed & $\begin{array}{l}\text { Twenty-one new studies were added in the 2007 update (pub- } \\
\text { lished in Issue 2, 2008 of The Cochrane Library). }\end{array}$ \\
\hline 13 February 2008 & $\begin{array}{l}\text { New citation required and conclusions } \\
\text { have changed }\end{array}$ & $\begin{array}{l}\text { There are now } 78 \text { studies meeting our criteria for testing inter- } \\
\text { ventions to help patients to follow prescribed, self administered } \\
\text { medications. }\end{array}$ \\
& $\begin{array}{l}\text { Despite the new studies, our conclusions remain the same: most } \\
\text { people do not follow self administered medical treatments as } \\
\text { prescribed and interventions to help them follow treatments } \\
\text { are marginally effective at best, especially for long-term medical } \\
\text { regimens. Strategies that appear to have some effect for long- } \\
\text { term regimens involve combinations of counseling, reminders, } \\
\text { self monitoring, feedback, family therapy, psychological thera- } \\
\text { py, manual telephone follow-up, and supportive care. For short- }\end{array}$
\end{tabular}




\begin{tabular}{lll}
\hline Date Event Description &
\end{tabular}

term treatments, high adherence can be achieved by simpler means, including counseling, written information about the importance of taking all doses, and personal phone calls.

The authorship changed to: Haynes RB, Ackloo E, Sahota N, McDonald HP, YaoX.

$\begin{array}{ll}29 \text { August } 2005 & \text { New citation required and conclusions } \\ \text { have changed }\end{array}$

The title changed to 'Interventions for enhancing medication adherence.' The authorship changed to: Haynes RB, Yao X, Degani A, Kripalani S, Garg A, McDonald HP.

29 August $2005 \quad$ New search has been performed

Twenty-five new studies were added (Issue 4, 2005), bringing to 57 the number of randomized trials meeting our criteria for testing interventions for helping patients to follow prescribed, self administered medications.

Despite the new studies, conclusions remained essentially the same: most people do not follow self administered medical treatments as prescribed and interventions to help them follow treatments are marginally effective at best, especially for longterm medical regimens. Strategies that appear to have some effect for long-term regimens involve combinations of counseling, reminders, self monitoring, feedback, family therapy, psychological therapy, manual telephone follow-up, and supportive care. For short-term treatments, high adherence can be achieved by simpler means, including counseling, written information about the importance of taking all doses, and personal phone calls.

7 February $2002 \quad$ New search has been performed

Fourteen new studies were added (Issue 2, 2002), bringing to 33 the number of randomized trials meeting our criteria for testing interventions for helping patients to follow prescribed, self administered medications. Despite the new studies, conclusions remain the same: most people do not follow self administered medical treatments as prescribed and interventions to help them follow treatments are marginally effective at best, especially for long-term medical regimens. Strategies that appear to have some effect for long-term regimens involve combinations of counseling, reminders, self monitoring and feedback, and supportive care. For short-term treatments, high adherence can be achieved by simpler means, including reminders and instruction about the importance of taking all doses.

\section{CONTRIBUTIONS OFAUTHORS}

2013 update:

- RN - oversight and involvement in all stages of the 2013 review and data extraction for eligible studies.

- NW - involved in all stages of the 2013 update.

- TN - involved in all stages of the 2013 update.

- $\mathrm{NH}$ - involved in programming the data management system and uploading data to RevMan.

- RJ - involved in all stages of the 2013 update.

- AK - involved in all stages of the 2013 update.

- TA - involved in all stages of the 2013 update.

- NM - involved in reviewing and abstracting articles and some aspects of text preparation for 2013 update. 
- $\mathrm{Al}$ - involved in reviewing and abstracting articles and some aspects of text preparation for 2013 update.

- SJ - involved in all stages of the 2013 update.

- BS - involved in reviewing and abstracting articles and some aspects of text preparation for 2013 update.

- El - involved in reviewing and abstracting articles and some aspects of text preparation for 2013 update.

- RM - involved in reviewing and abstracting articles and some aspects of text preparation for 2013 update.

- DJ - involved in reviewing and abstracting articles and some aspects of text preparation for 2013 update.

- CC - involved in programming the data management system and uploading data to RevMan.

- RBH - oversight and involvement in all stages of the 2013 review and data extraction for eligible studies.

2008 update:

- RBH - oversight and involvement in all stages of the 2008 review and data extraction for eligible studies.

- EA - involved in all stages of the 2008 update.

- NS - involved in reviewing and abstracting articles and some aspects of text preparation for 2008 update.

Previous versions of the review:

- Sunil Kripalani - involved in reviewing articles for eligibility for 2005 update.

- Xiaomei Yao - involved in all stages of the 2005 update.

- Amit X Garg - involved in reviewing references from literature searches for relevance and for calculating agreement statistics for the 2002 and 2005 updates.

- Aqeel Degani - involved in searches up to 2003, reviewing articles for eligibility.

- Heather Pauline McDonald - involved in all stages of the review for the 2002 update.

- Patricia Montague - involved in all stages of the review for the 1998 update.

\section{DECLARATIONS OF INTEREST}

- $\mathrm{RN}$ - RN received a research grant to assess barriers in hypertension management and a congress travel/accommodation reimbursement from Boehringer Ingelheim, and is co-investigator on research teams that received Canadian Institutes of Health Research grants for testing a hypertension implementation program in low- and middle-income countries as well as building a Canadian research network to reduce stroke in atrial fibrillation.

- NW - none known.

- TN - the update of this review was partly supported by a Knowledge Synthesis grant, KRS 262115, from the Canadian Institutes of Health Research.

- $\mathrm{NH}$ - none known.

- RJ - none known.

- AK - none known.

- TA - none known.

- NM - none known.

- Al-none known.

- SJ-none known.

- BS - none known.

- El - none known.

- RM - none known.

- DJ - none known.

- CC - none known.

- RBH - the update of this review was partly supported by a Knowledge Synthesis grant, KRS 262115, from the Canadian Institutes of Health Research.

\section{SOURCES OF SUPPORT}

\section{Internal sources}

- Health Information Research Unit, McMaster University, Hamilton, Ontario, Canada.

All staff, faculty, and student time other than NW, TN, AK, and BS was donated. 


\section{External sources}

- Canadian Institutes of Health Research, Canada.

1 year of funding provided partial salary support for a project manager (NW), research assistant (TN), and 2 students (AK, BS).

\section{DIFFERENCES BETWEEN PROTOCOLANDREVIEW}

Everything was the same except for the following: 1) we updated the search filters (see Appendix 1); 2) we extracted data in duplicate; and 3) we assessed risk of bias using the Cochrane 'Risk of bias' tool (Higgins 2011).

\section{INDEX TERMS}

\section{Medical Subject Headings (MeSH)}

*Drug Therapy; *Medication Adherence; Patient Education as Topic; Publication Bias; Randomized Controlled Trials as Topic; Self Administration

\section{MeSH check words}

Humans 